$8 x$ :

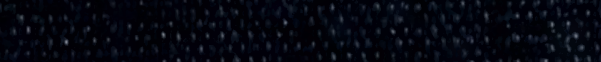




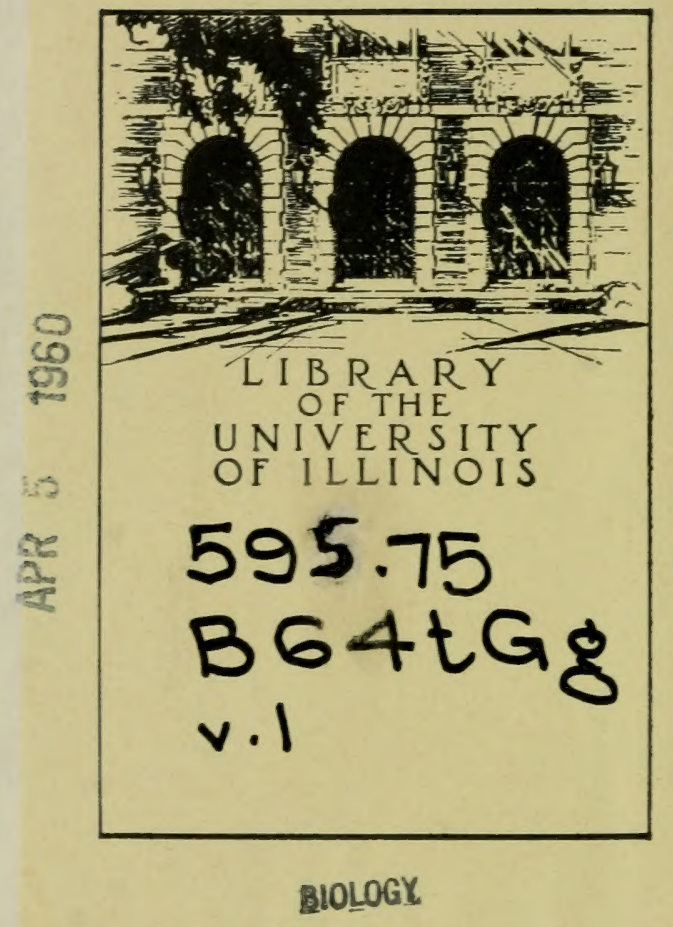



Digitized by the Internet Archive in 2010 with funding from University of Illinois Urbana-Champaign 

8.

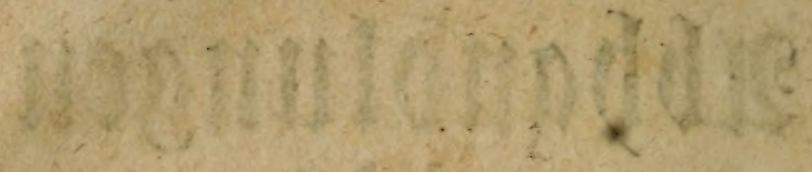

\section{प1262 87,0}

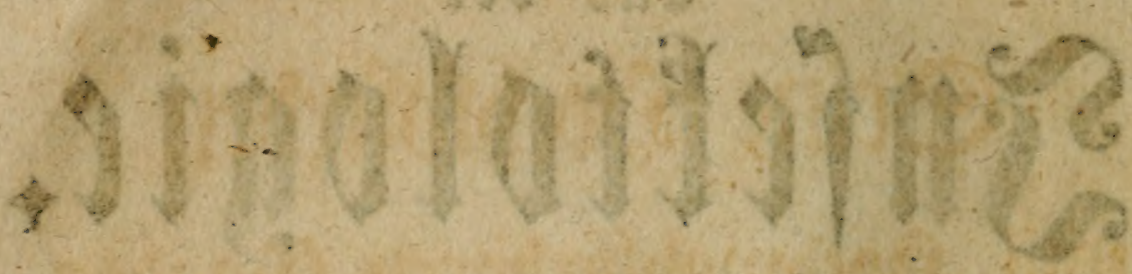

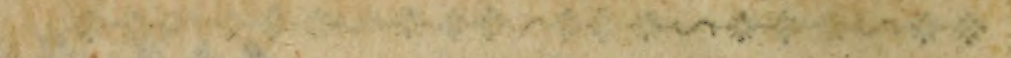

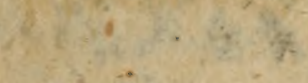

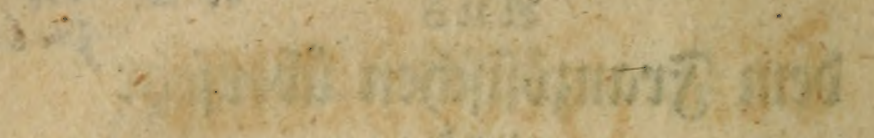

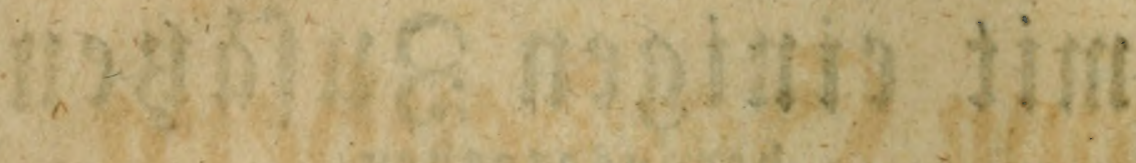

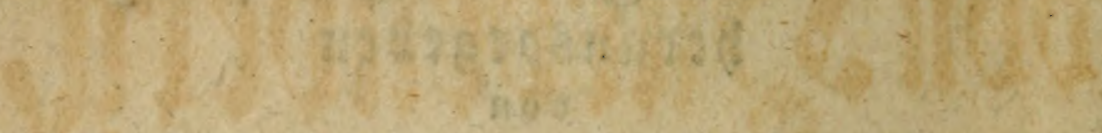

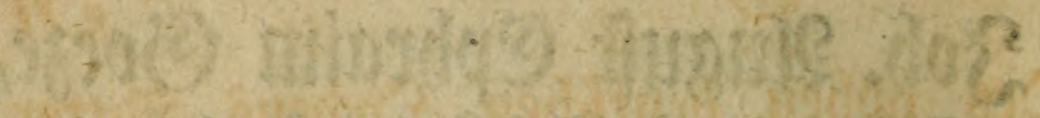

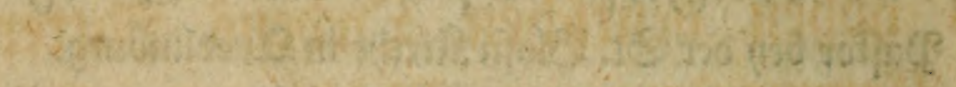

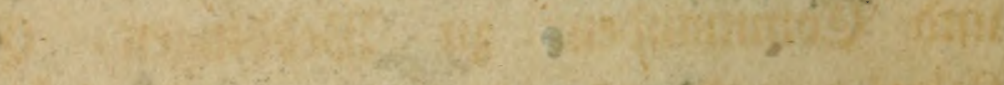

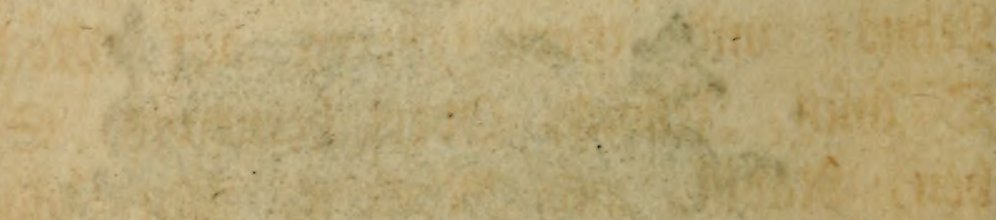

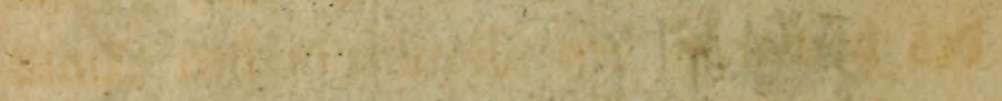

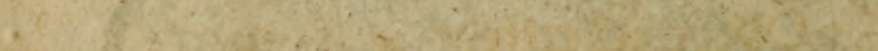




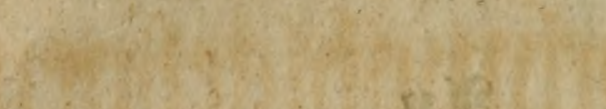

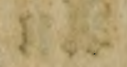

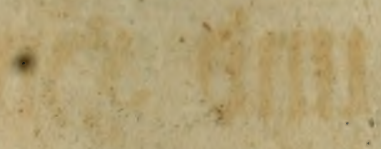

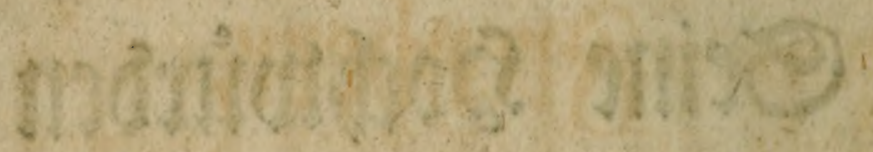

$\left(\frac{1}{4}+\frac{1}{2}\right.$

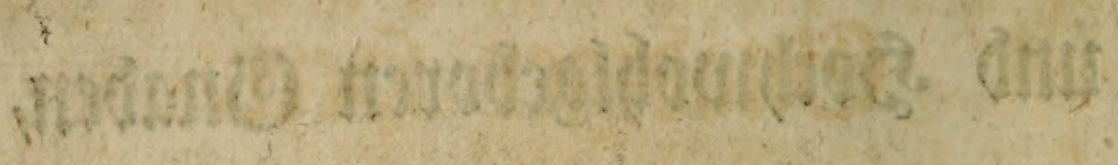

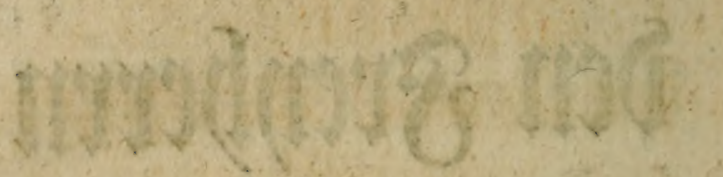

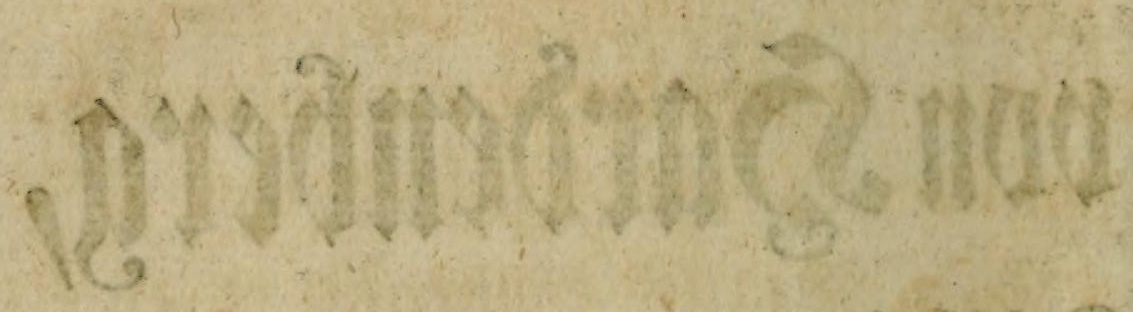

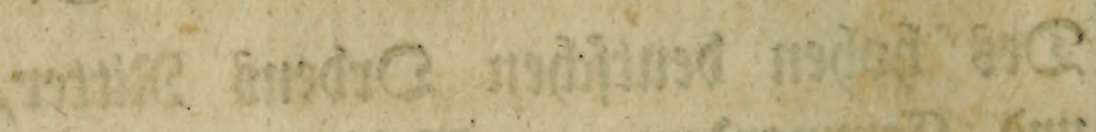

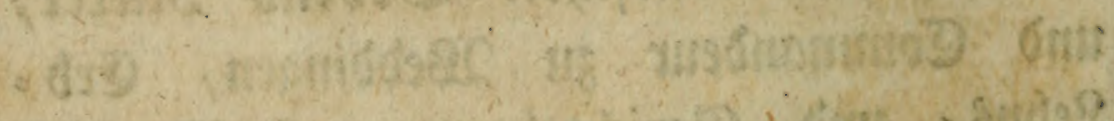

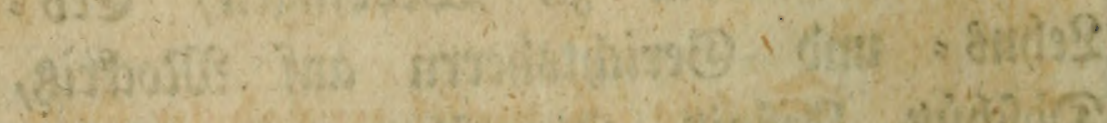

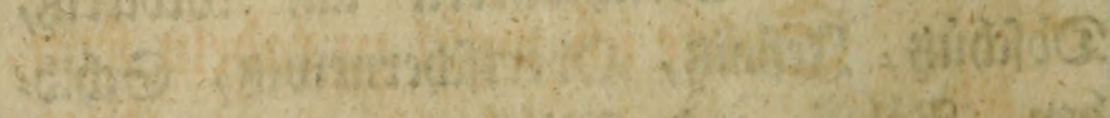

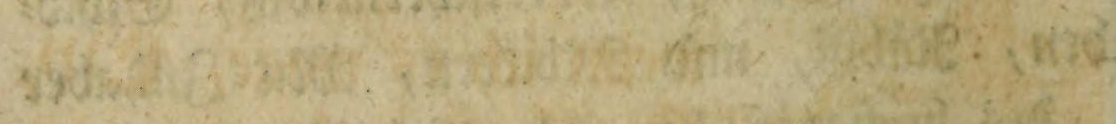

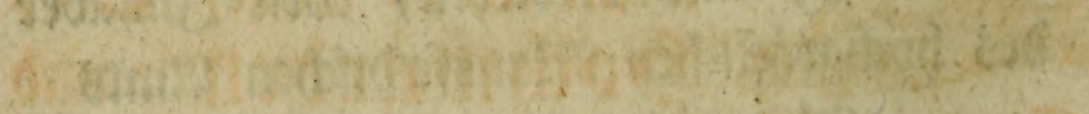

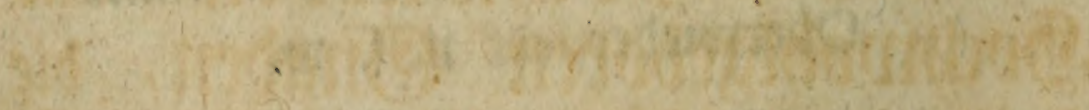

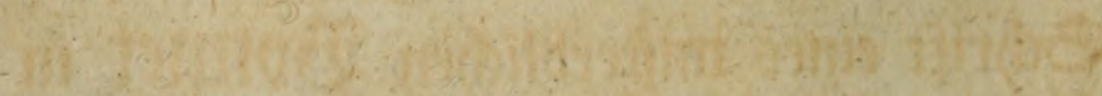

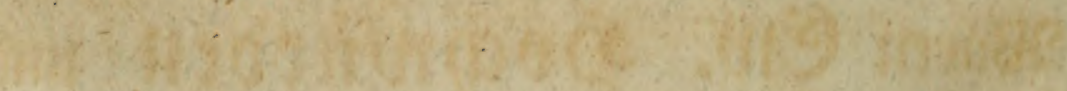




\section{Şod)wointotiget \\ inid Sodfinobligebontet fret)bert,}

Gonådiger Sctr.

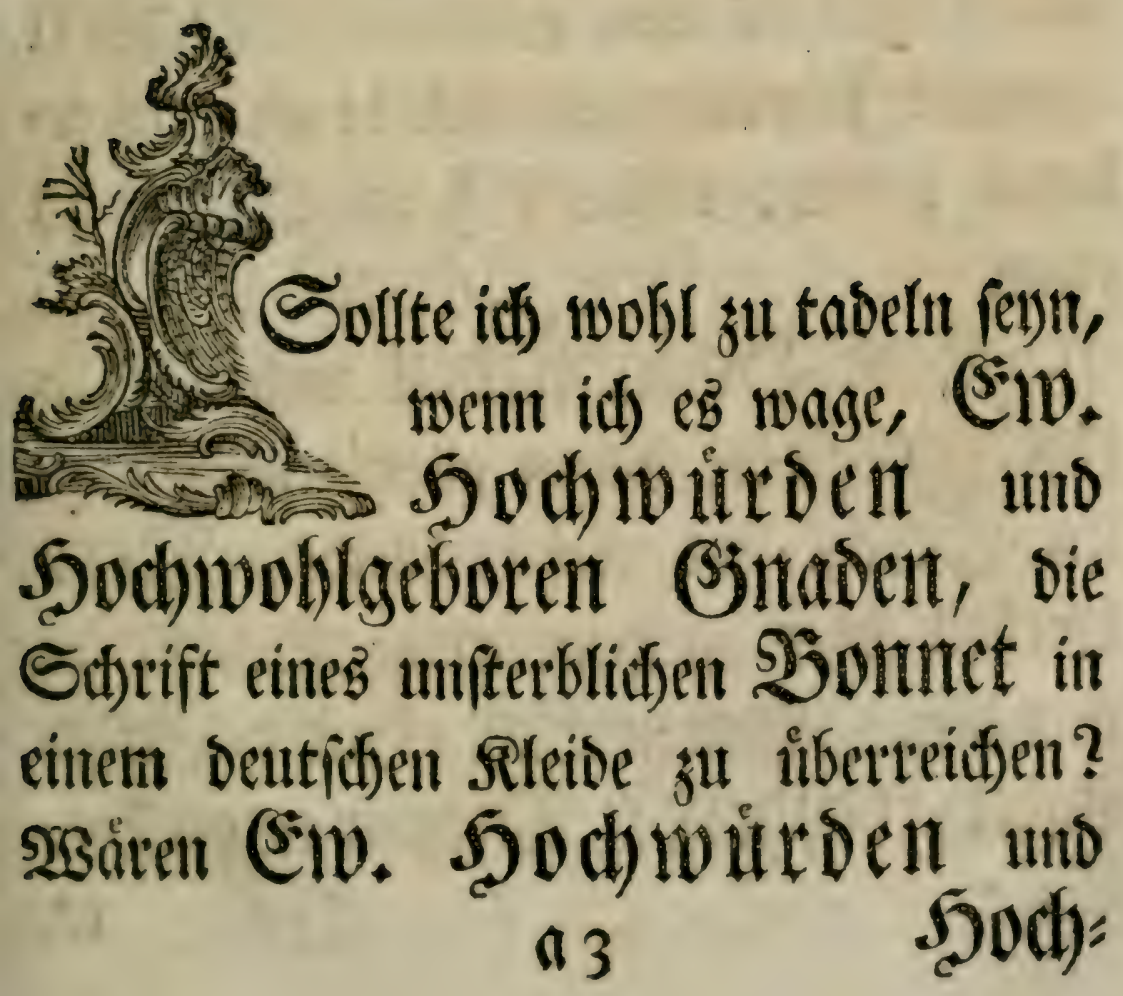


Soodbrobflgeborett niffe ein fo grof

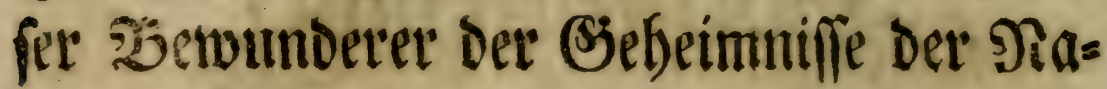
ture, waire id) nid)t burd) mefyr als eine \$robe uiberseitgt, wie hod Dieferben,

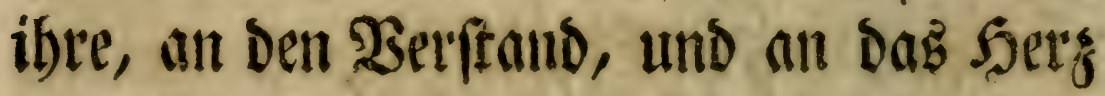
Des Dieniftent rebenden wilifte id) nidd)t aus̉ ber (Erfabrung, wie vertraut (Ew. Sodhwiteden uno Soct)woblageboren, mit einem গieall= muit, SYuffon, SBomare, und SBon: net umzuget)an pilegen; formute id lefs:

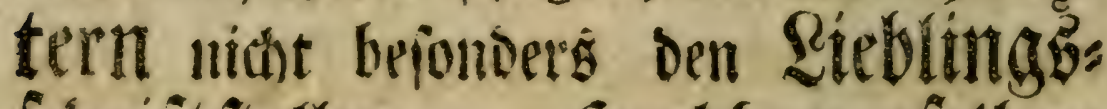
fidriftiteller von Sodboenenfelben nennen: nimmermebr nurbe id) mir: er= laubt baben, Diejen filbnen Edritt jut thun.

(5w, Sodinuiront uno Sod): woblgeboren haben aber gewifiermâ fen Selbit das nåd)ite sed)t, Sero Uttbeil ůber gegenwattige Ed)rift salt

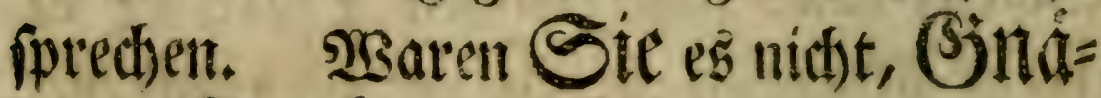
Diget Stenlyetr? Sie vor einem Salt= 


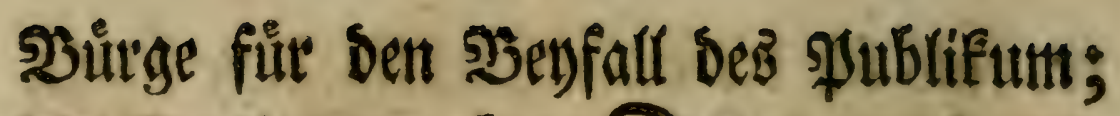
bie Fortbauter aber Seto gnábigen

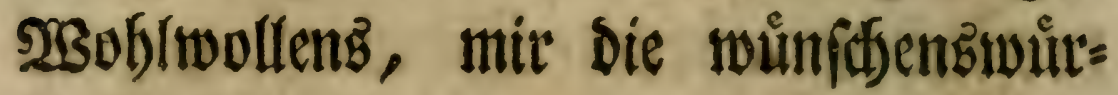
Digite (s)

S̈n weld)er fít)meidfelnben Shoffinung id mit Der tiefiten (Ebrfurd) erferbe

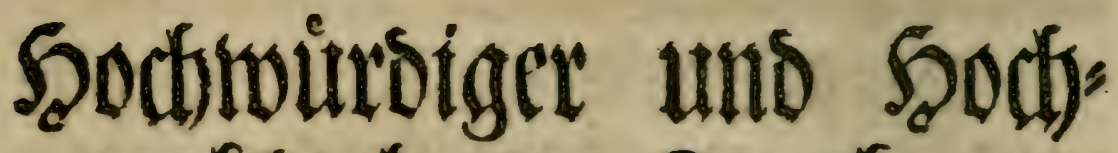
woblgeborner Ftew) bert

(5ww. Sodd)wurbent

und 5od)woblgeboren Gitadent

untettfánig gefjorfamfter

ร. 2. E. Gineze. 


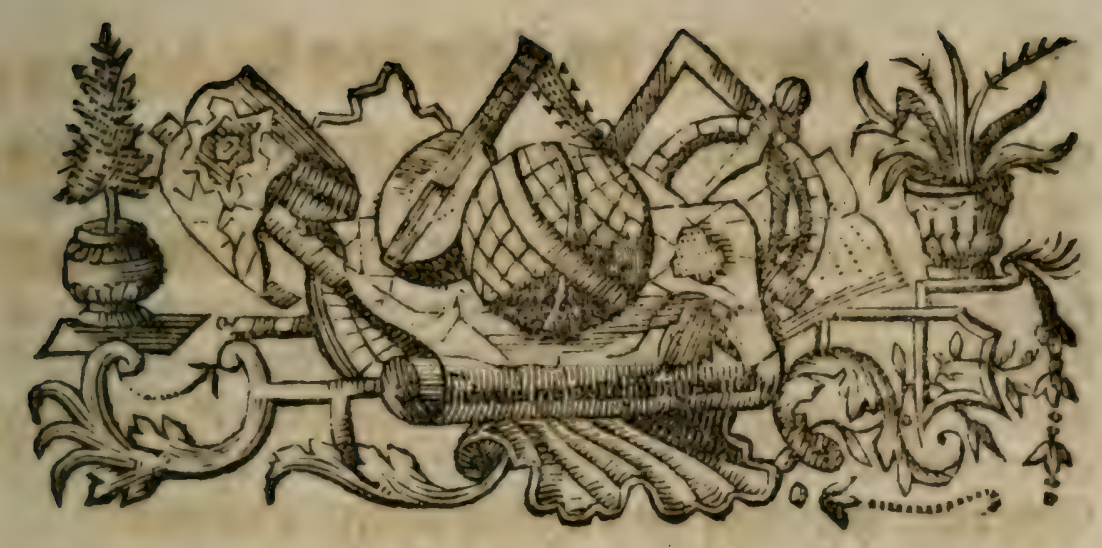

\section{Sotrede deb Heberjeţer.}

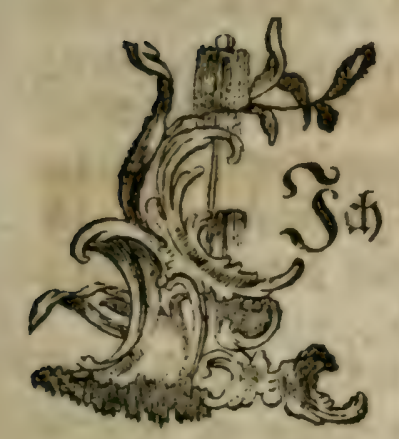

habe eigentlich nichs notbist eine Bonnet dhe Sdbrift mit einer neuen $\mathfrak{3} 0$ rrede gu begleiten. Int reiner eigenen bat Der Derfâs fer felbft fitjon allez gefagt, was

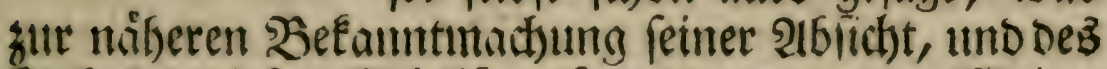
Jinfaltż Diefer Schrift erforbert nutbe. IRBeiter bedarf fie wohl keiner (Empfeflung an Das Publis Eum, am wenigiten ber meinigen.

(Eben fo úberfikisig wurbe es (enn, wenn id) bie Sirünoe rechtfertigen wollte, bie mich) z"l Der lleber=

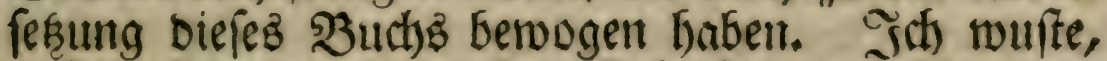
Dẩ Diefes eine Der eriften Sthriften beż Zonnets war, bie er bereits bor oreifig Jahten, in feiner Jutt gend herausgegeben hatte. I If) wulfe, Daß́ el Darin ben manchen intereffanten Giegenftánden Der श2atul=

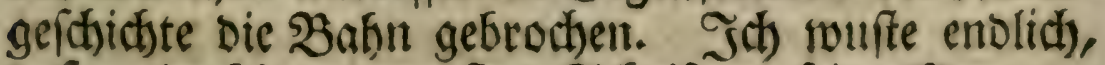
Daß̧ et in feinen neueften Sdjriften, feine Piennun= 


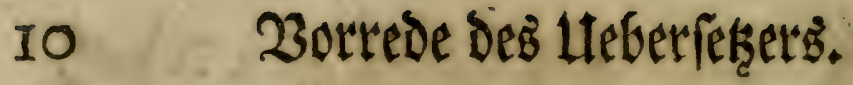

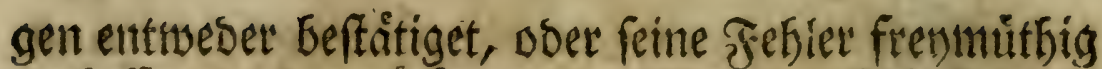
verbefiert, uno zutuictegentonmen hatte. Fith fam al=

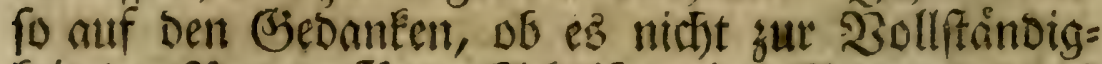
feit Der Bonnet|chen Schriften int Ganzen etwaz

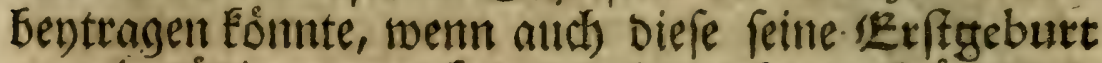

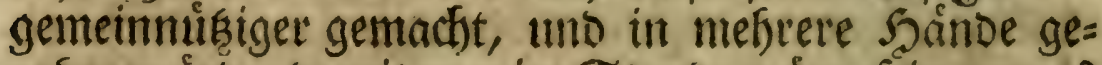

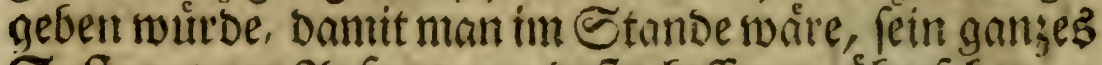

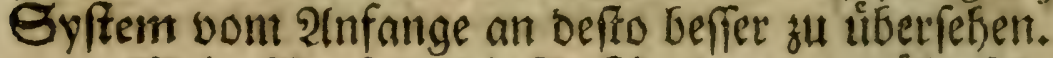

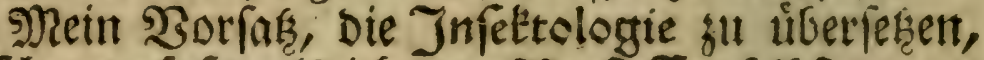

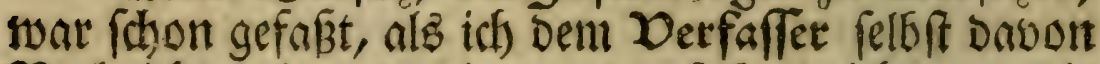
Sachbricht gab, und mir yon Demfelében nicht nur bie

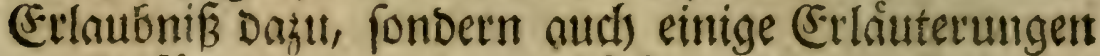

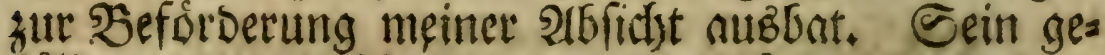

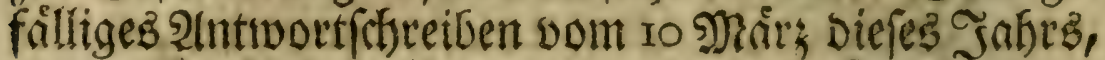
won Defien Jinfalt ifl unten meinen Lefern Siechen=

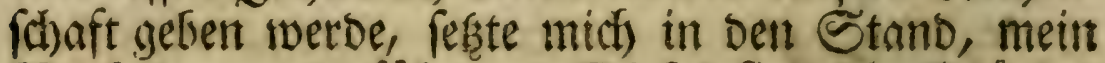

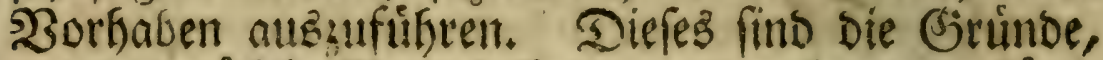

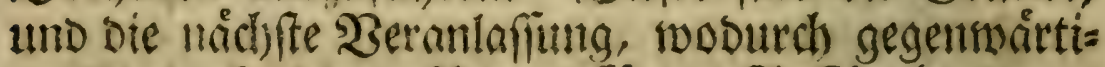
ge Ptusigabe ber Zbonnetícben InfeEtologie zit

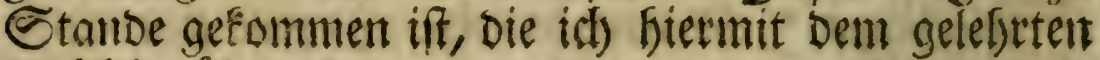
publito iibergebe.

Indeffien farm ich nicht unterlafient, midf) nods borther mit meinen geneigten Lefern etwo bै all unter=

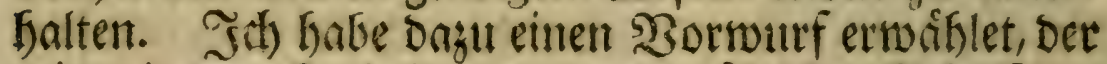

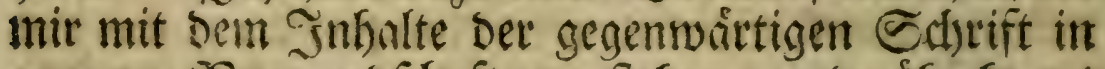

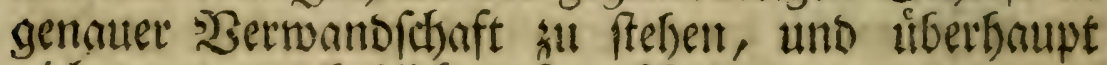
nicht gants unerhéblich) ju fennn ficheint.

Die Zonnetfabe Echrift befferfict auts lauter

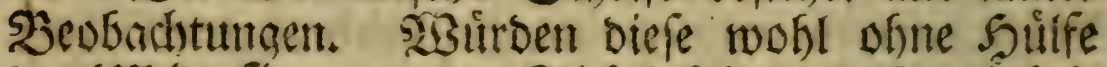

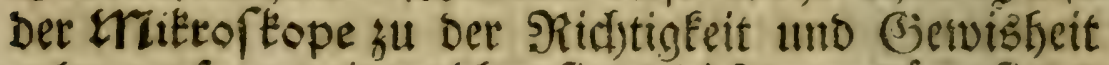
gelanget fernn, mit welcher fie gleidffam gepráget fint ?

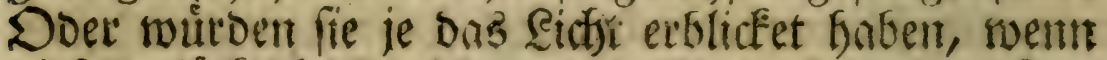

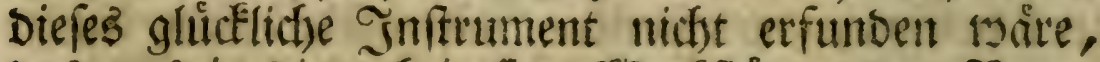

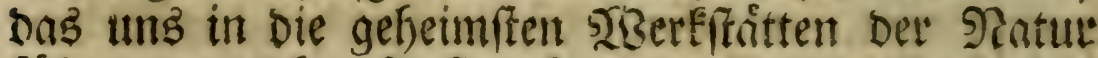
fübrt, fit twelchen fonft unfrem Ituge und Geeife Der zugang auf ewig verfiblofien war? MReine Lefer 


\section{Zorrede des tteberfę̧еtร. II}

erlatben mir alfo, etrong meniges von ber sent"

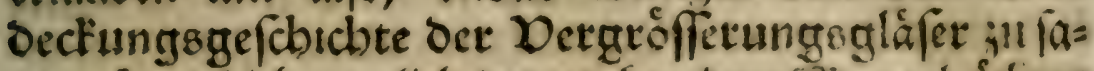
gen, fo orel id) nemlid) Davon ber) Dem Mmangel ád)iet Queilen babe finden fómell.

Da $e^{3}$ aber in ber Raturaed fidfte allein suf ridftige 23 crind)e und (Erfahrungen, bejonders ben Den Jnfetten ontumme, und ein jeglicher eingeftefent mußs, Daß́ Diejelben von ber grófieren 23ollfonmen= Geit und Deutlicten $20 r$ ffellung mitrortepifcher Jn= ftrumente affifangent; fo ivill id) $3 w e y t e n s$ etwas

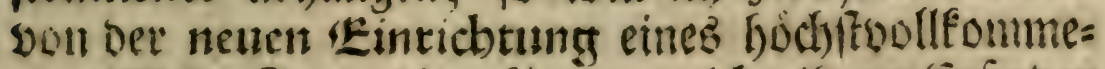
nen eruttrofkeps bingufugen, welde ti)rem (Erfinder unvergesblide (shre madt, uno mit weld)em inftru= mente die von mir, Der Bennerfaben Tmêtrologie angebaingten Beobad)tungen angeifellet fimb.

Dann wiro es immer nod) Zeit genura fenn, meine geringe Plebeit felbit zu beruffren, was id) $\mathrm{ei}=$

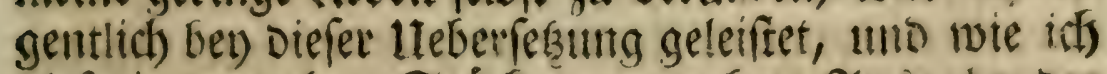
Diefe in mandjen Stricken vermergete 2hügabe Der Sontnet ichen Infertologie eingeridtet habe.

I. Schon oft babe id) bet) nir felbit Dent ltrias=

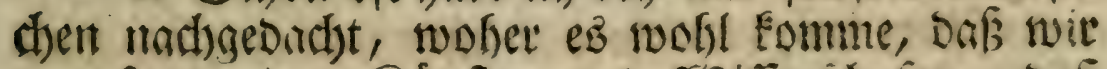
bon fo wenigen Rünten unb sibifien(d)aften, Duß wir von io wenigen mifslidhen (Entoecfungen, eine riditige, unto von ibrem erffen ttriprunge an, bis auf umfre Zeiten fortgefuithrte Ge(chichte baber. Sid) slaube, Daß s wir folgende, als bie noid)fient annefimen

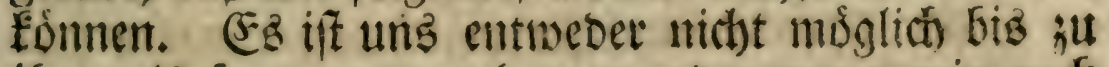
ifrem Irfprunge ;ll gelangen, Doer menn wir auth bis Dalin Dringen fónnten: fo wirto uttz in Der Tol= ge ber Jjaden fehlen, Der uns wieber atts biefen $\mathrm{ea}=$

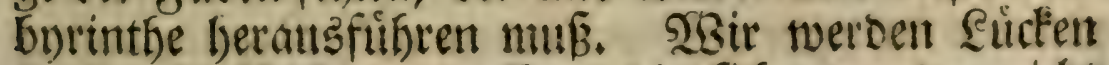
in ber (Sefchid)te antreffen, bie fich enttweder nicht sodlen ausfillen laffen, Doer bie eben nididt recht vie= le aแลู่วนfu!llen Euft baben. 
Tุas bas erffe betrift, fo twird uns bie sents

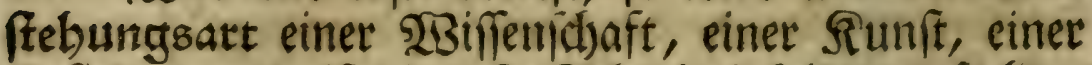
Erfinduntg gemín Die er/ite Edywierigfeit verur fact)en. Syier muß nun bie Gefhichte unfer Drafel werben. Man befrage es: : wie find bie allermeiften UErfinoun"

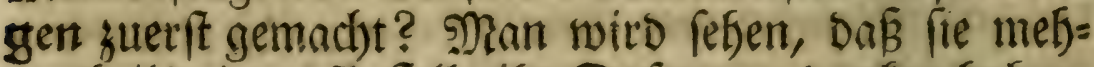
rentheils einem כufalle ifgr Dafern zu Danten babert. Selten wird es auf Die 2trt geichehen fernn, Daß́ Der (Erfinber Durch ein Raffinement Darauf gefommen, Doer Feine (EntDeckFung Durd) geometrifhe Bermunft=

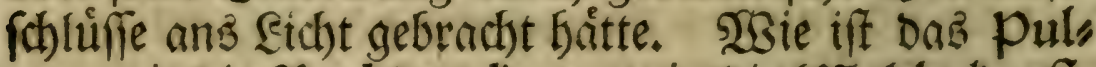
ver, wie bie Zucboruckerey, wie Die ETLablerkunft, wie fino die Zuchitaben, uno taufend andere Dinge erfunden worden? Tarchgehends hat die (Empfindung

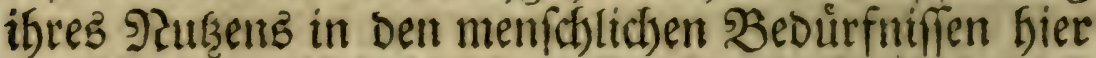
oder Da einen fobofferiftsen Ropf erweckt, Das nocf) robe (Eifen unter bie Feile su nehmen: iid) twill fagen,

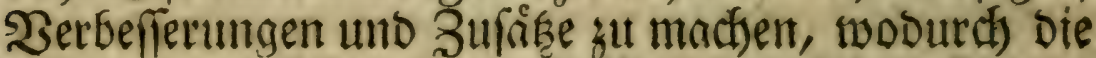
erfundene Sache ;u Der Bollfonmenfeit geftiegen, worin wir fie jegt nusen. Sino aber Daruber nicht oft Saecula vergangen, else Die $\$ 3\}$ hilofophen, Die $\Re a=$ turforfcher, Die Ruinftler Das gerworden fint, twas fie jeftst heifien, ehe 佂rasme, Teutone, Leibnige, und Dolfe aufitunden, unb in ben Sisifienfichoften fpra= chen: es ivertoe eicht?

So iftę vermuthfithauth mit Der Sache sugegant= gent, von Der ich jefrt etwas aus der (sjeichichte anfuif)= ren will. Die Dergroffermnggglẳer gehóren zut

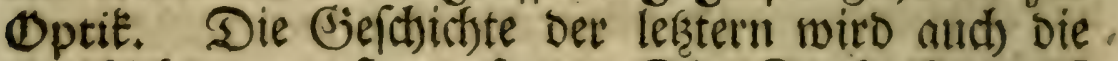
Gejectidfte Der erfteren fenn. Die Sinnft ift gerwis efer, als bie SiBifienif baft getwefen. Denn vermit= telft Der optifichen Inffrumente iff fie erft gu Dem Range einer 9 Biffenif aft erbobert.

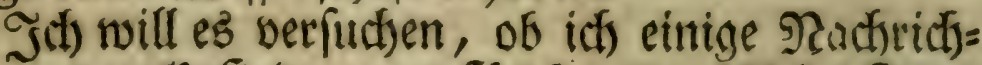

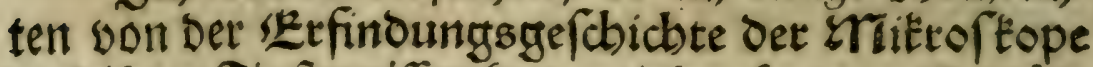

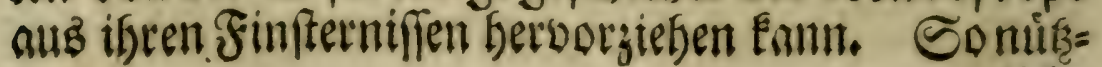


lidbe Sinftrumente, bie fo viel zur nófern Gienntnif Der tieffen SRaturgel)eimniffe bentragen, follten Die

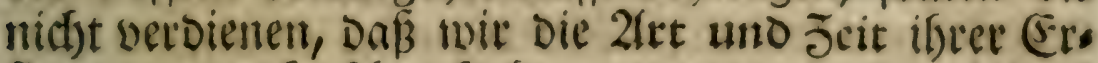

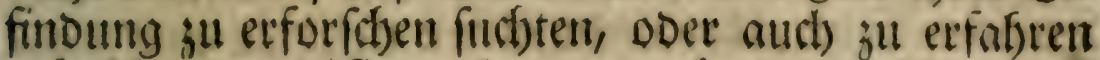

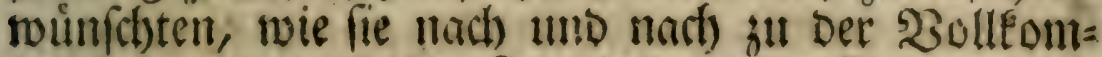
mentheit emporgefoben find, in Der wir fie jeęt erbli= cFent, uno gebrautisen fónnen?

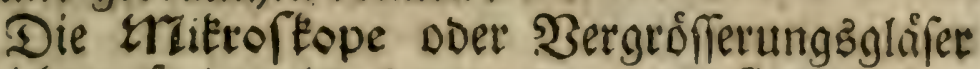
find nid)t auf eimmal Daz geworden, was fie in umfien Sagen fimb. 刃an bat verichiedene Prten Derfelben, iworaus erfhellet, Daß̧ fie nach uno nad) muifien erfun= Den feinn. Tith unterfid)eide hier bie bloffen Gläfer won Den Inftrumenten. Nlan hat einfacbe und 3 " fammenge (éte Mifrojfope. Jene beftehen ans ein=

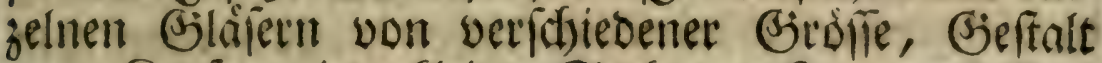
und Siraft, eine fleine Sache groß vorzutellen.

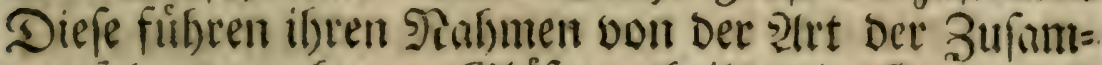
menjefsung mefreter Gjlafer, theilb Die Gorade Der

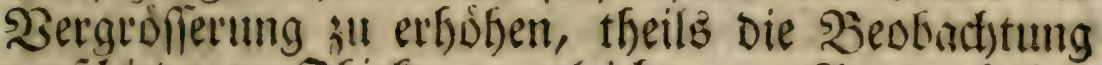
verifhiedenter Dbiefte att erleichtern. Şende haben fo woht oon ithen "Erfindern als won iften Kerfin" oungsorten gemeiniglich alld ifre ?amen befom=

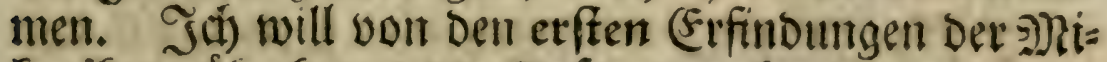
frofépe úberfoupt Den P(nfang madien.

Det (Erfindung Des Glafes hat plinius a)

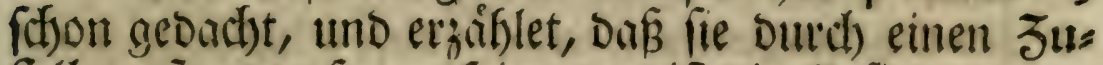
fall entitunden (er). SGingegen ift Die (Erfindung Der eigentlidjen optifichen (Blafer, Der Srillen, Der Sern uno Dergrofferungsgläfer, nad) Den bewaéfrteften Bengniffen, viel neuer, aber Doch nidst mit vólliger (Semisheit auszumadben, in welche Zeit fie eigentlich) ju jefsen (er) ${ }^{b}$ ).

a) Hift. nat. lib. XXXVI. c. 36. Nan veralcide namit sie

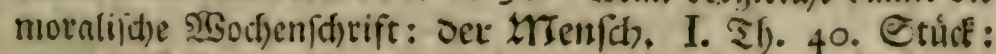
yon Der Erfindung Des Bltafez.

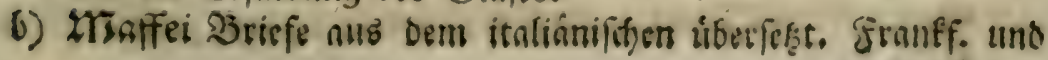




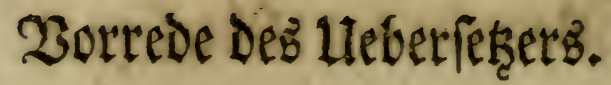

3war nach bem Senes und Petratch Gaben

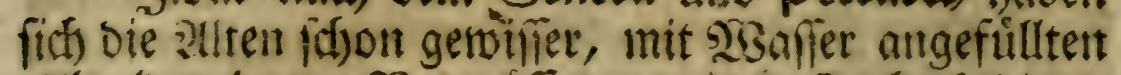
Glustugeln zut $\mathfrak{B}$ ergrófierung einer Eadje bebient. Dermutteifit Derfelben tomnten Die fleinften und Dun= felfen Butchitaben grófier und beller gejefien werben; allein bon Den Brillen, und andern Gläjern, rvie wir fie jefrt baben, findet man ben ifnen nidht bie ge= ringite Spur c).

Die Errindung und ber Befirauch Derfelben iff siel neter. (Fin gemiffer Miond), Ramens Jordan, Der um das Jahr izos gelebt, hat in einer feiner

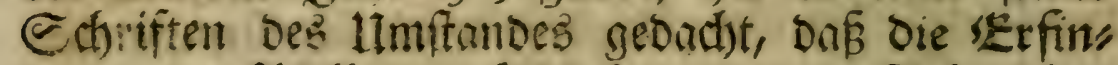
oung oer Strtlent noch nicbr 3wannig Jabre ber fey. Doch mir Esmmen in Der (jejedichte nod) weiter Gunatsagchen. Mnabillon, Diejer grofle Fenner Der शlterthimer, füfret hiervon eine befondere 2Inefoote an. Er habe in Der Dioecefe Trefinghen it Deutict)land, in Der $2(6 t e t)$ Scbeir, eine fotolaftiche Salforie oom Comeftor gefunden, Die un Das Jahe 1240

รeip3. 1755. 8. p. 192. 2ullgemeines thagazin bet

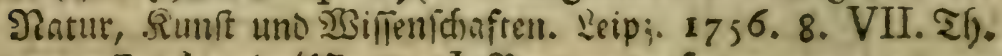

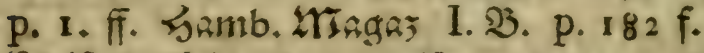

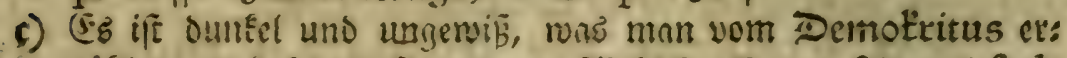

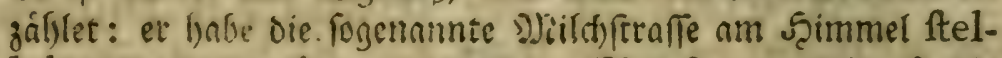
lularum congeriem aenaunt. Eben fo untifftig If bie Ereflátung der Conficillorum, Deten plautus Fragm. Medicus. ed. Gronov. 8. P. II. p. 48 r. gedenft, wenn

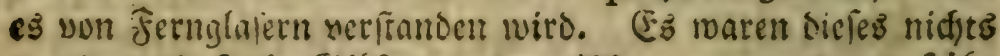

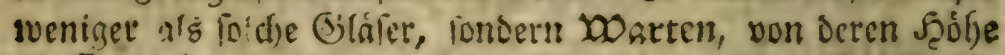
Die Speculatores in Die Jernne Feten finnten. 06 ptoler

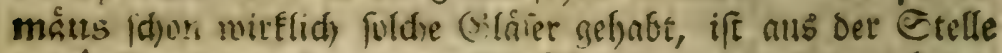
Des à Porta magiae naturalis lib. 17 , cap. 5. quod per fexcenta millia adventantes naves conípiciebat, cben fo meniz in ermeifen, wie idjon Pet. Borelius in ieinem raren Fraftut: de vero Telefcopii inventnre. Hag. Com. 16,55. 4. Cap. 1. p. 1. M ane fe bat: Credenduin eft inter arcana remanfife, et noftro tantum tempore publici juris facta fuiffe. 


\section{3ortede Des Hleberféserb.}

I240 ge(d)rieben, vor welif)er bie frenen Sinffe, unb unter Denfelben Die Slitronomie, unter Dem S3iloe Des mit einem lantgen Robee nad) Den Sternen ferbenden Ptolemains vorgeffellt gewefent. Dod getratet er (iid) niást ; beftimmen, ob Dả Sefherohr ;ur Beit Diefes Sternfundigen filyon in (Sebranth getwejen,

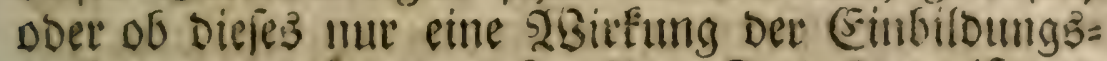

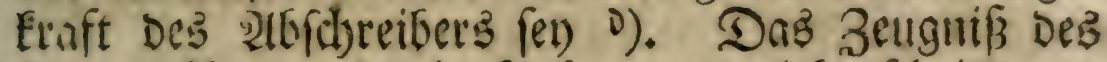
Rioger Bacon, ber im Sabre 1292 gelebt, fobeint bon

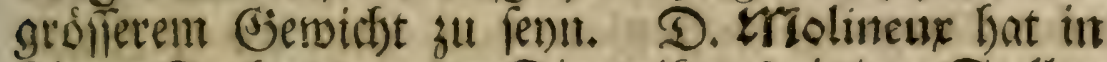
feinem Traftat bon Der Diontrif aủ einigen Stellen

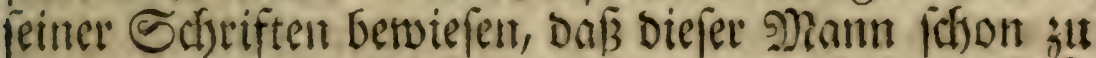
feinen Beiten sie WBirtung hohler unb erbabener Bjlä= fir, uno fogat bie sitt ifter 23erbindung getwuft e). Soll man Dem du Fresne trauen, fo ift Die (Erfinoung Der optif(den (jilifer nod) elter. (Er beruft fid) auf eine Etelle einez griedrifa)en Didsterß Proḱoprodo" nus, Defien Gedidst wider Den alegumenus, in ber 23iblidthef Des Roniges von Tranfieid) in Der Sand=

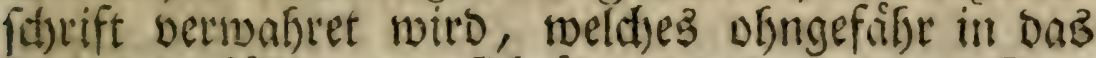

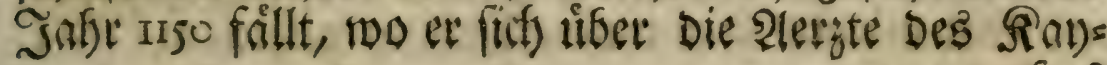

fer's

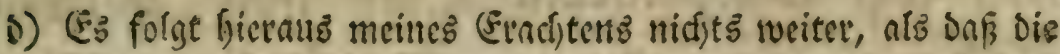
2flten Durd) looble Tiófyren ben Feimine! betrad)tet baben. SSir fintent ater nidht bie geringfent Epuren, Daß̄ bntin

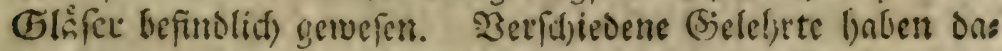

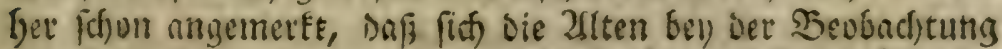
Der Sterne nat lanjer uno bobler Roffrell obne Glâfer be:

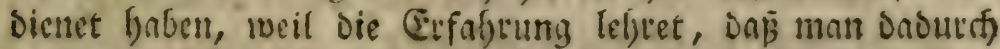
entfernte Bicienftánde beutlidfer fehen Eanu, uno Die úber: flúbigen Siontftrablen abgebalter iveroen.

B) Die cine Etelle nub feinem Sricfe ad Parifienfem, cap. 5.

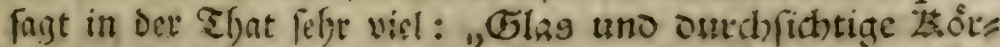

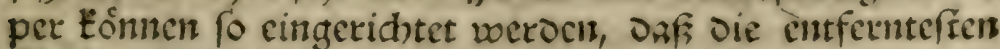
Gachen gans nabe fobeinen, tuno ungetelort, fo oa man Die Eleinefte Edhrift in cinet unglaublichen Weite lefen, in eine trenge Dinge, wenn fie athd nod, fo Elein fins, feben tann, uno oafis sie Grerne uns fo nabe ethibeinen, fils es tns gefält, " 
fers siemanuel Comnenus luftig macht, Daß̧ fie ben 2utstwurf thes Sianfers mit einem Glafe angefefen haben f). Emenagius aber, Dem biefe Stelle wont Dem ou Cange nitgetheilet war, trifft vielleicht bie

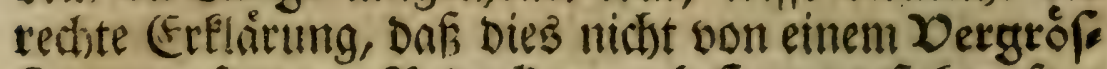
ferungs, fonbern Zedeclungsglafe zu verftehen (en),

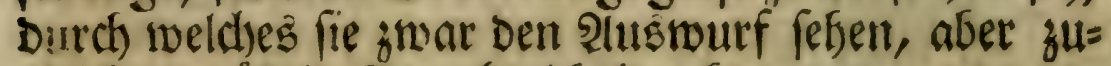
gleid) Den uibeln (sieruch) albalten fonnten.

Pius anbern Zeugniffen erhellet, Daß̧ bie eigent=

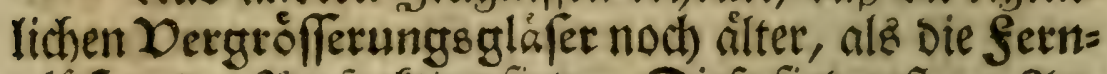

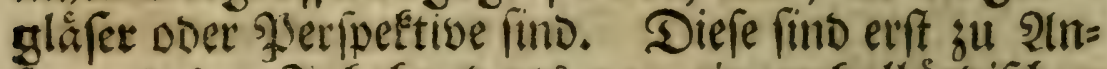
fange Des I7 Jafhrfunderts von einem Gollänbifhen Meiffer, SRamenß Jacob metius, unt nach Diefem von Dem Gerififmten Galilåus erfunden morden 9).

FEs if nber Damit wie mit andern (Erfindungen sugegangen. (Fin jeder Ort, wo bavon Spuren allatreffen waren, wollte fich, wie ber Dem Infange Der Zucborudkerey, bie Efre ber Erfindung zueig= nen, und Den Erimber in feinen Mauren gebabt $\mathfrak{h a}=$ ben. SiBie lange baben die Etriote triaynz, Zarlem uno Strafburg uiber Diefen গ3orłng geftritten? biß ein Scbópflin erft in unfren zeiten, foldben Der lef̧= teren aus ungejweifelten Dofumenten beylegen fơnnen.

Eben fo menig if man baruifer voflig einig,

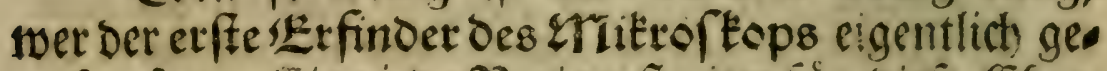
wejen fer). Eine jede Piation fitreitet fur diefe (Ehre. Die Stalioiner geben fre ifrem Lanosెmanne, einem Neapolitaner, Dem fontana, weicher Mrennming Enorboff b) Genyfichtet. Die Syollänoer hingegen

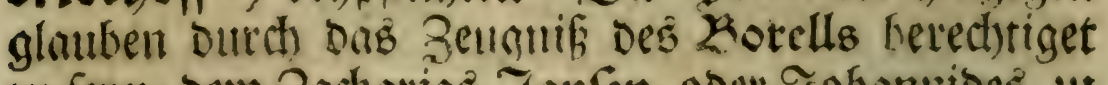

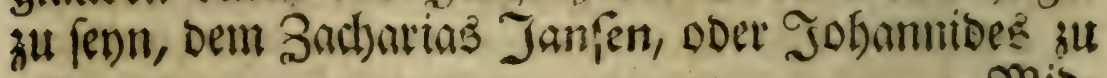

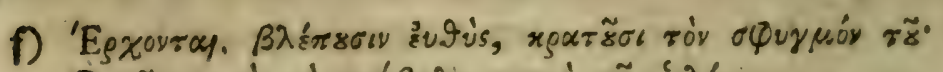

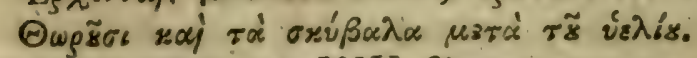

3) bamb. Pranga. XIX. 33. p. 75.

i) Polyhift, ed. II. 1714. Tom. II. p. 284. 
midoelfurg in Seelant, welther rsgo gelebt, nach ifint afeer Dem Shant Lipperbey, und alfo ifree $\Re a=$ tion bie (E) ree Diefer (Enfindung zuzufdsreiben, wie= wobl diefes mefr Die Erfindung Der Celef'tope, als Der eigentlid)en zmiktorkope betrift i). Snoeffen

i) (E.s ift in ber That felfr viel, was Petrus Borellus de vero Telefcopii inventore cap. XIV. p. 29 aแb obrigfeitliden 3eunniffen etrviejen bat. Da siefer Traftat fo felten, und bie Eadje fo fonderbar ift; fo will id) Daraus ein foldjes Zfteftat mittl)eilen, meldjes iffun 'feines Zflters wegen ver: Dient geforetet ju werven.

Iam tempus adeft teftimonia exhibendi, quibus optime convincitur, Middelburgenfi civi Telefcopii et Microfcopii Inventum deberi: En illa igitur ex Autographis.

Nos Confules, Scabini et Confiliarii Civitatis Middelburgi in Selandia, juffimus audiri et examinari loannem Zacharidem Confectorem Confpiciliorum in $\mathrm{Ci}$ vitate noftra, aetatis qui effet Annorum quinquaginta duorum; Et etiam Saram Goedardam, quae inhabitat Aedes, quarum fignum eft Crux aurea, in Porta inte. riori hujus Civitatis: de cognitione certa, quae apud illos finul et fingulos eorum effet, quisquam videlicet homo in dicta hac Civitate prima Confpicilia longa, five Telefcopia confecerit. Illi ad Interrogata retponderunt, et declararunt haec quae fequuntur.

Et primo praedictus Ioannes Zacharides affirmavit illa Telefcopia primum effe inventa et confecta a $\mathrm{Pa}$ tre fuo, cui nomen erat Zacharias Ioannides, idque contigiffe (vt faepe inaudiverat) in hac Civitate Anno Chrifti 1590. Quod tamen longiffimum Telefcopium illo tempore confectum non exceffit quindecim aut fedecim pollicum longitudinem. Affirmavit tunc duo talia Telefcopia oblata fuiffe, vnum videlicet llluftrifimo Principi Mauritio, alterum vero Archiduci Alberto, et tantae fimilis longitudinis Telefcopia in vfu fuiffe in Annum 15rg. Tunc eum demum, (vt affirmabat hic Teftis) ipfe et Pater ejus, nempe praedictus Iohannes Zacharias Ioannides invenerunt fabricam et 


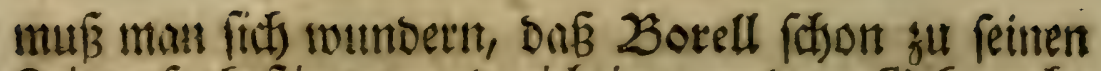
3eiten fo beftimmt uno richtig von Dem Sjebrauche

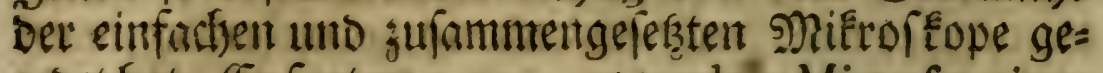
rebet Gat. Er fagt pag. 10. - et tandem Microfcopium vel mufcarium aut pulicarium Confpicilium, quo pulex in Camelum, et mufca in Elephantum exfurgunt, fit ex duobus vitris tubulo inclufis: vitrum oculo proximum eft convexum, et ex minuto fphaerulae fegmento fąum, cujus diameter duorum pollicum effe debet: alterum eft vitrum planum; poteft et fieri ex duobus convexis et praeftat -

Fiunt vel vnica fphaerula tubo inclufa, cui opponuntur obiecta, vel capfula fubiecta vitrea, cui induntur minuta quaevis, vel phiala admota ei et ad-

nexa,

compofitionem longiorum Telefcopiorum, quibus etiam nunc vtuntur nocte ad infpiciendas Stellas et Lunam. Infuper affirmavit quemdam nomine Metium, Anno 1620. advenifie Middelburgum, et comparafie tale Telefcopium: cujus confectionis modum conatus eft imitari quantum potuit. Idem et tentaffe Cornelium Dre. bellium. Infuper dixit hic Teftis, cum haec funt in. venta Patrem fuum inhabitaffe Aediculas quae funt in coemeterio templi novi, vbi nunc fubhaftatio rerum publice fit.

Poft hunc audita efí et depofuit Sara Goedarda, et affirmavit jam efle fere, 42 aut 44 annos circiter (nam de certo praefixo tempore non poterat dicere) cum Confpicilia longa in hac civitate primum a Fratre ejus Zacharia loannide jam mortuo confecta fint, qui habitavit aedes prope Monetam, junctas Templo Novo. Scientiae fuae rationem dixit, quod illa vidiffet innumeris vicibus Fratrem conficientem talia Telefcopia.

In fidem dictorum Nos Confules et Scabini prae. dicti haec Sigillo minori noftrae Civitatis juffimus firmari, et per vnum ex numero Secretariorum noftro. rum fubfcribi, tertio Die mentis Martii, Anno 1655. Locus Sigilli.

Subfignatum Simon van Beaumont. 


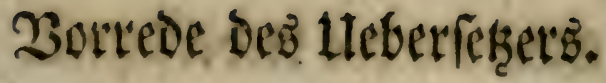

nexa, vt liquores percipi queant. Vel inftar tubi ductitia quae remittuntur et producuntur ad libitum, et quibus fubiiciuntur obietta, et in eis nunc plura vitra, vtpote quatuor vel tria induntur, et fic obiecta maiora apparent.

(Eins will ids Gier noch berififen, baf nemlich Der cigentiidse Eirfinder Der fogenannten einfactent

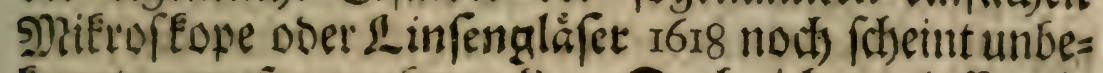
Eannt genceien ju (erst t). Doch id) verlafie bie Dunflen Beiten, uno wenoe mich zu Der nettern Gefdridste.

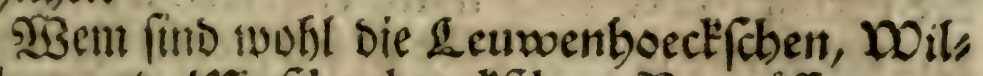
fonfaben un! zriuchenbrockfaben Bergrofferung $3=$ glafier unbetannt? Die erfferen find zu berubibm, als

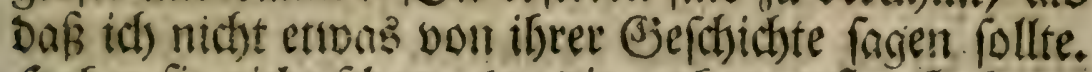

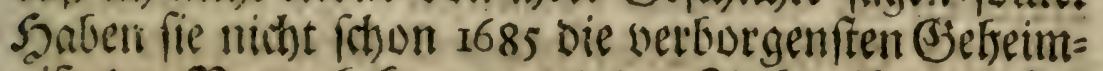
nifse ber Ratur befannt, und Den ?Ruthm ifrees Erfin=

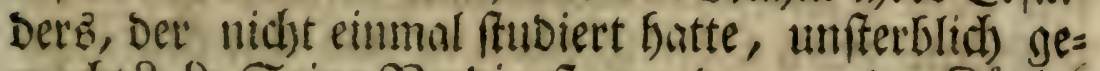
mad)t? 1) Eeine ßerbienfte wumben von Der Rönig= b 2

lichen

E) Doolf in Elem. Dioptr. p. 355. hat Diefes zum STetweife nngefúftet, weil Hieronymus Syrturus de origine et fabrica Telefcopiorum nichté savon gedente.

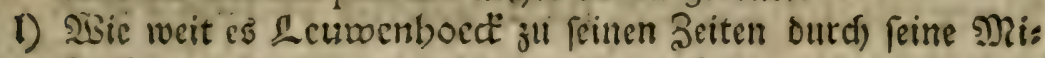
Erufeope gefrail)t, wie viele grolle, widftige uno wunserbare

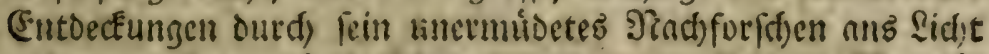

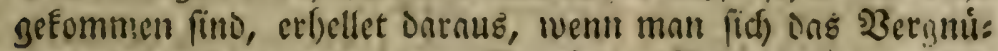

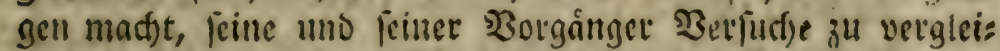
djen. Şinter meintem Joorellus frehet eine Centuria feinet obfervationum microfcopicarum von $16 ; 6$. Die 68 D6: Fervation fantelt de Infeetulo viridi, von weldsem er siefe

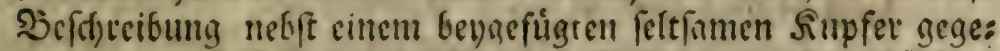
beıt bat. "Infectula viridia in foliis Sycomori, vel Pfeudoplatani, aceris fpecie funt, quae diaphana videntur in vitro, et cornua divifa et furcata in apice habent, oculos magnos et nigros habent, licet animalia parra fint: per 24 horas vixit unum eorum, ficque eft. Credo fuiffe Locuftae rudimentum, vt reperiuntur in majali fyuto coeli, in pratis, herbis adbaerente, et ideo 
licten Societrit Der SBifienjichaften zu Eondon fo ges

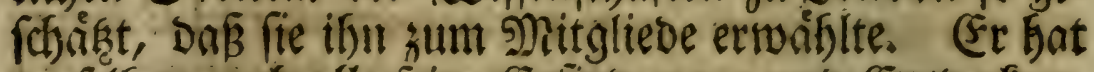
Derfelben aud) alle feine Erfindungen und Sintbeclun= gen in Den lefrreich)fen zBriefen übergébet.

Saker hat von feinen S̈lajern einige Nachrich= ten und 26 biloungen in Rupfer geliefert $\mathrm{m}$ ). N(ad) Reuwenboecks Tobe find fie alle Der Societất ge= (đ)entt. İn allen waren es 26 Siláfer, und ein jedes Gatte fein beftinmtes Objeft. Z Zaker fagt Davon: fie wairent einander in ber form alle gleid), und in Der Brofiffe, ober auch unter einander ivenig unter= febieden gewejent. (Er habe fie felbit drei) Mronat sur Itnterfuchung gefabt, und feine GiebanEen Daruber 1740. in Dem 458 Stúcle Der philofophifchen Erans" aktionten Der Societåt borgelegt. (Er melDet unter

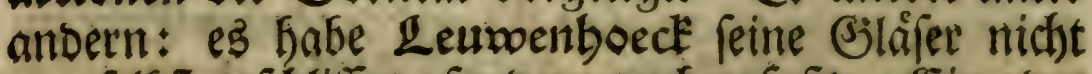
nur felbit gefdulifen, fondern auch) gefaßst. (Ein odeet bóchifens iner Obiette babe er auf eine Nabel ge= leimt, uns für jedes Glas vernafiet, fo daß̉ ein ie= Des Inftrument zu einent DDer zwey Dbjeften, uno fonft zu nichts babe foonnen gebraucht werben. (End=

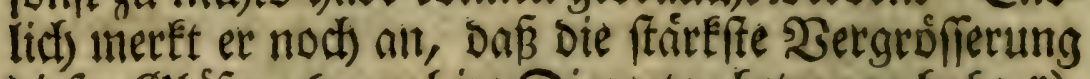
Diefer (Gláfer 160 mal im Diameter betragen fabe n).

NBie

oculos magnos habuit, quia erat animal adhuc recens natum: omnia enim animalia recens nata oculos habent

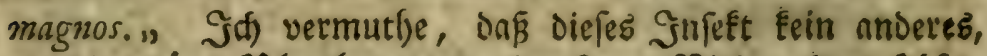

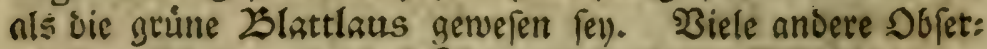
pationen fandeln de infectis anonymis. STie weit war

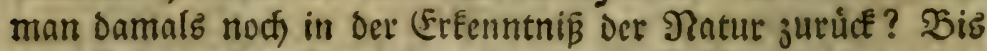

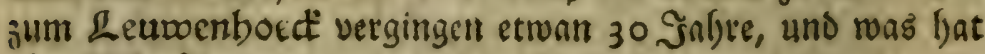
et geleiftet?

m) 2 Seytráge zu núbliḑen uno vergnnigenoen (Gebrauch uno

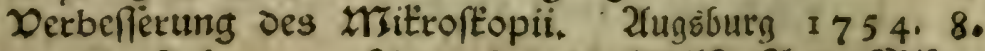

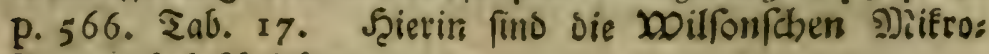

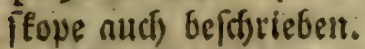

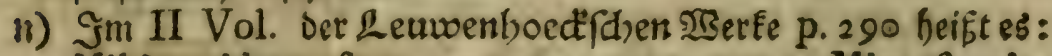
Mihi quidem funt centum, centumque Microfcopia. 


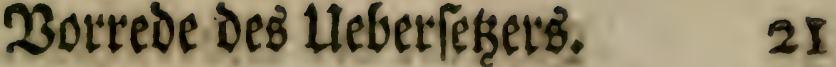

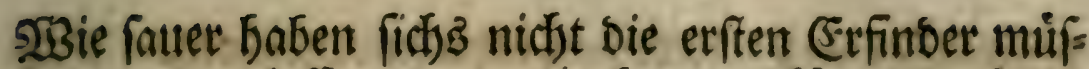
fen werben laffen, und wie bequem Énnnen wir in unfiren Tagen $\mathfrak{B e r f u c b e}$ und 3 edobactumgen anffel= Ien? SBuirden wir aber fo weit gefonmen fenn, wenn

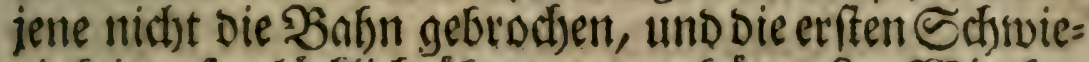

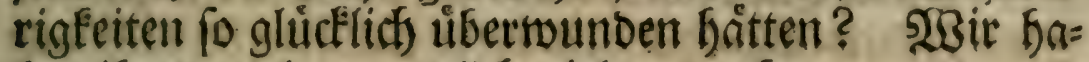
bent ifnen viel, unenolich viel zu banten.

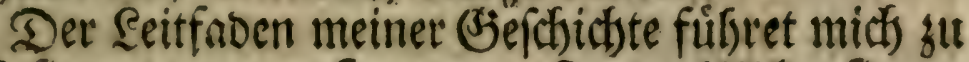
Der Erfinoung Der zufammengeferzten snierofése. Db man gleid) einen gerwifien (Sornelius Dorebbel in Engellonb fuir Den erffen Erfinder ber jufammen=

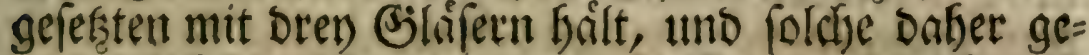
meiniglich 2onglieanta nennet; io ift es Doch nicht mit Genvibfeit auszumachen, weil aus Dem oben ange=

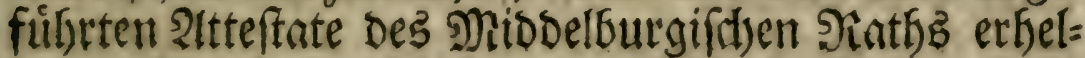
let, Daß Diefer Drebbel 1620 nad) Mids delbut'g gefom=

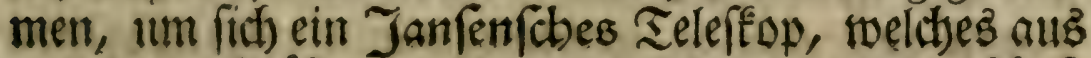

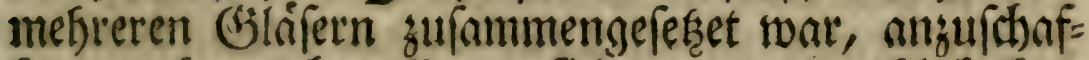
fen, nad) welcher (Compofition er vermuthlid) ber= nach Feine zufammengefeste Niferofépe eingeridstet.

Siernuf bat man von Zeit zu Zeit gefucht an Den zriteroftepen allerlen) 2 Berbeffertugen anjubrin= gen, nachoem es bie Durdffichtigen unb unourchfich. tigen Obięte, und andere Seburfniffe erforberten.

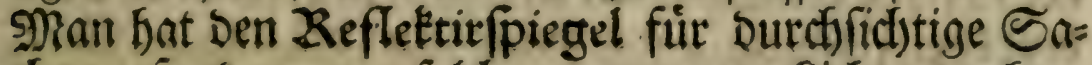
d)en erfunden, um folchen von unten eicht su geben.

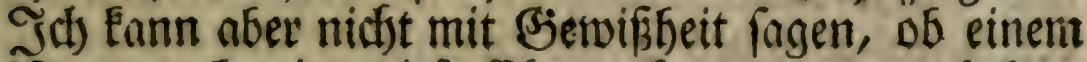
Fleuton bereitz diefe (Egre zufomme, ober ob Lies berkúbn biefe (Erfindung zterfit nact) Engelland ge= bracht. Mant hat ferner Collettiogláfer, metallne zoblipiegel uno bergleicfen fingugefigt, um bie un. b. 3 Durct)=

Die neteften und volf(tansigften Nachtid)ten ven ben Leu:

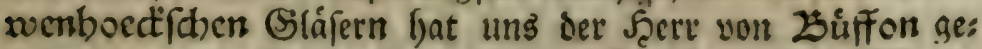
geten, oer uft Gielegenfeeit gebabt, fold)e famt einem Zlecos bain iu unterfudjen. S. 2tllgemeine Gefbidhte see 7.tutu. Şerlin 1772. 8. IV. Th) P. 4. 
Duthffithtigen Dbjekte von obent fll erleuchten. Die= fes hat vermuthlid) Die erfte (jelenentseit zu Der (Ev= finoung Der Sonnenmitroftepe gegeben, Davon uns

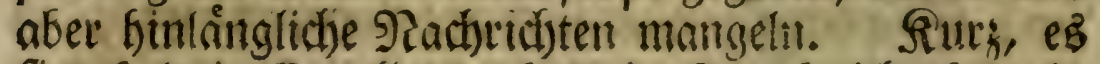
find ba!d in Engellans, bald in Frantereich), bald in Deutfichland und Solland berúfmte 3 erbefferer Die=

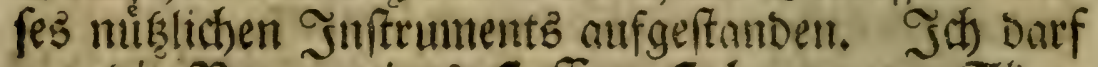
nut Die গRamen eines Cuffo, Culpeppers, Etat; Iets, eines Joblots, mufcherrbecl's, 23ranoers, Zettels, Teubers, 23ifchoffs und Liebeekúbns nen= nen; fo werden fienter bon felbft wifien, wo fie ivei= tere SRadsrichten zu futchen bobent.

Da úberhaunt Das̉ Etudium der গaturge, fahidhte in unjerm Jabihumberte fo boch gefticgen;

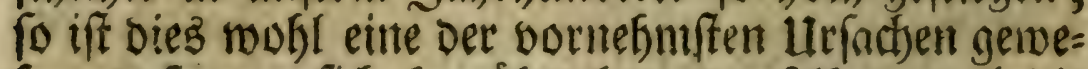
fen, Daß́ man fid) kemuifet bat, Demfelben Durch Die Kunft zt Sallfe jut fommen, ober bie triter oftope an verbefferit. MReine Lefer werden es von felbft er.

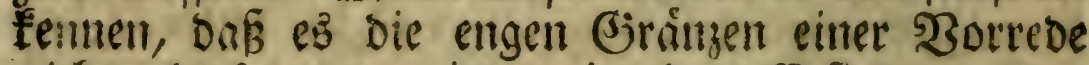
nicht erlaubert, won jeber einjelnen (Erfindung oder Berbefierung eine Fadyricht z" geben. Den!r man hat in untien Tagen fait für jedes $\Re$ Raturreid), uno fir ieben Theil Der গcaturfunde, s. (E. für Die 2unas tomie, fur Die Zotanie, u. F. w. ein befonberes 2 Mis Erofleop erfinden, wie Denn Die Marfoballichen, uno einige Lieberkúbn (che bloß zur Feobad)tung

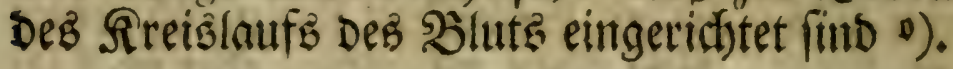

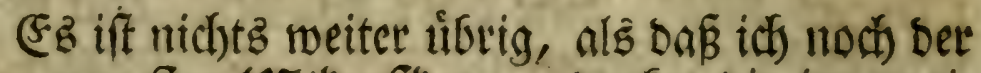
beuben neueften strierortepe gedente, bie im vori= gen

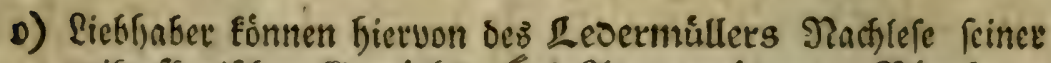

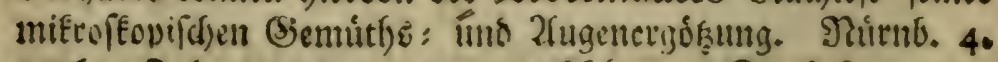
1762 . Fab. 23. 24. p. 45 . nadjelent. Eonft farm mant

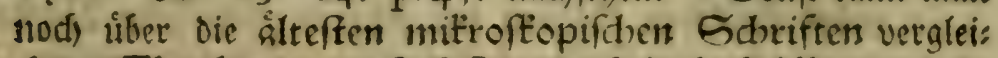
dern: Theologie des Infectes traduit de l'Allennand de Mr. Leffer par P. Lyonet。 à la Haye s742. 8. Tom. I. p. 17 . 


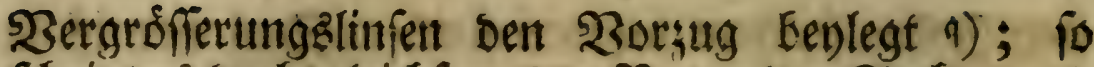

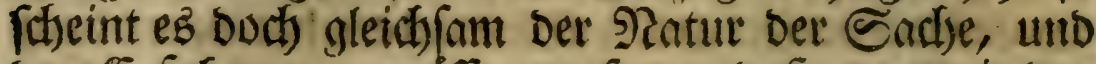
Der Erfafrung gemaffier zu fernn, Daß́ man mit Dent 3ufammenteferten trititof'topen, nicht mir meit bequemere; fonbern auth weit ridftigere Şeobach)=

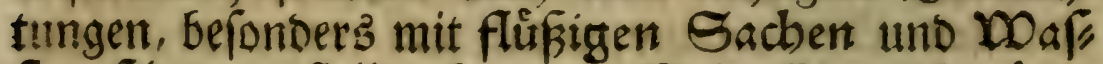
ferinfetten anfellen fann. Nein Exempel wurbe

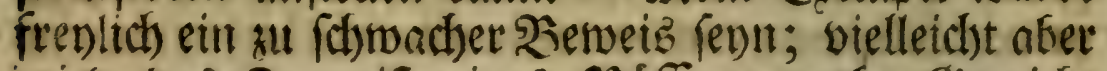

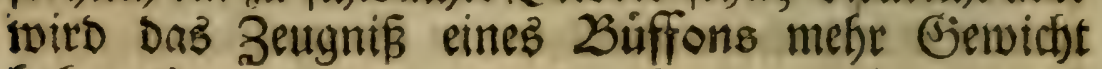
Gaben r).

Das Boffmannfche EMittrortep ift bont Det

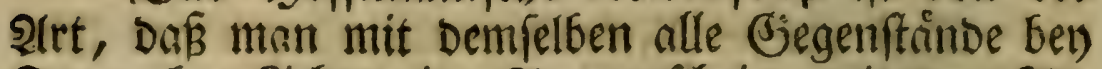
Tage, bery Eictste, im Sonnenichein, mit Dent Sie= fieftirfpiegel, mit Dem Colleftioglare, wie man mut will, auf bie leichtefte und Eequemfte siBeife, infont= Derbeit mit einer feffr gefdywinden 3 erainderung ber

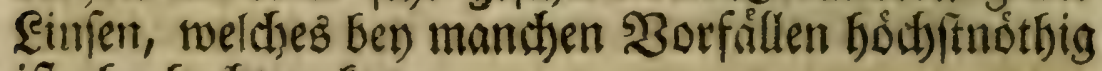
ift, beobachtent Eamn.

Das nene und widbtige an biefem 2 Trietrofteop iff erfflicb Diefez: Daß́ man Daben vier DEularglajer

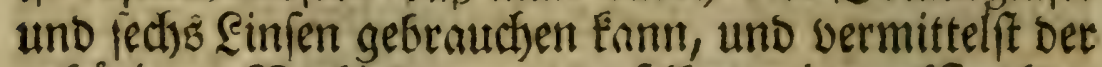
gehórigen $\mathfrak{B e r b i n b u n g e n ~ D e r j e l b e n ~ e i n e ~ e i l f m a l i g e ~}$ Bergroffierung ju madhen im Stande ift, Deren ftất" = ite fich bis auf s strillionen erftreclt' $s$ ). Durch biefe Eann man auf Dem trićckenftuggel bie allerfein=

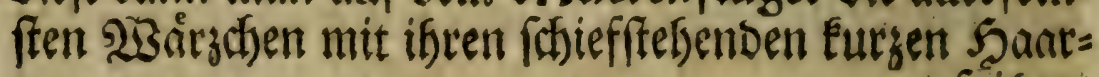

fpirent,

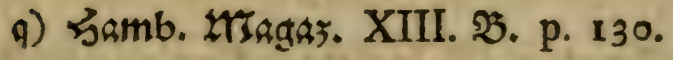

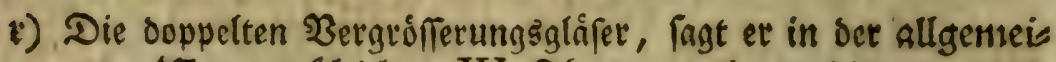

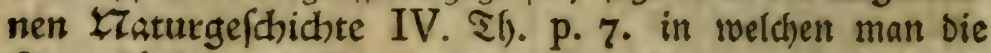
Eegenffánde von oben therunter betradjtet, verbienten einen

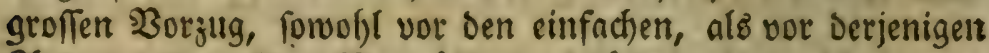

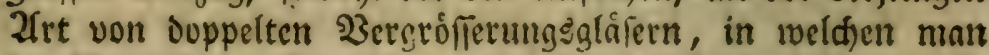

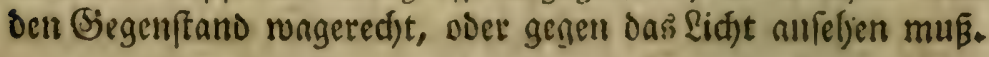

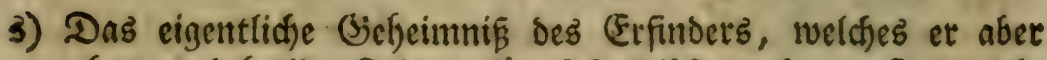

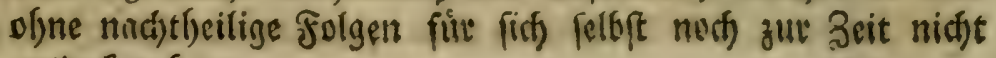
entocten Ennn. 


\section{Zortede des Lleberfę̧et'. 25}

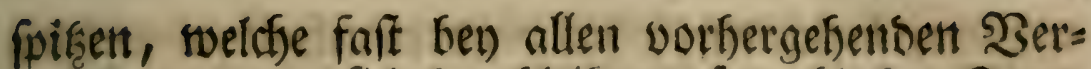
grofferungen unfithtbar bleiben, fowofl ben Sage,

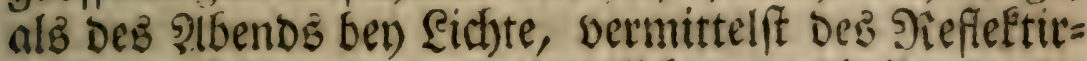
fpiegele, fefir gennu und Deutlid, untericheiden.

Das voritigliche Diefes Imitroftops beftefet 3weytens nicht eigentlid) in Dem (iufferlich fibon auf =

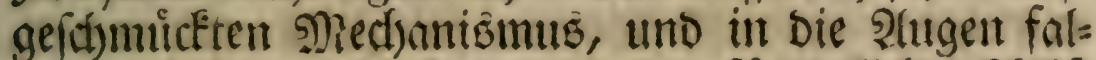

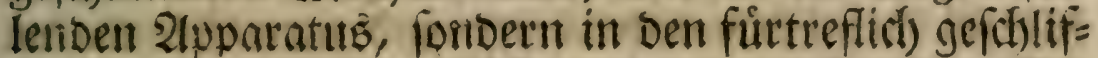

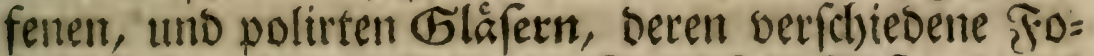

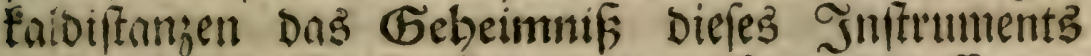
musmadjen. Diefe allein, uno nid)t Das antfierme= Fentliche, verbienen nach ifrem Wiserth geichåkgt, uno einem Rúnfter bejafilt zu werben, Da es ben Den meiften 2nnglikanis, Die ich) unter Shinden gefabt, gerabe umgefefret ift, bor fie ainfierlich) St)muct ge= mig, aber (chlechte Ẻläjer fabent.

Id) Eoume orittens a Der eigentlichen probe eines vorzuglichen Mifroff́cops. Diefe mußs mant nicht mit bem Siefleftiripiegel, fonbern mit Dem rei= nem Tageslichte bon oben, uno ber) unburchfictstiget Ro orpern mad)en, Damit fie iffe naturliche Fartbe uns

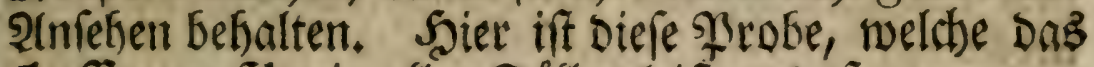
Zoffmannfbe in allen Fâllen leiftet: Daß

etftlicb bey Den ffirffifen $\mathfrak{B}$ ergroffierungen die Gegenftánde beftandoig helle, groß Dornefimfte ift, in Dem reinfen eid)te foharf afge=

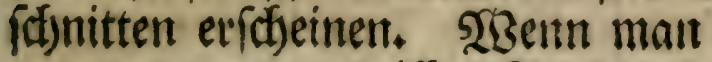

3 weytens weiffen Sand, ober Staub von bem

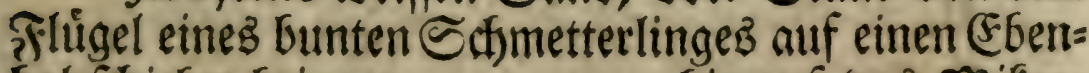

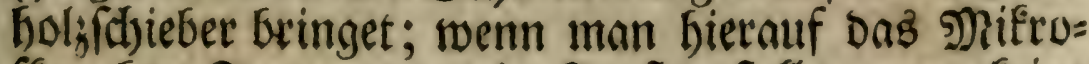
flop ber. Tage gegen ein Tenfter ftellet, wo keine Some finfheint; fondern wo man bló̉ Das reine Shimmelslicht Gaben Eann; wenn man ferner mit Dem (Erleuthtungsglafe biefes helle Tageşlid)t auf Dem Obiefte concentriret, und al benn Pidstung giebt, of

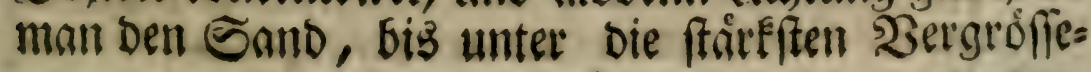

rungen, 


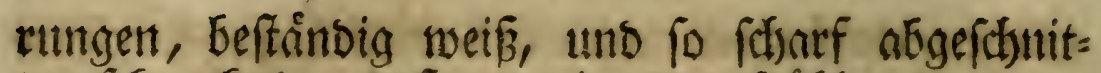

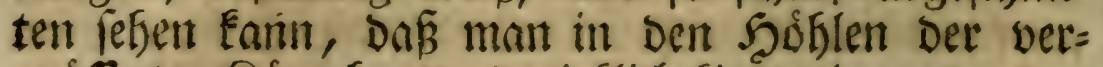

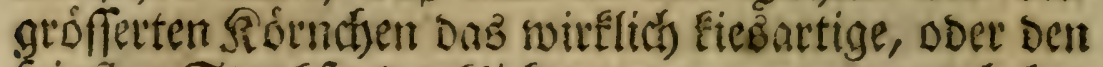

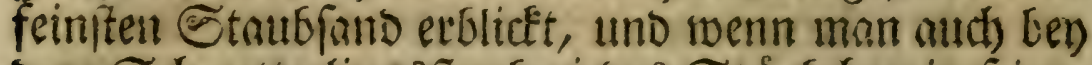
Dent Edymetterlingşfaube jebes Stâubchen in feiner

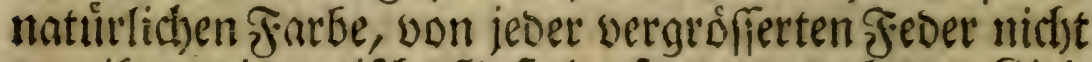
nur iffre prismmati(che Gieftalt, fonbern auch Den Siel, Die feinffen গebenfeberdfen, unb fogar Die Goblen

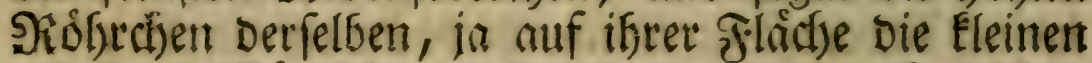

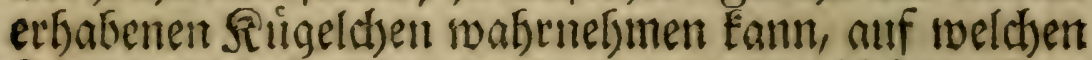

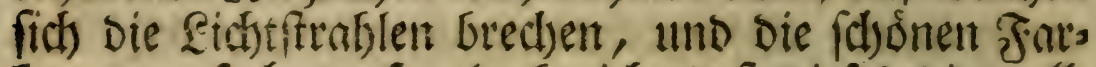

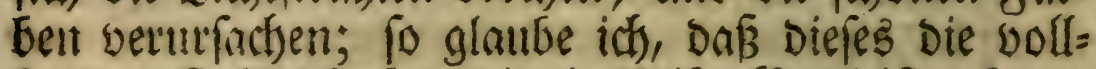

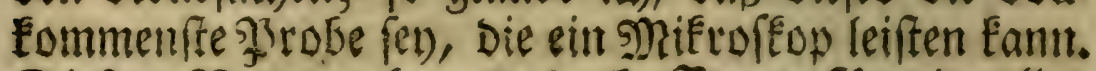

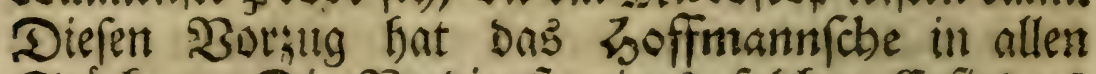

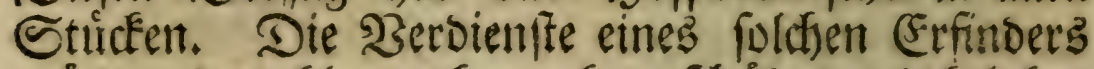

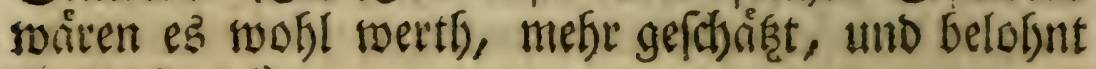
ju werben $t)$.

3enounbertung und Freube breitet fich allegeit

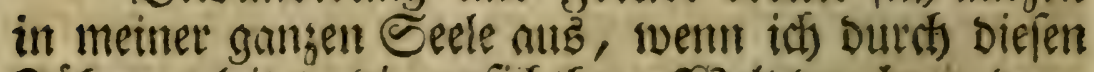

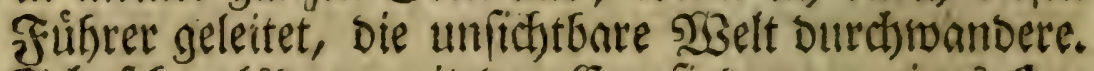

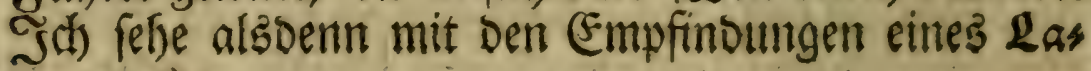
motte "):

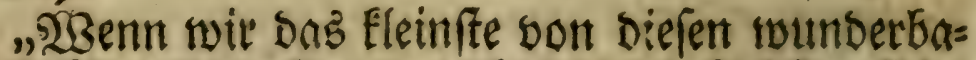

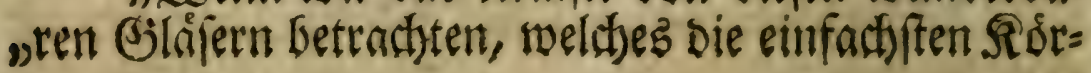
gper

t) Nouvelle Bibliotbeque germanique Tom. X. p. 354. „Les Obfervations microfcopiques de Mr. de Buffon et de Mr. Needlam nous ont decouvert une nouvelle Nature, et femblent nous mettre en droit d'efperer bien de' nouvelles merveilles. Elles font fi curieufes et importantes, que, quoique l'experience ait fait voir, qu'elles n'etoient pas au deffus de la portée des Particuliers, elles meriteroient cependant d'être encouragées par le Gouvernement; qu'on y appliquat plufieurs Obfervateurs; qu' on leur diftribuat les differentes matiéres à obferver; et qu' un propofat un prix pour l' Opticier, qui leur auroit fourni le meilleur Microfoope -

4) Jamb. Itragas. I. 2B, p. 201. 


\section{3ortede des Lleberfęer's.}

„per bersielfâltiget, uno die fleinften, unb ber natse nyar niatt in die Sintre fallenten vergroffiert; was

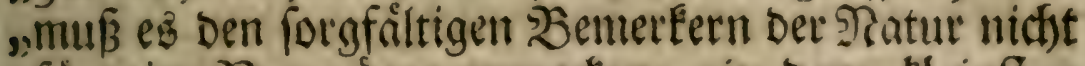
"fult ein ßBergmigen erwecken: in Dem Eleinftent „Gaamen Den Stamm, die Blatter und 3weige des

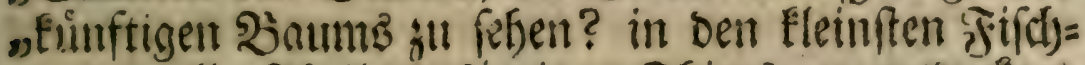
,rogest alle Theile Desjentigen Thierz gll entbecken,

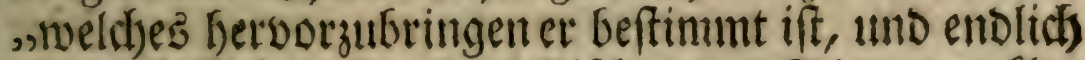

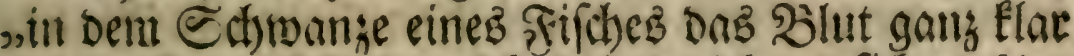
"umlanfent zu ferfen, welches, wie idh verfichert bit, "Dem Zarvey bie erfe Inteitung gegeben, Den 1tm= "lauf Des (jeblut im imenjh)lichen Rórper ausfúndig

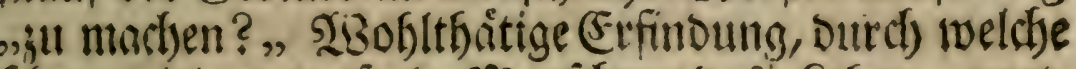
faton vielen taufend Mlenjaten bas Eeben geret= tet iff!

III. Zuleseft Bin idf mur noch verpflictet, meinent genteigten Lefern von meiner geringen $2($ rbeit bey Diefer lleberfersung einige \$ied)en(d)aft zul geben. s) (eine vornefmite Bemuithung habe ith Daranf gerid)= tet, Den Sinn Dez Detfaffers nufz genauefte gu tref= fen, uno, wo mogglich), fo auzzubricten, bas bevoe Epract)en Daben nidyts verlieren. Das billige pus blitum mag urtfeilen, ob id) Diefent Zmecte erreinitit

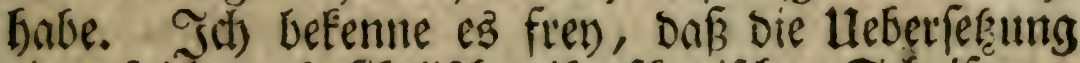
einer foldyen phyfitalifd) mifrof fopifchen Schrift un= endich) (ct)werer, als einer andern moralif(c)en ober bi=

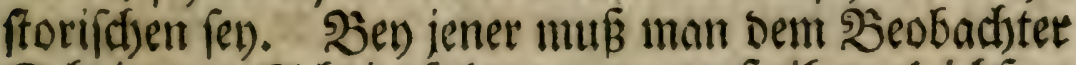
Echritt vor Sd)ritt folgen, man mur ifm gleich)am

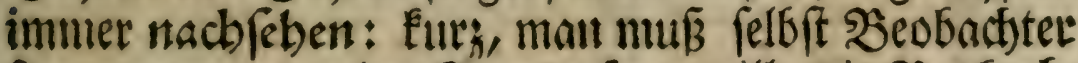
(et)n, wern man im Stande fern will, die SBeobacts=

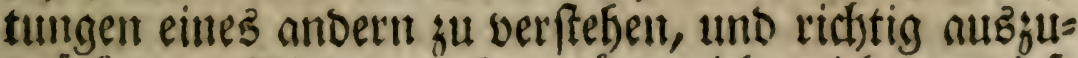
Dritcen. Nimmerniefse wirbe id) mich an biefe Sd)rift, ber weldher tiberbem fo viele Guiclen auşith= fullent maren, gewagt haben, wenn ich nicht felbit icton feit einigen Jahten, Die গatur mit berwaffneten 2u 
macht, und alfo daburds in den Ctand gefereset måre, nidst uur feine Menmung ridftiger zu fafien, fonbern

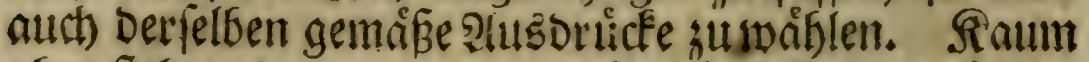

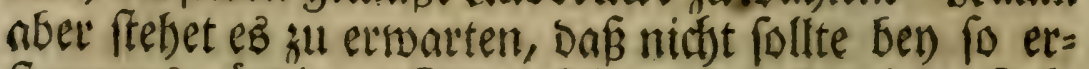
fraunenswuiroigen Rleinigkeiten, ben fo vielen zah)=

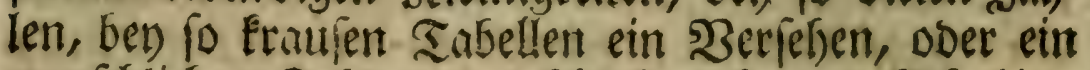

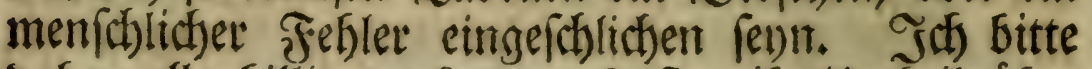
Daber alle billig Denfenden Lefer, iffr utrtbeil über

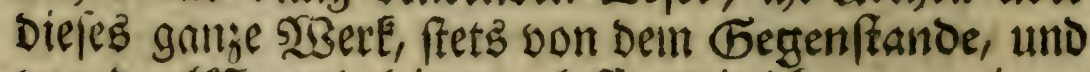

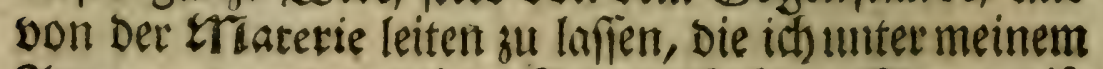

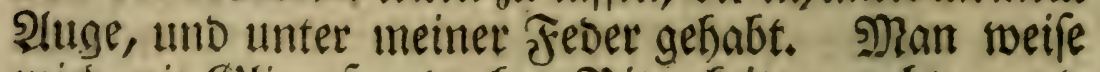
mich) mit (Silimuf und obne SBitterefeit zu red)te; und

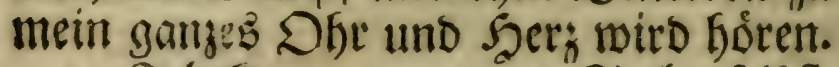

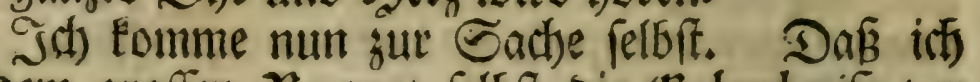
von bem grofien Zonnet fellbft die \&Erlaubnif zur Iteberfésung Diefer feiner Echrift erfaltent, Daß́ er mir felbit Stoff gegeben, biefélbe fo vollftándig, al3 móglict) zu madten, (aun id) mit feinen eigenen $2301=$ ten berweifen $\mathrm{F}$.

Seert Bonnet erinnert ferner bie Dructffebler Dez Originals zul verberfiern, und bie binten benge=

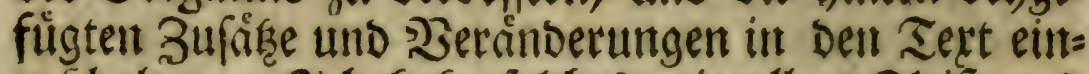

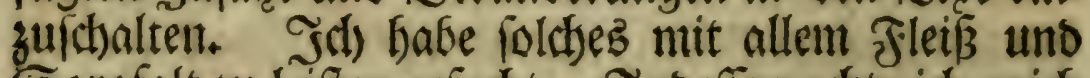
Sorgfalt zu leiffen gefiucht. Sinbefien adbte ith midy

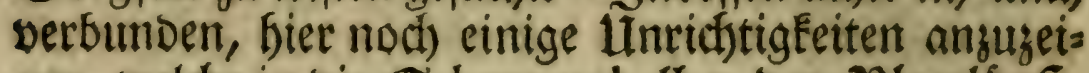
gent, welld)e in die Geburtstabellen Der 2Blattláufé,

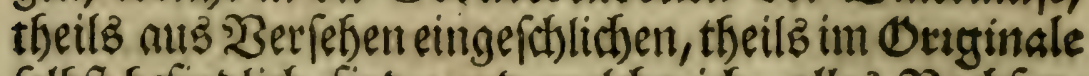

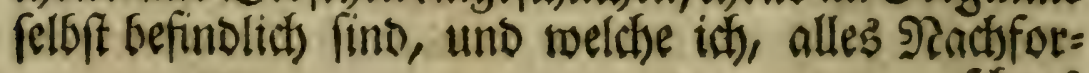
fichens

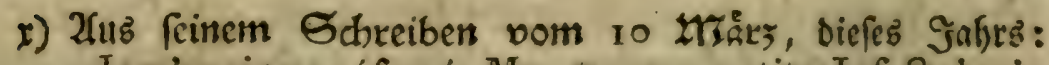
„Je n'avois pas éfperé, Mr. que ma petite Infectologie auroit un jour les honneurs de la Traduction. Cet ainé de mes Enfans ne me fembloit pas fait pour jouir des prerogatives de fes Cadets, que diverfes Nations fcavantes ont bien voulu adopter. Cette production de ina jeuneffe vous derra donc, Mr. d'être mieux connue de vos Compatriotes, et l'Auteur vous prie d'en agréer les temoignages de fa jufte gratitude." 
ben fabe ich abermal nidft genuft, wo id bie úbets flúfige wegnefinen follen.

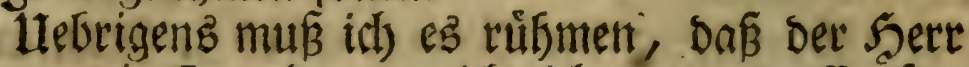
Berleget Die Correktur, weldse ich wegen Der Entfer=

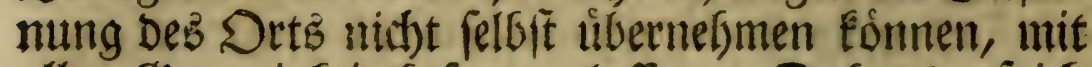
aller Gentantgeet beforgent laffen. Daber Darf ich Dem geneigten Lefer mur einige 2 erbefierungen anjei= gen. 5. 16. Lin. 7 an fatt auszublíben, lies auf" 3ublikben. 5. 53. Ein. 23. an ftatt Rooertbiere, lies Rabertbiere. 8. 119 . Sin. 15, an ftatt Schne" ckenmuctên, lies Scbnakenmucken. S. 263. Eint. 2. an ftatt erfí, lies vefít S. 310. Lin 15. an ftatt: an oen - finden, lies: es ift aber felten, nuitme in oiefem zuftande 3 findern.

Die Kupferplatten des Originals haben mir

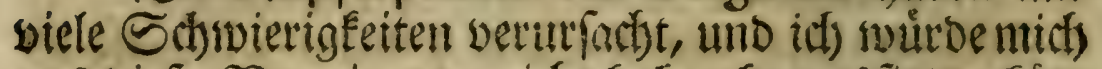

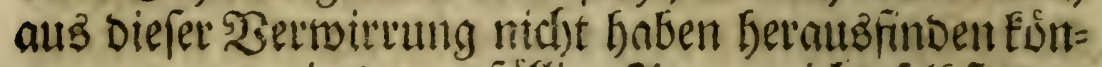
nen, wenn mir Der gefíllige 2utor nidjt felloft Dent

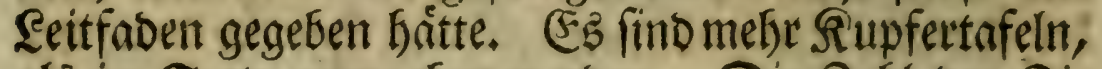
als im Terte angegeben werben. Die Zabl Der Tri= guren trift nirsends su, und bie 2inseigelettern in

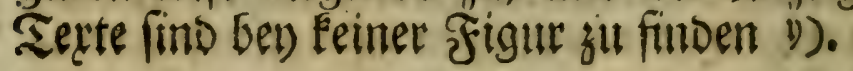

J(1)

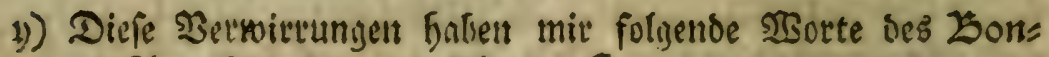
netf́chen @iviefés aufgeflárt: "Comme cet ouvrage, auquel vous avez la bonté de vous interesfer fi vivement, n'avoit pas été imprimé fous mes yeur, il s'y etoit gliffé quelques fautes d'impreffion, dont la plupart font faciles à corriger; mais, il ne vous feroit pas auffi aifé de lever les embaras, qui naifent des renvois des Planches. Voici donc de petites directions, qui ne vous feront pas inutiles.

Mon Manufcript etoit in quarto, et divifé en 2 Parties. Chaque partie avoit 2 Planches. Le Libraire de Paris ayant preferé $\mathrm{d}^{\text {'imprimer }}$ in oćtavo, partagea $c n$ deux claque Plancbe du Manulcript: il en donua donc 4 à chacune de 2 Parties de l'ouvrage, et negligea d' en asertir le Lesteur. Je ne pus le lui faire remarquer. 
firgel' Des (Originals werden aud) nadi Diefem Reitfas Den, ifre Supfer felbft leicht aus einanber féżen, und

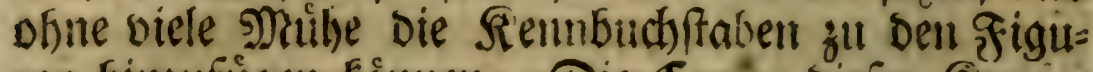
ren binzufuigen Eomnen. Die Copey Diefer Siupter aber iff fo serathen, Daß́ meine Lefer hoffentlich $D a=$ mit iverben zufrieben fenn.

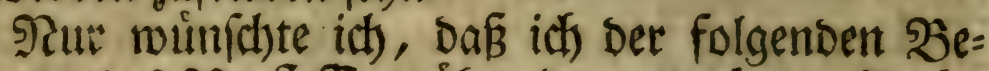
f(d)werbe Des Derfaffers uiber oie unticbtige Jeich" nung eines Dofferwourms gur I und XVII Dbjer= Dation Des II. Theilš Der InjeEtologie, ebent fo leicht Gátte abjelfen fonnen t). Diefen DefeEt habe ich laffen nuifien, wie er war: theils meil es ntir ummóg= lid) genveren, in biefigen Bjegenden eimen Dergleithen

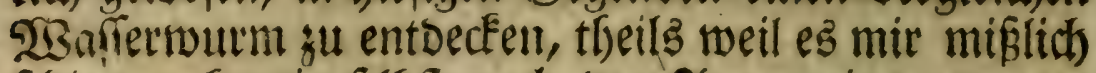
fdient, 06 mir felbit nod) Der 2lutor eine accurate Zeifinumg Davon hâtte ifficken Esonnen. In feinem 3 woeyten Shareiben vom 30 Junius hat er mir jwat

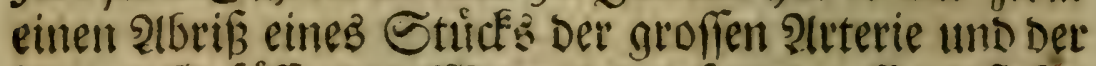

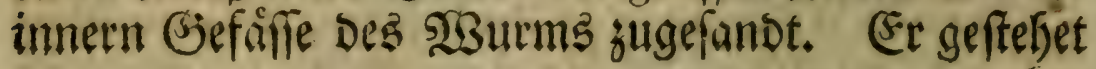
aber

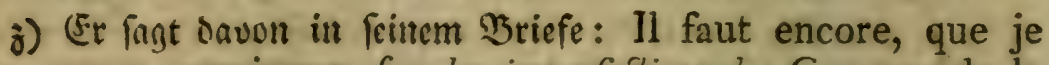
vous previenne fur les imperfections des Gravures de la 2de Partie de cette Infectologie. J'en avois moi meme crayonné les Deffins. Y'ous n'ignorez pas, que I' Obfervacteur rend bien plus fidelement la Nature, que le fimple Graveur, qui ne la connoit point, et qui n'o. pere que mechaniquemeitt. J'avois reprefenté par des traits tres fins de belles Ramifcations de Vaiffeaux, que javois decouvertes de part et d'autre de la grande Artére cians mes Vers d'eau douce de la premiere éfpece. Ces Ramifccations n'ont point été rendues par le Graveur : apparement qu'il n’avoit pas la vüe affez bonne, pour les appercevo $r$ dans mon Deffin: quoiqu'il en foit, fa Grasure eft extremement defectueuffe, et ne prefente rien de confus. Je parle de la Figure 5 de la Planche rre. Le Graveur a de meme très mal exprime plufieurs mes Def.

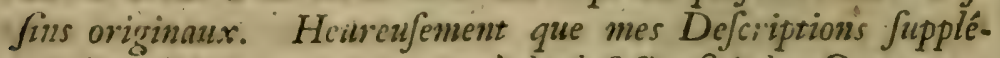
ent jusqu' à un certain point à la deffectuofité des Gravures; mais l'imagination du Lecteur a toujours quelque chofe à faire, et j'avois defiré de ue lui rien laiffer à faire. 


\section{Zortede Des Heberfekerts.}

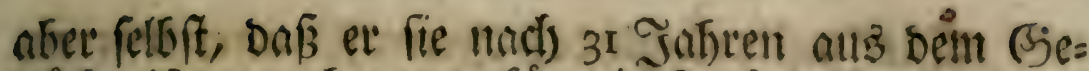

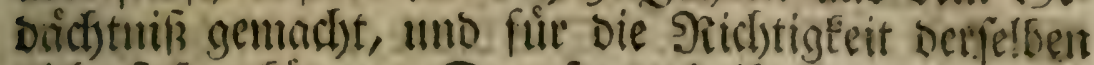

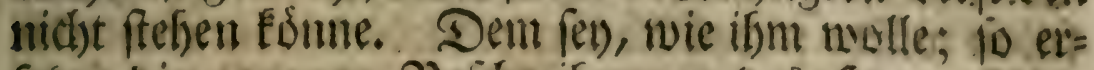

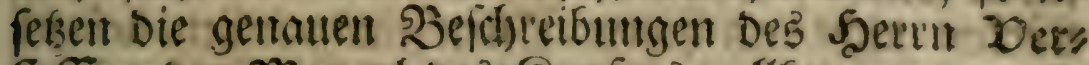

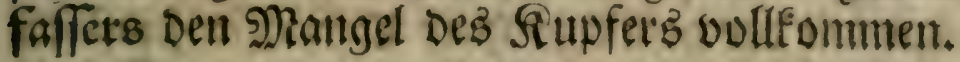

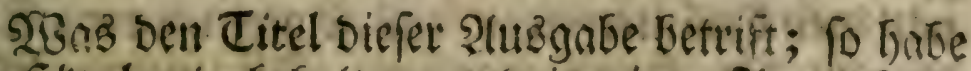

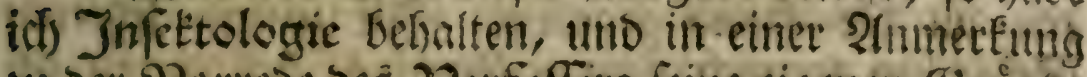
jul Der 23orrebe Des Dertaffers feine eigenen Girinbe Davon angefuifut. (Eigentlich) und gentur zu revert, murbe ber zweyte Theil biefer Edtrift: 26handhng antis Der belmintbologric haben betitelt werben muifo

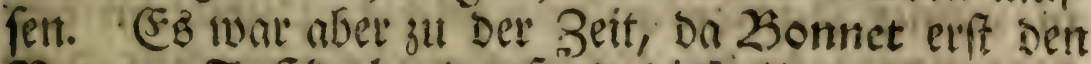
Namen: Infertologic effanb, bicjer Lunterfdied nod) midht befant, tmb es liegt autch nithts Daran, weil Der Detfaffer nicht Die Pibficht hatte, ein Syftem 3 h

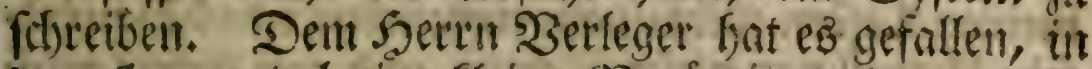

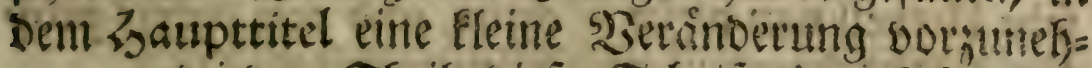
men, unb jebem Theile diefer E chrift einen befondern

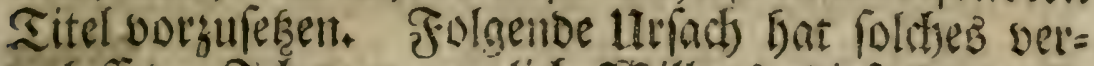
anlafiet. Idch war nemlid) Sisillens, Diefe 2lusgabe Durid) Das Dritte Dolumen gu vermebren, weldites Sherr Zonnet in Der 2Bortede veriprodjen Fatte. Jich befrug ifn besfoll, und er antrwortere mir: Da nicht eigentlich biefes britte $\mathfrak{3}$ olumen, fonbern einige einjelne Memoires, bie er Daju beffitmmt, Gerauşge=

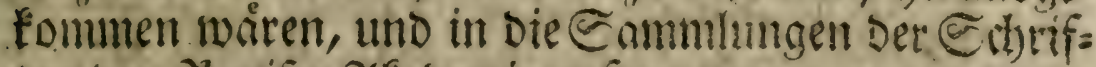

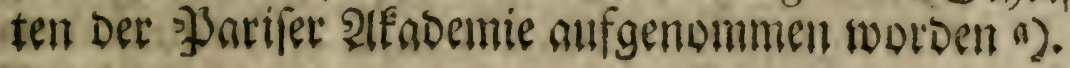

a) Șier ift feine cigene Erfflórunty. „Non, Mr. je n'ai point compofé ce 3 me Volume de l'Infectologie, que je femblois annoncer dans la Preface p.XVII. 'D'autres occupations font renues à la traverfe; mais j'ai enroyé en differens tems à l'Academie des Sciences de Paris plufieurs des morceaux, que je m'etois propofé, d'inferer dans ce 3 me Volume. Cette illuftre Compagnie a 


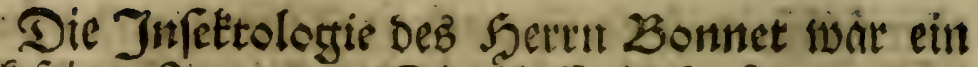

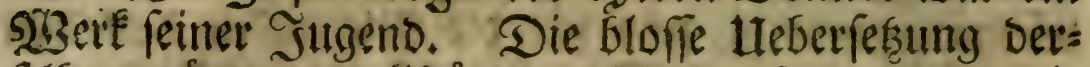
felten wuirbe unvollftindig gebliebeu fenn, wenn bie elicfent nicht an jebem Drte auBgefúllet wairen. Daju hat mir ber gefállige Serr Derfaffer felbit die nôtbigen Erkaiuterungen aแล feinen neueren Schrif= ten alt die Santo gegeben. In feinem lef̧terent Sdjreiben an mich bom 30 Junius, hat er mir be=

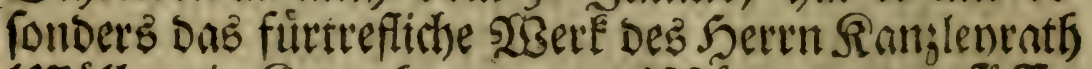
miullers in fiopentfagen: von Do ürmern bes fúffent und faljigen Doaffers empfoflen. Sidh hatte fichon in Ineiner Injeige aut Das gelefrte Publicum vont meiner vouthabenden lueberferzung, verfprochen, Diefe

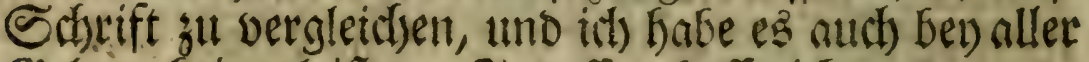
Gielegenteit geleiffet. Indeffen boffe ich): es merbe meiten Lefern nicht unangenefm (ên: Das Lonnet: fobe Urtheil won diefer Schrift, unt von diefent grop Fen Zeobacbter unferer Zeiten ju Gơren b).

Meine

bien voulu les adopter en quelque forte, en les publiant elles memes dans le Recucil intitulé des. Scavants etrangers.,

Es fino dir 5 erfen Boluntina der Memoires de Mathematique et de Phyfique, prefentés à l'Academie Royale des Sciences, par divers Savans et lî̀s dans fes Affemblées. 4. Paris. Imprimerie Royale. 1750. f.

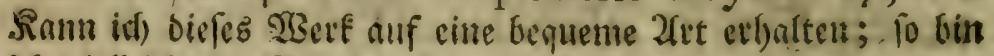
if) vielleidjt im Etanbe, Dnraus Eunftig einmal oen oxitten Ebeil oer Infettologie nกร \&idjt ju feellen.

6) Mon digne Ami, Mr. Miiller de Coppenhague, Membre de plufieurs Academies, a publié $177 \mathrm{I}$ un bel ouvrage in quarto, fur ces memes Vers deau donce, qui font le Sujet du Tom. II de mon Infectologie. Ses obfervations font très intereflantes, et contiennent quantité des faits nouveaux, que je n'avois pas été, comme lui, à portée de voir. Il a donc fort perfeEtionné mon travail, et il à étendu fes Recherches fur plufieurs 
Mreine Lefer werben biefe Etellen in ben 2 n" metkungen unter Dem Terte finden. Itnd bon Dies

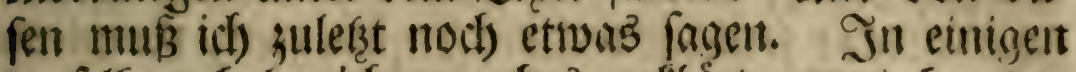

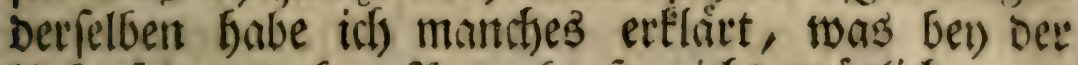
Iteberferzung of ne glaraphrafe nidft moglidh war; was aber Dod) of ne (Erflárumg Dunfel geblieben wa: re. In andern babe ict) Die Linneifoben recipirtent flasifichen Infektens uno Kirànternamen angefüfrt,

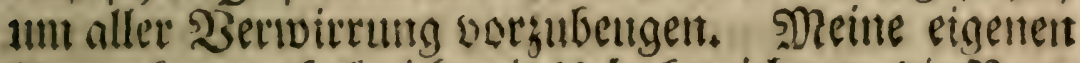
2mmerfungen falbe ich mit Ueb. Geseichnet; Dic boris net fchen aber entweder Dutch ein 23. Doer Dutch gat

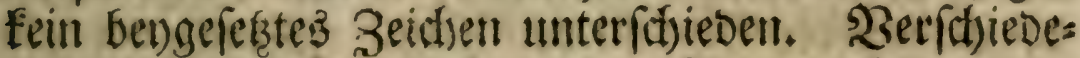
nez, wab im Driginale an ben 9iand gejerzet war, brabe idf un mefrere SBequemlich)eit willen in Det Tert felbft gebracht, weil Der Sefer po Ebaraftere ge= nug ju untericheiden bat.

(Enslid) babe (ii) andi) in bem 2nhange 3um 3weyten Theile einige eigene inifiv f́opif h) 23 cobact)= tungen bengefüget. Firenfid) ift es viel bon nir ge= wagt, foldbe Den Zonnetichen an Die Seite zu Fersen.

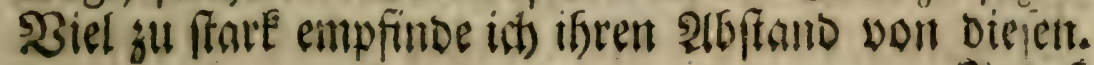
c 2

SInDef:

plufieurs éfpeces de Vèrs de meeme getrè, ou de gett. res analogues, qui ne m'etoient point connues. Yous rendriez fervice au Public en enrichiflant vôtre InfeEtologie allemande des Decouvertes de l'Oblervateur Danois, qui font relatives k̀ mes obfervations It fufa firoit, que vous donnafiez un Precis de ces Decouvertes, et que vous montrafiez à vos Lefteurs ce que Mr. Mïller a ajouté á ce que j’avois vû; car il n penetré bien plus avant que moi dans la Carrière. Il a beaucoup de fagacité et de patience, et je le regarde à jufte titre comme un de milleurs Ouferiaturs du Siede. Son Ouvrage eft orné de très bonnes Figures; entr" autres celles des petites Anguilles, que l'Auteur' a res prefentées groffies au Microfcope Pl. Il et III, et qui me paroiffent de la meme efpece que celles, clont j'ai parlé Obf: XXl. 


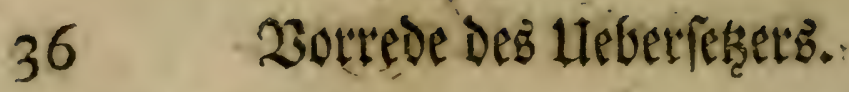

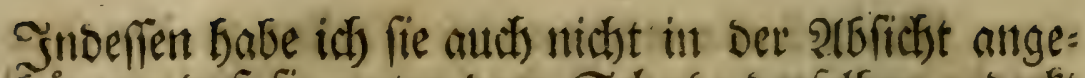

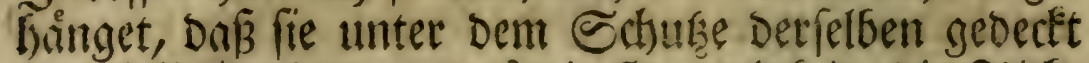
Fenn follten; fonbern Daß̉ bie (Sennuigleit, Die Pitid)= tigfeit, unb weit getriebene 230 ollfommenbeit Der

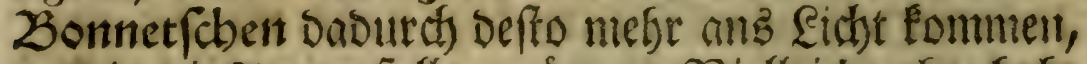
anb in bie פlugen fatlen mógte. 2Sielleicht aber frabe id) Dodf woff einen guinftigen zaugenblick, wie fids mein 2(utor ausbrichet, gehabt, eine fuir Die গaturges

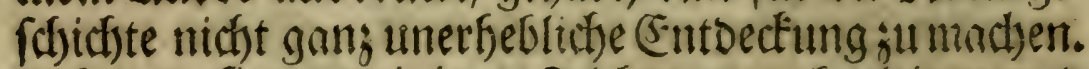
Ind) bafe fie nut einigen Beidjunungen begleitet, und meine Lefer mógen urtheilen, ob Die Rupferffiche

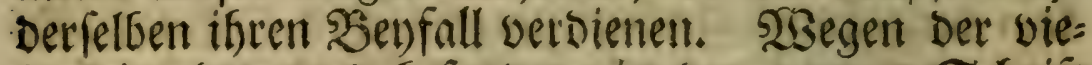
len eingelnen und befondern in ber ganjen Echrift enthaltenen MRaterien, habe ich fuit nothig erachtet, fie mit einem Regiffer zut verfertert.

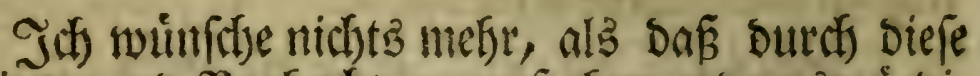
शrbeiten und Beobad)tungen fo benundernsiwirdi= ger Bjefchöpfe, Der unbetannte Gott: Der im Rleinen fo groffe, Der im utnfictstbaren fo fictstbare, Der im 2erborgenen fo offenbare, weife unb herrliche Echöpfer, vielen feiner vernunftigen Siefhöpfe bes Eannter iverde.

Ouedlinbutg, Dell 20 September 1773. 


\section{the}

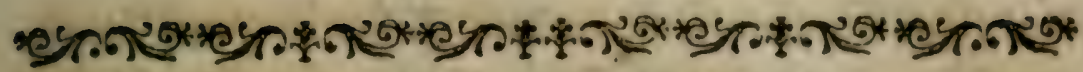

\section{Sortede Deß Berfânet:}

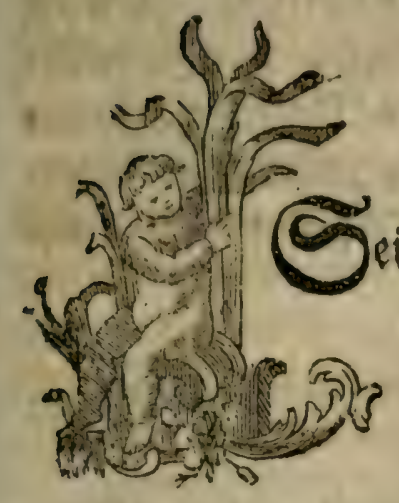

eitbem Die Prilofophie ift berbeflert morben, bat man aud erfit ans gefangen, Die Jnfeften mit 2 uf = metefanteeit, uno nad) Giruin= Dent zu Geobadten. *) Diefer glictelidfen (Epod)e, ftubierte man nidft fowohs die ?ratur felbit, als mur eigentlid) Die smennungen einiger Philofophen. Won Begebentheiten futdte man fidf wentiget Durif bie Erfalinung, als Durd)

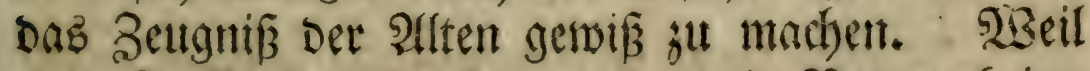

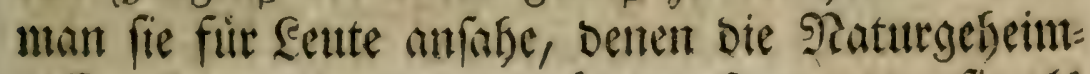
niffe allein anvertrauet wâren: fo wurben fie als Drafel befragt, uno fo gar ifre Fusbructe uno Sruthuimer wurben bergortert.

Ilnter biefen llmfintmben fonnte die sRaturge: (iffidjte wentg ober gat nidjt junthment. Da ez

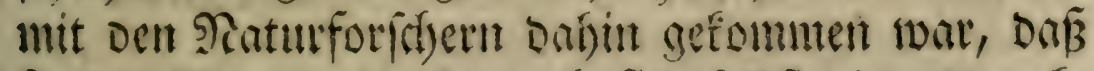
fie die Siten, und bernadif fidi) felbft einander $a b=$ c 3

fortie=

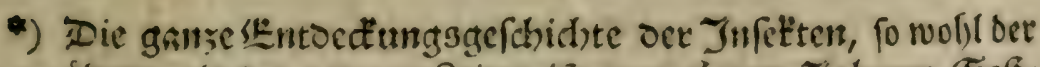

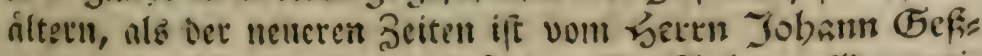

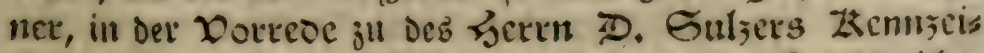

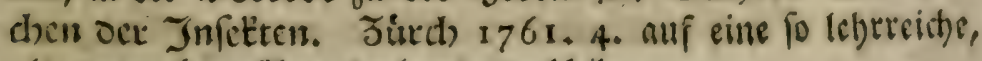
als ansenelyme 2fit aliget)andelt. Hlcb. 


\section{3ortede Deธ่ Zetfaffetร.}

fogrieben; fo trugen fie in ifree Edyriftent, mit rwent=

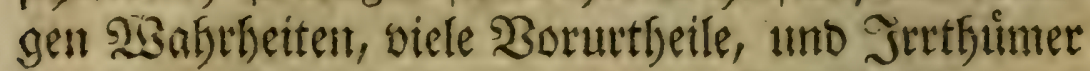

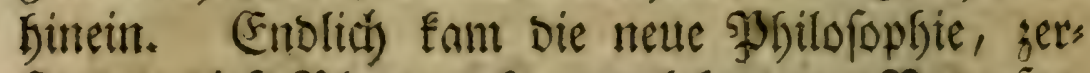

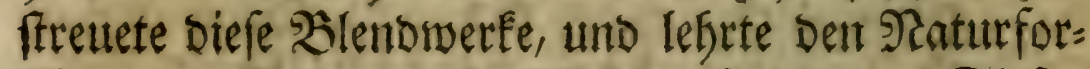

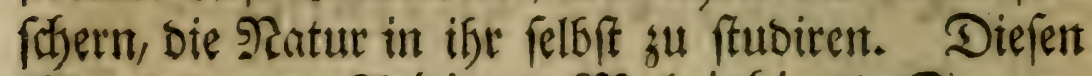
2Beg Gaben Die Medi, Die Mialpigfi, Die Erwam:

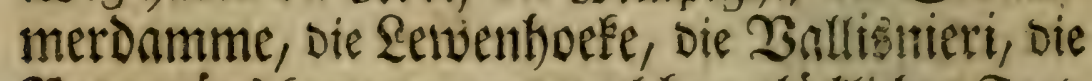

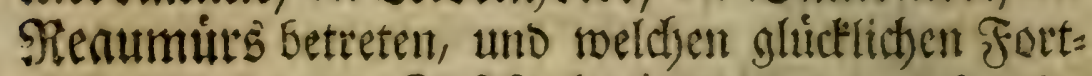

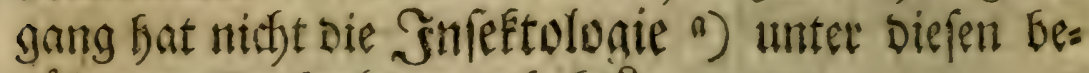
rifismten seobactetern gefart?

Einem

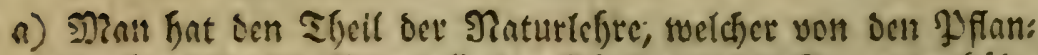
jen fantiett, Die 25otanik, Den Theil, Der oie Eteine enthált, Die Rithologic: Den Tlyeil, Der Die Sdynecken betrad)tet, Die Condyyliologie genentet. Da aber Die $23 i f(n e n f j a f t$ Der Jinjeften nudj feinen befondern פanmen batte; fo glaubte ich, ons (c) lie die Infetrologie nennen fornnte. 25.

Sietrifier bat fid der Ђetr Derfaffer in feinem gefalli: gen Edfreifen, Deflen id) idjun ill oer Borrede geond)t, weiter erElaret, und mir die ErTaubni gegeben, feitre Ereflärung be:

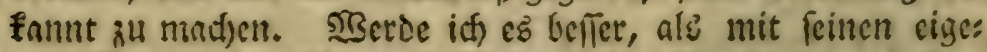

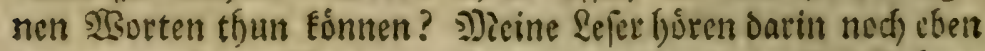
Den angeneffmen $250 n n e t$ reien, Der er vor oreyfsig Jafreen

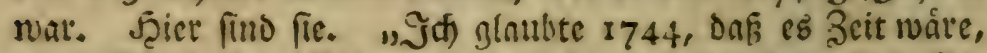

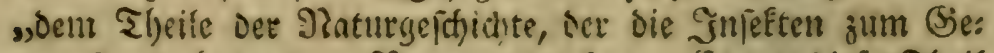
„genfande bat, sinen Taanten ju geben. (Es war Diejer Tlyeil "nun

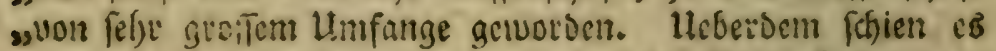

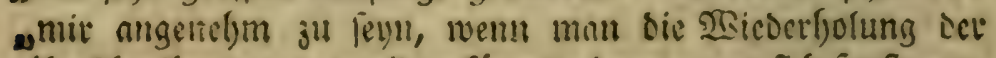
"Itmidercioungen vermeioen fónte, Deren mant fid) fonfr, jur

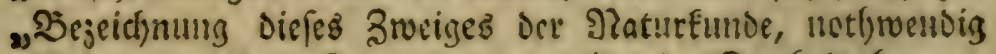

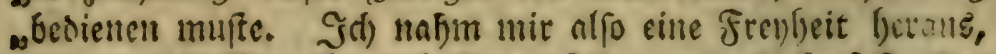

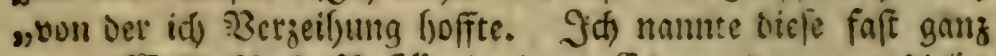

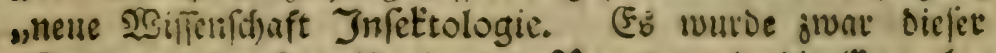
sarwitterausdruce zu Paris uno Xuveroon, in sie KEncyclos

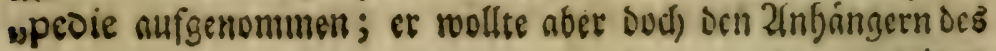




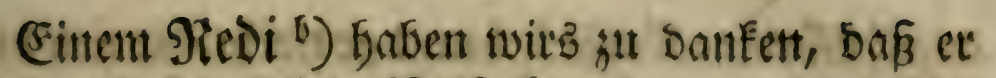

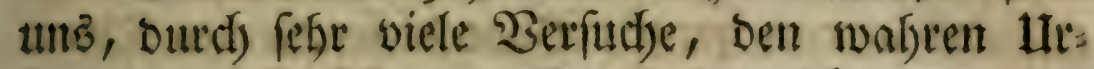
fprung Der Jnfeften geseiget hat, weldfen bie alte, mit taufeno abergläubiclden uns abentheuerlicthen

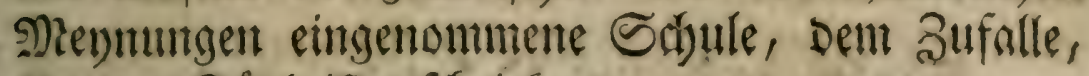
oder Der Tráulní̄ zuperrieb.

\section{Minlpighi c) bat uns in feiner füttrefficten} Differtation von bem Seidenwume, Die tremun= i 4 Dertits:

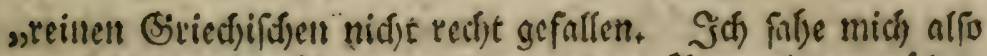
"getrótbiget, biertifer etwos in meiner 25etrachtung ibber "oie L Tatur ju fagen. Die Sisorte ftuthen in IX. Tb.

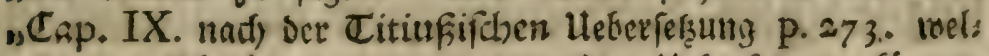

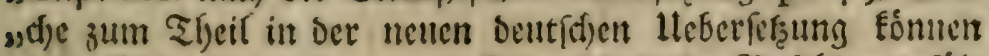

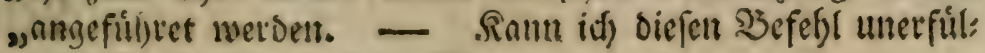
slet foffen? Sçer fint Die stsorte :

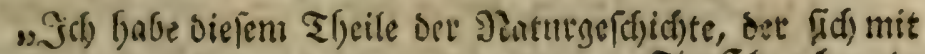
suen Inleften abgiebt, den Dinmen Infektologie

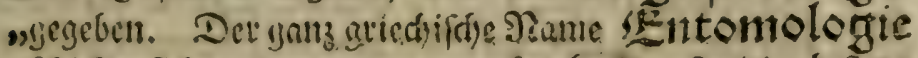

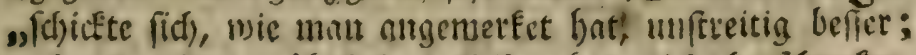

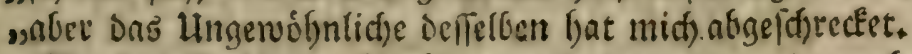

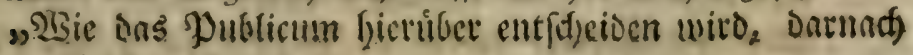
"lvill id) misl) ridbten."

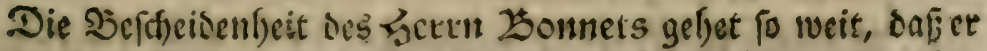

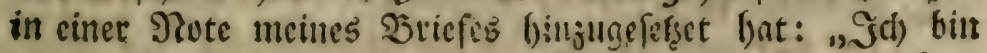
whod) jef̧t beceit, Ben Siamen Entomologie votjuziehen,

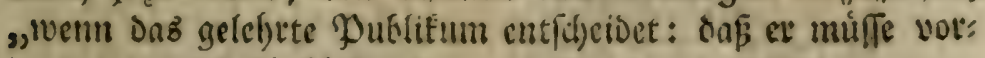
igcjogen tuerbert. Hlcb.

b) Experimenta circa generationem Infectorun. Diefes

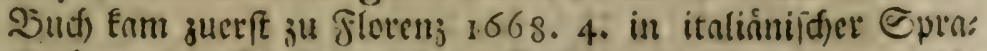
d)e hetaus. (Es find melyere alufangen exfolget, onvon die

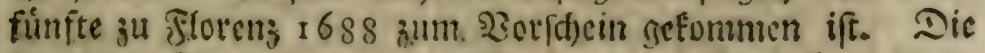

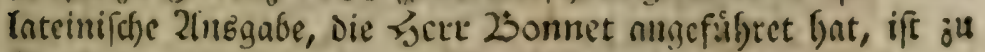

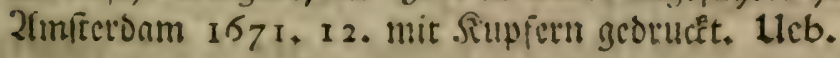

•) Differtatio epiftolica de Bombyce. Die prédftizen 2Setfe

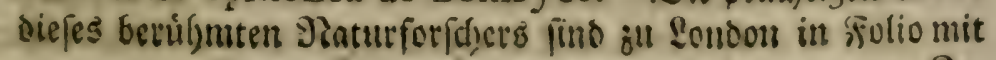




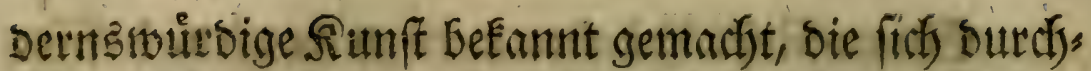
gehenos in Dem ganzen baule Diefer fleinen Thiere befundet, bie man bisher für unvollfommen gebals ten Gatte.

Gwanmerdamm D) Gat Das wafre jener vorgegefenen 2 erwandlungen ans Eidjt gebradte, bie Der (Eintilbung fo fefre gefitelen, und Durch) Die er= babenften bat uni gelefret, Daß Der Edtmetterfing foch un=

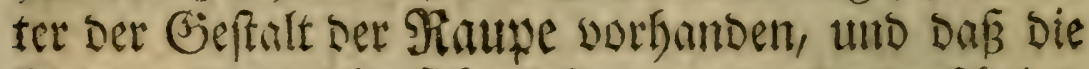
Syuppe, in weldye fich Diefe zu verwandeln fitheint, nur Der mit gewiffen Shainten befleidete Schmetter= ling felbfit fen, Darin er gleichjam eingenvickelt liege.

Setwen=

I 2 Supfertafeln, unter folgenten Titel Gerausgefommen : Marcelli Malpighi, Philofophi et Medici Bononienfis e Societate regia, Opera omnia, figuris elegantiffimis in aes incifis illuftrata, Tomis duobus comprehenfa. Sie fino aucf) ju Seidert in 4 ans Sidft gettreten. Die geleffertes

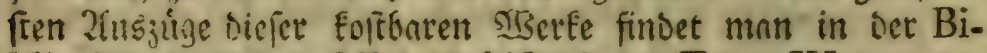
bliotheque univerfelle et hiftorique Tom. IV. p. 189. Tom. V. p. 52. Heb.

D) Hiftoria Infectorum generalis. Der Şetr Derfaffer zile:

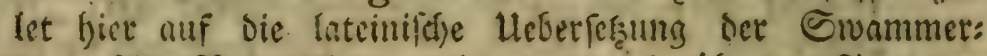

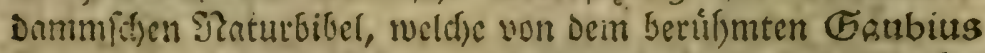

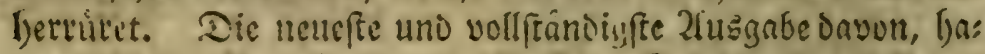

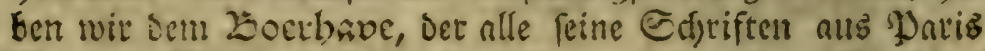

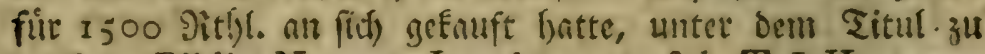
Danfen: Biblia Naturae Lugd. 1738. fol. T. I.II. Dawon

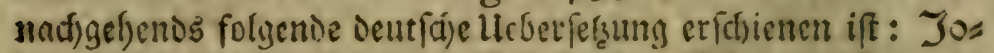
hann Gwammetoamm bibel oer Fintur. Leipsig i752. Sol. 1leb.

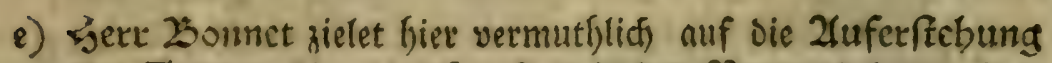
oer Eooten, Die man fo oft mit Det 3 Zeriunndelung cince Saupe, it cinen Echmetterling verglidjen bat. Ewam: merosms zbibel oer Flatur. G. 9. Heb. 


\section{3ortede dé 3erfaffers.}

Sewentfoef i) bat mit solife feiner fuitrefli: d)en Bergrofferungeglafer, in jenter ungálbaren Sienge unendith fleiter SThierchen, für tub eine

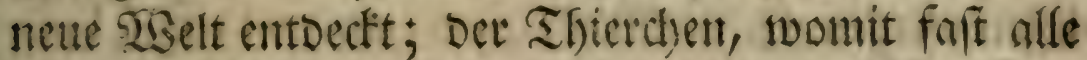
Fend)tigfeiten, uno infonoerheit Die angefullet find,

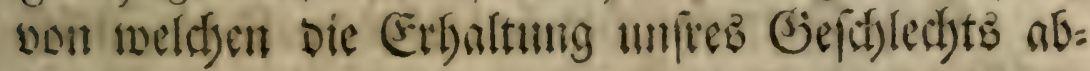
banget.

23allisnteri g) hat tuns nit cinet feltenten (jos fifichte, von veriftedenen, wegen ifjer sift, und wegen ifres fleiffez merfwurbigen Jufeften be=

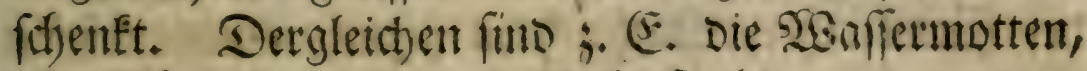

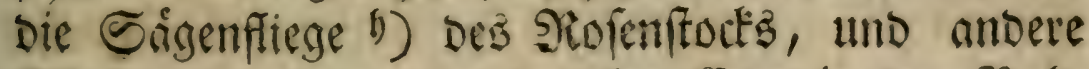
Fliegenarten, bavon einige iffe (Eyer in ben $23 a l g$ f. 5 Der

f) Arcana Natarae. Defe fint in einigen Gundett Botiefen an

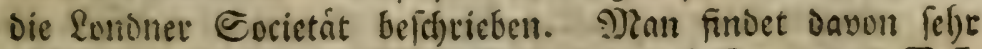
Fojone Thuszige in det Biblioth. univ. et hiftor. 1686.T. I. p. 469. 1687. Tom. V. p. 372.383. wie audi) in Den Actis Erud. 1719. Lugd. Bat. 4. p. 11. 1720 . p. 78 . Uleb.

3) Galleric. de Minufe. Go frefet in meincm Eremplare am Siande. Die Sdyrift Des 2 allisnieri hantoelt cigentlid) de

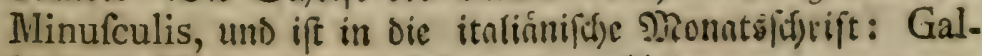
leria di Minerva cingetudet worden. Uleb.

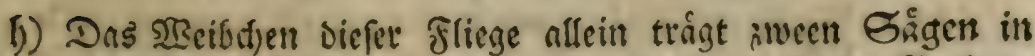

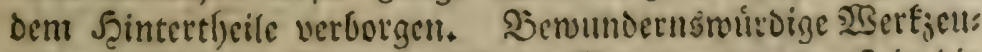
ge, womit es die Natur verefoen! Dantit mus es erft in bie

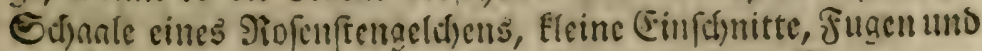

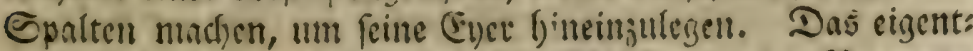

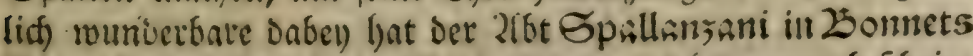

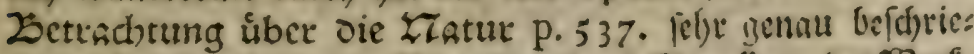
bent, gleich wie man dic Genealogie und Gtraftur ber șerf:

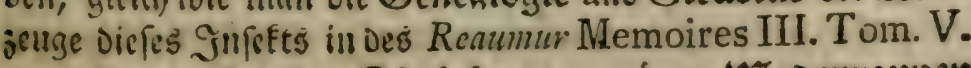
p. 136. 142. findet. Die befannten grimen trasoemrampens nuf Den ziofenbirfdien, find oic Larven, weidse fich in diefe fliegen verwandeln. Heb, 


\section{Botrede des 3erfafferg.}

Der lebenbigen Taupen, ') andere unter bie bicfe Sout Der gefornten Thiere, $F$ ) andere in Den 2nus

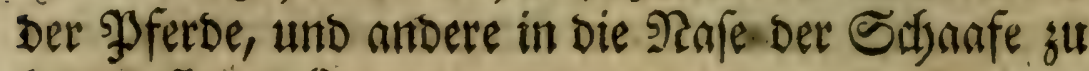
legen pflegen ?.

Rein शratturforficher hat aber wobl bie InfeE= tenleftere bolfeommener, und wuirbiger gemtacht, in

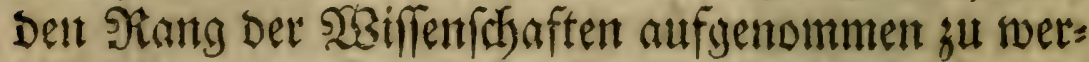
Den, als Der berifmte Sert von Meaumir, m) Die

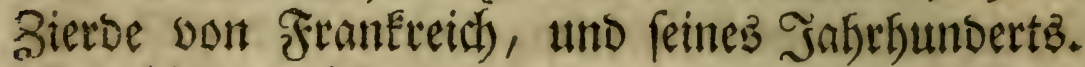

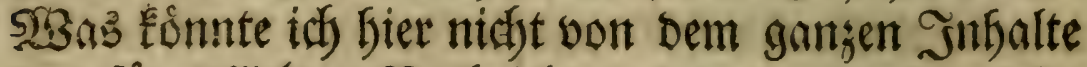
Der fuirtreflicben Nachrichten fagen, womit Diefer groffe

i) Ichneumon, KRăupentoooter. Linné S. N. ed. XII. T. I. p. 930. Sphex. p. 94 r. Uleb.

§) 3. (E. bey Dem Doilopret. 2fus benen in bie Seaut eines joliten Tifiers gelegten (Eyern entftefgen die weiffen zrzaden, veldye fie rie ein Gieb outd)lddjern, uno in gemeinen \&ebent 帒ngerlinge beiffen. Heb.

1) Ifte biefe Zrtten bat Limé S. N. ed. XII. T. I. p. 969. un: tet Dem Ramen Oeftrus, Bremfe, begrifen. SGion zu

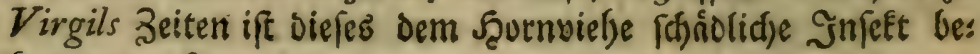
Eannt getwejen.

Eft lucos Silari circa, ilicibusque virentem Plurimus alburnum volitans, cui nomen $A$ fllo Romanum elt ; Oeftron Graji vertêre vocantes: Afper, acerba fonans, quo tota exterrita filvis Diffugiunt Armenta: furit mugitibus aether Concufius, filvaeque, et ficci ripa Tanagri.

$$
\text { Virgil. Georg. Lib. III. v. 148. Uleb. }
$$

n) Memoires pour fervir à l' hiftoire des Infectes. $\mathfrak{X}_{\mathfrak{a}}$

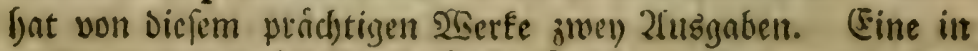
groß 12, von juólf Eomis à Amfterd. 1746. uns cine in 4 in fed) Sainten. S. Iournal literaire Tom. XXIV. Pr. part. p. 49. 
44 Zortede Des Zerfaffers.

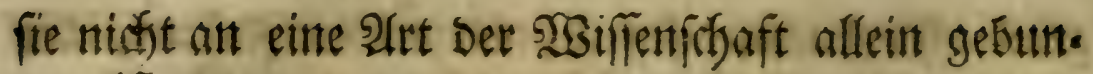
Den ift.

Dar if) seitig genug Gelegentreit Gatte, niiø mit biefer furtreflicfen Secture zu beluftigen; fo mu= fie iff mich notisnenbig, won einem 23erlangen be:

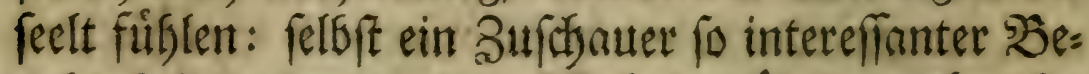
gebenfeiten ju werber. Jifh bemifgete mich alfo, Dem Setrn von Reaumir nathjureben. Sthritt bor Ect)ritt, fo su reben, forgte ict) ifm. In einem fo weiten, und biafser fo wentg betretenten frelde, ift es nifit fajmer nette (Entbecfungen ;u mad)ent. Der fa)arffichtigfte, und aufmerffamife Beobacter Eann nicht alles wafirnefmen. Stulerdem Eann man von einigen glickllichen Sorfăllen beguinftiget werben, welde andern nidyt begegnen. Dafer Darf

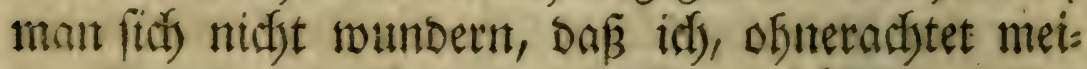
ner Jugens, mandje befondere Umiftanbe bemerft babe, Die einem to (charfitidtigen Seobadtung: geifte, einem Renumir, entgangen find. Durds eine, ifm gants naturtiche Siute, warb idf fuifn ge=

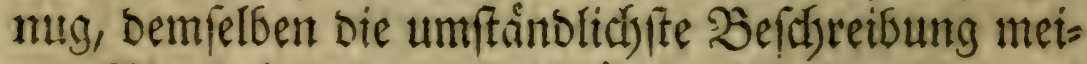
ner beobactungen, frermutthig mitsutheilen, und

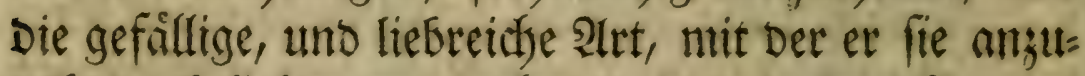
nefmen beliebte, trug litidt mentg gu meiner (Ermun= terung ber, meine Unterfudjungen weiter zu treibent.

Der Serr von Renumur ifte es alfo vornem:

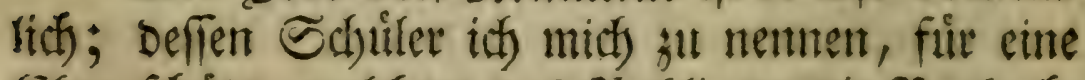
(E) tungen jul Danfen bat, Die ich ifm ief̧t vibergebe. 


\section{3ortede deछ 2 etfaffer's.}

Cie breiten fich) uiber ;1ween Der wigtigftent Ent:

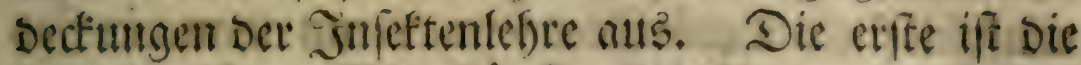
Erjengung Der Blattláne, ohne Begattung. Die zwente betrift bie. Siermelynung gewiffer 23tirme Durd) Qfbienter. (bouture) In 2mfefunng Der lefs= ten wiro man fier Die erftannlidyen $2(3)$ underdinge

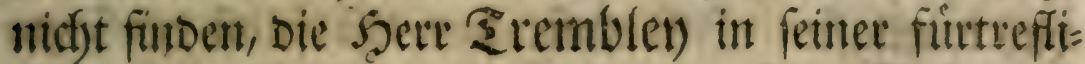
(d)en, und feit furzen befanntgemadyten Solinpen= gefitsidtete, ") mit fo vieler Deutlidt) feit uno (Ein=

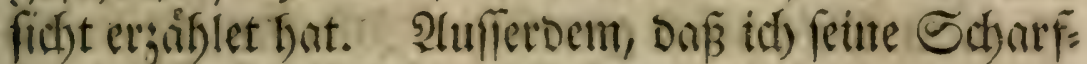
finnigfeit nicft befíge; fo geforen auth Die mir vor:

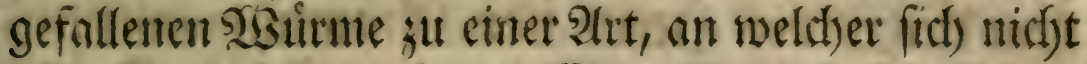

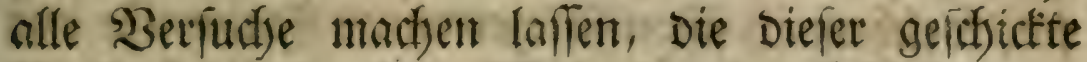
Seobadter, mit feinen $\mathfrak{P}_{\text {oltypen, }}$ to gluctelich ange= ftellet bat.

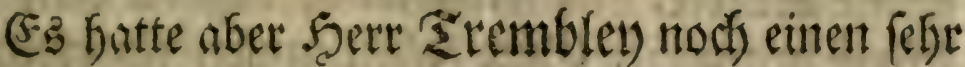
groffen Bortheil vor mir voraus, Daß̧ er nemlici) $\mathrm{ci}=$ nen Raturforfher zum Freunde Gatte, Der auller Der Giabe ju beobad)ten, nody riberDem bie Stumft verftand, gan' vollesommen juseid)nen und in Supfer

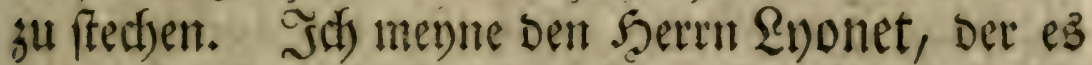

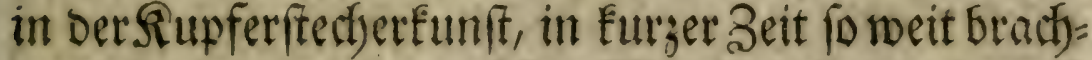

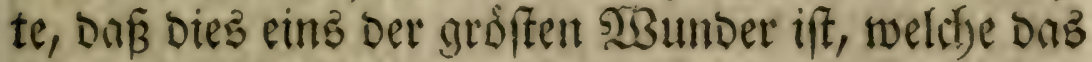

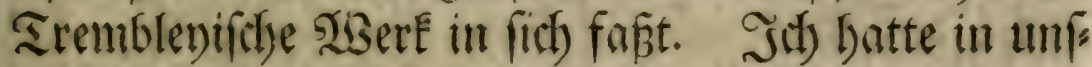
rer Stadt ${ }^{\circ}$ ) nid)t mur niemand, Der im Stande ge= nejen twaire, Die Ylatten zu Diejem SISerf́e zu ftechen; fondern $e^{3}$ feflte mir aud) an einem âeiffner.

Dare

i) Mem. pour fervir à l'hiftoire d'un Genre de Polypes d'eau douce, à bras en forine de cornes. Tom. I. et II. à Paris $1744 \cdot 8$.

D) Simf. 


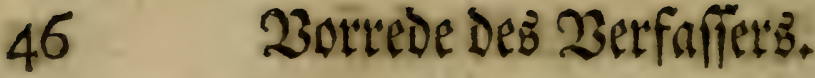

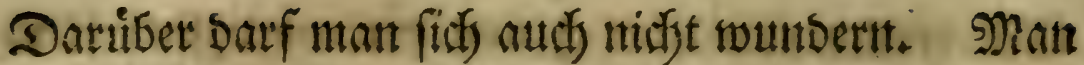
mus felbft eit Beobadfter fenn, went man ein Jits feft, und vornemlich ein Jinfeft von ber art meiner SBurmie, Daran bie meiften Theile fofwer genug zu unterficheiben finto, gluetelich abbilden will; fonft trift ntant wobl Die figur im Girofien; man verfeglt aber Das migtigfte. Jah mufte mir alfo felbft die Figu= ren jum jwenten Theile zeidfnen, ofneradjtet ich Das Beidynent nie gelernet Gatte. Die erfte Tafel ift mein भrobeftuitf gewefen. Sindeffen woulte ith

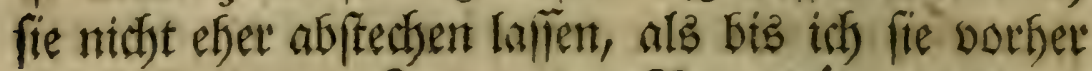
Dent Itrtbeil bes Sertn von Peaumir unterwor= fen, weldjem icf fichon feit geraumer aeit einige bout meinen Sisurmen überifsickt hatte. EB hat aber Der genteigte Serf fall, Den er Diefen aeiduningen zu

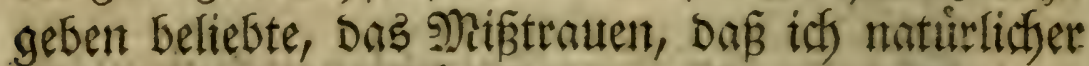
פSBefe gegen ifre Giute baben mufte, ungemetn ver: imindert.

Sith Eefre zu Den Soobadftungent zutrief, Die int

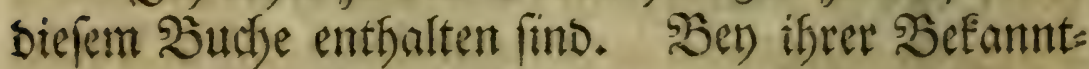

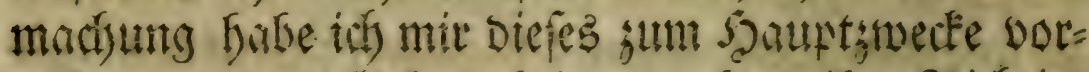

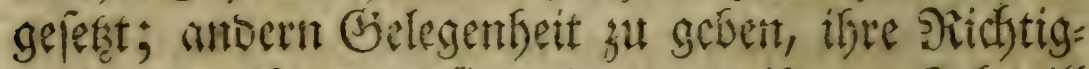
Eeit ju erweifen, und fie weiter ju treiben. Jus mill

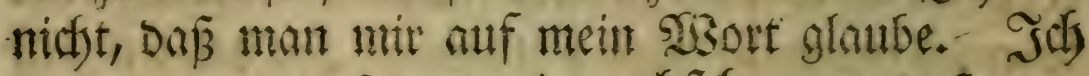

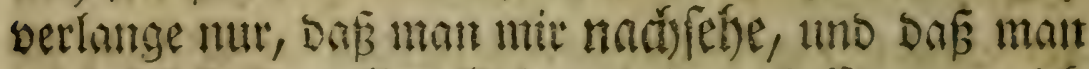
mich) felbft, bey aller (bielegentheit verbelfeie, wo ids midf) Eann betrogen baben. (EB twird mir Dafker nicfts angenefmer fentt, als ivennt idf erfaben oollte,

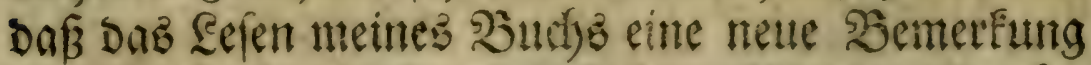

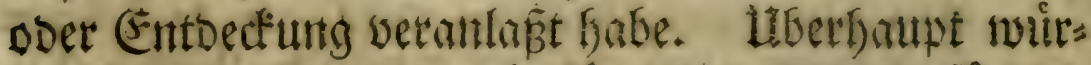

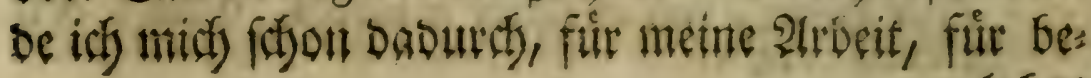


ifnert einent britten folgen laffen, welch)er meine über

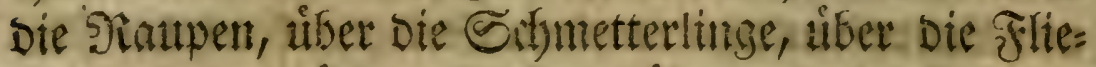
gett, P) und riber bab fo beruiginte, aber fo unbes fannte J̃nfeft: Den Bänowwtum, ober bent Eitts fied!er, (Solitaire) gemachten şesbadjtungen in

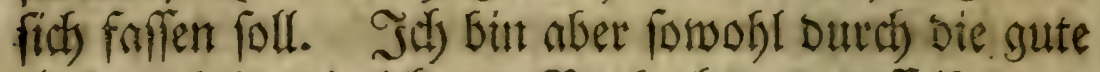

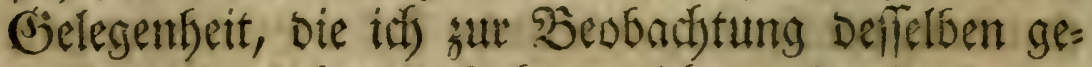
Gabt, als Durds Das Eitdyt, welches mir Die neuern Entbectumgen gaben, it wen Etand gefereset, einige

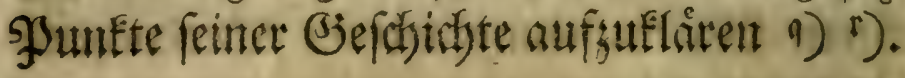

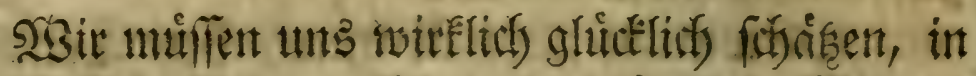

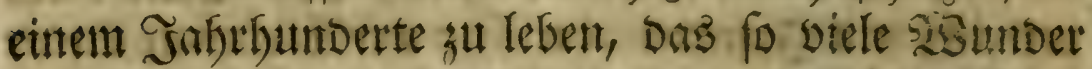

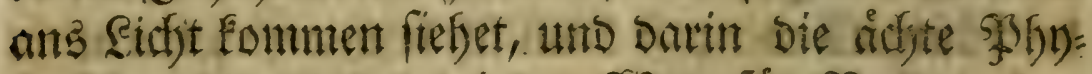

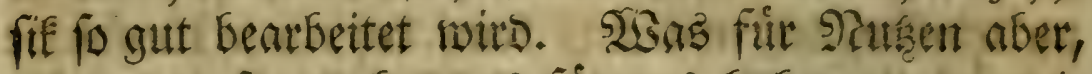
swird man fagen, Eamt ę fúr uns baben, loem noir

p) Diefen SBeobact)tungen tverbe id) Finleitungen wotfergen, woriu ich), um jene leid)ter ju verftel)en, zugleich) einen 21 briß̄ Der we:

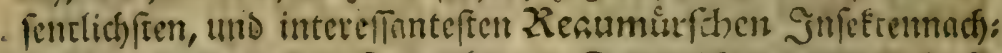

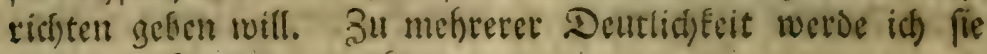
alt) mit Supfern verfeljen.

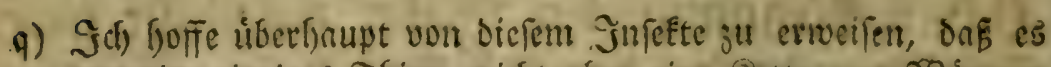

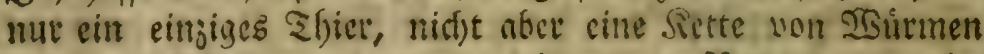

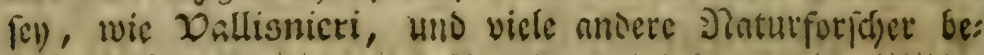
bauptet babell.

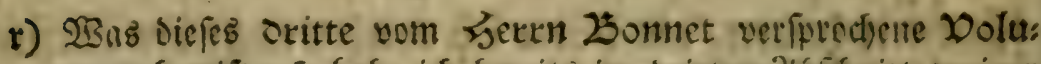
men betrift; fo babe iff beteits im oriten 2(6) (f) nitte meiner

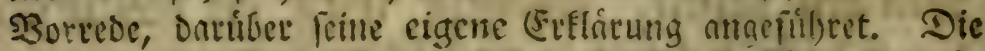
Dillertation fur le Taenja freflet nuch in ien Memoires de Mathematique et de Phyfique, prefentés à l'Academie Royale des Sciences, par divers Scavans, et lûs dans fes Aflemblées. I. Tom. Paris 1750 4. p. 478. wie ich

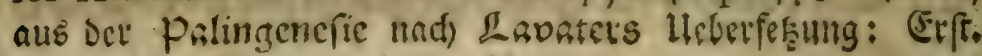
श. p. $607^{*}$ gelernet lonbe. Heb. 


\section{Zortede DeB 2 erfafferz.}

nud) twillen, Daßs fit) einige Infeften ofne Segat: tung erjettgent: ttmo Daß $\mathrm{CB}$ andere giebt, aus wel: ifen, ween fie in intefrere Sticke zertheilet find, eben fo viel gan; bollifándige werben, Die bem erften gleicfen, DuB aus biefen vereinigten Stúcken zufatm: ment, por iffer abfonderung beftunt.

Diefe grage benntworte iff überbaupt: Daß́

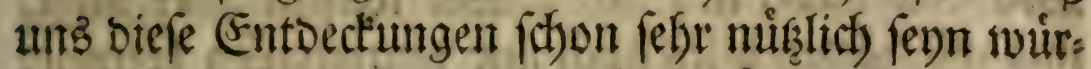
Sen, werm fie auch weiter michta thaten, alz unz ge: gen bie alfomeinen siegeln vorfichtig zu madjen.

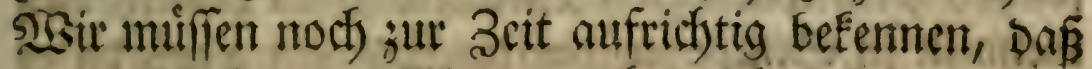

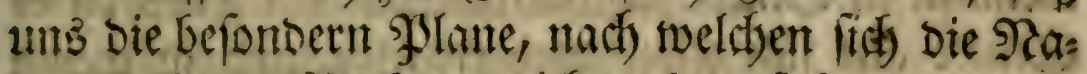
tur in ifren siberfen gerichtet bat, faft gam unbe

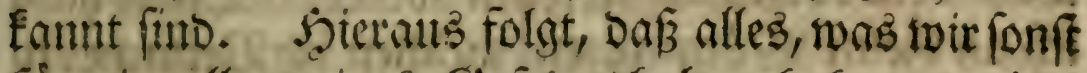
fir ein allgememes biejers gethalten haben, voriefzt nut, alz das. Siejultat foldher verfuche muife ange= ferent werden, Die nicist weit genug baben Esnnen getricbent twerden.

$\mathfrak{2 B e n n}$ nir umb aber in eine senattere ltnters fudjung einlaffen, und Die Natur Diefer Entbectuit: gen; infonberbeit berer InfeEten, tiefer ;uerfor.

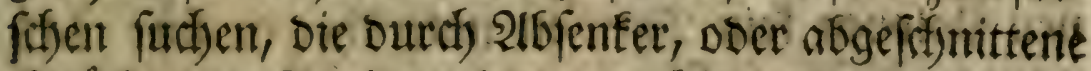

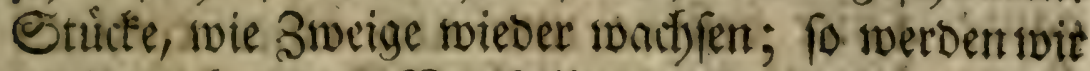
Darin nod) andere Wortheile gervahe werben, bie un: fere Erefentnifs, in vielen wichtigen JunEten Det

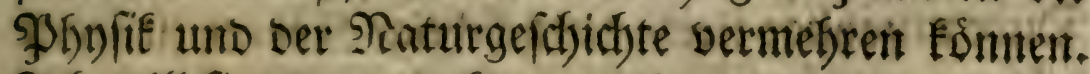
Jit) will fie nur gan; fur; anjeigen.

Das ift Der erfe von Diefen Wortheilen, baß́ wir Dabur(f) won Der thierif(d)en DeEonomie rifftiges $\mathfrak{r e}$, und bollfándigere ઊesgriffe befommen. Man 
feintet woffl in Ganjent Die voritermiftent Theile,

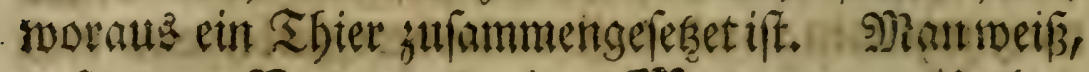

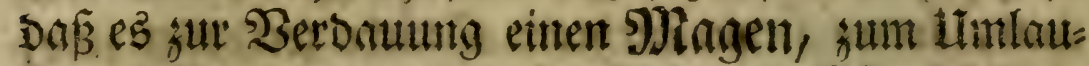

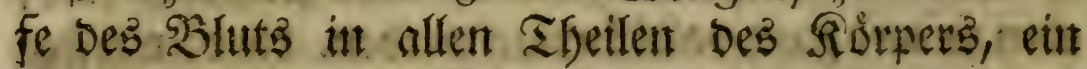

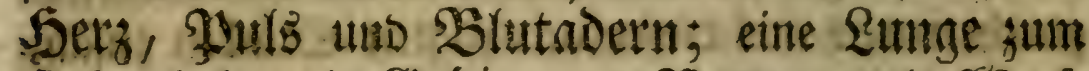

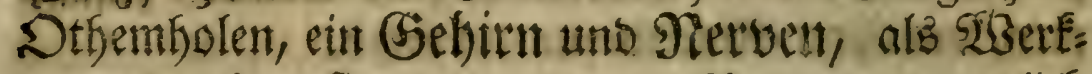
zerge ber (Empinbung, und zut Z3erwegung endich)

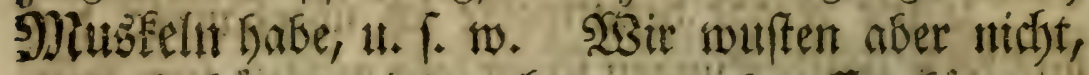

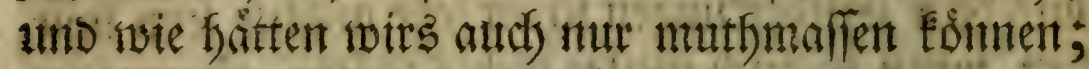
Dafs es Thiere gebe, in welchen alle Diefe Theile ein

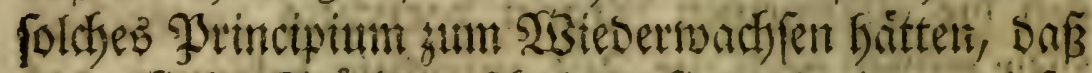

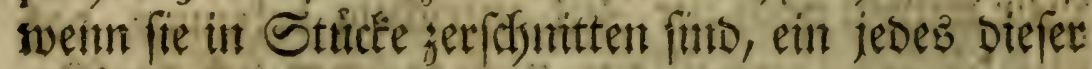

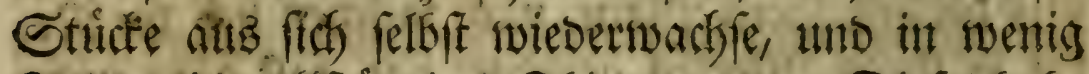

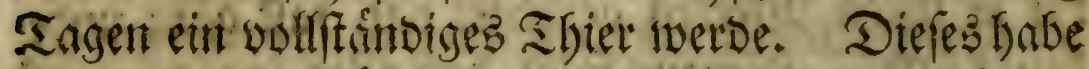

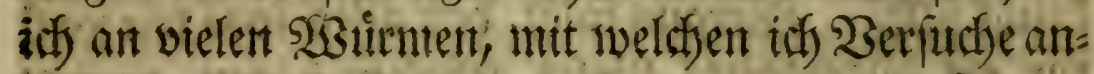
geffellet, nut Errftaument wabrgenommen. Olgners

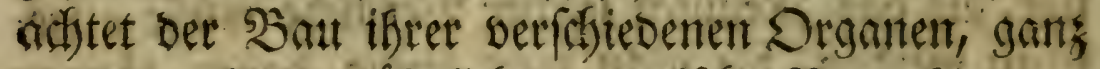

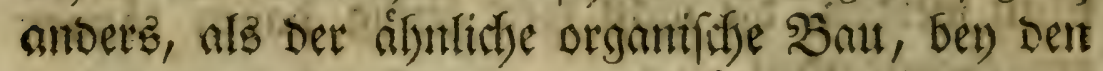
Ints Gefanuteften Thieren eingerichtet iff; to fomme er Dodh in Dem Sisefenttlichent Damit tiberein, wie mant ber) Dent Eefen meinter Seobadjtungen ferhen miro.

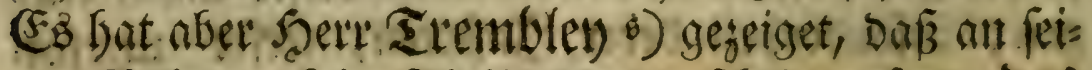

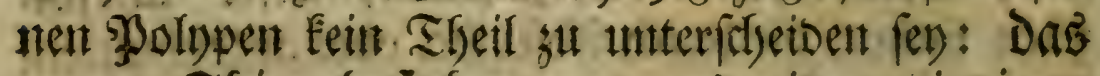

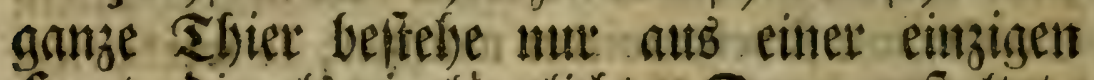
Sonut, Die als ein länglidter Darm geftaltet, tund an beyden Enden offen fert: unt in Derent

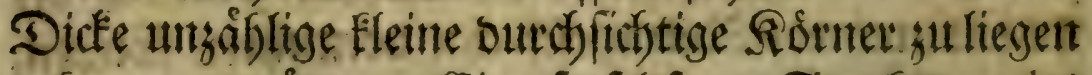

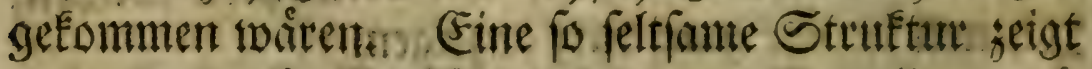

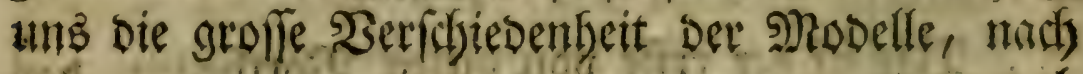
I0el =

ร) Nienoires pour l' hiftoire des Polypes Tom. I. p. 108. wist et $f$, de l'edition 8 . 


\section{Zorrede des 23erfafiers.}

nifft vollig ben Grumb erforfitset. Die wieberthol: ten SBeobactiungen Der Naturforfther, ifber Daz

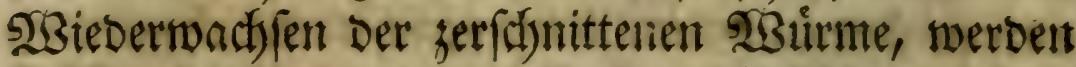
unz vermutfflid), Die uns hierin nod) feflenden (Ein:

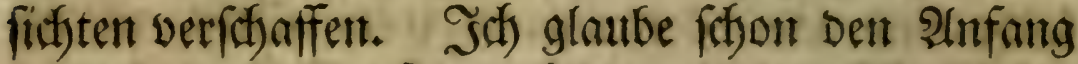

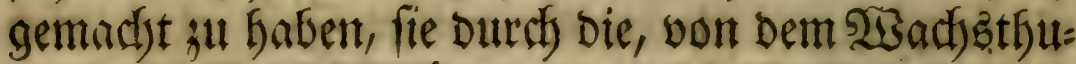
me verfisiedenter Sisurme, entworfenten Tabellen, ") und Durd) Die bengefügten P(nmerfungen, auf Die Spur zu bringen.

Die nenere P(natomie bat fich mit bem grofient Raturgeheimmiffe: Der Erzeugung Der Thiere frarf beforififtiget. (Ez ift alfo zu vernutthent, Dañ fich bie 3abl Der feltenen Entbeckungen, womit fie bişther be: reichert iff, Durch Diejenigen ungemein vermefren merbe, weldye Die Raturforfither an Den Imjeften zut madjen nicft verfáumen merben, bie man burch Dab ftuckneife Berferneiden bervielfältiget. Solltent

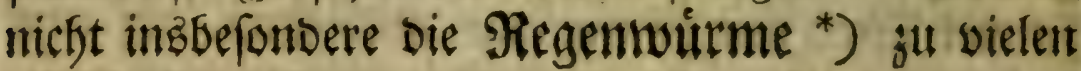

foit=

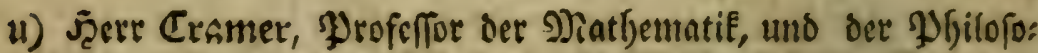

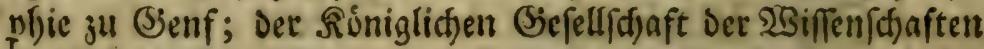

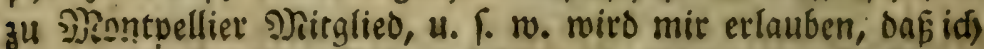
iffm meine lofp!loige Erfenntlid)feit fúr bie geneigte 2lufmerE: famfeit begeigen burfe, bie er gegen bie (Fintid)tung Diefer Tabellen, uni gegen alles, was diefe ß̉eobad)tungen úbertbaupt, betrift, berviejen bat. Der Freundichaft, roumit er mids

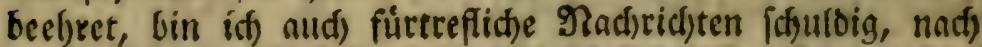
weicfen id) mids forgfáltig geridfet fjabe. (Ë ift diefer be: rúlsmte. Profeffor nicht nut eill grofler Dintbematifel, und

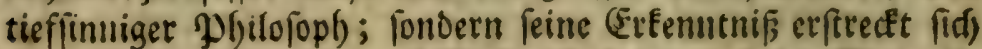

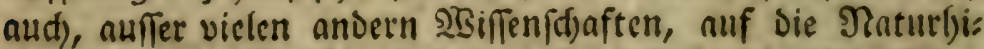

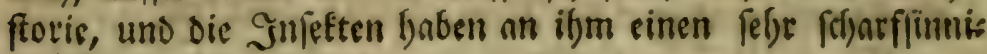
gen Servunterer.

*) Reuumur hift. des Inf. Tom. VL pref. LXXVL. 


\section{4}

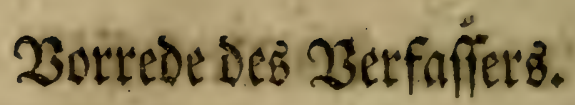

tradffung hat nich) ouf einert, biefleidyt etriwas

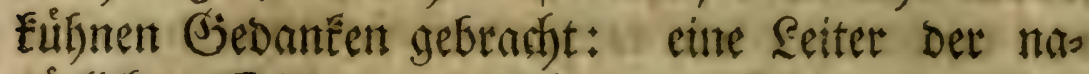
túrlicten Dinge gut mactent, Die 'man ant Enbe Diefer 23orrebe fintoen wird. Jid) babe fie nut fut भyrobe entworfen; fie faun uns aber bodf

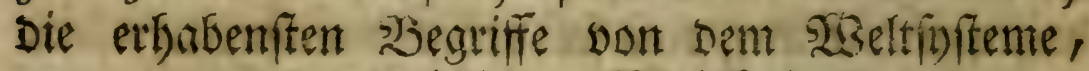
und von Der unenofithen 2Beiśfeit benbringen,

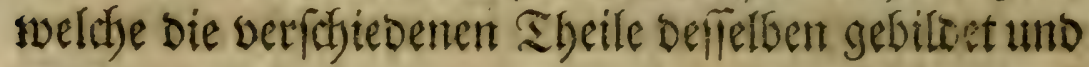
vereiniget hat.

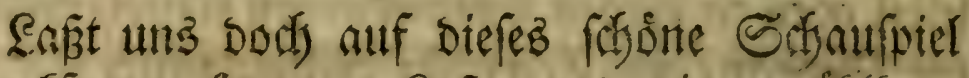

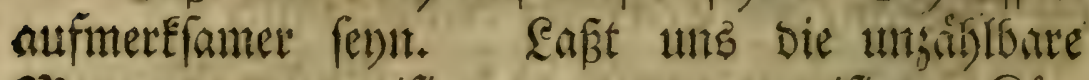

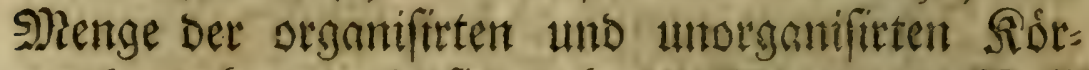

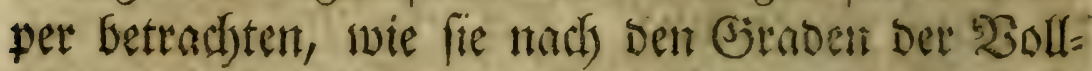
fonmentreit, ober Des 3 zorsuges, Den ein jeser

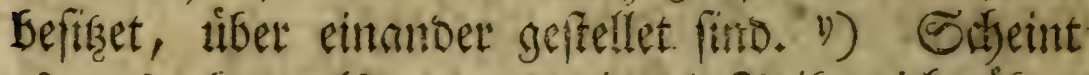

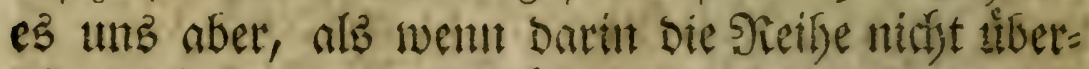
all gleidi) fortgebe; fo ruiret bas bon unferen no dis ferbe eingef(d)aintent (Einfichtent ber. Je mefor fich Diefe ermeitern; Deffo mebr forther Eeitern ober Stufen werbent wir aucli entsectent. Danut

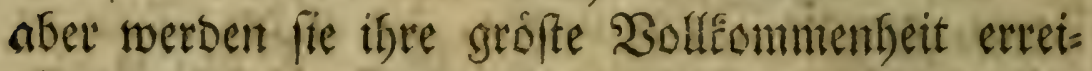
chen, weent bavon Eeeite mefre jul enttbectent 'úbrig iff.

Rómen ivic folches abee Gienieben Goffen?

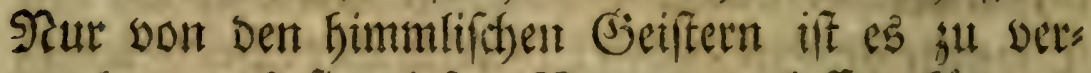

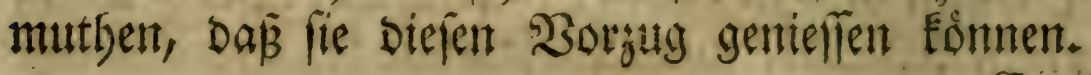

Ent=

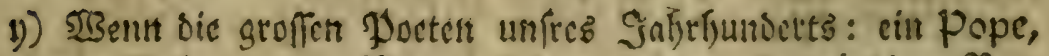

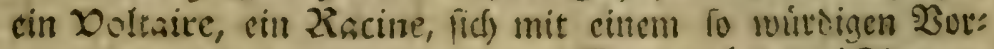

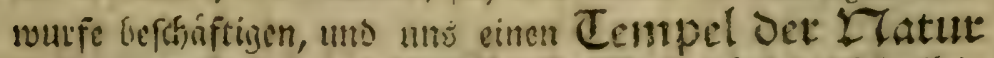

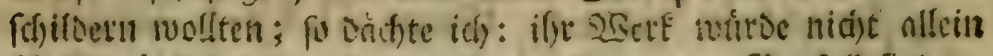

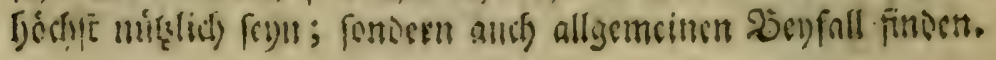




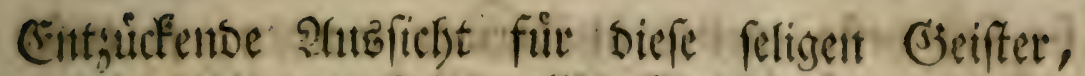
wellite ifhnen bie Eeiter aller sisefen zeigt, die zu

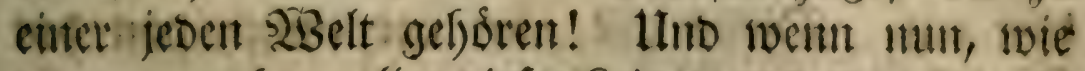
ich) vermuthe, alle biefe Leitert, Deven-2mablt bennthe unentich ift, mure eine einzige ausmachen,

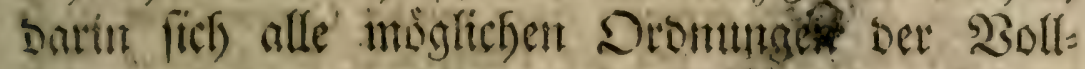
fonmentheiten sereinigen; fo mus man geftehen, Dur man fich nichto groflers, atmo nichts erfates = nets Denten Eóne.

Es ift alfo gwifchen allen Theilen biefes gant:

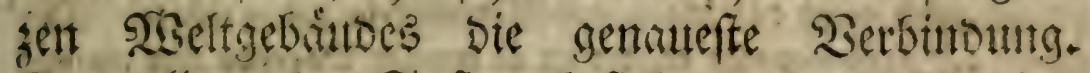
Dab allgemeine Suftem beffebet aub Der 2ieweint= gutig befonderer Siffeme, welche gleichfan bie

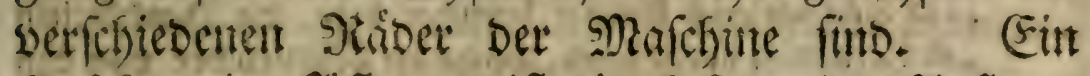

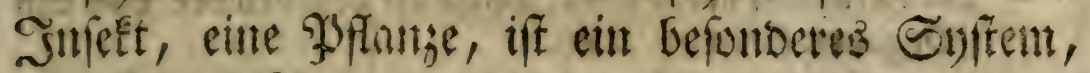

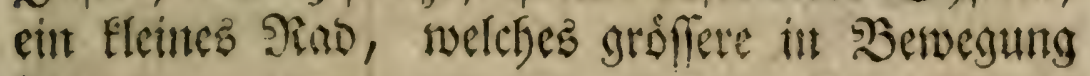
fergt.

Diez fint bie bornefmitent Bortheile, bie

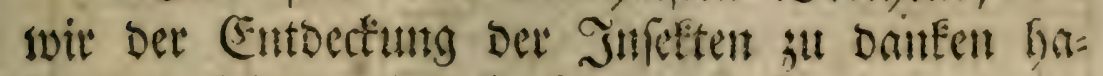

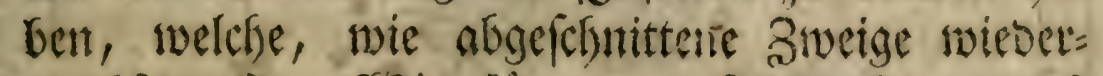

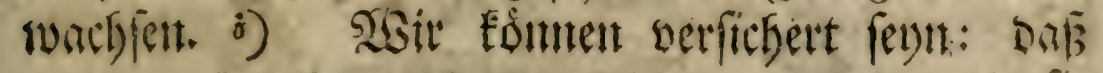

$$
\text { D. } 4
$$

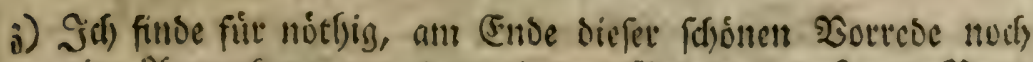

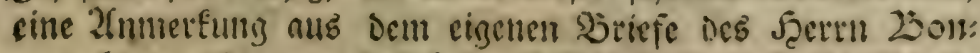

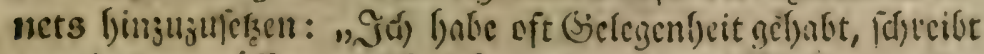

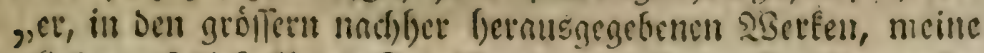

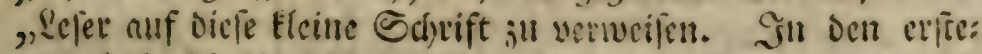

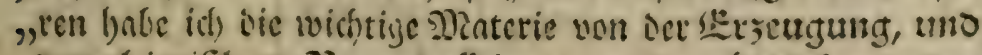
,,oen thicrifthen Rieproouttionen weit grínolid)er unter:

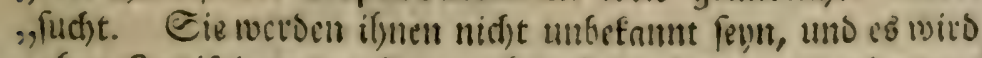

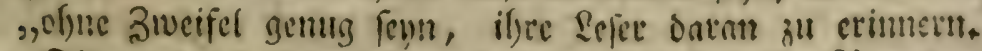

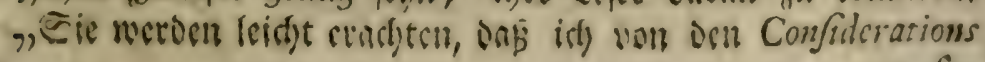


fie fich befto weiter ausabeiten werben; ie tiefer wir jene erforichent. Eine Sỉabrheit Elânt die ant: Dere auf. Diefés gilt aber vortnentich bon ben

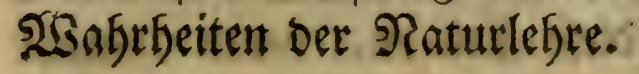

9. Jur les Corps organifés $17 \sigma_{2}$ : von bet Contensplation de la "Nature, 176;; von der Palingenefie philofoplsique 1769 .

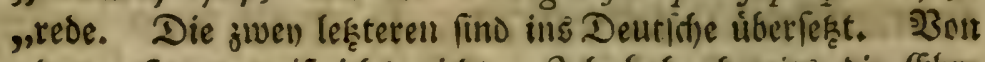
,Dem erfteren weif idns nid)t. Id) babe beteits Die (El)te "gefabt, ifnen iu melden: Das ich nod) left jung wat, als ,id) Die Infettologie (d)rieb. Jal) fonnte nut bie vornefm:

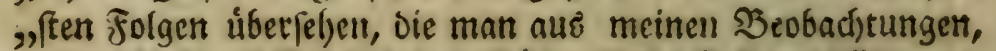
,im Berlyaltniß gegen bic organifhen Reprosutionen, ,und gegen bne nllgemeine Raturiiftem jieljen mógte. Die: , , fe folgen waten es, die id) it meiner Dorkede nue entmor: g,fen batte. (fe feliten mir abet Damals noch viele fafta, ,Davon die meiften nud nicje entoecft watell, uni ourd) bes ,ren Sidjt ich mid) nad)het bemulbet balie, bie Duntelfyeiten ,einigermafien aufjufláren, weldje die Zaturlebre von oen ,Organen bededften. Heb.

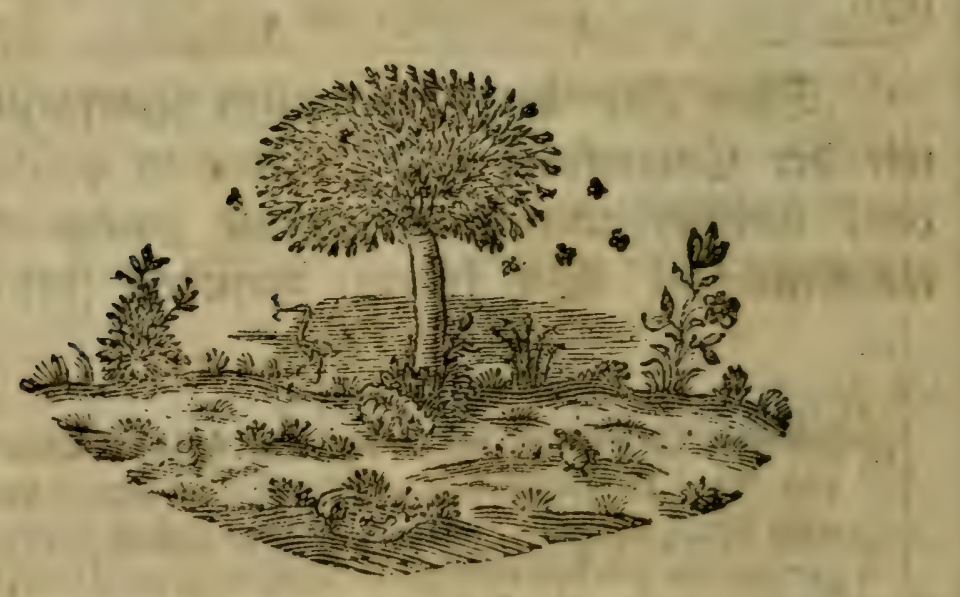




\section{Entwurr einer Seiter Der naturlictedt}

\section{Dinge.}

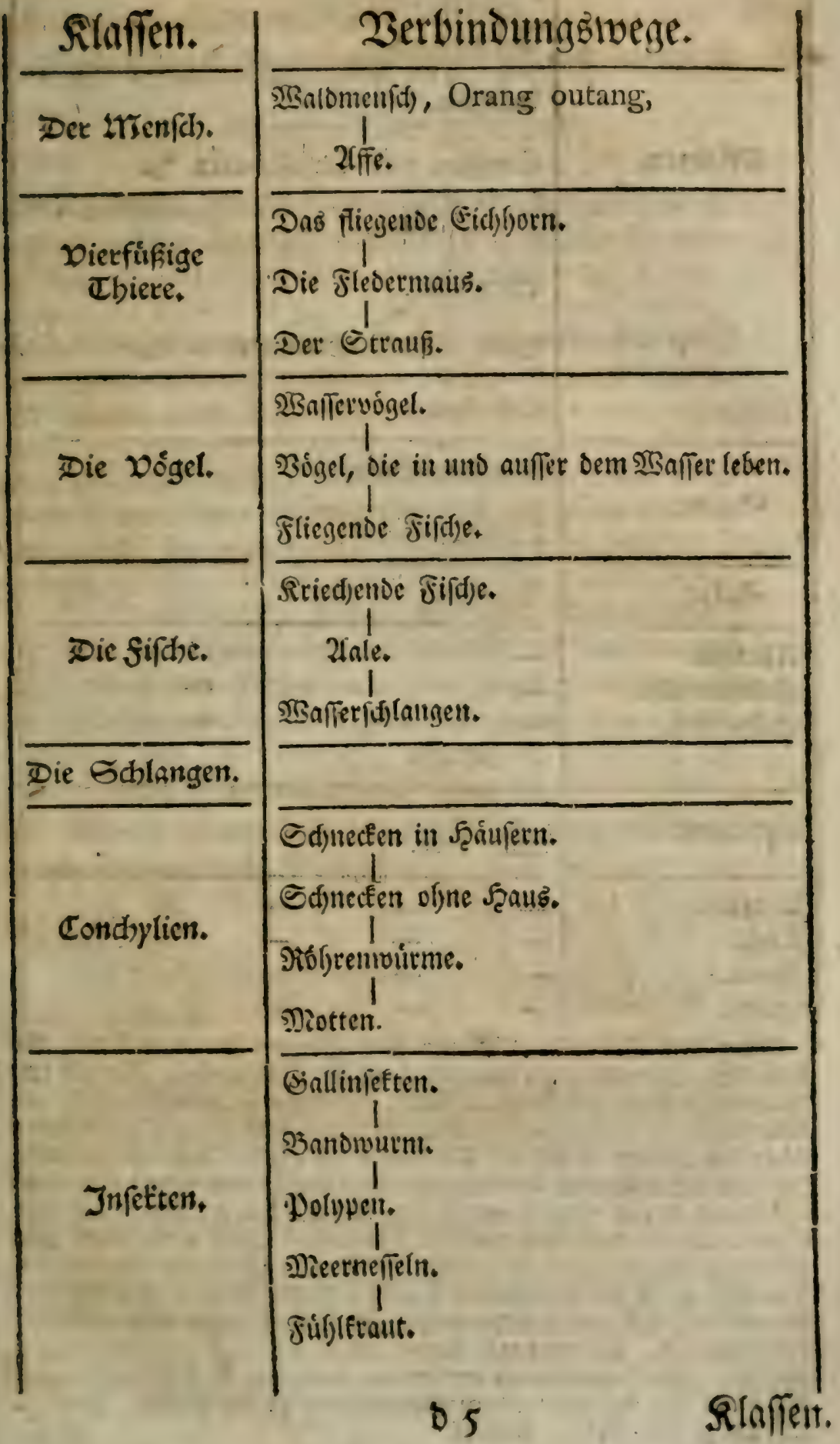




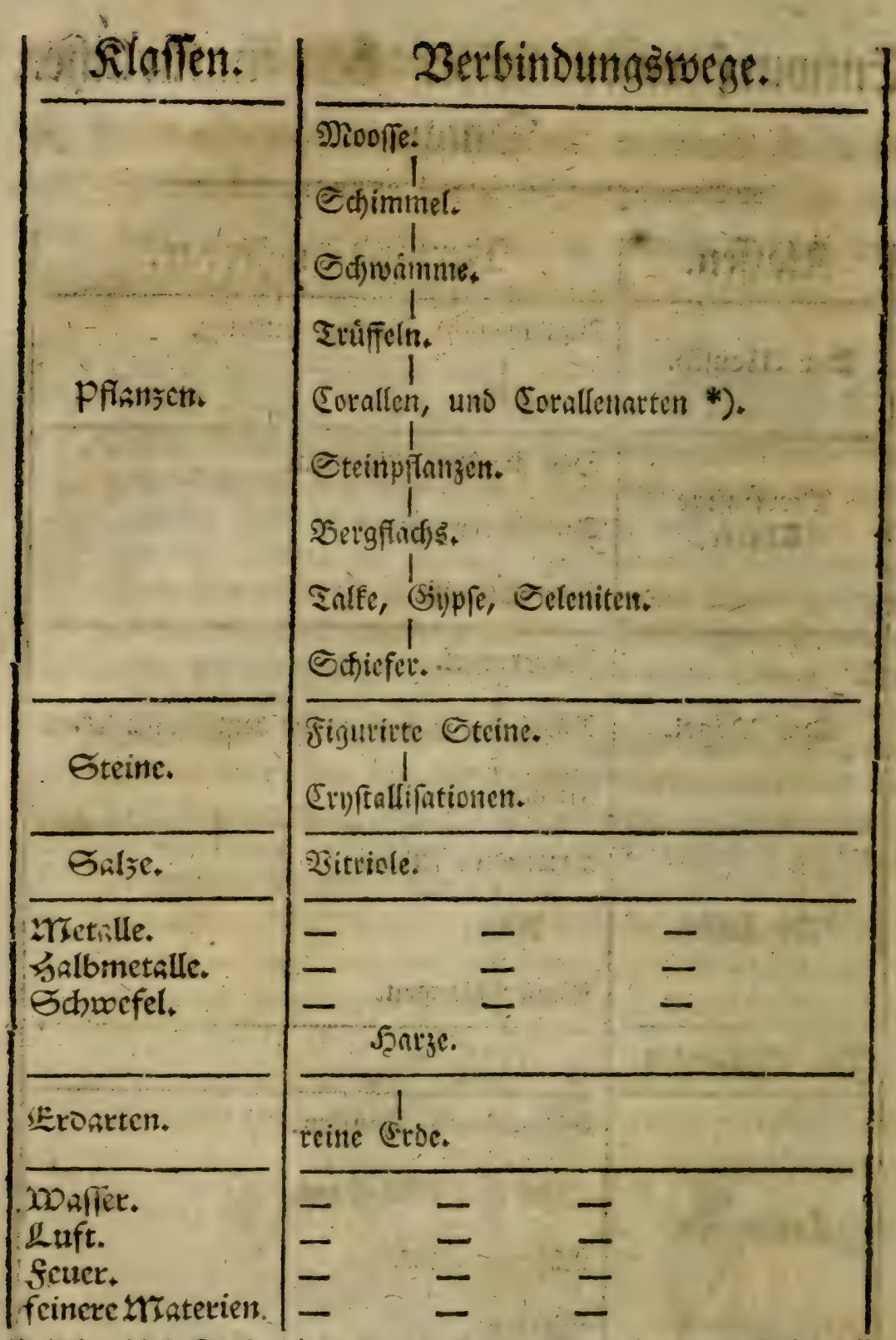

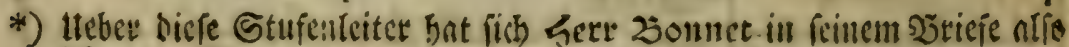

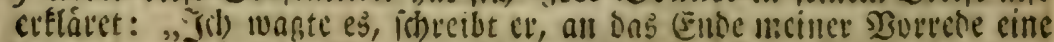

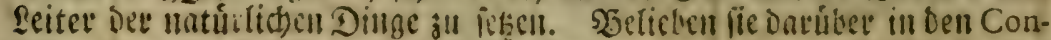
fiderations iur les Corps organiés. Art. 209. unt int Der 2jctrnd)tung

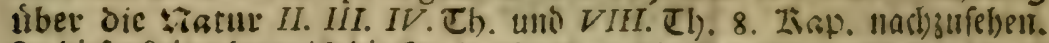

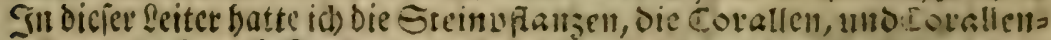
arten, als fo viel Stufen vorkeffellit, init meldhen bie sintur aus den

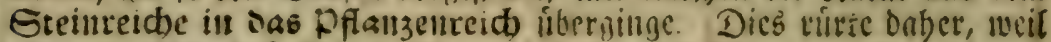

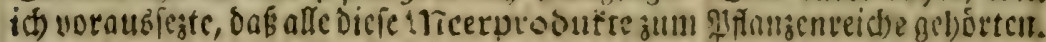

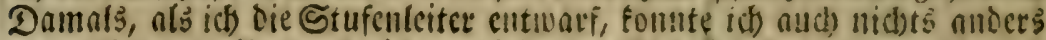

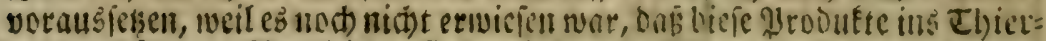
reich geborten. Sarraleid)en fie bamit Die Confiderat. fur les corps organ.

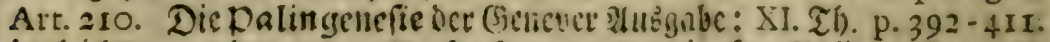

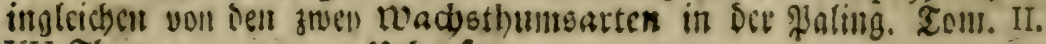
XV.Thb. p.110-112., Heber. 


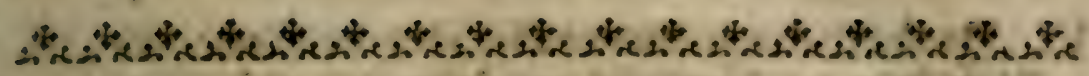

\section{פ̧ergeidfini}

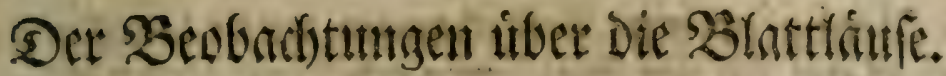

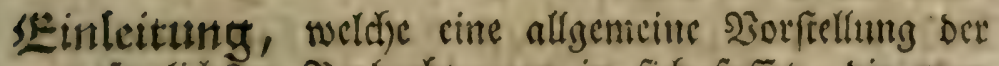
mejentlict) iten Bicobactitungen in fiff faffet, bie man

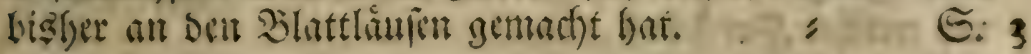

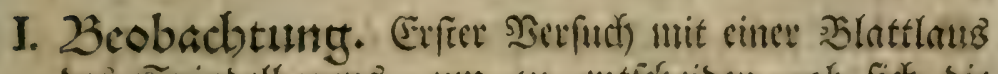
Des Epintorlbums, um ju intigheiben, dob fich Die

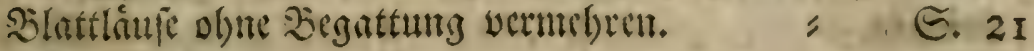

II. Beobachtung. 3iwenter und britter Serfuch mit

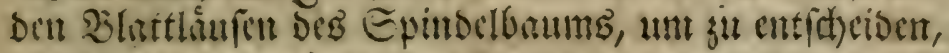

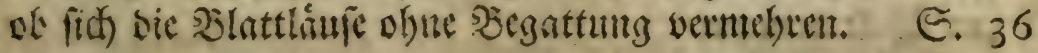

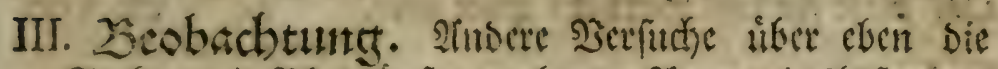

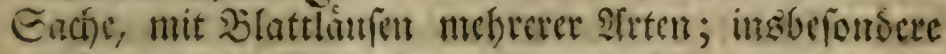

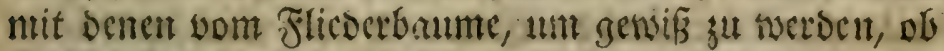

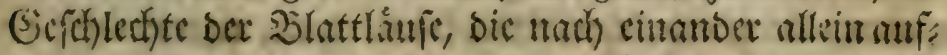
gejoyen fins, bie nemlithe (Eigenichoft erforlten, fict)

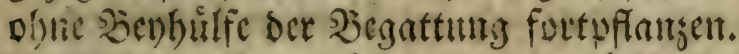

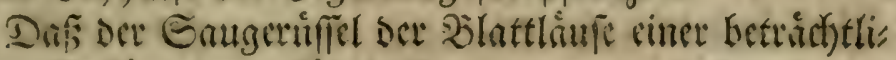

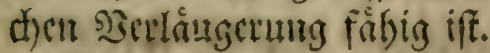

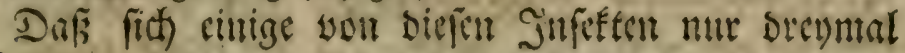
biuten.

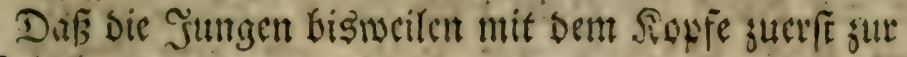
S્Belt fommiti.

$$
\text { " " " ङ. } 46
$$

IV. 23cobachtunct. SIndere Siscruche nit ben Blatt: látlen bes Epindelbautnte, un gerwif j"t werben, bof

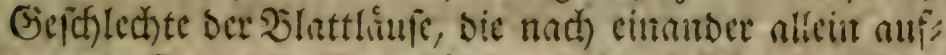

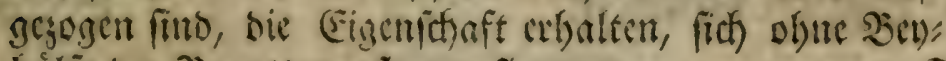
bulfe Der begattumg fortjuyplangen.

હ. 51

V. 23eobachtunt. Sinbere 3ituthe liber cbett bie Endje, mit blattlintpur bes 23 egerifijs. = E. $5^{6}$ 


\section{Berzeianin der 3 eobatutungen}

VI. Beobacbtuntg. Indere úber eben bie Gadie, mit

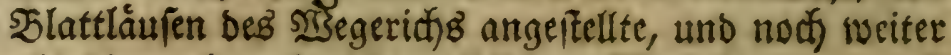
als bie worbergehenden, getriebene $\mathfrak{B e r}$ 'ud)e.

VII. Beobachtunty. Beobachtungen, welche betweifen,

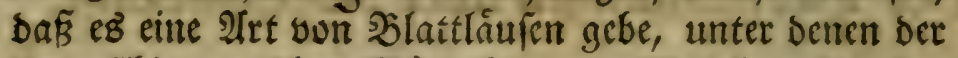

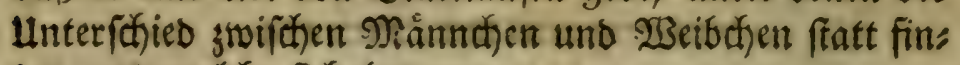
bet, und welehe fich begatten.

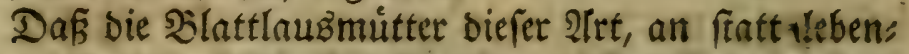
biger Şungen, bisiveilen Foetus zur 213 elt bringen, uno mit ivelefer $\mathfrak{B o r f i d}$ t?

VIII. Zeobacbtung. Beobachtungen úber bie Foetus, welche bic bicken Silattlausmitter ber Eiche zur 233 clt bringen.

$\leq \cdots$

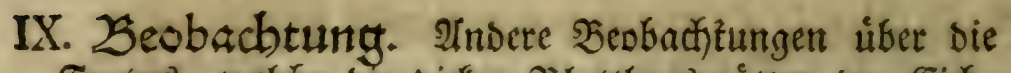
Foetus, weldi)e bie dicken Blattlaubmitter ber (Eid)e zur wselt bringen.

Dá̧ biefe Foctus nirflicte Ener finb. $=$ ङ. 100

X. Zeobacbtung. \$eobactungen, weldfe betweicn,

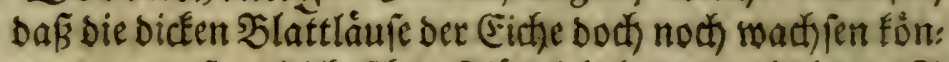

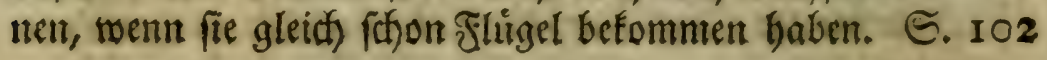

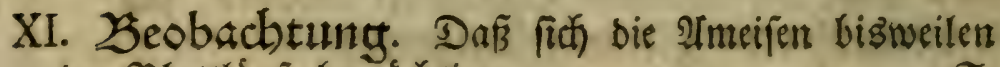

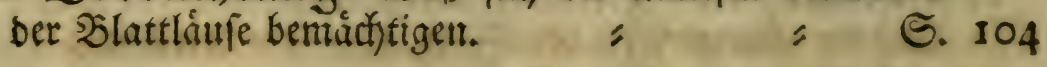

XII. Zeobachtung. B̧eobactunthent úber sie Blatts lausmutter ber bicten Sitt, welche auf ber (Eiche leben, uns von benen bie Sraut nach ifferm Sode abgebet, wenn mant fie ouct) nur facte nit Dem Finger berufbet.

XIII. Zeobachtung. Dẩ fich nuch bie Sitt ber bicfen Blattláule, Derent Siegattung criviefen ift, obne biefe Sengulfe vermegret.

: E. 106

XIV. Zeobachtung. (in andercr Эerfuch úber eben bic Eactie.

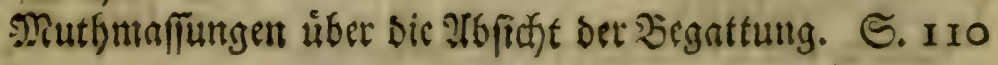


XV. Beobachtung. Dấ es unter ben Mánncten ber Differ S3lattláufe Der Eiche, geflugelte und ungefligel: te gebe.

$$
=
$$

:

XVI. Zeobschtung. Won Der Irt, tvie fif Die Diffen B̉lattlátle ber Eiche báuten.

"

S. 118

XVII. Z3eobachtung. Dẩ bie biffen Flattläufe Der (Eid)e bie Zlweige nidat verlafen, Deren Blátter ver: trocinet fins.

Scobat)tung über bie von biejen Slattläuren, ouf fold)e 3rocige in groffer \$Jemige gelegten Ever.

S. 119

XVIII. Z3eobacbrunty: ưber (Eic)enblattlaużmutter won ber vorfergebenden 2 irt, bie in einer Biudje of ne গabrung gelaifen marem.

XIX. Z3eobacbtung. Veriuche, meldje untwiver(prects"

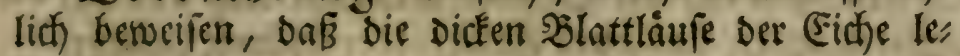
bendig gebálgrende, und Enerlegende sugleich fint. Є. 120

XX. Zeobachtung. Dái Die Slattláule fđjone Farben geben Esnnten. ,

હ. 126

XXI. Zeobachtunty: üeber ein febr bequemes und

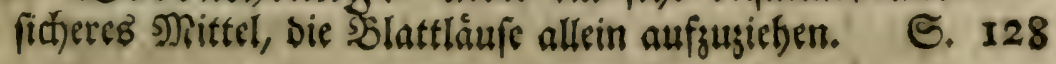

Cabelle von ben Berånberungen beș IhermometerB. S. 130

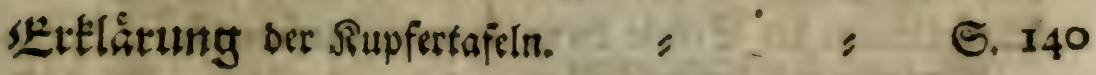

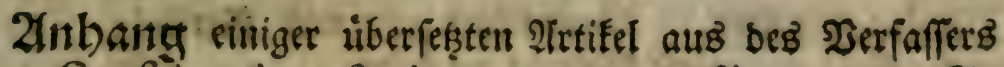
Confiderations fur les corps organifés.

S. 145 .

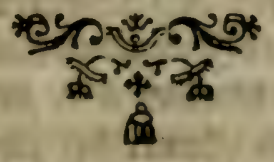




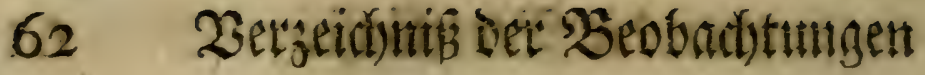

\section{Berzeiditio}

Der Seobactungen uber einige 2frten 23 intute

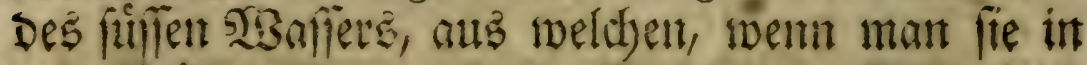

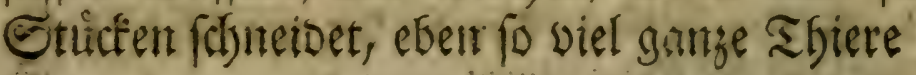

\section{werbert.}

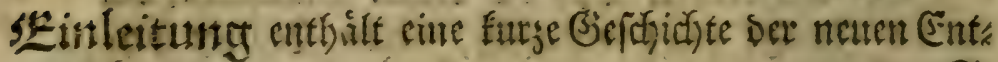
becking.

I. Beobachtung. Beffercibung Des Misurms son ber

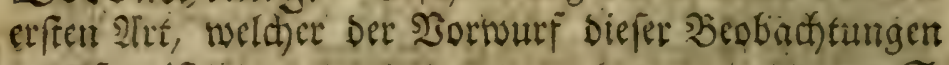
serselen ifit.

II. Zesbachtuneg iber cinen Nisurm, Der in ser Mitte

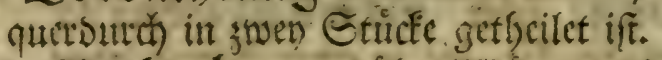

હ. 184

III. Scobacbrung tiber N33utme, bic in 2. 3. 4. 8 . 10. 14. unt 26 Etticfe gertbeilet fint.

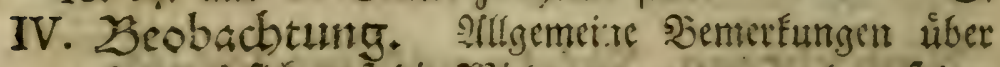

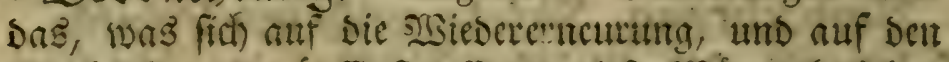

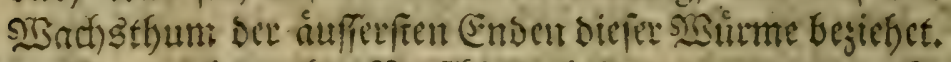

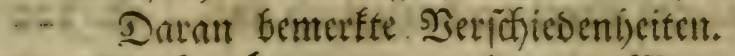

€. 188

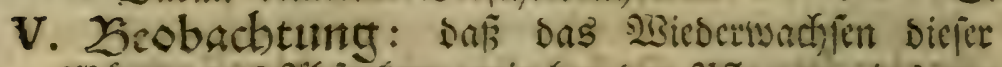

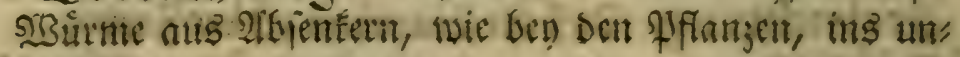

Anolieffe gethen fantin.

" 3 E. 191

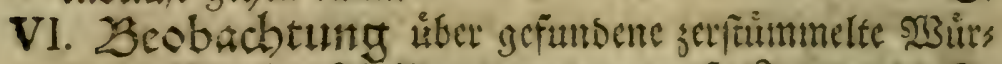
me. Sisie ibre Sheilung gutgegangen fer? - :

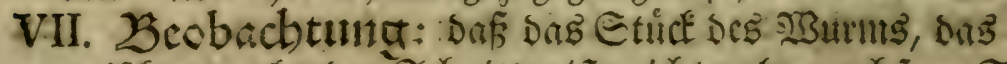

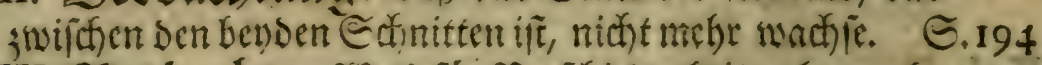

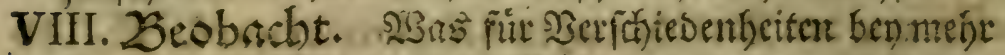

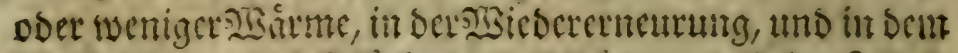

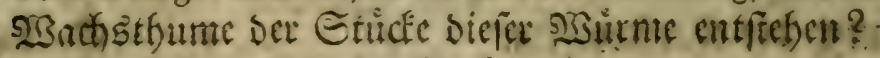

Sieriutche mit Diejer Eartje.

IX. Seobacbtung. Sicobadfungen uno 2erfuthe

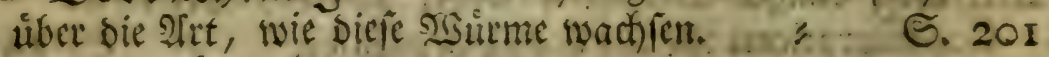

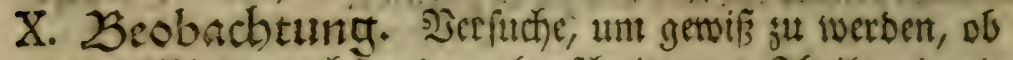

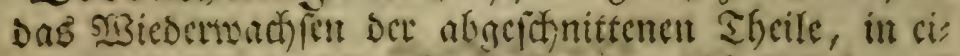

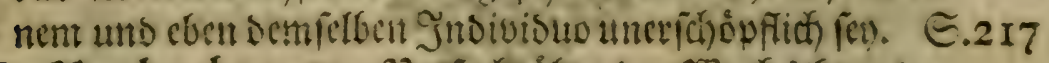

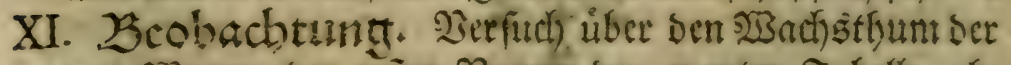

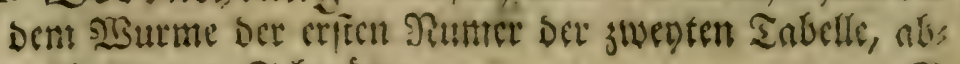
geiftinittenen E(h)winge.

XII. Żebl= 


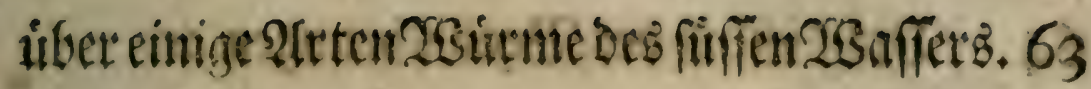

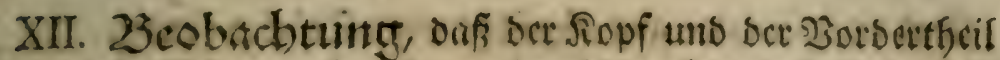

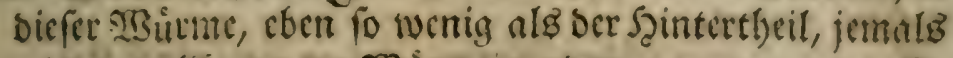

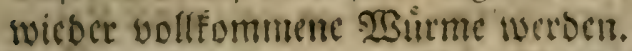

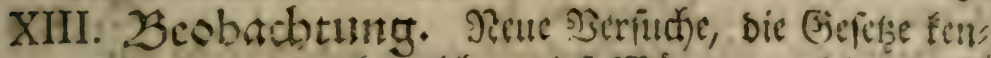
net jul lemen, nech) weldten biefe gisurme wachfin. E. 228

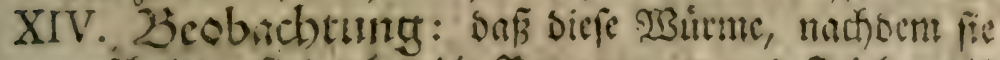
zerichnitten fins, ebir bie Senvegungen uno Sticbe, als soeks jul bethalten fheinten. "

XV. Scobacbenia, saf Der limlanf besBluts in bies

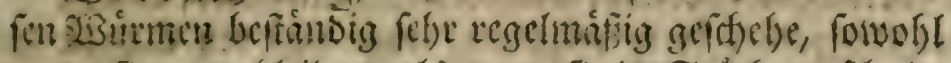

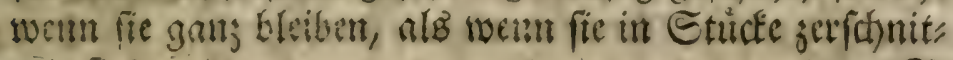
teit fins:

sit....

ฮ. 242

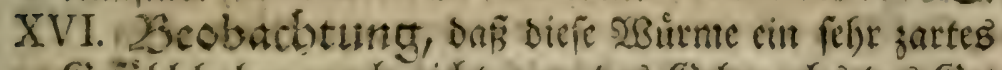

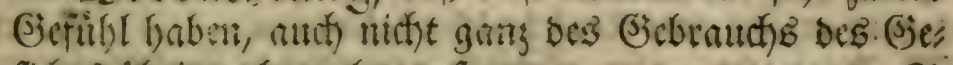

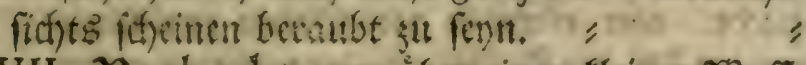

ङ. 243

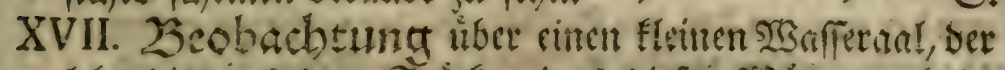

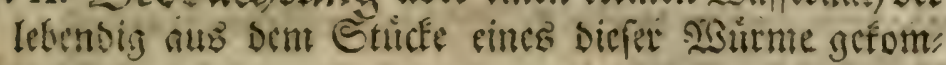
men ift.

巨. 244

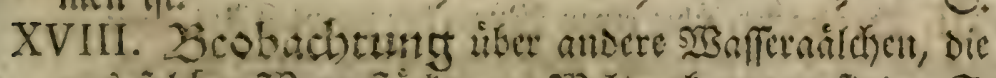

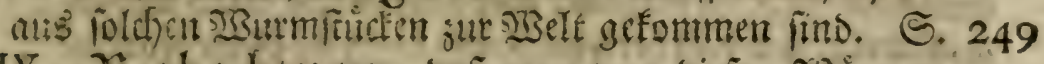

XIX. Zcobachtung, bn man won diejen sisurmen.

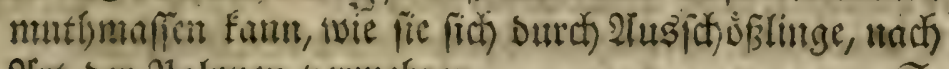
Sirt ber Plolgpen vermebeen.

XX. Zeobacbetung, liber cinten Silutn vou Der erfen

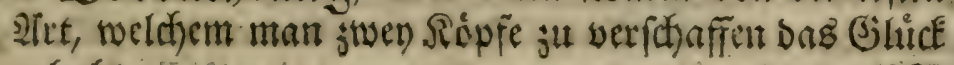
getsabt.

S. 253

XXI. Beobacbtang. Beobact)tungen unb Nerfinte mit

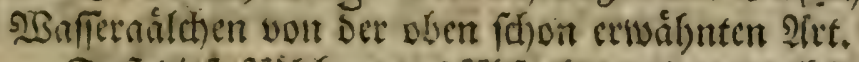

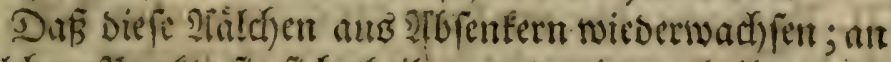
welchentsunite fie finth theilen, und wieder theilen, unb mit weid)er (Befidininbigkeit.

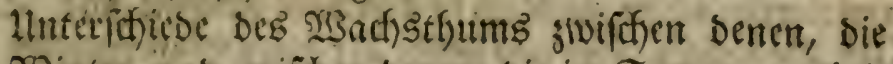
im sisinter, unb zwichten benen, Die int Eommer getheis let fint.

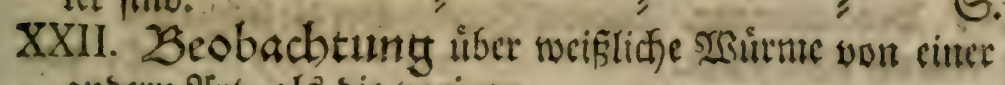
S. 258 anbern 2 irt, als bie vorigen.

Siranfliciten, weld)en fie benoe unterworfen fint. S. $26 z$

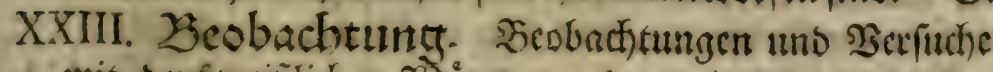
mit bert weis̄lichen 23̧urmen, ober mit Denen won Der (if)on sben crwábnten anoern sint. 


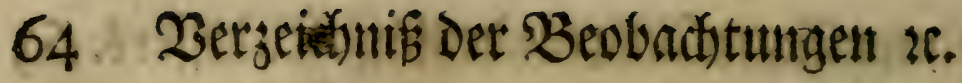

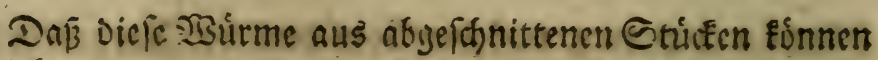
sermefret wordent.

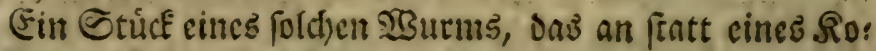
pfés einen Echwang betommen Gat.

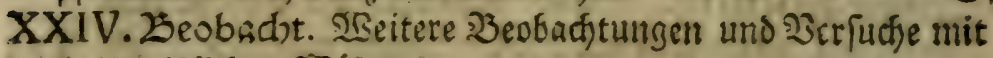
Den weigfifjen 23 itmetr.

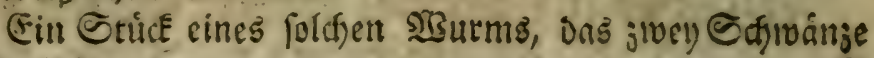
noiedrtbefommen.

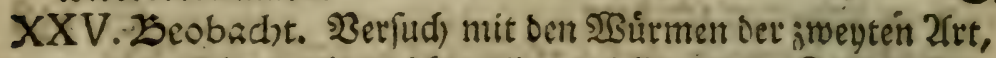
um zu erfalycen, ob es nid)t gelingen follte, ciner Sopf an fratt eines Esfmanjes hervorzubringen, wenn man den Edfnitt

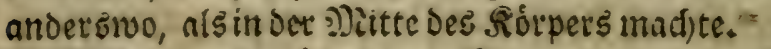

S. 281

XXVI. Zeobadht. úter einen $2 \mathbb{B} u r m$ Der zrweyten $2(t r$, Der in

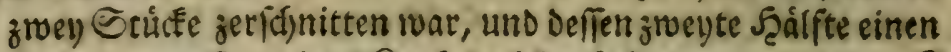

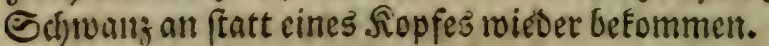

XXVII. Zseobecht. úber eincn in vier Etruffe gettheilten

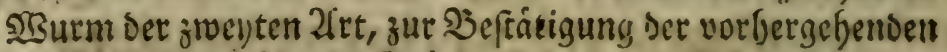

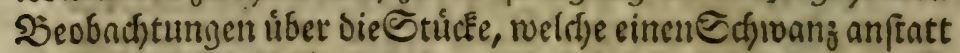
eines Ropfes betominen.

ఠ. 284

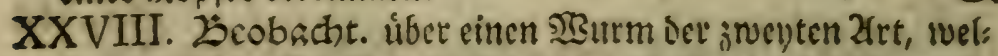
d)em mant Den Ropf orcunnal, aber nid)t allejeit gleid) lang ab:

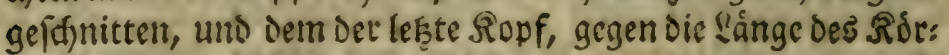
pers gered)nct, idfief angewath) fen mar.

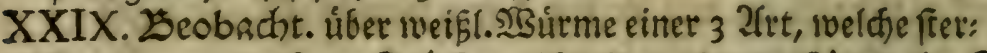

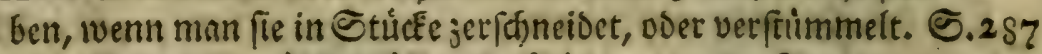

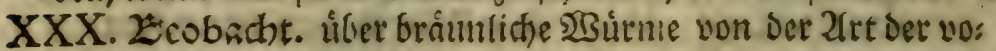

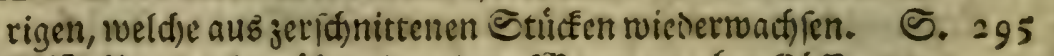
XXXI. Seobadbt. uifer sine viette NSurmart obne fúfle, oer falfche Taufenofurs genanut.

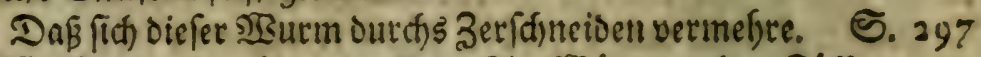

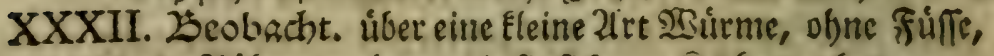

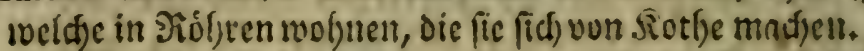

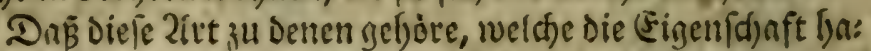

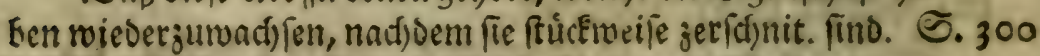

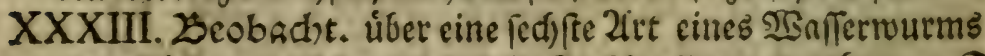

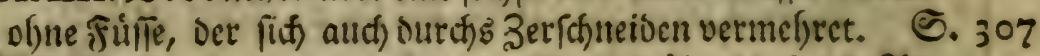

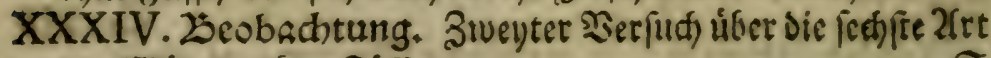

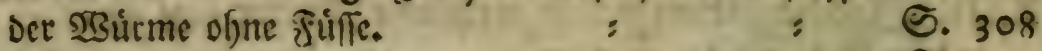

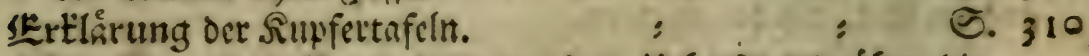
Znbang einiger Seobnchtungen bez lteberfef̧ers úber bie

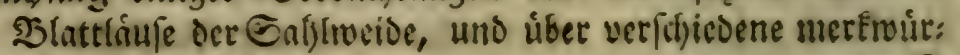
Dige Fafferinjeften.

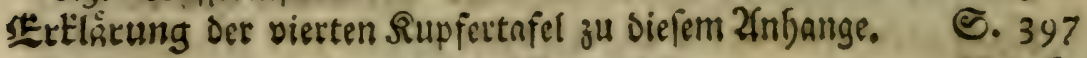

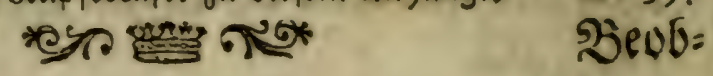




\section{शrbbatolung}

\section{กนร Der}

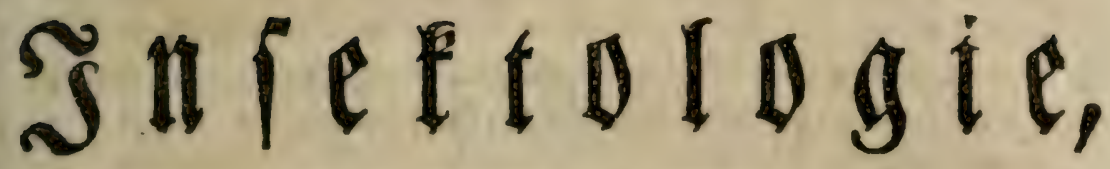

DDER

כeobatitungen

uber

Die şlattlåufe.

\section{Ërfter Sheil.}





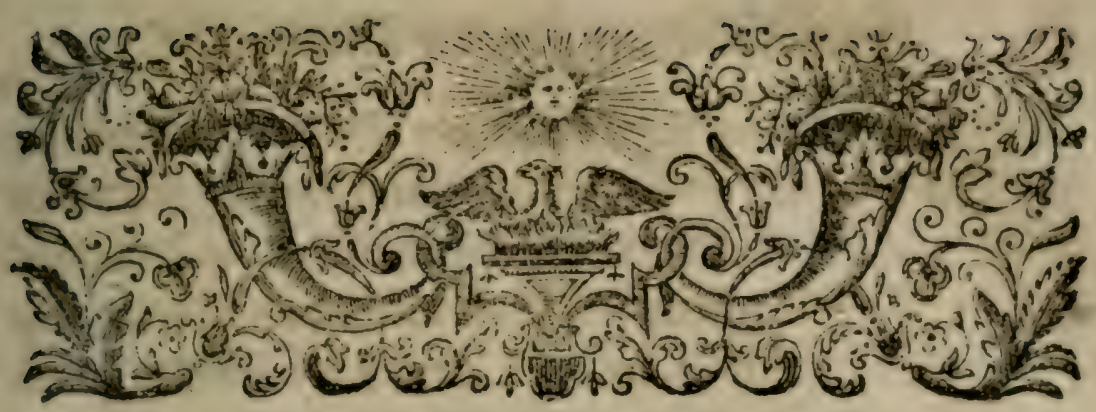

\section{Seobadtutungett}

ifber

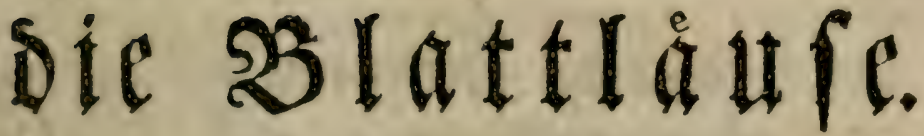

\section{Eituleitultig.}

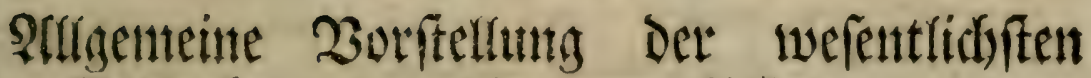
Sbeobuchtungen, Die man bišber an Den DLlattlautent gemacht bat.

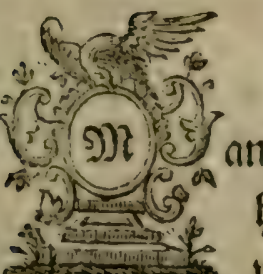

an Sarf Die SinfeEtent nidf)t Gefontoer's ftubiert Ģaben, wenn man bie SBlattlíule erfenten will. Llm firf if̧ree wieber ju erimeern "),

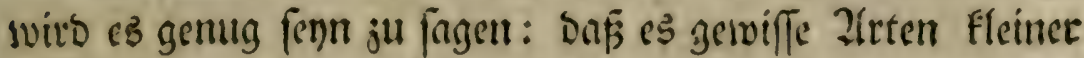
Stliegen find, bie firb in groffer Menge, an bie jungen Stiebe, If 2

(รaf.I.

a) borr 2bomet will fagen: man fann biefe Infeften fifont

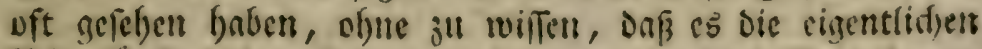

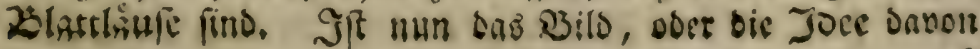




\section{4 Şeobactutungen uீber bie ßlattlåme.}

(Faf. I. fig. 1.) an bic Sblatter ber B̉äme, unt an bie गुFanjen fesen, bie fie jufammentollen, (fig. ll.) und Datan fie oft einen Siefdrwulft bon monftrofer Dicke verurfadjent. (fig. III.) (Es pflegen fidt) aud) bie Sinfeften, bur(t) bett Gitaben, Den fie thun, yor ben Zfugen ber meiften Mens fithen fenntlict)er zu mad)en, als fie es surct) bie genatufte Ṡefthreibung werbert. Ilnterbeffer will id) hier bech einen

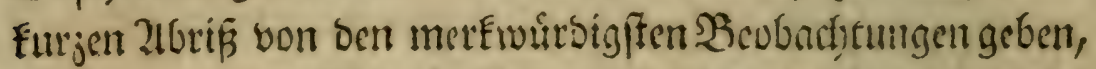

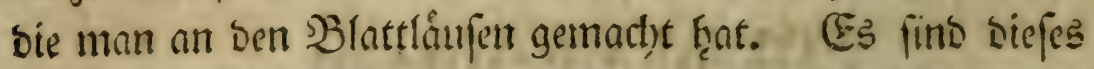
vorlaufige Renntniffe, woburch man basjenige leidfter witb

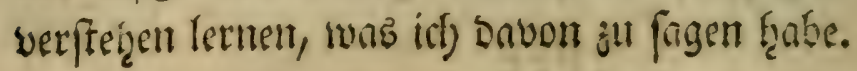

I.

I. Llebertzaut fino fie fefre fleit b); gute 2lugen

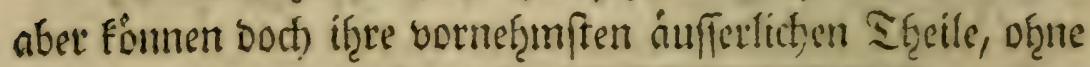

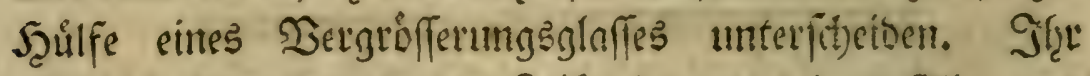
Reib ift beunabe wie ber Reib einer gemeinen fliege ges ftaltet: (fig. IV.) Daf er nemlid) cinte propurtionirte Dicfe

gegen

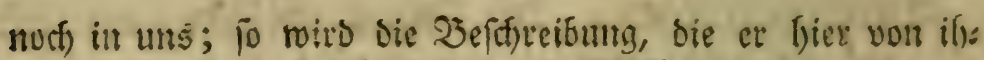

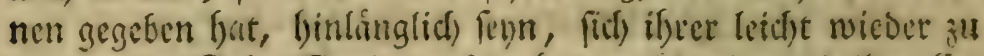

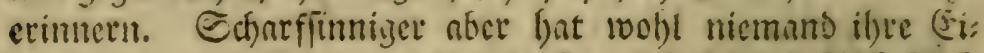
genid)aften zufanmen gefä̉t, als Linné S. N. ed. XIT. T.T.

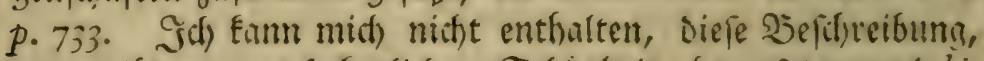

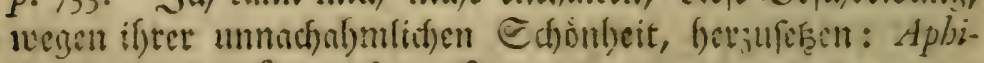
des pariunt aeftate viuos foetus, autumno ponunt oua. A copula parentum foecundas nafci filias, neptes, proneptes, abneptes affeuerant Entomologi. Aliae apterae, aliae alatae, absque fexus difcrimine in eadem fpecie; pleraeque duo cornua poftica abdominis gerunt, quibus excernunt rorem melleum; bac Formicarum vaccae. Species difficile diftinguuntur, difficilius definiuntur, nec femper in diuerfis plantis diuerfae fpecies, adeoque pauciores mihi Apbides, quam plantae aphidiferae. $1 \mathrm{cb}$.

b) Reaumur Memoires pour fervir à l'hiftoire des Infectes. Tom. III. Mem. 9 . 


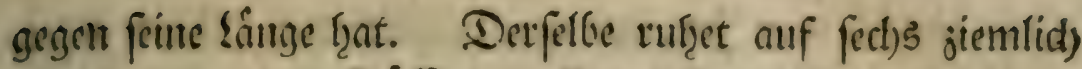
Iangan unto jarten Fuffifen. Ben ben meiften 2leten ift et

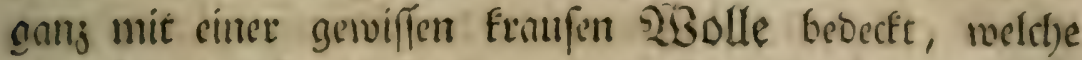

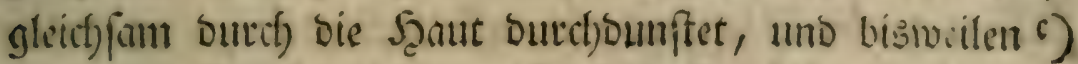
über cinetr Boll lang wirb. ( $a f$. I. fig. VI. c, c.)

2. Der Sopf ift in Sietrad)tung bes Rospers fleitt,

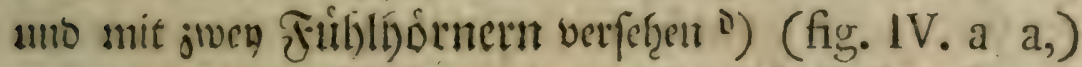
welit)e vont ifzem ?tnfange, bis zu thęrer äufferften Spitze,

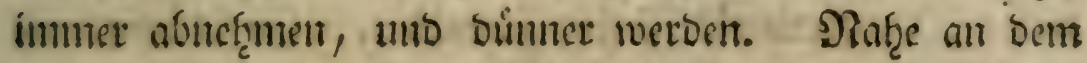
$\mathfrak{I}_{3}$ Dite,

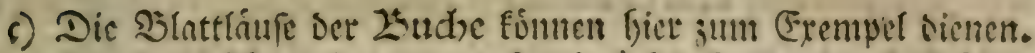
Reaumur Memoires pour fervir à l'hiftoire des Infectes.

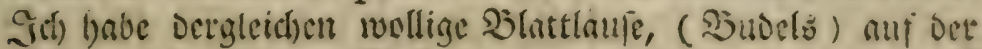

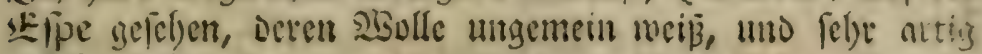
Befráluelt wat.

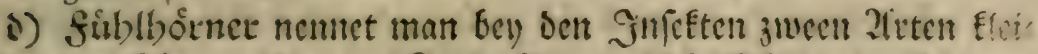

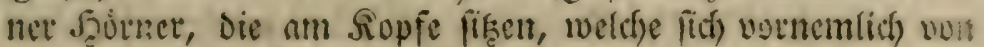

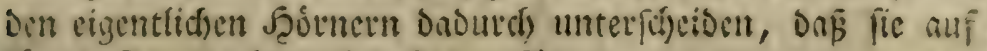
ifferm (Strunde beweglidy find. 25.

Die lingeren Kopfipisch Der Infeften, die ans mefy:

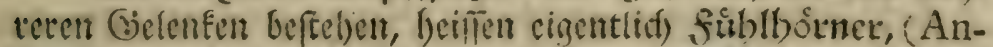
tennae) Die verfóbiedent (jeftaften uno Etellungen baben;

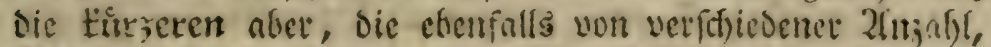

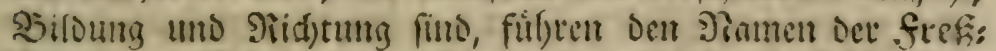
fipiscr. (Palpi, tentacula, antennulae.) QSertoen bie

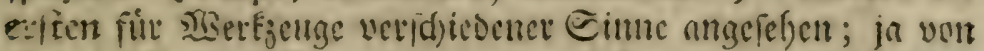

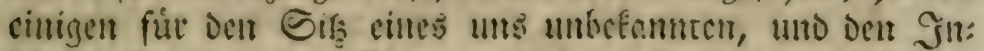

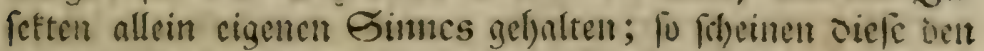

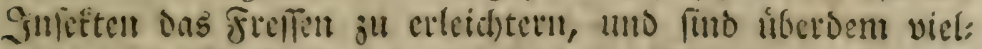

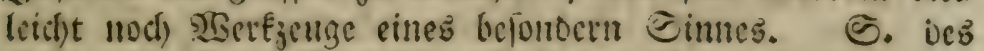

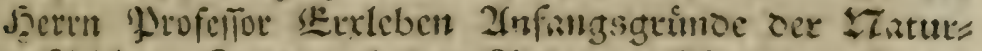

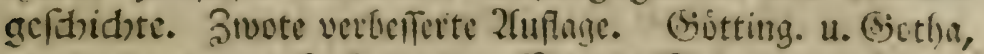

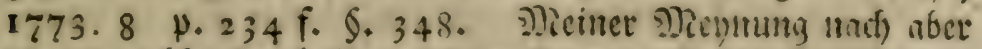

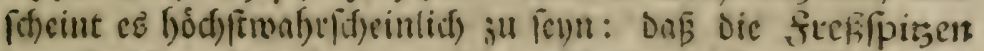

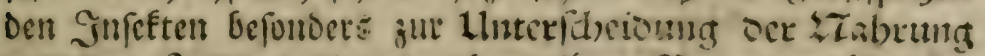
uno des futters bienten, of es ifrer Jantul gemás, oder

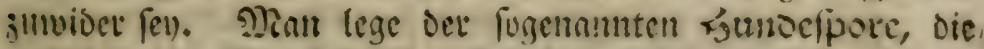

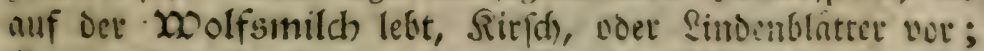
fie wit' fie erft mit ifgen furgen Episen befíblen, uns gleich 


\section{6

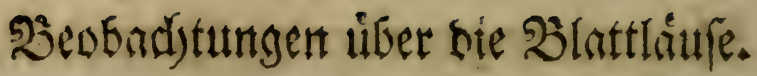

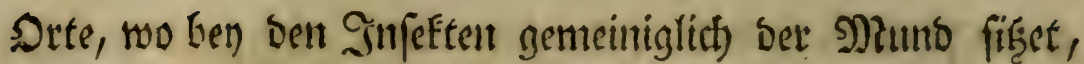
geigt fiid) ein feiner Sangeruiffel, (trompe) (fig.IV, $t$,)

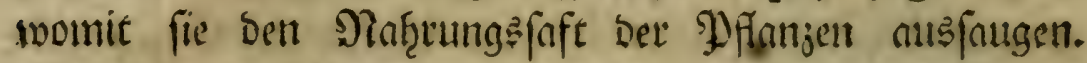

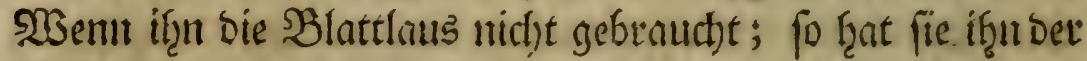

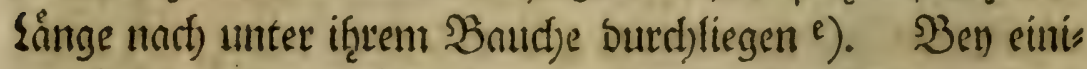
gen i) ift er fo unmáfífig lang, Don er finterwarts eitr grofs fes Entre unter if̧nen herevorffef̧et, welct)es vollfounmen wie

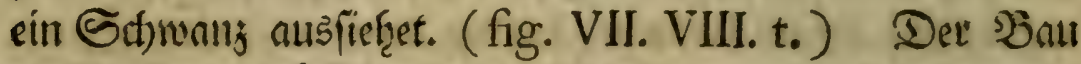

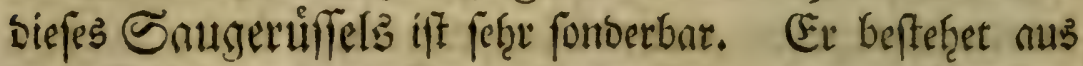

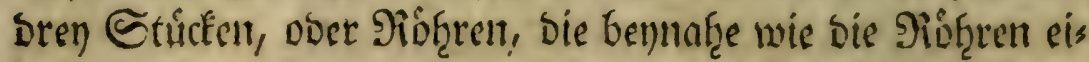
nes Đoerfpeftiva, eine in bie anoere gehent. (fig.VIII, p, o, t.)

-3. 2luf

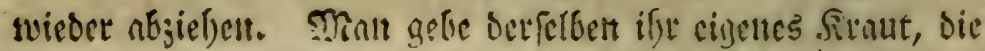

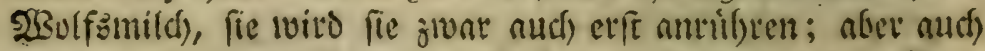
gleid) anfangen zu freelen. (E)eir jo iveroen es andere Siau:

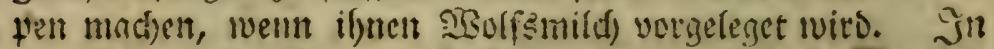

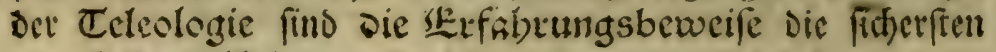
uno beften. Heb.

c) Dafier befommt man siefen Gangeriafiel audj pefe fetten ju

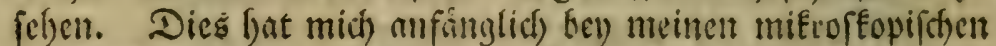
כ3erfuchen oft gemig betrugen. Entweder Das Gillett, ween

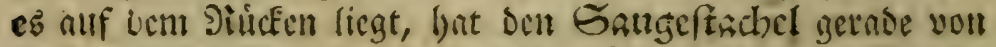

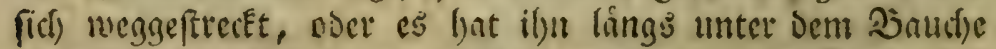
ouri)tiegen. Sn beyocn șallen mus man den Jucus des

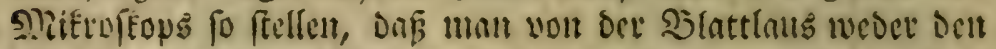

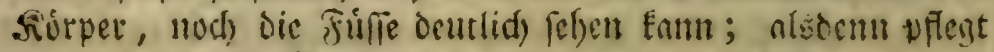

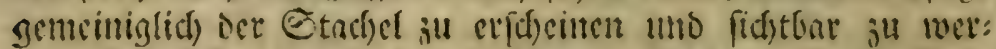

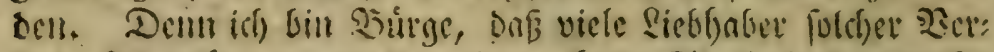
fud)e 2 battlánfe gemu! Getract)et, iffen Gtachcl aber, biefer

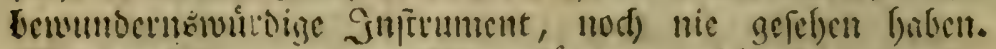

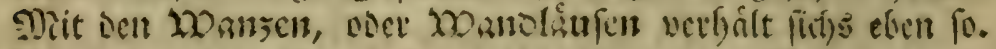

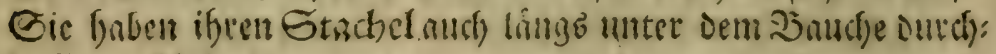
ricgent.' 1lab.

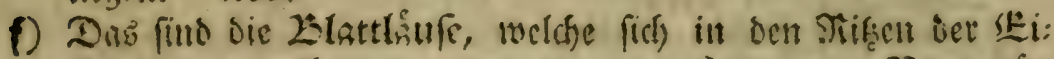

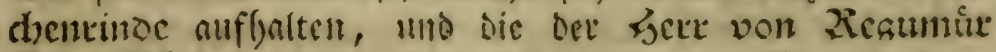
Tom. IIJ. p. 334. unto in feillen folgenten slientoires be:

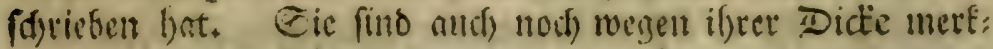

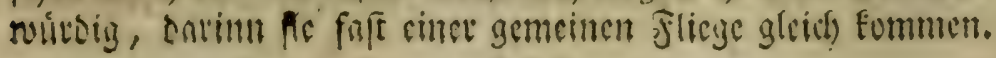




\section{Ḑeobad)tungen ủber bie Blattlåufe.}

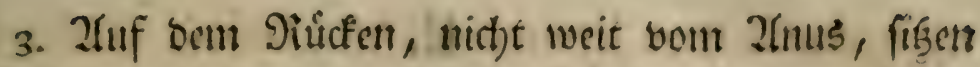

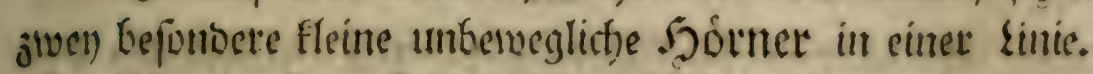
(fig. IV. c, c.) Gic fint viel Furzer mo bicker, als bie

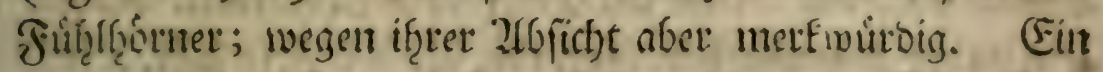

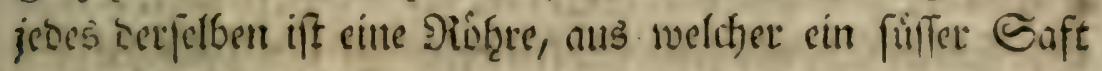
quillet, woutnd bie 2tmeifen gef̧et, uto bavon man in bes: 9) Rebicin (Sie(trauth marbt * ). Hebrigens find biepe Şornet nicf)t allen Slattlausarten gegeben, uno in biefer 2rbficht founte man fie it stween Samptflaffen theilen. Die.

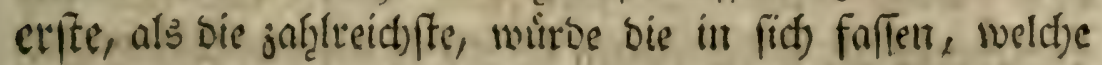

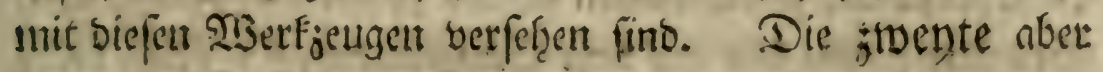

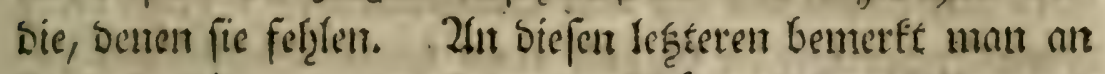
ftatt Der f̧orner jwo jirfelrunde Mánde, (fig. VIIl, c, c,) meld)e bem Serrn bon Sienumix ju gleithen ßetrid)= tungen fóbig fotienen.

4. Endid) giebt es unter ben SBlattlaufen, tmb was bas metfwurbigfte ift, in jeber Fantile biefer Eleinen Jut feften, einitge bie Feine Thligel ḩaben, unb bie auch niemals Slugel befomment: anbere fraben betent viete, bie bet Flus gelu ber fliegen gleich fint, unto wedche fie oben auf ben seibe ant einatber getegt tragen. (fig. V.) כon biefen refeterent fagt man, bof fie fith berwandelit, wenn fie nus Dem Granbe ber ungeflugeften Sinfeften ju ben gefligelten sithergetret, welches gefthief̧et, wenn fie if̧ren bollfommenett

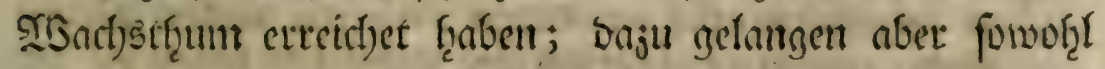
sie erften, als bie anbetn nidjt cher, nls bis fie fid) ceff einis gemal geţåutet hૃaben 9).

$$
\mathfrak{I}_{4} \quad \therefore \quad \text { II. }
$$

II. E3

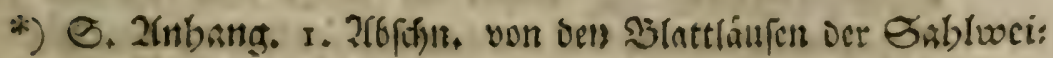
De. II. 25co6. $11 \mathrm{cb}$.

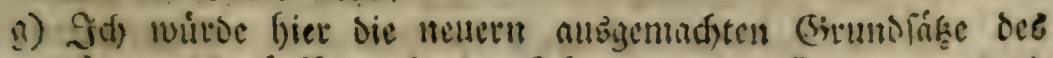
Keten Derfaffers, in bet Relgse von oir Ergengung, unt Sort: 


\section{II.}

Es giebt gewiffe Snfeften, bie ben Blattlaufen fef̨t

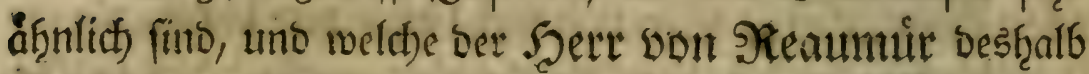
Z̉aftntte genennet hૃat. (fig. IX. X. XI. p, p. XII. XIII.) Sie halten fith, wie jene, hृaufenweife auf ben Dुflanzen auf, und fangen if̧ren Gaft aus. Sie berurfact)en gleithfalls barauf verffhiedente 2fustvichfe. Duritr aber fino fie un

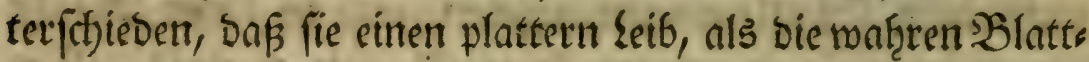

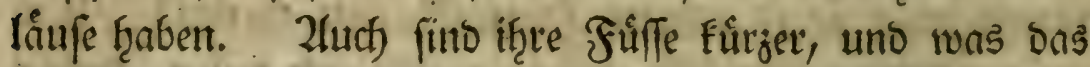
vortief̧mfte ift, fo befonmmen fie alle zu genviffer Zeit Flügel. Eine 2lut bavon lebt anf bent Buct)sbaume, b) (fig. IX.) Deren Excremente bie Sieftalt eines langen Sdjwanjes an: netrmen, (u, s.) ben biefe fleinen Infeften finter fiit) ḩer jief̧en.

III.

Fortpflantzung biefer Infeften, nus feiner 25etrachtung ibber

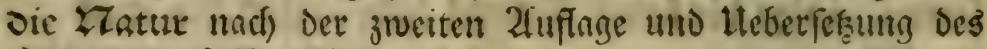
Sern Profeffor Titits. Lrip. gt. 8. 1772. anfüloren,

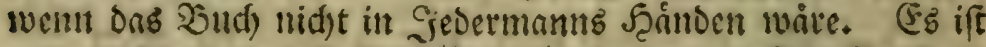

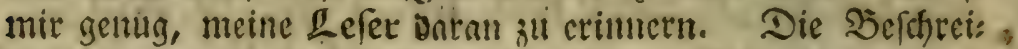

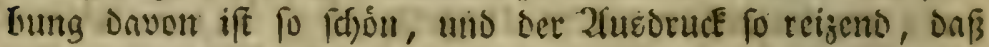

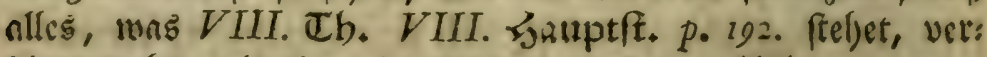
oient mebr, als cinmal gelefen zu vorden. Uleb.

b) Man findet fie oarauf im Zpril uno whay. Diefe Laftar:

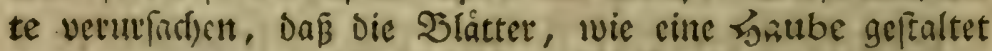
sertien, aus beren vielen fid eine bohltugel bildet, Die bie: fen fleinen Ginfeften sut $2 \mathbb{B} 0$ fonung Dienet. Reaumur T. 1 II. Tab. 29. fig. 1. 2.

2fuf Dem feigenbaume natbret fid eine ansere Sirt

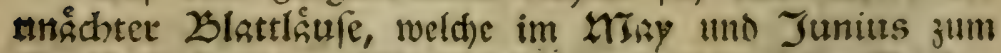

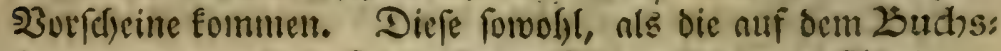
baume verwandeln fid in fleine Fliegen, Die man Epringer nennet, weil fie wie bie Sloffe fyringent. (Sinte oritte 2lit Dirfer Suleften lebt nuf Den WDeifsoornen, wo id) fie im Junius sefunden babe. 


\section{III.}

I. Die groffe 2jerfichedentzeit aber, Die man zwifhen Den matmigfaltigen 2trten ber Blattlaufe bemerfet, beftȩ̂et in ter Farbe. Sin cinter Itet fint fie grün, in étter antoern gelb; einige fint beaum, nmbere violet; man firtoet oneuns tee weiffe, fotwarge, und bismeilen graue; cinige find blapss

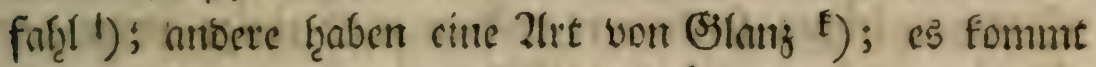
aber biefer (Stanj oft von einem 23 ummthen her, bas die

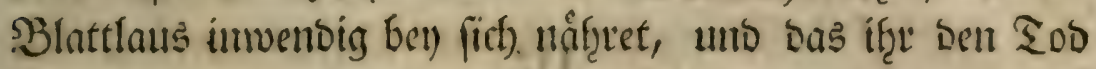
verurfact)t I). (Endid) fino cinige 2lrten bals brami, ba!b

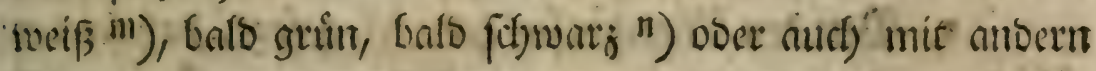
Farben, ferce artig geflectt.

2. Die Blattlüfe madben eine Rlaffe foldyer Sçec:

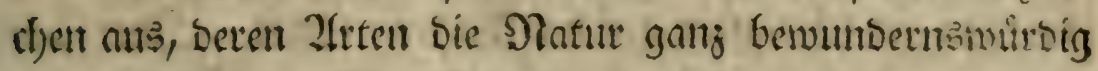

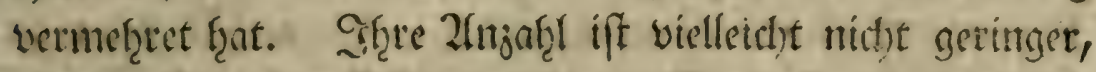

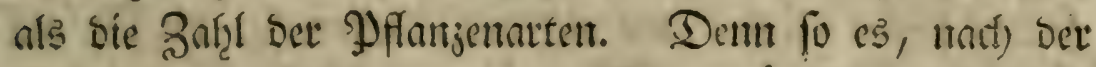
2fumetfung bes Sertu bon Sieaumut o), noct) nitht If 5

ล4รื"

i) So if bie Farbe der blattlínfe yon bem flicoce, Mrobn, uno den groffer Gattenbobnen, (Sautolmnell, Faba, Linn. S. N. T.II. ed. XII. P. 48 \&.)

f) Diefe ?frten von Slattlätfen finder man auf oer Lidnis,

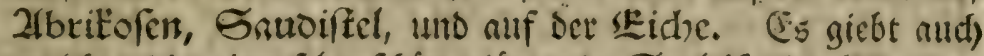

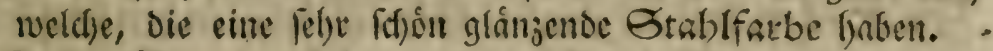

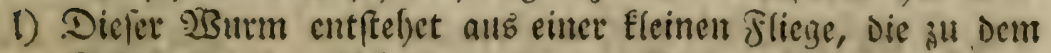

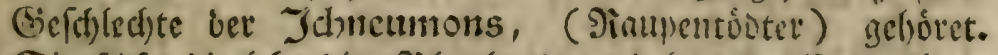

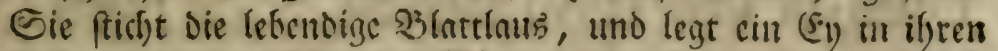
Icit, woraus nad)fer cin 23 urmejen entfeflet, Das auf ibre

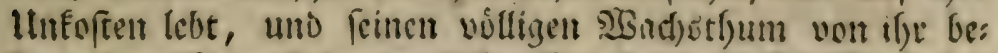

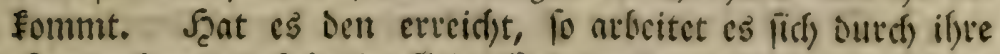
Seaut, Geteitet fid) cin flcin (Gefpimmfte, worim es fich is

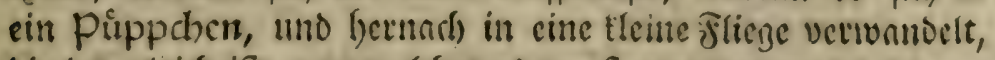

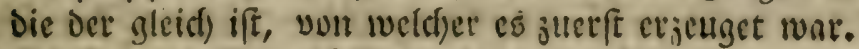

in) Eo fino vie Ṡlattláue Der $100 \mathrm{ecm} u t h$.

in) Dergf(cid)en fiel)et man nuf Den Ëauerampfer.

1) Tom. III. des Memoires fur les Inf. pref. p. 15. de l'edit. de Paris. 


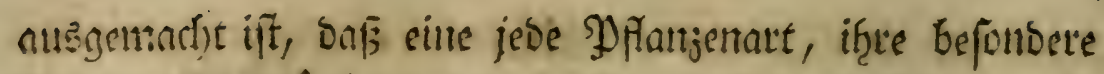
2tret von Bblattlăufen ţabe; fo ift es ooch wenigifens genviß,

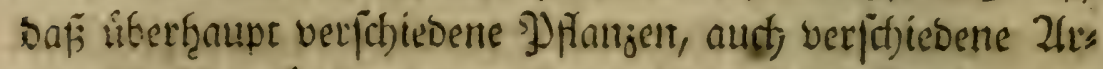

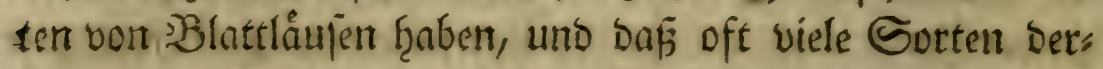
felben einerien Dy fanje lieben. Es giebt nidf) allein weldse, bie auf Den SBlättern, auf Den B̧lumen, p) unto auf Dent Stengeln leben; fontern es woof̧nen aud) einige unter Der

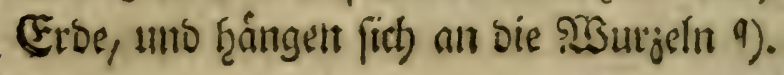

\section{IV.}

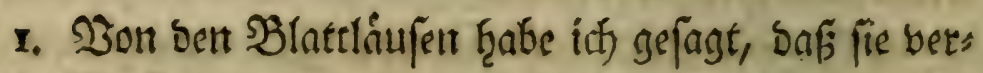

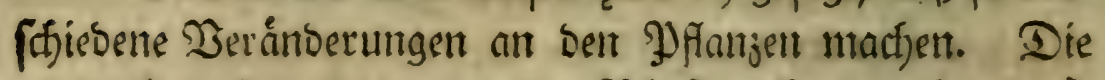
merfwuirdigften fino bie groffen Blafen, (₹af. 1. fig. III.)

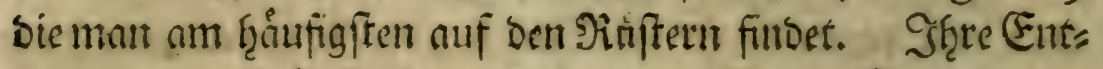

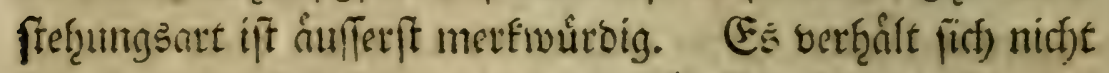
fo mit biejen BBlafent, wie mit ben (Ballen *), bie fiich auf

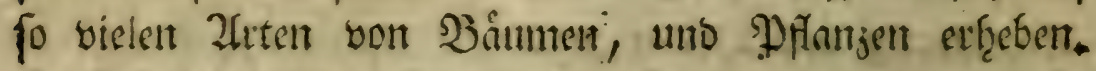

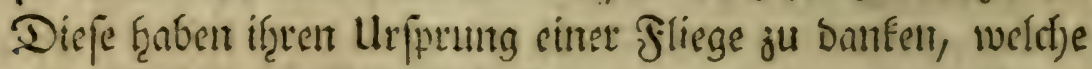

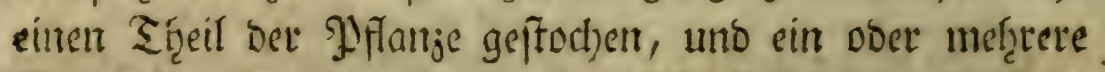

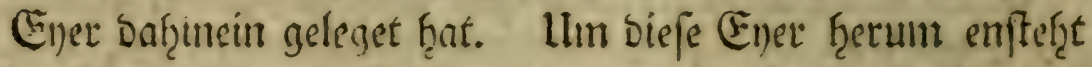

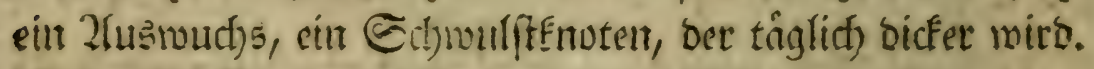

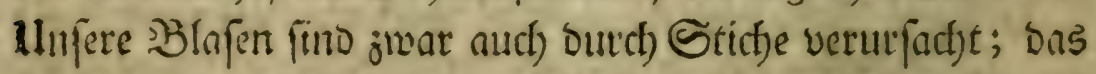

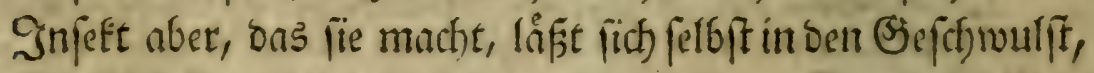
ben es aufgetriebent hृat, mit einfftiteffen. Da legt es ben

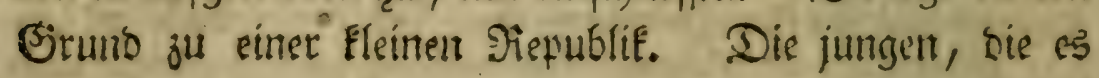
barit

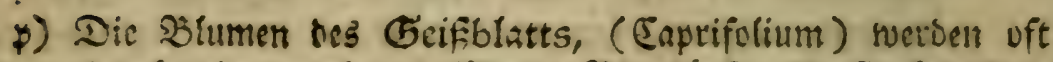

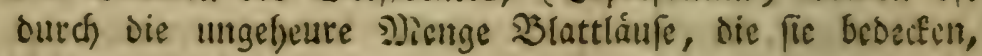
ganj ungeftalt.

q) 2ian fimbet fie an ben $2 B u r g c(n$ Der Lidhnis, Det Gd)anfs gâtbe, ( Millefolium) der Camillen, Der butnosjunge

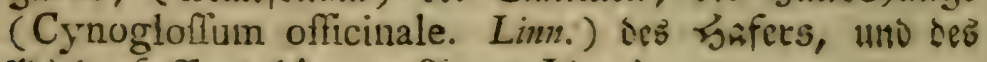
Zišlberfulfes. (Arum, 2ltun. Linn.)

*) Malpighi de Gallis. Reaunur Mem. 12. T.III. 


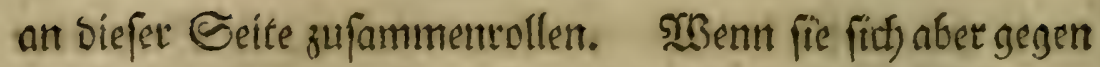
bie s)itte gu nieberlofien; fo werben burd) fie baferbit ver:

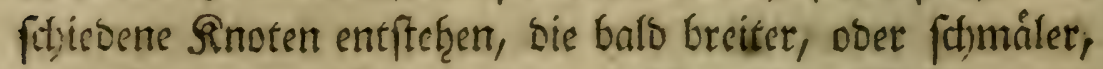
bald Giứner ober niebriger fims, nachbem if̧e Stid)e gegans gen, Doer bie Stelle befthaffen war, wo fie mit ificen Stn c)eln gejogen ţatten ${ }^{b}$ ).

\section{$\mathrm{V}$.}

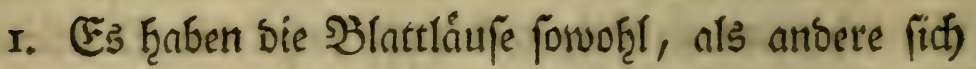

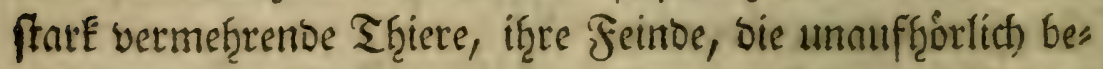

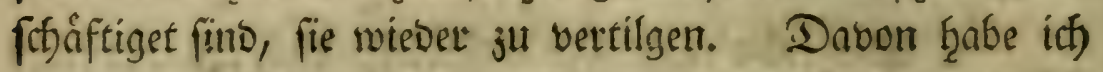

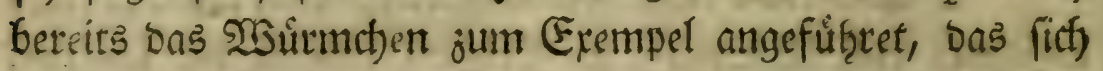

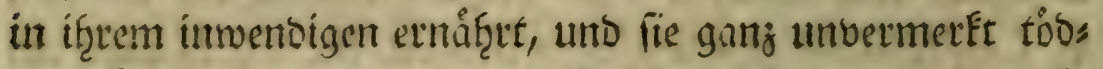

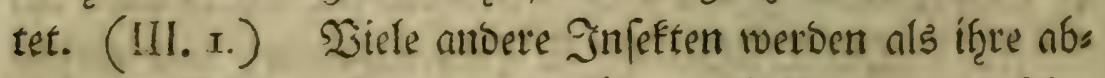
gefagten Feinoe geborell, uno führeent mit if̧nen Den ḩeftigs

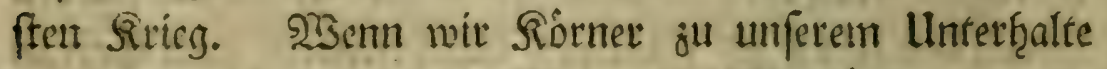

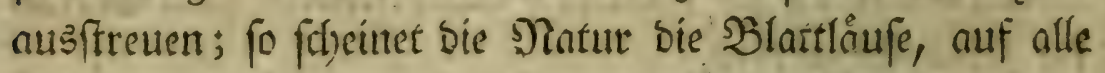

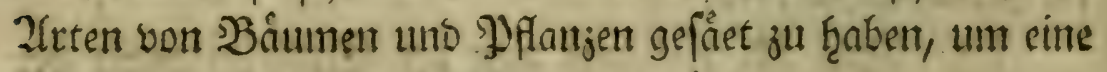

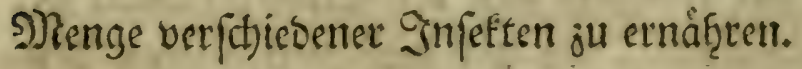

2. Es fionnen biefe Guffeftent in zwoen Mlaffen: in

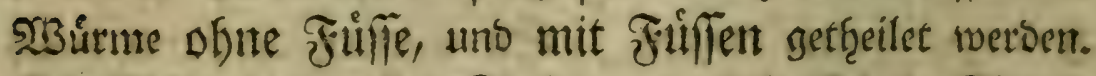
Die Sisurme ber erffen Rlaffe verwandeln fidt) in Fliegen

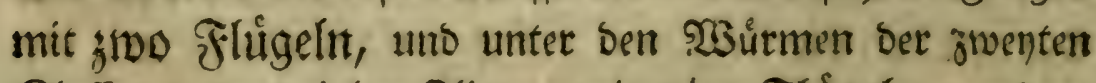
Rlaffe merben einige fliegen mit vier Flügeln, andere Rifer ${ }^{t}$ ).

3. Dic

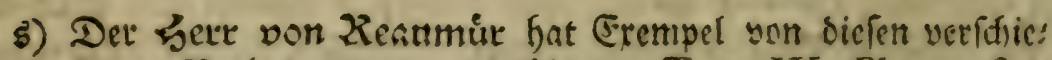
Denen 2ietánderungan angefúbret. Tom. III. Pl. 23. fig. r. 2. $\mathrm{Pl}$ 24. fig. 4. 5. $\mathrm{Pl}, 26.7$. 8. 9. 10.

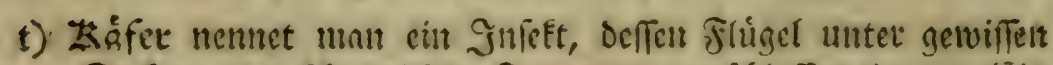
Decfen, noer (d)uppidsten Tütteralen velidiloten liegen. (Eir pilder if 3. (5. Det Hrayther. 25. 


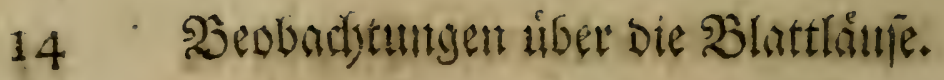

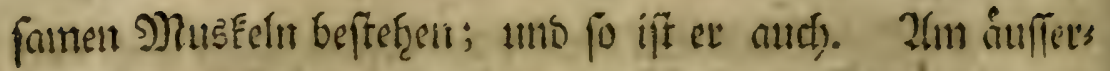
ften Enbe beffelten jeigt fiit) cine Zfrt vom Drenjack, ober

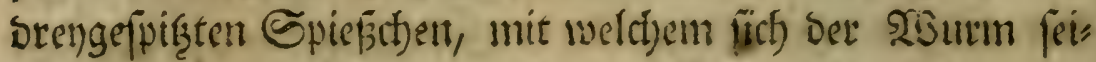

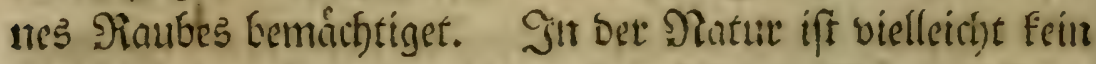

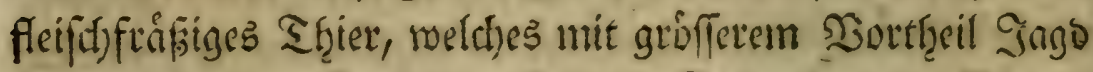
madjen follte. Er liegt auf einem Stengel, ober $\mathfrak{B l a t t e}$

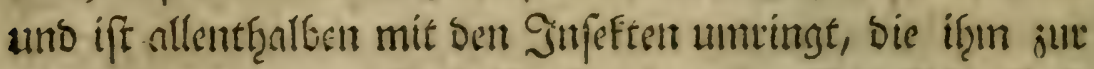
Dhaf̧rung bienet. ( furfent nid)t mur, nichte eimmal bor if̧m ju fleffen; fonsern

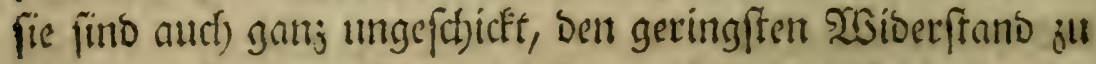

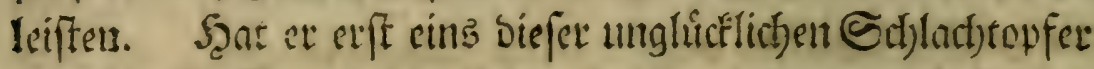

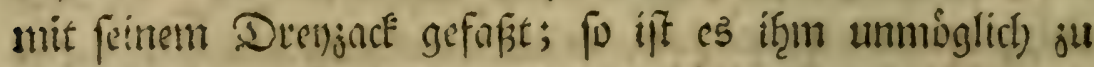

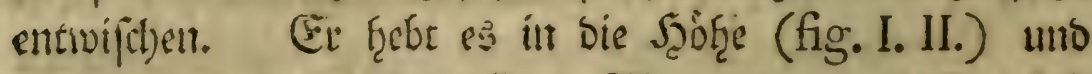

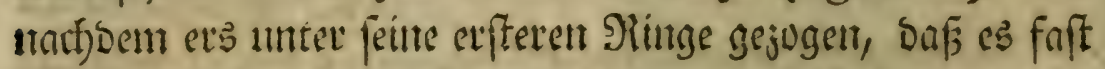

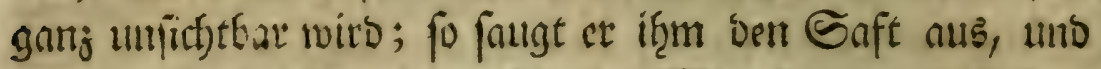
vertwandelt es int weniger, als einer Minute in eine trockene

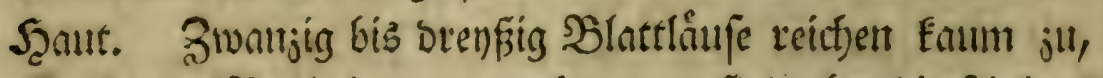

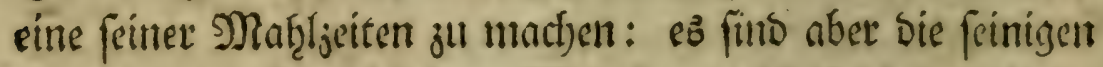

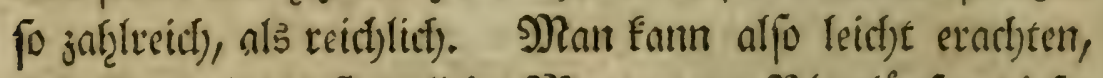
was vor eine erftaunlitife Nenge von SBlnttliaufen biefor 23umm verjeţre.

4. Die Blatelansfreffer ser juenten Slaffe geben beit

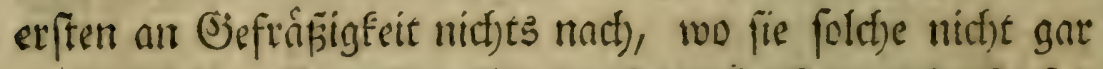

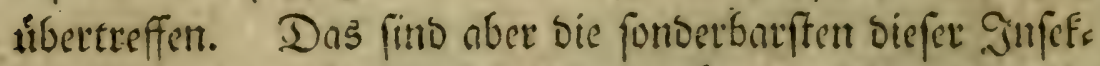

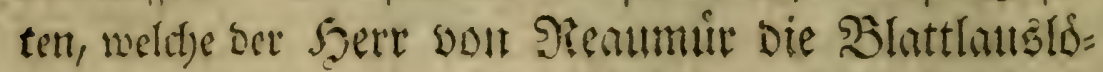
soen genennet frat $r$ ), (fig. IV. V.) weil thr. Siopf mit

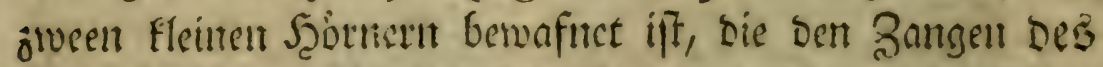

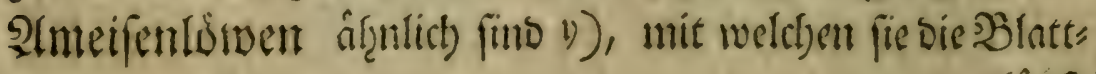
liufe

x) Men. fur l' hiff. des Inf. Mem.II. Tom. III.

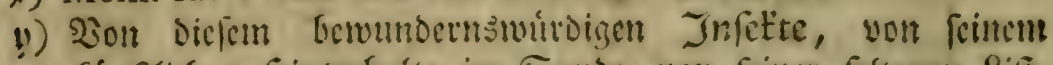

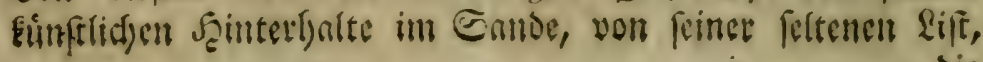
bir 


\section{SBeobact)tungen uiber die Şlattláufe.}

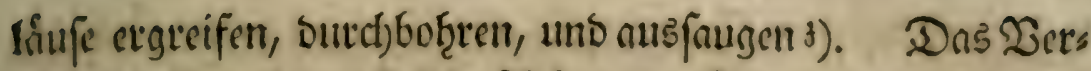
farzent von einigen ift fefre feltfam. Sie machen fict) nus

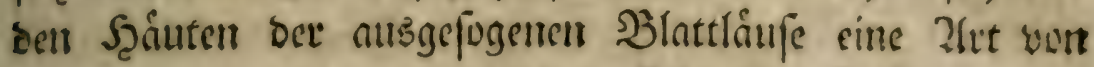
Befleibung, uno jul gleicher Beit ein Eiegesjeichen. (fig. VII. VIII.) ग)?an follte bier faft glauben, ben Sret.

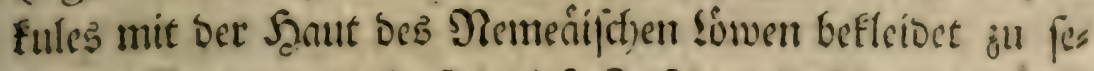
hृen. Es verwanbeln fith biefe Infeften in fehrartige folles gen, (fig. VI.) von Dem (jej(d)lect)te Der Jingfertyen a), weldye

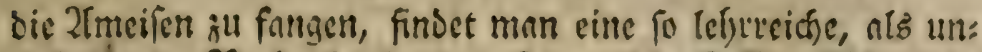

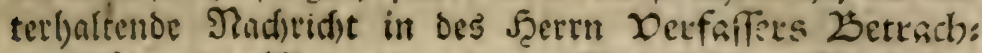
tung iber Die Zintur, nach oer Citiufifthen Zltsgn̈be. 巨. 545 fi. Heb.

3) Die 2jlattlauslowen fino you oreyerley Giattung. Die etffe begreift Dicjenizen unter fid, weld)e Eleine SGarjen an fiif) faben; an Den Eeiten eithet jeden berfetuen tritt ein

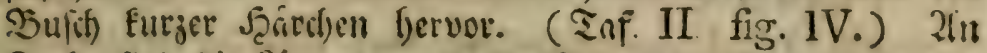
Tintbe fint Dic Lorven won Diefer (Siattumy nuf mel)e als cine

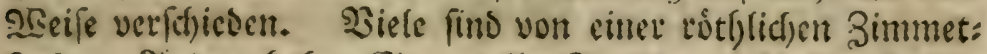
farbe. Ziniere baben Citrongelbe Etteifen. Zinbere balten

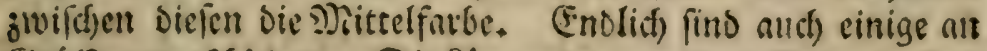
Girófie unterifjiçen. Die Qóment Der zweiten Gattung fins

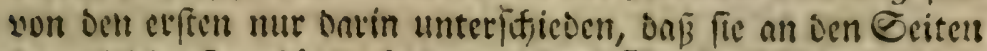
feime joldfe famarbuifche baben. ( Taf. II. fig. VI.) Slgre

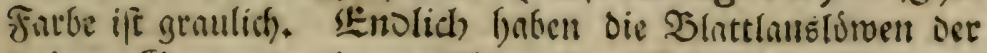

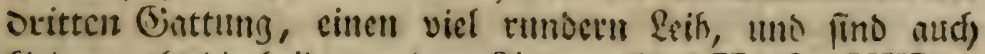
Eleimer, als bie heiden anuern 2liten. (Taf. II. fig. VIII)

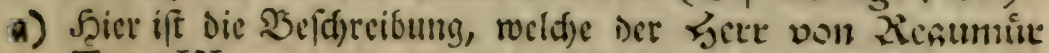
Tom. III. p. 385. von eintem folden Jingferchen gichet:

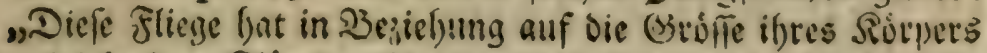

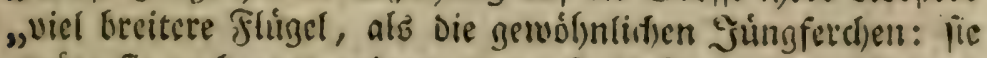
"trajyt fie auct) ganj anders, roenn lie in siulje ift. 2ilsoenat 1, formirent fie ein Dad), unter weldem Der fidener liegt. "Ëie fint auth viel feinter und zarter, nis man befbiseiben

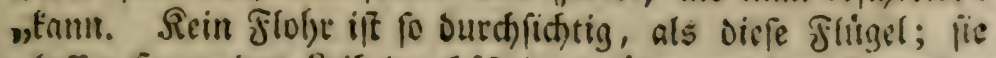

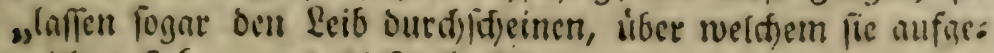

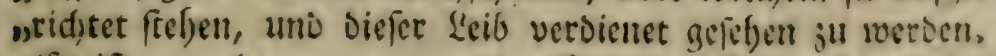
„St if vont einem jarten uno glangenoen (Brutu, bismeilen

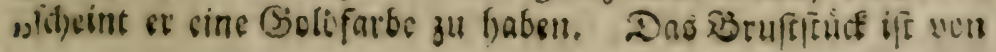




\section{SBeobachtungen uiber die B̉lattláuje.}

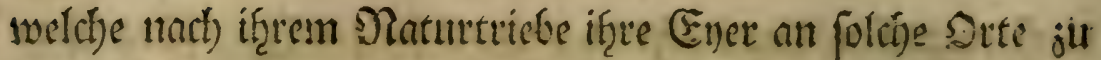

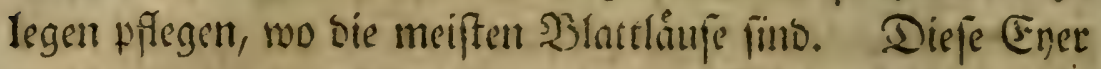

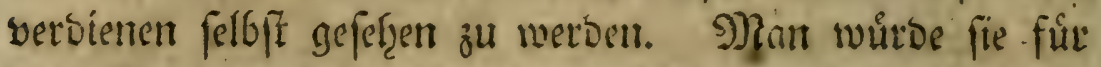

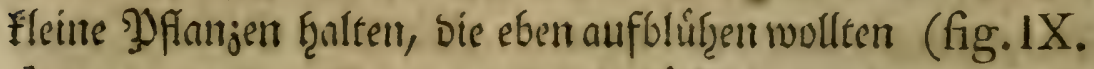

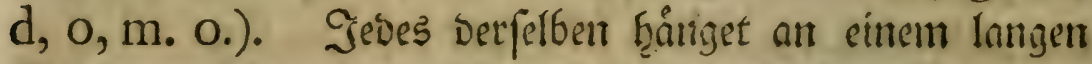
Stiele, welther eintem SBlumenftengel gleict)et, Daran Das

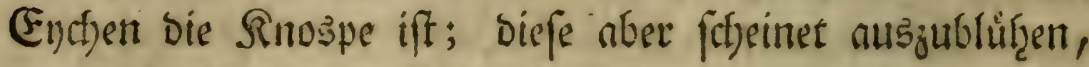
wenn bas Junge ausft)liefet.

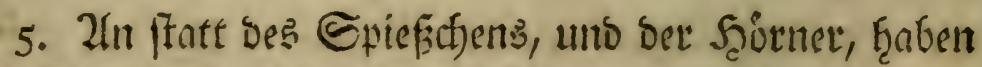

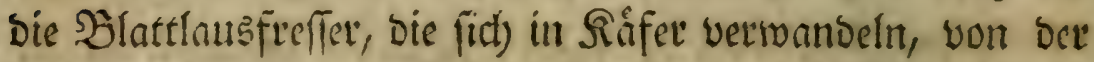

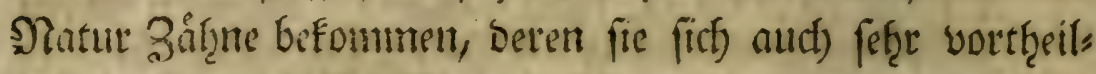
hraft bebienen. Die 2let, welche am meiften verbient bes merft ju werben, ift bie, weltife ben Namen bes weiffen

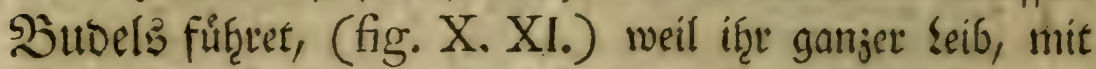

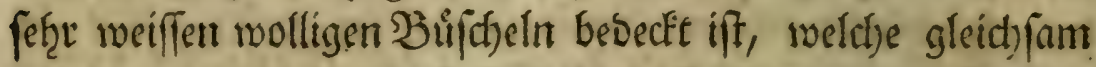

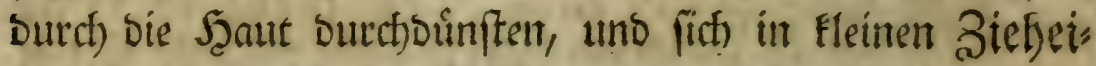

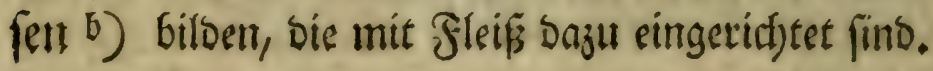

6. 201t

seben biefem Girun; was aber baralt am meifen glanjt, finto witwel grofle uno berworffet)enve 2luyen. Eie baben eine to:

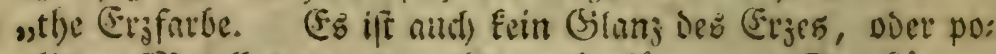
"litten s]ietalles, Der Dem iftigen beyfáme." Das :ôtuen: juingferd)en bee jweiten (5iattung, if wen Dem erft bejhriebe:

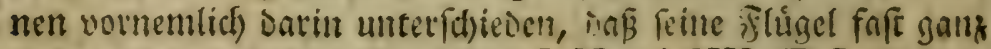
unourd)fidstin fint. S. Linné S. N. ed.XII. T. I. P.y II. Hemerobius n. 2. 3. Perla, albus. 1leb.

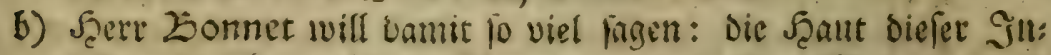

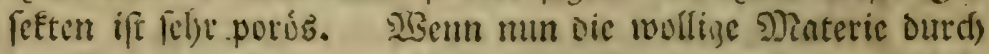

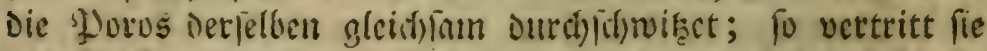
Die Ctelle cines fleinen J̃icheifens, Durd) weid)es ber feinfte

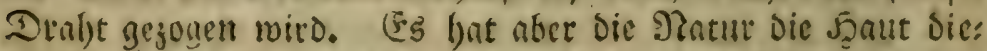

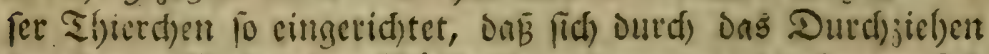
Der feinen sisolle, Die Sbiliffelden formiten, die fie an fids tragen. Die Prnupen, Die Epimen, uno nudere Snletten,

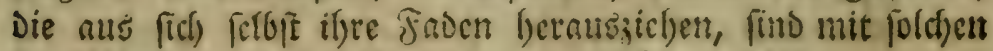

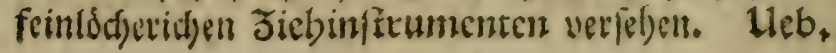


d)en frat. Dạ muf man aber ben unfern Blattlaufen,

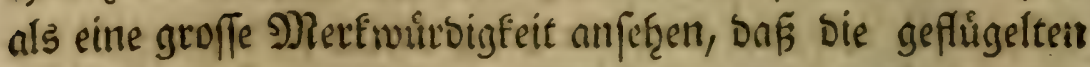

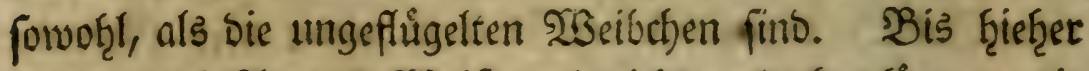

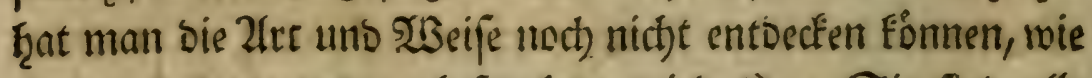
eins unb bas andere befrudfet wirb $\mathrm{e}$ ). Sie finb alle

\section{Sebentig:}

Lampyris. n. 1. Noctiluca: habitat in Europae iuniperetis graminofis. Es giebt rifrigens nod) verjachiedene

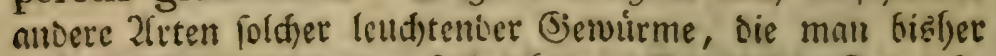
nod) nicht genugfam unterfuchet fat. Bor einiger 3eit gefe

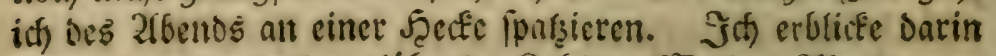

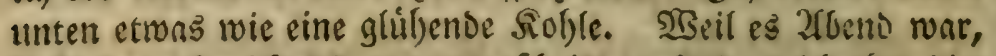

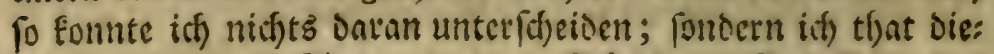

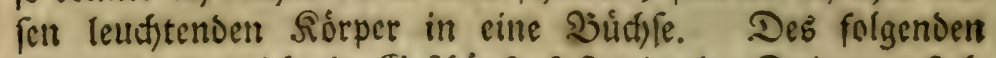
Miorgens fant idf ein Siefdjupf, faft wie eine Spinne geftals

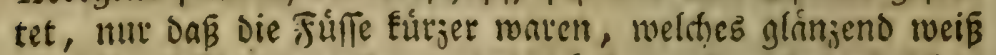
aแรfafe. (5) wat tout, uno idf babe nod) nicht erforidsen

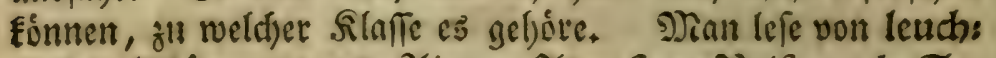
tenoen Doirmen uno fliegen 210 anfons Keife nadb Ge:

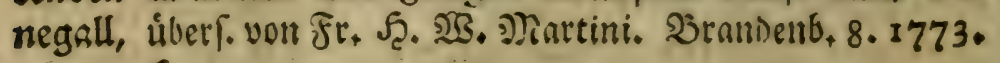
p. $135 . \mathrm{f}$.

Ein áfnntidjes fefje artiges Erentpel bat Der bert von Reaumuit angefúfirt: Mem. pour fervir à l' hift. des Inf. T.I. p. 33I. "Es ift fonderbar, Daß bie Edjmetterlinge, "Die Das Tagestid)t idjeuen, eben biejenigen fint, Die fid) nad) "f)ellen Bimmern, ober aud) nach Dem Eichte jichen, Dar in

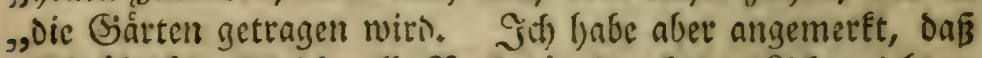

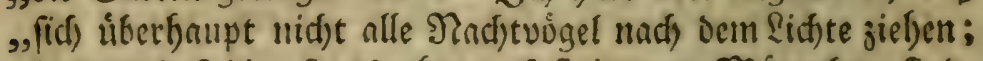
,fonbern ons bie, fo es thun, faft immer Mainndjen fitto.

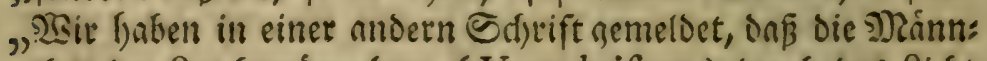

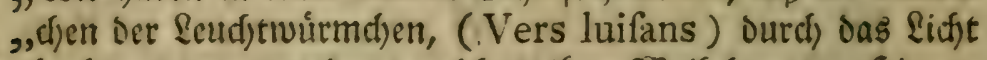

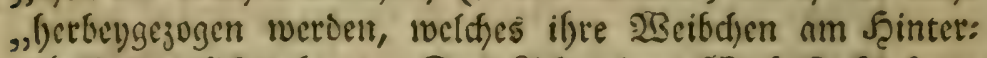
,theile yon fich gethen. Das Qid)t eimes ș

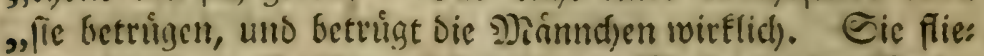

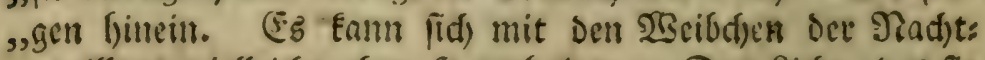
,papilfuns vielleidjt cben fo vertbalten. Das ?idjt, Das fie

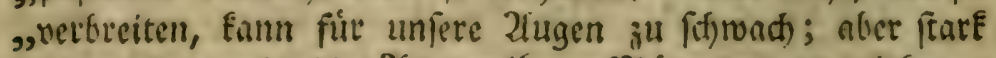
"sjentug foun, in Die ?fugen ifrer פisinnd)en su wirken." Ileb.

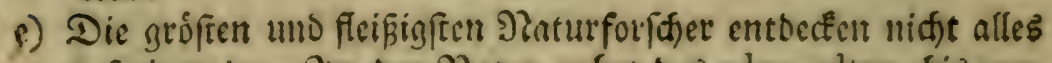
nuf cinmal. Jn oer 9?atur gefoet das plus vltra biz zum 
Eefendiggebántende. So bald fie bas 2llter jum Beus gen etreict)et traben; fo f(t)einen fie audd) viele 2Soct)en nad) cintanber, nid)ts anbers's ju tḩun. Die Sungen foummen

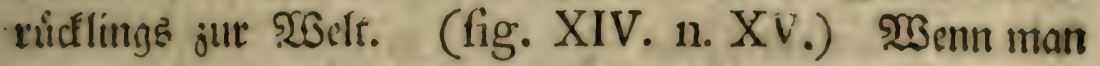

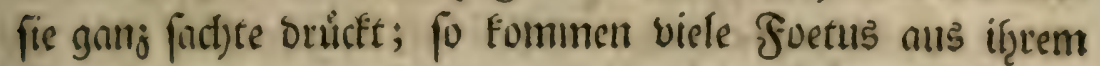
Scibe, Darunter Die grojîten leid)t für \$Blattläufe ju erfennen,

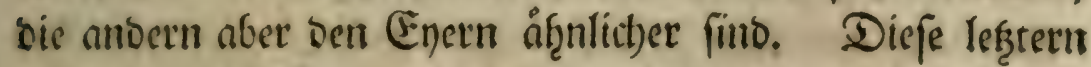

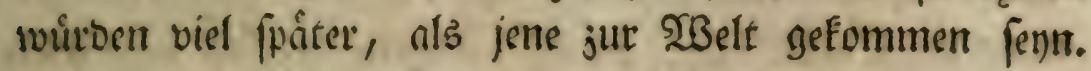

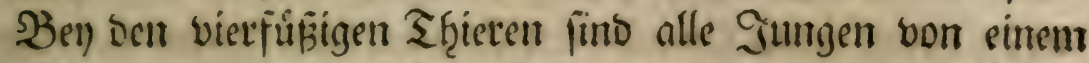
Wurfe, entrweber gleidf) großß, ober bennag̨e von einerten Srioffe: fie fino audi) foft alle gleich alt, uno formmen bens

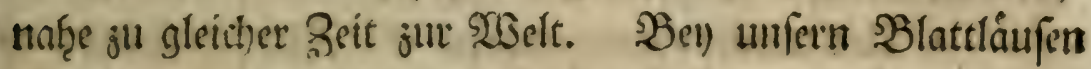
ift es, wie man fiefeiet, ganj anber's, und Das iff noch eime andere Seltentreceit, bie wir an if̨nen bemerfen.

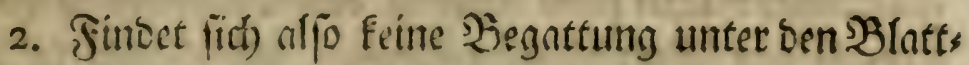

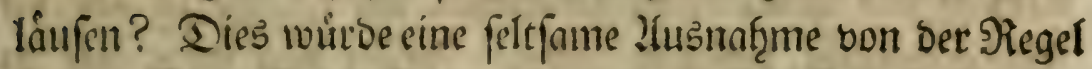
fenn. Som Etrauffe an, bis sur flcinften fliege, bie man beunerft ţat, wiffen wir, Daf bie Warmeçrung beftánoig

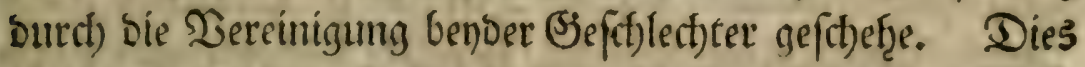

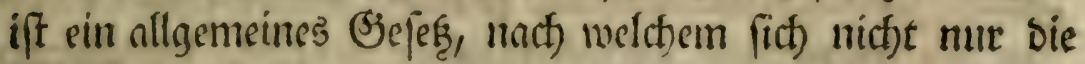
Sögel; fonoern oud) alle, wenigitens foft alle, befannte

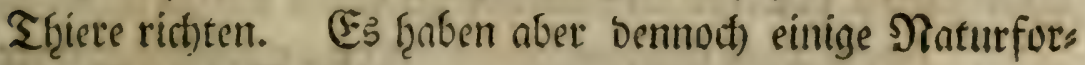

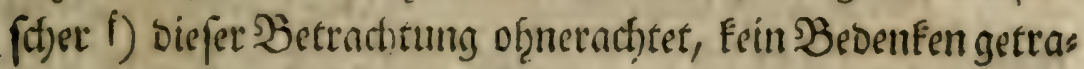

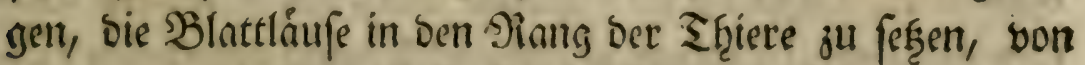
benen man glaubt, Daßj fie fith) felbft genug wáren. Zlnoere

\section{2}

fino

unendidjelt. In Der 25etrad)tung trber die Zattre,

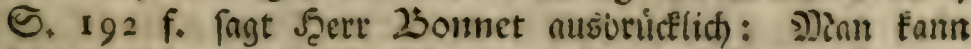
leidft zufelen, wie fie fid) paaren. - Die sianndien

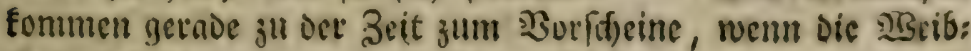
d)en zu legen anfangen, u. โ. w. Heb.

f) Leurvenboek, Ceftoni, Bourguet. Arcun. nat. Oper. Vallisn. T. I. in fol. p. 374. Lettres philof. p. 73. 


\section{0 Beobachtungen uiber bie Blattlåufe.}

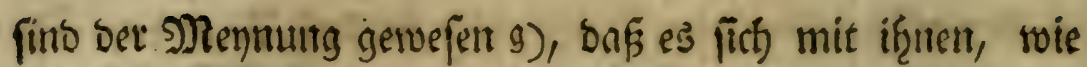

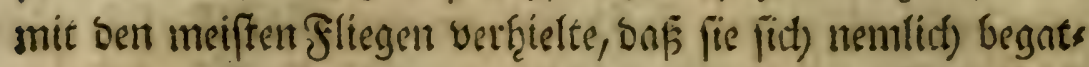
tetelt, uno (Ener legtent, aus weelchen bie jungen SBlattláufe

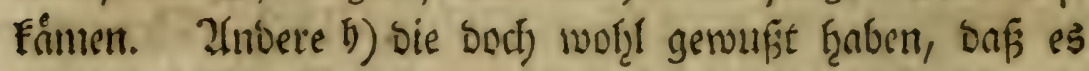
lebenoiggebáą̧rentoe finto, ḩaben bie geflügelten fừ bie Månncten gef̧alten: Der NRennung ber Zllten, weld)e bie

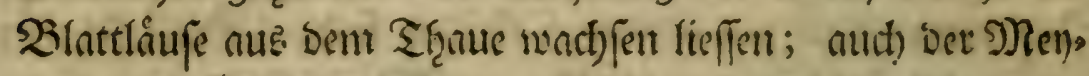

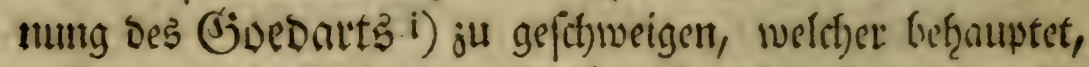
Daf fic nus eintem feuch)tent Sefäme enteftindent, welth)es die Zlimeifen auf bie פPFanjen jut tragen pflegten. Doch bers gleichen Menmungen wiberlegen fid) feloft.

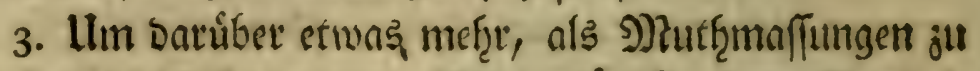

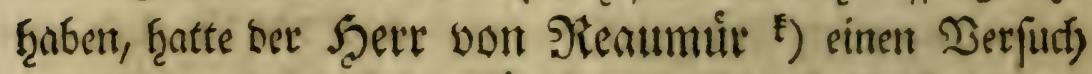
vorgefid)lagent, Det if̨m anfänglict) vier bis fürfimal nicht ges glúcflt war: man follte nemlich) eitue Şlattlaus tref̧men, fo bald fie aus \$ntterleibẻ geformmen wåre, unt fie auf bie

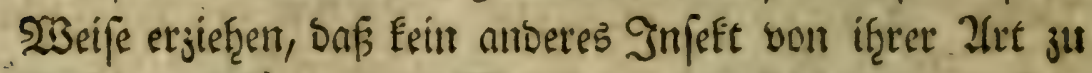

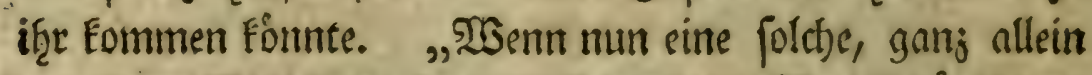
,errogene SBlattlaus, fagt ber Scerr von Эieaumúr, Dens

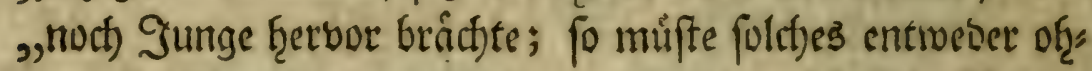

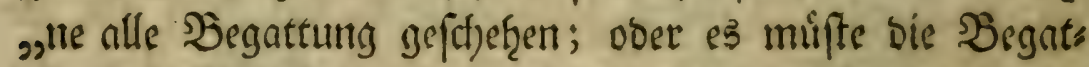
„,tung felbft fatjon int Mutterlétbe gefchéren fenn. ",

Durct) biefe Einlabung Des Şerrn von Fieaumuir

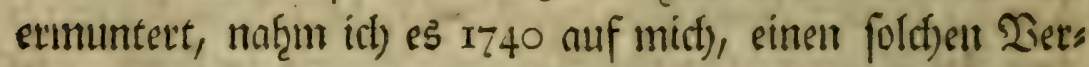
furt) mit éner Blattlaus Des Epindelbaums anjuffellen ').

Erifte

3) De la Hire Hift. de l'Acad. Roy. des Sciences An. r zo3.

b) Frifcl de PAcad. de Berlin Act. Berol. Tom. 2. Mem. Io.

i) Num. 13 s. de l'Edit. de Litter. Tom. 2. de l'Edit. franc. Exp. 22.

₹) Toin. III. p. 329. des NIem. fur les Infect.

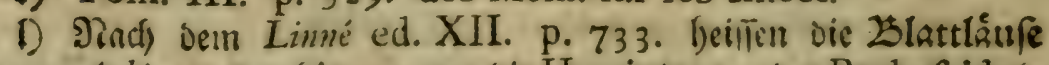
Aplis, uno geffóten unter bie Hemiptera, ocer Probofcidea, sveldie 


\section{Erite $\mathfrak{\text { Seobactuturg. }}$}

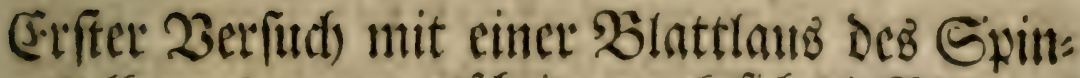

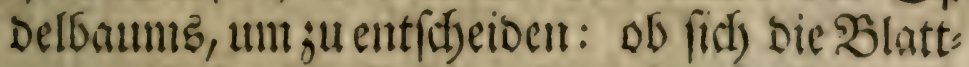
laufe ofne Begattung verntebren.

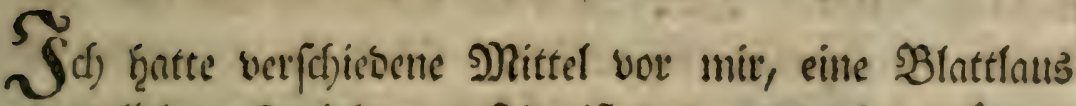

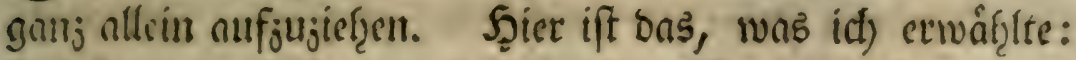

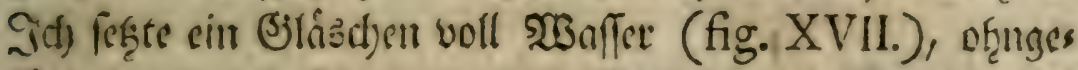
foffert bis an dent Sçals, in einten Błtumentopf (fig. XVI.),

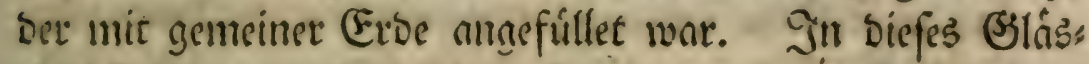
(b)en freckte idf einen fleinen Bweig bes Sprinbelbaums. m) (fig. XVIII.), mit bem unterften Enoe, Dem iff) nut vict bis

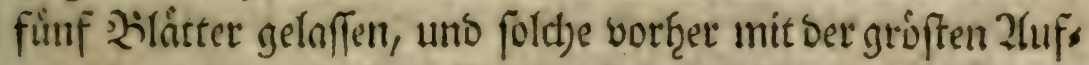
merffamfeit, nuf allen Seiten befeten Ęatte. Zluf eins

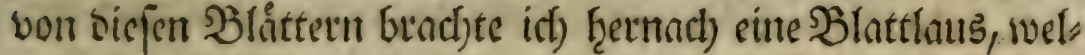
che if̧re ungefligelte slutter, Den Zfugenblick etft, vor meis nen 2lugen geboren bृatte. Bulferet bebeckte id) ben fleinen Ŝrecig, mit einem glafernen S̈eföfle, (fig. XIX.) bas mit feinem Ranbe getrau auf bie Dberflacte ber Eroe bes Blu=

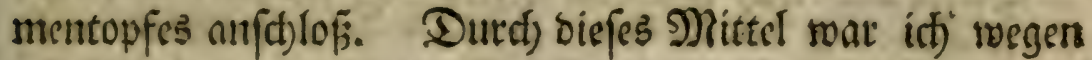

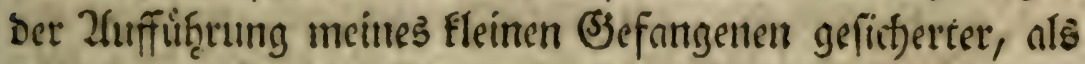
Afrifus wegen ber Danaë, ob fie gleirt) alf feineu Ber fę̧l, in einen elgernen Thturt sintgefpertet wat.

\section{$\mathfrak{B} 3$}

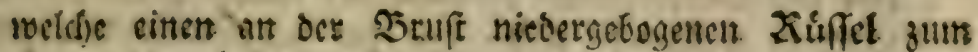

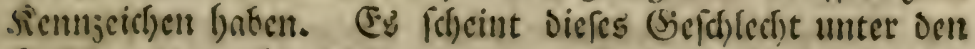

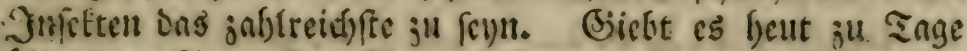
ùber oreyfigtanfeno 2liten befaunter IIflanisen; bat jebe Detfelfen ibre cigene Jamilie von Sלlattlüfen; fo mad)e man ien edjlus auf Ganze, uno auf die inbiviouelle slienge jeder 2lit. Woic viele midgen mun nid)t nod ouf ben untes Eannten (Situridfent wognen; uno wie vicl an Den Dours zelur uno planjan unter der Erise feyn? Lleb.

m) Arbor fufaria. Evonymus. Linn. Hib. 


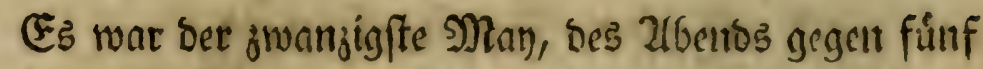

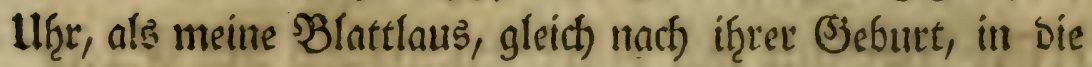

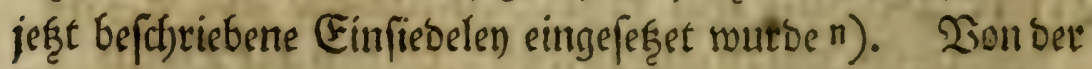
Seit an war ich Darauf bebacht, ein genaues ₹ngebudh ifrees Sebens zu ḩalten. Darin hrabe id) alles, bis nuff if̨re ges ringften sbenegungen angemerft. Nidjt ein einjiger von

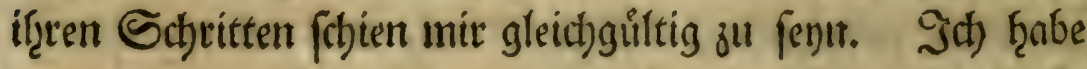

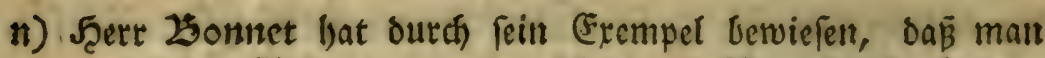
aud) folche Eleine uno gering fógeinende Yaturbegebent)eiten, in Der Eprade Des angenebmiten ZRomans, befareibeu fónne. Er fagt in Der betrachtang úber die Zantur.

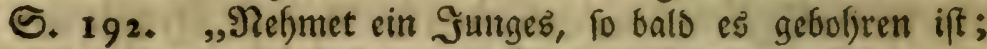
, fȩ́et es nugenblicflid) in cin Ela volffommen allein, uno

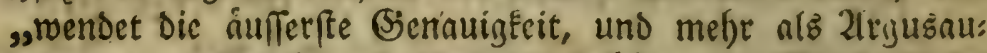
,ggen an, Deffen Jungferjhaft zu Gefyiten. Wुent diefez , fleine (Einfledlergen ein geivifies 213 nchsthum errcidhet bat; ,, fo fânget es ant ju geváb)en, uno in Zeit von etlidjen Ta:

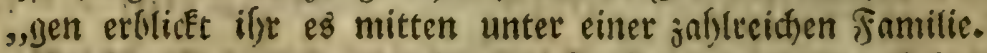
,\$) Tradhet mit einem einzelnen biefer Jungen den nemlidien

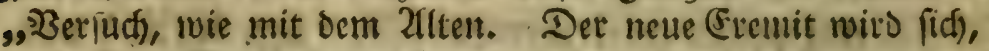
, swie feine Diutter vermefyen; und eins von Dieferm sweiten

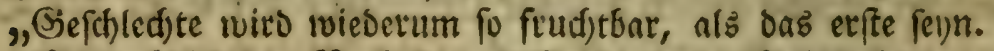

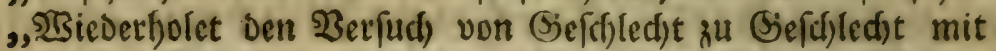
,gleidjer Sorzfalt, mit gleid)er $20 r$ ridjtigkeit, mit gleidhem

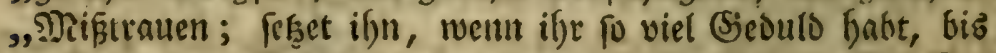
gonfo neunte (sefdiled)t fort, unto ifer werbet in allen Be:

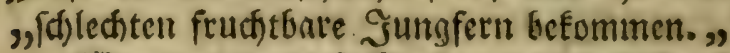

$28 \mathrm{em}$ wiro Diele Stelle nidje gefallen? Diógten boch ftatt ber fahalen tno vergiftenoen Romane, lauter fold)e eole uno unterfialtende Fiomane ser rounberwollen Эlatur ge:

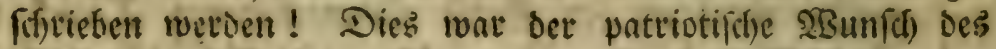
Jeren von Reaumur Mem. pour fervir à l'hiftoire des

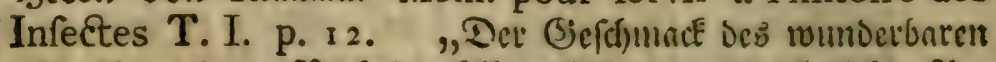
,ift allyemein. Mach benffelfen liefet mant viel lielier פio:

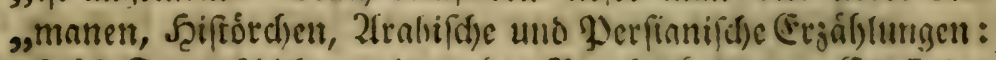

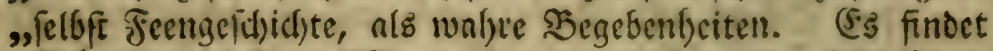

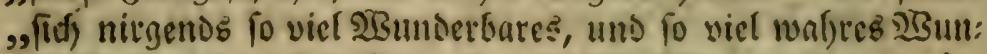

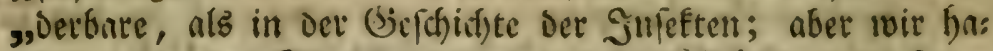

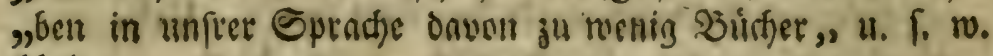
Heb. 
24 Sืesbachtungent úber bie Slattláule.

14. Die Puppent jeigen unts nictits fonterbarrevs, als bie

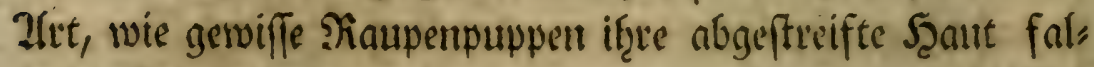

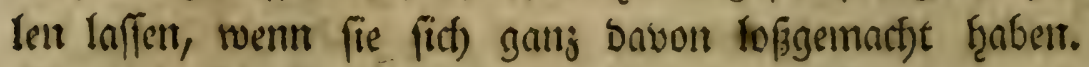

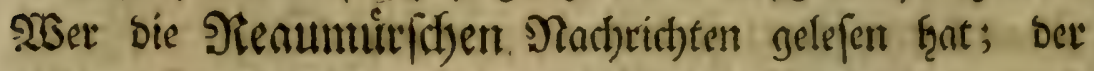

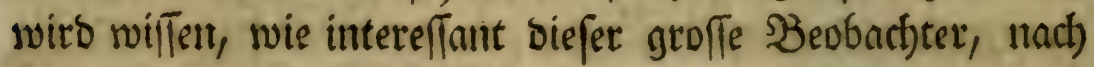

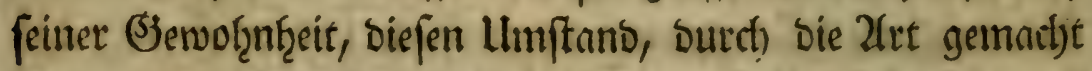

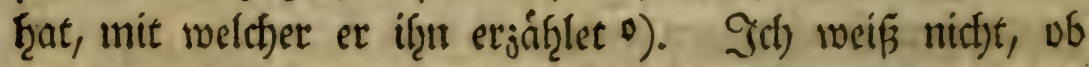

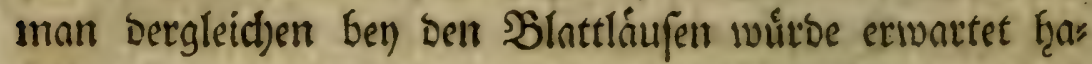
bent, Die baju eben feine rect)te gefiticfte Gilleften jul fennt (cheitren. Sanbeffent fabe id) boch) an ber SBlattlaus, beren

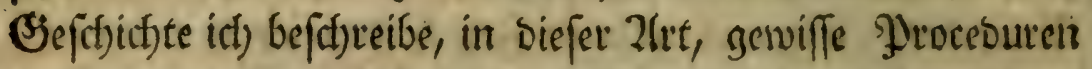
waatergenomment, weldye nidjt weniger verbientent bemerft jut serben, ob fie gleidf) nicht to auffallento waren, als beyl sen Doupen Der Dormeaupert auf Der शReflel.

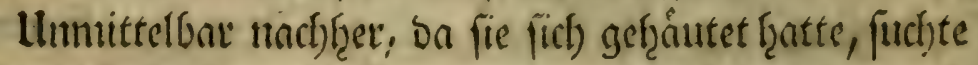
fie aud) bie alte Syaut lof zu werbent. Sie fafste fie mit

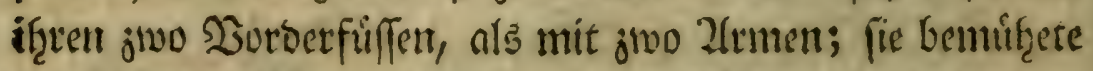

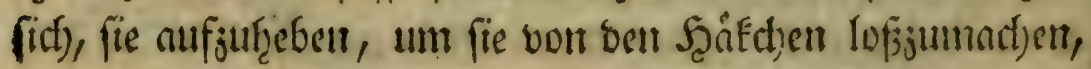
wountit fie noch) ant bem Şlatte, ober Gtengel anţing, auf

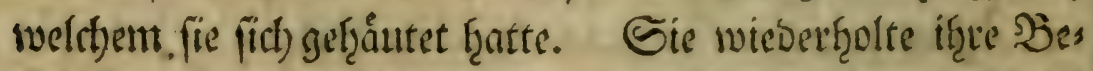

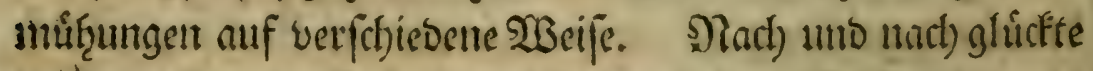

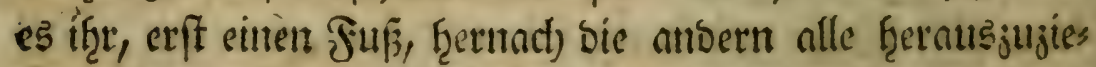

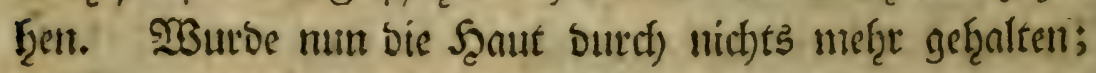

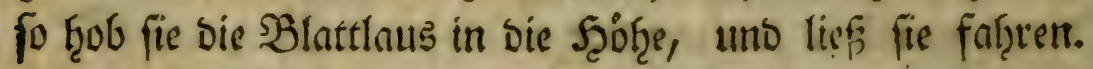

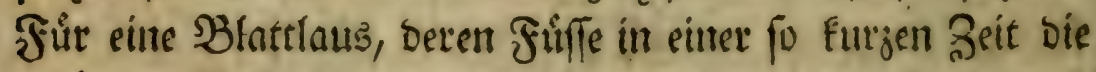
gefriorige Bieffigfeit nod) nid)t erţalten (ૃatten, war es fren)lich) eben feinte leitgte 2lrbeit. Wiele hiberb̨eben firt) audj biefer Mứţe.

Biellectbt wirt man mid) aud) befiduldoigen, ins Sint

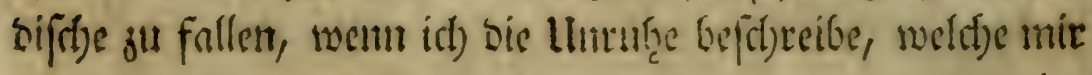
meine

c) Mem. pour l' hift. des Infectes. Tom. I. Mem. 10. 


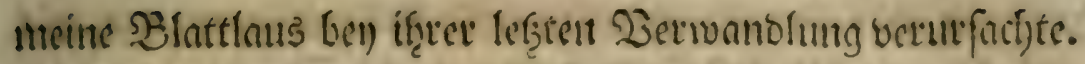

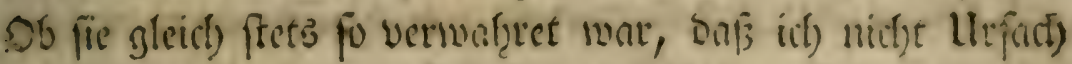

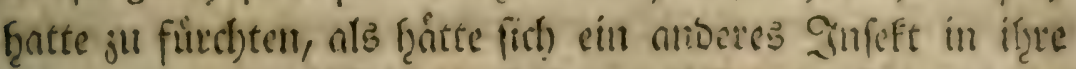

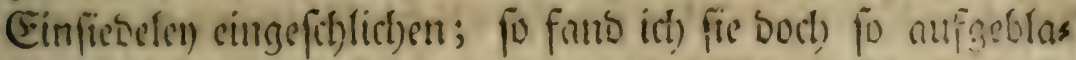

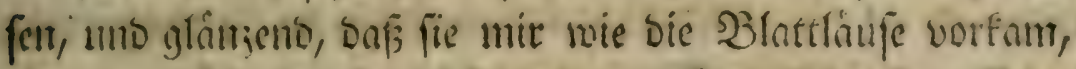

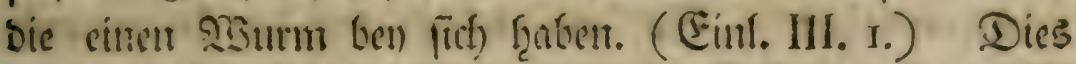
aber vergrofferte meine furt)t, mid meiten Rummet, Daf fie nid)t bie geringfte Şemegung jut machen fóten. Bunn

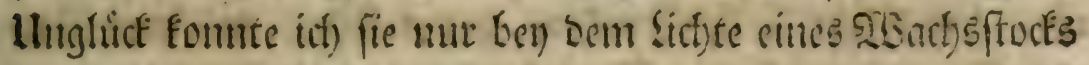

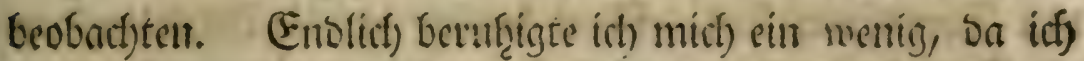
bemerEte, Daf; fie ifre Scant verwantelte. Dori) blieb ich) nidft gainj bhate Gorgent. Sie lng auf ber Eeite, balb

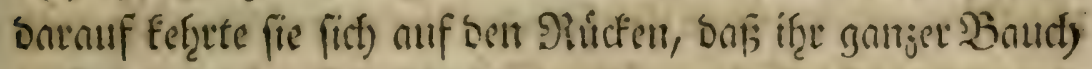

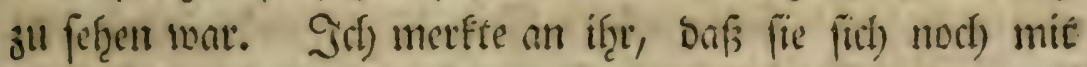
Den Finfen regte, bie fie bister, wie bie Duppen jufanment gejogen, und anf bie Şruft gelegt Ģntte. Sie belwegte fie

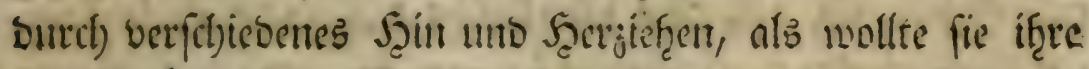

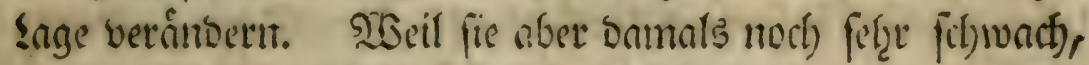

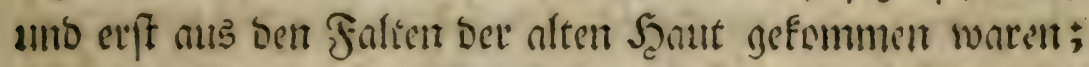

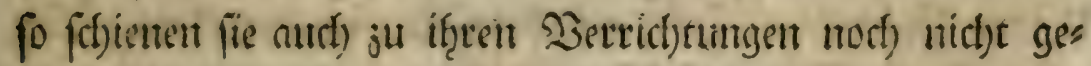

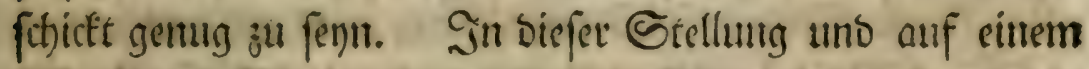

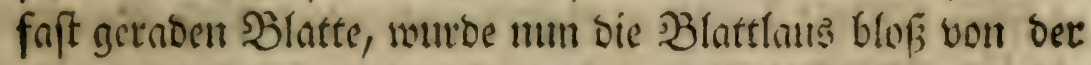
Şaut getralter, an Der fie noch) mit bet älferften Spifze

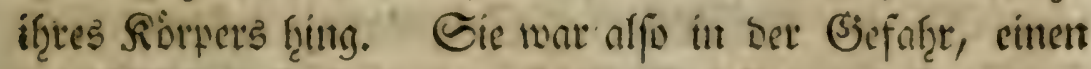

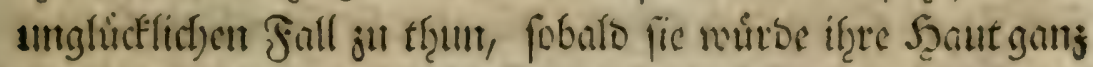

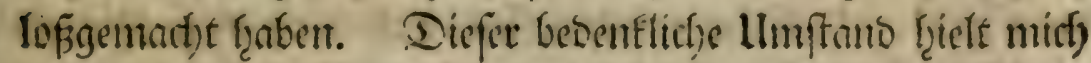

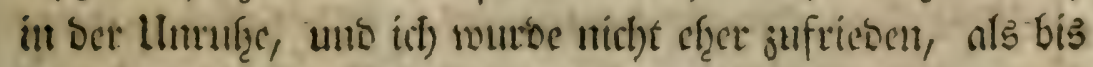

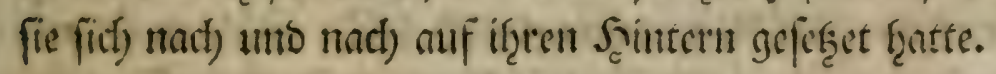

Des folgenben Morgens ben guter Beit, utrerliefs id

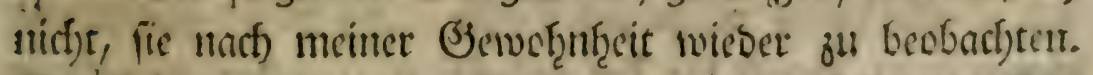

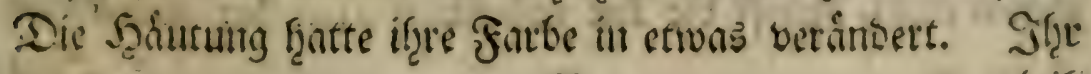




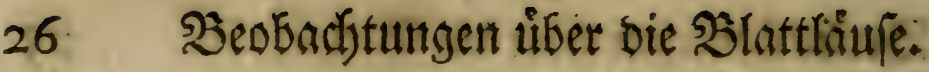

Leib war ferte braun, unt bell nafe fo braun gemorben, wie

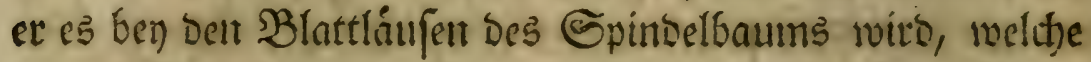

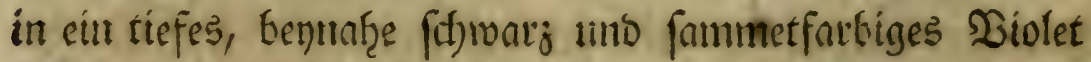

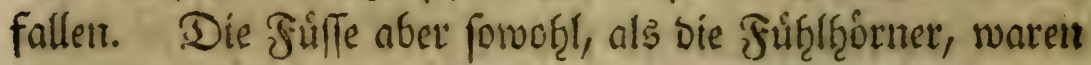

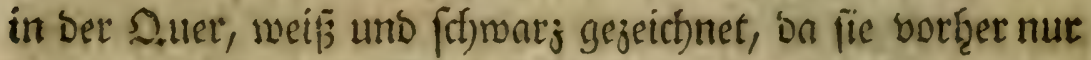

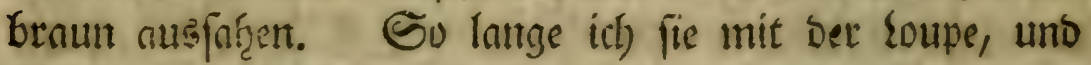
fdief gegen Das Şelle betrachtete; fo bemertete idf) auf Den Geitent, mit Den fletinen Şörnern (EinI. I. 3.) in ciner Gis

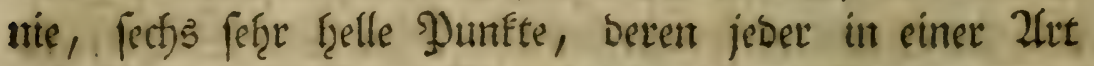
yon Sertiefung lang. Slum brachte id) Die SBlattlous an

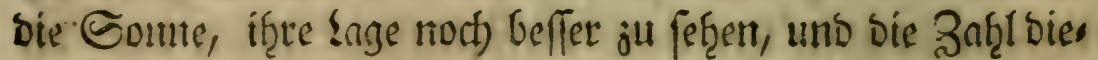

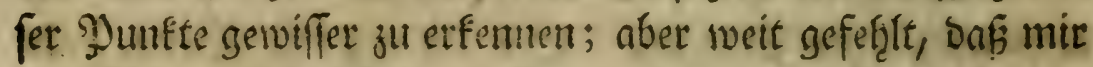

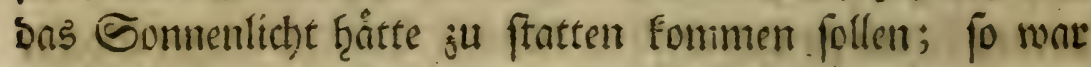
es mir bagegen f̧inberlict). Das (itd)t murbe burt) ben

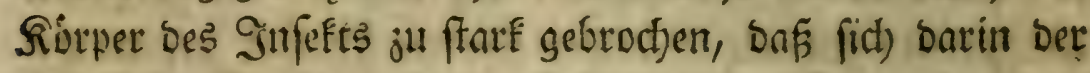
(Bilanj Der DJunfte verlor. Sid) trug fie aljo an if̧ren ets

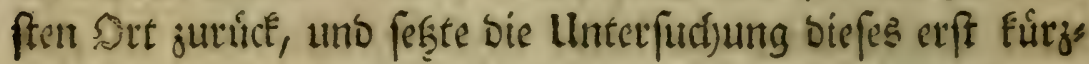

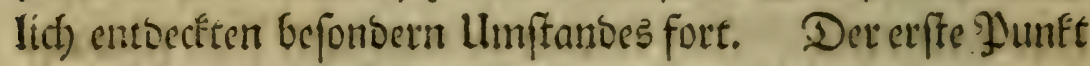
war nichs tweit vom Kopfe; ber fechste ware bidste bel bem Elitnent Serne, und frano mit bemfelben in einter Sinie. Ein

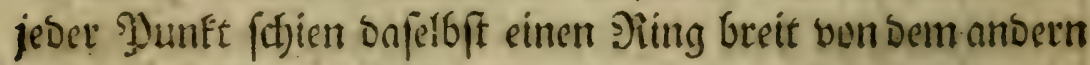

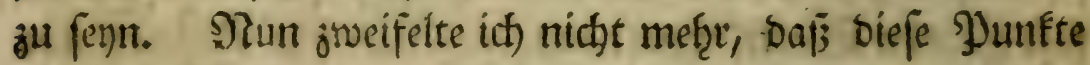

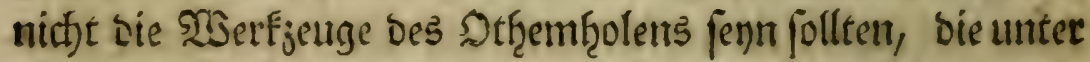
Dem Namen, Euftlócher (Stigntata) befannt fino. Da fie nun mit Den fleinent Şo bruern in einer Sinie fiegen;

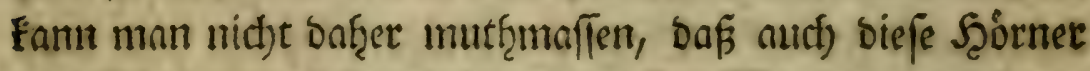

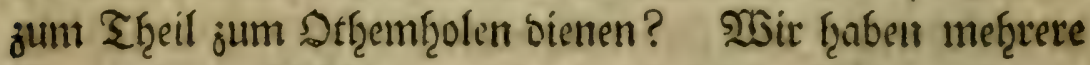

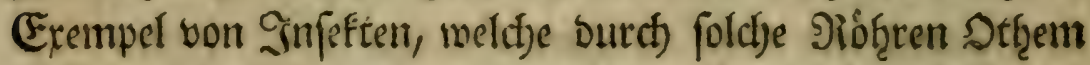

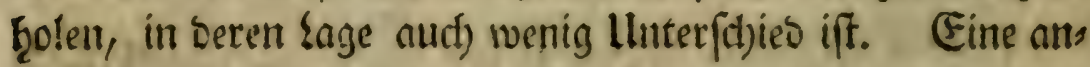

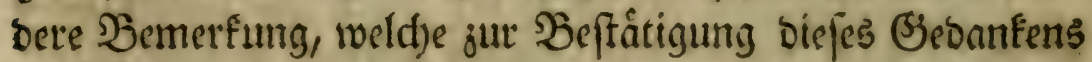
Dienen famm, betrift die 2lut uno 23 eife, wie ber aub biefen 


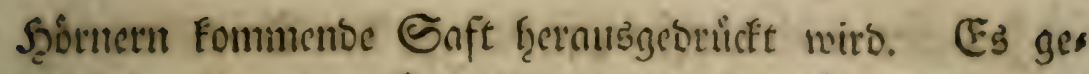

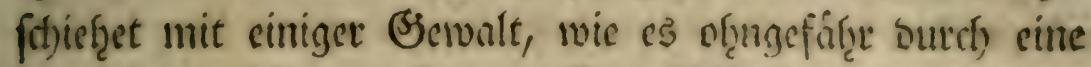
Trumpere gefdechen mogte. Eigentlich fonnte biefe Sadje

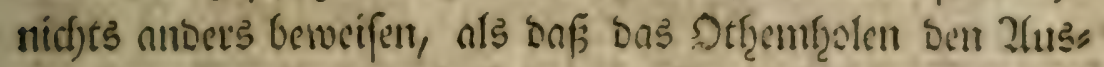
swurf ber Fenct)tigfeit befórbere. Dem aber fen, wie işun wolle; fo habe id) in Ifbicht allf biefe Szorner etwas ents

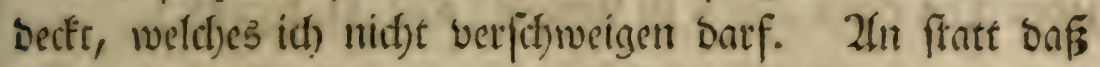

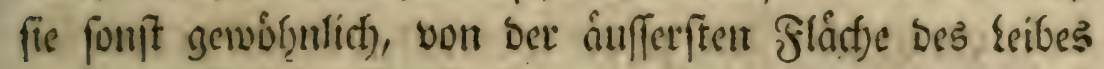
gerabe nuffitef̧en (Eiml.), fo waren fie fo niebergelegt, dafis

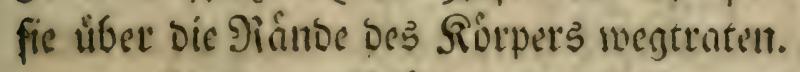

„Zữ Den Sblatteen bes YPfnumenbaunns, bie mit „R̂lattlaufent bebectit fino, fagt ber feert vont Sient:

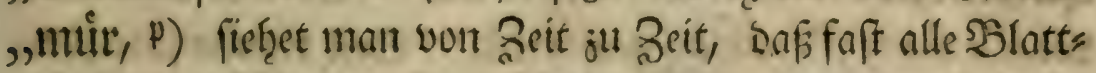

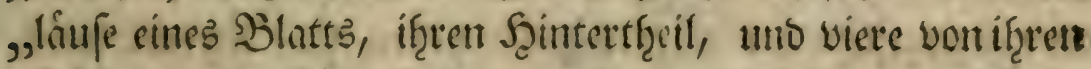

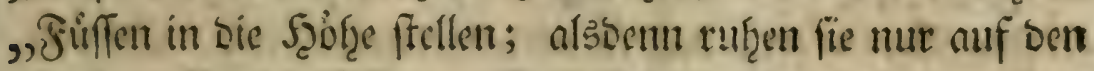

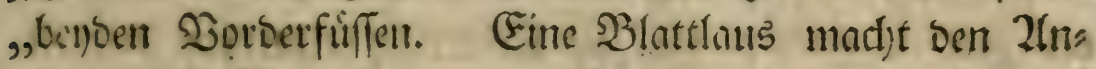

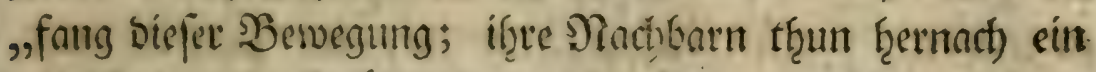

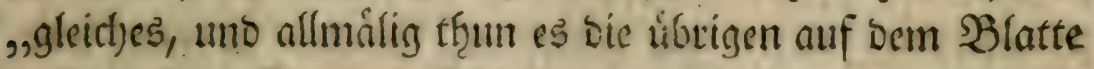
,alle nad). Darin beftefret thre ganje llebung; Demu fonft „f́mmen fie nidjt von Der Stelle.,

Mir fithien es inbeffen beftánbig wid)tig genurg, bie

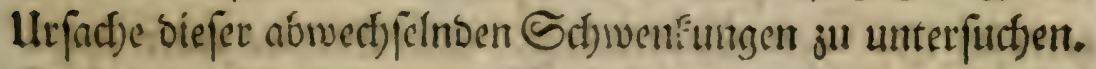

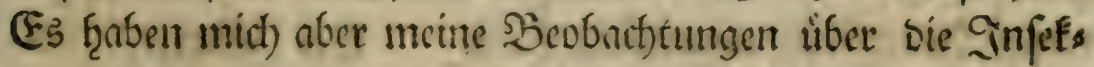

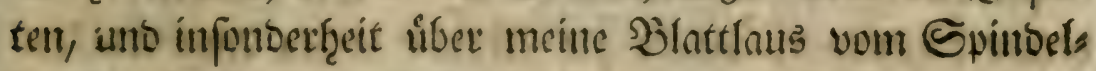
baume, Gelef̨ret, Dáz fie baju bienen, Den Zluswourf ber Ercremente, "Doer eintes Enfta, Det ifzre Etelle vertritt, ju beförbern (Einl. I. 3.). Denn es gefchntęe nichte ef̧er, als wenn mun balb sin Tropferhen bon biejem Safte follte aus:

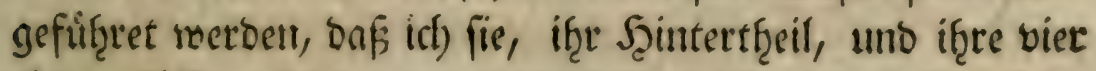
Shinterfüffe aufrid)ten, und wedtfelstweife nieberlaffen faţe, wels

p) Mem. pour l' hift. des Inf Tom. III. p. $2 y 6$. 


\section{8 Şeobactutungen tiber bie Blattlíufe.}

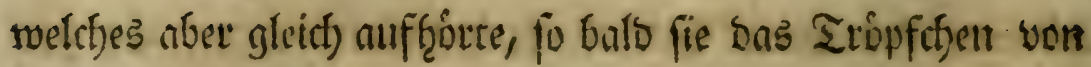
fictj) gegebent ḩatte.

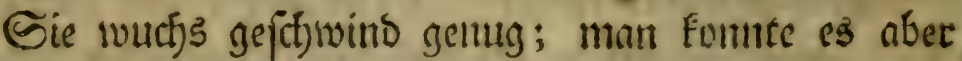

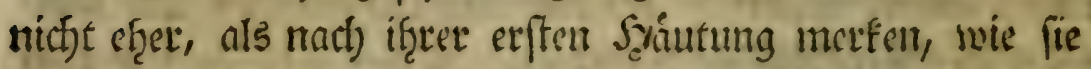
ougetommon f̧atte. Sid) ḩabe mich) bemuifzet, Dabon für

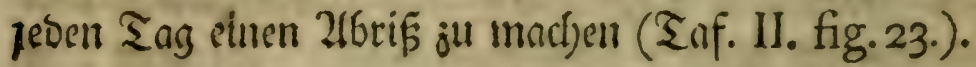

Es ift aber 3eit, ju ber wichtigften @etelle in bem !es bent meines Eirititeolers ju fommen. Da er glúcflict) vort Den bier Siranffęiten genejent war, Die er burchgef̧en mus fer; fo war er entlith) ju bem Bicle gefommen, wohin ich) if̧n ju beingen beforgt gemefent war. EEr war mun eine bollfommene Bblattlaus geworden. Seit sem erften Sus

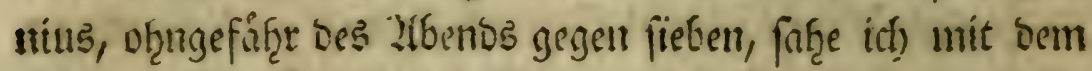

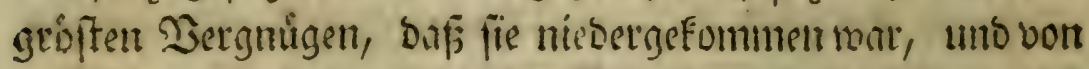
Der Beit an gloubte idl), fie SBlattlausెmutter, nemten

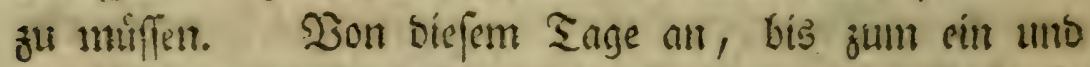

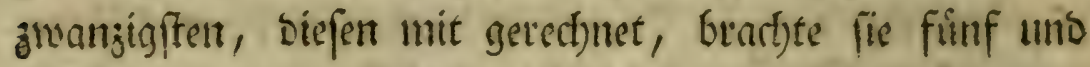
neunjig Sunge, alle ganng lebentig, uno bie meiffen bor meinen Zlugen zur siselt. Syier if eine Eabelle, mos rin idf) mit ber gróften (Siennuigfeit, Die mir mogglict) gewejen ifit, Den Besurtetstag, umo Stunbe einter jeberz biefer Bifattlauje angemerfft ḩabe. Der Stern * bes

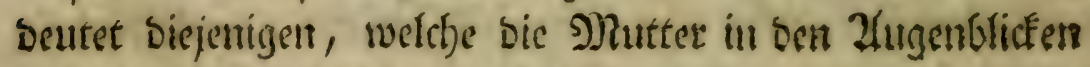
géoren f̧atte, wo idf) es niff) bemerfte. 


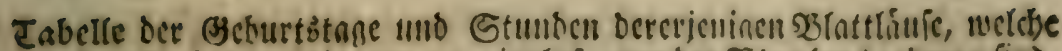

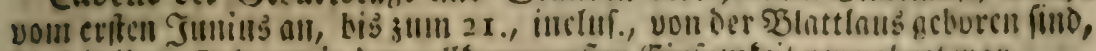

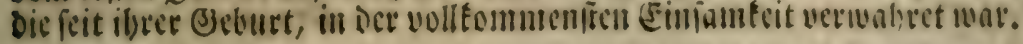

Tane 3alls bet Babl her icien Miolmittag

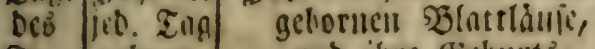
Su, pebori. tuto ine bielurts:

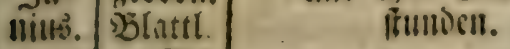

I $231 .-031$.

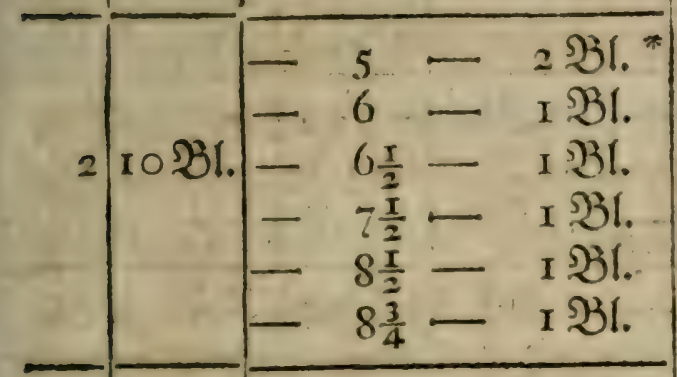

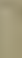

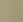




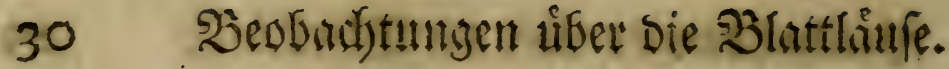

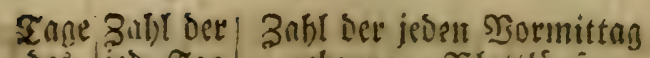
bes jern. Tang gebornen soluttlámie, gu= geborn. uno ible (s)eburts= 11ius. กิ5Tatr.

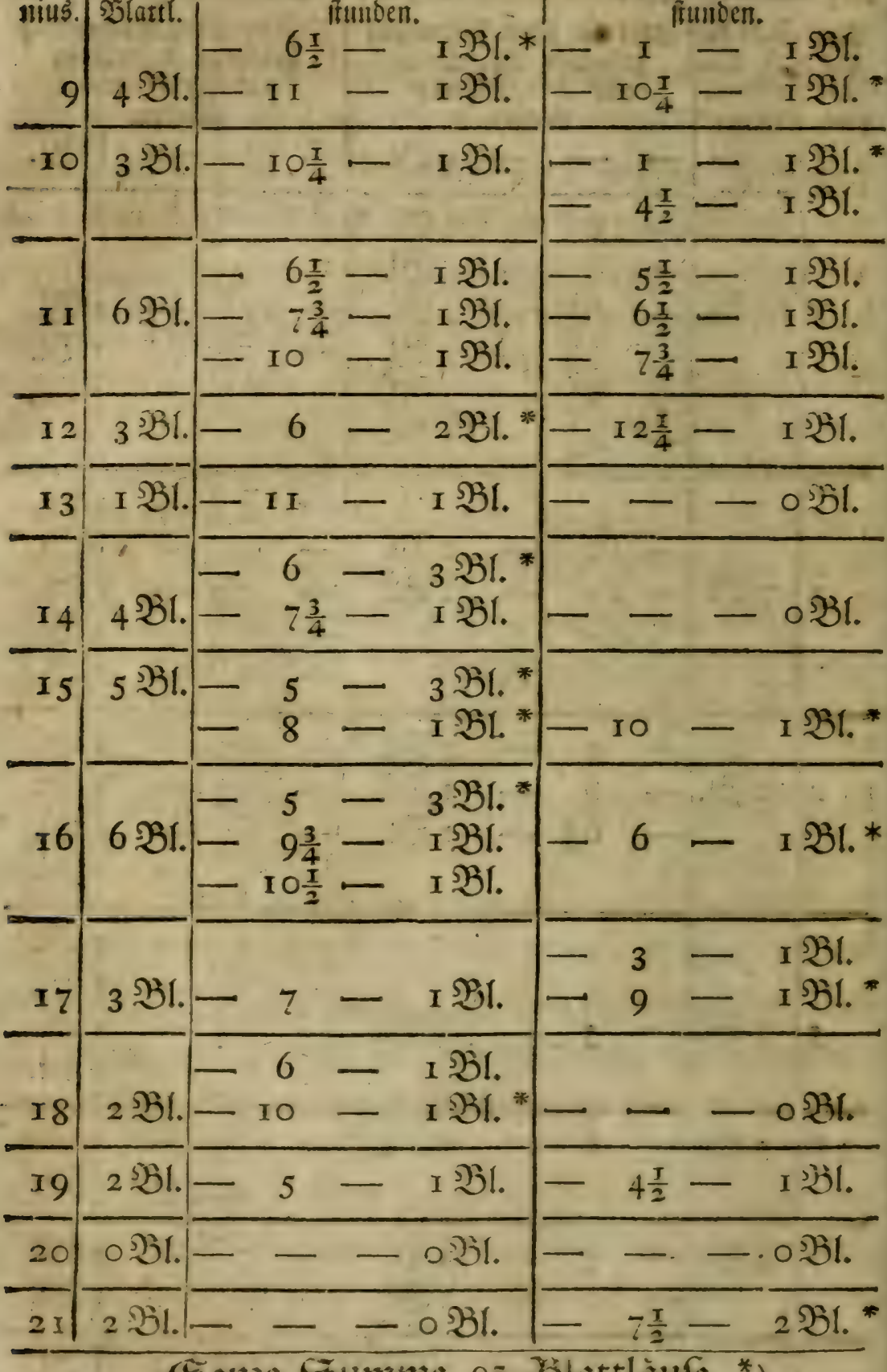

Ganje Summe 95 Ḋhatlălfe. *)

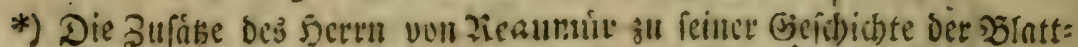
lálie ini III. Toun. in III. Mem. wie nuth line liber Dreje zountet=

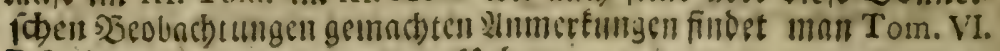
P.II. Mem, 13. p. 340.354. 1leb. 


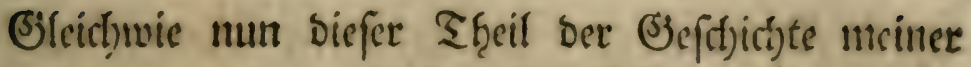

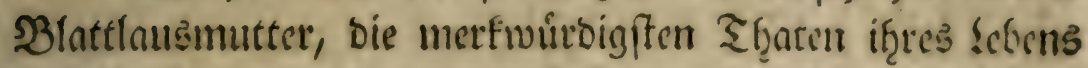

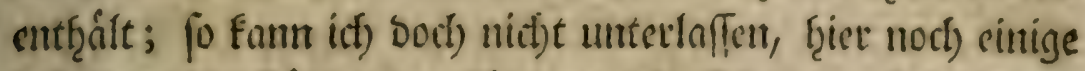
befondere llmftânde anjufúfrent, die fich Darauf bejiefzen,

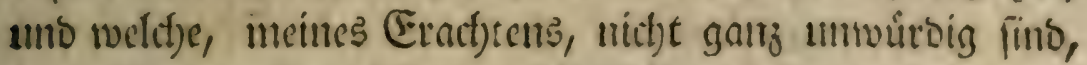
bemerft ju werben, ob fie glcich) Gel) einem Iinfefte, baran wir meţrere Derfftiebentgeiten, als an ben Blattlaufen wafctmef̧ment, vielleicl)t nicht verbicuten migten, ergififlt ju

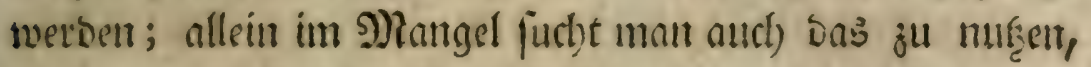
twas man jut Beit bes lleferfuffes nid)t ad)tent wurbe.

211 s meine Blattlausmutter jun fünftenmale nieder. gefommen war; fo war ifer ganjer !eib ber fläche, wo fie

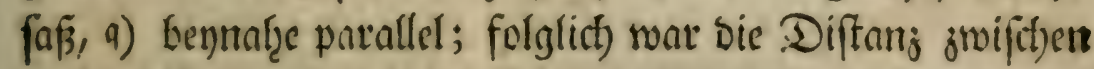

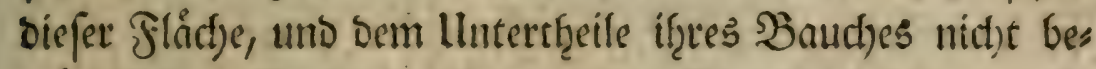

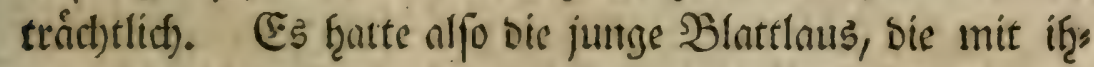
rem Rörper alle 2lugenblick immer mef̨r jum fam, bereits bie Dberfląct)e Des Stengels, auf weldyem bie Mutter faßj, mit Dem Enoe if̧res Seintertf̧rils r) erreidt)t, ba if̧r Қorbertf̧eil noct) in Mutterleibe war. Nun burfte fie nid)ts weiter thun als fidf) vollig lofjumadjen, weld)es if̧e fchwer gemug wurbe geworben fenn, wenn baben bie

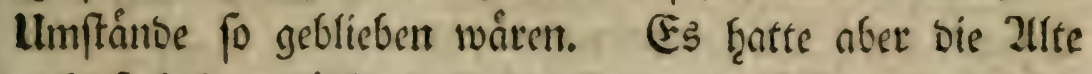

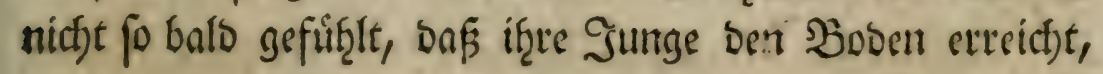

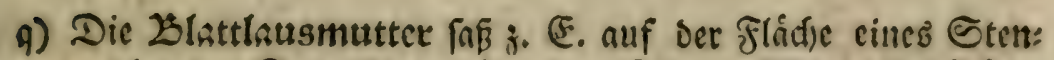

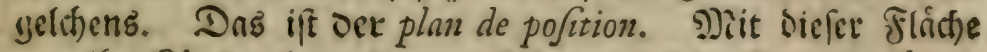
mar ifge Sidrper beynabe parallel; is wito aljo son iffrem

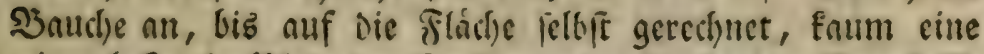

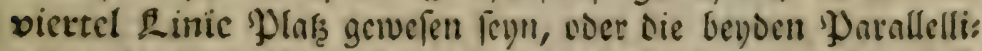

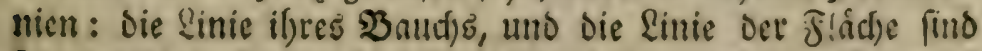
faum einige Şaare breit auseinander getve fen. Co muß man fid) ofmuefálye sie Endse vorftellen. Das folgente mito es mod) mel)r aufEláten. Ueb.

r) Die Blattláfe tounnen mit Dem bintertbcile zแerft. Eselt. (ธ. Die Eint.) 


\section{S3eobarftungen úfer bie Şlattláué.}

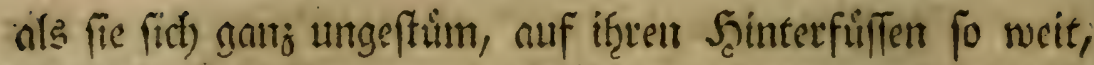

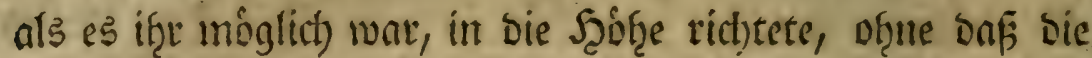
jumbe Deswegen burfte ben Stengel farzen loffen. 2luf

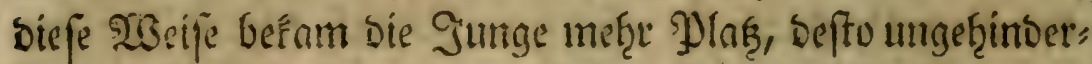

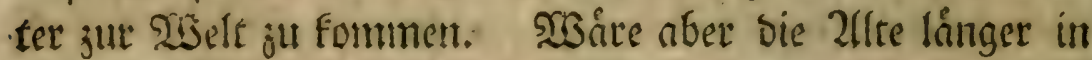

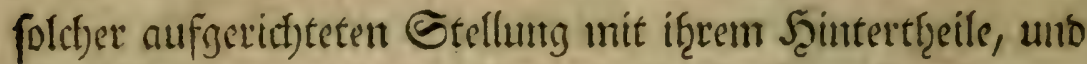

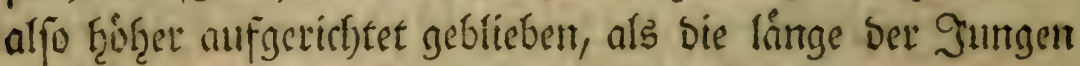

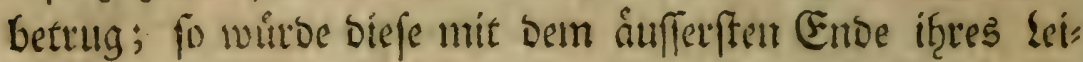

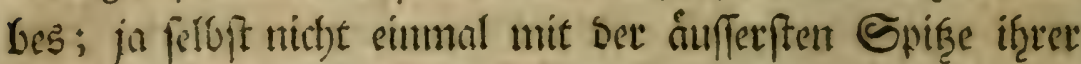
Shinterfúffe, Den Etengel fraben erreichen fómen; uno fie

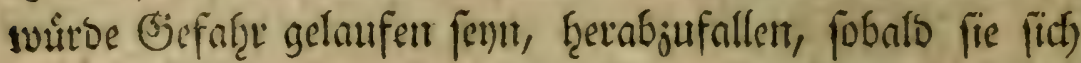

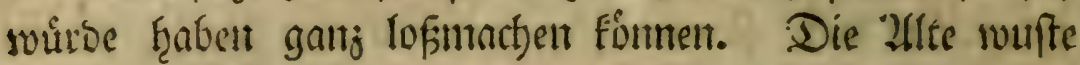

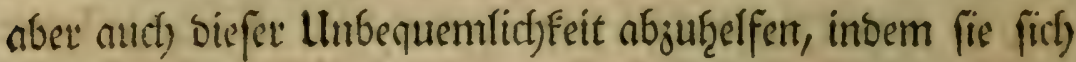

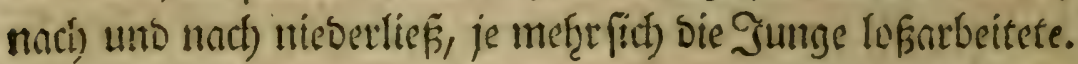

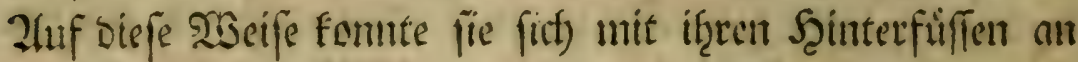
Dent Stengel anţ̧ánzent; fo Galb biefe foldsen nur Geritretent. Dies ift vielleich) eitre von bent ltrfactent, warum biefe Sins

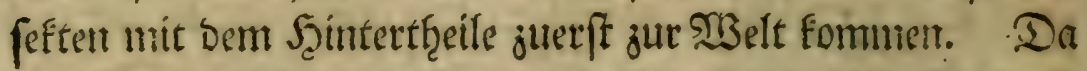
if̧re Zorberfúffe viel fürzer, als bie Şinterfúffe fint; fo

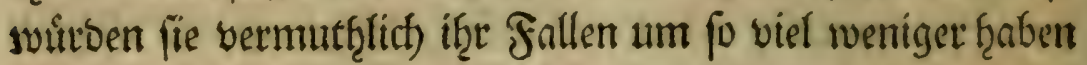
verfínbern fonnnen, wemn fie, wie bic Sungen ber) anbern

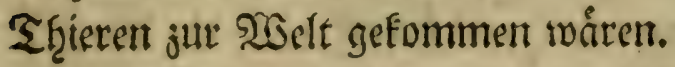

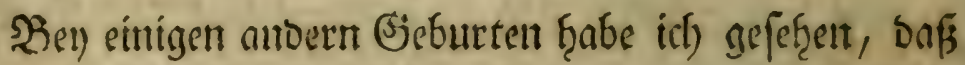

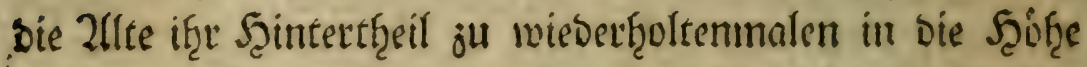

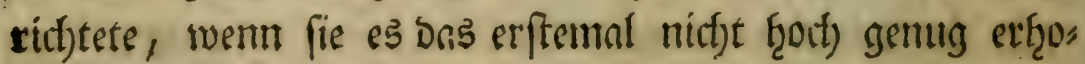
ben f̧atte.

Ein jumenter llinftano, weldfer vicles berteright, ber Suturgent einen glücflict)en ?tusgang ju ver(pred)ent, ift bie

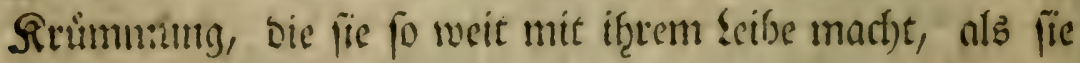

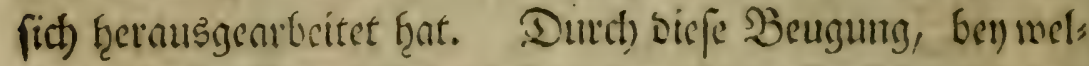

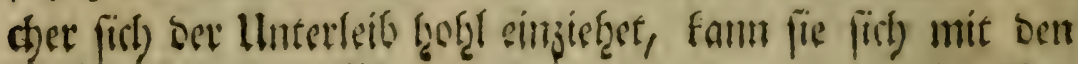


Şinterfiffen viel leidfer anflannnern; ja fie werben baburd) viclimef̧r nâfrer jull bem Blatte oder Etengel bingebrad)t, nuf welit)em bie allte fifzet; eben forvobl, als bie Epize bes 2tmts, (รaf. I. fig. IV. V. q.) weldte fich and) hier in ets won unit anf̧angen fantr, weil fie noch) mit bem Safte tibers jogen ift, ber bie Junge in Inutterleite befeud)tete.

So gelaffen bie Sלlottlinfe auch ju fonn folyeinen; fo foumen fie bod) unter gerviffen Llmftánoen aufgebracht und jothig werben. Dies ift es, swas iti) noct) an meiner

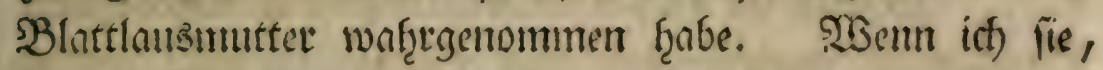

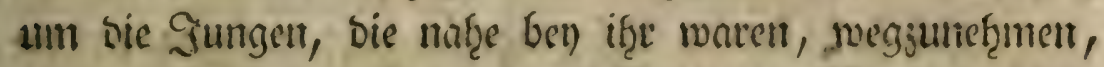
faum im allergeringften mit Der Epifze Der जatad beruifzes te, ber $(i t)$ mich) zu biefer albfich, beoiente; fo futze fie mis ifreem Scintertheile, und if̧en Scinterfüfen ganj ungeftum

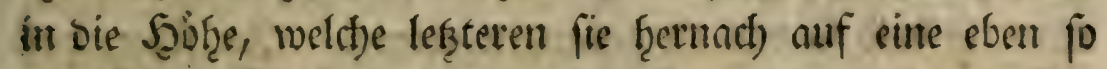
ungeftume গiseife in if̧re vocige Gtellumg bract)te. Ein anbermal frectite fie foltite vour allen Geiten nus, fo meit fie Eonnte, um bie Nhoel gleichfain ju faffen, jog fie ternach)

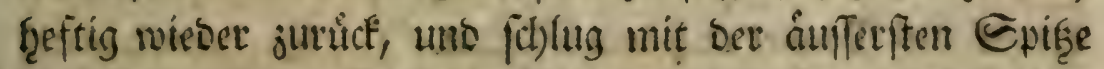

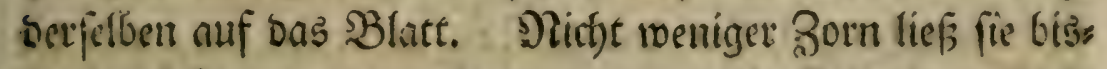

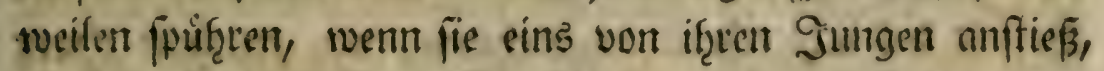

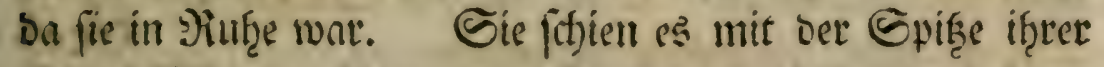
Seinterfüfle ju fithlngen. Das war aber én luftiges Sit) nufpid, Daßj fie fiet) baju bisweilen siner Sumgen bes

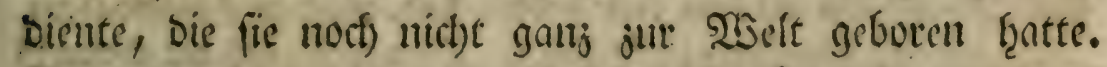

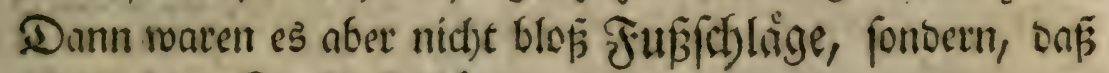
iit) fo rede, Reulenfdiclige.

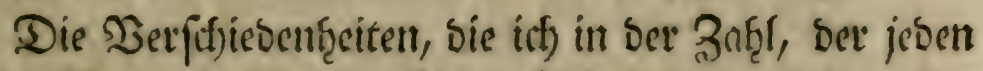

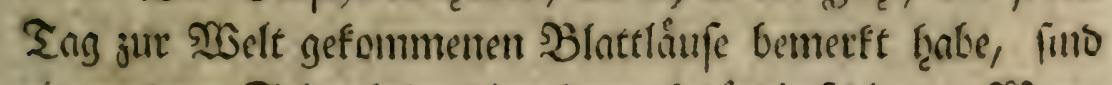

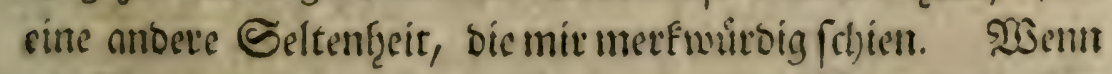

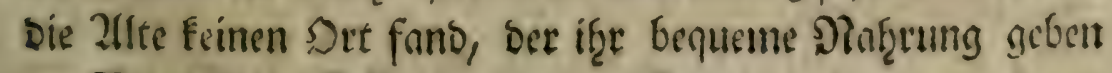
Bonnet I, Tf). 


\section{4 Şeobucftungent ủber bie Slattlåufe.}

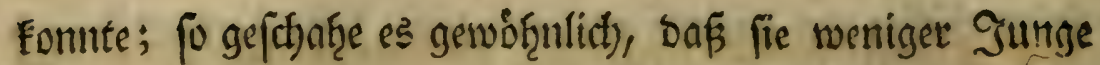

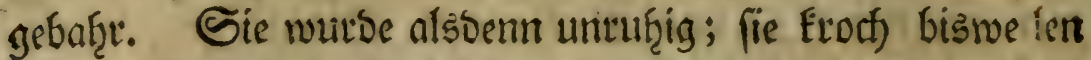

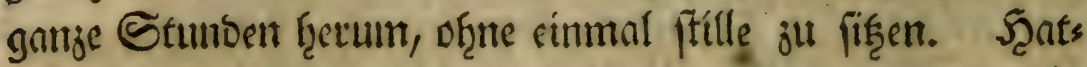
te fie aber endicth einent foldien Det angetroffen, wie er fur fie fenn mufte, fo lief fie fict) fogleid) bafelbft nieder.

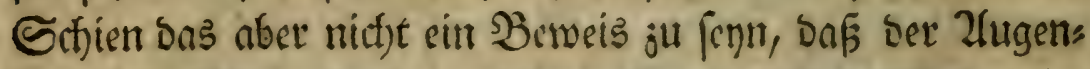

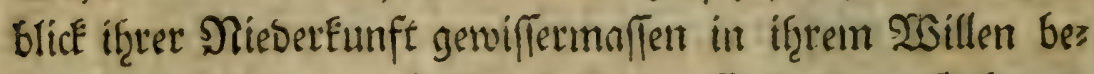

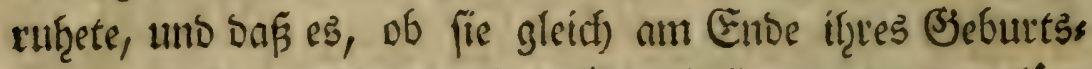

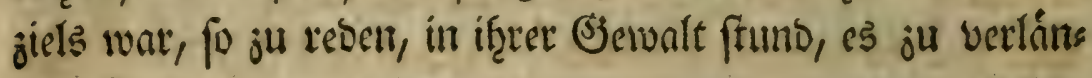
getn?

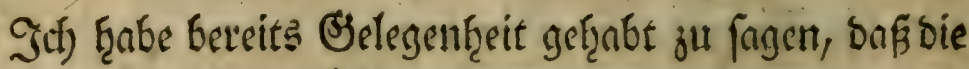
Excremente Der Blattlaufe flứfing fints. So waten bie

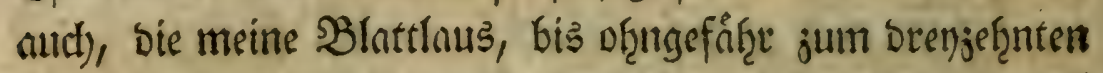
Sunius von fict) gab, als ith bemerfte, safs fie fitt) berbicts ten; fo bals fie von if̧r gegangen waren. 2fin ftatt, baß gewiffe Bonftarte unter ben Blattlaujent, (Einl. II. I.) Die

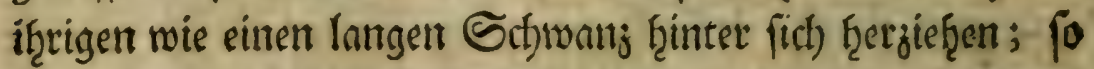
trug meine Blattlausmutter bie if̧rigan, wie cin jufanmitens

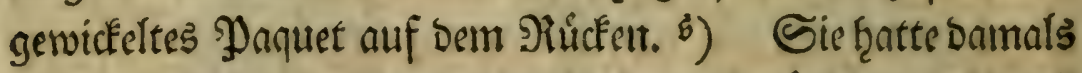
fifon angefangen, if̧re Seibeşgeftalt zu verínbern, uno bie

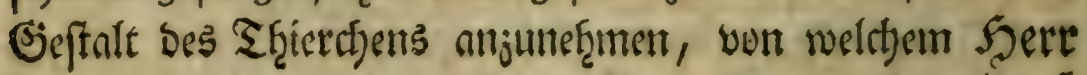

s) Eollte bie Diaterie der tratten Doolle, roumit bie meiften

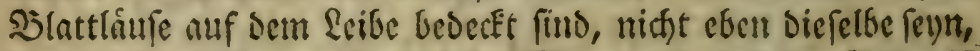

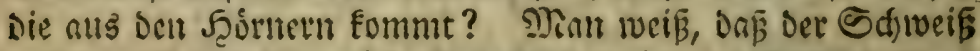

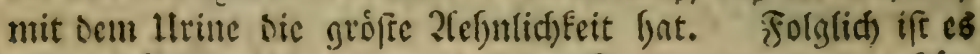

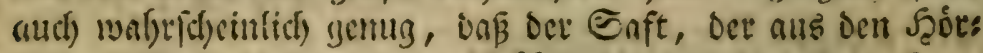

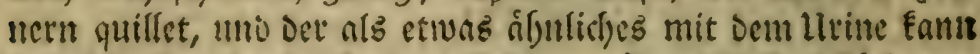

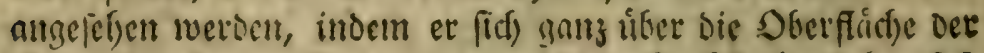

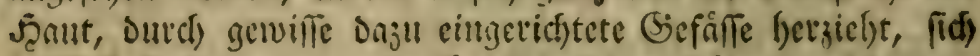

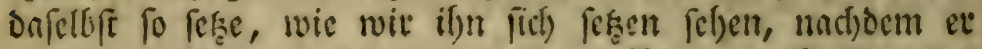

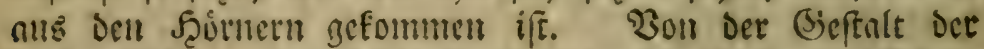

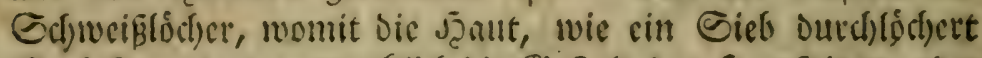

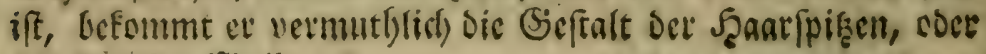
Der Eraufet $\mathfrak{S B}_{\text {olfe. }}$ 


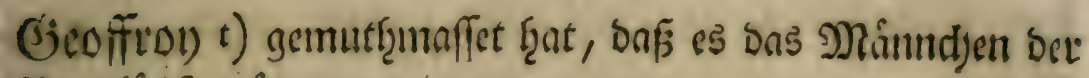
:Blattlaufe tvire.

Dannit ich aber entulich bic (Seffefict)te meiner ß̧latts

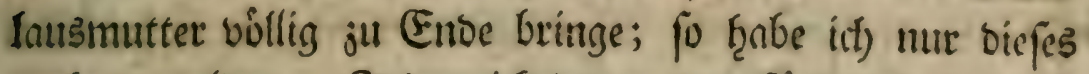

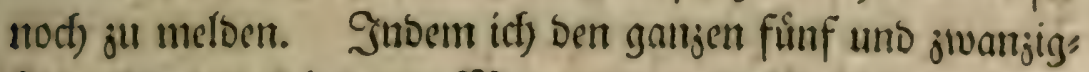

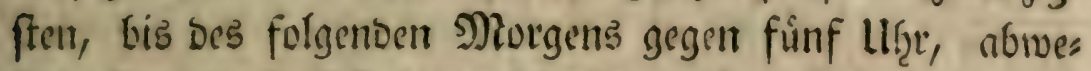

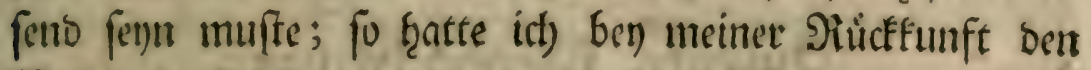

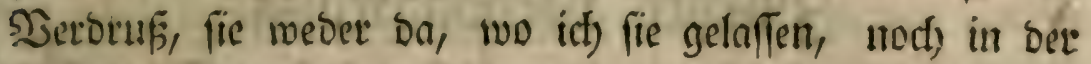

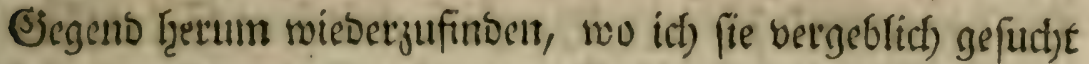

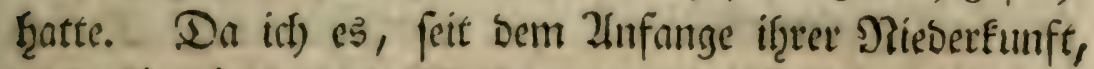
nicl)t fưr notthig Gicelt, fie fo genau einjulperten; fo fratte fie fich) of̧ne Zweeifel siejer Sislegentreet bebient, um fid) ans

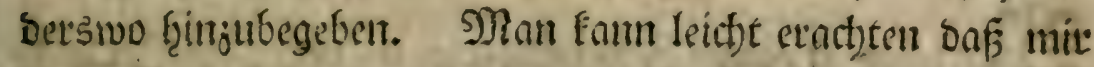

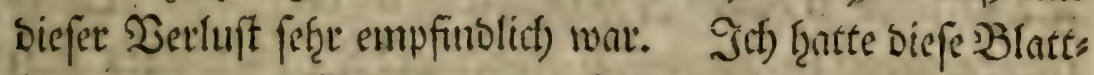

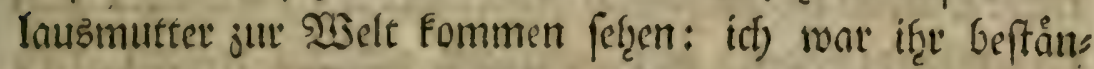
Dig úber cinten Nonat gefolget; uno idf) machte mir cin Sergutigen Daraub, meine beobact)tung, mit gleidjer

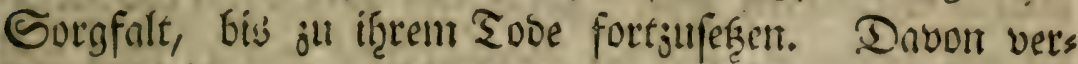

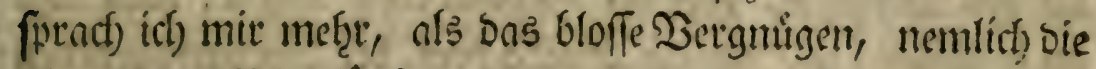

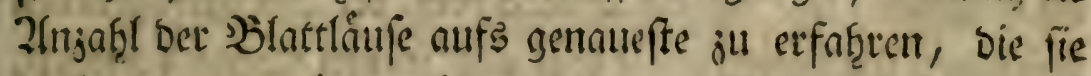
viefleidf) nod) würbe geboren f̧abent. Nach) Der ferge grof

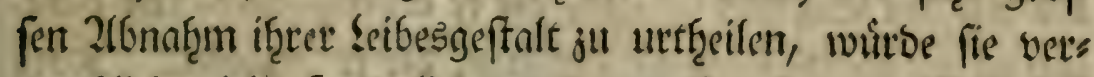

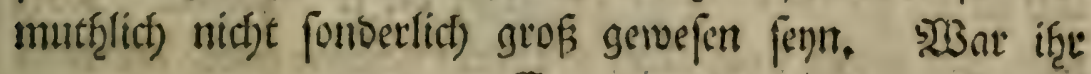
(5. 2

Bauch

t) Mem. de l'Acad. des Scienc. I724. Eb if Dies cine ant:

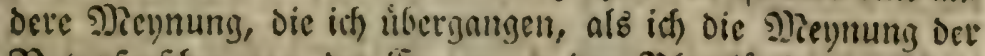

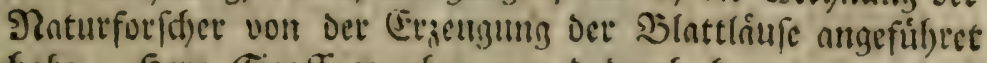
babe. Fener Gicoffroy ater war badutch hevogent worten,

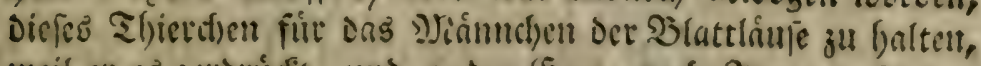

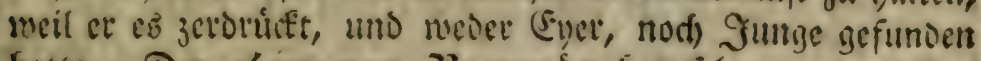

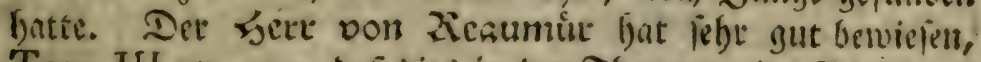

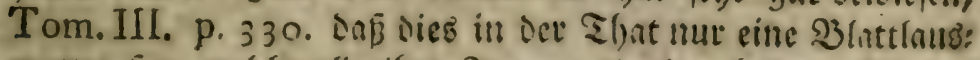

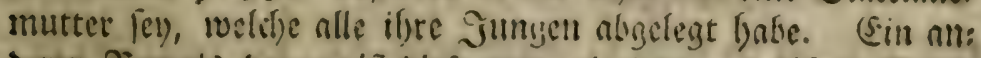

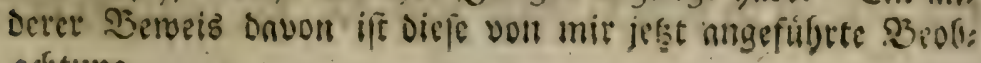
ncjtung. 
36 Seobachtungen uiber die Şlattláufe.

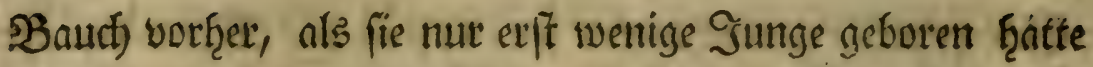
gants ruto und aufgeffiwollen; fo mar er jesct platt, uno

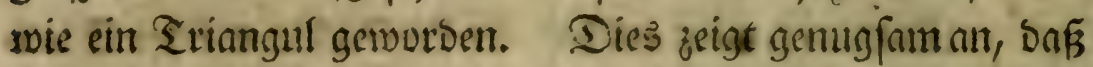

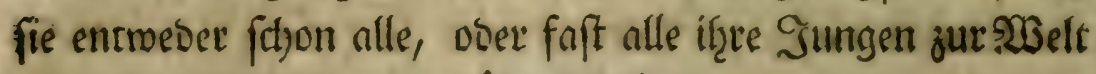
gebrardt), bie fie f̧atte gebáf̨ren follen.

\section{3weite 2 eobad) tunty.}

A(nderer und Dritter $\mathfrak{B}$ erfuch mit den Blattlät: fen Des Spindelbaunts, zut Entichetoung, ob fich Die Şlattlåufe olne Begattung vermefren.

S23it leben in einem Sntretrunberte, wo unter ben Beobact): tungen, ween fie vorjüglith fonberbare ḃegebentheiten jum

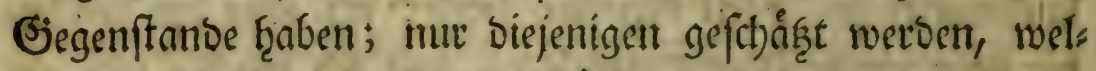
de bis auf bie geringften llmftánoe getrieben, uno meţr, als

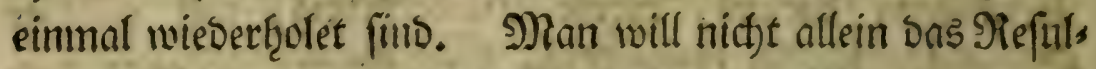
tat bes Serfuct)s, ober ber Şeobachtetung wiffen; man will auch wiffen, wie fith) ber Bbeobact)ter, ben ben berfchiebenen

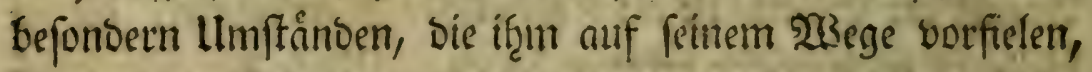
bis auf bie Eif)niertigfeiten, bie er antraf, berţalten habe,

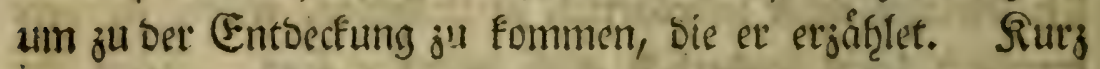

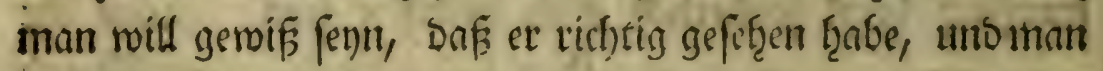

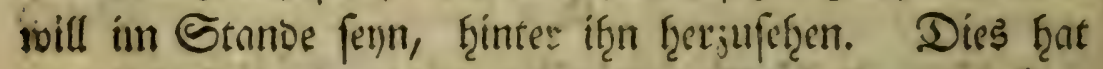
mid) beroogen, meine vorf̧ergeţente Şeubact)tunt weetter

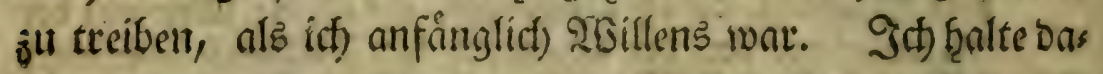
fúr, Daf eime fo aufferorbentlictie Sarthe, als bie SBermetrs

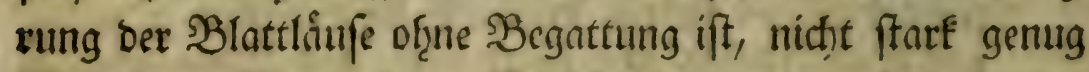
fónne berwiefen merber. Ess ift aber, wie gefagt, in Der

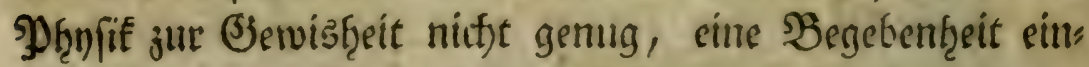

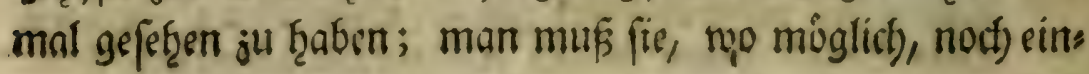


mal unterfuchen, uns ben ber jweyten llnterfudjung ebelt bie 2hifmerffanteit, uno Sorgfalt, als bet) ber erften bes sucifen. In bem folgenton Sintre wiebertzolte id) alfo, nach) eben Diefen (Sinutofirten, meinen Derfuct) mit bet.

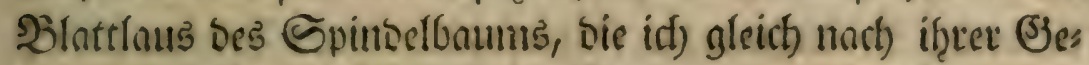
but ganj allein frf̧te, unb fie bis ju if̧rem vollfoummenen alter nufjog. Daju mutbe id) nod) Durd) pinen anbern viel friteferen Bemegungsgumo ermuntert, bor nir viel zu

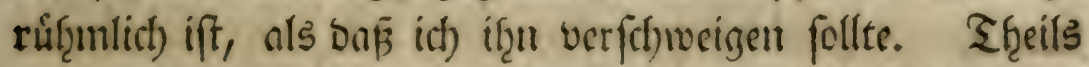

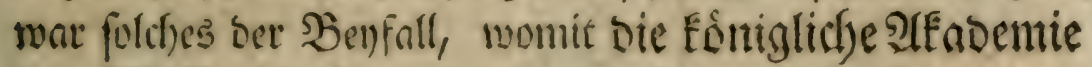
Der Sisiffenffyaften, uno insbefonbere ber Sert bou Sienumuir biefen Derfuch) beeţrten; theills bas von if̨nen bejeigte 2erlangen, Denfelbent fo oft micbertholt zu fethen, als ich nur fonnte. In siefer 2lbficht jog id) nun jween 3 B latts

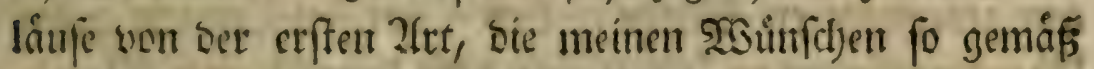
gemefen war, ganj allein anf. Die etffe war ben jnanjige

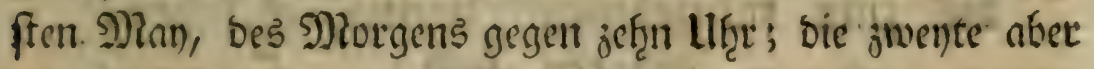
an bimfelfen Tage, bes 2l6entos gegen fünf llf̨r geboren. Den bernßigften beffelben Monats, bes 2lbenos gegen fralb:

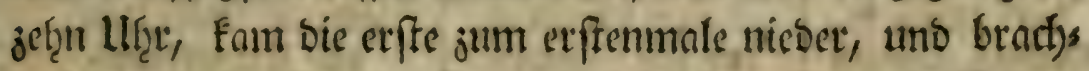
te bis zunn funfjefrnten Sunius, inclufive, nenusig Sunge

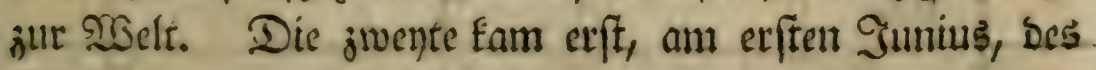

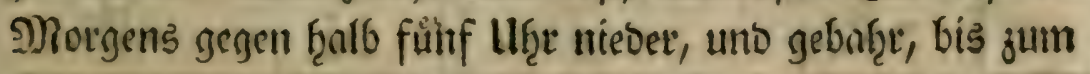
fisbjef̧nten, inclujive, nur bren uno viergig Sunnge. Es

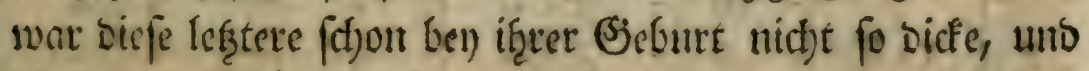

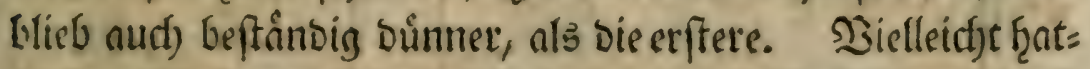
te fie nitht fo vid foetus im seibe; folglid) wat fie nictst fo fruchtbar. Sie múrben nber benbe vermutb̨lid) nod) meţr Sunge geboren frabent, wenn mist) nict)t cin Fieber úberfallen, unto gुȩ̧intert f̧âtte, weiter fưr fie ju forgen; Daf̧er glaube iț, bof fie verf̧ungert fino.

C 3 Shit 


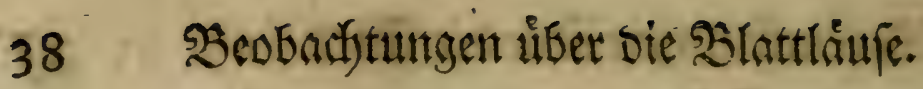

STier fint bie Sabellen von ben Bseburten biefer benben Blattlaufe. Der Etern * bebeutet nact) meiner Erflinung

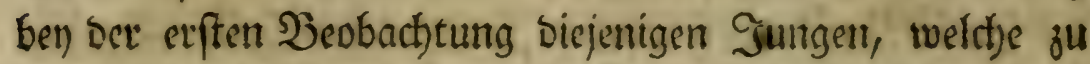
Der Zeit jur

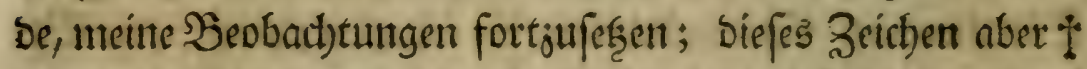
geiget biejenigen anr, bie entweber gleich geborent wurben, Doer feit menigen 2fugenblidten erft jur sibelt gefonmen waren, als id) meine \$beobadjtungen wieber anfangen fonnte.

\section{Tabelle}

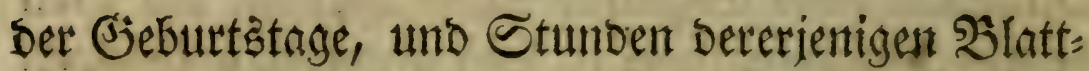

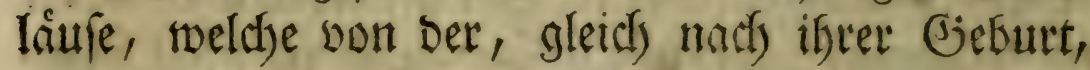
an juanzigiten Maue, Des Miorgents gegen zefn

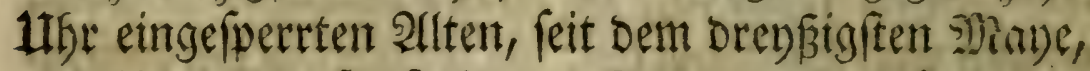
bis jum funfsefnten Junius, inclufive, geboren find.

\begin{tabular}{|c|c|c|c|c|c|c|}
\hline $\begin{array}{l}Z_{2} a g \\
\text { Des } \\
\text { Maue }\end{array}$ & 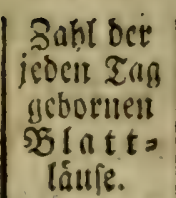 & 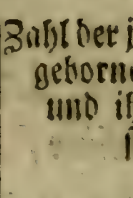 & 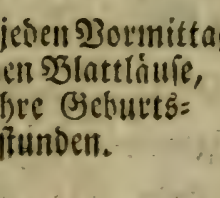 & 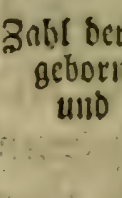 & 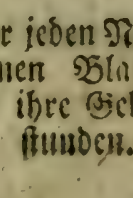 & 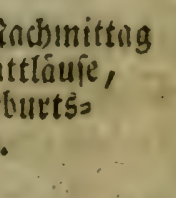 \\
\hline & $\mathbf{I} \mathfrak{B} !$. & - & 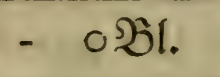 & $9 \frac{1}{2}$ & - & I $\mathfrak{B l}$ \\
\hline 31 & I I $\mathfrak{B 1}$. & $\begin{array}{r}6 \\
-\quad 9 \\
-10\end{array}$ & $\begin{array}{l}-\quad 5 \mathfrak{B l}{ }^{*}{ }^{*} \\
-\quad \text { 工 } \mathfrak{B l} . \\
-\quad \text { I } \mathfrak{B l} .\end{array}$ & $\begin{array}{l}2 \\
4 \\
6\end{array}$ & $=$ & $\begin{array}{l}\text { I } \mathfrak{B l} . \\
\text { I } \mathfrak{3 l} \text { × }\end{array}$ \\
\hline & z $\mathfrak{B l}$ & $\begin{aligned}- & 4 \frac{x}{2} \\
-\quad & 7 \frac{x}{2} \\
-\quad & 9 \\
-\quad & 9 \frac{3}{4}\end{aligned}$ & 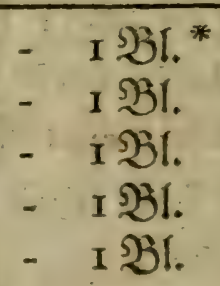 & \multicolumn{3}{|c|}{$\begin{array}{l}9-6 \text { abivefento. } \\
6-2 \cdot 31_{0}^{*}{ }^{*}\end{array}$} \\
\hline
\end{tabular}




\section{Şeobact)tungen xiber bie Şlattlâtue.}

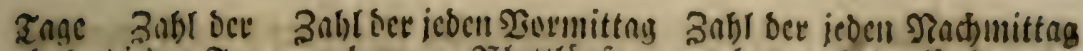

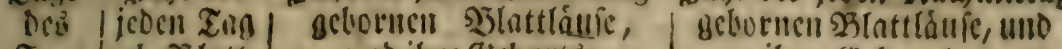

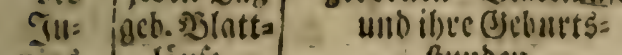

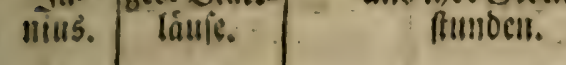
bie (Seburts= inutiocis.

\begin{tabular}{|c|c|c|c|c|c|c|c|}
\hline 2 & 7331. & $\begin{array}{c}5 \\
8 \\
9 \\
10 \frac{x}{2}\end{array}$ & $=$ & 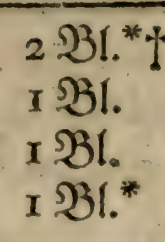 & {$\left[\begin{array}{l}2 \\
-5 \frac{\pi}{2}\end{array}\right.$} & $\begin{array}{l}-5 \frac{x}{2} \mathrm{ab} \\
-\end{array}$ & $\begin{array}{l}\text { brofertis. } \\
2 \text { 2B1. It }\end{array}$ \\
\hline 3 & 8 SBl. & $\begin{array}{l}6 \\
7 \\
10 \\
11 \frac{\pi}{2}\end{array}$ & $\overline{-}$ & 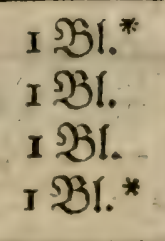 & {$\left[\begin{array}{c}3 \mathrm{w} i f(\mathfrak{h}) \\
4 \\
-9\end{array}\right.$} & $\begin{array}{c}2-3- \\
-9 \mathfrak{a b w} \\
-2\end{array}$ & 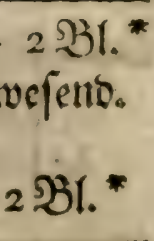 \\
\hline 4 & $6 \mathfrak{B l}$ & 6 & - & $4 \mathfrak{b l} l^{*}$ & $\begin{array}{r}4 \\
-\quad 10 \\
\end{array}$ & $10 a b_{1}$ & \\
\hline 5 & $9 \mathfrak{B l}$. & $\begin{array}{l}6 \\
6 \frac{x}{2} \\
8\end{array}$ & $\overline{-}$ & $\begin{array}{l}3 \mathfrak{B l} \text { " } \\
\text { I } \mathfrak{B l} \text {. } \\
\text { wefend. }\end{array}$ & 4 & -5 & $5 \mathfrak{B l}_{0}^{*}$ \\
\hline 6 & $6 \mathfrak{B} 1$. & $\begin{array}{l}5 \\
9 \frac{3}{4} \\
\end{array}$ & 二 & $\begin{array}{l}3 \mathfrak{B l} \mathfrak{l}^{*} \\
\mathbf{I} \mathfrak{B l}{ }^{*}\end{array}$ & $\begin{array}{ll}- & \mathrm{I} \\
- & 8 \frac{\mathrm{x}}{4} \\
\end{array}$ & $\bar{Z}$ & $\begin{array}{l}\text { I } \mathfrak{B l} .^{*} \\
\text { I } \mathfrak{B l}{ }^{*}\end{array}$ \\
\hline 7) & $7 \mathfrak{Z l}$ & $\begin{array}{c}5 \\
6 \\
8 \\
10 \frac{3}{4}\end{array}$ & $=$ & 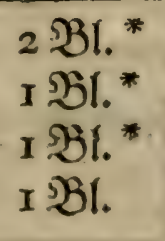 & $\begin{array}{r}-x 2 \frac{x}{4} \\
-\quad 4 \frac{x}{2}\end{array}$ & $\begin{array}{l}-1 \\
-1\end{array}$ & I $\mathfrak{B}$ \\
\hline 8 & $4 \mathfrak{B} \mathfrak{l}$ & $6^{4 \frac{3}{4}}$ & 二 & 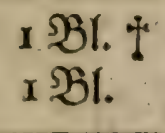 & $\begin{array}{l}6 \\
7\end{array}$ & $=1$ & 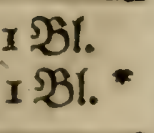 \\
\hline & $4 \mathfrak{B l}$ & $\begin{array}{l}5 \\
7 \\
8\end{array}$ & $\bar{E}$ & 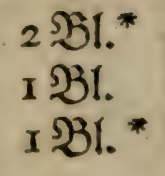 & - & - & ○'BI. \\
\hline
\end{tabular}


40 Şeobachtungen úber die Şlattlâtue.

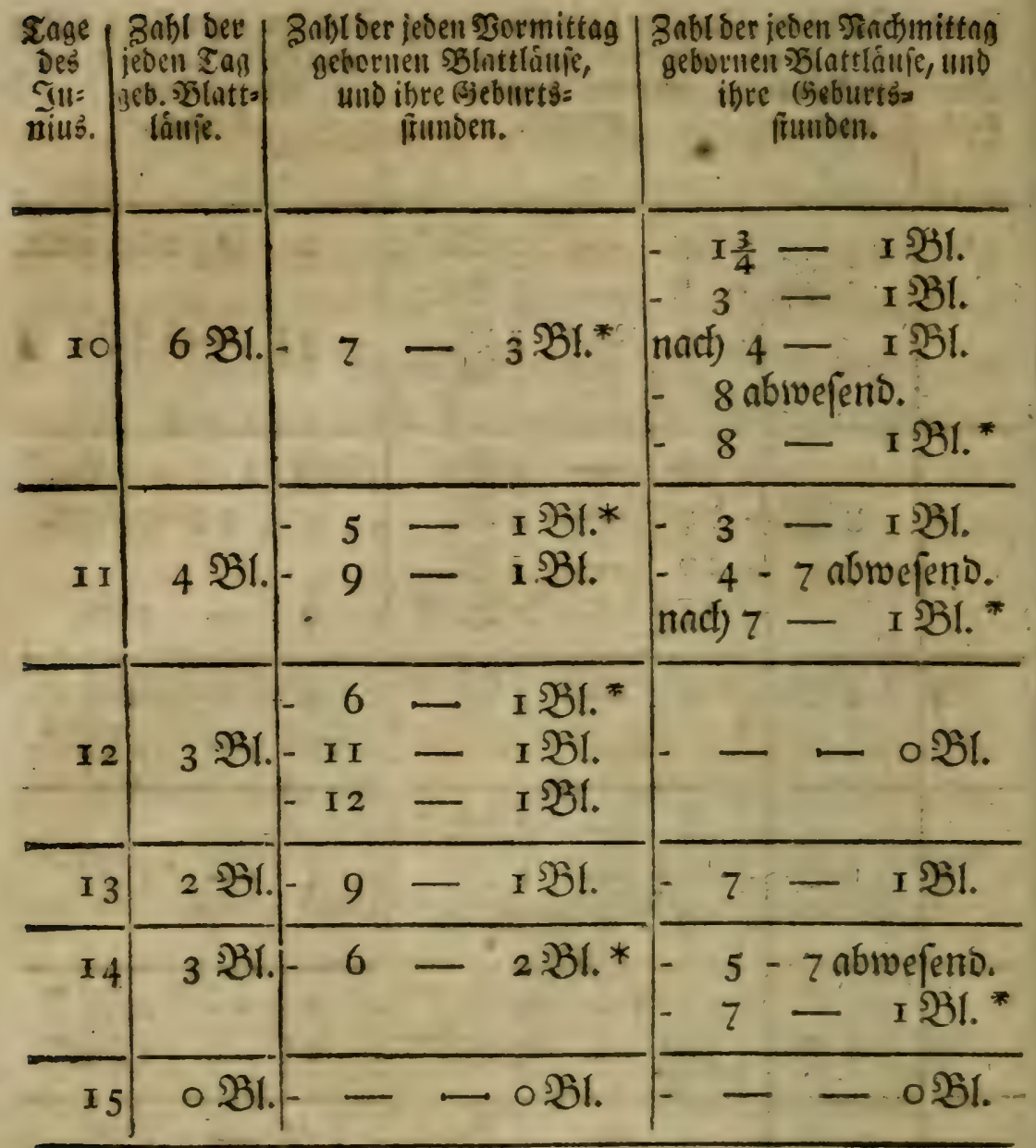

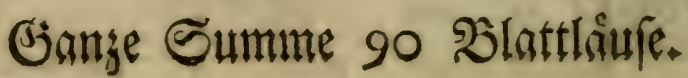




\section{Beobact)tungen úber die Şlattlâue.}

\section{sabelle}

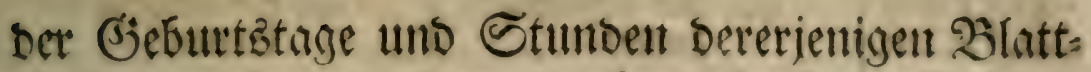
liufe, weldie won Der, gleith math itrer (beburt,

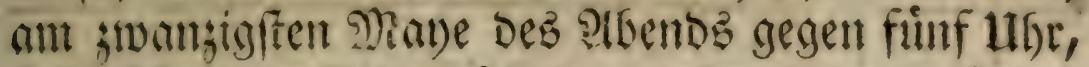
eingefperten Sllten, feit Dem erften bis zum fieb= jefnten Junitus, itcluf., geboren find.

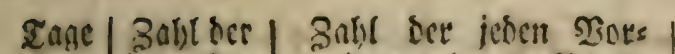
Dis jeocn 3.1n! Itl. geb. Silatt: niitı̉. láuje. mittan aetioencn Slatt= láule, unto île अ? = buttsinuben.
Sabl Det ieden Nandomit= tne neburnen Silntt= fallie, umi ifire (se: burtsinumen.

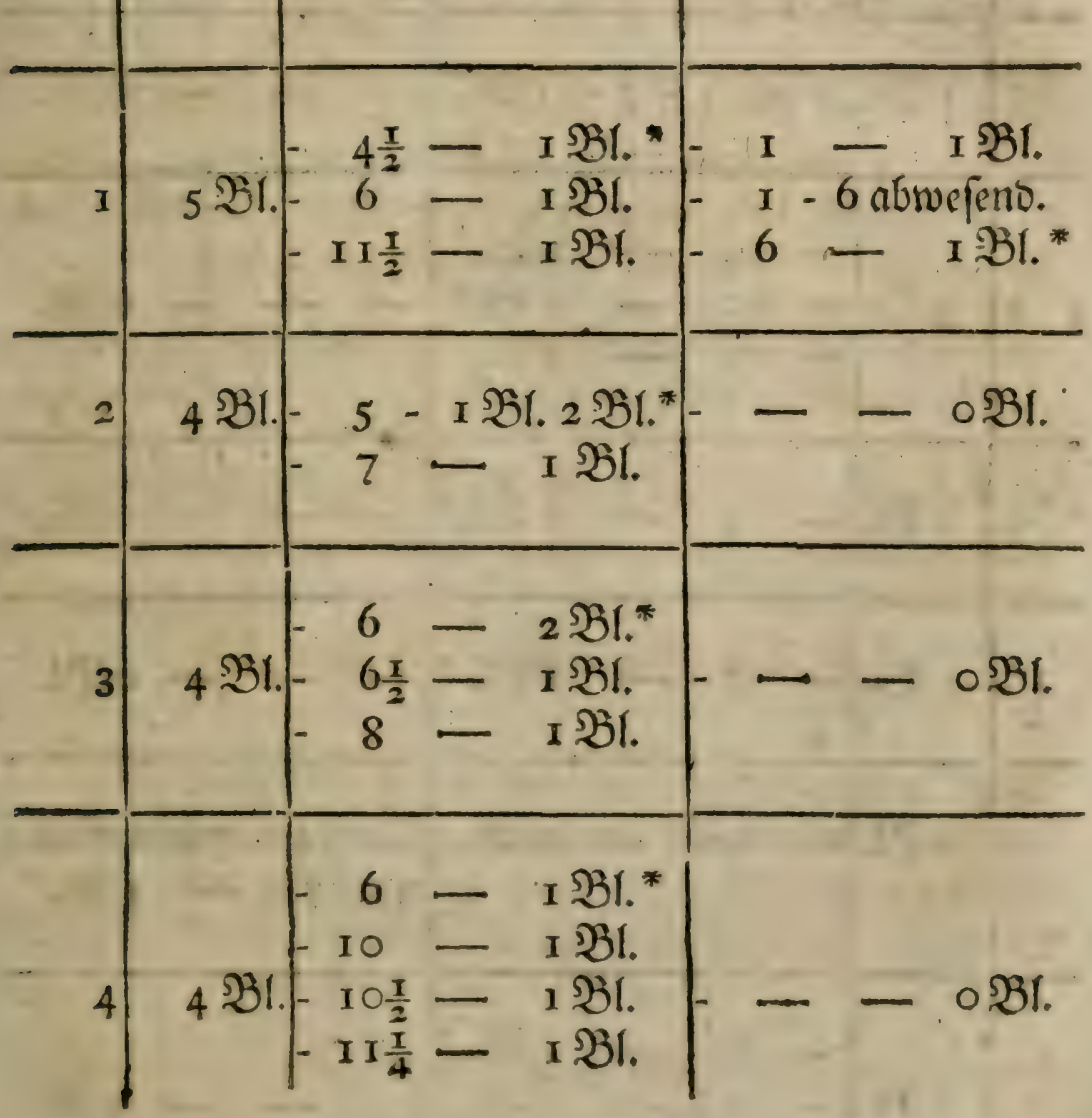




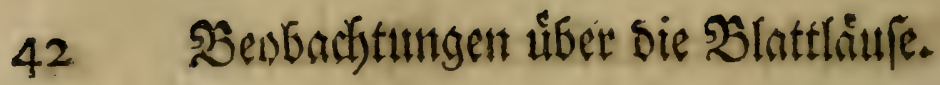

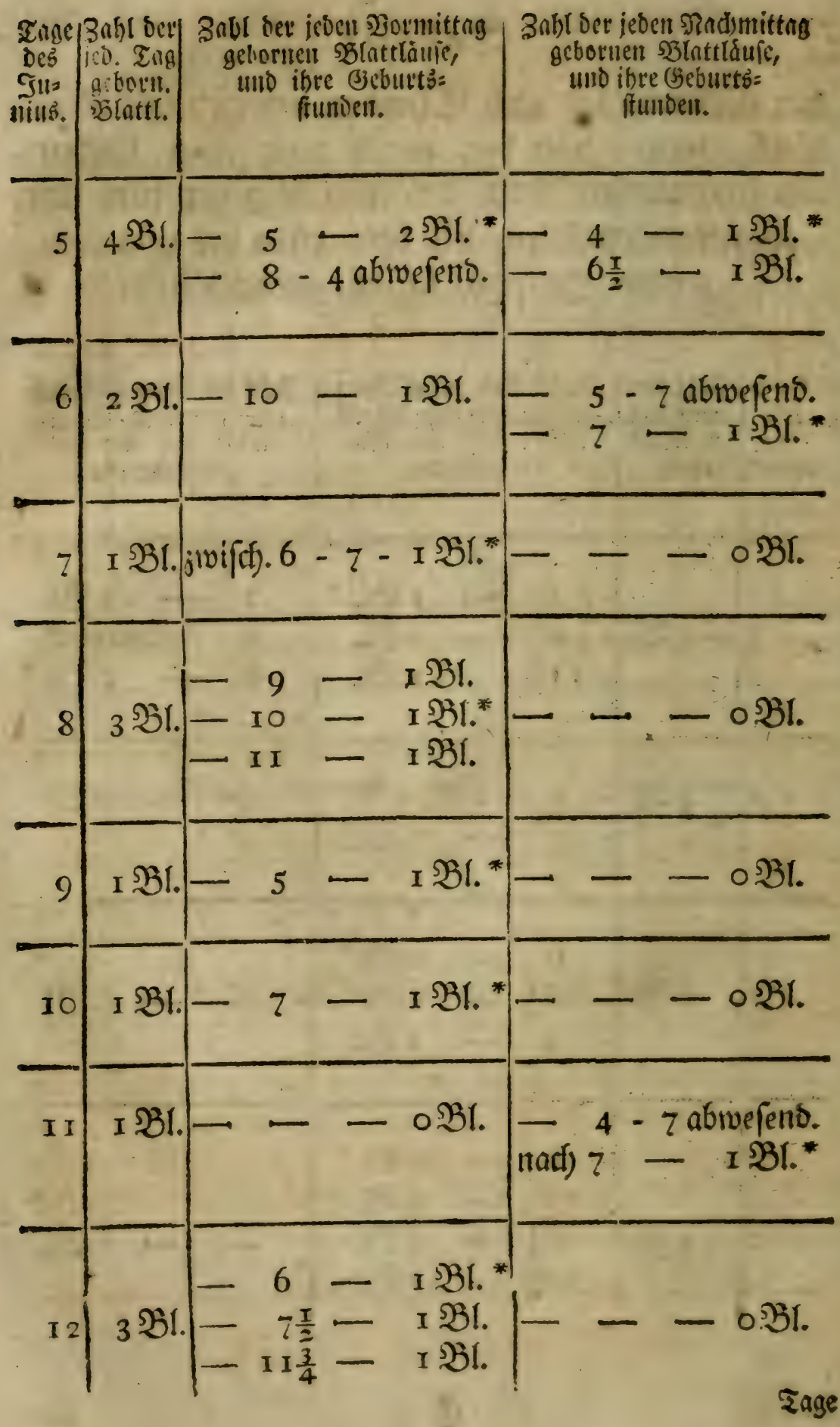




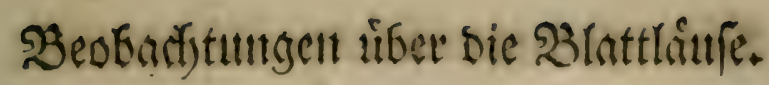

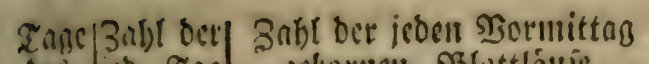

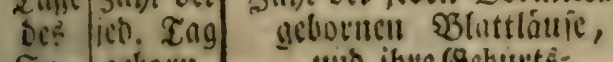
Sull gebotn. unto ibue Behurts =

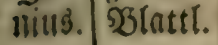

3abl bee jeten NactsmittuB gevoriten כ3 Inttlítule, und il)te (Seburtb= ftutioen.

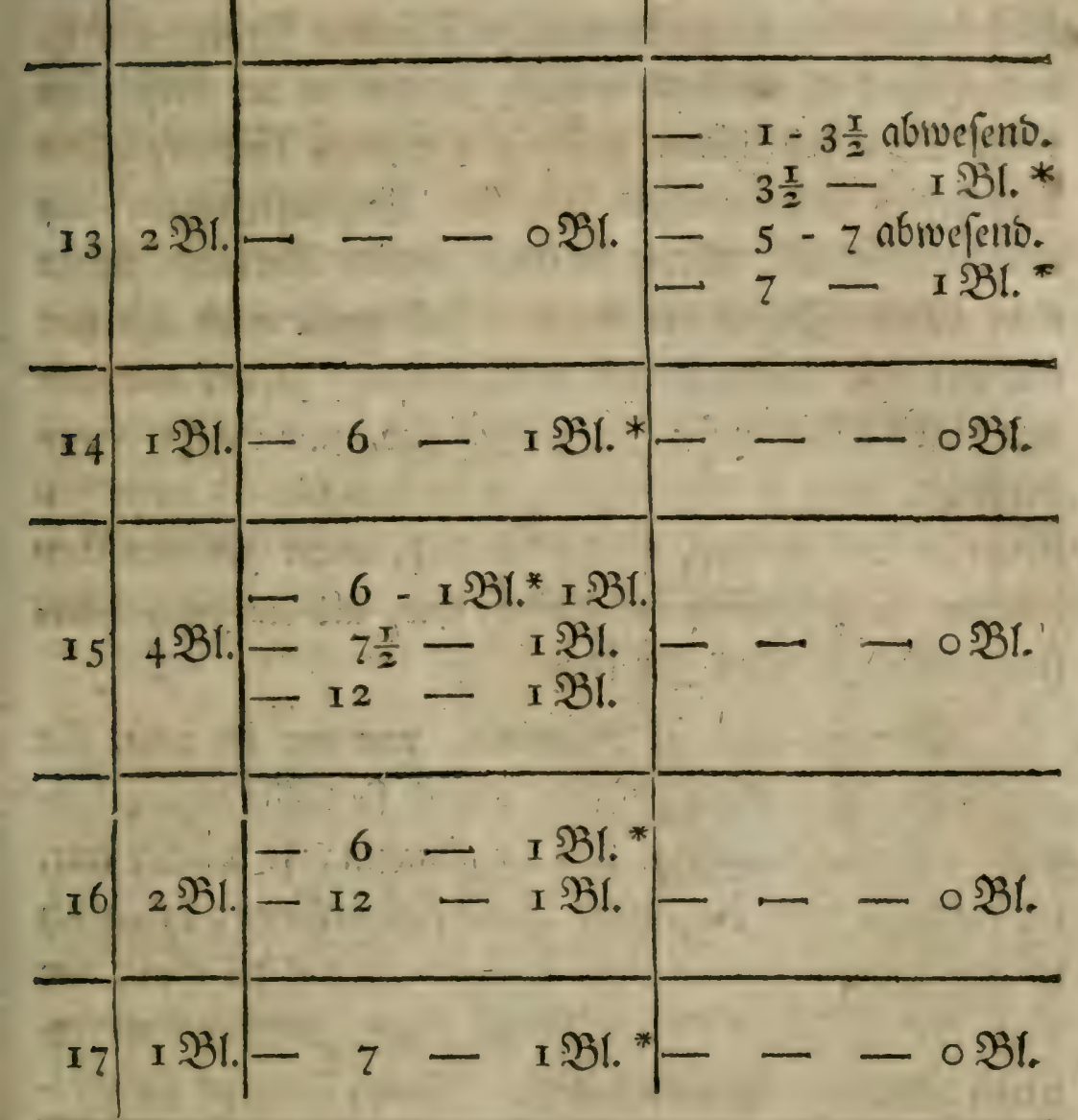

Da mić) baక fiebet genóthigt hatte, meine Beobs ad)tumgen einjuftellen; fo fommte id) fur incine Blatts lausmutter nicfte weiter forgen, weldfe unct) etlict)en Songen ftarb, nact)bem fie nod) vorţer - 6 Junge jur 2 Selt gebracht fratte.

Gange Summe 49 B̉attlăufe. 


\section{Seobach)tungen ưber bie ß̧attlåufe.}

Siun folle ich auch) noch etwas von ben Sungen fas getr, weld)e fowoţl bie erffe SBlnttlausmutter, als biefe bens

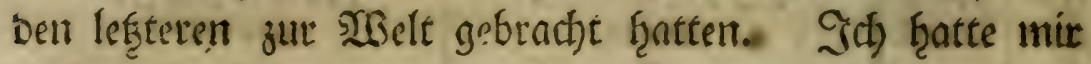
aud) anfänglich vorgetrommen, verfthicosene Droben mir if̧, nen ju machen, mosurch gewiffe fragen in ber Beffoichte biefer Shietchen fiàtten aufgeflart werben Fonnen; allein mancherlen unvermuthete Zufälle: B̧efhåftigungen von einer anbern 2(rt, nótf̧igten mich), meine Serfuche, bis ju

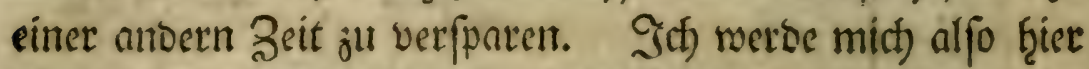
nut auf eine Beobad)tung cinf(hrinfen, ju Der mit eitte von biefen Bblattlälen Gelezenteit gat, uns welche beweis fen wiro, baff, fo fojwerfällig, uno langfam u) biefe Sim feften ju fenn fobeinen, foldbe bennod), unter gewiffen llm,

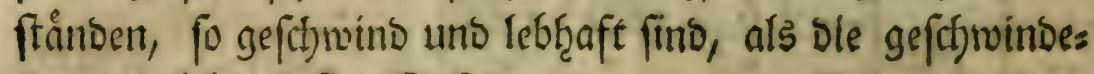
ftèn uns leb̧rafteften Jirfetter.

Es Ģatte aber bie BInttlnus, von ber ith rebe, feit gtwo Tngen ganj allein gefeften, als id) fie vôllig geţáutet ans trof. Da ic) bas Silas von if̨r atnnaţm; fo beuctite mir, als wenn fie noch) intt eitrem Scinterfuffe anfinge; inbem ich) fie aber gennuer betractetete; fo fano ich, bap die Scout nur

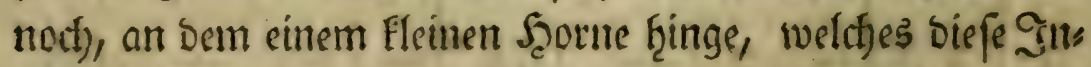

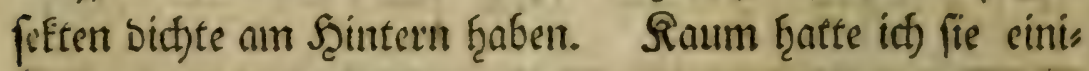

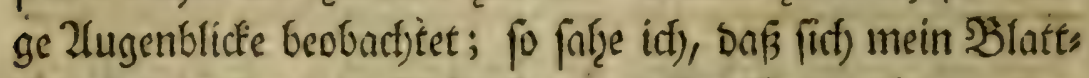
lausct)en anfieng ju foutteln, um if̧e Şaut nbjumerfent.

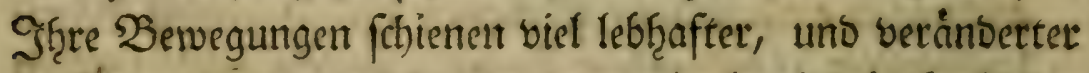
3u fentn, als bie, weld)e bie, von mir bercits beobactjeten

ans

u) Der Name ber Pucerons, fagt bet కerk von Reaumitr, bátte, meines (Erachtene, mul den lebfaften Injetten muifien geyeben merden, weld)e fef)e furtig, roie Die flóbe, fpringen.

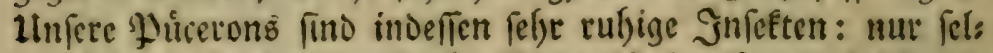
ten friechen fie fort, und ifge Sant? if langfam und fojwer: fillig. Nlem, fur les Int. Tom. III. p. 283. 


\section{Beobadjtungen uiber die Ḋlattláufe.}

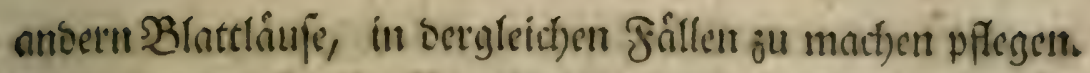

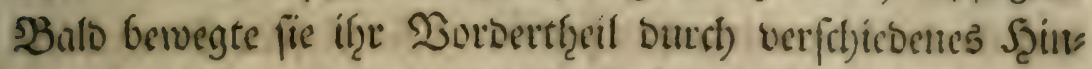

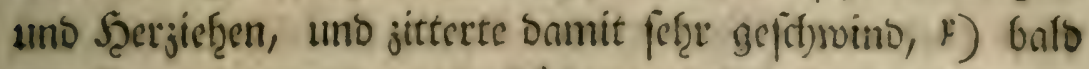

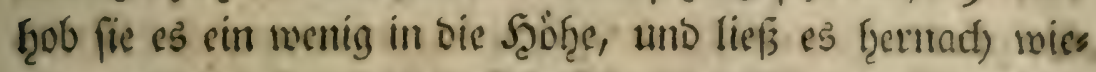
Der nieber. Gu gleit)er Beit fafze man fie, mit ifzren Syins

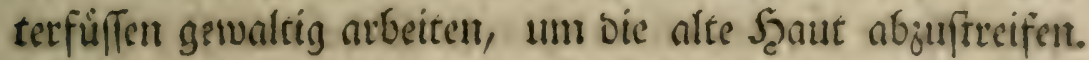
Daz verfaffite mir aber bas grofte Dergnirgen; noth

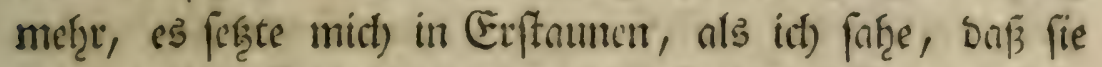
fict) mit einer \$Behendigfeit in ber suft herumbref̧ete, (pirouetter) bie befto bemumbetnswurdiger war, da fie uts ter bent Blatte faf, uno folglich befto Teidjter Giatte fallen fonnen. Shre Sotberfiffe foienen ber Siubepunft ju fenn,

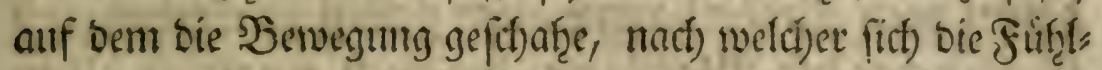
fiornet buth) andere faft beftinbige 2 enegungen rithteten. Sn biefer B̉ewegung fohe ith) fie bie ganje 3eit Durt), ba ich) fie beobact)ten fonnte, welches of̧ngefäfer brenviertel Stumben baurete, und jwar, wie idl) es ofgne alles

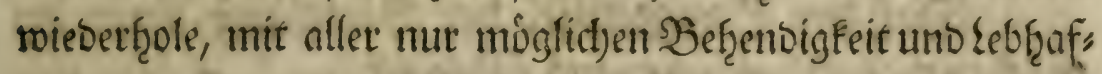
tigfeit. Da mir nun biefe flétre Reitbaţn (manége) y) fefre feltfam vorfam; fo besiente id) mich), um fie befto bef fer ju beobachten, eines ftarferen Dergrofferungäglafes, a!s

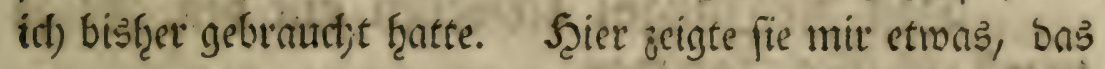
id) noch) ni(d)t waf̧rgenommen ḩatte; Dafs nemlid) Der Caus geruf

x) Der Şeer Detfaffer hat bier Daร Șort Vibration gefrandyt, reldjes sine befondere 2fot Des Bitterns hedeutet. Noun Denfe

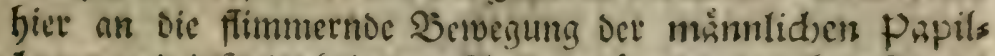

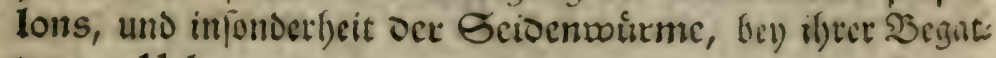
tunin. Heb.

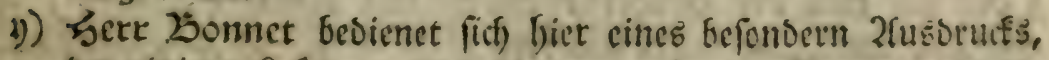
Det siniaen Refern Dunfel fofeinen mógte. (Er veryleidjt die

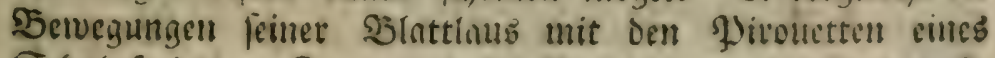

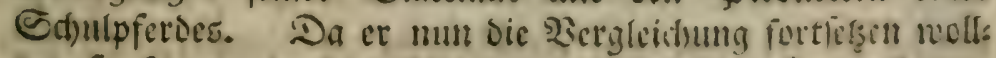
te; fo fonnte at bier feit antores, als manége nefoment. Lleb. 


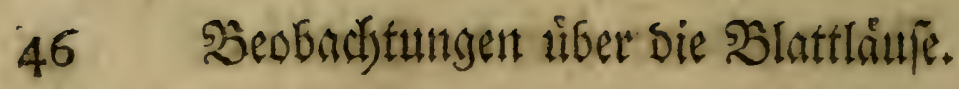

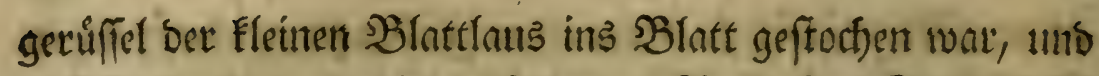

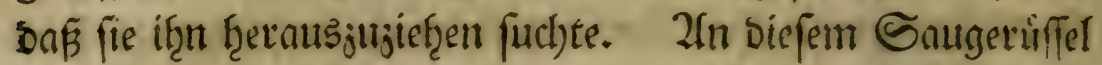

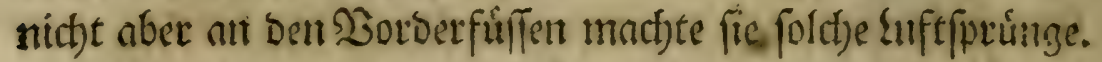

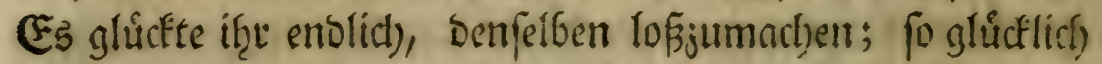

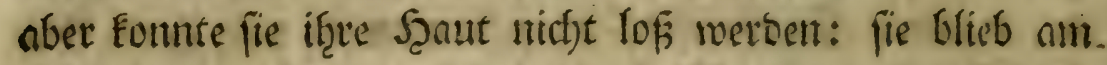

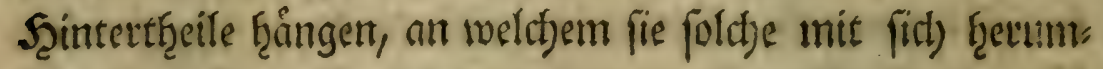
tragen unifte.

\section{Dritte Beobadftutity.}

2nbere - Serfiutje ůber ebent Die Sacfje, mit BInttlliulfen von mefreren 2rten, insbefondere mit

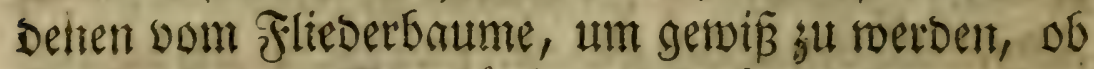

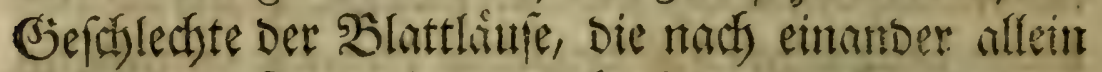

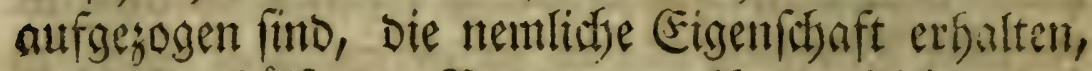

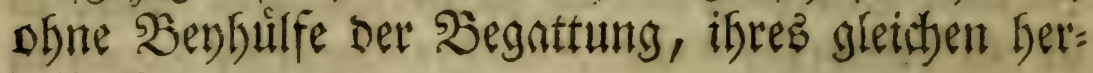
vorzyubringent.

Dá̉ Der Saugeruifier ber B̧lattliuffe einer bes trichtlich)en Berlângerung fífig iff.

Daß̉ firf einige unter Diefen Jurféten nutr brey: mal båutetr.

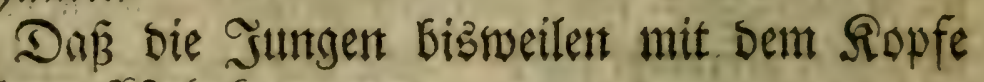

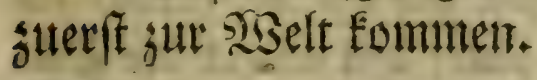

S. lange inf bie B̉Tattliufe bes Epinbelbaums unters

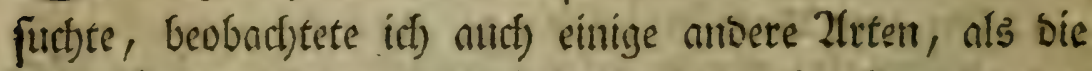

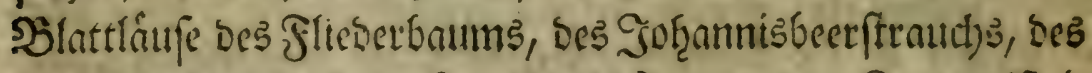

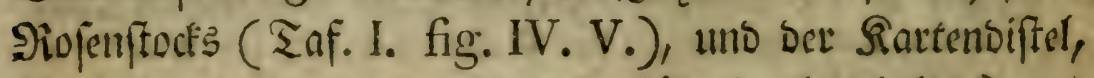

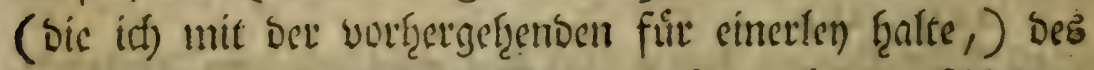

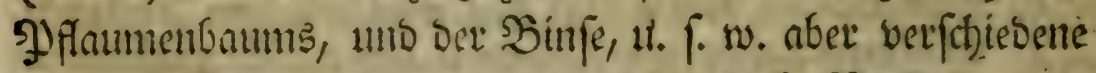

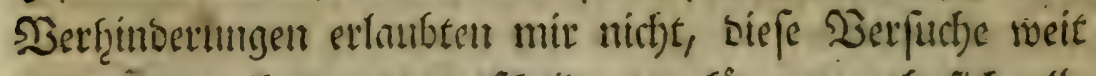

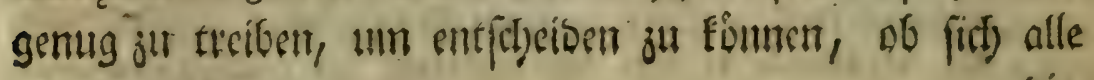
bies 


\section{Şeobadtungen tiber Die Blattlåufe.}

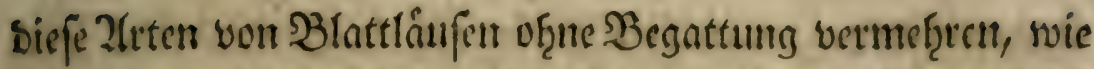

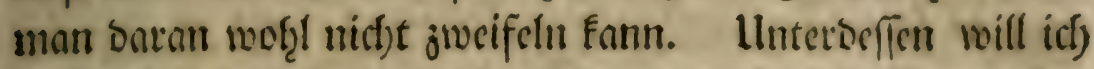
ood) nidft unterlaffen, f̧ier bns metfwutroigfte von tḩnen nmjufüfrten.

Nadjbem id) vicle B̧lattlâfe bes Spintodbaums it Der vollfommenften Einfamfeit aufgejogen hatte, utb alfo

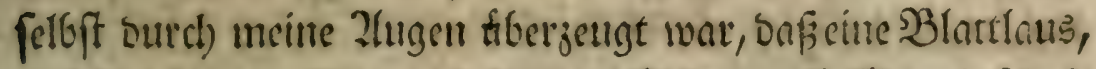

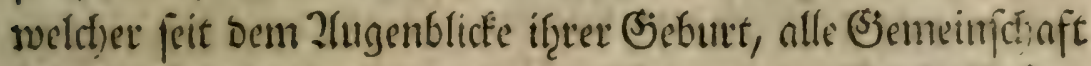
mit ifres gleidyen unterfagt gewefen war, im Stanberware,

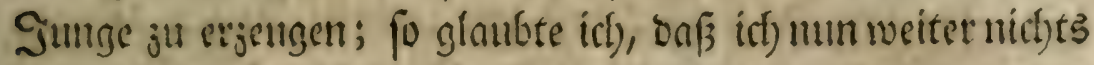

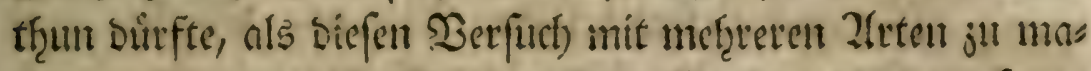
chat. Eine geniffe Mutf̨maffung *) aber, bie mir Sert

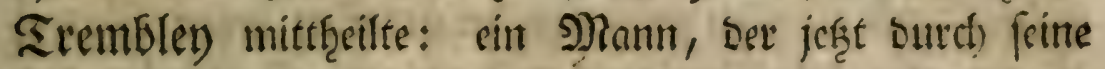
fdione Entochung ber Polypen, bie man, wie abgefdunit=

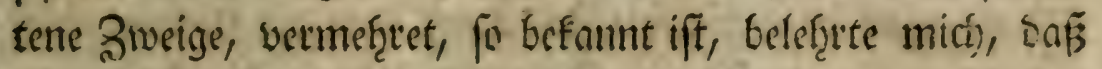

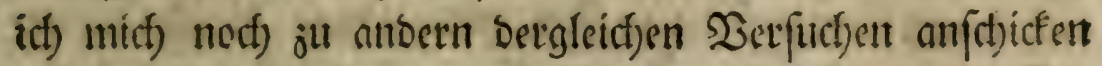

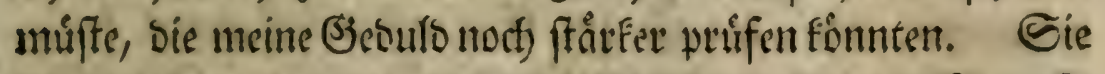

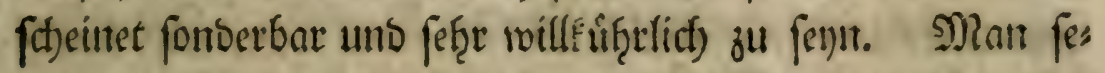
fet nemlict) voraus: Daß eine einjige Begattung bey bett SBlattlaufen genug (enn fonne, viele nad) cinander folgende Sefeftechte ferborjubringen. Llin aber ju zeiget ob fie suahte ober falfich fev); fo fäme es anfänglich) baranf an, eis ne SBlattlaus von bem 2fugenblicfe if̧rer Sicburt, bis ju if̧er erften Nieberfunft mit cinem Jungen, in ber volls Eommenften Einfanteit ju fralten, weld)es ebenfalls múfte, soie feine Mutter, ju einer beftánbigen Einfiedelen verbanmm twerben. Trbáre biefes ju feinem reifen 2llter gefoummon, uno f̧ätte abermal Junthe herborgebract)t; fo muffe mant

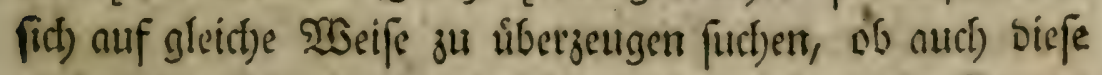
nod), of̧ne fitf init einanber begattet ju f̧aben, im Stande feyn

") Corps organif. T. II. Art. 303. p. 103. 


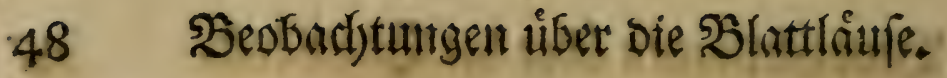

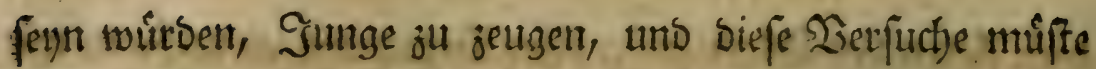

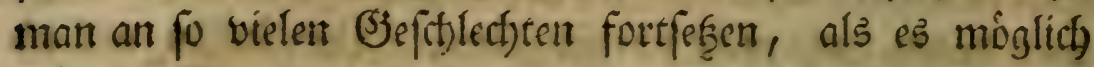
wáre. Das war nun bie Zltbeit, bie iff mir vorgenoms men. 2fus ser Folge biefer \$beobact)tungen roirs man fes

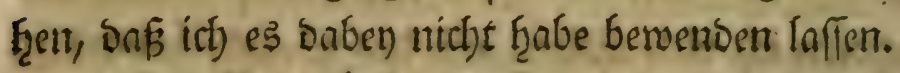

Die SBlattlauje des Fllieberbaums waren bie erffen, mit meld)en id, ben Infang biefes neuen 2 erfund)es mach)te; unt er ging gliceflith von ftatten. Den grobiften Sullius,

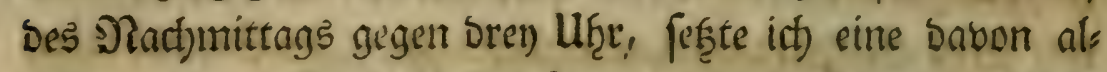
lein, Die ben 2tugenblick erft vor meinen Zlugen geboren war. Den juantigigfent Deffelben Monats, Des \$orgens IIm fect) wartete aber bis jum jwell unt jwanjigften gegen Mittag,

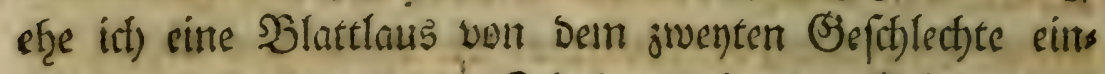

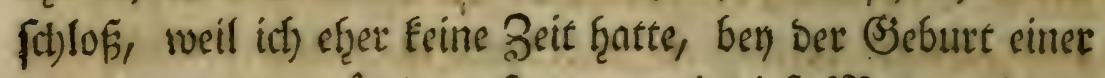
won benen gegertuvartig ju fenn, twomit biefe Mutter niebers. geformment war, bie idh) jut Einfamfeit beftimmet hatte.

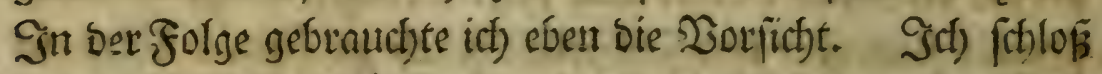

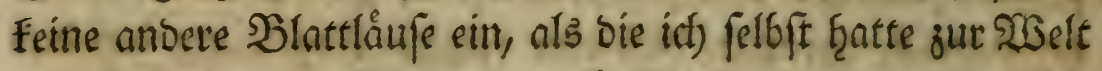

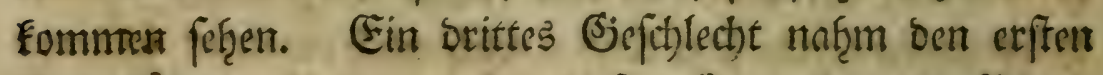

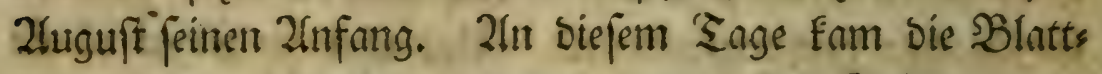

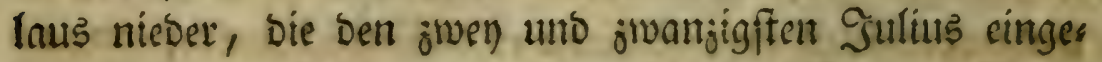
fperret war. Den vierten 2tuguft, of̧ngefôther bes פinchs mittags unn Eing, fef̧te itit) eine B̉latclaus von biefem brits

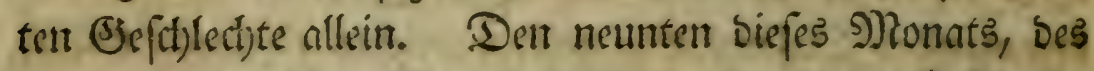

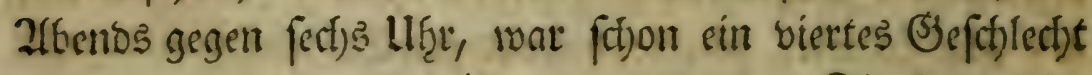
von biefer lef̧teren ans lick)t gefommen. Sie fratte bier Siunge jur 2 selt gebrad)t. Defferfen ₹agebgegen Mitters nat)t, wurbe eine SBlattlaus bes vicrten (jeffollect)t3, Die um biefe Beit geboren war, aus ber Bsefellfiftaft inces gleis

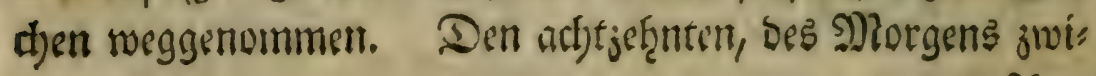


so Şeobachtungen úber bie Bllattlåufe.

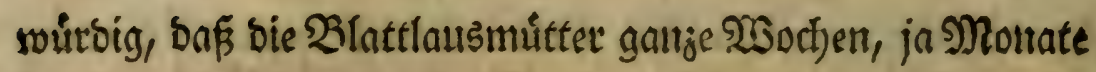
Durch, nicht bie geringfte Epsife jul ficf) nef̧men follten: ba

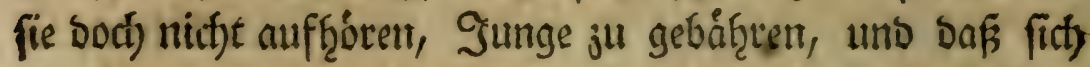
bie Foetus nichts beftoweniger ju recl)ter Zeit entwickéln,

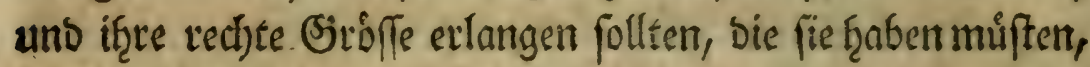

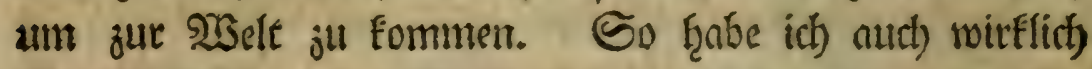
Blattlausmutter bes Spindelbaums, und cinige andere 2lss

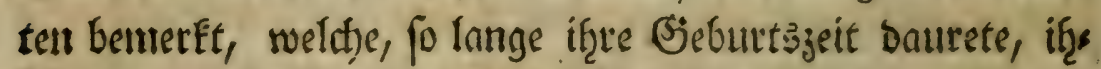

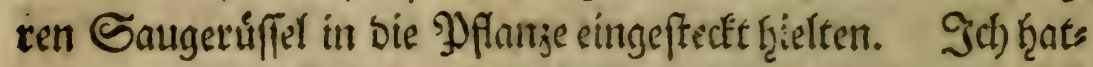

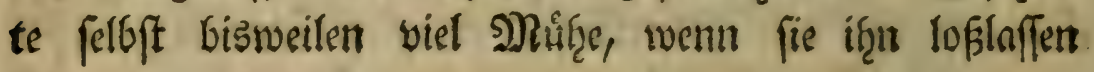
follten.

Ez Fomment aber bie SBlattlånfe, wie bie meiffen

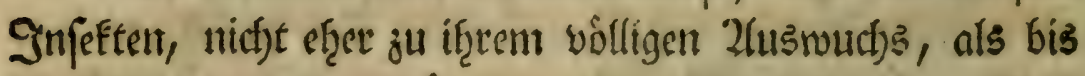
fie fiif) einigemale gef̧åutet ţaben. (Eint. I. 4.) Man

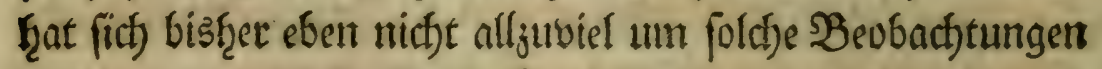
befúmmert, bie uns zeigen finntent, wie oft fie fich berwante

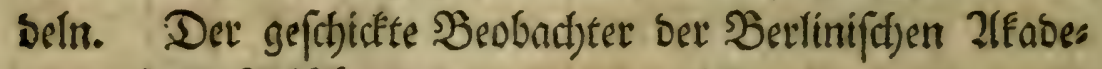

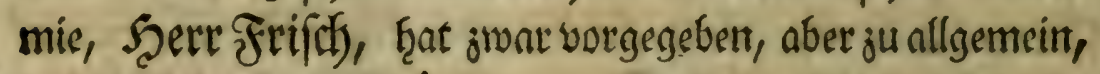

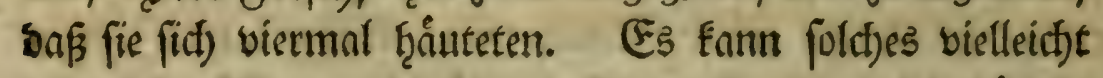

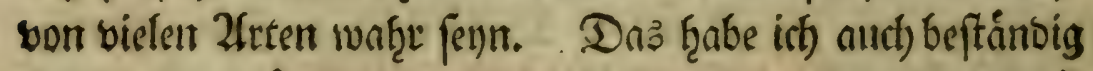

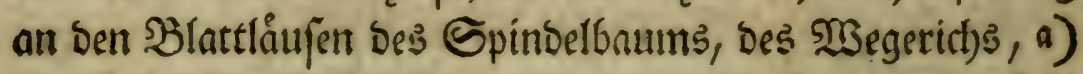

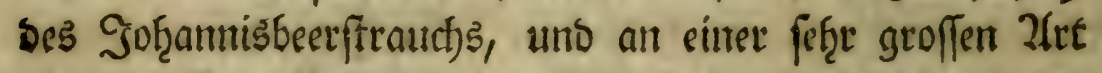
waf̧rgentommert, Die ouf ber Eidje lebt, unb bie ich) anberss

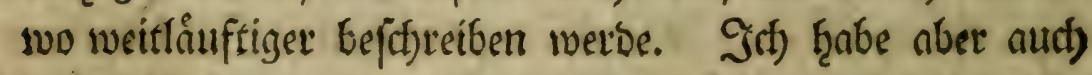
welthe beobactset, bie biefe beffywerliffe Dperation nur brelys mal ausftef̧en. Solches waren 3. E. Die Blattláufe bes fllieberbaumb. Eime Blattleus von biefer 2frt, welthe ben

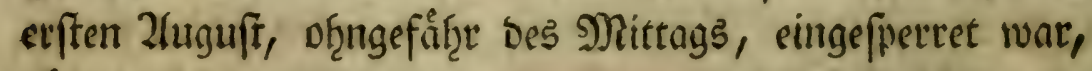

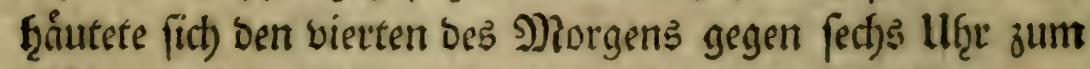

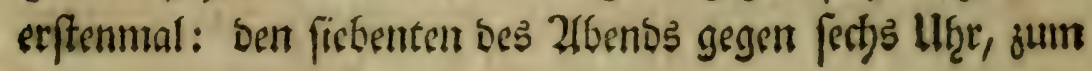

a) Plantago. Lim. $\mathfrak{H} \mathfrak{c} \mathfrak{b}$. 
nllbermmal; Den neunten, bes Sj?orgen gegen fünf Uthe jum

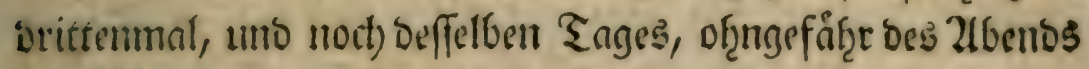
um fet)

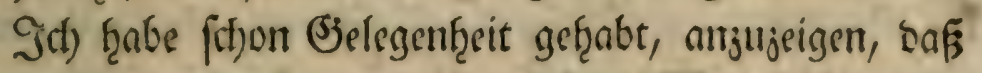
bie Jungen mit Dem Şintertheile juerft nus פMutterleibe foms men (Eint. VI. r.). Ilnterdeffen ḩabe ich bod) auch eitue Sumge gefefent, welche mit bem Sopfe juerft, uno mit bem Ṡauthe oben, von einex geflugelten B̉lattlauts bes siojent

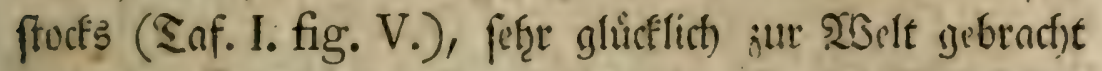
nurbe. Denn fobalo fie getoren wor, fletterte fie auf ben פiticken if̧rer פiutter. Diefelbe gebahrevor meinen 2lugen

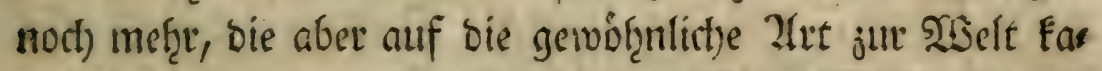
men. Folglich fann biefer jest angefuifete fonll, als ein

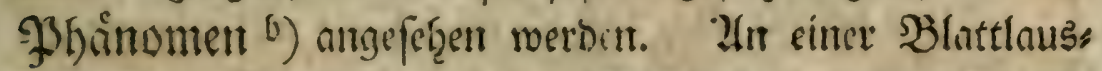
mutter bes 2 segertit)s, frabe iff es nod) einmal, aber mit

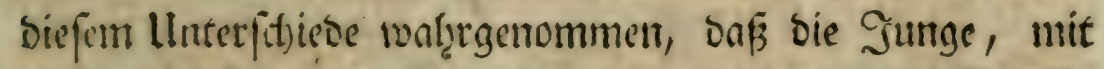
sveld)er biefe lef̧tere niebergufonmen war, mit bem Şaucbe

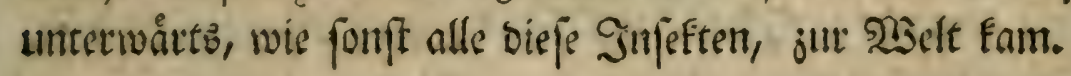

\section{Sierte Beobadtunty.}

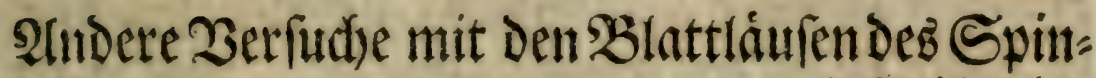

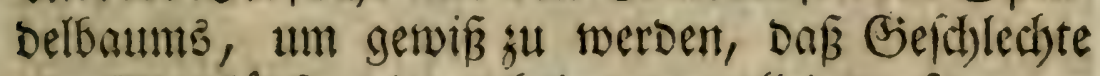
Der SSlattlaiule, Die nad)einander alleit anfgejogent

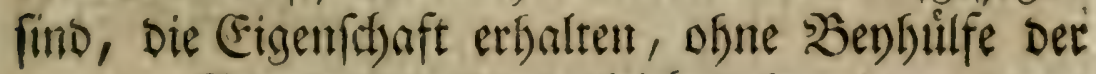
Sెegattung ifres gleichen bervor= jubringen.

(S. s wat alfo nod) nict)t genug, vier (Befhllect)te bon Blatts

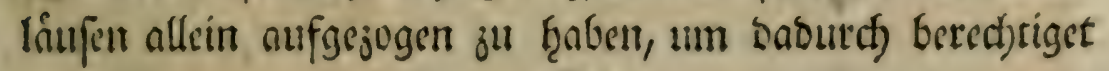
D. 2 j山

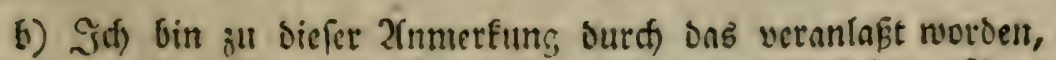

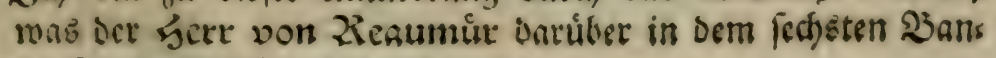
de feiner Dismuites p. s $^{6} \mathrm{x}$. fagt. 
ju fentr, ben Zweifel abjulefrneth, wovon id) in ber borthers

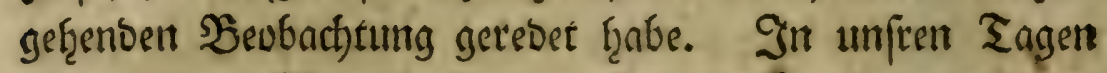

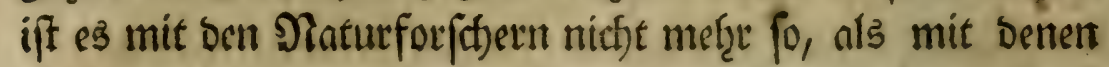
im 2fltertf̧̧ume. Diefe, nur fưr Zlbentţeure cingenommen,

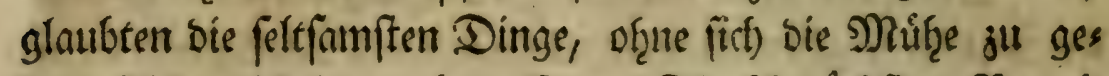

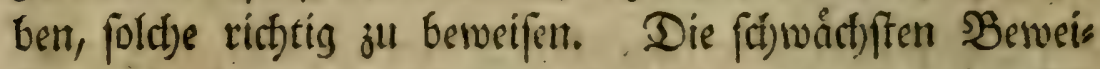

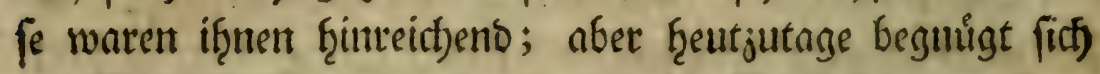

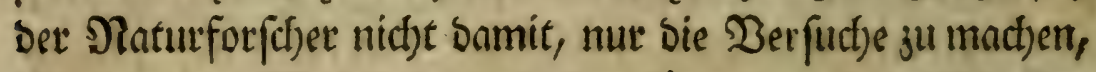

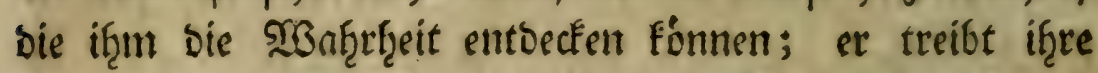

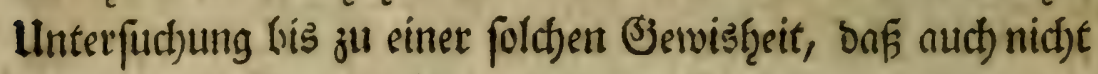
Der geringfte Zaweifel úbrig bleibt. Eve fann es nich)t eins

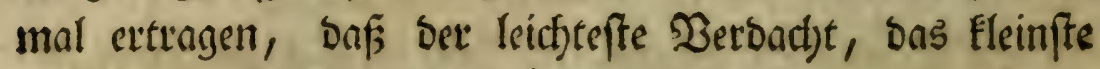

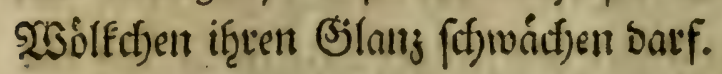

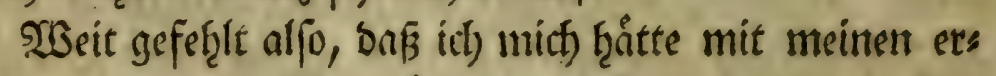

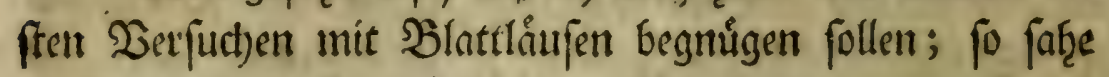
ich) fie als bloffe Enttwuirfe an. Sidh glaubte nur erft mit

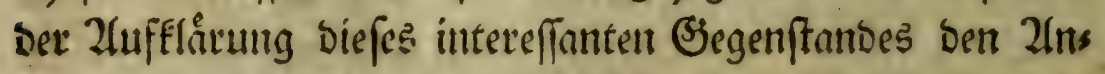
fang gemact) jut fૃaben, uno jofickte midl) alfo von neuen an, folcten wicber vorjunef̧̧utert.

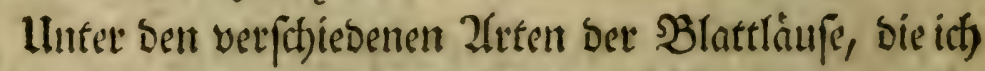

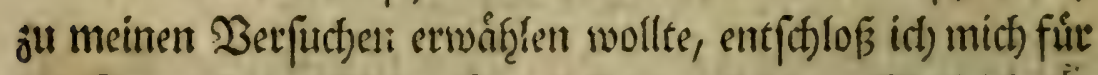
Die Sorte, bie auf bem Epitroelbaume lebt. S3eil int ein

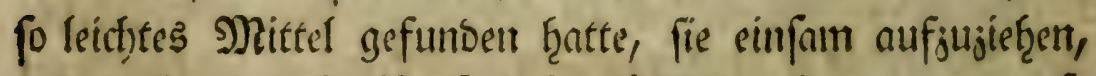
und weil mir biefer 2 erfuat) fo glieflitit) gefiungen war; fo

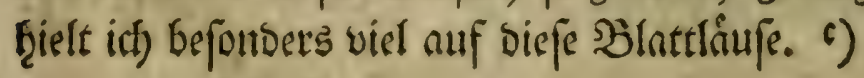

(5:

c) Es ift biefes cine felfr artige, aber faft allgenteine 代rfobrung

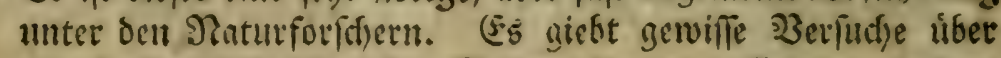

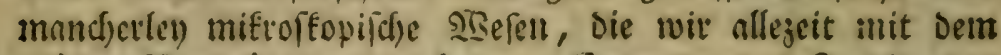
gróften Detgmigen wiederfjolen. (Entweder das Jnfett, Dats ninu unter|udf), empfief)(t fich) uns burch die Minnnigfaltig: feit Dex EntociÉngen, womit es unt jeoergeit beloljnt, oder

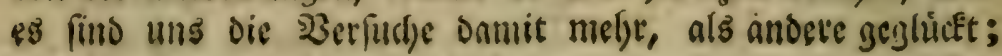




\section{(E.rftes (Gef(d)lect)t.}

Den fedfsten Man 1742 , bes פRadjmittags gegen

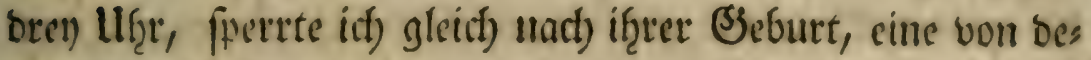
nen S3luttlifufen ein, welthe von ciner ungefligelten SBlatts Iausmutter bor meinen Zfugen jur 23 elt gebrad)t war.

Dent ein unt givanjigften, Nactmmittags gegen bre!

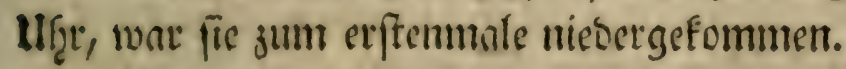

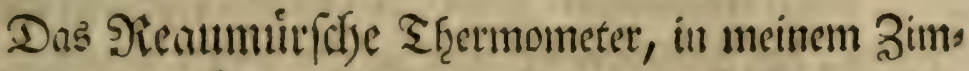

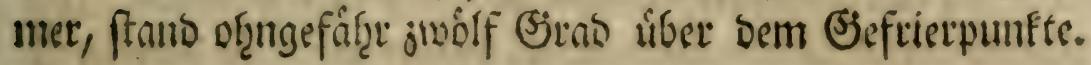

\section{Siwenteg (seffiledst.}

Den jwen und jwanjigfen fegete idf) eine von ben Gunt gen ber Blattlausmutter bes erffen (Befhled)ts allein; es war bie fectste, und bes Mrittags jmiftsen eilf und jwoilf

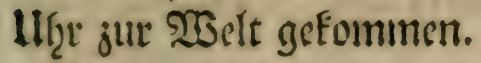

Den vierten Junnius, war fie um eben bie Zeit, mit

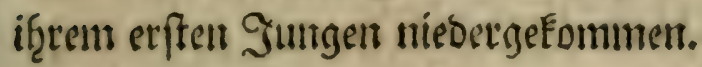

Das Thermometer ftand peit fưnf bis pect) Songen,

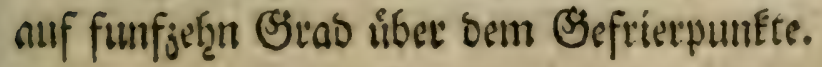

\section{3}

Drits

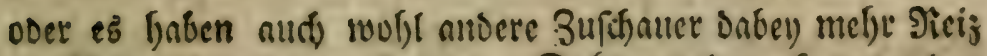
zut Servunderung cmpfunven. Dalfer werden oft unter Den Sinfeften geviffe 2ltten, wie bier bem Serten 25 onnct, Die B3lattlaufe des Epindelbanums, umfere favoriten. So if

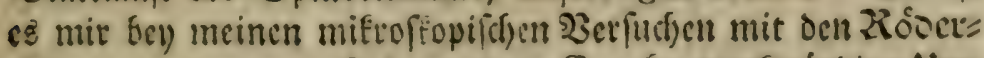

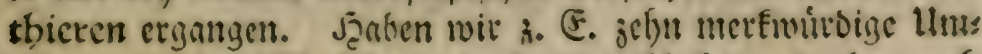
fránoe an einem Infefte entsecett; eb bleibt uns aber nod'

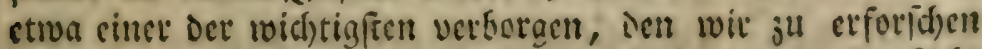

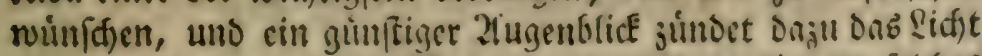

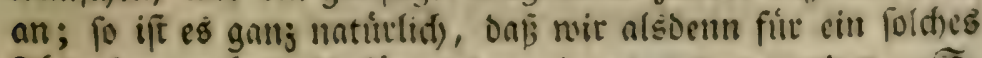
Thierthen melor, als fir nubere cingenoumen werben. $\odot$. Das 17 , uno 18. Gribd ses zannoverifhen :Ningazins 1773. Hlcb. 


\section{Drittes (5)ef(t)led)t.}

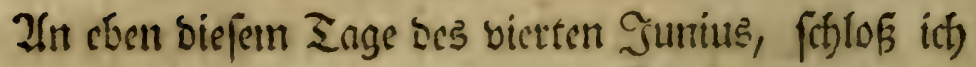
bie anbere Blattlaus gleid) nach) ificter Sroburt ein, Die bes

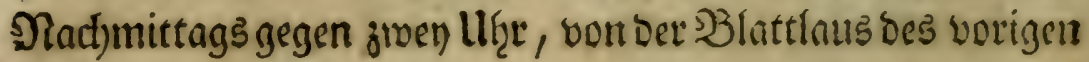
Gefdlect)ts geberent war.

Das Thermometer frano feit einigen Sagen นิ6er

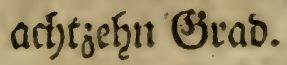

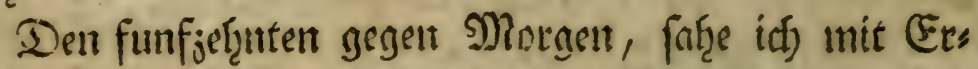

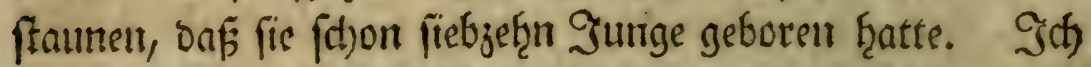
fage, mit Erftaunen, weil es frhien, als menn fie ifreen volts

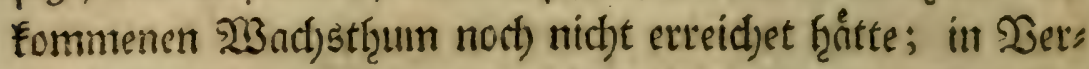
gleid)ung mit ben SBlattlausmúttern Der benben erften Gres

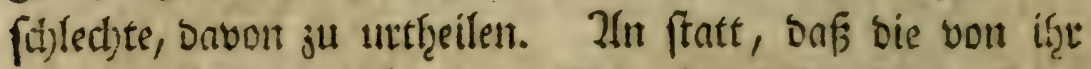
gebernen Siungent, ḩâttent ins Schwaize fallen follent, fielent fie ins Grime, of̧nernatitet fie inbeffent Zeit gemug geţabt heatten; DunEel ju werben.

\section{Bierteg (sefdilerft.}

Int eben bem ₹nge, als am funfję̧nten biefés Mlos nats: ûbergab idh ein Julliges von bem vierten (Jejej)lect)te Der Einfamfeit, welches erfit vor meinen Zlugen gebos ren war.

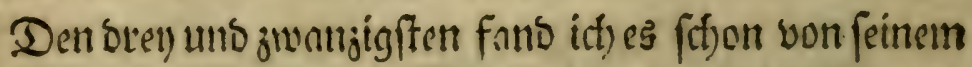

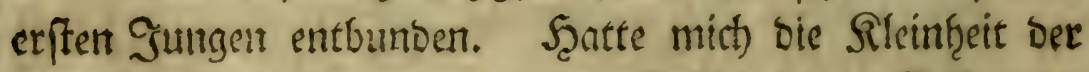

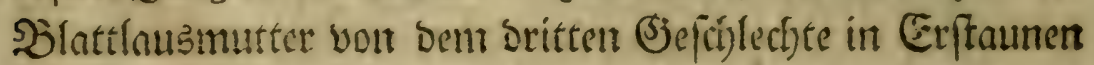

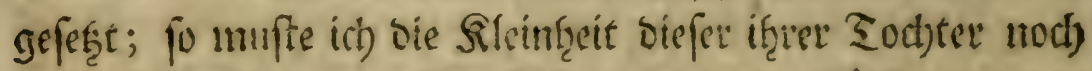

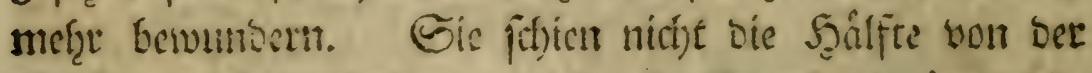

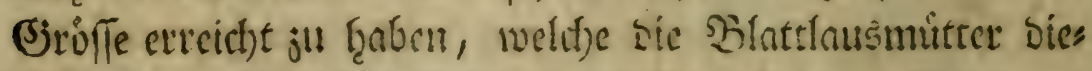

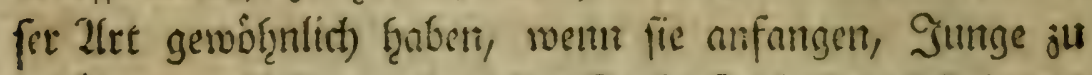

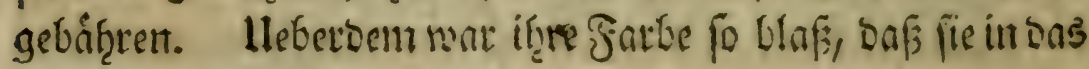
Eelatomgrime fié. 


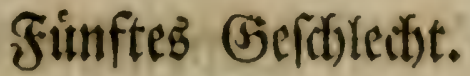

2(11 chen bem ₹nge, am bec) unb jwanjigften Junius,

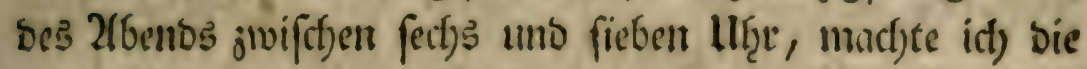
stitte Ṡlattlaus jum Einfiebler, Dic ben Zugenólick erf̨t

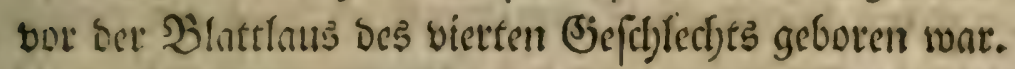

Dns Thermometer war feit einigen Tagen bon fects jefrn bis net)jefrnt Sirno geftiegent.

Den vierten Gullits, Des \$llorgens gejen adjt llf̨t,

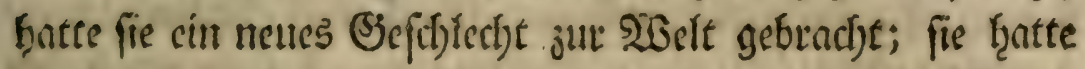

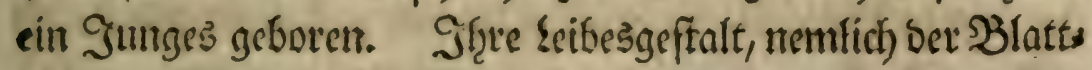

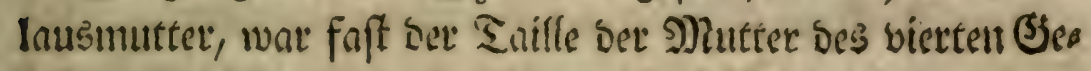
fdjledt) glesit), bie jlu ebent ber Beit eingefefet wat.

\section{Secfsites (sefdilecht.}

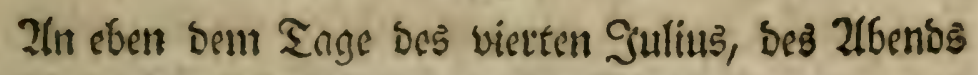

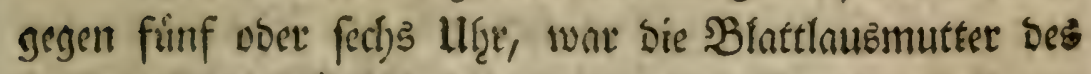

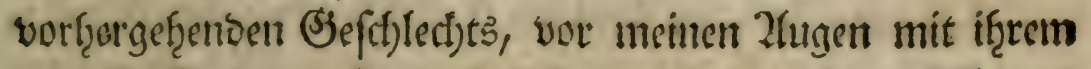
jmenten Sunten niebergefoummen; unto gleich ben 2fugen. blid fergte idf) fie allein; fie lebte aber nut ofrngefáf̨c jwo Sage.

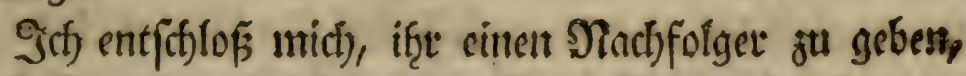

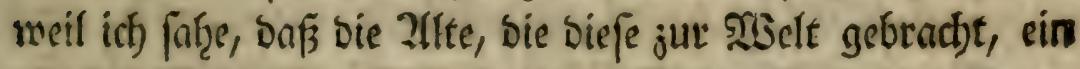
gleithes Schidffal geţabt hृatte. Einige Sage vor if̧rem Sooe mat fie feţr untufig getwefen; fie lief unnufgeorlia von ciner Seite jut anoctu, als roenn es if̧e an Draf̧rung

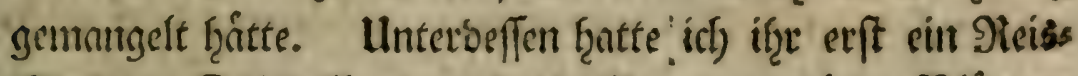
d)en voin Spindolbanme, mit vollfommen grưmen Blattern gegeben. Ja) muite arfo anbere SBlattlaufe nef̧men, bie

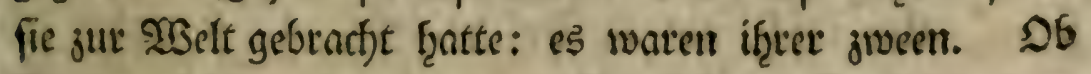
fie aber gleich) autd) mit cinem fef̧r faftigen Brveiglein vet; forgt waren; fo ftarben fie beffen ofgnetactetet. 


\section{Beobarftungen úber bie ß̧lattlíuje.}

\section{Şunfte Beobat)tutty.}

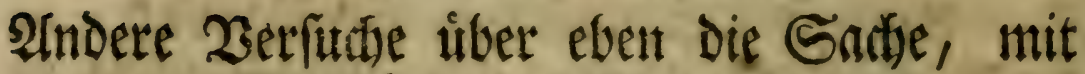

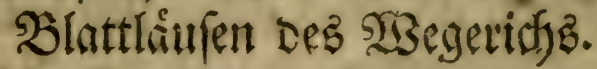

S a es mir mitten in Sonmmer, als idf mirs ant wentige

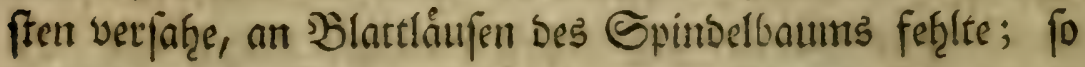
wanf idd meine Zlugen auf eine anbere Zlet, Die fich on bie

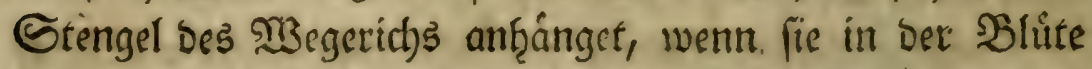

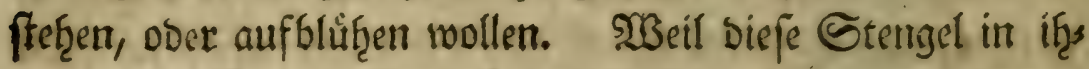
ree gan jen Långe bollfformmen glatef find; fo faum man baran

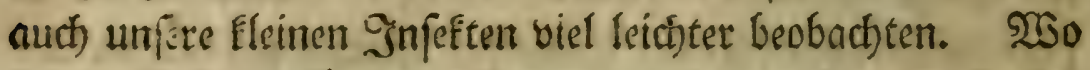

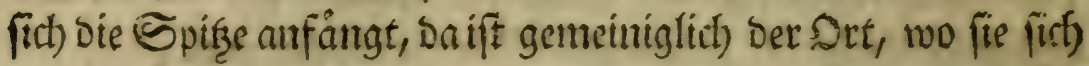

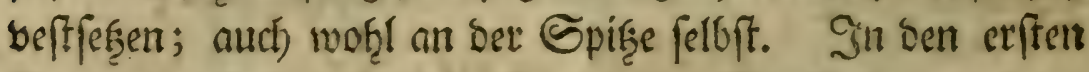

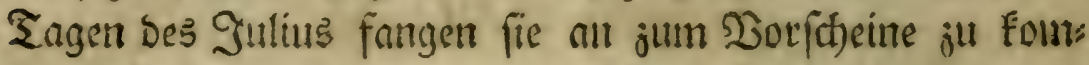
ment, D) uno finto bis gegen bie splitte bes Eeptenbers aflis genein. Sim áuffertititen fint fie ben Blattlaufen des

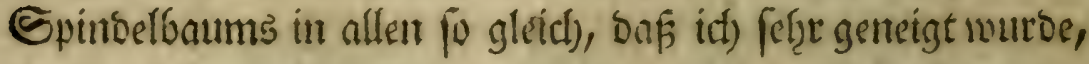

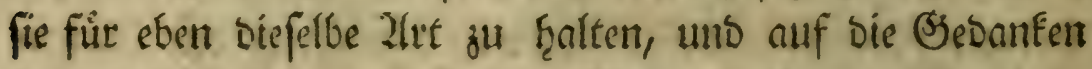

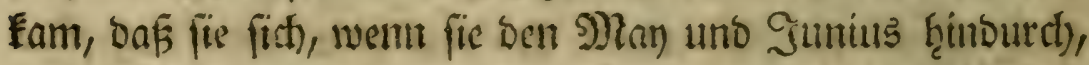
auf bem Epinbelbaume gelebt ţấtten, (benn um dieje Zeit

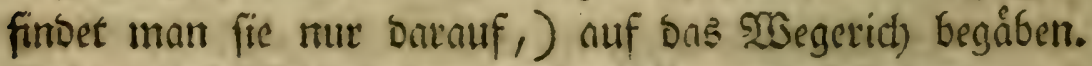

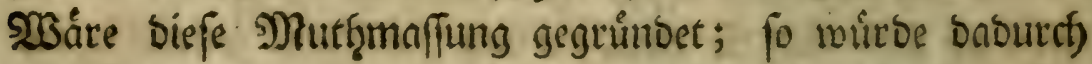

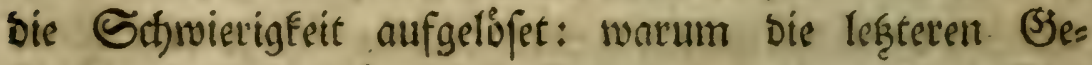

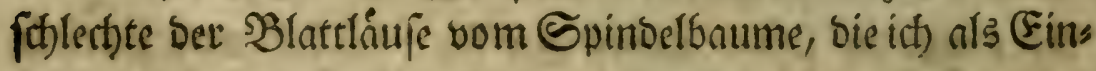

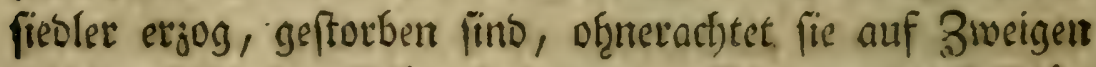

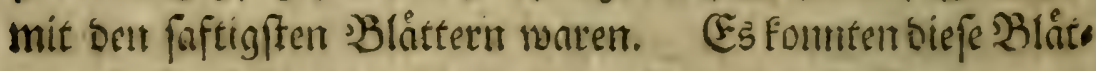
ter, of fie gleich) Dem Znfefęen rnady in gutem Stantoe was

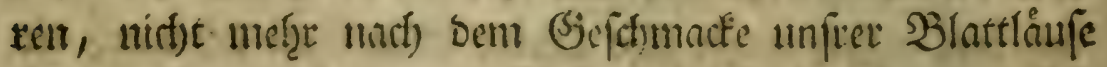

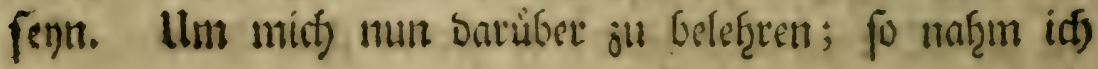

mir

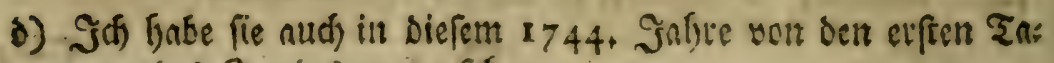
getl ocs Juniuz an, gefefon. 


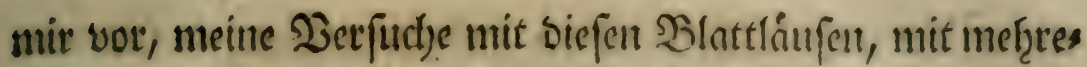
rer Sorgfalt, wieber anjuffangen, uno Die Đrobe ju mackent,

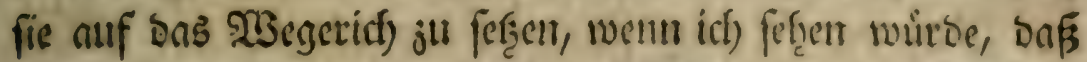

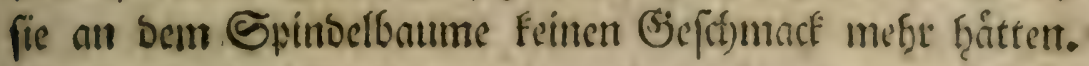

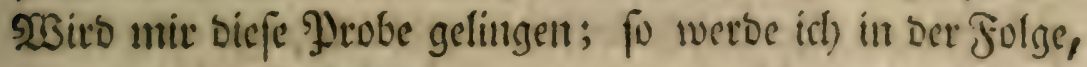

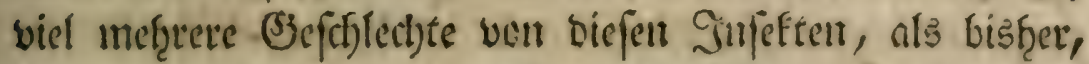
allein aufjieferen fionnert. In siefer Errwartung aber, bis

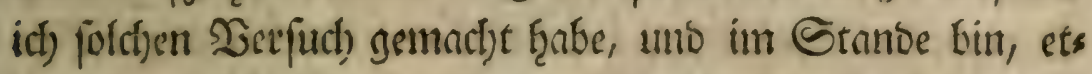
svas ju entfryeiben; will ich) bier bas Tngebudf) meiner

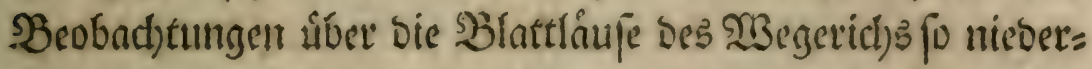
f(t)reibert, als went fie mit benten vom Spinberbaumenictfts gemein f̧âtten.

\section{(Exiftes (3e) d)}

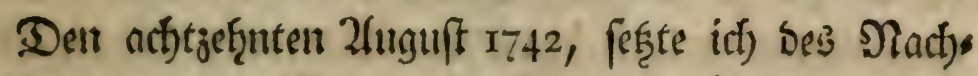

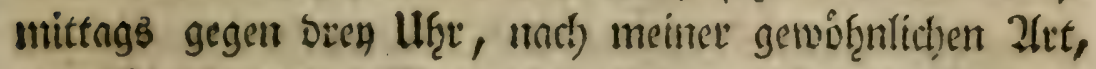

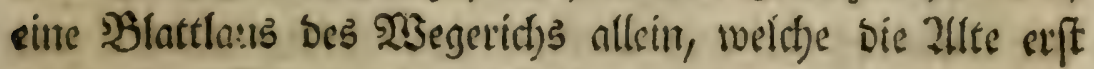
vor meinen Zlugen geboren fratte.

Das Thermouteter war fumfjeşn Örno.

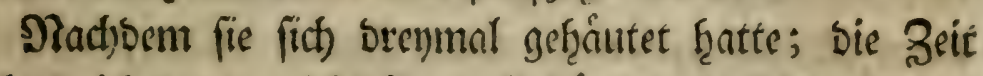

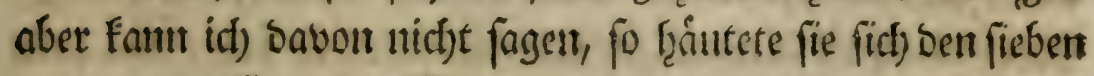
uno jwanjigftet, bes Mlorgens gegen ad)t Uther, zum viero tenmale, unt gegen jwell llţe war fie Mutter geworbent.

Den fünften September f̧atte bicfe Blattlousmutter forton bier uno funfoig Juntge geboren.

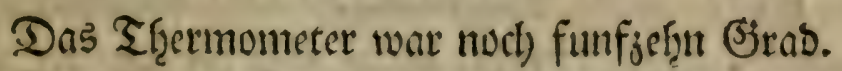

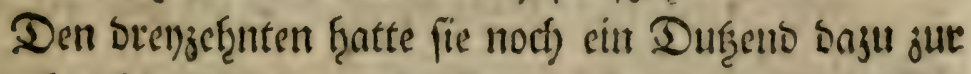

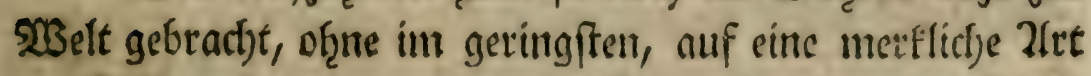
an Dif̛e abgenommen ju fraben. Dies war aber bns

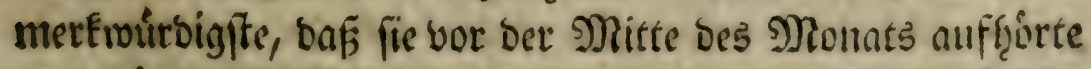

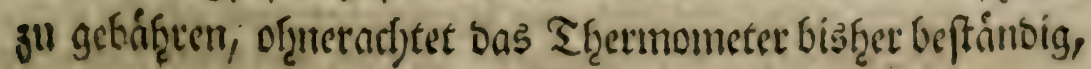




\section{8 Şeobacktungen uீber bie Slattlåufe.}

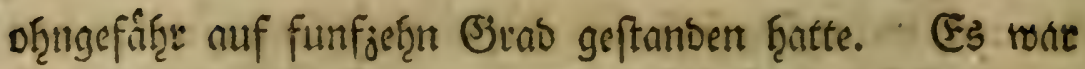

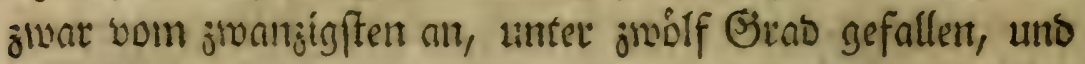

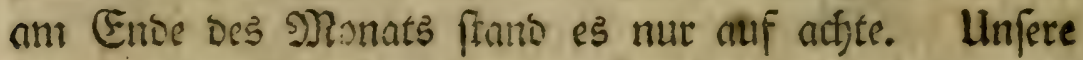

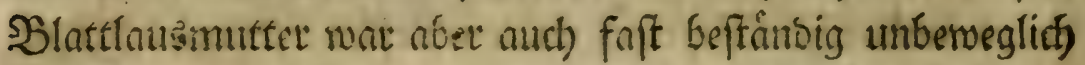
geblieben; fie hatte fict) an Den Trbegeridffftengel angeflams

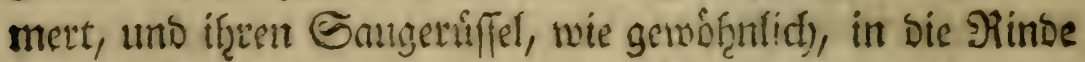

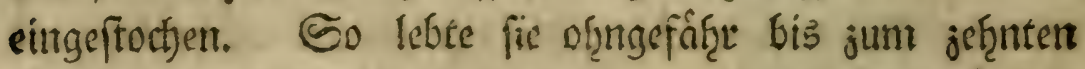
Detober, sa ich fie tobet fand, Don fie nur nocis mit Ser aullf(ers

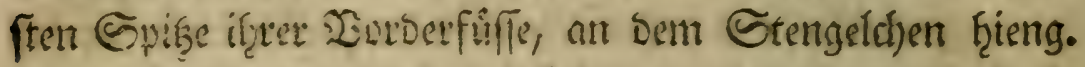

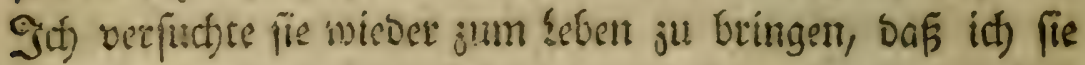
an cinen noutren Sor trug; es war aber vergeblitf). Ulns

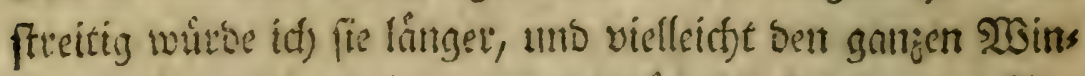
ter Durdf, exţa:

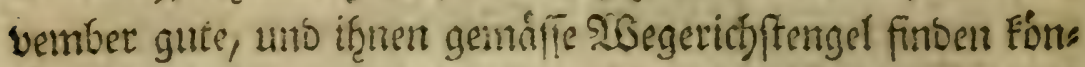

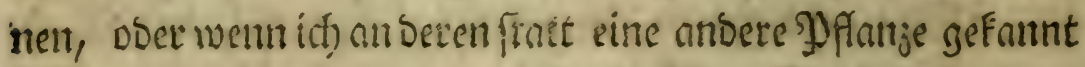

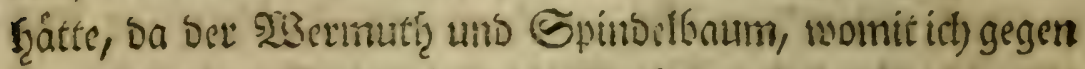
Das Entre bes Septembers bie Yyrobe mattete, als mir Das

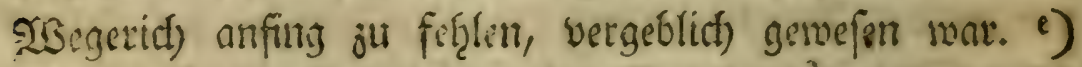

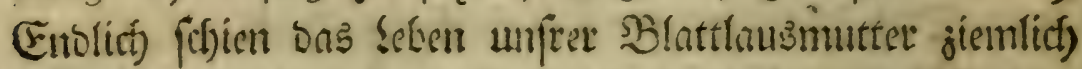

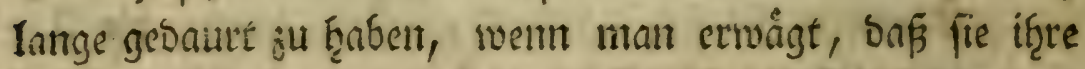

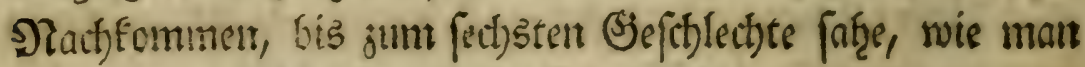
in Der Folge biepes Gournals finten wiro.

\section{3wentes (seferdeled)t.}

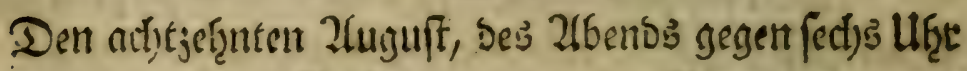

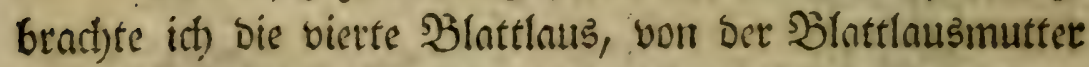

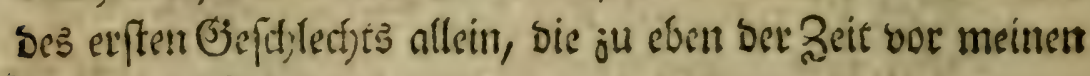
Zlugen geforent war.

Sie

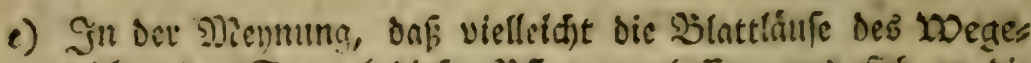

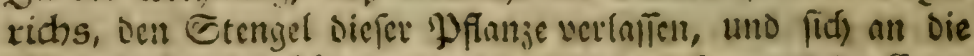

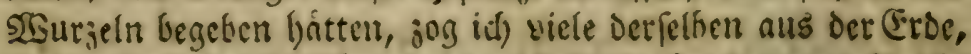

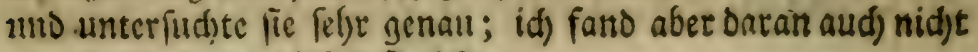
ein einjiges von diefen Jnfetten. 


\section{SBeobactytutgen tifer Die 23lattläufe.}

Eie fratte ben fünfren September, bes Mors

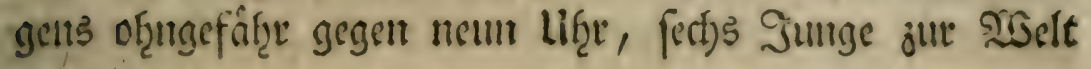
gebract)t.

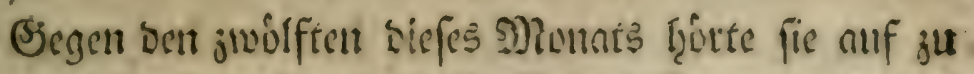
lebent, nacljocm fie nod) ein ţalb Scljock Gimnge ans, sidf)t gebrad)t f̧atte.

\section{Drittes (seldi)lectit.}

Den bret)jefrnten biefes 9)?onnts, war bie fiebente

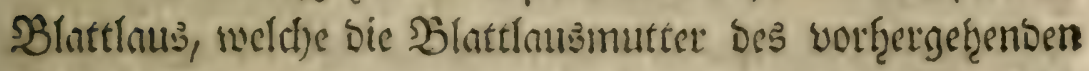

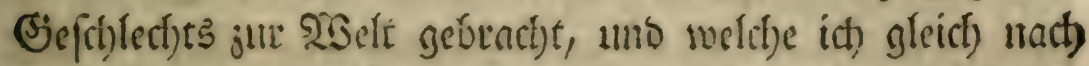

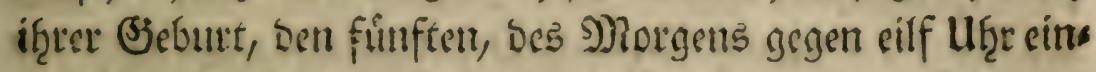
gefergt frotte, mit vier Stungen niebergefommen. Sie war

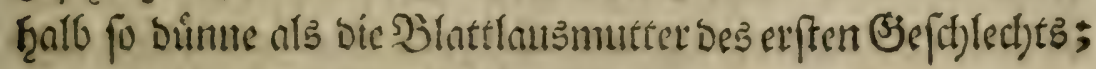

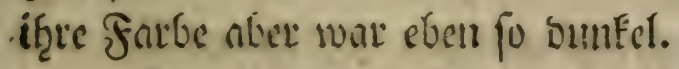

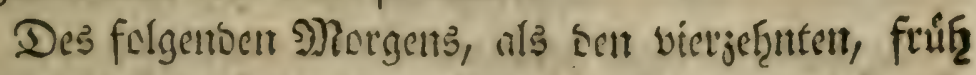

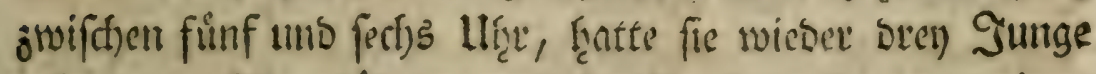

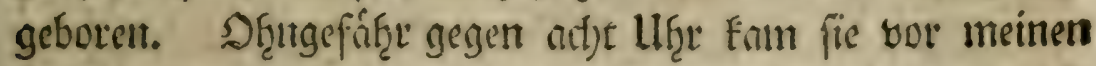
Zlugen, mit bem adjetn uteber, welches ich alfobald in bie Einjamfeit fofictete.

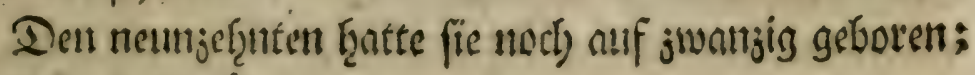
tzernact ftarb fie. f)

\section{Bierteg (scrdilect)t.}

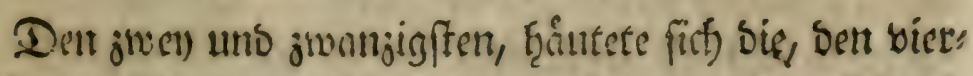

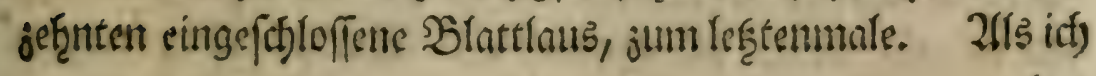
ben

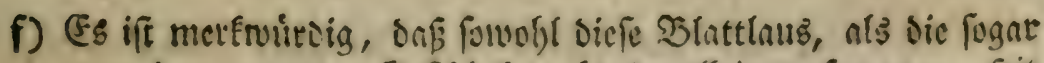

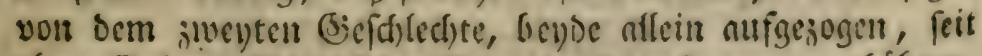

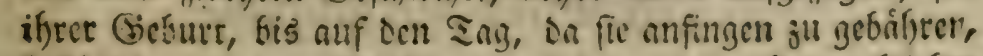

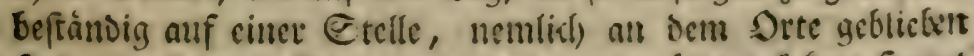

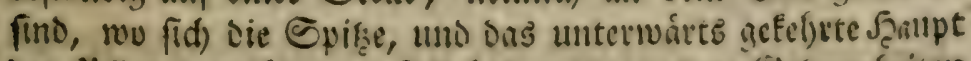

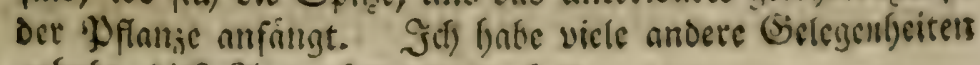
getbabt, Dicfe 2lunertung ju madjen. 


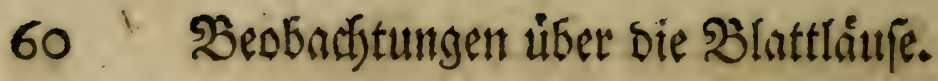

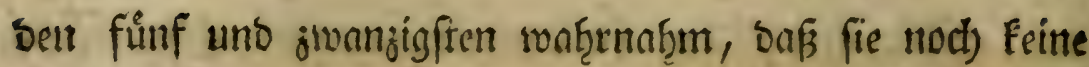
Siunge geborent ḩatte, ofenerechtet fie foft fo bicke, als bie

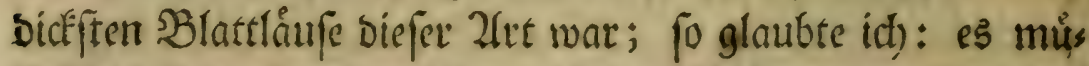

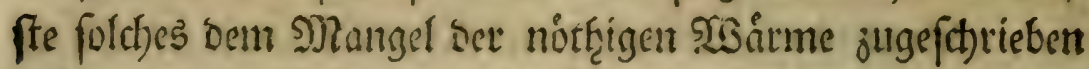
werbent, on Dos S Thermometer in meinem 3immer, feit Den orely und jmanjigften, of̧ngefähre nur auf act)t bis neun

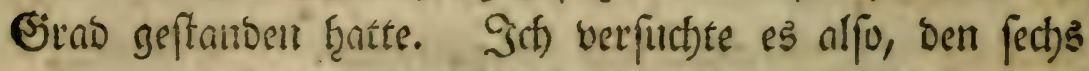
anto zwanjigftem, meine SBlattlaus in einen 2tbjoblag ju tras gen, Der f̧inter cinem Camine bey ber Rúche angebradjt

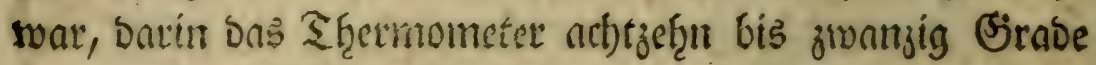
ftano. Dafelbft lief ich) fie biefen und ben folgenben Tag Des 20 ormittags sine Beitlang fref̧en; Die úbrige Beit bon

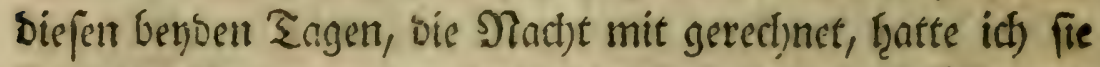
in einer Rammer, wo sas Thermometer of̧ngefáfict jef̧n

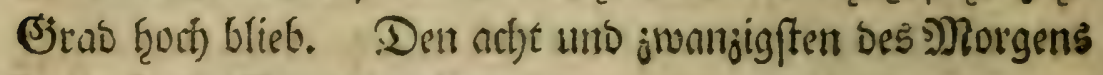
batte fie ein Santiges geboren.

Den brenfigiften Des Morgens ḩatte fie beren fect)

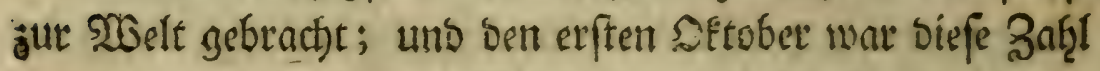
mit brenen vermef̨ret. Şis Ģief̧er lief ich fie in ber ets soáf̨uten Rammer. Ifn bemfelben Tage aber bes erften Detobers, trug ich) fie wicber in meine Stube jurick. Da Fam fie nicht niteber, wie ist) es vorther gebadjt ḩatte, unb lebte Gier feloft nur einige Tage. SInbeffen vermuthe

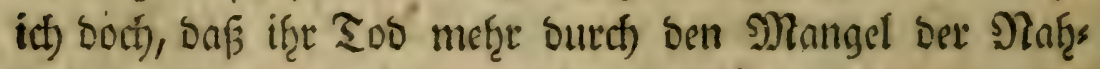
rung, n/s burd bie verminderte 23 situne if veranlaffet wotbett.

\section{Fünftes (5e)}

Den ad)t unb jivanjigften September, bes ßormits

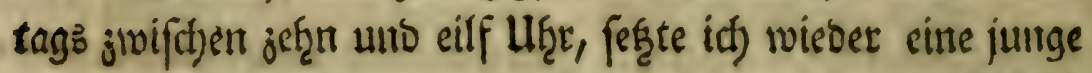


62 Bెeobadjtungen úber bie Blattlåufe.

\section{Sed)ste Seobadtutitg.}

\section{2(ndere uiber eben Die Sadue, mit Blattláufên} Dez 23 egerict)s, angeftellte, uns noch weiter, als Die vorfergetemben getriebene Derjuche.

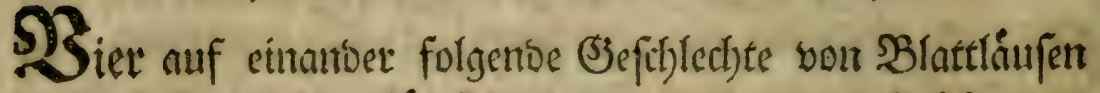
bes fliteberbaumb, finfe bes sisegerichs, unt fectje voin Spindelbaume: alle in ser bollfommenfiten Einfamfeit

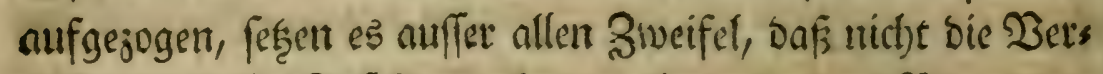

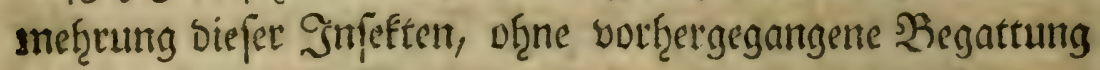

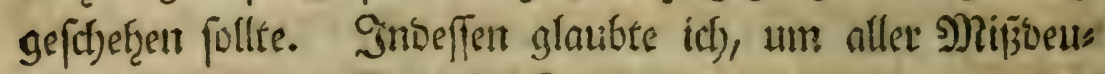
tung vorjulbengen, in biefer Sache noch nicht genug gethan

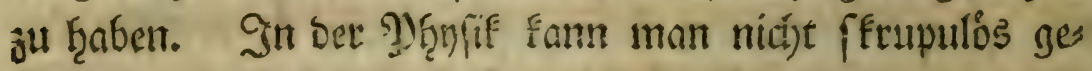

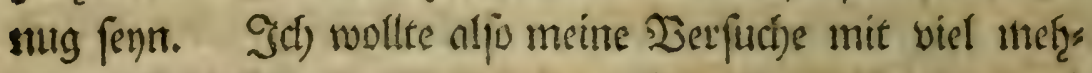

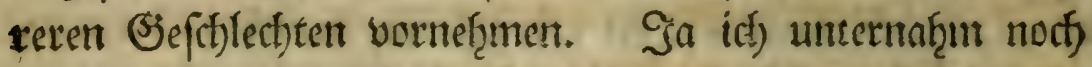

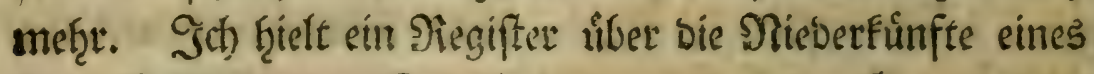
jeben (Befft)led)ts. Sict) that es mit ebent Der Bennuigfeit,

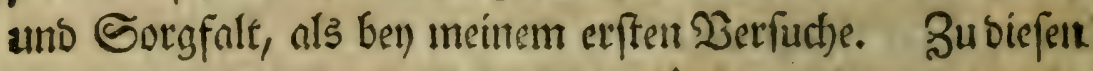

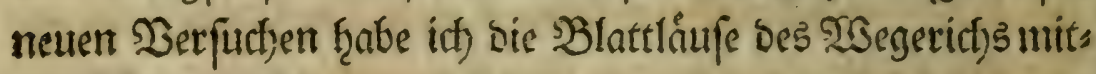
gebrautht. Sie wurber aber ef̧er als bie nngefangen, von welthen in Der vorţergeţenden Sbeobart)tung geţants Delt ift.

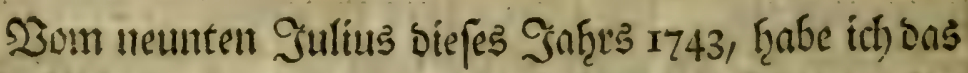

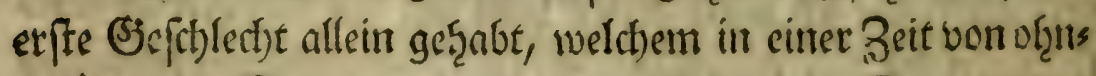

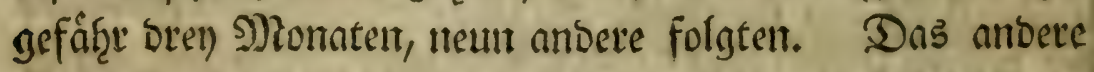

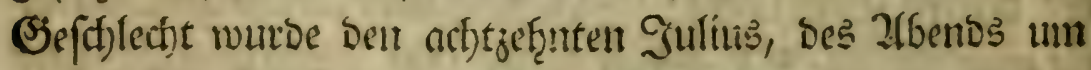

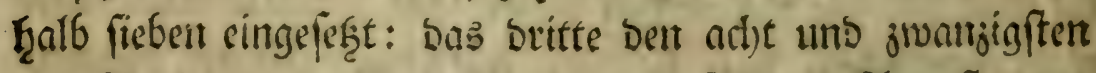

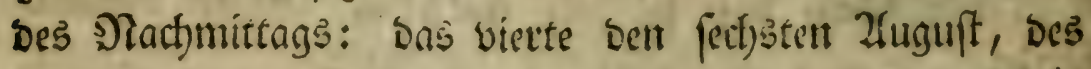

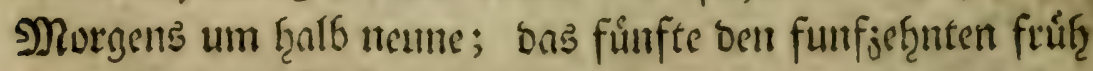
Drenviertal auf ferbfe; Das ferfiste ben been und jwanjigftent כormittags ein Siertel auf jublfe; Das fiebente Dent eit 


\section{4 ミeobachtungen ưber Die SIattlåufe.}

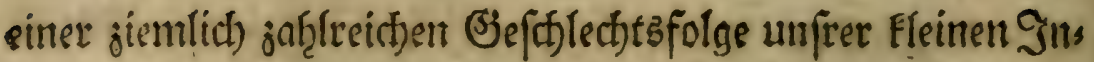

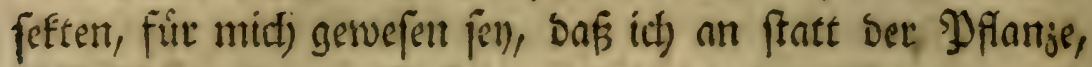
auf ber fie cine gemiffe Zeit gelebt, unbefernach) baran ben

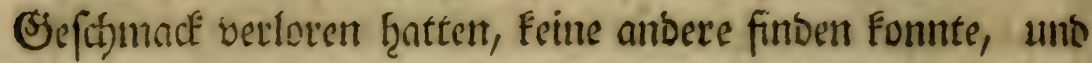

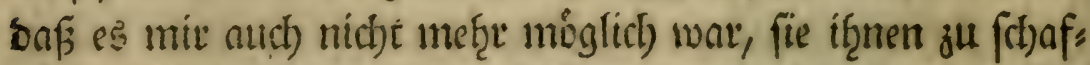

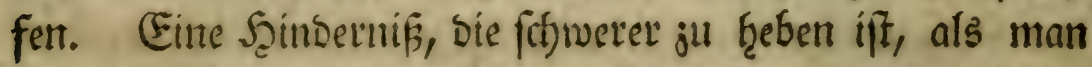

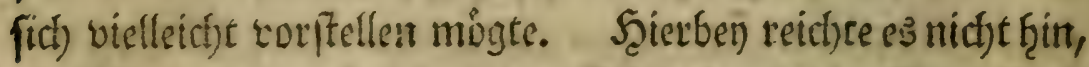
zu wiffen, baf biefe, ober jene פDflanjen gleiche Eigenfichafe

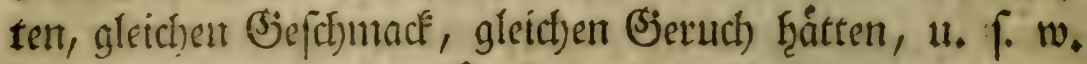

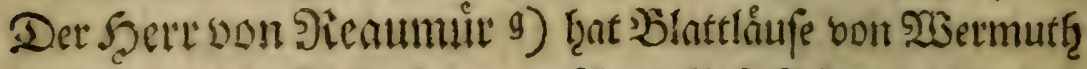

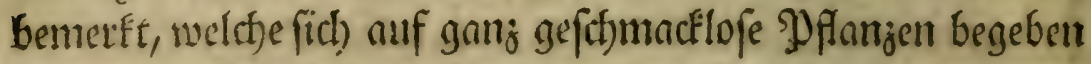
hzatten. Dies frat ifrn bervogen, mit Eitunte ju fagen: es

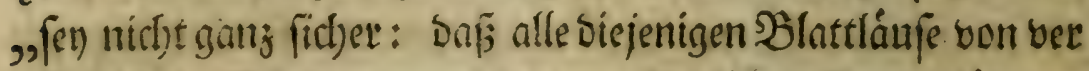

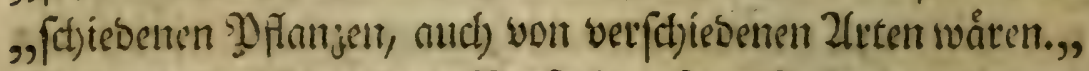

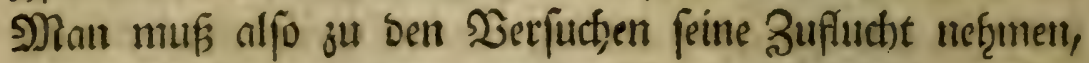
unb bamit bis auf sinet gewiffent Dyunct abivedjęln. - Ein

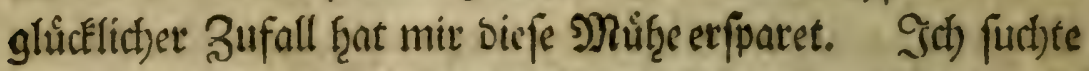

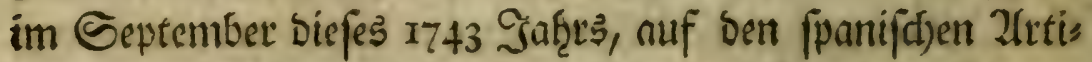
fhocken eine Dorntaupe, von weldher ber Sherr von Sieau= muir b) getedet, und bie er mit Bárenflaudifteln, *) gefuts

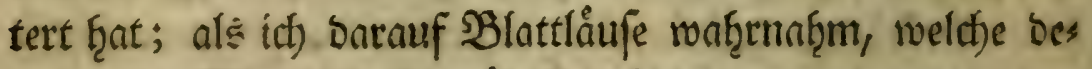

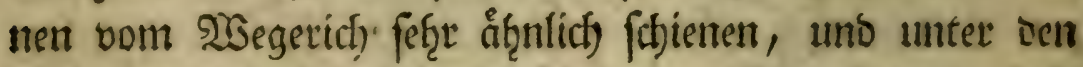
Blättern biefer 2irtif(t)ocken faffen. Dies bracl)te mich)

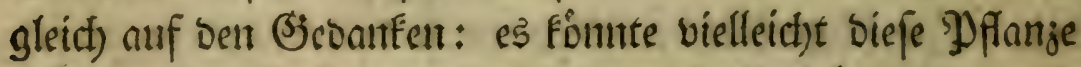

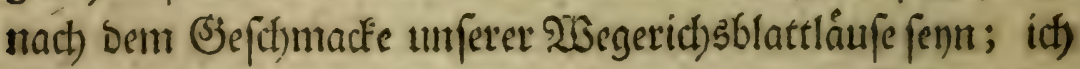
faumte nid)t, Damit bie झlyrobe zu mad)en; Der (Erfolg aber

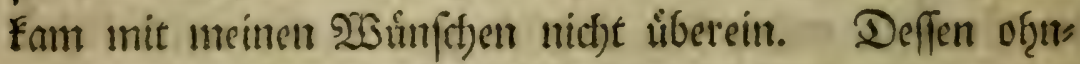

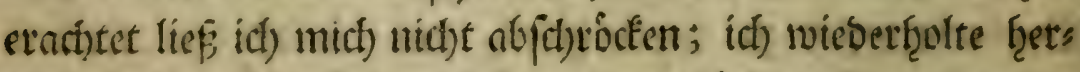

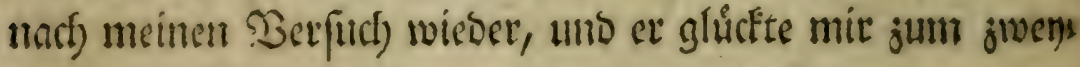

n) Mem. pour l' hift. des Inf. Tom. III. p. 286 .

b) Tomi. I. de fes Mem. p. 428.

*) Carduus acanthoïdes. 


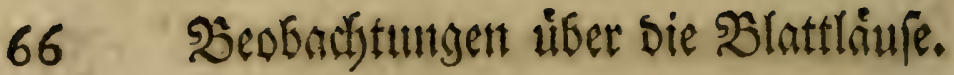

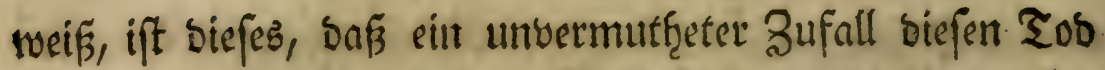
woţl nidft verurfacl)t ţabe. Dem fẹy mut, wie if̧m woolle;

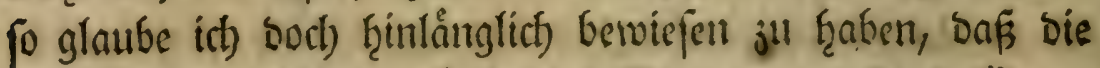

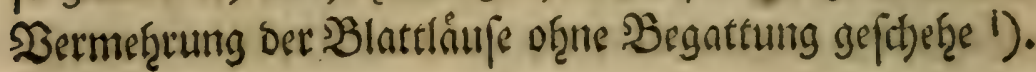

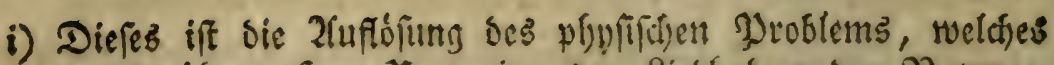
Der berififmte Serr 25reynitus oen Rietbabeen Der Siaturge:

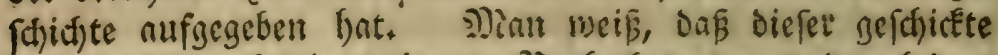
Beobadfer nad) (einen eigenten 23eobaditungen, und nad) dem Zeugnife bes Seertn Ceftoni, anfänglich) geglaubt babe, daß̧ nur basjentige Infett, weidjes unter Den S?amen Graine d'Ecarlate de Pologne, im Sateinifach Coccus tinctorius Po.

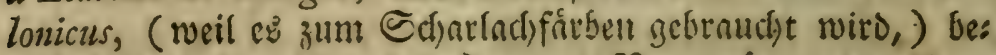

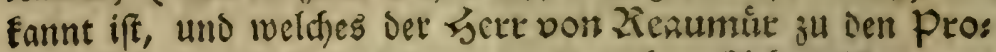
gallinfetten rechnet, Die man wegen iffer Zfefjntidffeit mit oen eigentididen Gallinfetten fo nennet, fid) ofjne Siegnttung vermefre. Mian weis aber aucf), bas cr nad) gennuern כeobad)tungen, als bie erften waren, von diefer פiscunung abgegangen ifr. Diefes beweg ifn, eine problematifde

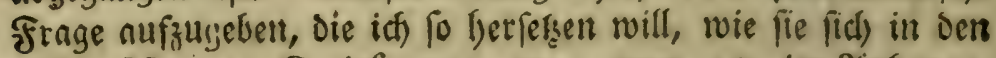
Actis Naturae Curioforum, 1733. pag. 28. im 2intonge, uno in bent Commercio litterario, in oet nnoern 200 dee Deffelben Jabres findet.

"Liceat vero interim hac occafione, fogt f̧ert „5reynius, fequens Naturae Myftis, nec iniucundum, "nec inutile, difficile quamuis folutu, proponere.

Problema plyyscum.

"An indubitate demonftrari poffit, in rerum natu„ra genus aliquod Animalium vere Androgynum, id "eft, quod fine adminiculo Maris fui generis, ova in "et a fe ipfo foecundata parere, adeoque folum ex et „a fe ipfo genus fuum propagare poffit?

- _Genus animalium eiusmodi Androgynum, fert Jeerr 2brevnitts binju, licet a multis iisque primi „ordinis Naturae Confultis ftatuatur, a nemine tamen, "quod equidem fciam, ita demonftratum fuit, vt non „multa, eaque haud leuia, ei polinnt obiici dubia., 
Sollte mant aber, of̧neract)tet fo weit getriebener Ders

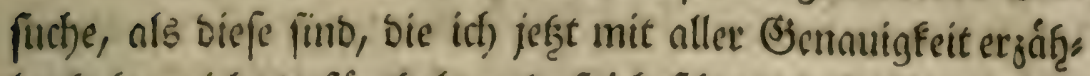

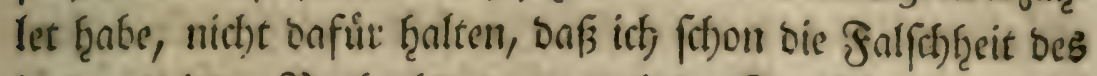

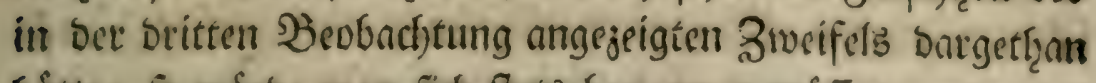
Gritte; fo wúrbe man fid) frets bequemen muiffen; entweber

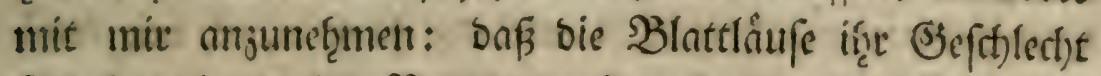

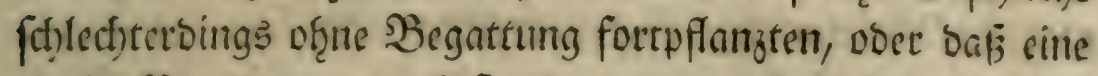
eingige be egattung, menigftens ju newu nach) einanber folgent

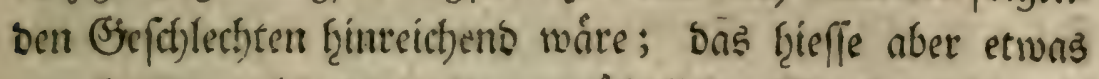

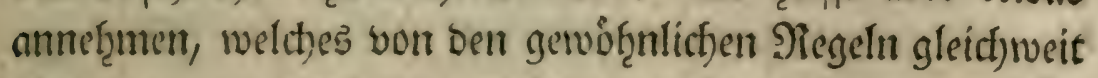
abgienge; wo das lefeftere nicf)t gar viel weiter bavon entfers

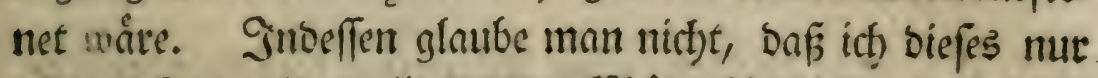

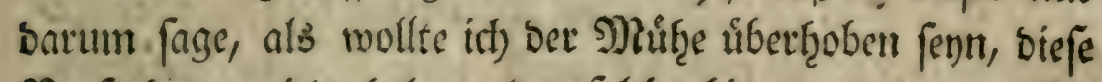

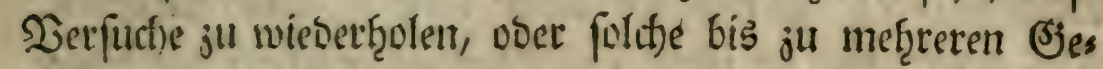

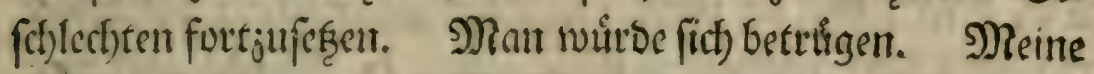

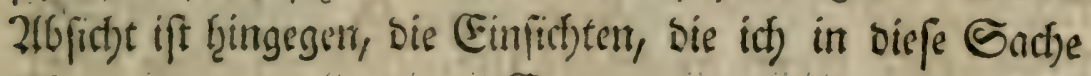

E 2

erţal:

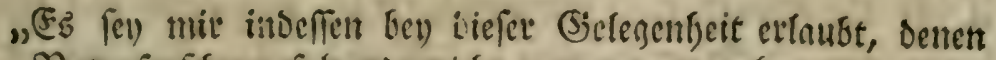
„) Naturforf(f)ern folgende nicl)t gan

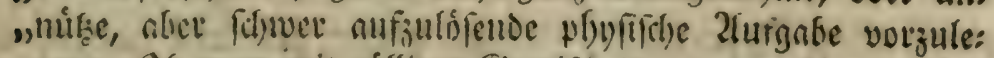

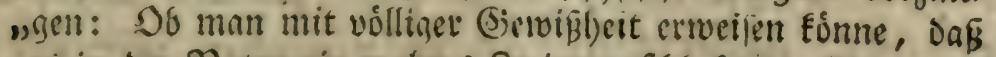

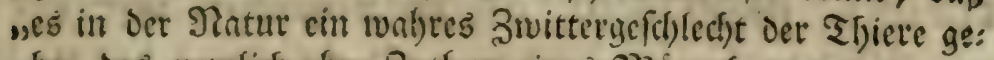

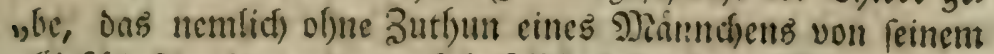

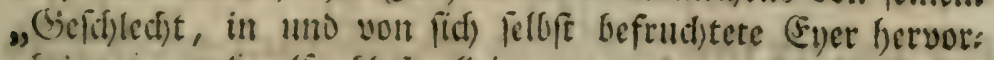
„bringen, unto nlfo blop allein aus uno von fidd felbfe fein

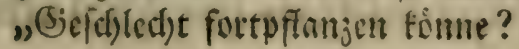

- - "Obigleidf wiele Raturfunbiget vom erfen Piange

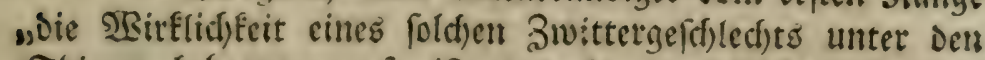

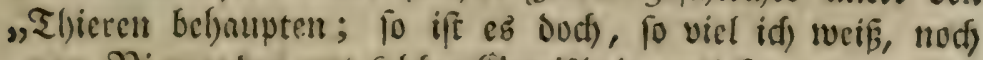

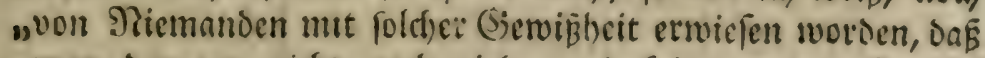
"man Danegen nidjt nod) vicle, uni feine geringe Salveifer „mađijen fómte. "

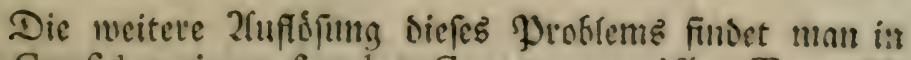
Den Confiderations fur les Corps organifés. Tom. II. p. 99 f. Heb. 


\section{Beabad)tungen ùver bie Blattlåule.}

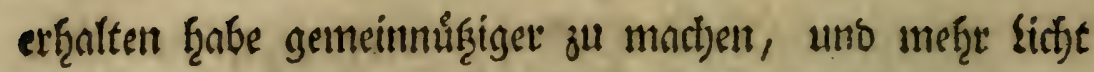
Daruber nusjubreiten. Sids felbft aber verjweiffe Daran gar nief)t, Daf es mit nichtet gelingen follte, biefe fleinen Sins feEten renigftens bis zum brenfigiten (Sefd)lechte alleun auf:

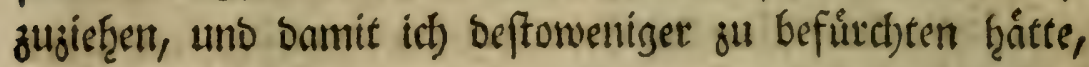
if̧er unberfef̧en bernubt jul werben; fo maf̧m ich mir vor; mę̧rete 2lbformmlinge von einer Mutter auf einmal sinjus

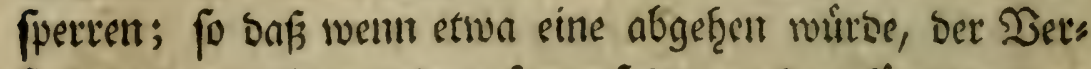
fuch) boch mit eiter anbern fortgeferet werben fonnte; unb

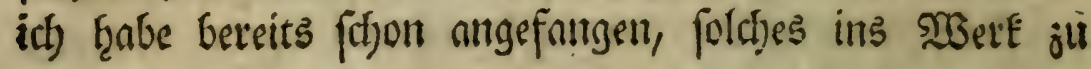
ricteter.

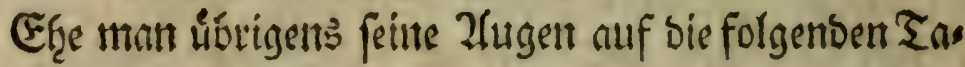
bellen ridjtet; fo will idf noch brey Stúcfe anfüferen.

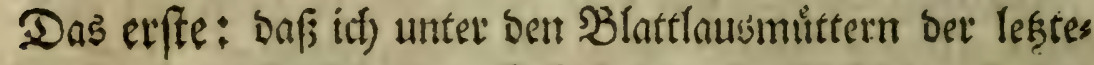

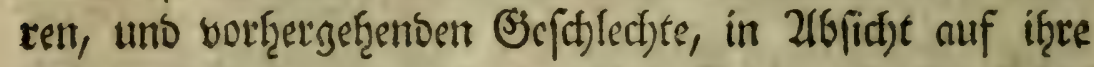

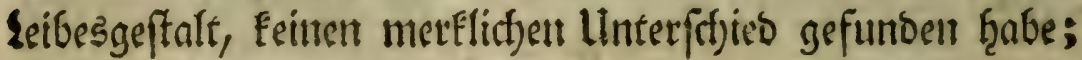
nusgenommen was bie Bieftalt ber erfteren betrift; Die an Didfe bie andern weit genmg uibertraf, unb nuth biel fruchts

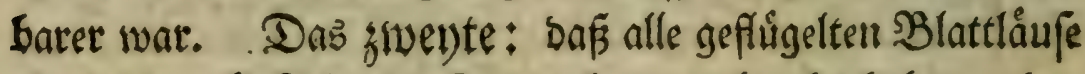

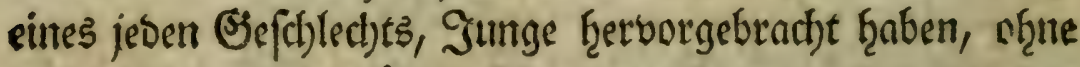
baß ich fie jemnals f̧âtte, fich) untereinanber, ober mit ben ungefluggelten begatten fef̧en. Das britte: Daß̧ if̧re 2lits zabl merflic) Fleiner, nls Der ungefligelten gewefen ift, ins

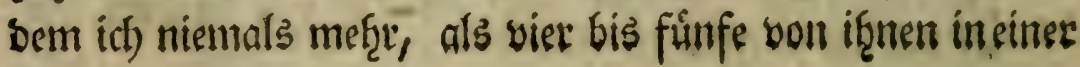
Samilie gefeţen f̧abe. 


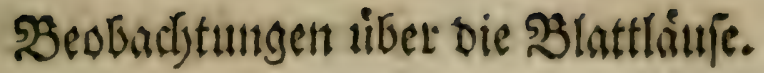

\section{Tabelle}

Der Gieburtatage and Stunben, Der voin adjt;efnt= ten Juliub, bis junt fiebenten 2 guff, inclufiwe,

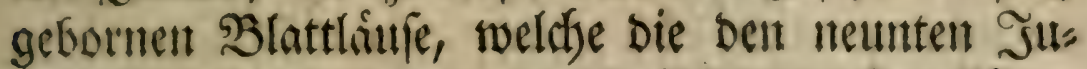

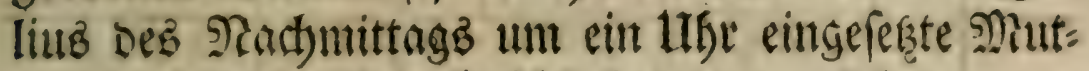
ter Deb erifen Gejhlechts erzenget hat.

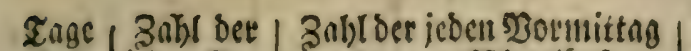

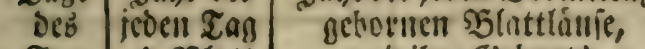
Ill= geb. Blatts und ilsec Bebuttg= thiแb.

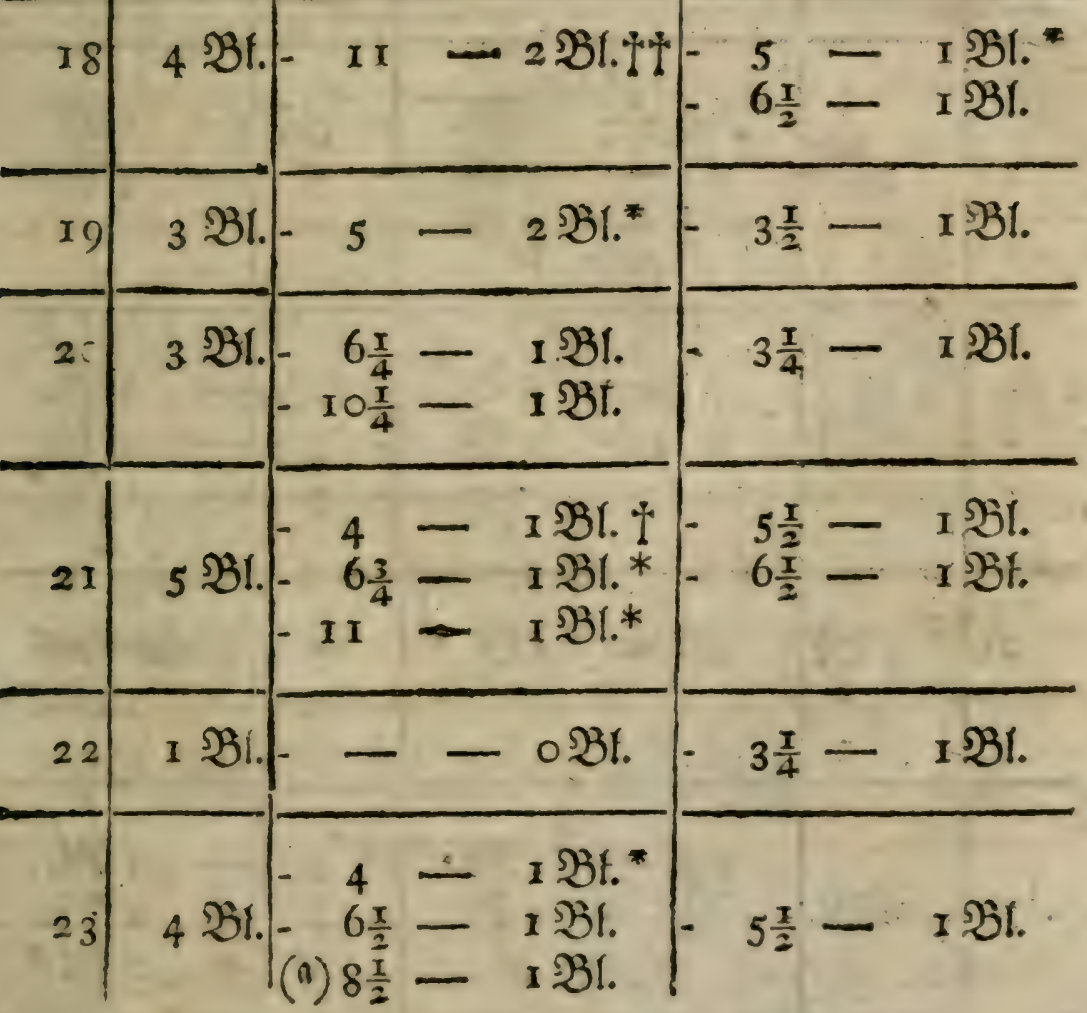

Sabi ber jeben Mact)mittag Bebuenent sblattlánie, unto ibec (seburtso phunber1. fitunder. 
70 B̧eobachtungent itber bie Şlattlátle.

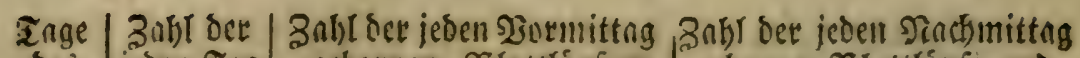
Des jeoent Trig gelormen SIattlálle, Ttt: geb. IJlatt= und ibee Gellurts: İแI. láuie. fitmoen. geburnen DSlattláule, und ibte Gebutts: fituiden.

242 2B1. $-8 \frac{\pi}{2}-1$ BI. $-4 \frac{3}{4}-\mathrm{IBI}$

25 3 $31-4-\mathrm{IBI}=4-\mathrm{IBI}$.

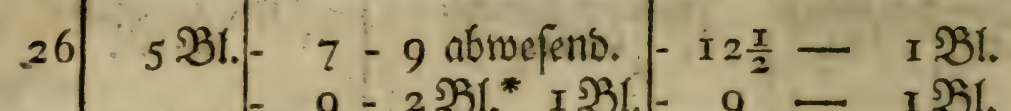

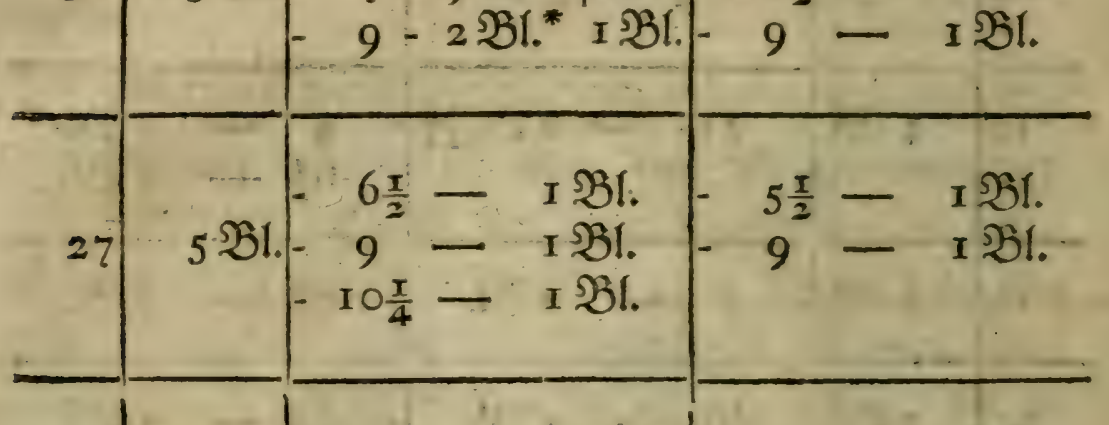

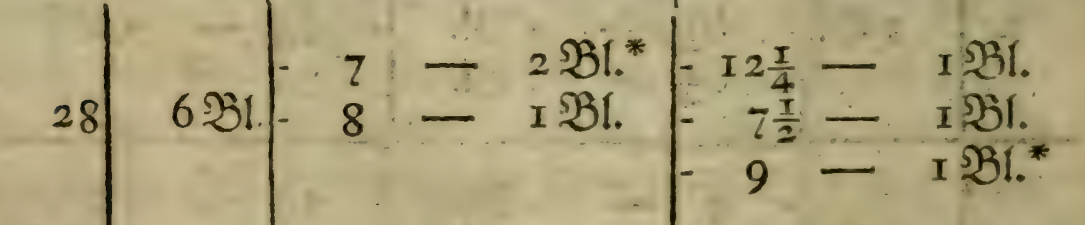

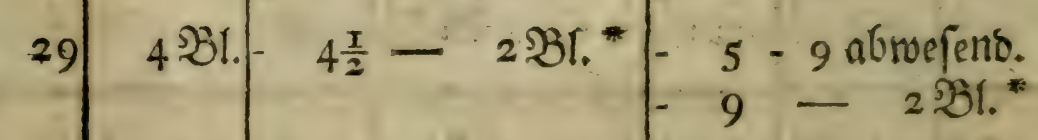

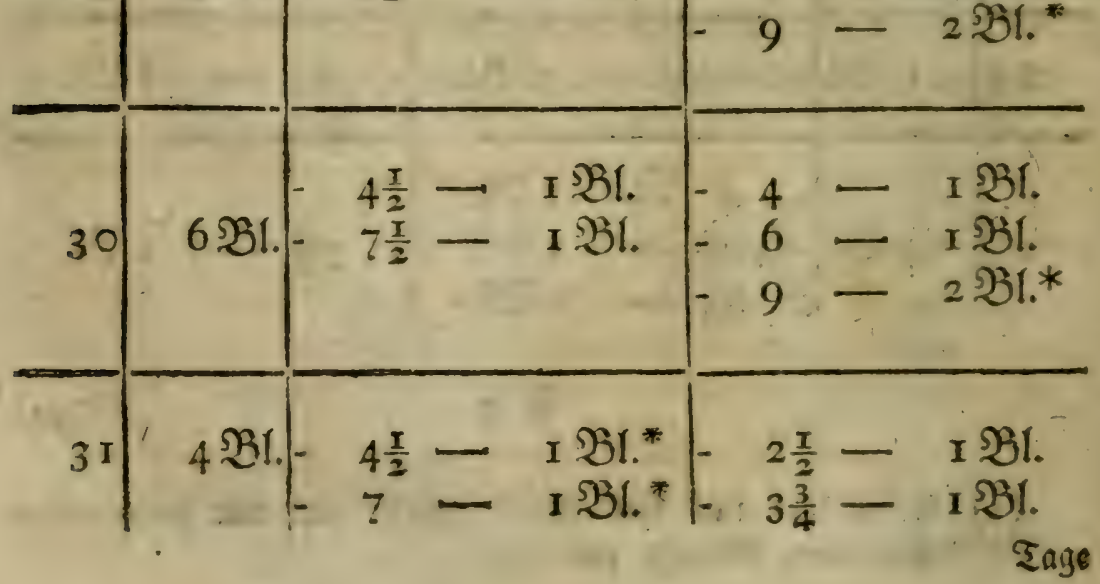




\section{Şeobadjtungen tiber bie S̊lattlåufe.}

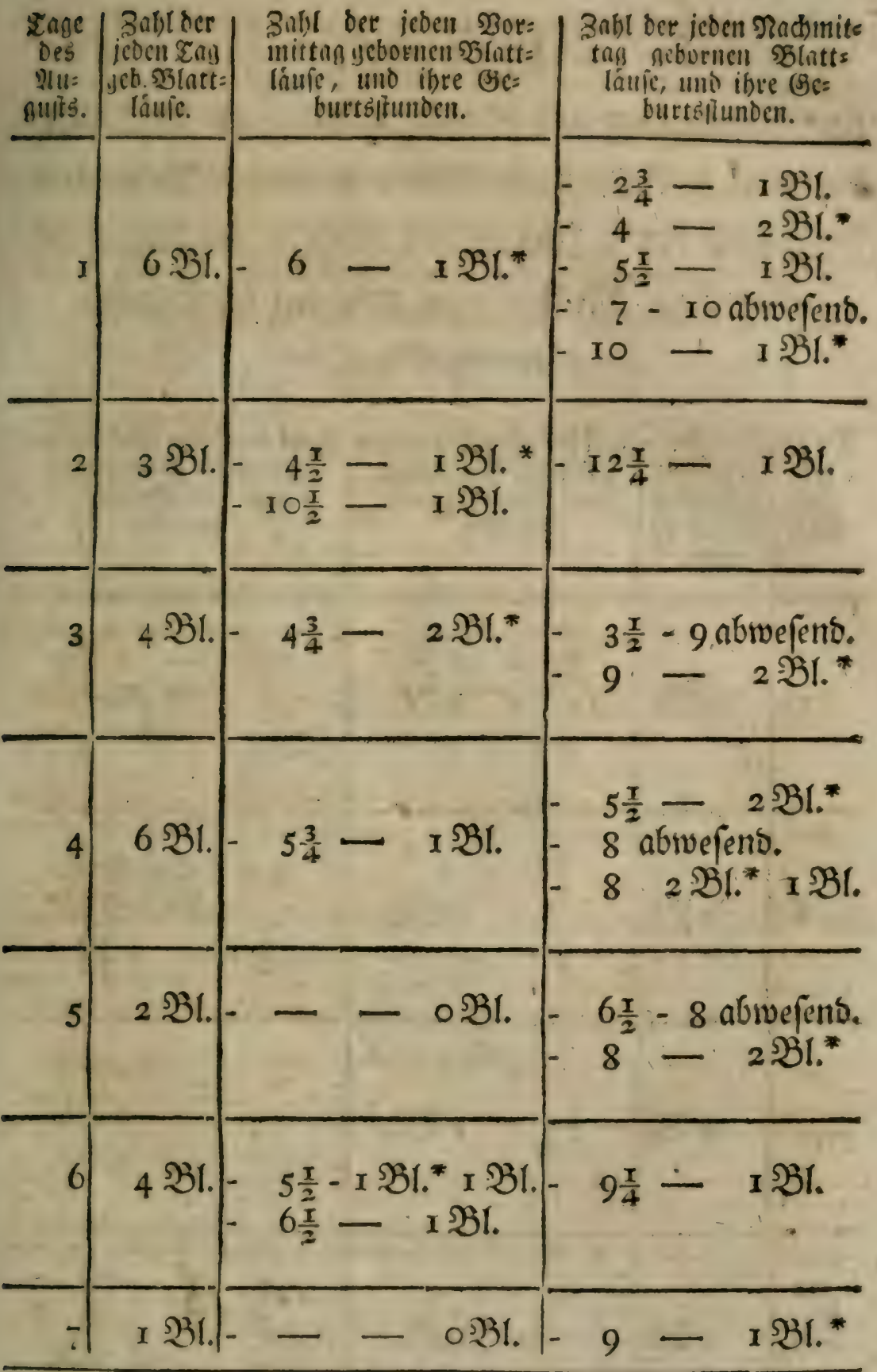

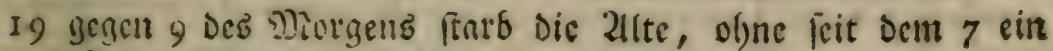
Junges neforell zu baben.

Sange Summe 81 Sblattåule. 


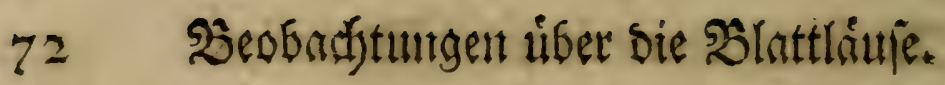

\section{Tabelle}

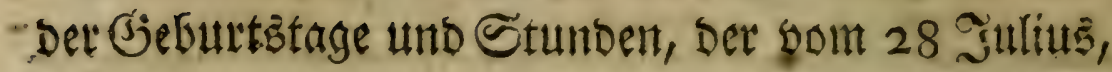

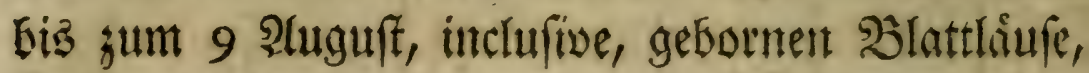

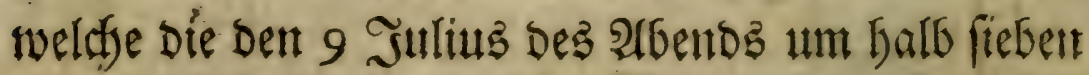

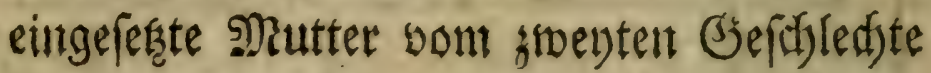
ergetrget hat.

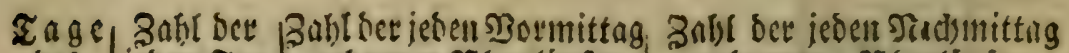

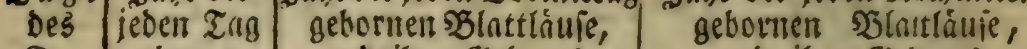
Su= geboenten unt ibre Bekutts= und ibre Besstrts= lius. $\mathfrak{B}$ I $\mathrm{t} t \mathrm{t}=$ fitundert.

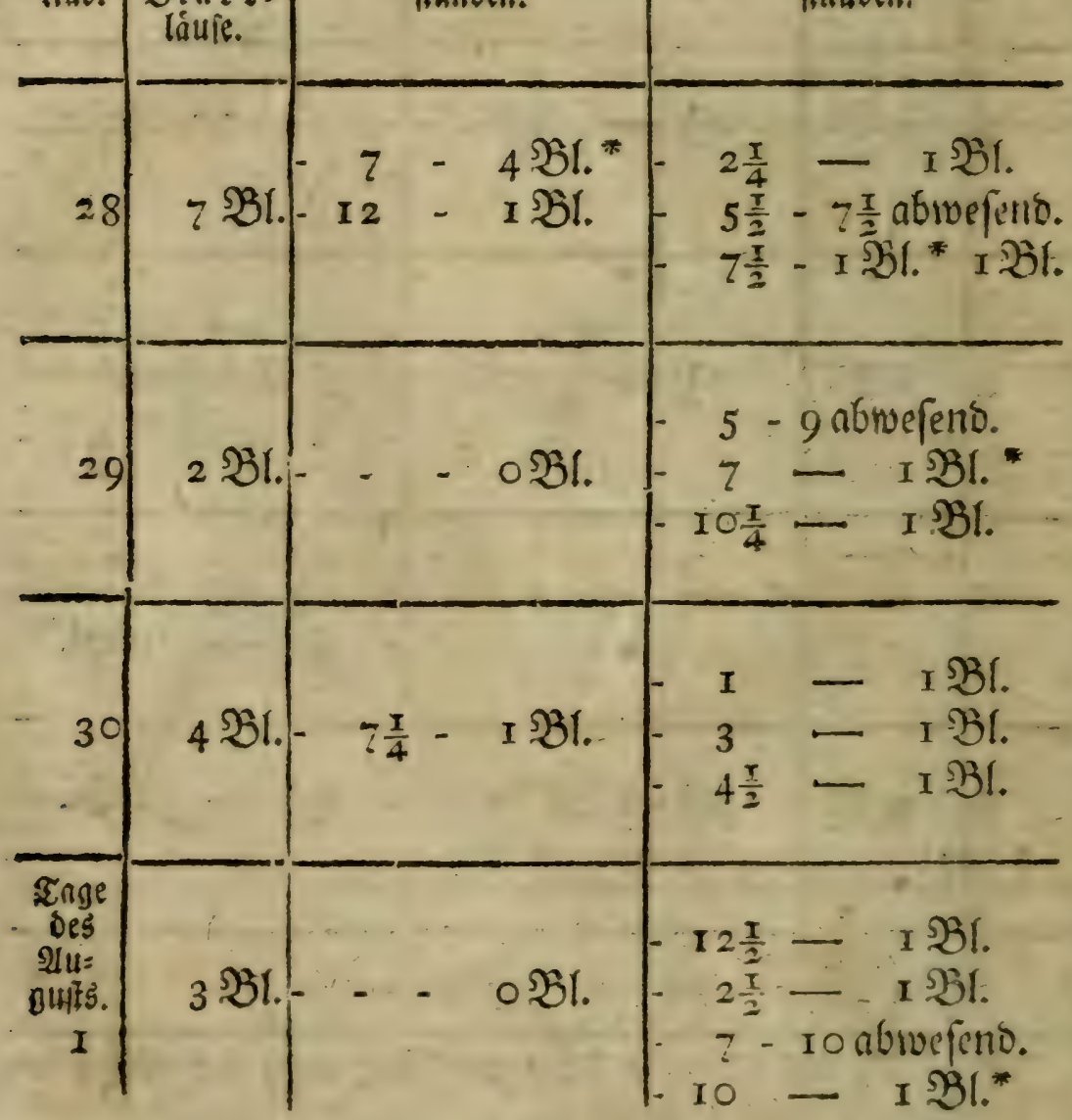




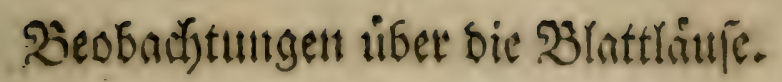

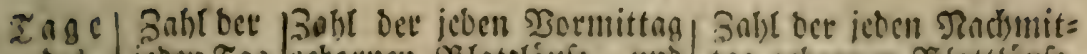

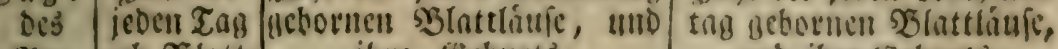

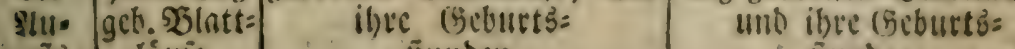
ตแกเร låuic. inulioen. ilumber.

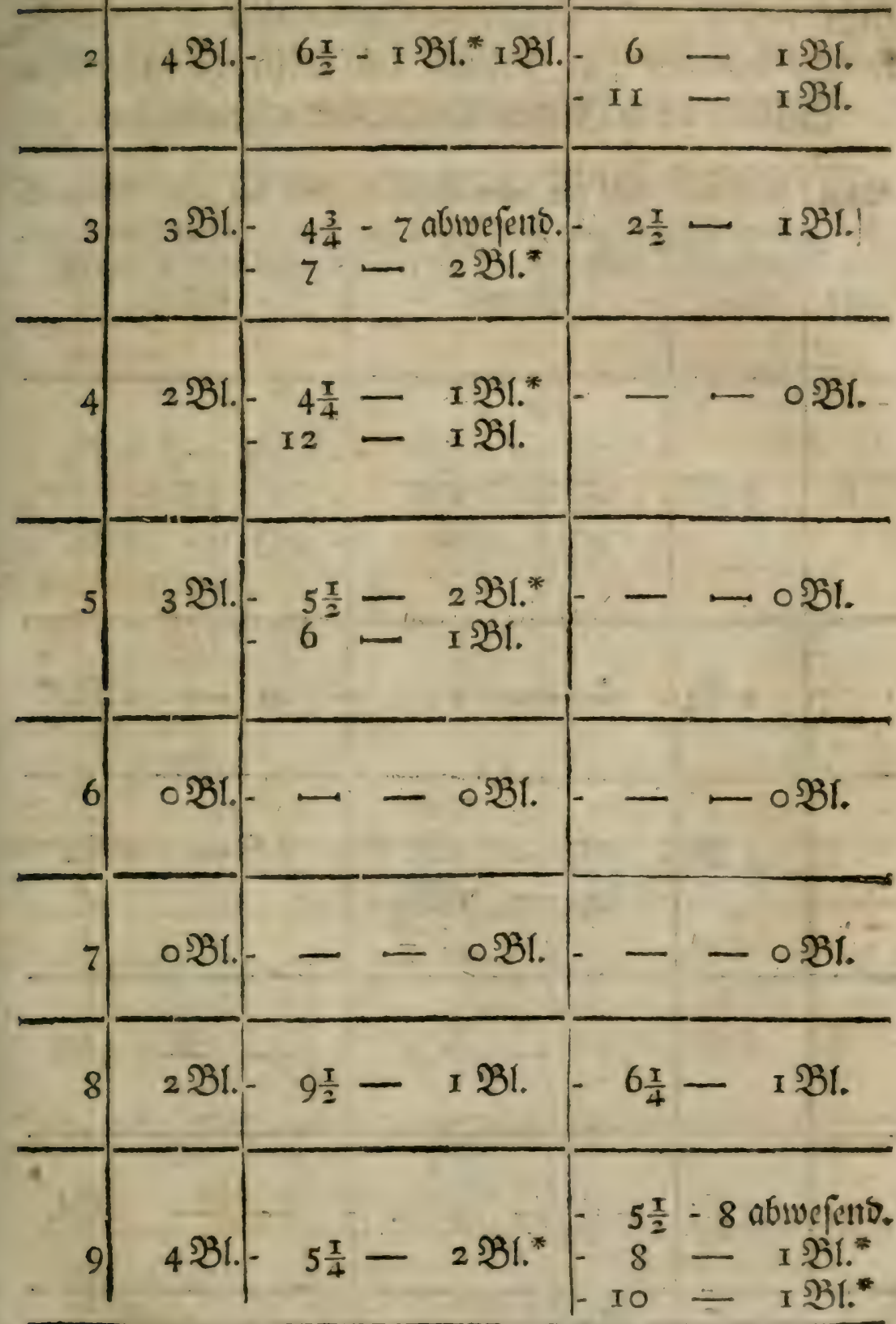

Durd) einen Zufall frarb dic 2lite.

Ganje Summe 38 Sלlattáme.

$$
\text { E. } 5
$$

Tabelle 


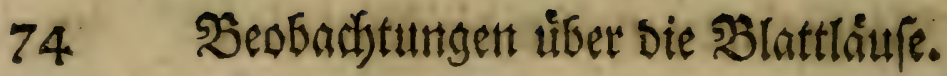

\section{sabelle}

Der Geburtstage unt Stunden, Der bom 6ten bis gum 10. 2luguft, inclufive, gebornen Blattliufe, twelche Die Den 28. Julius, Des Mrittags eingeferge 5i)iutter vom sritten (jefd)lechte ergeuget hat.

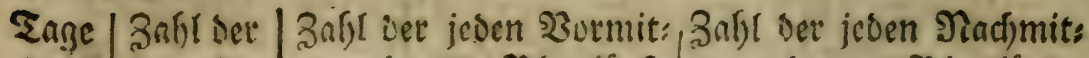

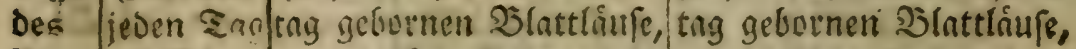

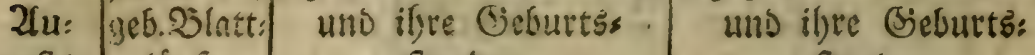

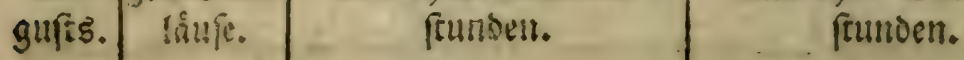

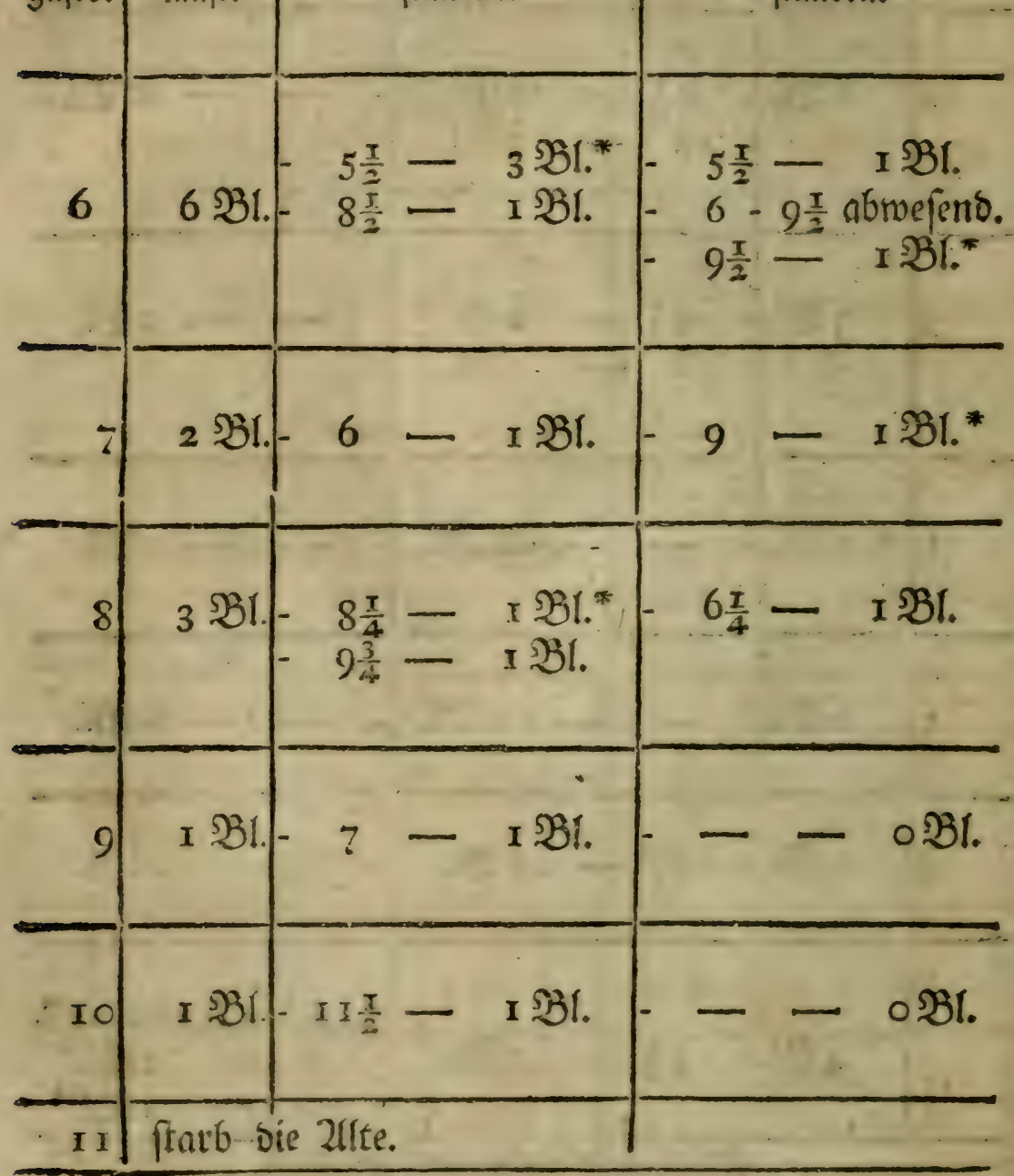

Ganje Summe 13 Slattíüle.

Es Eelle 


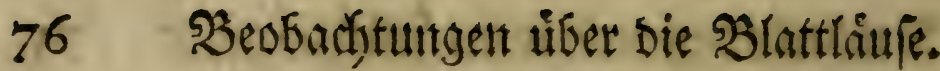

Tabelle ber Sieburtstage und Etunien ier vom 23. 2linguft, bis zum x. Eept., incluf., geb: Ṡlattlaule, weldhe die Den 25. 2lug. frúl) un

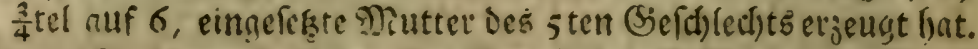

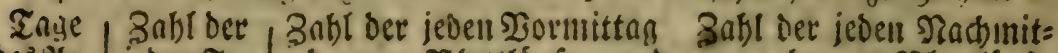
Deß2)

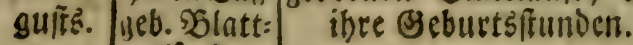

\begin{tabular}{|c|c|c|c|c|c|}
\hline 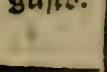 & löule. & 的 & 年 & 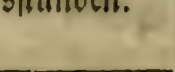 & funden. \\
\hline 23 & $7 \Re 3$ & $-\quad \begin{array}{c}7 \\
-\end{array}$ & - & $\begin{array}{l}2 \text { SI.* } \\
\text { I } \mathfrak{B l .}\end{array}$ & 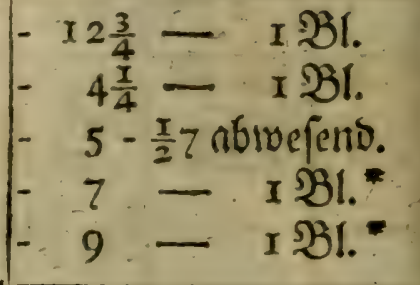 \\
\hline 24 & I 321. & $5 \frac{\pi}{4}$ & - & I $\mathfrak{Z l . *}$ & $\therefore-$ - OXII. \\
\hline 25 & $6 \mathfrak{B I}$ & $\begin{array}{r}-5 \frac{x}{4} \\
-\quad 8 \\
-\quad 12\end{array}$ & $\underset{-}{-}$ & $\begin{array}{l}2 \text { Bl.* } \\
\text { I } \mathfrak{B l .} \\
\text { I } \mathfrak{R I . *}^{*}\end{array}$ & $-\quad 5 \frac{\pi}{4}-$ I $21 . *$ I $B 1$. \\
\hline 24 & $3 \mathfrak{2 B I}$ & $-\quad 5 \frac{\pi}{2}$ & - & 3 $21 . *$ & $-\quad-\quad-031$ \\
\hline 27 & $4 \mathfrak{B I}$ & 9 & - & I $21 . *$ & $\begin{array}{l}2-1 \mathfrak{B l}{ }^{*} \\
-5-13 l^{*} \\
-9-13 l^{*}\end{array}$ \\
\hline 28 & 4.231. & $-\quad 6 \frac{x}{2}$ & - & 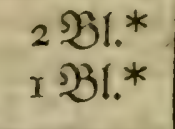 & $-2-1331$. \\
\hline 29 & $2 \mathfrak{B l}$ & - II - & - I $\mathfrak{Z}$ & 31.*, $5 \mathrm{SI}$. & - - - o \\
\hline 30 & $7 \mathfrak{B I}$ & $\begin{array}{r}5 \frac{1}{2} \\
-\quad 6 \frac{1}{2}\end{array}$ & - & 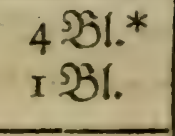 & 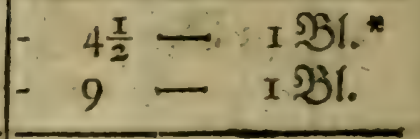 \\
\hline $3 I$ & $3 \mathfrak{Z I !}$ & $-\quad 7 \frac{x}{2}$ & - & × 31. & 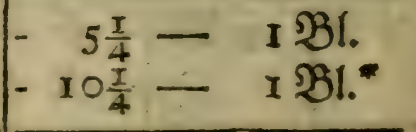 \\
\hline $\begin{array}{l}\text { Se: } \\
\text { str. } \\
\text { ine }\end{array}$ & , & - $\begin{array}{r}5 \frac{x}{2} \\
\text { ftatb }\end{array}$ & $\overrightarrow{\sin x}$ & $\begin{array}{l}\text { I } 31 .+ \\
\text { (lte } a) .\end{array}$ & I- - - OBI. \\
\hline
\end{tabular}

Sanje Summe 38 B̉attlaufe.

a) Dn id fie officte, nubm ids noch vier woblgelfaltete foecus bernus. III Dicte batte fie felfr nbgenommen. 


\section{Şeobaç)tungen tiber Die SBlattlåufe.}

\section{Tabelle}

det Geburtstage unb Stundell, Der vom 31. 2tuguft bis jum 9. Eeptemb., incluf., geborn. Blattláufe, welche Die ben 23. Sept., Wormittags um 1 I $\frac{1}{4}$ eingeferfete 2llte Des Gten (Befdilect)ts erjenget ḩat.

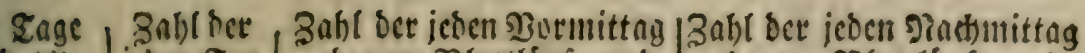

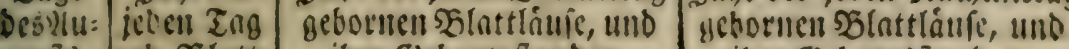

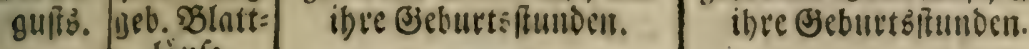
lătíe.

\begin{tabular}{|c|c|c|c|}
\hline & 5361. & $-\ldots ß 31$ & 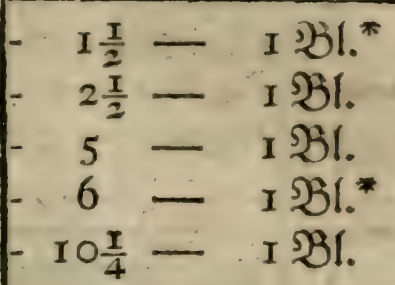 \\
\hline & $z \mathfrak{B l}$ & 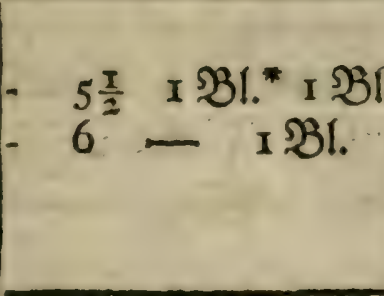 & 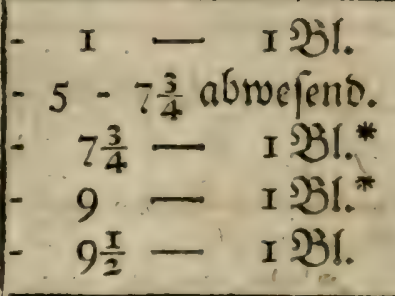 \\
\hline & $5 \mathfrak{B l}$ & $\begin{array}{l}7-1 \mathfrak{B l} . \\
7 \frac{3}{4}-\mathbf{B} 1 .\end{array}$ & 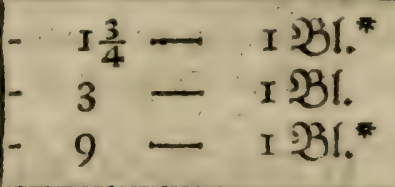 \\
\hline 3 & $5 \mathfrak{B l .}$ & 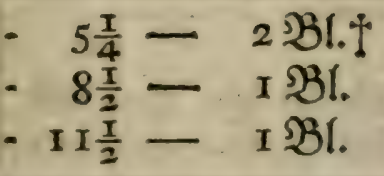 & $3-\mathrm{r} \mathfrak{B l} \mathrm{l}^{*}$ \\
\hline 4 & $3: 31$. & 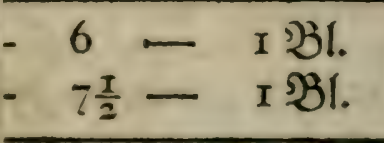 & $-\quad 3 \frac{x}{4}-I B \mathfrak{B}$ \\
\hline & $52 B 1$. & $-\begin{array}{r}6 \frac{3}{4}= \\
-12\end{array}$ & $\begin{array}{l}3=x \mathfrak{B l} . \\
-4 \frac{3}{4}= \pm \\
-8 \frac{2}{2}-x \\
-1\end{array}$ \\
\hline
\end{tabular}


78 beobacftungen ůber sie STattláufe.

\begin{tabular}{|c|c|c|c|}
\hline $\begin{array}{l}\text { Tage } \\
\text { bes } \\
\text { Sept. }\end{array}$ & 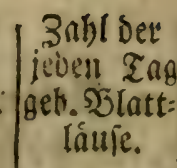 & 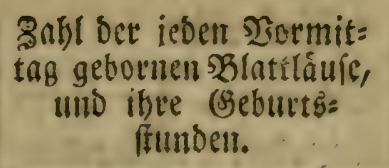 & 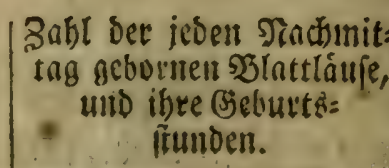 \\
\hline 6 & $3 \mathrm{SBI}$ & $\begin{array}{l}5 \frac{x}{2}-1 \text { BI. } \\
6 \frac{x}{2}-13 \mathfrak{l} .\end{array}$ & $3 \frac{x}{4}-x \supseteqq$ \\
\hline & ० 31 & $-\quad-0331$. & - - - o \\
\hline 8 & $\begin{array}{l}\text { i B latil. } \\
\text { unt } \\
2 \text { Foctue }\end{array}$ & 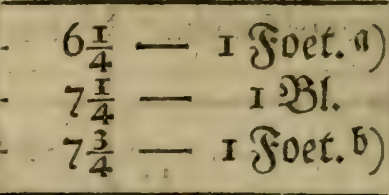 & OBI. \\
\hline & I foetus & - $5 \frac{x}{2}-\mathrm{I}$ Foet. $\left.\mathrm{c}\right)$ & - - oßBI. \\
\hline
\end{tabular}

\section{Gintge Summe 33 Şlattlåule und 3 Foetus.}

a) Zlfe Theile biefes foctus waren fefre Eenntlid). Dic 2lse. bradjte mefje, n!z eine Etunde zu, Deffelben loz̧̧unerden. Eie fiel gleids nadifer auf Den 50 ober.

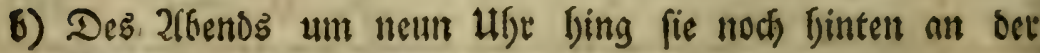
2fiten.

c) Den zeffnten ses 2fbenss um neun Utfr, trug bie 2flte nods, ben Soetus, an iffen Scintertfeile, womit fie fidjon Dest meunten nievergefonmen war.

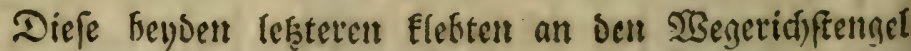
ni, uno vertrodEneten lernad) Daran. Sd) (d)

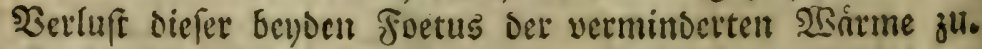
(.). Die Tabelle Der 3erínterungen Des ₹lermometers. 


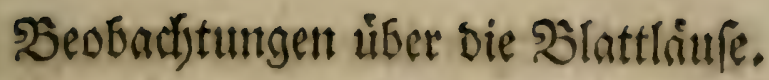

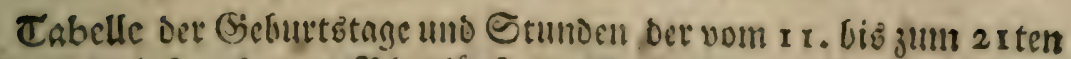
Eept., iucluf., geformen 23 Inttlaule, weld)e die den 3 x. 26unuft, פRad):

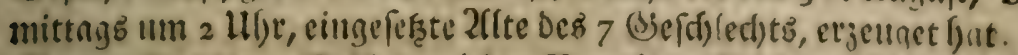

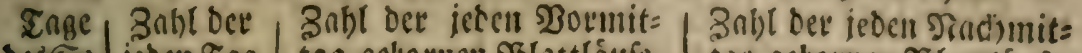

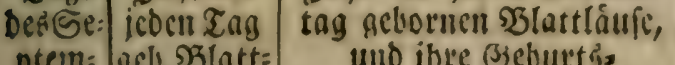
ptem= Beb.SBlatt= herz. láufe.

\begin{tabular}{|c|c|c|c|}
\hline & & & \\
\hline I I & I 231. & $--\div \circ B 1$ & I 231. \\
\hline 12 & ḃ.. & $\begin{array}{l}-6 \text { - I } 31 . * \text { r } \mathfrak{B l} . \\
-\quad 8-\mathrm{I} \frac{x}{2} \text { abweqeno. }\end{array}$ & 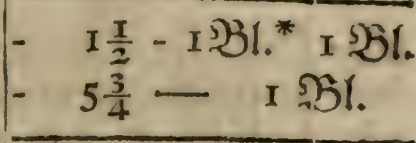 \\
\hline I 3 & & $-\quad 5 \frac{3}{4}-13 l_{0}^{*}$ I $\mathfrak{B}$ & - - o.21. \\
\hline I 4 & 3 & $-9 \frac{x}{2}-3 \frac{3}{4}$ abwe $f$ & $\begin{array}{l}-\quad 3 \frac{x}{4}-2 \text { - } 31 . * \\
-\quad 4 \frac{x}{2}-\quad x 1 .\end{array}$ \\
\hline 15 & BI. & 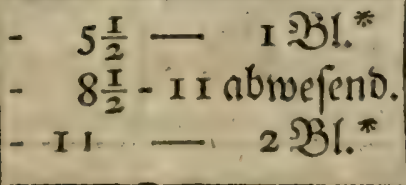 & $-\quad-$ \\
\hline I6 & $4 \mathfrak{3} !$ & $-\quad-\quad$ o 1 I. & 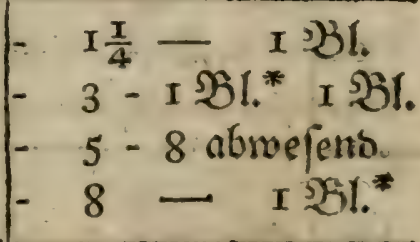 \\
\hline 17 & I 31. & $-8-\quad$ II. & $-\quad-\quad 031$. \\
\hline 18 & & - — - o & - - - o B $l$. \\
\hline I9 & 2 शु!. & $6-1231^{*}$ & $-9-\quad$ I \\
\hline 20 & 2 231. & $-6-2 \mathrm{Bl}^{*}$ & - - o ORl. \\
\hline 21 & $7 \mathfrak{B I}$ & 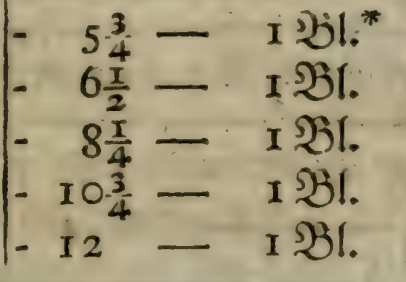 & 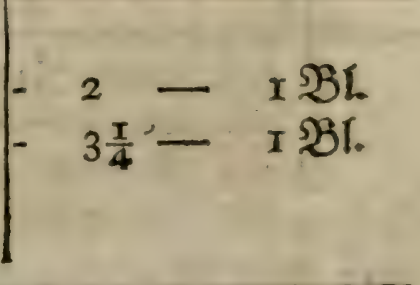 \\
\hline
\end{tabular}

25 fruf̧ wat die Zllte todt.

Sanje Eumme 30 Ḋlatilupe. 


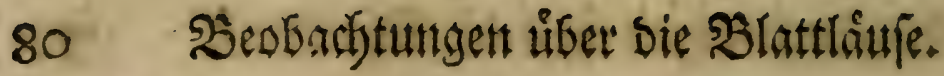

\section{Tabelle}

Set Geburtatage ultb Stumben, Det boin 22. Gis jum 25. September, inclufive, gebornen SBlattlåue, welche bie ben I Iten bes Diacfinittags um 2 llf̨r eingeferte Zlite bes achten (biefdlectits a) erjeuget hratte.

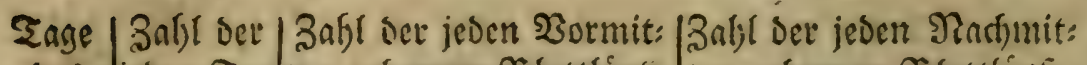

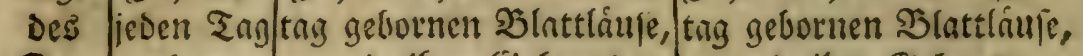
Ee: gebortr. und iffere Gielurts: uns ihre Gieburt: ptemó. Ḋlattl. frunden.

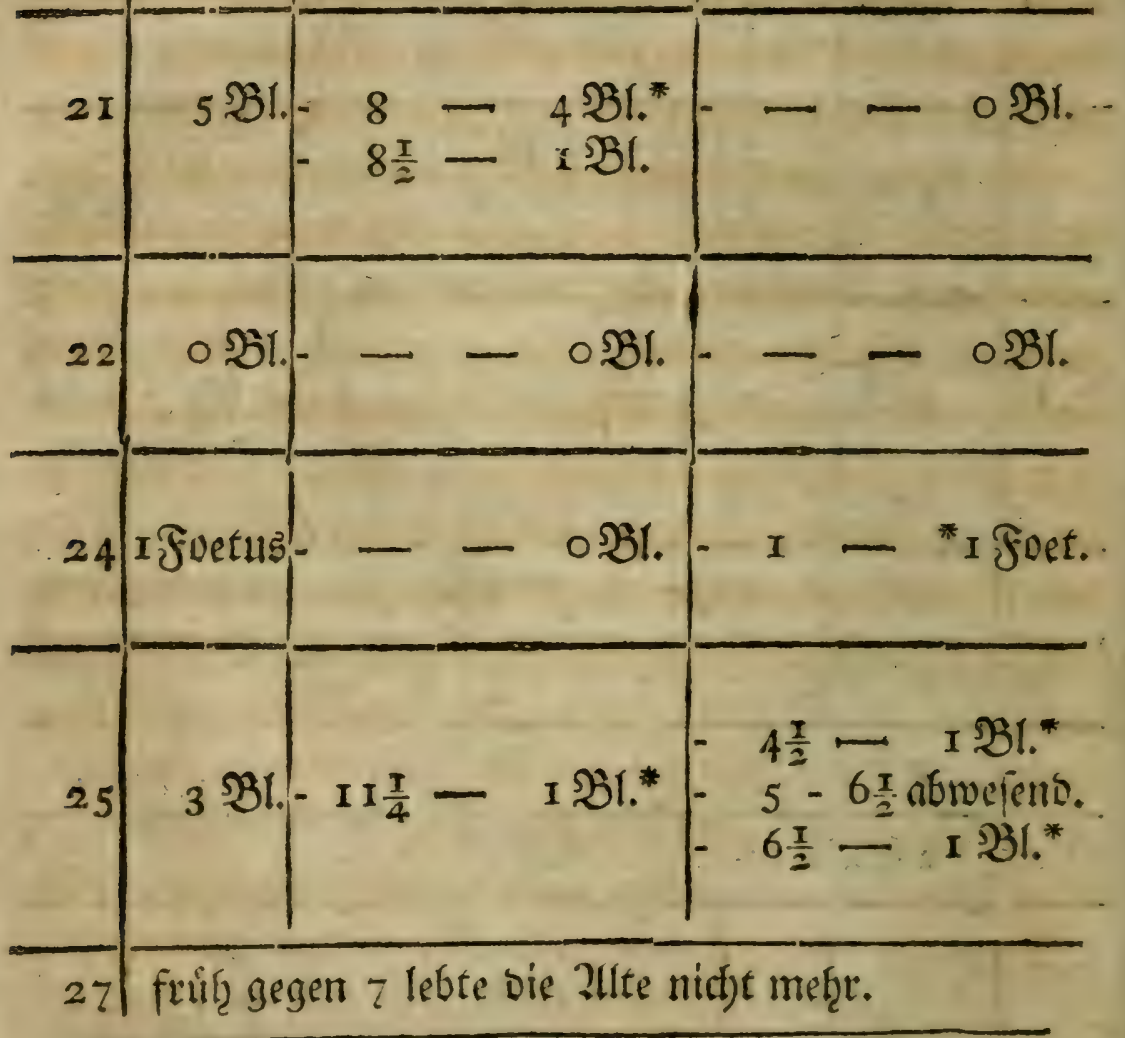

Sianje Gumme 8 Blattlâfe, und I Foctus.

a) Diefe Silattlausnmutter fatte vom 20. bis jum 22., unt vom_

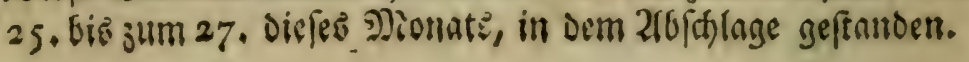




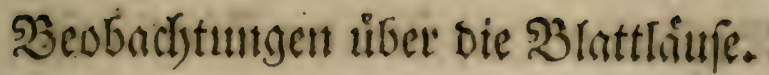

\section{Siebente Beobadtung.}

\section{Secobacitumigen, welde}

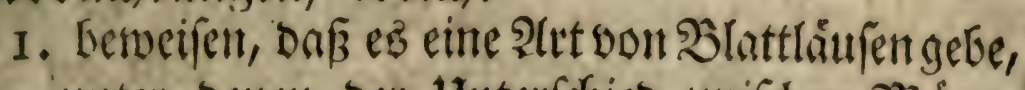
unter Denten Der Interforted gwifden Mrann=

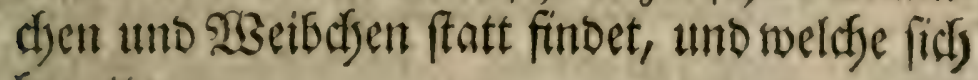
begatten.

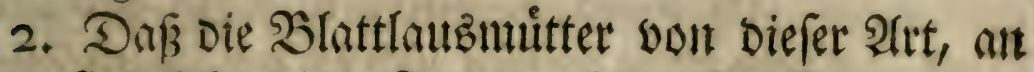
ftatt lebentiger Șungen, biżweilen Foetus jut SiBelt bringen, uns mit weldber $\mathfrak{B}$ orficht?

\section{5}

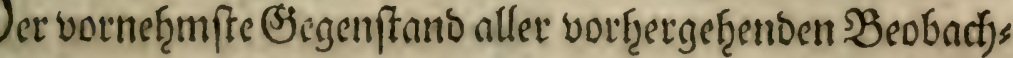
tungen war ber şeweis, bn unter ben B̉lattläufen feine switeflid)e ßegattung ftatt finte; bof ce ganj befonbere Smitter find: Zwitter bie fict) felbft getmig find, und bies wirb meines Ernchtens, benen hinlänglid) erwiefen fd)einen, meldhe biefe Bbobad)tungen lefen werben. Jith bit aber verfict)ert, Daf viele meiner sefer ju fothlieffen gencige fenn twerben: als wenn biefe befondere Eigenfit)aft Der ganzen

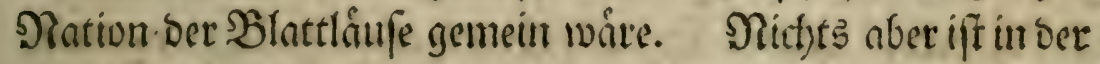

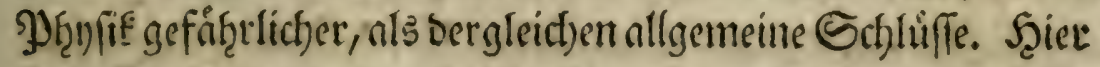
fino SBobact)tungen, welche beweifen, buß es menigftens

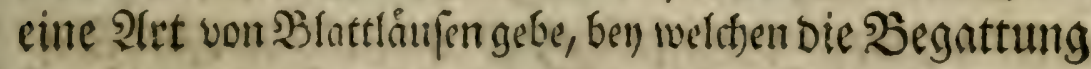
frattfinbet, wie fie unter ben ffliegen, ben Sthmetterlingen, ano unter fo sielen anbern 2leten, von Jufeften unt S Giceen iff:

Uleberf̧aupt bavon ju reben, fins bie Blattláme fef̧t fleine Injeften, nuf weldte mant vislleict)t niemals würbe 2!(t)tung gegeben fraben, wenn fie fich) weniger vermef̧rtent.

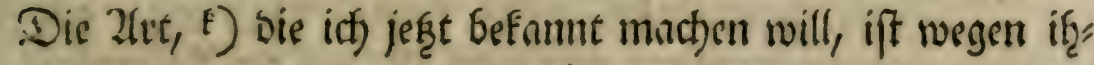

IPL

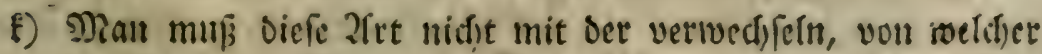
Der J̧ere von ZReñamure Tom. III. p. 334. in frinen \$lis: 


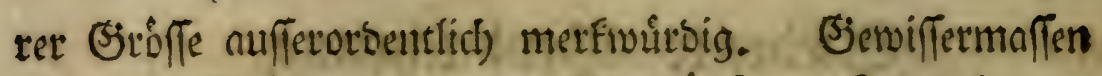
ift fie ber Elepḩant unter ben Blattlaurfen. Sidf ḩabe von

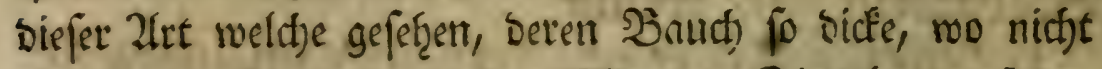
bicker war, als einer gemeinen fliege. Sie leben auf ber

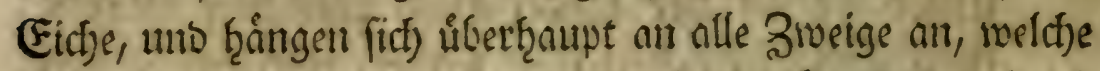

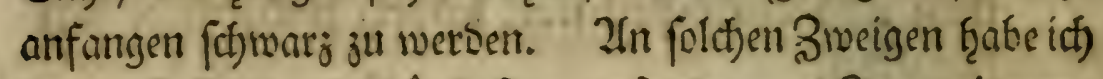
fie wertigftens am ţăufigften gefunber. In geringerer

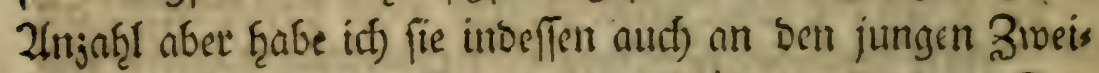
gen, uno felbfit an ben Etielen ber Bllátter gejef̧en. Der

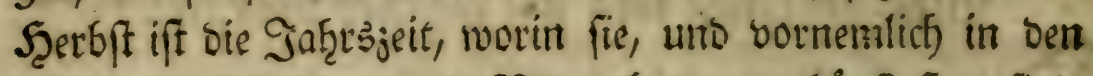
Monaten SEtober, uno Nobember, am f̧åufigften fint. Surr; borţer, ef̧e fie bas 2llter erreict)en, worin fie jur Zeus

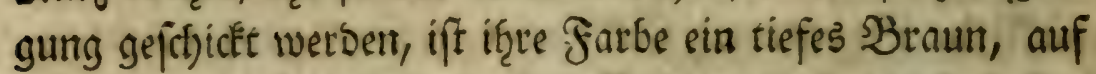

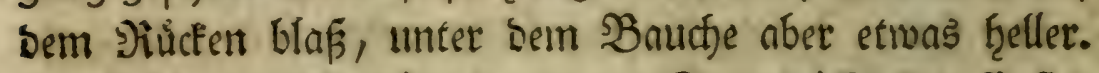

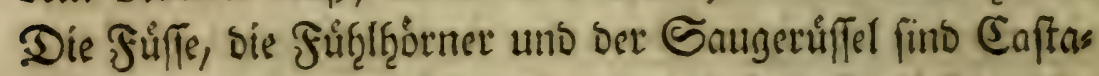
nienbraun; biffte am Şintern noer, ţabent fie anfratt ber

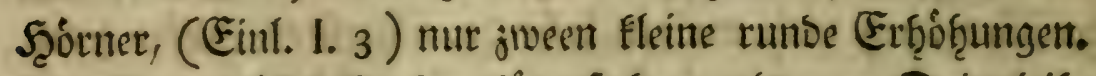

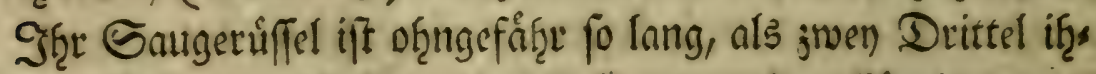

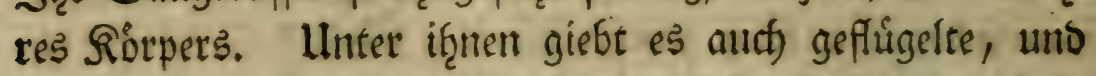
ungeflugelte, wie unter allen Zrten biejer Injeften; biejer

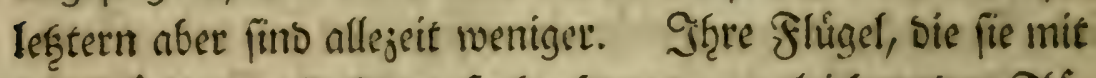

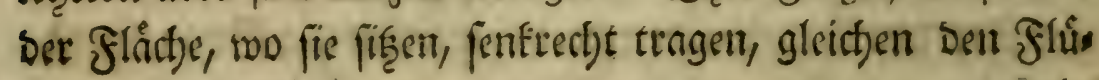
geln

moites tebct. Jd) glaube, baß̄ fie fid) wotnemlich Datin von

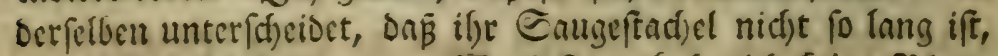

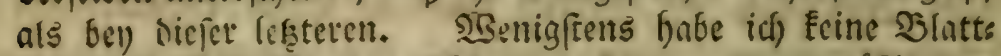

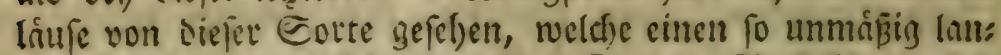

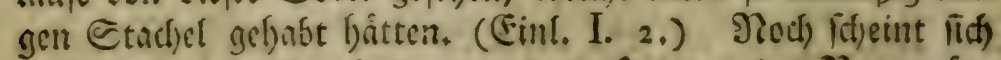

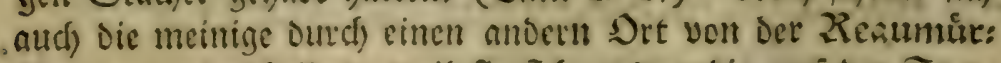

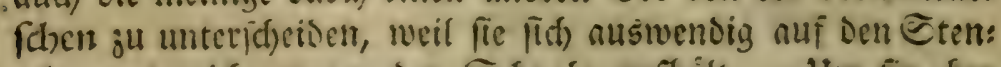
gelı, umo nid)e unter Der Ed)unle aufloâlt. Itm fie aber

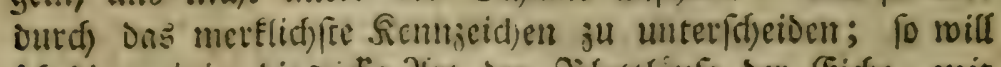
id) Die meinige die side 2litt Der Silattláule Der (Fid)e, mit

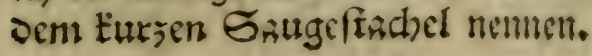




\section{Beobadjtungen niber bie Blattlåure.}

geth ber (d)metterlingsartigen Fliegen, 1) uno futo

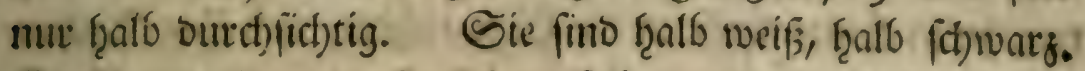
Es fetheint als werm fie firt) Derfelleen nict)t funberlict) bebies

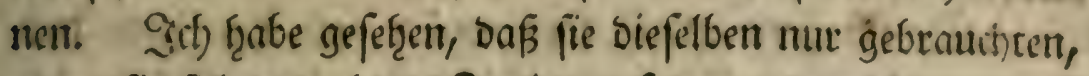
went fie fict) botr eitnem Zweige ouf ben andern fot)rungen, als icf) ben éin wentig fof uttrelte, auf bem fie faffer. Rurg,

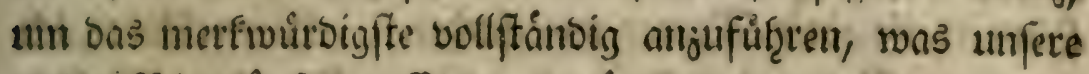

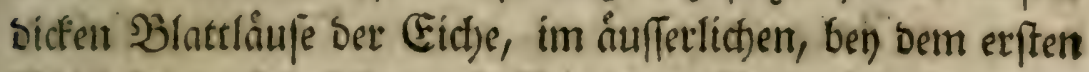

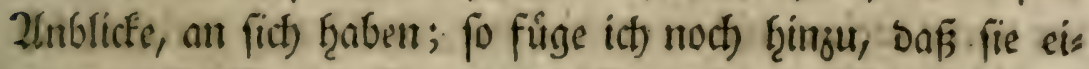
nen jiemlid) frarfen (Serud) von fiit) geben, Den id) aber nict)t ju beftinmen, noct) mit etwas zu vergleichen weif. S.ęier

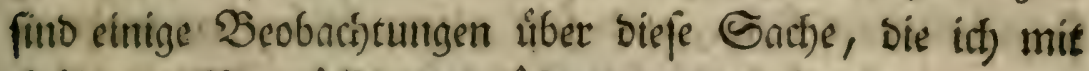
Şülfe Det ¿ergrơffecungsglläfer gemact)t ţabe.

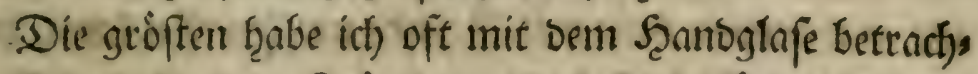
tet. Die befondern Sinóttlen, ober Birffeltrinoe, wobon Der seer Don Sieaumur glaubte, m) Dafi fie bamit eben Das verridjten founten, was fie mit ben Scótnern thăaten,

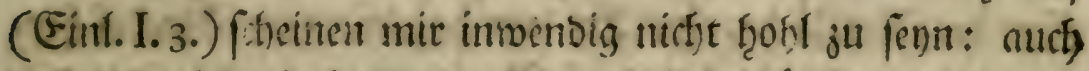

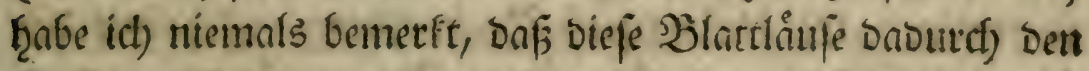
Soft von fith) geben, bavon itf) oben fagte, (Eint.) Dafi es

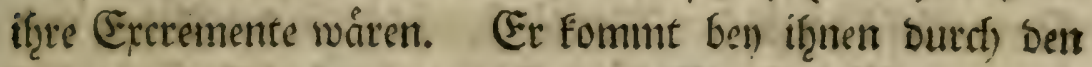

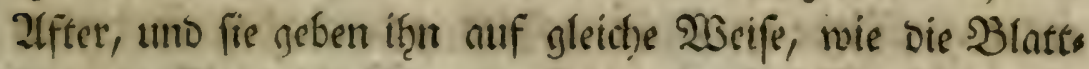
lous bes Spindelbaumb, von fict), Deren (sefdji(d)te ict) in bet $\mathfrak{F} 2$

ets

1) Daan nernet fammetterlingsartige fliegen foldfe, beten Flut:

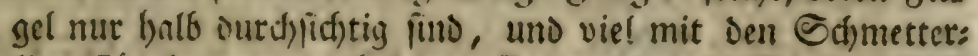
lingsflutrefn, gemein baben. Reaumur pour fervir a l'hiftoire des Infectes. Tom. IV. p. 137. Den Infeftens fermern fiud fie unter bem Yamen Der frúblingsflicge be:

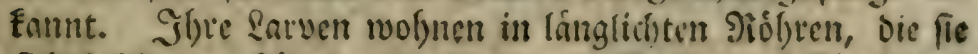

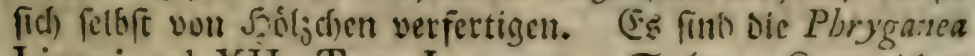
Limnei. ed. XII. Tom. I. p. yos. Gutisers Siemmiciden Der infeftern. 3üred, 1761. 4. p. 133. fig. 104. Uleb.

ii) Memoir. pour l' hiftoire des lnfectes Tom. III. p. 28 . 


\section{4 Şeobachtungen ưber bie Şlattlåufe.}

exften Beobachtung beffirieben F̧abe, baf fie fich nemlid

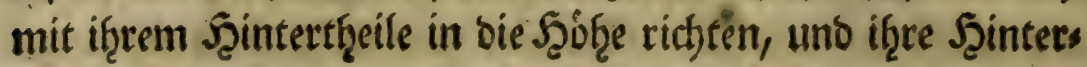
fúfe berwegen.

Da ith gern gemís fenn wollte, of ben if̧nen bas

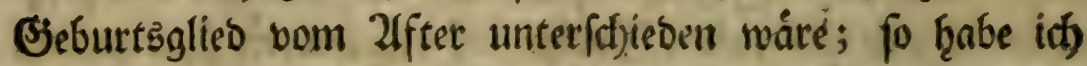
foldjes wab̨rgenounment, als ich) mit ber Loupe bas Enoe am

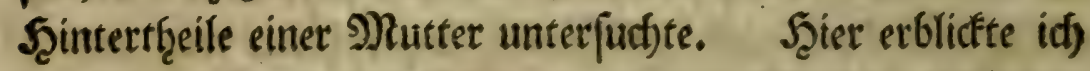
unter bem Zlnus eine Defnung, wie ein Srichter geffaltet, ber vorne weiter, als inmentig war, unb burd) weldsent if verfhbiebene Soetus herausbrúctite.

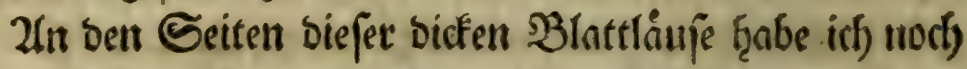

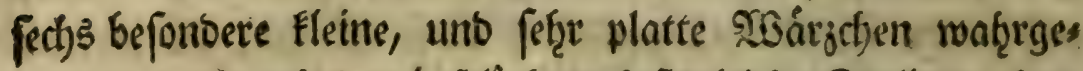
nommen, bie mit ben Suftlochern faft gleiche Stellung bents ten, uno wobon man mit Srunoe mutf̧maffen fanut, bá fie ou eben bem Sebrauche bienen.

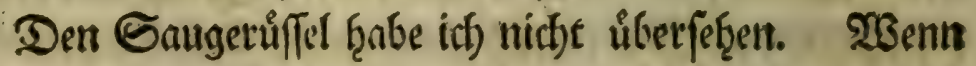

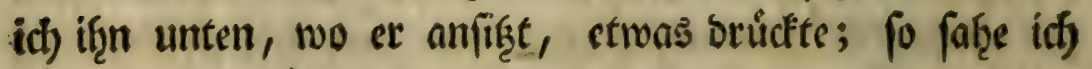

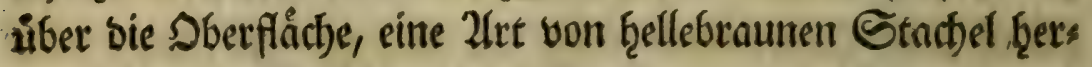

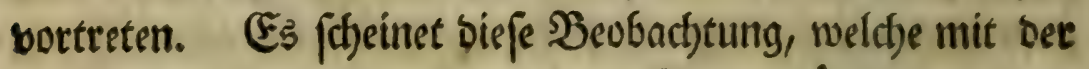
ỉbereinfomt, bie ber Sherr bon Reaumür n) an bem

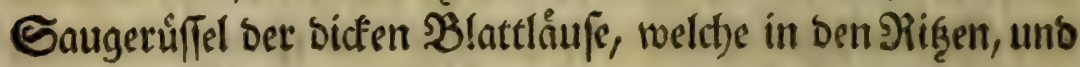

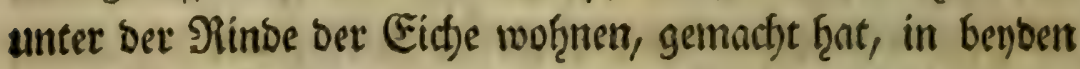
eine gleidfe Etruftur anjuseigen. NRactjoem ich ein ans bermal eine von biefen bidéen sblattlåufen, ziemlich unfact)te oben von eittem 3rweige abnaţm, wo fie if̧ren Saugeptact)el angebeftet f̧atte; fo erbflidt'te idf) einen braunen, nufferor= Dentlid) jeinen Faben, ber weit úber sas Enbe ber Erbeibe wegging.

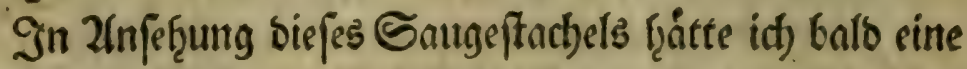

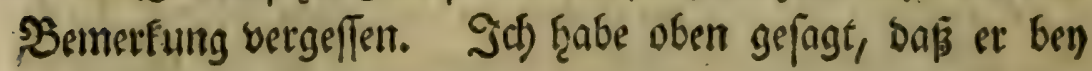

in) Tom. III. des Mem. fur les Inf. p. 33\%. 


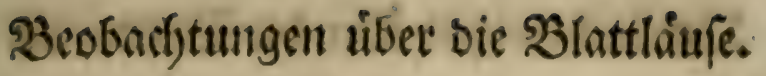

ben Blattloulfen, bie zu ifrem vólligen Zllter gefommen fino,

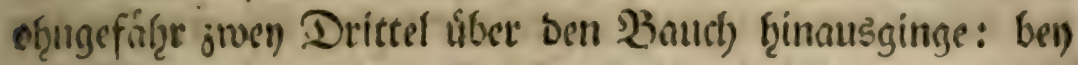
Denen aber, bie erff jur 20 elt geformmen, ober bie nod) Fehre

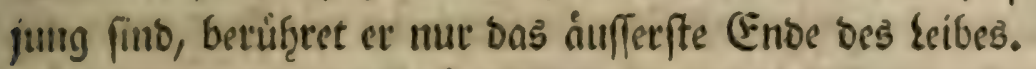

So fie fict) gleid) háaufig nuf ganj glatte 3weige, uno in

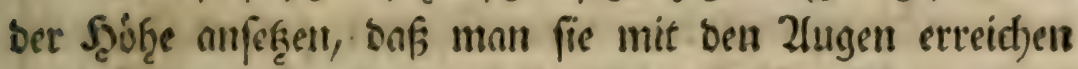
foum; fo ift es boch nitht fo leidft, als man fictse vielleidyt vorftellet, biejenigen von unfern Blattláufen abjunef̧men, die man befonbers beobadten will. Man mus etpe eine Ifrmee groffer Zlmeifen wegfoffeffen, bie fie allenţ̧alben um.

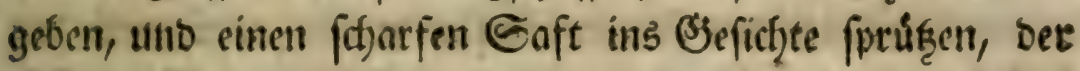
eben bie Empfindurn inadjt, als Fleine Nabeln verurfact)en múrbell. SWenn man fith) einige Zeit nimmt, bie mit bies pen bicfen Blattlaufent, uno 2tmeifen bebectsen Eidjenjueige ju betrad)ten; fo wirb man ein ferter beluftigendes Sctjaus ppiel feţen. Man mirb waf̧rnef̧ment, wie fie ben 2lmeis

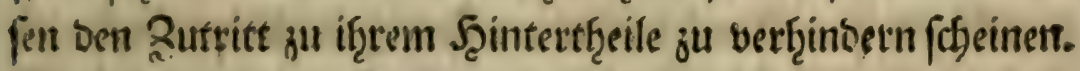
Man wiro fermer bemerfen, wie fie fict balo linfs balb

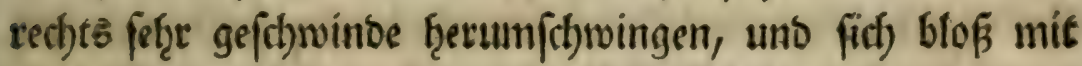

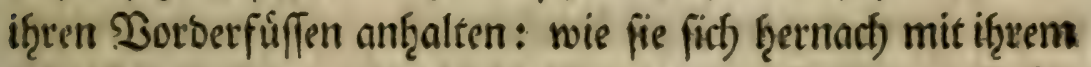

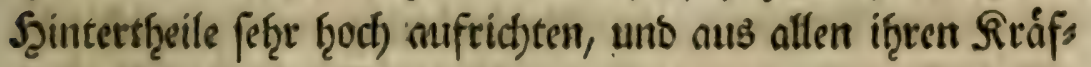

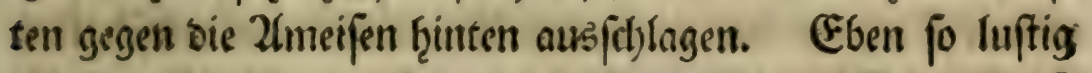
ift es aud) mit anjuferten, wie fie fich auf gleid)e 23 eife

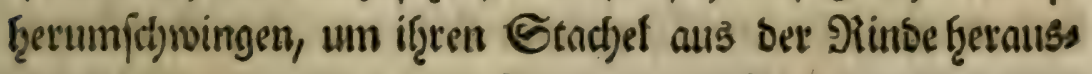

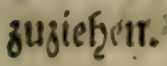

Llin midf nun rect) forgfältig von ber Escithidjte bies fer Blattlaufe ju unterristen; fo fpertte iid) iun 2lunfange bes Dftokers 1740, wie iif) mit benen boun Spindelboume gettran ḩatte, vier bis fúnfe ber gróften, mit ciner antern, aber biel fleinern, uno gefligelten, won eben ber 2 rrt, eir.

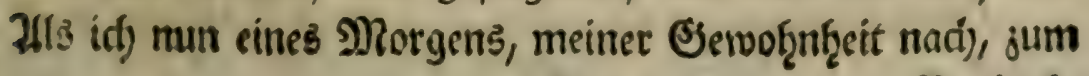

$$
\cdot \hat{S} 3
$$

Beobad)s 
86 Beobachtungen ưber bie Blatțlåufe.

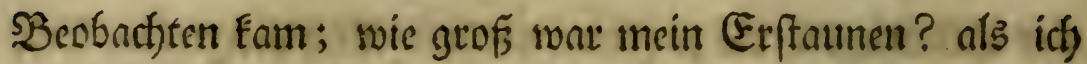
Die fleine SSlattlaus, auf eitrer ber Diffen Mütter, in ber

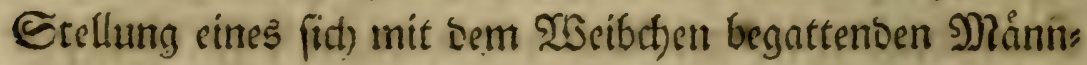
chens fir

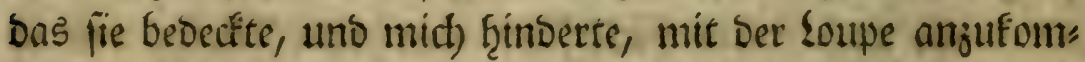

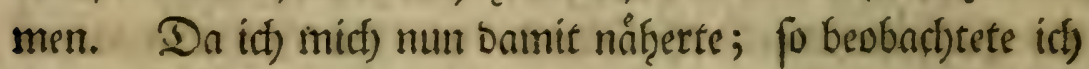

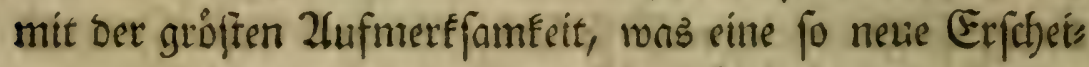
nung erforberte. Die benden SBlattlaufe fidjenen orbents

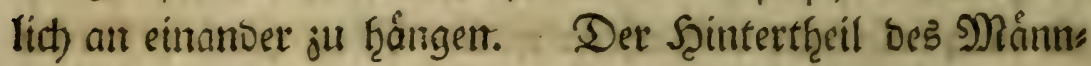

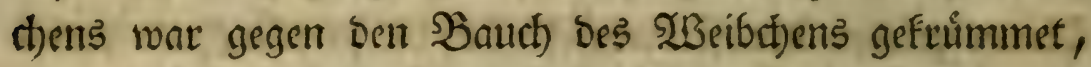
uno ber \$rt, wo das Zengeglied fenn mufte, war nach ber Definung zugerid)tet, bie es einjunef̧men pflegt. *). Sie

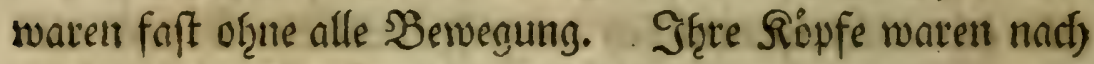

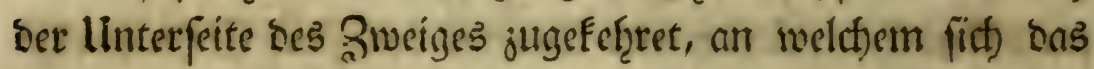

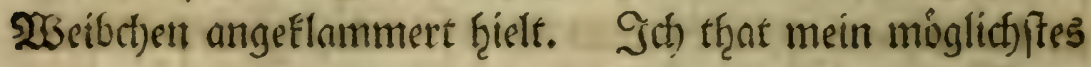
zu entsecten, of if̧re Dereinigung fo genau war, als fie e’s zul fenn fetien. Da icl) aber ben Zmeig etwas anturrete; fo fung Die Eleine Blattlaus an, if̧re Etellung ă veránbern. Gie Eam balb wicber mit ber anbert in eille sinie, von ber (ie fid) ḩertrad) ganız abfonberte.

Eine fo unerwartete Beobact)tung madt) mich' ferge

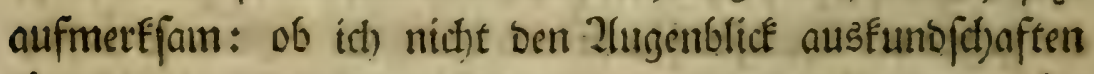
Eonnte, ba fich bie fleine Blattlaus aufs neue begatten nuit:s

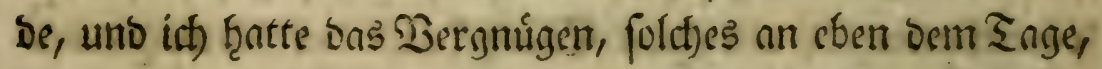
umb auch an Dem folgentoen, meţrmal zu feţen. Es ging aber baben alles folgentorgeftalt ju.

2Bar

*) Dicfe, und die folgenden Zusturice find es, mortuver man dem Berfaffer in bem lournal de Trevoux die bitterfferi 23or:

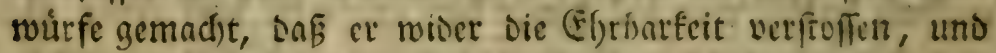

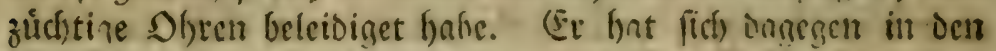
Confiderations fur les corps organifés. T. II. Art 304.

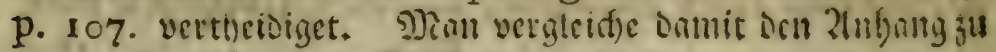
Dem erfen Theile Ber Injeftologic. Lleb. 


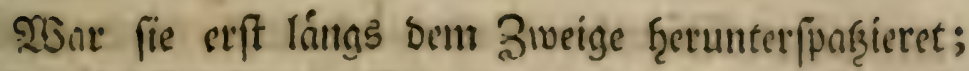
bratte fie cine frillepirgenoe Blattlausmutter angetroffen; fo bicelt fie fich oabey niche lange anf, fich um fie Gerumguberes bृen, uno ju bem red)ten Drte himjufoumnen. Sie griff fie gleid) auf ber Stelle an. Sie fletterte auf fie frcrauf, es mogte (enlt, auf weld)er Seite es molite. Sid) will cinmal

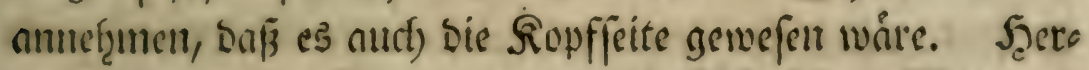

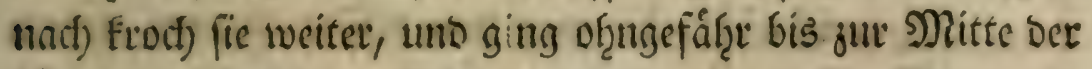
lange des leibes. Da mad)te fie cine f̧albe 20 entoung.

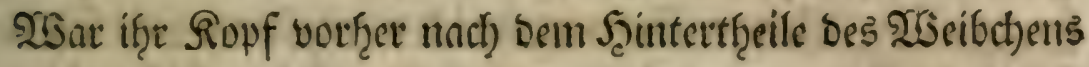
zugefefret; fo war er mun untgewant, und nact) ber anbern Seite gerichtet. Das wat aber nod) nict)t gentig. J) Jan

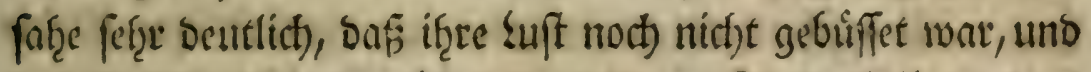
Daf fie fich eiffrig bemuif̨ete, mit if̨erm Scintertheile ju bem

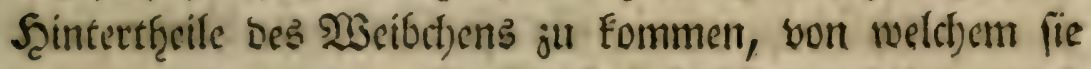

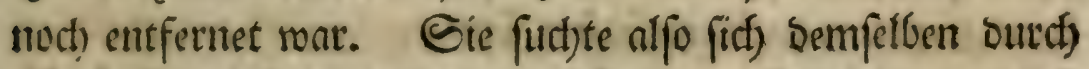

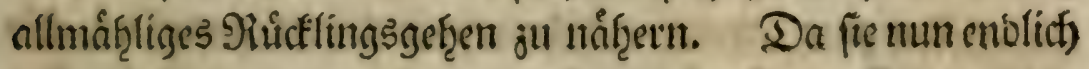
gantj unḩe bajugelnunget woar; fo mactjte fic bie Spif̧e if̧res

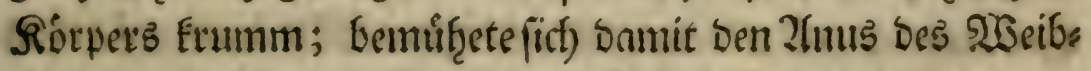

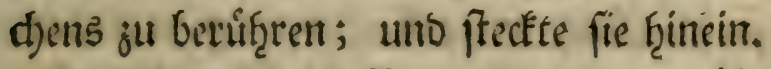

Lltter biefen Soewegungen, worúber sinige Beit ver

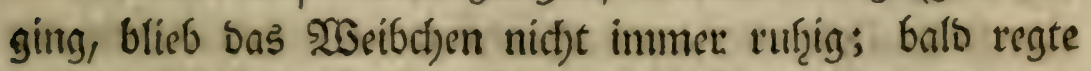

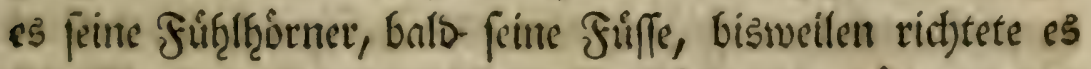

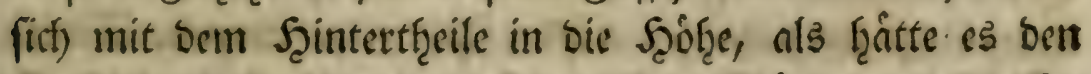
Saft von fidf) geven, ober fict) von bem Mannd)en lofiresifent wollen; sublich) fing es an fortjufried)en. Es mogte nun

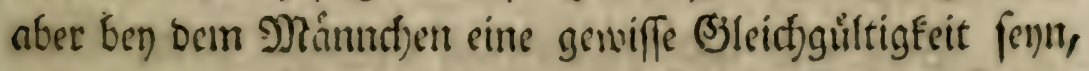
ober es mogte feine Diedfunng nit)e fo recht finden; fo vers

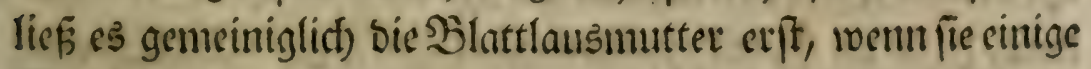

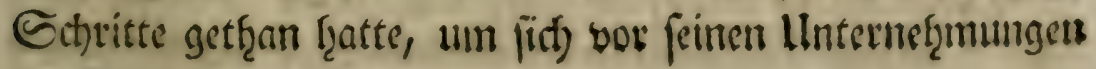
in Gidjerf̨eit zu fergen. 
Das Mäintrden wutbe aud) nicht immer gleich) gut

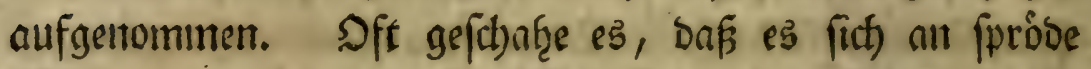
23seibcthen mactite, Dem feine Eareffen nitht gefielen, unto bie

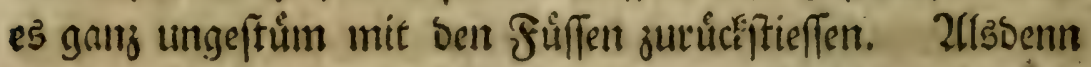

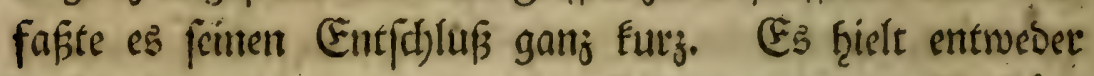

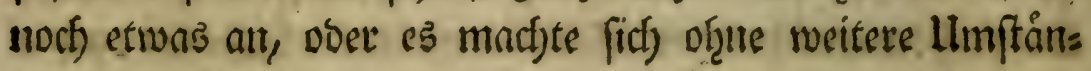
be fort.

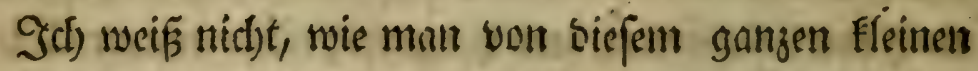

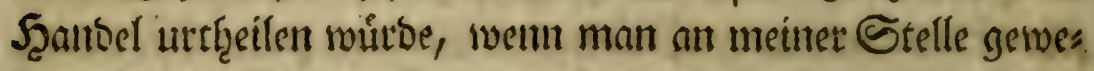
- Fen weire. Meiner Seits benfe id wenigftents: die 23or:

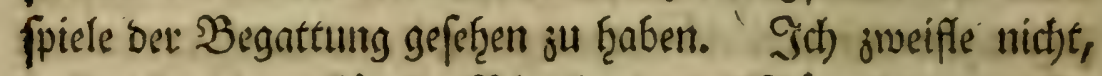

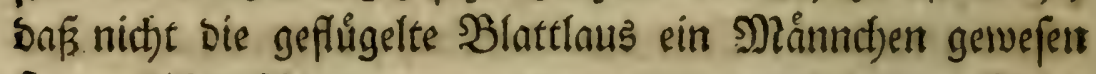

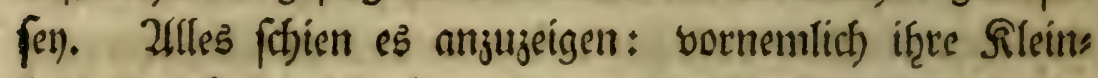

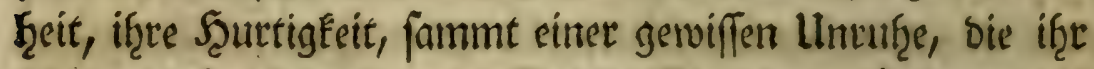

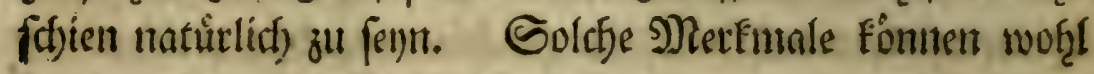
Eeine zwendocutige Rennjeictjen fenn.

Ulun aber etwas entifbetibenderes unb gewiffers fúr Inich) jut fraben; fo mulfe ich mir eitre anbere jul verjifjaffen

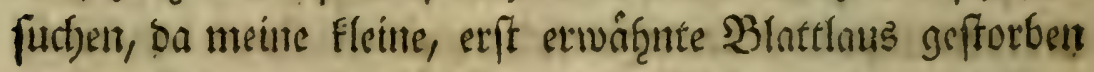

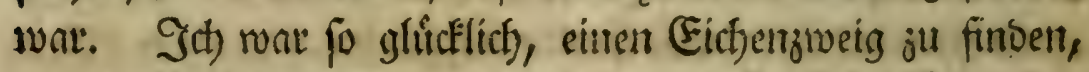
ouf weld)em unter ber groffen Menge bicfer SBlattlâfe, eben eine foldje fleine war, wie ich) fie nur wưnff(t)en fonnte, bie

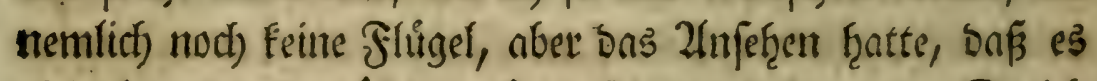

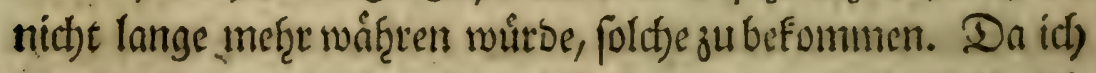

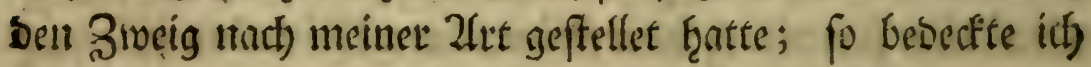
fie mit einem Zuckerglafe. ( $a$ af. II. fig. XIX.)

Som vier uno zwanzigften Detober, ba bie fleine SBlattlans Flligel befoummen ḩarte, Gis jum Enbe bes \$los

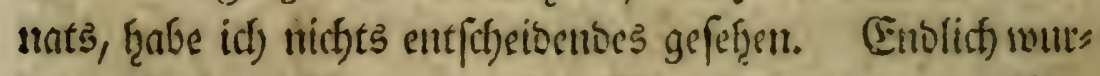

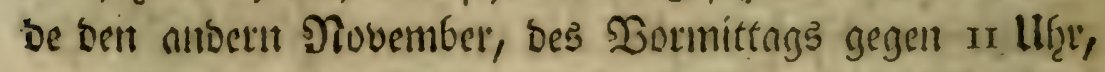

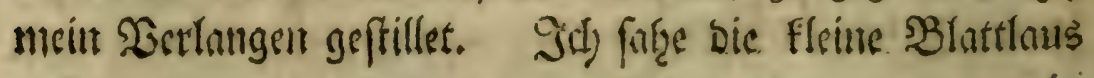




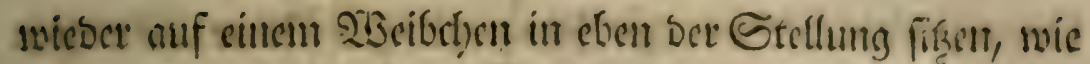

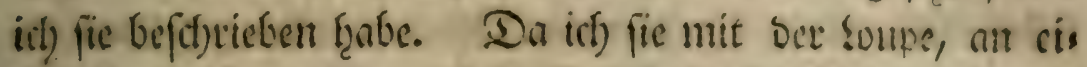

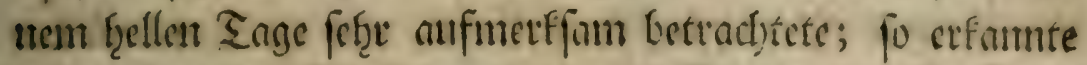

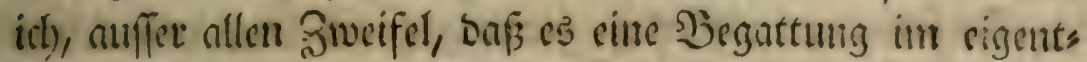

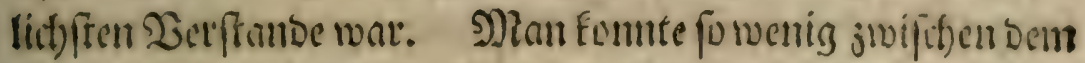

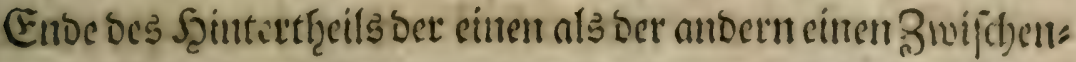

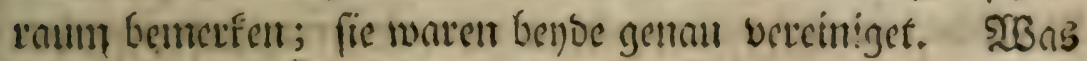

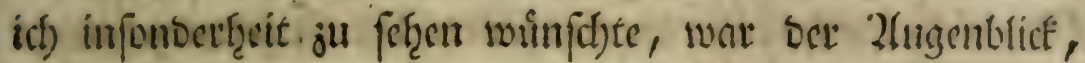

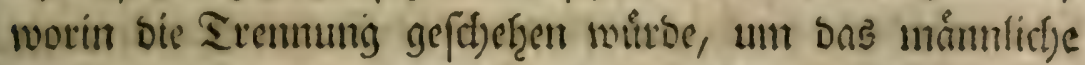

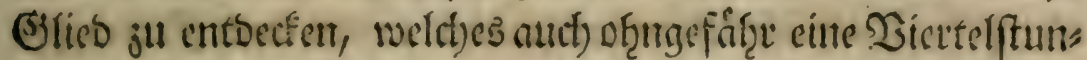

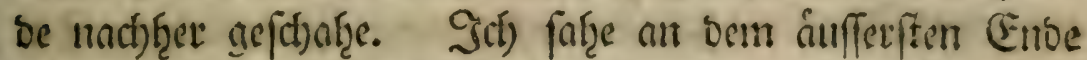

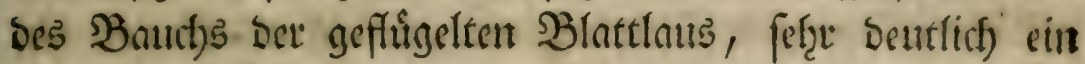

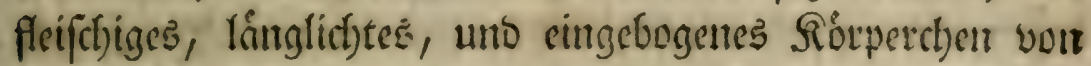

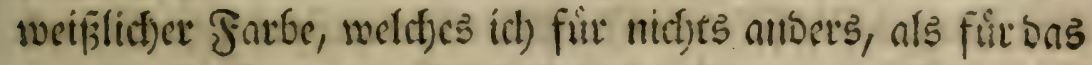
vornef̨mfte 3eugungsglied fralten fonmite.

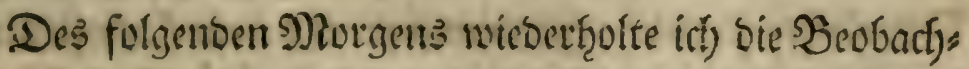

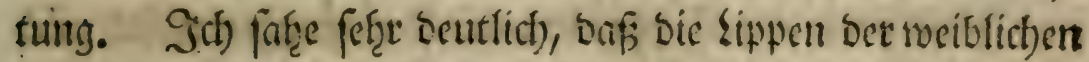

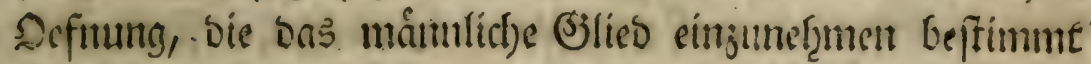
ift, waif̧zenber biegattung merflicl) von cinanber fruntoen,

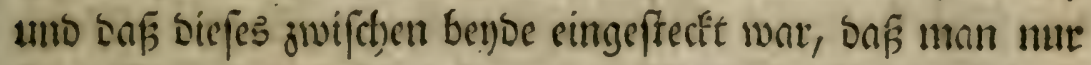

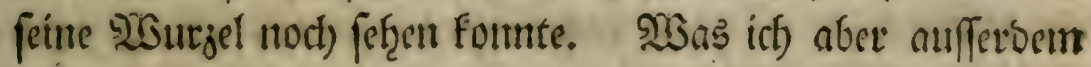
Diefesmal erblicfte, waren zwo gewiffe ?tnhąnge von braus ner Farbe, womit Das Matumeben an feintem Scintertfeile

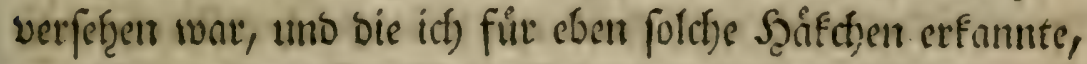

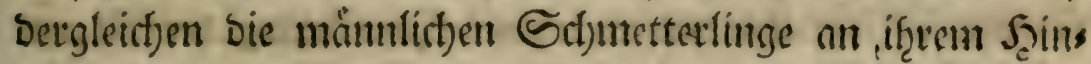
terţ̨cile tragen. In if̧ree Mhitte lag bas Zeugeglieb.

Sin ben folgentoen bren Sangen faţe idf) feine SBegnts tung. Da es ferget falt war, unto id meine Blatetláufe in ciner Sianmer ḩatte, wo idf) fein Feuer madjen fointe; fo trug idf) fie in eitre warme Stube, weil iit) glaulse, son

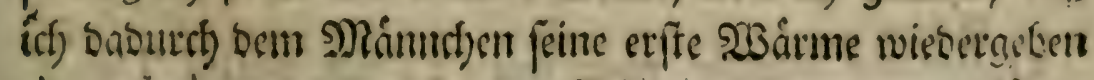

$$
\mathfrak{5} 5
$$

fงrm: 


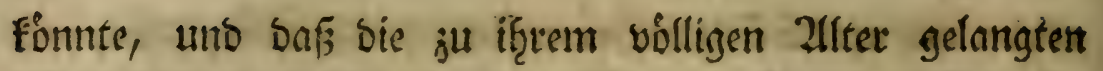

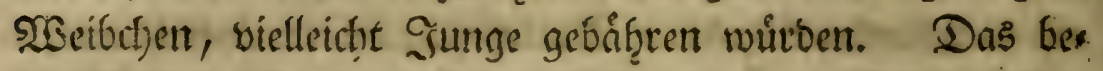
wereffifelligte ich noch) beffelben ₹nges, unto an ebent bem ₹as ge fahe icí) vier bis fứnf Đegattungent, Die aber von Eeiner Iangen Daucr warent.

Es raren mir nur noch) ủberall fiebsn ungeflitgelte

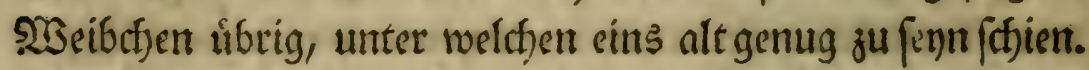
So bicke alith bie aitoern für biefes Infeftenge(f)lect)t fenn mugten; fo fament fie boch biefer bell weiten nicht

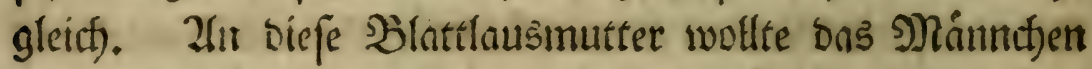
am allerliebifter. Jit) bemerkte, bafís es in einer Zeit

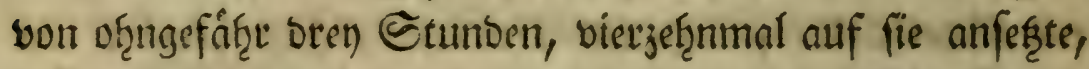
Dabey) aber eigentfict) nur eine brenmalige wirflidye $\mathfrak{B}$ egat:

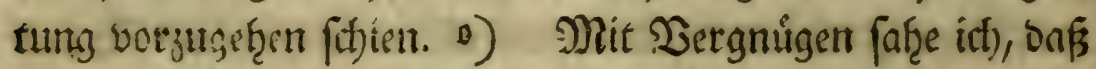

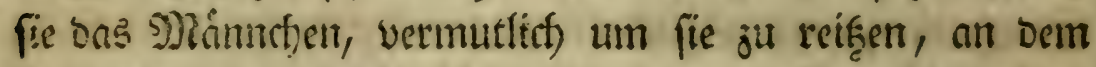
Unterteibe, ju wieocrţ̨ottenmalen, mit bem Enoe feiner lángs ften Sưffe ftreitifelte. Zu eben ber Zeit mact)te es (iid) nod) woţl funf bis fect)smal an anbere 233 eibrt)en. Faft follte

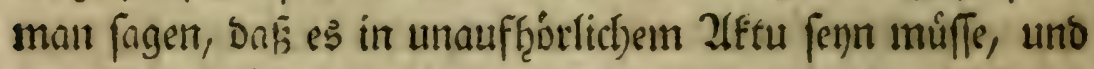

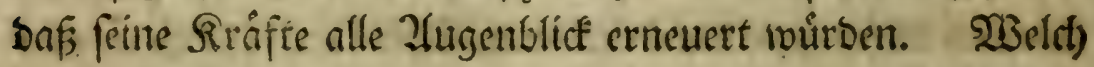

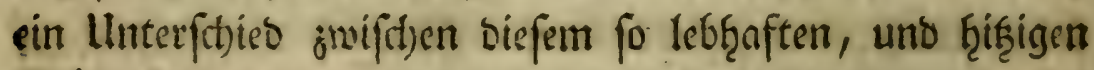

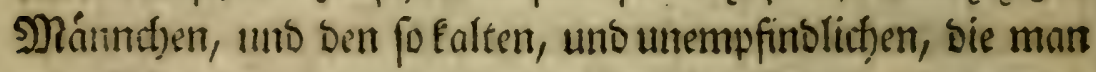
Dem Bientenveibdjen zugefellet fant? p) Dody wie berwuts

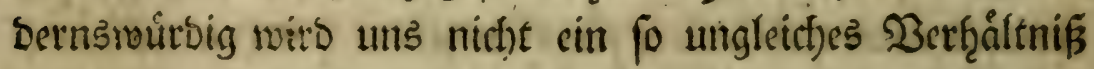
yorfounment, wenu man ủber biefe Einricftung ber Nintue narf)benft? Sür ein cinjiges SBienenweibrt)en f̧at fic eine gruffe

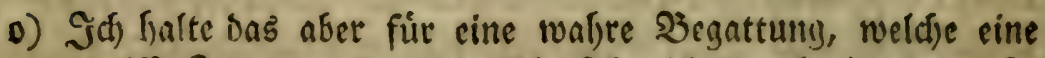

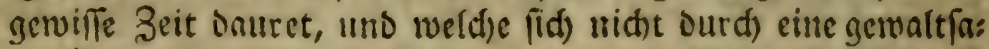

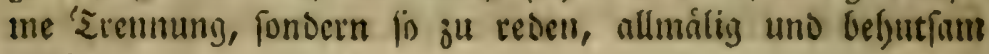
ensiget.

\) Reaumur Memoir. pour fervir á l' hift. des Inf. Tom.V. Miem. 9 . 


\section{Beobachtungen uiber bie Э̧lattlíne. $\quad$ 9x}

groffe Menge Mámucben beftimunt. Sisíren bicfe nut

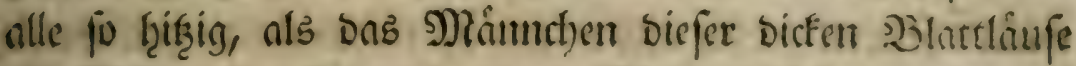
Der (Eid)e; fo mutroe Dies Dem Rienenweibchent nichet tiule ferer befthwerlid) fenn: fondern es wirtbe basutrd) auci) bie

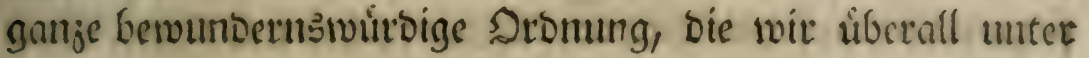
Diefen flitegen bemerfent, geftoret werben. Da es if̨e ater gefallen f̧at, Diefe Eintid)tung ju mathen, Daf es im (j) gents

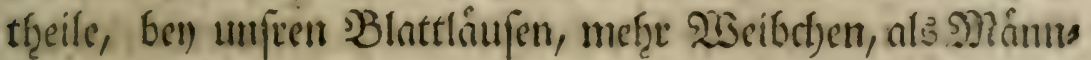

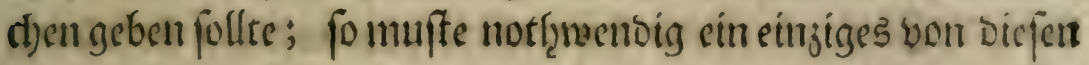

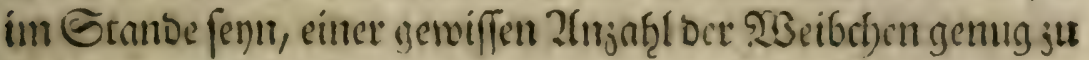

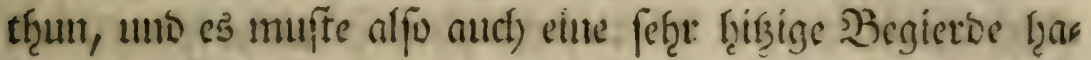

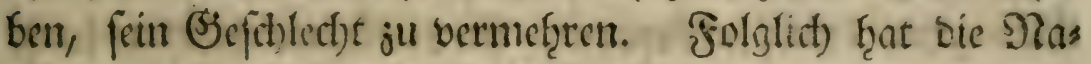
tur, ber Bienenfontigin ebent biefe ḩegierbe eingepfangt, uno

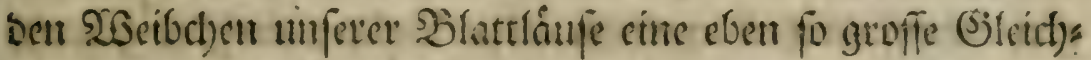

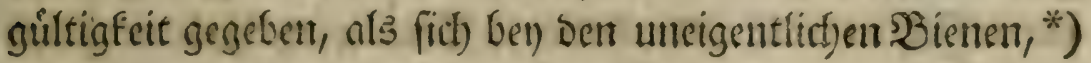

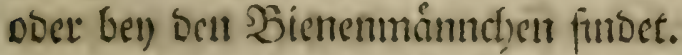

Sidt) frabe nod) nidfts bon gerviffent aufferorbentfict)ent, unt faft frampfţaften Bjemegungen gefagt, weld)e mein Blattlaus̀mánndf)en bięwcilen mad)te. EFs war nur bes Nad)ts ruffig. Ben Sage war es foft immer in Berwes gung. Sft tḩat e's nichtes weiter, als lángs Dem Zwweige

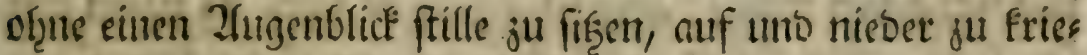

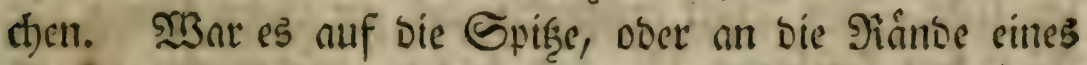

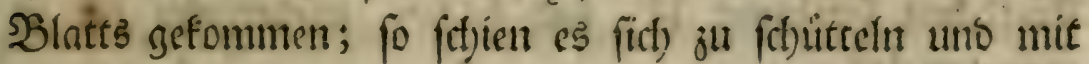

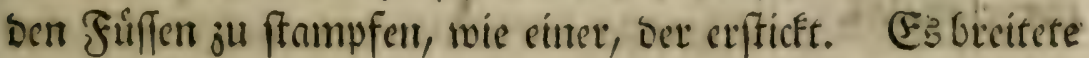

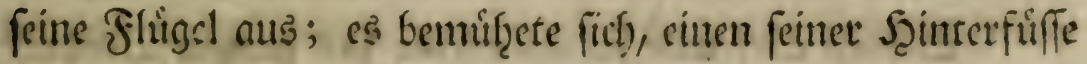
Liber biefelben ferzulftecten. Es mad)te mit feinem ganjolt seibe lauter Serberef̧ungen. Şald warf es fich ouf bie cine, bald auf bie anbere Eeite. Ein andermal ricftete es

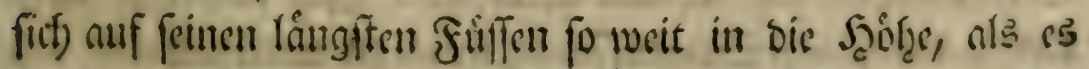




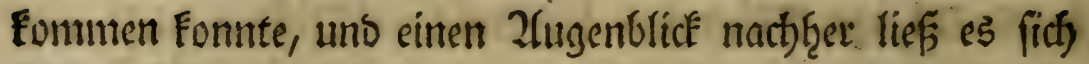

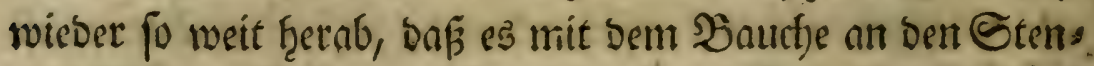

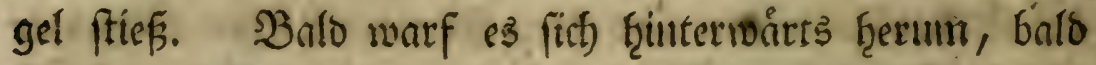

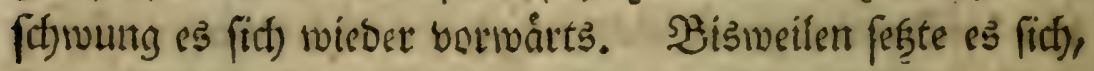
fo ju reben, auff ben Şintern, intoen es fid) mit feinelt Wors

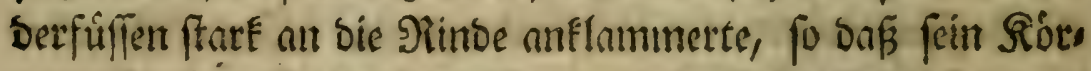
per mit ber Spizęe Des Stengels trennafee fenfreet)t twar. Zluf biefe twumberlitbly Stellung folgte gleid' wieber eine ans Dere. EEs frectite feine S.interfüffe aus, uno zog fie folang,

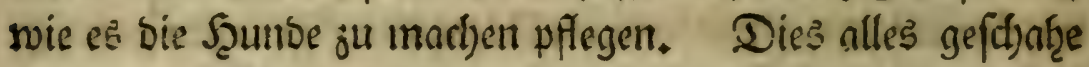

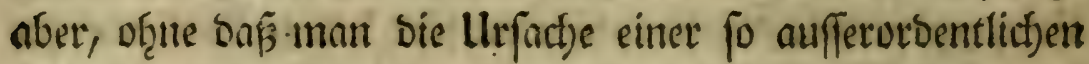

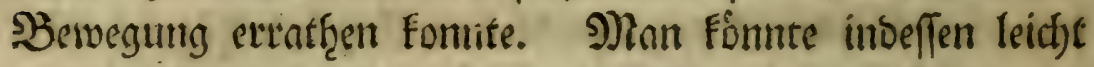
auf ber Gebanfen fommen: es múfte mit bem Tode rins gen, wern man es it einem, bem Ifnferen nach), fo gerwalts famen Zuftande erblicken follte. SMan wiro if̧n aber gleich)

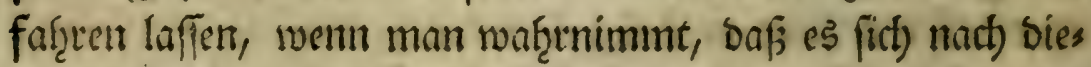
fen Zirten von Conbulfionen eninigemal begatte, uns firt' ebent fo, wie vorther verţalte.

Eintes Tages, es war ber neunte, fahe id meine fleis

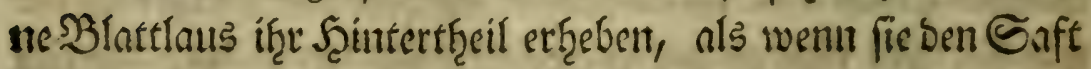
von fiid) geben wollte; aber idf erftaunte ferge, ba fie an beps

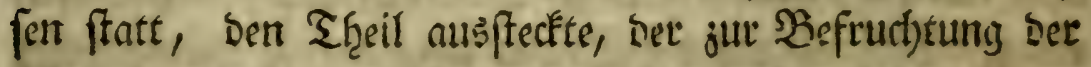

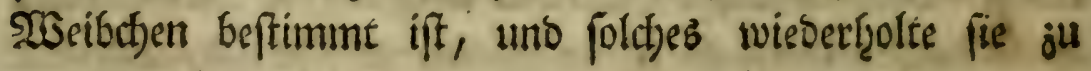
żuenerumaleit.

Enolid) aber war fie ant eilftent bes ganjent Sormits

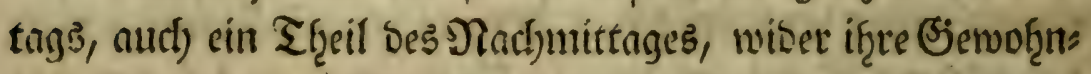
Ezeit fef̧r rutig. Eie blieb bis vier Stunden veft auf bem

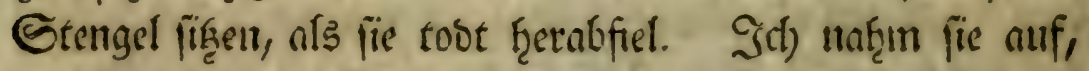

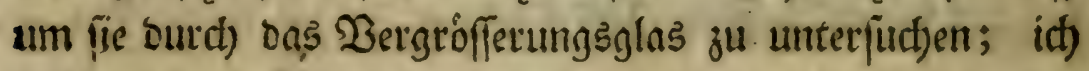

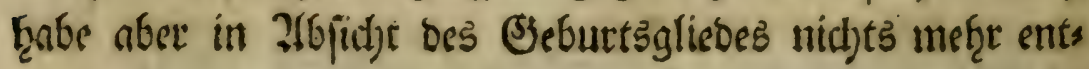
Declit, 
bectit; als was idf) angefưfzret ţabe. Dirfen Tang vertor id) aud) noch) jiveen Blattlausmutter.

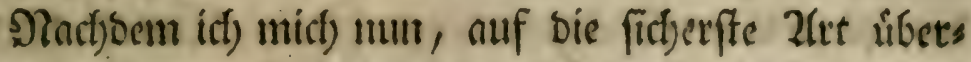

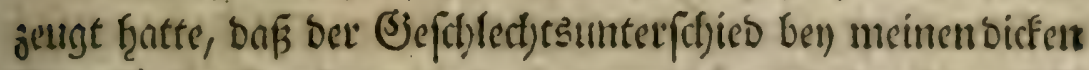

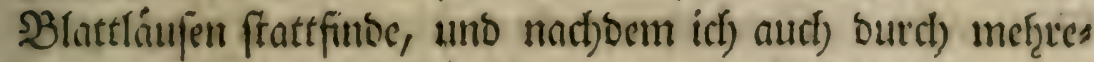

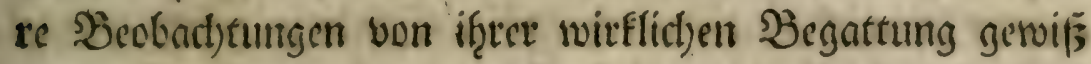
worben war; fo war num nichts meḩe - ibrig, als mich) noct)

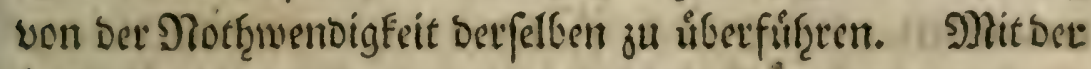
sufferften lingebuld erwartete iil) biefe Säh)e, als eine von

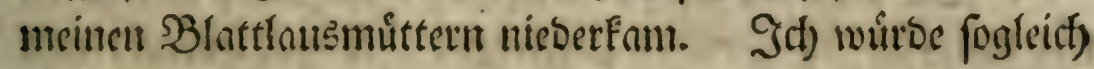
bie junge Blattlauts allein geferfet, und and) fo aufgejogen

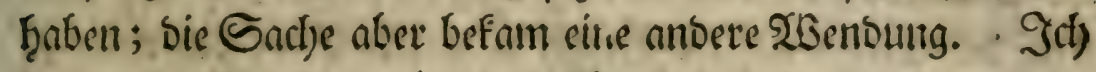

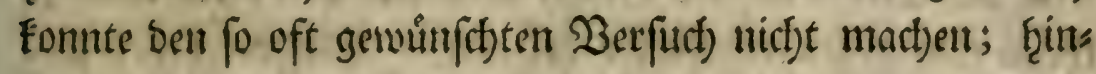
geget aber machte ith eine fonderbare und ganj unerwartes

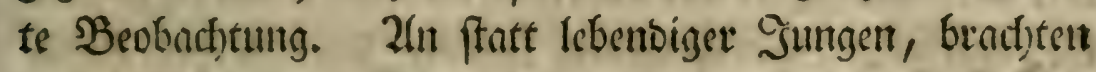
meine Mhitter nur Foetus zur SWelt, weld)e an Beffalt

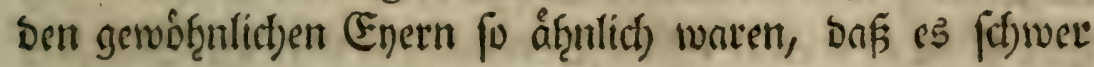
war, fie nicfte bamit ju verwet)feln. Zflles baran war volls Eommen glatt. Das Mifroffop felloft Eonnte nicfyt bie ges

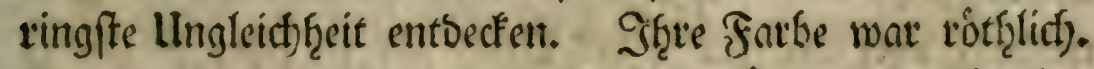
Sie waren etwas Eleiner, als bie BBlattlaufe diejer Zfrt ben if̧er Geburt finto. Ift Den Zweig waren fie angeflebt, und grófrentheills, wie bie Ener vieler ambern Sulfeften, bidt)te

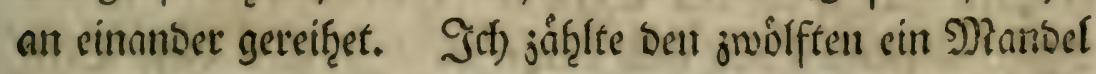
Diefer Foetus, an beren Feervorbringung bie bicke SZlattlauss

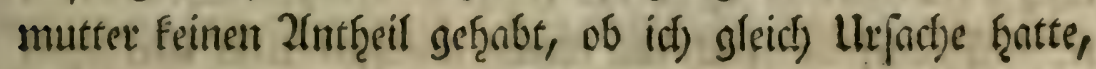

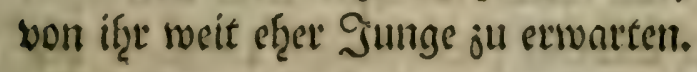

Es murbe mir bie Reit bis zu bem Zfugenblicfe fef̧e Iang, Da eine von meinen B̉lattlausmutttern mit einem

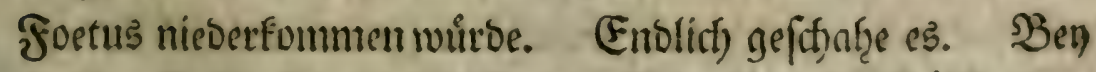

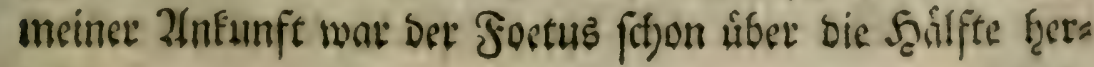




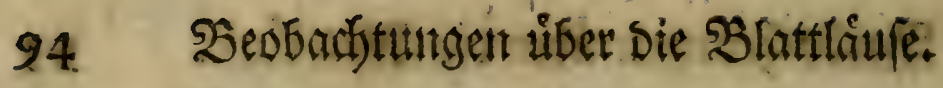

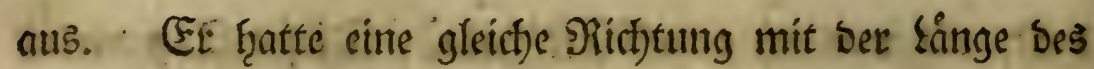
Swoiges, an welchem er mit Dem ganjen Theile. peines Leis

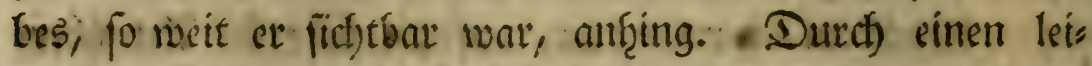
midj)ten Saft, womite er ứerjogen war, flebte er an ber Pitinte vefte. Sogleidh berwafnete id) mid) mit einer toupe,

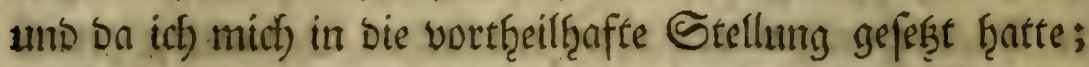

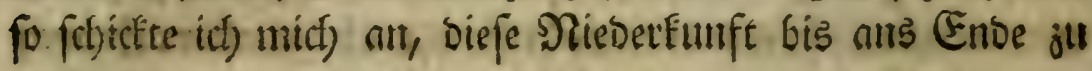
beobaid)ert.

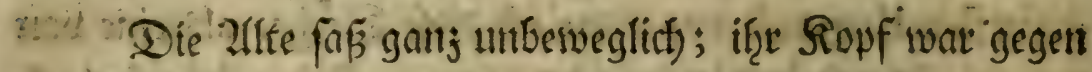

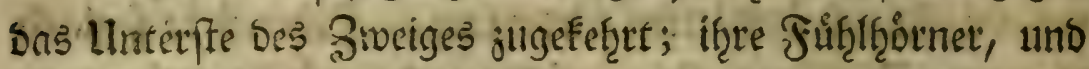

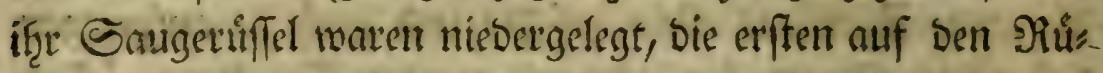
deen, Der andere auf Die' Sorruft, unt das Enoe Des Şinters theils ivar gegen bie Miimbe geftellet. Diefer legete befons

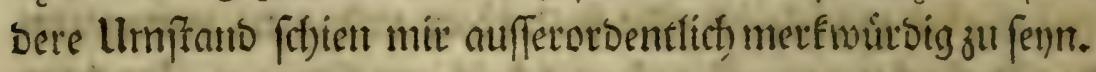

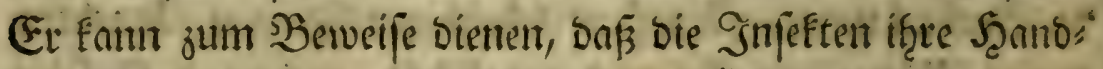
Jungsweife, nach Den llmftänben ju veránbern wiffen. Sidj

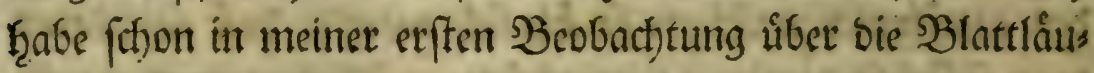
fe bes Spinbelbaums gefagt, als idb bas, was ben, if̧reet

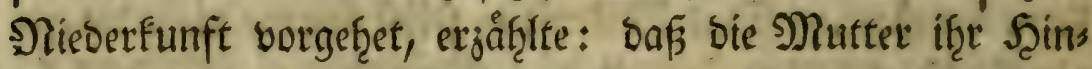

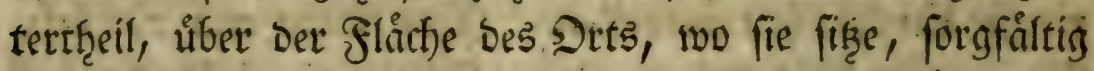

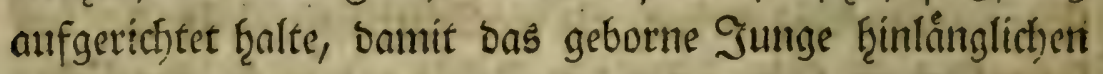

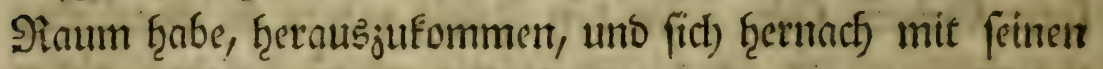
lángften Sưffen an sen Stengel anguflammern. Meente SBIattlansmutter war weit babon entfernt, ebent biefe Etels Iung anjunef̧ment, ba fie nur einen foctus jur $\mathfrak{W}_{3}$ elt brad)s

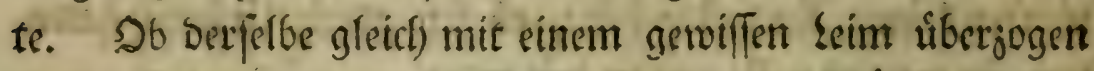
war; fo founte er bod) nifft in féner ganjen sainge an ben

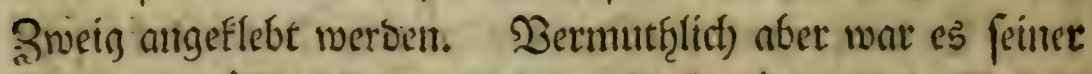

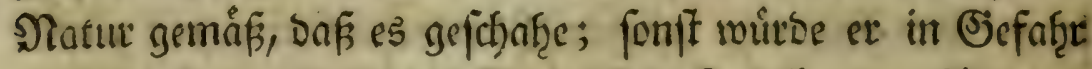

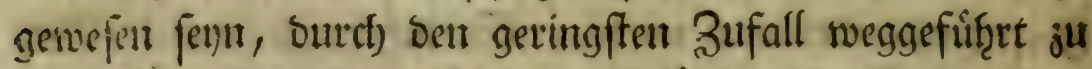
suerben. Sie war aljo fef̧r forgfóltig, bie Epif̧e iţres 
96 Seobachtungen úber bie Blattlíufe.

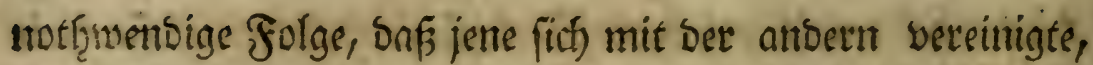

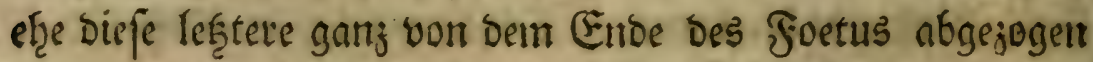

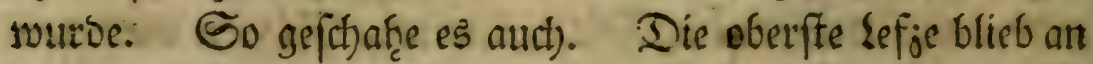

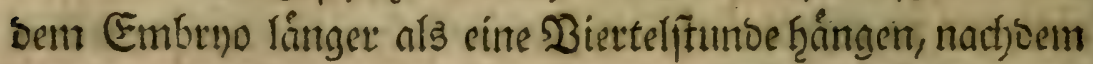

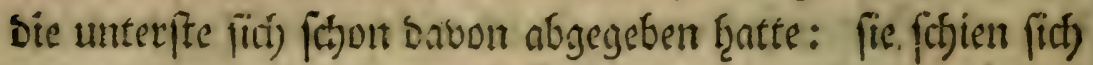

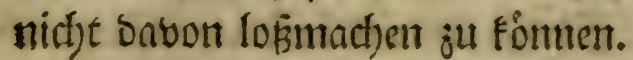

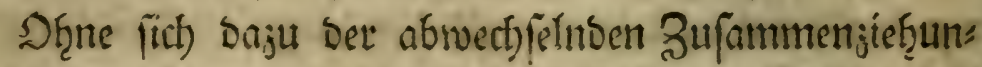
gen unt 2(tủbåhূnungent bes, bell ber Defnung ber Nutter:

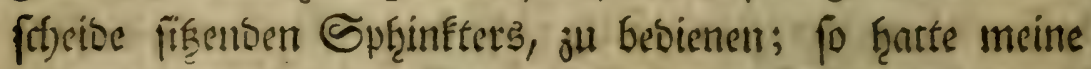
SBlattlausmutter, meines Evend)tents, ein gef(d)winderes unt wireffameres פJittel, fict) lof zu mact)en. Da fich Der hees"

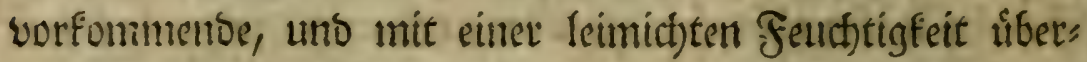

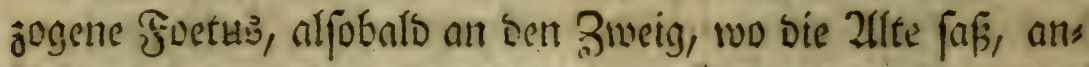
flebte; fo burfte bieje nitfts weiter thutt, als etwas vor"

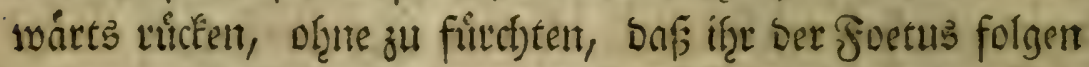

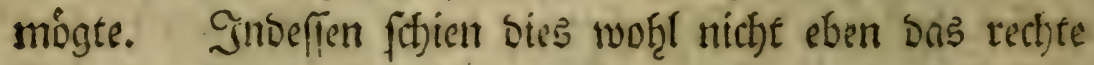

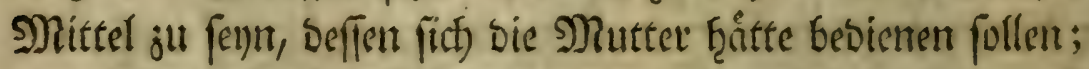
es wứrbe nuch fưr ben foetus nict)t gut gewefen fentr; vors ntemlict) ba ber leimichte Saft in Dent erfften Zurgentlicten,

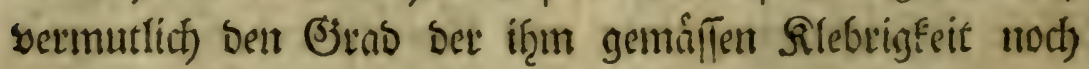
nichte erreid)t hatte. Eie jog es aljo vor, baf id) fo rebe,

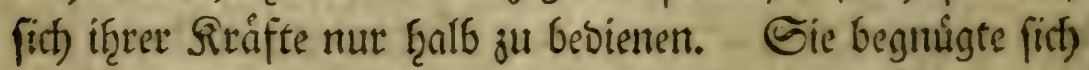

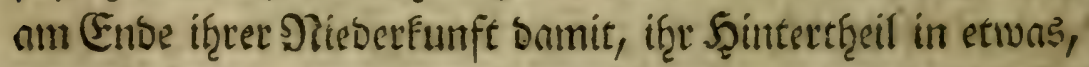

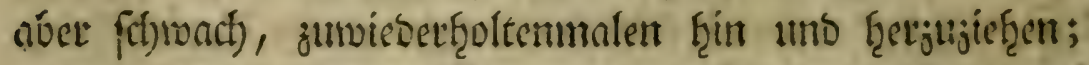

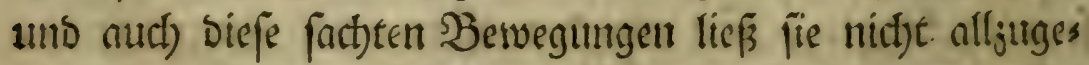
fotminte auf einanber folgen; fie madte jiviffont jeber cine Elcine गुaulfs.

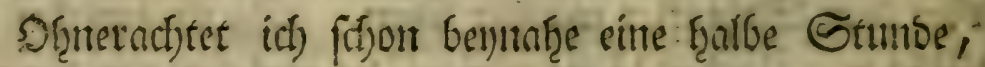

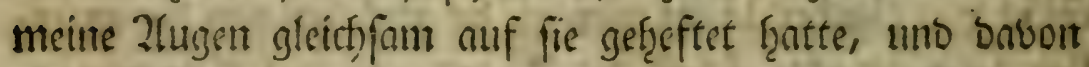

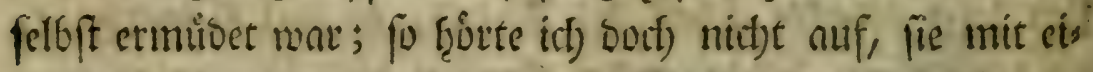
ner guten Soupe ju beobarbten. Enolich foum ber ?lugen 


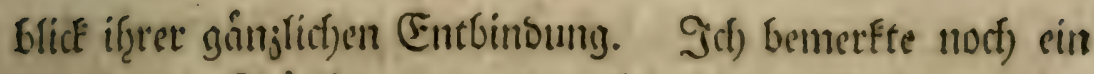

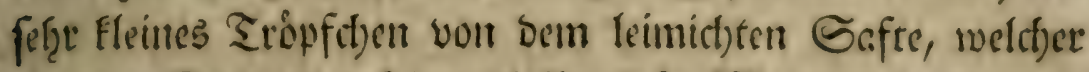

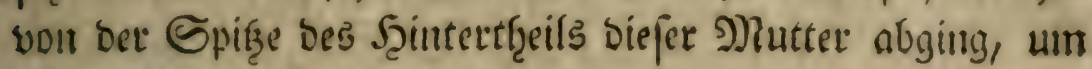
fiif) auf ben Foetus jujiefren.

Sưr Den foetus ift es fo wichtig, bnes fid, bie allte

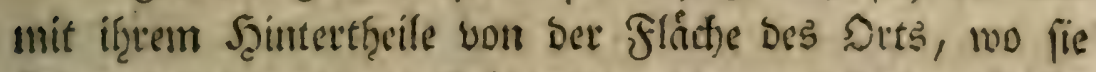

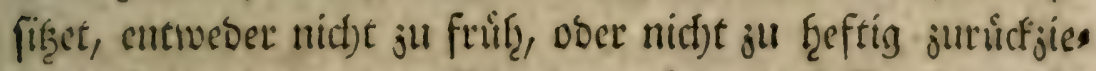

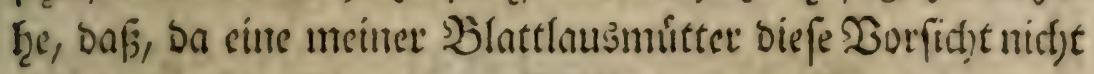
geverautchee, ber Soetus jum Thęel von Dem Stengel, wo er

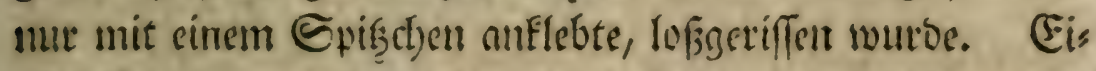

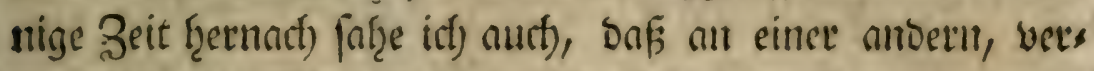

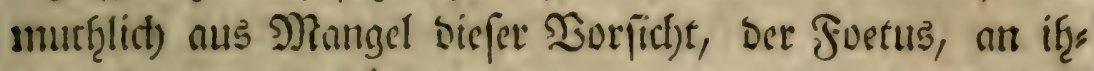

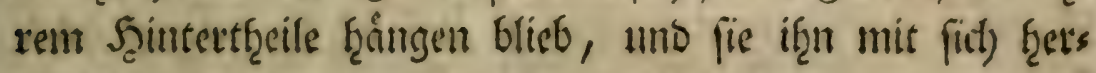
simtrug.

Şen Selegenf̧eit bes Safts, woomit ber foetus, ben feiner (jeburt úberjogen ift, bin idi) alf einen (Sebanfen ges

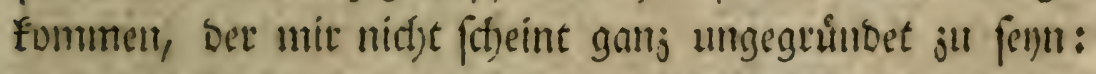

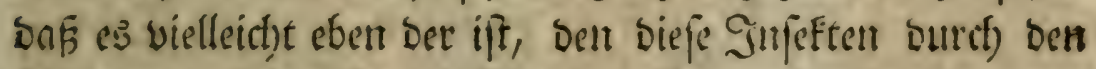
2lius von fiuf) geben. (Eint.) Eie fiaben benbe juveen Eigenf(t)aften: Die Silebrigfeit unt Durt)firt)tigfeit, mit eins

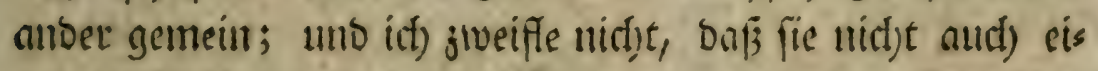

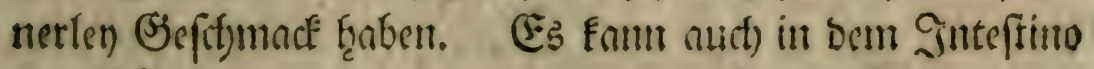
ber Şirmutter ein gemeiuf(t)aftlidjer Cannal fenta, Durúf) suelchent biefer Gaft gef̧et.

Den vierjefthten Plobember verfor ich) cine von meis

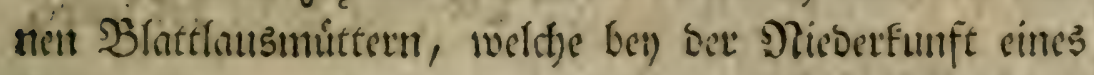

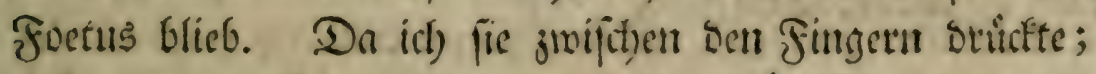

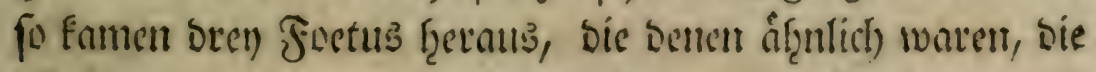

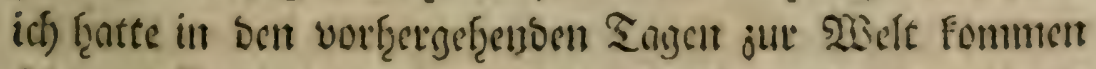
ferben. Daber) mact)te iff folgento S3imnerfung: Das bie

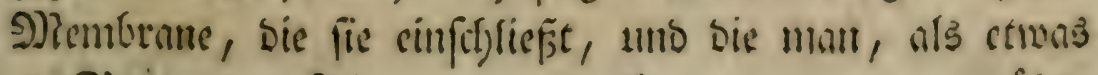
Sointet I. Th). 


\section{B̧ebadjtungen tiber bie Blattlåuje.}

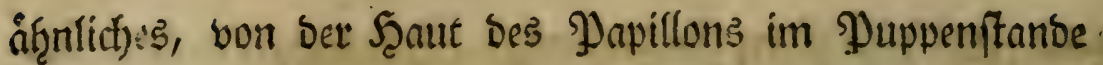

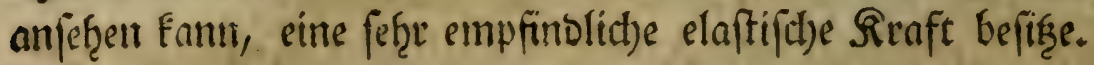
Wenn itf einen von biefen Foetus mit einer Nabelfpire ets. roas bridfte; fo jaf̧e ith feitte Scaut nachgeben, uno fict)

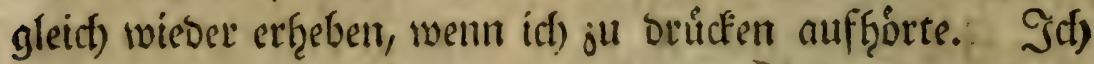

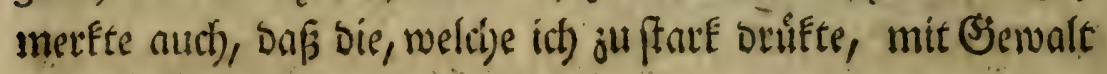
getplaf̧ten.

Doif ich will bies Journal nicht ju weit treiben: "s

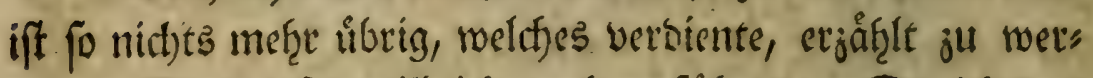

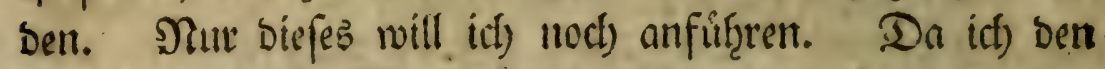
funfzercnten biefes 9) Ronats ineine Blattlausmutter in meine. Sammer jutitctragen mufte; fo lief ich fie bajeloft andst. Sage, in weld)er Beit fie auf bein Smeige, wie angeleint. blieben, weil fie ofrne 3weifel von ber Rålte erftartet waren. Sie waten nun bis nuf brene, bie Didffre mitgerect)nt, wes niget geworben. Den been unt jwanjigften trug id) fie in bie warme Stube, un ju verfuchen, twas bie 2 Bárme für eine 2 sirfung nuf fie fraben witrbe. Diejenige, welche mit ber Dicten i̊brig blieb; Denll es feftite noch eitre von

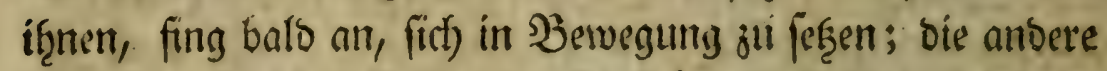

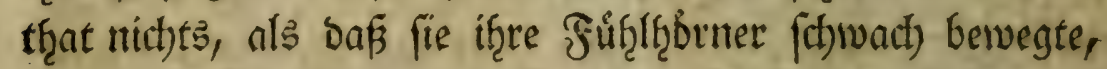
unb obngefâthe uad) jween Gtunben, fiel fie ganj fait)te auf

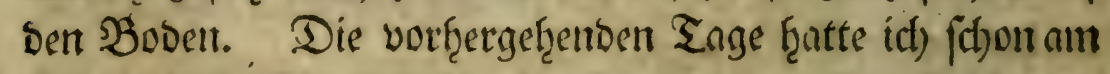
Enve if̧res Şintertf̧eils cine 2art von weiffen Schimmel

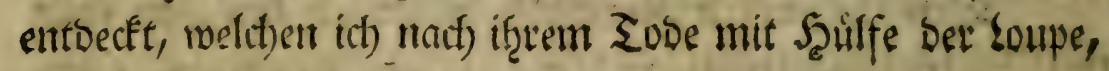
noch beffer beobactet thabe. 


\section{2(d) te 2eobatiftumg.}

Beobadittmgen itber Die Foetus, weldhe Die Dis c'ent $\mathfrak{B l a t t l a u s m u i t t e r ~ D e r ~ ( E i d ) e ~ z u r ~} 28 \mathrm{~B}$ elt

\section{bringert.}

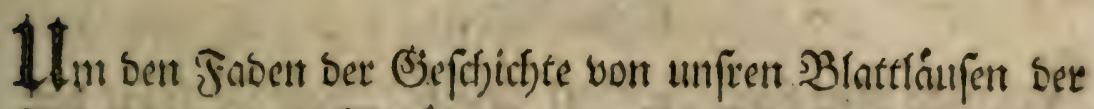

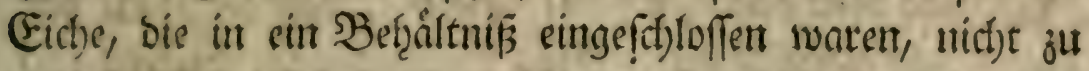

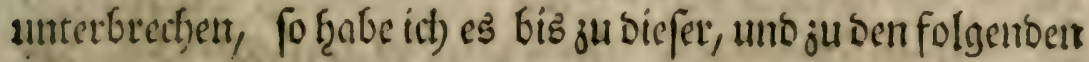

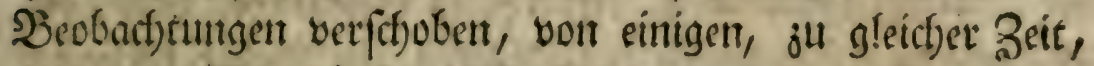

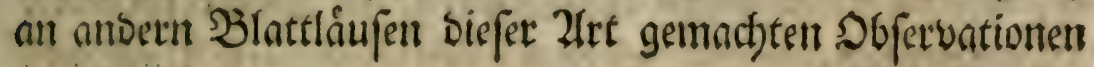
, ofu tesen.

Die erffe biefer Beobactjtungen betrift bie Foetuß. Sd) fand Dergleicljen am ein uno brensigften Detober, eine

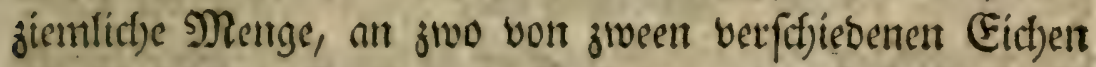

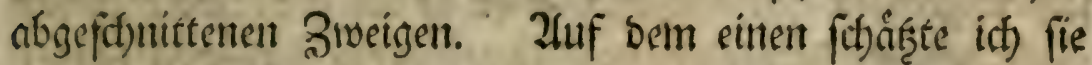
mef̧r als ein Sdfuck, auf bem anbern aber auf ein Manbel. Sie warent bentathe, wie tie Ener von bielen Sefjemetterlins

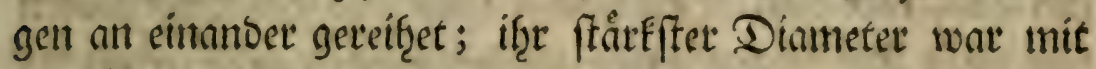
Der lange Des Zrweiges parallel; auf welthem inbeffen einige

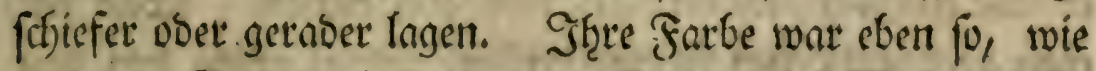
ant betren Foetus, bie vor meinen 2lugent bur siolt gefom melt waren, nemlich rótḩlict). Sn ber Didfe waren fie

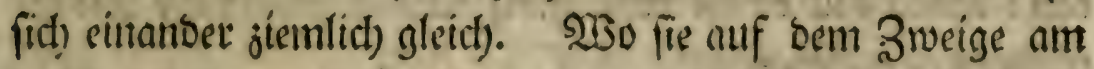

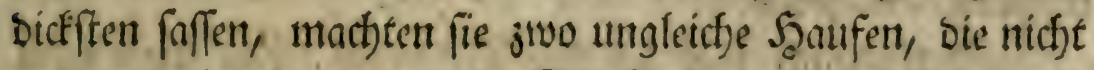
weit bont einanber waren. Die kiftigen waren in einiger Entfermung fíer und ba jetfftenet. Die auf bem anbern Şweige machten mut einen f̧aufent aus. Sic waten aber

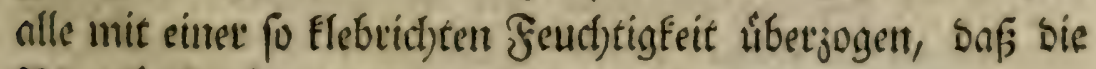
BZlattlệfe Ģängen bleben, Die baruber geţen wooltent. 
100 Şejbadftungen ůber bie Şlattláufe.

\section{शeutte Bepbad)tuntg.}

2tndere Beobadtutungen ifber die Foetti, weldse.

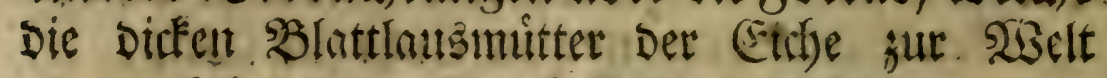
Gringen: Daß̧ Diefe Stwettls twirflidje

\section{Ener find.}

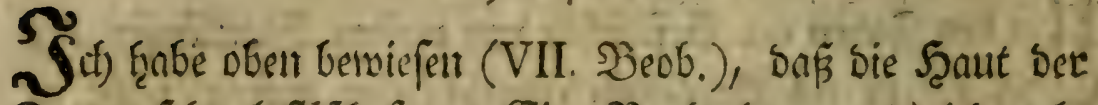

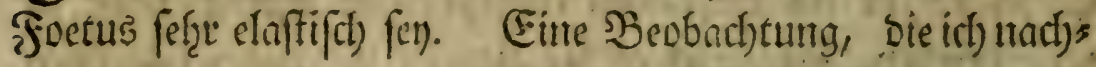

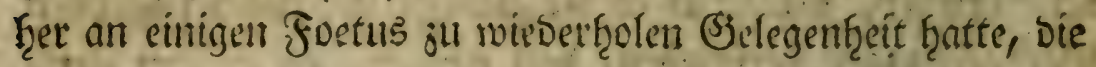

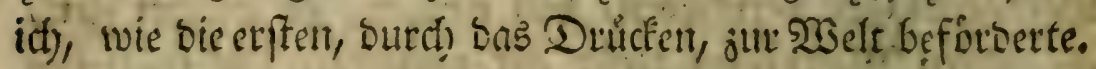

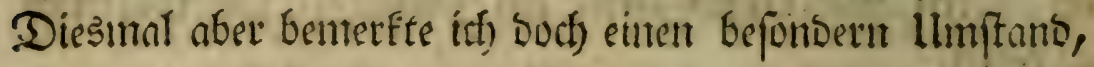

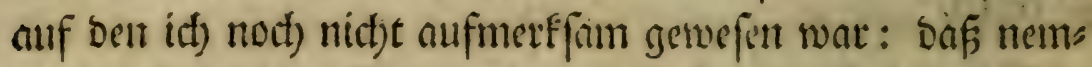

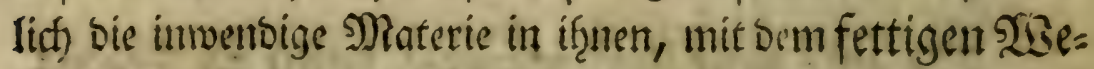

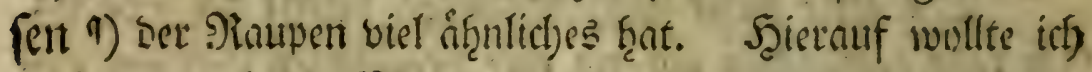

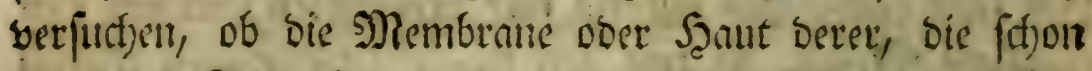
feit e einiger Beit gelegt warent, eben fo beugfam unb elaptifift)

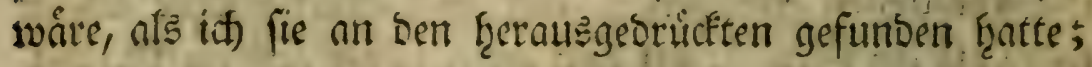
fie frbjen mir abeer beffer ju fenn, und ber Saft, ben fie in

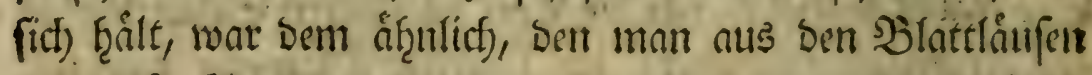

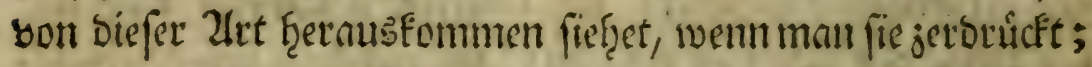

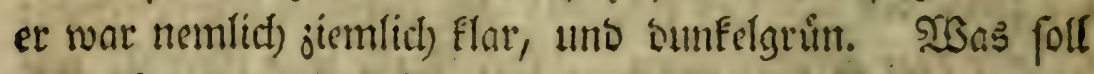

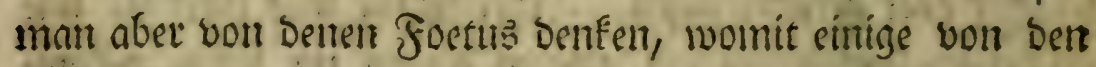

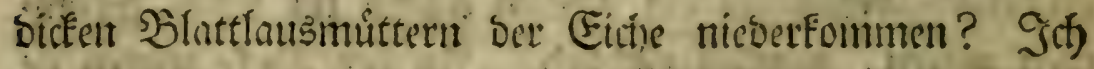

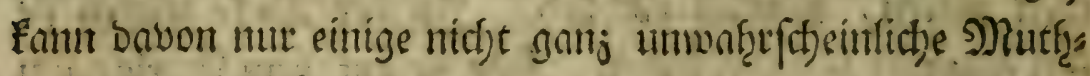
masfiungent angébern.

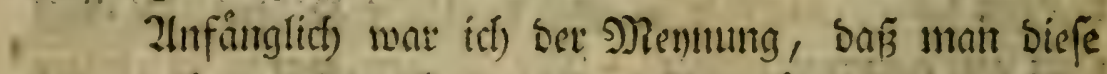

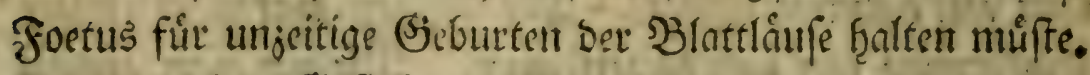

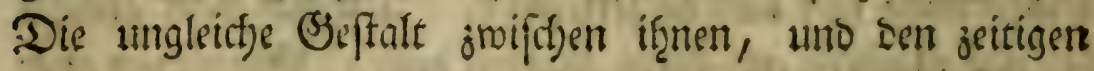
Sblatts

ๆ) Dab fettige Woefen in Den Tampen if sie gelbficfe Nintetie, bie cinte gervifien Fettinfeit gleidfet, uno Die lylare ausfullet, meldje uon antern Theilen leer aclofien find. Reaumus Me-

. moir. pour fervir à l'hift. des Inf. Tom. I. p. 145. 


\section{3eobadjtungen ûber bie 3lattlánfe. Ior}

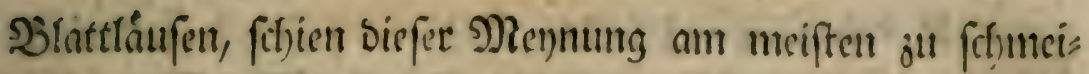

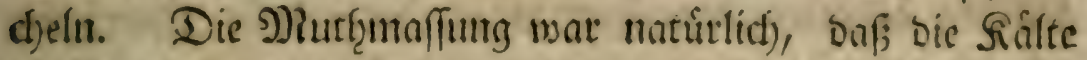

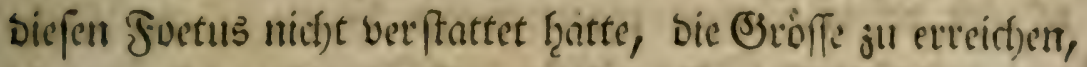
bie Den jeitig gebornen Jumgensigen iff, uno bie fie in enee günftigetn Jnf̧rsjeit wuirben erlanget haben.

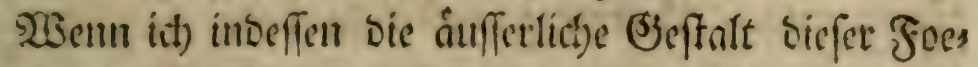

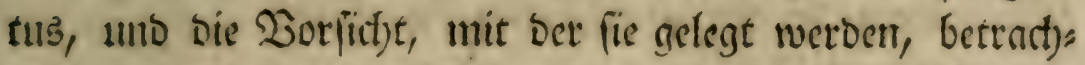

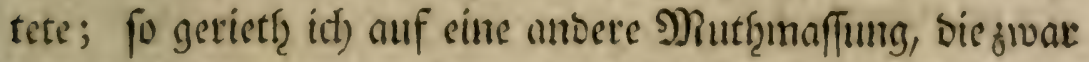
fefze fonberbar suar; aber mir gleidh geficl. Sidl) bilbete

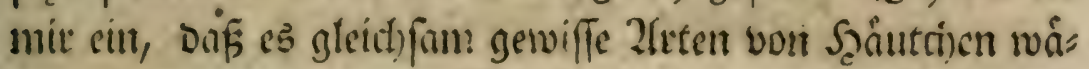

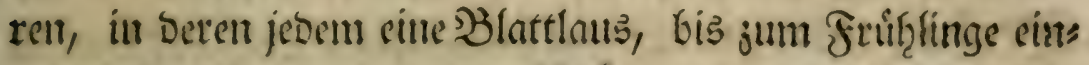

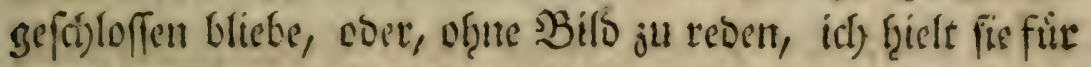

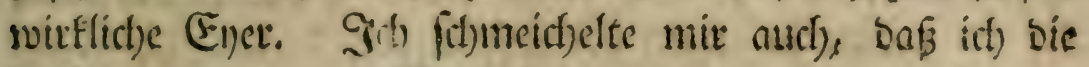

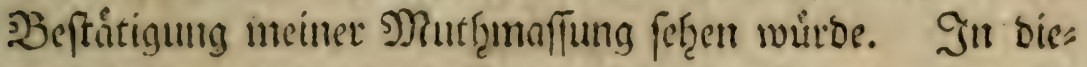

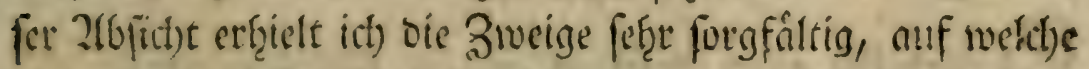
cenige von biefen foetus gelege wnen; instefontore aber bent, auf weld)en bießBlattlausmutter forfen, bie id) mit sis

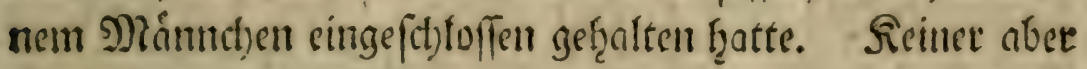
sumbe lebenoig. Sie wurben alle felwaro, uno vertwocts neten.

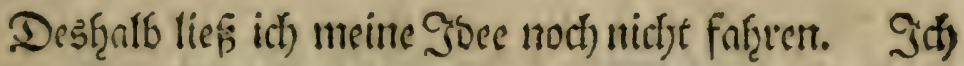
verglid) meine Bilattlausenet mit benen, aus weld)en ges

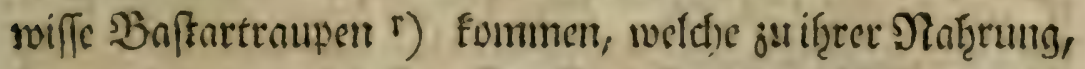
fo ju reben, ben feinfren Dumft einfangen miffen, ben bie

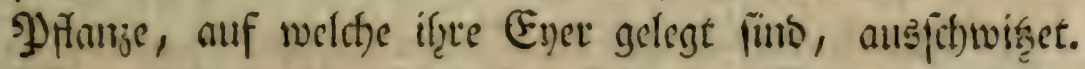

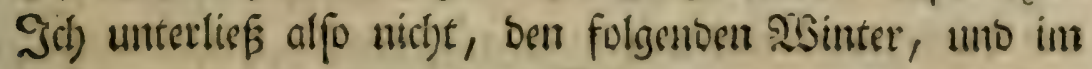
(s) 3 Infifans

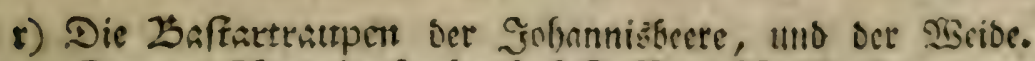
Reaumur Memoir. fur les Infeet. Tom. V. 25afrittranpe nentet mant ein jebes Jnleft, weld)es einer Sinupe itt Der (sies

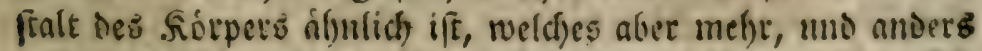

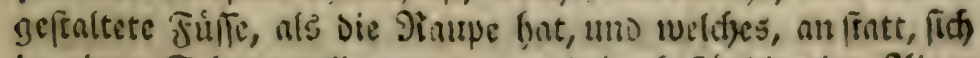
in eillen Ed)metterfing ju verwandeln, beftantius cille fliege mit vire Slügetn wirs. 


\section{P̧eobachtungen tíber bie Slattlåufe.}

Zlnfange Des frútįlinges 1741. biefe Ëner, Dber foetus ju juchen; allein alle mein Sucten war vergeblich; ich erfamus te mur baraus, Daf́ meine bicfen Blattlâufe ber (Eidje

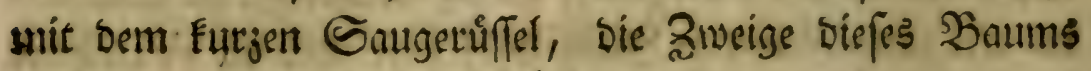
verlaffen, wenn fie if̨re B̉atatter berlieren, Dber wem es fálter wirb. Linftreitig wiffen fie unter ber Finbe, ober

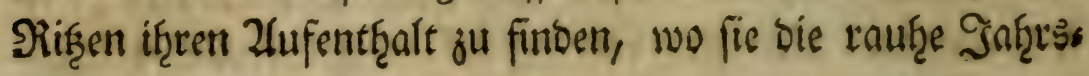
zeit jubringen.

\section{Zefinte Seobactutung.}

Beobaditungen, weldue benveifen, Dafí Die Diffen Blattláufe der (Eidhe Dod) nodh wachjen fénnen, wenn fie gleich) folon frlugel befommen baben.

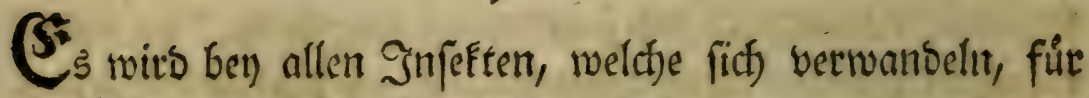

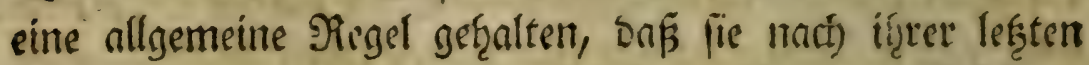

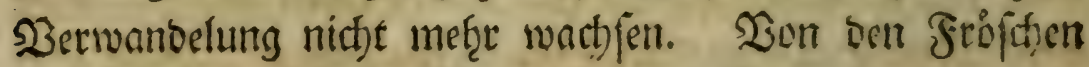

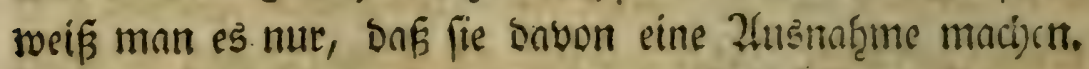

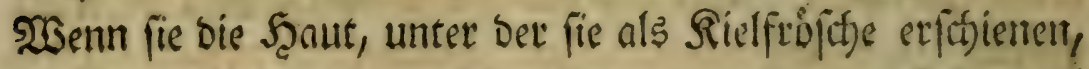
abgelegt ḩaben, fo wachjen fie inmer fort. Isth weis

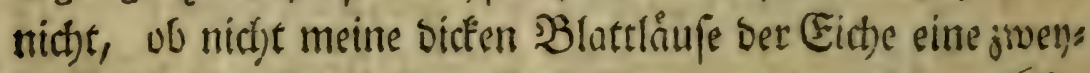

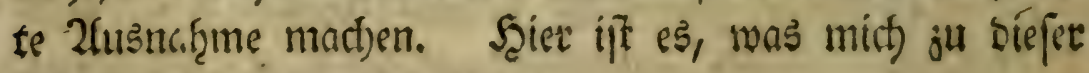
Mutţmaffung bewogen ţat.

2(Is idf eitres ₹ages im Nonat Detober r 740 auf cis

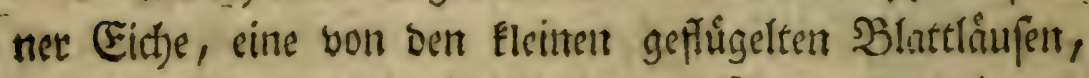

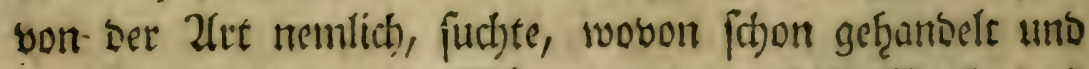

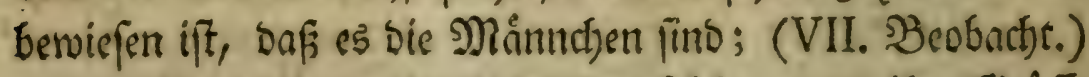

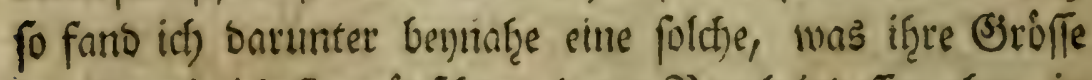
betrift, wie id) fie winnfitte; beven Bound indeffen aber, in Sergleiduung einer anbern Eleinen gefligeltent Blattlaus viel 
biffer war, bie id) imenig Sage vortzere fid) F̧atte begatten

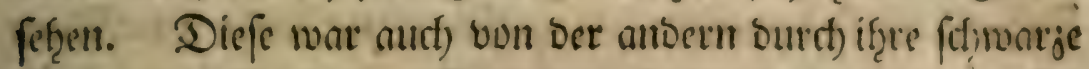
Farbe unterfitieben. Diejenige aber von ber idt) ribe, fiel

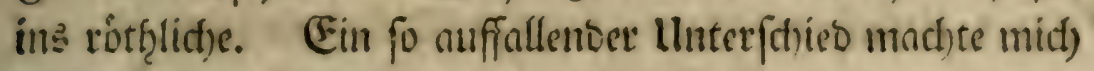

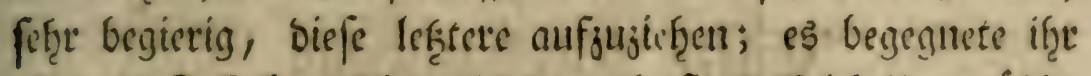

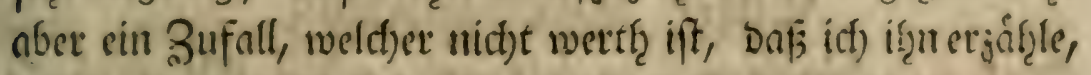

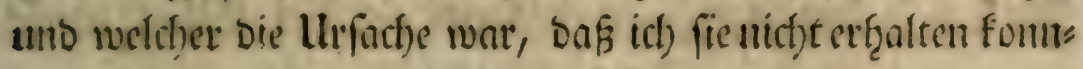

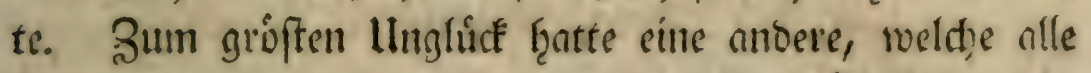
sienfimale an fiid) trug, bie Den Blatrlausmánndien eigen

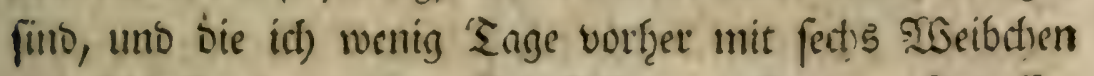

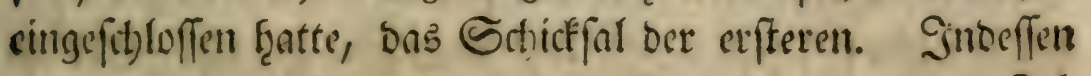

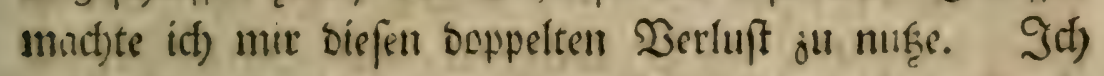

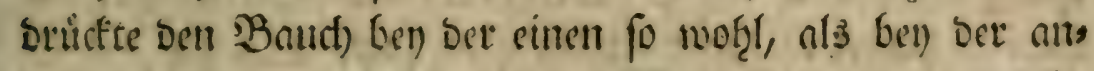
Derr. 2lus Der, bie ich) für bas saseitet)en f̧iclt, fam sin

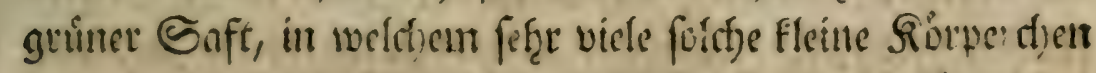
von einer bunflen sararbe fict)manument, bie ich) alfo für nictits anbers, nls für Soertus, ober fúr Einer fralten founte. Ttu

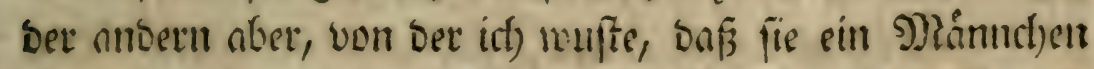

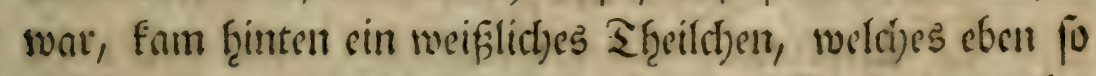
geftaltet war, als bas ith) in ber fiebenten Beobnd)tung bes fiftieben ḩabe.

Eine anbere Blatflaus ber (Eid)e von ebent ber ?lrt,

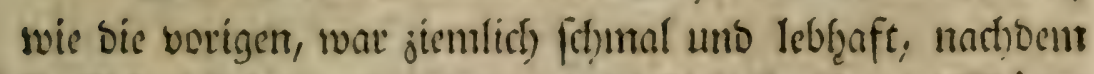

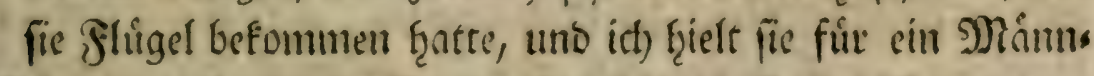
chent; nact) einigen Sagen aber fatge idf) lie fo bicfe werbent,

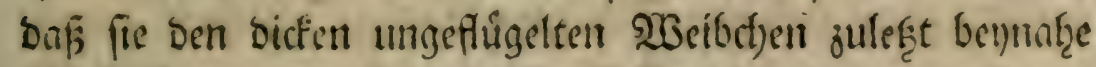

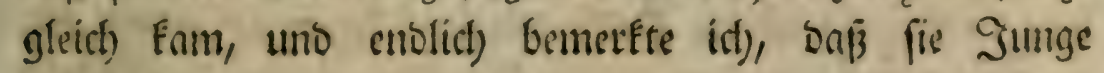
gevaf̨r.

Siefleidf) wirb man mir antworten, baf es mit bicfer

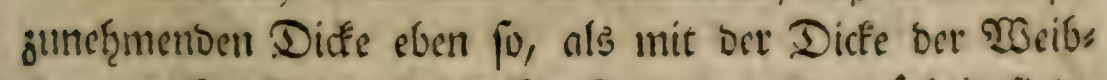

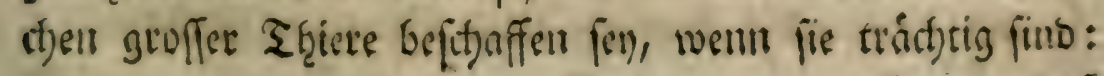




\section{Beobactutungen úber bie Blattliure.}

Dấ fie etwa von benen Foetus fretruire, weldfe bie Şaut ber

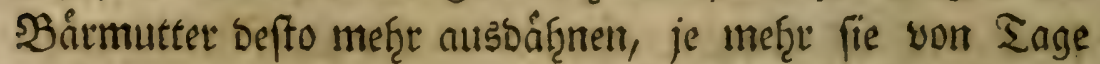

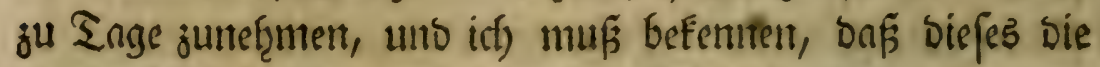

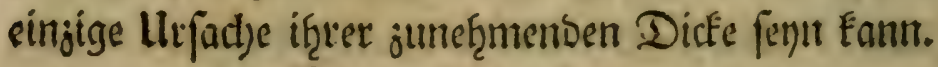

\section{(Eilfte ஒeobadtutut.}

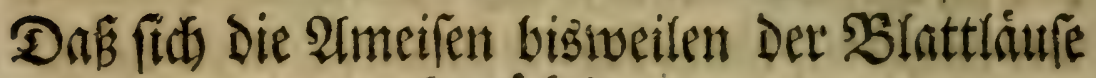 bemaidftigen.}

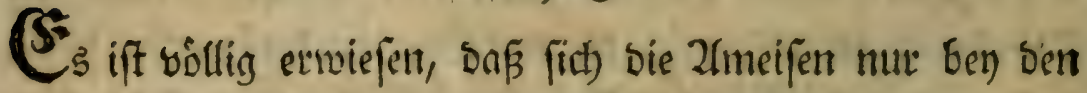

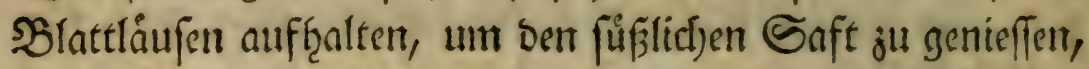
ben fie von fich) gebent, uno bas fie fich alfo nicht feeloft an

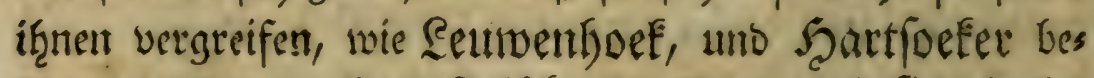

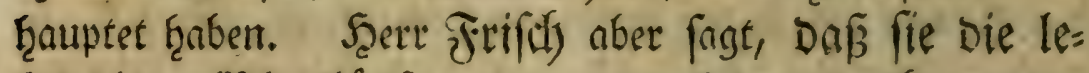

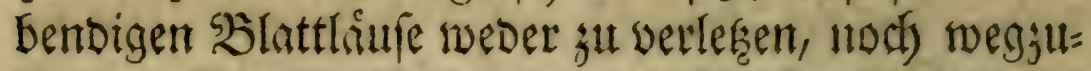
tragent pregen. Deffen of̧neraditet liefere id) Giter eine

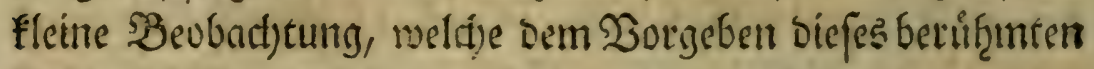
Vaturforffhers fojeint getabe entgegen ju fentr.

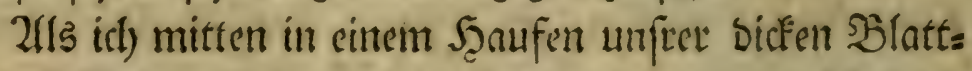

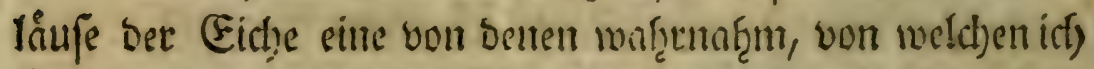

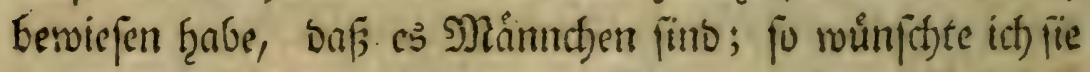

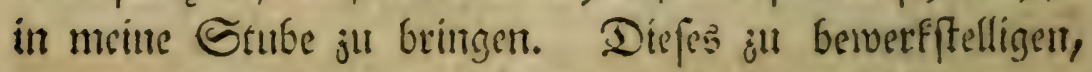

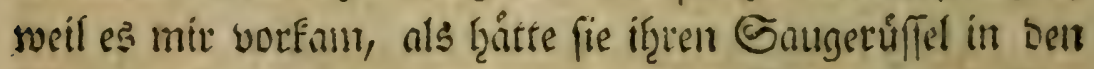

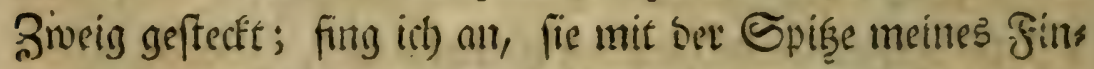

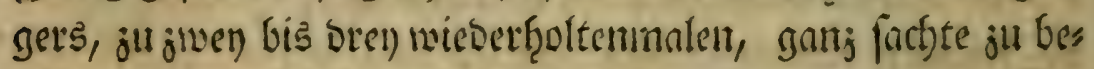

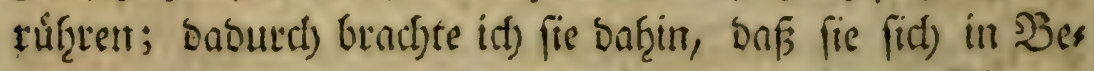

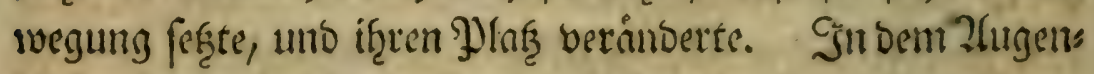

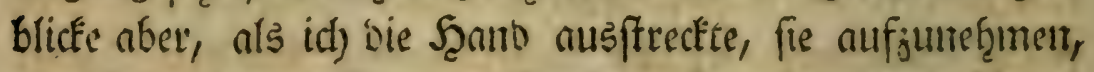
exgriff fie eine von ben groffen Z4meifent, womit bie 33latts

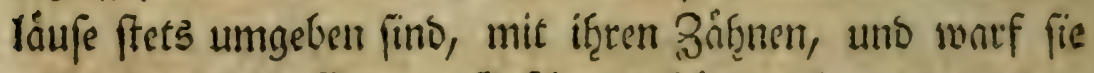

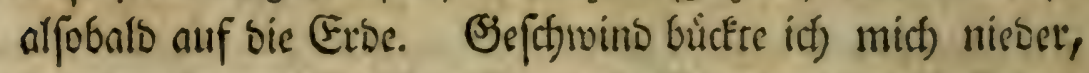

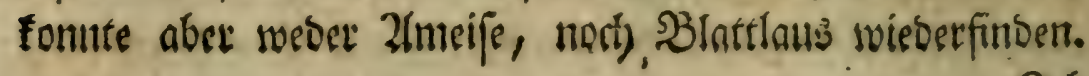




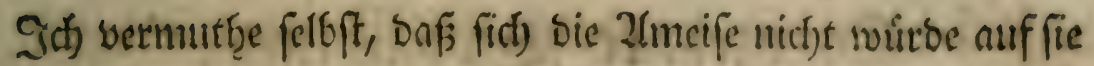

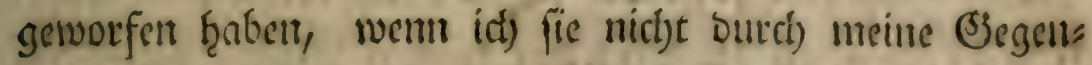

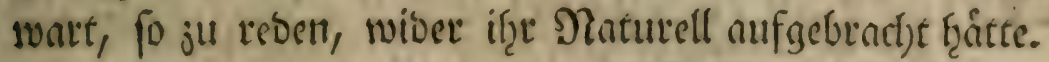

Ulebrigens entbeffe ich an diejer fleinen Blattlaus eis nen befonbern llmftanto, ber mich jweifelf̧nft macht, ob nid)t bie bet)oen Z(rten SBlattláufe anf Der Eiche, eitrerlen

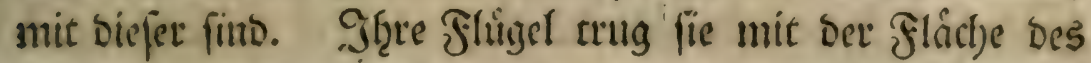

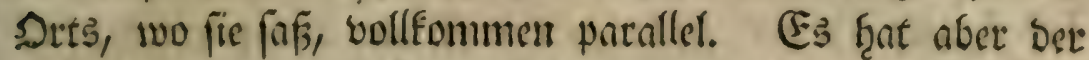

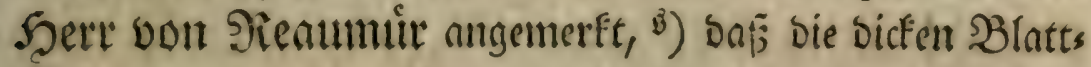

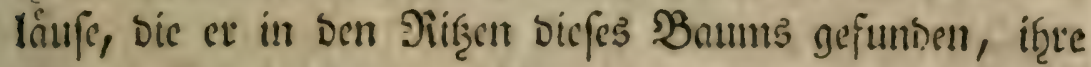

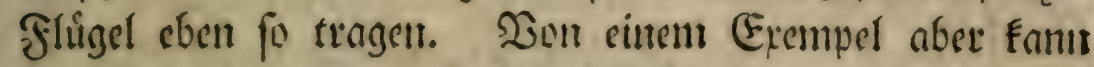

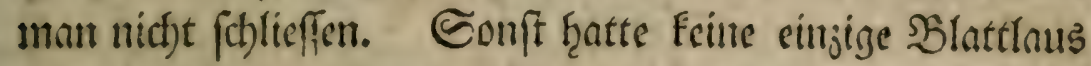
Der von nuir beobad)teten 2frt einen fo langen Sangerúffel,

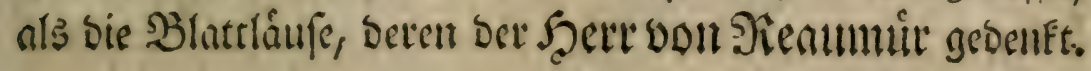

\section{Zwo lffte $\mathfrak{3 e o b a c i t u t u t y . ~}$}

Beobatitung Dicken Sht, Die suf Der Eiftje leben, und won Denten Die Şatt nach iffem Tobe abgehet, werm mant fie gan's fad)e mit Dem Finger beruibut.

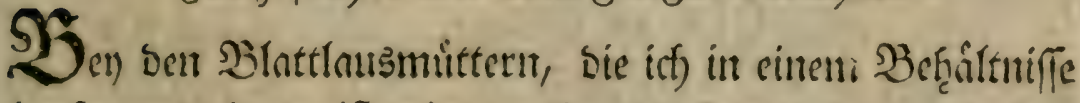

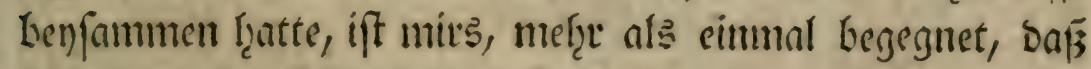
id) fie on bem zlueige figen fante, als werm fie gantj lebens

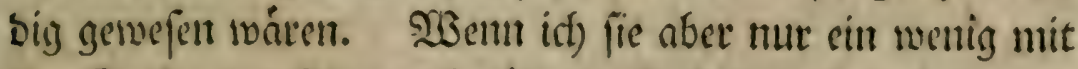

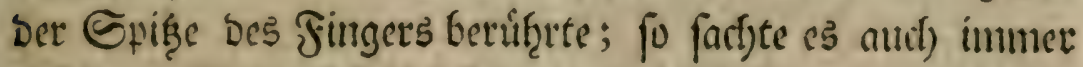

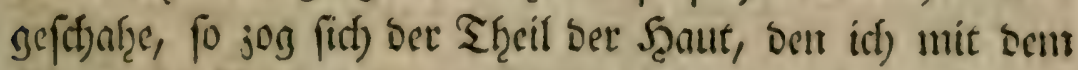

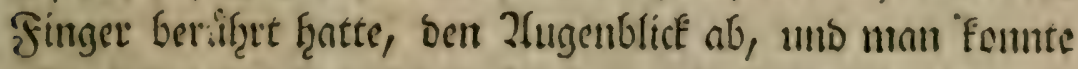
alles intwentige fren liegen fergent. Sben ûber Der 23 mtube

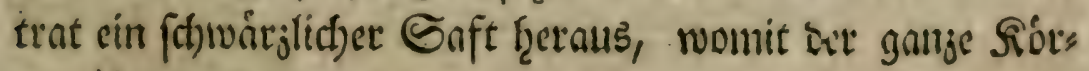
per úberjogen wurbe.

(S) 5

b) Toin. III. de fes Memoir. p. 334 .

Dreiv: 


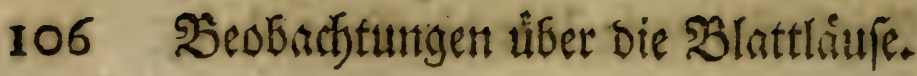

\section{Dreazebnte Beobachtutity.}

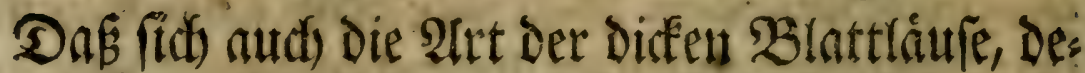

ren segnattung errvieren iit, ofne diefe

פonfuilife vermefre.

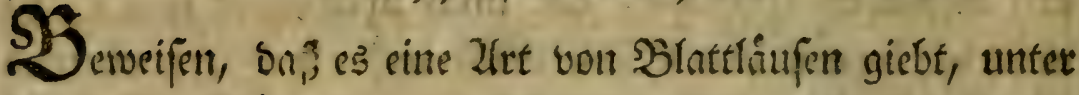

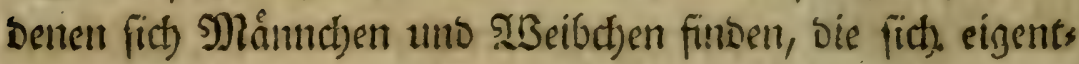
lid) begatten; Das heifift ju ber Frage 2lullef geben: ob

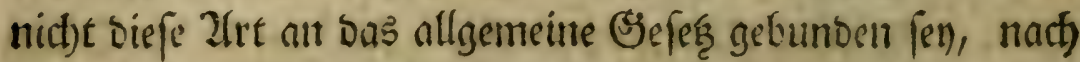
weld)em dic Ergengung, burct) Die Bereinigung benoer OSes (fiflect)ter, uns zroar baburdh allein, gefthes?. TSenn inat

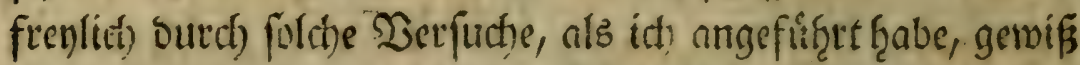

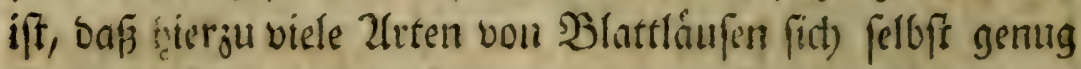

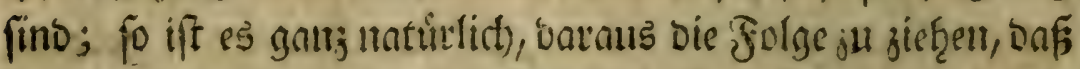

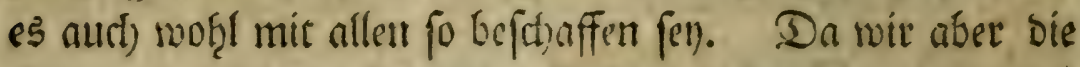
Dromung, nact) welcher liit) bie Natur in thesen befonbern

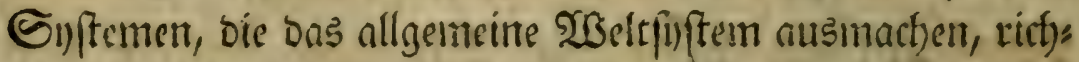
tet, fệr unvollfommen fennen; fo múffen wir gegen fordte

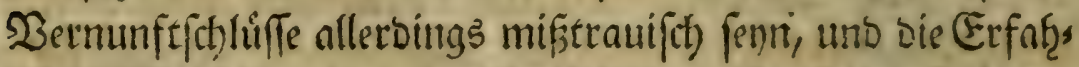
rung fo oft befragen, als wir fénnen. Dbgleid) bie Afna=

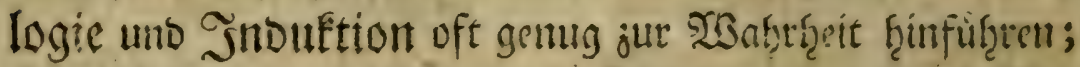
fo berrủgen fie body Gisweilen. Davon gieft uns die Pas

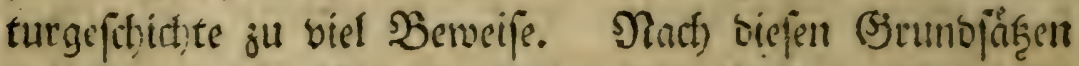

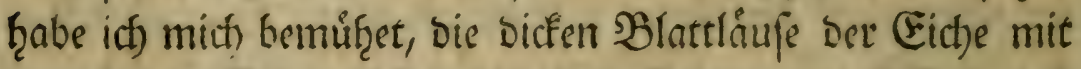
Dem furjen Gaugeruiffel, von if̧rer B̧eburt ant, einfain nufs zujlef̧en. Da úterbem ber Şerr bon henumir, bem

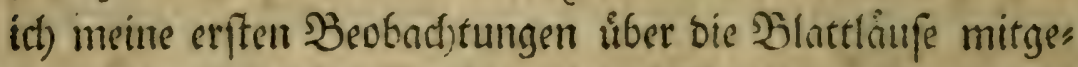

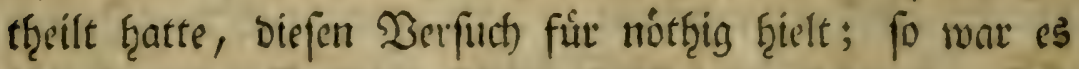

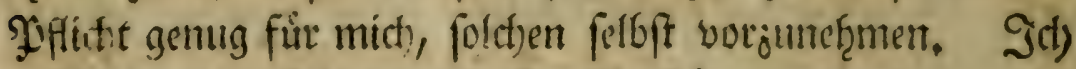

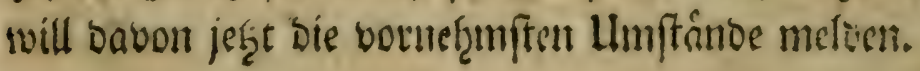




\section{Sanebutch) Der $\mathfrak{B}$ cobaditumgen uiber Die Diffen} slattlaufe Der (Eid)e mit Dem futren Eantgerufifer,

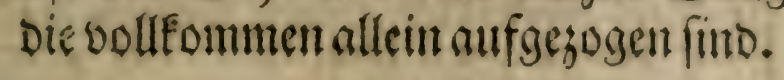

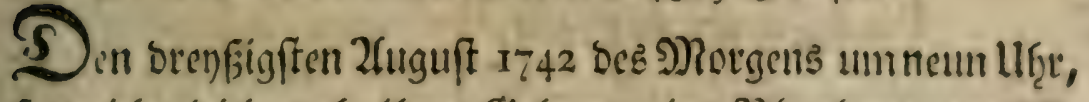

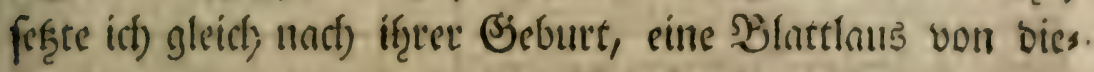
fer Zlrt, allecin, bie vor meinen Ztugeri grboren want.

Derr jiventen Sepsember, bes Macţmittages gergen

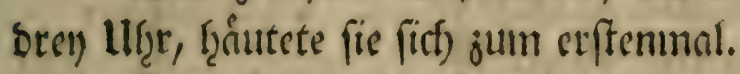

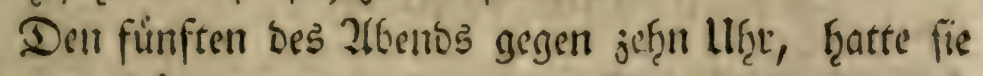

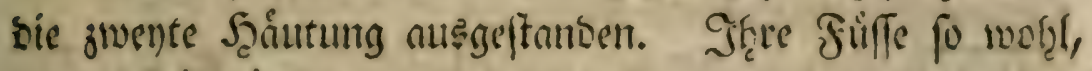

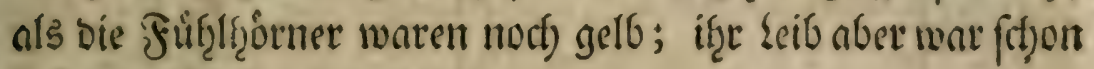
foft gantj braul gewoorben.

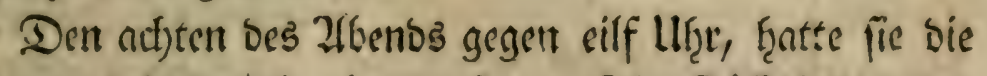

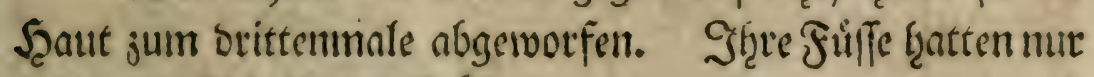
nodt) ben Schjein bes Gelben.

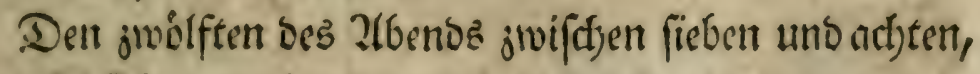

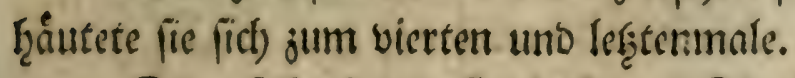

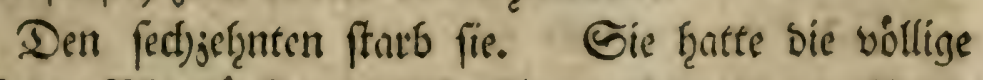
Brtoffe ber Blattlaufe vont biffer 2lat erreich)t, bie jull thereen

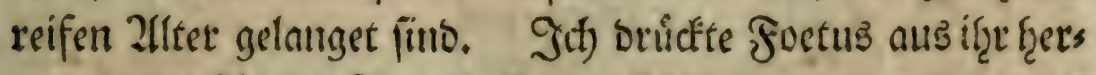

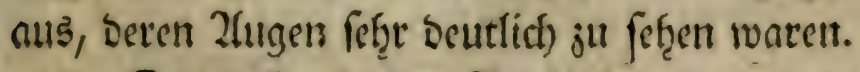

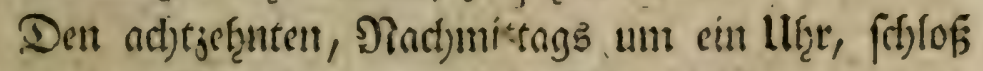

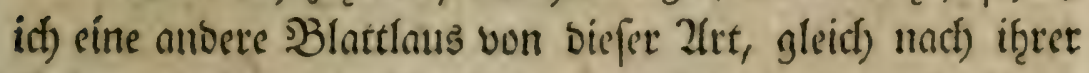

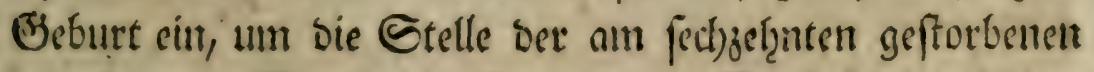

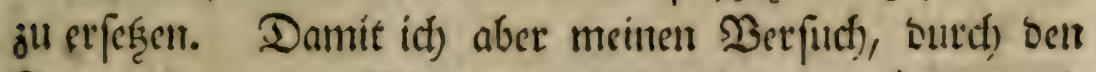

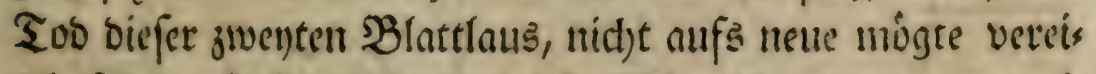

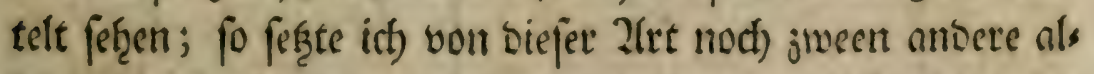
Iein: bie cinc ben neunjoģnten, unb Den jwanbigffen bie anbes

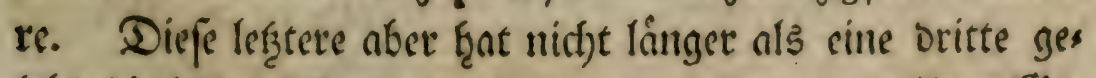

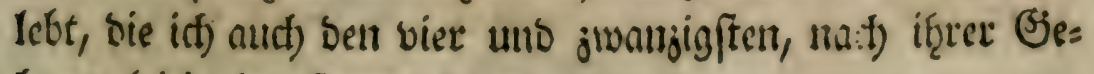
burt gleith eingerpertet ḩatte. 


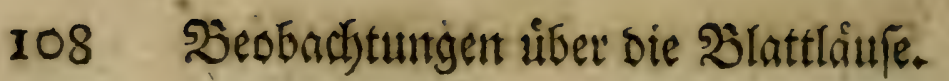

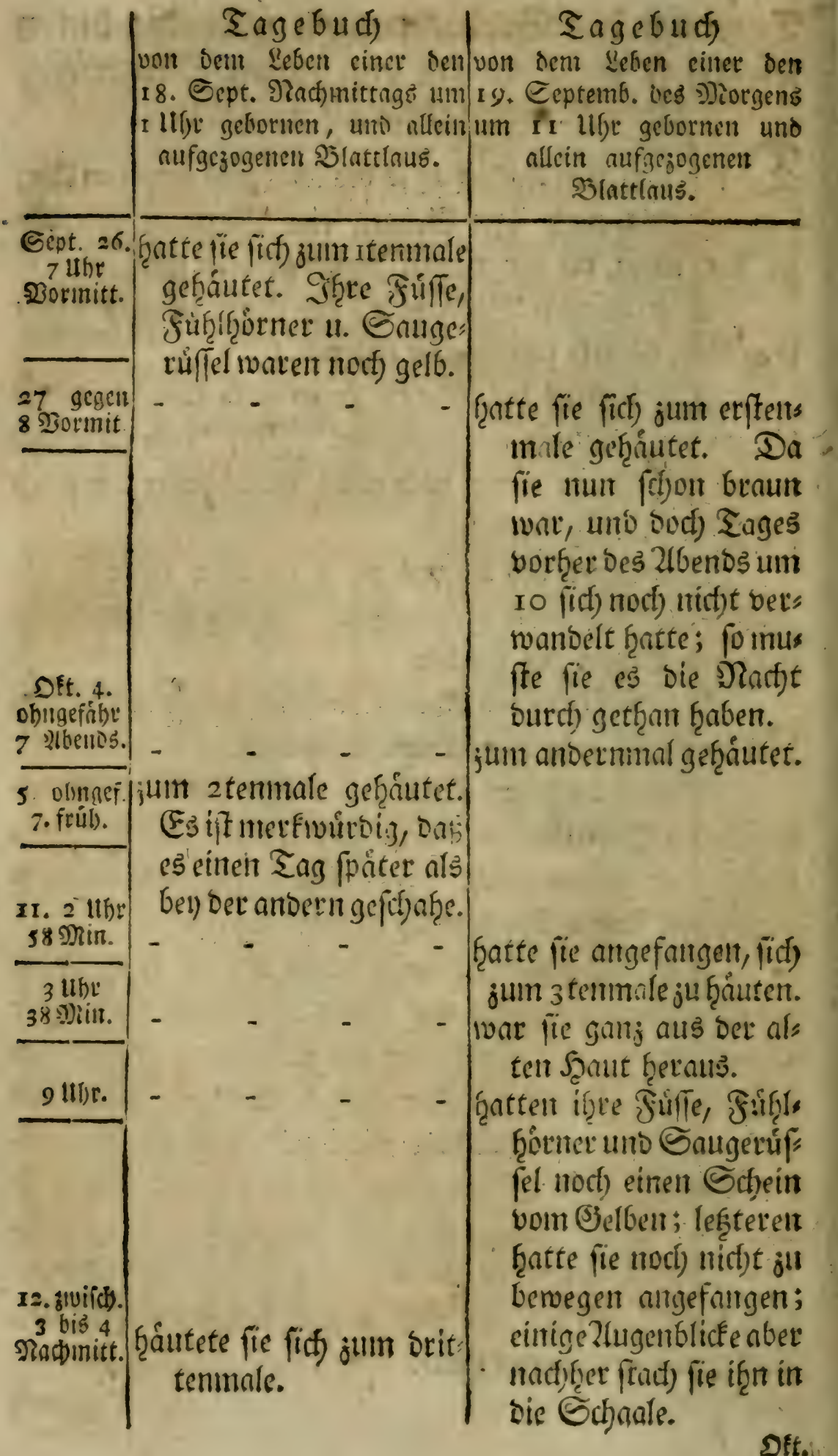




\section{3edbactutugen tifer Die Blattláufe.}

Dft. 23. Qca. 3 ubr S?a(b)

24. genen

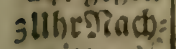
mittags:

s?

Sicubr. 5

8. \{tuál).

11. frith.

24. frủit.

fanto id) fie beynafe toot, ober cigentlidjer zll tedell, von Det Nadjteñlte erfantrt, on: tin bав Tlermometer aulf 4 Sirad ulber Den Sefrict: punft gefallen war. Id) trug fie aljo in sie warme. Etube, um fie twicoet atif: zuleben; es batte aher bic gesatme auf fie nidor viel 2̧sirtung melor: Sith fafie

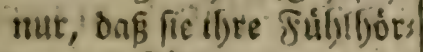
ner: unb frife cin tuenig be: wente, ofme von der Etelle 3ิ4 formmett:

25. frifi, liwat fie toot. angefangen batte zu gebály: rén; und id) foldacs oet ver: mindertent : fd)rieb; fo trug id) fic in bert vorigen 2 f(ifd)lag, ontin bie gecwólynt. Fimperatur $5_{5}$ 20 Sirnde Des Picaumúr: (4)en Sbermometers. ifr. batte fie cinten 5oettis gut Bebradst, Den ids mit oet Range des 3roeiges parallel liegen fand, 4. nuf weldsenz fid) alle aufferlid)en Sbeile Det 2 lattlaub, erfaben lie: geno jeigten. Io bemerfte alid), Dấ Dic SBlattlaus in Der Diffe (d)on merflid) abs: genommen, 06 fie gleich nut erft biefen cinen foetus ge: boren batte. Golte fie auf ju rebert. 


\section{Sienzelunte $\mathfrak{3 e o b a d t u n g . ~}$}

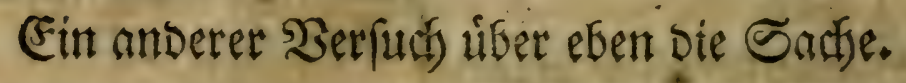

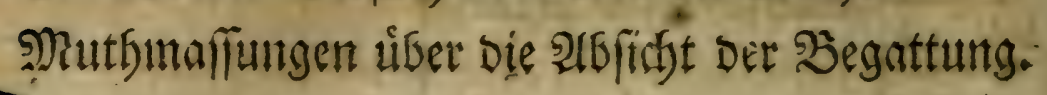

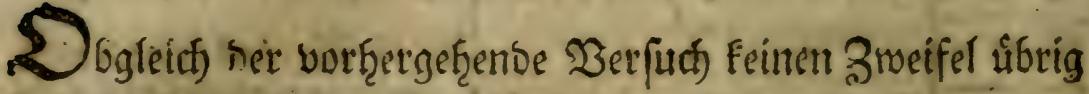

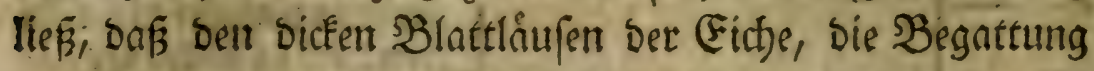

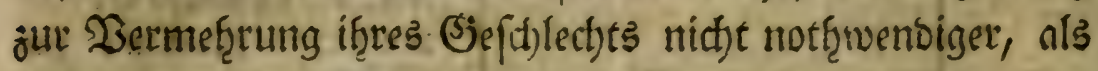

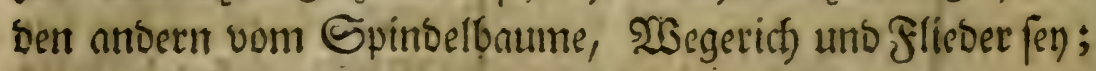
fo gluubte idd, ba mir vor ben Gentent vorigent, allein aufges zogenen Bblattláufen, bie eine gar nithte, bie anbere aber

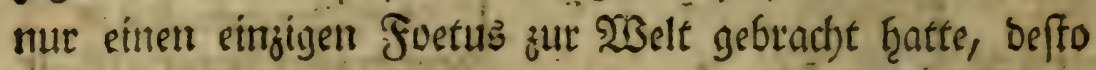

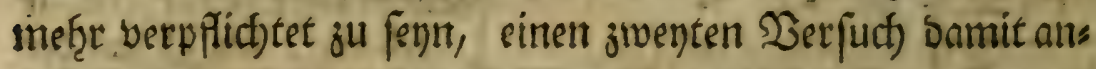

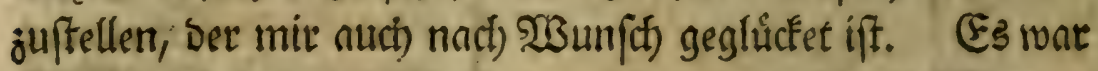

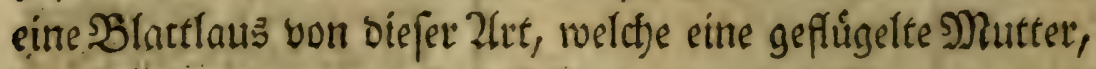

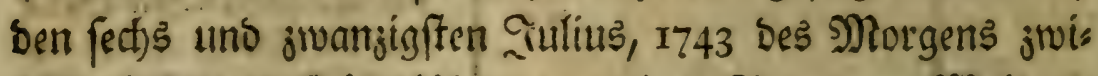

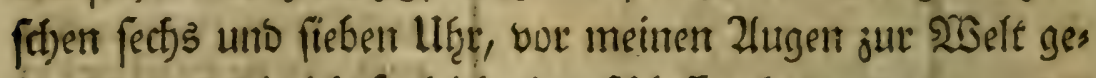

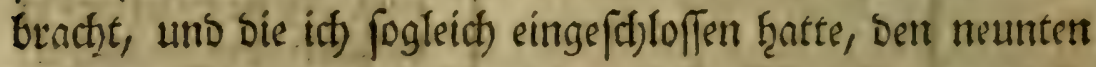

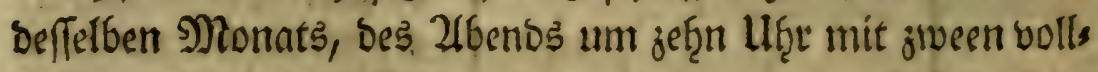

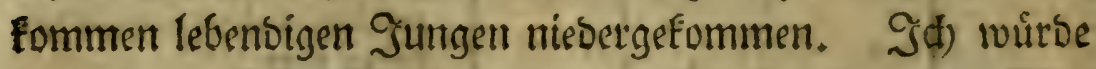

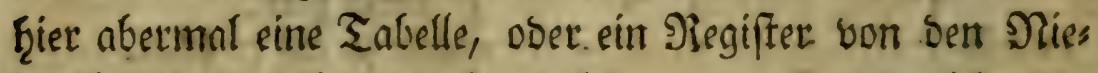

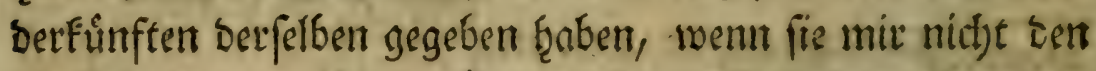

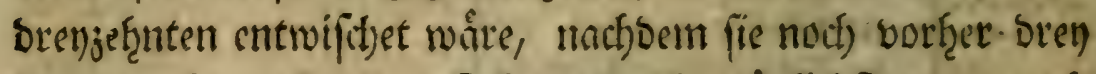

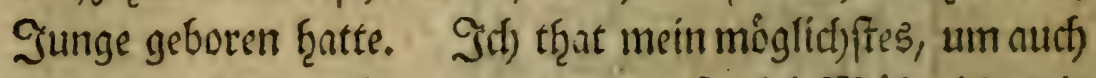

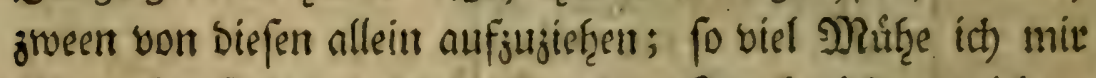

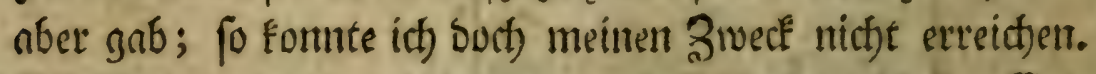

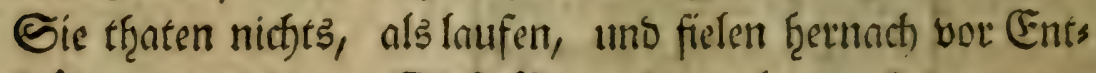

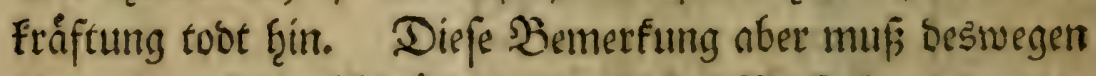

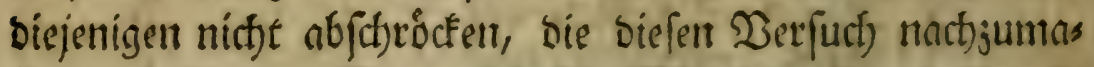

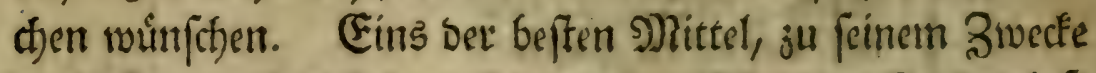

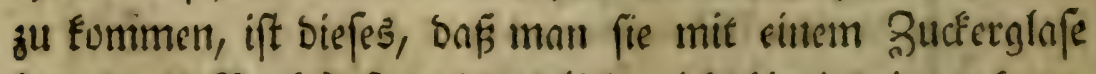

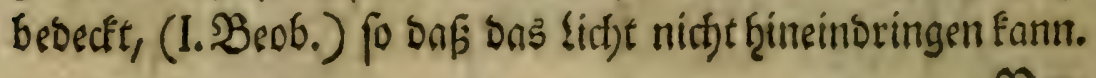




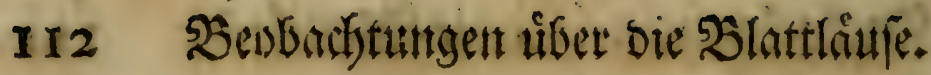

men, einten 2 erfüb) bemt andern entgegen ju ferzent: wortum

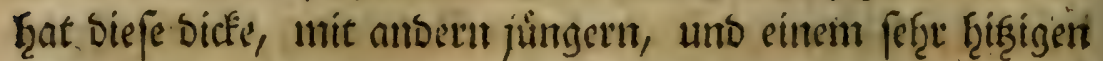

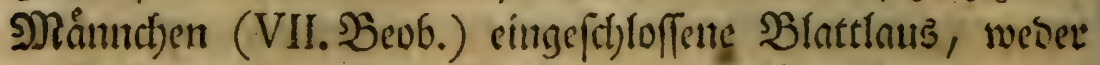
Blattlaule nod) Soetus jur 23 elt gebracl)t, mitterweil biefe anbern viele Ener legren, ob fie gleich) die (jemeinfthaft bez Mainnchen lange fo oft nicht genoffen ḩatten? Sch) wieders

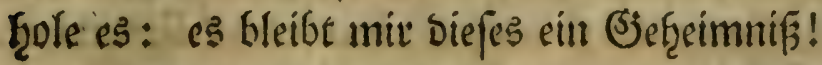

Sollte ich) aber niche ntod) ju viel Den Mlutf̧maffuns

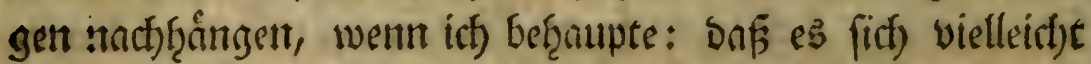

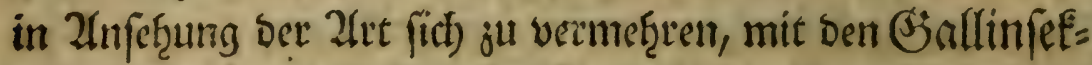

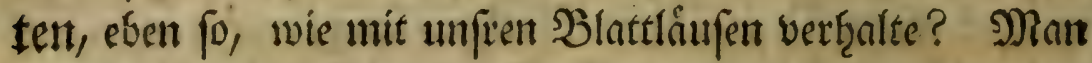

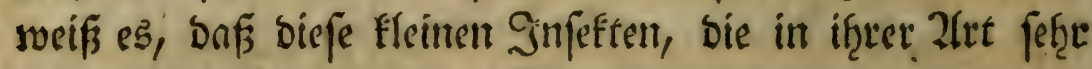

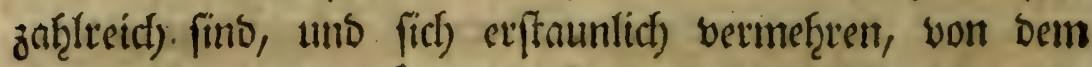
Seer oon Sieaumuir, wegen ber groffen Zlef̧nlict)éteit mit Den (Sa)llen Der PHanzen, (Jallimfeften ${ }^{\mathfrak{F}}$ ) genennet finto,

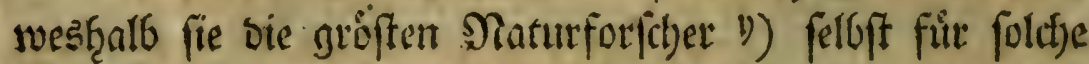

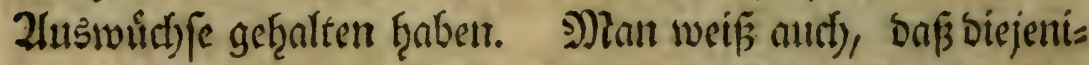
gent, bie if̧ere Natur ant beften gefannt ţabent, Hiber bie 2frt

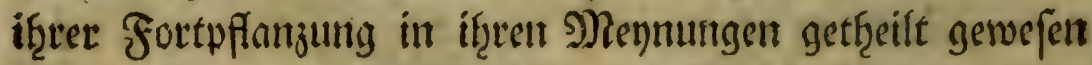

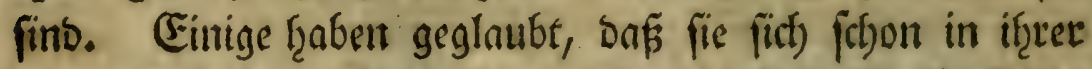
zarteften Rintohecit begatten; ;) anbere hraben fie fuir Z3wits

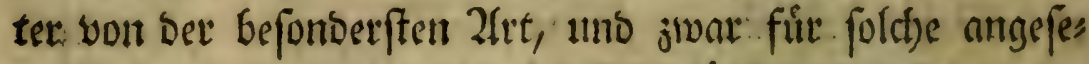
hen, a) ats id) glaube von ben Blattlåufent etrviefen ju has

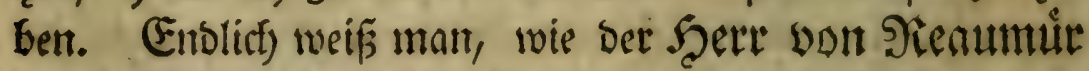

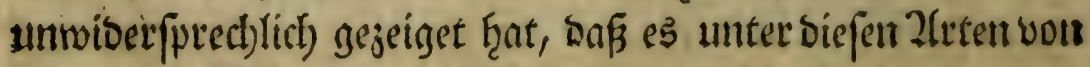

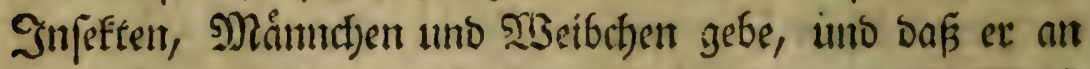
if̧nen bemertft frat, wie fie fich auf bie allergentauefte 2 Ee eife begattent. Diefes alles; als befannt, vorausgeféget frage ich),

x) Tom. IV. des Memoir. fur les Inf. Mem. pr.

y) Der Sirnf won tratefigli.

3) $230 \mathrm{n}$ Der Soite und Eedilean.

B) Ceftoni. 
of man nicd)t, nact) foldten Berfuct)en, als weldfe Der Şes

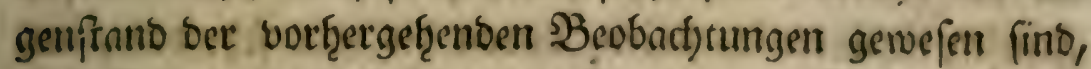

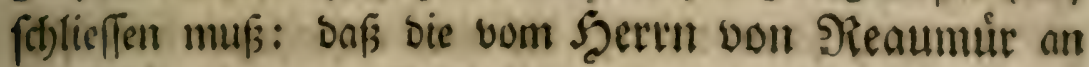
Den SR:annct)en Der Sallinfeften gemastite Entoectung, ein

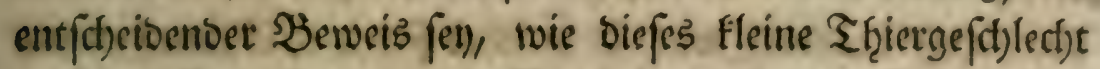
zu feiner Fortpflangung bie Sersinigung benber (Sefd)lect)ter

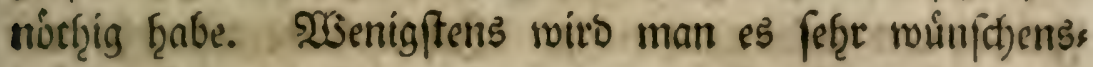
soirbig findell, baf inan fie, bon bem erften Zlugenblicke if̧, rer Seturt an, allein aufoief̧en fonnte. Ein Berfuct), Den id) nicht berfámen twerbe, anjuftellen, uno rooju ich) alle

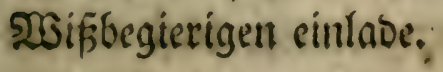

\section{Funfzefinte SBeobaditung.}

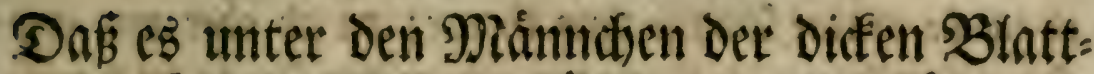 läufe Der (Eidfe, gefluigelte und ungeffü: gelte gebe.}

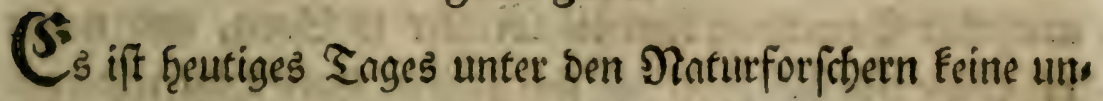
befannte Sache meţr, baßs es einige 2lrten bon Infeften

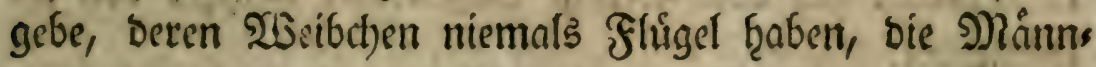
d)en aber bamit ftets verfeften fino. Berfaciebene Sorten

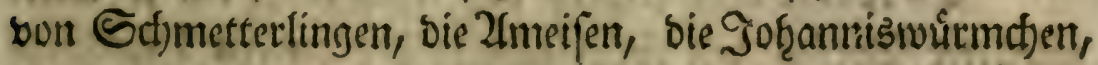
sie Salliufeften, unfere Blattläufe fino onoon fonserbare Erempel. Das aber fitheinet ganj was neues ju jenn, bafis es unter diefen lef̧teren M) Annnt)en gebe, welche wie ges

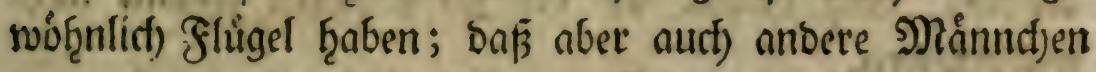
unter if̧nen of̧ne f̧luggel fint. Die bicken Blattlåufe bet Eicte fino es, Denen roir biefe Entoecfung ju banfen Gaben.

2lls icf) im 2(nfange bes Dftobers 1742 einige yon bies

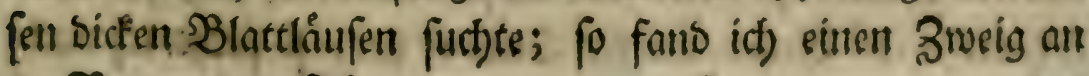
Bonnet I. Th. 
Der Eich)e, Der Damit reichlich) berféten war. Unter biefem

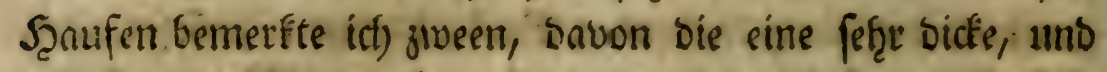

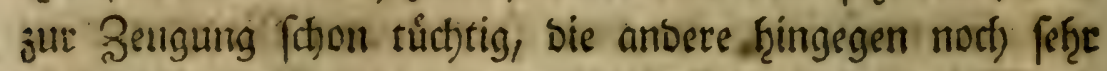

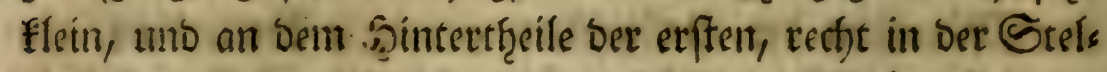
lung angeflammert worr, in tweld)er firt) bns MRinn(t)en mit

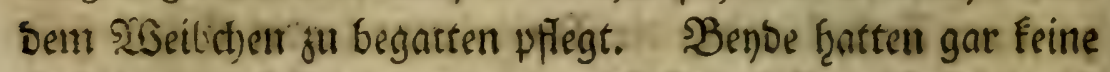

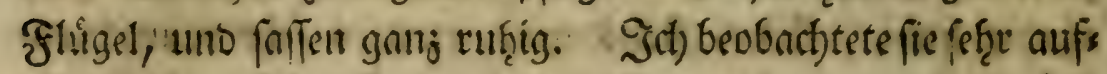

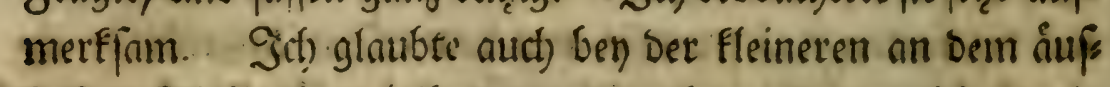

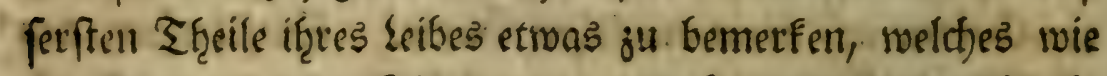

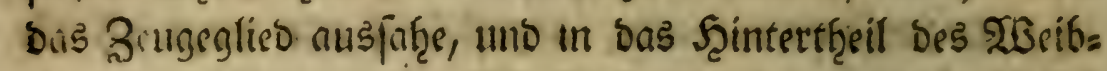
deens eingeffectt nar. Ilenferft ungebulbig, biefe benten Blattlaulue vódlig in meiner (Serwalt ju ḩaben, uno nad) meis nem Befallen beobaditen zu Eonnen, roolte ing verfuct)en,

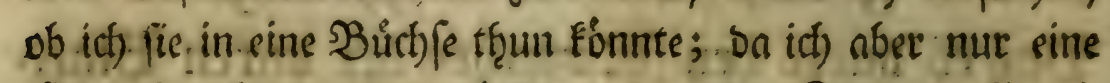

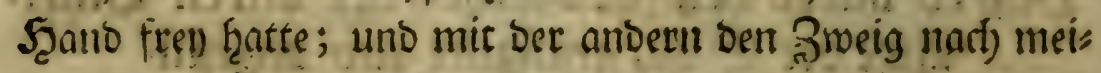

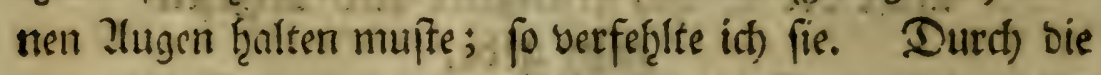
gemachte Bberwegung fam bie Dhutter in Bang, uno naf̧m Die fleine mit fitt) fort, bie fiid) nod) an if̧ren Seintertţeil ans

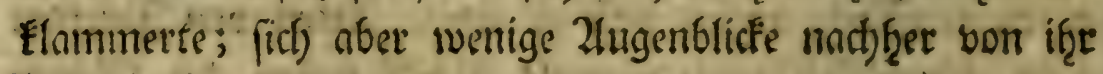
lofimadite.

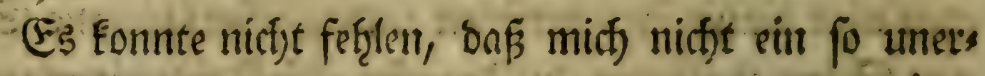

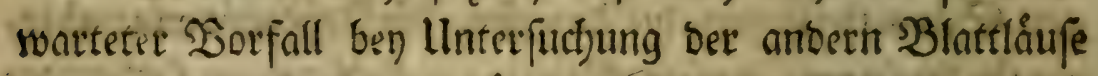

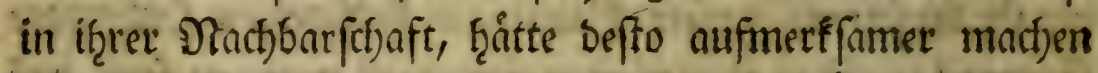
follen. Sith úberlief fie alpo ferge forgfốltig mit ben

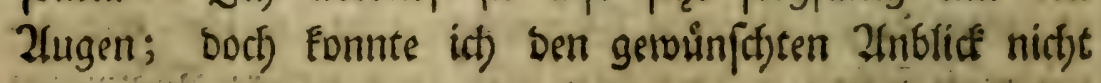
wieberfintert.

Do id) micl) aber aufferbem erinnerte, baß̄ bie fleine ungefluggelte SBlattlaus, bie ith) erft in ber $\mathfrak{B}$ egattung úbers raffht ḩatte, in Der Farbe bon ber gewóş̨nlicfen Farbe ber

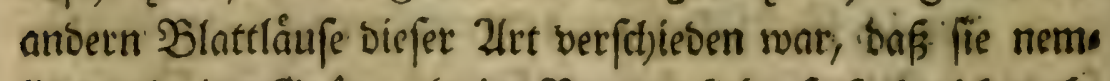

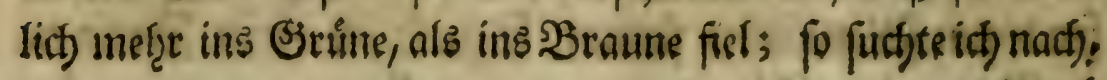


ob id) nitht eitre von foldfer Farbs, umo vou ber nemfid)en

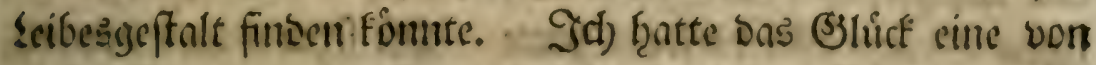
Diejer Gorte anjutreffen, dic id) init cinigen Blattlousmuts

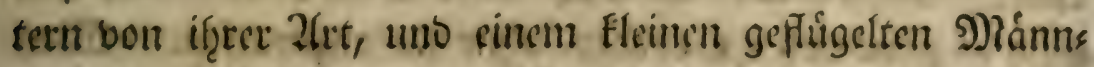
(b)en it cine DButbje that. Da id) fie mit in meine Stube genonunen fintte; fo brad)te id) fie nact) meiner $2($ rt in bie geţurige Stellung.

Das Fonnte itf) ater faft nidjt vermutfent, Daf mir Diefer Љ̧etfuct) sie ß̉eftátigung Der fonberbaren Begebenţeit, bie ict) gefegen, verfict)nffen wutbe. Daher getieth ict) in citt angentę̧mes Exfaumen, als ich) Des folgenden Tnges, als

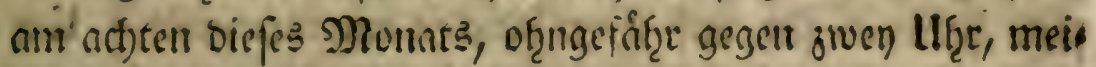
He fleine ungerhinglte BIattlnus in eben ber Stellung ans traf, won ber id) Eurj bortzer gereder ḩabe. 2Bie jufrieben founte idf alfo nict) mit mil felber fenn, baf id) biefen fitt) antgeftellet f̧atte. Dout) bns war nod) nid)t gemug.

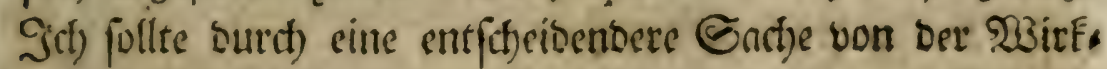

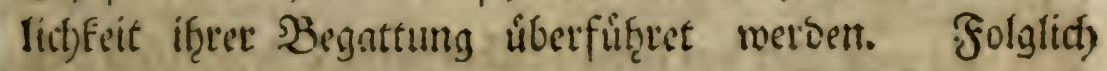
mufrm it) fogleich Das Suckerglas von bem Zweiglein ab, an welchein meine 23 latelaufe faffen, uno beobaditete die benocr fef̧r genaul, bie mir fefienen in ber Begattung 34 fenn. Es farm mir aber soch nicht fo vor, als ob fie es wirflich geroes. fen waicen. Einem anberen mogte es vielleict)t nicht fo

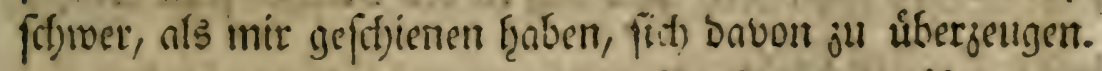

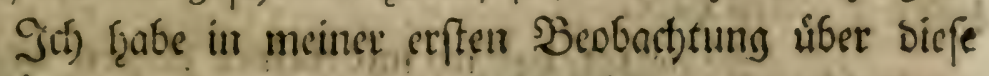

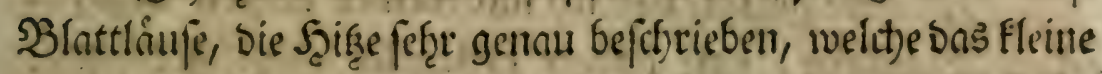
gefligelte sannd)en bejeigte, unn fict) mit benen jugleid) sins

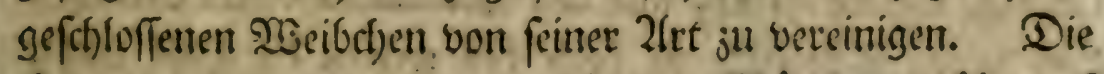

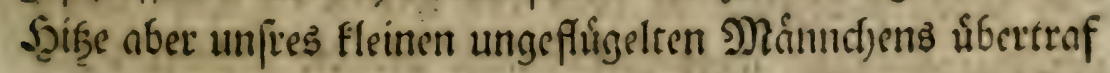
jene noct). Die Blattlausmutter, nn bie fit:s an liebften mact)en wollte, war eine von ben bicffen, absr andy sine von 
116 Beobacfitungen úber bie ßlattláufe.

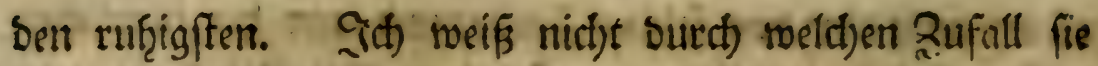

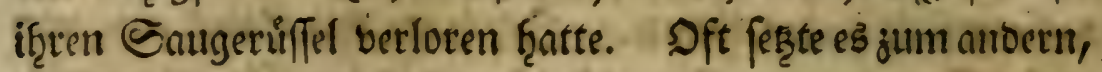
sritten uno viertenmale nacteinanber an, uno gevoóngnlid) ging es nicf)t bor in̨r borben, of̧ne fie anjupacten. Nan faţe es oben ouf fie flettern, uno balo vor, bald rúdíwárts

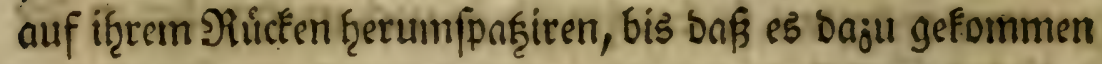
war, bie Epif̧e feines Şintertţeils an Dem Scintertţeile bes 23eibrtjens anjubringen. Da nun vorjeşt feine suft gebuifs

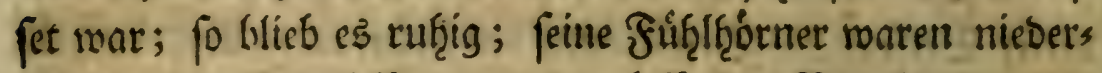
gelegt, fein Unterleib gegen den keib ber Blattlousmutter gefrưmmet, und mit ben åufferften Spiçen feiner Worbers

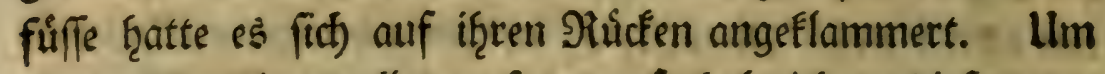
aber mit menigem alles ju fagent; fo frabe ich) an biefem uns

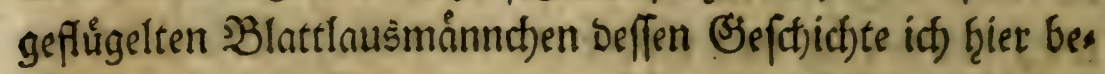
fatreibe, eben bie Baemegungen gefehen, oie iff) unter gleidjen Ilmftanben an ben geflügelten Mainndjen Der Blattlåafe bon

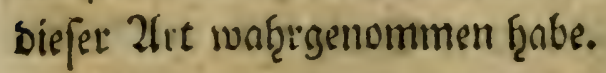

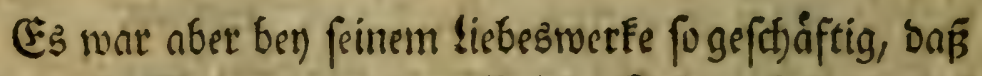
eas fotien, alle Natąrtung ju vergeffen. Selten faßs es auf bem Ziveige ftille, um ben Saft ausjufaugen. Sith wúffe

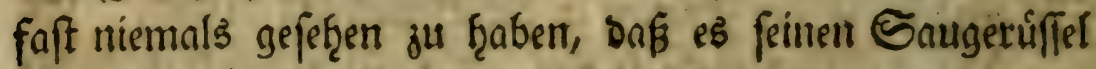

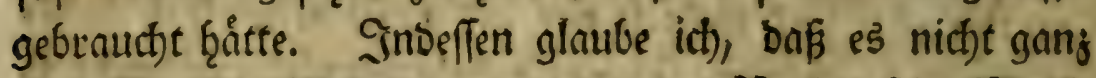

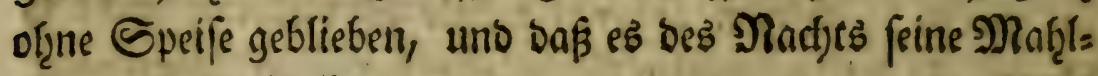
jeiten geţalten f̧abe.

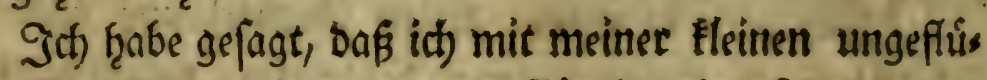
gelten Blattlaus, eine andere gefliggelte eingefę̧etet ḩatte. \$o biefe leştere gleich, alle ben Månnchen eigene Sennjeis

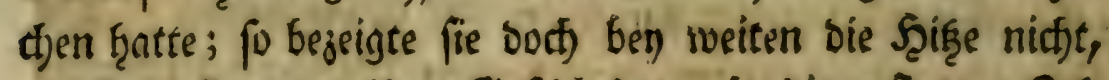

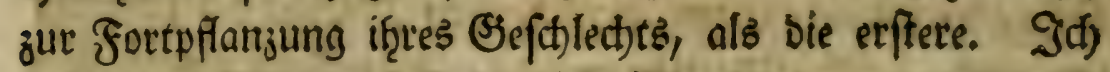

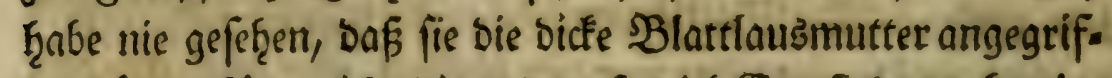
fen f̧ấtte, fứr weldje bie andere fo viel Empfinbung bejeigs 
te. Ginbeffen war es buct eben fo lebraft, wie es bie geflis getten 23lattlausmánnd)en von biefer Sorte zu fenti pfegen.

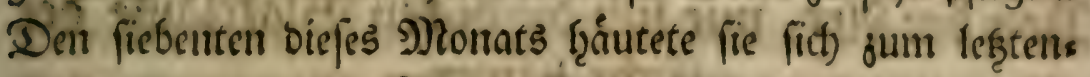
male; uno gegen bie פlitte beffelben fano id) fie toot. Ei.

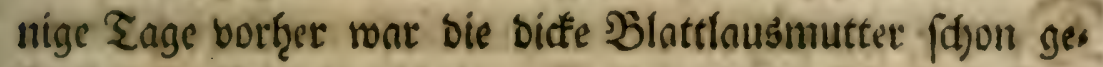
frorben. ßon ben úbrigen 23 eib(t)en rebe id) hiier nid)t, weil ict) fie ouf einen andern Sroeig geferęt ḩatte.

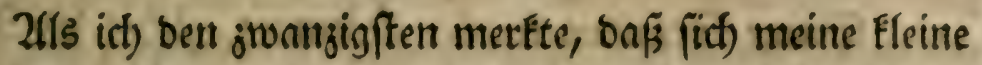

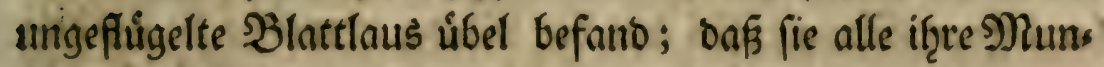
terfeit verloren; baf fie fid) an ben Ŝweig nict)t mef̧e ans: bielt ; fo entichlof ict) mich, fie jwifhen meine Finger zu nef̧men, um mich butch Den 2lugenf(h)ein ju úberjeugen, ob.

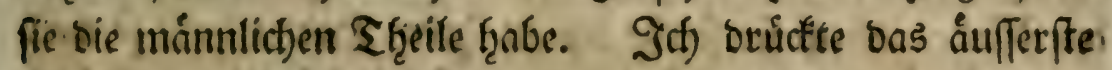

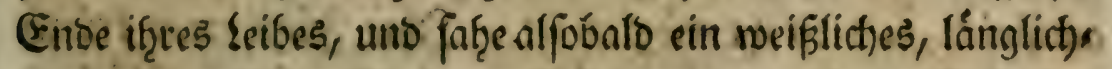
tes, uno nad) bet Seite bes Ructens : ju, wie ein Birfelbos gen gefrúnmtes Theild)en f̨eraustreten; bas fid) audt) in eis se feine Spif̧e endigte. Surg, eben for ein Rorperchens? wie id) in ber fiebenten' Beobad)tung befitgrieben frabe, - b)

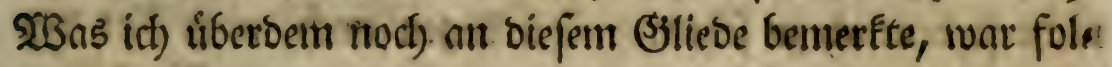
gendes: Daf fid), went id) vefthielt, bamit es fich nicht nier Der einjief̧en fonnte, feine Spife verlangerte uno verfürgte;

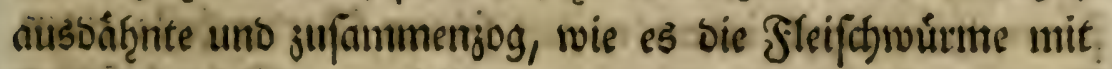
if̨rem Ropfe thun.

Hebrigens fothien es nid)t, als ment biefe fleine Blatt, laus fligelbecken gef̧abt ḩätte, uno fie roat aud) nicht fo sicke, als Die gefrúgelte. Wenn fith biefe benden Blattlaus.

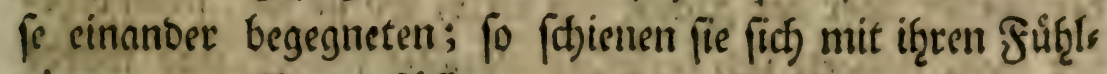

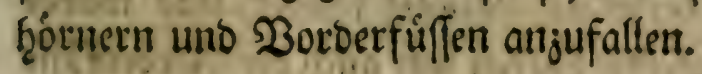

SE 3

Sedf:

(1) Reaumur Mem. pour fervir à l' hift. des Infeetes. Mem. 4. 


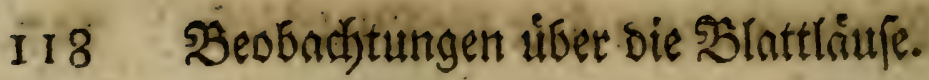

\section{Se(t)sebitte Beobaditung.}

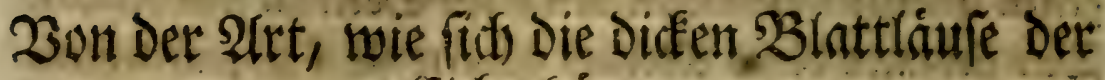
(sidje báuten.

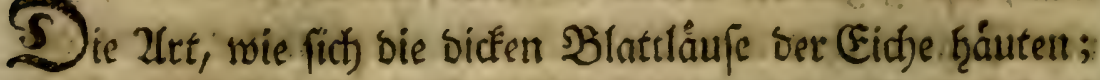
mas aud, vor biefer Dperation ţergę̧et, uno darnuf folget, veroient umftantslidfer befofrieben ju werben.

Einige Etunben vor ber Şåutung, jief̧et bie Blatts

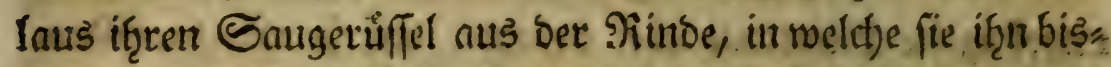

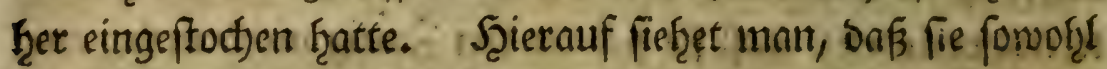

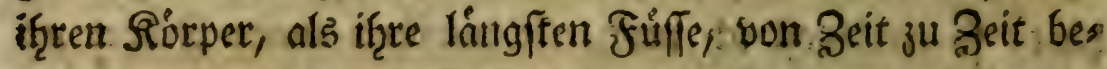

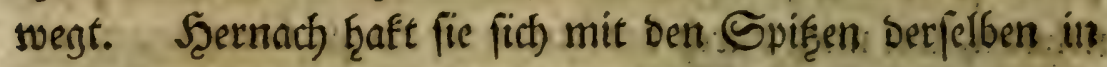

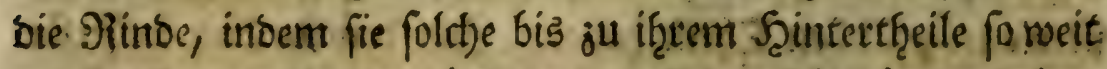

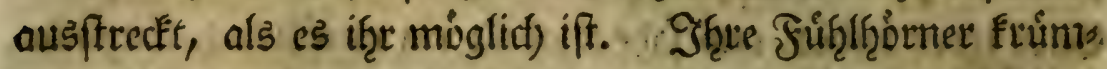

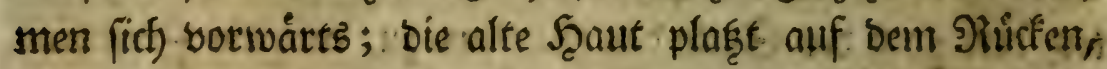

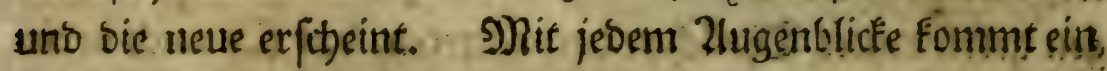

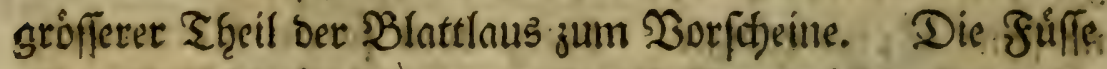

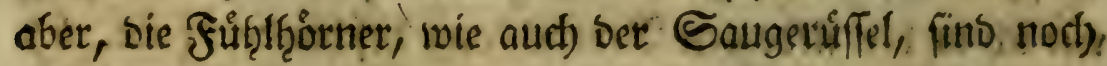

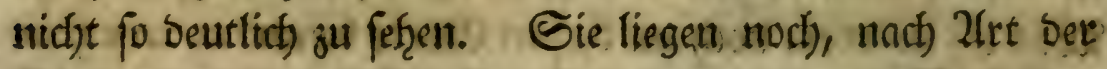

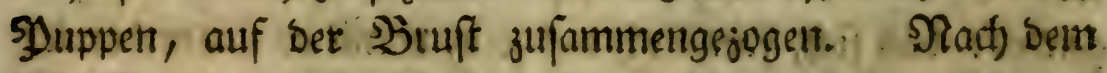

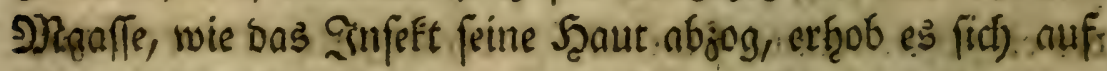
fónen Seinterttheil, indem es mit feinem Sorbertf̧eile einen. Sogonen befdrtieb; menn nun enolid) imen Drittel feines: Sorpers aus ber Scaut getreten finto; fo fangen alle äuffers

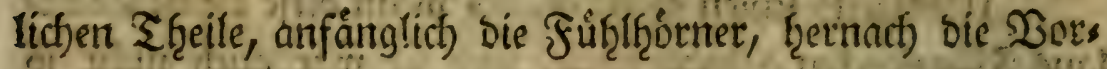

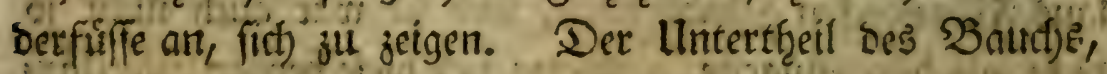

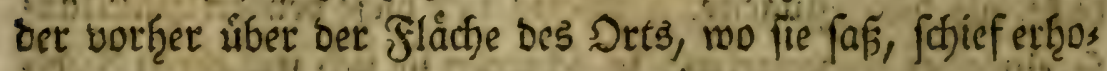

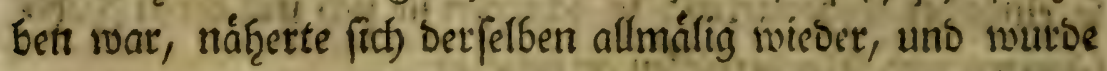

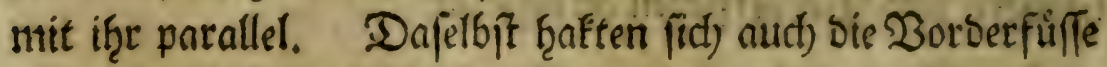
an, uno fo fråutete fict) Der úbrige కeib vóllig. Der Şins

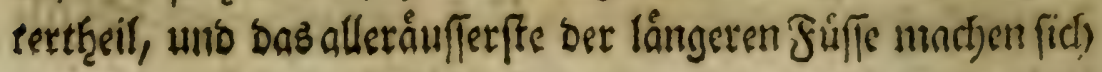


jullef̧t bun ber Fenatit lof.: Die ganze Dperntion ift Gismei. len in ciner $\mathfrak{B}$ iettelftumbe zu Stantse gebract)t; fonlt nber, suent is fálter ift, erfordert fie twoh̨l sine Tृalbe Etumbe.

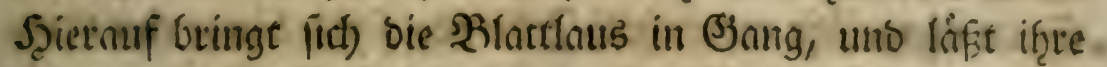
alte Seaut an Dein Stengel ţangent. Invermerfe toiro fie

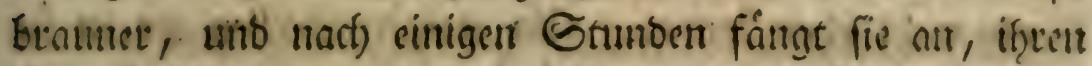
Eingeriffla ju gebrautchen. Din fetze barúber bie Piegis fer ber brenjefcuten Beobad)tung nad). llebrizens oarf

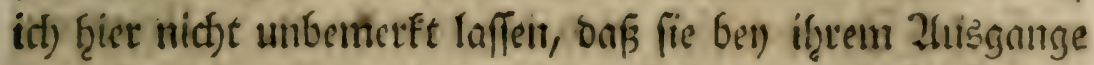
aus bet alten Seant, nicht fo bicfer aber viel langer fothien, als fie bov unb nad) feer war.

So hrabe ict) aud) eimar bemerft, safi fict) eine voit Diefen şlattlaujen, faft gernbe úber if̧re Şaut etriob, als fie fid) gang nus berfelben feerauşog, faft wie es ber:Serr vout

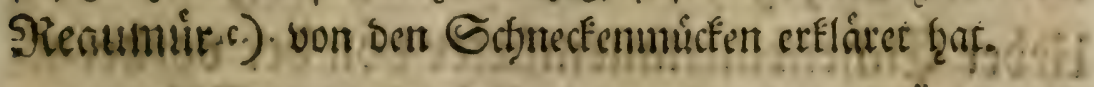

\section{Eiebzefute Seobaditumg.}

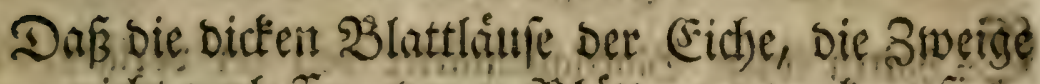

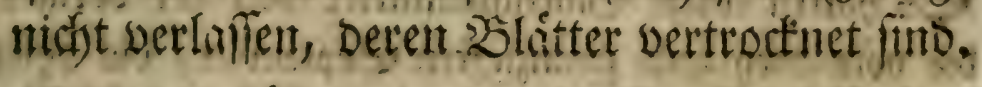

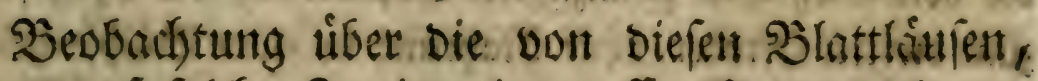
ouf folche Sweige, in groffer פeenge gelegten a) Ener.:

\section{D}

frneract)tet bie Blâtter bet Zweige, ouf weltien fich unts

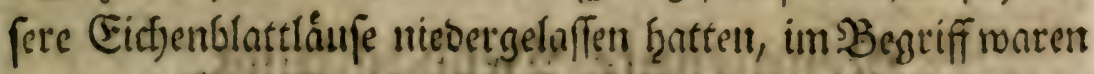
zu bettroctren; fo verlieffen fie foldhe Seswegeit nicht gleidy,

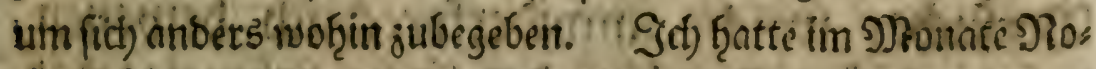
vember, einen foldyen Sroeig in meiner Stube, uns et wat noc) mit biefen SBlattlaufen pefti bevolfert. Es befanten fich onrauf weldbe von allem Zller, uno von benberlen Ses

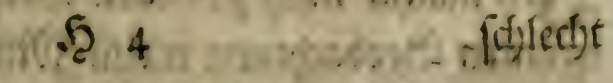

S.) Tom. IV. des Mcm. fur les Infoit dern. Mem. 


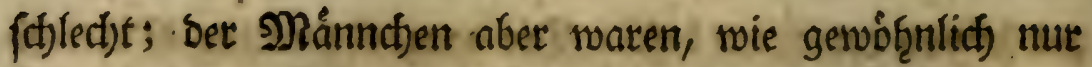

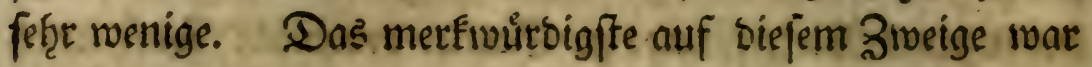
ein Scaufen Foetus, ober Eiyer, melcter pber nut auf einer

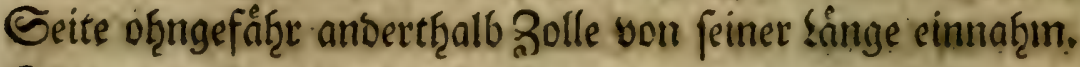
Sie waren fo naţe eint ben bas anbere gelegt, onẩ man bie

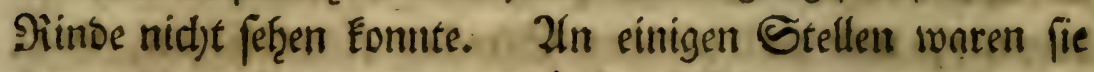
fogar eins auf bas anbere gef̧áuft. Sie waren roth, unto

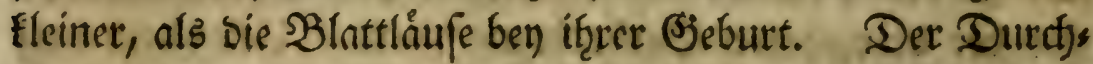
meffer bes Zlweiges fieelt bren bis vier sinien. Ilnvermus thete Berftreuuligen verffatteten mir nid)t zu erfafiren, was nus siejen Enern geworben ift, unb ob Daraus im folgenben Srứţlinge, Slattláure geformmen fino.

\section{Ad(d)tgefnte Beobad)tung.}

Ileber Eidtenblattlausmutter von Der vorberge:

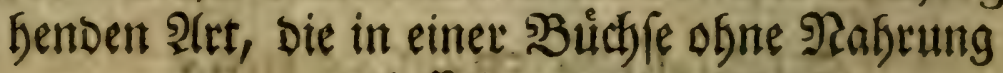
gelaffen waren.

(S. hiatten cinige Blattlausmútter bon bet vorigen-2lrt,

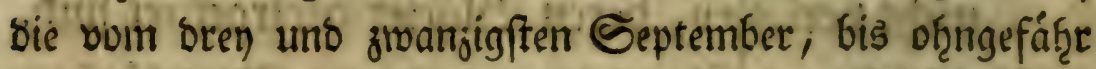

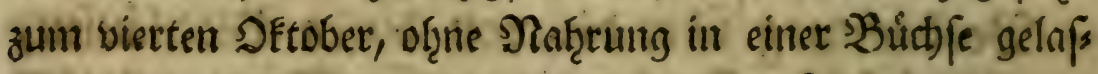

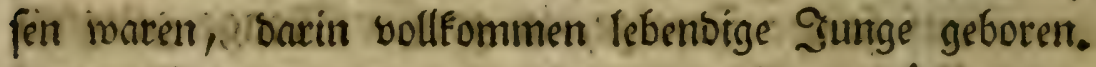
Zntere Sefangene aber, bie f̧ier einige Tage.fpåter einges (f) loffen waren, ḩatten Ener gelegt.

\section{Reungefnte Beobadtung.}

Berfucte, weldse unnwiderfpredslids betweien,

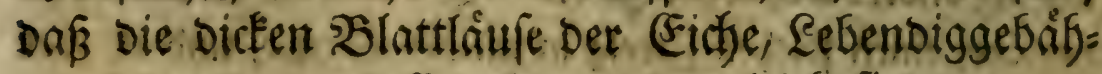
rende, und everlegende ;ugletich fint.

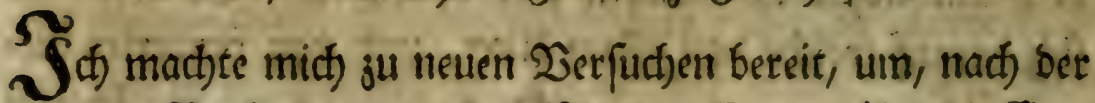
neunten $\mathfrak{B}$ eobachtung meine Mutţmaffungen úber bie Ėner

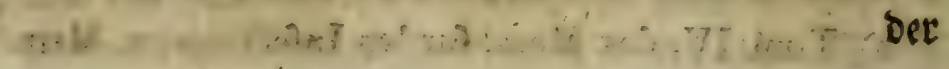


bet bicken Eid)enblattláufe zu beftátigen, als ich bon bem Serm Tremblev), aus dem Seang, unter bem bren uno juanjigften Zluguft 1743 , cin Scjreiben erf̧iclt, worin er

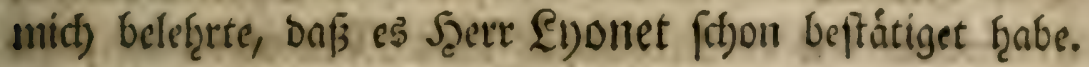
Scier ift Der Zlusjung diefes St)reibents.

„, Seetr $\mathbb{E}_{\text {b) }}$ ) „oie Sie fo oft beobadytet, unto inter weldyen Sie im Seerbfte

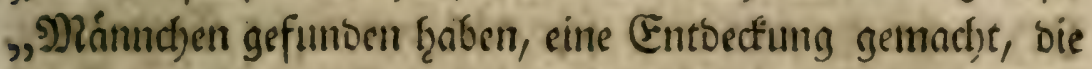

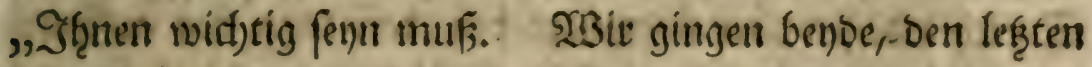
,2(pril, D) in bem Scolje ben Sotguliet e) jufammen pas , Ȩiren, unt Scetr Enonet, ber alles fieţet, entbeckte auf „,Det Điinte einer Eifte, fleine lánglichte uno bráunliche , Sớrperct)en, Die er gleid) fưr (Ever ḩiclt. Er naf̧m fie „mit nad) Şaufe, und et f̧at wirflidfe Blattlaufe austom. ,men fefren.

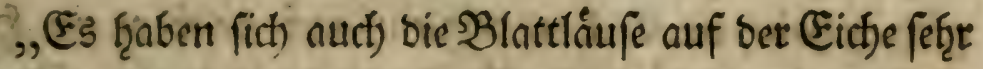
,bermef̧ret, auf welthe diefe Ener gelegt waren. Seer ,Evontet befucf)te fie bon Bcit ju Zeit. Nun aber legten

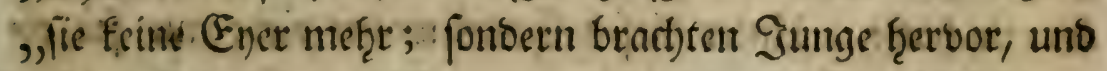
„STerr $\mathfrak{E}$ yonet gmeifelte num gar nicht, Daßj fie nicht gegen , Den Scerbft Ener fegen wúrben, ba er fie Den Sommer

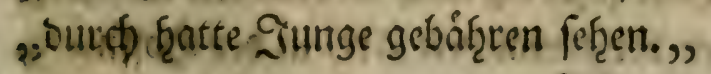

\section{$\mathfrak{S} 5$ \\ Sewifi,}

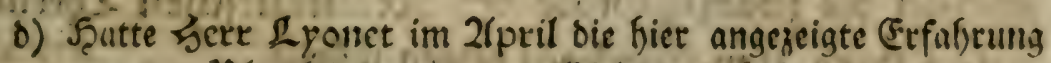
von oen Blattlatiseyein oce (Eidhe; io fabe id) im vorigen

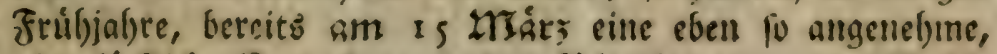

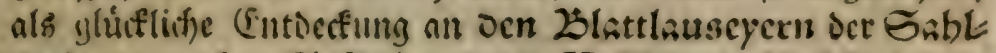
uncipe gemudst. S. 2nbang oes II. Cb. Der Infettologie. Uebrigents bat fecre Erembley diefe Emtoerfung veitlaujtig befdricben: Memoires pour fervir à l' hift. d'un genre de Polypes d'eau douce, à bras en forme de cornes. à Paris, 1744. 8. pref. p.XVI. Leb.

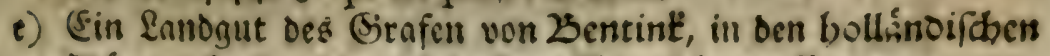

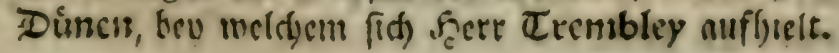




\section{I22 Seobachtutgen úber bie SBlattláufe.}

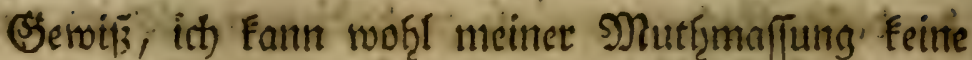

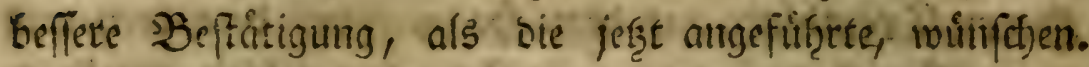

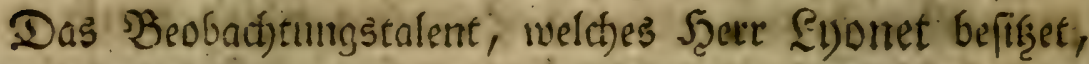

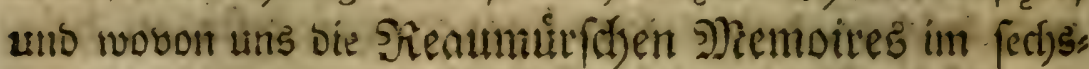

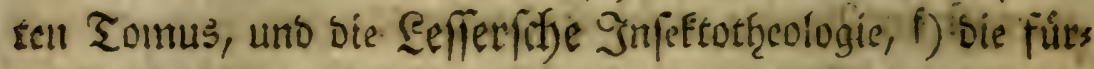

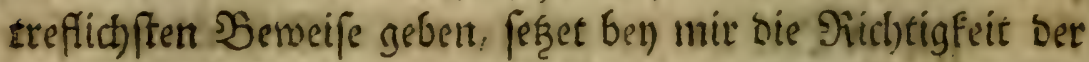
bon

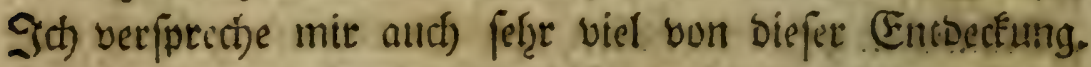

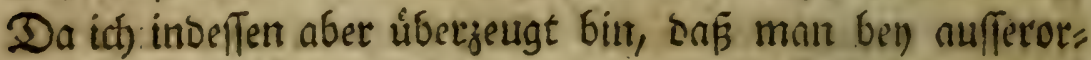

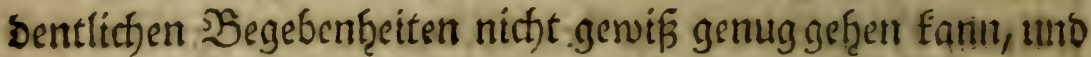

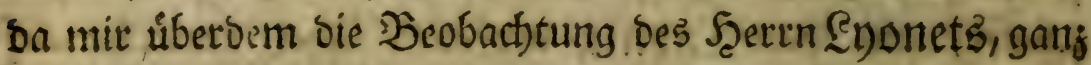

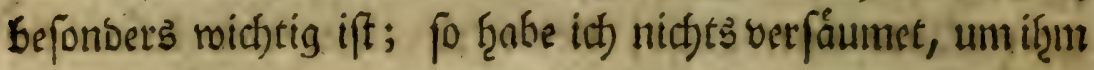
genau madjouferent.

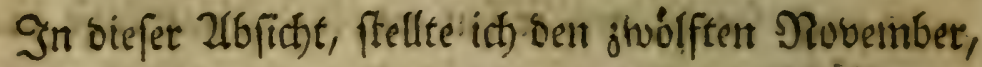

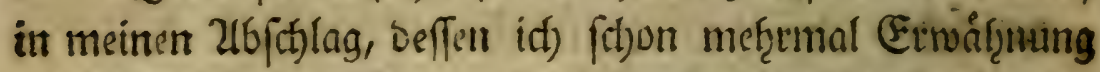

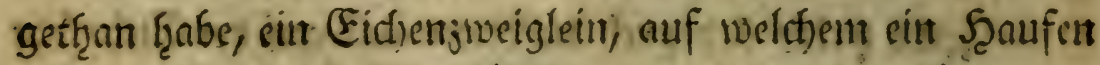

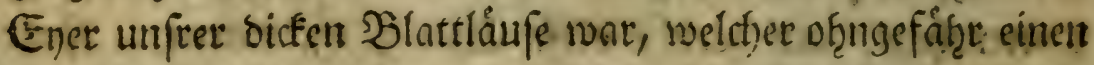

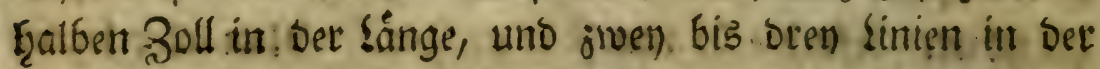

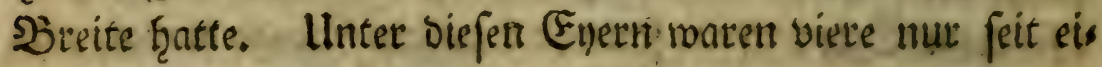

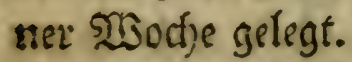

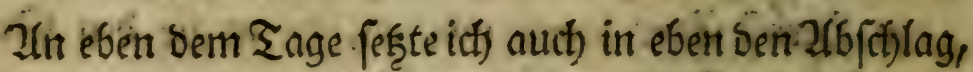

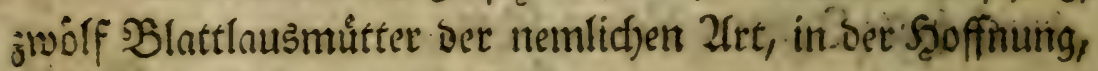

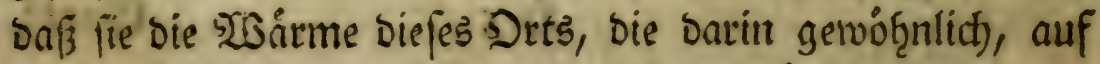

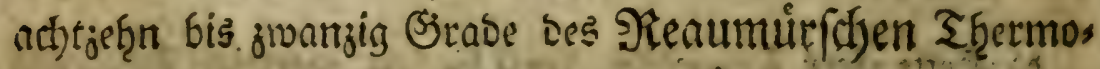
imeters ftano, jum Enerlegen teif̧en wưtroe.

Den

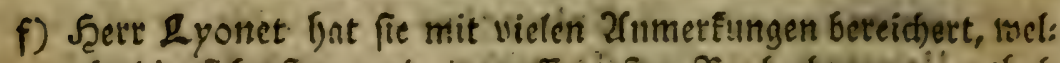

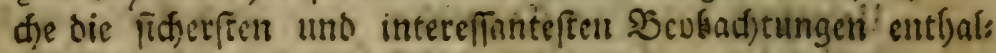
ter. 25 .

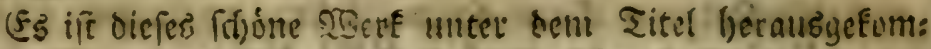
men: Theologie des lifectes de Mr. Lelfer avec des remarques de Mr. Lyotiet, à la Haye, I742. \&. Tom. I. II. Leb. 
Den biel) uno gunnjigften maten bie (Fince vertrocts net, unb alle Şlattlatsmuttev waten geftorben, thine Junge ḩervorgebradjt ju ḩaben; ausggenommen sine einjige, bie mit citten jismlict) groffen foetus niebergefommen sai,

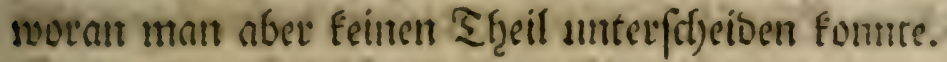

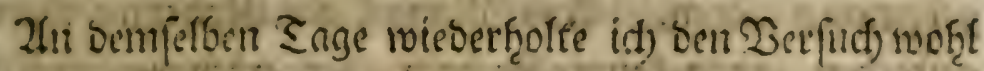

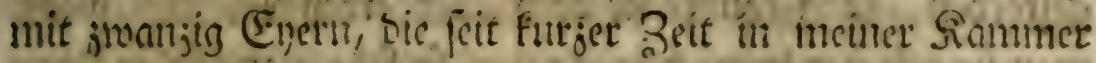
gelegt twaten; unb tind)te bavon mit allet nicthigen \or:

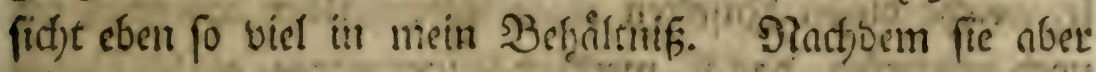
einen ganjen Monnt barin giblieben waren; fo fafge idf), baßj Die Ener, on fratt nusjufommen, Semnod vertiockitet waren.

Den neut und jwanjigften ging id) aus, auf ben

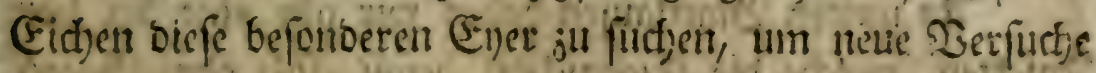
anjuffellen." Ith fant bergleichen auf bren verphtedenent

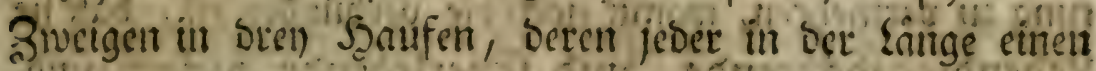

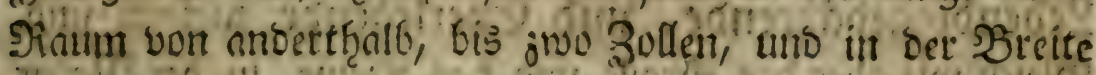

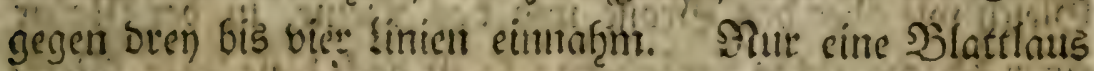
erblictete id) nod), bie fid an einem von biefen Bucigen ant bieft, aber fefte fletu wai.

Diachoem id) bie (Ener mit ber Soupe unterfuctit hatte fo femerfere ing batalif, marmorirte folvarje uno weiffe Flecte. Ulurigens waren fie alle mit bent leimiditen Safte gatio tiberjogen, womit fie ait Der Slinbe Flebtert.

Den beenfigften that iff cint Etúchenen vour cincm

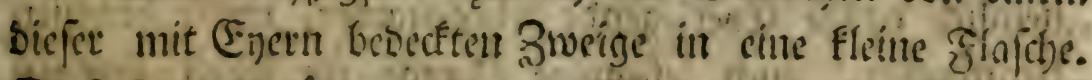

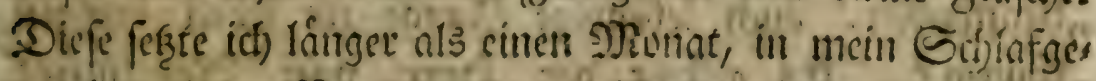
mach), mit ber Sorficht, fie bes פiachte unter mein Sopfs fúffen ju legen; Dn icl) ater inerfte, bẩ bic Ener ganj platt

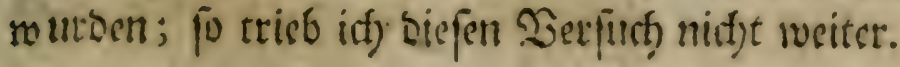

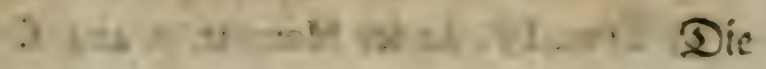




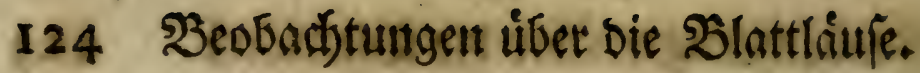

Die anbern benden 3weige, auld nod) einent brittent,

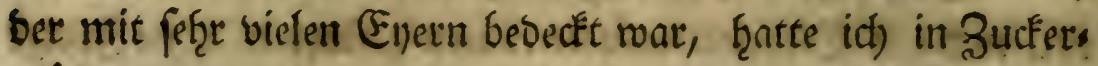
glójer geţ̧an, unb auf beın sanbe in meinem Eabinet ges

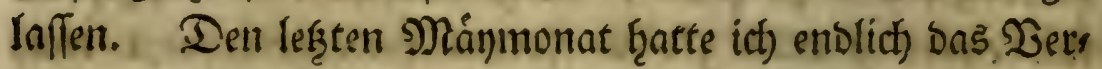
gnủgen, Eleine Blattlaufe zu fef̧en, Die aus Diefen Enern auşs gefoummen waren. Zlus Mangel ber Naf̧rung waren fie gefforben, iman fonnte fie bod) aber erfennen, uno went

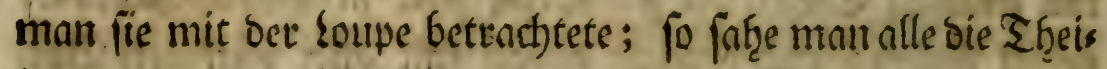
Te, weldhe biejen Infétent eigen fimb. Slur bas muś id)

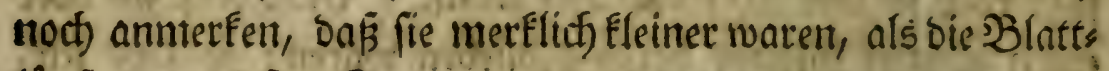
ráufe von biejer Sorte, weiche lebenbig geboren werben,

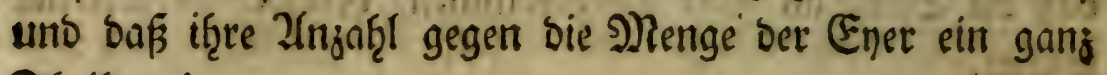
TEţeil geringer war.

In unjeen Blattlaufen f̧aben wir alfo cine 2let bon

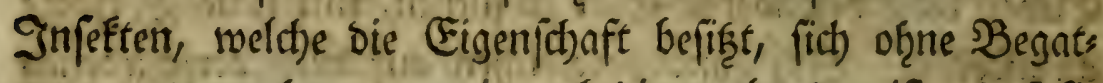
tung ju vermergen, womit noct) bie verbunben ift, baß fie Rebendiggebäbrende, und Enerlegende jugleid) fint.

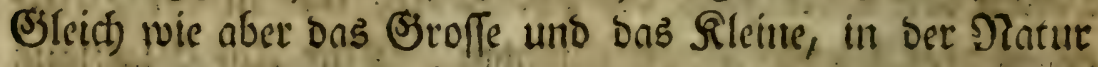
einer Sache nidyts berándern; fo iff bod, biefe legte Neres

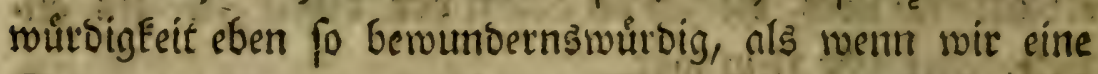

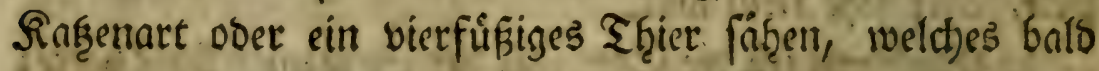
rebenbige Gunge herborbrád)te, bals Ener legen múrbe, nus weilden bergleithen Gunge fámen. Reoi frat eine Frage nufgerworfent, welthe gerabe bas Begentţeil von ber jef̧t entfojiebenent ift, und welthe ber seert bon Reaumuir 9) meitlauffig benntwortet haat: ",06 nicfec , nemlia) einige Enerlegenoe fliegenarten, unter gewiffen "Llimitánben, aud) lebenbige Junge jur ş3elt bringen "foumen?, Es geftefet ber Scerr Dout Fieaumuir:

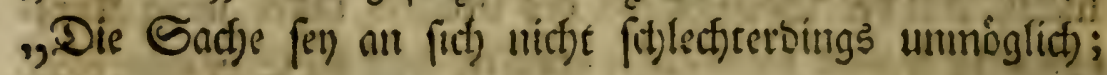

B) Tom. IV. de fes Memoir. p. 404. f. 
„es miffen aber, wenn fie sefftefgen follte, Daben biele fer̨e "fonberbare llimftánde jufammenfomumer., ",

श2Bas inict) aber betrift; fo werbe ich nach ber (Ent: bectung ber Bllattlaufe, bie Bivipara uno Dvipara zugleity.

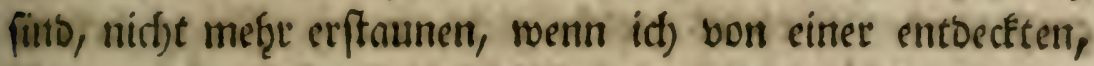
Enerlegenten fliegenart ḩoren follte, weld)e balb, wie gea wób̨̧nlid) (E)er legte, balb aber mit lebentoigen Sungen nieber.

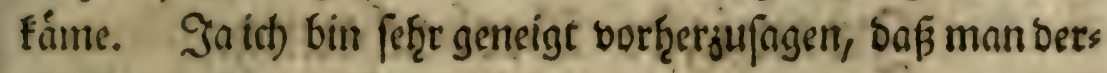
gleicfen nodf) entbecten werbe.

Die Mennung, weldte bie Naturforf(t)er angenoms

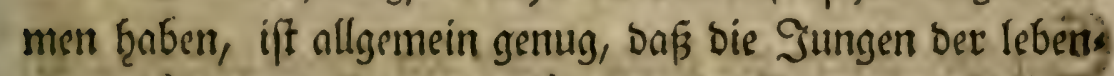

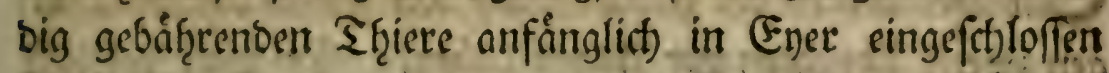
fino, wirb fie aber nicf)t burd) Die Entbectumb beftitiget, ju ber unfere bicfen $\mathfrak{B}$ lattláufe Der Eidje Selegentzeit geges ben ḩaben?

Ein anberer befonberer thinftand uiber iveldien biefe Entbecfung viel Sidft nusbreitet, betrift bie 2(rt uno 23 eife,

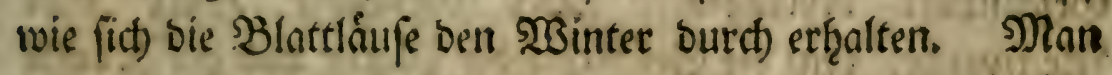

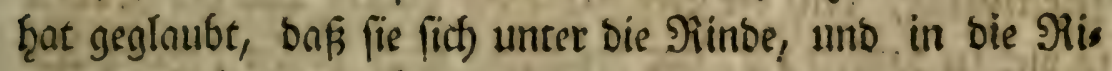

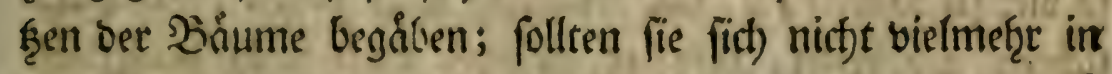

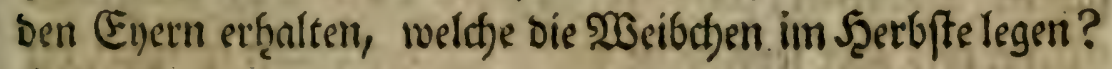
(IX. Beob.)

Şaben aber wob̨l biefe Ener, un befructitet ju wers bert, bie Rraft eines Månnthens nỏthig? (XIV. Beob.) Dies ift noct) eine wichtige Frage, Deren Erflárung übrig ift. MRan wirb aber oģne Zlweifel baju gelangen, wenn man sine ganje Beftulect)tsfolge bon Den bicfen Eidjenblattlaulfen allein aufoitegret, unb bie von ben

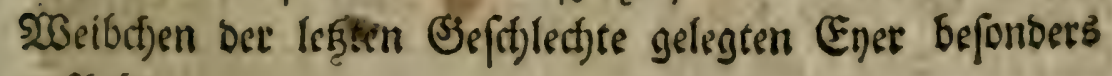
aufferbt. 


\section{Beobachtungen ưber bie SBlattláufe.}

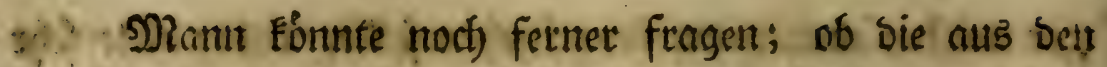

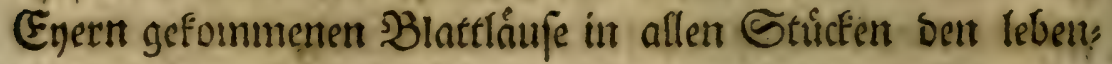
big gebornen sithlict) wairen? ob fie ficl), zum Erempel, eberi fo oft ţautent vurben? ob fie zu gleich)er Zeit eben fo grof metben? of es weldise giebt, meldje fllugel befons

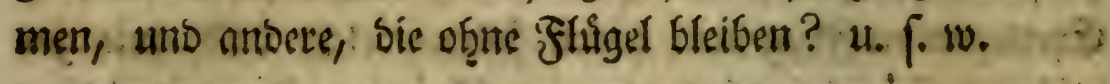

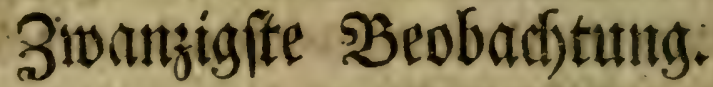

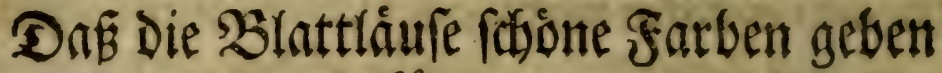
is fontuten.

(Sin Beobadjeet Del Natur mus ben feinen Unter[utdun

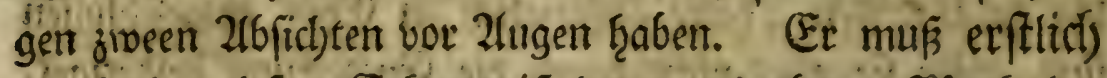
burch eine tiefere Erfenntnif Der wornberbaren TुBerfe Der

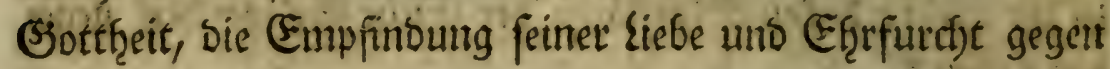

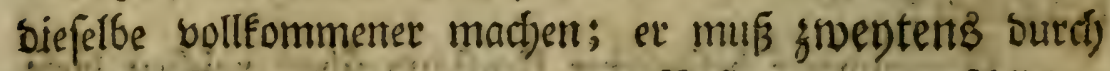

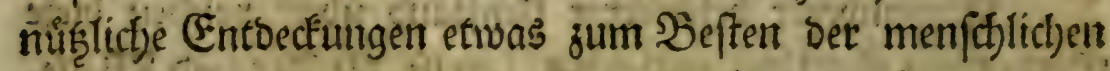
Befellifhaft bentragen. Der berifrinte Scerr vont

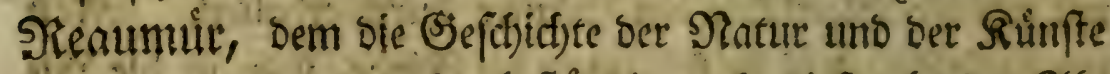

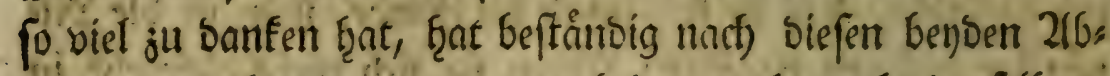
firbten gearbeitet, uno er arbeitet nod) nach benfelbeit. 2Benn uns aber jente, fêtre vielen Entbeckungen nemlich), Die er uns geliefert ḩat, nod) nicht fo mif̧Gar geworben fint,

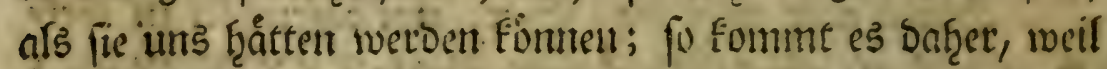

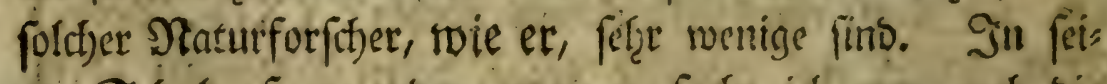
ner Ectule, fo ju reben, erjogen, futhe idf mun audf bie

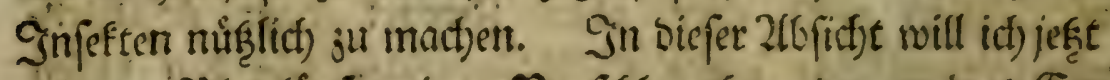

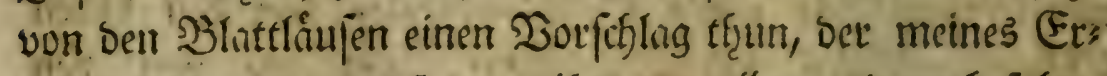
nechtents berbient, baj man içn vor allen anbern befolge.

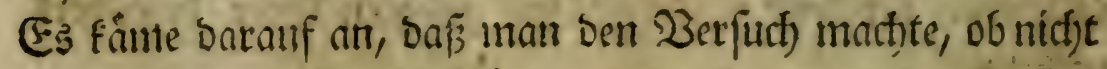

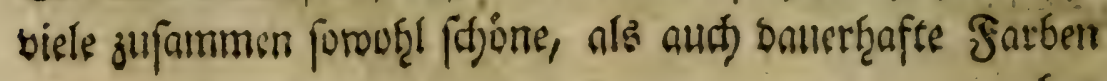




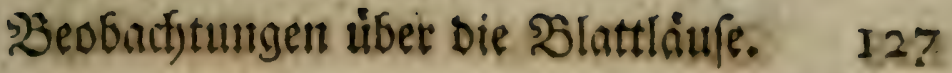

geben follten. Gith bin burd) bie jerbrúcteten berwogen roors Dent, es gu glauben. Man fagt, Daf bas fefodte Girtin

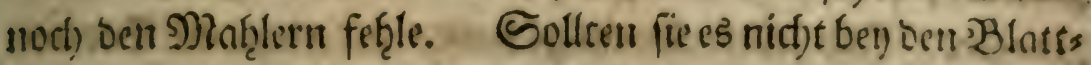
Iáffen firtocn? Ztus Der leichten 2(rt, wie fid) Diefe Infeetten vermef̧ern, und ans ber ungę̧euren Menge if̧ree befendern

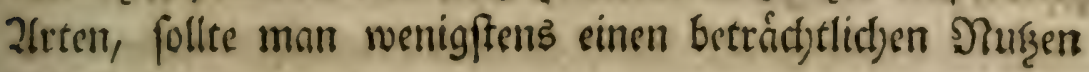
fotlieffen.

thebrigents túret ber Sorfatlng, fict) ber Blattlaufe zum farben ju bedienen, nicht allein von mir fer. Scerg

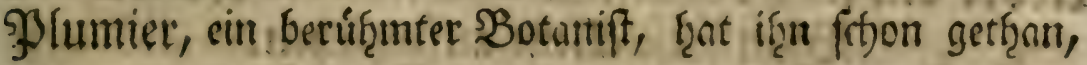
twie unan aub feiner 2lntwort megen ber Eocí)enille fergen

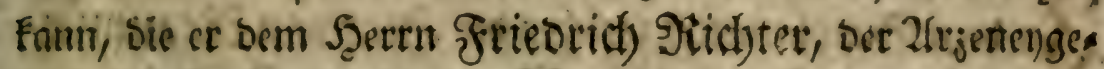

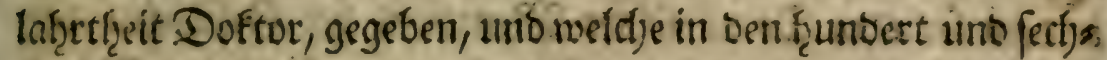
jigfen 2letifel ber Memoires de Trevoux, fúr dás Sahte 1703 Des Septembermontats, p. 1682. f. eingerücț if. Scier ift Davon Der. Zlussug.

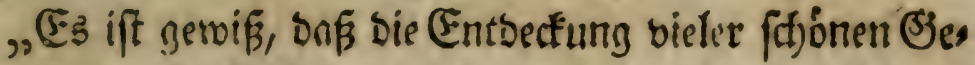

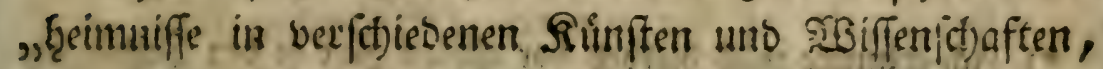
,"nur burd) einen foltben Bufoll ju ans gefommen if, wie

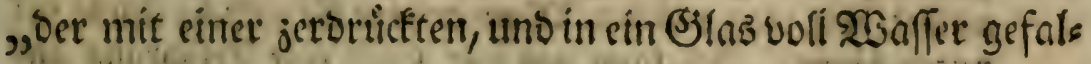
„genen Epinne gewefen, welches fie blau gefárbet? hrat.

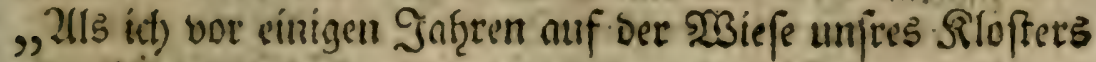

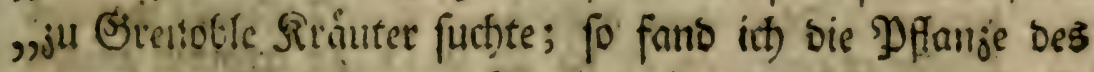
„gemeineir Sif̧einfarns, Tanacetum vulgare, C. B. "Pin. 132. Dat ith fie ausgejogen bृatte; fo merfte idf,

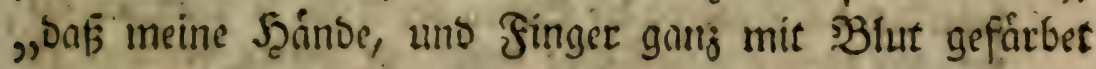
,"varent. Sith) befturitjte barúber, vornemlith ba id feine

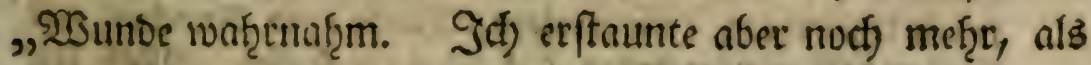

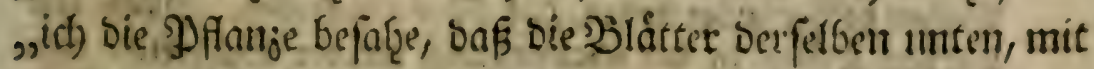

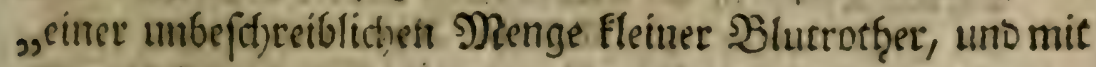
„einem eben fo ruthen Safte angefúllter Inffertent gants bes 


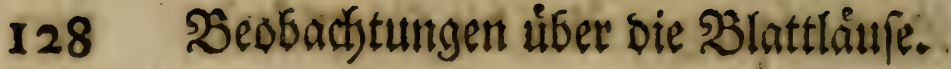

„bectet twaten. Sie waren fo jart, baßs id fie gleid) jers „ovuictefe; fo wenig if) fie aud) mit bem Finger betúf̧ren

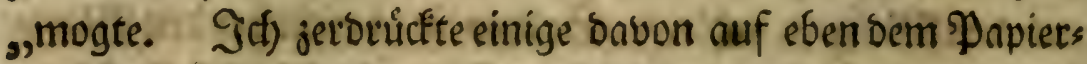

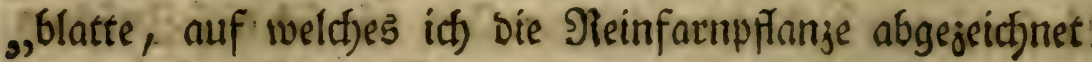

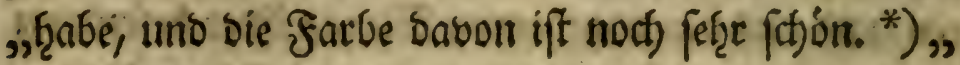

\section{Ein und jwangigite 3 eobadftung.}

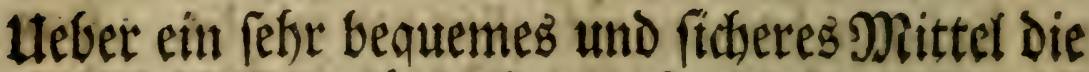 Slattlaufe allein aufzugieben.}

SU

Sn bem Supplemente, welfjes bet Serr bon Feaumur, in Dern fectsten Somo feiner गlemoires Der (Sefuidfte Der Blattlaufe bengefüget hat, fins fidon berfictiebene Mittel angegeben, twatd)e mit gutem Erfolg fonnen gebrauctit wers bent, um die Blattlápe allein aufjujief̧en. Id) aber habe ein

*) Эa) erinnere mid, fietbey vor einiger 3eit in ben Zeitungen

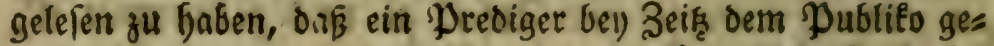
melDet, wie mant aus ben 00 anzen eine furtreflict)e Farbe be: reiten Esonne. İ) fann von mir feloft eine (Erfafrung an: fúbsen. İ fanto eine zicmliff grofle sertrocenete Raupe, Die eine ounfelfraune Farbe fatte. Şre 2fit mat mir un: befannt. Dies beluog micls, fie in einer Taffe mit roarmen

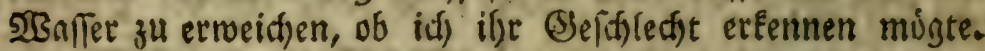
Sie Gatte samit eine. Nacist geftunden, und des folgenden 9) batte fid bie Fatbe an bie Seiten der Talle fo ftare angefe:

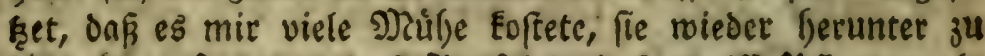
bringén. Scat man bud Bevfpicle, Das gewifle Pflanzen, als rubia tinctorum, (Fátbertótbe) સriild uno Znochen oes Bieljes rotbgefárbet baben, Oas Davon gefrelTen. ग) Jan lefe biervon weiter in Der Sammlung t'leinet Edhriften von D. I. 21. Unzer: phyfiłalifac. Xint. uno Leips, 1766. p. 345. Die foune 2lofanolung: vom Füusen einiger In: felten ;ut fritberep. Domnet Letr. über die LFat. p. $x$ ro. f. 
ein anderes erwáb̨let, welct)es mir nuct) bequemer, uno fict)e. ret gefdienen. Şier ift bas s) Jittel.

Sh) nef̧ıne ein Zudferglns (Taf. II. fig. XX.) mets d)es itf) bis zut Scalfte mit 20 nffer anfutlle. 2luf bie Defs mung Deffelben paffe ich einen runben गुlappendecfel, in wels

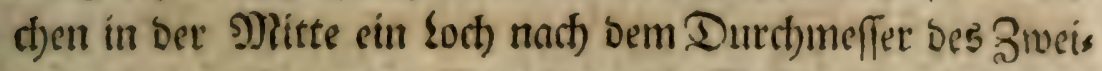

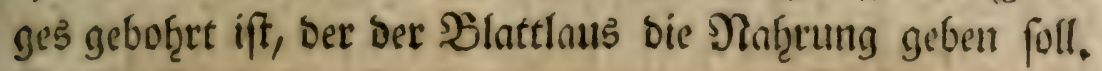
Diefen Zroeig bebecte id) mit einem andern Bucferglafe, fo, bas foldtes mit feiner Defnung, nuf bas gennuefte auf ben. Yappenbeckel anfalieft: (fig. XXII.) Damit nber nirgentos ber geringfte leere Raum bleibe; fo fotutte id) trodfnen Sand um ben ganjen शiand f̧erum. Daburch verḩute id), Daf fich feine Blattlaus, ober ein nitberes Snfeft, fo

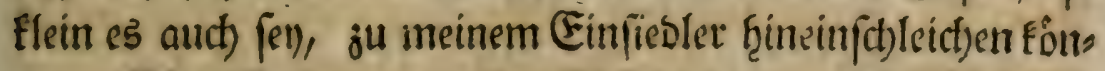
ne. Das iff aber ju meiner 26 fitift ber vornef̧mite Dor: theil biefes Mnittels, onß bie SBlattlaus, ment e's if̨t eitt: fállt, Den Zmeig, Darauff fie fif̧et, ju verlaffen, foliten herers nach), nach) einigen Promenaben auf Der Pappe, ober um Das SIlas ḩerum, wieberfinden fant. פan ţat alfo nicht ou beforgu, fie zu berlieven, wie fold)es oft gefthief̨et, wenn man fich ber andern, von bem Sert'n bon Sienumit an: gejeigten NRittel beoienet. 'Rurj, Iman broutht Gier ments

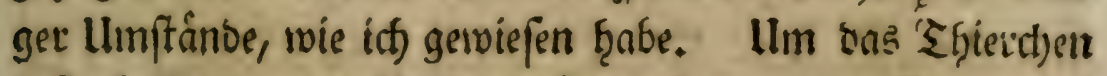
Defto beffer zu unterfideiben, fo barf man mur Dappe von einer farbe nefgmen, bie von ber feinigen ganj verfoties Den ift. 


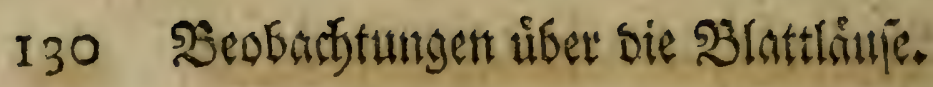

\section{saberle}

Der Berinbertutgen Deß Thermometers, (i) Dont 9. Sulitus 1743 , bis zum 27. September, inclu= fine, zur Enláuterung Der fechsten sbeobachtung.

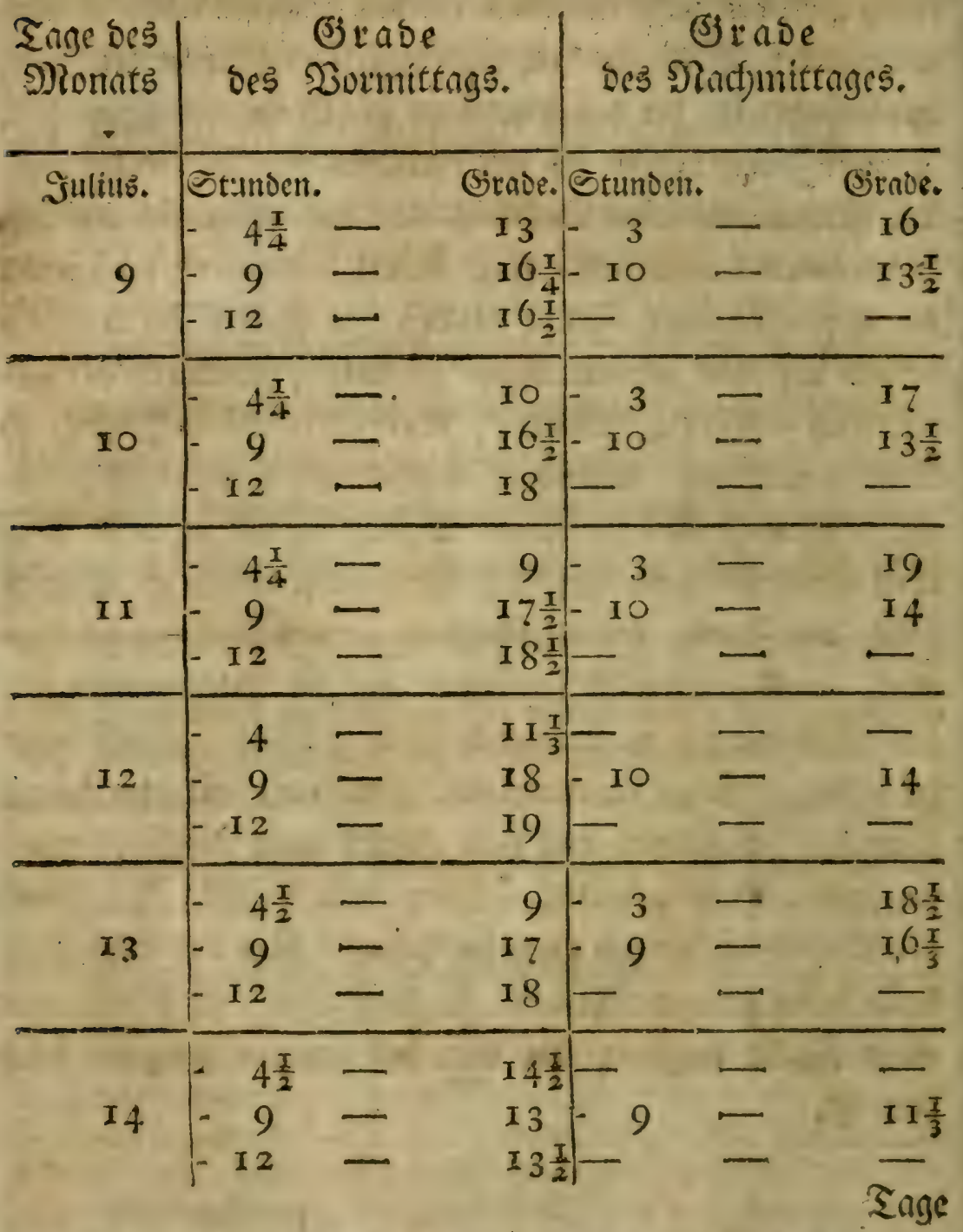

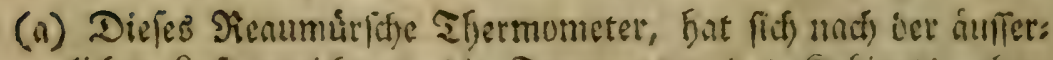
lidfen Enit gerichtet; Die Semperatul des fiabinets aber,

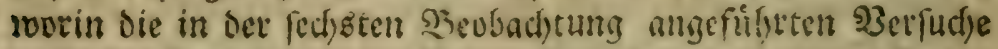
gemaclit finto, was won siefom sraulfen, nur sinije Sirave vericticoen. 


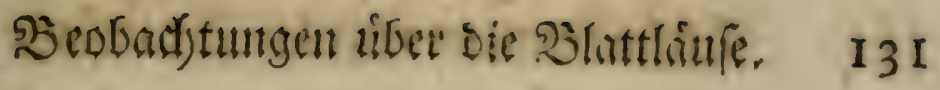

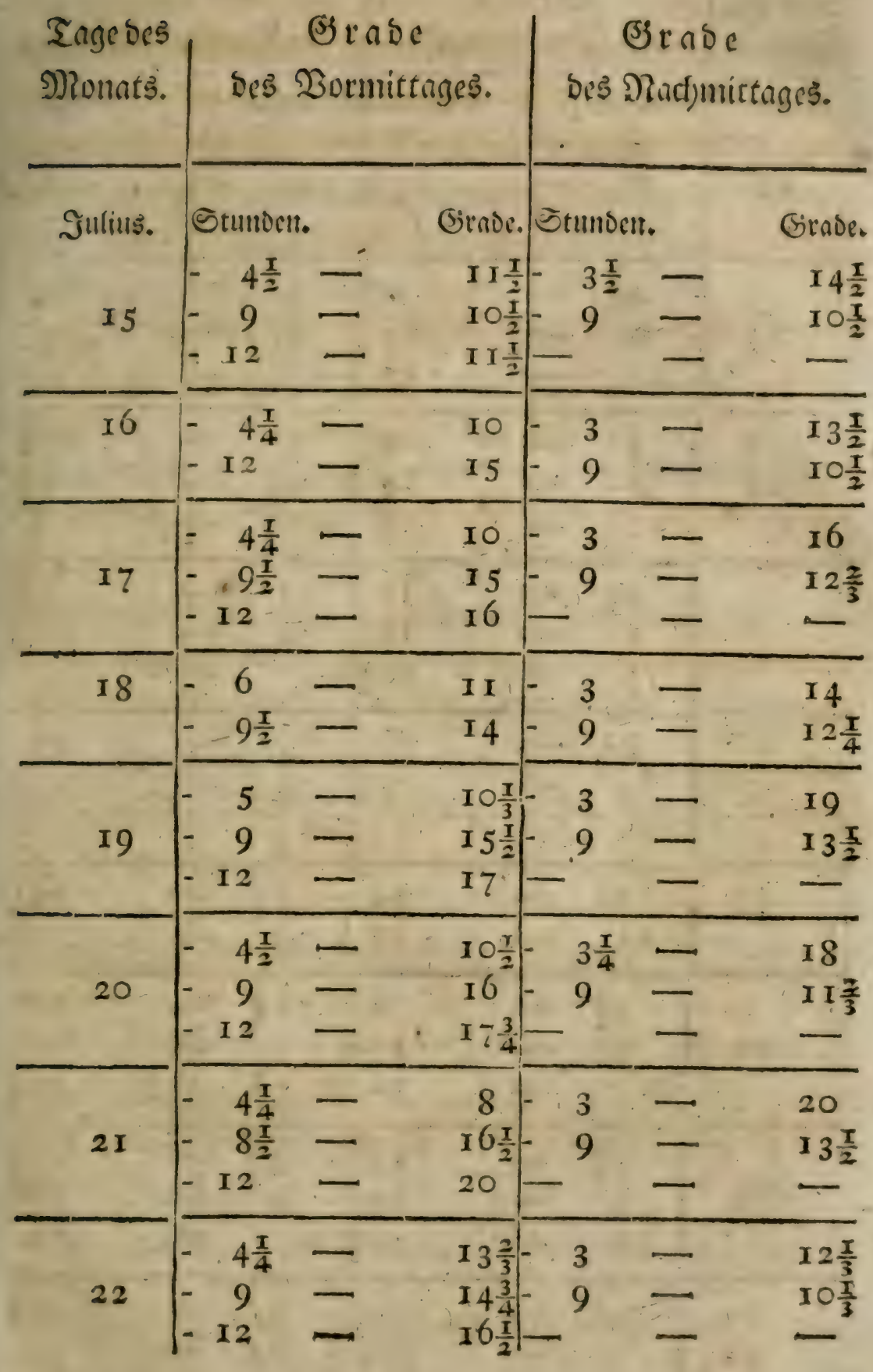

32

Tage 


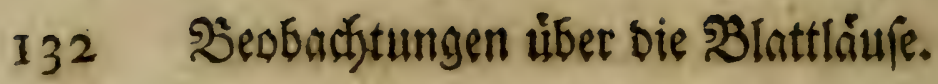

Tange be Slonats.

\begin{tabular}{|c|c|c|c|c|c|c|}
\hline ¡ัuliub. & $\begin{array}{c}\text { Etunben, } \\
-4 \frac{x}{2} \\
-9 \\
12 \\
12\end{array}$ & I & $\begin{array}{c}\text { Sirade. } \\
9 \\
\text { II } \\
\text { I } 4 \frac{1}{2}\end{array}$ & ${ }_{-}^{-}{ }^{-}$ & $=$ & $\frac{\text { Sirabe. }}{10}$ \\
\hline 24 & $\begin{array}{r}4 \frac{1}{2} \\
-\quad 12 \\
-\quad 2\end{array}$ & $=$ & $\begin{array}{c}9 \frac{1}{3} \\
14 \\
17\end{array}$ & $\begin{array}{r}3 \\
-\quad 9 \\
-\end{array}$ & $\underline{-}$ & $\begin{array}{l}18 \frac{3}{4} \\
\text { I } 2 \frac{7}{2} \\
-\end{array}$ \\
\hline 25 & $\begin{array}{r}4 \\
-\quad 9 \\
-12\end{array}$ & $\underline{-}$ & $\begin{array}{c}8 \frac{1}{2} \\
17 \\
19\end{array}$ & {$\left[\begin{array}{l}3 \\
-\quad 9 \frac{1}{2} \\
-\end{array}\right.$} & $\bar{Z}$ & $\begin{array}{r}19 \frac{\pi}{2} \\
14 \frac{\pi}{3} \\
\end{array}$ \\
\hline 26 & {$\left[\begin{array}{c}4 \frac{1}{4} \\
-12 \\
-12\end{array}\right.$} & $\overline{-}$ & $\begin{array}{l}\text { II } \\
\text { I } 9 \frac{\pi}{3} \\
20 \frac{I}{4}\end{array}$ & $\begin{array}{r}3 \\
-\quad 9 \\
-\quad\end{array}$ & $\overline{-}$ & $\begin{array}{l}21 \\
16 \frac{2}{3} \\
-\end{array}$ \\
\hline 27 & $\begin{array}{r}4 \frac{\pi}{4} \\
9 \\
-12\end{array}$ & $\bar{z}$ & $\begin{array}{l}14 \\
21 \frac{\pi}{2} \\
22\end{array}$ & $\begin{array}{r}3 \\
-\quad 9 \\
-\quad\end{array}$ & $\overline{-}$ & $\begin{array}{l}23 \\
14 \frac{x}{2} \\
-\end{array}$ \\
\hline 28 & $\begin{array}{l}4 \frac{1}{2} \\
12\end{array}$ & E & $\begin{array}{l}13 \\
18\end{array}$ & {$\left[\begin{array}{l}3 \\
-\quad 9\end{array}\right.$} & $\overline{-}$ & $\begin{array}{l}18 \frac{1}{4} \\
12 \frac{1}{2}\end{array}$ \\
\hline 29 & $\begin{array}{l}4 \frac{1}{2} \\
-\end{array}$ & $\overline{-}$ & $\begin{array}{r}8 \frac{1}{2} \\
17 \frac{1}{2} \\
-\end{array}$ & $\begin{array}{r}12 \frac{\pi}{2} \\
-\quad 3 \\
-\quad 9 \frac{\pi}{4}\end{array}$ & $\bar{z}$ & $\begin{array}{l}19 \\
20 \\
14 \frac{1}{4}\end{array}$ \\
\hline 30 & {$\left[\begin{array}{c}4 \frac{3}{4} \\
9 \\
-12\end{array}\right.$} & $\bar{z}$ & $\begin{array}{l}10 \frac{\pi}{3} \\
19 \frac{\pi}{2} \\
21 \frac{2}{3}\end{array}$ & $\begin{array}{r}3 \\
-\quad 9 \\
\end{array}$ & $=$ & $\begin{array}{l}21 \frac{\pi}{2} \\
16 \\
\end{array}$ \\
\hline $3 \mathrm{I}$ & {$\left[\begin{array}{c}4 \frac{3}{4} \\
-\quad 9 \\
-12\end{array}\right.$} & $\bar{z}$ & $\begin{array}{l}12 \frac{1}{3} \\
2 I \\
23\end{array}$ & {$\left[\begin{array}{l}3 \\
-9 \frac{3}{4} \\
-\end{array}\right.$} & \pm & $\begin{array}{l}22 \frac{\pi}{2} \\
17\end{array}$ \\
\hline
\end{tabular}




\section{3eobachtungen uiber bie \$2lattliufe.}

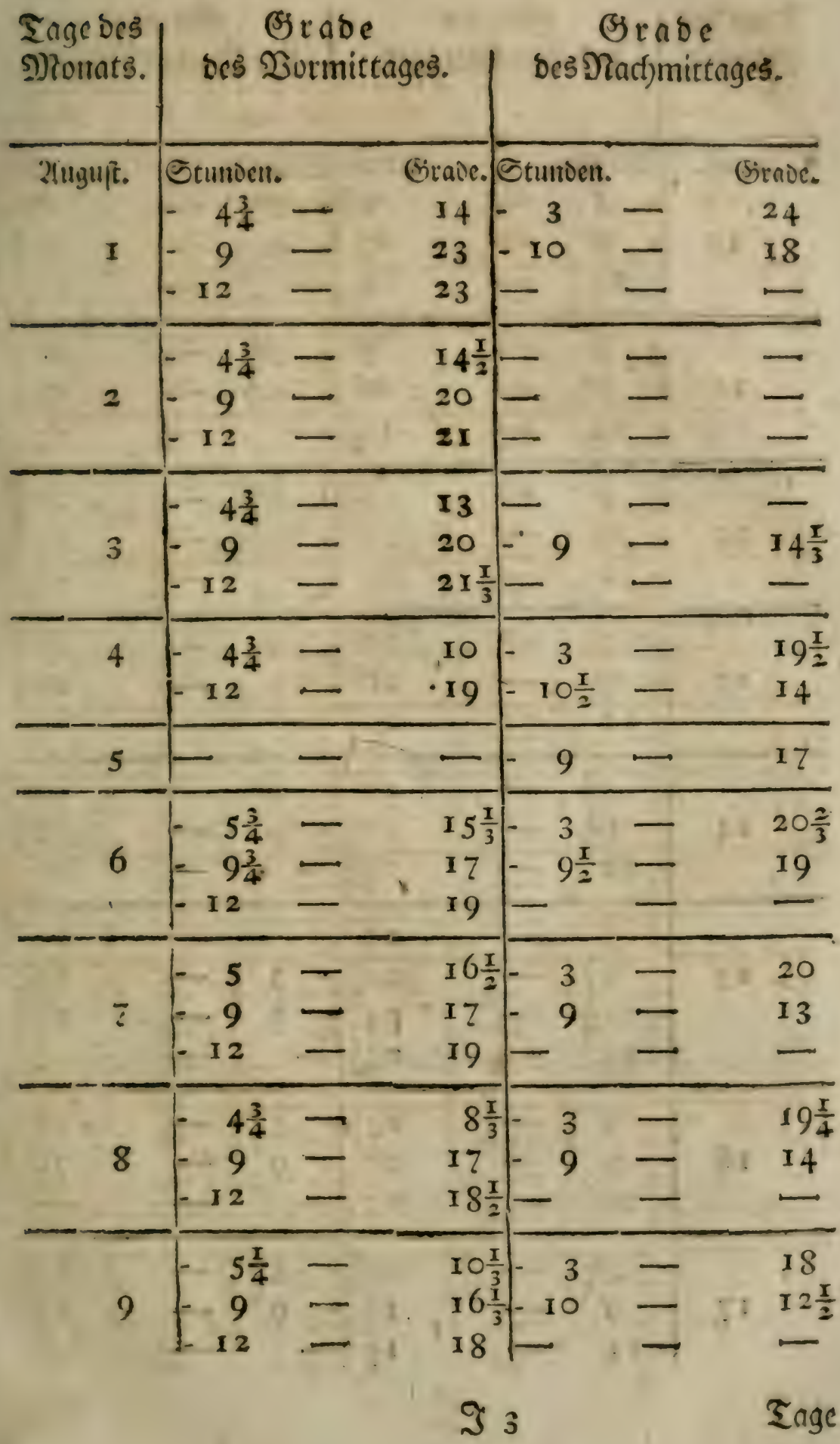


134. Şeobacftutgent liber bie Ḋlattlåufe.

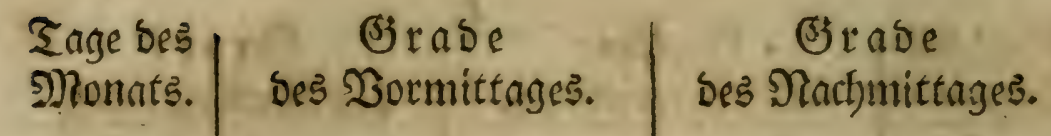

\begin{tabular}{|c|c|c|c|c|c|c|}
\hline $\begin{array}{l}\text { 2luguft. } \\
10\end{array}$ & $\begin{array}{l}\text { Stumben. } \\
-\quad 5 \\
-\quad 9 \\
-\quad 12\end{array}$ & - & $\begin{array}{r}\text { Girabe } \\
8 \frac{3}{4} \\
\text { I } 7 \\
\text { I } 8\end{array}$ & $\begin{array}{l}\text { Stumient. } \\
-\quad 3 \frac{x}{4} \\
-\quad 9 \\
-\quad 9\end{array}$ & - & $\begin{array}{l}\text { Sirade. } \\
\text { I } 9 \\
\text { I } 3 \frac{x}{2} \\
\end{array}$ \\
\hline I I & $\begin{array}{l}-5 \\
-\quad 8 \frac{x}{2} \\
-\quad 12\end{array}$ & ב & $\begin{array}{r}9 \\
18 \\
17.9 \frac{2}{3}\end{array}$ & $\begin{array}{l}-3 \frac{x}{4} \\
-\quad 9 \frac{1}{2} \\
-\end{array}$ & - & $\begin{array}{l}2 \mathrm{I} \frac{\mathrm{T}}{2} \\
\mathrm{I} \\
-\frac{\mathrm{I}}{2}\end{array}$ \\
\hline I 2 & $\begin{array}{r}5 \\
-\quad 9 \\
-\quad 12\end{array}$ & \pm & $\begin{array}{l}10 \\
20 \\
12\end{array}$ & $\begin{array}{r}3 \frac{x}{4} \\
-\quad 9 \frac{x}{2} \\
-\end{array}$ & E & $\begin{array}{l}2 \mathrm{I} \frac{\mathrm{T}}{2} \\
14 \frac{\pi}{2} \\
\end{array}$ \\
\hline I 3 & $\begin{array}{r}5 \\
-\quad 9 \\
-\quad 12\end{array}$ & - & $\begin{array}{l}12 \\
\cdot \quad 20 \\
20 \frac{\pi}{2}\end{array}$ & $\begin{array}{r}3 \\
-\quad 9\end{array}$ & - & $\begin{array}{l}21 \frac{1}{2} \\
16 \frac{1}{2} \\
-\end{array}$ \\
\hline$I_{4}$ & $-\begin{array}{r}5 \frac{x}{4} \\
9 \frac{1}{2} \\
-12\end{array}$ & E & $\begin{array}{l}13 \\
18 \frac{1}{2} \\
19 \frac{1}{2}\end{array}$ & $\begin{array}{r}3 \\
-\quad 9 \\
-\quad\end{array}$ & - & $\begin{array}{l}22 \\
16 \frac{\pi}{2} \\
-\end{array}$ \\
\hline I 5 & {$\left[\begin{array}{l}5 \\
-\quad 9 \frac{1}{2} \\
-11 \frac{3}{4} \\
-12\end{array}\right.$} & - & $\begin{array}{l}12 \\
22 \frac{I}{2} \\
24 \\
23 \frac{I}{2}\end{array}$ & {$\left[\begin{array}{l}-3 \\
-9\end{array}\right.$} & - & $\begin{array}{l}- \\
23 \frac{x}{2} \\
18 \frac{2}{3} \\
-\end{array}$ \\
\hline 16 & $\begin{array}{r}5 \\
-\quad 9 \\
-\quad 2\end{array}$ & - & $\begin{array}{l}13 \frac{1}{2} \\
20 \\
22\end{array}$ & $\begin{array}{r}3 \\
-\quad 9 \\
-\quad\end{array}$ & E & $\begin{array}{l}18 \\
16 \\
-\end{array}$ \\
\hline I7 & $\begin{array}{r}5 \frac{1}{2} \\
-\quad 9 \\
-12\end{array}$ & E & $\begin{array}{l}14 \frac{x}{2} \\
18 \\
19\end{array}$ & $\begin{array}{r}3 \\
-\quad 9 \\
\end{array}$ & - & $\begin{array}{r}19 \frac{3}{4} \\
14 \frac{I}{3} \\
\end{array}$ \\
\hline
\end{tabular}




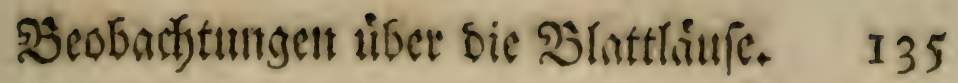

\begin{tabular}{|c|c|c|c|c|c|c|}
\hline Diona & bes 2 & & iges. & DeE S & & ge5. \\
\hline $\begin{array}{l}\text { ?แЗ } \\
\text { IS }\end{array}$ & {$\left[\begin{array}{c}\text { Stunditi } \\
5 \\
8 \frac{\pi}{2} \\
-12\end{array}\right.$} & - & $\begin{array}{l}\text { oirate. } \\
12 \\
\quad 15 \frac{x}{2} \\
15 \frac{x}{4}\end{array}$ & $\begin{array}{l}\text { Stunden } \\
-\quad 3 \frac{\pi}{2} \\
-\quad 9 \frac{x}{2} \\
-\quad\end{array}$ & - & $\begin{array}{r}\text { Girnde. } \\
15 \frac{\mathrm{r}}{2} \\
12 \frac{\pi}{4} \\
\end{array}$ \\
\hline 19 & {$\left[\begin{array}{c}5 \frac{x}{4} \\
-\quad 9^{-1} \\
-12\end{array}\right.$} & - & $\begin{array}{l}10 \frac{x}{2} \\
16 \\
17 \frac{x}{3}\end{array}$ & $\begin{array}{r}3 \\
-\quad 9 \\
-\end{array}$ & - & $\begin{array}{l}18 \\
14 \\
-\end{array}$ \\
\hline 20 & $\begin{array}{r}5 \\
-\quad 9 \\
-\quad 12\end{array}$ & - & $\begin{array}{l}10 \frac{1}{2} \\
17 \\
17 \frac{x}{2}\end{array}$ & $\begin{array}{r}3 \\
-\quad 9 \\
-\quad\end{array}$ & 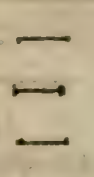 & $\begin{array}{l}18 \frac{1}{2} \\
14 \\
\end{array}$ \\
\hline $2 \mathrm{I}$ & $\left\{\begin{array}{c}6 \\
-\quad 9 \frac{x}{2} \\
-\quad 12\end{array}\right.$ & - & $\begin{array}{l}14 \\
16 \\
18\end{array}$ & $\begin{array}{l}3 \\
9 \\
-\quad\end{array}$ & - & $\begin{array}{l}19 \\
14 \frac{\pi}{2} \\
\end{array}$ \\
\hline 22 & $\begin{array}{c}5 \frac{1}{2} \\
-\quad 9 \\
-12\end{array}$ & - & $\begin{array}{l}10 \frac{\pi}{2} \\
15 \frac{7}{3} \\
17\end{array}$ & {$\left[\begin{array}{l}3 \\
-\quad 9 \frac{\pi}{4} \\
-\quad\end{array}\right.$} & - & $\begin{array}{l}18 \\
13 \frac{3}{4} \\
-\end{array}$ \\
\hline 23 & $\begin{array}{c}\quad 5 \frac{I}{4} \\
-\quad 9 \\
-12\end{array}$ & $=$ & $\begin{array}{c}12 \\
14 \frac{3}{4} \\
17\end{array}$ & $\begin{array}{r}3 \\
-\quad 9 \\
-\quad\end{array}$ & - & $\begin{array}{l}19 \\
15 \\
\end{array}$ \\
\hline 24 & $\mid \begin{array}{l}-\quad 5 \frac{T}{4} \\
-\quad 9 \\
-\quad 2\end{array}$ & E & $\begin{array}{l}12 \frac{1}{2} \\
15 \frac{1}{2} \\
18\end{array}$ & $\begin{array}{r}3 \\
-\quad 9 \\
-\quad\end{array}$ & - & $\begin{array}{l}\text { I8 } \\
14 \frac{3}{4} \\
-\end{array}$ \\
\hline 25 & $\begin{array}{r}5 \frac{x}{4} \\
-\quad 9 \frac{1}{4} \\
-\quad 12\end{array}$ & - & $\begin{array}{l}13 \\
18 \\
17\end{array}$ & $\begin{array}{r}3 \\
-\quad 9\end{array}$ & - & $\begin{array}{l}17 \frac{1}{3} \\
13 \frac{3}{2} \\
\end{array}$ \\
\hline & - & & 34 & & & Sng \\
\hline
\end{tabular}




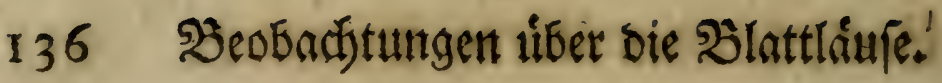

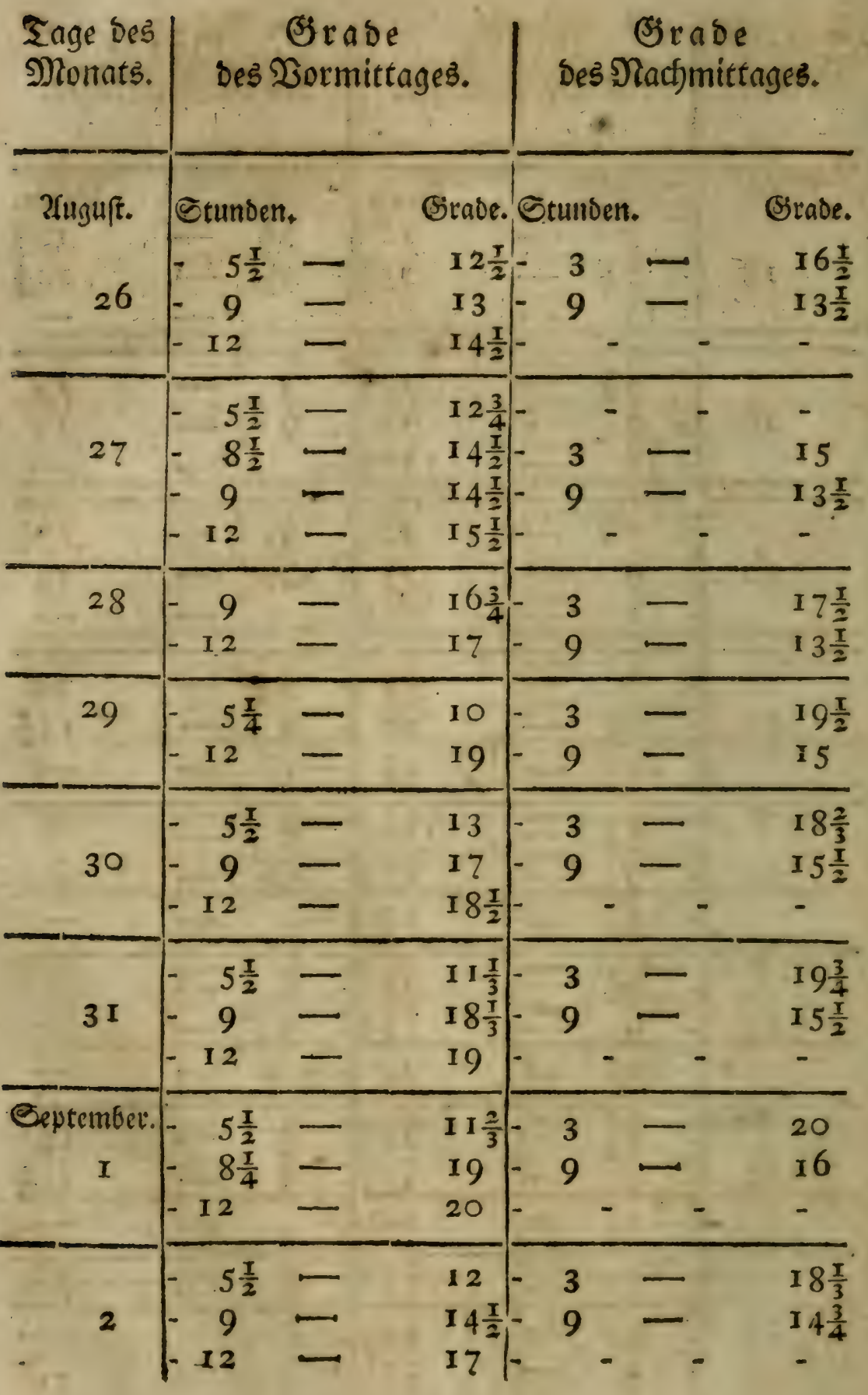




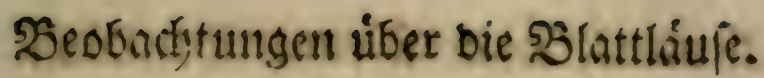

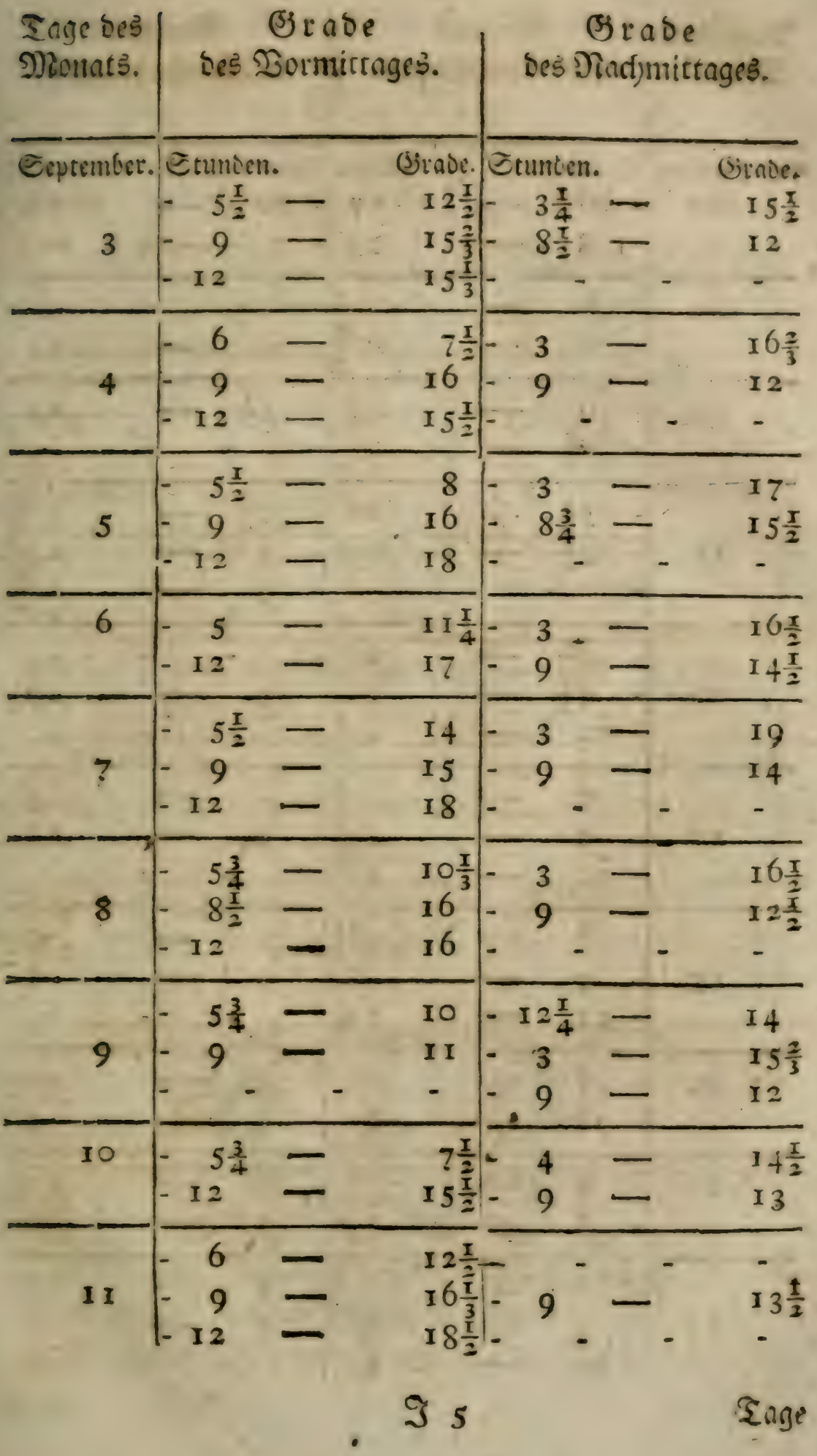


I38 Beobactungen ỉber die Blattláule.

\begin{tabular}{|c|c|c|c|c|c|}
\hline \multirow{2}{*}{$\begin{array}{c}\text { Tage bes } \\
\text { Snonnts. } \\
\begin{array}{c}\text { Expiember. } \\
\text { I } 2\end{array}\end{array}$} & \multicolumn{3}{|c|}{$\begin{array}{l}\text { Srabe } \\
\text { Des Dounittages. }\end{array}$} & \multicolumn{2}{|c|}{$\begin{array}{c}\text { Sirabe } \\
\text { Des פiadimittages. }\end{array}$} \\
\hline & $\begin{array}{c}\text { Stunben } \\
-6 \\
-\quad 8\end{array}$ & - & $\begin{array}{c}\text { Girnde. } \\
\text { I } 2 \\
\text { I } 3\end{array}$ & Stunden: & $\begin{array}{r}\text { Sirade. } \\
13 \\
-\quad-\end{array}$ \\
\hline & $\begin{array}{r}6 \\
-\quad 9\end{array}$ & - & 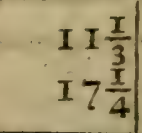 & $\begin{array}{l}3 \frac{\pi}{2} \\
9\end{array}$ & $\begin{array}{l}17 \frac{x}{2} \\
15\end{array}$ \\
\hline & $\begin{array}{l}6 \\
-\quad 9 \frac{x}{2}\end{array}$ & - & $\begin{array}{l}13 \\
I 7-\end{array}$ & $8 \frac{\pi}{2}-\square$ & 14 \\
\hline I & $\begin{array}{r}-\quad 5 \frac{3}{4} \\
-\quad 8 \frac{1}{2} \\
\end{array}$ & - & $\begin{array}{l}12 \\
14 \frac{x}{2}\end{array}$ & $\begin{array}{c}12 \frac{\pi}{4}= \\
-3= \\
-9\end{array}$ & $\begin{array}{r}16 \frac{2}{3} \\
17 \frac{1}{3} \\
12 \frac{1}{2}\end{array}$ \\
\hline I6 & $\begin{array}{r}-\quad 5 \frac{1}{2} \\
-\quad 9 \frac{\pi}{2} \\
-12\end{array}$ & - & $\begin{array}{l}10 \\
18 \\
18 \frac{\pi}{2}\end{array}$ & $9^{-}$ & $\begin{array}{l}- \\
152\end{array}$ \\
\hline II & $\begin{array}{r}6 \\
-\quad 9 \\
-12\end{array}$ & - & $\begin{array}{l}12 \frac{1}{3} \\
16 \frac{\pi}{3} \\
14 \frac{2}{3}\end{array}$ & $\begin{array}{l}3- \\
9-\end{array}$ & $\begin{array}{l}15 \\
10 \\
-\end{array}$ \\
\hline 18 & $\begin{array}{r}6 \\
-\quad 9 \\
-\quad 12\end{array}$ & - & $\begin{array}{c}8 \frac{\mathrm{I}}{4} \\
8 \\
10\end{array}$ & - & $\begin{array}{r}9 \\
8 \\
8\end{array}$ \\
\hline I9 & $\begin{array}{r}6 \\
-\quad 12\end{array}$ & - & $\begin{array}{r}5 \\
\text { II }\end{array}$ & - & $\begin{array}{c}\mathrm{II} \frac{\mathrm{T}}{2} \\
8\end{array}$ \\
\hline 20 & $\begin{array}{r}-6 \\
-\quad 9 \\
\end{array}$ & - & $\begin{array}{c}7 \\
10 \frac{x}{2}\end{array}$ & - & $\begin{aligned} & 2 \frac{x}{2} \\
& 8 \frac{x}{2}\end{aligned}$ \\
\hline $2 I$ & $\begin{array}{r}6 \\
-\quad 9 \\
-\quad 12\end{array}$ & E & \begin{tabular}{r|r}
$9 \frac{1}{3}$ \\
$10 \frac{1}{2}$ \\
II
\end{tabular} & {$\left[\begin{array}{ll}3 & - \\
-9 & -\end{array}\right.$} & $\begin{array}{c}13 \frac{3}{3} \\
9 \\
-\end{array}$ \\
\hline
\end{tabular}




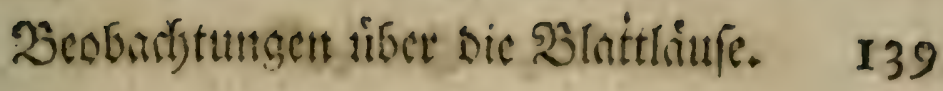

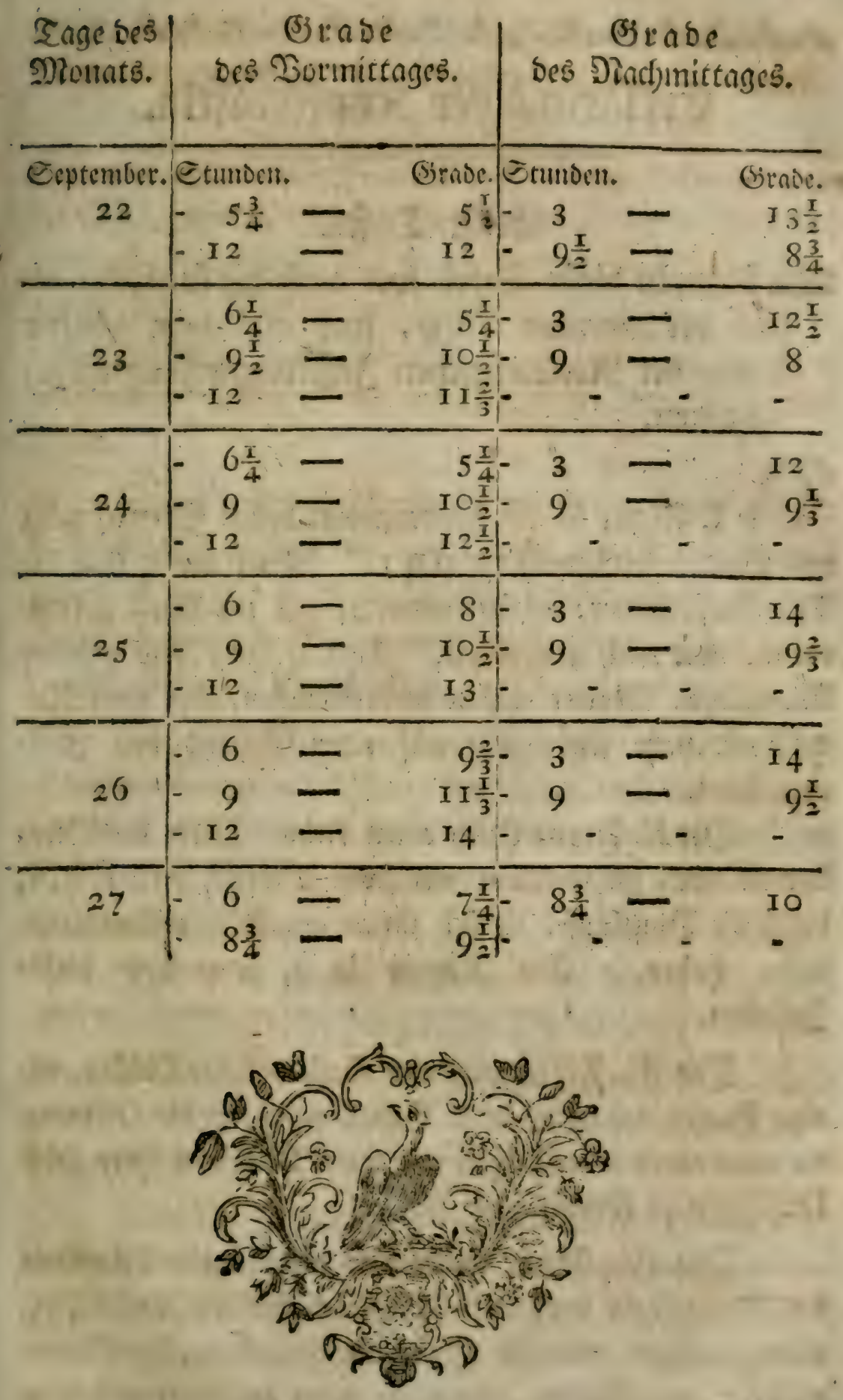




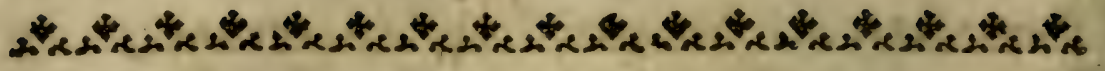 \\ Erfflírung Der Rupfertafelin.}

\section{Erfite Tafel.}

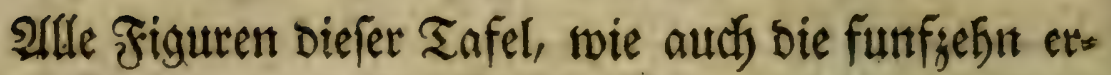
fien Der zwenten ₹afel, find aus bem Dritten

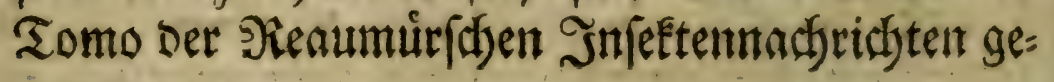
nommett.

\section{\$)}

ie I. FFigur ift ein Slieberzroeig, beffen Etengel ganj mit sBlattlaufen bebectet ift, p q r. Son p bis q fitro bie

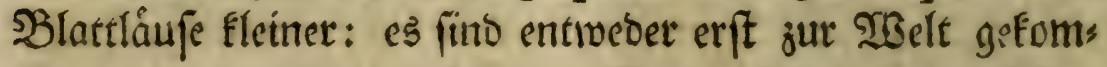
mene, ober nod) ganj junge. Son $\mathrm{q}$ bis $\mathrm{r}$ fint groffere Slattlåufe; Mutter, welthe niederfommen, ober if̧rer Nies berfunft nahe fino, und auf eitret Stjitjt bon Siun gen fifien.

Die II. Figut ftellet einen fleinen Zweig bes Birn: Baums vor, an weld)em fidf jreen sBlatter, a d, f, h, i; burch bie Blattlạule, bie fich) unten ange fert, bufammenges tollet fraben. Die Rornet in i, fino von biefent Sinjeften.

Die III. Figut jeint eine Sballe bont ber Siûfer, wie eine SIlnfe; $u, u, u$, Diefe Salle; p, o, r Die Defnumg,

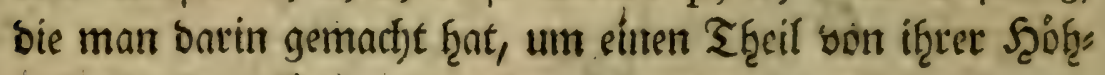
lung feţen ju fonnen.

Die IV. Figur ftellet eine ungefligelte SBlattlaus

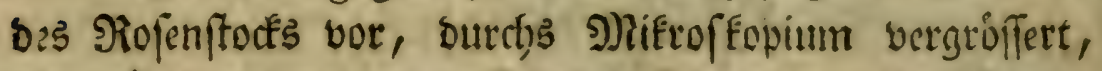
oberwárts unto von ber Scite betract)tet; t, ifer Sauge" ruffel in ber Stellung, wenn fie banit bet Saft auscinem 


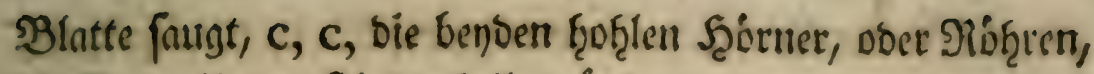
Die fie an î̧rem Şinterthęile trågt.

Die V. Figur ift eine geflugelte Blattlaus bes 2R:

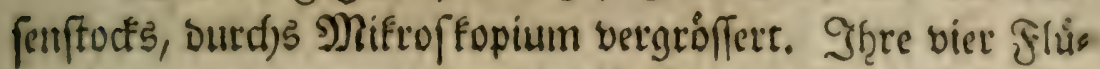

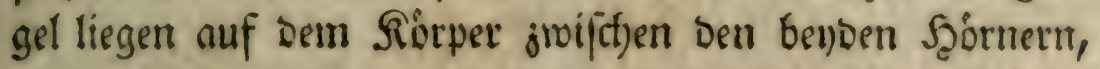
eitrer an Dem anbern, uno ftef̧en fenfred)t ouf ber Slä́che,

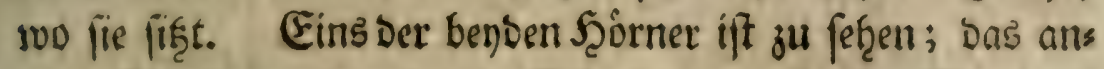

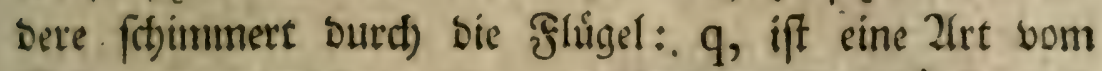

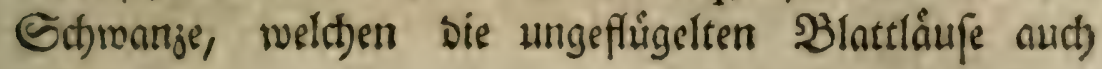
hุaber.

Die VI. Figur iff eine BIlattlous ber Bunfje mit ber

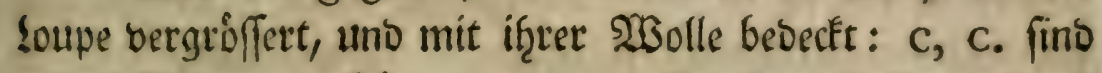

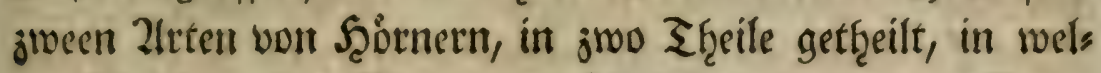
(t)e fict) bie woullige MRaterie gemóţnulid) theilet: t, Das Enbe, wo ber Siopf ber Blattlaus ift.

Die VII. Figur geigt naturlich eine von ben biden

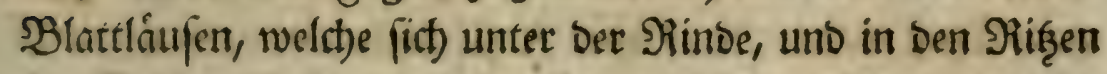
Der Eitfye auff̧alten: t, Der Saugeruiffel, weld)er unter bem

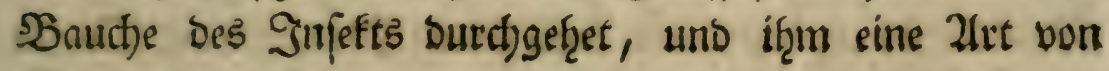
Sthroanje matjt.

Die VIII. Figur ffetlet eben bie borige Blattlaus vor, burd)s Mifrof fop bergróffert, uno bon vben betract)tet:

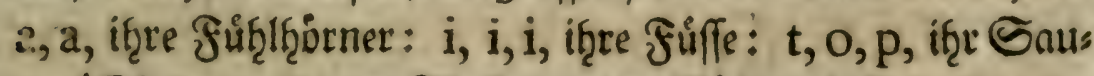

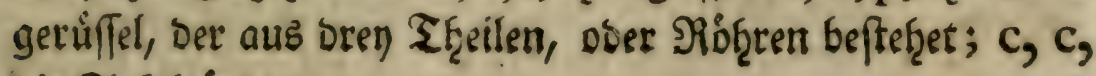
bie Birfelránbe.

Die IX. Figur ift eine $\mathfrak{B}$ aftartblnttlaus bes $\mathfrak{B}$ udf) 3 bautmb, mit Der Loupe bergróffert, uno weldte am Scinter

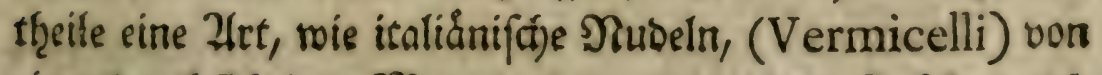

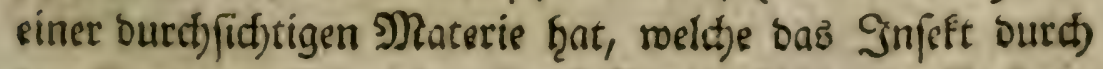

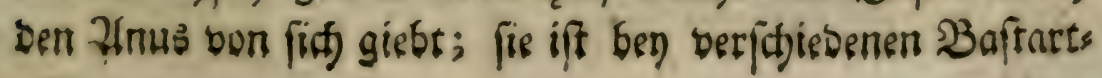




\section{I42 Enflirung Der Siupertufeln.}

- blattlaufen verfocteben jufanunengebref̧et: u, s, biefe Zrten Sermicelli.

Die X. Figur ftellet in Siroffen Die Fleine Fliege vor, in welthe fich Die Danftartblattlaus Des :Butbstoums verwantorlt: $t$, ifer Saugeriffel.

Die XI. Figur zeigt cinen Ş̧eil vom Feigenblatte,

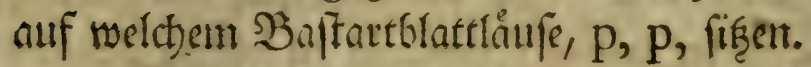

Die XII. Figur ftellet eine Bafturtblattlaus Des Feigenbaums, in Siroffen, unb von oben betrachtet bor: e, e, ifre fुlugglbecten, in a, ift if̨r Ropf.

Die XIII. Figur jeigt im Siroffen, von oben uns yon bet Gsite betradjtet, Dos geflutgelte Snfeft, in bas fith bie Saaftarthlattlans bes fergenbaums verwanbelt.

\section{SIndere $\mathfrak{E}$ afel.}

- Die I. Figur jeigt einten 20 urn, ben SBlattlatiss freffer, Det auf einem Etucffichen fliebergrweige liegt, unto jum Theil mit biejent fleinen Injeften bedeclet ift: u, bicfer 2Ourm, ber fich ciner B̉lattlaus bemåcttiget, p, p, p, bie

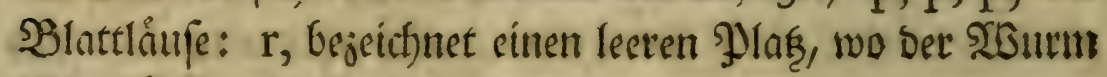
Blattlåufe gefreflen frat, bie jubor ba waren.

Die II. Figur ftellet in groffen ben vorigen 203 vor, s, s, Die finterften 2 Serfigenge Des Sthemfiolens, wels che er vorjef̧o faft bebecft f̧âlt, $O$, einb ber vorberften Gufts Iocter, p, eine Blattlans, Die biefer 23 um ausfanget.

Die III. Jigm ift cine fliege, in bie fï) Der 204 urm ber erften uno andern figur verwantelt.

Die IV. Figur ftellet einen flcinen B̉lattlaustowen Der erifen 2 rt, naturlich vor.

Die V. Figut if ein Blattlauslowe Set andern Irt in naturlitger Strofle. 


\section{EnElårung Der Supfertafelit.}

Die VI. Figut jeint bas Junngfert)en, in weld)e fich vie Fleinen Sowen vermandeln.

Die VII. Figur ffellet einen bon ben fleinen Somen Der britten Itet matirlict) vor, welche fict) mit ben Sçaten Dex aus̈gefogenen shlattlanfe bebecten.

Die VIII. Figur jeigt biefen fleinen Sorven, mit Det soupe vergruffert, $f, f$, pente Bebeckung.

Die IX. Figut ipigt baz Ende eines Pf Inumen: baumjiveiges, nuf weldjem Sliegen von bem SBlnttlauslo:

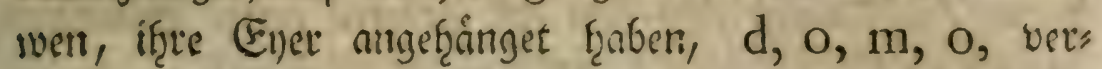
f(t)iebene Eleine Şanfen, ober vielmeţe Bufftel von biefen Enert.

Die X. Figur frellet bas fleme Infert in feiner nas turlid)en Groffe vor, Das unter Den SZlattlaufen ber weiffe Şuoel beifit.

Die XI. Figut ftellet es mit ber soupe vergrof fert vor.

Die XII. Figur ift ein Wurm, Der BInttlausfreffer, weld)er fich in einen halbrumben Siafer bermandelt. Er ift frier in naturrlict)er Broffe vorgeffellet.

Die XIII. Fitgur frellet Den f̧albrumben Siffer nas turrlic) vor, in weld)en fid ber Blattlausfreffer ber borigen figur verwanbelt.

Die XIV. Tigut zeiget in groffen eine ungeflugelte Şlattlausmutter bes Birnbaums, welct)e ein Junges zur 2Welt bringet, c, c, bie flcinen Sciorner, q, q, 2lat besflets St)wanjes, n, bie geborne Bllattlaus.

Die XV. Figur ift bie sorige Blattlaus, bie it if̧s: ret ఇieberfunft weiter gefommer iff. Das Sunge ift foft ganj ats \$Nutterleibe herous; es jeiget und ftredft feile fert) füfe aus, i, i, i, i, i, i. 
Erbe yor.

Die XVI. Figur ftellet sinen Blumentopf mit

Die XVII. Figur ift eine glajenne Flafhe, welche in ben Topf bon ber vorigen figur foll gefeget werben.

Die XVIII. Figur ftellt Den Topf Der fectjoef̧nten

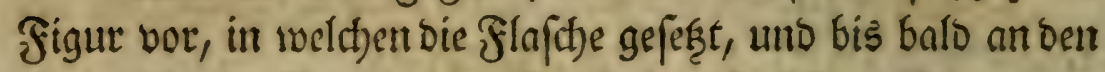
Shals mit ber Eroe in Dem Sopfe bedectet ift. Uleber bem Şalfe Der Şlaftte ftef̧et ein fleiner Stengel mit B̉lattern herbor, auf beren eins eine erft geborne junge SBlattlaus geferget ift.

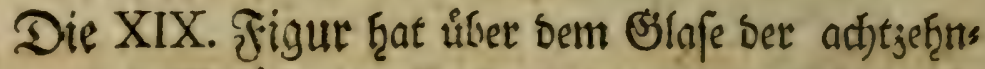
ten Sigur, sin Befás ober Zucferglas, unter welchem bie BBlâtter verwaf̧eet finto, welche Der jum Einfiedler gemact)ten

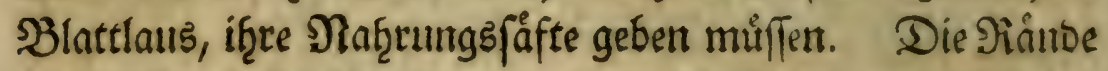
Des Zucterglafes foffieffen genau an Die Erbe, und find Das mit bebect.t.

Die XX. Figur ift ein Sucterglas f̧allo voll 2̧after.

Die XXI. Figur ift ein Yappenbectel, in beffen

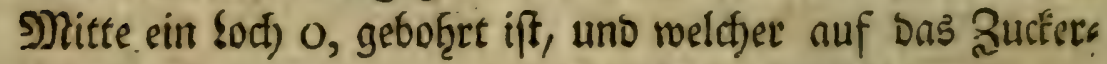
glas Der żwanjigften Sigur muß gefę̧et werben.

Die XXII. Figut jeigt biefes Zandéerglas mit feitrem

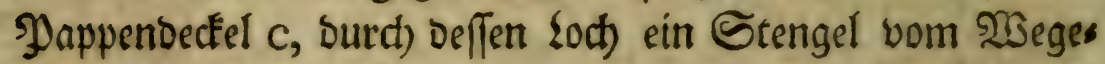

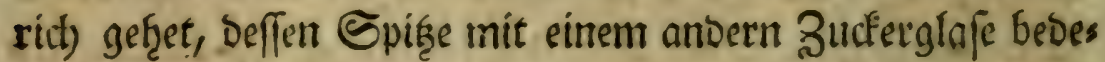
ceet ift, weld)es mit feiner Defnung genau auf bie গুappe foflieft $\mathrm{c}$.

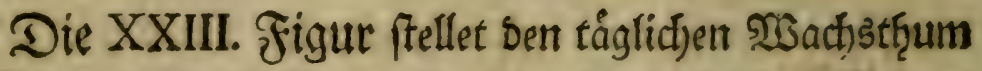

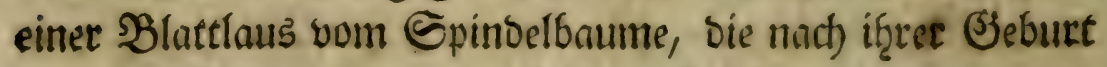
eingefthloffen worben, in natưlliffer Siroffé bor.

2(nf)ang 


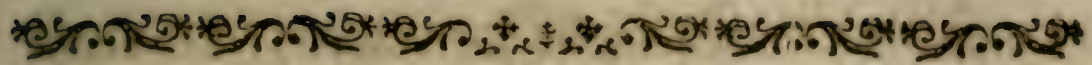

\section{Anthang}

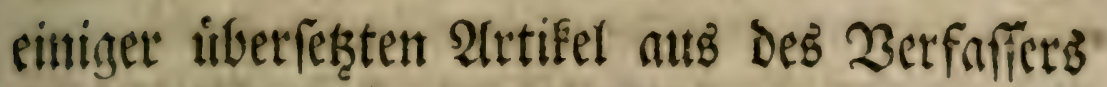

Confiderations fur les Corps organifés.

$$
\text { T. I. II. à Amft. } 1768.8 .
$$

\section{Zorerinnerung Deş Lteberféţerå.}

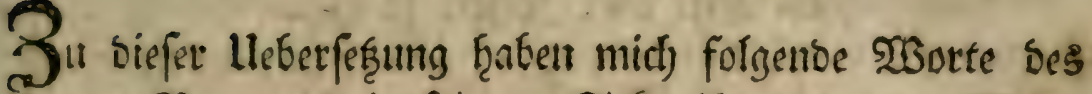

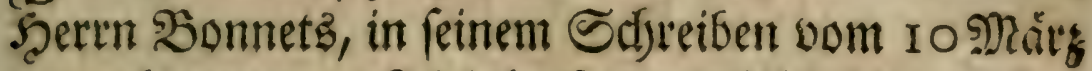
1773 bemogett. „Sidt facabe, fagt er bafertbft, bie interefflans "te MRaterie bor den Blattláufen, in Dem IV. Rap. Deß ,II. Tom. Der organifititen Rórper vom 302 biz ,jum 306. 2trtikel aufs neue vorgenomment. Sie

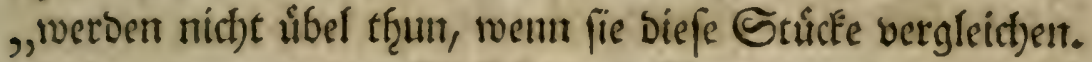

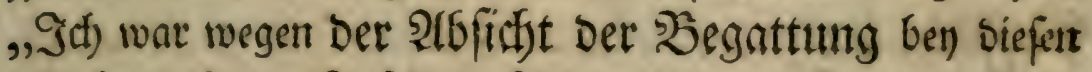
, Fo- Fonberbaren Sinfeften ferge verlegent. In Der XIV.

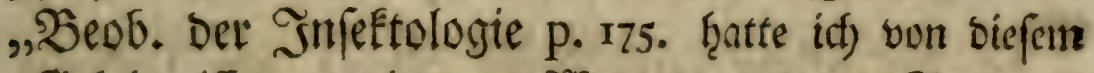

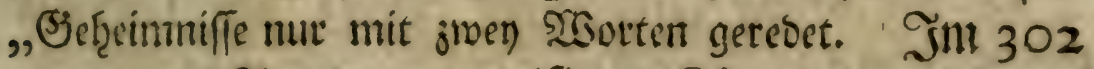

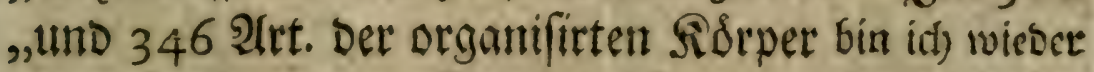

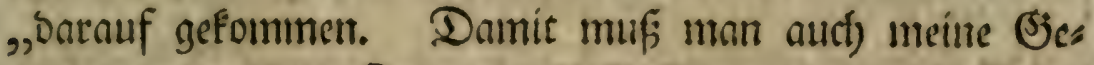
„Danfen, im VIII. Rap. Dez VIII. Th. und im III. Rap.

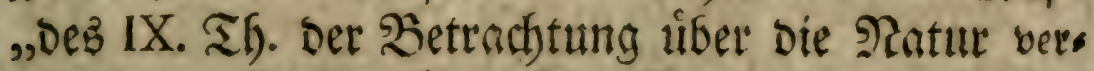

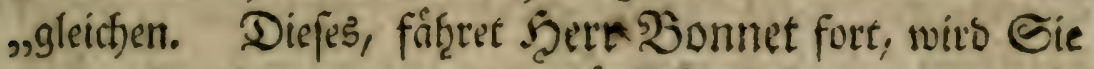

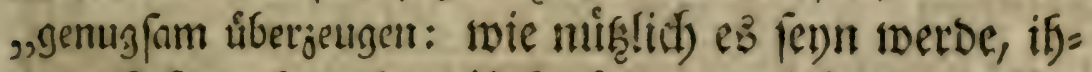
,ten \&efern, Ben ihrer Heberferseng, Diefe neuen 'Se= "griffe vor "wertweifen., " 


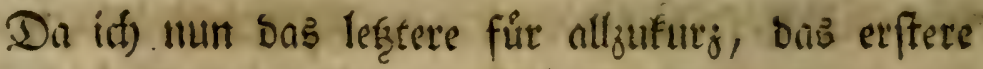
aber in einem 2luşuge fưr unvollfti̊noig ficilt; fo glaubte

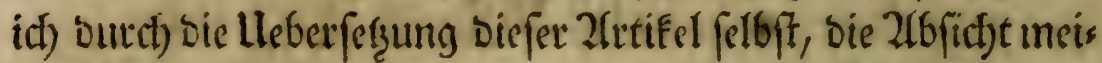
nes groffen 2(ittors am beftert ju erreichen, und baburd) jus gleich, úber Den ganjen erften Theil Der IMmeEttologie ein hุelletes sicd)t ausjubreiten.

\section{Betradbtungen ůber Die organifirten Siorper II. รf. IV. Rap. p. 99.}

\section{2lit. 302.}

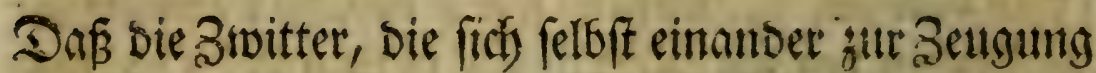
nicht gerug finto, Die sisirflichéeit Der wafren 2(ndrogynen nod) ungewiffer mactyen.

Reuer Girumb Daran zu zweifeln.

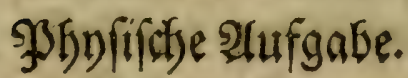

Sie Entbectung verfdiesener shiere von benberlen

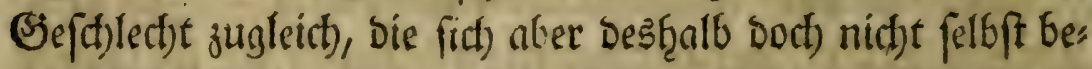

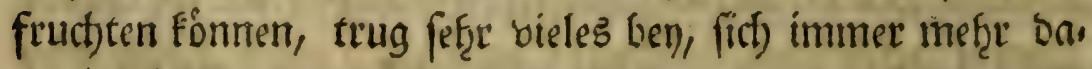

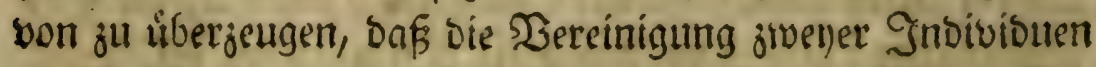

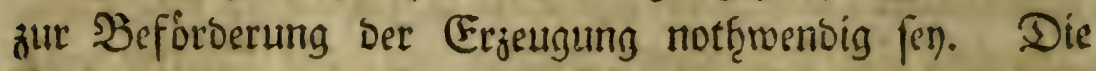

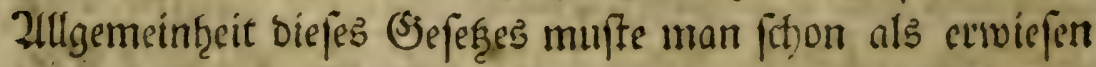
annef̧imen, fo balo man fict) nur verticthern formte, Don

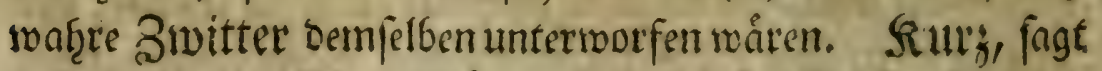
Der Şetr bon Dieaumúr: a) eB ift biefen Bnitterat=

ten

a) Memoir. pour fervir à l'hift. des Infectes. Tom. 6 . p. 535 . 


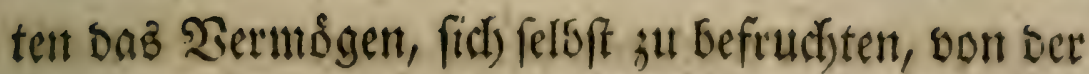
शratule nidjt jugeftanden: unzáblige fafta baben alfo eine Siegel beftätiget, welche bis nuf unfere Beis ten noch) Durch fein vollig genvifies Jattum, auffer

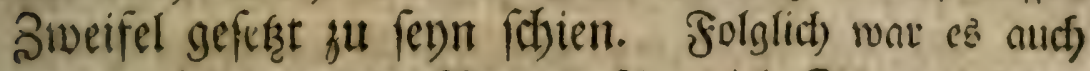

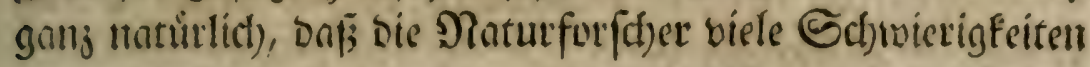

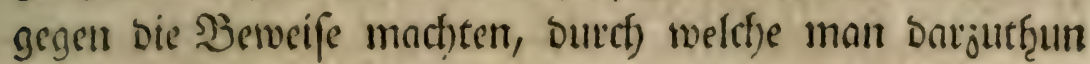

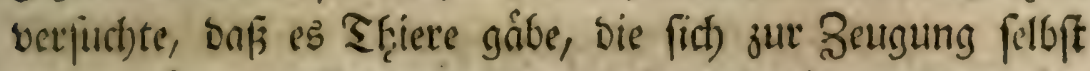

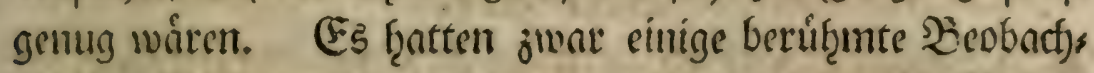

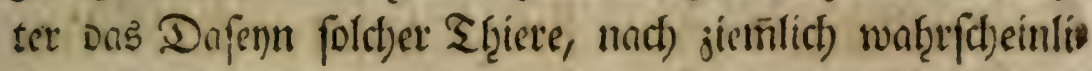
(t)en פRutfimoffungen angenommen; unter ben 2(rten aber, bie fie jul biefen fonberbaren Bnittem rect)neten, fanben fich

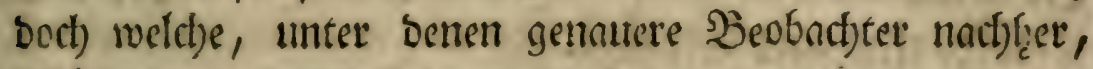

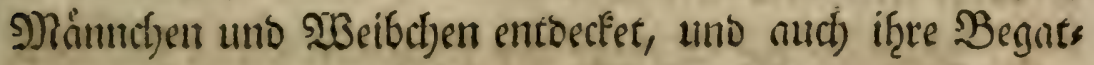
tung waf̨rgentummen hraben. Donon waten bie Gaallitt: feteten, vont weld)en iff) in biefent Rapitel bieles angefüfretet

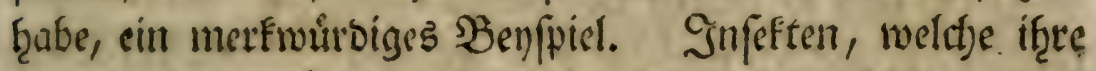
Stelle nicht veránbern fonnen, weld)e mit ber Yyfanje, auf

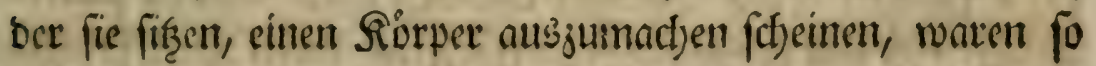

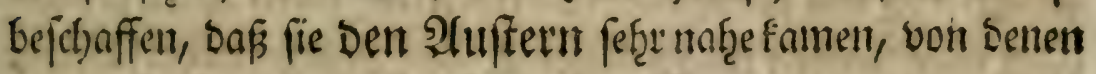
man glaubt, Daßs fie fich) of̧ne Segegttung vermeţren.

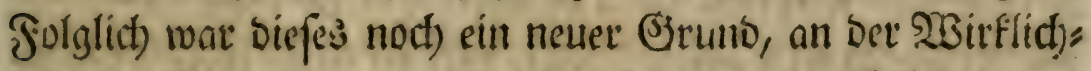

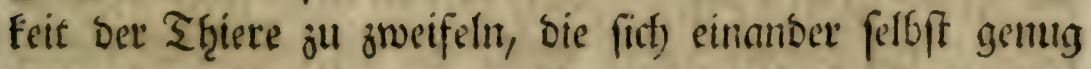
fint; folglict) aucf ein neter $\mathfrak{B}$ ewegungsgruno, fict nur auf unmittelbare, und vóllig erwiejene Erfag̨rungen einzulaffen. Dergleichen betrad)tungen waren es nuct, bie einent ges

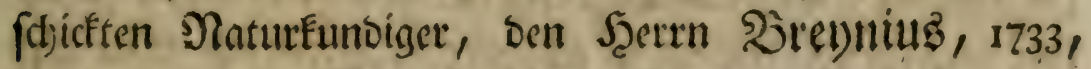
bewogen, Den Naturforftyern folgenie 2lufgabe vors julegen. b)

\section{$\Omega_{2}$}

v) Acta Naturae Curioforum 1733. p. 18 . im 2 $2 \mathrm{nf}$. 


\section{Problema phyficum.}

- - Genus animalium ejusmodi Androgynum, licet a multis, iisque primi ordinis viaturae Confultis Aatuatur; a nemine tamen, quod equidem foiam, ita demonftratum fuit, ut non multa, eaque baud levia, ei polfint objici dubia.

\section{1nt. 303.}

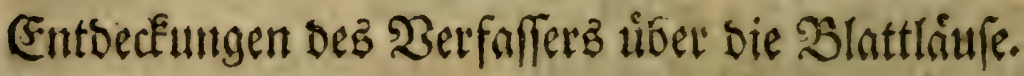
2uffófung Der phyfifchen Pufgabe.

Gejefjlect)te, bie nach einander allein aufgejogen fimo, umb ifre Erfolge.

Co war ber Zufftuno ber Naturgefofictite in Ners bealtrníf gegen bie fo oft unterfuct)te frage bun ben 2nbro: gynen; unt fo waren úberţaupt bavon sie Nennungen

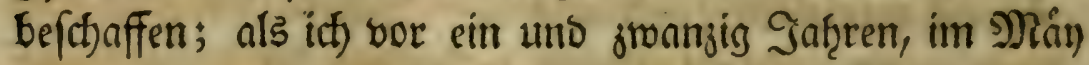
1740, meinen erffen Serfuch mit ben Slattlâuen unters

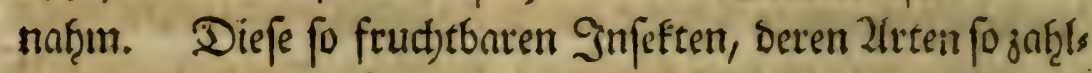

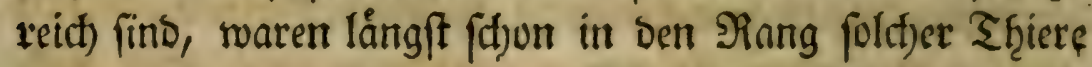
aufgenonumen, welche man ju ưbereilts in Die ßínffe ber waf̧,

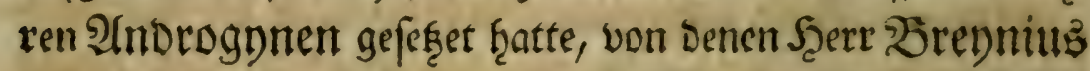
xebet. Es berweifet aber Diefer ưberilte Ect)luß nirfits

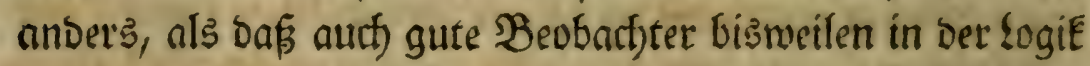

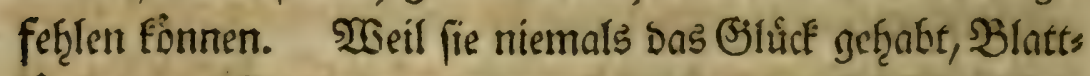

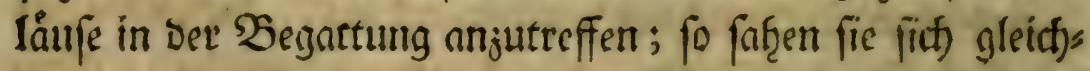
fam gejmungen, Daraus ju foffieffen, onf fie fidf of̧ne $\mathfrak{B}_{p}$ s gattung vermef̧reten. Es twat bies inbeffen mur ein Sweis

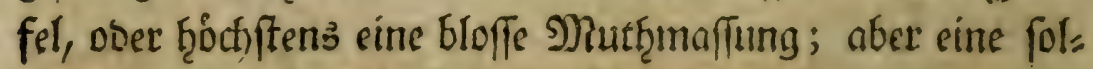
dje, bie ber Seerr von Pienumir baburd) in 2(nfeften bract)s

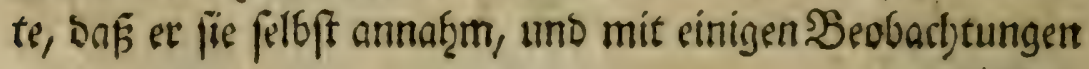




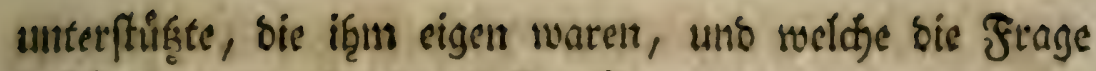
beftánbig unentichicóen lieffen c).

DRein erffer Berfuct) war fur biefectbe fifjon entfdecis

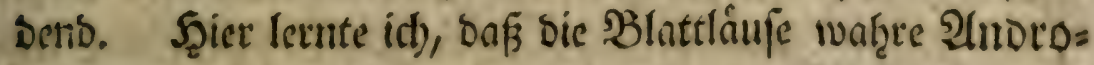
gynen waren. Man faint es aus ben Vl. Tom. Der Reaumirichen Mennoires, D) uno in Dem erften Trgeile meither Inffeftologie, e) fercen, mit welld)er Sorgfalt uno

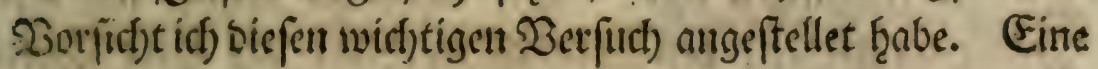
Sblattlaus, bie id) volt Dem Zlugenblicte in̨rer Befurt an for

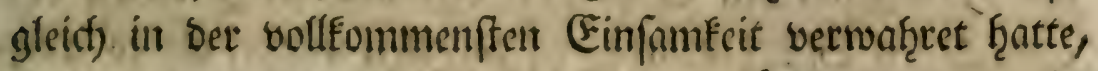
bent)te in berferten vor meinen 2lugen, fuinf uno neungig

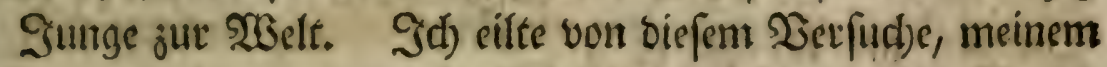
bereits verewigten groffen freunbe, bem Sherrn oon Эieats

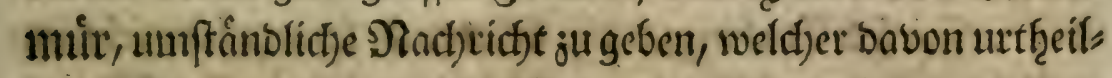
te: Don er verbiente ber Iffabenie mitgetţeilt ju werdent, bavon er cine ber vornefrmften Bierben war. "Da id) ges

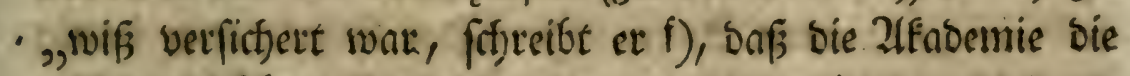

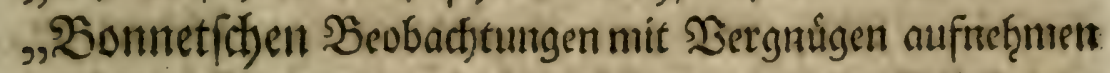

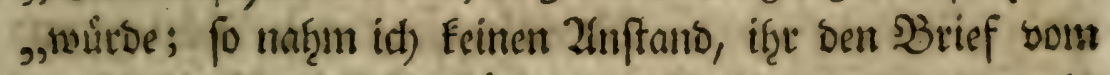

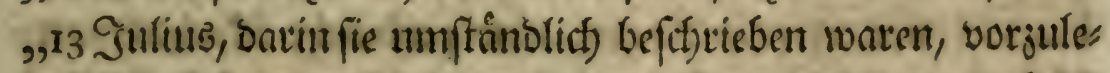

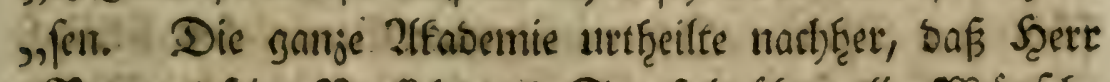

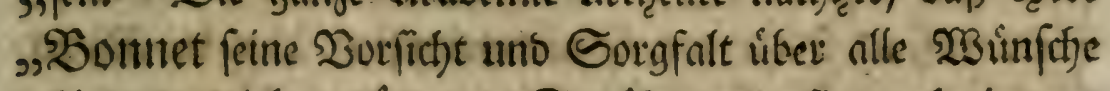

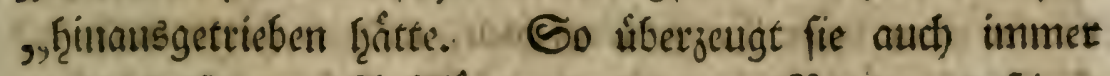

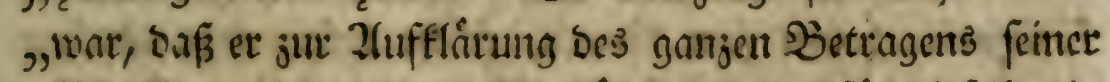

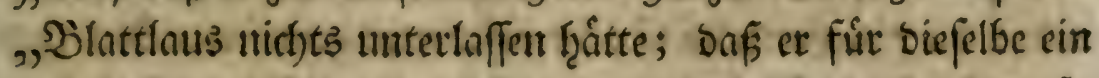

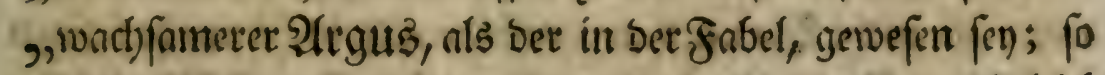

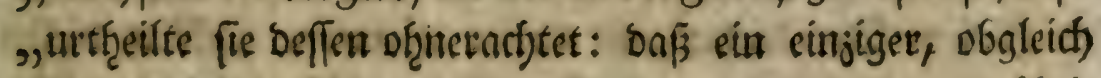
I 3 , úbr:

c) Mem, ponr fervir à l'hift. des Inf. Tom. III. Mem 3 . Tom. VI. p.523. P.

b) p. $530 . \mathrm{f}$.

e) I. u. f. 23cobaditumgen.

f) Ib. T.VI. P. 53\%. 
, מ̂́ „ein Faftum auffer allen Zmeifel zu ferzen, welit)es cinem „allgemènen, uno burd) bie llebercinffitmmung aller biş̨er „,anseftellten Beobact)sungen, beftátigten Befecţe, gernbe ents „ggegen wáre. Man fat mur gar ju biel Exermpel, Duf „e einige Linftánbe ben fdarffict)tigften uno oufinerffamifen "2tugen entgangen find. Die 2ffabemie fonnte fict) alfo

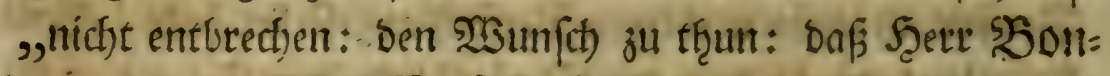
- "Het ben nemlicfen Serfucb, fo oft, uno an fo vielen bers

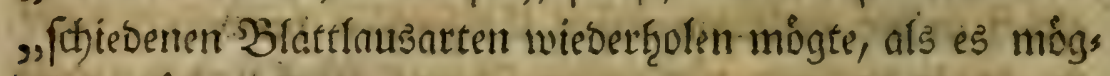

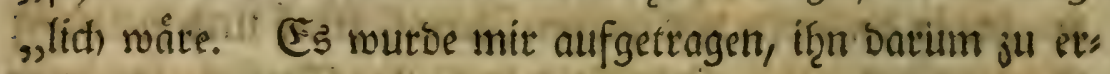
"f futchell, und id that eb.,"

Diefes Verlangen ber affabemie fonnte idf nidfet uns

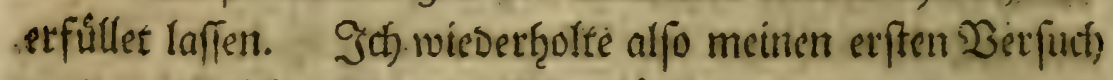

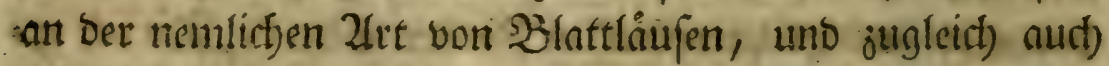
mit einigen ambern 2trten. 9) Der (Erfolg war imuner Derfertbe. Allle, bon bem Zfugenblicfe if̧rer B̧eburt on, ganj allein nufgejogene Sblattlaufe, wurben Mhitter, uno

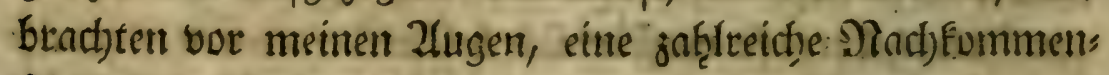

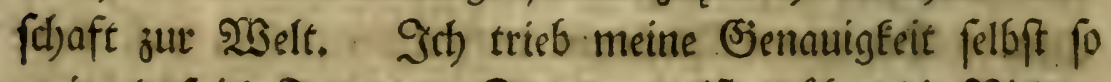

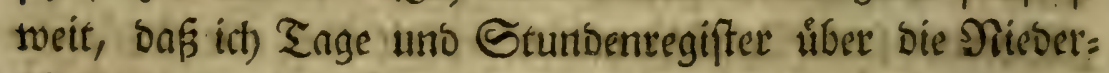

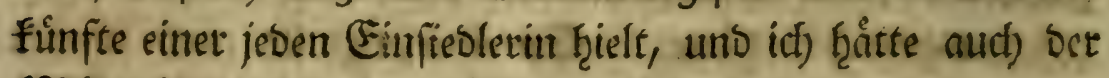
- Mlíhe viberţobent fenn formen, foldt) befanut ju mact)en,

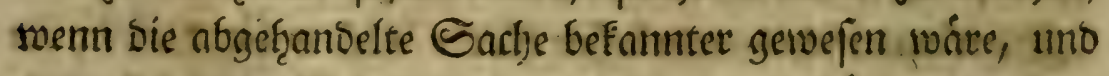

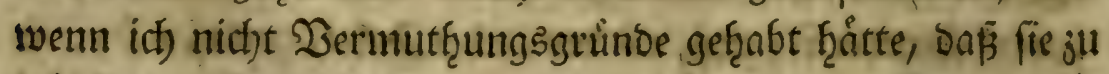

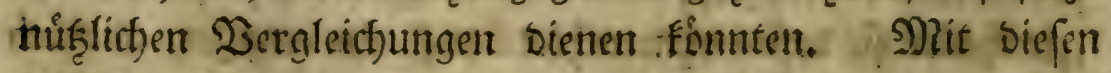
neuen utro init einer wirflich zmeifelnoen Eorgfalt angeftells

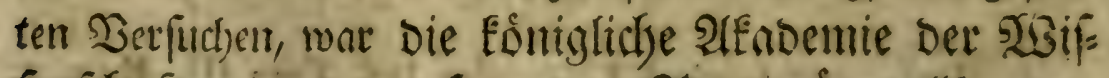

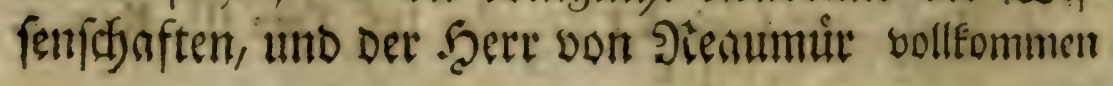

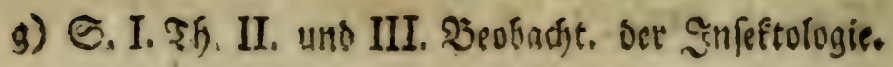




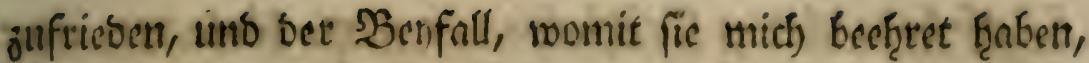

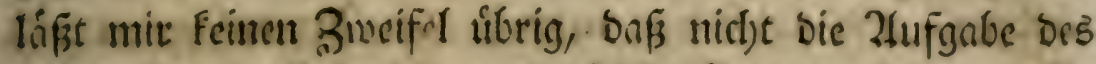
Scerrn SBreynius völlig aufgelópet wâre.

Diun wollte id) aljo meine Zlugen rufen laffen, bie

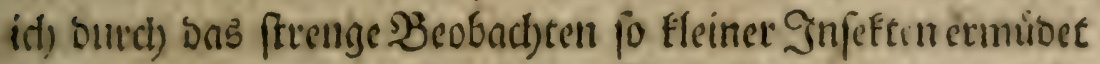
fiatte, als mid) eitre bom Şertu I te unctivartete, unb fonberbate Sermutţung, * $)$ in eine

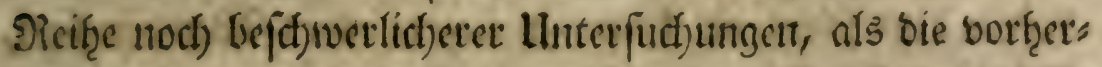

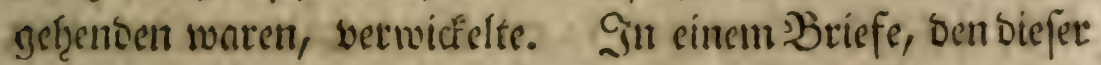

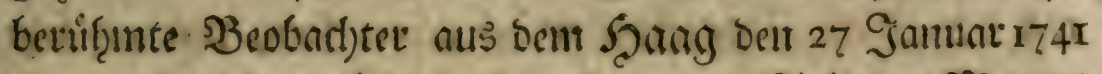

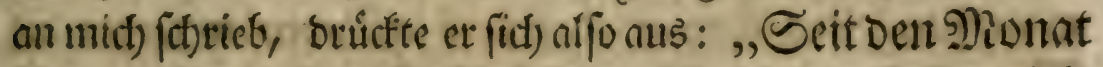

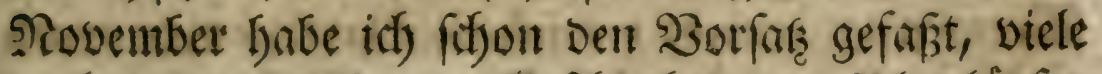

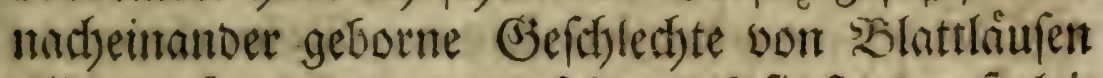
allein anf; she 2 int Junge Gervorbringen wirben. In Fallent, Die von Dent gewodhnlichen lumftintoen fo weit abge ben, ift eb erlaubt, alles zu verfuchen. Schlagte zu mir felbit: wer weiß, ob nicht eine eintige begat=

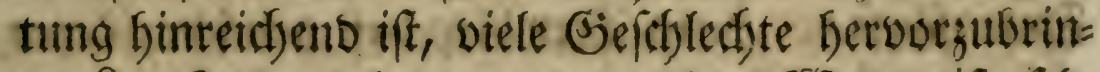

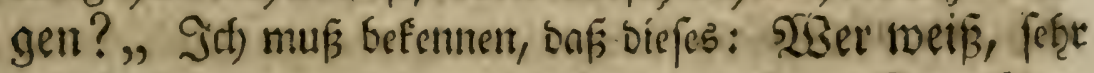

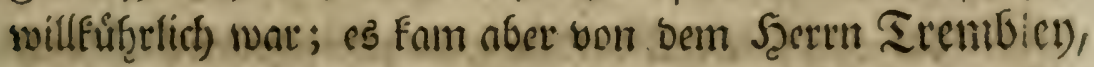

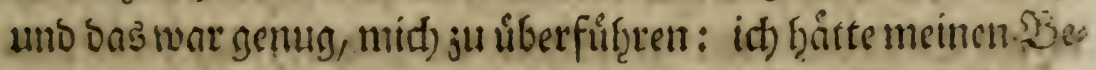
sweis noch nirfst weit gemig getrieben. Der beenfoll eities:

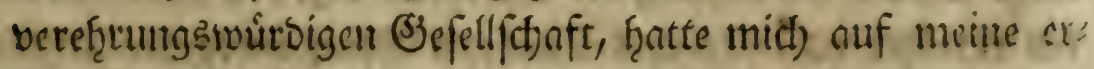

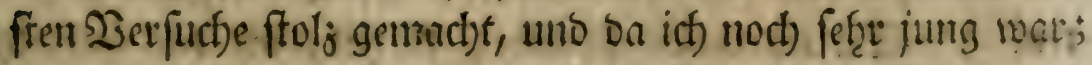
fo war mirs unrettríglict' baf fie, auf irgent eine 2(rt, ourd) Den geringffen Gmeifel follten gef(t)wád)et werden. Diefer Silweifel reiżte meine Eigenliebe, uno ich naf̧m inir vor,

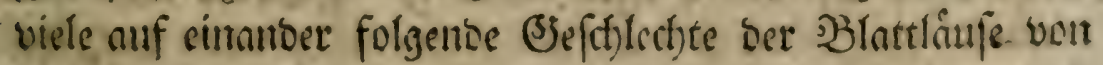

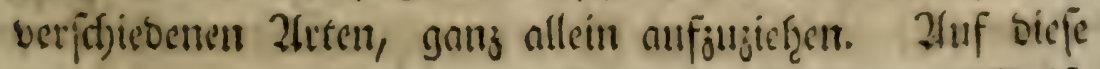

$$
\text { S } 4
$$

203 ife

") E. bie III. Beobuditt. ber Sulfifterofoyie. 


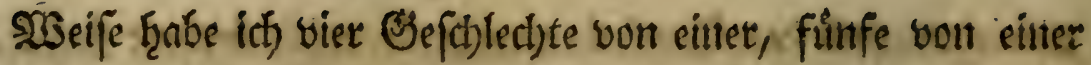
anbern, unb fed)fe bon einer britten 2(it aufgegogen. b) Durch biefe neuen. Serfuct)e war es nun frtenge bemiefen,

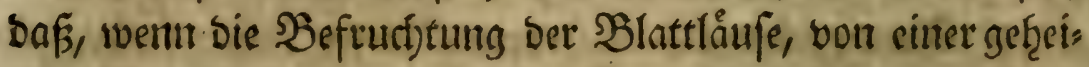
men ß̉egattung, Darauf Şerr Trembley jielet, f̧errúf̧eren follte; fo múfte biefe B̉egattung f̧inreichento feun, wernigs

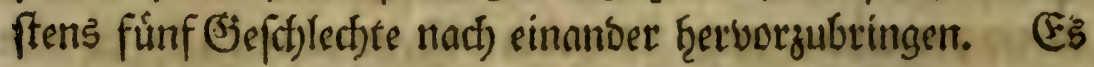
svúrbe bies fothon ein faum ju begreifenbes 20 outber fenn,

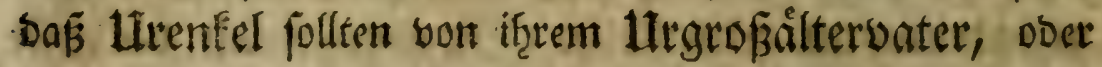

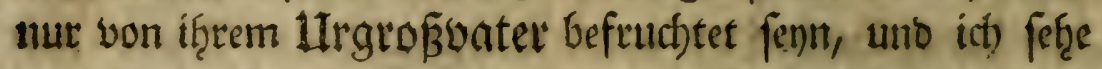
es meinen sejern fdyon an, tấ fie fein Bedenfen tragen, Die

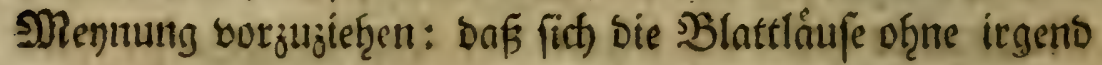

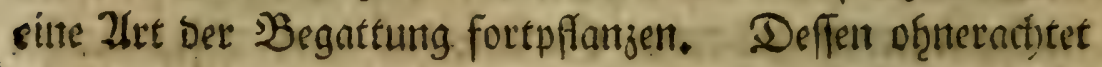
glaubte id noct) nif(t)t genug getţan ju ḩabent, eine bloffe

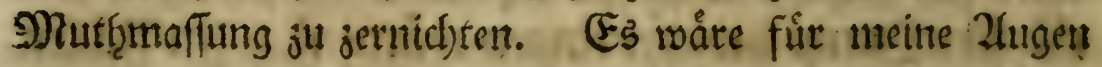

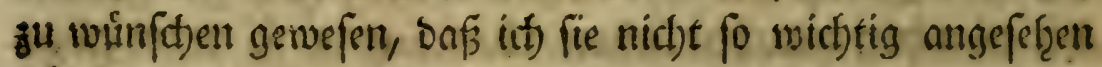

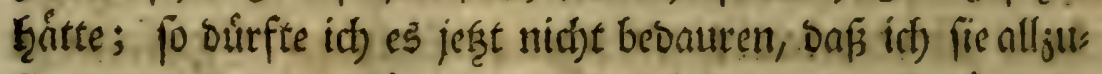

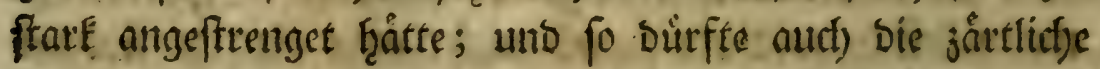

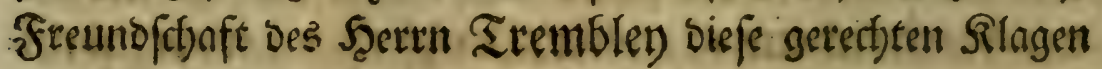
nidt) init mir theilen.

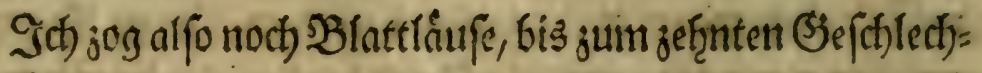

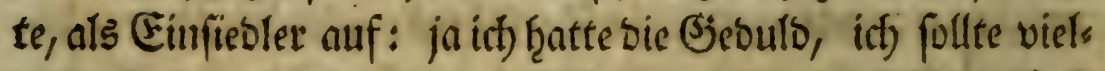

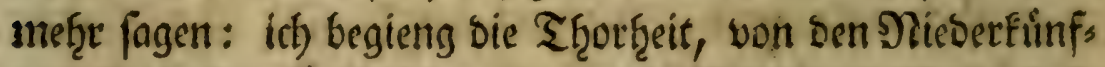

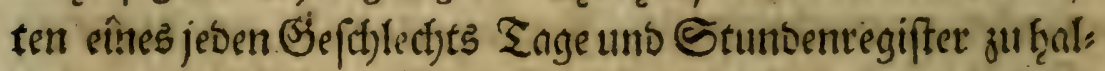

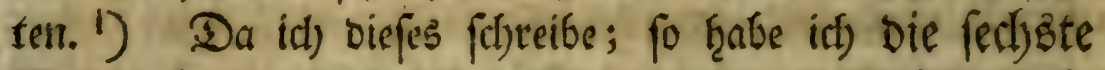
Bevbadjtung Des crften Theils meiner Sinfeftologie

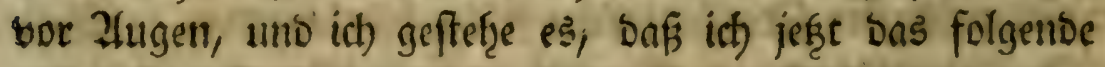
sicdst ofgne (Erftaumen lefen fantr. $f$ )

„Sollte malr aber ,ofents

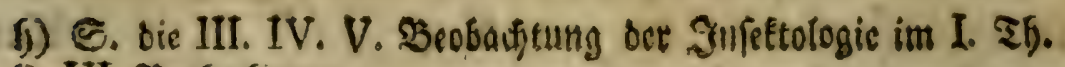

i) VI. Destiaditung.

8) Im Ente stefer \$eoto 


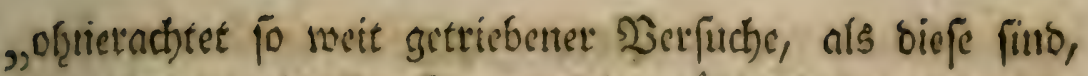

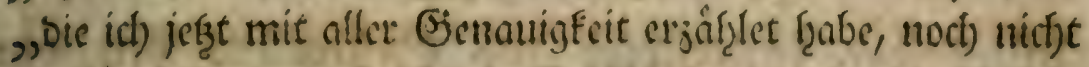

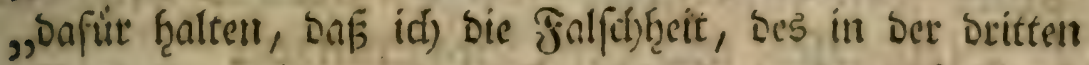

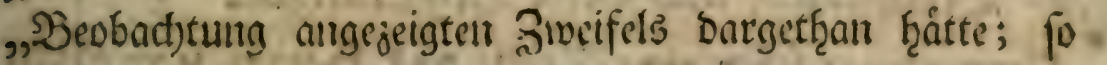
, wưrbe man fich) ftets bequetnen múffen; entroeber mit mir

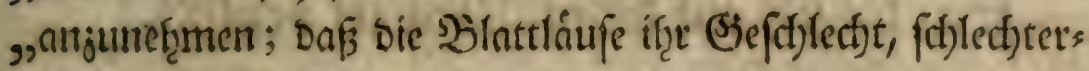

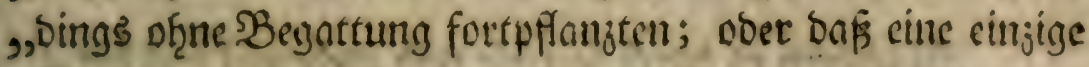
, B̧egattung menigftens fun neun uad) eintanber folgenden

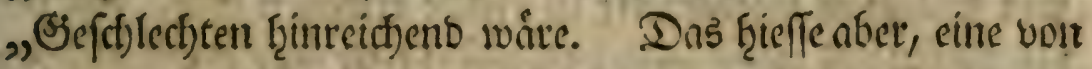
„Den gewoifzulid)en Regeln, gleid) weit entfernte Sad)e an: ,nef̧men, wo nicht) gat die !efetere noct) weiter bavon abs gggienge. Snbeffen glaube man ja nicht, baß̧ ich diefes mue

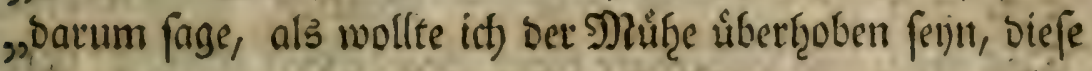
,, Berfuche jul nieberf̧olen, ober fie bis ju mef̧reren Şes

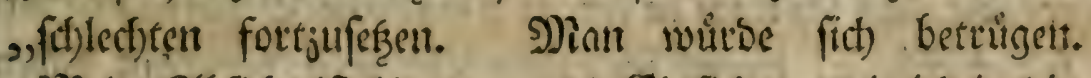

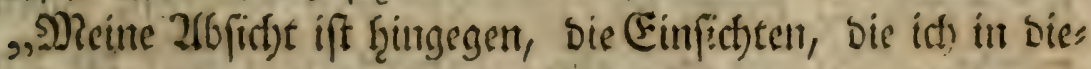
,fer Sache exţalten ḩabe, gemeinnůg̨iger ju madjen, unto

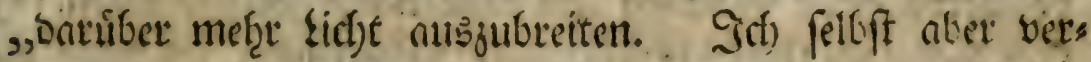
gsjweifle gar nicht, baf es mit nickt) gelingen folle, biefe , Eleinen Infeftent, wenigftens bis jum dren) figften (Sefchled)s "te, alleim nufjujiefzen." - So fchlof idf vor nct)ts

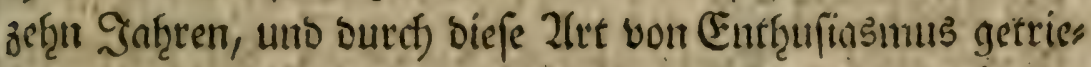

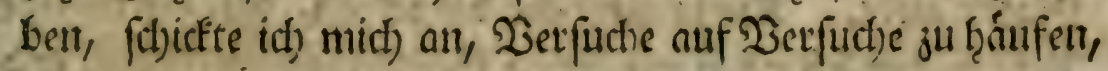
sveil it) vornusfergen fonnte, baß̧ Die ganje llnternebnung

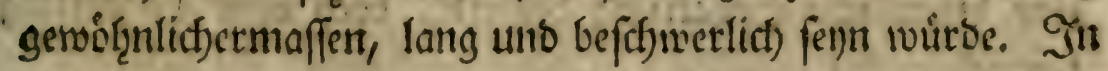
meinen 2fugent war es nut nod) ein Şotppiel, unt idf) F̧idt

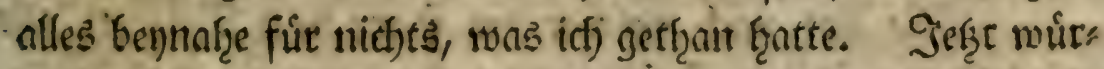
De ich) uiber biefent Enthrufiasmus Ind)en, went bie Folgen

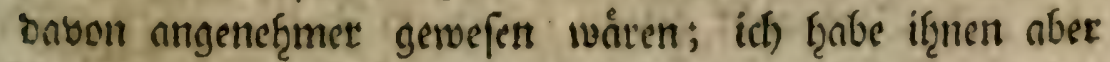
bod) tie Interfutfungen ser Dflanjenblátter, unb bie 2(naly) ber Seclenfrafte ju danfen. 


\section{2int. 304 .}

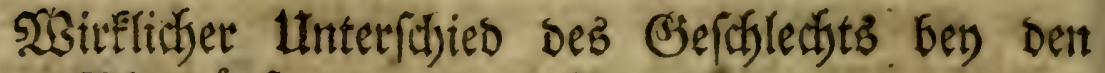
Blattlåuen, uno ifren פegattungen.

2nmerfung ưfer eine Stelle bez faerrn von Büf: fon, Die fith auf biefen ßorwurf begiebet.

Nachoem es burch fo viele uno metremal mit bet gro:

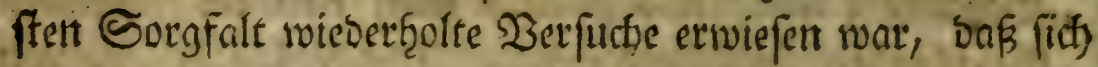

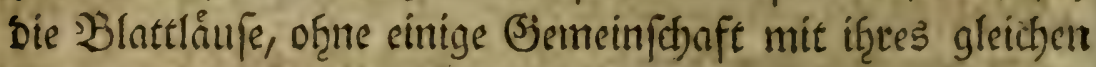

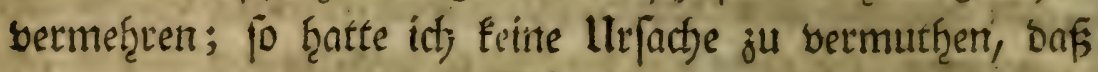
ich) unter biefen Infeften MPäntchen und 2 seibchen entbes

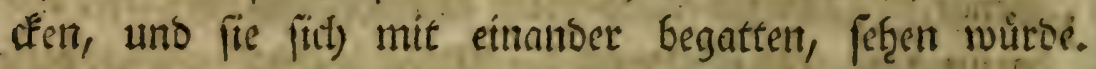
Das neue, uno fonberbare biejer Begebenţeit erforbert noths

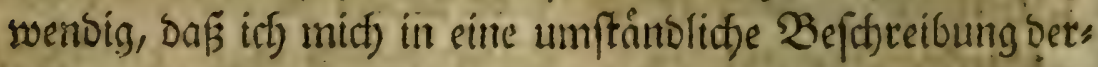
felfen cinlafle, womit id) meine Sejer gern berjhont traben wưrbe. Id) fahe mict) alfo genothiget, mich) uber bie sies beswerfe einer Şattung ber Blattlåje ausjubreitent. D

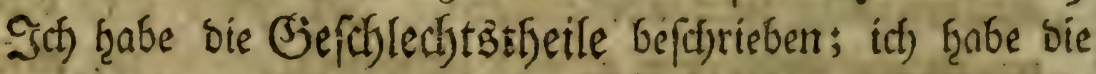

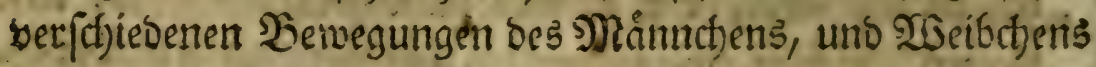

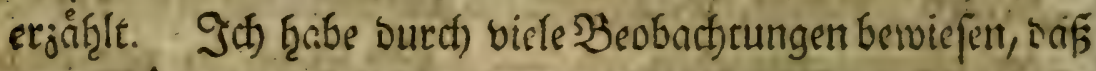

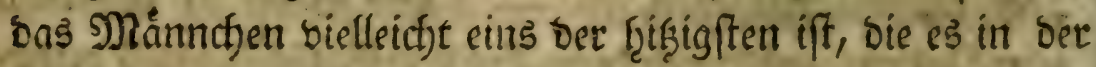

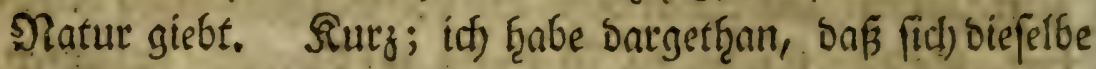

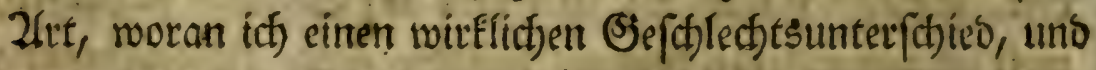
sine eigentliche Begattung bemerft, bod) Dine Begattung vermeţre. m)

Die 2lrt, nach welcher bet Sert bon Suiffon alle biefe fafta erflart, ift fo ounfel unb givenbeutig, dari fie alle, bie mein Buth nictjt gelefen ḩaben, in Bweifel laffen wirs, ob diefe fafta audf) red)t beobachtet find. „Atnoere Thiere,

1) VII. 2estactitung.

m) XIII. XIV. 2̌enf. 
,fogt er, ") fint, wie bie Slattlaufe, meil fie feine befons

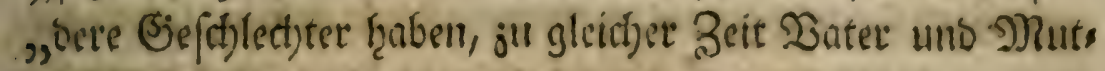

tet;

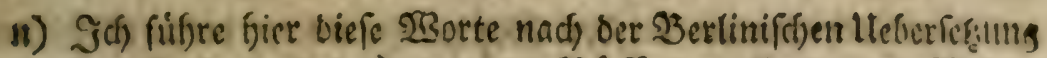
Oet 2tuggabe bes Sctru von 23 infons allgemeitten Ratur:

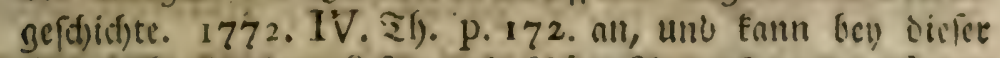

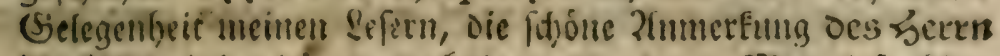
30. Lisatini, nidit vorentibalten. p. 173. 9)?an lefe biet:

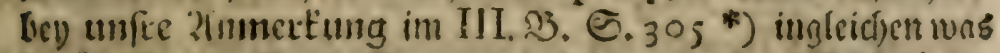

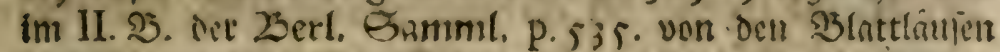
gefanget wotien. (Fo giebt untev bielen llngejiefer, weld)eb

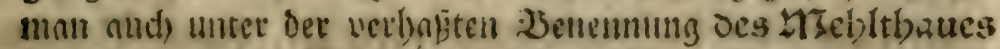

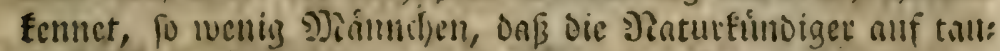

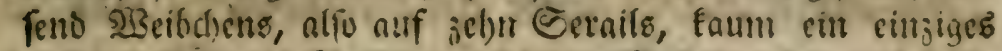

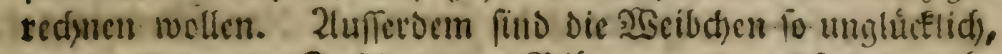
ganj veft an Der Gubjang oer Şlótter anjumadjen, unt ifje Eebetage nicht voll Det Etelfe jll Eommen, Daber fic nuth 5500 Jullue ronten milfen, eise man fie für Sbiere nebal: ten Gat. 2 tr.

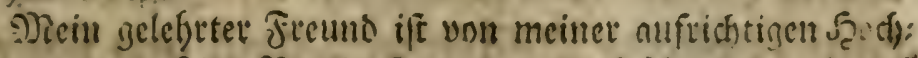

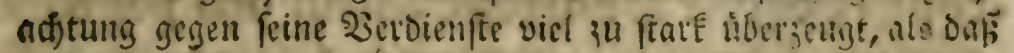
ex bier bas (Sjegentbeil glauben follte, wenn id) ibm úber sicfe Znmerfung mit einer freymutbigen Offenl)erigtert, einige Stocifer entuecte.

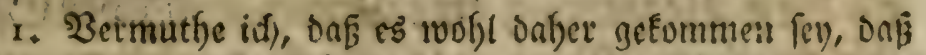

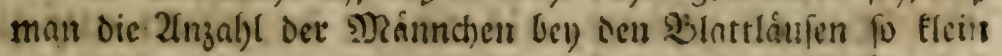

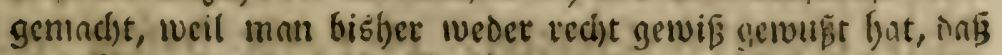
Diefe Sbietd)en beyderley (Siefidechts find, no d) aud) bemetkt, Das fidj oie zrainnchen nur zu einer gevoiffen Jabrszeit bánfiger zu den $2 B$ eibdjen cinfinden.

2. Ed)cint es aud; fcir allgencines פaturge

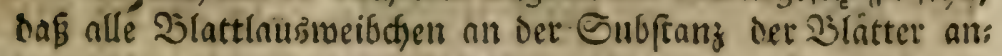

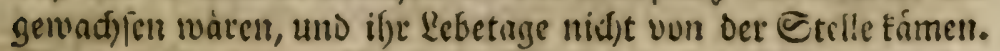

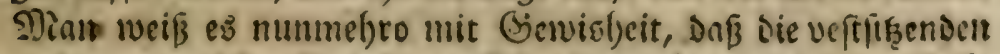

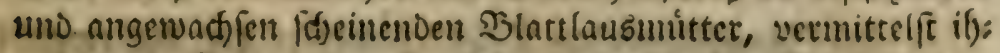
res in Dit Ed)nale oes Zweigleins eingelenEten Etad)elb, bic: fe Etellung anneljmen, un fich auf fold)e siseife Defto velict

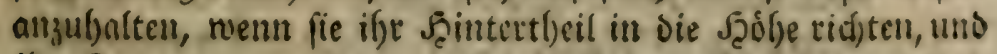

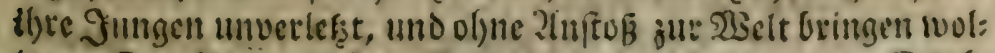
len. Die Zometfdhen 2erfudfe forvobl, als einige Erfal)s

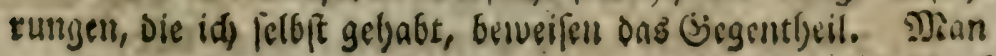


„ter, fie jeugen von fich felloft, ofrne vorthergegangente Đaas ,tung, ob fie gleidf) sumveilent, went es ingnen beliebt, fict) begats

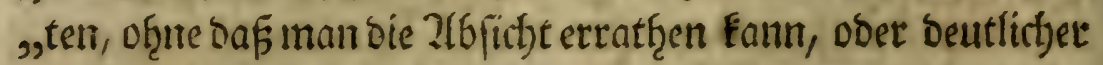

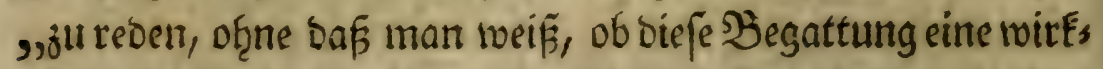

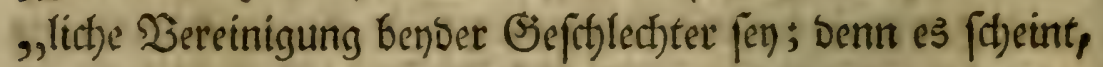
,als ob fie berferfeen auf gleidfe $21 r t$, entweber bernubt,

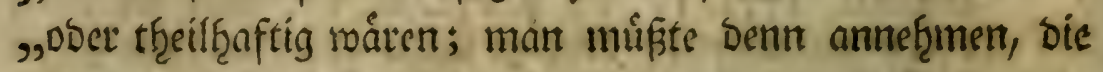

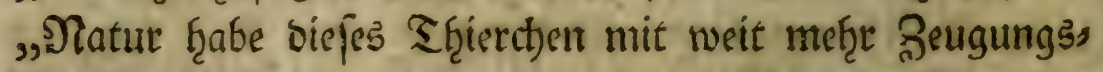
,F Fraft, als irgento ein anberes ausgerufftet, unt if̨m nicht

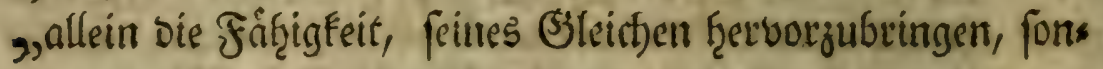

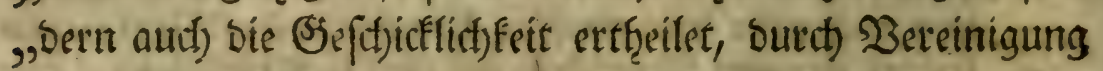

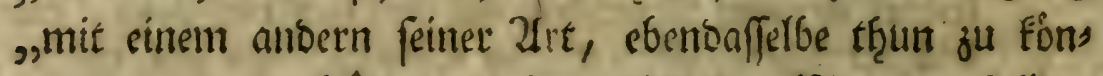

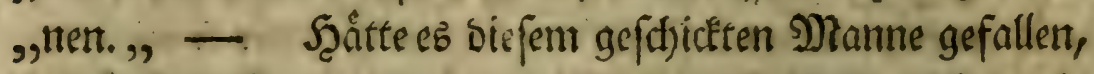
meine Sthrift mur mit einiger Jufinerffameeit ju betrach) ten; fo wúroe er fitt viel beutlidjer und beftimmter ausges

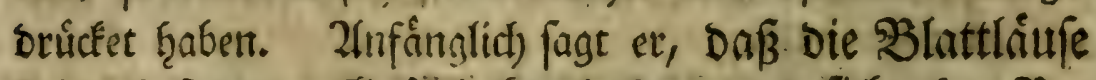

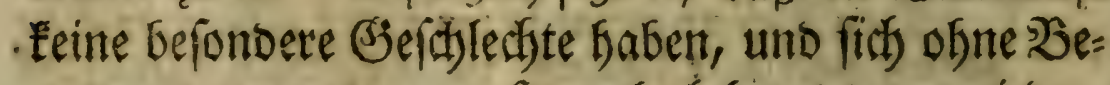
gattung erseugen. Szernac) bef̧auptet er wieber, Daş fie fich begatten, ofne Daßs man wifient Eomnte, ob Diefe Begattung eine $\mathfrak{B}$ ereinigung Der (jefhlechte fen, weil es fatiene, als ob fie derfelben muf gleiche 2(et, entweder beraubt, ober theilfaftig iwarent.

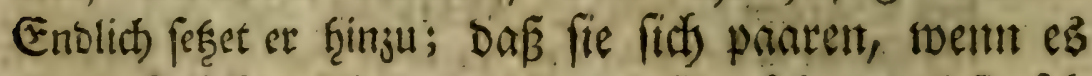
ifnen Beliebt. Scieraus fotiente faft zu folgen, ba fie for

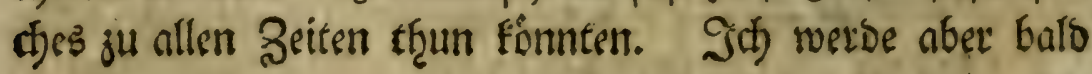

jeis

barf bie gethą)renden Ş Sinfruntente oft altrif)ren, uno aufbebcn; fo tociben fie balo

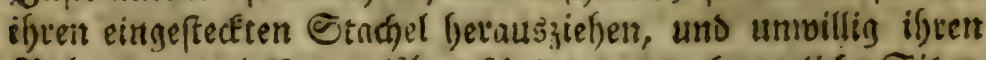

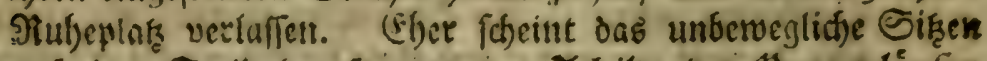
nuf ciner Etelle ben fogenantnten Edrilo oier Oeangeláufen sigett zu feyn, an benen man weber Juffe, nod, andere fór:

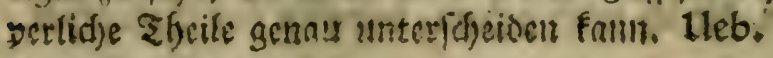




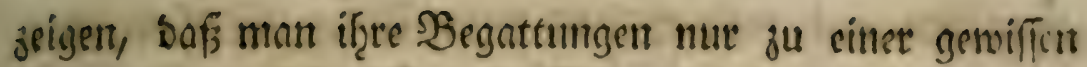

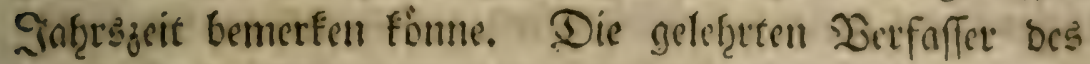
Iournal de Trevoux bqaben mir in bem Z(uşage, *) batin fie meinte Infeltologie beuttheilen, einen ¿ornurf gemad)t, ben ich nichtet etwartet ḩatte. Die Eache betraf

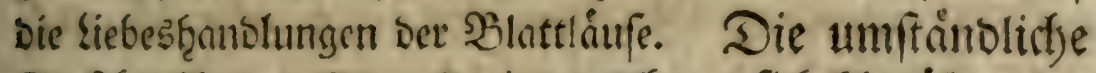
Soefdreibung, fagen fie, in tweldye er fich fieruber ein. láft, jeuget von einem Mante von Erfahrung.

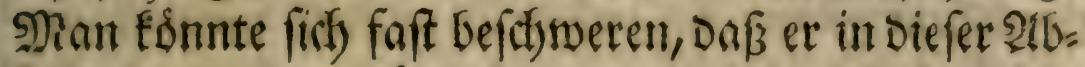
fidjt Der Elugen Zasirtlichfeit vieler feiner Sefer nicht

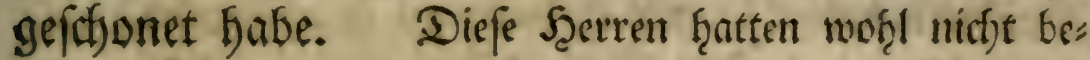
Dactit, Daf man, wenn auch Der Maun oon (Erfal)rung

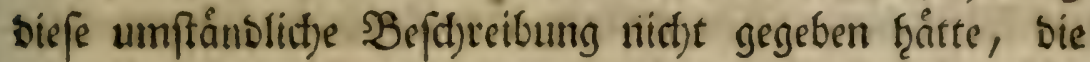

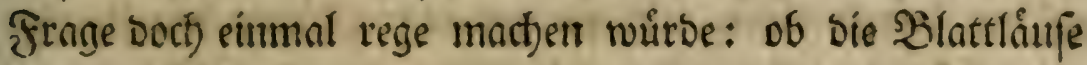

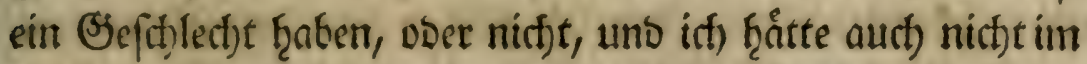

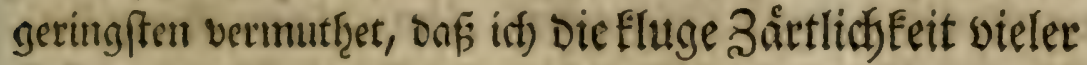

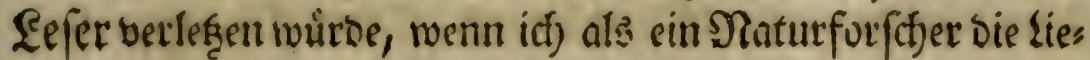
beswerfe fo fleiner Sulfeften befatriebe. Berwis bie anatos

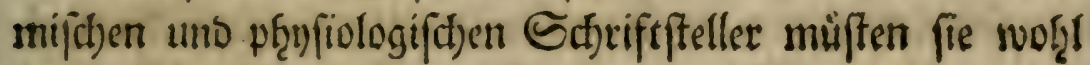
auf Die Zlte noch) meţr berlef̧en.

\section{2rt. 305 .}

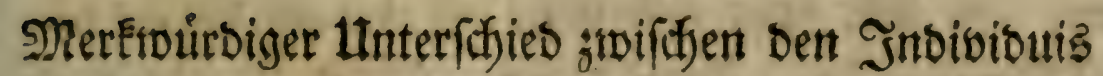
einer und eben Derfelben Irt unter Den $\mathfrak{B l a t t =}$ Iåufen.

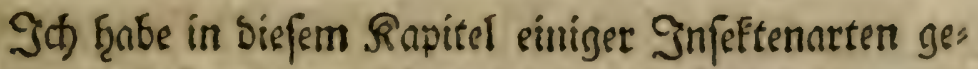

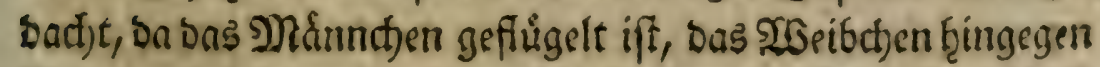

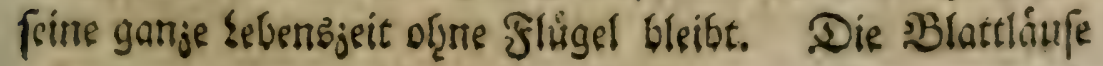
jeis

*) गुin 1746, p. 412 . 


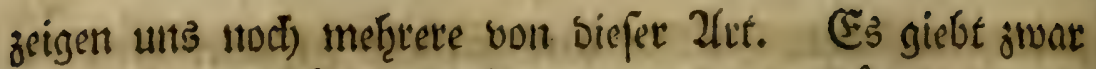

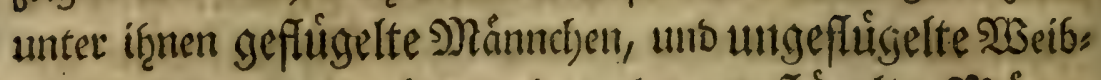
chen; mant furbet aber bod) aud) ungeflugelte Mañ

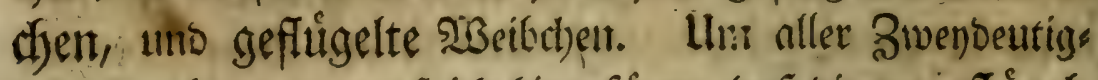
feit vor

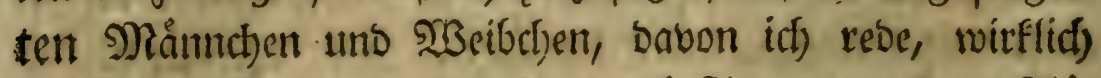
Dergleidsen fino, uno niemals dagu beftimmet werben, flus:

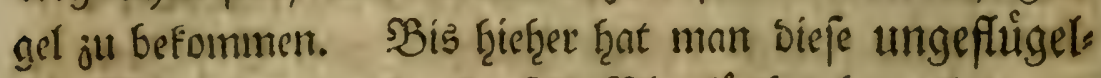
ten Miannd)en nur bey unfren Blattlaiffen bemerfet, uno iit) hৃabe fie aud) felbft nur bey einer einzigen 2lut biefer Sins feften gefunben. *) (Es ift bies eben fo merfmúrbig, als

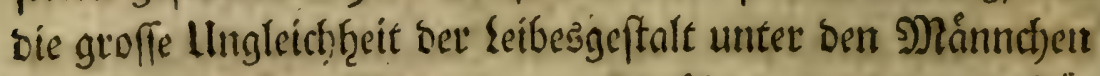

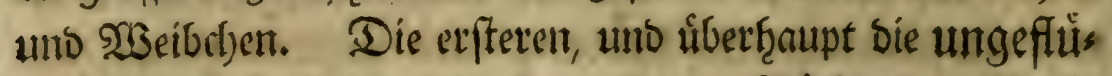

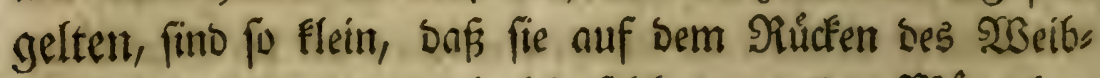

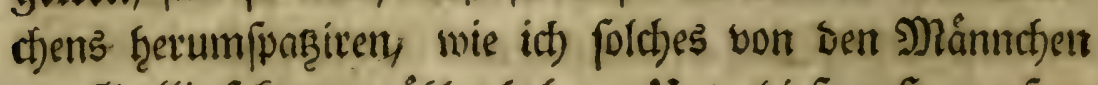

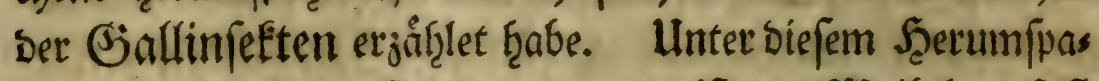

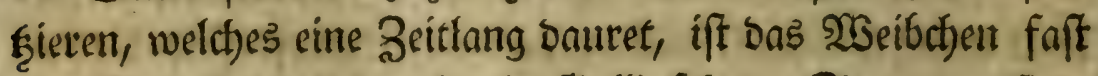
eben fo unbeweglich), als ein Baallinfeft. So unemyfints

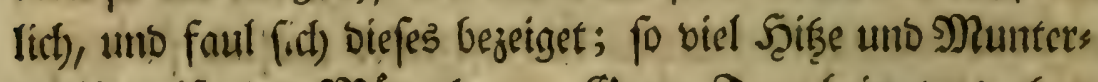
Feit betweifet Das Mánut)en. Ejanje Sage bringt es of̧ne

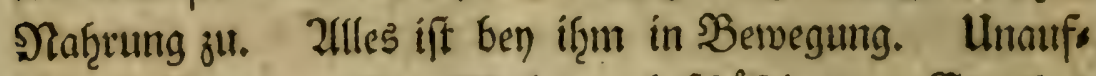

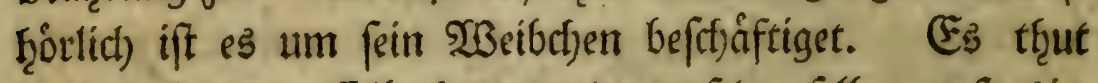
nict)ts, als un Daffelbe ţerum, ober nuf bemfelben ju fpaf̧ies

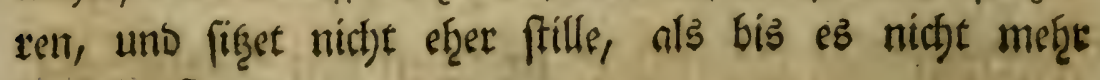
vertieft ift.

\section{2lit. 306.}

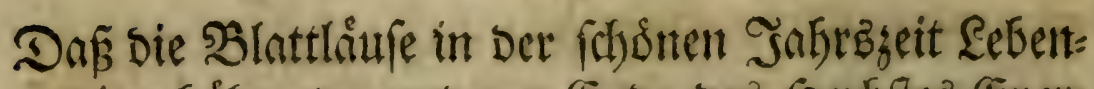
diggebaibrende, ulld am Ende Des Serbfteb (Evet: legende find.

Diuthe

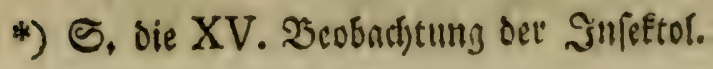




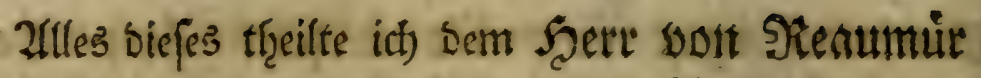

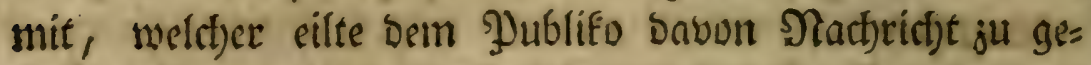

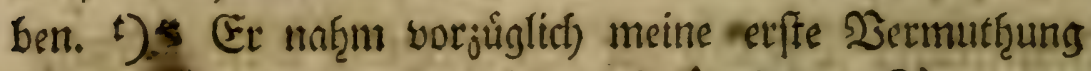

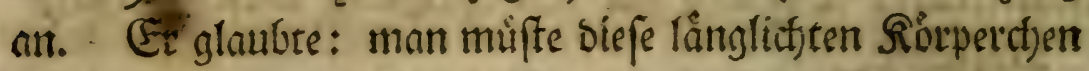

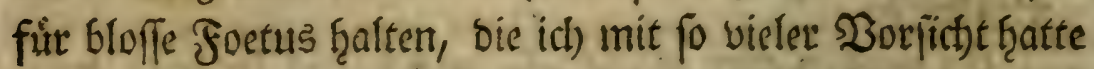

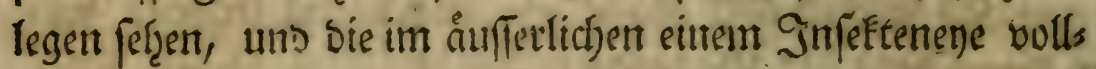

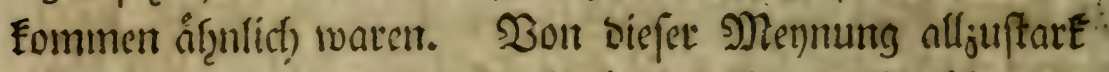
eingenommen, wagte utufer beriffrinte 2ffabemift, úber bie

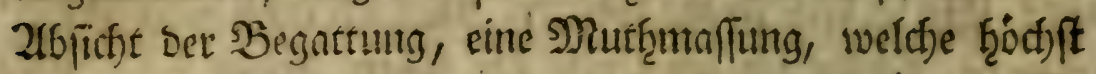
forberbar foheinen muf, unb die ex p. 552 erflaret. Er

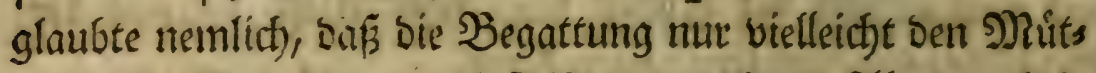

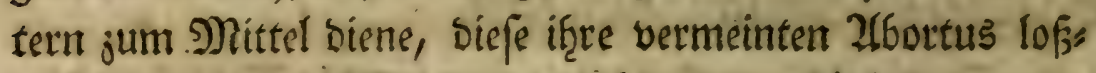

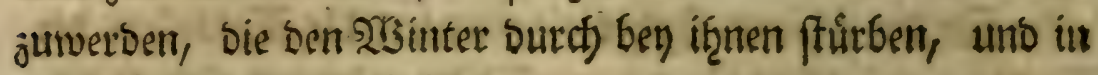
Der. Bårmutter verburben.

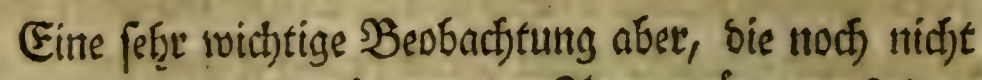
gemad)t war, als ber Seerr von \$ieaumuir bas fect)ste

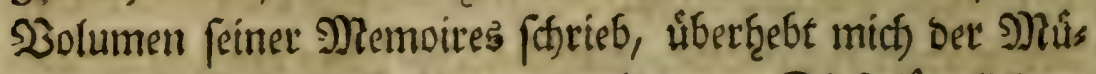

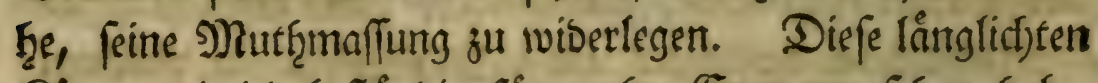

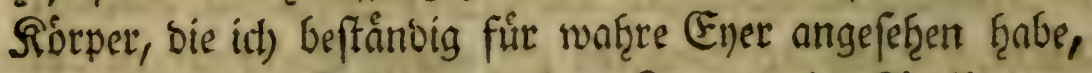

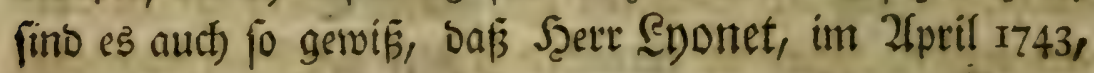

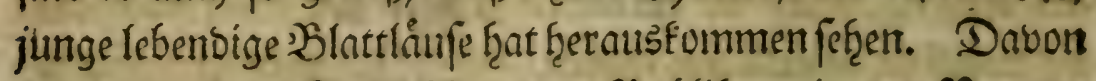

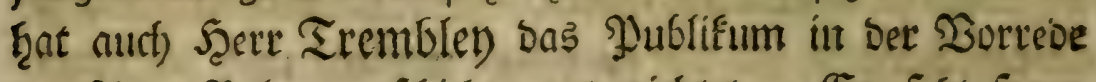

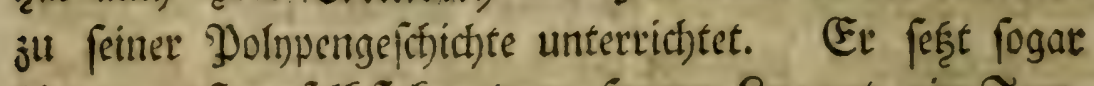

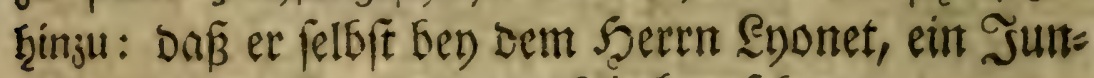

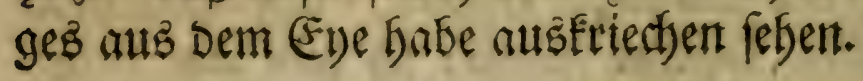

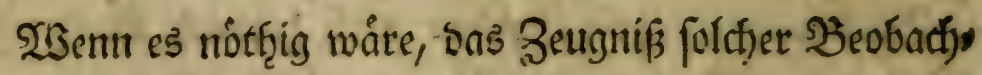

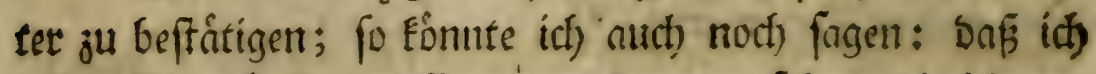
junge Şlattláufe, aus Enerri ausfommen fergent, bie id) am

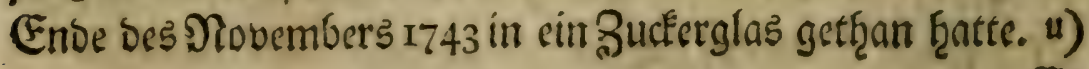

t) Memoir. Tom. VI. p. 556 . ᄃ.

u) Snjettulog. 1. Tis. XIX. \$Sco6。 
Ės waten thbrigens biefe BIattlínfe merflich) Fleinet, ats bie won ben Mhittern lebenoig gebornen: icf) Eounte foldtes aud)

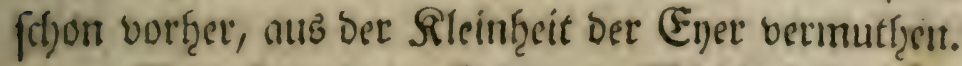

Der Seerr von Beer, ein Mitglieb Der fofwediften

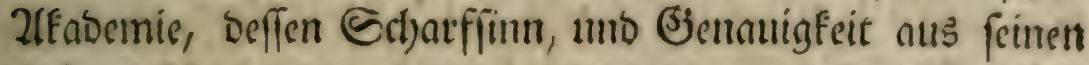

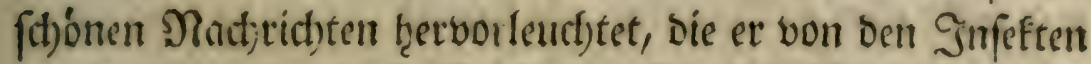

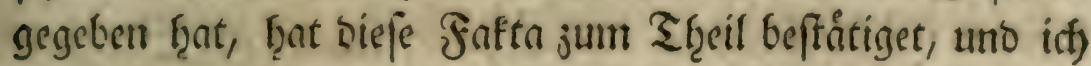

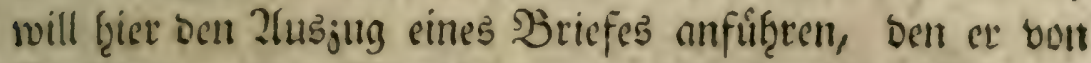
Sroffigulm ben 24 Zfinguft 1759 an mid) f(t)rieb. SBev al= Ien शrten oon SBlattlåufen, auf Den B̧åumen ober

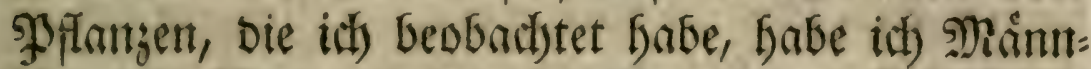
chen und \$yarumgen wahrgenommen. Die 23 eib= (c)en legten beftándig (Ener, Durd weldhe iffr (jie: (chled)t Den Siginter Durd) follte erbalten werdent.

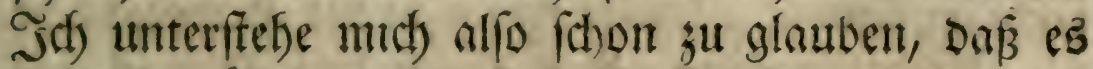
mit allen úbrigen eben fo bejisatien fer).

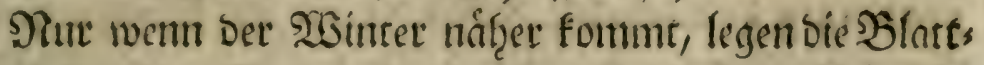

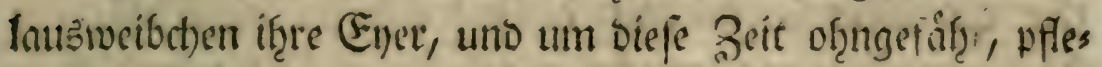
gen die Mlánnthen ju erfitheinen. Es ift alfo jwifthen Der

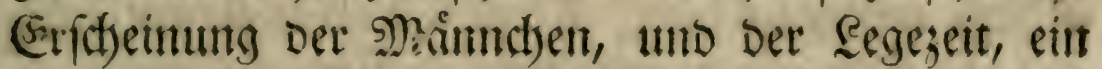
geheimtes 2ierbältnifs. Dies futien wir noch, unto Das ift Elăren nußs.

Man mag ben teib eines 25 eibctiens ofnen, ju weets

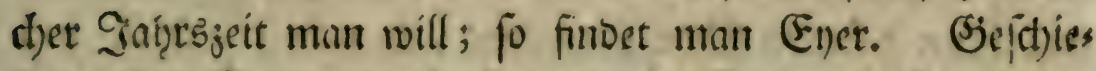
het es in Sommer, fo findert man Ener uno Siunge jus gleid), bie zur Sieburt reif fino. Die Sumgen Der !ebens

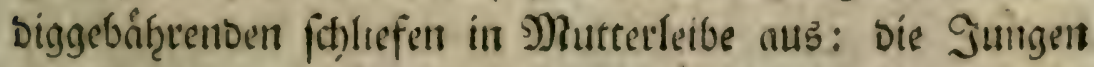
Der Enerlegenden, weeni fie fithon aus Mutterleibe Geriüs

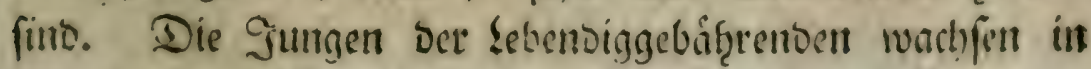

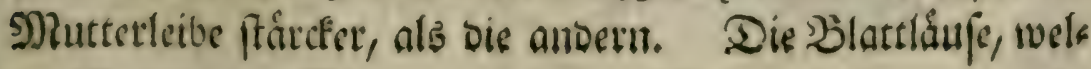




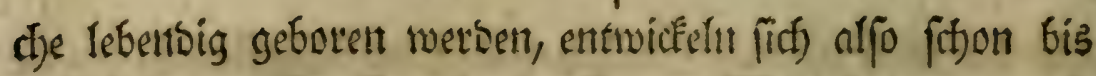

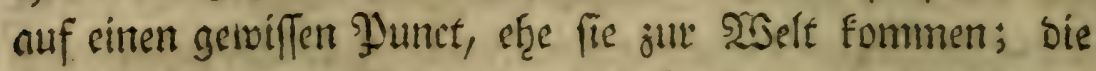

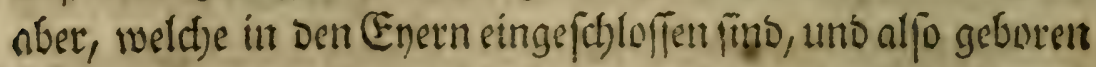
merben, wareen nicht Dajul beftimmt, fict fo jeitig ausjubildoen.

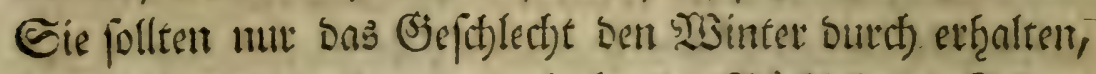

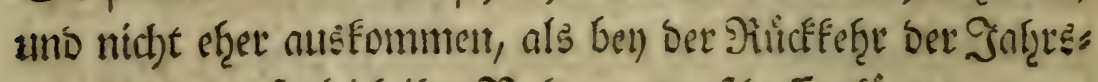

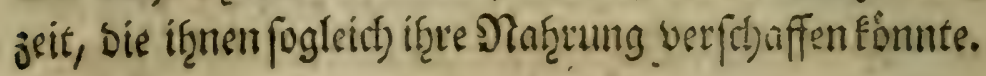

Die Entruidefung aber fefect bod) eine Ernif̧rung soraus. Folglich fraben bie Blattlinule, weld)e lebendizges boren werben, fhou im Mutterleife eine Naf̧rung befom: mett, weld be bie nicht empfangen Eounten, bie it Den Enern

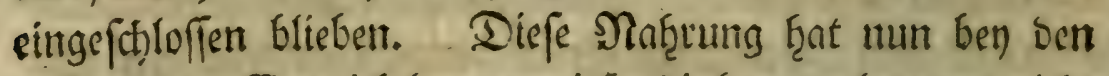

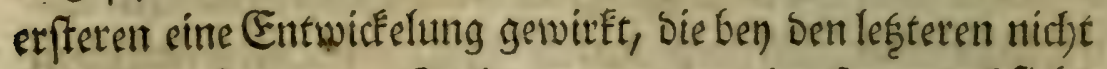
gefhetren fonnent. Sollte mun uid)t Die Scauptabfid)t Der Begattuntg fent, ber Diefen Den \$Nangel Der Rafrung juerferen? Sollte nicht bie Sanmenfeuctitigs feit bes ग) Mannchens baju beftimmt fenn, bie Stelle Der

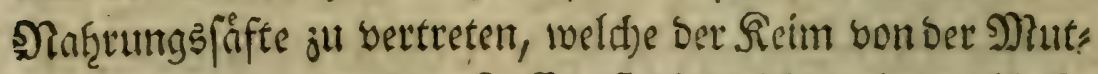
ter nicht empfangen Eantr? Es ift bies nichts als cine bloffe,

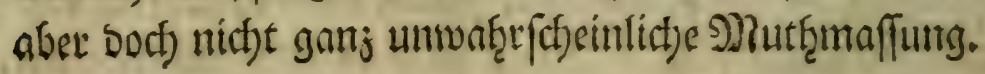

Man fonnte fie leicht baburef ertweifen, twenn man

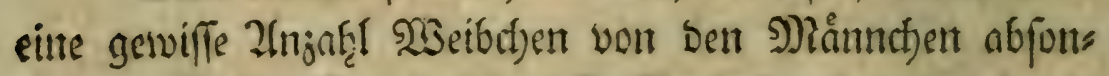

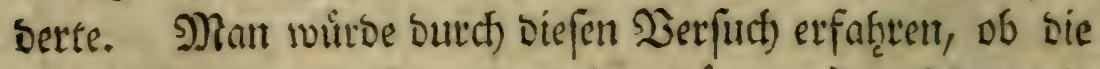
von if̧nen gelegten (En) fruchtbar wåren. x) Dhnerachs tet aller 2lufmerffamfeit; bie man auf bie Şlattläufe ges wenoet ḩat, find fie boct) nicht genug ausftubiert, uns if̧re OSejeffichte jeigt uns noch immer inteteffante Begebenf̧eiter, Deren 2lufelarung noch tibrig ift. Diejenigett aber, att bes nen inan jeşt nid)t mef̧e jiveifelt, weil an if̧nen alles bureh

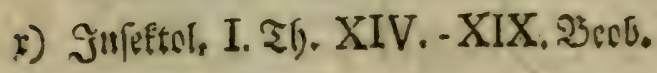
eine - 


\section{2nfang.}

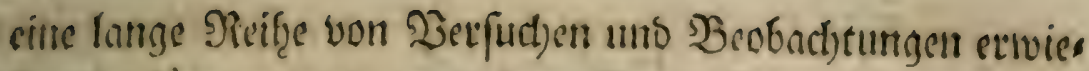
fen ift, formen uns, nad) Dem Zengniffe Des Şerrn von

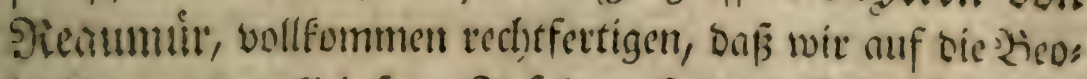
bactitung Der fleinften Sinfeften fo biel Beit gemeendert ถุaben *).

\section{2lit. 346.}

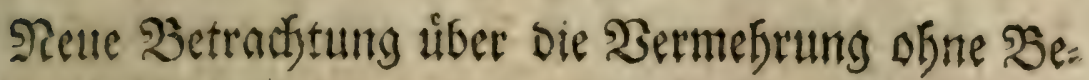
gattung.

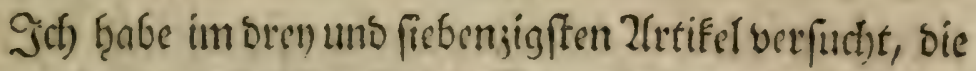

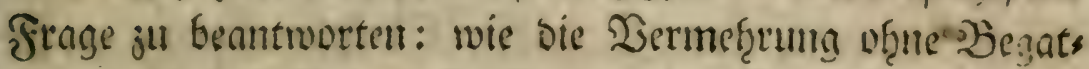

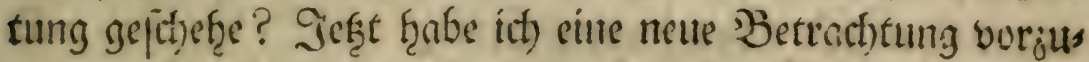
tragen. Die Ginfeften, moldthe firt) of̧ne B̧egattung fort,

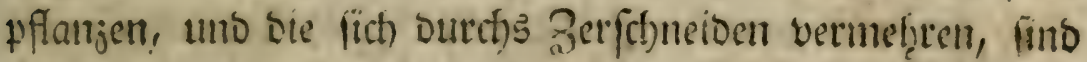
alle fefter tweich), (mollufea) grebftenţeits fogar gullertars tig. Solglich) muiffen ifzre Embrgonen nod) viel meicher, noch biel jarter fentr. Die S geile Diefer Embrnenen bas ben alfo ein: unenblich) fleine sibiberftefrungsfraft. Das Seet;, uber Das Srgan, Das Deffen Gtelle vertritt, formte

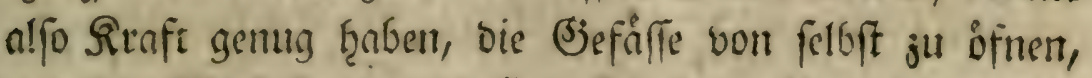

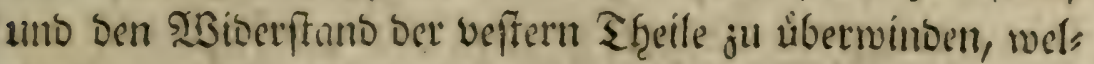
d)e feine gróffere 2e pltigfeit, als ein fluibum, haben. Die Dem Sepefge ber Begnttung unterworfenen Snleften, trabent

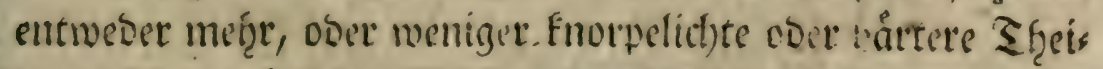

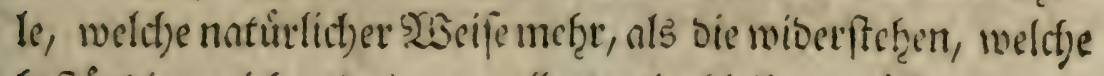
Eeftänbig weich), ober gar gallertartig bleiben muifer.

Folglith fino ben ben 2(ndrognnen, bic priparirten Saffee, welthe bis Shutter Den Embryonen mittheilet, Gins

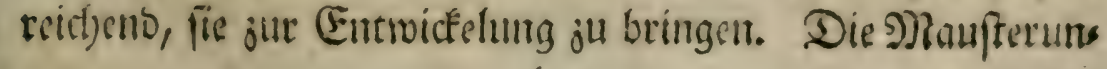
*) Memoir. fur les Infect. T. VI. p. 524 , 


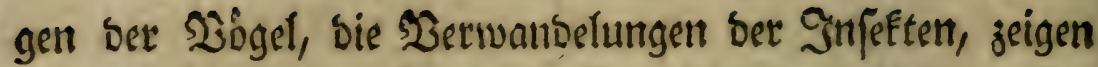

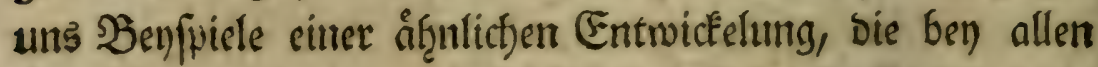

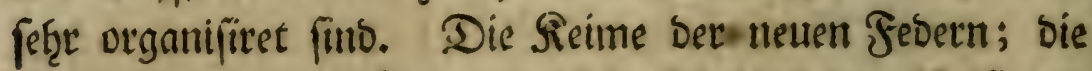

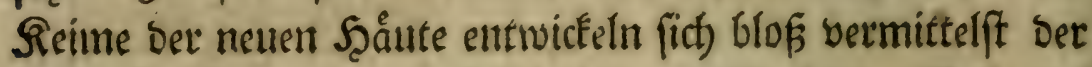
Safte, bie fie von bem Inbivibuo empfangen. Faft auf eben bie 2lrt bringet bie Piaupe Den Schmetterling jum

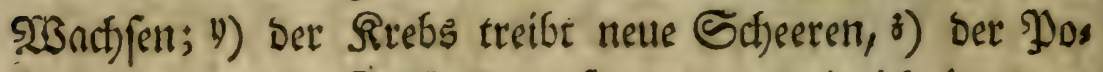
Inpe einen neuen Sopf, a) 11. ケ. w. und wie ich in bren

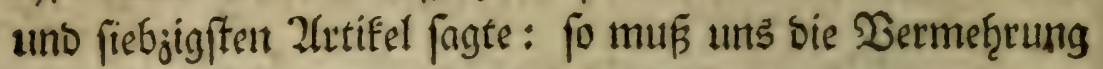

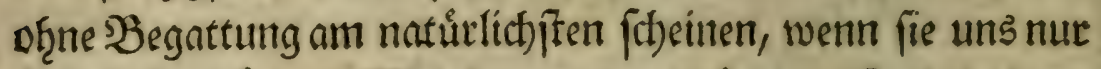

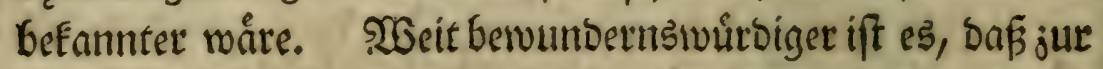

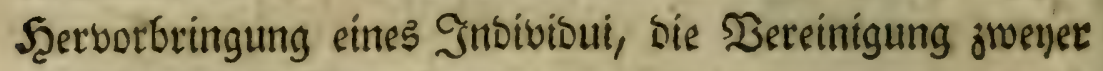
nmbern von ber 2lut erfurbert werbe.

y) $2(1 \mathrm{tt}, 160,16 \mathrm{r}$.

3) 2utt. 262 .

a) $210 t, 264$.

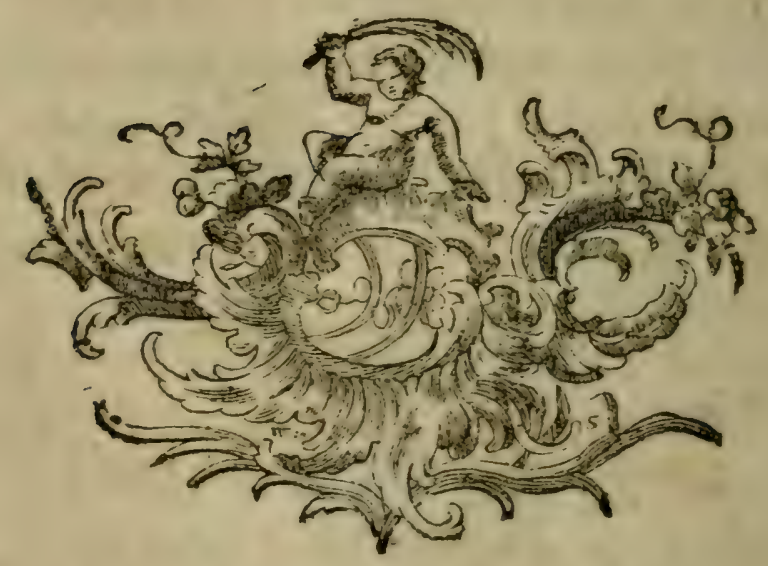




\section{Ibbandlung}

ลแบถ

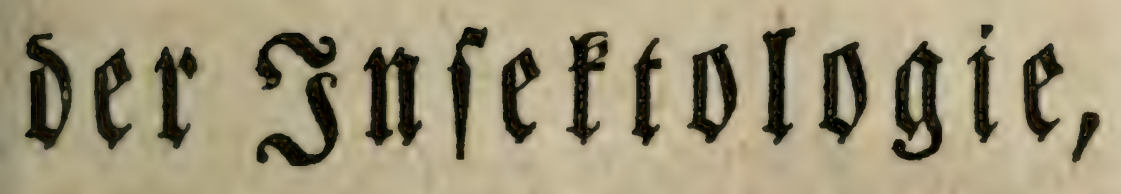

DDCE

$\mathfrak{B e o b a d}$ tungen

it ber

cintge $\mathscr{A}$ ten 2 bitume

Deb filffen $23 a f f e r b$,

aus weldjen,

wenn man fie in Studen fdnetiot,

eben fo biel gange 2 sirme werben.

\section{Sweyter. Theil.}





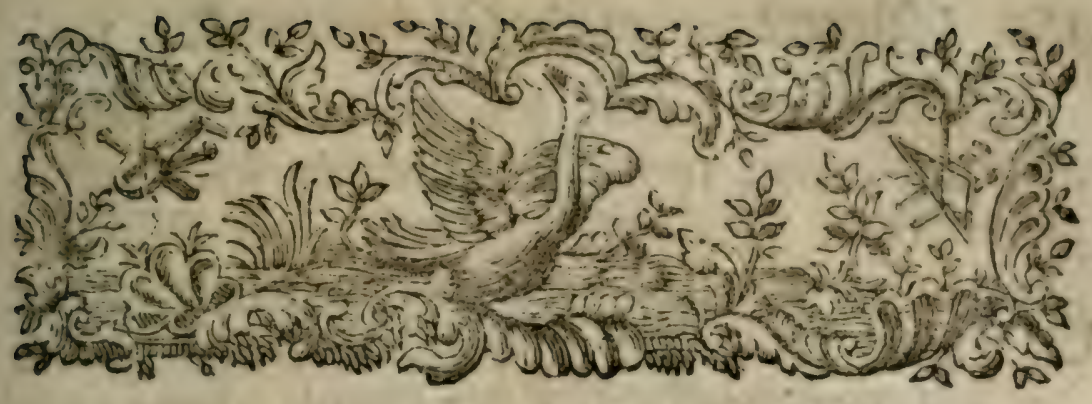

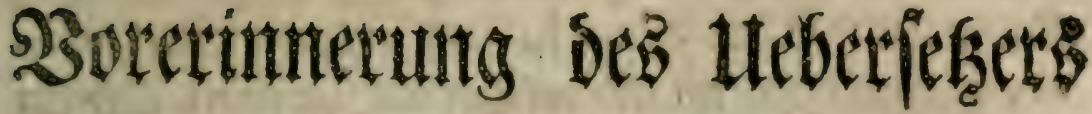

ju Dem jweuten Theile

Der Sufetologie.

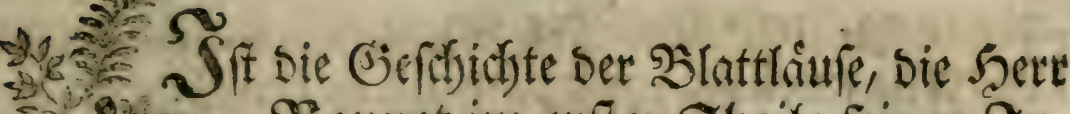
5. Q. 2.0 feftologie geliefert hat, munderbar ge=

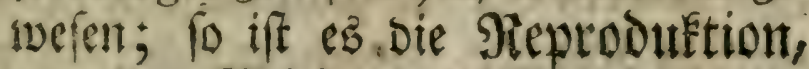

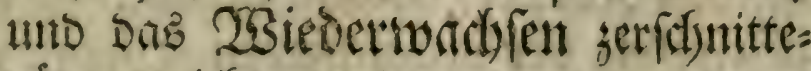
ner 23 affertwutume nicht wentiger, Davon unt Der Seer $\mathfrak{B}$ erfaffer feine erfen 2 erjuche in Diefem zwenten Sheile mitgetheilet bat. Man Eann aber

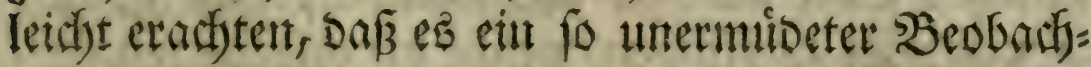
ter Dabel) nicht toerde Gaben bewenden laffen. Sei=

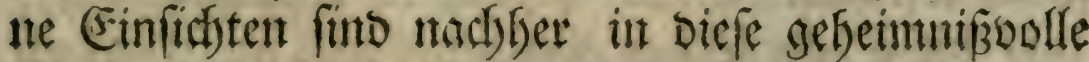
Sadje befto vollfommener geworden; je weiter er feine Derfuche getrieben hat. (5r hat fich Dartiber in feinen neueren Sd)riften felbit crelaret, und id)

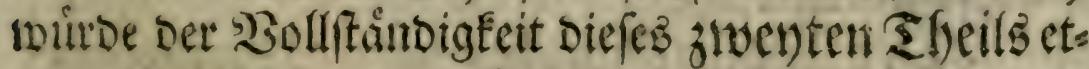

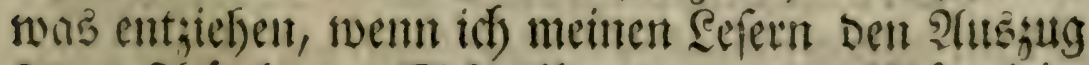

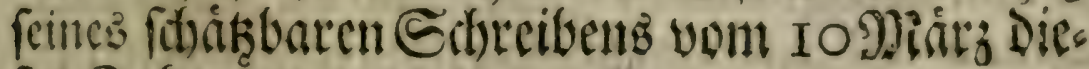
fể Jaflutiơ vorenthalten wollte. 


\section{Borerinnerung Des Lteberfęcers.}

"İch habe auds, (d)reibt diefer gefállige ,fFreund, gan; neue Setradtungen uber Die io

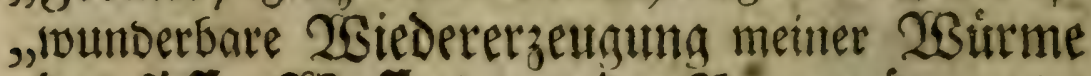
"Des fúffen 2 anfers, und der Fiegentwirme, im „II. Th. im I. Rap. Der organifirten Rorper, uno , im I. II. Siap. Deß IX. Tl). Der Setradtung uber "Die Ratur befannt gemacht. Die erftaumens: ,wuirbigen Entbeckungen Des atbts Spallanzani „Gal)neten mir Den $283 e g$, in Dem lef̧teren 233 erfe, Die= ,, fen groflen (jegenftand wieber anzugreifen, und eint „,wentig tiefer zu erforfaten. Eben diefez babe id ,auth im X. Theile Der ઝalingenefie verfucht. „Diejenigen, weiche DaB Siseitláuftige nicjt gern le=

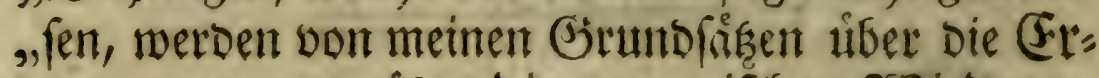
"zeugung, und uiber die organiften 2Biederge "burten, einen Eurgen Entwurt in Der Schrift fin= „Den, Den idh meiner Walingenefie unter Dem Titel: "(5runtris Der 'Betradtumgen ưber Die organt: "firten Siorper, vorgererget babe. Es ift aber Der "Itrfprung Der organifitten $\Re$ orper eine fo forwe= "re, und Dumele Sache, Daß̧ man ę einem ?Raturs

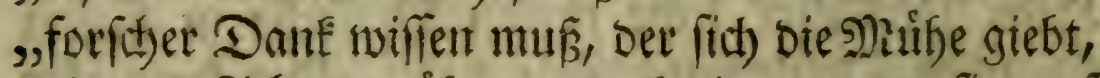
„einiges Eidyt Daruber anşubreiten, uno fie auf

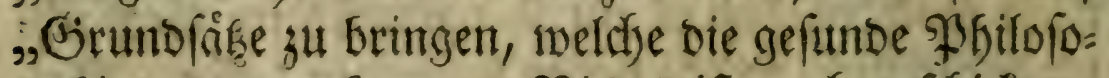
„phie ertragen Eann. Fichts ift auth) gerchickter, „als Die Theorie Der Feime, Geift und Seer zu „Dem grofien 2 sefen zu erfeben, Defien anbetungs= „,wurbige SBeisheit alles ju Den edelfiten 3wecten ,worbergeoronet bat.

„Der $23 a(t)$ sthum Der organifoten forper , iff ein anderer Dunffer (Segenftand Der פraturlefre. "Raum erblicten wir etwaš von bem gebeimen Mie =

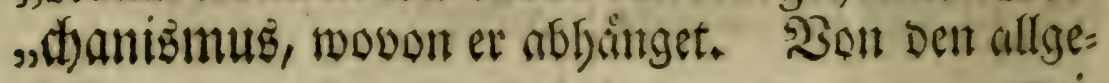
,mei: 


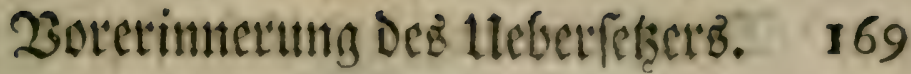

„mecinen Geferzent beffelbent wifien wir etwas methr. "Jit) habe fie in Der Zortede zut Jinfeftologie „p. XXIV. Deruifret. In ser Edyrift lelblt habe ids ,viele Fafta und s(nnmerfungen sefammlet, welct)e

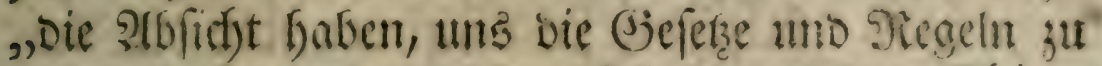
„entbeden, nach weldyen fich ber) unfern Tbier= „Pflanjen, bie wieberwadhenten Theile in iffen „verictjiedenen Entwicfelungen rifjten. In Der , Folge aber verfudjte idf) tiefer in biefes verborgene „Seheimnif zu Dringen, indent ich die Fafta feloft, „Die bon mir, und anbern beobadytet waren, zu „STlife nafm. Sie werben bab Siefultat meiner „Beobachtungen uiber biefent oo intereffanten Giegent= "ffand Der vrganifuen Naturlefre, in Dem analytis

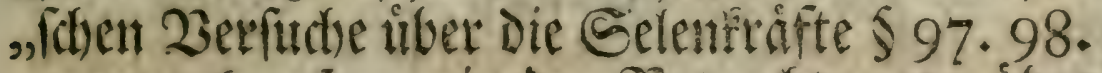
"99. I 760. ferner it Den S3etradtungen liber "Die organifitten Forster. Ift. I 70. it Der Be= ,trniftung uber Die STatur VII. Sib. VII. Fap. ,twie antif in Der galingcnefie XI. Th. p. 389, „390. findent. Jin sem lerteren siberfe werden fie

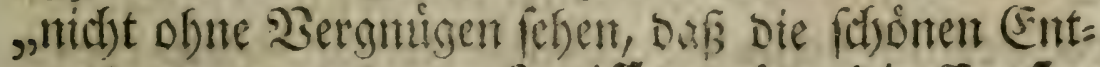
, Deckungen Des Sertn Seriffant, diber Die Entite=

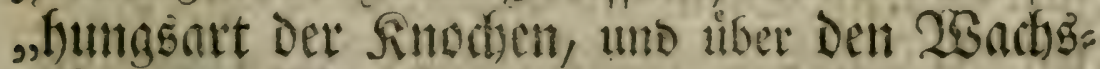
"thum Der Mierrforper, Die geringe Theorie voll= "fommen be|fétiget baben, nad) weldyer ich midh be=

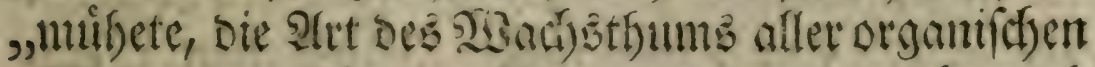

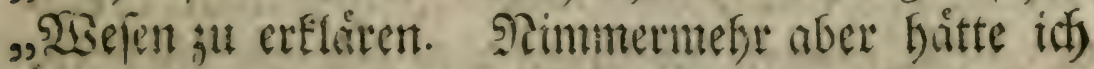

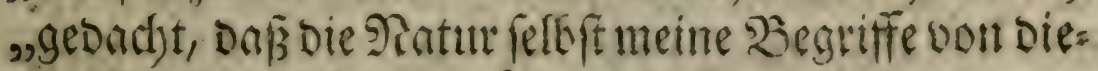
, fer Sadje bettitigen wuirbe, wie fie wirflitify an Denen ,gethan, Die ith mir von Der Wraecriftenj Der Fiei. , Ime in Den siseibdyen, und von ciner Samutabfidt ,Der Befrudtumg gemadt)t batte., So weit ges

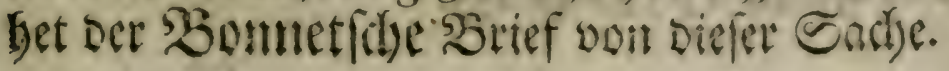




\section{I70 Borerintertng deg Lteberiegets.}

2us biefen oon ifm felbft nachgenveferten

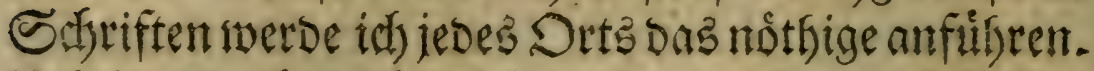

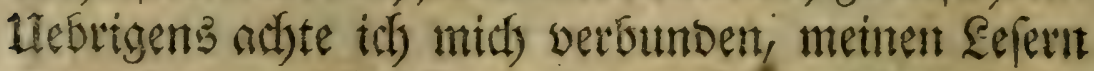

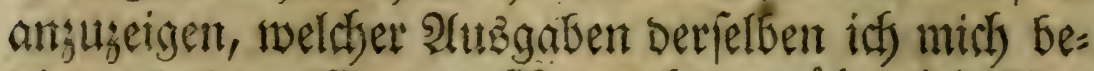

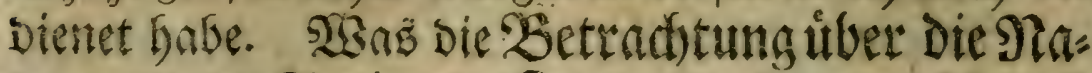
tme, und bie झalingentefte betrift; fo werbe id) mid)

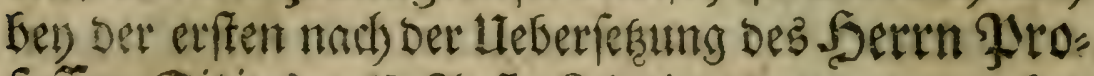
fefror Bitug: II. Suft. Reipsig gr. 8. 1772. bey

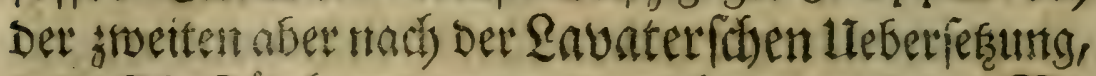

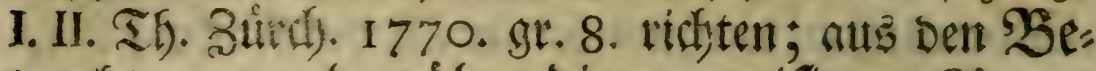
tractutmiten aber itber die organifiten Rorper príl

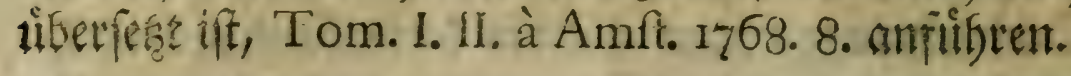

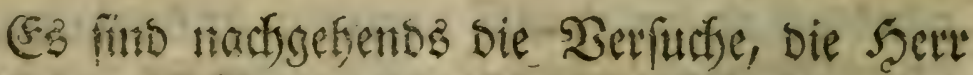
Sonnet in bifem zweiten Theile befhrieben, won

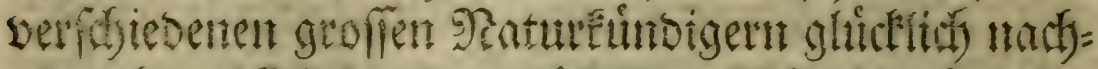
gemadjt. Die bahin geboremben Sdjuiften find fol= gende: Roefels Jinfeftenbeluftigung 92.93. Sup= plementstabelle. 111. Th. p. 50\%. Sbefcheibung Drever Sd)längelein, oder sistimer, welthe gleid) ben 2trm=

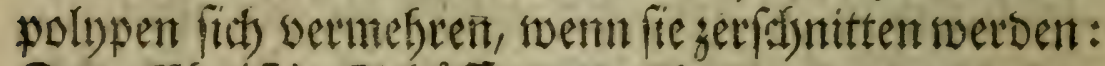
Jac. Cbrifti. Gibafferb Beforteibung einer befon: Dern Irt fleiner SGaflernale, wellye Der AbEandlung won ben grimen Srmpolypen, unb Den gefoumaintsten

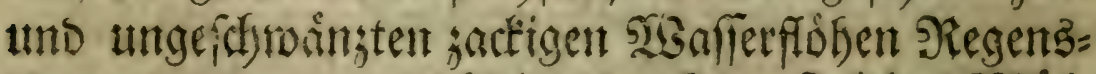
burg. 4. 1755 . angefánget ift: Stto Friedr. Mails ler von 23 tumern Deb fúfen und fargigen 23 anferz. Ropentragen. gr. 4. I 77 1. m. R. Des 9Jard)efe Ecipio Minffei Siebanfen won Den Infeften, Die fich aus fich felbft wieber eryengen, in Der Sammlung

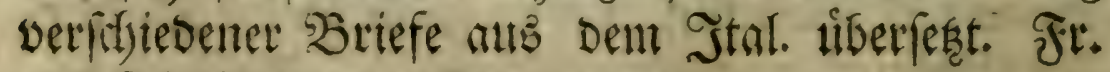
unto Leipsig gr. 8. 1758. p. I33. 


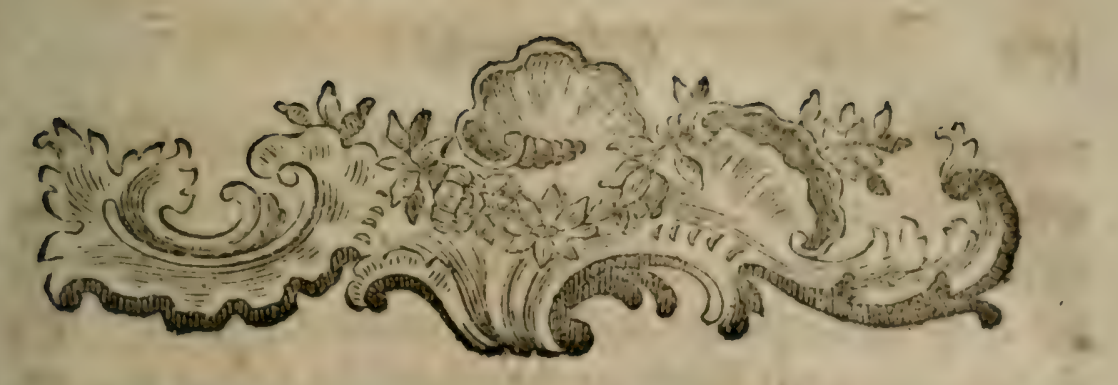

\section{Weobactitutitgen}

ilber

\section{eintge Irten 23 inne

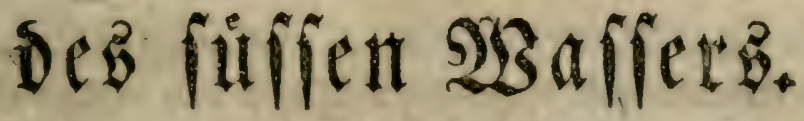

Einleitung.

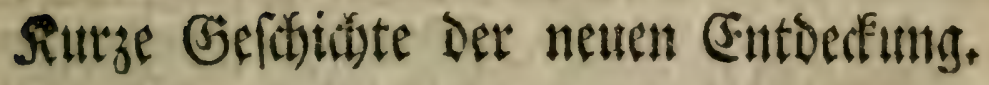

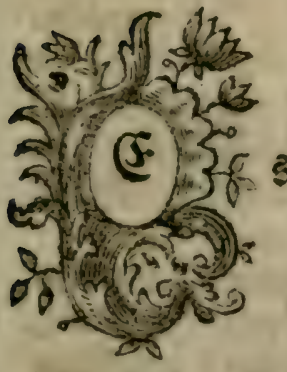

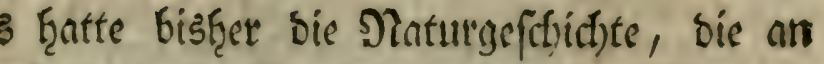
fonterbaren B̉egebenteiten fo frucbtbar ift, noch nict)ts aufferoroentlict)ers, als bie (Eis gemfthaft gejeigt, weld)e verfhiebene Sirfets tetr mit einanber gemein baben, Daj fie, wenn man fie in Stutcen fannitoet, eben fo viel ganze Thicte, unt sul allet

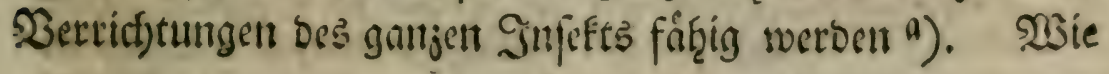
man

a) 26uter ben Gdjriftent bes Seertn Derfaffers veroienen (ien)

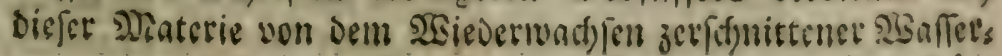




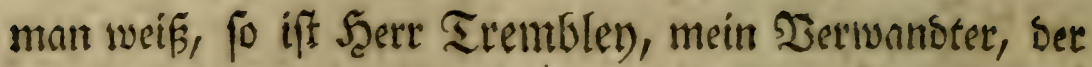
erfte Ulrf̧eber biefer Entbecting *), Der fich gegenwairtig

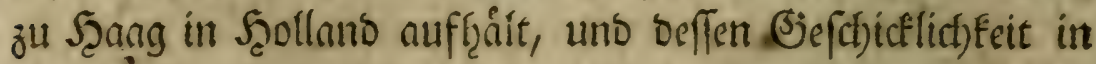
Der BBeobartitungsfunft weit ůber meinem lobe ift.

Es gefchaf̧e gegen Das Enbe Des Jänners I74I, Daf er mir for:

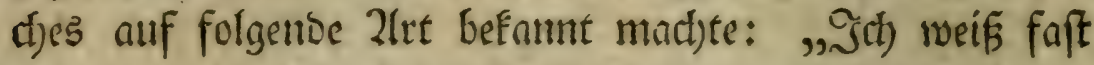

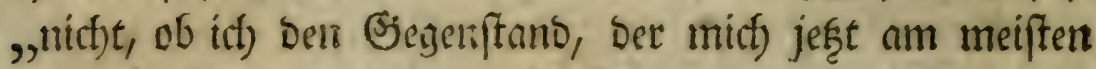

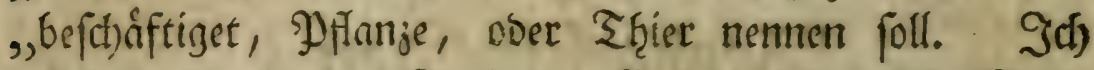

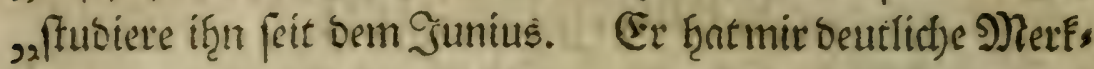
,male geturg von ber DPflanje, unb vom Thiere gejeigt.

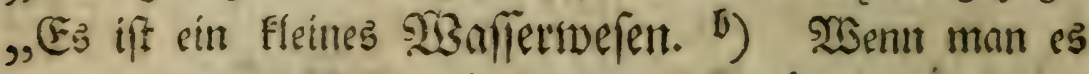
,jum erftemnale fief̧et; fo follte man fojwơren, Dáj es ein DPFint?s

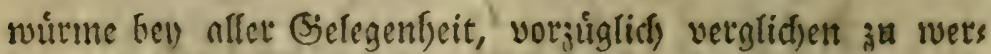

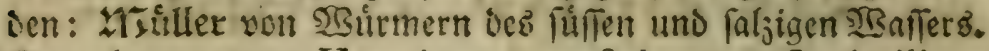
\$openf) 1741. 4. Vermium terreftrium et fluviatilium etc. fuccincta hiftoria Auctore Oth. Fried. Miiller. Vol.I. P.I. Hafn. et Lipf. r $\because 73.4$. Reaumur Mem. pour fervir à l' hiftoire des Infectes. à Amft. \&. 1748. Tom VI.

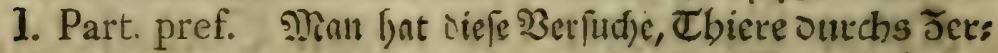

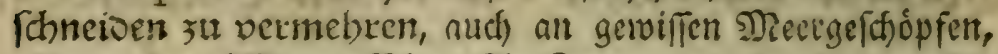
nis an ben Ditecuteffelit, Geefternen, u. F. w. gemacht. Die Entoectungen: cines Iuffiel, Guettard, uns Gerard de Villars, Die vief ivunterfores entfalten, fat ber berk von Zleaumir am angefúbrten Srte p.LXXI. be/6)rieben. Heb.

*) Erembley aber lent dielen Borzug dem Gyoner bey. Poly. pes d'eau douce Tom. II. p. 155 .

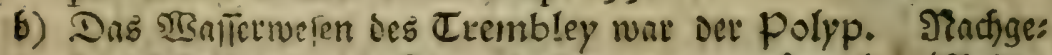
benos far:o er gleid)e Figenrithaften an ocr gejungelten Lraioe,

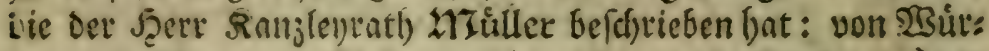

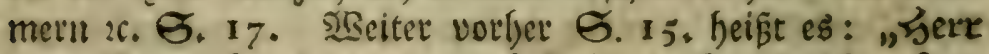
von Rechtmiti fant Die gesurigelte in Franfreid), Sacte

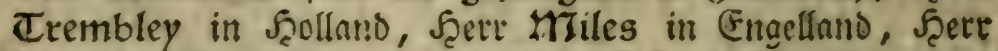
Zioefer in Teut(d)lano, uno neulidf foll fie aud) in Sdjweden

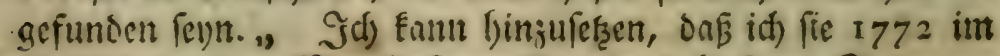
Sultus, in ocm gicertinfenwafier einte fiefigen Stadtgras

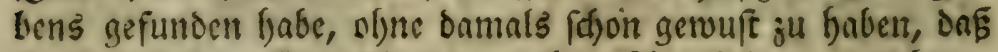
fie fo befonvere (Eigenfdyaften in ifger 2lit, fidh zu vermebren, befile. 


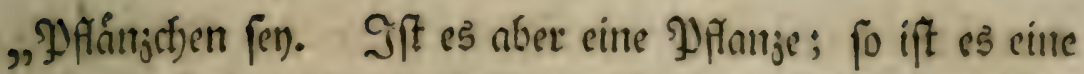

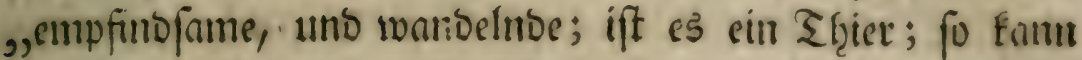

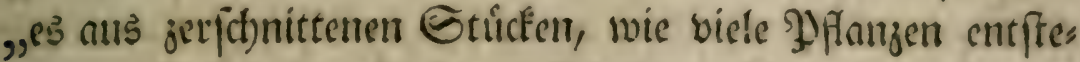

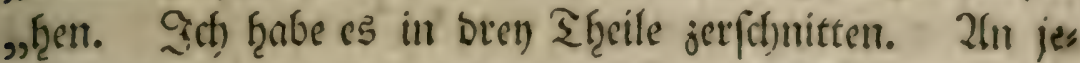

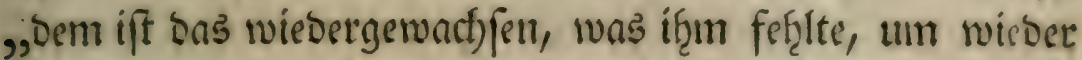

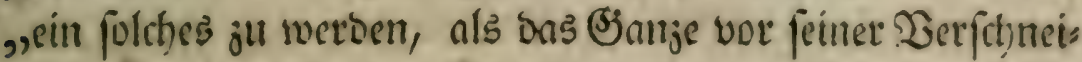

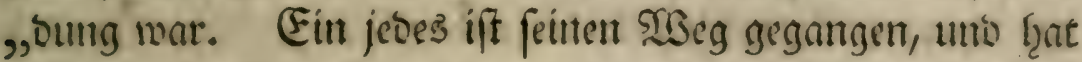

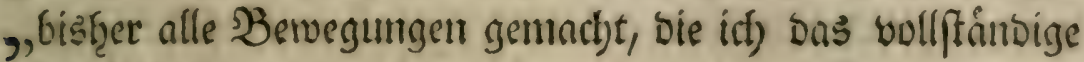

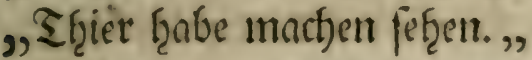

In einem anbern Sct)reiben voum vier uno jrongigs

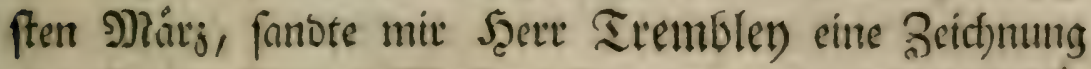

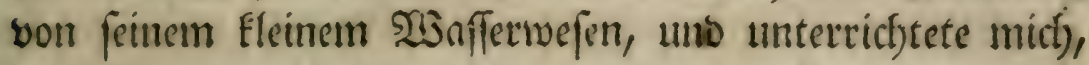

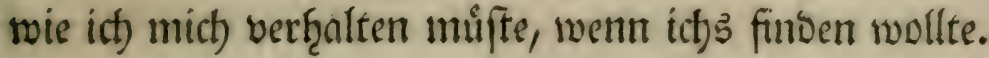

Mef̧re beburfte es nicht, meine ganje Nenbegierbe aufjurvectert. Soll Ulngebult, fie ju befricoigen, ging ith) fogleitf) ins fello; aber vergeblict). Ifn fintt eines fo aur

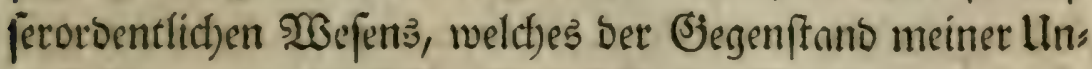
terfurfung werben follte, fand idf) eine Sorts, von einem

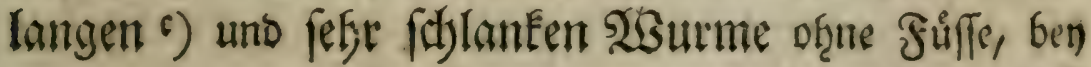
wol.

befing. Trsie oft trift e\&

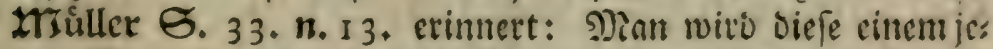

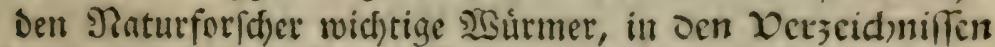
Der nerturlidhen Gegenftẹnoe vergebens fudben, uno in jeoem Eumpfe finoers. Das Dounserbare, frrit Seerr

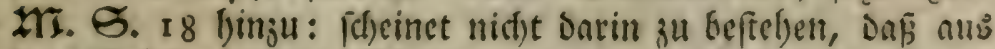

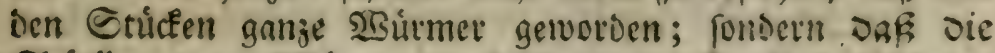

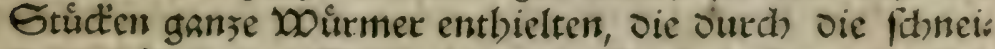
Denve bano des beobachters in freybeit tamen. Tati felje, on liches J̌etheilen, meltrete werben. "Nleb.

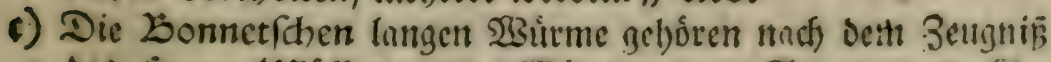

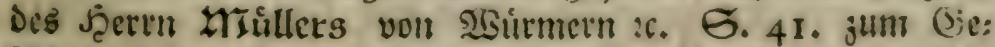
[d)led)re Der Jiegenturirme. (Lumbrici) 5. 33. "Die

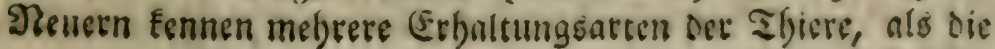
2ltten, 


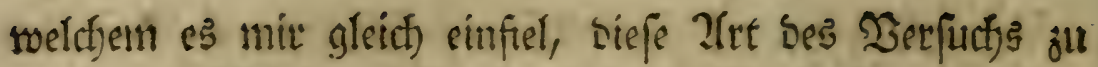

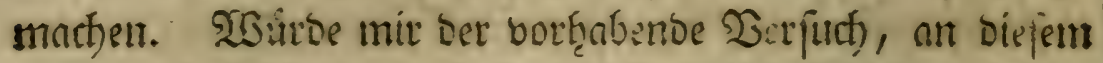

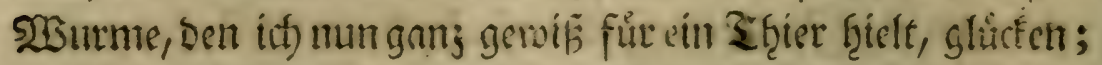

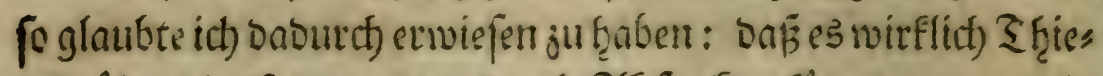
te gåbe, die, fo ju reben, Durth) P(bjenfer formten bermeţs ret werben, welches bie futione uno gant; nete Entoeckung Deb Scerrn Tremblel Gepltatigen müroe. Der Serfirt) ging glicflich) von ftatten. SNein in jwen Etưcte jerţ̧eils

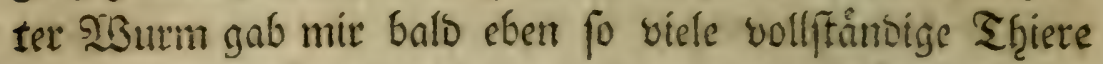
wieber. Daben unterlief ith ticht, fie alle Sage fefre ors Dentlich, mit aller Sorgfolt und Zufmetffamfeit gut beobachs

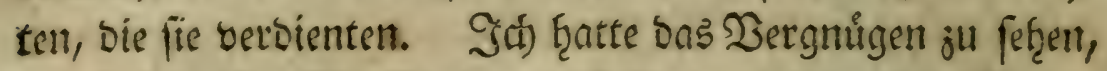

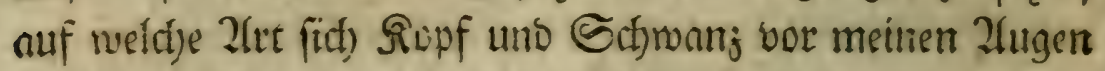
Gilbeten. Iab) fahe, wie fict) bie Eingemeide in bem einem uno bem anocren 23 urme verlängerten, und wie.diefe neuen Sigane if̧re Serridtungen, auf eben Die raseife, wie sie Zllten, wicser anfingen. Slach biefem jweifelte ich nun

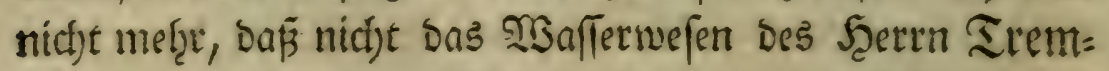

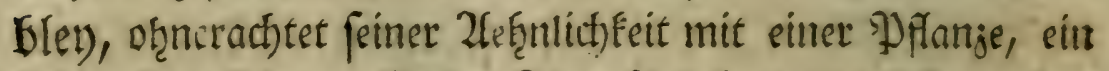
Shier fenn follte. Sinber That fatrieb er mir faft ju ebent Der Beit, Daf es roirflich ein Tfier wäre, Dem ber Scert

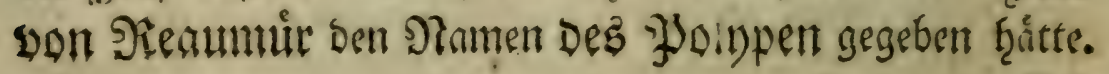
Iits

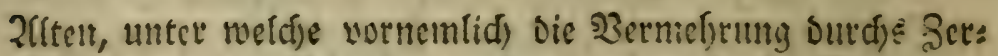
theilen, und Das Bernoigen, ohne vorljergébente Degattung ju gebályen, gefort. Devoes hat meit libr werther Jitunt, Sert Lomet betviejen. Eetne ßer|ud)e mit Den Dlatthu: fen, uno mit oen langen Doumern, Gallen bie plobe ace

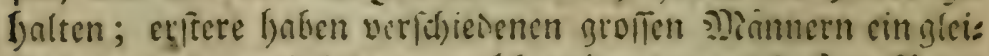

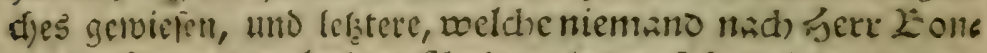
ret gefunden ;u baben facinet, baten fid) aud unter mei: nen 2ugen ourd) maturlici)es uno tunftidies Bertheilen ver:

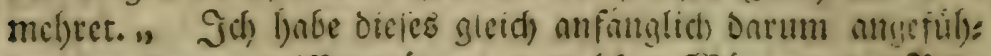

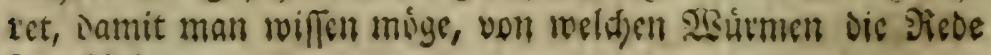
(c1). Heb, 


\section{Einfeitung.}

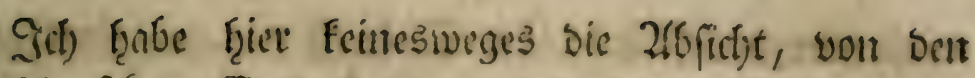
Irentblenfíjen Entbectungen eine genaue SBeffrecibung gut geben. Diefes frat fet)on Der sert vont Sienumur in Der fromen, ben fechsten Bande feiner Jufeftennach)= richten vorgefeften Sorrede, vollfommen gethan. Jich

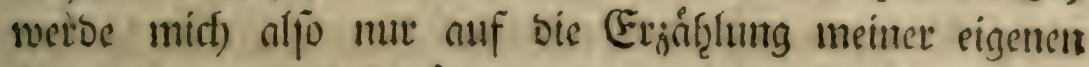

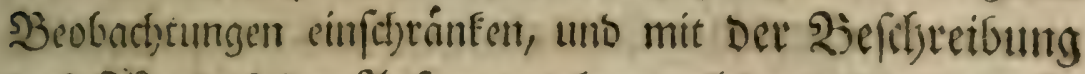

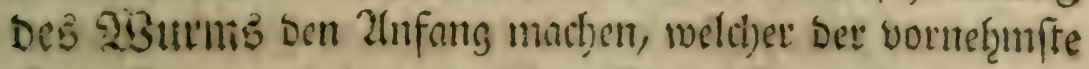

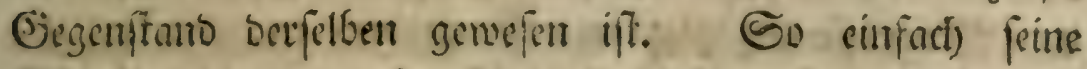

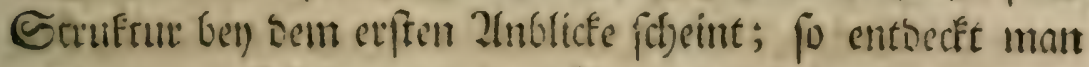

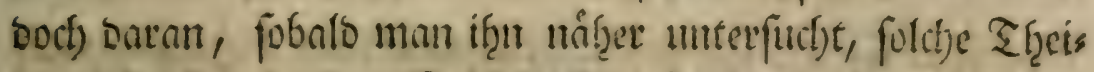
le, bie unfere 2hufmerffamfeit eben fo fratf, als bie Shecile

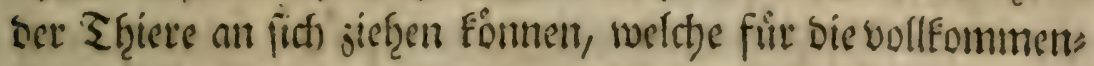
ften gef̧alten wetbe!t.

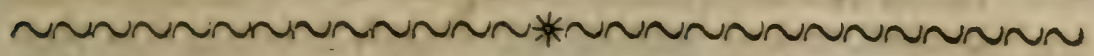

\section{(erfte Bedbaditung.}

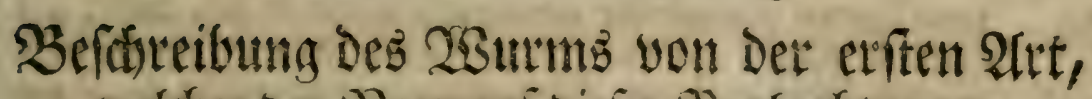
welder Det Dorwurf Diefer Seobadftungen geweren iff *).

Ser Trum, bavon die Slede iff, (Saf. I. fig. I. II. III. IV.) ift braumbothlict); **) in ber פRitte bes Forpers oumes ler, als gegen bie Endoen. D) Sin ber !ange ift er ofenges

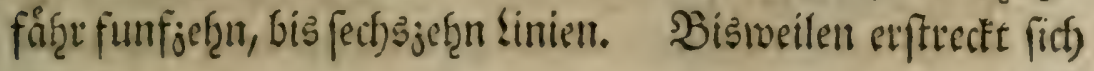

*) Corps organifés. Art. $=44$.

biefe

*wis) Art. 259 .

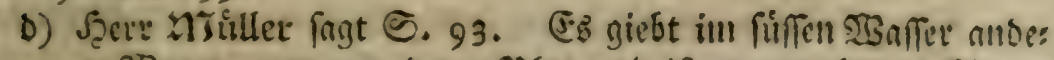

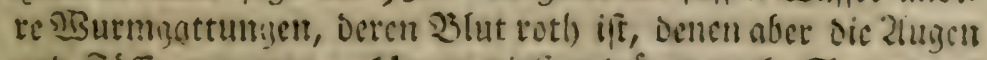

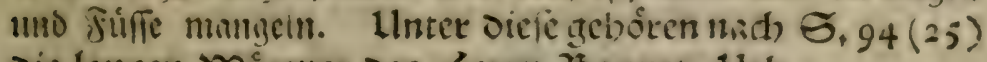
Die langen Do intmer des łaetrn ZSonnet, Heb. 
Diefe riber zmo Zoll. Die Dicie iff wie eine Biolinfante,

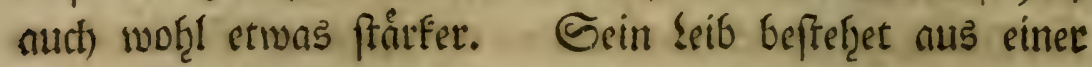
פieif̧e membraneufer Pinge, bie immer fletner voerben;

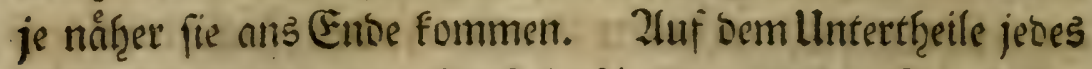

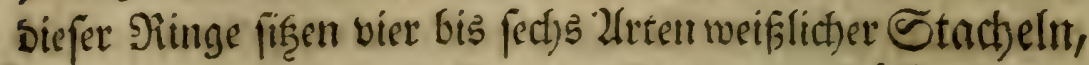
(fig. V. c, c, c, ) welcte bie Stelle ber Fuiffe ${ }^{e}$ ) vets

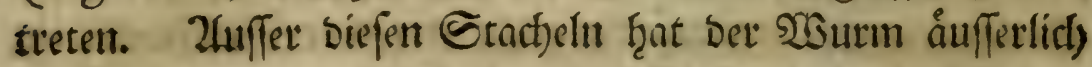
noth etwas ferger merfwurrbiges an firfl, welthes iman unter Dem Sergrófferungsglaje mit ¿ergnigen betract)tet.

Es

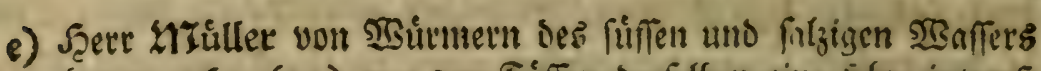
hat p. 161. (53) von oen Fúfen Derfélben cine jefje interefs fante 2linmerfung gemad)t, vie isf) ganz bertechen mus.

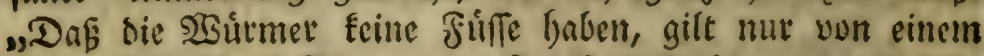
Theil Derfelben. Sey einigen fint fie offentar, wie wiv an

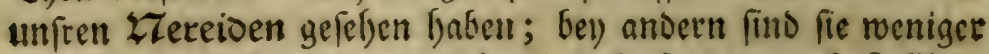
merflitf, weil fie nidje nur fefgr sinfoch, fondern aud) fo tlein uno verftedt fins, Daf fie nidjt obne 2Bergrofferunggglas, uno nut alboan, wenn Ber 23 urm fie aus oem \&eibe ber:

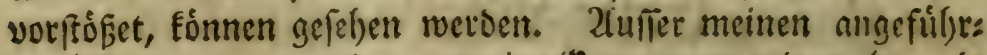
tent Zaioen pranget Der gemeine 帒rowourm mit mef)r, nls

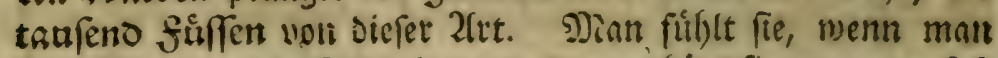

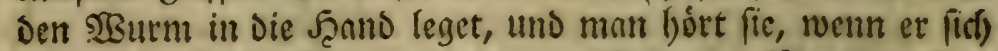

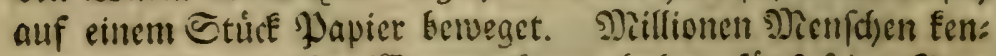

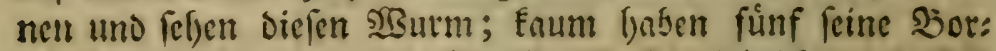

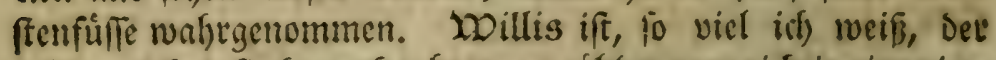

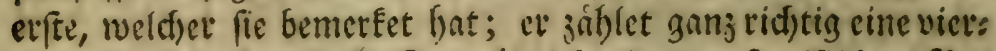

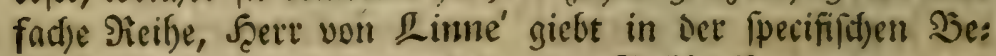

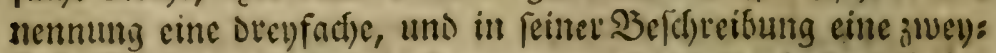
fache Sieifye an; id finte bey Denen, Die id) beobad)tet babe,

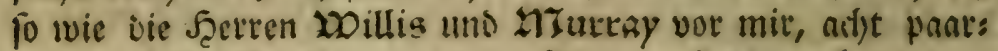

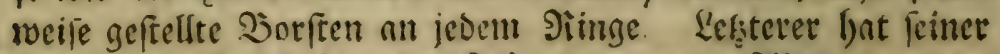
Echrift de lumbricorum fetis eine sennue 2lbbiloung Der: felben beugefinget. Deefe Sorften mangeln gantjlid) irm Gpublicurm, (gleifywie Dem 贷rowurm Der Dreyfade

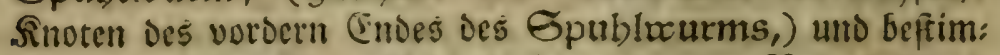

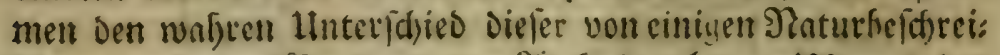

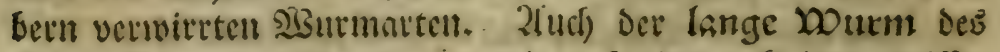
Şert! 25 onnet, unt cin von mir gefundener fleiner weiffer

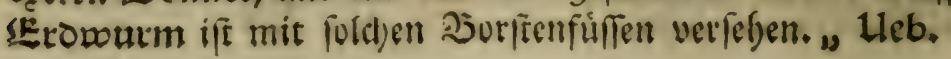




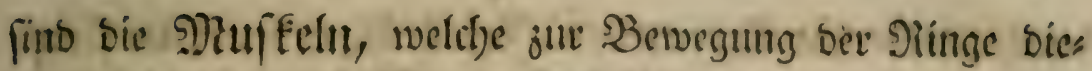
nett, unt eine groffe Menge Zirfellinien ober Folten verurs

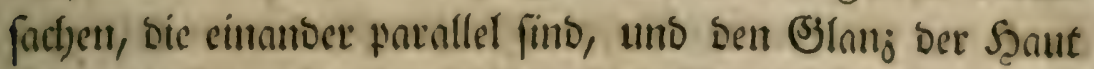
ungemein vermethen, weil fie ertrabent liegen. Der Ropf (A) Frat feine fo beftánbige Bjeffalt, wie ber) Den groffen

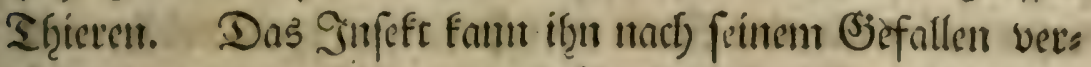

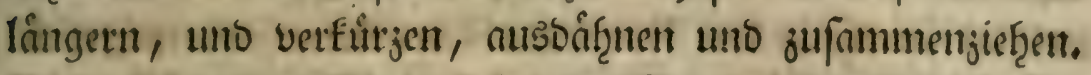
33isweilen jeigen firth nuf bensen Geiten zween fleine (Evo

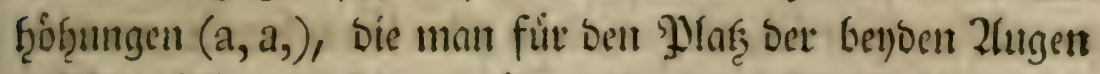
anfefenen follte. Sben briber endigt er fich) aud) in eine

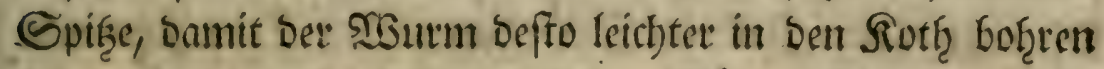

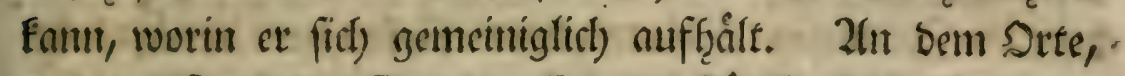

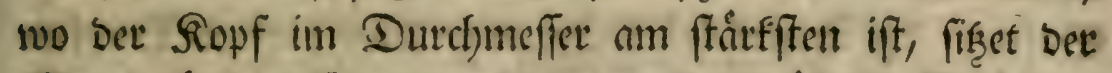

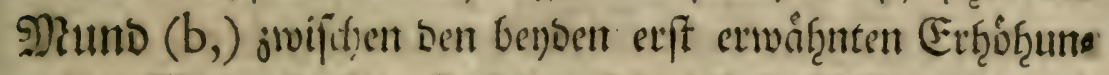

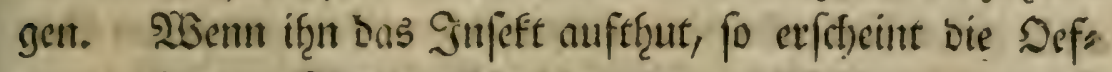

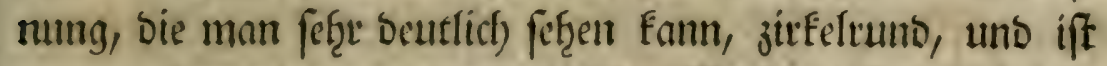
gang unţer mit einer jiemlich) bicken Muffel (fig. VII. k,)

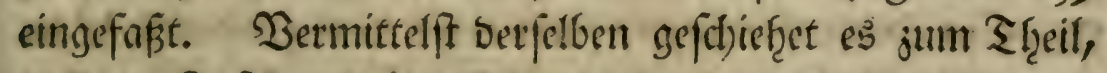

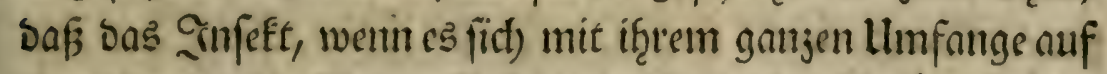

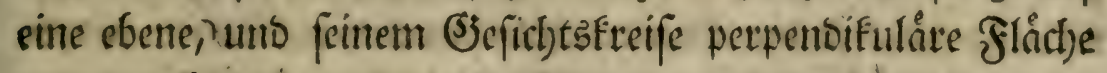
genau anjchliefst, von einem Stte zum anbern foinmen fann. Es ift mir mef̧re, als cimmal begegnet, bafj idf) gefef̧en frabe, wie fict) ůber bem Mruno, cine 2(et von SBlafe (fig. Vl. h.) ertrob, bie mechjelsweife bald biernus getrieben, balo roieter einwairts gejogen mutrbe. Son ber Seite betrant)tet, Geatte

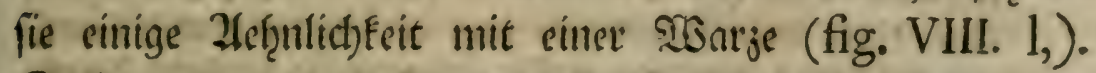
Sollte bas wofgt bie Bunge unfres Infefte, oder wenigftens

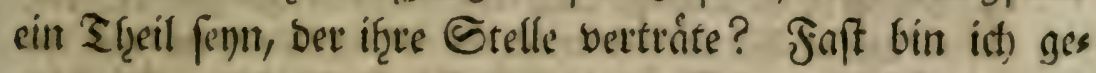
neigt es ju glauben. 2tm anbern Ende Des Roserpers ift eine länglict)e Sefnung, (fig. X. n, XIV. q,) Deren ftán's

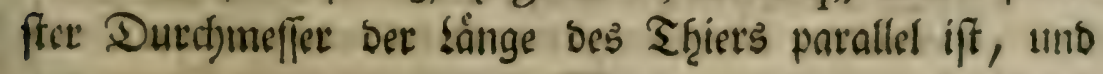


ourch) weldye bie Ercremente (fig. I. II. e, e, e, u. F. w.

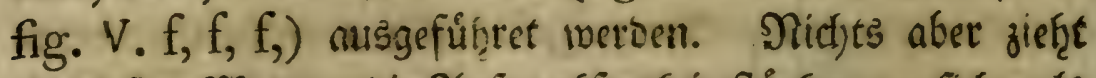
an biefen 23 urme bie 2lufmerffamfeir stärffer an fich, als

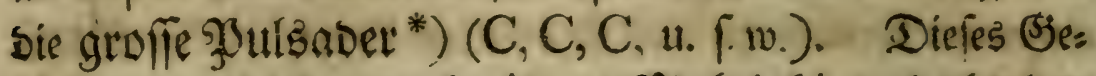

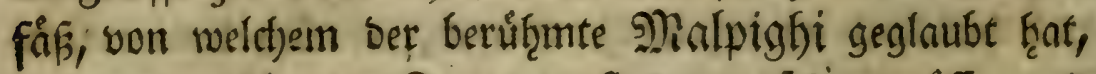

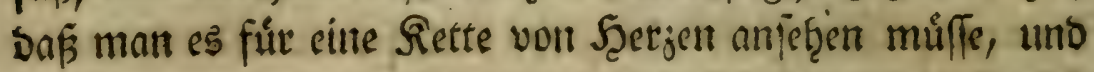

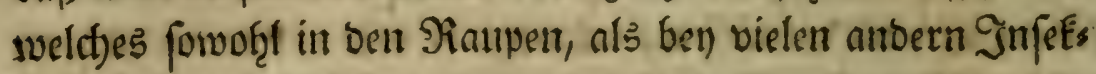

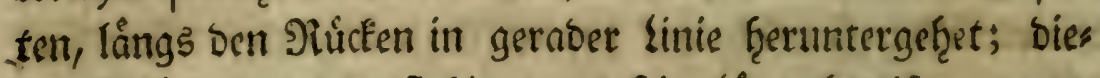

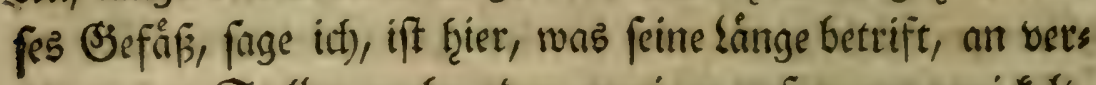

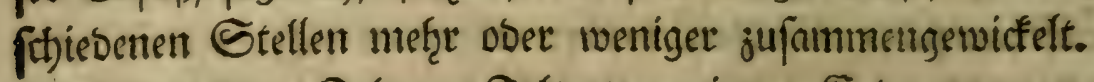
Dft liegt es mur Falte an Falte bont einem Enoe jum ans

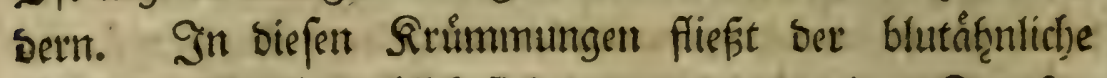
Saft. Illle Zlugenblicf fieferet man bavon cinen Tropfen von bem áufferften Ende bes Scthwanjes abfaţren, uno in

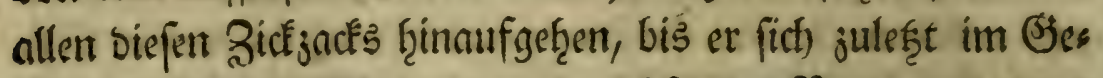

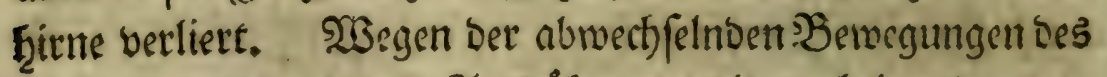
Zufammenjief̧ens unb Zlusbåf̧nens, bie nacheinnuber bon

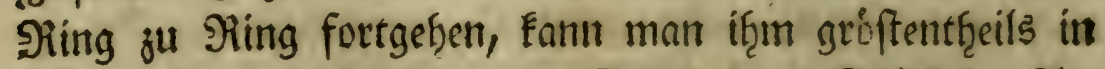
feinem Eange leicht) folgen. Selbft jebes Stủck ber $2(r s$ terie, weldtes in bie Breite eines von biefen ?aingen einges

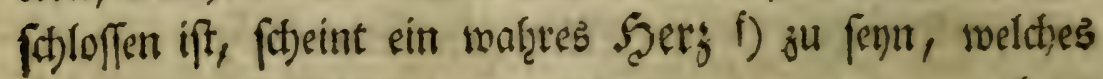

*) Corps organifés. Art. 244.

Den,

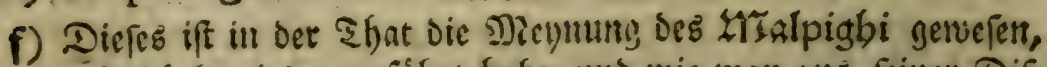

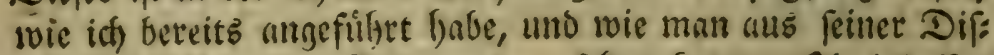
fertation úber Den Scioctuvurm fecten fanm. Ob intoeffen aber gleidf Diefe Bervierffâtrigung Der Seerzen wunberfarer, als cine lángs bent ganzen Sốrper gejogene cinfache Zitterie fenn mógte; fo wáre id) borl) faff geneigter ill glaubent, Daßs

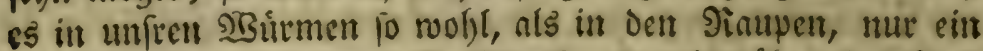

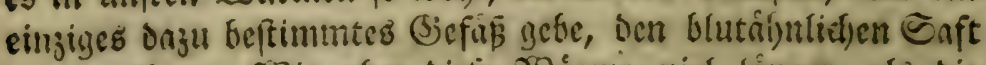

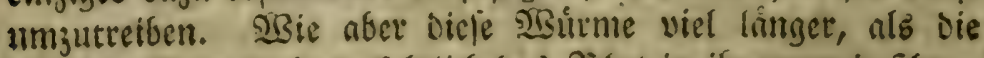

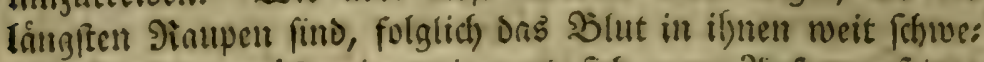

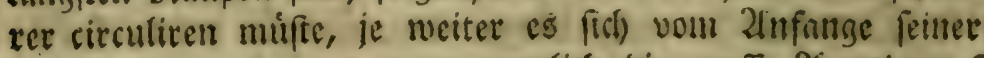
כeswegung entfernte; wemu nemlid) bie grofle Zleterie nuf 
beti, von bem vorţergę̧enben, empfangenen Safttropfen ful bem folgenben fortfróft. SMan famm Dicpes Sct)autipiel Der beffánbigen Betwegungen ber Softole unt Diaftole nict)r genug bewunbern. Wisill man es rect)t genieffen; fo M 3

мแนต

eben Die 2(rt, wie hel) sen Tinupen eingerid)tet waike; fo bilbe ic) mir ein, Daß Die 9Ratur Da, uro jeder Ping mit Dem an: vern verciniget ift, cine gervifle Klappe angebrad)t babe,

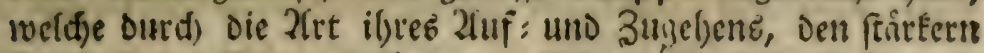

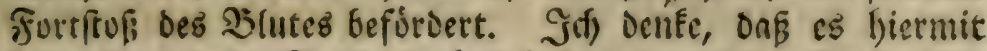

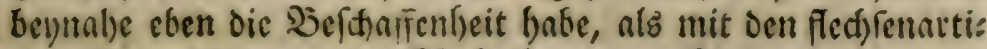
gen Sinterfeftionen ser Mufculorum rectorum, sDer mit

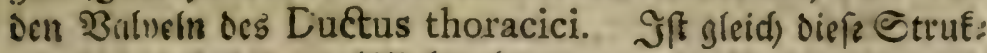
tut viel einfad)er, als Hralpigbi meynet; fo ife fie Dod), meis nes (Exad)tens, nidje weniget wunberbar. 25 .

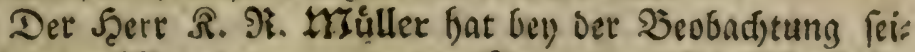
net bunten Zlereioe p. 1 24. Die Jieynungen Der phyfiolo:

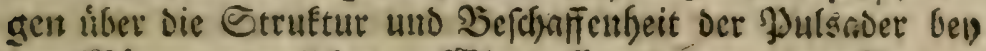

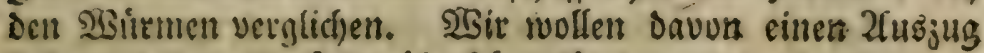
liefern, oen meine Eejer úbréfefen tónnen.

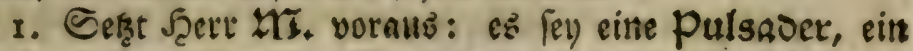

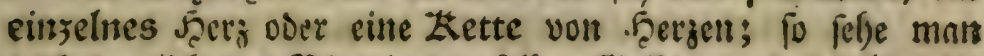

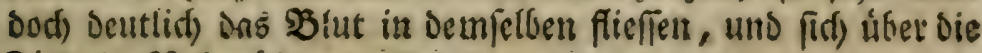

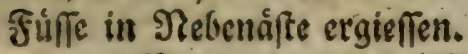

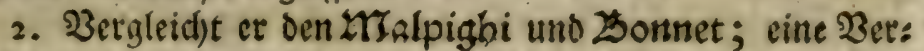
glecidung, Die wir ats eituen ted)t fdjonen Commentak úber

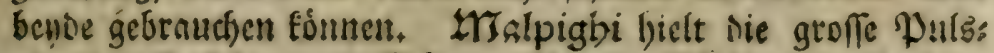

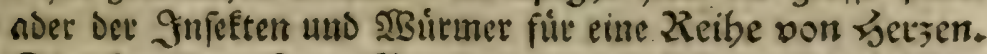

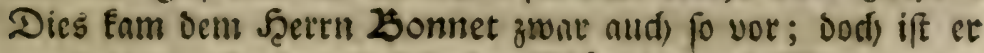

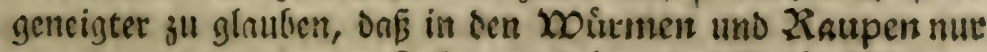

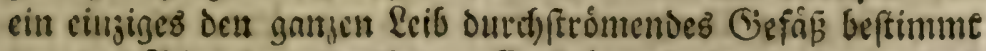

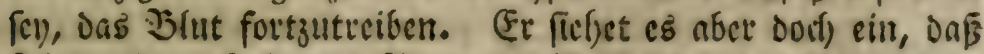
fid) in cincin fo fangen Pinum Die Pieigbarfeit Des SJlute yers

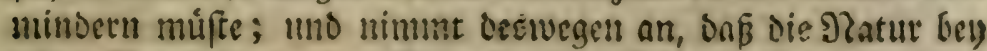
jeber Bereinigum\} Der Gelenfe eine Kâppe, Den IImtriel

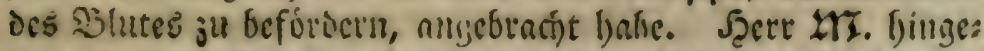

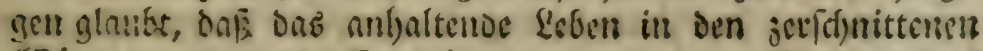

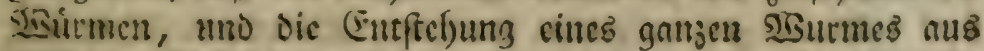

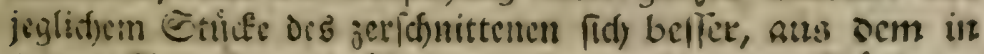
feoem Gelente nodh úbrigen gansen un: unbefthódigten

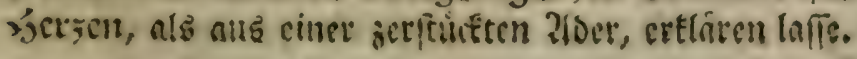




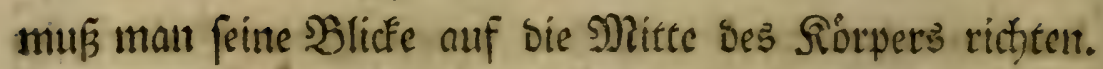

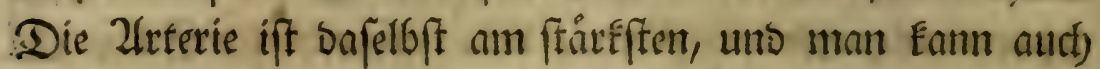
Da viel beutlicter, als an benoen Enven ferten, mie alles

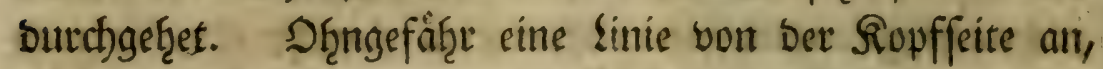
fheint bie Zlrterie mur noch), als ein feitner Faben, Der foum

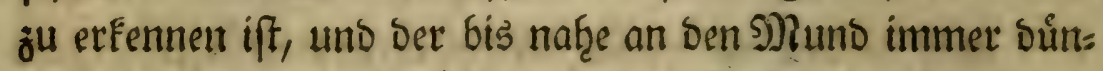

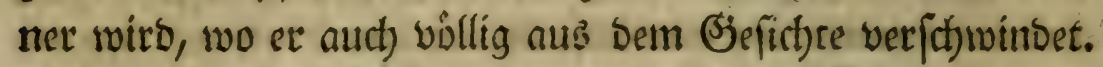

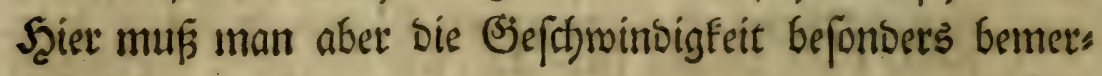
fen,

3. Erläutett er feine Mieinung butch folgende Sieban: Eent. FE fónnen, fagt er, die Zlappen des Setrn Zonnet

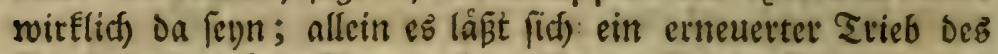

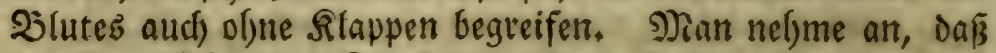
Det fleine Theil des Ranals in jeden Gielenfe bey der 2luf: naf)me bes Słlutes weit, und bey Dem 2rbfune enge (ev; To

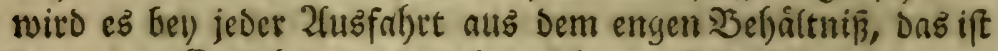
bey jever (Finfabit in Das benadjonrte Bielenfe, mit neuer Sraft flieflen; oder Daß̧ Der vordere Theil Desi Sianals melie nachgiebt uno erweitert wiro, als oer folnente; fo wiro fids ons Slut vor ven engetn femmin, uno fids in den engen Siaum bineindrangen. "Ilno Diefes bat Seer triuller vor:

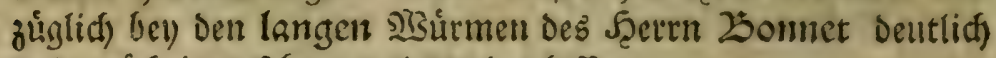
uns praid)rig gejefyen, uno malen lafien.

4. In cinem von Jeer tra. Ged)riebenen faoenwurme

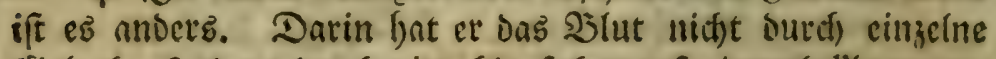
(Siclenfe, fondern Durd) vier bis fechs auf cinmal Hompen: weife surd)fafien felsen. Diefe ât bes Ṡlutlnufs ift nid)t allgemein. tralpigbi bat fo woobl gefelgen, Dnß̧ Jeer 2tr.

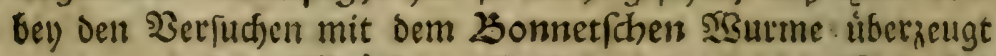

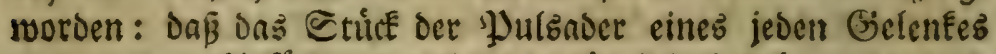
ein eigenes (Gefáf ausmad)e, bas fur fid) beftelje, und audi) ofjne Dafeyn Der andern lebe, ja fid) in einem gangen $\mathscr{3} 3$ ur: me erneure:

5. Die Dlutaoern find bel) vielen SIJutmarten fdyrve:

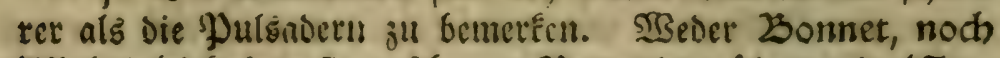
27alpigbi baben lie gejeben. 2settacht. uber die Zat. 8. Cb. 4. Kap. (Etfterer vermutijete eite groffe Slutader lings bem Daud)e feines langen 2 urms, fie ift aud) mitt:

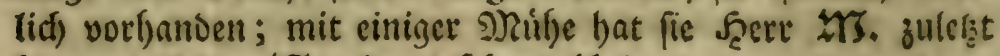
beyoe an feinet zereide gefelgen, Heb. 
fen, mit welet)er bas B̉lut an biefen Drte feirten \{auf bes

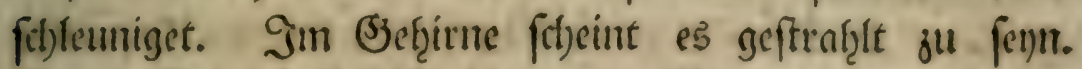

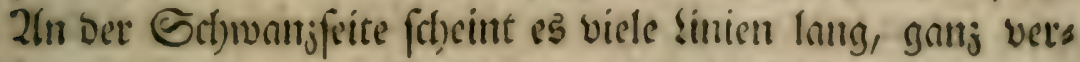
anbert ju werben. Dufe abued)feltoen Bufammenjief̧ut=

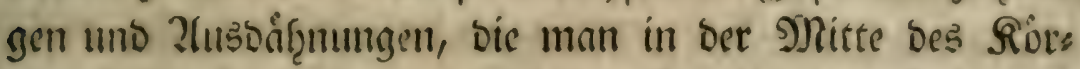

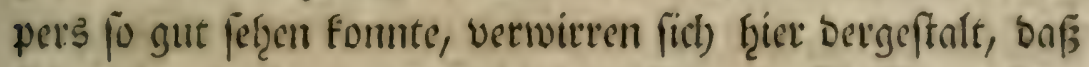
fie nicht meţe ju unterfacheiben finto. 2ln ifceer frott fiefzet man mut gewiffe vellenformige SBetwegungen, ober

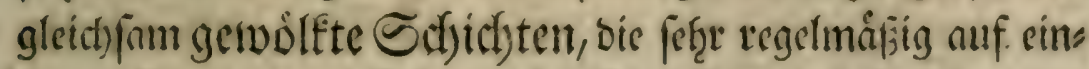
ander folgen. 9) Da, wo fich) jeder Siing mit bem andern vereiniget, bemerft man fleine Siefaffe mit vielen Zweigen (fig. V. d, d, d, ) weld)e von ber groffen 2(rterie heerjufom= men fitseinent. Da id) indeffen an if̧nen feine Gyftole unto Dinftole f̧abe entoecfen folmen; fo follte man waf̧rycheins

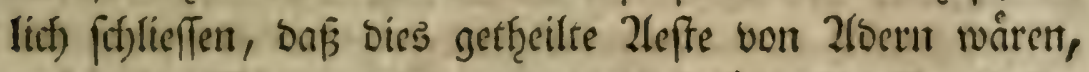
weld)e bas B̉lut, in einen vermutţlid) langs ben Baud) lies genben Şauptjwein ủberfüfretr. Ilmuittelfar unter bet Scauptarterie ift Der Ranal Der Fingeweide (D, D, D, ) langs Durch)gejogen, ben man an fich) felbft fo gut nicht jeferen fanu, als vermittelft ber Erotheile womit er gemeiniglict) nurgefillet ift. Et ift ebenfalls, wie bie Eingenveibe ber groffen Sfyiere, mit verfdiebenen Sieifen muffulojer Fibern verfe(zen, weld)e burd) ifere ausbåhnenbe Rraft bas lleber.

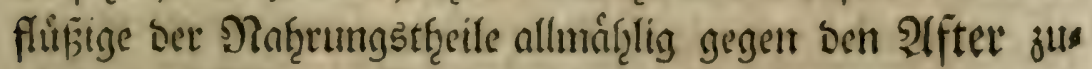
treiben. SBentr man fie aud) nicf)t mit bem 2(uge ent

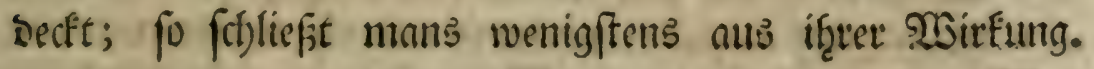
श 4

Man

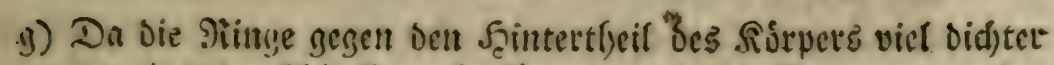

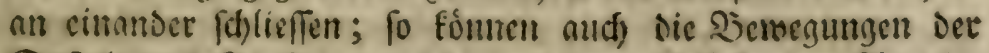
Enfrute uno Dinftele, weldse in jebem Etuife Der 2irterie,

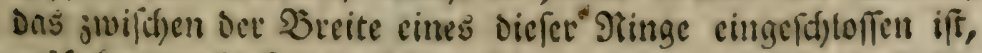
geiffelen, nitht jo beutlidy wal)rgenommen werden; und on:

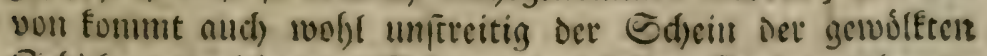

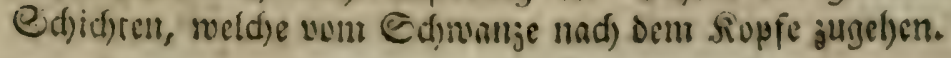


Dlan fief̧et es ja beutlict), wie bie Excremente vou Sot ju

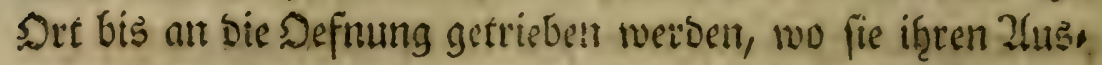

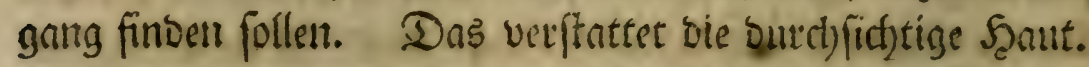

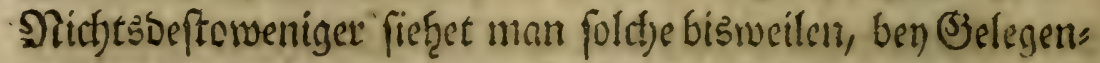

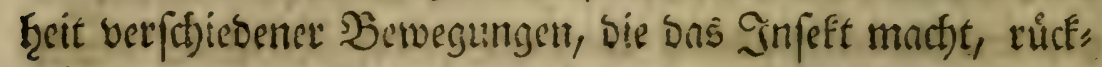
waerts gę̧en. Eint anbermal focheinen fie ju faufen, uno nad) Dem Zfrus ju fthenell fortgeriffen ju werben. In ges

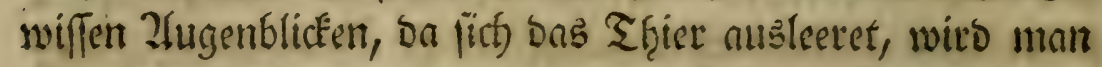
gegent Das Sdjwanjente zu cine gewiffe Berwegung, wie cin

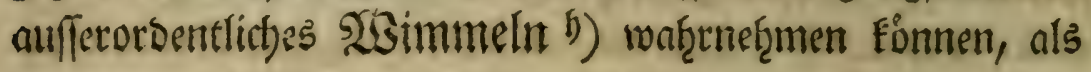

wenn

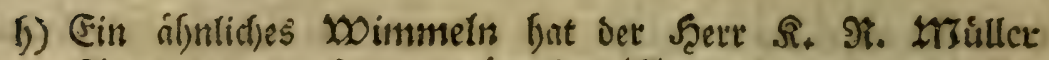
S. 29 (e) an feiner gezuningelten LZaide bemerft, und fids

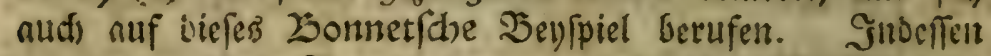
wirb es uns ein Selveis ber mannigfaltijen 2 Beish)eit des

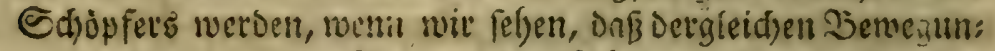
gen in dem interfon Sbaue folcher șürme nidht einetley (el), aud) nidht von cinetley Ulefach entfeffe. Seert Lonnet iff

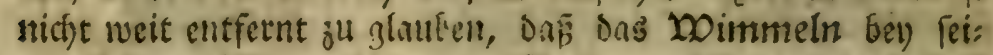

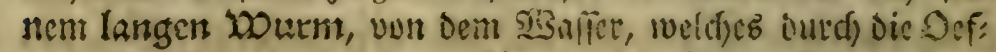

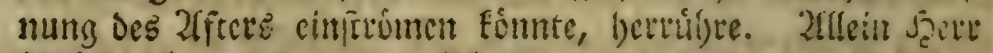

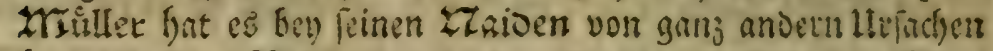

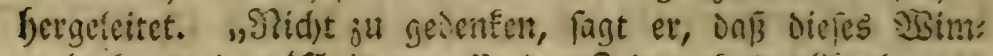

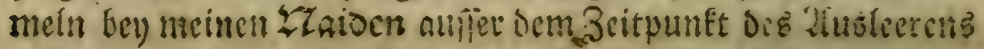

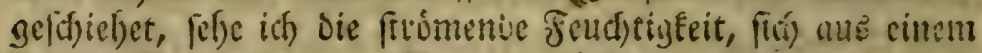

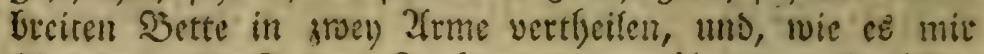

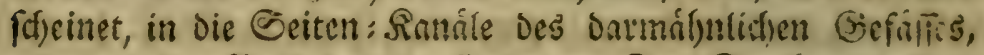
Dier in bie Dulsaber ju niellen. Der Etrolmm verlict fid) in cintiger (Entfertmung von bem Iffer oft it ben jertl)cils

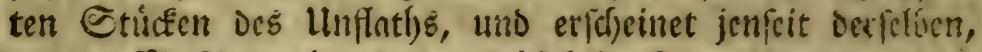

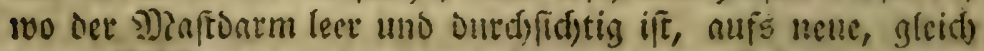

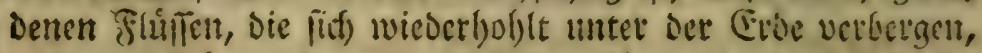

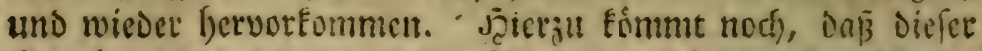

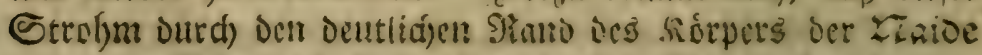

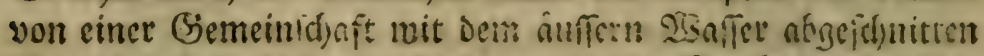

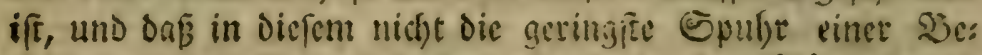

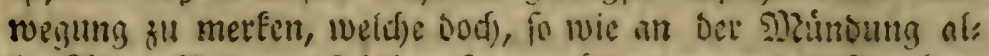

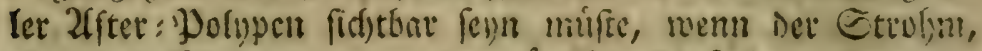

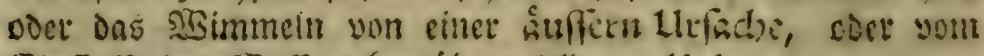
Einfune Des ASaffer betriblen folle. " Heb. 


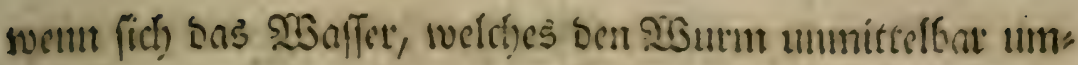
giebt, ber Defmung, Die ifem ber 2ffter barbietet, bebienen

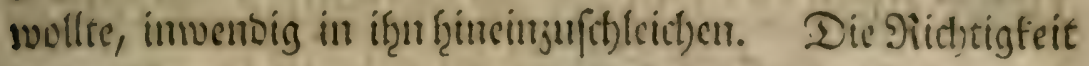
biefer Sergleich)ung wirb man samens befto beffer bentetyeis fen fonturn, weil man bemerts, bof alsbenn bie Exeremente,

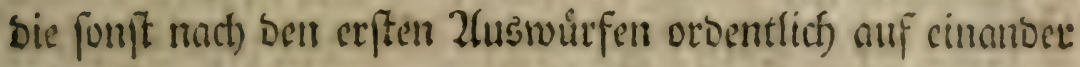

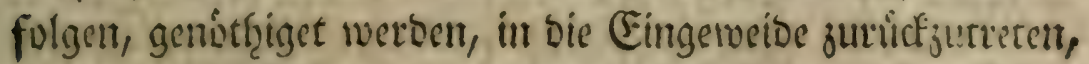

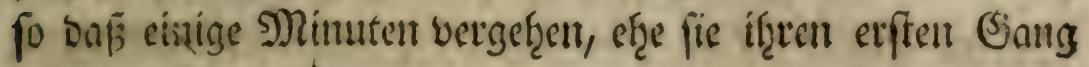
svieber nef̧unen formen.

Ein anderes fetcr intereffantes Sd)aupiel, bas man bismeilen intwenbig in biefer 2 ret von 2 urmen erblict, bes

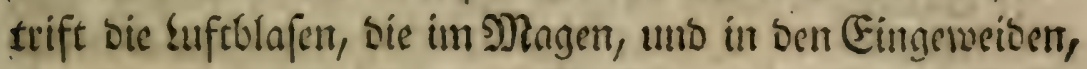
sine bey ber anbern liegent. 2(n ftatt aber, baf; bie Fifd)e bie in cime Blafe cingefchloftene Luft in if̧rer Sienalt fraben, unt fich berfelben jum Zuffiteigen uno פitederfinten bebies

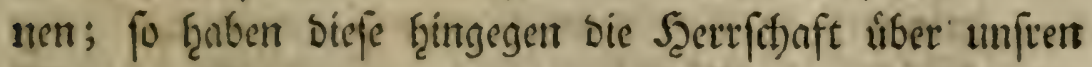

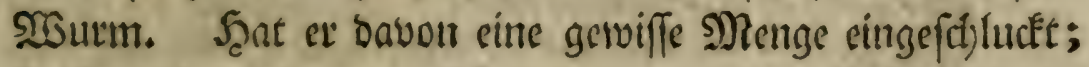
fo ift es if̧m, aller untaufhejorlich angemanoten Rtáfte oḩnets

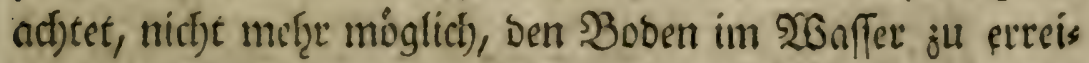
c)en; et mur oben bleiben, bis er alle suft wieber bon firs

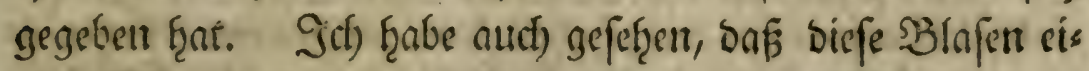
nige Nrinuten lang, wect) felsuveife gegen bent 2(fter gejugt, umb von ba wieder nad) Dem Ropfe jugetrieben wutwon.

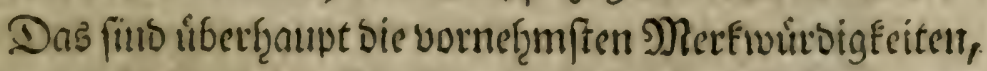

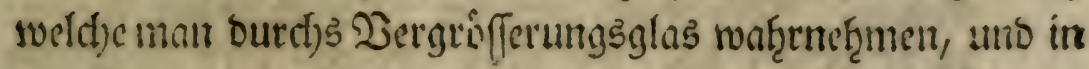
Dem Bane biefes Sinfefts *) entbecten Fann. Sft diefe Struf" tut cimmal teet)t gennu befannt; fo wito man ůber bas S.junber Det Erncutung fo vider Seganten defto meţe ceftaunent.

$$
\text { 2) } 5
$$

Bwet)=

*) Seert Lonnet nemet feine 2istirme balo Infetten, Gurb Ebiere,

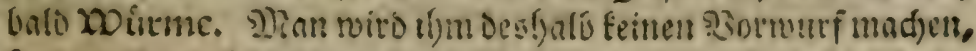

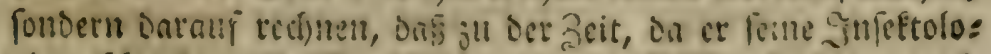

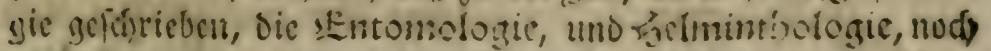

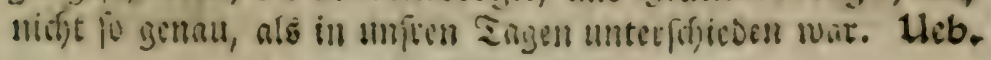




\section{Smente SBeobadrtutig.}

Heber einten 28 urm Der in Der Mlitte querdurn in zwen Stricée getbellet ift.

s.

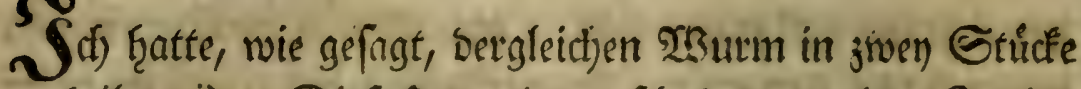

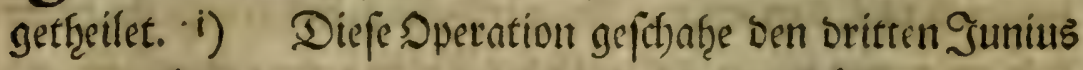

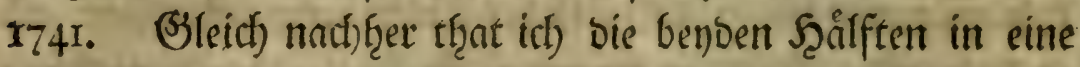
gläjerne Soffe, bie im Durchmeffer bren bis vier Zoll hatte,

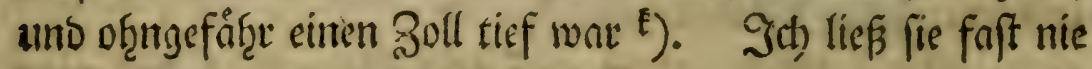

aus

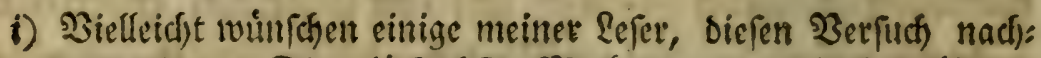

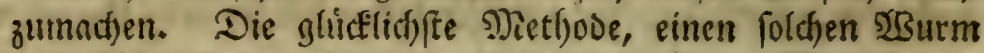
ju jetichneiden, gefdjiel)et auf folgende 2tit. Sian bringt

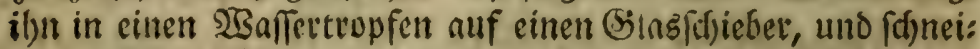

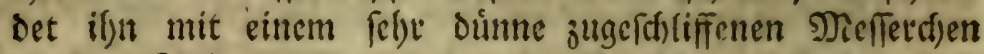
Durd). Dabey muß mant mir vie

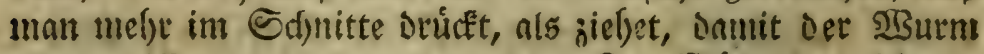

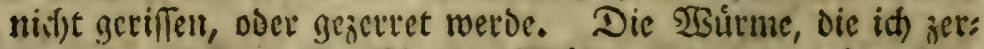

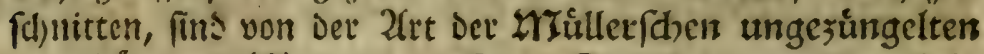
uno bo̊rtigen ZZaioen newefen. Sie fdjeinten weisgraulid, oljngefályt joey Rinien lang. TSill man fie zeerifłneiten; fo Darf man Den (Sitasfibieber nur úber einen grinen Tifch bals ten; fo wirs die Speration leidft von ftatten gefen. Lleb.

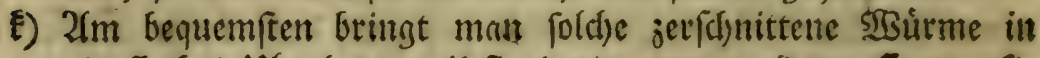
ein fladjes Ulyrglav, weif lie barin, unter einem Compofis

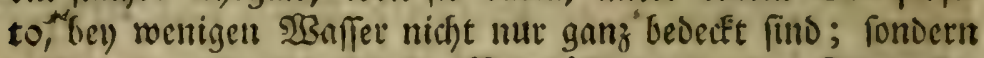
aud) unter ziemlid) frarfell 23 ergroflerungen den focus bes balten. Mran Eann Diefes auf eine sedoppelte 2frt bewerf: ftelligen. Sian nimmt entweder bie zerfchnittenen Stuife,

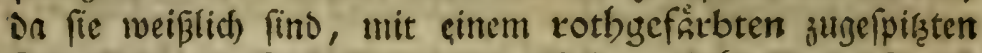

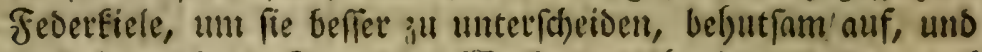

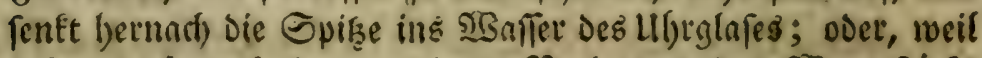

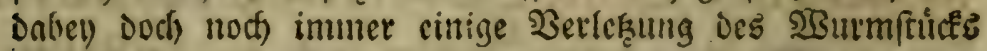

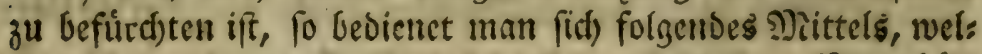
c)es id) am bequem(ten uno fid)erften gefunden. SRan fjâlt

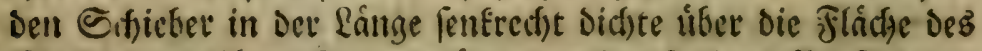

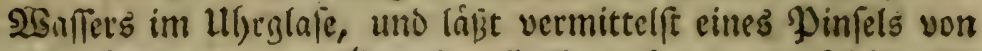
oben herutter cinen 'zropfen fieflen; io nimmt foldher bie

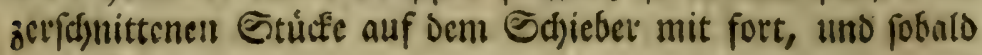




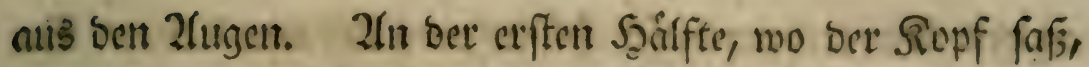

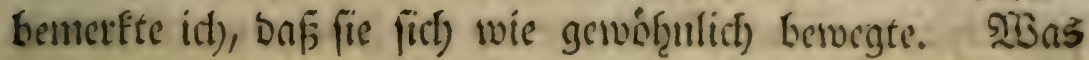

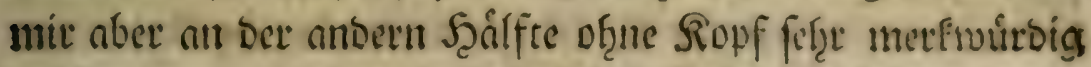

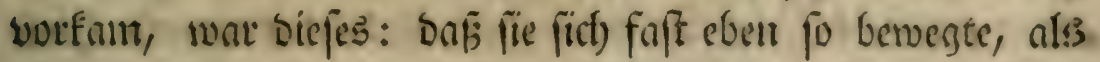

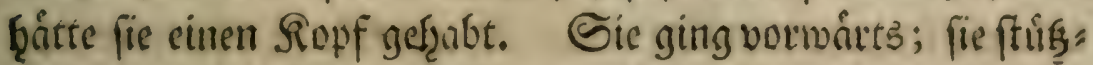
te fitt) ouf bus Enoe bes నorbertţeils; fie ging fogar jiems

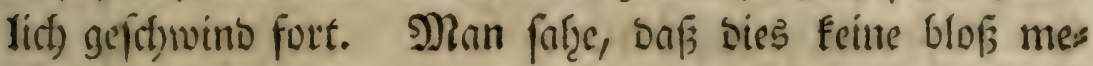

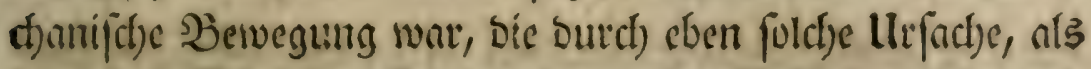
ben einer (Eibere entffanben fen, beren Ect)wants firf) nod) fortbervegt, weun ex gleid) f(t)on voun giumpfe abgefonbert

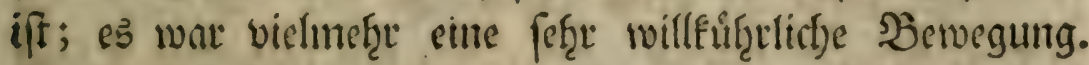
Sraf fie etwas ant, bas if̨r im sisege lag; fo bemerfte man,

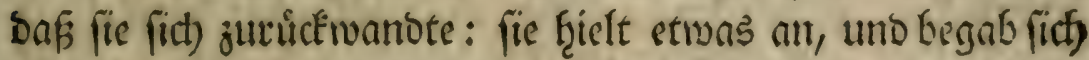

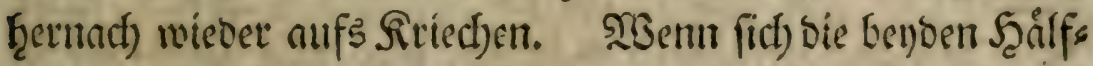
ten einander begegneten; fo war es, als faitten fie niemals jut einem uno eben bemfelben Infefte gethouret; fie fojienen weber éinanber ju furben, nod) vor einanber ju flief̧en. Eis ne jebe zog fict) von ber @eite; doer wernu fie benbe nath cinem Drte jugingen; fo faun bie erffe gemeiniglich) ber ans Dern juvor. NRiemals aber zeigte biefe lef̧etere beutlit)er ein

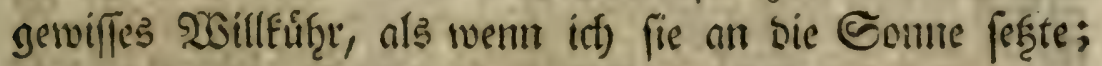

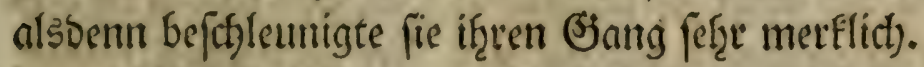

Nad) jwo Sagen glaubte idf), in bie Saffe etwns Evrbe,

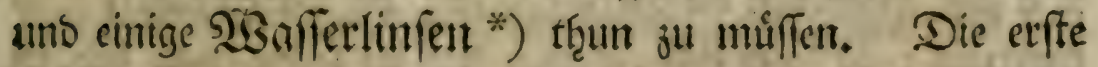

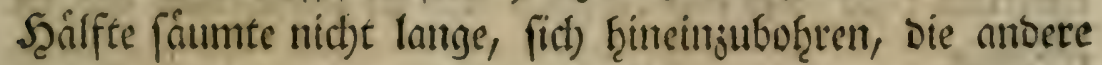

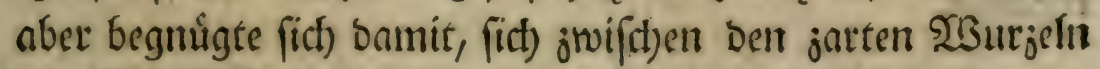
ber Meerlinfet ju verberget. Llm biefe Zeit bemerfte it')

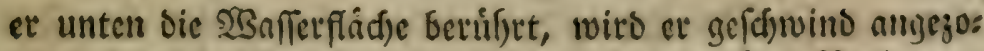

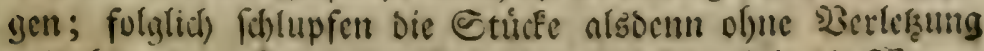

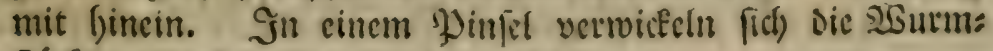
ftucfe ju ftarf in Den Şaaren. 1leb.

*) Lens paluftris, \#icerlinfe, Entenfloot, Ëntengries, wie man fie an einigen Diten ju Hennen wfligt. Heb. 


\section{3esbachtungen ůber einige 2rttent}

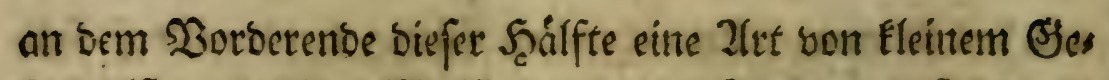

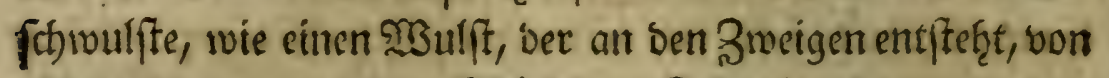

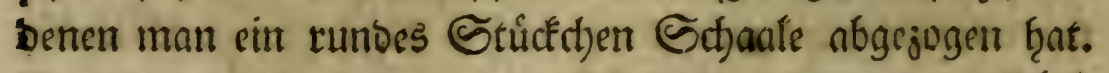
Das fontte ith aber an bem Seinterende ber andern Şålfs te nicht fo gut unterfdeiben. Diefer Troulft futen iţe bas Sirteć)en ju erleichtern; wenigftens war fie bnburch vor bem Sieiben mef̧r gejictert.

Des folgenten Tages fare id) an bem Schnitte einet. jeben Scalfte einen flcinen 2(nwurt)s, ber wegen feiner vers fthiedenen Farbe ins 2utge fiel, welche fier viel ḩeller, als in Dem úbrigen Rorper war. In Den folgenten Sagen

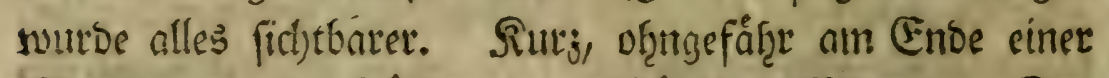

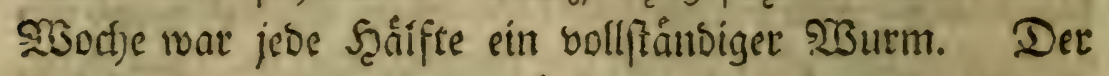
Sopf, Der an ber jwenten Scáffte angewad, fen war, foun in Der Sieftalt mit Dem erften überein, uno Das Thier fonnte bamit alles, wie mit biefem verrichten. Eben fo war nuch Det nene Sthwanj piefer erften Sä́lfte bem an ber juentett

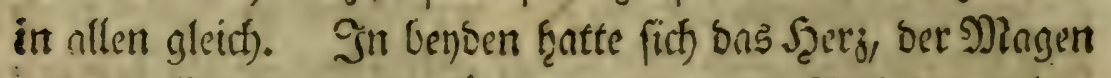

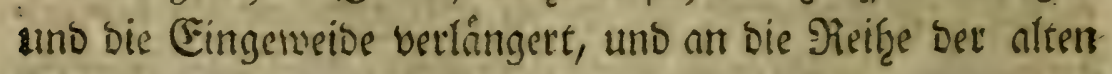
Sitnge waren neue angewact) fen. Rur fte গুษ Den. 20urime gleid)fals, Die auf biefe Zirt entfanten waren.

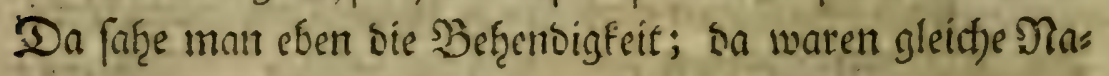
turtriebe; ba fano fich einerlen $\mathfrak{d}$ ite ju leben, unb fith au etralten.

Jit) war auth beforgt getvefen, iferen Mad,stf̧um, won Zeit ju Zeit, mit ber móglid)ften Śenauigkeit ju melten.

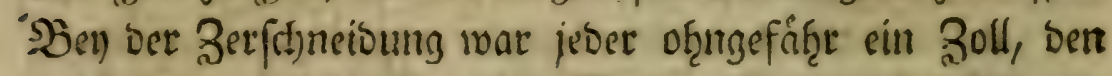
swer) uno jwalrjigften bes Monnts b̨atten fie beynaţe fituon jiverye. 


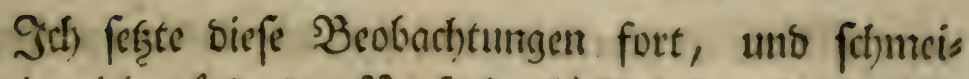
cjelte mir: ich wurtbe ben Derfinct) gliưflict) fo weit treiben fósuren, als es nur móglith) wáre; fie famben aber nact) einis

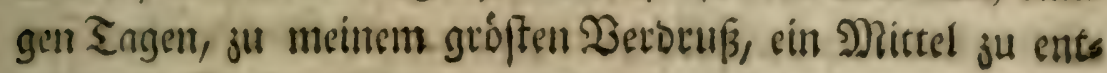
wiffent. 1)

\section{Dritte $\mathfrak{B e n b a d t u n g . ~}$}

Heber 2 sirme, Die in 3wen, Dren, vier, actit, zeln, viergeln, und fedts und zwangig Stride. zertheilet fint.

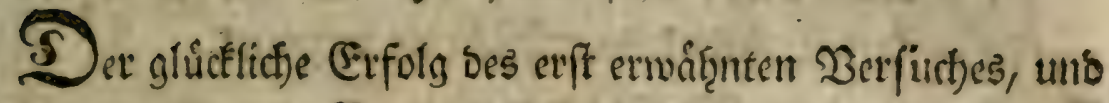

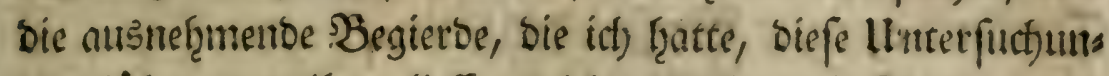

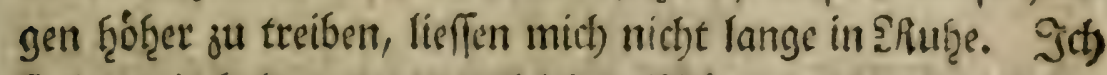
fuifte mir balt antoere bergleict)en 233 írme, wie ber erfte ges twefen war, ju berifhaffen; unt ich war fo glüdilith, fie wies Der ou filloen.

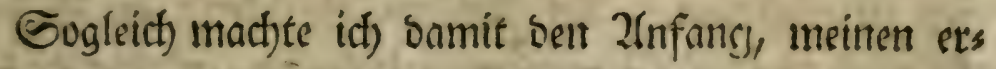

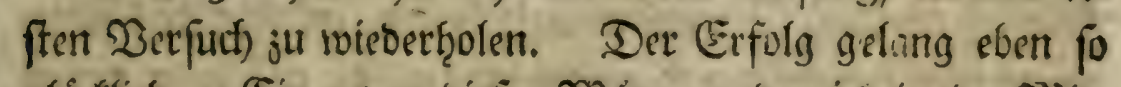

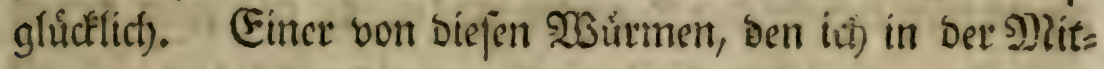
te querburd) "') geffthnitten ḩatte, gab mil in wentig ₹agen

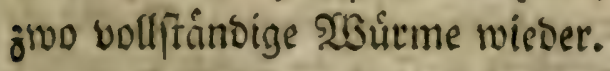

Scierauf verfurt)te ind) Die Zertf̧eilung weiter ju treis

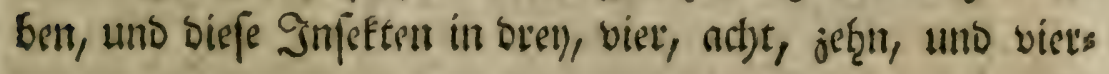
zef̨n

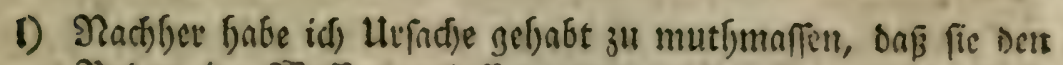
Sjoden im şsaffer vertafien, uno an Den Eeiten oer ₹alfe

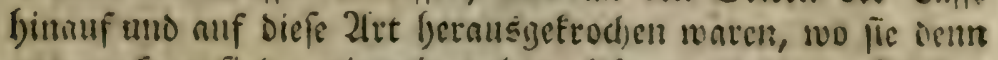
angetrocknet fint, wie mir meb)rmal besegnet ifr. (5) wae

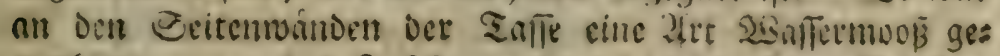
suadjen, wotan dab Suleft um fo vicl lesthter binalfeticd)en

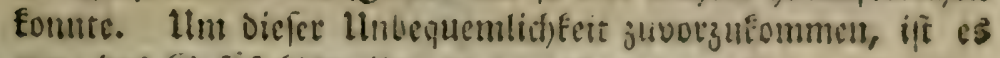

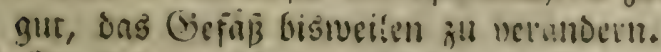

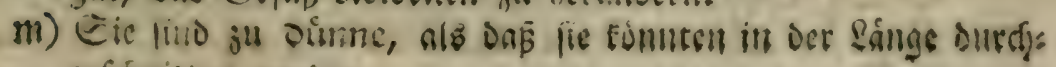
gefajultten weroen. 
zetrnt Estúçé ju forneiben, unb faft alle befamen Sopf uno Shwong wieber.

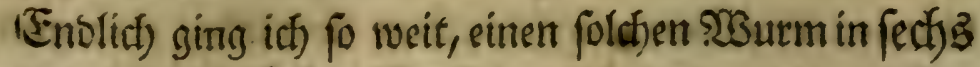
uno żuanjig Stuicfe -ju tţeilen, *) Davon bie meiffen rviebergerwach)fen, Deren viele aber vollftánbige Thtiere ges worben fitto.

\section{Sierte Beobadtunty.}

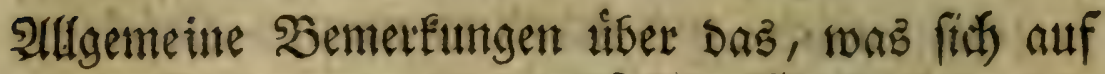
Die (Ertettrung, und auf Dent $2(3$ ad) Bthum Der

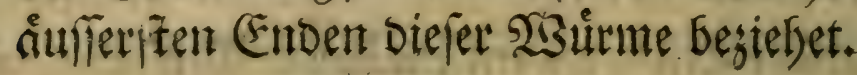

\section{Daran bemerEte Der fafiebenfreiten.}

Sั

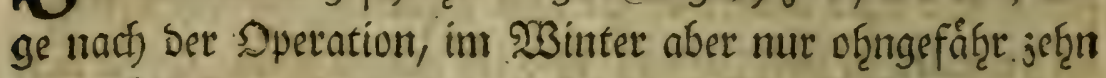

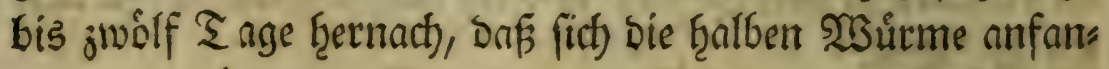

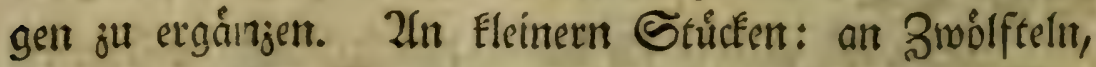

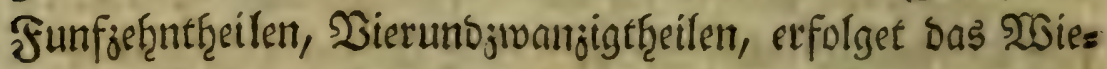
Derwadffen ben weiten fo gefidyinbe nicfje, wie man untert

feţen

*) Seerr Syonet if nadjyer nod) weiter gegantgen. (Ev hat eis

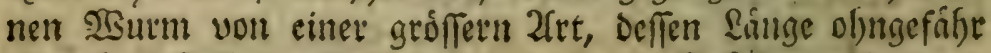
vieltefallo 3ulf geroelen, it 30 , ja in 40 Sticfe jerfdnitten, uni coen fo viel nelte Sirme vieder befommeis. Der Ju:

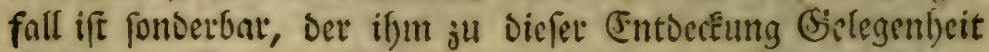
gezelien. Da et mit Diejen 23 surmen die Numplyen Det

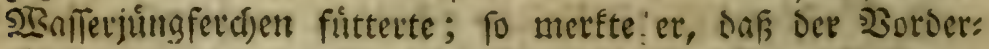

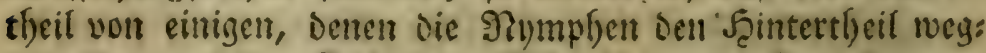
gefreflen, auf Dem Doden Der Edjanle, morin fie jufoumen waren, foltlebte. (5e metfte ferner, baj bels ciniuent ber

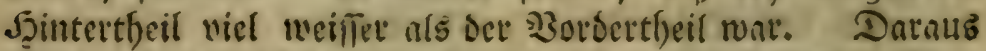

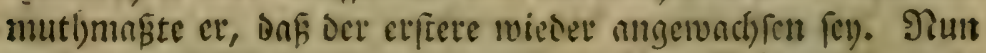

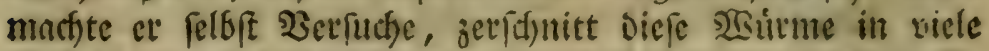
Stilcfe, uno befam nus cinem ganje familien wieber. 5 . Reaumur hiftoire des Infectes. 'Tom. VI. I. Part. pref. p. LXVII. Heb. 


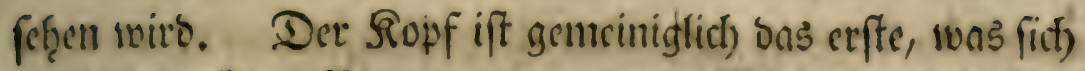

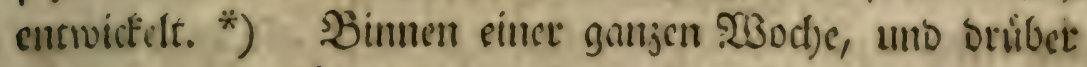
wirto er imuner lánger, bis baß er of̧ngefábze eine sinie, $n$ )

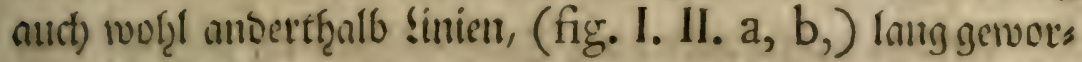
Den ift; alsocnn fioret er allf ju wad)jent. So verfialt fiths mit bem Ecthwanje nidft. Nact)oem biefer gar balb

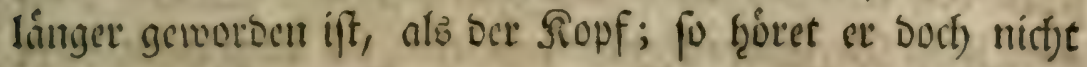
auf ju wachfert. Er numunt von ₹age zu Tage beftainoig

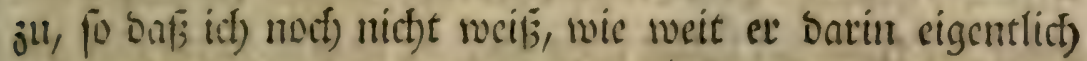

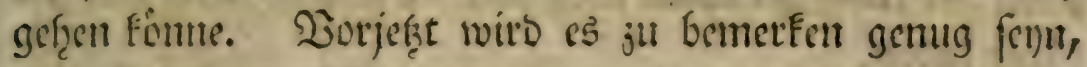

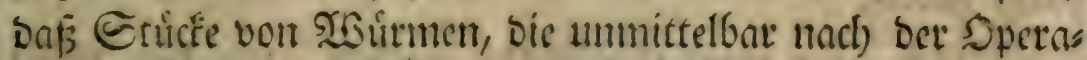
tion nicf)t mef̧e, als jwel) bis brel) sinien fratten, in meniger

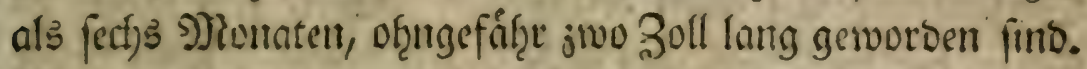

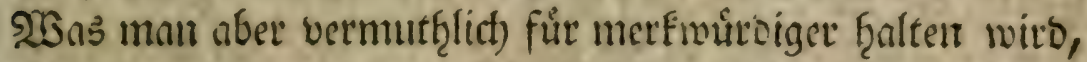
ift biefes: Daf bergleict)en Sruidfe ju gleicher Beit, eben fo weit, als andere, vier bis fünfinal fo lange, gemadbjen finto.

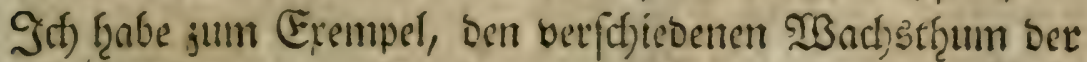

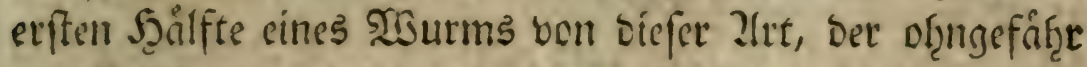

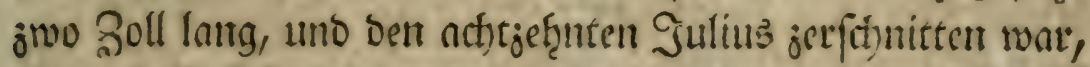

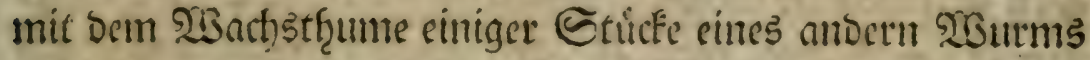
verglict)en, Der won cben Der 2lrt, Der eben fo lang, whro an eben

*) Corps organif. Art. 260.

n) Dantit will id) ni(d)t fagen: als of ser cigentlid) fogenannte Supf, ooer Der Theil, Der Dns Gellien, ben Nimno, u. T. w.

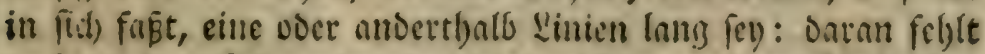

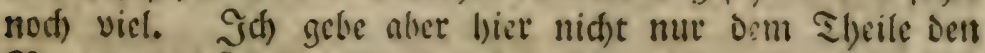

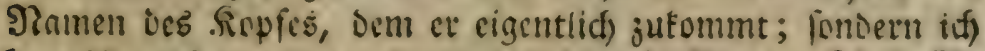
begreife aud) Barmuter eine gevvilie ?lngaftl Sinue (fig. I. II.

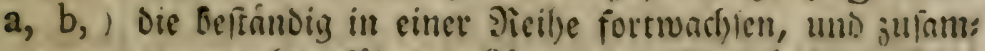
mengenommen ofjugefâbe die Lantue cince Linie bafen. Dies fómite man wols, wenn man will, Das sioriderlbeil Dos Sus feftes nennen. Hun oer sturie wellen bobe id) biejen Luter: fdied meggeinjen, umo es war mit genu!g, foldjen bier an: juicigen. S. Confiderations fur les Corps organif. Art. 247. 


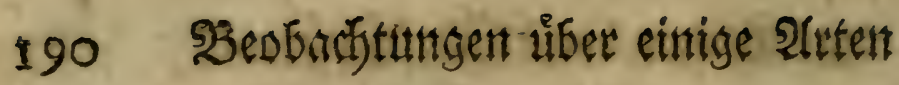

ebent bem Tage in ad)t Stucken gefothitten war; uno id bin er|taunt, Do ich) an bem sinem fo wof̧l, als an bem ans bern die Stưcée bennatze gleich)gerwachfen fanto.

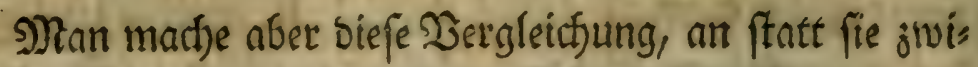

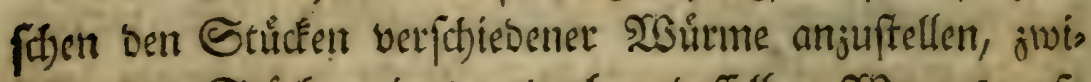

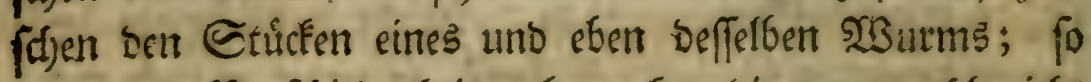

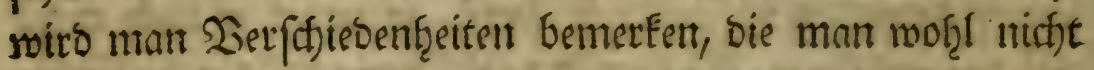

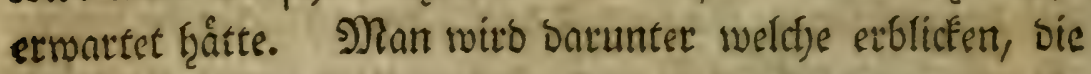
zroólf bis funfoef̨n Sinien lang finto, ba andere Enum vier bis fünfe hraber.

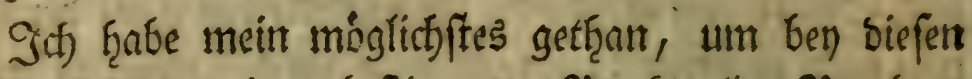

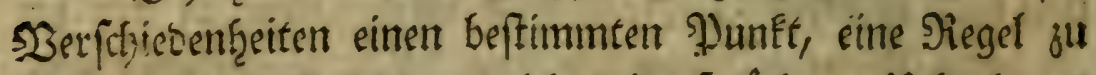

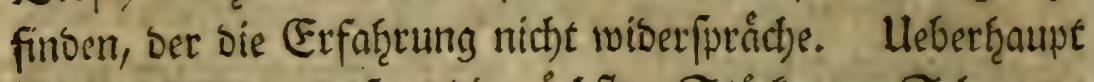

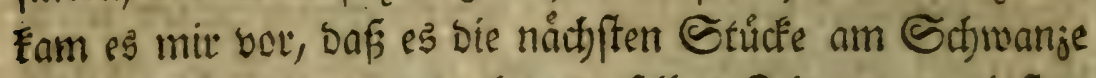
swarent, bie ju einer und eben berfertben Zeit am wenigften

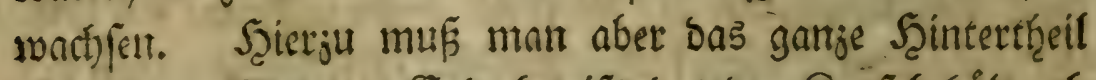
rect)nen. 223as bas Enbe betrift, bas ben Ropf befrält, ob folches gleit) oft in einer uno eben berfelben Zeit einen linns gern Edtwanj befommt; fo ift otes leştere bod) nid)e ims

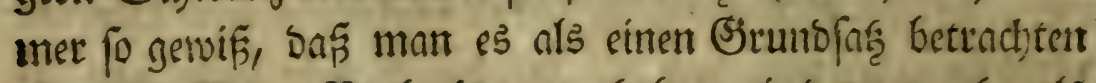

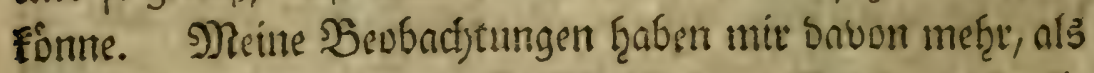

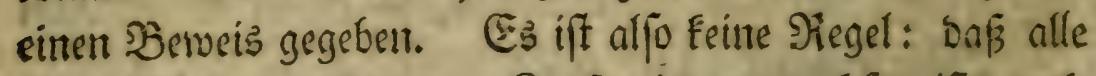
Mittelftúcfe, welcten ber Ropf wiebergetwad)fent iff, autd)

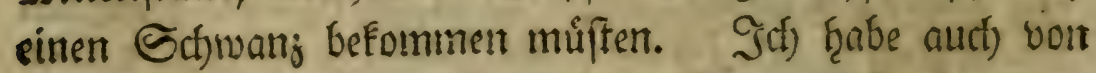
Dem Segenentrfeile Erempel gethabt. Das gewiffe nber ticers

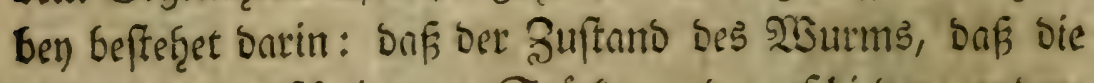

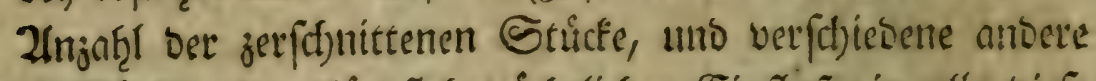

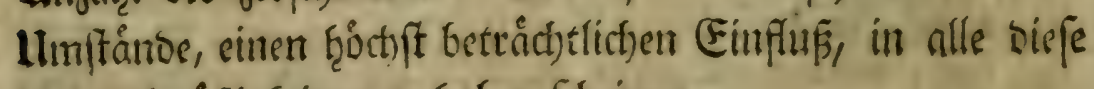
Unregelmáágigfeiten ju f̧aben fopeinen. 


\section{F̧unfte -}

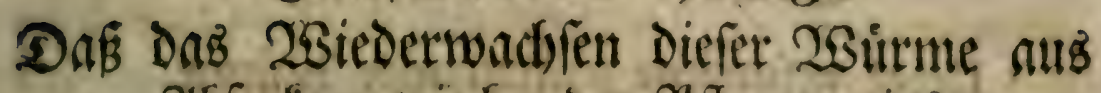
शbjentern, wie ber) ben भुflanjen, ins unenblidfe gefen Eaum.

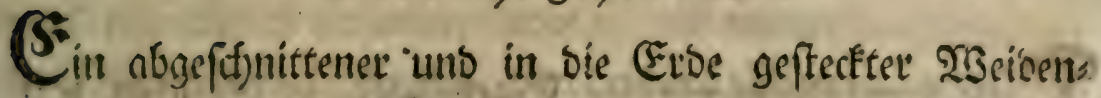

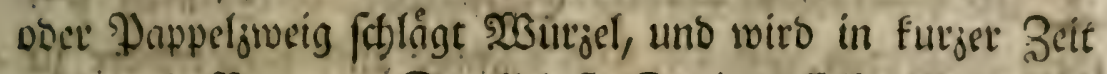
wieser ein Baum. Der fleinfte Zwoeig deffelben Fann wives Decrum sinen anbern $\mathfrak{B}$ aum erbeugen, und fo ins unentolidf)e.

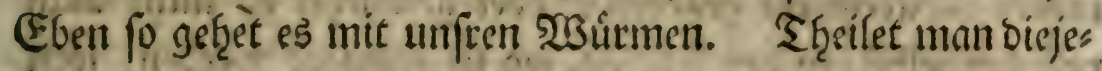

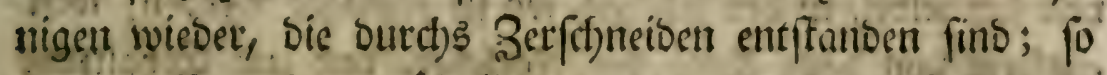

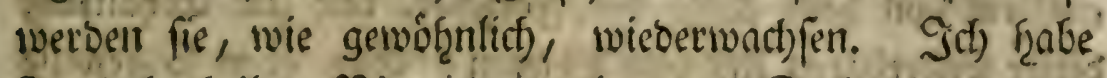

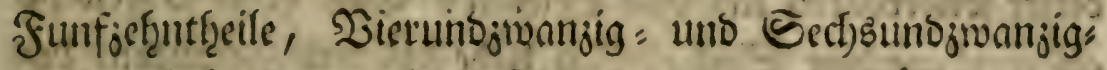

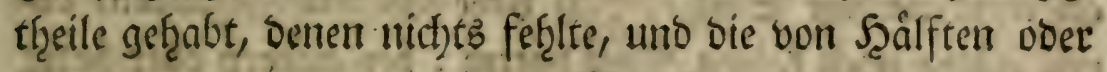
Sierteln geffonment warent. NRan fann hieraus urtheilen,

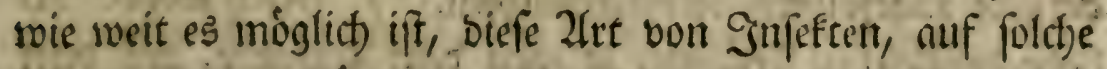

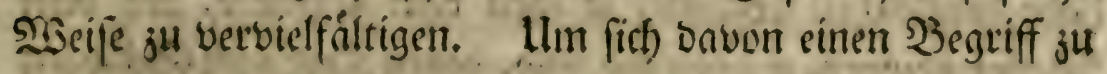

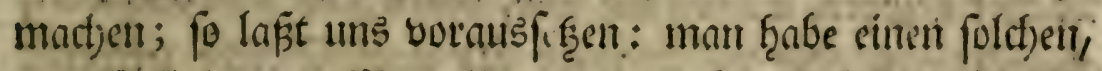

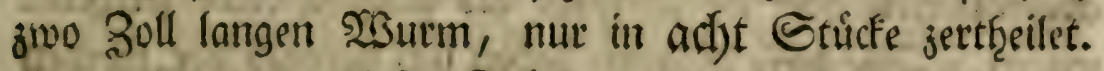

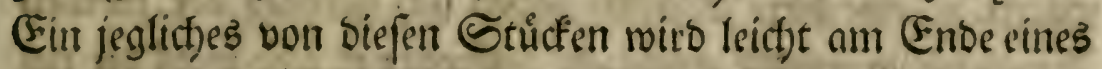

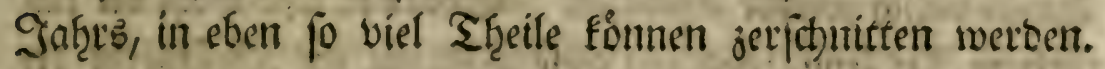

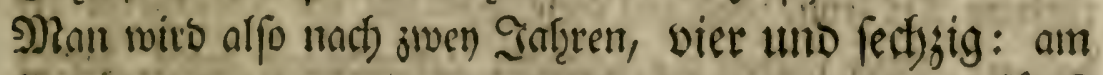
Entee Des britten 5 12: Des vierten 4096 und des fúnf:

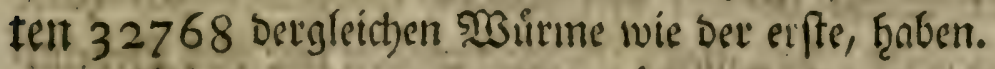

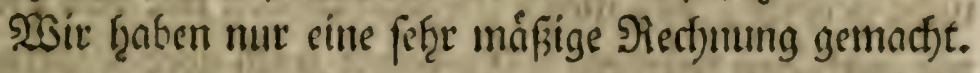

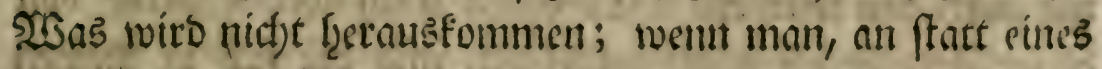

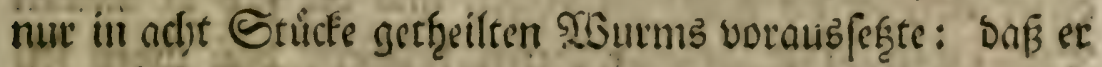

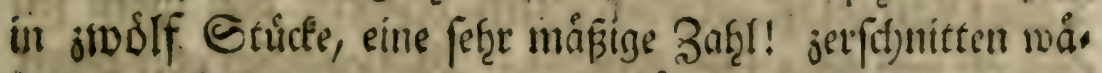

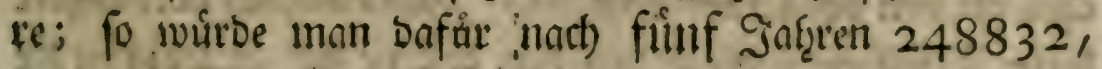

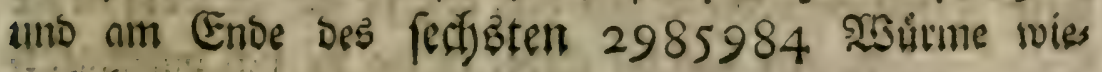
pertrabert. 


\section{23eobad)tungen ůber einige 2ritent}

\section{Sect)Bte Beobredtututg:}

Heber gefundene gerftimmelte 233 irme. IBie ifre Theilung zugegangen (er)?

Siepe bemunbernsmúrbige Eigenjijaft, in Sticten zers

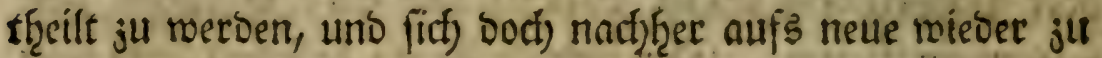

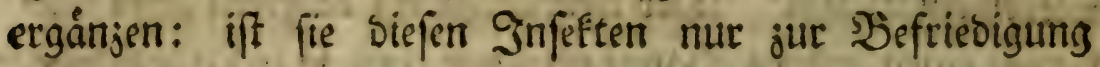
unfrer Neubegierbe gegeben? ober ge[thieb̧et es nitht nuth) voin fict) felbift, in ben fluffifen, wo fie erjenget iverbent, weit entfernt yon bem Zluge ber Forfater, uno jur Errģattung biefer fortberbaten Ilat von Thieren? Eine eben fo gewiffe

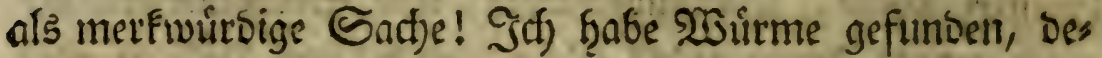
ren einige nod) feinen Siopf fratten; ber) anbern aber ḩatte

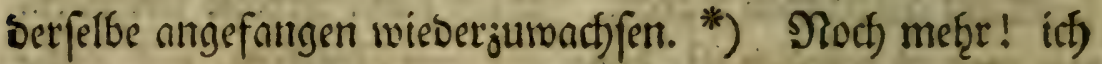

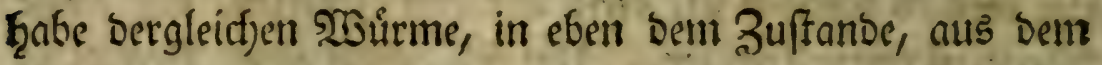

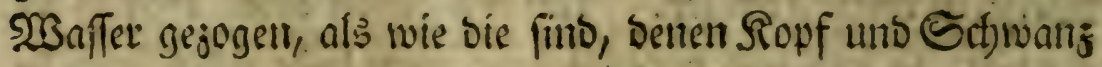
abgefd)nitten, abcr bie in meţr als juven Stricfe jertḩeilet

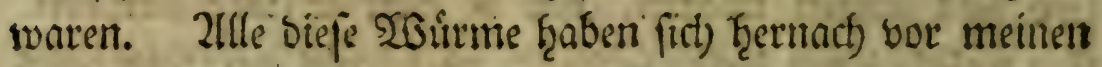
Zlurgen bóllig mieber ergánzet. Sollte es alfo wof̧ bie nas

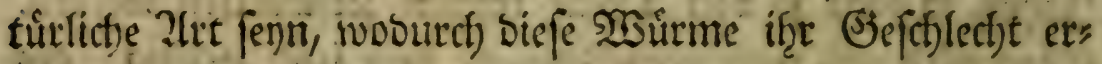

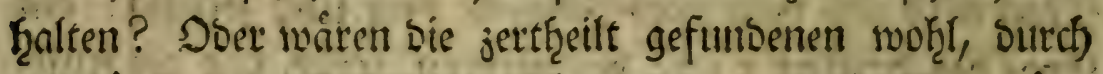

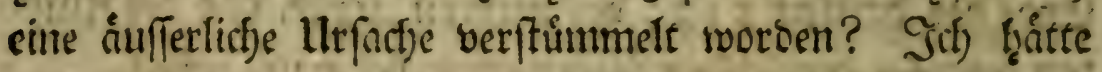

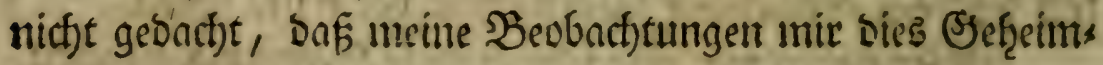

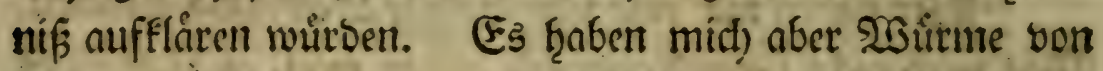
biefer 2 (rt, bie ith ganj nufbef̧ielt, unb bie firf) in meinetr

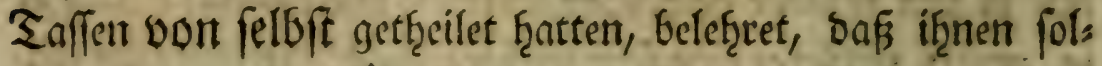
ches oft von of̧ngefóą̧r begegne. Semeiniglict) aber rưf̧zet

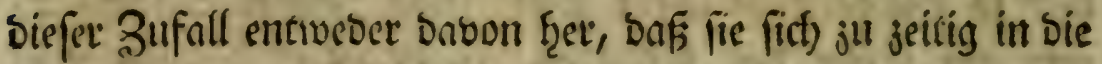
Erbe begeben, uder baj bie Erbe, in bie fie fict) f̧ineingebos

*) Corps organif. Art, 296 .

ret 


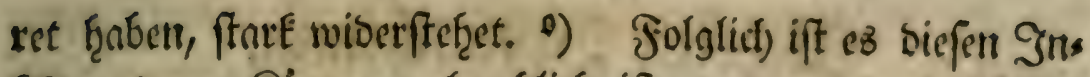

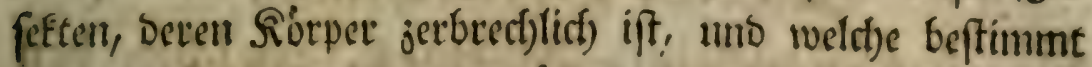

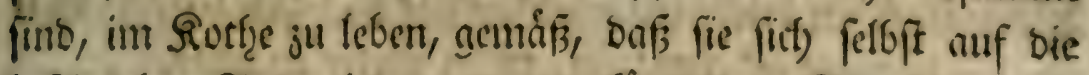

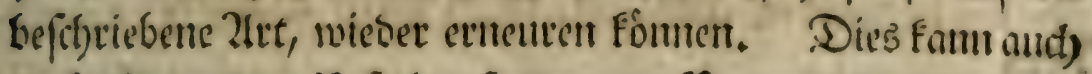

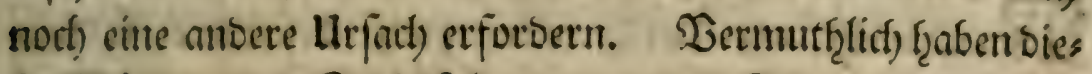

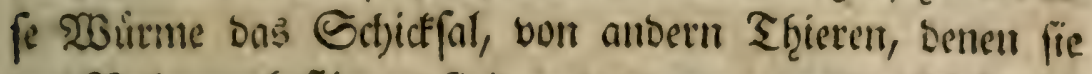

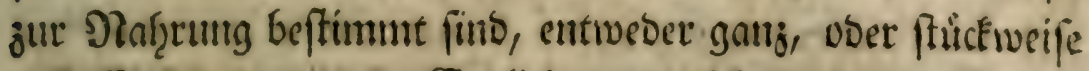

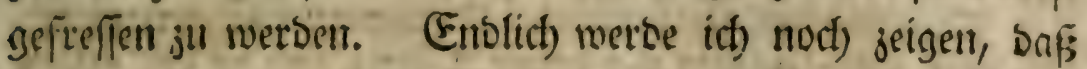
fie bișveilen von einer fefre fonderbaren Rrantheit anges griffen werben, Daven id) unten weitliuftiger reben will:

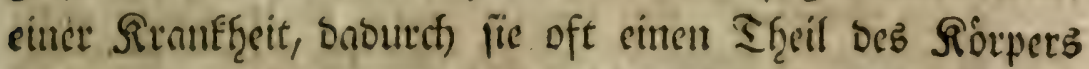
verlieren, ben fie f̧ertuad) Gald wieder eben fo ergingen, mie es bie jerf(c)nittenten tf̧ut భ).

\section{श 2}

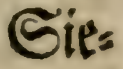

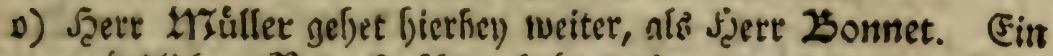

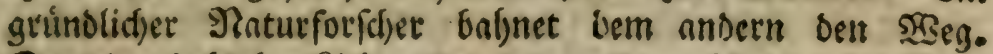

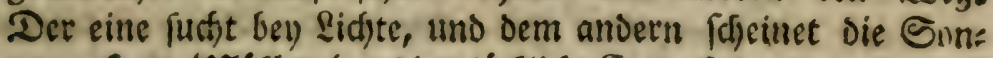

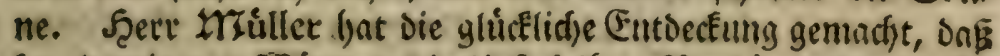

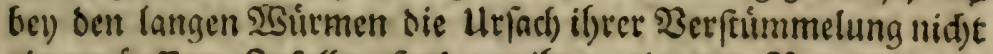
einem áufiern 3ufalle, fontern ibrer eigenen Natur beujus

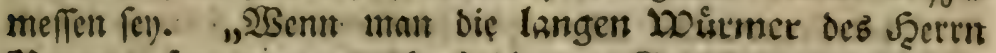

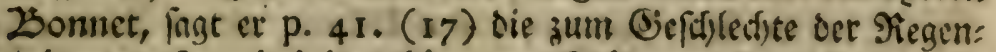

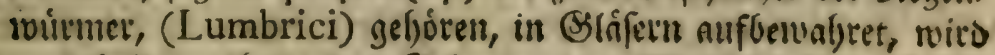

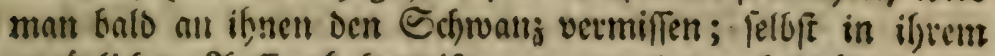

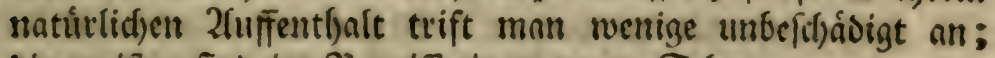
Die meiften fino im 3cegriff cinen neuen Echwans, nnvere ei: nen neuen Sopf, nod) anbere bendes ju entrviffectn. Şere

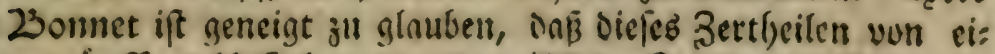

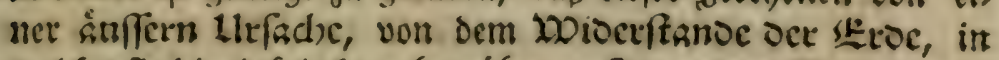

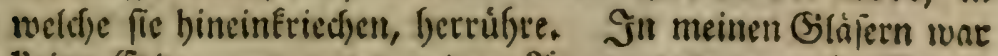

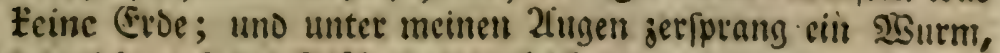

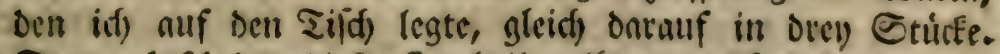

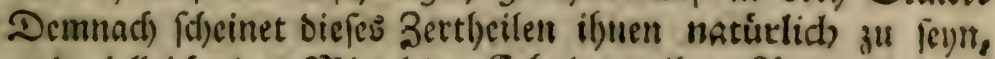

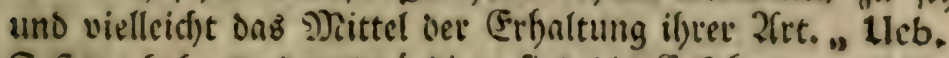

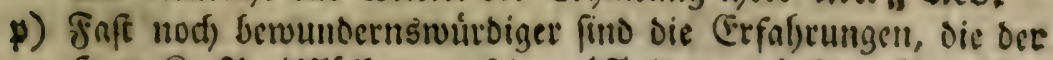

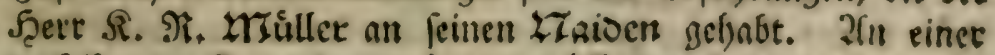

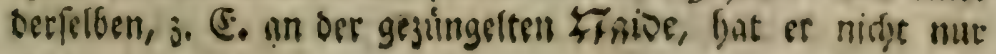


194 Bืeobachtungen ůfer einige शrten

\section{Sieberte Beobadtuturg.}

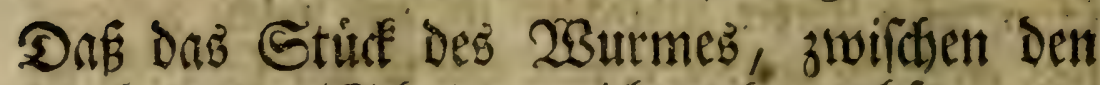
berden Schnitten, nidft mebr machfe.

9) Ran weíf es, Durd) eime ganj befonbere Erfaţs

rung,

Dent Hutterwurm gefelen; fontoert auds in eben Demfeltent Miuttermurme, sic seutlidffien Epurent zu vier Jeugungen,

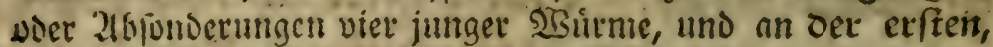
uno zweyten fohon wieser bun 2linfang. zu netuen Jeuguns

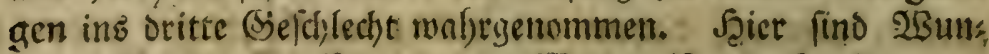
Der in Thunbern. (Ein cinjiget Isurm if Die Duelle uner:

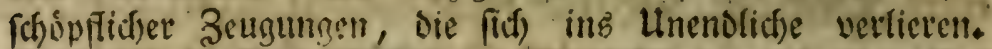

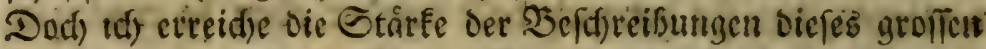

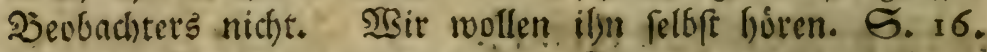

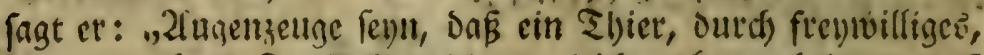
ober ungefátes Sertbeilen feines gleidjen ljervorbringt: ‘aß aus einem jeben Strufe cin vollfunmentes Tfjer tviro: Daß̄

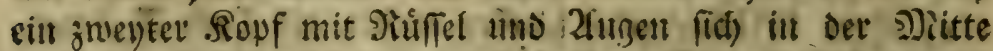
Des Sörpers -eines bereit's vulftindigen Tfjeres bildet, und mit oen binterfen Gelenten diefes Thicres davon ges bet; Daf ein gleidhes in Zturyem Dem entlaufenen woies Detfăbet, Doer, wie meine neuere S3eobndtungen zeigen: Thiere votzufinten, oeten Reiber aus ibren Jungen von verfitievenem 2flter zufammengefest feyn; die beyoe, 2ritter uno Yungen, einen zrano, einen Zlfter gemeins fehaftlich baben: entweder geljọtet biefes int bie Sieichichte Deet feen, voet es verbient gefeben, uno mit aller 2lufinerffam: feit wieverfolt zu werben. Es. find nitht aus einet sucidjent פ) הaffe gleidjfórmiger Ságeldjen beftefende Polypen, Die biefe

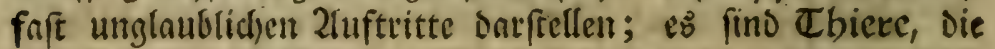
aus Deganen verfajiedener 2(rt beftefyen, uns in Denten man die perifrnttiffye Demegung ifter innern Theile Deutlich walgr: nimmt. - Das bounderbare (d)einct alfo nicjte fowobl

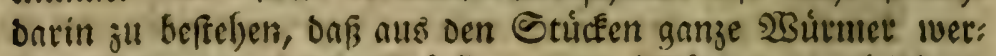
Den, fondern onf die Gtude ganze bourmet entbielten, oie ourdh oie faneidenoe bano oes Leobachters in frey: beit tamen.

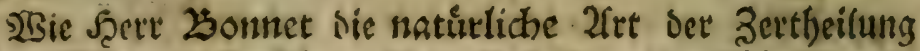

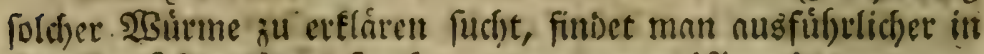
Den Confiderations fur les corps organifés. Art. 27\%. 


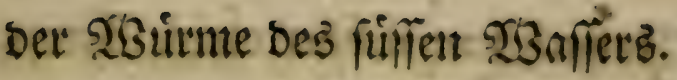

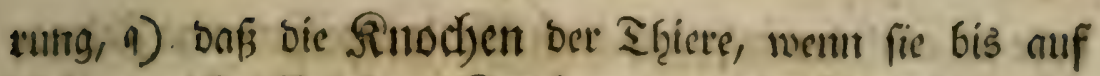
sinen gewiffen glumft jul Finochen gemorben fimo, nicht weis

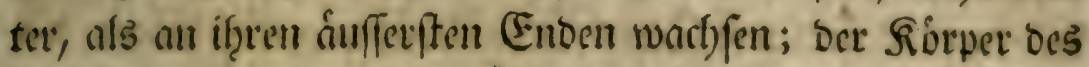
2Beins bleibt in biefer 2(bjict)t eben derfelbe. Wiele

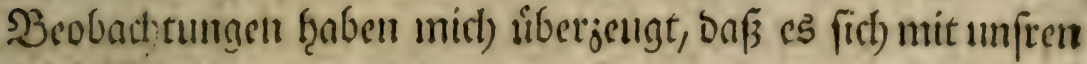
Trutrmen eben fo verţalte: Der Stamm, bas abgefdnnittente

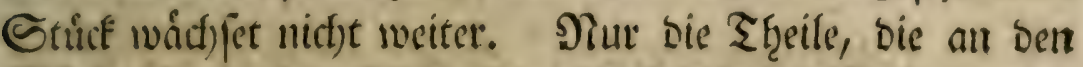

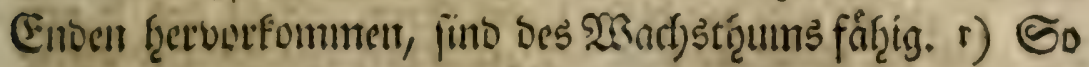
ग) 3 hृabe

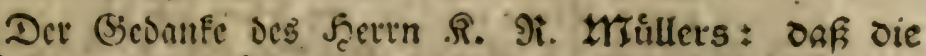
Stide ganje Witmer entbiclten, dic outch die fancis

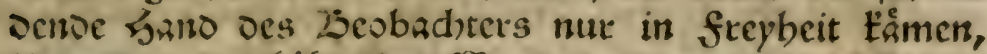
if grof, uno ethoffet Das ZBunderbate ungemein. Sonnte noet bagegen nidit erfitid eingenendet serben: Colte aud

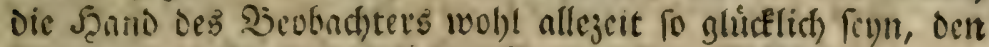

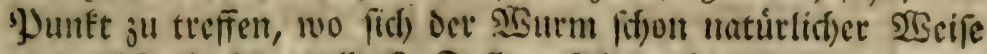
won le(b/t theilen wollte? Sollten fith alld) sweptens Damit

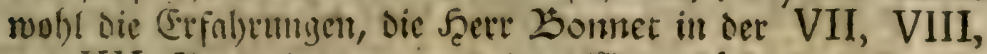

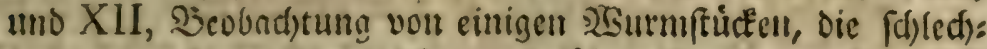

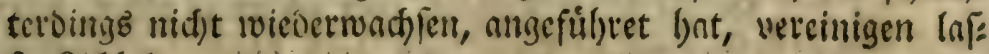
fen?: 1lcb.

q) La Stat. des Veget. de M. Hales de la trad. de Buffon. p. 287. Confiderations fur les corps organif. Art. 167.

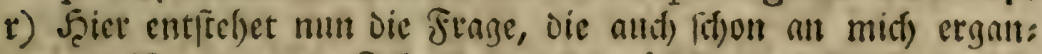
gen ift, wenn ber E(hwang wiederwád)fet, uno ourd) gewille

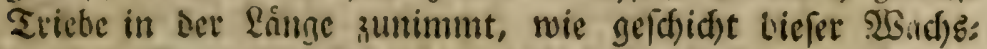
thum? STo ber Ednitt gefobelsut, entfefet eit fleinet

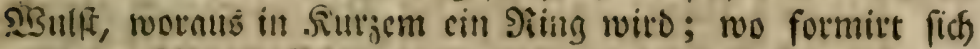

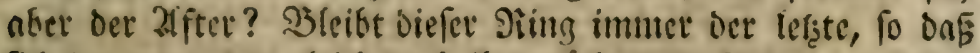

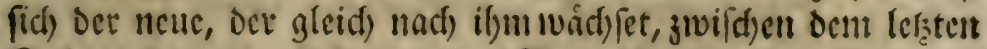
Scftionstinge, uno demjenigen Siinge formiret, Det unmittel: but vor dem ferning, ben er bey) feinet Entfefbung berifbete? Dier follte fich wobl ber neue siing auferfintb sem neu for: mirtell Simie bilben? *) Slan vetmutbet nid)t unted)t, Daß3

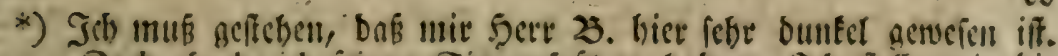

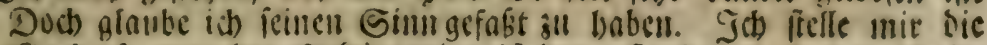
Gad)e jo yor: Der Eeftionerin iff ber erfie, ber an hem jerichnit=

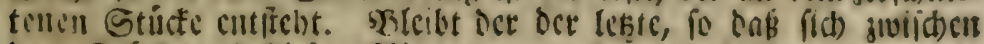

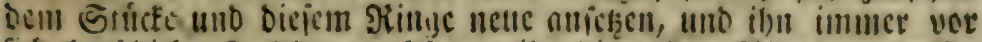
(iib) beritbichen? Doer madjen an ibn bie antern Ringe von anfer

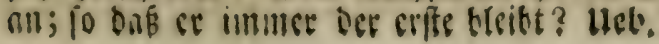




\section{Beobachtuntgen tiber einige 9 (rtent}

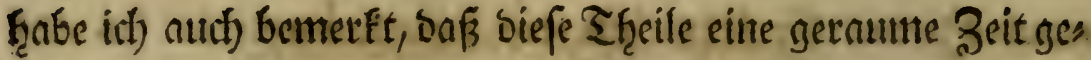
Eraud)ent, bie Farbe von jenem wieber jul befonmen. It)

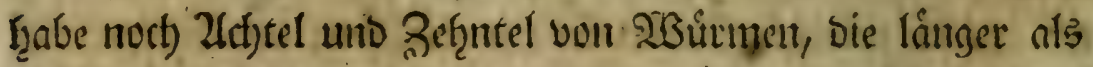

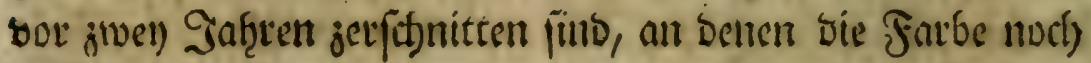
fetert Eermetlid ift.

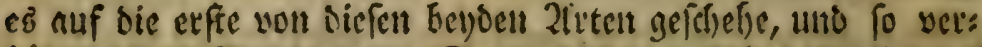
Gált fid) Die Sat)e aud). Daraus nbet entfrebet eine nnocle

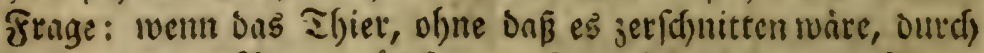

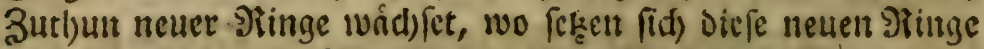

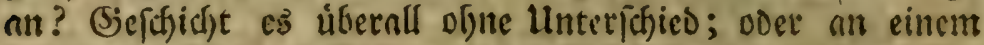

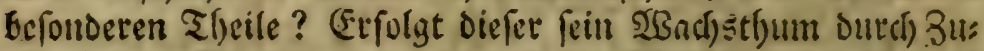
tfun neuct Siinge, oder nut ourd) Dic 2fubdáfmung oet alten? Diefe Frage zu ent/djeiben, muß man einen von biejen 2 But: ment von feiner Geburt nu, bis zul feinem vollfonmenen 2Sacjsitfum, aufgejogen, und in Diefen belyden ßुJerioden feinte

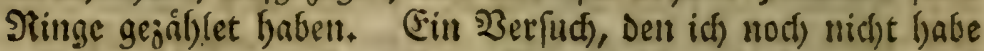

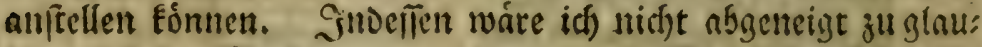
ben, Das Der 213 a

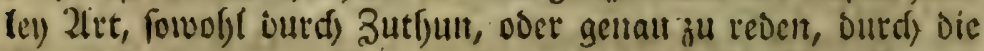

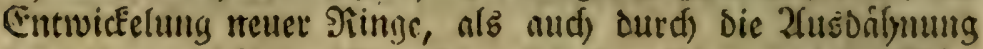

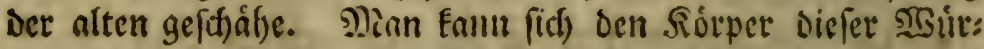
the unter Dem Silde cince Staflffeder worffellen, Die in einet

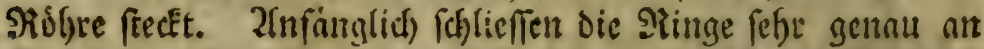
cinander: allmäliy entfernen fie fid); und auf biefe 2trt muf

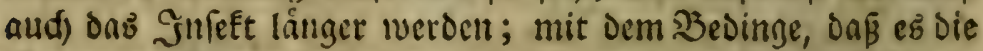

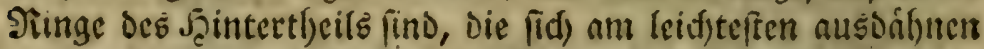

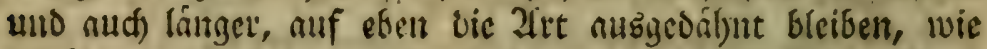

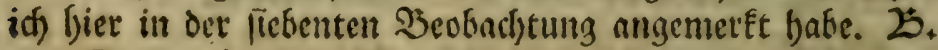

Diefe grimolidje 2tmmerkung Des Serrn Derfaffers voll: fténbiget und verftánolid)er ju mad)en, will ich oamit die (Sie:

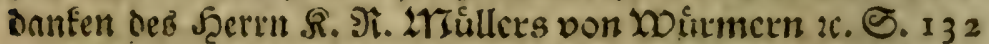
vergleid)en: "Oct aufmetEfame 25onnet tourde bereitb vol

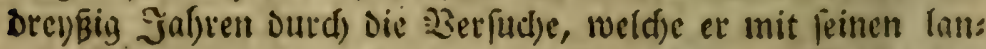
gen $\mathfrak{G u t m e r n}$ unternafm, vetanlaffet ju fragen: Gefdjicbet

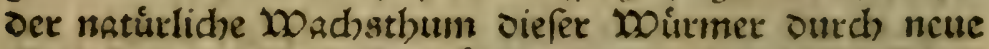
Gelente, ooer outd) 2lusofilbunng oct alten: Die frnge

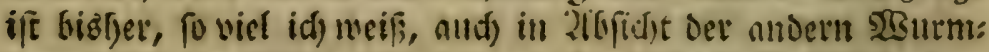

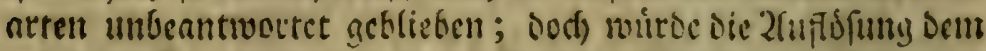

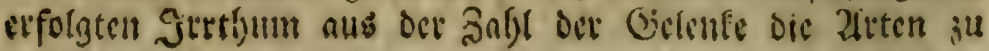




\section{Sidfte Beobad)tung.}

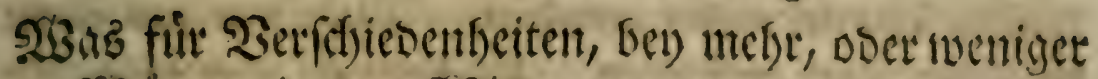
SGairme, in Der siBiesererneututh, und in Dent

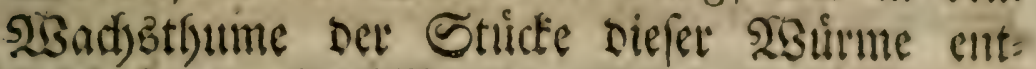
ftefent?

\section{Serfucte nit Diejer Sadje.}

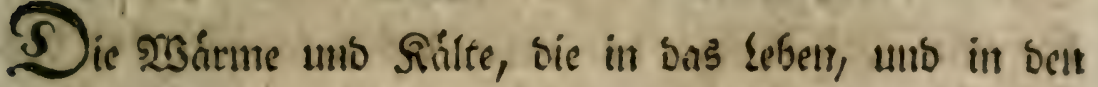

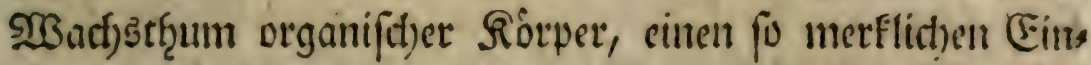

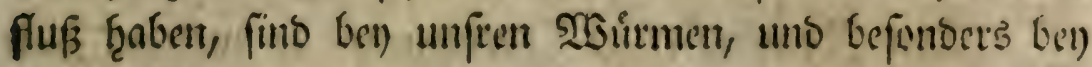

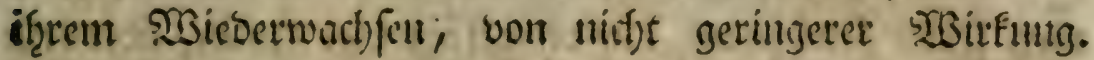

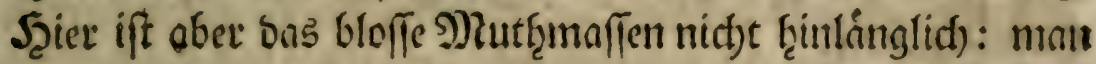

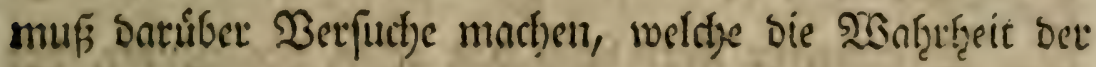

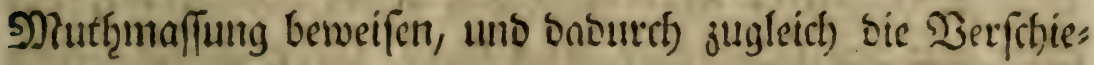
Denţeiten jeigen, bie nus biefen benden entgegenfteţenten ¿erţälttuiffer entfpringen.

Diefe 2(bjict)t ju erreichen, umb aud) ju verfuts)en, ob

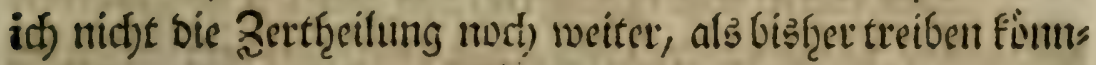
te; fo jerfidnitt id) an (Enbe bes Jamuars 1742 jwel) meis

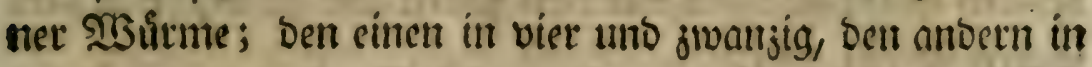
fect) uno junatigig Stúcfe. Sener wat nแร bem erften D 4

Stů:

beftimmen, vorgebeuget balien. Ee wutbe fie felfft aufaeld: fet baben, went er nid)t onrzus mebre erforbett bátte, als in

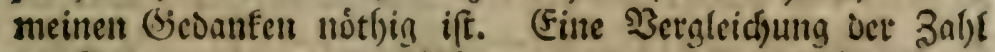

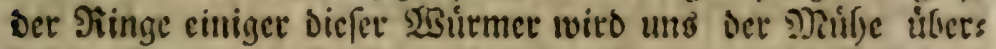
beben, fie, um die jrage gu beantmorten, von if)ret (jichurt an, biß zum vólligen $2 \mathrm{E}$ ถd)

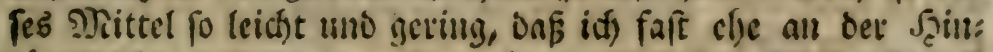

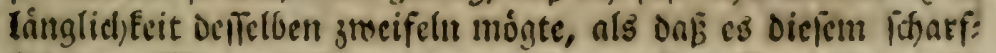

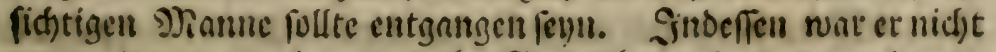

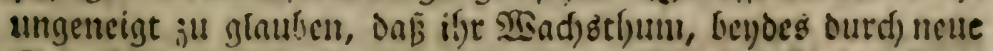

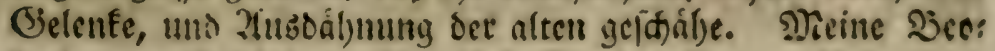

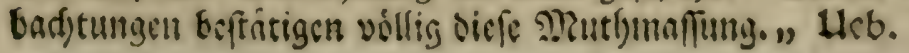




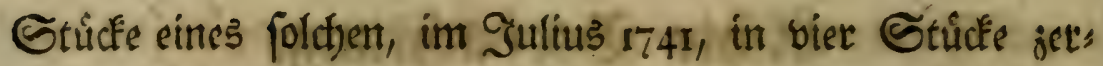
theilten 2 Surmts wiebergewarbjent. Diejer war aus cinemt

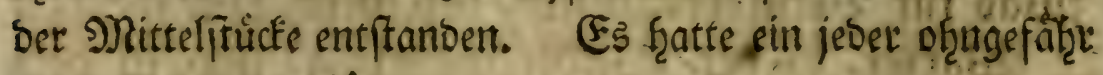
ziven Boll in ber sánge.

Nur nach) ber Mitte bes Mairz f̧atten bie folgenbent

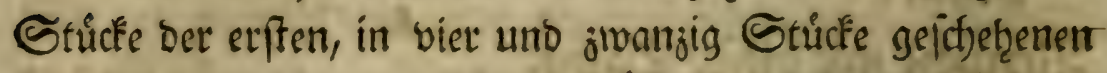
T ţeilung, angefangen, firf) jull ergänjen, nemlich bes fects ste, Das act)te, Das neunte, bas eilfte, Das obrenjefente uno Das pectjojelente.

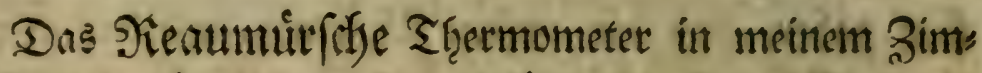

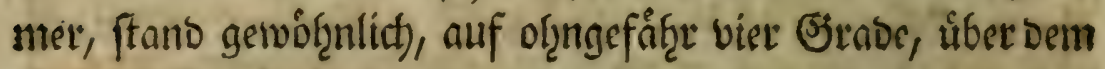
Jefrierpunfte.

Den britten 2(pril f̧atte bas ad)te, Das neunte, bas

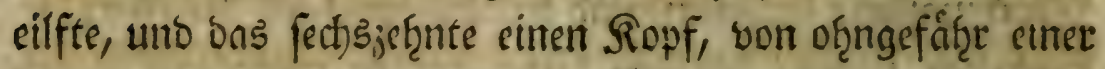
ḩalbent sinie nieberbefommert. Er war rect)t gut gebilbet, Der Sthwang aber war fúrjer.

Den eilften war bas vierte, bas fünfte, bas fiebente,

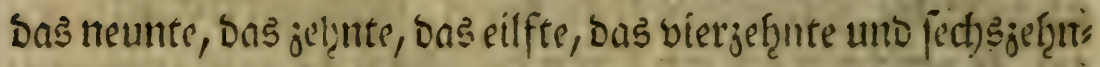
te nort) vóllig am twaren fie alle toot.

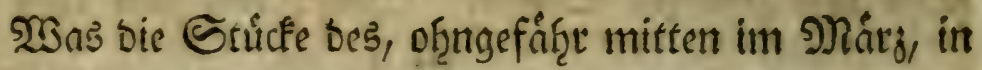

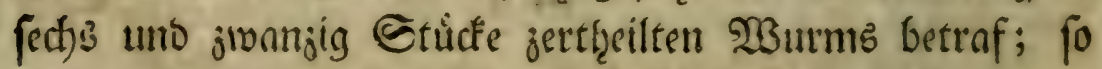
hantten folgente, als bas givente, bas britte, Das vierte, Das.

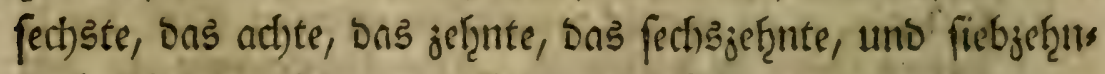
te, bereits angefangett, vollfommene Şgicre ju merben.

Dent britten Ifpril hatten einige, als bas vierte, Das

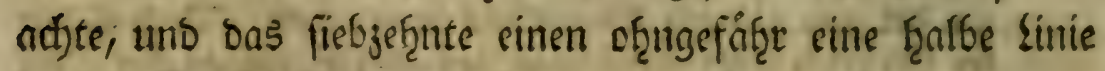
langen ßopf bifoummen.

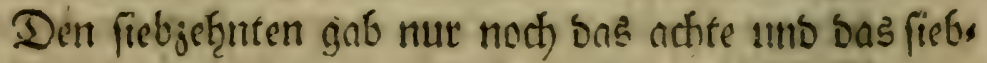

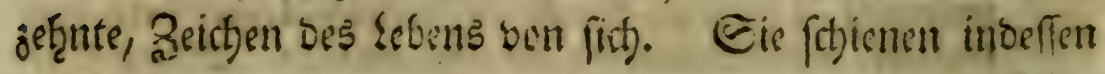




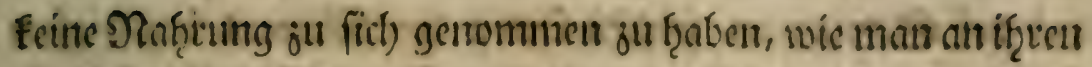
Durtbfichtigen Eingemeiden erfennen fonnte.

פachoem ich orn Erfolg Der benoen vorţergetzentoen Serfuche befdrieben, bie in Den SISintermonnten angeftellet waren; fo will idh jefert nod) sitten britten angeigan, ber in

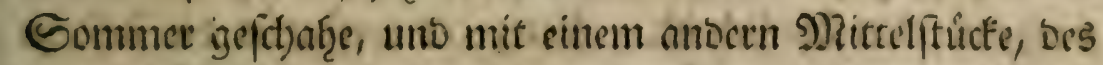
in vier Sgeile jerflchittenen 23 urms gemad)t war, welches felfift Den oritten Juliub in fed)s ant jwanjig Stưcle jes" theilet worben.

Den Drenjeţnten fॄntte bas britte, bas vierte, Das fünf" te, bas fed)ste, Das neutute, bas jef̨utte, bas silfte, uno bas amolfte cinen ganjen Ropf und Sthwanj swicoerbefommen; Den fect)s uno jwanjigften aber nåfeerte fich) tur bas fiebente, Das jwanjigfte, und Das jwe1) unt jwanjigfte Dem Zuftante

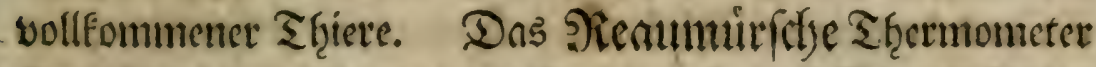

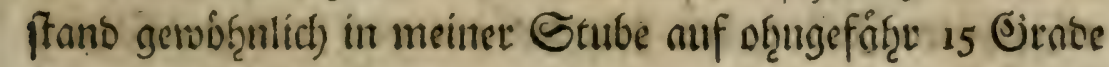
uiber Dem SEefrierpunEte.

In diefem Sage fृatten cinige, als bas britte, bas vier:

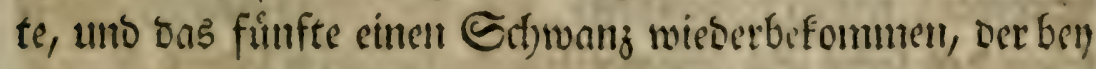
einigen cine, ben anbern, anbertfralb sinien lang wat.

Das jwente, Das fumfjeţute, bas (ed) sjeftute uno ad)t:

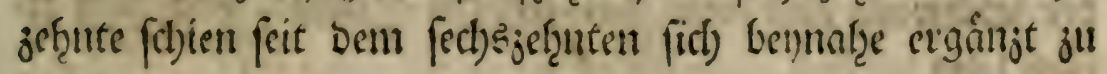
hraben.

Die anbern frarben, ofene fich erneuert juf grabull bie meiften aber vor Dem funfoctenten.

Wir fetzen alfo an biefen Derfuchen, bafider Gommet

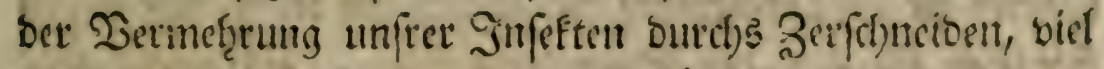

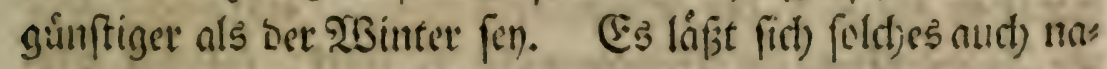
tirtlid) vermuthen. Mitd)tsbeftoweniger ift es an Bemi, baf; f̧ier viele ansere llmptánbe, auf bie man sben nicht nufmerf's foun ift, cinen Einfü haben foumen. E\& fom jum Erems 


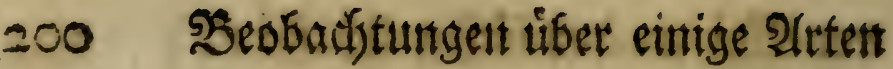

pel ber Sthnitt an foldfen Detten bes Rörpers ben biefem

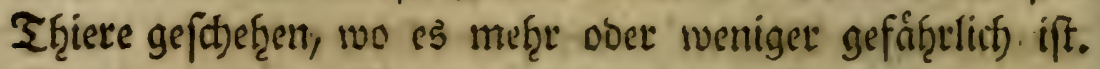

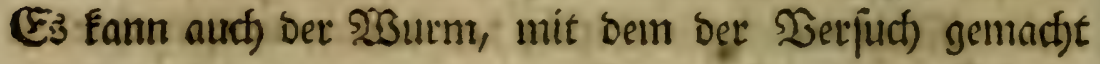
soíto, mef̧r ooer meniger im Stantoe fenn, ben Echnitt ausjubzalten, als cin anoerer, Der į̂m fonft Dem áufferlicfen

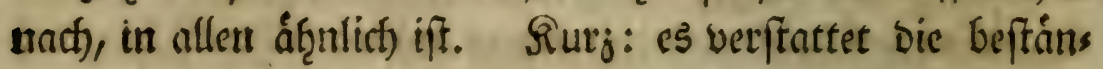

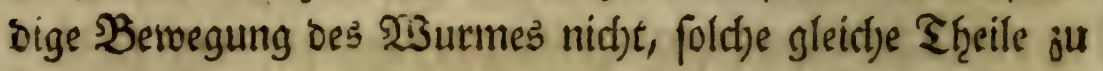
macthen, als man will; cine llngleid) freit melthe bie Duelle

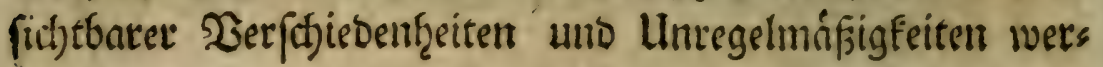
Den fantr.

Dem fen aber, wie ir̨m wolle; fo iff ţier nod) ein Bets (uuch) mit biefem (E)

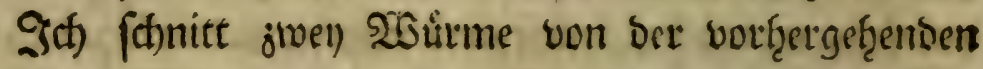

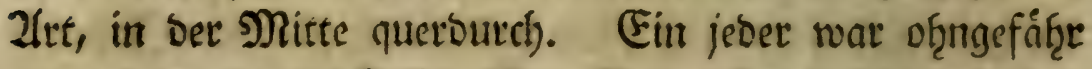

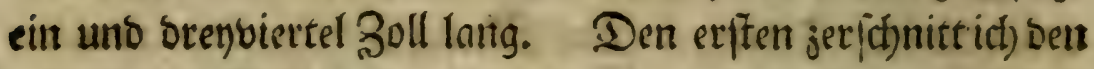
ad)tjef̧nten Sullus, Den jwenten an bier uno jwangigften Jamuar.

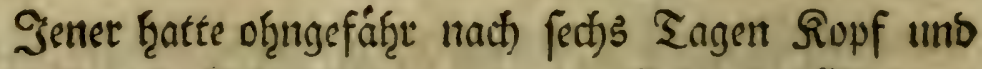

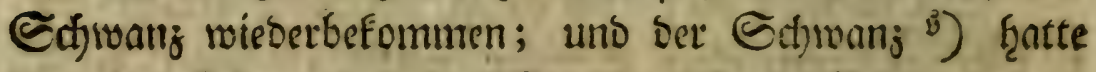
fHon ben fect)s uns jroanjigften 2luguft jefgn sinien.

Diejer ḩatte fith ben jivólften Februar völlig ergántit; der Sdywanj nber war ben jef̧nten Sunius, exift jef̧n sis . nien lang.

Zluffer benten bereits oben angefưf̨rtten 23 irfungen,

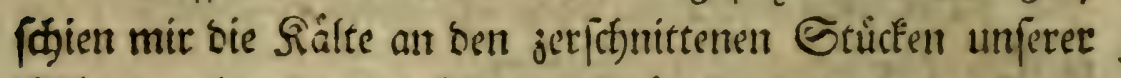
20 ürme, eine anoere fef̧e metfwúrbige Gervorgebrad)t ju Gaben: fie blitiben nemlich) viel lánger am teben, als in ben ftárffften Braben ber Sommervóarme. Lluffteisig mar

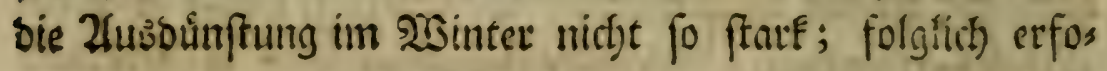
Derte

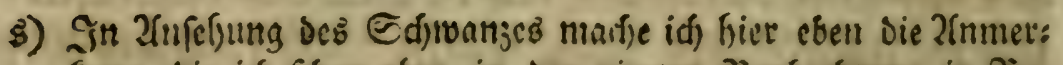

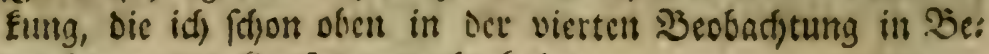
tradjtung bes Sopjes gemadjt babe. 


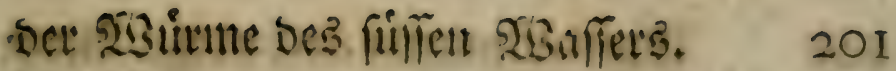

berte fie aud) feeine fo ftarfe (Expersung, als in ber wámeren

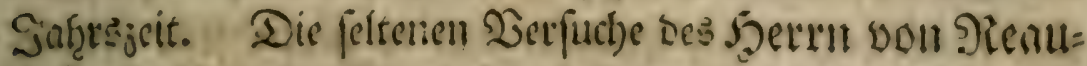

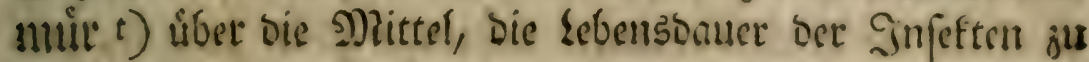

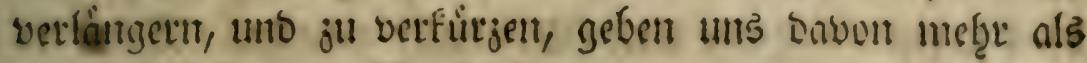
cine ?lit befonoerer Benjpicle.

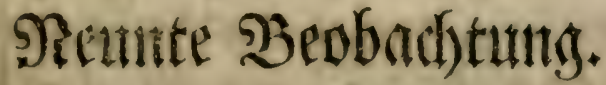

\section{Seobad)tungen und Zerfuthe ciber Die Sirt, wie Diefe Saburme ward fen.}

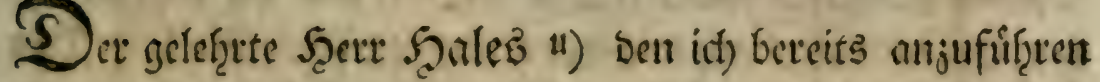

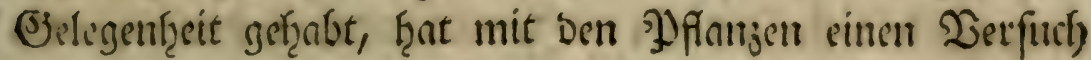

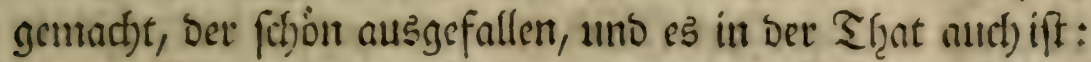

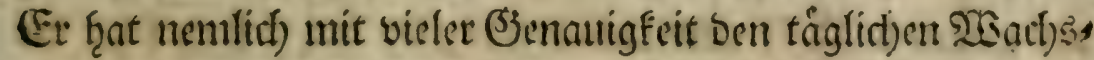

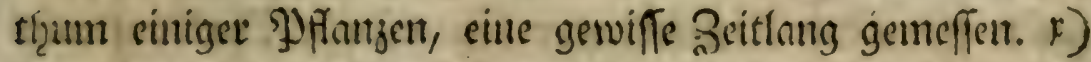

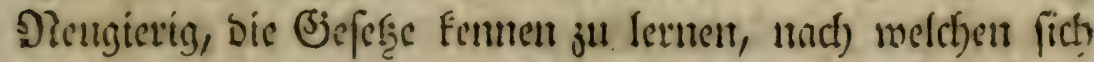

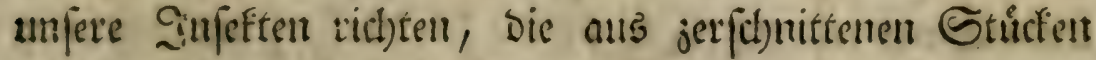

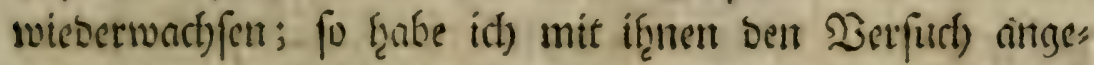
ftellet, Den id) je(şt bejt)reiben will. Sid) frabe nemlith cine

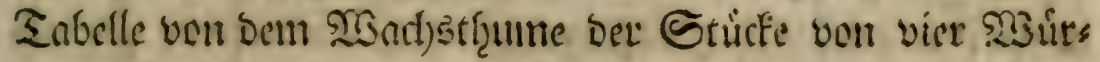

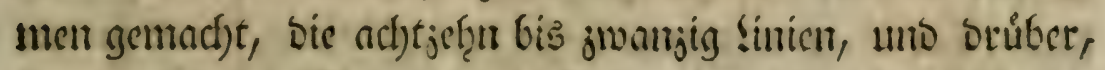

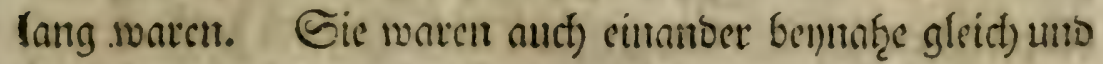

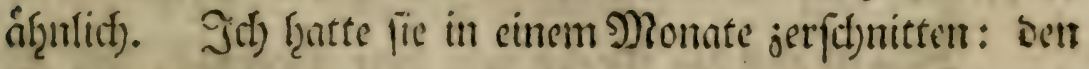

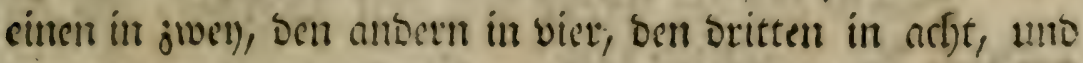

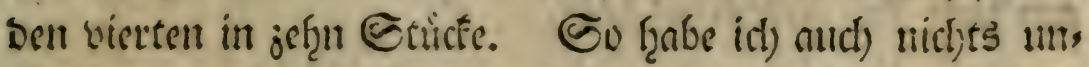

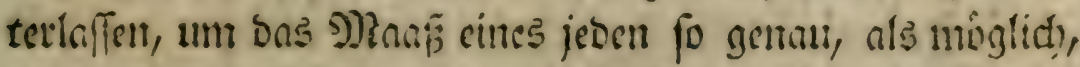

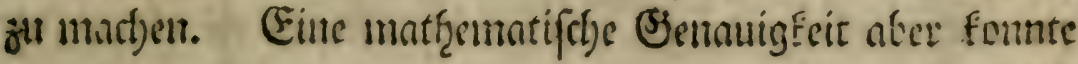

t) Memoir. pour l' hift. des Infeet. Tom. II. Mem. I.

u) Stat. des Vegetat. p. 280. f.

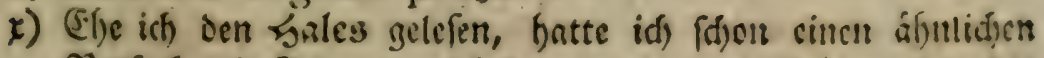

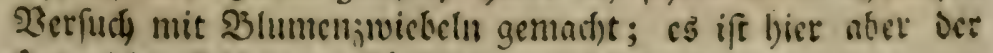

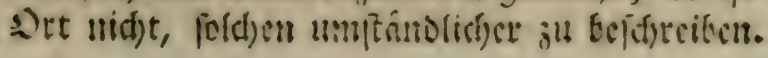




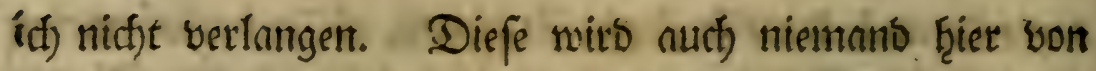

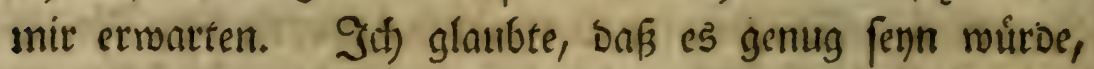

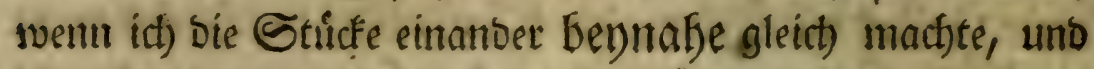
eben fo ḩat Der Scerr bon Rieaumurir gebacht. Denn es

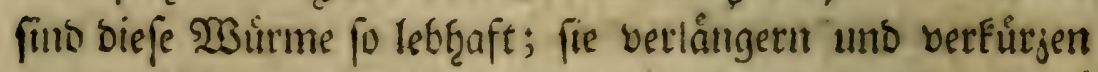
fich mic fo vieler Befformintigfeit; fie falten fich auf fo vies lerley) Zlet zufammen; Eurs, fie firto fo jart und empfinolict),

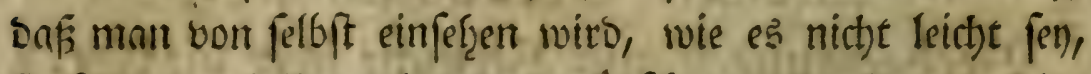
fie fo ju jertfectien, nls man wünfthet, unto als man eine

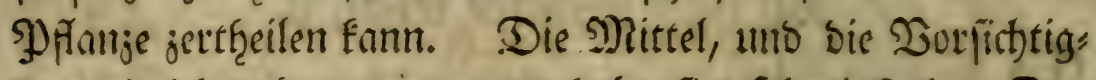

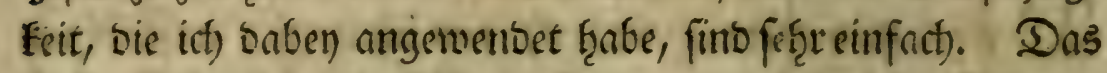

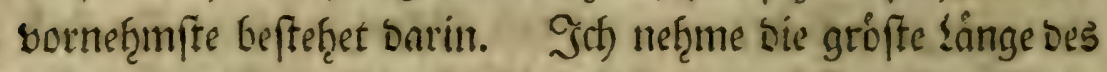

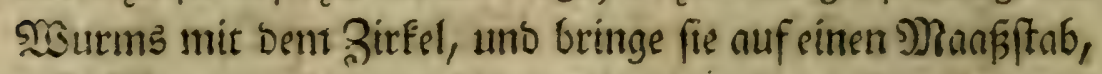
Der genau in Zolle uno Simien getheilet iff. Sidh fage bie

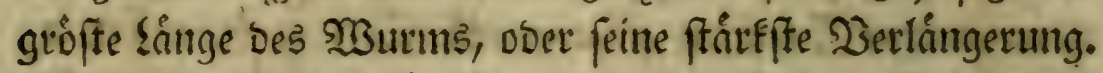
Diefer Zfusorucf fidjen mir an Deutlidjfent ju fenn: weit

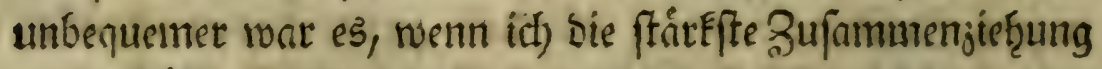

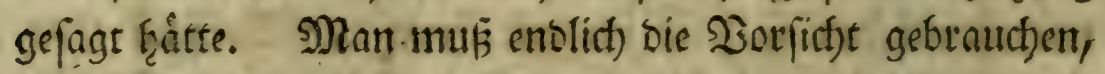

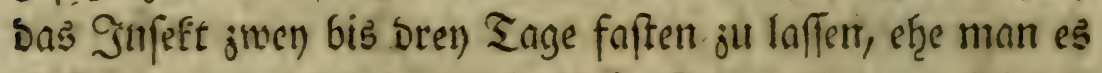
miffet: es wirb fict gemie in biefer Zeit nusleeren; folglid, fann man Daran basjenige beffer untericheiben, was zu Den

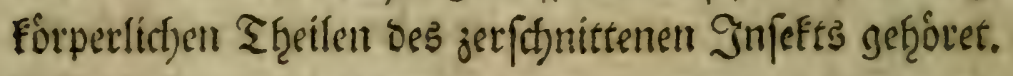

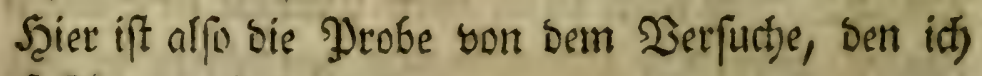
auf biefe ?rt angeftellet trabe.

In ber naidffiten Tabelle felloft, wie aud) in ber brits ten und vierten f̧abe ich), um bie 2lobition ju erleich)tern, bie Mronate ju brenfigig, uno ben Gebruar zu acjt uns grbanjig Sage geredjnet. 


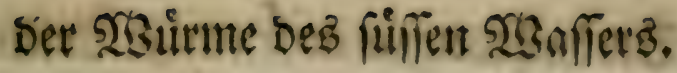

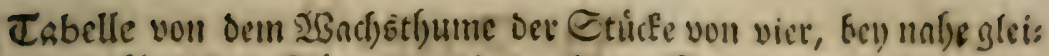
d)en uno âfunlidjen SGúrmen, Die in cinent Dionate: Der eine in 2, Ber andere in 4, Der britte in S, und bet vierte in so ₹lgeile, zer: (d) nitten roaren.

\section{Sil 3wey. A. B. \\ I. 2 .}

3eitraum. XVIII. Julitis $174 \mathrm{I}$. Dperationstng.

Mronat | Tage.

6

XXIV. Jultus.

Sopf bon B. - Sct)wanj volt A.

5

XXIX. Julius.

I I

7

I 8

Sopf von B. (er hatte allfge: hórt ju wach)(ent) Schwan von A.

8

Sovf volt B:

Scfwanj von $A$.

V. 2luguft. XIII. 2luguff.

26 Schroang von A.

I 3

9

Schwam voll A. XXVI. 2fuguft.

I

25

Sdjwanj von A.

XXX. OEtober.

St)wang von $A$. XX. Rovember.

$2 \mathrm{I}$

Sctwoni bon A.

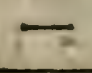

Lange Der toies Dergeruadjenen

Tbeile.

3ulle. finien.

$\frac{\frac{\pi}{2}}{\frac{1}{2}}$

I

$I \frac{T}{2}$

I

5

;

8

IO

4 SJt. 5 S. Det feit Der ¿peration vergangenen Deit. 
204 2eofacftungen uiber einige 2rten

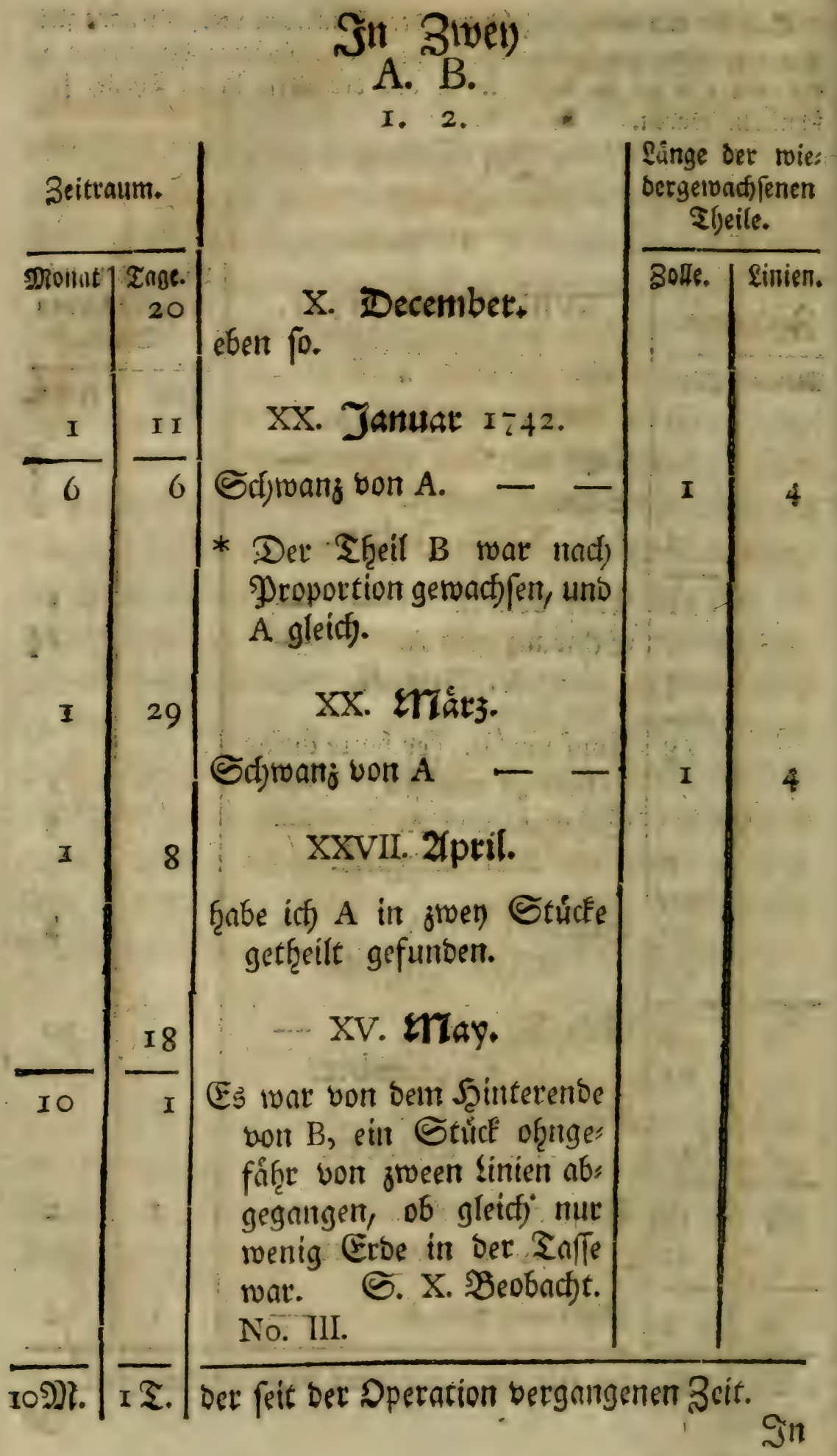




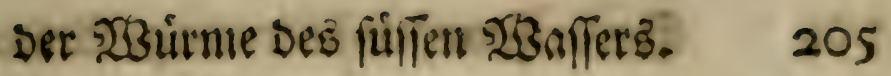

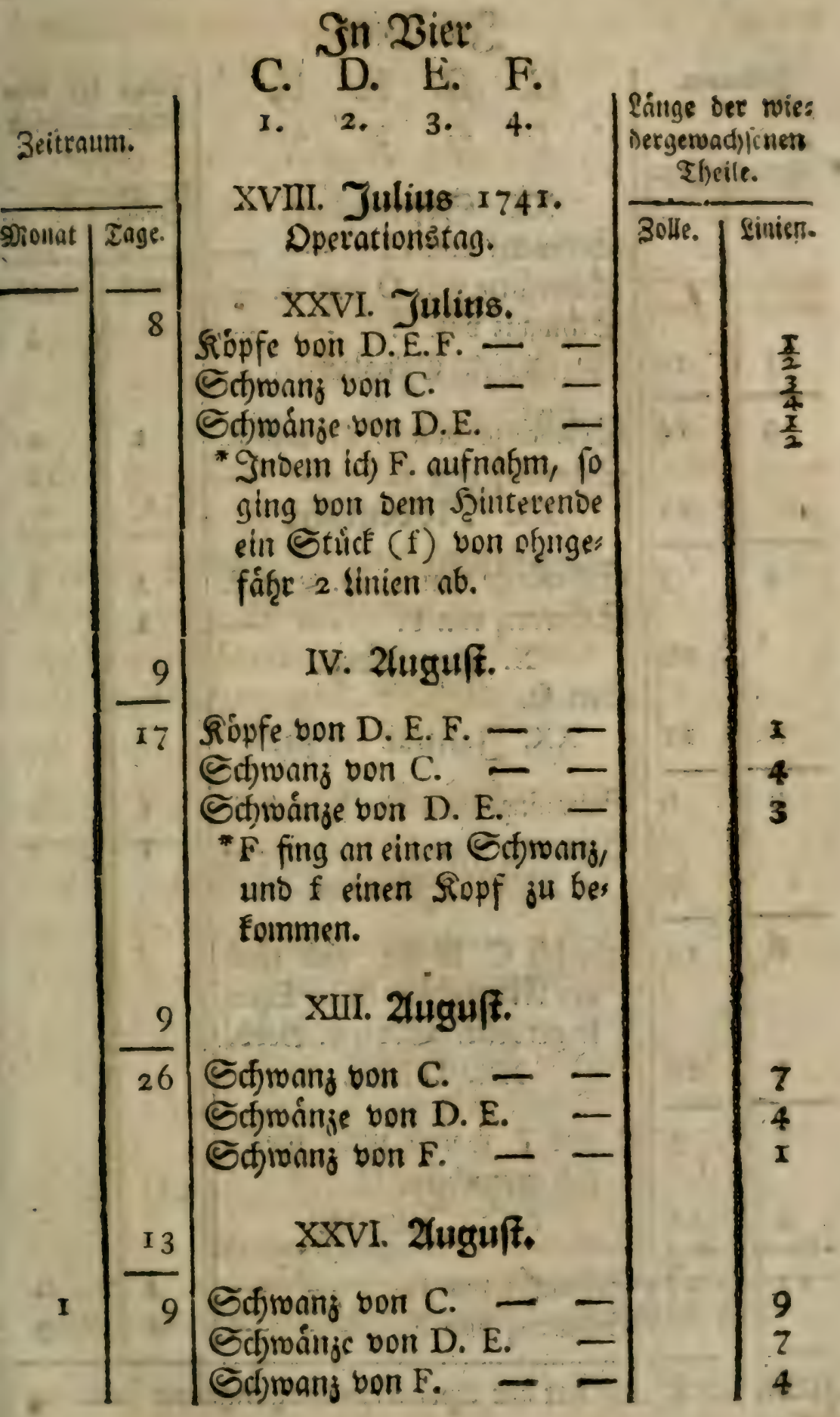

Sin 


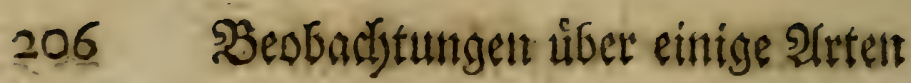

In 3 ier

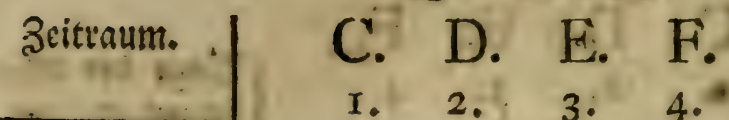

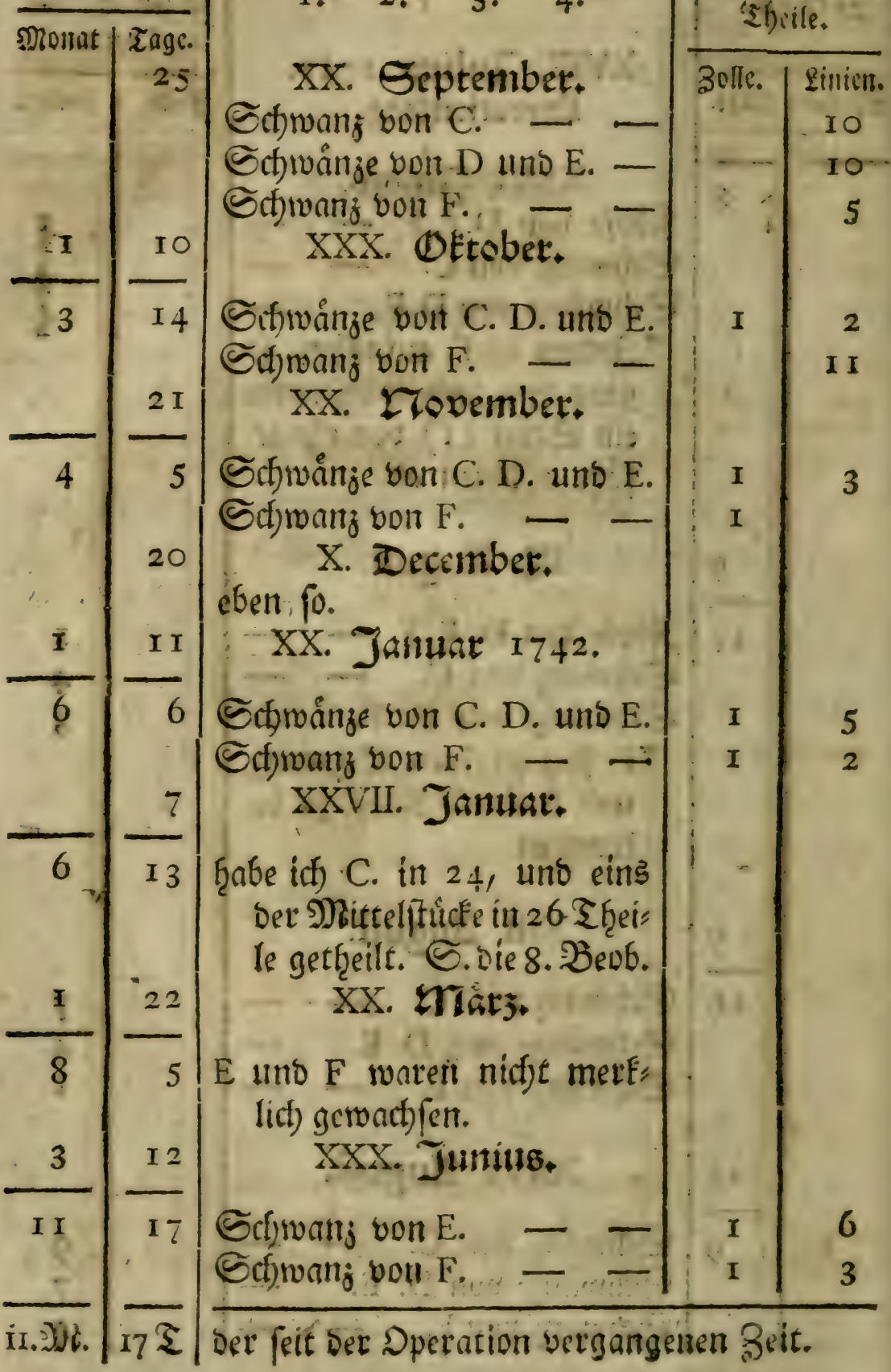


Sn $\mathfrak{3 i e t}$

C. D. E. F.

1. 2. 3. 4 .

Seitrnum.

פionat | Tage.

3

Ţabe idf) E. it 26 Stúcfe jer: theilet. S. Die 8. Şeob.

XX. Iulius.

war $F$. nicfte fonderlidf ges wadfert.

\section{Julitis.}

x. 2fugu任. eben fo.

3

war von bein Şinterente yon F ein Stîck von of̧ngefáf̧r 4 Sinien abgegangen, wel: ches ben 14 . auffiorte ju leben. Id) habe in Der Salfe feime llejact) Diefers Bufalls entbecfen fennen.

824 IV. Emay I 743.

F. in Sanjert.

\section{2luguft:}

Einge ber wis: Dergetond) ienen

Tbeile.

3olle. $\mid$ sinicu.

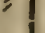

Der feit Der Dperation vergangenen 3eit.

.

Sontmet 2. Tf.

ऽ

Eit 


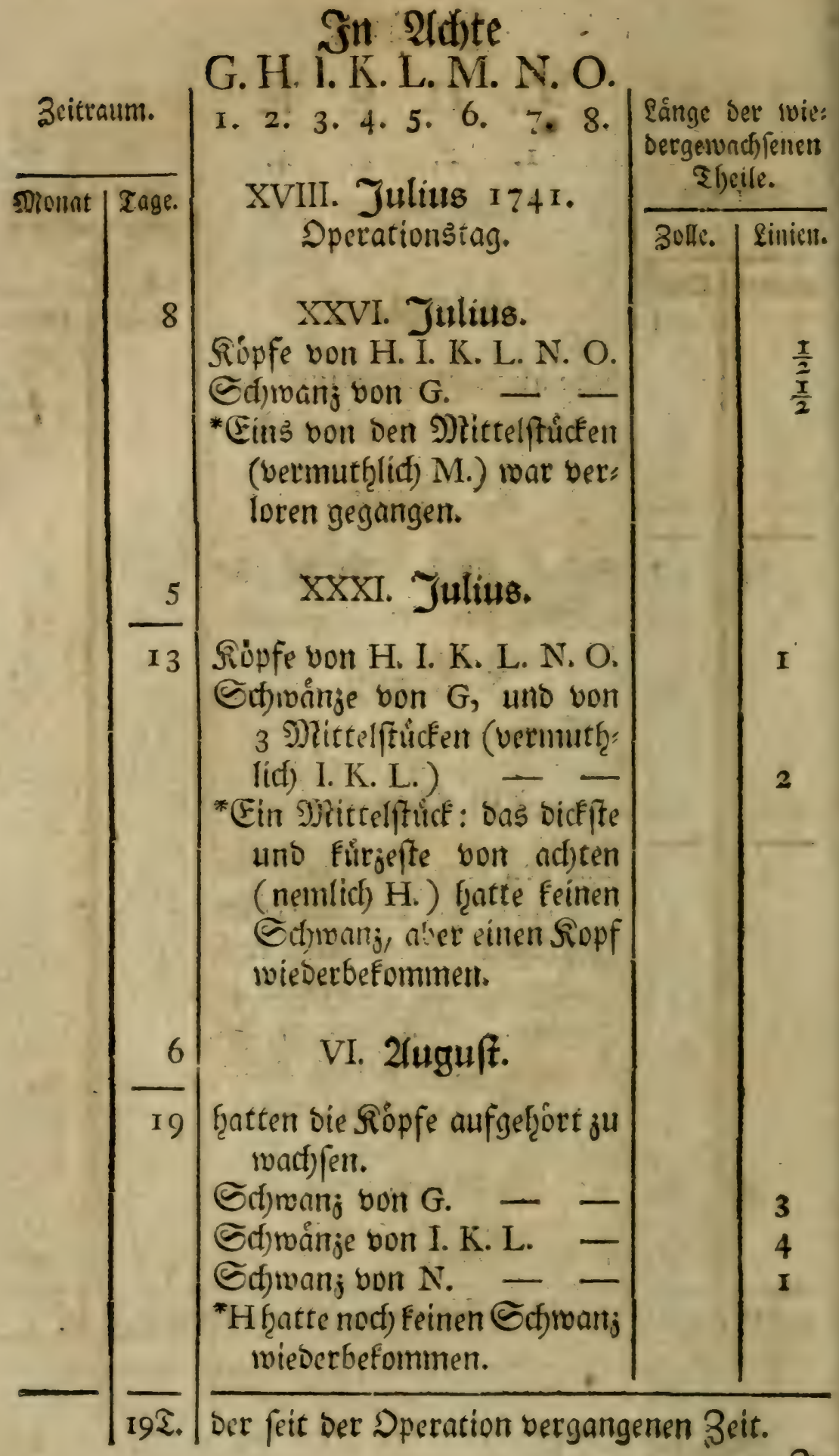




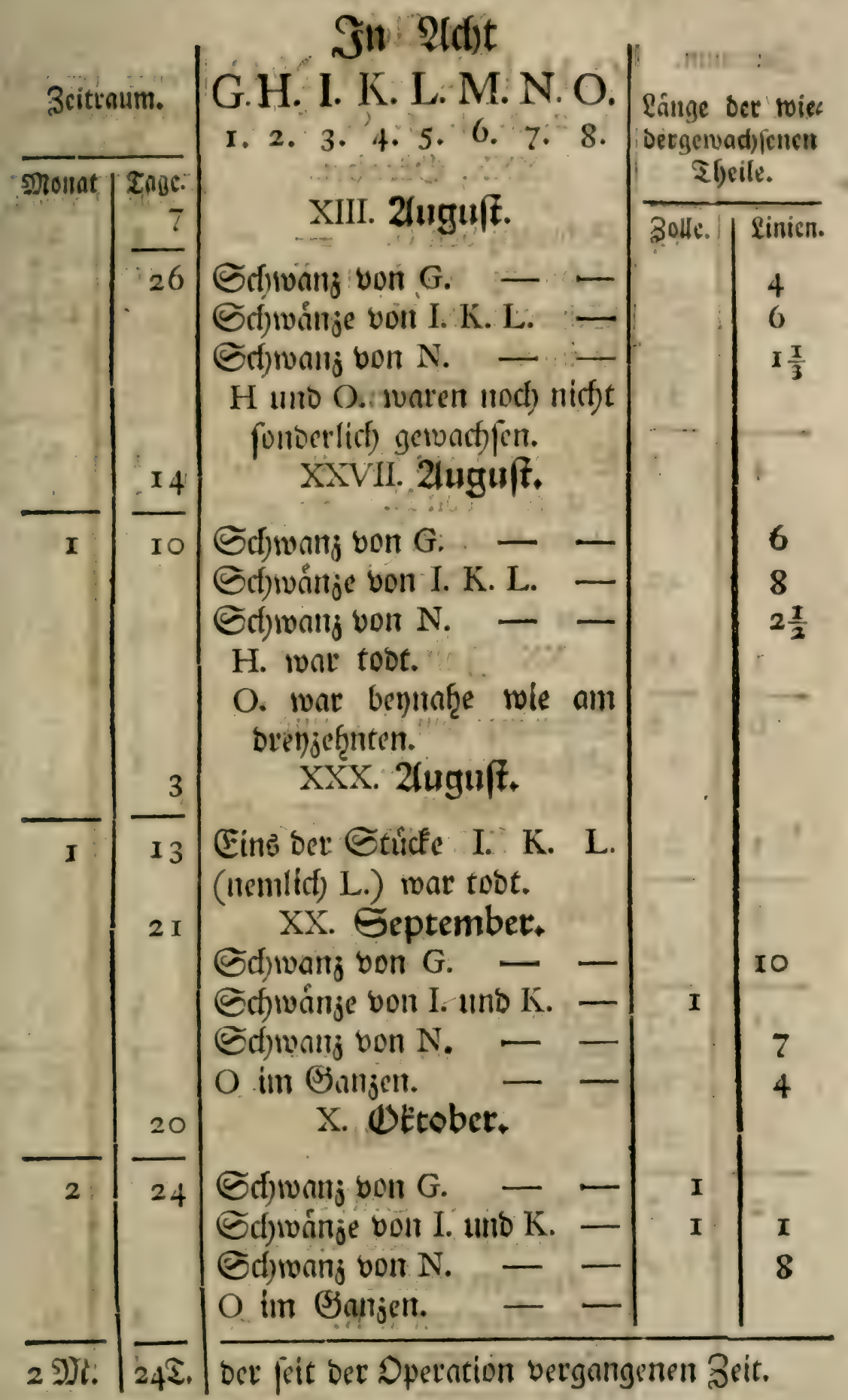




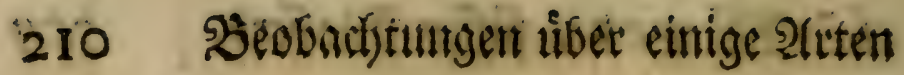

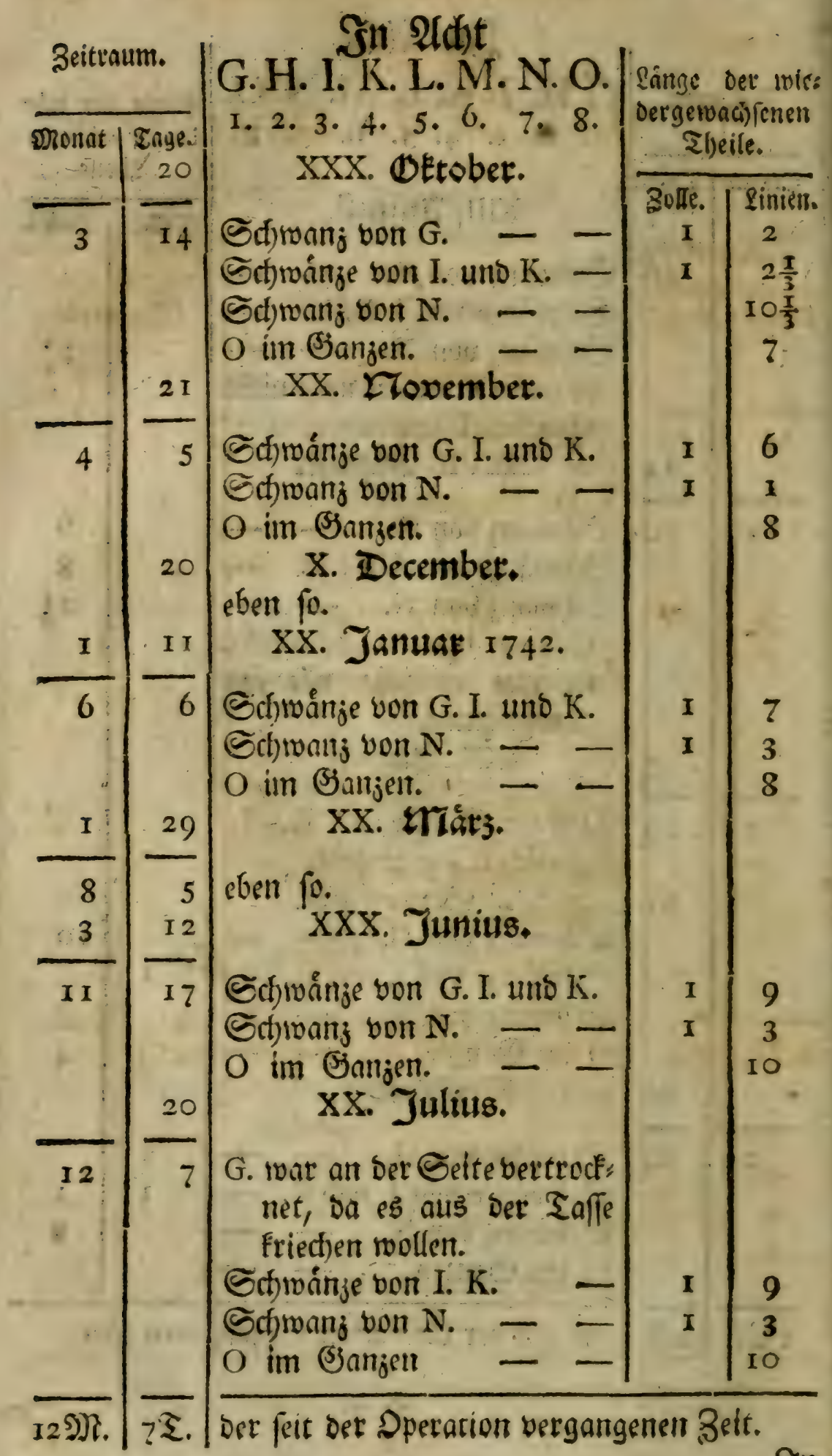

In 


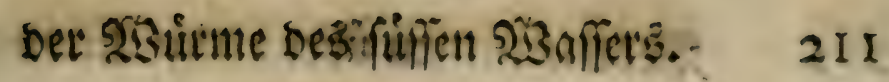

\section{Sn: $\mathfrak{A d}$ t)}

G. H. I. K. L. M. N. O.

I. 2. 3. 4. 5. 6. 7. 8 .

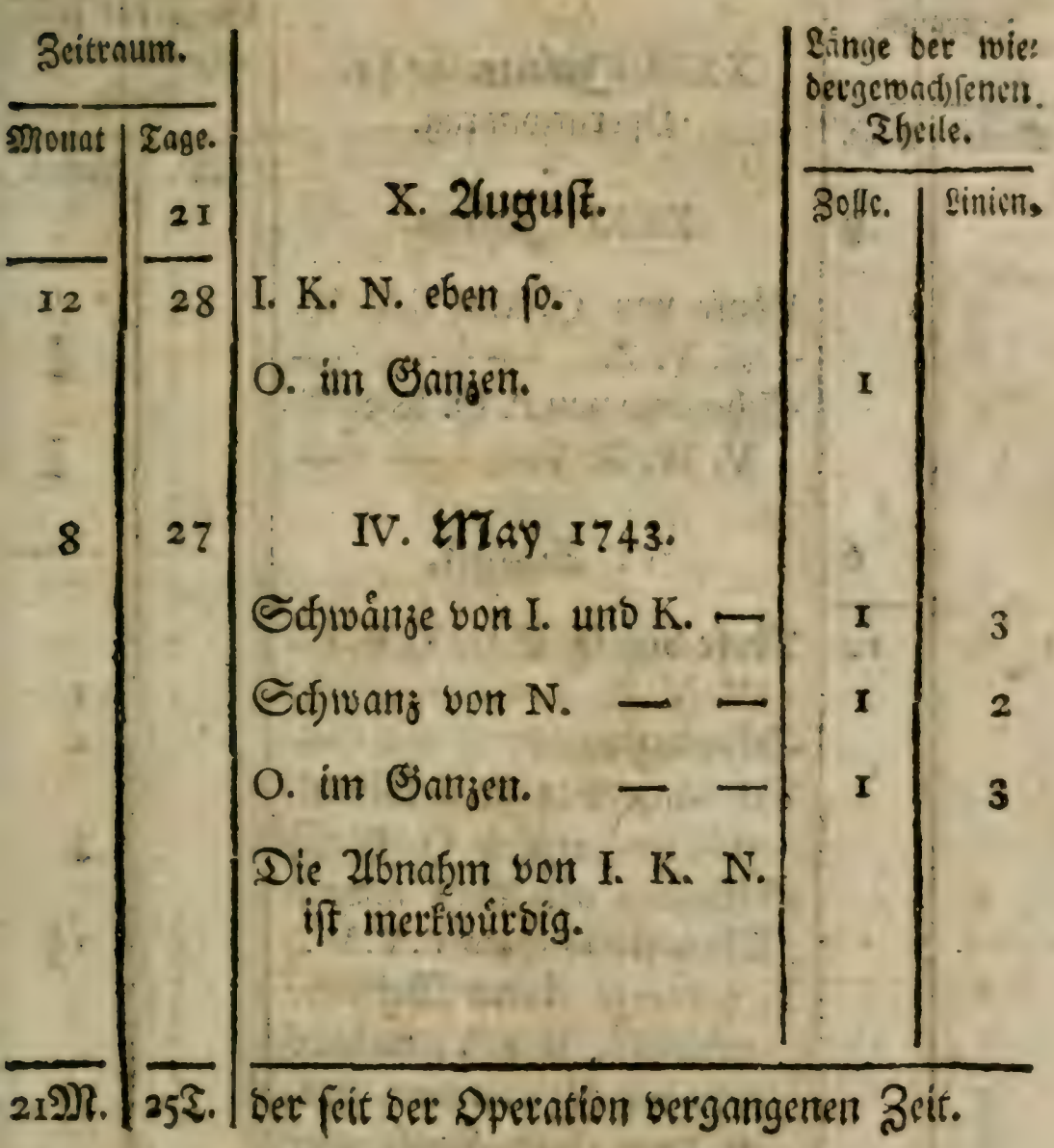

D 3

Jin 


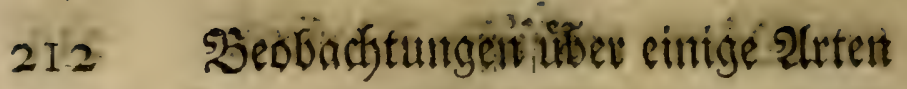

\section{In: 3 eth}

\section{P.Q.R.S.T.N.W.X Y.Z.}

$\therefore$ 1.2. 3.4. 5. 6. 7. 8. 9..10.

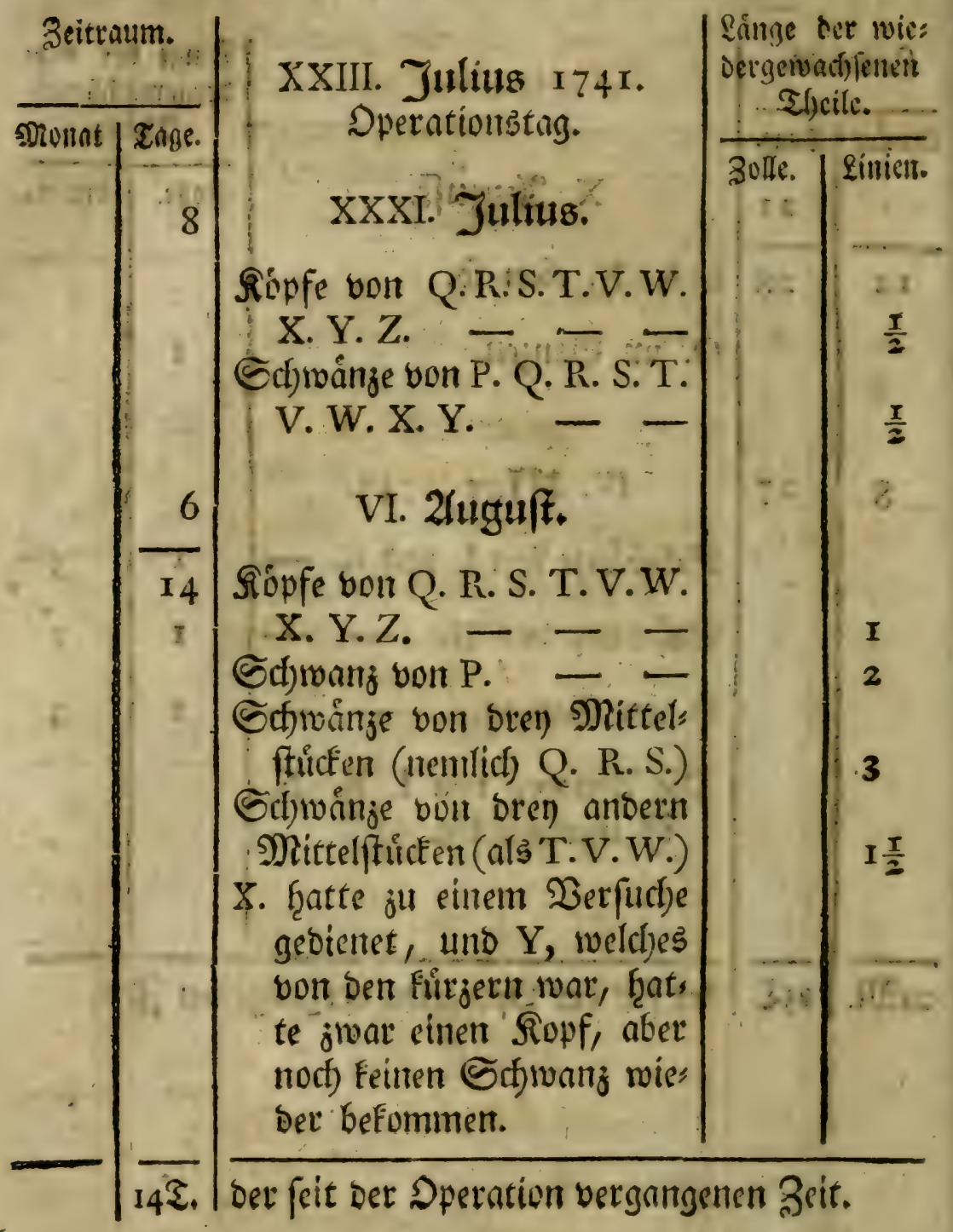




\section{Sn 3effin \\ P. Q. R.S.T.V.W.X.Y.Z.}

r. 2. 3. 4. 5. 6. 7.-8. 9. 10.

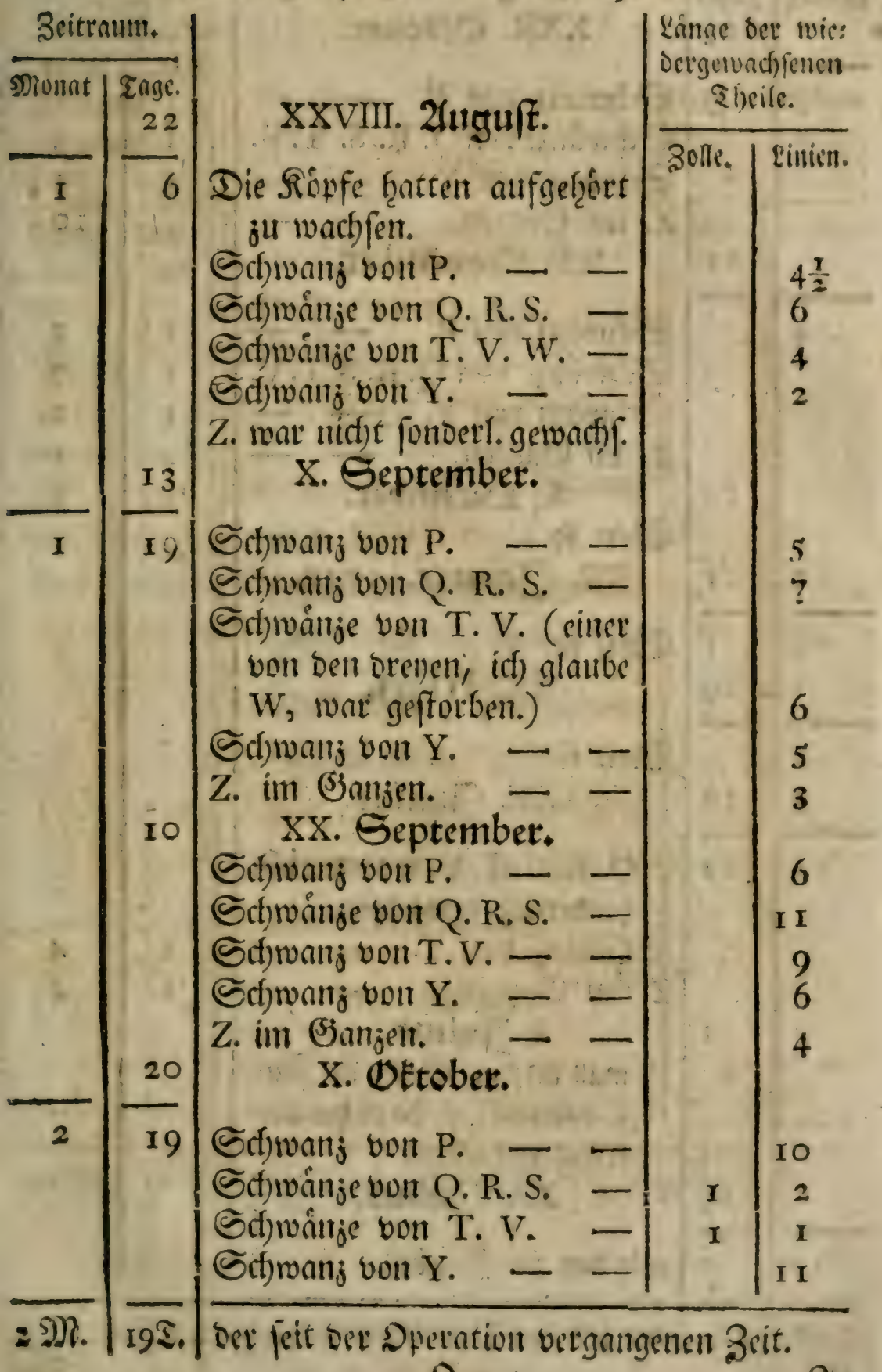

$$
D_{4} \text { In }
$$




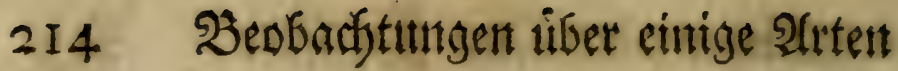

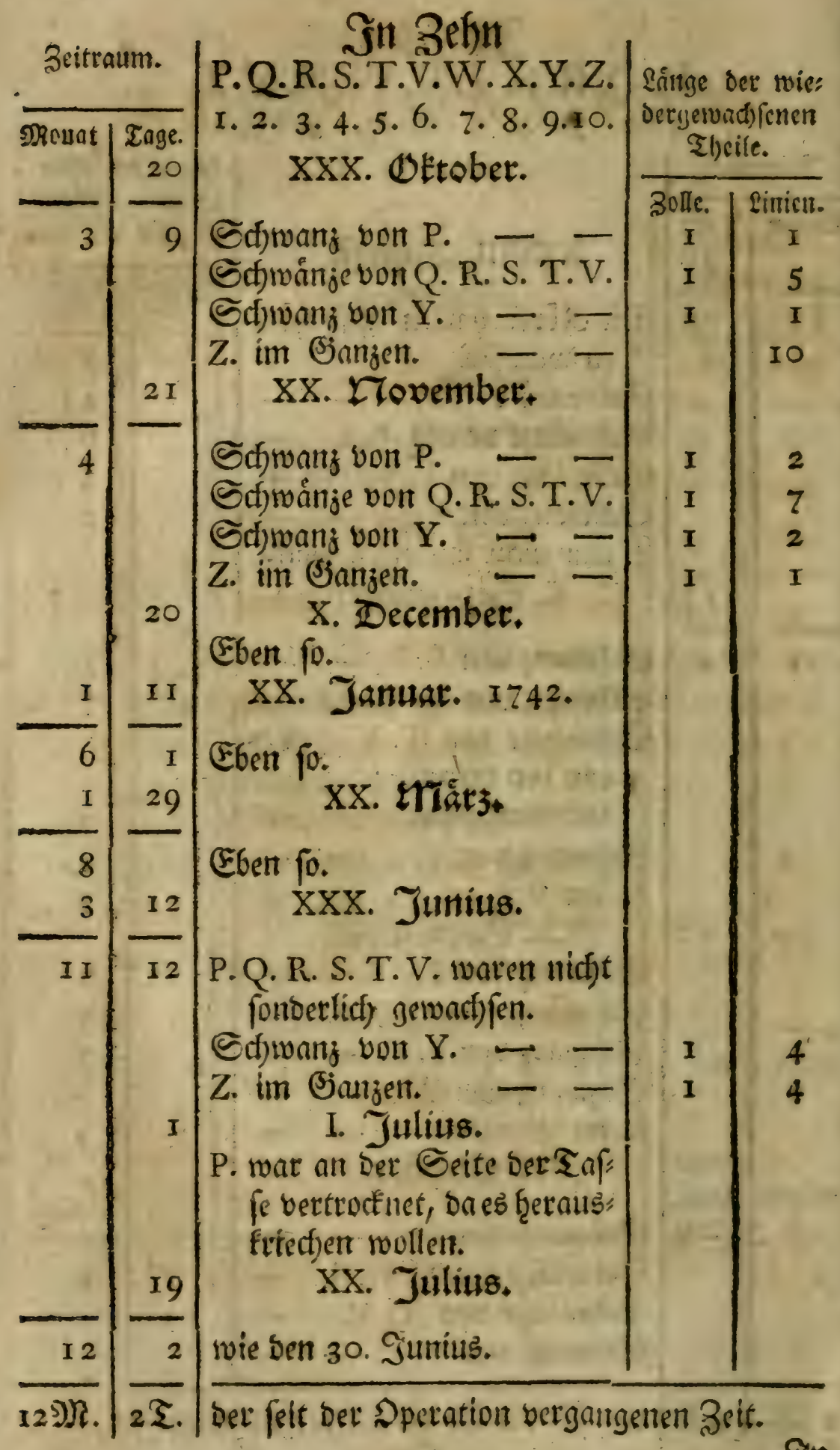


216 Seobachtungen tíber einige शrteit

\section{2nmerfungen uiber die erfite sabelle.}

S. will hier bie Schmierigfeiten nidft miebertrolent, bie

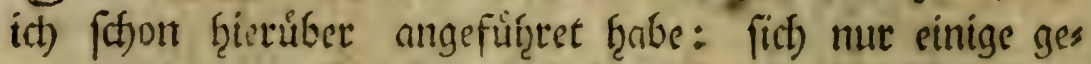

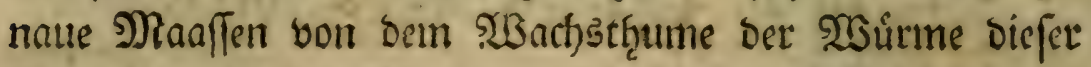
Znet ju madjent. Nan wirto fict) erinnern, baf́ ich) fie auch mur bennafye genau fabe macten wollen. Es fen aber in biefer Tabelle ber Grad Der Senauigfeit, wie er wolle; fo fiffeint es mit bodh, bas bnourch wenigftens biefe brey) Eáfe beftånitiget werben.

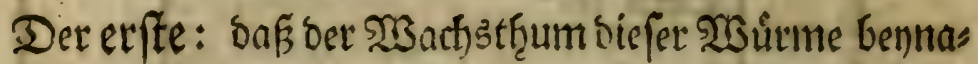

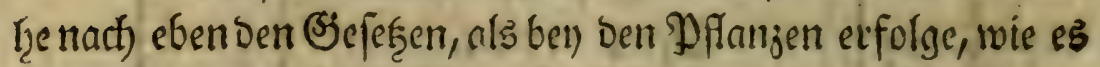

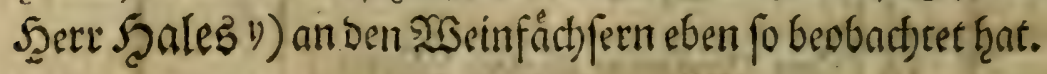

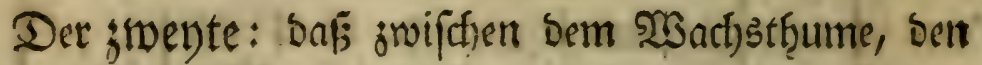

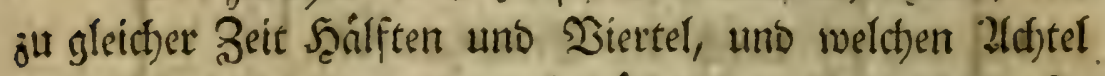

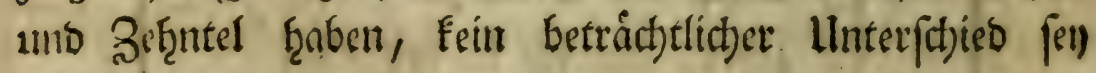
(IV.'Beob.)

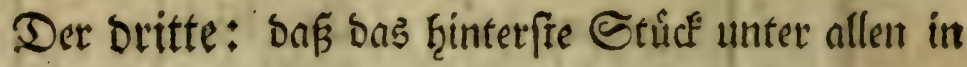
gleidfer Zeit am wenigften waddfet; nach Demfelteen aber

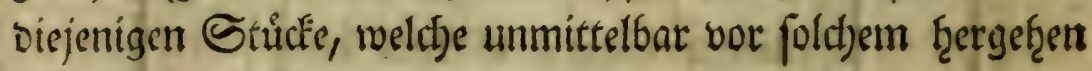
(IV. BBeob.) *).

y) Stat. des Vegetat. p. 28r. f. de la trad. de M. de Buffon.

*) Sev diefen IX. erften $\mathfrak{B c o b b . ~ v e r g l e i f f e ~ i n a n ~ b i e ~ C o n f i d e r a - ~}$ tions fur les corps organifés. Art. 192. โ. 


\section{Befinte Şeobadiftung.}

3erfuthe, um gewif 3̆ werden, of Das

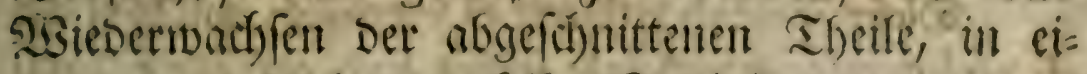

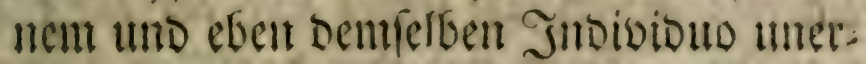
(choppfilic) (een. *)

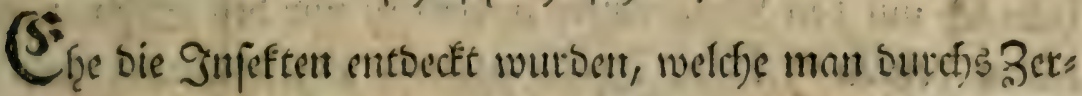

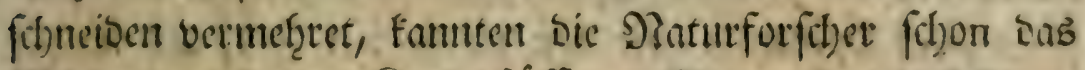

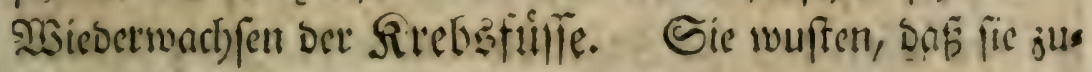

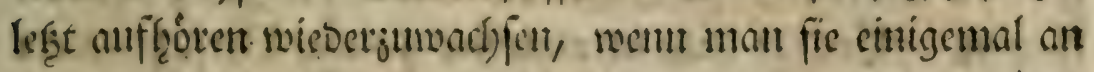

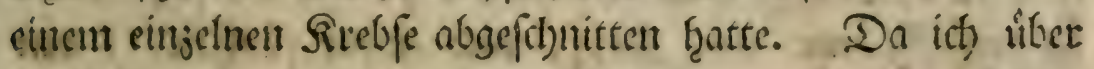

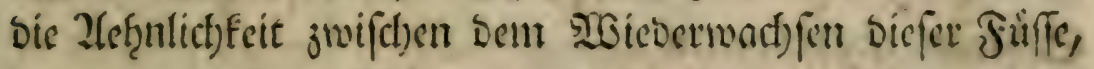

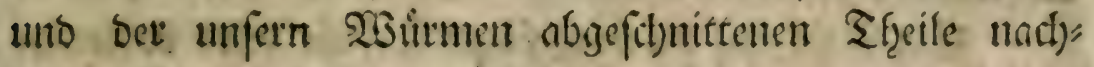

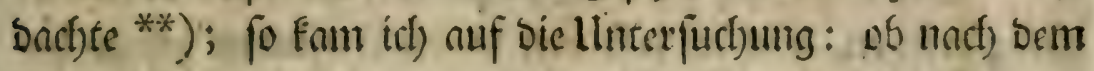

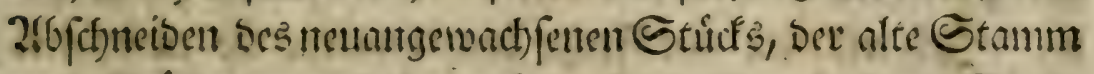

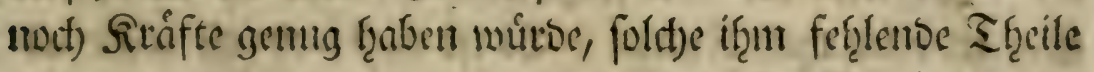

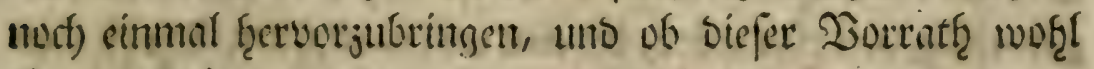

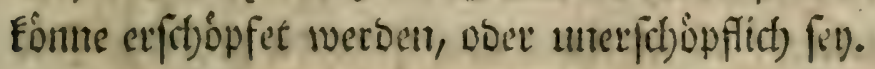

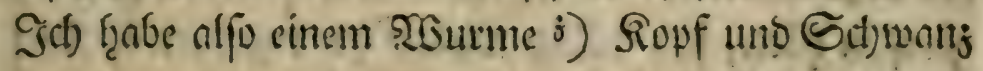
nad) eillanber wieber abgef(d)nitten, fo ballo firth inur biefe

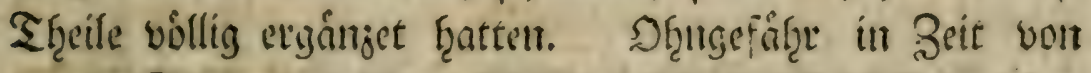

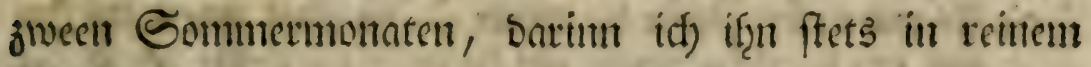

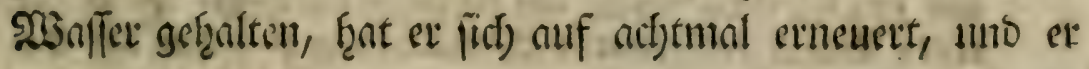
ḩatte

*) Confiderations fur les corps organifés. Art. 252: $=62$.

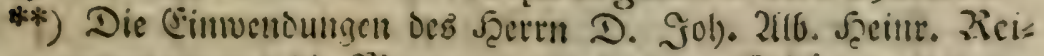
marus gegen die Dienmungen uno ganje (5xÉlintumgent un:

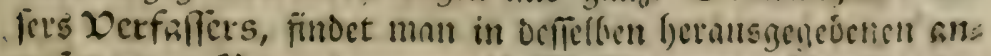
gefangenen 2 etrindtungen $\zeta$. E. Reimetus ibot oie bes fonoern 2(rten ock tbierifhen Kunftriebe, uno in 2 (ns

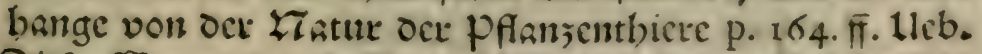

8) Diefer গুS

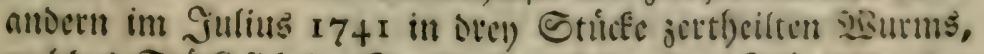

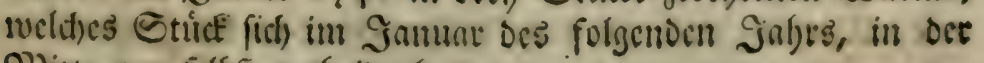
glitte won fe(teft getbrilet batte. 
hatte fdoon angefangent, es jum neuntenmale ju tḩun, als ex frarb.

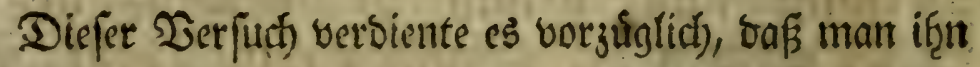
oft verámberte; und idf) feabe folctes aud) nuf alle erfinnlis

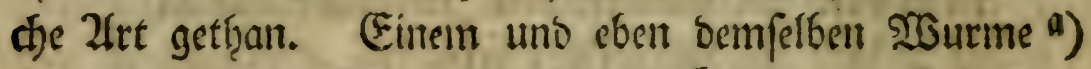

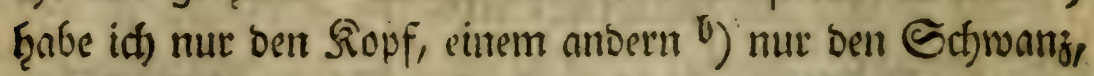

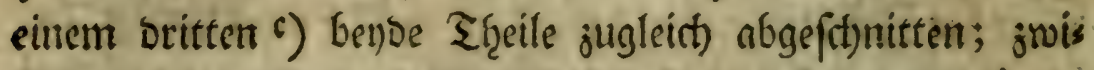
foten jeber Dperation aber lief ith fo biel Zeit, als notthig

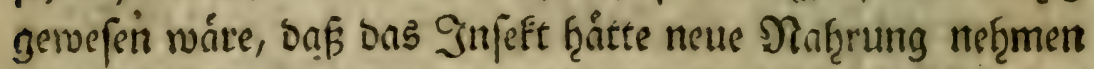

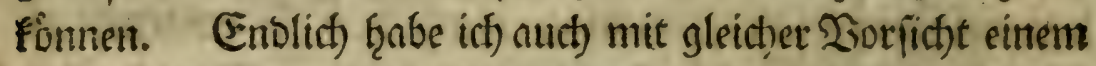
biertent D) nur ben Repf, uno einem funften e) Den Sajwand abgejfutittent.

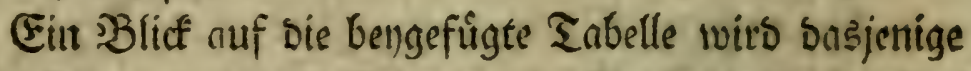

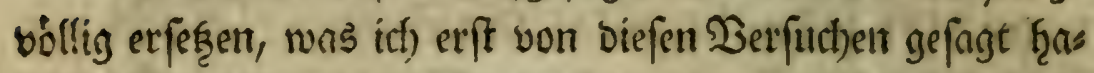
be. Id) will mur eine Frage beantworten, bie man biets

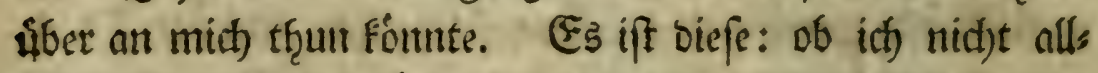
zuboreilig gewefen wáre, bie neu angewnat)fenten ₹̧̧eile wies

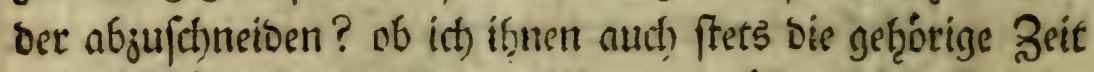
gelaffen f̧ä́tte, fiid) vóllig wieber ju ergánjen? Faft follte

man

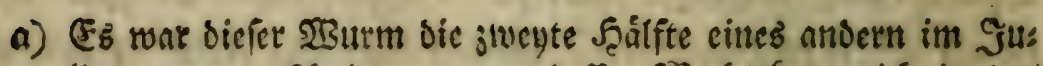
lius 1741 jerfdjnittenen, vont beflent 3 Sachetjume id in Der exften Tabeffe oer neunten Leobadhtung cine Litt von Tas geregifter gegeben lobe.

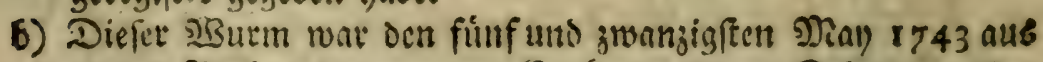
cincm 2jad)e genommen. (5r Gatte feinc! Ecfimang, ober Seintertlyeil verloren, umi fung wiedcr an cinen neuelt ju be: fommell, belien !ninge lieteits àvey Drittel ciner Sinie wat.

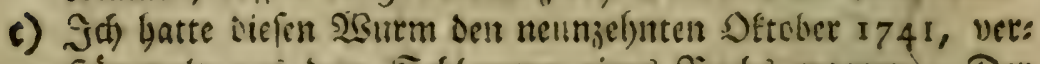

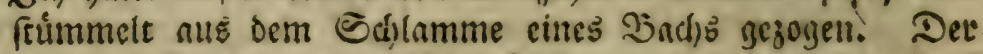

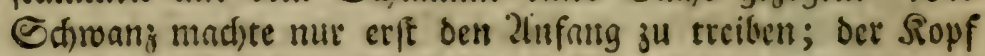
aber batte jajon Dren) Мiertellinien.

b) Er mar chenfills, wie oic vorigen, ins \$ian 1743 , in vemfel: Gett Sande gefuniet?.

e) Derfelbe toar mit ocm vorfjergebenden im . Iunius beffelben Jaljrs an einem Drte gefunden. 


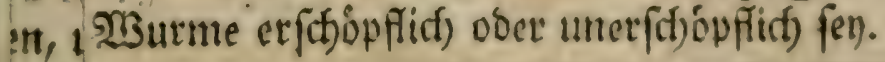

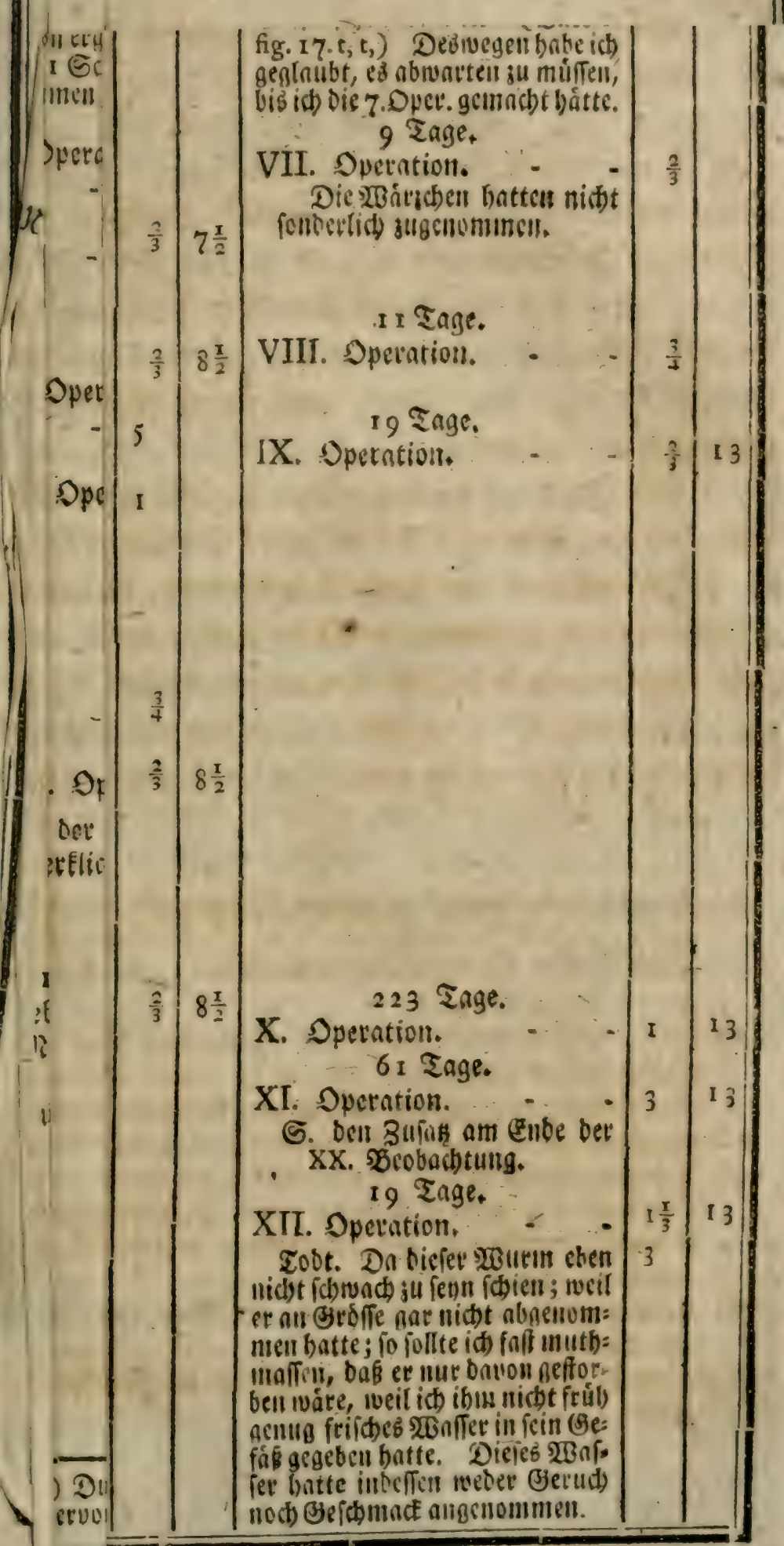




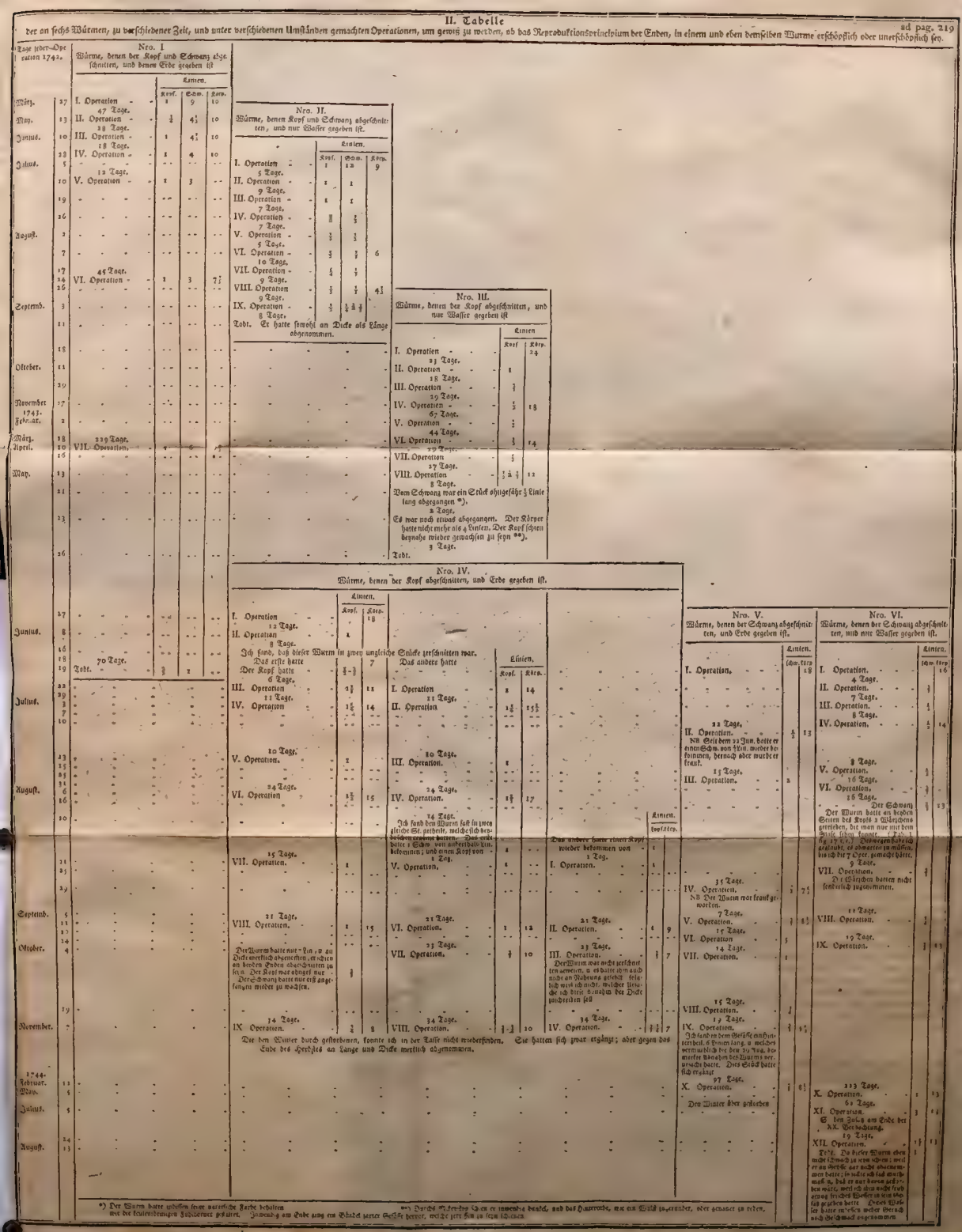




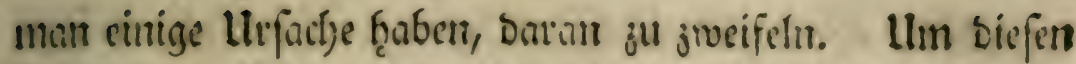

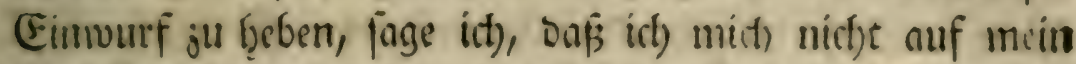
Eloffes Sefict) verlaffen, foubern jeocsmal ons Mifroffop

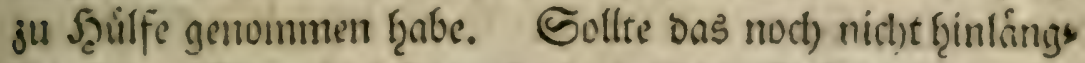

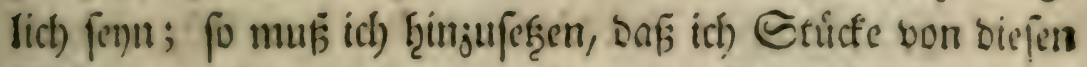

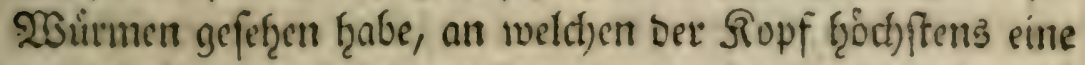
bralbe Sinie lang war, uno fhon bie wejentled)ften Derrict).

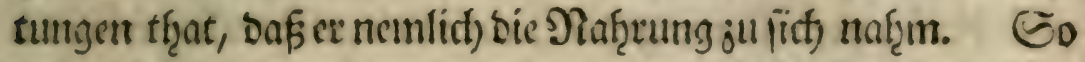

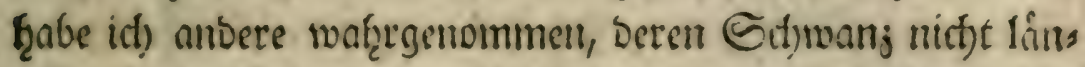
ger, als ein Drittel einer (inie war, baran man bock) fetce Deutlid) bemerfte, wie fid) ber 2 ffter aufthat, Die Ercrement= te von fid) jull geben. (Ex erff(j) jwar nod) nidjt unter Der (Sieftalt ciner lánglid)ten Spalte, wie er in ber Folge

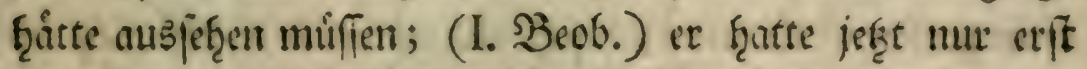
eitre Zft von Einf(t)nitt; (fig. XIII.p,) bas mejentlict)e aber fonnte man baran fotyon inmer bemerfen.

llebrigens barf ich nitht vergeffen anjumerfen, bnß

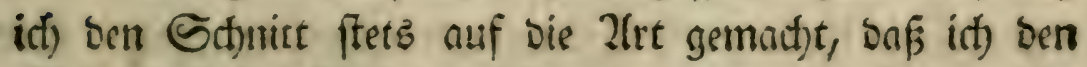

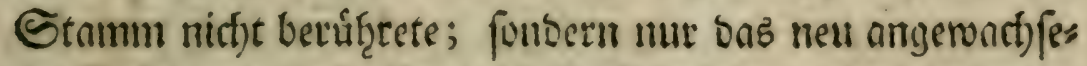

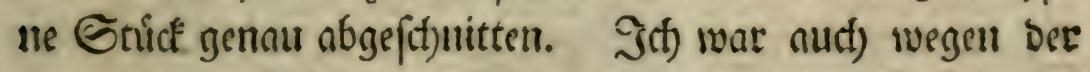
merflich verjafiedenen Farbe biejer benden Stiufe in Stanbe, fie feloft ju unterfitheiben. (VII. Bevbadts.)

\section{Slnmerfungen úber die jtoente Sabelle.}

Sabellen, bie nact) biefer 2frt eingerictjtet waren, wurben biel feltene 2(nmerfungen liefern, woburd, man bie Sact)e, bie ben (Sicgenftand fold)er Şeobact)tunigen ausmact)t, nufs flaten formte. Da nber bas, was ict) jef̧t witflidt) in bies

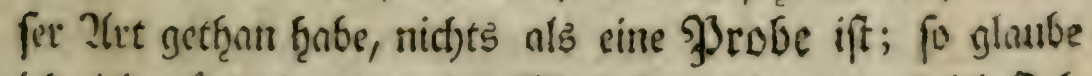
ich, icl) wirtbe in ber guten Methobe feţlen, wenn ith Fol=

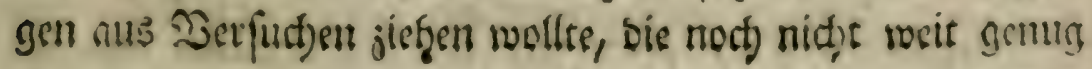


getrieben, ober noch nidjt oft genug mieberţ̧ofet wáren.

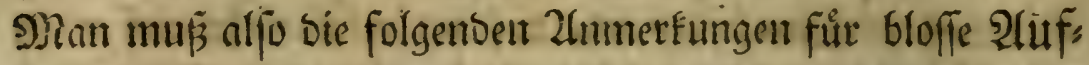
gaben, ober Fragen ḩaten, bie id) einer reifetn linterfit d)ung unterwerfe.'

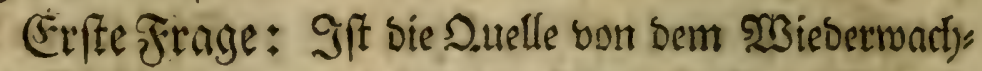

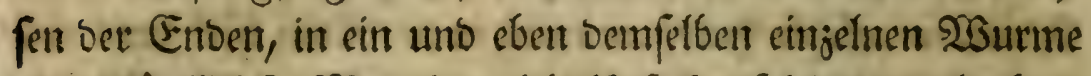

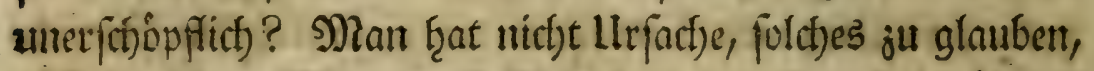

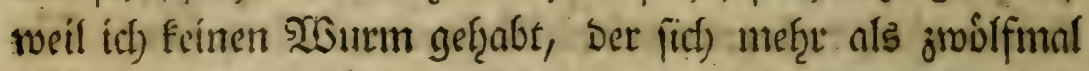

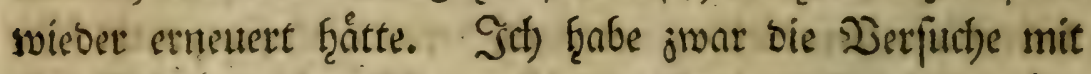
Den Sisturmen No. IV. und V. nitb) weit genug treiben fons nen; man faum aber ficter glauben, baß́s fie ju mef̧reeren Sperationtent nidd)t mef̧e bienlich) waren, Da fie gegent bas Ende Deß Şerbftes an Didfe und sainge merflict) abgenoms

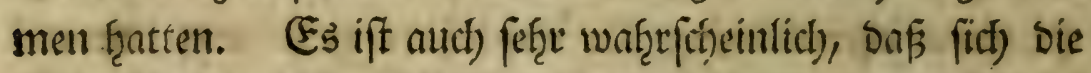
Eigenfchaft, weldhe bieje Jinfeften fraben, einen netten Ropp uno Sd)wank, an ftatt Der abgefdynittenten wieber ju treis

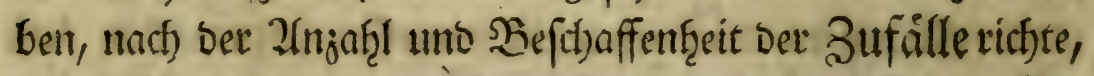

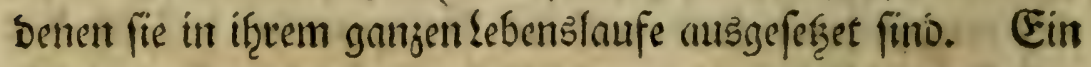

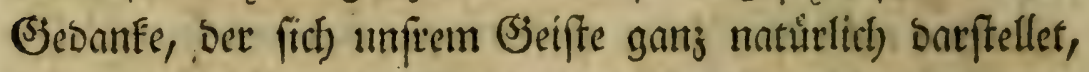

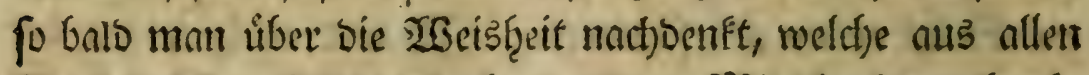
Daturwerfert, Gejonbers aber aus ben Mittelit hererborleud)s

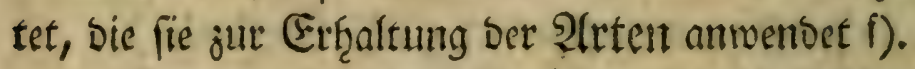

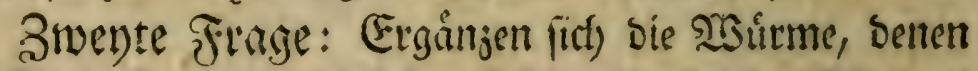
man. Eroe gegeben, viel offerer als bie int Gloffen 2 Saffer? Es ift jut verumutfent. Strtoeffen nach der Sabelle, als Dem

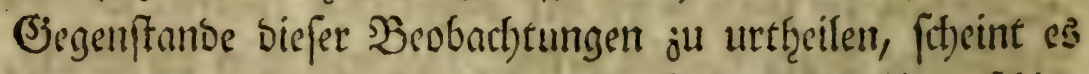

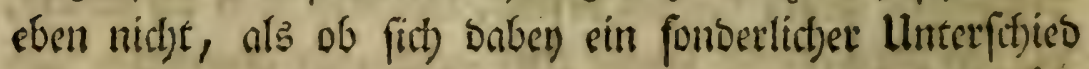
befains

f) Mann vergleifle mit ben bisflerigen Beobnditungen, hes Dets falfers Confiderations fur les corps organif. Art. 52. 247. bettud)tung über Die ЭRutur. p. 148. 153. Palingenes fic. I. T). p. 9; - 123. 370-403-437. Rcaumur Memoir. pour fervir à l' hift des Inf. Tom. VI. pref. LXXIX. Heb. 


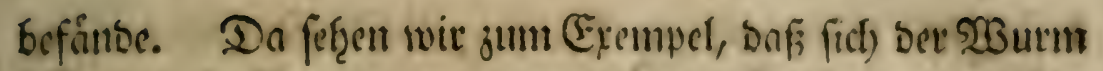
No. 1. bem Eroe grgeben war, in siner Beit von ofengefâtge

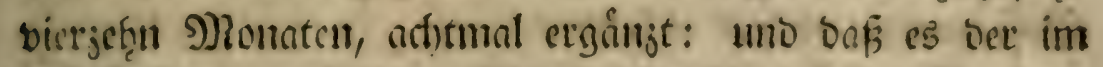

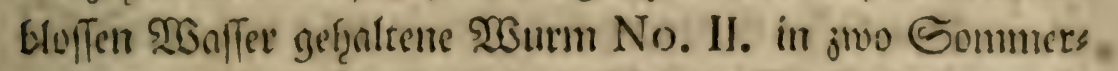
monnten, "ebent fo oft gethan habe. Dielleidft war die D.uelle Des șieberwat) fens ben Dem sinem, umb bem nus

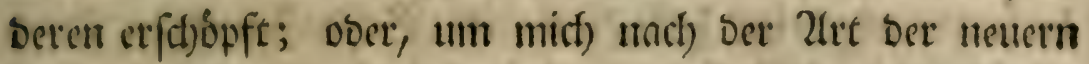

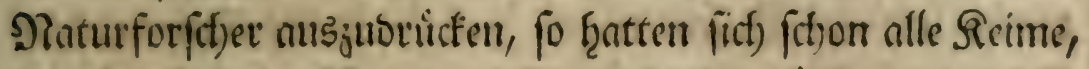

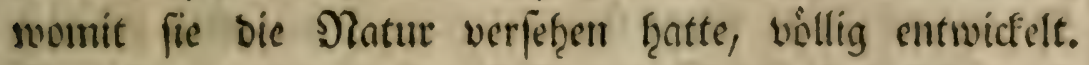
Dem fen wie ifim wolle; fo fofeint es mir vorjuglich merts

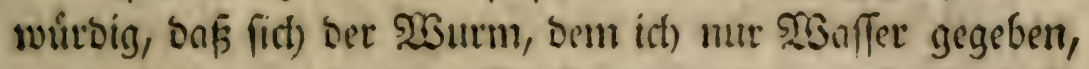
act)tmal ernenert f̧atte. Diefes jeigt cine groffe Sraft in Dem Rebensprincipio stefer Snfeften an. Nimm man bie sange bon jebcm, an biefem erivåf̨nten $20 u r m e$, miebers gewart) fenen Siopfe uno Schwanje; fo wirb bie fecrausfoms menbe Summe Den Gtaum felbit, nach Der erften Dperas

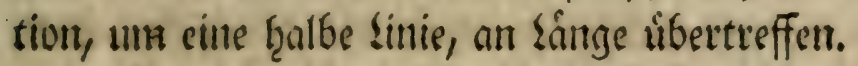

Dritte Frage: Siefchieget sab șbiedermadjen bet Enben gefduminber an ben 23 ürmen, Denen man Erve, oder

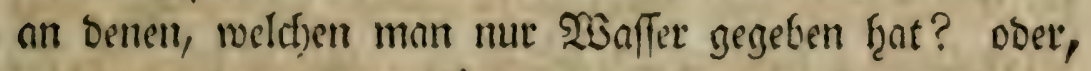
reld)es auf eins hernusfoummt, wat) fen bie erften in gleict)er 3eit gef(t)rintor? Da bie Werfuct)e, auf welct)e es f̧ier ans

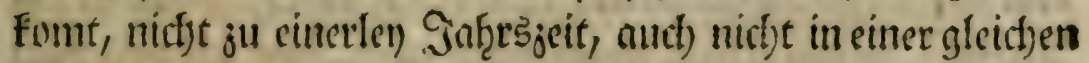
SWBarme gemad)t fino; fo faun id) (VIII. Beob.) úber bie= fe Frage nid)ts gerviffes fogen. Wistl man indeffen ben ber

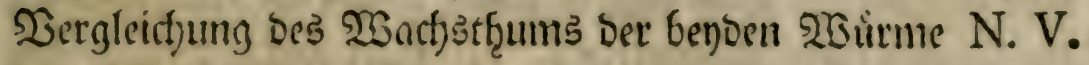
unt VI. fref̧en bleiben fo wirb man waf̧rfit)einlituer sie Sact) bejaţen fömnen. Eunft ift es ganj naturlicf), Daf

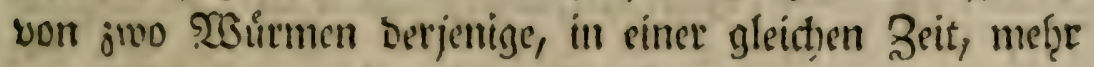

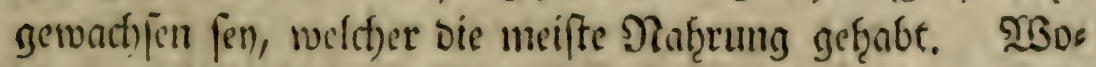

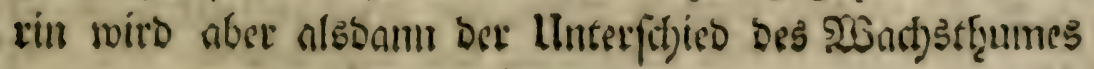




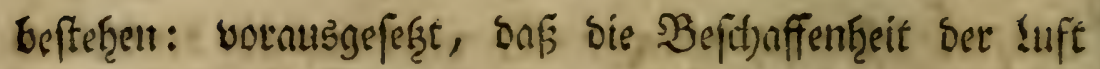
gleicl) gevefen? Dies ift $c_{3}$, wie mir beucft; nuf beffen Şeffimunung es fier anfommt.

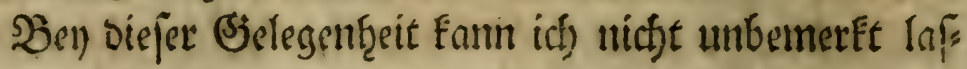

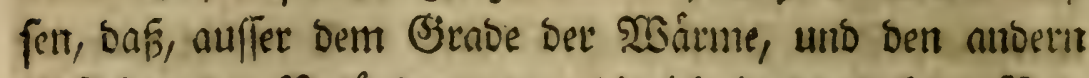

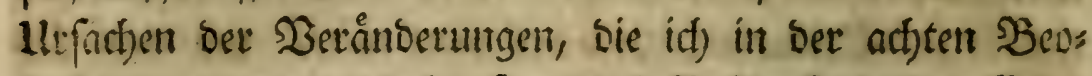

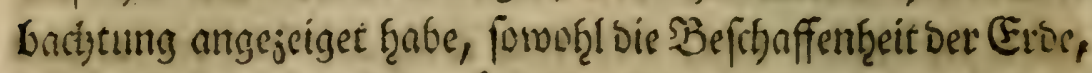

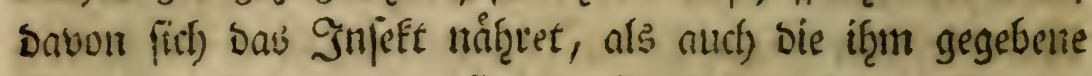

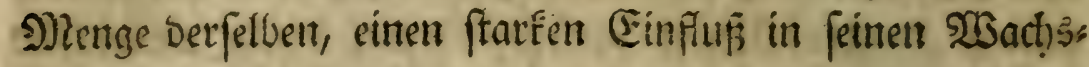

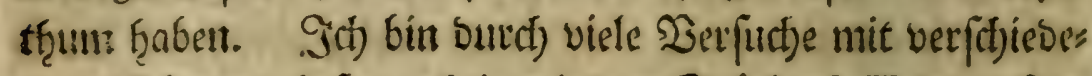

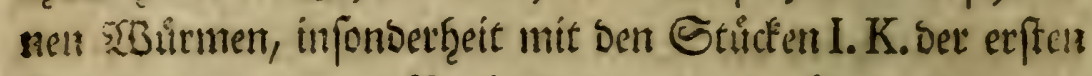
Tabelle ber neunten Beobadytung, Davon ůberjeuget wors

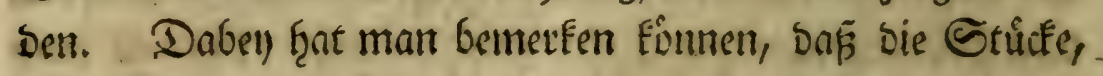

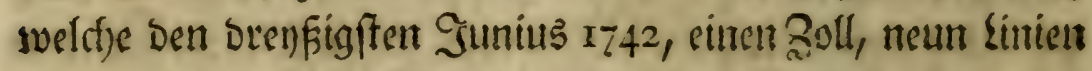

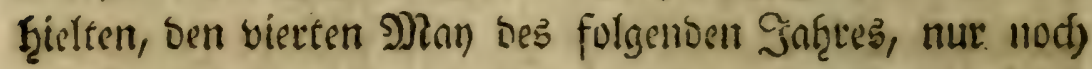
ein Drittellinie fratten. Da lie fict) nutr nich)t von ferble getheilet fratten, wie biefen 133 tirment oft genug begegnet; (Beob. VI. IX. זab. I. X. Tab. II. No.III. IV.

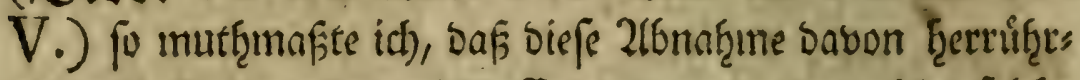
te, weil fie entweber nicht (Erbe genug, ober nidfte foldte

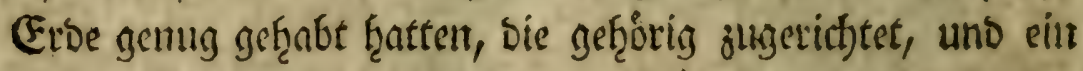

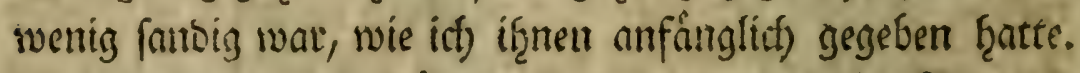

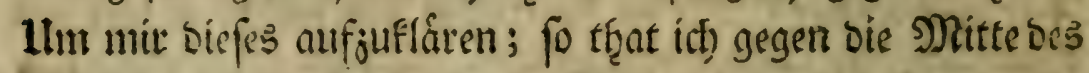
Zlugufts, in bie ₹affe etwas Sthlamm, bert id) von bem

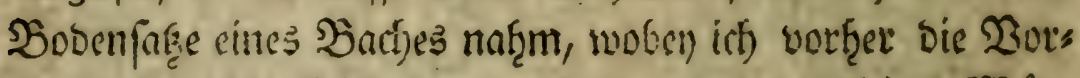

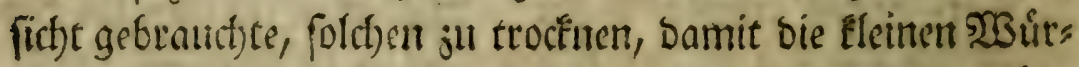
me Darin fterben mighten. 9) Sil sinter Zeit von of̧ngeffif̧̨:

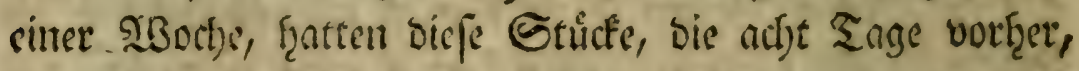

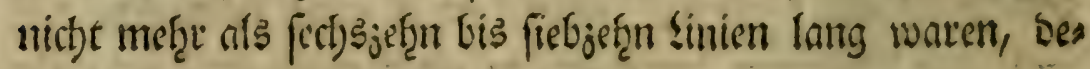

ren

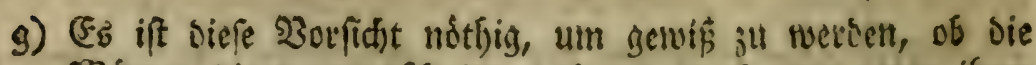

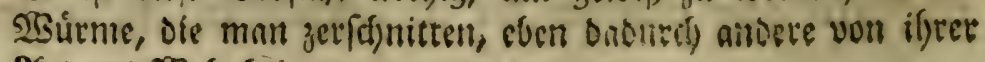
2trt jut șelt bringen. 
ret biet unb zwanjig. Gie waren and nach Deoportion bicte genvorben. Folglict) ift fein Bweifel, bajs nict)t biefe

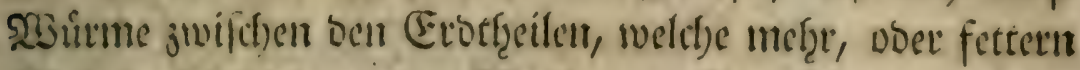

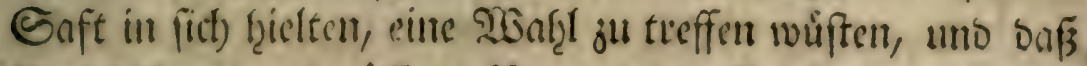

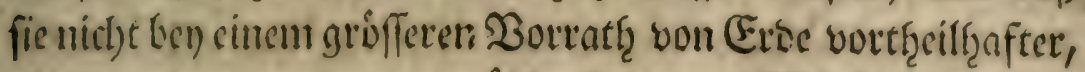

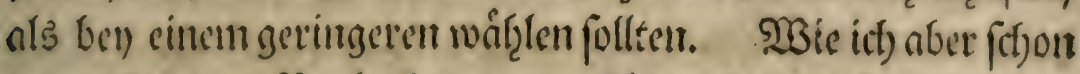

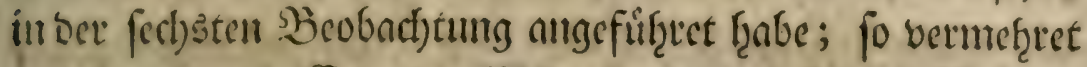

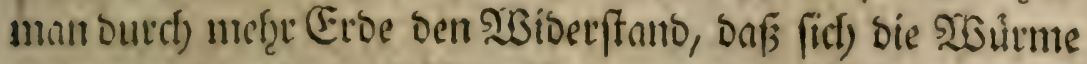

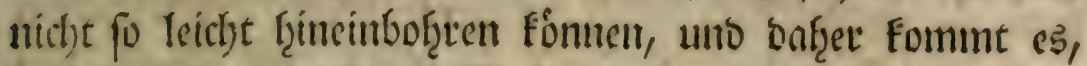
buf fie fich jerteiffen. Ein verberuflict)er Llmftans! gd) unterlief nicht, es mit ben Stücten, Darrauf es b̧ier anfom, ju verfuct)en, beren fith ein jebes wentig Sage nad)fere in

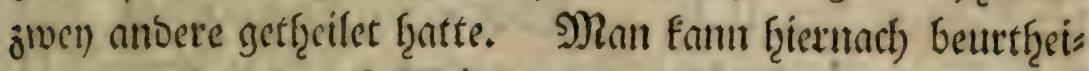

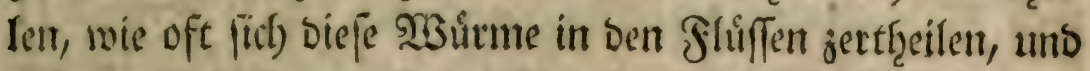

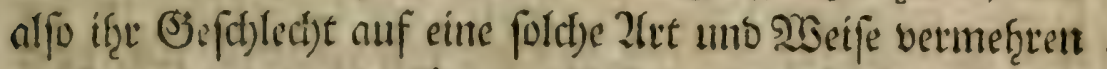
muiffen, bie man eher für eine llefact), iţren Sod ju befors Dern, f̧alten follte.

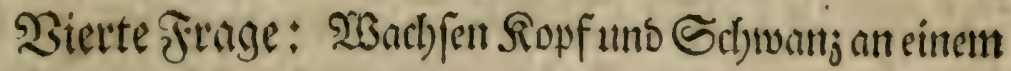
unto eben bemfelben Intoiviout gleich? Diefe Frage hrabe idt

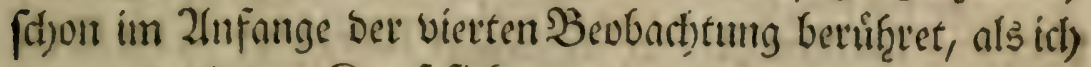
fugte: Daß Der Ropf fich genteiniglide) guerfit entwidte= Ie. Die Sperntionen, bie ith Init Dem sisurme bet jiventen Dlummer biefer Tabelle vornaf̧m, fohichen biefen Saf vols lig ju beftatigen, ober weld)es citterlen ift: Dafj ber Ropf it gleit)er Seit an meiffen wad) Je. Nan barf mur, un fich Davon jut ubergengen, Die f̧olge biefer Dperntionen anfehent. Darnus wito man cefenten, Daf, wem biefer lef̧tere fifjon cine bqalbe ober bren Dicrtellintent lang geworben ift, Der Sit)wanj mur erft sin Biertel ober cin Drittel ḩat. Da Der llmlanf Des જ̧luts voun S(j)wanje nad) Dem Siopfe ju: Sonnet 2. Th. 


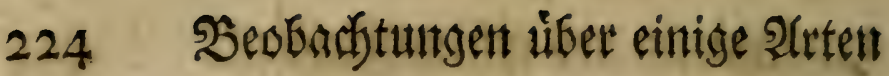

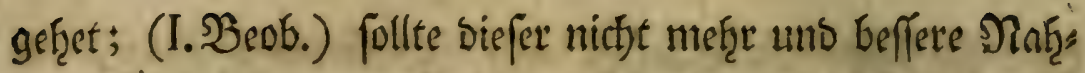

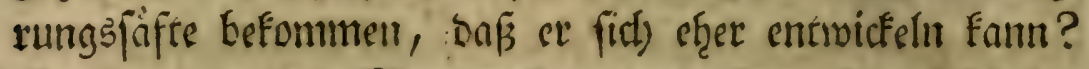
Es fer) nun biefe Mlutḩmafingng, wie fie wolle; fo fageint

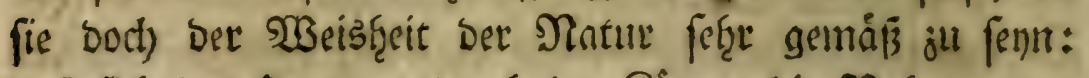

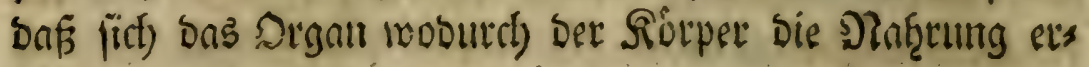
ţålt, am erften bifloé.

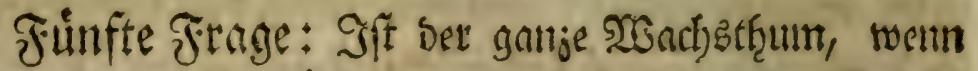

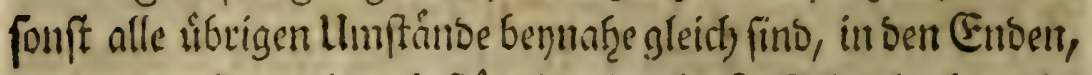
nach jeber Speration, beffánbig eintetlen? Sich glaube, bies fes verneinen, und beweifen ju fornnen, Daf er abnefrme.

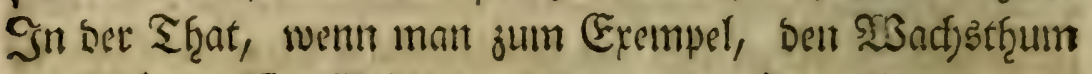
Der 23 úrme No. II. III. nad) Den erften Dwerationen, mit

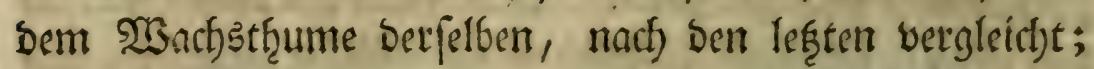

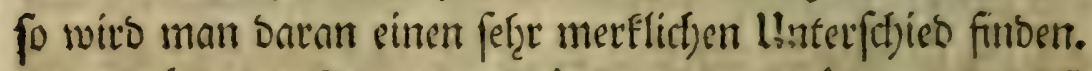
Die Srâfte bes Tryieres erfothopfen fich allmálig, uno bieje

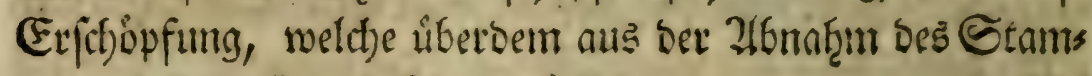

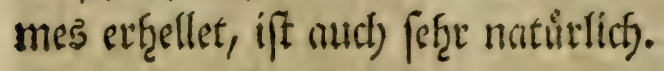

Sechate Frage: Wadj)en Die auflerffent Enben beftranbig mit Dem Rórper in geraber simie, ober an ber Geis

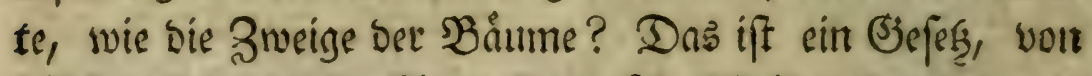

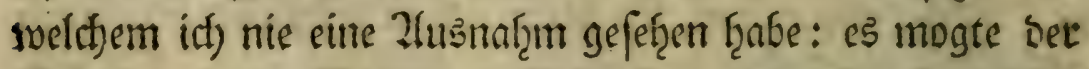

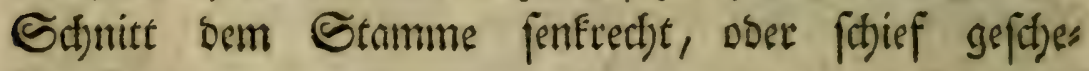
ţen fenn.

Siebente frrage: Simb bie netten Srganen, bie ber Stamm nach) jever Dperation treibet, beftánbig gleid,

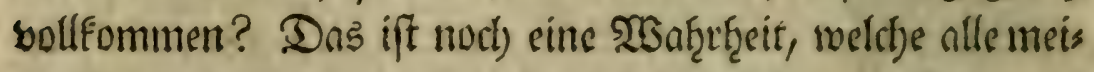

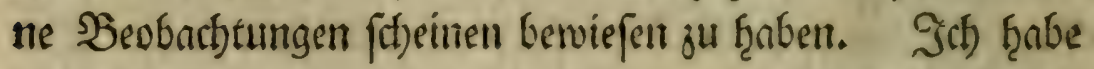

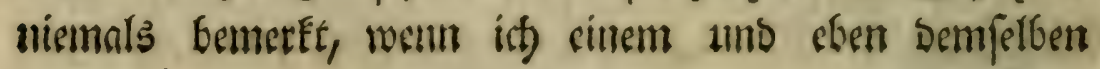
श्turs 


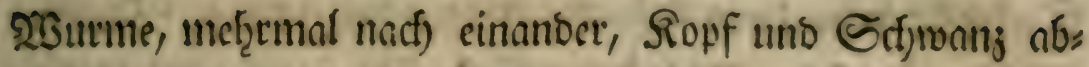

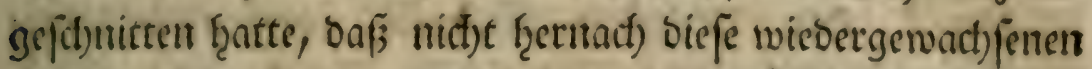
Szeile cben to gut gebilbet gewefen waren. Inoeffen svill id) Daraus feinen Sd)lup mad)en, Daß̧ ficr niemals Ilntegelmápigfeiten vorfallen follten, weld)e bas Innethen bzaben, als went bicfe Sţcile organifiret wátent. 2alles, was jufonmengejeftet, ober cine Mafitine ift, ift bergleis c)en Serånberungen nothiwenbig unterworfen.

\section{Cilfte Beobadtuturs.}

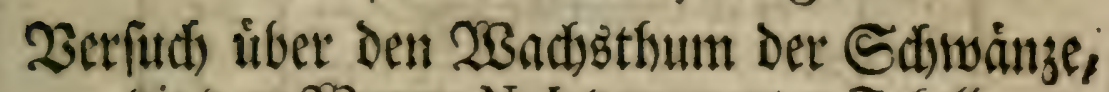
Die Dent 2 Bum N. I. Der zroenten Tabelle abgeffonitten waren.

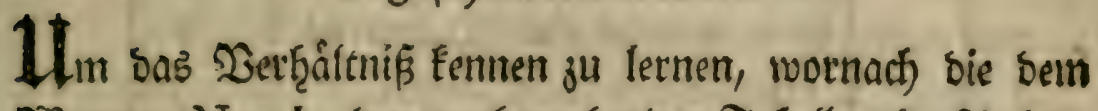
220urme No. I. Der vorḩergeţenten Tabelle abgefdunittes tren Sdjwanje wathfen wưrben, fo frabe ich. fie von Seit ju Seit gemeffen, wie man in bet folgenden Sabelle feţen wirs. 


\section{6 Şeofrachtuntgen ůber einige 2rtent}

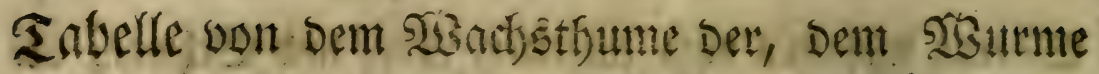
No. 1. Der smenten Fubelle, abgefunittenen Echwainge.

$$
\text { A. B. C. D. E. F. G. }
$$

XXIV. 2luguft 1742. Långe ser rie:

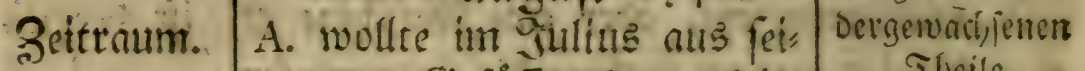

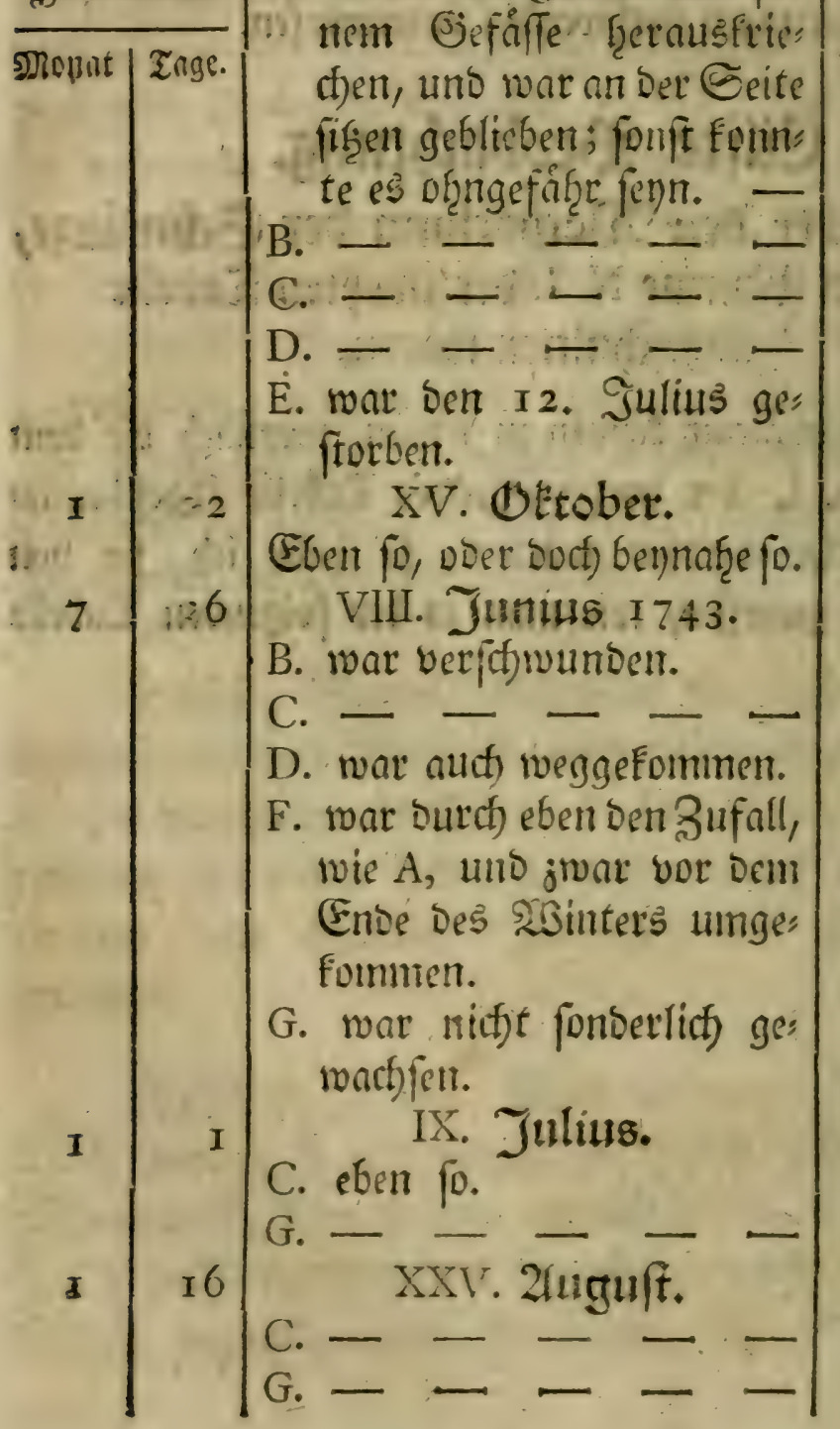
Elcilc.

3olfe. Simien. 3olle. sinicn. I 


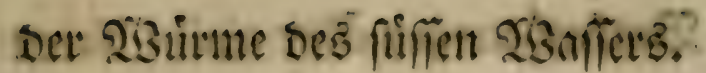

\section{Bundfte 3eobaditutitg.}

\section{Dấ Der Siopf uno Der 3ordertheit Diefer}

Sistirme, eben fo wenig ats ber sintertheil, iemals wieber bolifonmene sisurme

werbert.

(6)

Singe hiabe ith noch) nicht frinlanglich brantwortet,

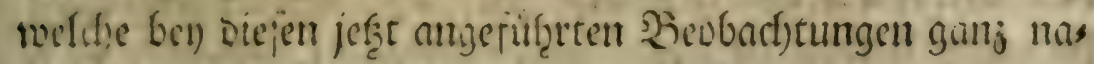
turlich) entfrefect. Es ift Diefe: ob bet Siupf uns Der Sibmant, ben man einem sibume nach cinander wieder nojelineibet, fo mie fie villig wieber angewachjen finto; of biefe Stzcile felloft vollfommente Banje weroen? Solitanf

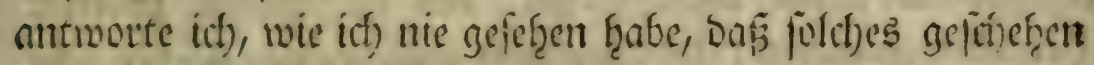
(e). Der eine forwoḩl, als ber antere, haben gemeintiglich), vier unto jwanjig Etumben nach Der Spetation, Das Sebert vitluten. SBisweilen gefor)ahe es fpater, cin nntermal fruis

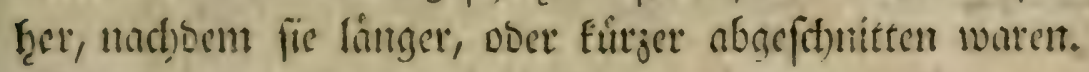

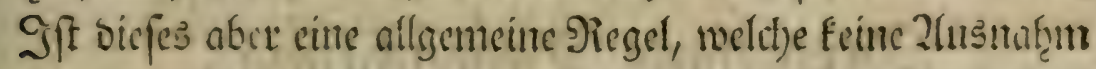
lecioet? Inffanglich fentte ich gemutfrmaffer; menn dieje

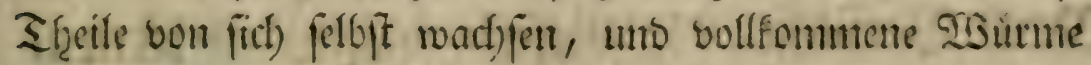
werten follten; fo miften fie for on einen gewiffen (Gitab von

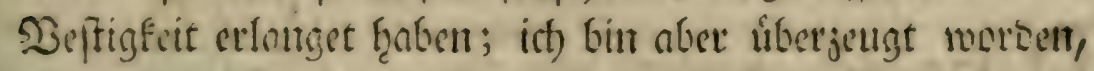

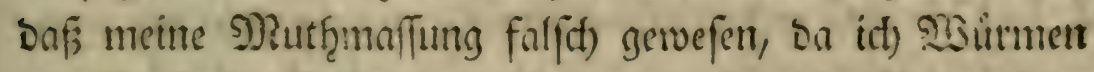

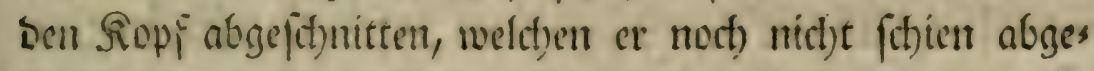

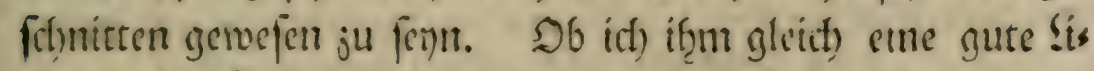
nie in Der Singe gelaffen fratte; fo ift er bud) nidt)t wiederges

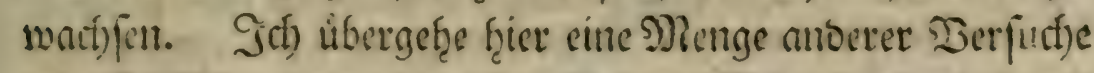
mit Stillid)weigen, bie ith mit Dem Sdhwanje, aber mit

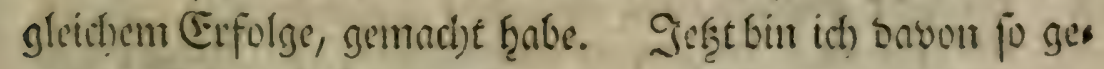

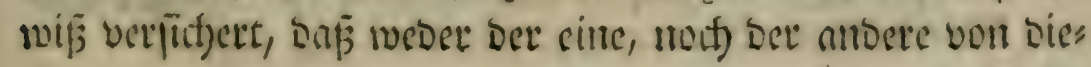


fen Theilen, vollfommene Thiere werben, baf idt) es int bies fer Sadje, als einen Brunbjafs anfere; woraus int biefe

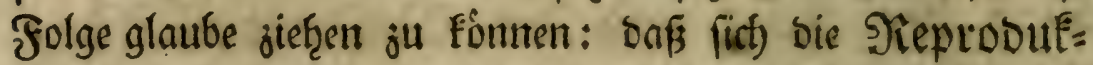
tionşquelle nidft in bem ganjen ßórper biefer șoirme bes

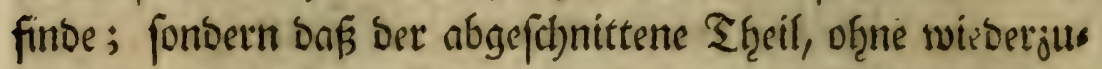

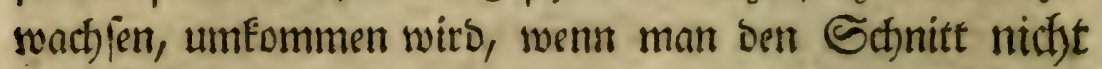

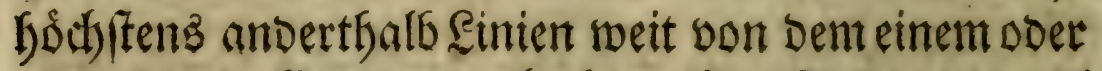
Dem andern (Ende gemadit hat. 1) Sollte nudb woht bie groffe Zirterie an biefen benben orten (1. 23eob. ) nad)

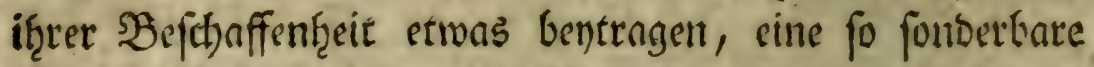
25infung bervorjubringen? Man famn biefes mit eben fo

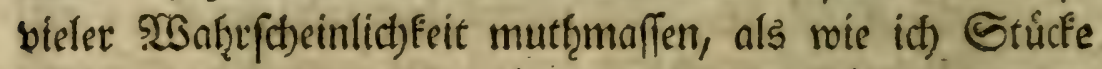
geferenen trabe, bie nicht länger, als bie Şaiffte zmeener Drittellinien waren; bie aber boch zwifhen ben benben jeget

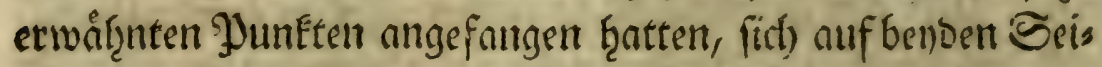

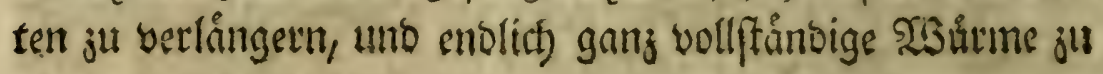
werben.

\section{Drenjebnte Deobaditutng.}

Netu Zerfutd)e, Dic (jefege fennen zu Yernen, nad) weldyen diefe sisurme wadjen. *)

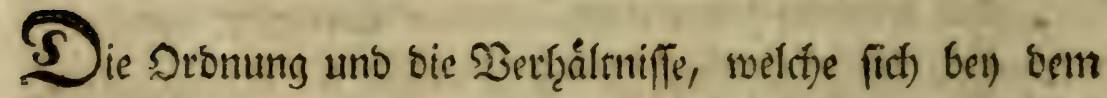

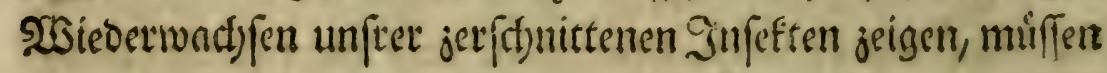
-. meis

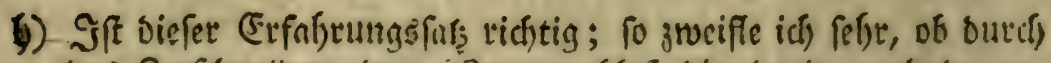
Das Berfúneiden cines isurme, filoß bie barin enthaltenen, uno zur Bellgung fettigen sisume, in Frevbeit geicket werhen. (FE wate alöbenn feine cigentlid)e Reprosution, fonvern nur, onß id) fo rede, cine (5cburtsbilfe. (5. Mriller oon 200irmetn ic. 8. 18. vergl. mit 9Rot. (p). Uleb.

*) Corps organil. Art. 247. 


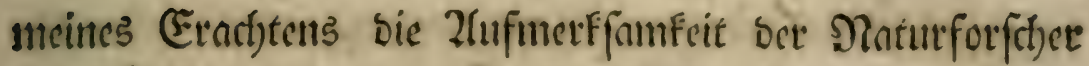

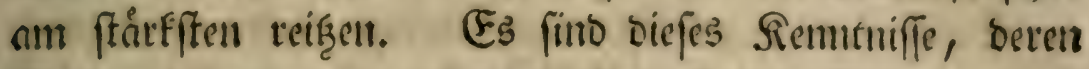
Dluf̧ent feitnesiveges auf biefe ?ltt fleiner Thiere einges

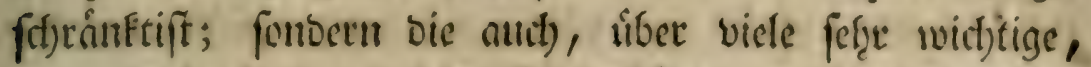

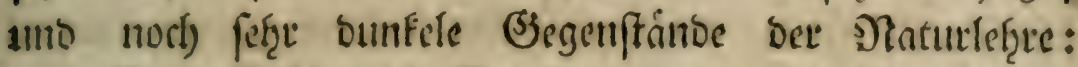
äun Eremper úfer die Eirjengung, unb ben 2 bad)sthum

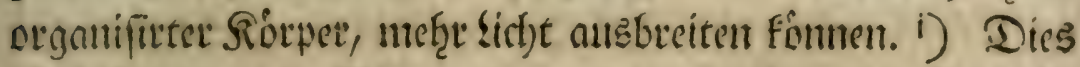
ift befortbers ber ßBetvegungagrumb gewefen, eine Tabelle

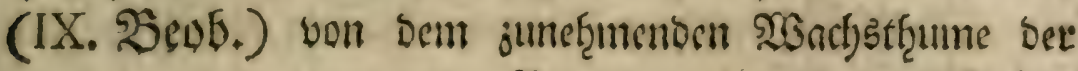
ग 4

Sticle

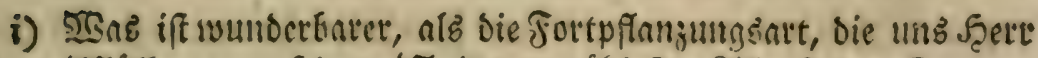

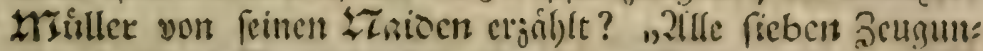

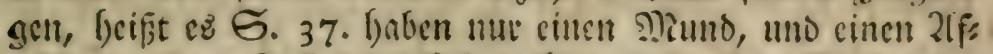

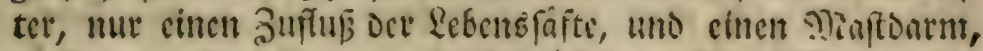
11. F. Iv. alpo alles gencinfliaftlid). Die 2nutter bat nid)ts als ben slinns, und bie Junge vornus, momit fie ib:

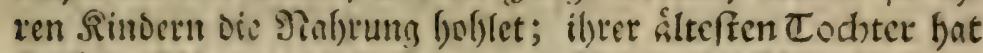

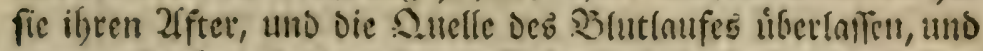
unter alle bat fie bas lergete Gielint ibles Eeilies getbeilet, ofje feloft babei) ju verlictert. „, -

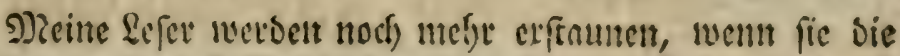
fieraus gejngette folge, in ber vict;cbnten Rote erwaigen: „2)

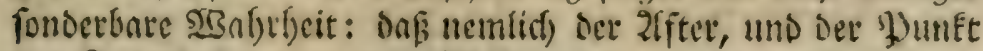

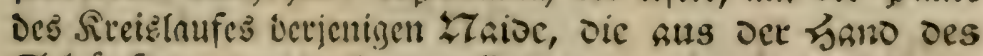
Gubopfers unmittelbar getommen, snnod) in Felbiget Etarte oafeyn, mo bis an ons 促noe Der Dinge forto aus ven Kónnte, uno milfe, wocnn nid)t cine Utefad)e von sufs

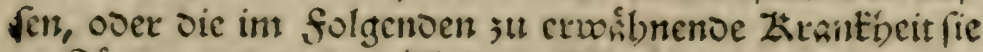
zerfóte; tmo oafies Thioen = 2ffter gebe, oie, ob fie gleid) einige taufeno Jabre alt fino, Scibern, weldhe feit wonigen Uagen entfínocn, Die gewóbnlidien Dienfe tbun.,

Lidht genug! weld)ez mad) 25onnets 3eugitis sutch

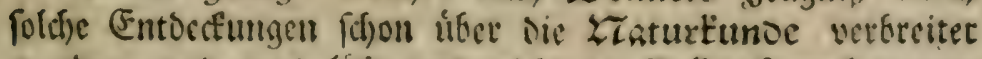
worben, unt was lapt uns nid)t Dic Jutunft noth crwar: ten? Heb. 


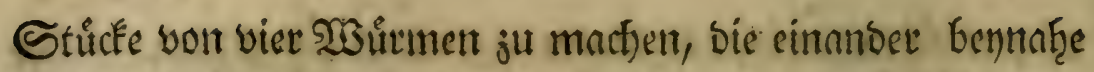

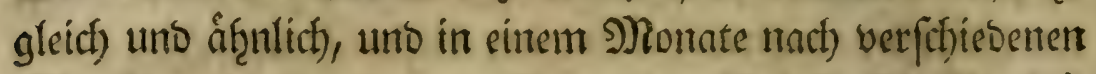

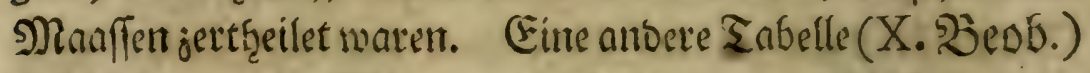
habe id) yon Dem 2 bicberwach)(en ber, von verfchiebenten eins jelnen Stucken, thach) einamber wieber abgef(thnittenen

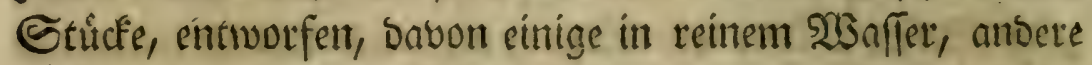
in : sBaffer mit efwas Erbe gef̧altẹn waren. So werbeid! fier in eben ber Zlbfit)t eine vierte Tabelle geben, sueld)e eine Maafleiter von brey 23 ưtmen ber jef̧t erwåf̨nten Irt

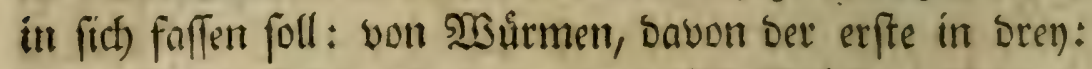
bet anbere in ject)s, ber britte in jwolf Stucke gefojnitten

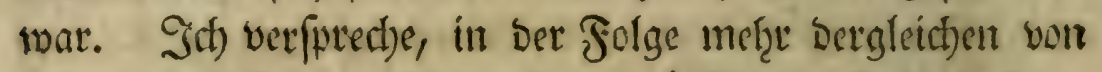
anbern juliefern, welche noch weitlinftiger, als biefe fentr, unb gleithfam eine ganje Sammlung ausmachen follen.

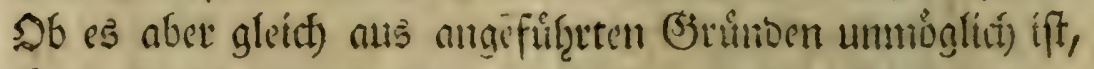
(IX. Benf.) eine volleommene Bjenauigfeit ju erreid; fo muf man beswegen biefe 2(rbeit bod) nicht anfigeben, weil es hice auf feine mathematifde, fonsern phylfidie Jies nauigfeit anfoummt. 


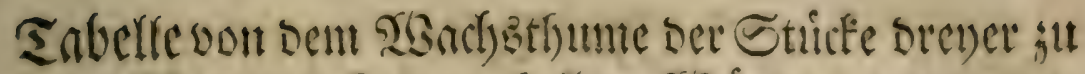

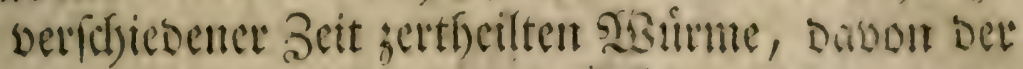
eine in Drei), Der anoere in fed)s, InID Der Dritte

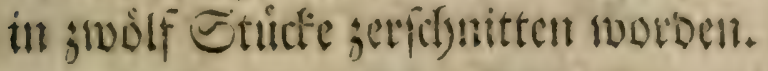

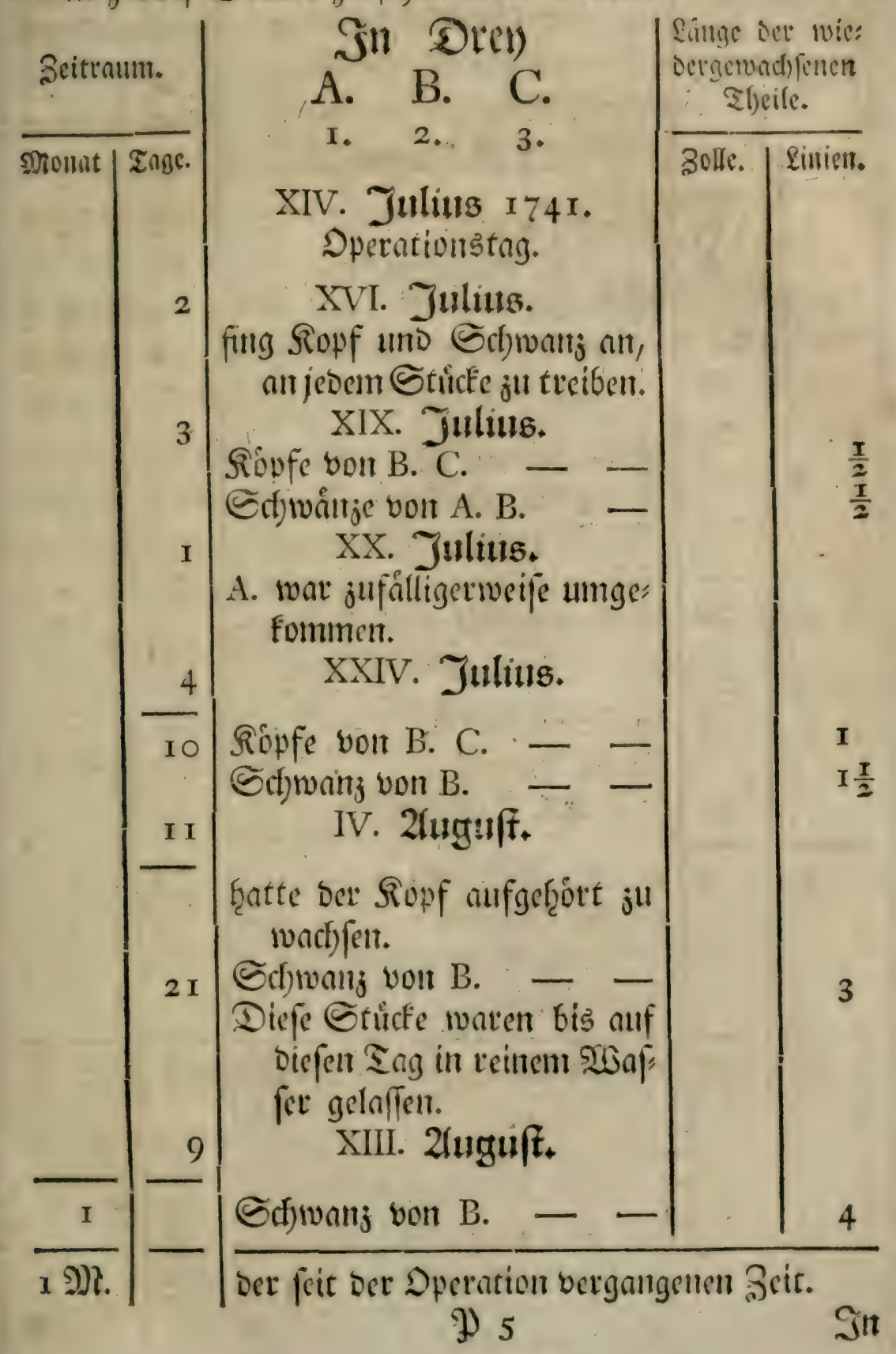


232 Şeobachtungen úber einige $\mathfrak{A}$ rten

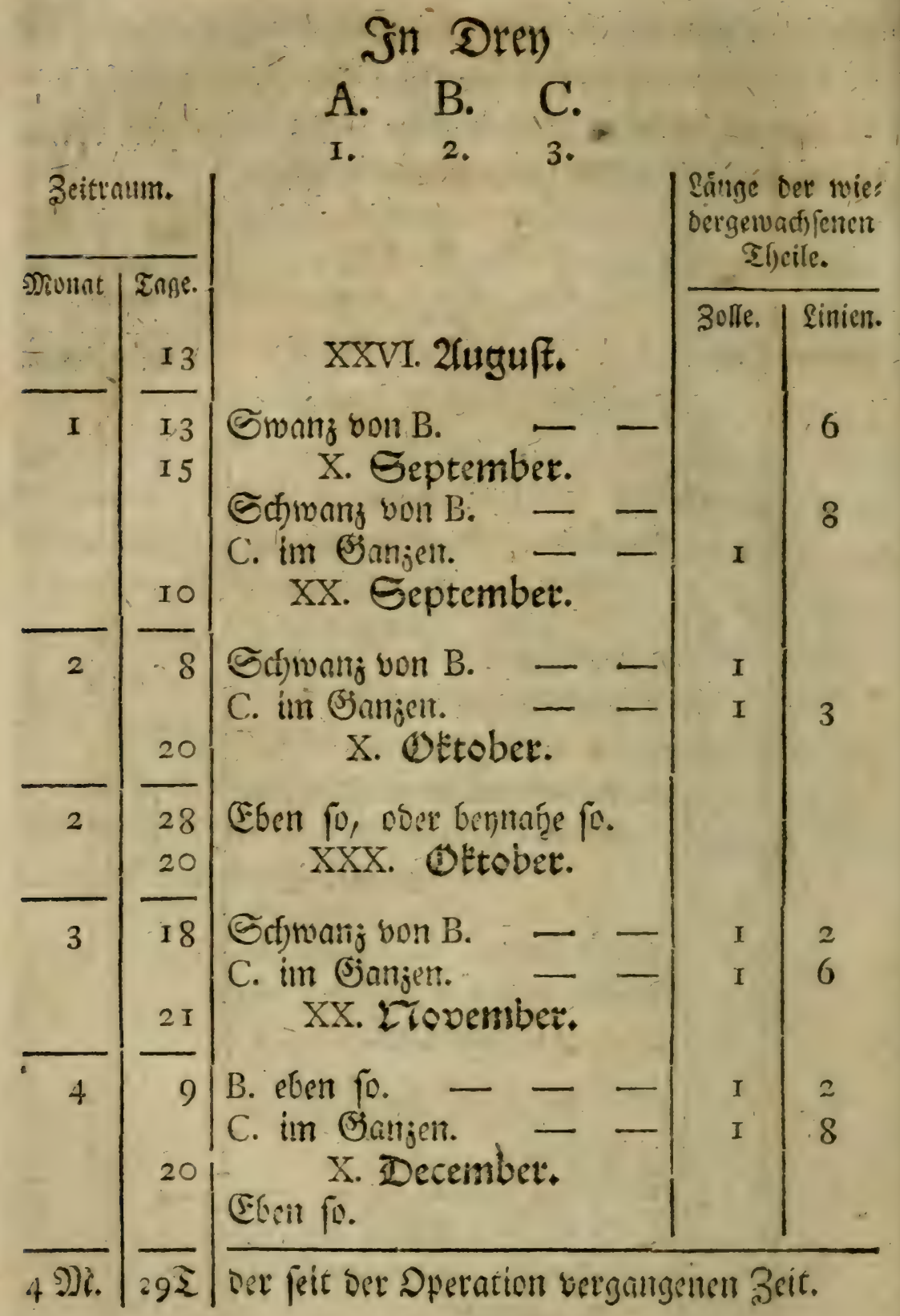


3cittumtm. $\mid$ D. E. F. F. G. H. I. I.

Dionat 1 Tage. XVI. 2luguft. 1743 . Sperntionstag.

2

bratte fich an bas Jeintertheil von $D$, sin jefre merffict)er

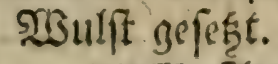

4

6

wat ber 23 ulft voit $D$ vers

forwundels, und es fratte Diefes Etuick angefangen, eimen Edywanj wieber ju befommen, weldyer bits mer'fmuirsige hatte, baf er foft eben po bicte, als ber Sobr: per war, ba fonft diefer Sgeil inmer Ditnter ift. $20 \mathrm{~m}$ 2(nus entoedite man butedfs

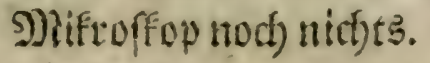

Souf uon E. - - Síppfe von F. G. H. I. Ethmall bon E. - Gdyange von F. G. Det Grfwanj wort $\mathrm{H}$ fing als lein an ju treiben.

2 XXIV. 2fuguit.

8 Siopfe von E. G. H. I. Solf von $\mathrm{F}$. - Echwan. von D. E. Ed)ruánjevon F. G: - Der Eckmang won $H$. war nitf)t fontoerlidf gewadjent.

Eänge Der wie: idergervad) pener: Focile. 3olle. Sinicn.

$\frac{\pi}{2}$
$\frac{\pi}{3}$
$\frac{2}{2}$
$\frac{1}{3}$
$\frac{3}{3}$

SS. Der feir ber Pperation vergangenen Beit. 


\section{כెeobaciftungent uiber einige Irtent}

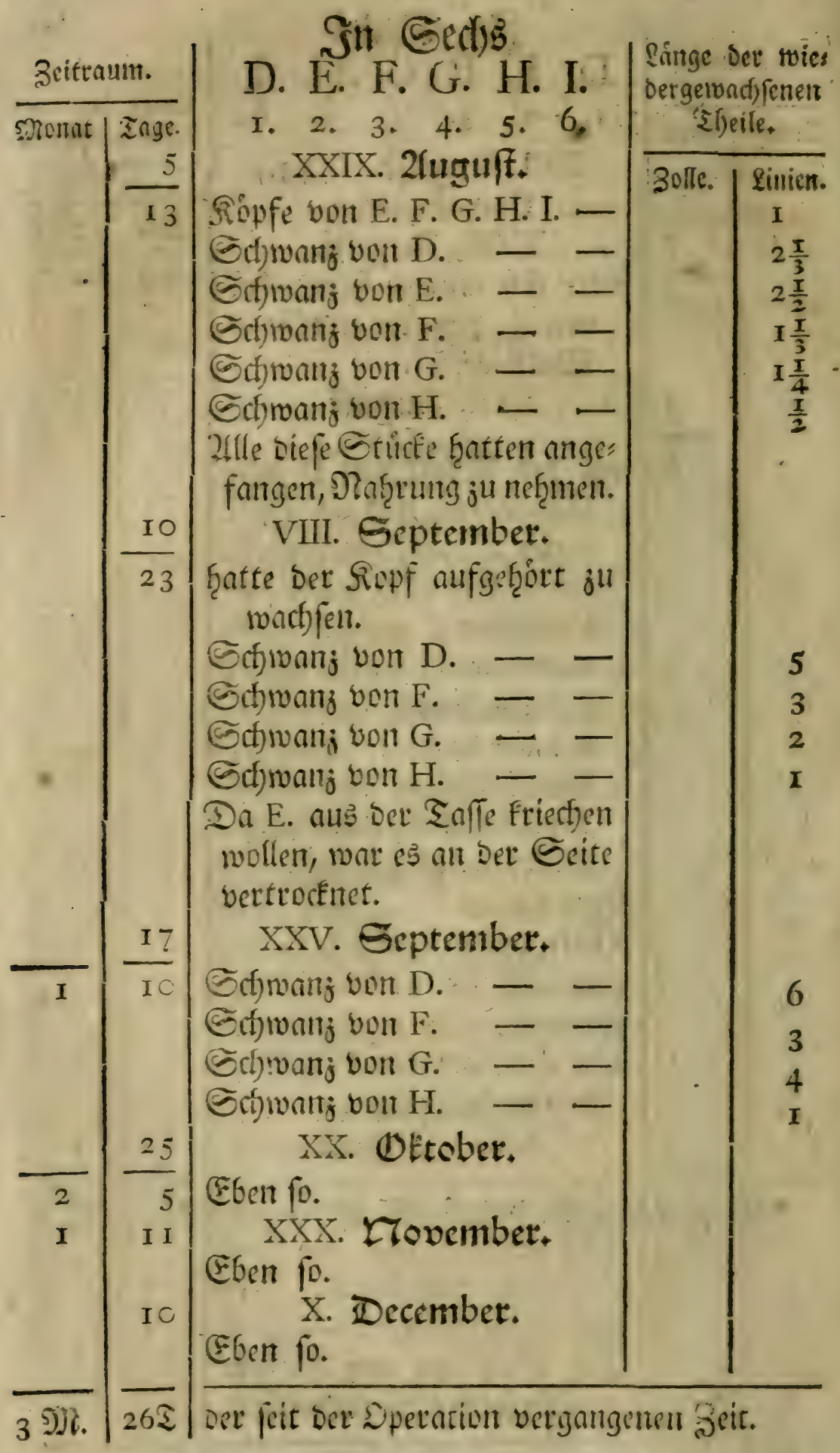


K. L. M. N. Ö. P. Q. R.S. T. V. X.

I. 2. 3. 4. 5. 6. 7. 8. 9. I0. II. I2.

\section{3citraum.}

Spionat I Tage.

I

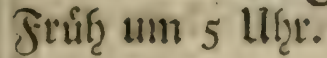

K. war toot.

2

Sesgen 6 llfer Des 9lorgent.

$\mathrm{X}$, war geftorben.

$\mathbf{I}$

batten alle Eructe angefan:

gen, wieber jut rondjen.

2

6 Sopfe von L. M. N. O. P. Q. R.

Schwainge von L. M. N. O. P. Q. R.

S. war etwas weniger ges watfjent.

$T$. V. F̨atten nod) weniger ge" trieben.

Siopfe volt L. M.

Giopfe von N. O. P. Q. R. S.

Ropfe von T. V.

Sifruarije von L. M.

Ed)wânge von N.O.Q.R. -

Edfwanj von P.

Erfwanz vout $S$.
Sáme Der Ivie: Detizetuad) letren Tljeile.

כulle. I Inim\}.

$\frac{x}{3}-\frac{x}{2}$

$\frac{I}{3}-\frac{x}{2}$

8乏. Der feit Det Dpetation vergangenen Seit. 


\section{23eobadfuntgen uீber einige 2rten}

\section{Sit Swolf}

K. L. M. N. O. P. Q. R. S. T. V. X.

I. 2. 3. 4. 5. 6. 7. 8. 9. I0. I 1. I2.

Seitraum. | Der Sct)mang bon T.V. war | lánge oet wie: noch fo toentig gewadjfen, Derigetuatfenen Dafi man es int bloffen ?h: gen fout nioft bemerten sollc. Imien. fonnte.

XIX. 2ưguft.

I I

Roppfe yon L. M. N.O.P.Q.

R. S. - - -

Ropfe von T. V. $\overline{-}={ }^{\mathrm{I}}$

Schmainge von L. M. -

Erchwant von N. -

Erfimållje von O. Q. R. - -

Sinwang von P. $\rightarrow-$

Sdjwanj von $T$. - $\quad \frac{x}{4}-\frac{T}{3}$

- Der Stawanj von V. war faft gar nicht gemachfert. Zllle biefe Sticke fratten an: gefartgen, Nanf̧runt ơ nef̧men.

5 XXIV. 2\{uguft.

16 Ropfe yon L. M. N. O.P. Q.

R. S. T.

S(j)wanj von L. Sd)wanj yon M. - Sthwánje von N.O.P.Q.R. Stfivanj von $S$. Stgwang won $T$.

V. war gar aidft getwathfen.

$$
\frac{2}{3}
$$

I

$3 \frac{1}{2}$

$3 \frac{3}{4}$

3

$I \frac{\pi}{2}$

I

165. Det feit Der Dperation vergangenen Beit. 


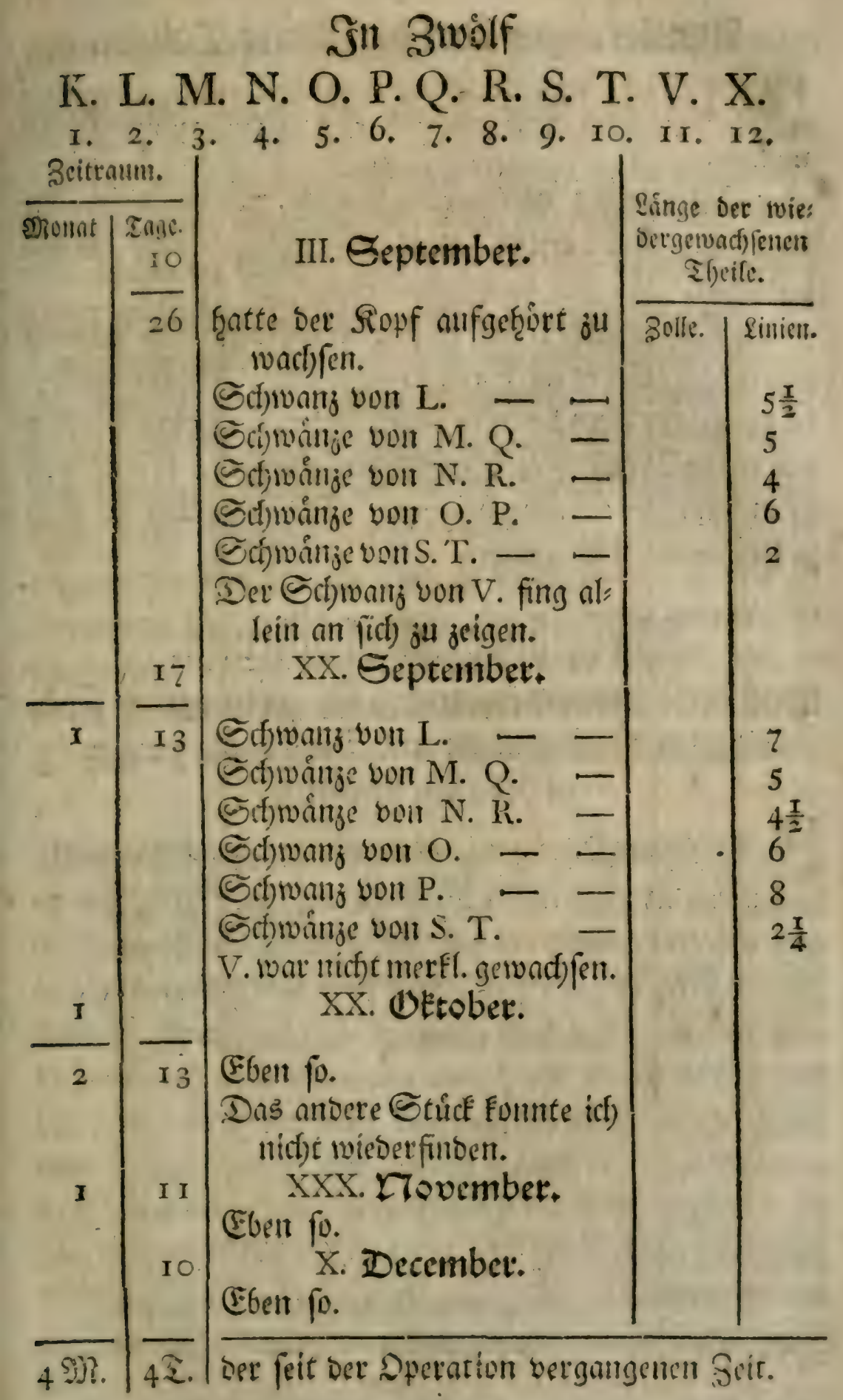


238 - Beobactungen uீber cinige 2rten

\section{Anmerkungen úber Die Bierte Sabelle.}

Sofh will iber biefe Tabelle nur joven Zfmmertungen maitjen.

Die erffe: Daf́f fie eben fo wobl, als bie britte, bic bren aus ber eriften gejogenten folgen, Doer Såge beffátíget.

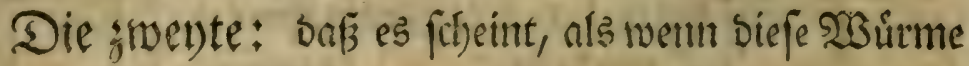
gegen ben sibinter auf hioren ju wach) fent. 2trabenn werben

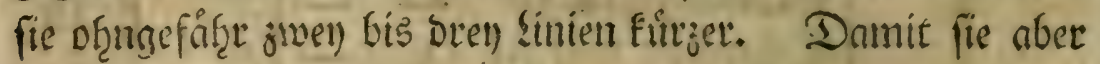

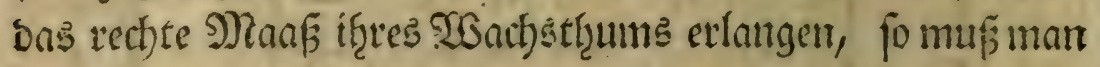

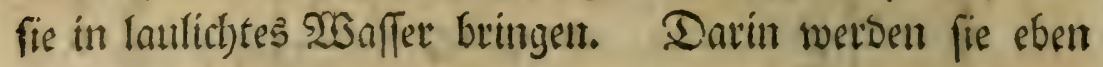
fo lantg, wie im Sommer.

\section{Siergebnte Beobat)tung.}

Dás Diefe 28 urmer, wenn fie jerfounitten find, einerler) Serwegungen uns Triebe, als vorther ju behaltent icheinent.

S.

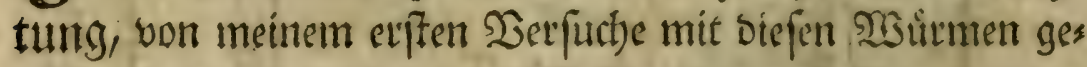

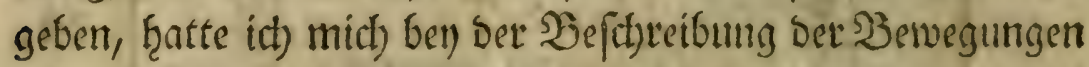
jeber Şålfte, in Den erffen Sagen nact) Der Dperation, etwas

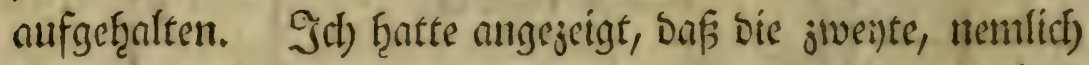
bie, welche Eeinen Rouf ḩatte, benntąe ebent fo vortwarts ginge, als weenu fie einen gehabt hâtte; bof es folien, als

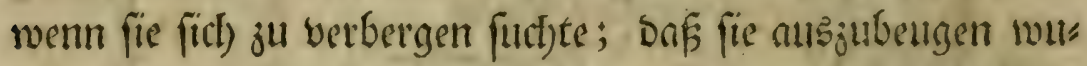

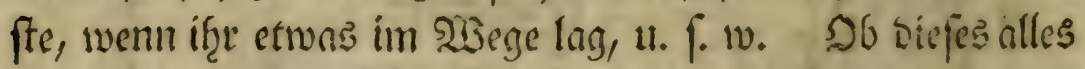

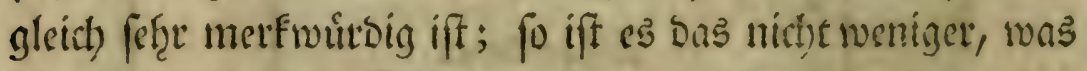

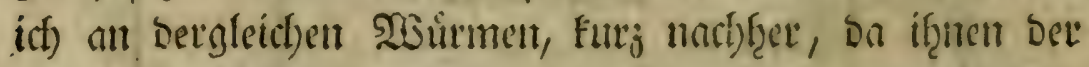
Sopf abgeffgnitten, waf̧rgenommen hุabe. Sall mentem grós

*) Confiderations fur les corps organif. Art. 285 . 


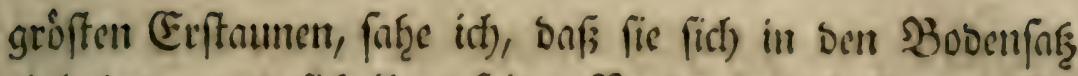
einbobzrten, und fich) iţres fpirzen Worbertheils bedienten, fich)

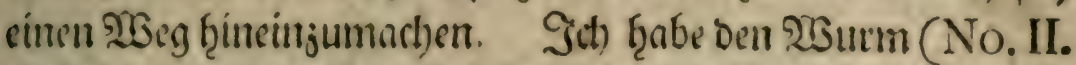
Sab. 11.) lanngs an den Seiten Des (3) lafes, worin it) if̧n aufs bewah̨ret ḩatte, Ģinauffriect)en fercen, ob er gleich) weder Ropf

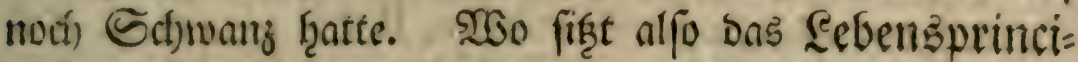
pium in fold)en शrourmen, went fie, nad)bem if̧nen ber Sopf abgefdrnitten ift, nodt) eben biefelben Berwegungen, ja was fage it Een? WBie vid anbere Sd)wierigfeiten ftellen fich úber: Dem ben biefer Sache, auf einmal unfrem Semutiţe bar?

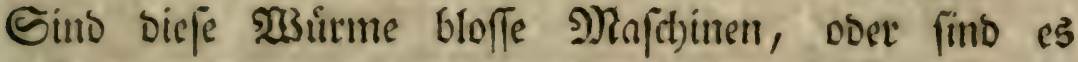
jufanmentigferte stbefen, beren Triebfedern eitre Seele in Serwegung feft? Ilno wenn fie ein fold)es J) Jincipium in

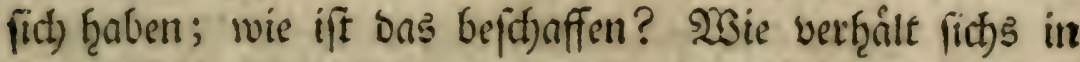
jebem Etưfe? Mh m man in jebem Sndiviouo eben fo viel Eeelen E) annef̨men, als es Stúcfe beffelben Indivibui giebt,

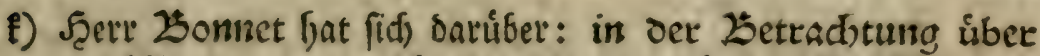
Die ZZatur p. 249. Fefor (d)arffinnig erflaret: "Die Polypen: fecle ift cinfach. Sie ift, wie jebe antere, untbeilbar.

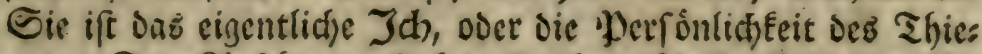

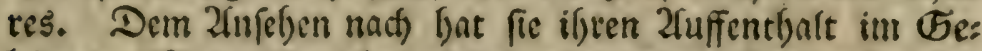
biene. Sigit wiffen aler nidft: woie, uno eb liegt nuth nidfts

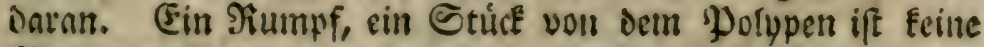

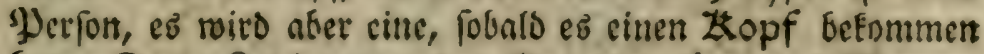
fat. Diefer Ropf war in Dem theime vorljer da. Doarums follte Darin nidbt audb eine Gecle práexiftiren: Gollte

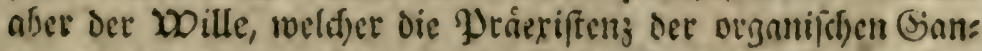

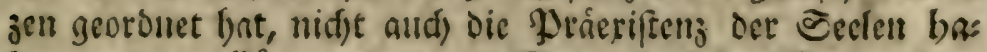
bers oronen tónnen? - 2 Sem jeglicher Zteim feile Beele bat; To ift jeglidfer Sein eill vermifotes STSefert. Diejes 2 Sejen wiro ein Jd, eine Perfon, fobulo sie Drgana ge:

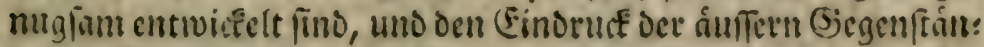
De sut Eeele bringent., $3 e t g l$ mit Den Confiderations fur les Corps organifés. Tom. II. Chap. III. Art. 283-290. 


\section{Besbachtungen úbet cinige 2 rten}

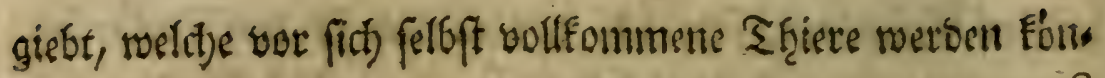

nen?

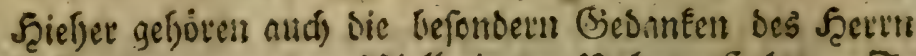
Drof. Crufius von oer Dielbeit oer Polypenfeclen. E. Deffelben 2 (nleitung iber naturliche 25egebenbeiten ordent: (id) uno vorfidhtig mad)ztwoenten. II. Cb. p. I229. S. 569 . ".TBeil Dod) aus jebem Eticfe tvicder ein ganjes uno befeel: tes Ifiet wito; fo id)einct faum ctivas anders vermutf(iá)

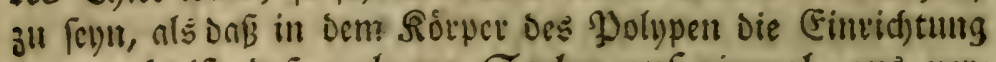

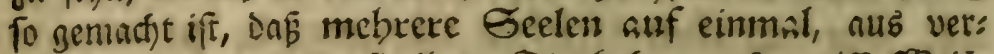
fajiebench Srten, mo fie iben Eiş baben, auf gesvifle șeije

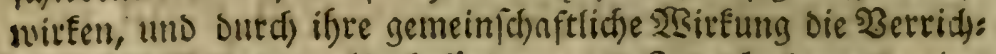
tung oes Polypen alfo befordern: Oaf Joch itgeno eine

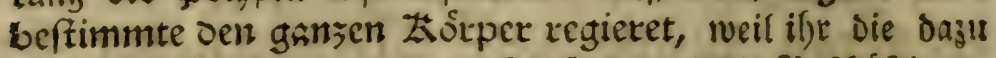
geborigen șerficuge unterworfen fino, uno die 23ejájáftigntu:

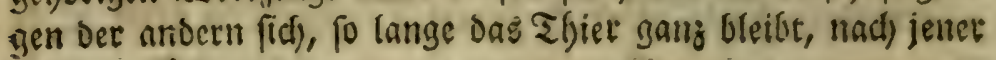
vicften millerl.,

9) Jeine Lefer mogen fier bem Eyfeme ifjen Vెeyfall

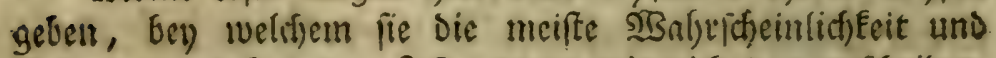
Ueberjeugung finden. Jef getraue mit nidjt so juentid)eiden, weil mir bie praemiffen wo!! Woillen, 2ulmacht, unb Eons nen, nod) immer eintige 3weifel úbrig lafien, of nid)t aud)

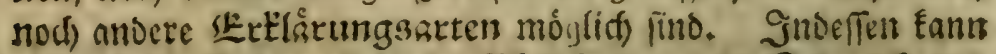
man biefes alles, was bende 'jofilofoplen mit Schmule und

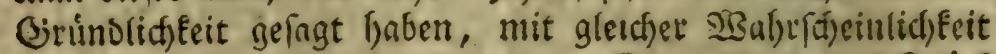
ouf bie toosfferwourme anwenoen. (Fin zerfónittenes Cture

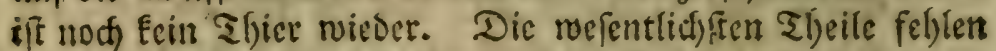

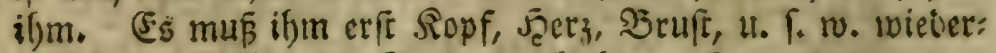

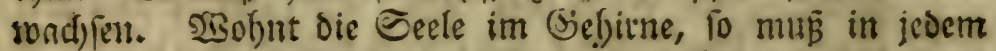

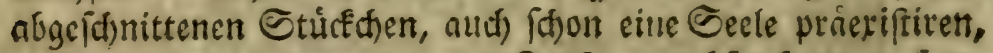
weil an jebes wicoer eit neuer Sopf amtuad) fen Eamm, u. T. w.

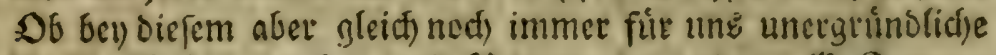
Siefen bleiben, wobev, mit bonnet ou reden: 佂efranen ano bewunberung ibren Gegenfano jwat erbeben,

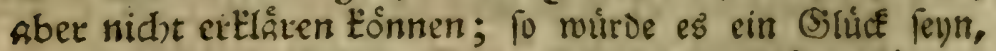
wenn man biefe (Siebrimniffe eben fo leicht erflaten finnte, als man im Etande ift, Die Eimmuirfe ju miderlegen, weltho

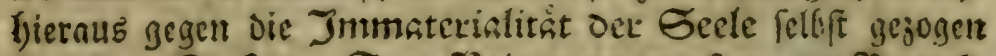
werben. ङ. Sern. Cam. Keimaxus angefangenen Sitind): tungen úber bie liefondernalrten der thieriffien Runftriebe ac.mit

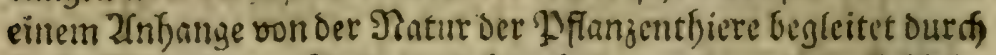

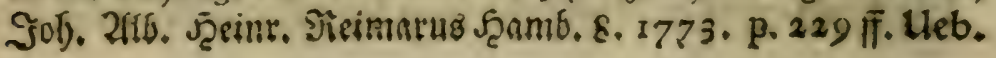




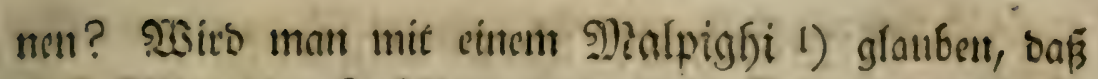
Diefe 2leten von Gitfiften, von einem Enbe jum anbern,

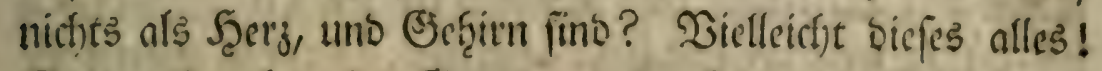
Gino wir aber in (Srumbe, babutch) meiter gefommen?

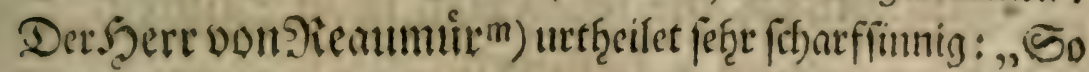
, weit fich autc) unfere Entbecfunnen in Der Эaturlef̧ce erftres

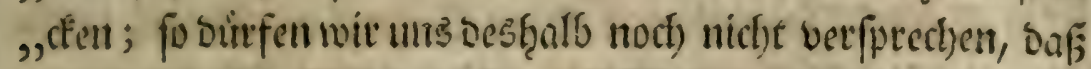

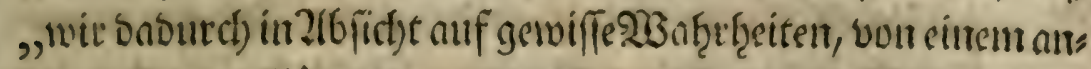

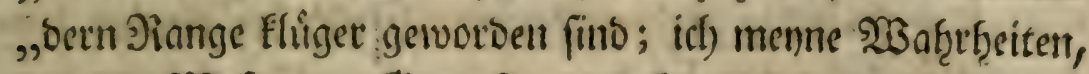

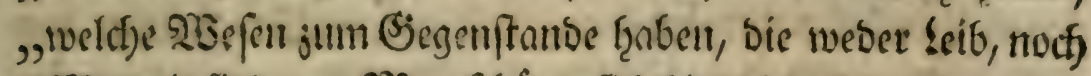

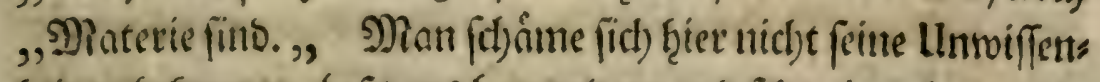
Fecit ju befentuetr. Lafit uns betwunbern tind (d)weigen lernen $n$ ).

1) Diff, epift. de Bomb.

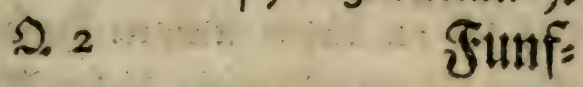

mi) Memoir. pour l' hift. des Inf. Tom. VI. pref. LXVII.

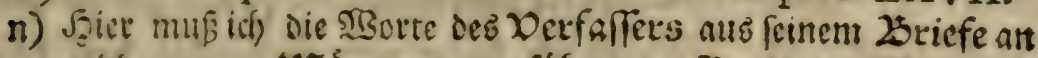

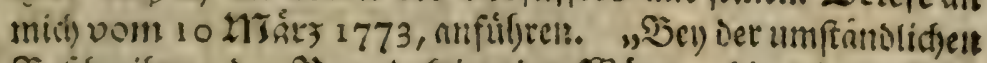

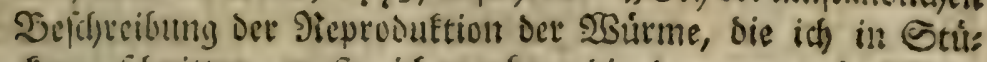

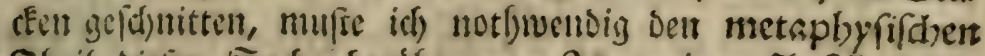
Theil viejer Eache beruffen. In meiner Infetologie II. Cb. XIV. 2beobacht. babe id) Davon mut einige sigorte,

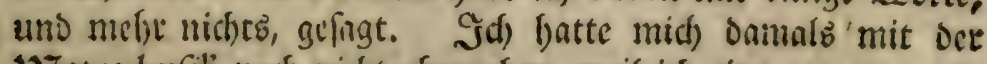
IIJetaphyfit nod) nid)t abgegeben, weil id) eine gar zu groffe

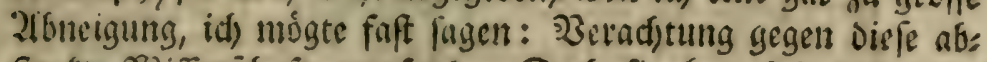

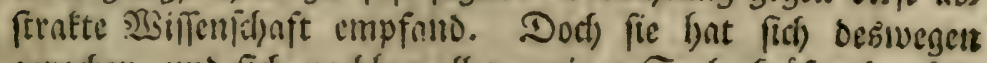
gerveden, unt fíd) uadber aller meiner Seclentrifte bemáds:

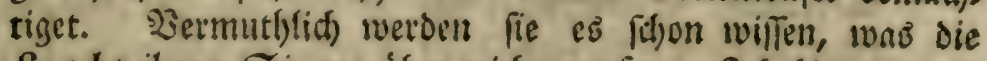

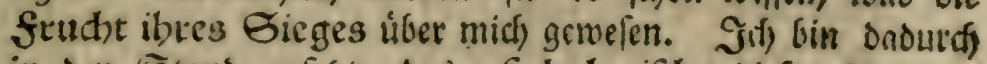
in. Dent Etand gefeste, Das pfychologifhe Diefes feltjament Pbaenomens tiefer zu elforf(c)en, davon id in meiner Jus seni mur bas phy fitalifane betrad)tet batte. Serveiren fie

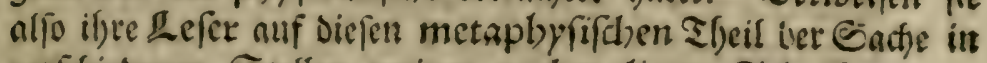
verichicoenen Etellen meiner nadhmaligen Edhriften, wo

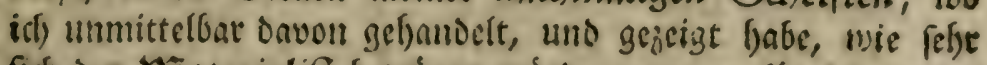

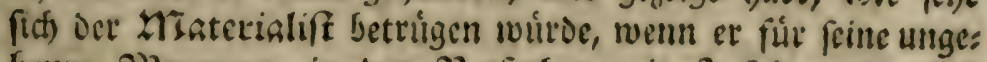

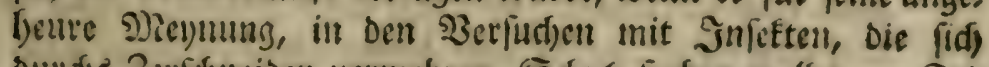

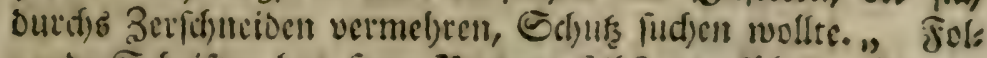

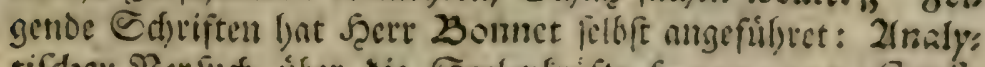

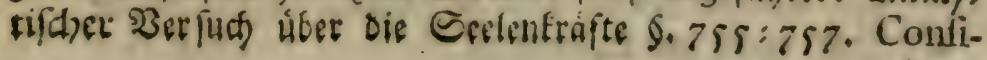




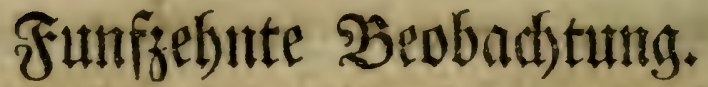

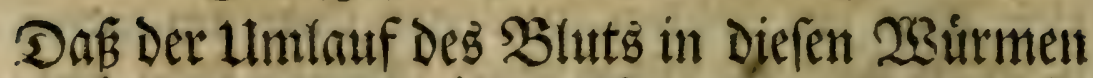

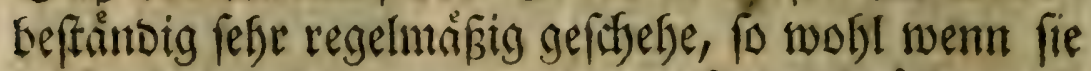
ganj bleiben, als wernm man fie in Stúcten (a) neiber.

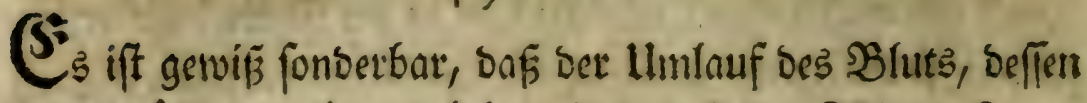

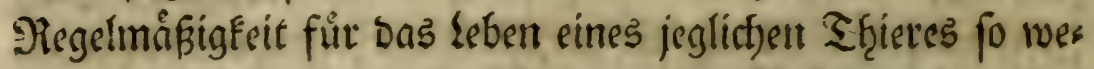

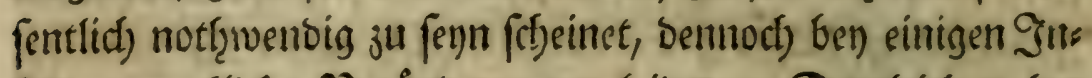
feftent merffitif)e ¿ierånberungen leibet. Dergleidfen ţat Der Gerififemte SMalpighi ${ }^{\circ}$ ) an Dem Seibenwurme bemerft.

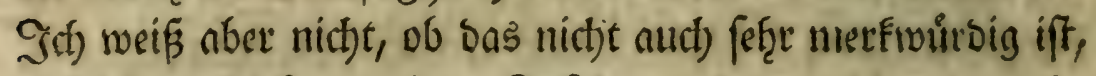
Daßj id) an biefen meinen Sunferten, Davon id) rebe, nies mals bie geringfte von bicfen ßeránberungen waḩrgenoms ment: zu welther Zeit ober in wellthem Zuftanbe idf) fie aud)

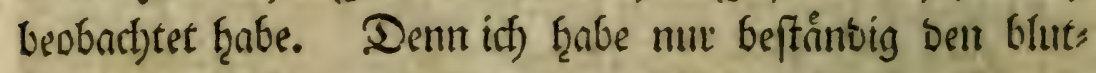
áf̨nlicjen Saft, yom Scthwanze nach) Dem Ropfe zullaufen

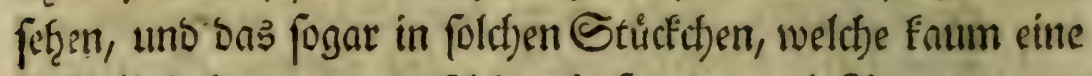

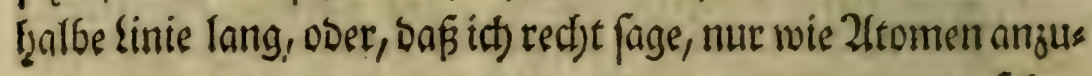

Fef̧en

derations fur les Corps organifés. Tom. II. Chap. III.

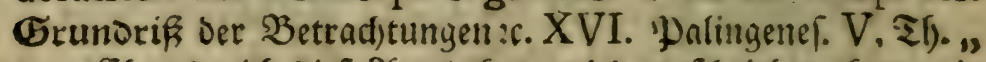

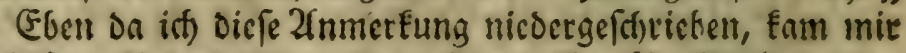

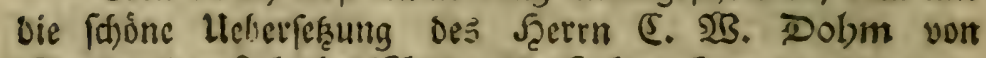
(Donnetš) piydyologifhem Derfuche. Lemgo. 1773* 8.

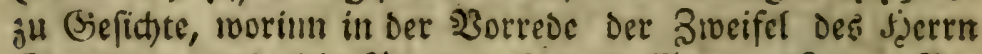

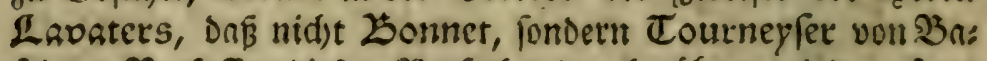

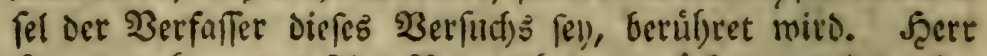
Lavater fyat zroar feine 2Betmutfyung jurúcfigenummen, aber

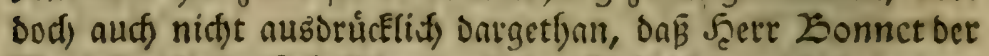

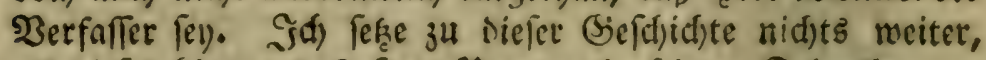
als biefes hinjul : Daß Şeter bounet in feirtem Sdjeriben ant

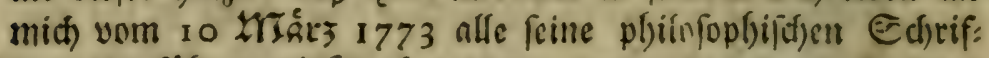
tent, angefiuffet, Diefer aber weder unter feitrem, nod) eincs

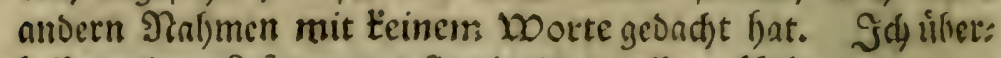
lafie meinen Refern, was fie glauben woullen. Heb.

•) Diff, epiit. de Bombyce. 
fefent waren. So mar íf) aud) im Stantbe ben 23orbers theil vom Scintertfreile zu unterf(t)eioent, unt mict), fo viel es

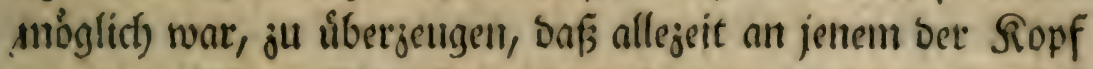

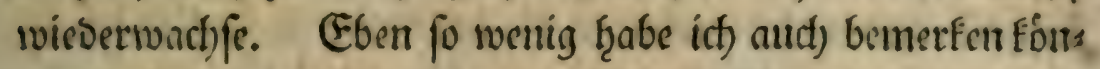
nen, baf nach) ber Dperation bas $\mathfrak{B l}$ lut gefichwinber ober lang: famer geloufen wáre. Man weís inderfen, baßß foldi)es nad) Detwunnoungen, bie nod) weniger, als biefe ţier zu bebeuten hąben, gemeiniglith) ju gef(t)eḩent pflege.

llebrigens red)ne ich nicht ju ben eigentlid) fogenamus

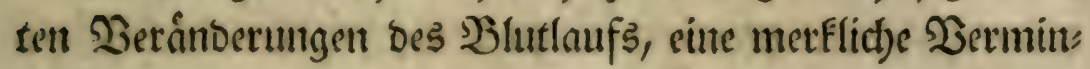
Derung beffelben, Die id) vft an ferget ausggef̧ungerten, uno

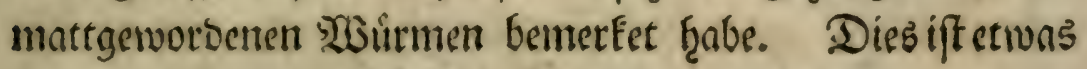
ferge natirlidjes.

\section{Ged)รzelunte Beobait)tung:}

\section{Dañ Diefe WGirme ein feftr zartes (Sefiill} baben; autf) nid)t gan; Des (jebrauchs Des

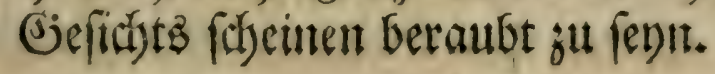

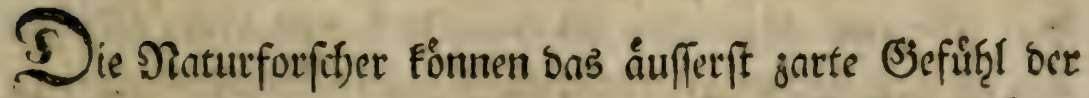

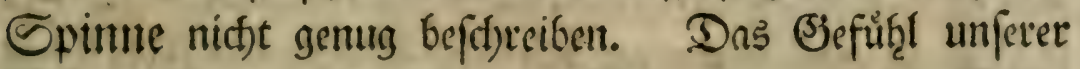

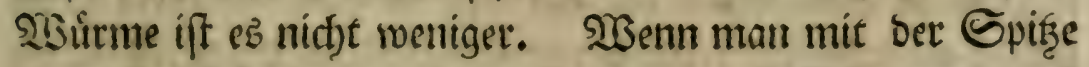

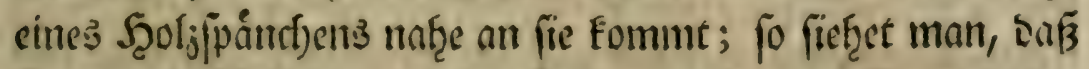
fie wie bie 2fale fiin unto fzer fïringen, ef̧e man fie nod), Das

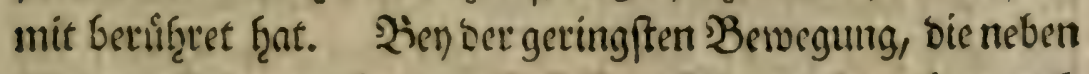

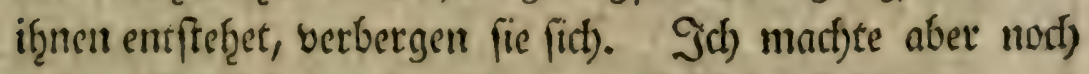
anbere 23 erfurdse, woben iff ungenvis blieb, ob idf bas, was

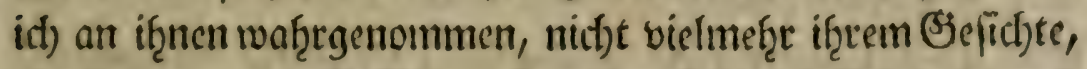

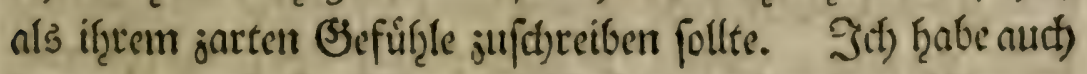

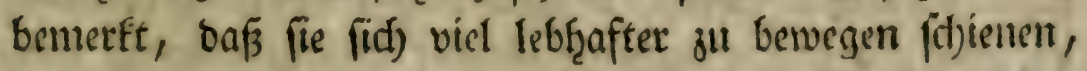
wem bie crffen Sonnenfrafilen auf bas șanfer in bent 


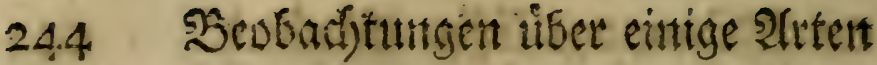

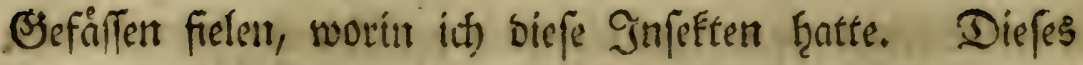
Eam mir eben fo vor, wenn ing fie in Schatten fergte, uno vermittelft eines Spiegels das Sonnenlicht auf fie fallen

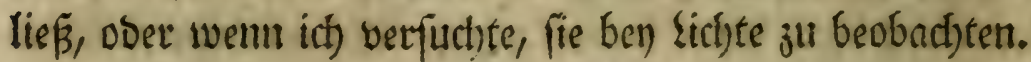

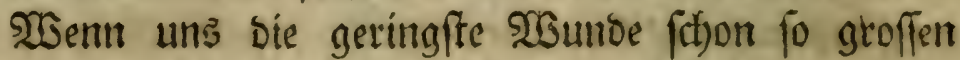

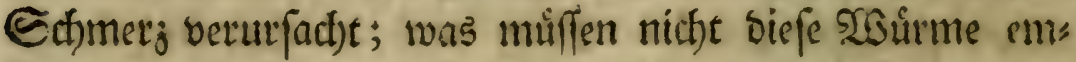

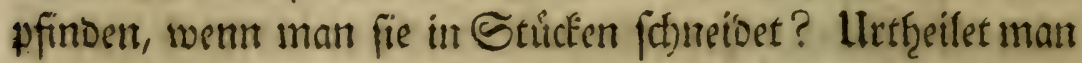
aber Davon nath Dem, was auf Diefe fthroceflithe Speration folges; fo follte man faft geneigter fern; folche nicht fo

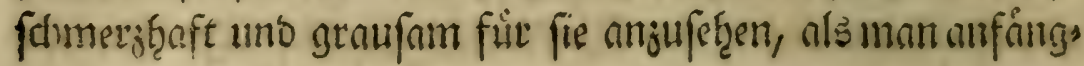
licb) gebact)t frat.

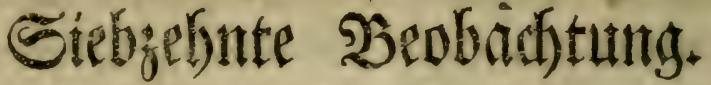

Heber einen Fiemen 23 afferaal, Der lebendig

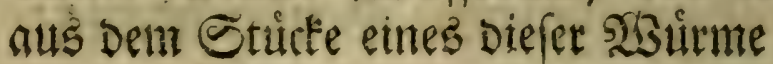
getommen iff. *)

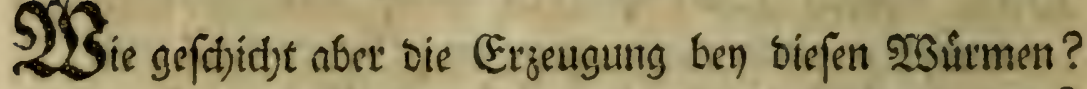
Sint es Eebendiggebáfrende, Dder Enerlegende?

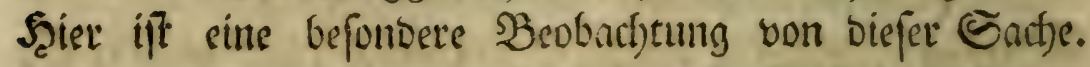

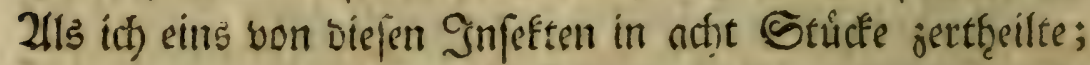
fo fafte ich) aus cinem ber nádiffern Stúcfe am Ropfe, silt

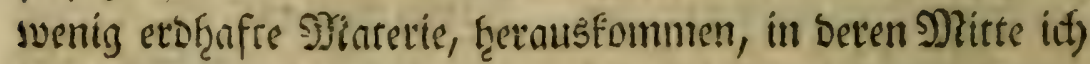

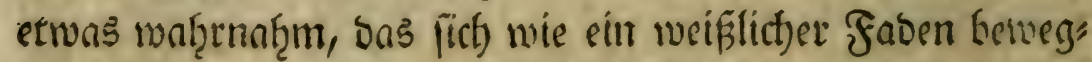

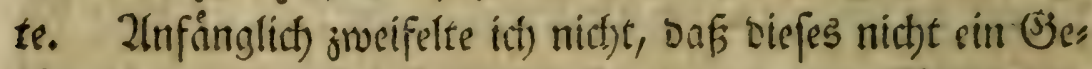

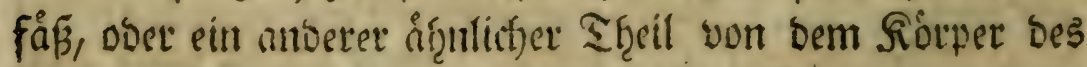

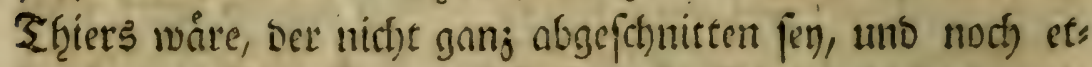
was won feiner tebensfraft äufferte. Da ith midh aber mit einer guten toupe wafnete: wie gro 13 war mein Erftaunen?

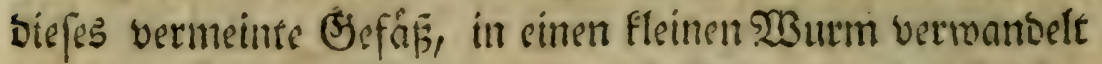

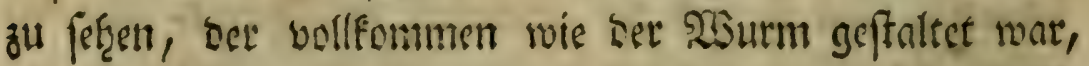

Corps organifés. Att. z;0. wels 


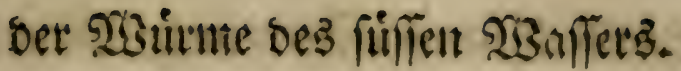

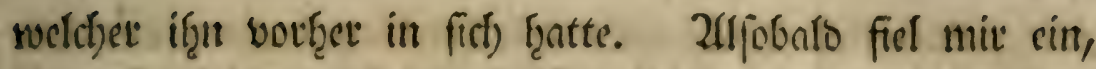

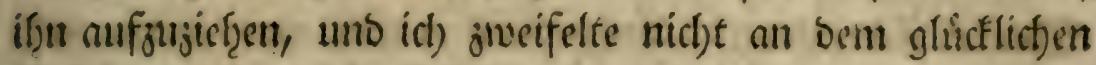

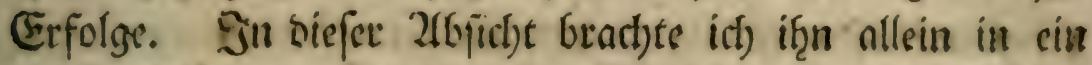

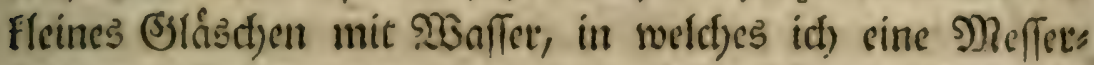

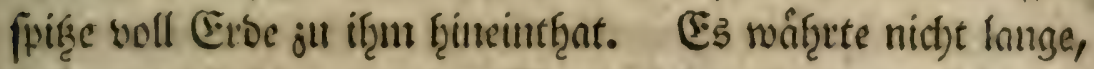
fo Fonnte icl) fithon aus ber s) Runterfeit, mit ber er ficly sins

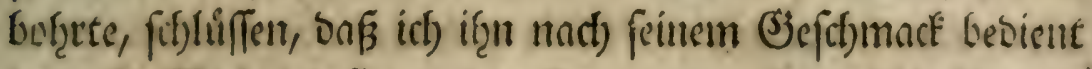

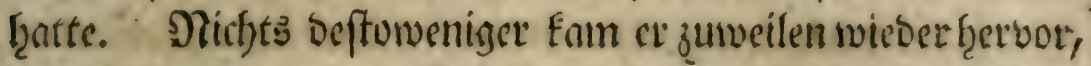

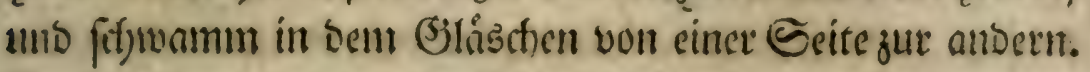
Dantu fonnte man bie Sebraftigfeit feiner Bewegungen nithe genung berumbern. S) San glaubte ein bergleid)en 2ấls

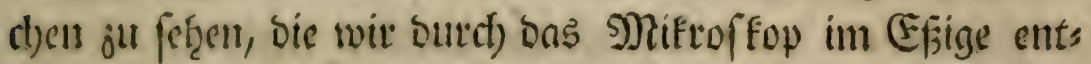

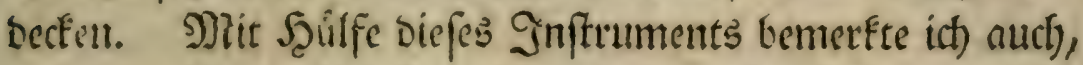
Dof feine Siinge fotherfer, als an Den groffen 23 ürmen biefer

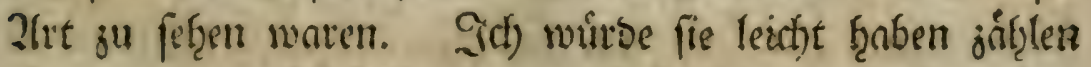
fonnen, wenn bies Sfierchen weniger lebhaft gemefen wâre.

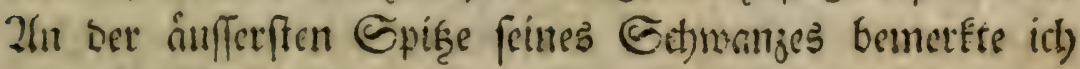

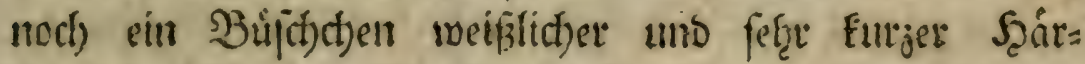

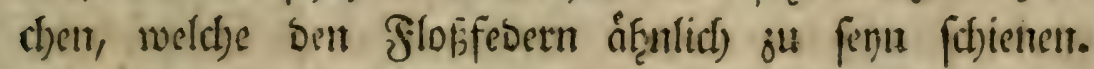
Es ge(t)ahe aud) bas Edfwimmen wirflich vetmittelft mies

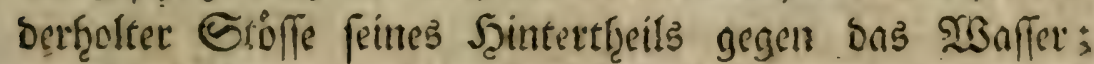
butch) Cróffe, bie er oft mit einer ausnef̧metiben Şurtigfeit nush nach Der entgegen gefergten Seite ju that. Es wat if̧m noch cinte anbere Bewegung cigen. Er Exúmmate fei: nen Rórper wie ein Pieif, umb gleid) jug et if̨n wieber gernoc.

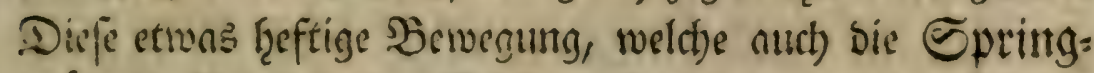
muime, *) Die in ben Erbfen gefunoen wetben; an fid) fras

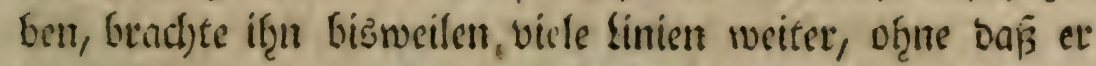

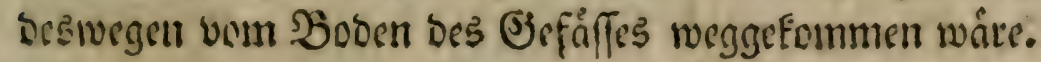

$$
\text { (2) } 4
$$

ZuIf

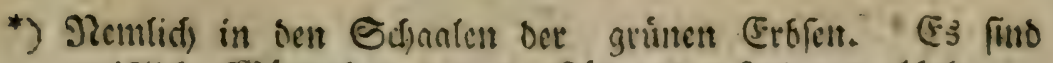

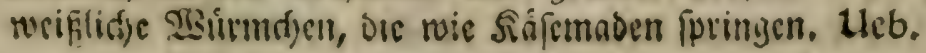




\section{Beobadytungen über einige 2rtent}

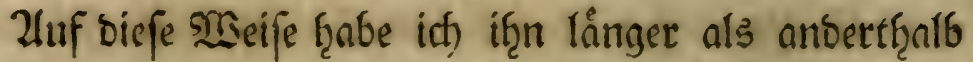
Monate beobact)tet. Sulez̧t fam er mix, zu meinem gros ften Serberus ourch einen unvermutheten Sufall meg. In: Deffen aber ḩatte idh boch zum Thęil wenigftens Dasjjenige

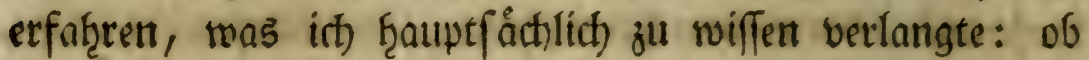
nemlich biefer $26 u r m$, Den ith) auf eine unnaturliche 2 (rt burd) eine Speration jur 2 Selt gebrad)t, bie man mit Dem Rayjerfinnitte vergleichen Eann, P) nicht nur fortleben, fonbern auct) noch in ber sange zuneḩmen wurbe. Llno bies

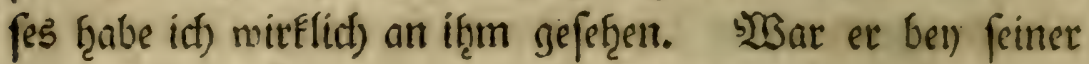

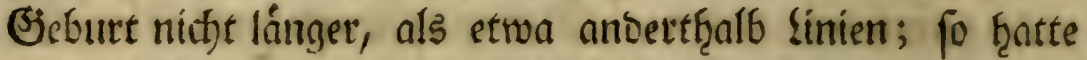
er wenigftens jween, als mir bns llngluce begegnete, if̨n ju verlieren.

Eine fo unerwartete Entodfung beivog mich, bas Sinwenbige biefer 2 Sturme, mit neter 2 ufmerffamfeit ju unterfurtyen. Wermittelft eines guten Scanoglafes glaubte ich) barin groffere 2 Surme ju erfenten, uno auf benden Sei. ten ber groffen 2lrterie fleinere ju fef̧en, Die bem vorf̨erbes

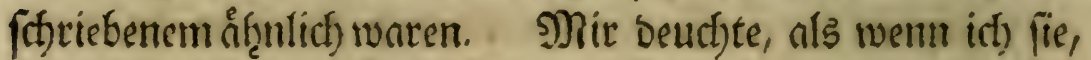
fith auf berfdésbene Seiten bewegen; als wenn ich) fie, fict)

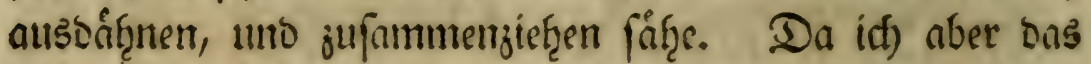
rect)te ßergrofferungsglas zur Scano nafeın; fo fing ich an jul jweifelli, ob bas, was id) fothe, wirflich) fo wåre, als es oul fenu fchien. Es fain mir vor, nls menn es vielınę̧r Sweige ber Giefoffe waren, won senen id) in Det erftent Bebbactutung gef̧antelt f̧abe, timo bis man fur alogánge ber Şauptatterie ( $a$ af. I. fig. V. d, d, d, ) F̧alten follte. Dn ich) inocflen, bicfen Werfuch firter oft wieberţolte, uno bie

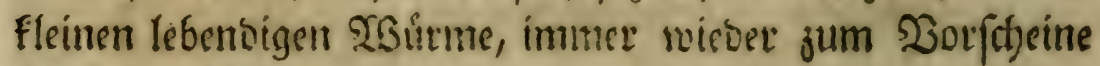
famen; fo blieb idt) omsifeltraft.

S(t)wer

p) (5. Confiderations fur les Corps organifés. Art. 250. visuller von Xcismetn $26,8.18,11 \mathrm{cb}$. 
Schwer aber ift mir's gewefert, mein tlrtheil, in 2 (b:

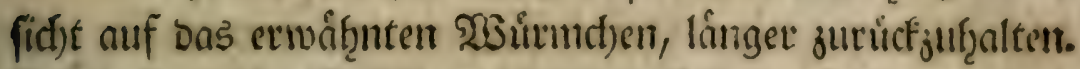
Sid) hrabe mich alfo nict)t entbredsen fonmen, foldjes, als eis

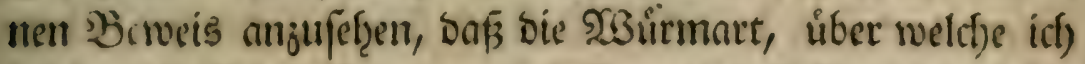
bier meitre SBeobad)tungen anftelle, ju Den Lebendiggebål)=

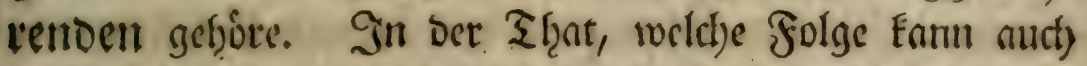

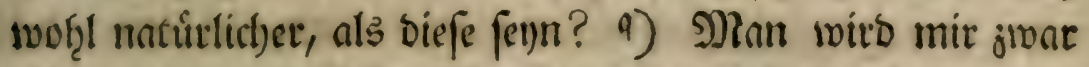

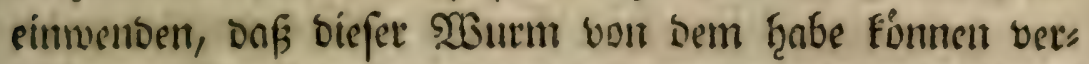

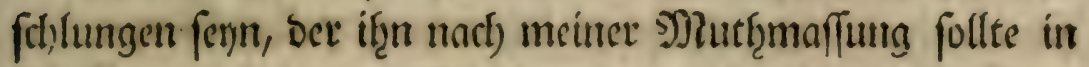

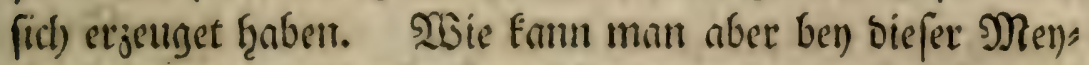

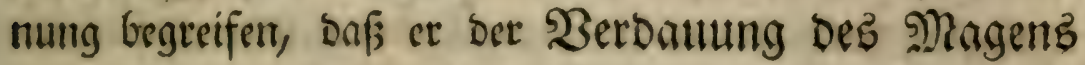
D. 5

hृabe

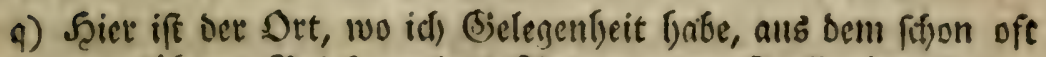

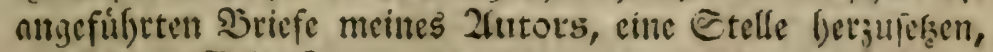
meld)e ber șelt feinen eigenen ganzen liebenswoitoigen Charatter vor Rugen legen mito: wie fich auch sie gros fien uno beribmteften Gelebter oes Setenntmifies nidht

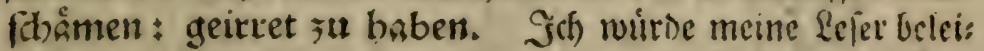

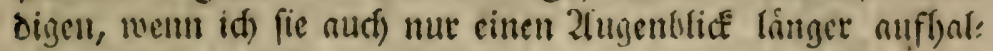
ten wollte. "Iidh var, fdjecibt er, in meinen lletbeilen úber woie Biegenfránde, Die id) vor 2lugen hatte, nid)t immer vor:

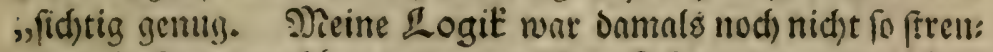
wge, als fie ce nadhler getoorden ift. Sith madje, leftêt er bin:

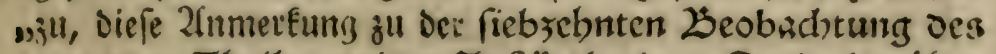
„„wecyten Ibcils meiner Infettologie. Darin bemúfete

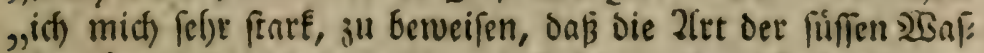
"Fetwuirme, Die id) Damals unterfud)te, ju den Lebenoigge: "bĭhrenoen gefóre. Ein fonderbares uno unvermutl)etres

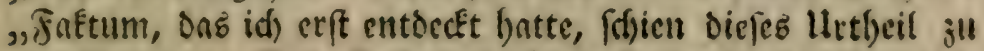

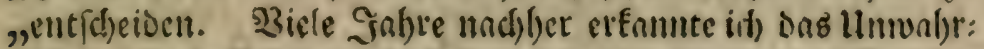

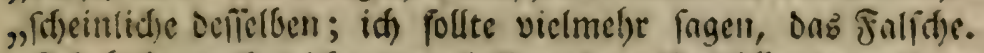
". Sch Gafie aud) nid)t unterlafien, bem publito in meinen "Confider. fur les corps organif. Art. 2 go. Dawon Piadf:

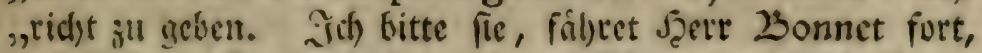

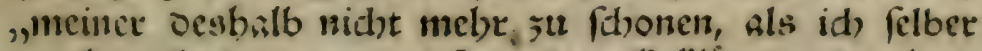

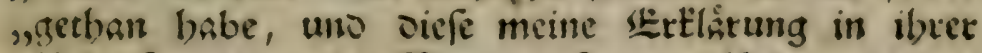

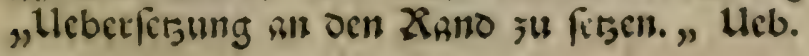




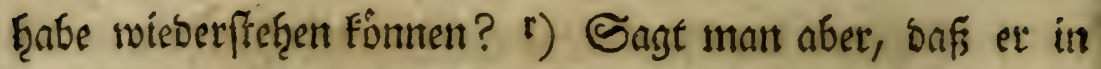

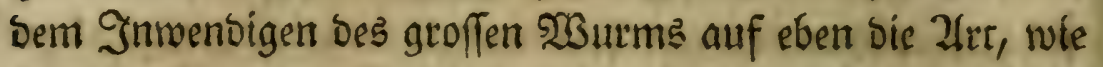

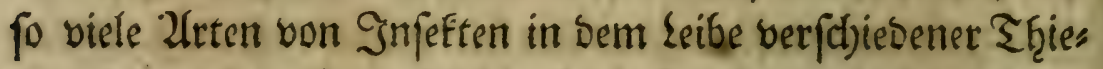
re erzeriget fen; ; fo werbe ich gleith) frongen; wie frat er Denut anverthalb Nonte, auffer feinem natúrlichen stre leben

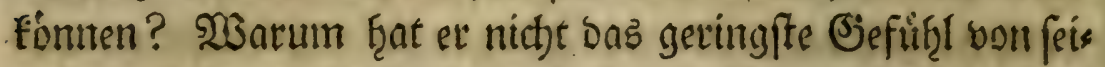

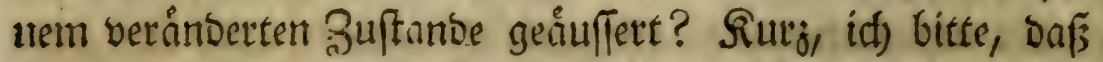

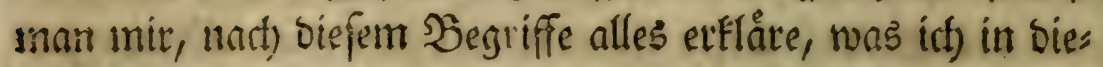

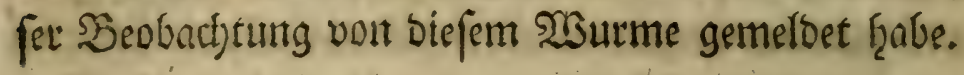

\section{Idbt:}

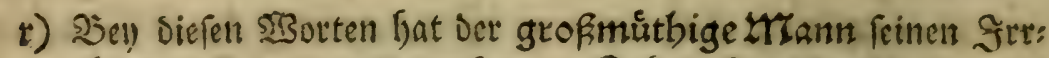
thum aufs neue widertufir. "Seben fie, fdreibter, wie

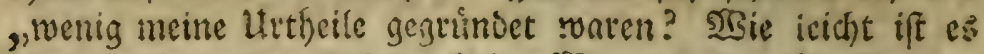

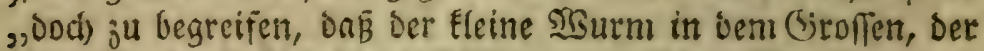

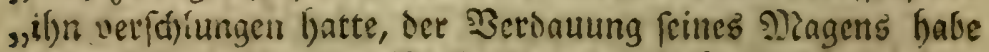
, miberféfen Eonnen. Wiefleid)t batte er ifit erfe vor Siut: yent verlidlungen. Uno vie viele untrughlid gerwifle (Erfaly:

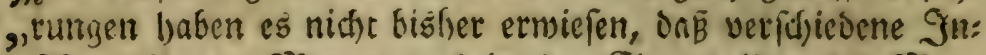

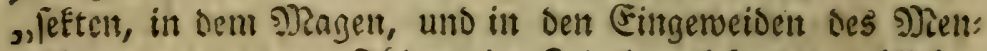
,jid)en, uno anderer Tfiere eine Beit lang lefendig gebliebent , fino?",

J) Tan letite an bem S3cyfpiele cines fo esfalyrnen und vor: fidjtigen Seufad)ters, wie (eid)t man fid) bel) mifrufEopif(d)en 2̧erfudjen betriggen, uno in Feinen Urtbeilen úbercilen fanm?

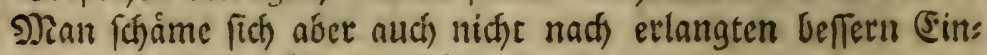
fichten ber siBnigrbeit Die (Éfre ju gebent.

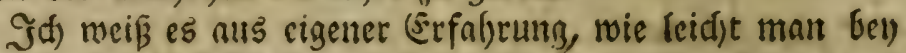
fold)en 23erfuchen fintergangen wirb, wenn man eimmal ge: roifle Sorurtheile fir cine Sadje im sopfe bat. Joil batte

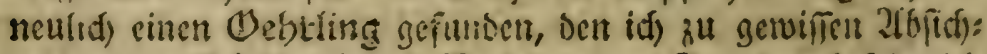
ten in eine Sitá) le that. SRach einigen Stuttoen belabe idh

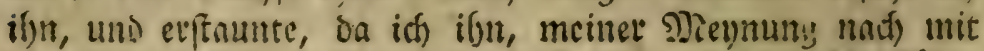
efen fo vicl Eleinem Unijejiefer befäet fano, als bet 2rastéfer an fich tringt, Den man den Cootengrŭber, (Silpha, Vefpil.

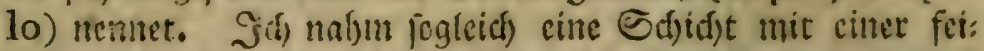

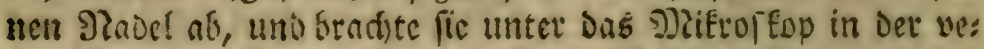

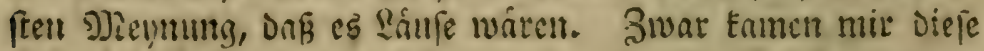

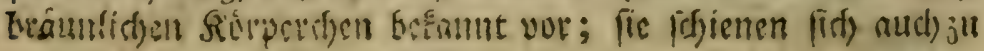




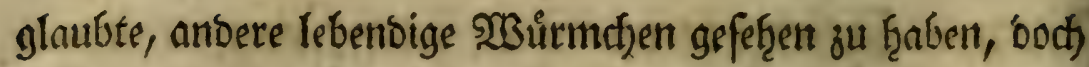
Feinesneeges fo glüclict) gervejen bin, aud) nur einen einjigen Diefer lef̧reten wieber, aus einem zerfdjnittenen Gtücfe ber exfferen ţerausjubringen. Es waren aber fect) sundogmants

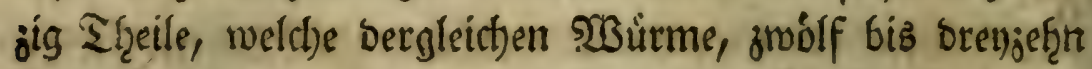

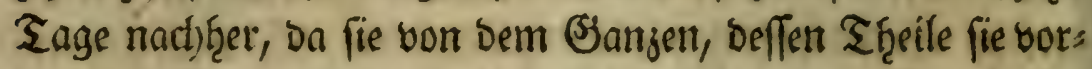
heer gemefen, getrenmet waren, geboren f̧abelt. Son biefen

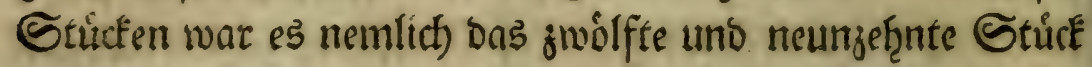
bes sisurms, von bem iff in ber adten şeobadstumg gereset halle, uns weldjer ben britten Sultus zerfthnitten

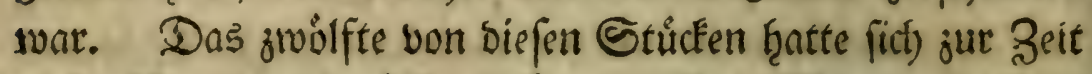
siefer @itebertunft völlig ergånzt. Sein Magen, und féite Eingeweide waren voll erbf̧after झtaterie. Das neuns żę̧nte aber f̧atte baumals weber Sopf, nod) Sd)wanj; es

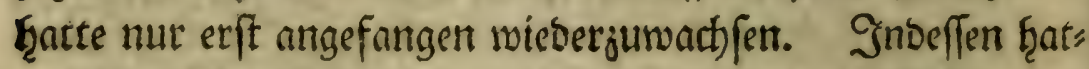
te foldjes vier fleine, Das anbere aber nur ein

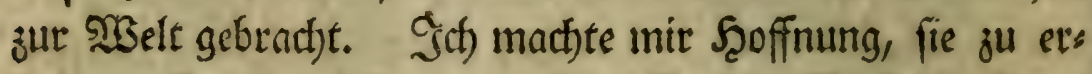
ḩalten: fie febten aber nur einige Tage. Sielleict)t ḩatte idf fie nicht fanft genurg aufgenommett, ba ich fie in ein ans

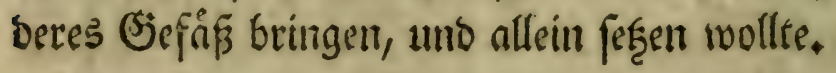

\section{ঐeantzefnte Beobatitung.}

\section{Dố mant von diefen 23 itrment mutfimatfen}

Eann, wie fie fid burd) 2us/chof slinge, nath Irt Der गुolypen vermebren. 1)

Siefe berúf̨mten भुolypen, an weldyen feert Tremblen

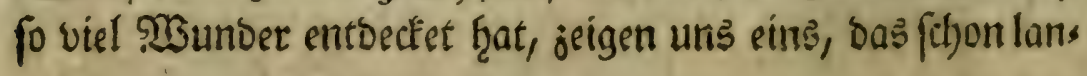

t) $23 e y$ biefar 19 und ber folgenten 20 23eob. nergieidie man bie Confiderations fur les Corps organifés. Art. 248. 249. 274. Heb. 


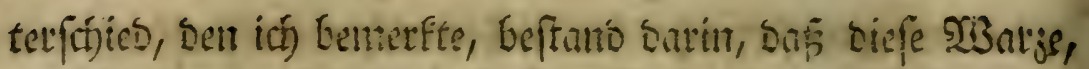

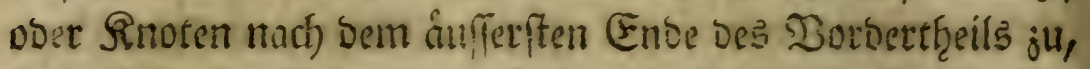
ben einigen melęr ober werniger sittgésegen war, als ben bèn andern.

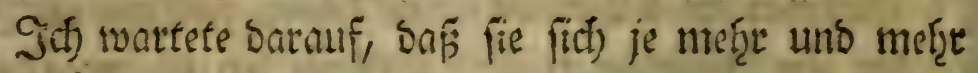
serlángern, uno unvertmerEt bie Geffalt eines fleinen 25urms antref̣men follte, wie es ben Dent jungen Dolnpen gef(t)iefet; icí) murbe aber in meiner Erwartung betrogen.

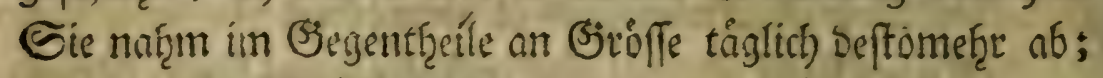
je meţr Das Stück fellof?, ju bem fie geţórete, in jeinem

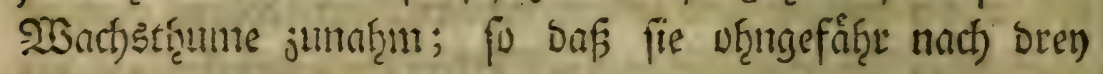

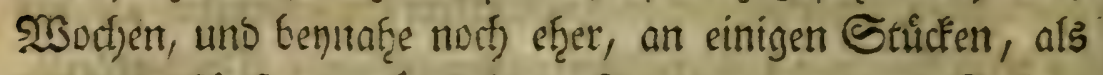
an bern finfert, ginglifit berfonmunten mar. Sollten

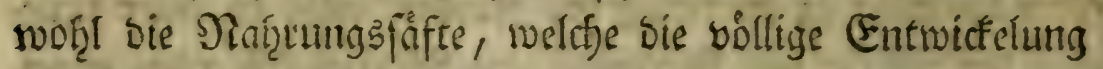
Des jungen Tisurms berwirfent muffert, Durd) Das betnetfbar: te Stúut aufgef̧alten fenn? Die Sacte Fommt mír nitht

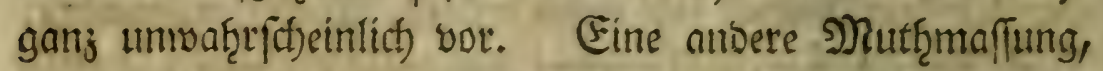

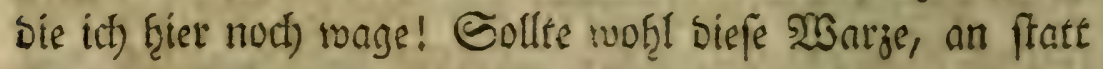

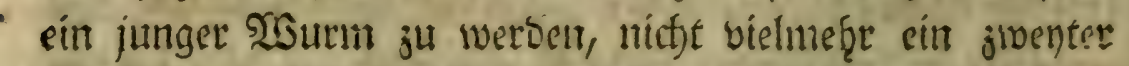
Souf fenn, Der wiber bie Sepefge Der פtatur geroadffen wáre?

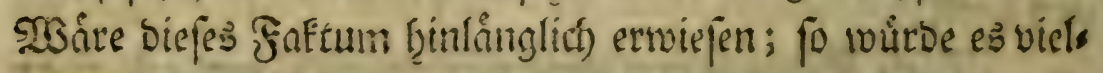

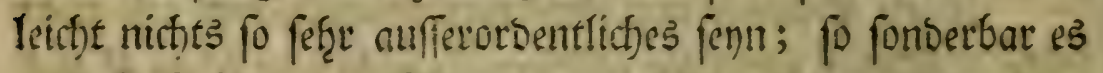

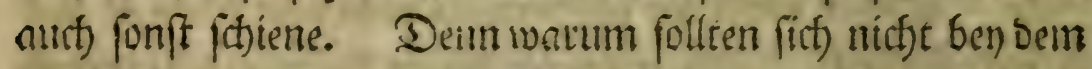

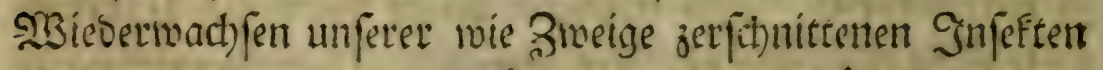

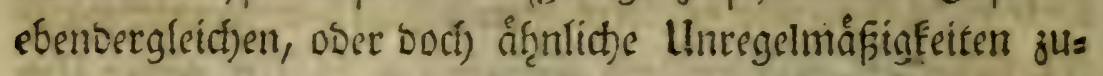
tragen, als wir fo oft ben ber Erjengung groffer Shiere, ferts

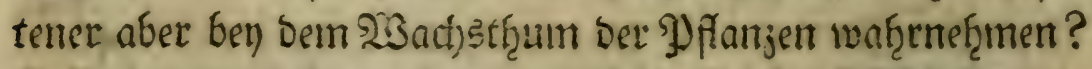
Eine Dromung Gíngegen, bie nietials von fith) felfift abrvict)e,

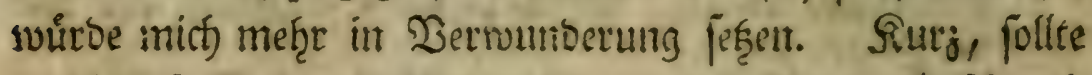

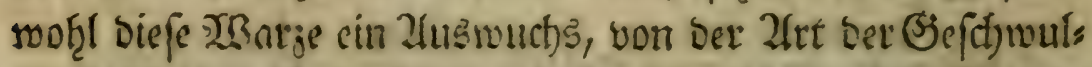

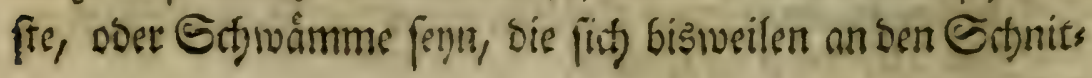




\section{23eobad)tungen über einige 2trten}

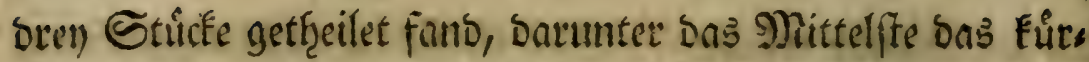

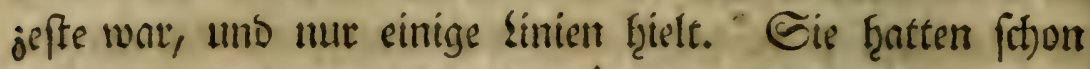
alle brel) angefantgen, fitt) jul ergänjen, gls id) an bem ญors berente bes britten, eime folthe 23 arje (Faf. I. fig. XV. B, )

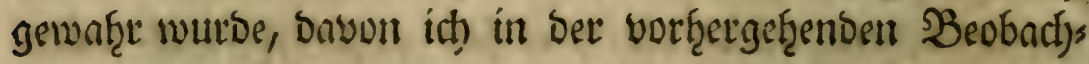
tung gerebet frabe.

Soll von bet Sorftellung, Daf bies ein jiventer Sopf

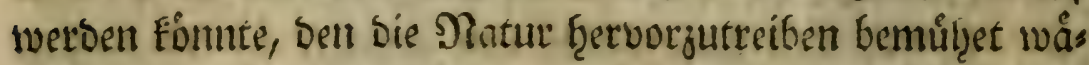
re, wartete idf einige Sage barauf, ob et fidd nicht ballo gantz entwickefn wurrbe. Da idi) aber bemerfte, Daf er inmer

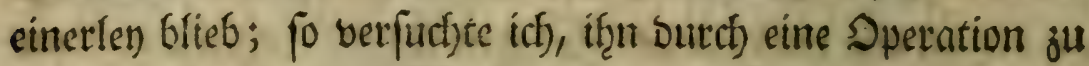
feinem vollfommenen গิS

Sid) mad)te bamit Den 2 nfang, baf idc) iţm ben Ropf

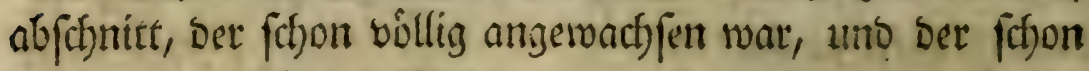

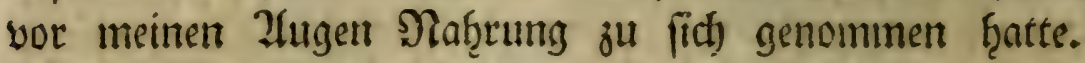

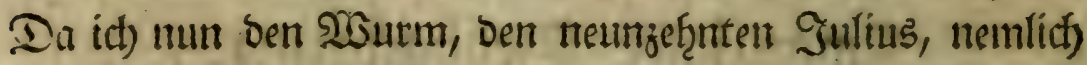

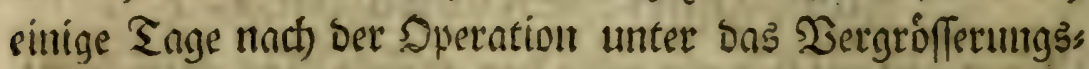
glas brad)te; fo bemerfte idf), baf ber neue Sopf bóllig ans gewad)fen; bie Sisnarje aber, Doer ber Snoten nicht weiter

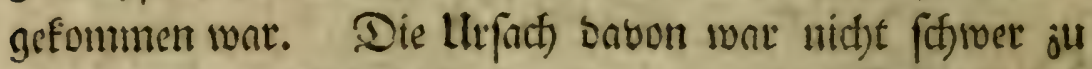

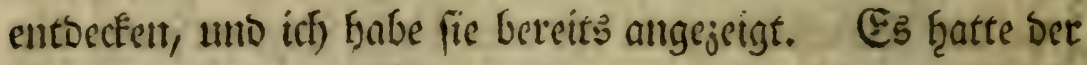

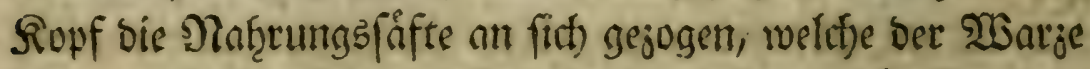

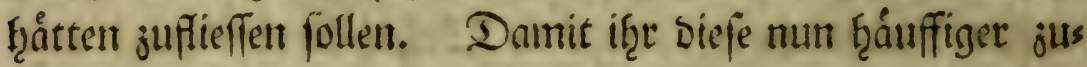

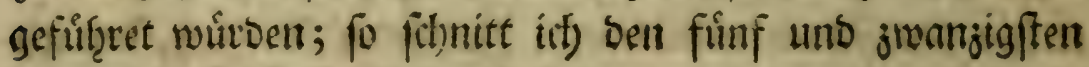
Dabon das äufferfte Ende ab.

Den fect)sten 2uguft fratte id) das \ergniggen, ju fes

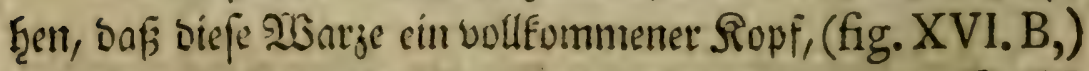
und eben fo lantg als ber ambere gewurbert war. Selbit

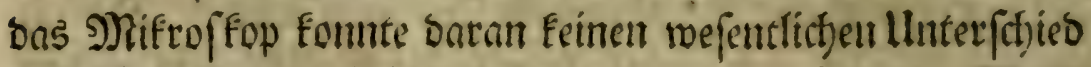
entbecten $r$ ).

खुenn

r) Şert Trembley if mit feinen Polypen weiter gefommen.

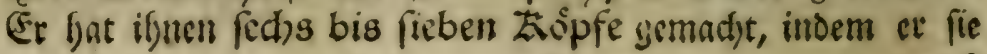




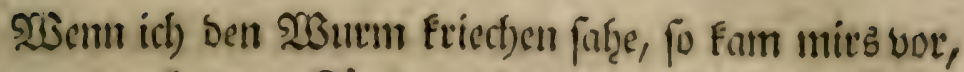

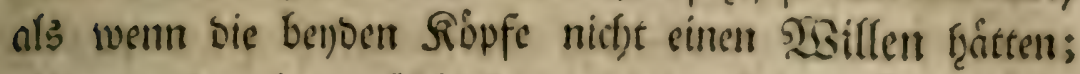
nls werm ber eine auf bie, ber anbere nuf jente Geite söge,

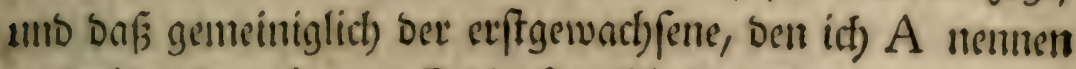
svill, úber Den jüngern B bie Şerrjọnaft f̧atte.

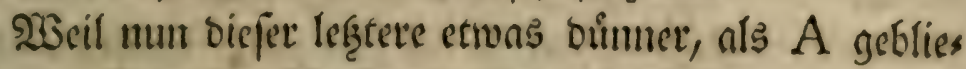
ben war; fo mollte ith) fie eitranter gleicher madjen, unb fothritt ben fiebjeçnten bas åufferfte Entoe von B ab.

Den vier uno jumangigften war es vóllig wieber ges

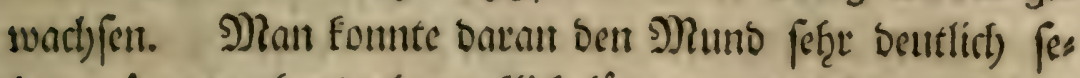

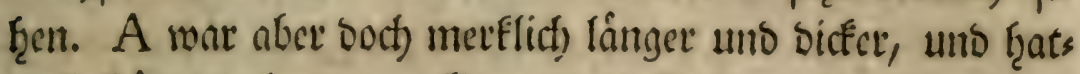

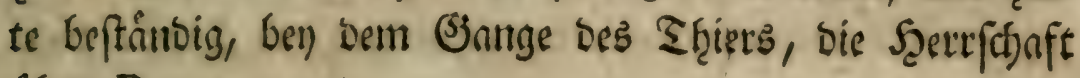
tiber $\mathrm{B}$.

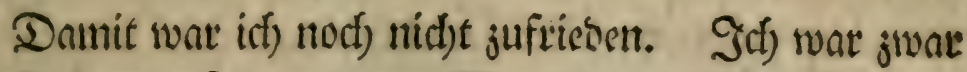

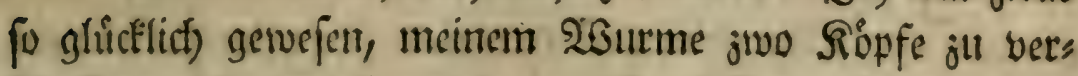
ferbaffen; iff) war aber niffet gensif, ob $\mathrm{B}$ ju eben ben wes

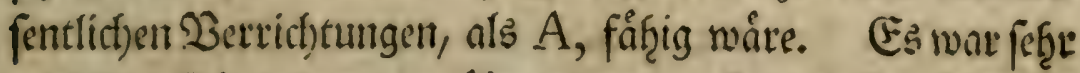

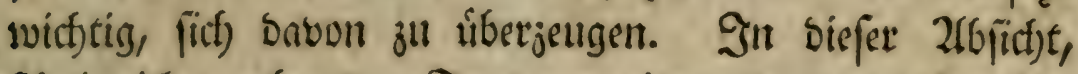

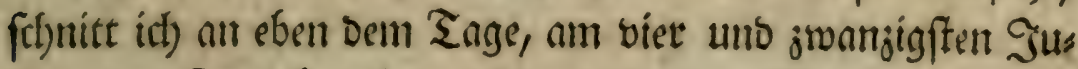
liue, ben Ropf $A$, ab, natjoem idf bem 2 surme bie Zeit selaffen hृatte; fid) ausjuleeren.

In ben erffren 2(ugentlicfen nact) Der Speration, bes merffe id, bof er fict) mit Dem Sopfe B im Retiect)en forts

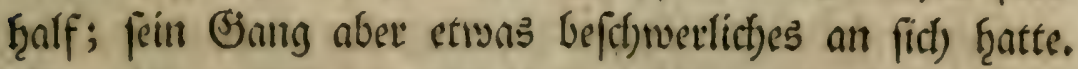
Man faţe es if̧m an, baf if̧m biefer jovente Ropf, lange

nict)t

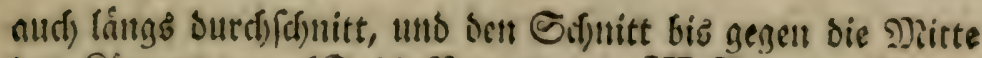

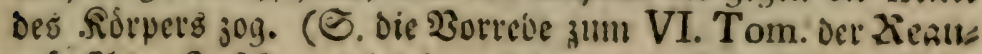

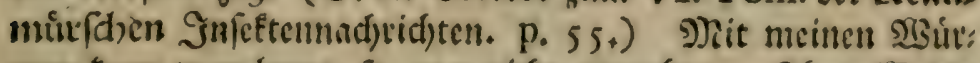

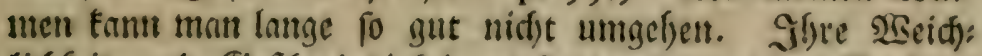

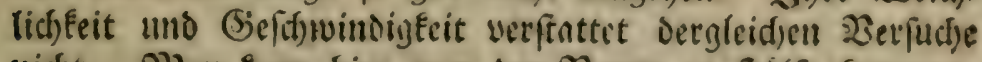

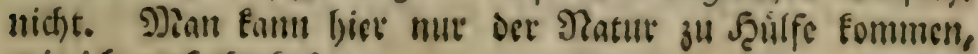
wie ifj verfucft flabe. 


\section{Sืeobachtungen uீber einge 2trten}

nicflyt fo gute Dienfife that, als ber abgef(t)nittente. Ere

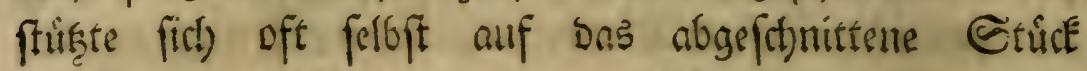
Defferloen.

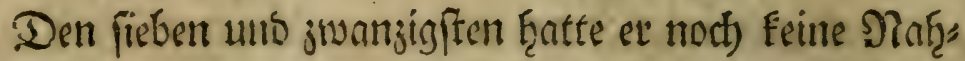
rung ju fich) genoummen. Seine Eingeweitoe maren Durct)s

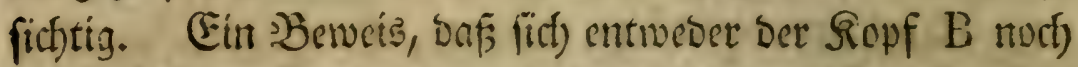
nidft voollig ergånjet, ober mit bem \$Plagen feine Ġemeins fiduft fratte.

Den neun unb jmanjigften war ber ßopf A wiebers

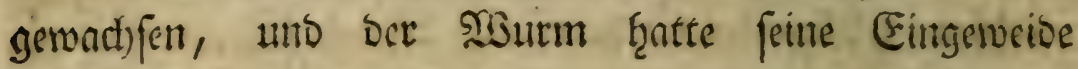
yoll Erbe.

Den ein uno brengigften funitt ict ben Sopf B bidfse

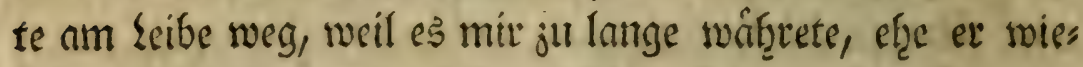
Der vollfommen ausmachjen wollte.

Den britten Eeptember war er fidjon zur Şâlfte wies

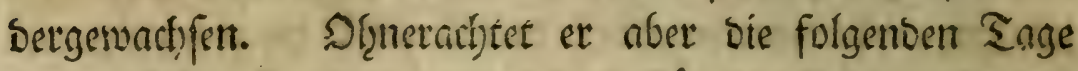
fortwuct)s; fo war er sodl beftanbig fleiner als ber andere.

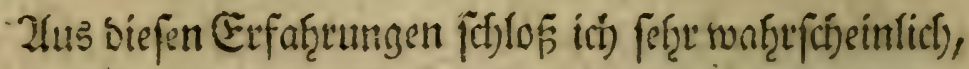

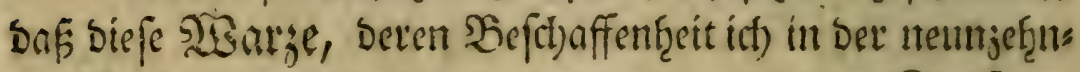

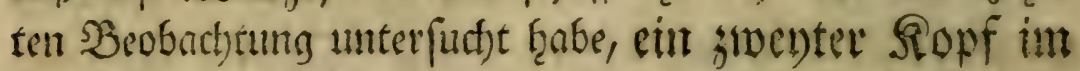
Stande Der (Entwictelung fer). $20 \mathrm{em}$ fid) Diefes fo verf̧ailt, wie idf) glaube; fo muf es uns fonberbar gemug

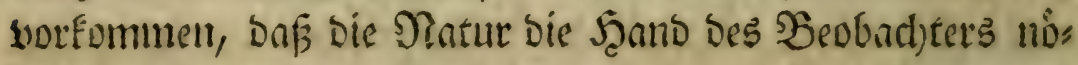

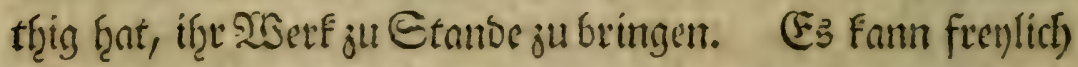
Sólle geben, wo fie beffen entúbriget fenn fant, uno mir fint in biejer Eacte nod) ju wenig unterrititetet, um gefdicft ba von ju utţ̧eilent.

Man wirb mir aber béfleich) einnenben: Daf bie

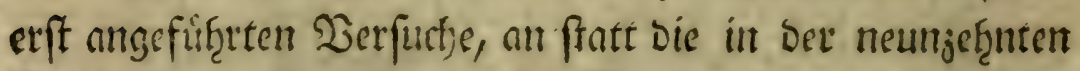

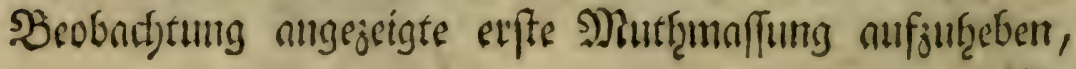




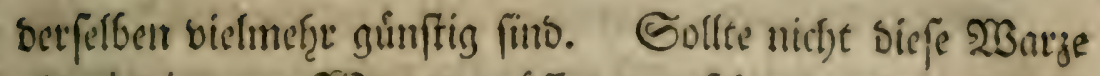

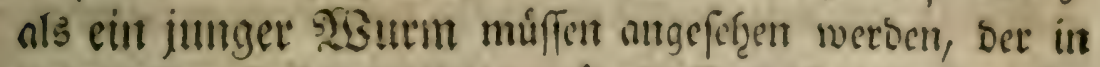
Dem anbern ftecten geblicben wire? Das ift ber Esinwurf,

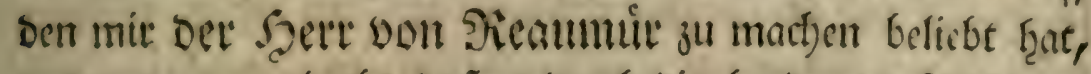

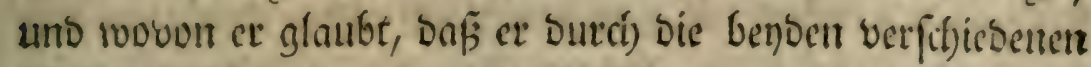

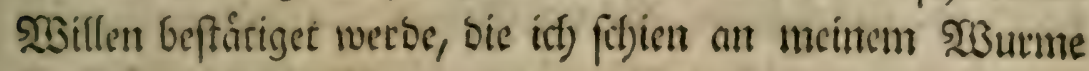
Eemerft't jut fraben ").

Zluf biefen (Einnurf faum idf) jwenerlen antworten.

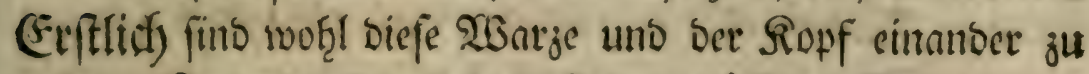
nahe. Swelntenz, ant bas ift von grofferem (Semictit, bes

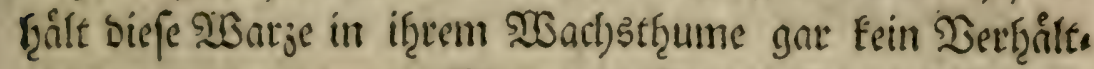

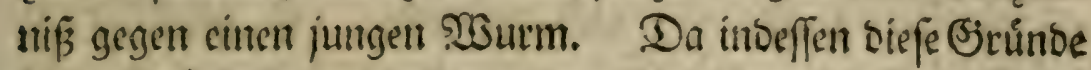

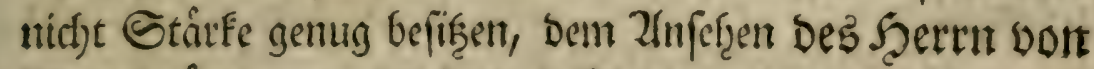

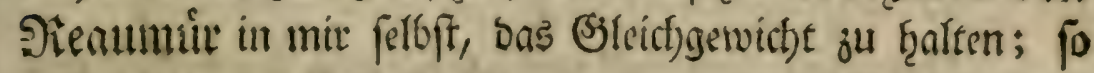
will id) mein lletheil bís ju einer neuen llnterfucfung verpparent.

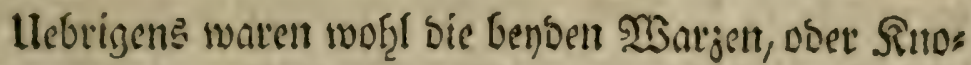
ten, bie ant benben Geiten bes Şutms నab. II. No. VI. fervorgefommen waren, von berjentigen nidje unterfityeiben,

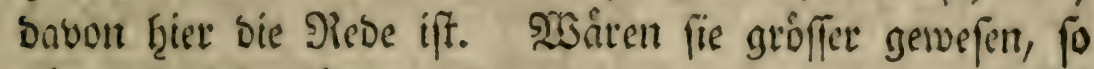

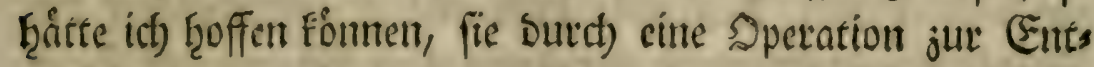
soiffelung ju bringetr. So aber berfuctete inth es vergebens.

Ulm bergleidfen noch) an anbert Tstirmen fertyorjus

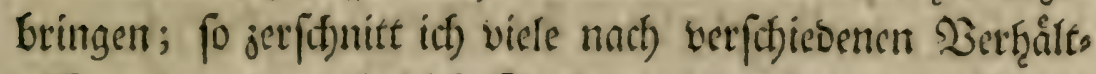

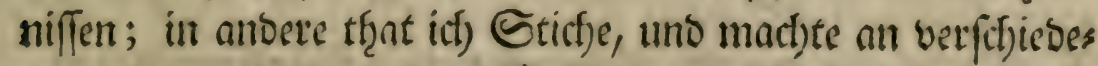

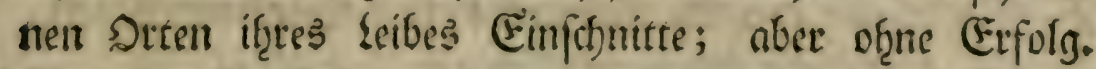

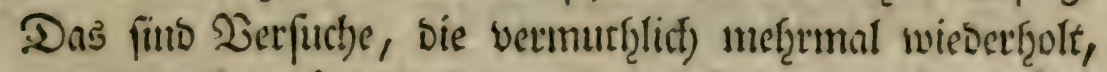

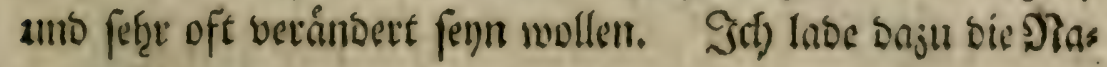
turforffjer ein.

\section{N 2 Meéne}

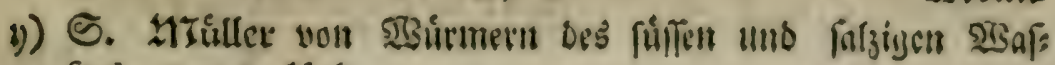
fers. p. 18 , Lleb. 


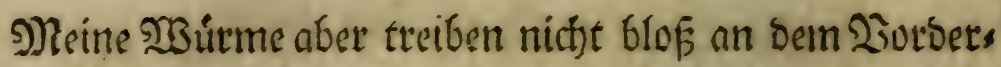

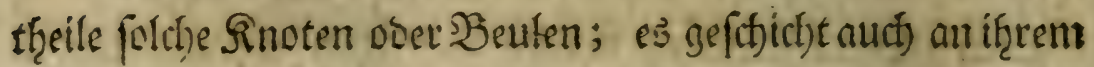

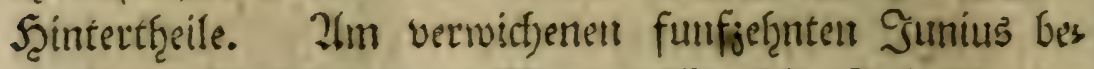
merfte id folches an bem 23 urme No. VI. Tab. II. und bas war bie llefact, warum id) mit ber eilften Dperation ver= jog. Ės verffit)want aber Der Sinteten, Der erft angefangen

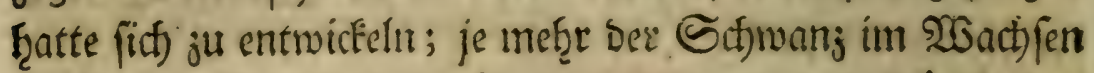

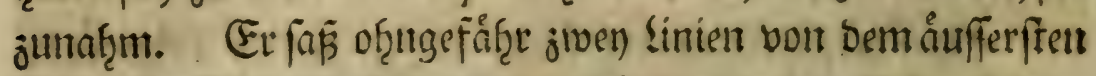

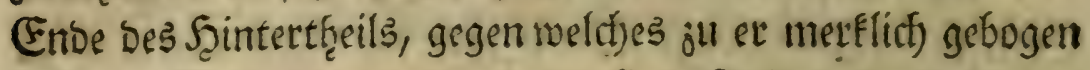

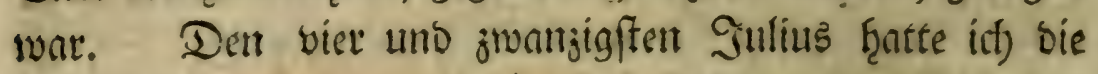

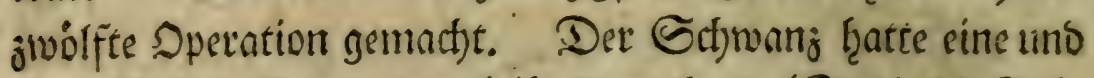
ein Drittel కinie; Der కeíb Dremjef̧n. (S. Die II. Tab. nin Enoe.)

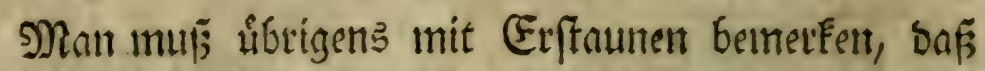

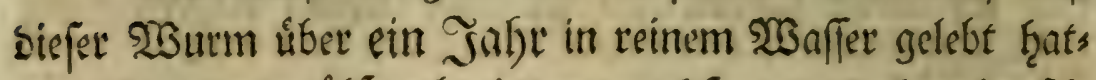

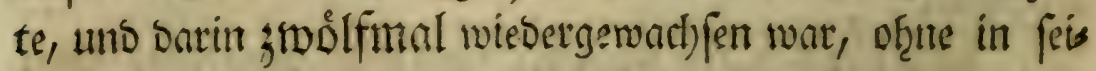
ner Seiberigefralt merflict) abgenommeir ju hૃaben. Şier

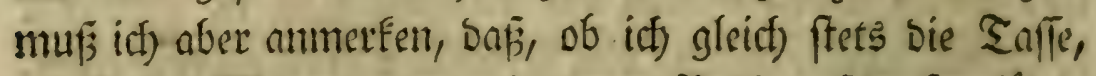
soorin ber 20 urm war, mit einem \$apiere ferge forgfâltig

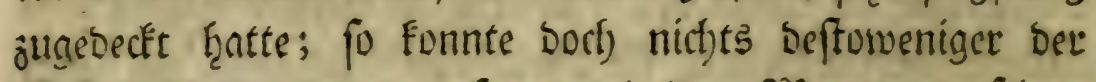

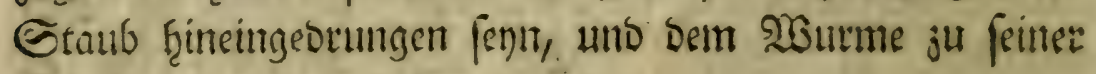
Erţaltung gebienet f̧aben.

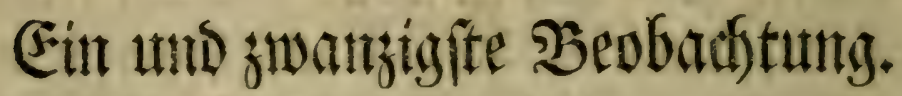

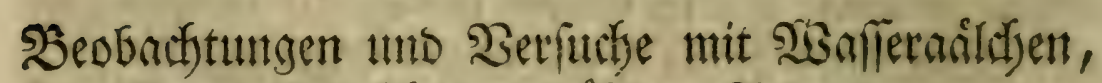

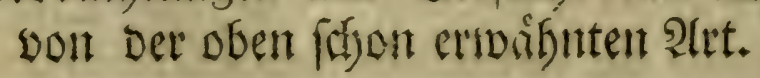

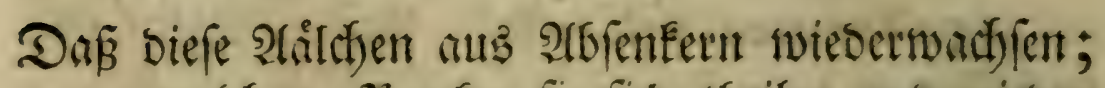

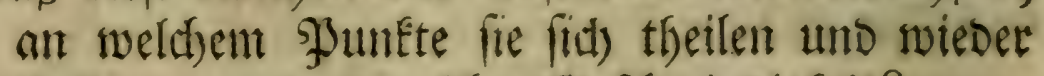
theilen; unt mit weld)er Gerihnindigfeit?

Inter; 


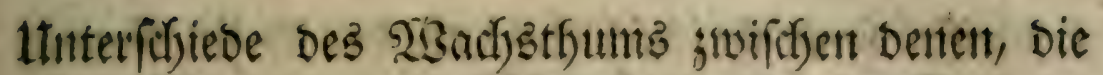

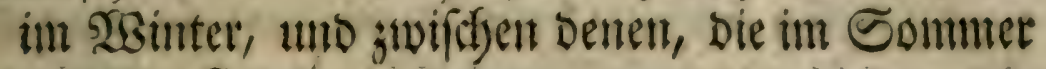
getbeilet fint.

9)

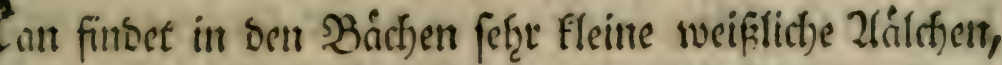

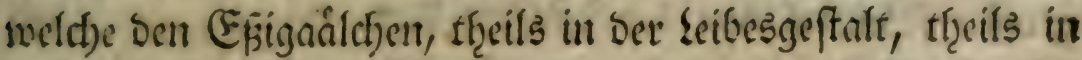

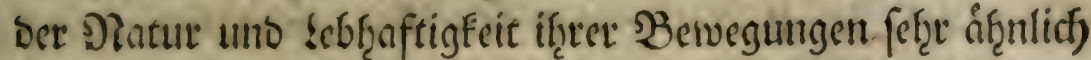
fint. 8) .0 unir gleid) if̧e llefprumg noct) nicf)t tect)t bes श 3

Eannt

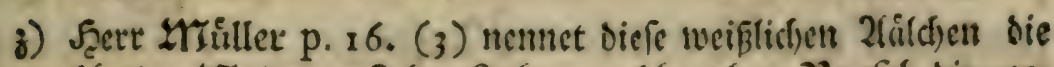
fártige :Tarioe. Bebn Gabre nadjlect bat Roefel bie ge: fehlingelte entoecft: Infettenbel, 1II. Th. p. 567. Cab.

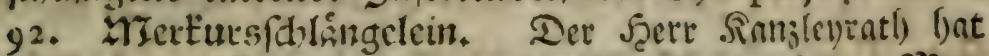

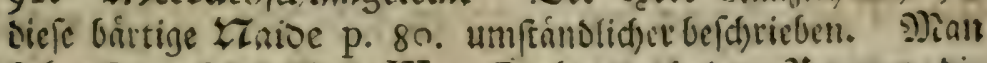

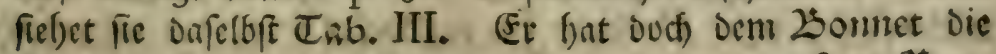
Ebre ber Erfindung getafie:t. S. 82 bei

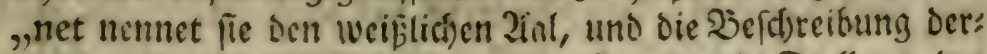
, felbent, Die am Scibe jetftemeten 万ăare, Die Etellung ber

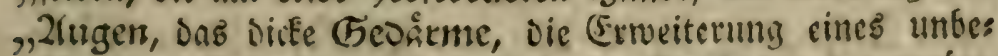

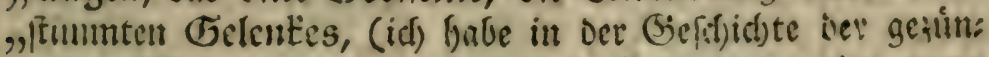
,gelten ZTrioe angejeiget, Daß biefe (Ericheinung cine neue ,3 Jugung anfintiget, ) uno bie fleinen fullibaten, laffen , niid)t wobl awcifeln, Daf fie nid)t cinetley mit unferer bärs

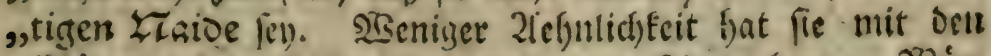

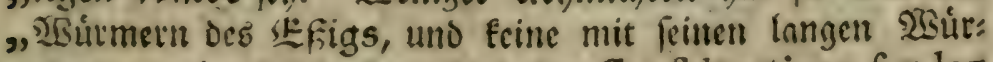
"ment, and) wiro (egteres in Denen Confiderations fur les "Corps organifés Tom. II. p. 18. widerrufen. (Er mely"

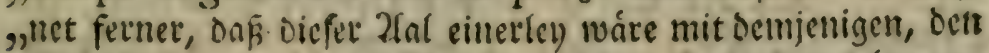
",et in Feinter 17 uno 8 Zeob. aur bem Reife jeintes langen "STurme ferworfommen gefeben ;u haben glaubte; allein ber

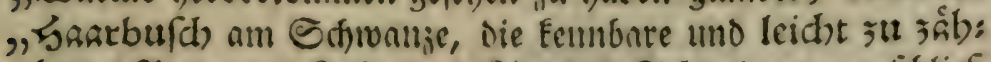

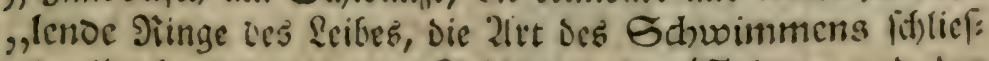

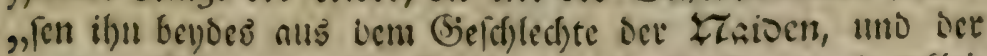

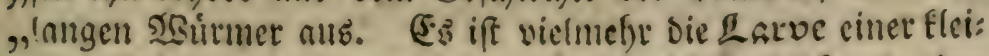

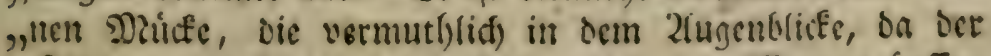

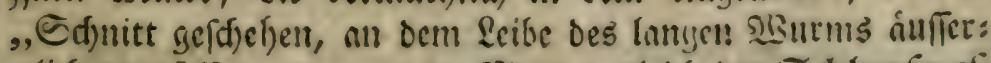

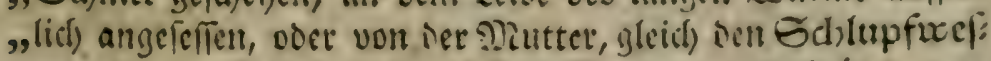

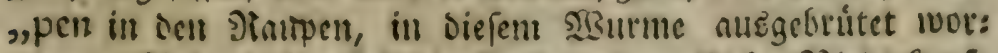

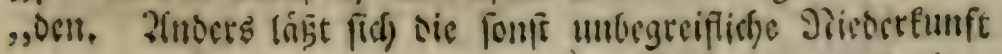




\section{Sืeobachtungen ůber einige 2rten}

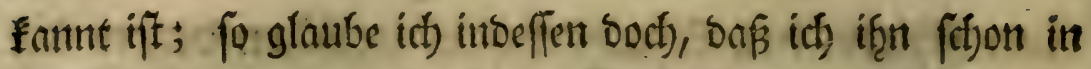

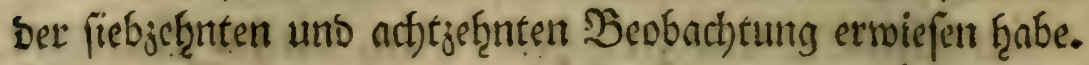

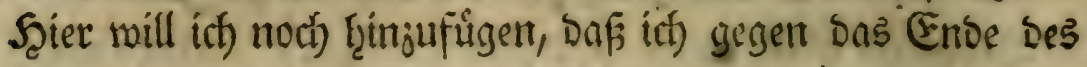

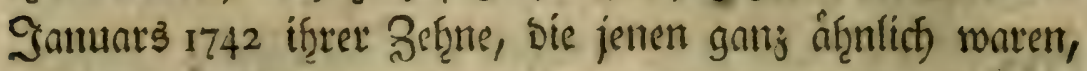

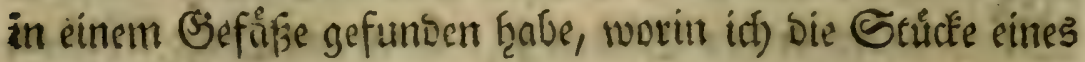
groffen 23 utmb von ber vorigen 2 lat, Den idh gesen bíe

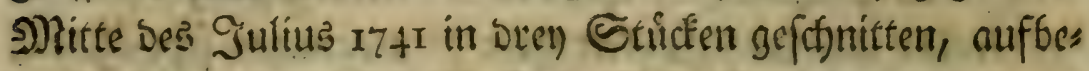
waţret f̧atte. (Dbf. XIII. Taf. IV.) Gie lebten uns zeigs

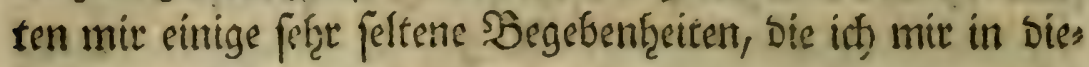

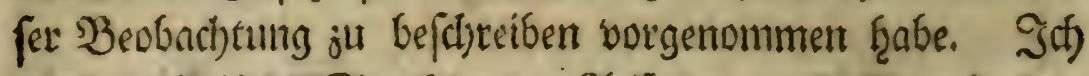
madje mit if̧ree Struftur ben 2lnfang.

Darin fint fie you bem Baue ber groflen, in ser els

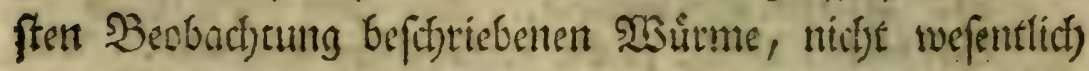

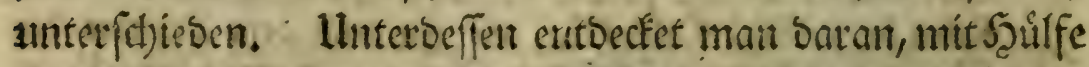

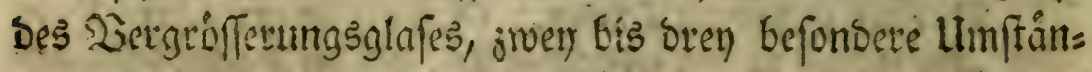
De, bie bas jueifelfraft madjen fonnten, was idh fiton von

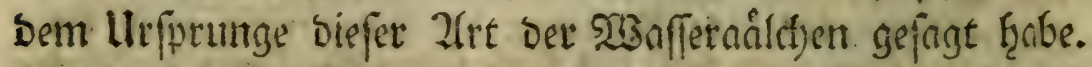
Der erfte betrift bie fangen an ganjent seibe jerftrentet

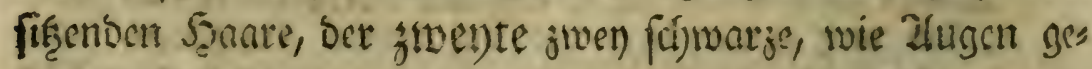

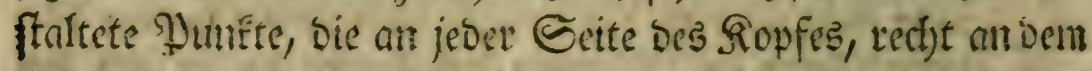
Sutte firgen, wo ber Durtsmeffer am fräreffent iff. Det Dritte enblict) ben Darm, worin Der Nagen, und bie Eins

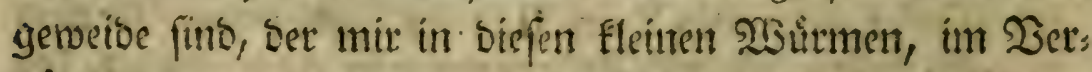

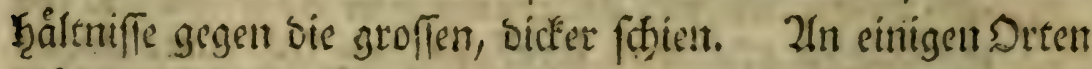
bläfet er firth) ftaré auf, uno ba iff auch ber Rreistauf bes

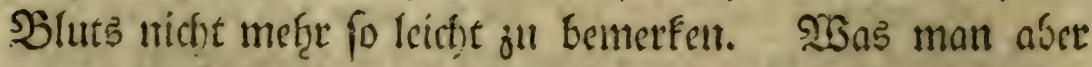

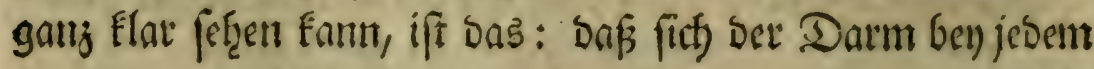
গู)

و(accouchement) Der Ctiufe ies zerffinitfentu Şurmes

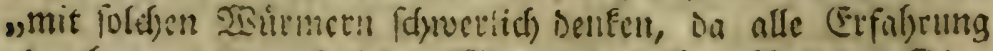

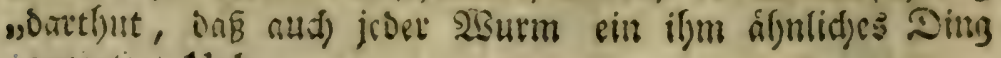
ijenget. „ Heb. 


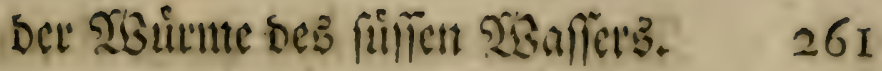

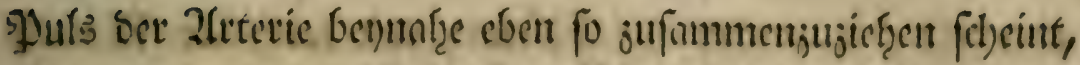

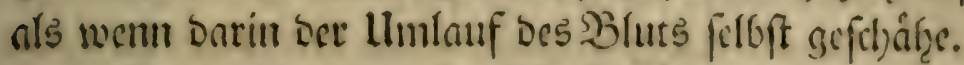

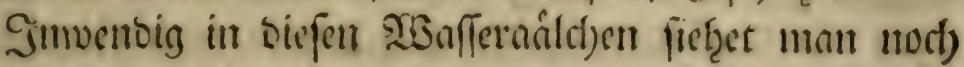
einetr befonbern llmifans, sweldyer verbient antgenerft ju werbent man fintoet tifen aber nur ben einigen. Eer beftes

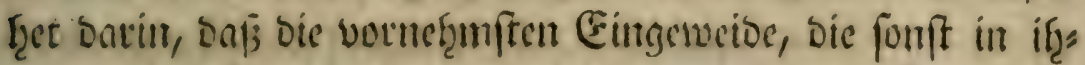

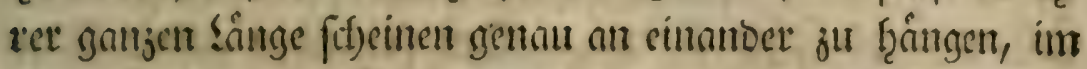
Begentreile in Der Mitte Des Seibes eine fleine Stennung

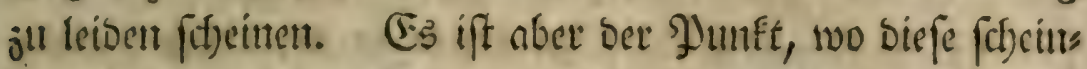
bate Stemung bes (banjen metrfbar ift, nid)t in jeden eitts

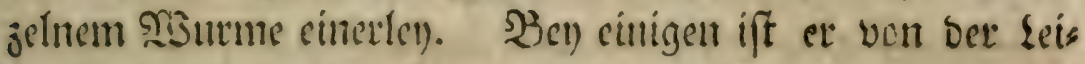

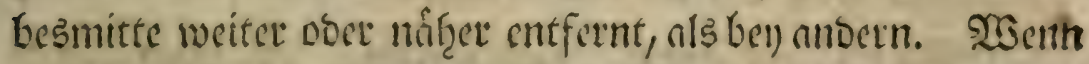
man bas Sinfeft mit bem Sergrofferungaglafe betrad)tet;

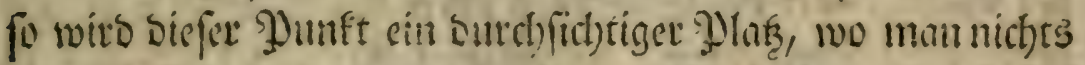

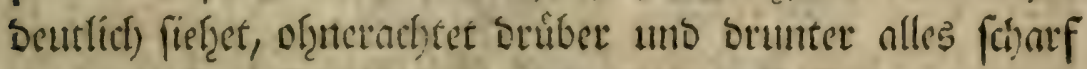

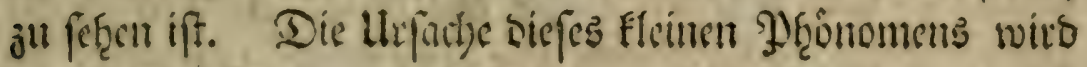
mant unter fintern.

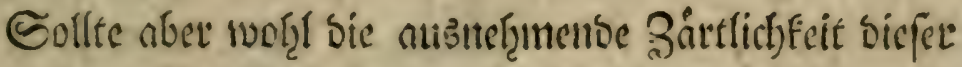

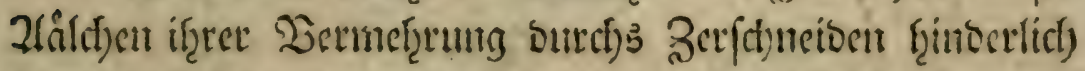

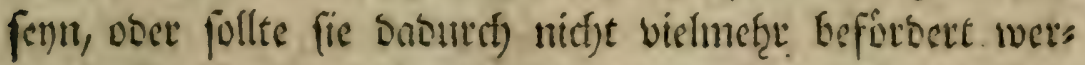

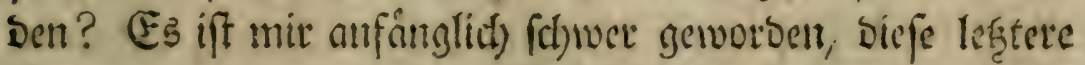

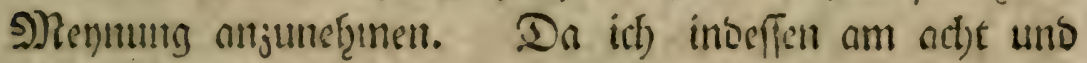

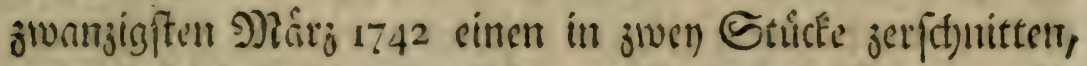

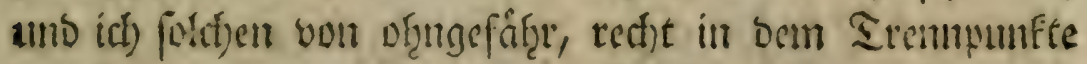
Der Cingenvetbe getroffen fratte; fo hratte fict) Des folgenben

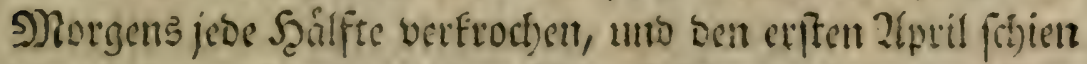

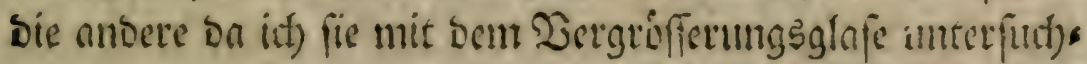
te, fich) gant ententert ful faben, (Es war nicht mut tor Sopf orbentlid) gebilost; fonderan was nod') weniger givelys

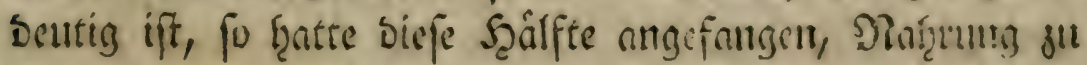

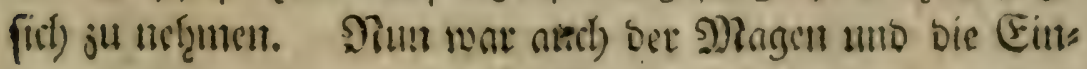




\section{Beobachtuntgen ůber einige Irten}

geweibe, bie vorferer leer fdjienten, mit erbf̧after. Materie angefúllet.

Seier aber ereignete fich etwas nod) fonberbaters. Sid hatte nemlich biefe burchs Berfdneiben herburgebradten 2lälchen in eben bas 2 Bafferglas gettean, unto nur fo viel ant gefeuct)tete Erbe bagugetţan, als man mit Der Spise eines ลaftruftuchers faffen Fonnte. Den folgenten cilften May

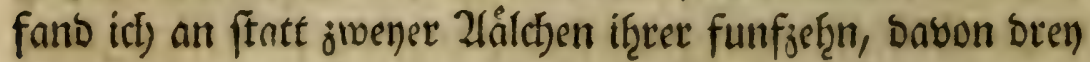
ober viete wob̨l fưnf bis fects sinien in Der länge ficelten, welche alle aber gnn ausmę̧ment jart uno bưnue waren.

Sn ich muthrmafte, bafz entweber bie Ungleich geit Des Stlafes, ober sin Steinchen unter ber Erbe biefe auffer"

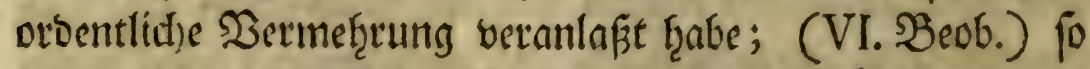
bract)te id) nod) beffelben sages alle meine Ualdsen in cin anderes STIns, beffen Boben fefrr glatt fdtien, uno sarin ich

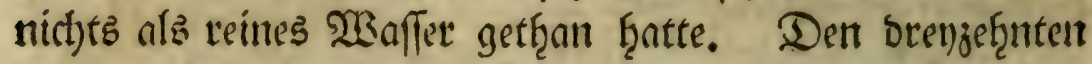

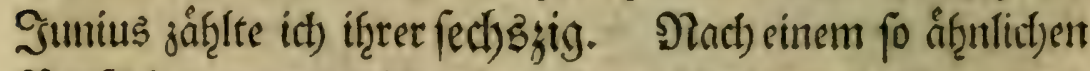
Serfuthe getrauete ich mir Doch noch nitft, etwas ju ent: fcheiben. (Es fel) mir aber nidfts beftoweniger erlaubt, ju

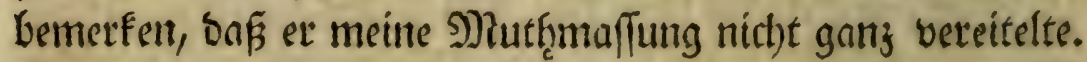
So glatt aud) ein Kivtper, wie j. E. ein (Silas, umfren Simten autb immer folseinet; fo Eant man boch fidjer ans nefrmen; baf er fưr unfere fleinen Infeften eine ḩơftrigte Flácbe fer. Das Mifrof fen úberzengt uns bavon. Zlber

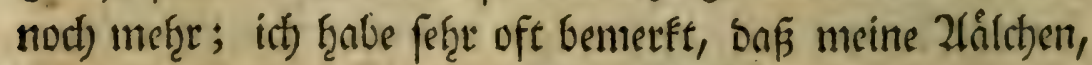

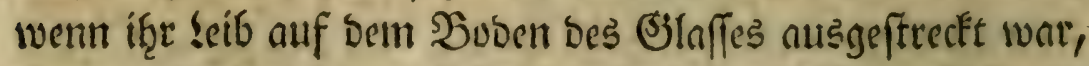

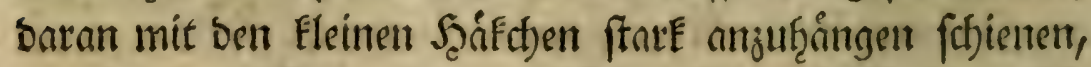
womit ifre Singe unten verfetren finto. (I. Beob.) Sft genug frabe ich audh ben Boorn, uno bie Seiten meinet

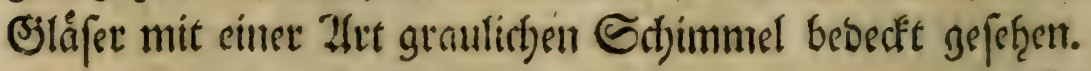




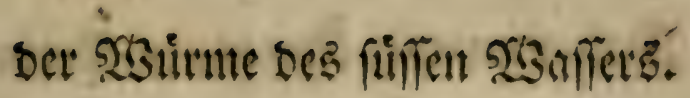

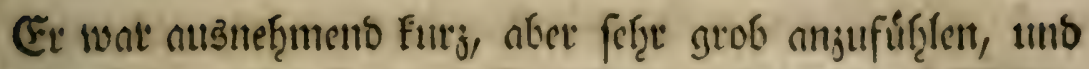

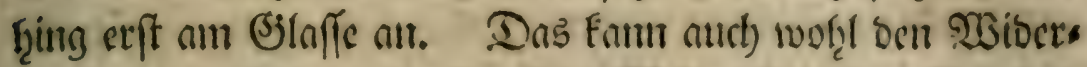
frans vermef̨ren, Den unfere finben.

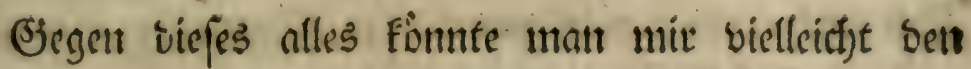

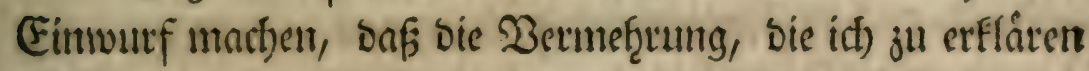

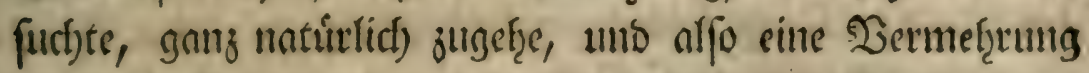

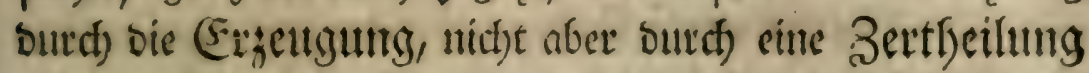
wåre. Lluf siefen Eintrurt f̧abe id) nut eins jul antwors tent. Sit) ntefime bie 2lntwort von ber gleid)en Didfe

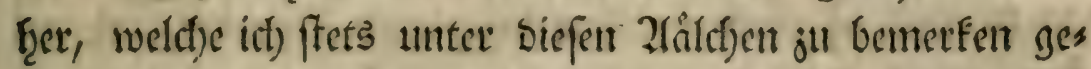

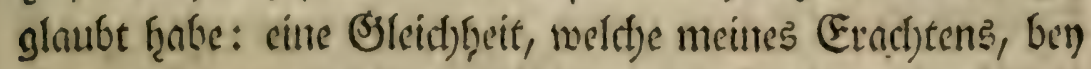

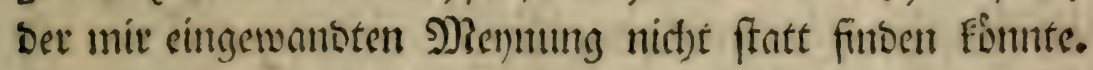
Da inteffen nber bie Erijelugung biefer şitrme auf eine

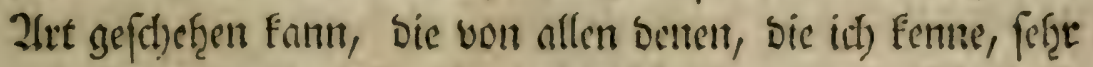

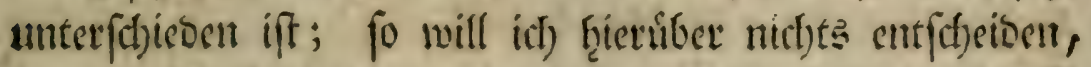
fonbern erwartent, baß mich) jemant cintes beffern belef̧re a). 月 5 Die

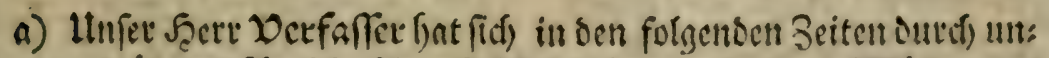

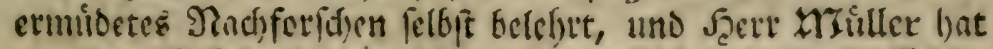

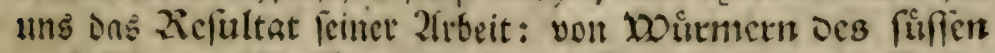

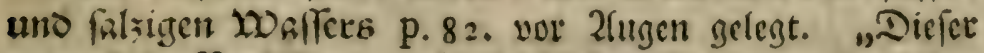

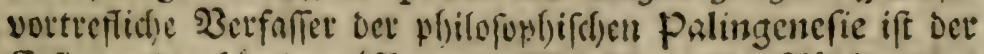

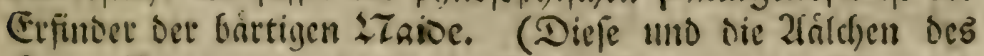

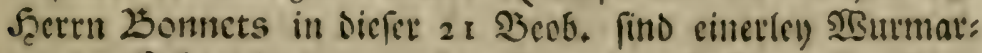

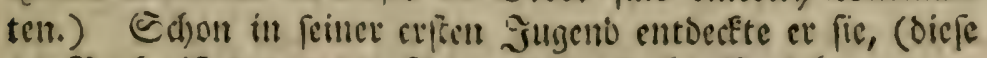

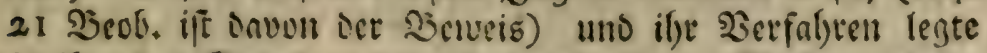

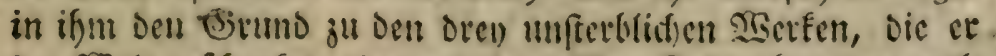

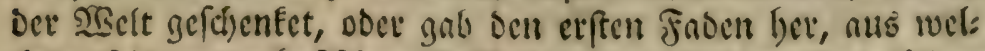

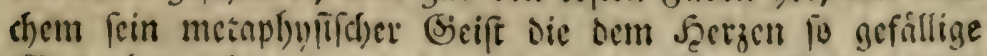
2Sieberfervorfiringung 3ufammengemebet bat. (Ex jerifignitt

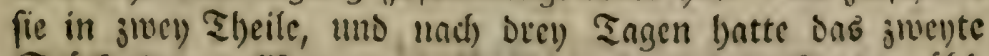

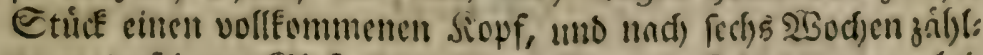
tc er in feinem Ginfe fratt cincs sisurms fed)sig won gle:

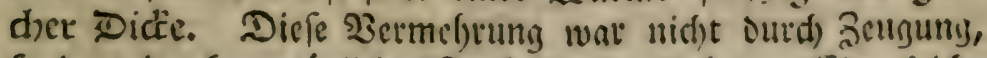

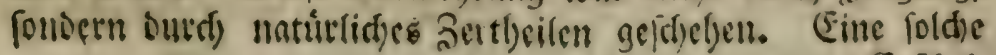

Erifhei: 


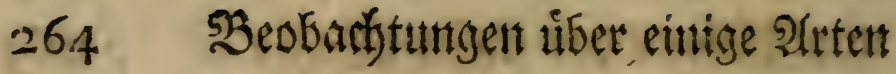

Die Bbefhrwintigfeit uno Seidjtigkeit, mit ber unjere

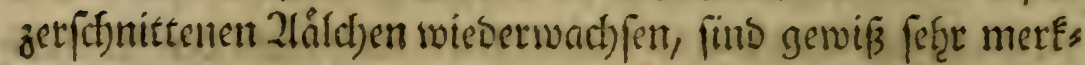
sourbige llinftänbe. Sgier liefere icti bnoon eitre andere

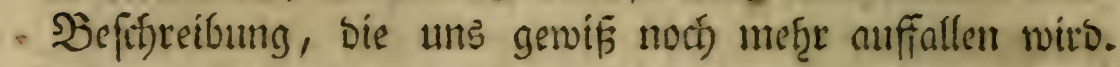
Sid) hatte furrjlich eins von biefen 2falchen in vier Stüfe

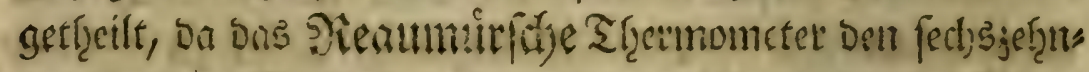

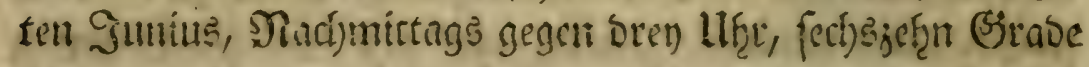
uiber Dem (sefrietpunte finb. S(h) machte Den Berfuch

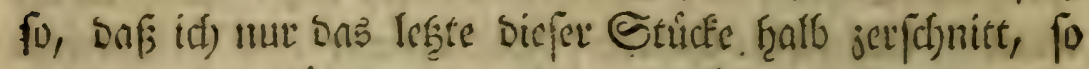

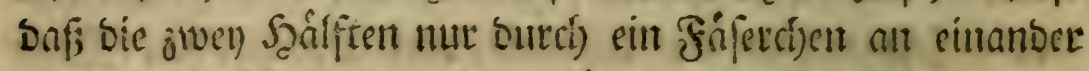

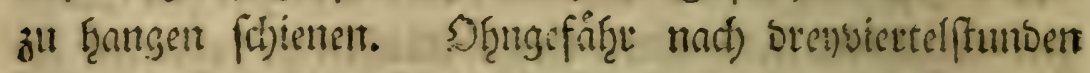
fond idf fie wicber fo genau an eimunoer gewadbjen, daf

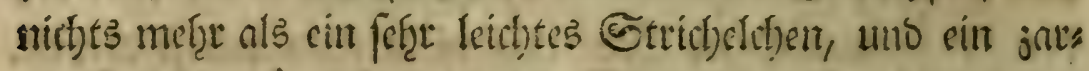

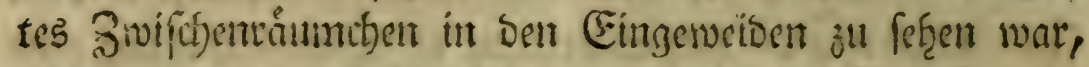
weldyes bem oben befdrticbenem gleich fam. Eine Etunte

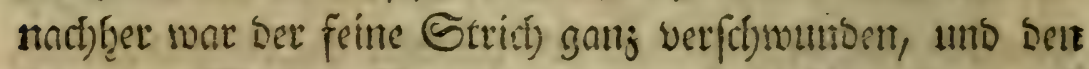
folgenoen J) Jergen Dormittng gegen fects llịt, war auch Feine Gpur Der Dperation mefzr ju fetcen. Die fo tiefe

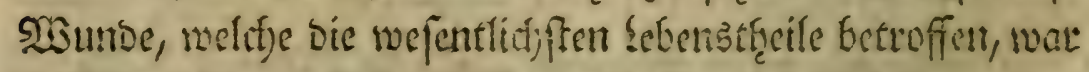
bollemmen jugeţeilet. Sa mas foge itif); fie wat gat

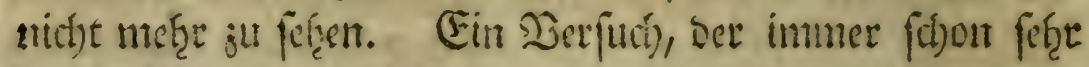

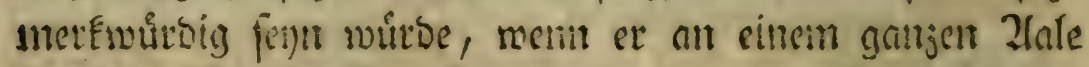

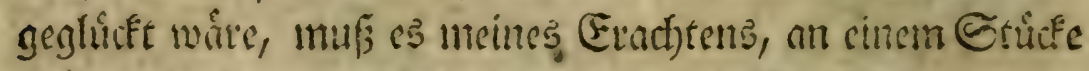
noch mefre forn, weld)es nur ter vierte STeil baven mat.

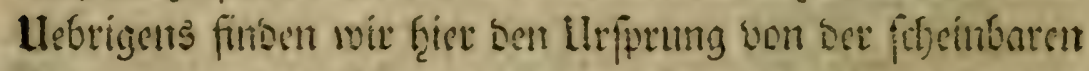

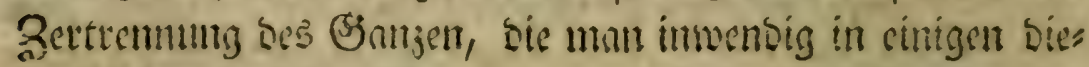

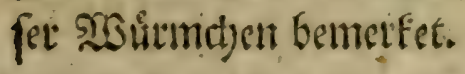

Dies

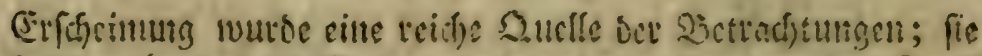

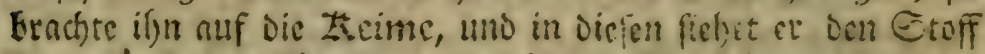

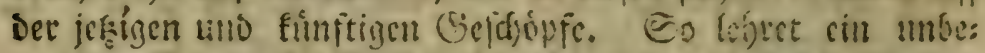

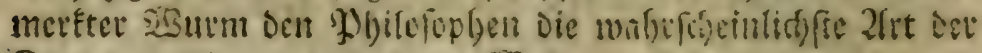
Fortoaner feines uno anterer 2 sejen. „ Heb. 


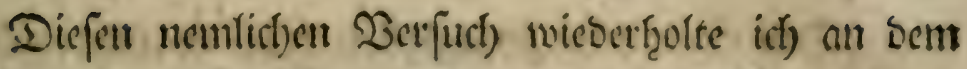

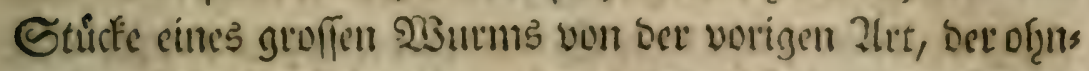

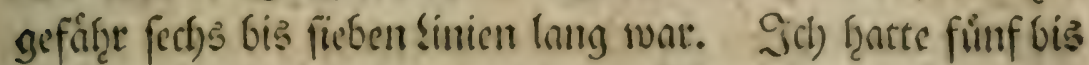

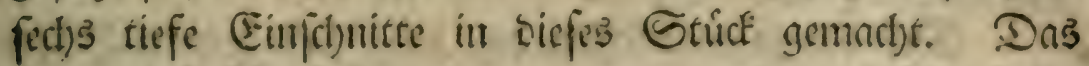

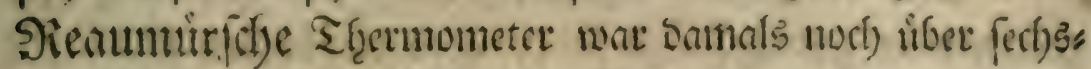
jef̧n (B)

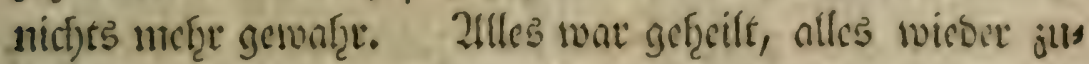

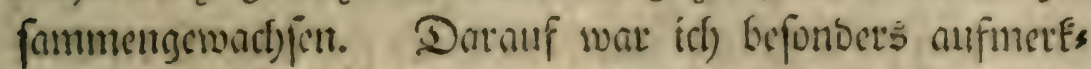
fom, ob nicht bet Hunlauf bes BStuts von siefen Einfd)nits ten etwas leiben wurrbe. Er fotien mix aud) ba, wo fie ties fer waten, mo nict)t ganij, Doch) wentigftents etruas aufgethals telt jult wetoent.

In ber ad) tent B̧eobad)

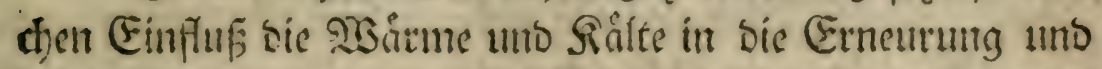

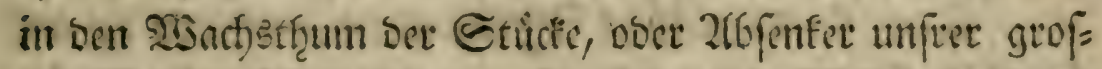

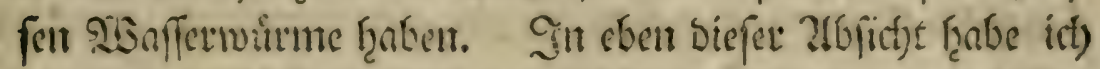

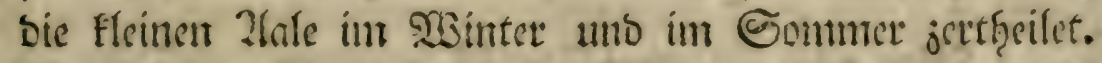

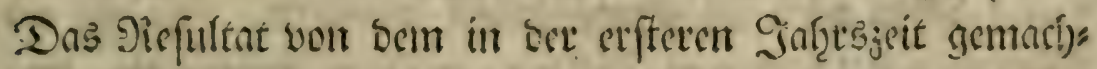

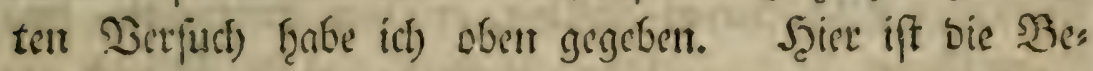

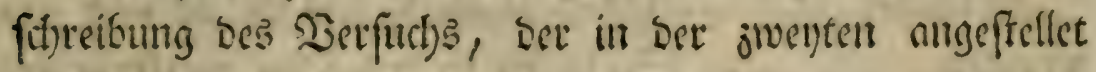
worben.

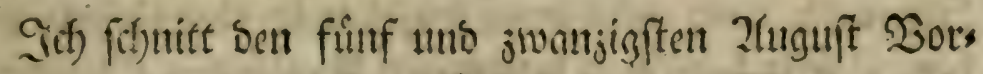
mittange, einen von biefen Zlitthen in ber Mitte burtd).

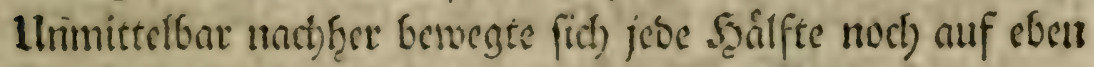

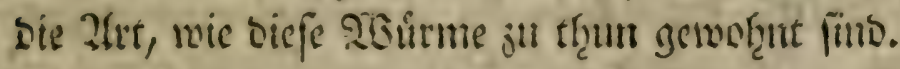

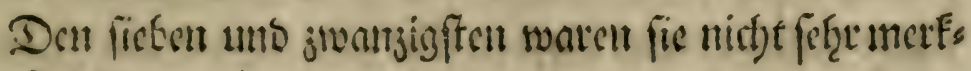
(ide) gevedefort.

Dent adjt uno jmanigffen fäisn ser neue Ropf

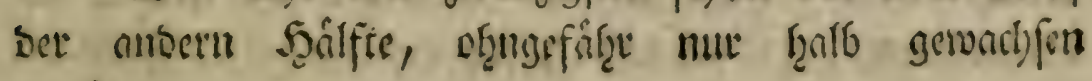
gu. fernt. 


\section{Beobad)tungen uber einige Irtent}

Sen neun uno swanjigften fratte er fich noct) nicht

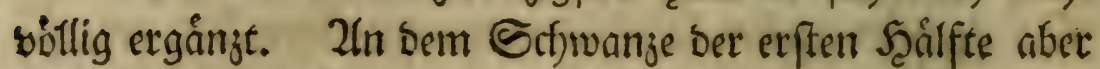

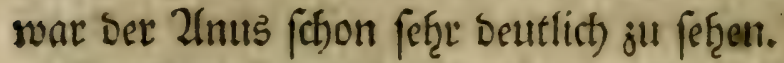

Den brenfigiften fobien ber Ropf ber anbern Şälfte

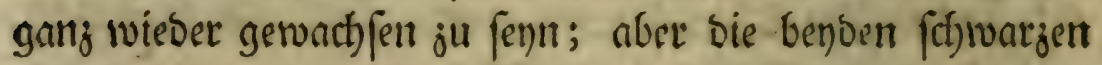
Dunfte, wie ein গyaar 2lugen, zeigten fid) noch nid)t. 2̧Seber bie cine, noth bic andere Şålfte fintte angefangen,

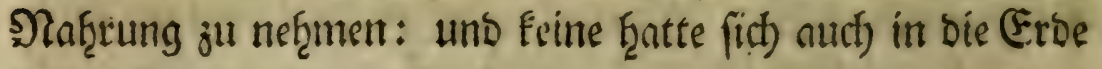
serfrectien.

Den ein unt brenfigigften ţatten fie fidf benbe in bie Eroe gebofict, ur: if̧r Magent war auch Dannit angefúllet. Dlun fingen fich nuch) am Sopfe ber jwenten Scålfte, bie ben): Den fleinen fhjwarjen Dounfte alt ju jeigen.

Das शieaumuinfdye Thermometer war von $\mathrm{I}_{4}$ auf fect)gjeçn Butabe geftiegen.

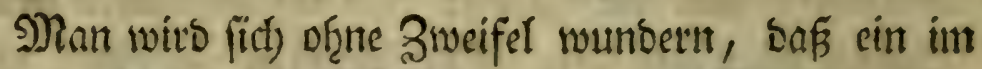

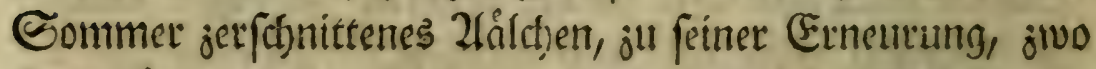

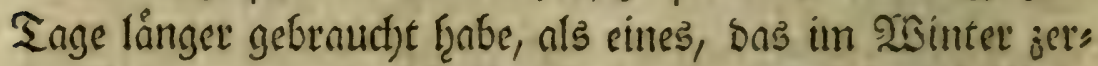

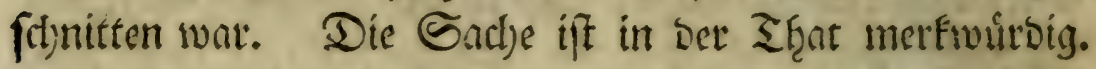

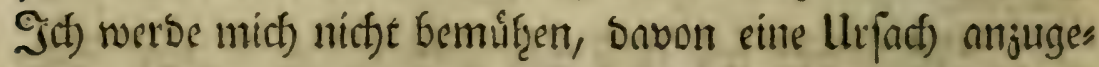
ber. Sie fann bon befonberen Umiftänoen ab̧angen, bie mir unbefaumt find; aber es foll mir nicht fofjwer werben,

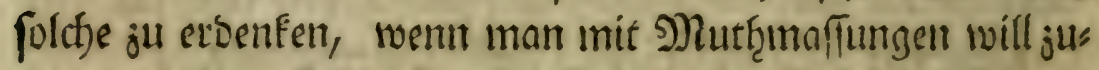

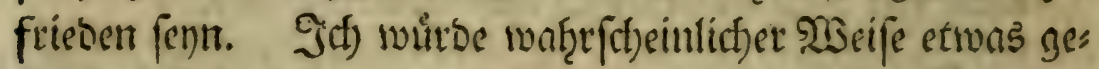

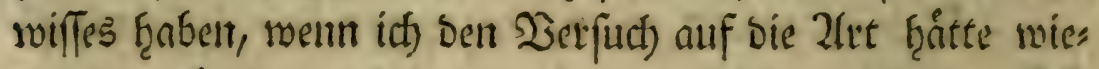
Derf̧olen fobmen, wie id) mirs borgenomment ţatte. Die

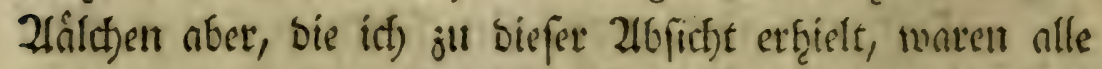

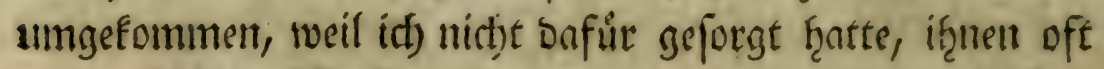
gemug friffles $\mathfrak{W}$ affer ju geben; Denn eine nnbere llejad) Davon fonn id) mir nicfst vorffellen. Demt fen wie trant 


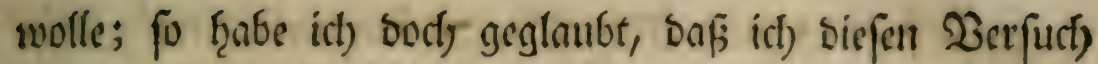

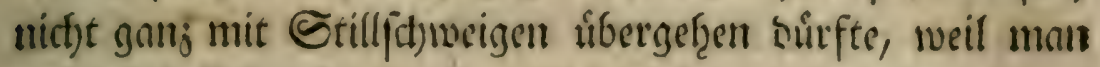
Daraus beffer, als auts eitrem andern, ben junefrmentoen

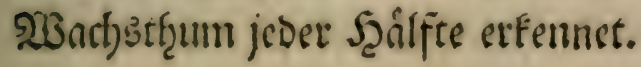

\section{3we1) und jwattgigite Seobad)tung.}

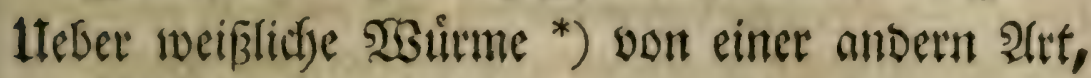
alB̉ Die vorigen.

Sirantheiten, welchen fie bende unternorfen finb.

(3:

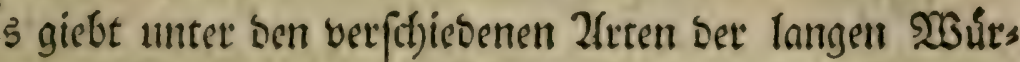

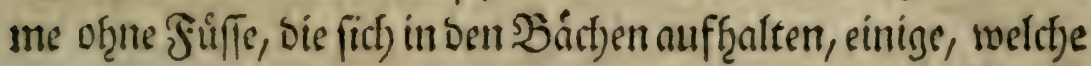
nur in ber Farbe bon einanber fdreiten unterfdieden ju jenn. Sid) Fente jum Erempel barunter rothlict)e unb gelblict)e, weifliche ober graulid)e, die fid in ber äuferlid)en (Jieftalt, in Der Dicfe, unt in ber sebensart ganj gleich finto; fiepfles

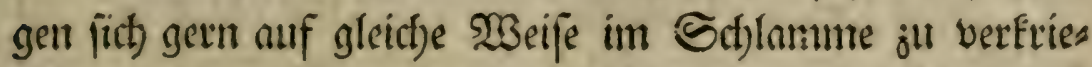

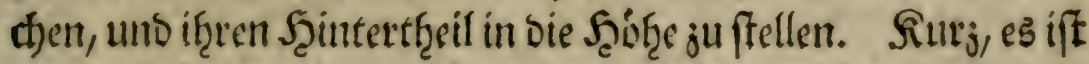

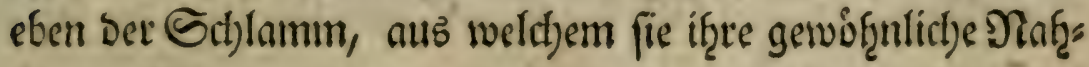
rung nef̧uinen.

Den britten Sullus r741 fanb id) eituen fold)en weipss ficfen 23 urm ber anbern 2 (rt, weld)er wof̧l bren Boll in ter Sange hatte. Jid) betrad)tete ifrn mit bem (Sud)glaje, wos Dutef) ith aber it feinem Bante nidfts bejonber's entoecten fonnte. Er fobien mir nidft fo lebteraft, als bic erfteren ju (e)n, und bieit fit) oft in fidf) felbft, wie sin Bwitusfunt zufaım!nengetvickelt.

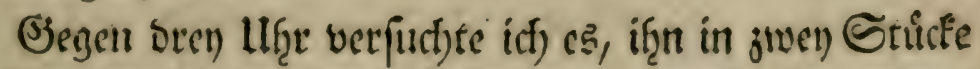
ju jerfdheiben; bie verffhiebenen Bెerwegungen aber, bie er

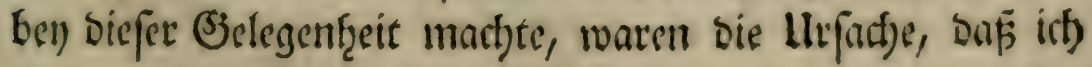

*) Corps organif. Art. $26 r$. 


\section{23eobactututgen ůber einige 2rtent}

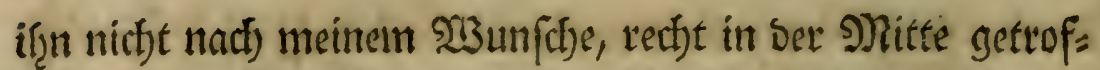
fen ḩatte. Der Sheil, Der Den Sopf beḩielt, war länger, als bas Solwaniffuct. Sill bemerfte folches eine Stunbe rach geer, unb bas bewog mich, jebes Stick in jwen anbere ju jerffutriben, fo Dofj ith nun meinen $20 u r m$ it bier Stus

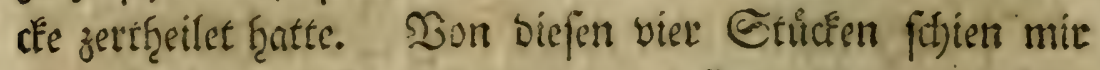
Dab erfte bey Der Sperntiont ant menigften gelitten zu f̧aben. Es bemifere fith beffánbig nod) vorwarts ju getren: es

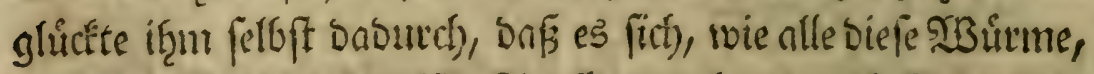
mit bem Ropfe fortfelf; feit Sjang aber mar befofiverlich. 200a bie anbern brene betrift; fo blieben fie nicht ganj uns beweglid). Sie benegten fith anf verfdiebene 2 Beife. Sornemlid) fit)ien bus vierte nach Dem erften bas untuf̧igs fle ju fenn. 2lls ich das STlas, worin fie wateri, alt bie

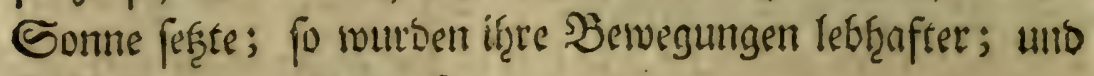
fie fothenent unrufigig zu fent.

Des folgenton glorgens benetfte id) ben ben viex

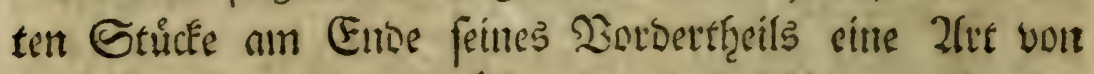

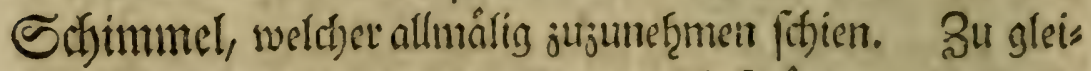
cher Beit fab̨e id) bavon bie Sinnge viel foljâfer, als fontt,

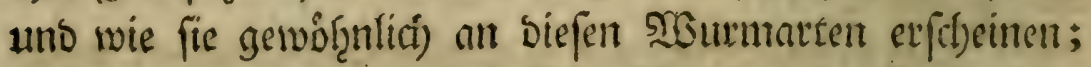

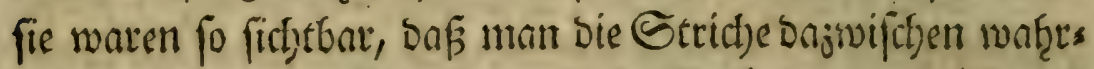
nef̧men Fonnte. Eine fo merfliche ßeränderung lief mith für biefes und bie andern Stücfe, nicht vilel gutes vermus

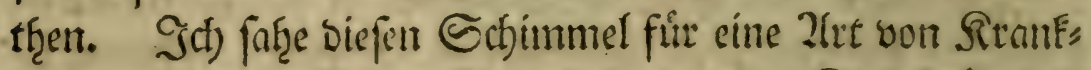

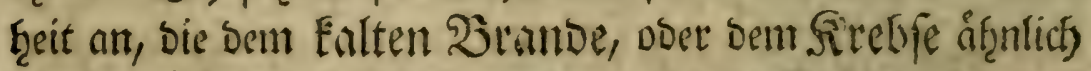
ift. b) Uluterbeffen bioute Das angefectete Stüct nicht auf, buret)

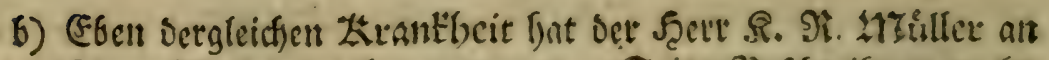

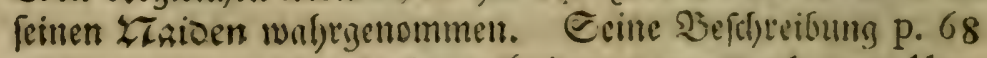
verbient wegen bet darin entfoftenen wunDetbaten 1 lin:

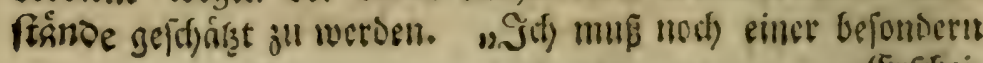




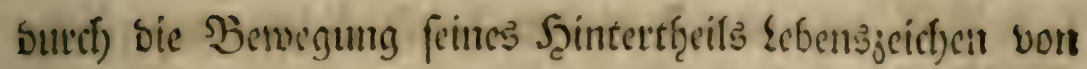
fiit) jut gebert. Das geffthatze bis des MRorgens unn fünfe, Da bie leręten Singe in eben ben 3ulftand famen, wie bie el"

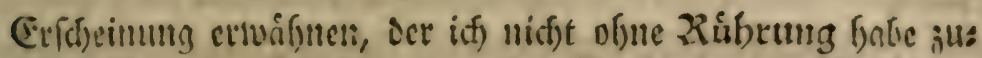

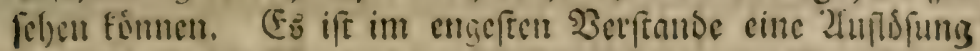

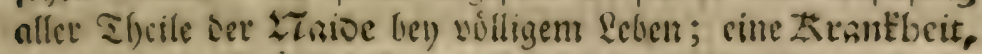

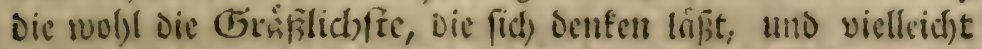

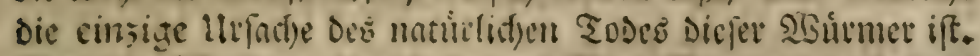

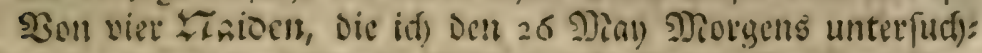

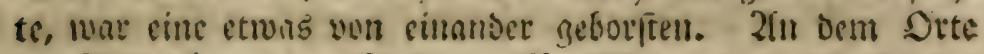

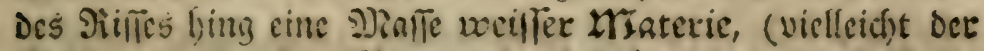

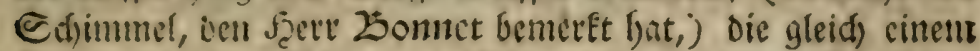

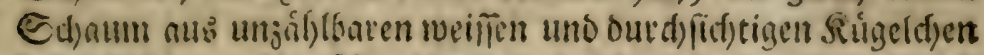
befans. - 2(m 216ento erfraunte id) nid)t menig, als ids

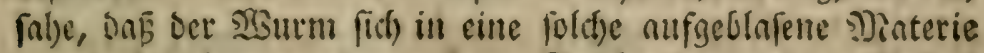
sermantele batte; es war teine Spubs bet vorigen Geftalt

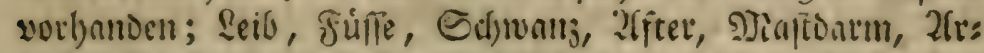
terie, alles mar ein Esf)aum, Demjenigen nid)t umgleidf), Den

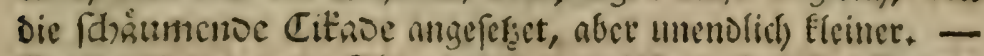
(Endict) if bas game Tliet Durd) cinen 10 itbel vicler Elemer Ziugeldun jelgangen. - Şert Zonnet fóblet J̧ert

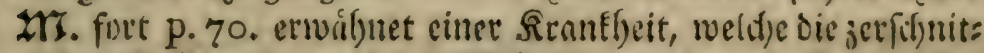
tenen Ethifi feiner langen Sisume verjebrte. (Ft verglei:

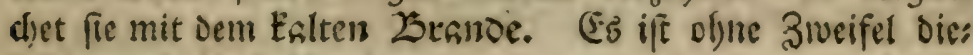
felbige, wie bie bef(litebene, "

Seer Zioefe! bat cinter geooppelten Kanthbeit geondit, Der bie Folypen untermotfen fini. Eie befonmen entweder

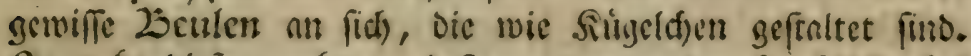
Se melfe diefe junefjuen, Defro matter werden fie feloft, bis fie entilic) vor ooct nadi icm 216 fallen Derfetben fterfich. Soer fie wetden von bet Lestuffudhe verjelfet. Dies fins Die fleinen eyformigen Cbierd)en, Die fids in ungefjenter

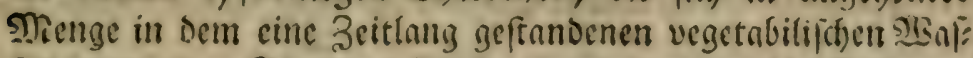
fer erjengen. Sie fersen fid) bey bunderten an die 'polupen,

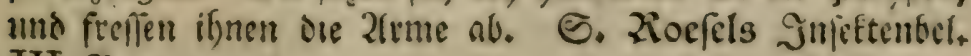
III. 23. p. $500 \mathrm{f}$.

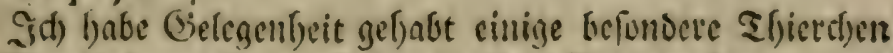

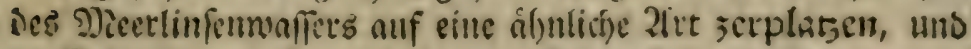
in Ed)aum vergefien ju Feben. Slicime Lelet meroen Davon

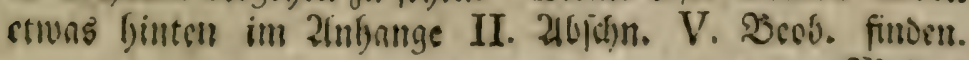




\section{Seobarffuntgen úber einige Inten}

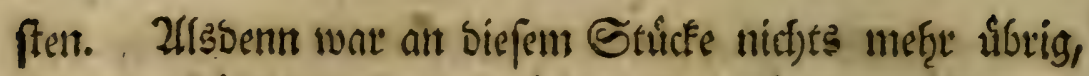

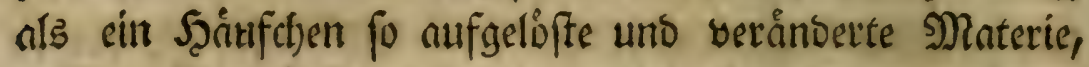

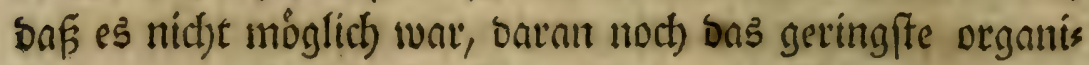

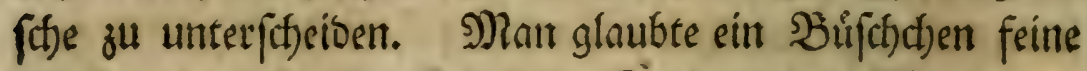

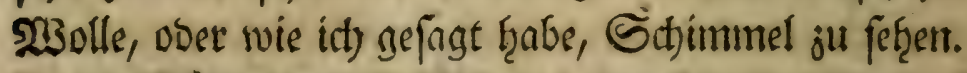

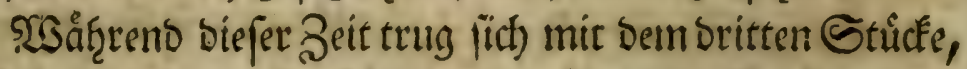

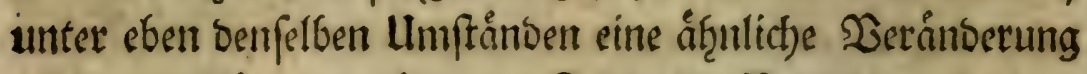
ơl, unt es häorte an ebent Denn Tage, bes Dovernittages gegen nd)t Hther, nuf ju lebent.

Das juente Fatte bes folgenben Norgens Wors inittag, als am ferthstent gegen jef̧n lthre eben Daffellbe Edjicffal.

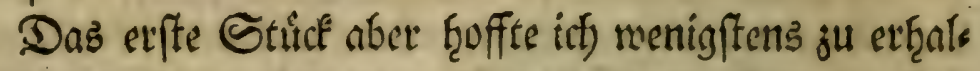
ten, weldfes fird) auch gants woof

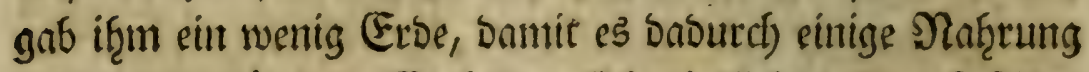

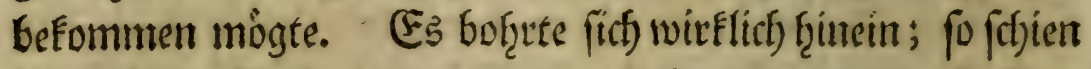

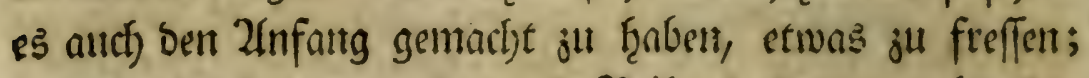
endlitf aber Eam es audf) an bie פieithe, Daf es yon eben ber. Rranffęit, weldje bie anbern aufgerieben, angegriffen unb

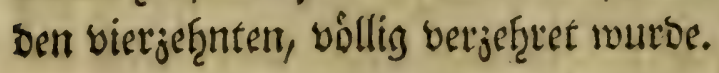

Sim Monate ?(pril 1742 jog ich) nodf) neum 233 irme

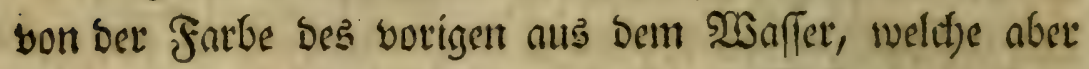

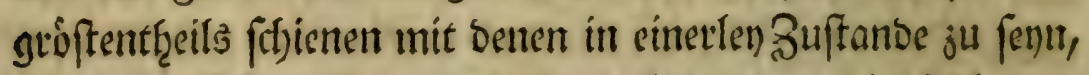

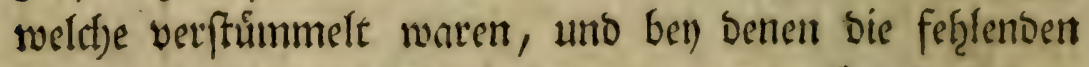

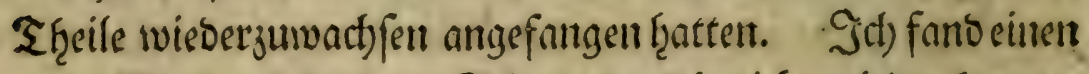

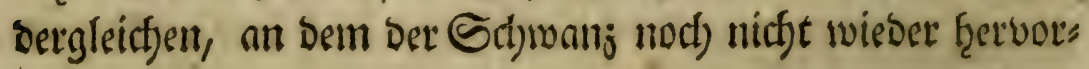
gefoun:

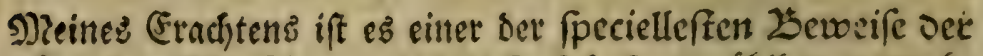

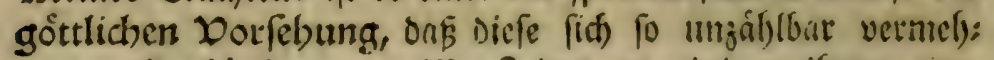
venten (Sefdjopfe, zu gewiflen Beiten, an cinigen ifnen elge: nen frantbeiten von felbft vieder fterben. SEo soirten fonft alle kibrigen Sireaturen julegt vor Infetten uns Gevourmen bleiben? 1leb. 


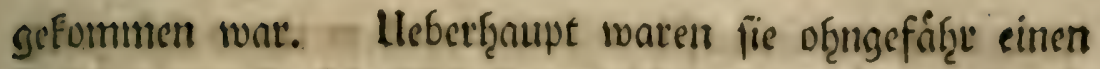

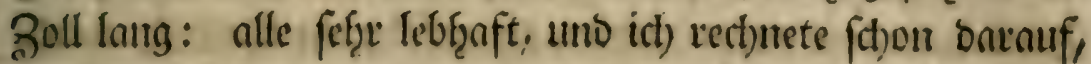

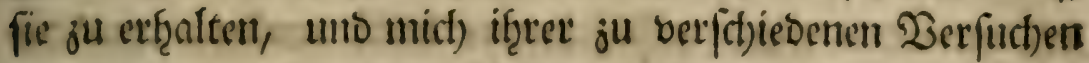

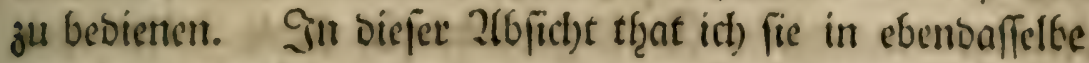
(B) gens frutf erffaunte $i(d)$, $D a$ idf) nutr noch einten einzigen an Eeben fanto. Die adt)t anbern waren von eben Der STanE=

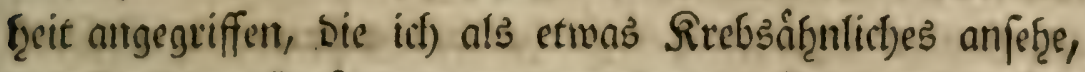

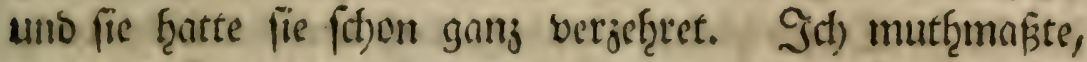

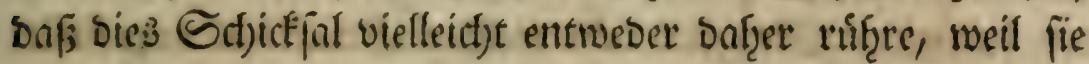

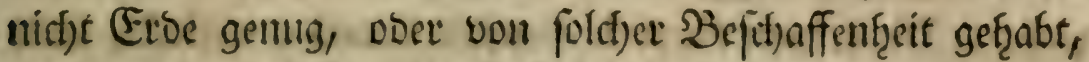

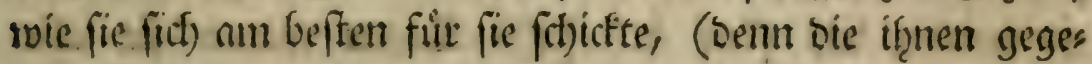
bene Evtbe f̧atte ict) aus ber Sct)act)tel genommen, worin 2tmeifentowent maren.) Sith gab aljo Dem 23 urme, ber bie andern úberlebt hatte, recht nngefeute)tetent, uno genugs

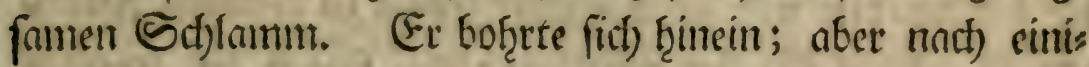
gent Tngen wurbe er wie bie alloern, von ebent Der RranE" ţeit angegriffen und verseţeret.

Ulnfere 2routrme von ber erften 2frt, unfere brauns vietf̧lichen 25 ürme finb. Der Siranffeit auch) unterwoorfen, bie id) erff befd)rieben fૃabe. (Dof. VI.) Ulm es ju betweifert,

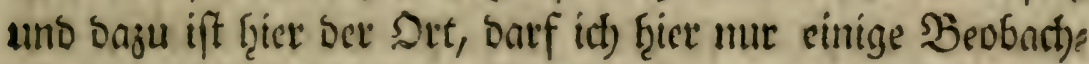

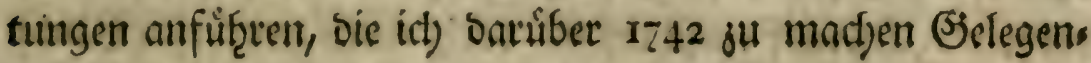
tzeit ţatte.

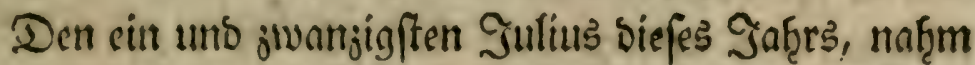

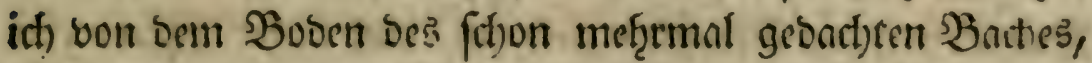
fúnf 23 sirme ber vorigen 2lrt, beren jeber of̧ngefäh̨r, anberts halls Zoll lang war. Sie waten alle feţr munter.

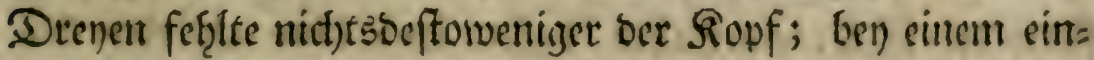
zigen fing er an wieber ju wat)fen. Dom jiventen 2tuguft.

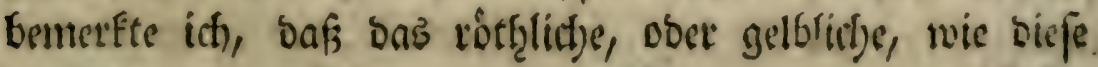




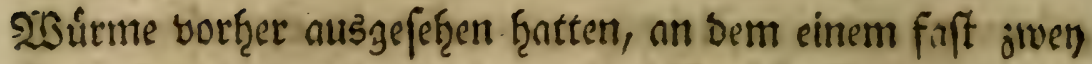
Drittel, und an einem anbern of̧ngefáf̧re cin Drittel, wei ફ. lich getworben war. Sich fonnte leitht Denfen, was bie Sertinderung biefer farbe ju bebeuten f̧atte. Ilm Den

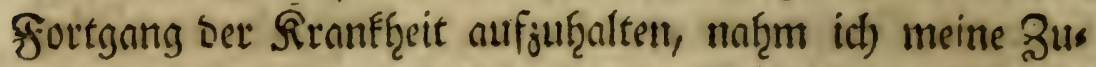

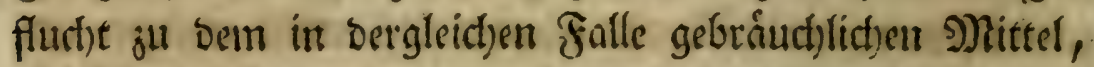

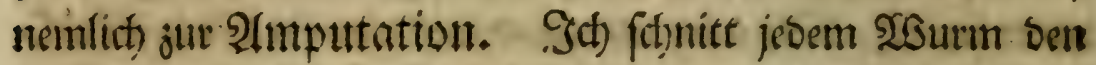

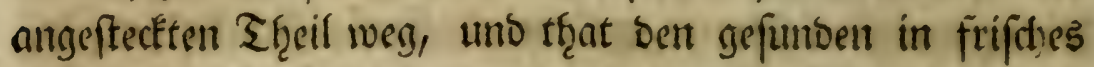

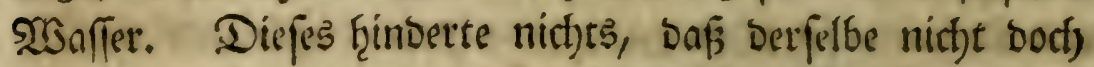
Des folgenton Morgens yon gleicf)er Rranffeit angeffectit war. Die anbern wurben ebenfals bamit angeffect', uns in mentiger als fünf bis jectss Tangen waren fie alle verieftert.

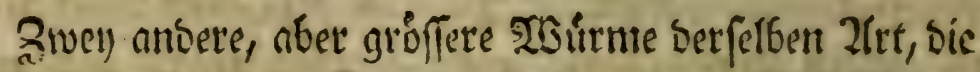

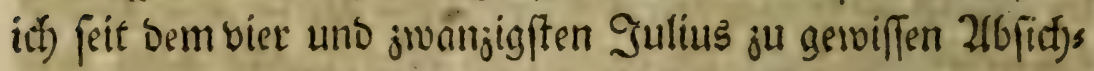

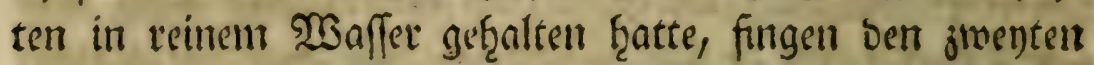
Zluguift aud) fduon an, wout eben ber Rranffecit angegriffert ju werben. Sid) Gemerfte, Dẫ fie an Den Geiten, Ģier unb

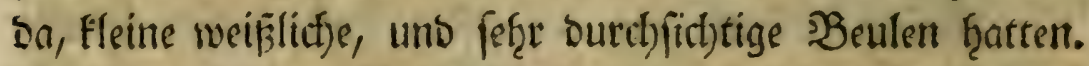
Diefe Şeulen voer Ungleicthęeiten jeigten fiid) vornemlict) am

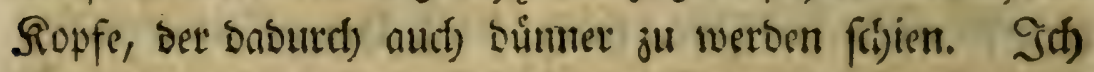
bemerffe noch, ba fie fie nicht mefre fo inunter waren, als

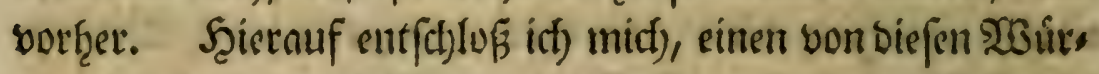

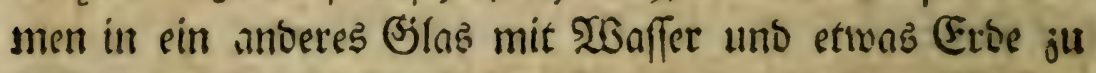
bringen; ben anbern aber liés id) im Gloffen $\mathfrak{2 B}_{3}$ fffer. Den vierten bes Morgens fand idn, Daß̉ biefer lef̧tere sin Siertel feines కeibes abgenommen ḩatte. Das fehlentoe

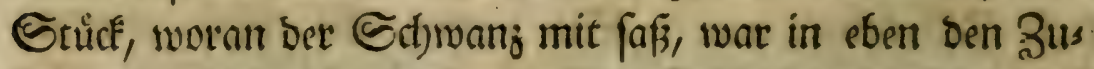

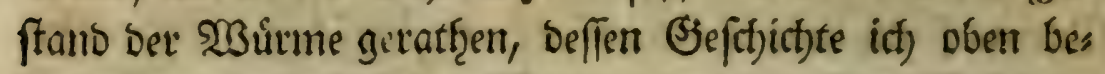

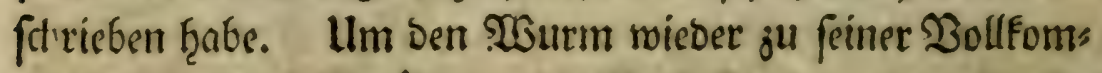

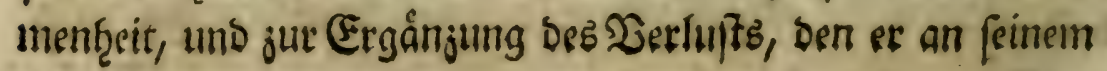




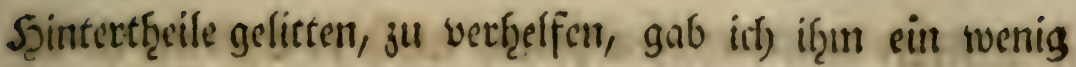
Erbe. Den neunten fing or an, an feinem fienterften Enbe etwas ju treiben. Den fedt) unb jroanjigften fant id) içn in jiven faft gleicf)e Stúcte getf̧eilt, bie noch) nidf)t angefans gen f̧attell, bab vileberjubefommen, was if̧nen mangelte,

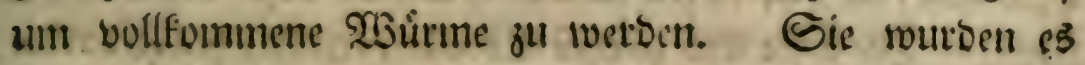
nber f̧ernad). EGen bas wieberfuthe feinem Eameraben.

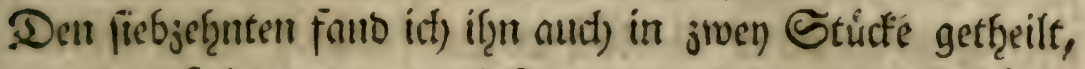

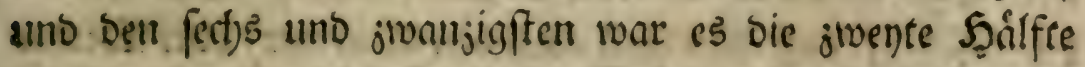

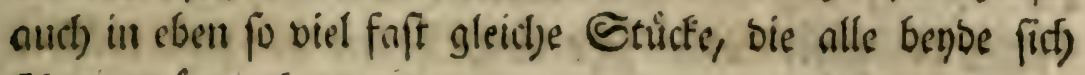
fthen ergónjet f̧attert.

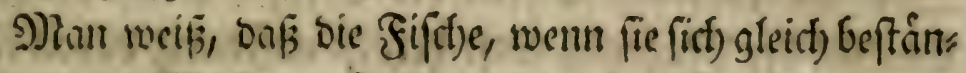

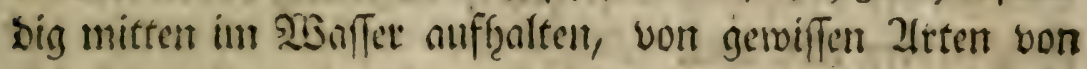

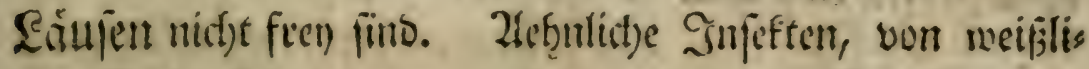

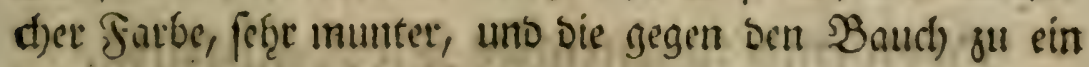

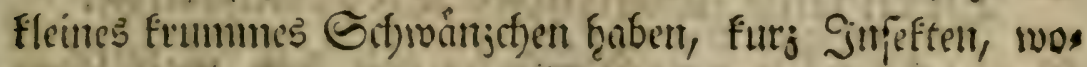
nit bas : 2 sanfer oft ganj bervolfert ift; bie aber fo flein

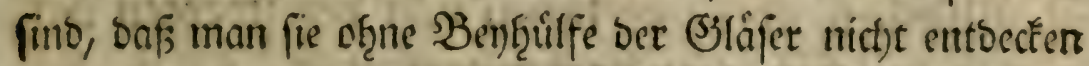

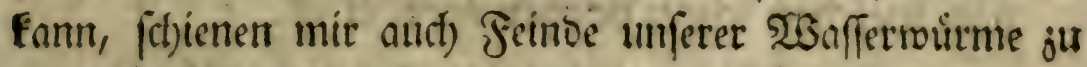

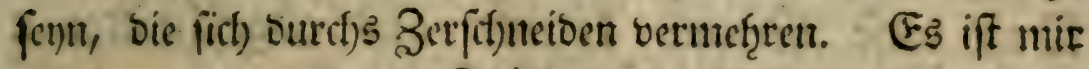
oft begegnet, Daf idh Stricke biejer Wurtme, unb gantje

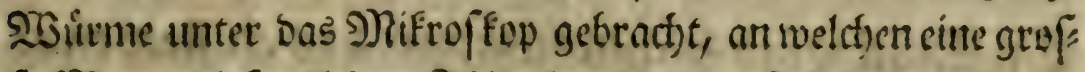

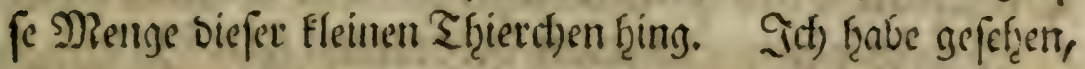

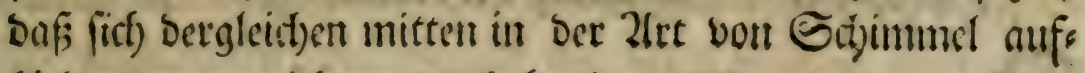
ficelten, tooboun ict) gerebet f̨abe $\mathfrak{c}$ ).

Sit) Ģabe and) (B̉eob. VI. und XXI.) jull ben lltras d)ent, bie beil unteren

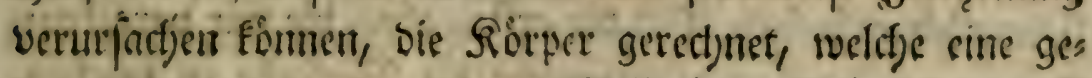

S 2

wiffe

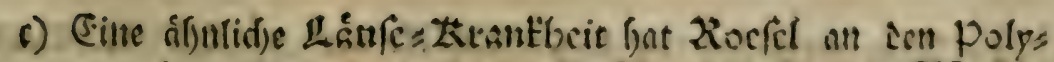
pers bemerft, uno in Jeiner Jinfettenbrlu|tigung III. 25. p. 501. S. 27. Lefiditieben. Lieb. 
274. SBeobadtungen ůber eitige शrten

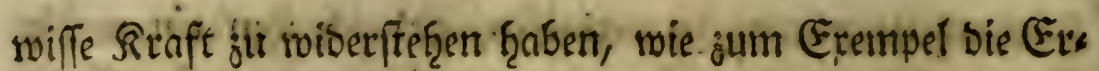
be ift, werm fie alljull bichte, ober ju ḩauffig ba ift, ferner fleme Steme, unb bergleidfert. Id) habe aber bod) firt)

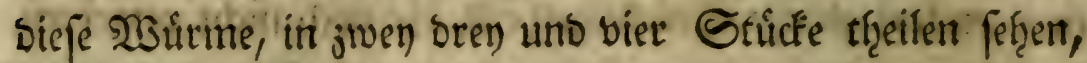

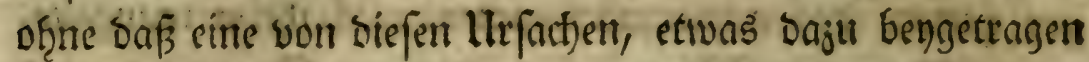
ḩâtte. Die erfte uns zrwente Tabelle No. III. Ģaben Davon fofont Beifpiele gegeben. Nod) mę̧reere werben witr in ben

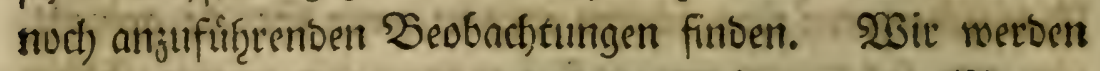

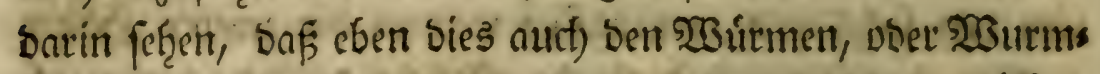

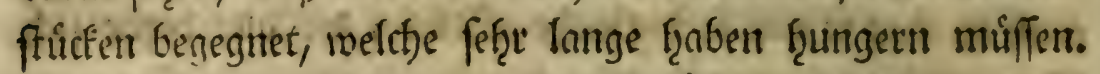
Das Zufammenf(f)rumpfen ber (Sefóffe, weld)es bon bem 5) Mangel ber Naf̧rung entffeņet, ift unftreitig babon eine ber vornef̧mften $\mathfrak{L}$ rfact)en.

\section{Drei) und juanjigite Beobadituth.}

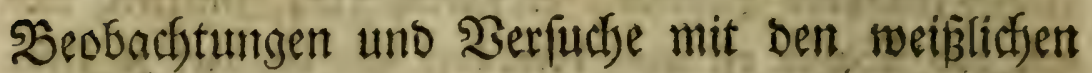
Sisurmen, ober mit Denen bon Der ziwenten 2 (rt, von weld)en fothon vorfer gerebet iff.

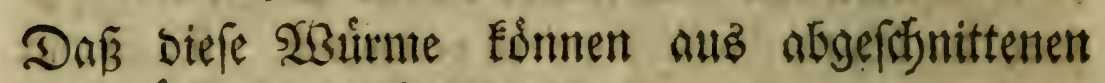
Stuifert vermefret werben.

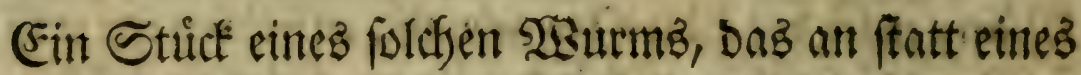
Ropfes einen Sdjuan; betommen fat. D)

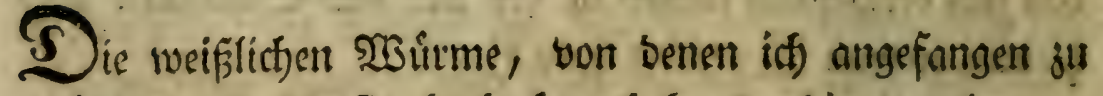

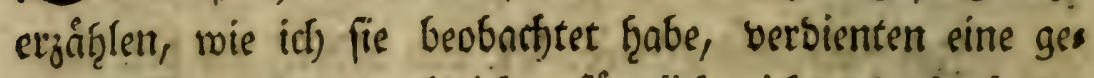

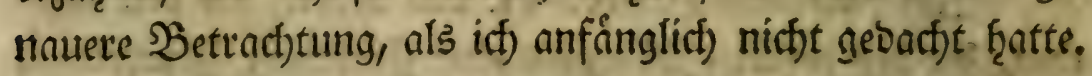
Der allougeffininde Tud der erften nber, bie mir yorgetonts men waren, verffattete mir nicht bie Şerfuct)e ju madjen,

bie

D) Jian vergleiche mit biefer XXIII. bis zur XXVII. Weos. Die Confiderations fur les corps organifés Art. 25 t. Gejonders Art. 261. Lleb, 


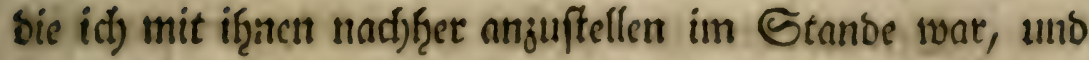

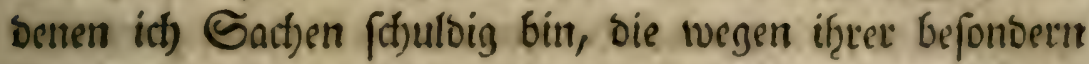

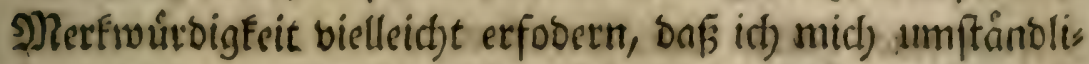
cher in ifgre Befforeibung, einlaffe, als bisfger ges fderę̧en ift.

Die verffhicbenten Beobachtungen, bie ifh semadft

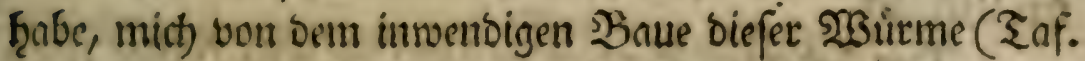
II. fig. I. II.) ju unterrid)ten, follen uns nidgt lange auff̧ats

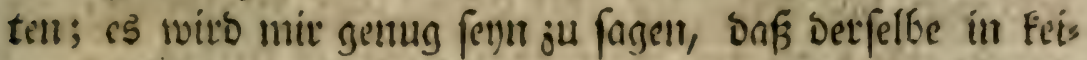

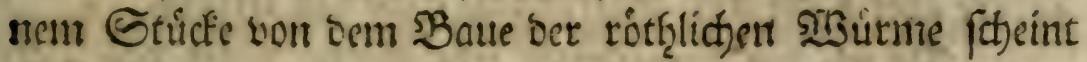
unterfdiesen ju fenn. Iflles basjenige, was id baran bes metfe frave, unt was man aud, an biefen fiter nidfet gut fies

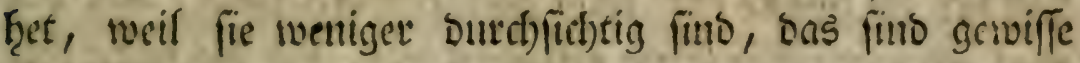
Edblánd)e, ober membranesife Sádie, (fig. VIII. A, A, A,) bie an Genden Geiten bes गragens ḩángen, uno weldt)e mir

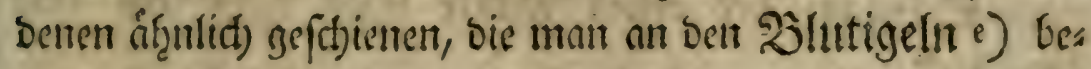

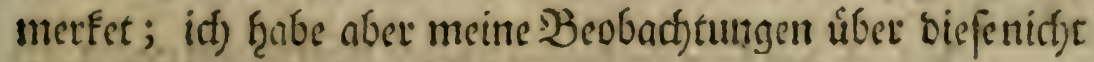
soeit genug getrieben, un etwas genaueres f̧erausubringen.

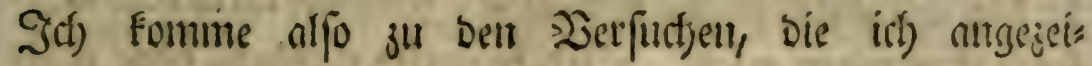
geet ţabe.

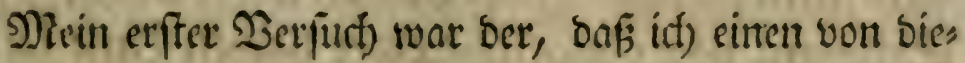

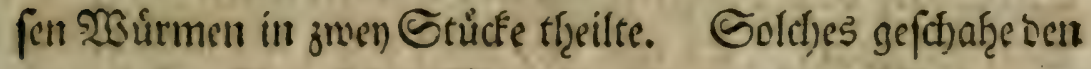

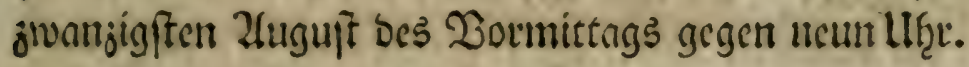

Den bren uno jwangigften, bes 2fbents gegen fectfs

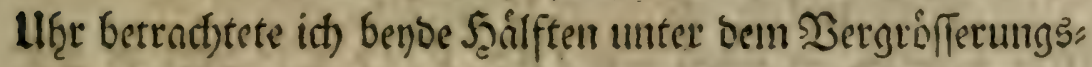
glaje, uno bemerfte, baßz ber ber erften ber Edjwanj ants fung rieberjuwadbfen; bie anbere aber nod) nicflet jugenouns men fृatte.

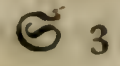

Den

c) Morand 2Inatumie bes 3 lutigels in ben Memoir. de l'Acad: Royale des Sciences. 1739. 
276 Beobarftungen libet einige 2hten

Den acht unt jwangigften gegen झlorgen wat biefe

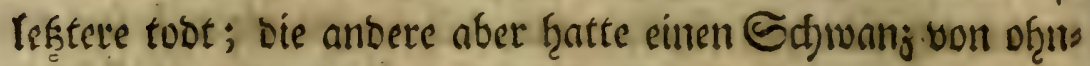

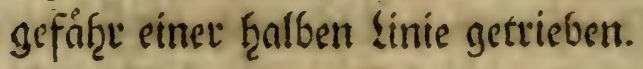

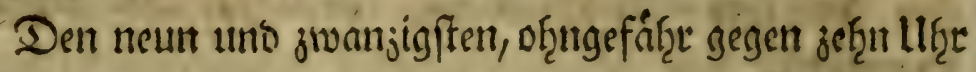
Des Wormittngs, wicberḩolte id) ben am jwanjigifen gemad)s ten ¿er [ut).

Den fiebenten September ḩatte bie erfte Şâlfte cinch

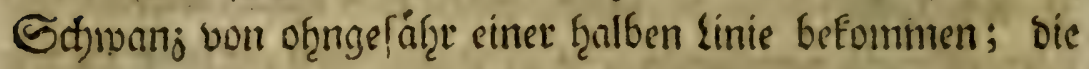
anbere aber hatte nur antgefangent, ctwas ju treibert.

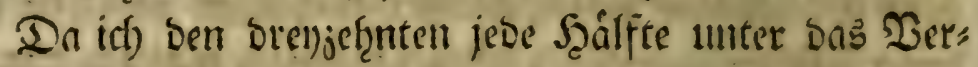
grofferungsglas gebrad)t; fo benturfte itl) mit Erffounen,

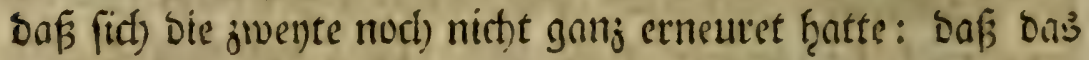

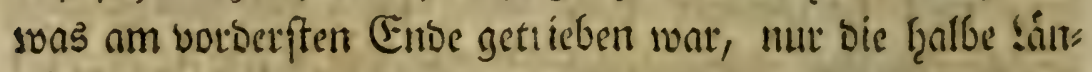
ge war, bie ber netue Ropf f̧aben follte, ofrnerad)tet ber

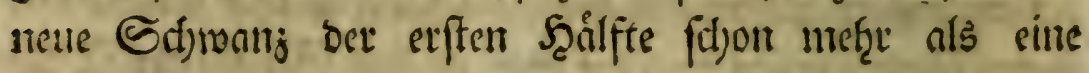
Sintie Gicelt.

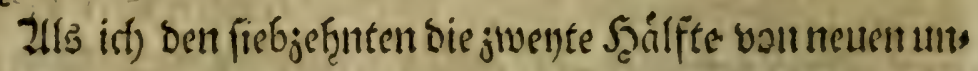
terbas Dergrifferungsglas bract)te; fo murbe idf in nod) grief

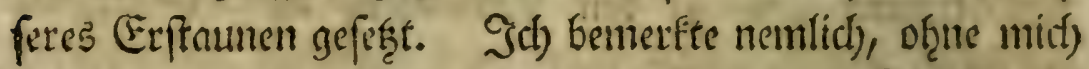

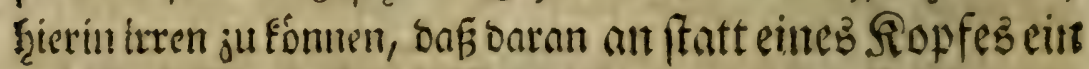

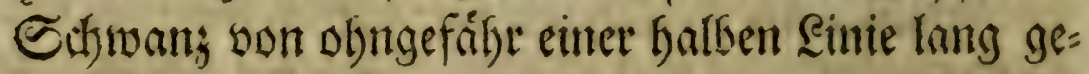
wachfen war. Es war dies nid)t etwa, wie man benfert

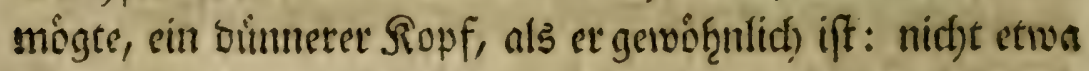
sine Biffalt bon Kopf und Sdywanj jugleid); nein! ç

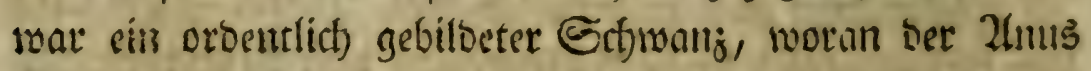
Fefre beutlich) ju fef̧en war (fig. V. Q. a); furz es ware

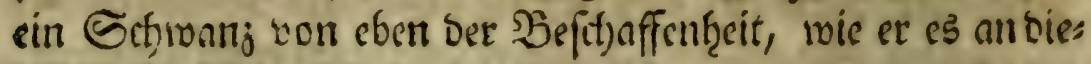

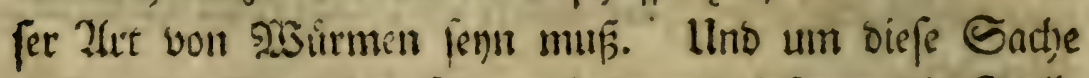
ouffer allen Zweifel ju fegen; fo founte biefer an bie Stelle

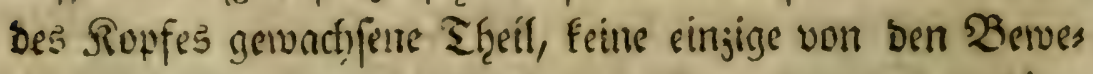
gunzen madjen, Die ber אopf ju madjen pflegt; er vertirit js 
te unb verlangette fich nidft: et zog fit) nicht jufammen;

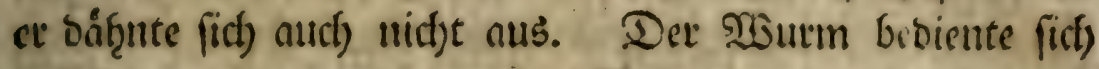
Seffelben aud) gat uid)t, weber פ?af̧ung zu nef̨unen, 'nod)

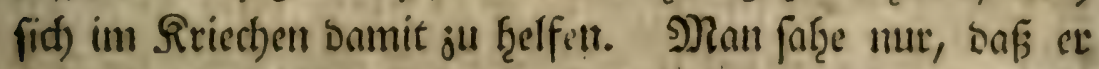

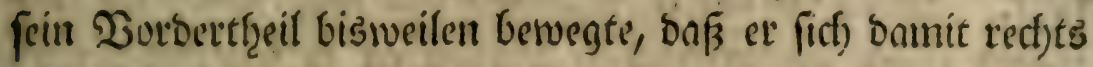

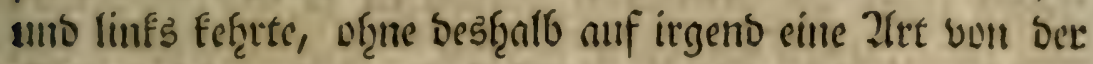
Strlle ju founnen. Faf̣t follte man fagen, bafj el feinen

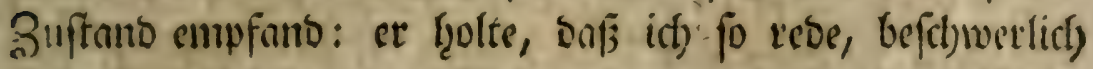

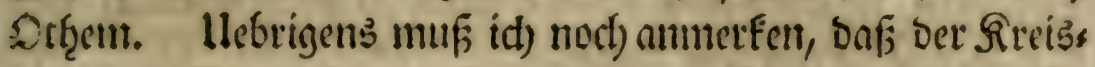
Inuf Des ß̉luts feinen Sanng nict)t veránbert hatte. Ev: ging beftánbig von lluten nact) bem Sbertheile ju *).

Id) war fef̧t begierig ju fetzet, was barauts mersent mógte, uno folnitt nod) au eben bem Tnge bie Seálfte in juen Stucfe. Llm befto fifferer ju getzen, lief ich fie mit

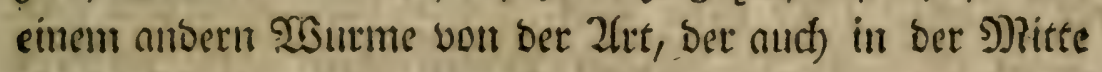

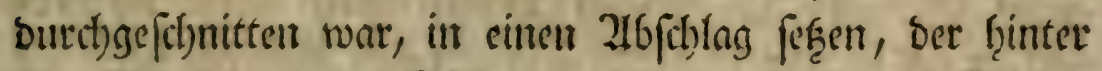
Dem Piaud)fange ber Riche angelegt war, wo bas शienu=

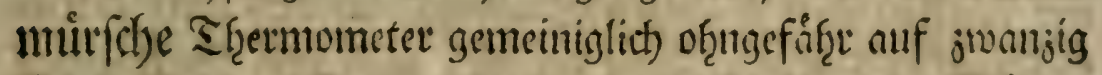

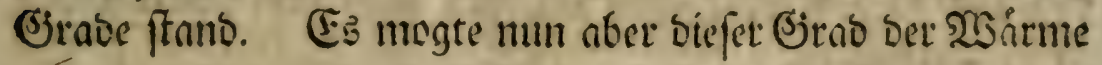
entweer folyon allouftarf für biefe Jufeften fenn, oder er mogte in Den 2(ugenblicfen, ba idf es nid)t bemerfte, nod)

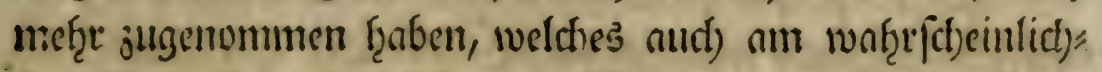

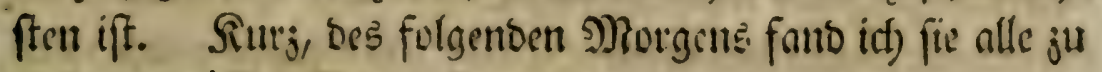
meinem groften Şerbruffe toot.

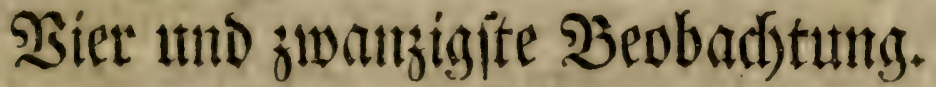

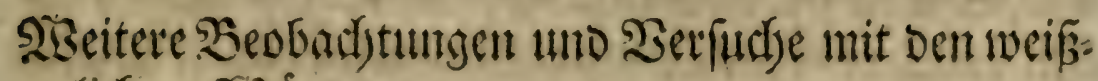
litifen sisirment.

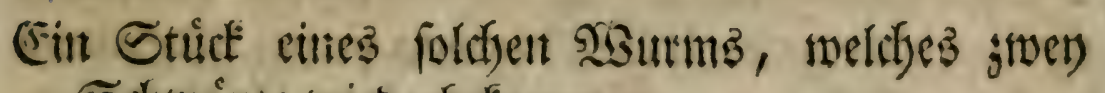
Schlowinge wiecerbetonumert.

*) Corps organifés Art. 258.

Da 


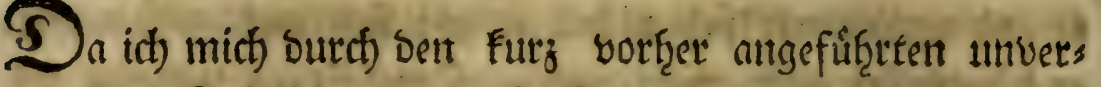
mutţeten 3ufall in meiner Şoffmung betrogen fahe; fo wuts be baburd) meine Neubegierbe, fo ju reben, befto mef̧r ges

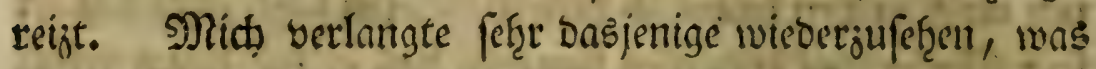
wegen peiner nusnef̧mentoen Geltenţeit fo fef̧r verbiente, zum jwentenmale gefefen ju werben. Den been unb jivalts zigffen September zerffrnitt id) bren von meinen weifflidjen 20ürmen, in jiven, uno einen altbern in bren Studce, unto Jię fie alle in meittm Zimuner.

Den eifften Dftober hૃatte baß erfte Stülét eines jebent 52surms einen orbentlich) gebildoten Scijmanz getrieben, woran ber 2(ffer fẹtre beutlich) ju feţen war; er ḩatte aber

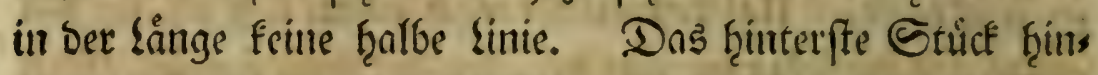
gegen fratte nicht das geringfte jugenommen; allein bas श)

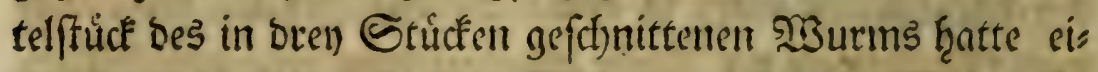

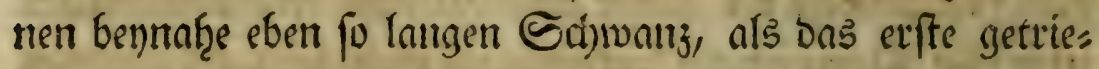

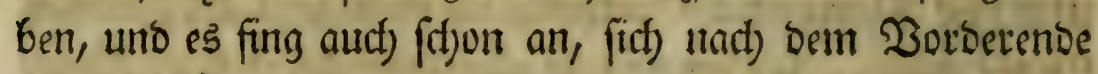
ju ju verleingern.

Den bier unb jwanjigften war ber Sctiwanty bes ers

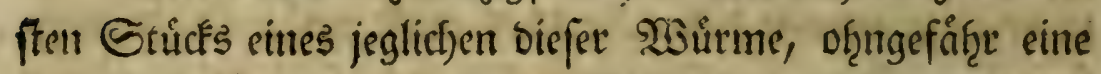
halbe Sintie lánger geworben. Das leģte war bentraf̨e nuch) eben fo wie ben eilften; mur bas Sorberente fidjien erwas runber geworben ju fern. T2as das Mittelftủct Des itr bren Stủclen gefdunittenen 2 Burms betrift; fo ḩatte folthes ftatt Des Sopfs einen Sdywanz wieberbefommen. Derfels

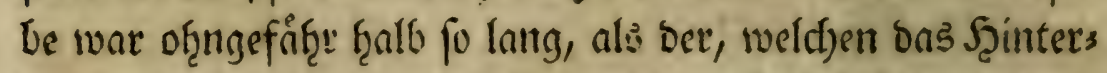
entibe getriebent hatte. Ulebrigens waten fie fild, bende einalls ber in Der Beftalt, in ber Đroportion, in Der Sarbe, u. f.w. yollfonmen gleiff. Was foll man aber f̧ier von einem fo 


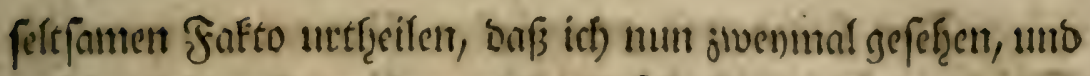

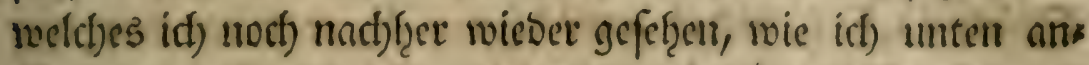
fühzers werbe, uno wie idf) es vermutţet ḩatte? 'Solltert

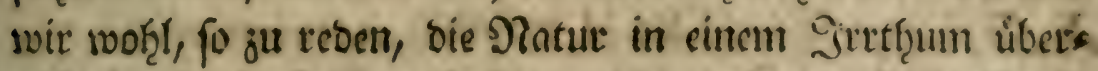

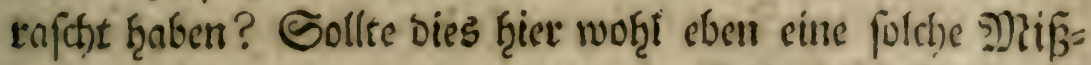

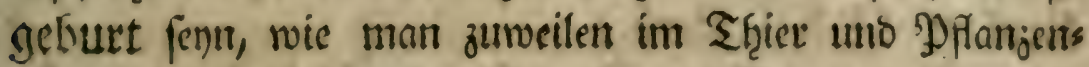

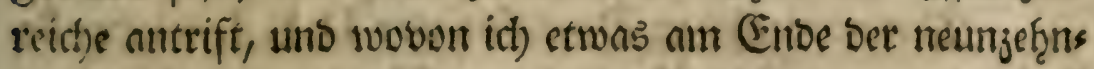
sent Bbeobant)tung f̧abe fagen mollen? Doer went man mit

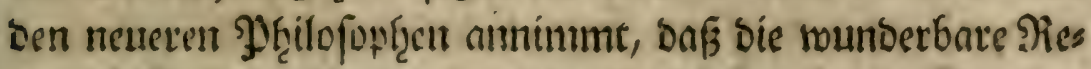
probufcion aller S F̧eile an bicfen Sinfeften, vermittelfit einer

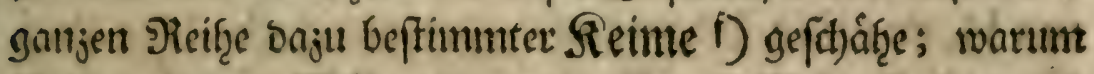

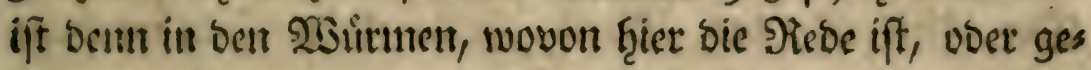

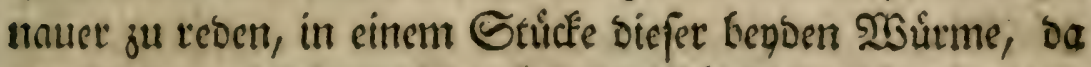
ein Schwanjfeim getriebelt, wo ein Sopffeim ḩätte treiben

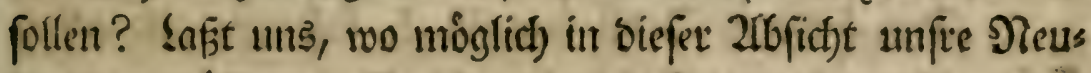
begierbe máfigen! Es ift noth nicht Zeit, baf wir fdjon volr

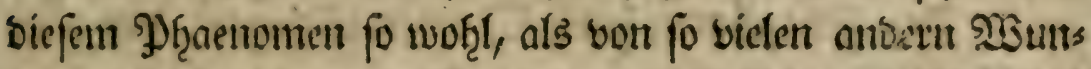
Dern, weldye bie neue Entbectunt ans Sidjt gebrad)t, Dett

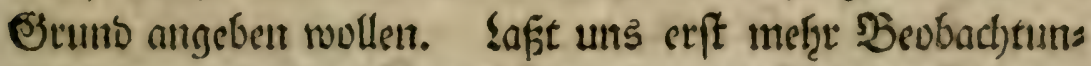

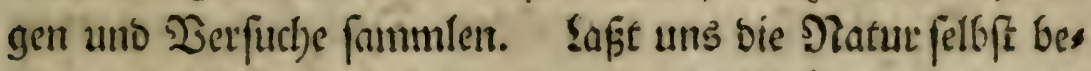
fragen, wie fie will befragt fents. Eine genaueve, uno nact)

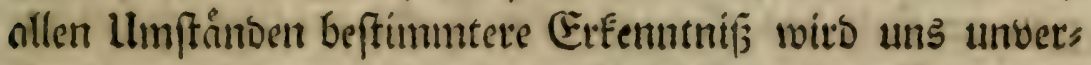

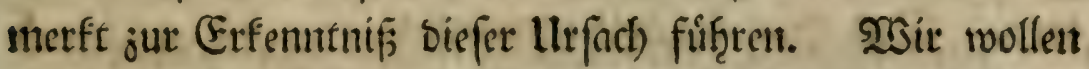

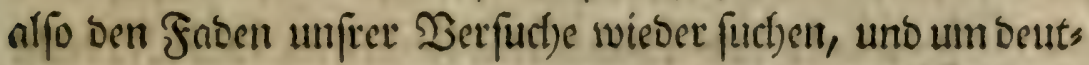
litjer uno genauter ju rebelt, wollen wir jebes Stứct burd)

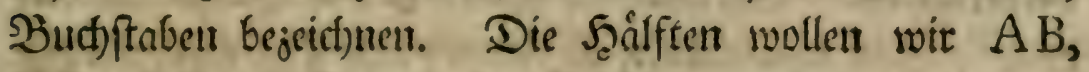
CD, EF, bie Drittel aber G HI, nennen.

$$
\text { S } 5 \text { Dent }
$$

D) Confiderations fur les corps organifés. Art. 260. Se: $_{0}$

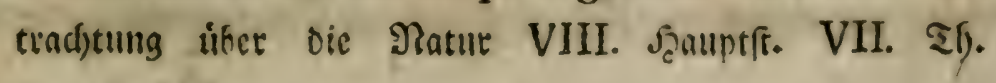
p. 148. 1leb. 


\section{Beobadjtungen úber eintige $\mathfrak{A}$ rtent}

Den fiebent uno jmanjigften શloventber waren bie Etidce D, F, I, nict)ts gewadffen. B, war vor Dem vier uno jronaigiften Sftober geftorben; abet bie Stúcfe A, C, E, G, fatten fo woh̨l als $\mathrm{H}$, merflich jugenommen.

Deffelloen Tages fdutte id sen Etriffen A, G, ben Sopf.nb. (XXV. \$beob.)

Den neunjefgnten December war D, F, I, wie ben fies bert huto jwanjigftert November. H, war fowofil an eis nem, afs an bem nubern Entoe, länger gelworben.

Den eriften Februar 1743 , war Der f̧inderffe Sdywants son $\mathrm{H}$, eine sitie, ber borberffe aber eine ballbe sinie lang. Der Ilmlauf Des Şluts Ģatte feine Seránberumg gelitten.

I, war wie ben neunjef̧nten December.

Den fed)äten Ifpril war H, I, faft wie am erften Sebruar.

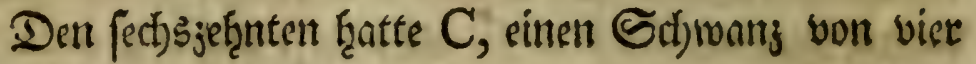
bis fưnf Ginien getriebelt.

E, wor geftorbent.

D, war wie betr neunzef̧uten Decenber, ansgentons

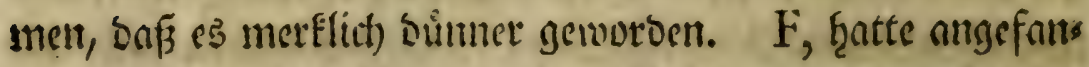
gelt, an ftatt bes Ropfes, eilren Sd)wanj wieber jubefoms ment. Das B̧lut lief wie gewoótrnlict).

Dert adjt uno guanjigften founte id $\mathrm{D}, \mathrm{H}, \mathrm{I}$, nicftet

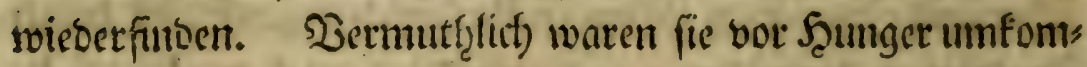

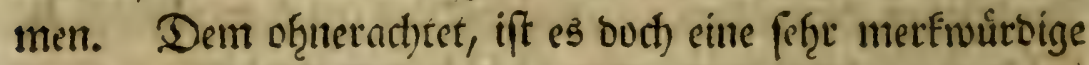

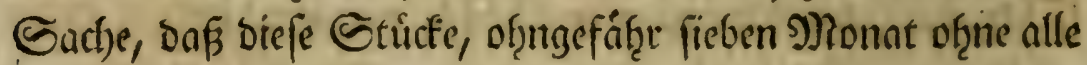

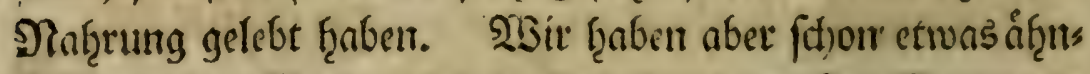

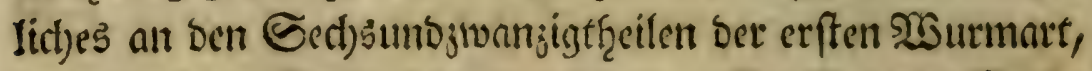

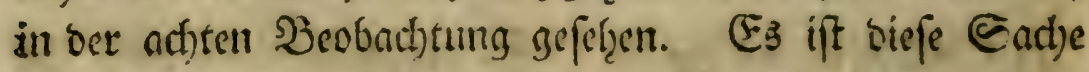

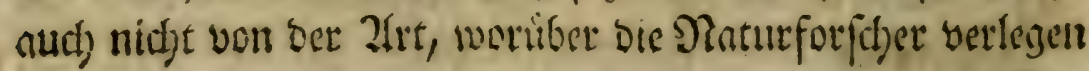




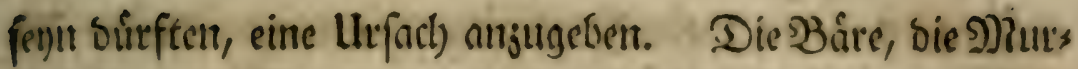
mettriere, bie Ertoratten; und unter ben Injeften bie Bbice nent, bie Zlmeifen, bie Juspen bon biffen Sianpenarten, ge, wiffe Schmetterlinge, u. F. w. lef̧ren uns, daß̧ es viele

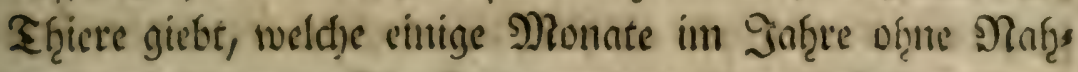

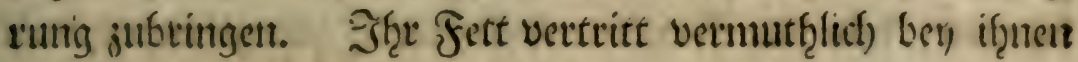

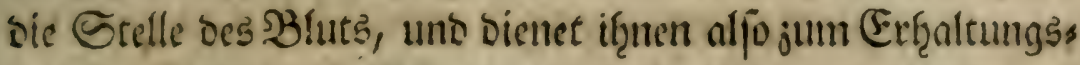

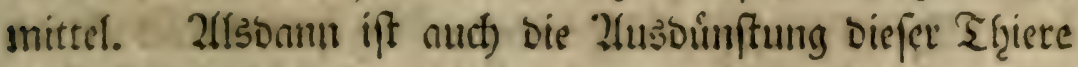

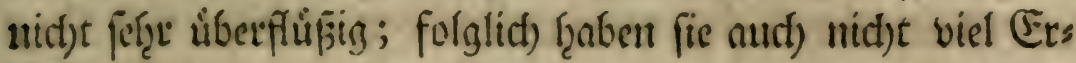

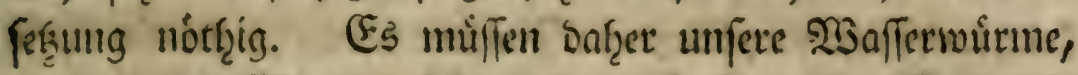
Die in einem Elemente leben, Dariut fo fetjon Der Girno Der 2asirme geringer ift, nls in ber aufferlicten tuft, not) wents

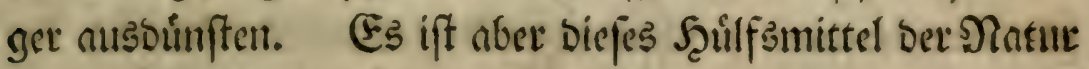

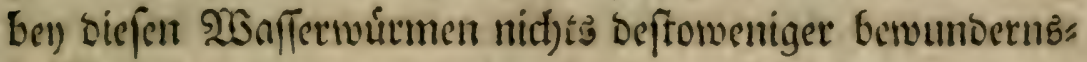

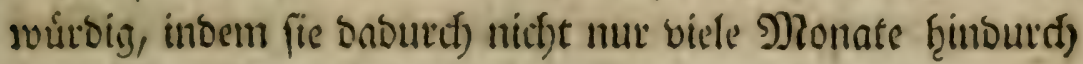

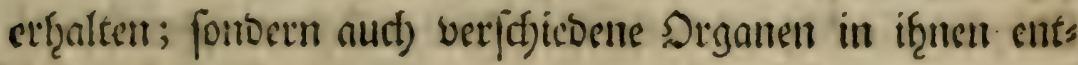
buiffelt werbert.

Den vierten Stmtus, ḩatte fict) Das Stiut F, in ber

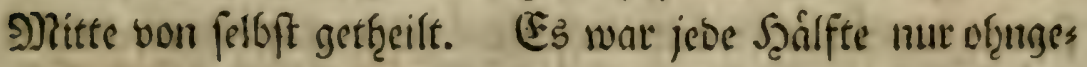

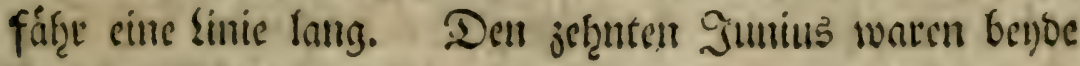
filyon geftorbent.

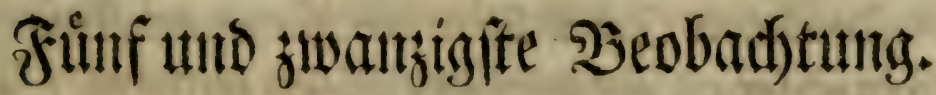

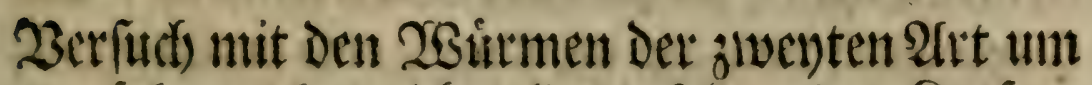

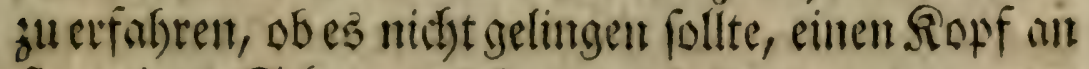

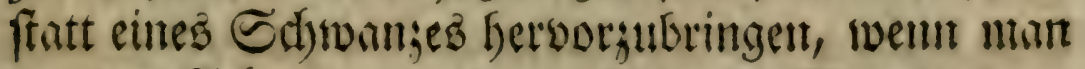
Den SdJnitt anteršwo, als in Der Mitte DeB

Rorperb madjte.

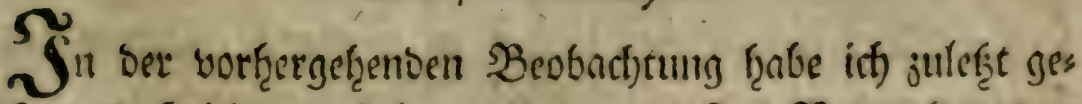
pagt, son int) nun fieben ant jiwanjigften November, bent 


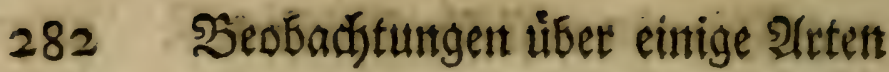

Stưdent $A$ und $G$, ben Ropf abgefdynitten. Mleine 216 , fict)t mar ju verfurfjen, ob id) nicht Daju geflangen fónnte,

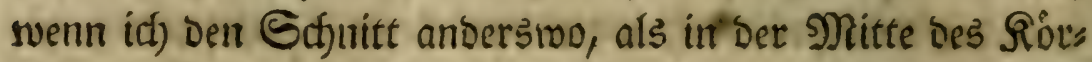
pers marthte, alles wieber in feinte naturtlitye Sromung ju fes Gent, ober einen Sopf, an ftatt cines Sctmanjes f̧erborzus bringen; unt bas ift mir auth in Der Ş̧at gelungent, wie man in biefer Beobbact)rung fef̧en wirb.

Den neunjeftrnten Decenber fing bas Stick A an,

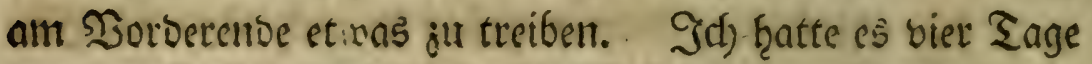

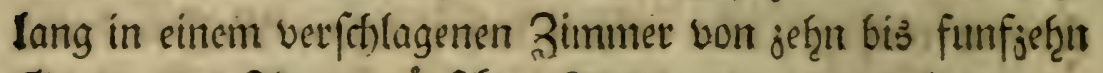
Graben bes Pieaumuirfid)en Thermometers geţabt.

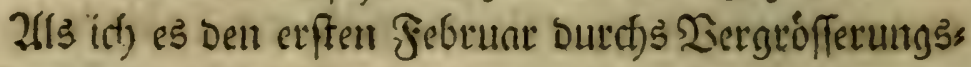
glas unterfuct)e; fo fothien es einen ganjen Ropf wieser bes fomment ju f̧abent; es waren aber פRagent uno Eingemeibe

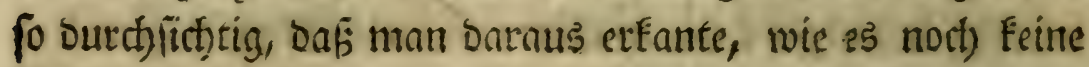

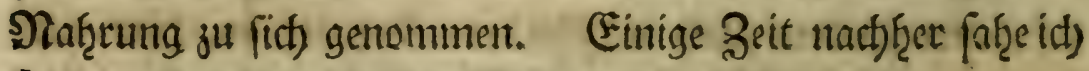
foldje erft mit erbf̧after Materie angefúllt.

Dett given uno jmangigften; Des folgenben Suntus,

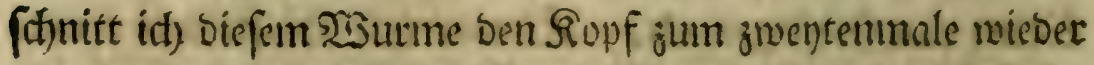

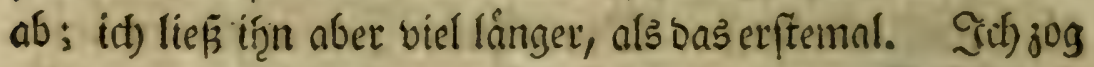

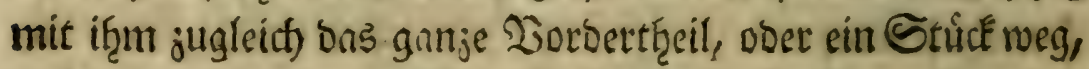
welches woh̨l anbertf̧alb stinien lang war.

Den act)en Jullus ḩatte Der Sibrper an \orberens be, einen Stywanj von jiven Drittellinien getriéber. Das

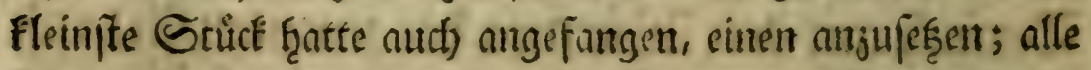
benoe aber ftarben noct) yor ber Mitte Des Mlonats; nur biefę leģtere f̧atte bas andere einige Tage úbartebt.

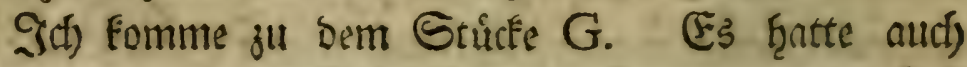
ficjon, ben neunjestrntent December, angefangent, an bem cuuf ferften Dorberenbe ctmas länger ju werbert. Den erften

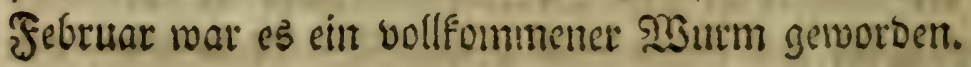




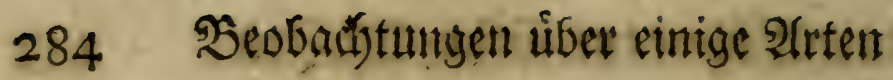
treibent:

O fing an an, ftatt eines Sopfs einen Sdjwanj ju

Dent sin uns jwatjigftent wav $O$, wie am brens jef̧̧ntent.

Den: inulften Suntus hatte ber Sdjwang von $\mathrm{N}$ fünf sinien.

O wat wie belt ein uno juanjigftent May.

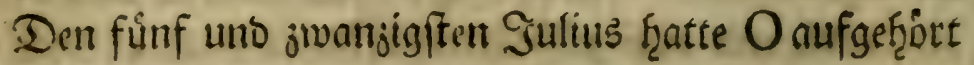
ju leben, of̧ne weiter genuachjen ju fenn.

Den fiebenten 2luguft fratte $\mathrm{N}$ im ganjent brens? . zện Sintên.

\section{Sieben unt juamigite כeobactutung.}

Heber einen in vier Stuffe zertheilten 234 um

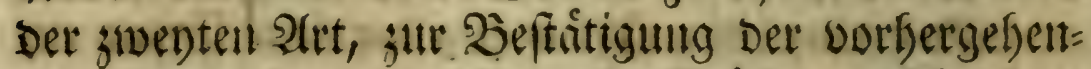
Den sbeobadtungen uiber Die Stritte, ivelthe ftatt. eines Sippfes einen Schwan: befomment.

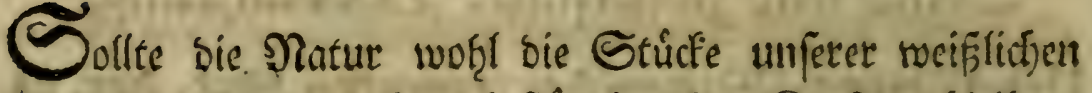

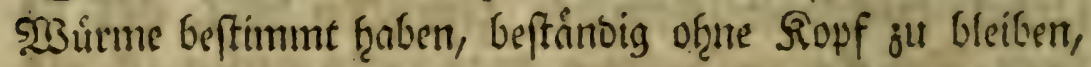
ober nidhts nls Sdjwainje ju treiben? Man fonnte foldtes

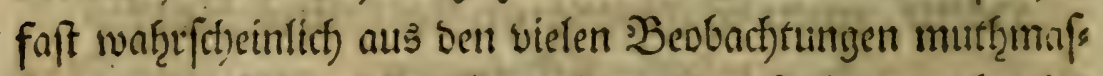
fent, bie ith) kiber siefen Begenftand angeffellt, uno bereits

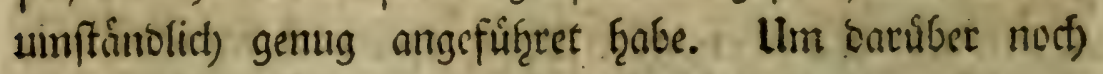

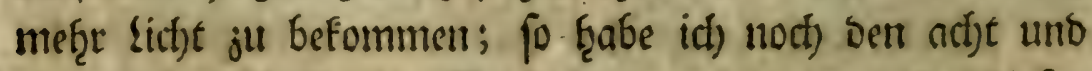

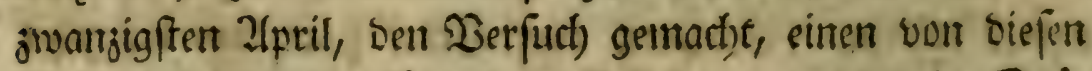

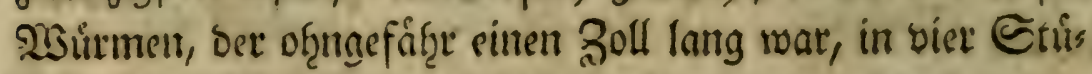
de $\mathrm{P}, \mathrm{Q}, \mathrm{R}, \mathrm{S}$, ju jertheilen.

Den oren)sef̧uten Man ḩatte $\mathrm{P}$ angefangen einen Erfjwanj wieber jul befonumen; er war aber ungeftalt; Das 


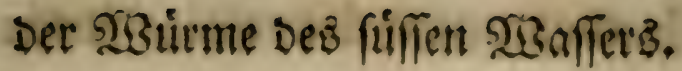

Enoe bavon war tunt unt gleid) fam geringelt. Nan fas

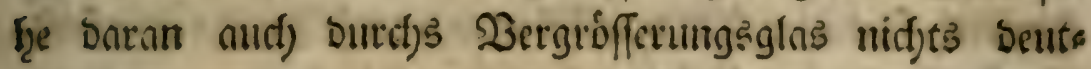
lidjez.

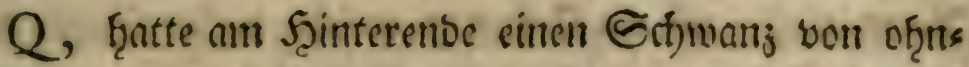

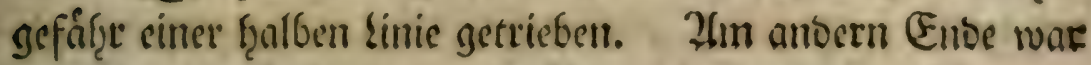
es eben niift) inerflitt) gewart)fert.

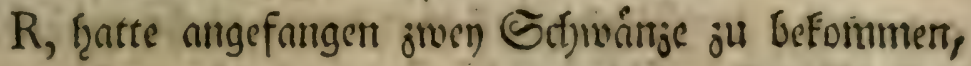

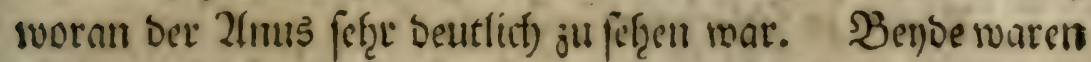
fie feg̨e furj; ber votberfte aber Fürjer als ber f̧imberfte.

$S$ war feit sen britten biefẻ Monnts tobt.

Den ein uno jwanjigften war ber E(t)manj bon P, foft in eben bem 3ulftanbe, wie ben brensef̧nten; wab firt) aber biejen Ian, an bem Sticke nentes jeigte, waren adtht

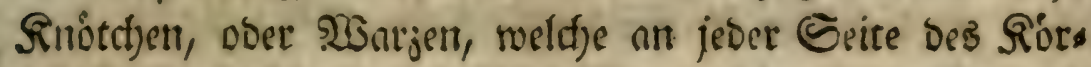
peres, viere auf ber rechten, uno viere ouf ber linfent freraubs getrieben waren, uns meltfje bent bloffen 2fuge fojienen furge Fúfictjen ju fern.

Der am Scinterente von $Q$, gemact) fente Stfwans Bzatte eime Sinie, ber anoere nber, ber fich erft am Sorbertf̧eile jeigte, war nict)t fonderlich) gewad) (ent.

$\mathrm{R}$, war bennaf̧e wie ben bernjsęrnten.

Dent bietten Sunitus ronet bie TSEntjent an $\mathrm{P}$, vers fet)munben, uno ber E(f)wanl soar beftánoig unigeftalt. Der )Ragen mo Die Eingeweibe fotimen audf Teer วu fenn.

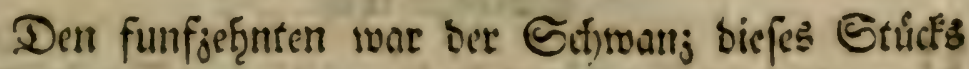
sine Maffe von fonverbarer Beffalt ( geworben; fie war ber fwhąarifthen áf̨nlidier, als irgenb eis ner anberti, uno fie war in Umfantge merflit, gróffer als ber Siorper felteft. Sie war aud), wie Der Sórper gan! ḩerum

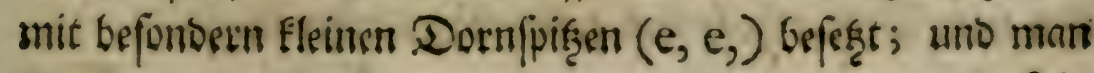


286 S3eobactungent hiber einige Prtent

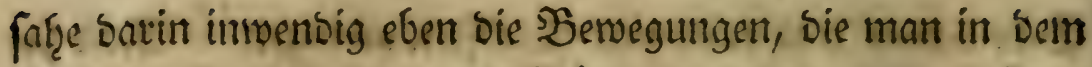

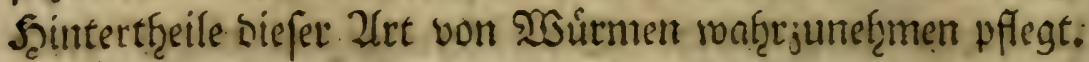
(I. Beobarít.) llebrigens jeigte fich Daran weber ein Zluus, noch) fonft ein Defnumg, welche Deffen Stelle vertres ten ţắtte.

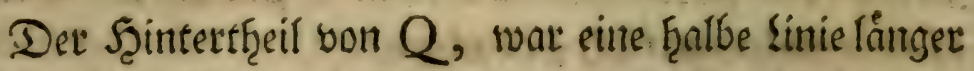
geworben; Der ¿örbertf̧eil war ber nemliche geblieben.

$R$ war in foflect)tem 3uftanbe.

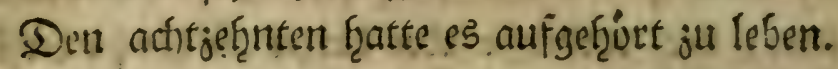

Dent bren uno jwangigften war ber lángfte Edjwang yon $Q$, voln falten biranbe angeffectit, und gantj voum Sürs per getremiret.

the Den vierten Эulius war bies Stilck tobt.

P, faft eben fo, mie ben funfiesnten Junius.

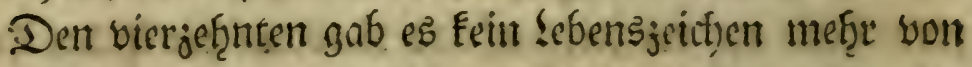

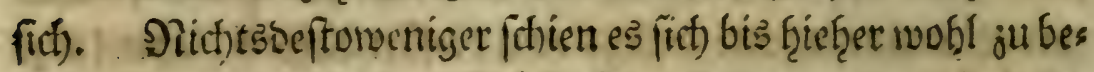

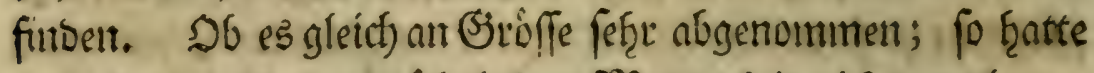

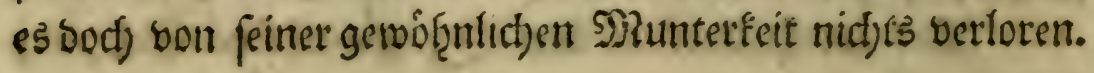

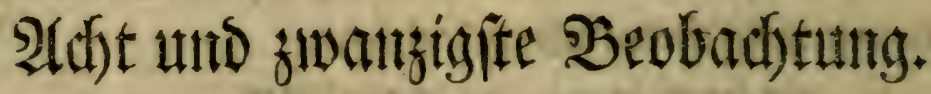

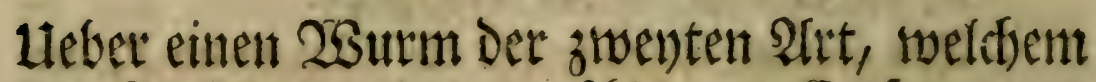
Der Ropf Dretmal, in veridjiebenen Entfermungen gom Ende abgeidynitten, unt Dem Der lergte, gegen

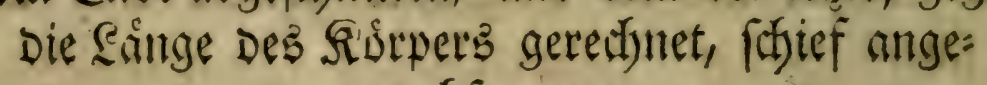
wadjent war.

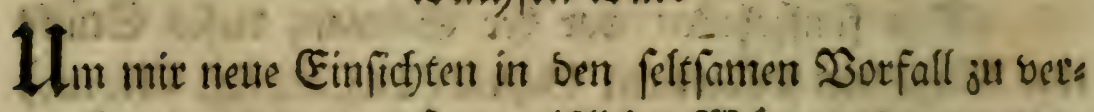

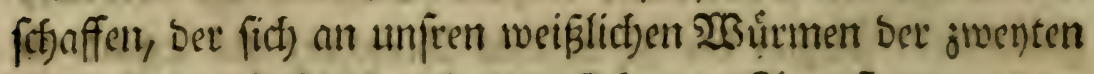
Zfrt geigte; fo fdunitt idh), Den fiebenten Zluguft $\mathrm{r}_{743}$, Dom

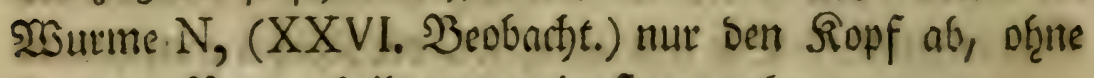

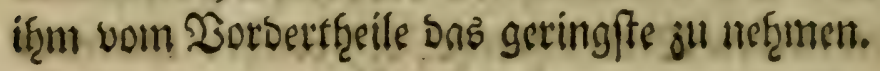


Den fechşzefruten war bee nelle Sopf billig wieber gerwatbfett. Man fatee aud) Erbe in bent Einges weiben.

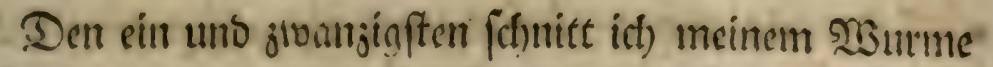
Den Sopf von neuen ab; aber f0, Daf Der Edutitt anderts bzalb Sinien vonn Enbe gefd)ahe.

Den criften Septembar fotien es, als f̧âtte er cinen ganj netsen wieber befommen, woran man ben Numo fifec gut unterfachoen formte; bas Enbe aber war noch nicht fo lang, als es in ber Folge werden multe.

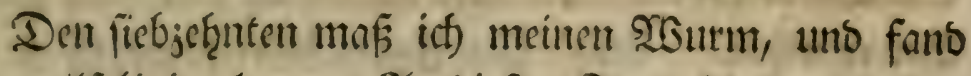

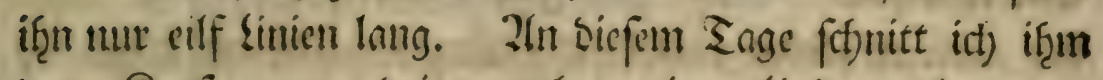
Dan Sopf jum brittenmale, eine sinie weit voin Ende 06.

Den brenfigften November fratte er einen menten Ropf getrieben, welither aber in Dergleichung ber Lánge ves seibes, merflid) frumn war. - Eiu befonbers merfwutbiger llins

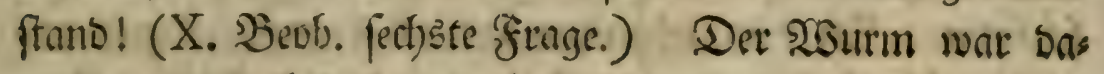
mals brenjef̨n bis vierjef̨n Linten lang.

\section{פieun und jwangigfte $\mathfrak{B}$ ebad)tunty.}

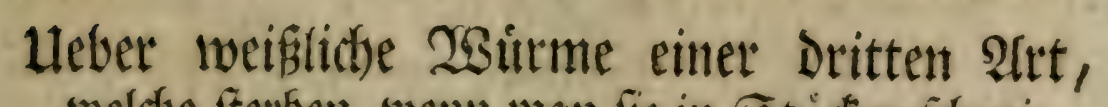
weld)e fterben, wemn man fie in Striden fonci: Det, oser verfitummelt.

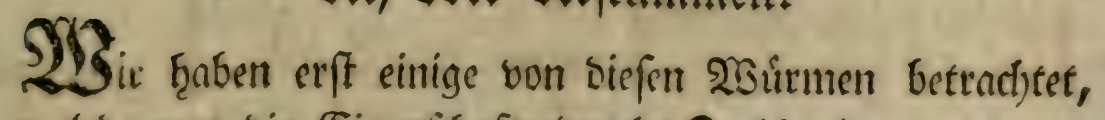
welthe nur bie Eigenjichaft, burd)s Berfatmeiben mieberjus

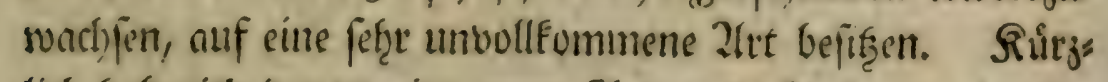
lict) f̧abe id) Dabon cine neue afrt entoecft, Deren einjelne Sbeile unfommen, wenn man fie ftucfueife jerfifnecibet. Bonnet 2. If. 


\section{8 Şeobadjtungen tiber eintige Frten}

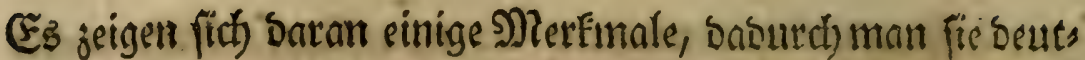

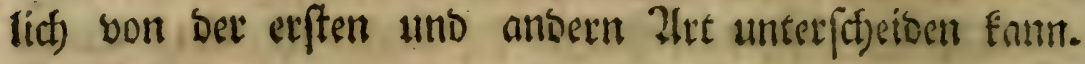
Sie fino

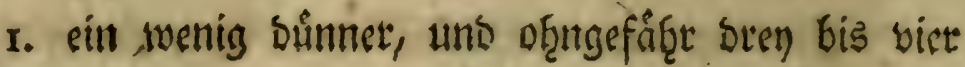
3oll fang.

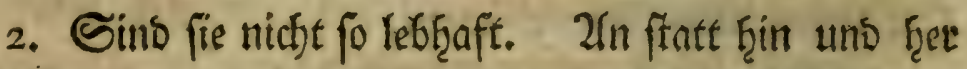

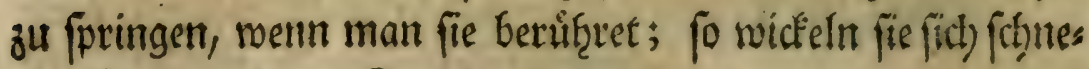
denformig wie cin Sintaul zufammen.

3. Estecten fie gemeiniglich if̧r Scintertheil nuts Sem

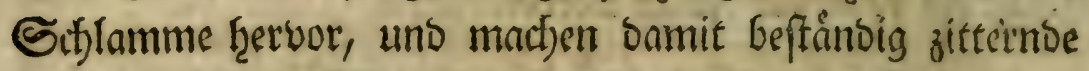
Bewegungen. THas inze Farbe betrift; fo ift fie nidjt ber) allen sinjelner einterley. Einige fallen ins 3 zraune,

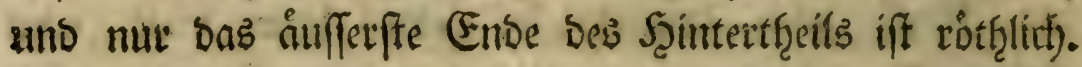
Die anbeen fiuto gamz graulich, ober weíflict). Diefe fino

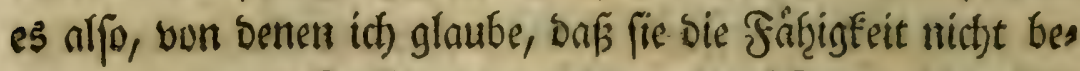
fis einige umftånolitit)e Beobad)tungen, weldye es zu Geweifen

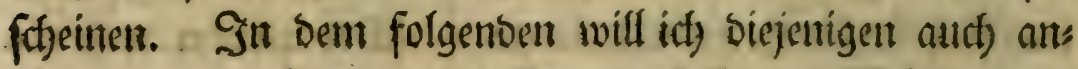

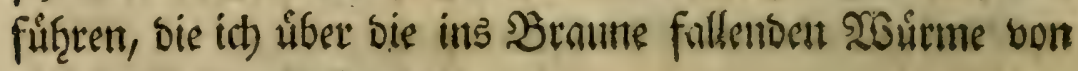
biefer Zitrt ongeftellet ţabe. 
Sagerenifter der Beobadtunngen liber jwer) meis: liche $\$$ Burme ber Dritten 2art, Davon jeser in fün Stricten geistuntten ift.

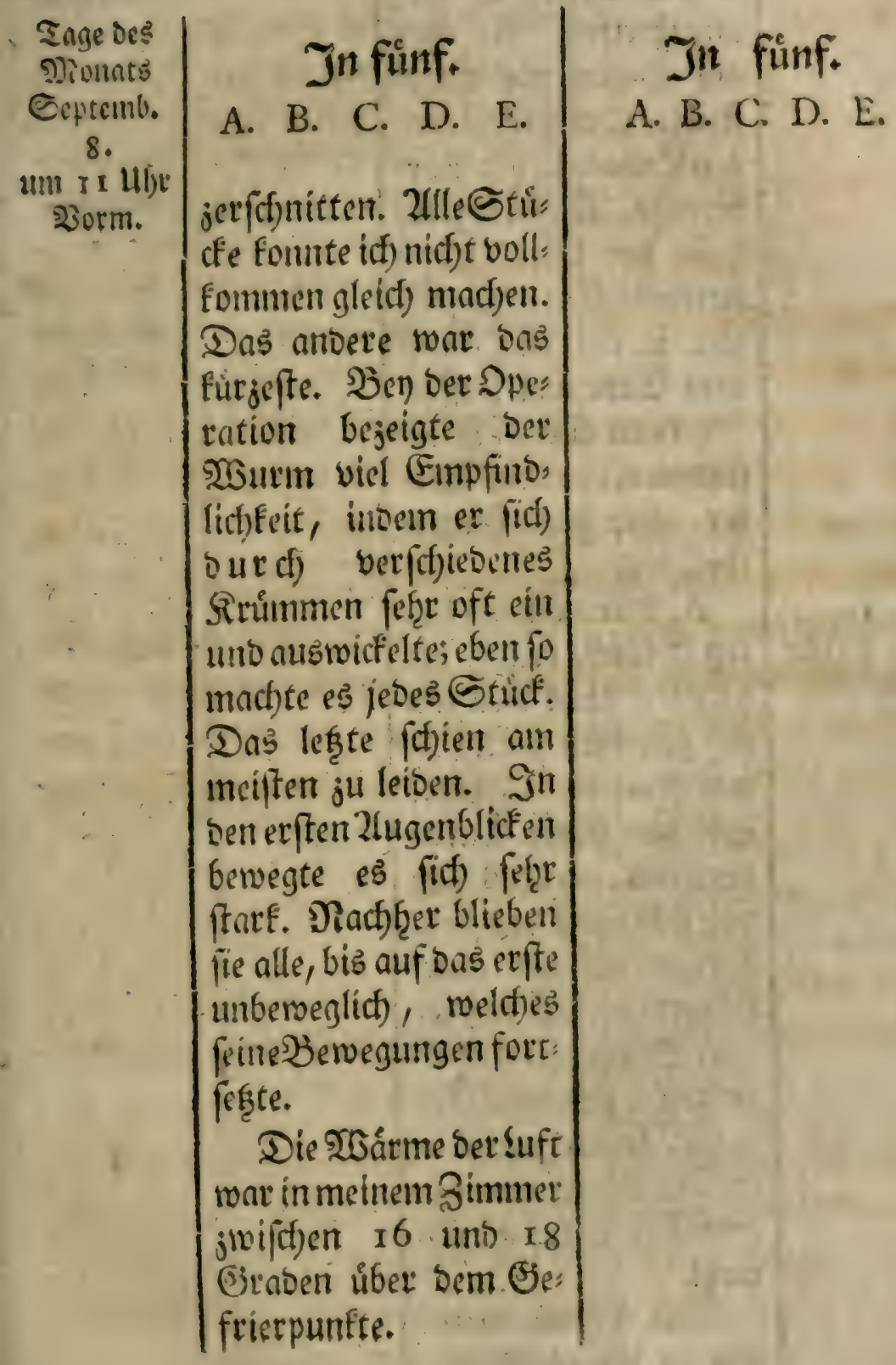




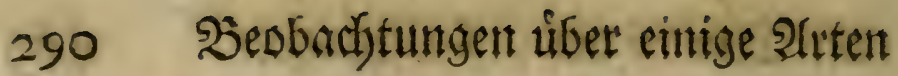

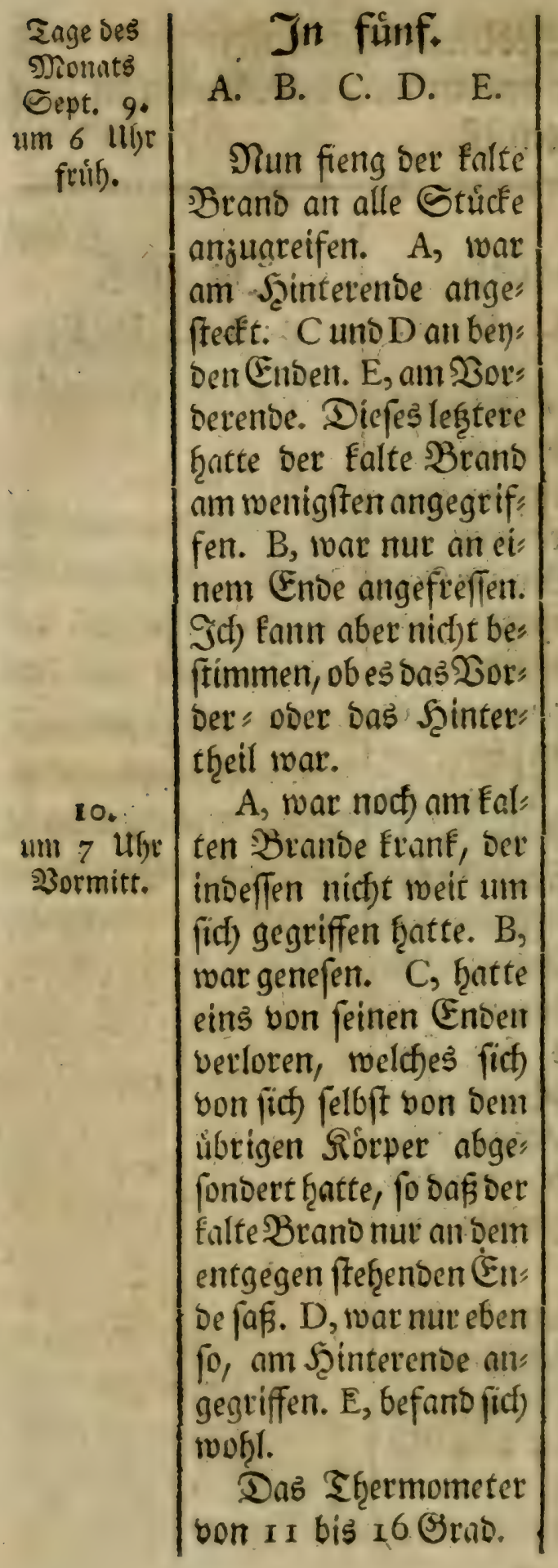

\section{In finf.}

A. B. C. D. E. 


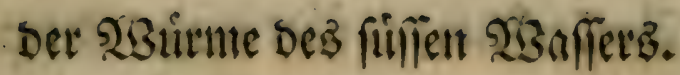

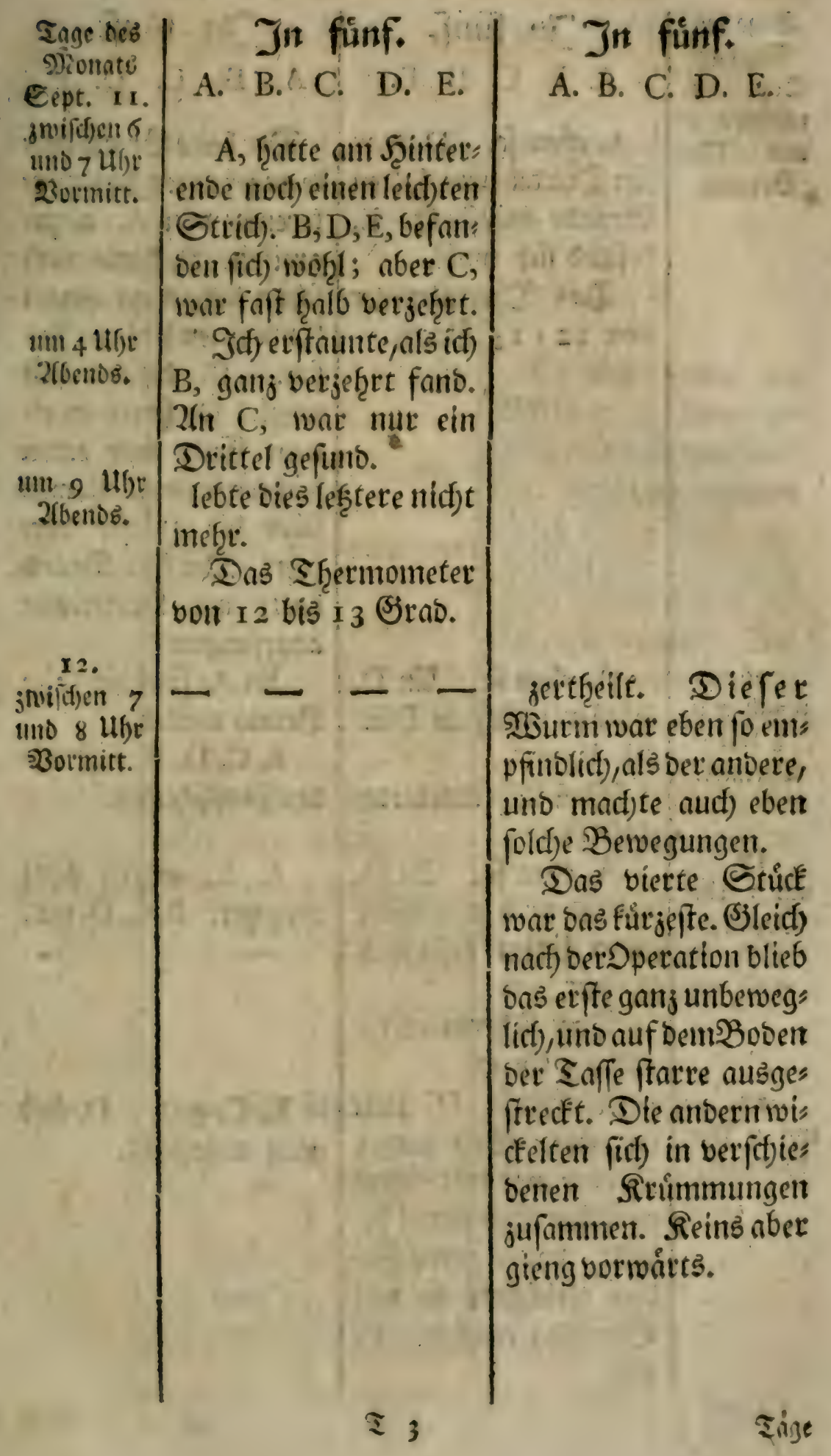


292 Şeobactuntugen uீber einige Frtent

Tage des
Dionats
Sept. 15.
amifdien 7
und 8 Itf)
Bormitt.
3twi[f]. 7 .

$8 \mathrm{ubr}$

230 rmitt.

17. Im 7 Ufr 25ormitt.

18. Imi 7 Ubt Burmitt.
In fünt.

A. B. C. D. E.

A, eben fo. D, war cin Drittel voin Falten Brande arrgeffecf́t. E, befand fid woht.

Das Thermumeter von 12 : 15 Srab.
In fuinf.

A. B. C. D. E.

Dêr f́nlte Srand ḩats te angefangen bas . Şith terenbe von $\mathrm{A}$, alljus greifen. B, hatte aud) iffon bavon an eitrem Ende einten léichten? In fas. C, befant ficts woferl. D, fratte an ets nem Ento mur einen leitften Etrich. E, ware über die Scalfte ver: jefret. Der falte:Brano ḩatte an Scinterentie angefantigen.

A, eben fo. Ifn $\mathrm{D}, \quad 2 \ln \mathrm{A}$, fráp ber Ealte lebte nur nod) ein Drit: tel. E, gut.

Das S Tzermometer noch $\mathfrak{1 0}$.

A, eben fo. $2(n \mathrm{D}$, waren noch of̧ngefäḩr jwen Sinien gefundes. E, gut.

Das Shermometer auf 14 Grat.

A, eben fo. D, ganz verjefret. Exin ganjer

Sóvper war mit einem gerviffen Schimunel be: Decl't, Davon jeder fa" Den gleidfaim to viel Straf̧lent madjte. E, gut.
Branto weiter.

$B, C, D, E$, faft wie Den funfäęnten.

A, E, waren gans verzeţrt. $B, C, D$, gut.

$B, C$, gut. D, foft ganj angeftect. 


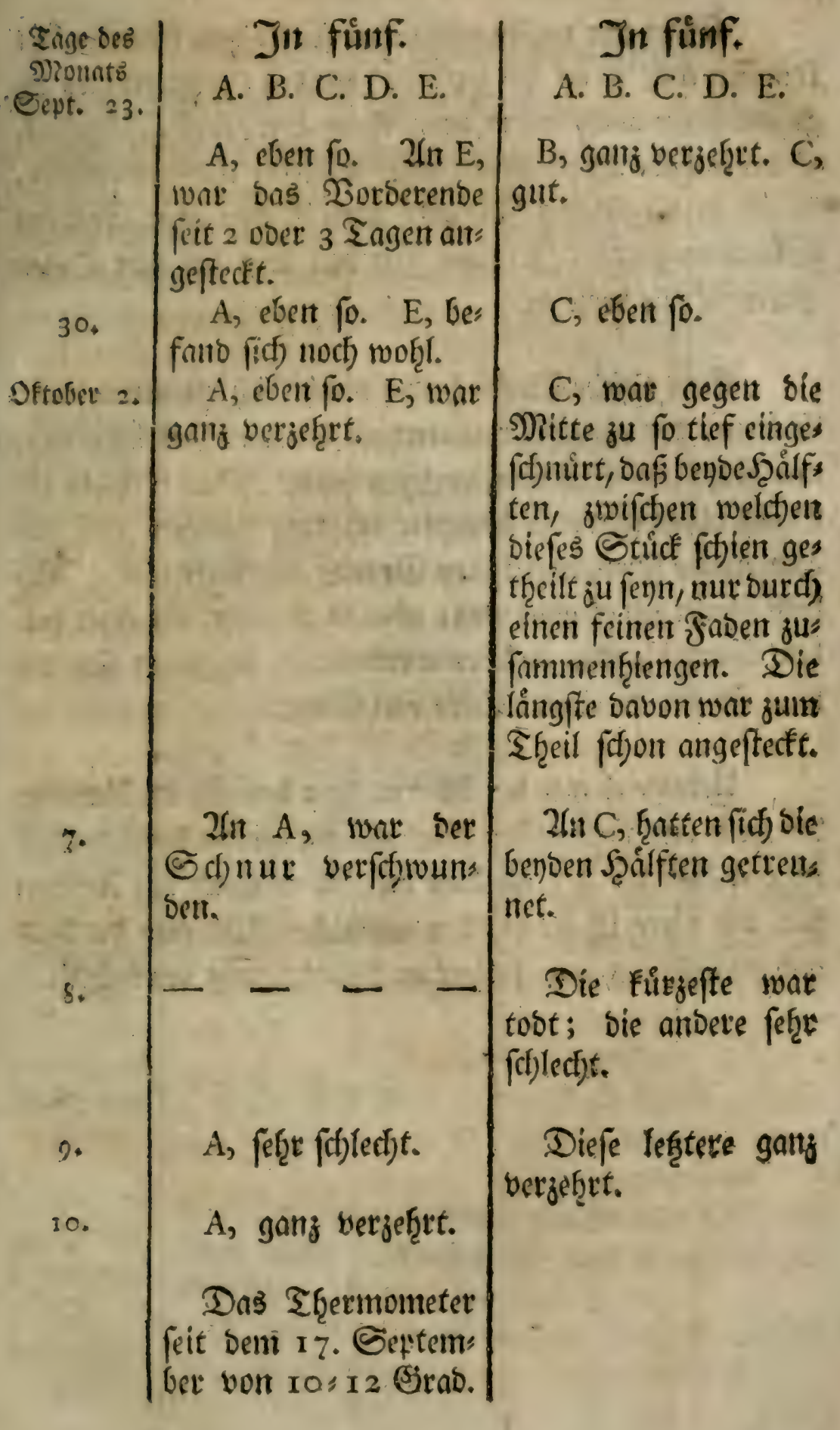

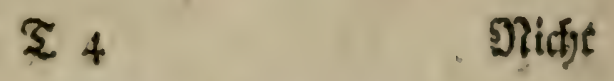




\section{4 Ђeobachtuntgen ůber cinige 2rten}

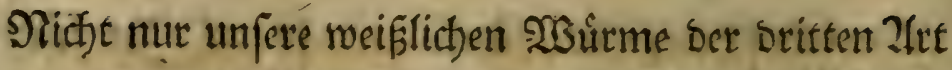
formmen um, wenn fie jertf̧eilet werben; fonbern bies bes

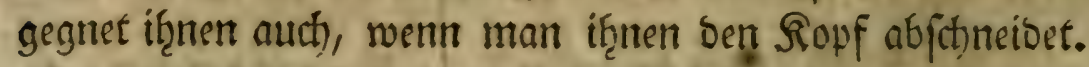

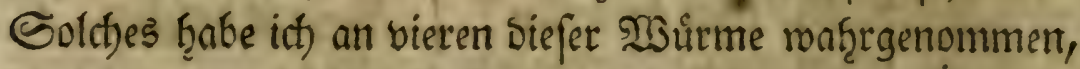

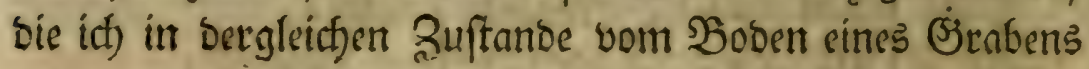
genommen hatte. - Sn einer Beit bon bren bis vier ₹ngen waren fie alle verserģrt.

(Fine gleicf)e B̧ecbat)tung machte idf an eittem biefer

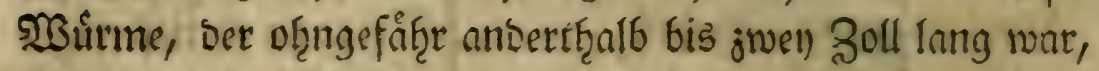
uno Ropf uno Ecţwantj verloren hૃatte. Da id) if̧n in eint

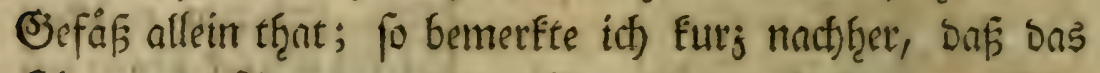

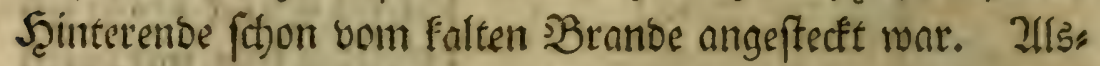
bals jichnitt id) es ganls weg; abee in treniger, als einer frals ben Siertiffunoe, welites merfivurbig ift, jeigte fict) ber Falte $\mathfrak{B r a n d}$ an diefem Ende von neuen. .

Ilebrigens war ber 230 urm, yon bem inf im 2 (nfange

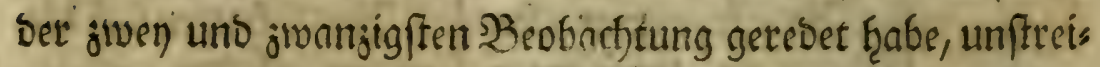
tig yon eben ber ?frt, als biefe bier, ob es gleid) Das IInfeţen

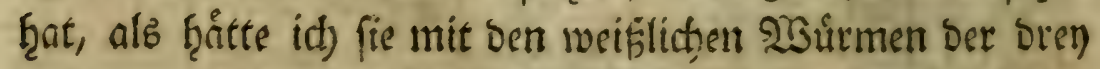
und jwanjigften, und folgenben beobadtsung berwect) felt. 


\section{Der SiBurme Des finfen 23afiers.}

Heber braunlitbe 2 Gurme Der vorfsergehenden

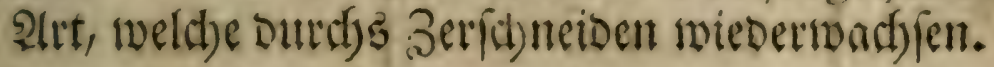

Sagerenifter Der Beobadttminen liber gnen bråmte lid)e 2 situme Der Dritten $2($ it, Davon Der eine in givel), Der andere in fün Stuiden gefonitten war.

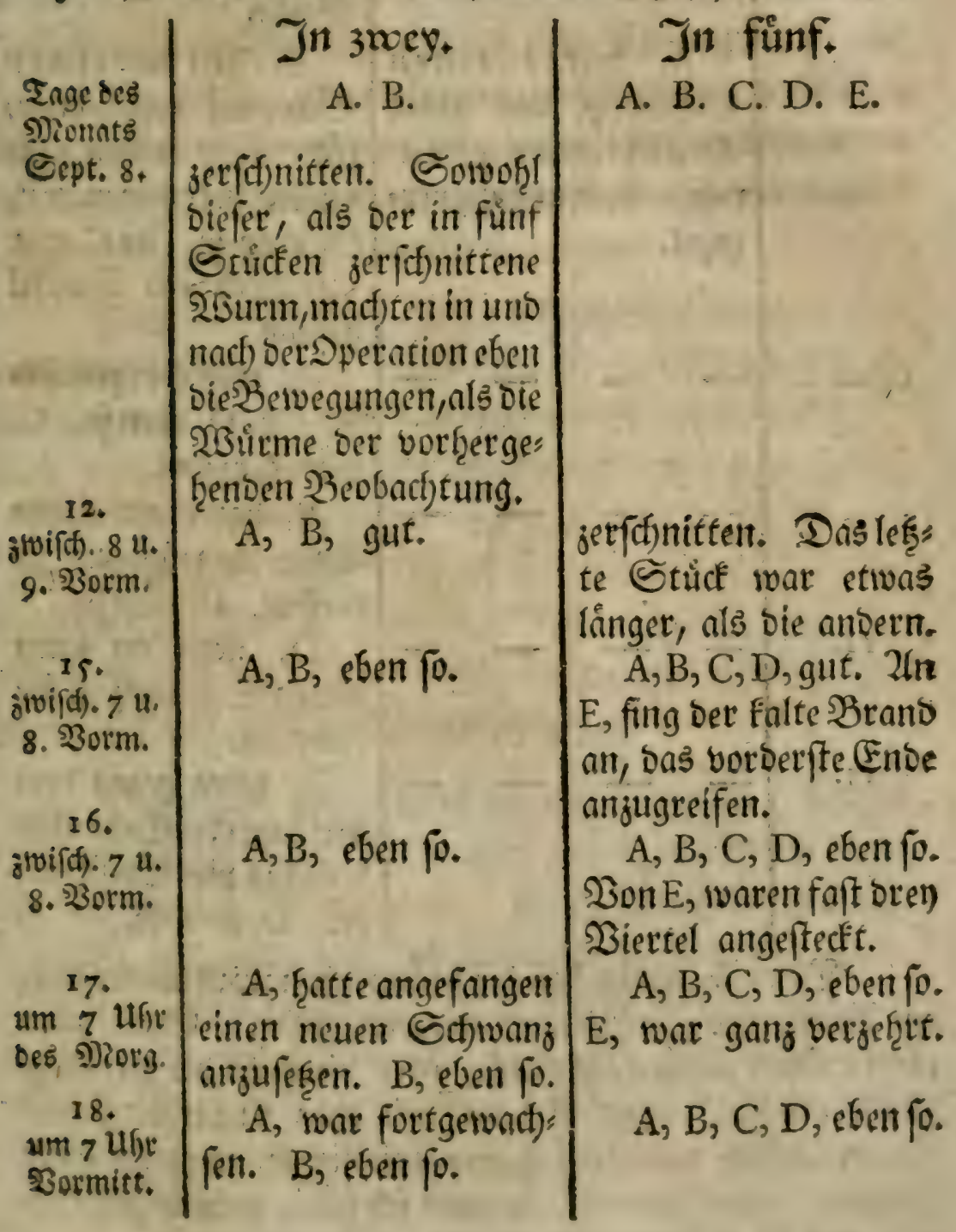




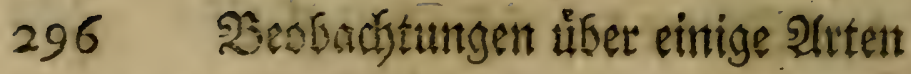

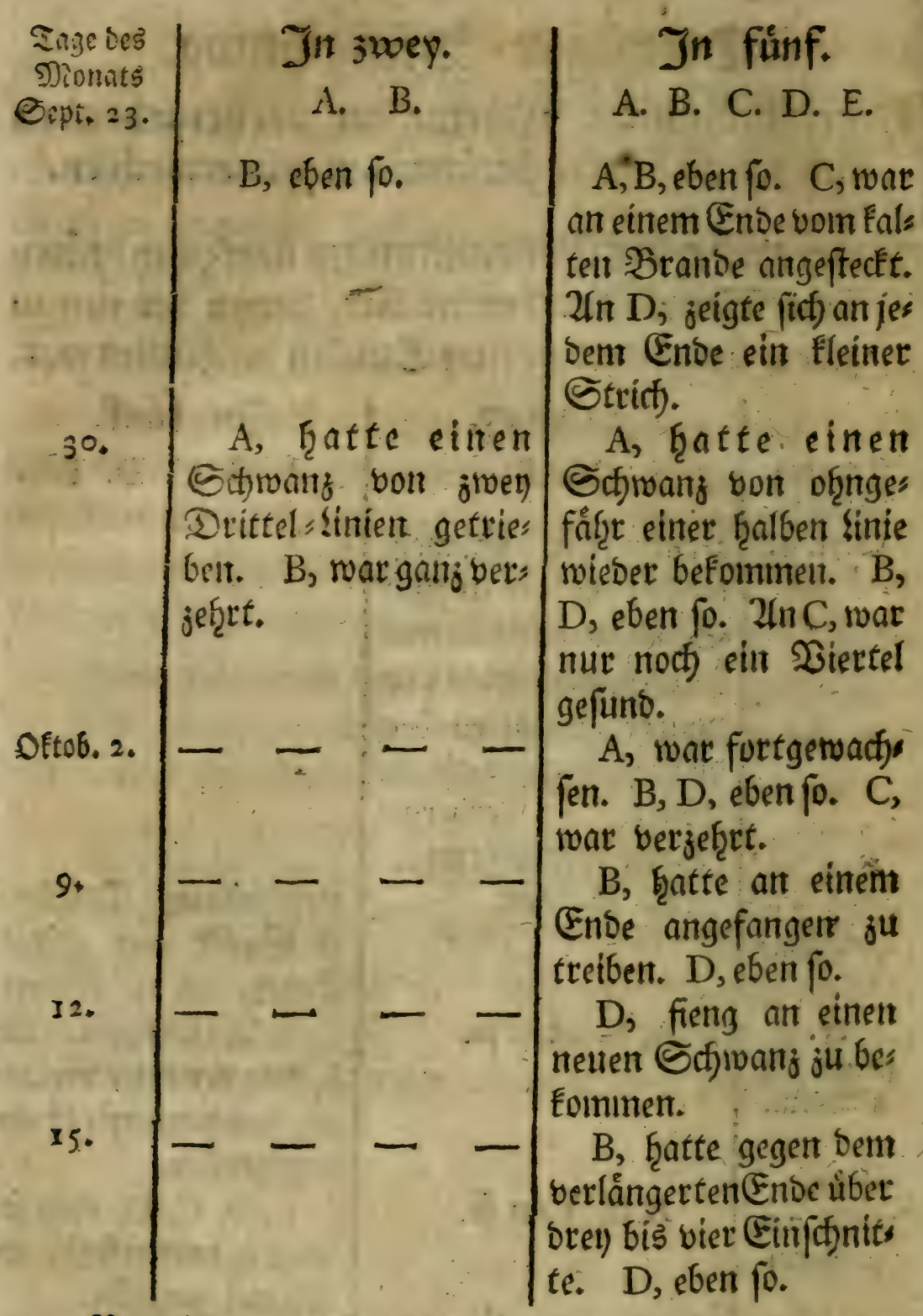

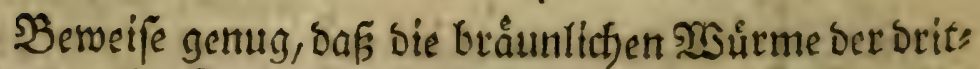
tett 2frt burct)s Berfinneiden wieberwad)fen. Sollte aber

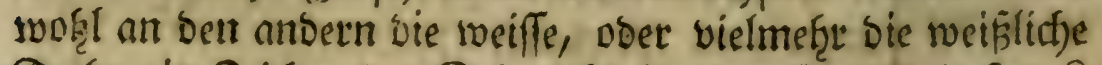
fforbe ein Beichen ber Sdlmad)heit ober Siranffect fentt?

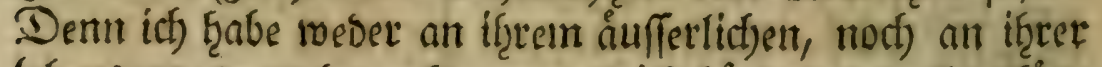

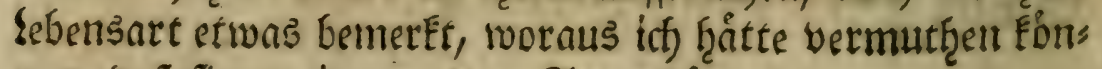
nen, baf fie ju sinet anbern 2 rt geţoren. 


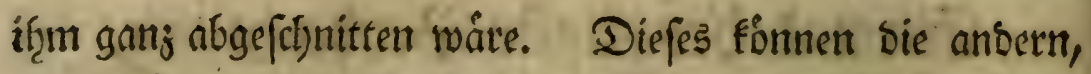

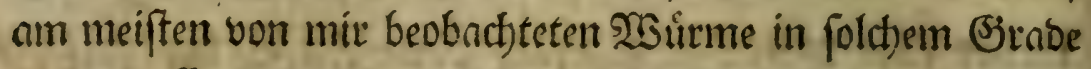

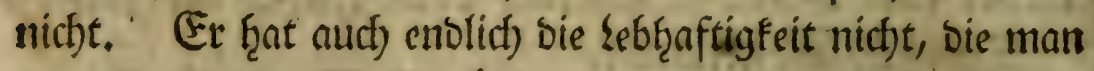
an unfren fleinen 23 affer åaldfen berwumbert. . Seine Berves

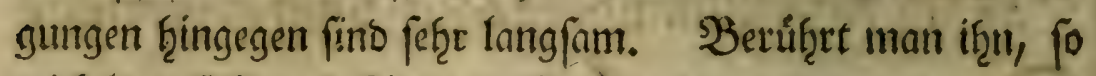
swicfeeft er firb nach) 2trt gerwiffer siaupen bufammen.

Den erften TSBurm bon diefer Zfrt, Der mir vorgefoms men ivar, Ģatte idt) ben jwen uno grongigften 2(pril in eben Dem Bzact)e gefunben, aus welchem biejenigen genominen

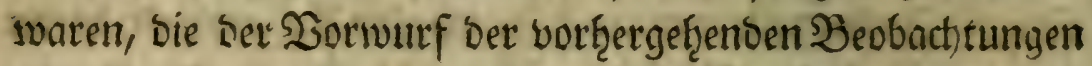
gervefen finb. Eve war of̧ngefáţr anoertḩalb Zoll lang.

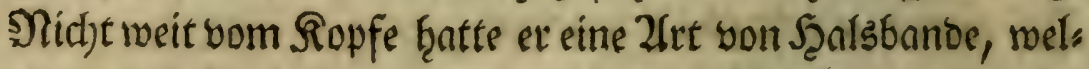

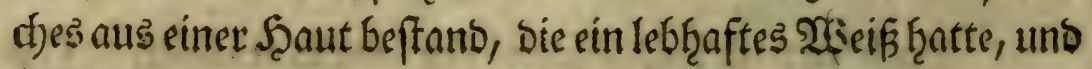
noffl eine Sinie breit war. Nan findet bergleichen biswveis Ien unter Den Siegentwutrmen. Er fohien Den Sthmans berloren, uns angefangen ju ḩaben, einen neuen wieber ju beformmen, ber noci) nicf)t úber cine sinie lang war.

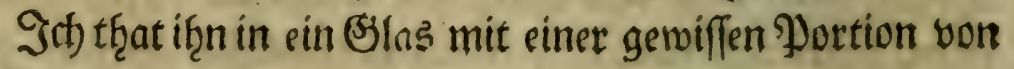

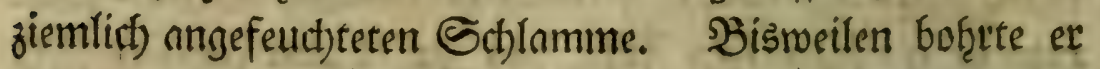
(iid) Init einem Shzeile feimes Sörpers ḩinein; Die meiffe Beit nber blieb er oben. (Endich) aber fing nach) einigen Ingen biefelbe Siranff̧eit an, if̧n anjugreiffen, bie idh für etwas

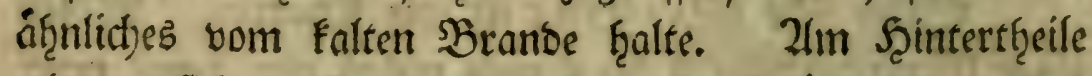
jeigte er fict) juerfit, uno frä tzernach) allmálig bis an bas Shalsbanb. Illedann ichien es, als wenn bet $250 u m$ ats

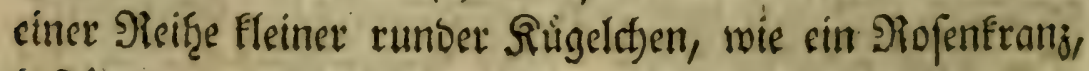
beftuntoe.

Solte mun unfer falfher Taufendfü auch wohfl bie Eigenf(thaft befifeen, fid) felleft wieder ju etnentern, wenut er in Stidcen jerf(t)nitten máre? Nan fan (eid)t erad) tent, Daf idf) nidgt werbe unterlaffen ţaben, Deşwegen oul metner 


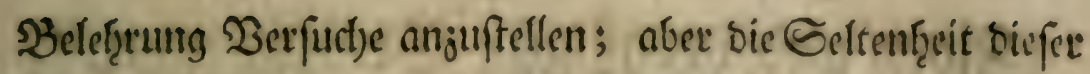

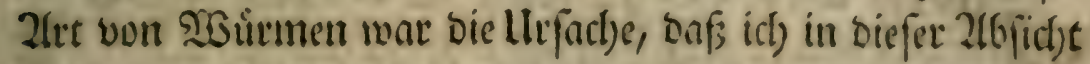

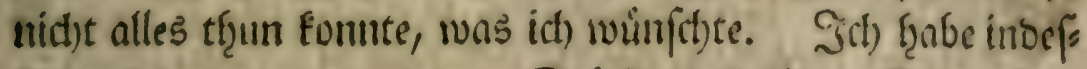
fen weld)e in jruel) uno bren Stucfe zertheilt. Det exftere wares allétn, Der fict) vollftandig wieber erneuerte. Er ges

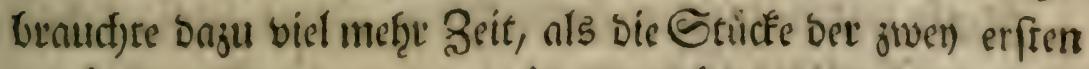
ermáf̨uten Wutmarten gewifhnlich) notḩig ḩatten. Man ruird fold)es aus ber Folge beurtheilen formen.

Den funf umb juanjigften 2uguft 1742 fdunitt ids

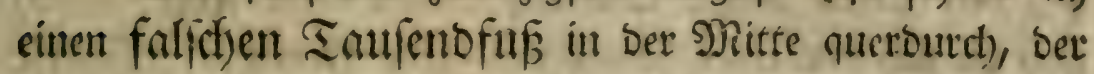
ein wenig furiger uno büner war, als Der, von Dem icf im Infange biefer Beubad)tung gehanditt ḩabe.

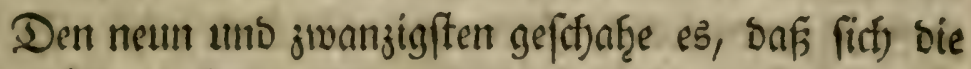

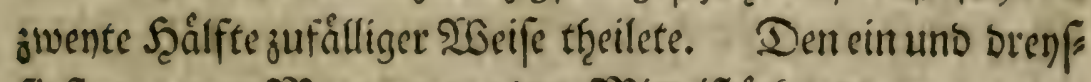
figften gegen Morgen war bas Mittelftuct toot.

Den jwolften Sftober fibien fith bas erfte Stúcf vóls lig ernetret ju fraben; bas antoere aber war noct) nict)t wies ber getwad) fert, unto cinige seit nach) geer frarb es.

Den fect) und jwanjigften May 1743 theilte icheinen anbern foliten 23 urm mitten burd).

Sin Infange bes Sunims toar bie anbere Scâlfte ungefommen, uno ben fect)sten Ifuguft hatte bie erfte einen Sct)ronj getrieben, Der moch nicht orey Sinien lang war.

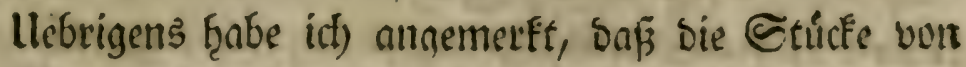
biefer Wurmart bey ber Speration nid)t fo empfindlid) fins, als bie anbern, bie iit) am meiften beobad)tet habe. Jit)

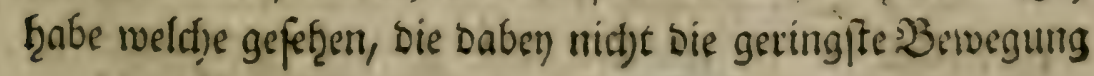
machten b).

3wey

b) Confiderations fur les corps organifés. Art. 279. 


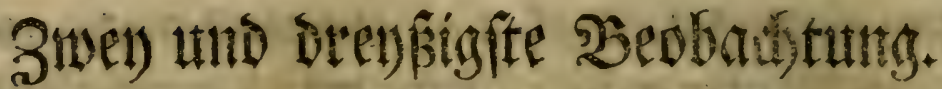

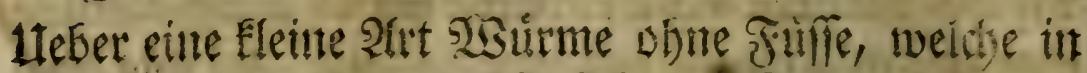
Ridfren ivofnen, Die fie fict woli Rotbe madjent;

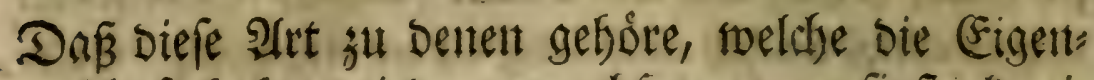

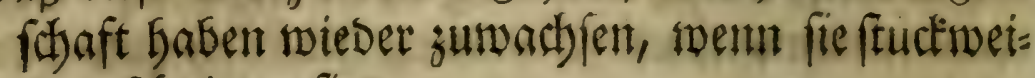
fe geridsnitten fiud.

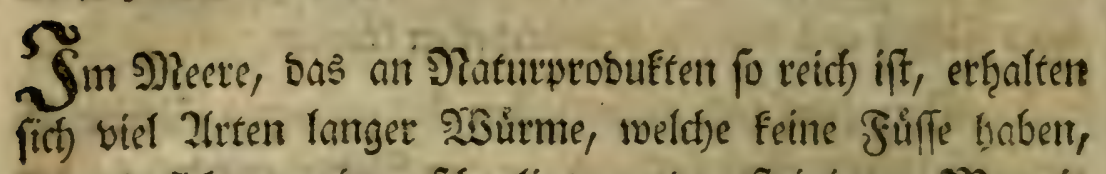

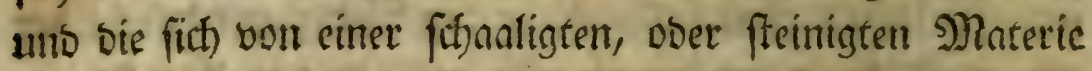

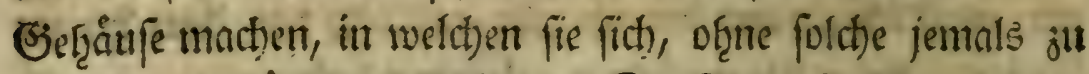

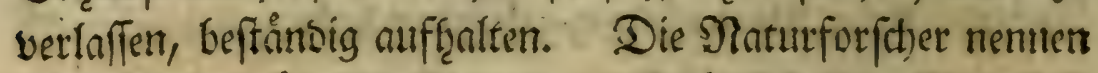

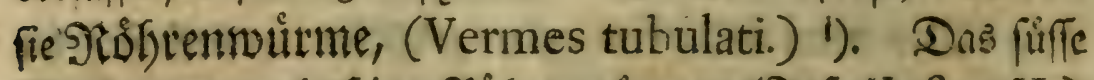

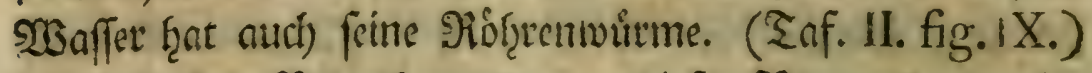

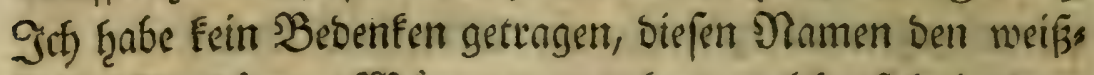

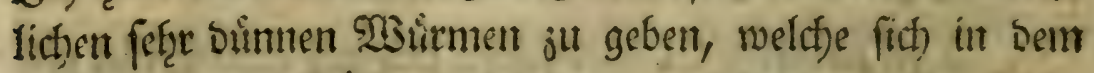

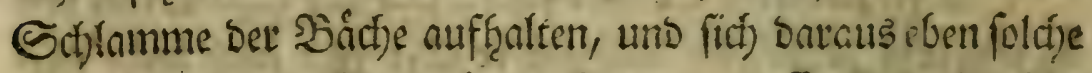

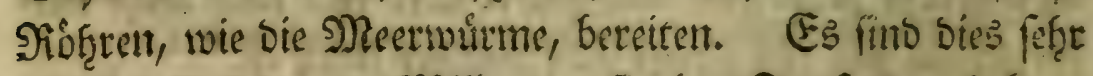

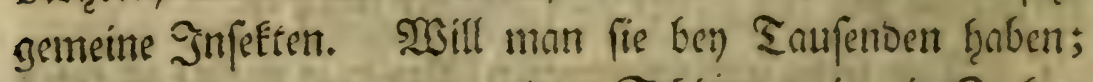
fo barf mant nur etwons bort bem Schlanme in ein Zucteers

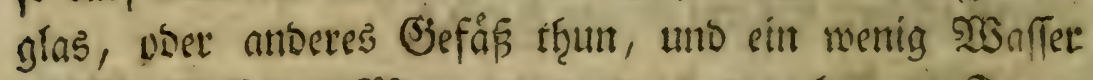

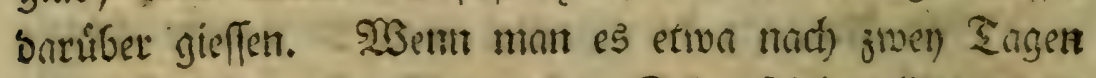

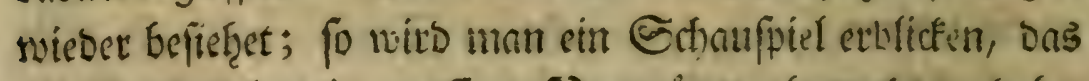
ich eninigemal mit groffem ¿iergnuggen betrachtet kabe.

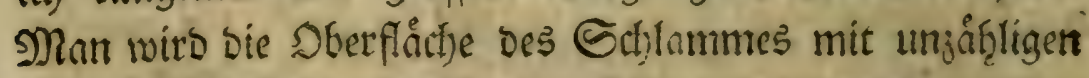

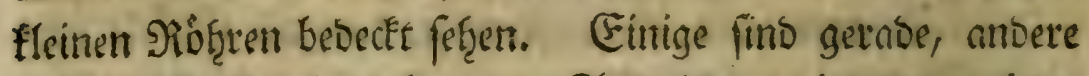
sweniger ober merfer gebogen. Zlus jecer wirb man eirren शुButm

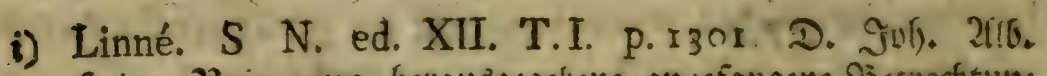

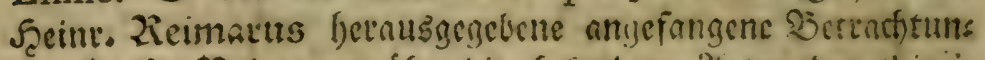

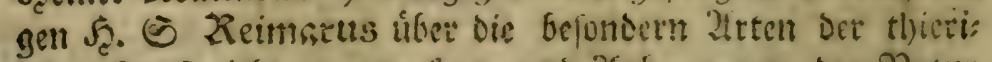

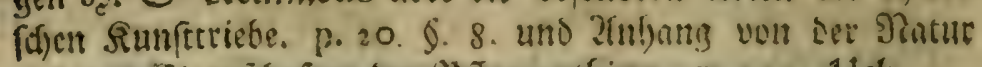

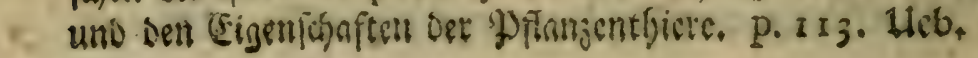




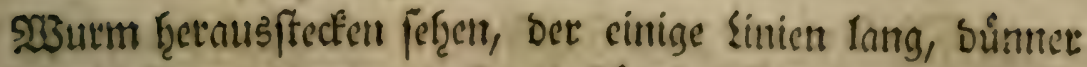
a!s ein Faben ift, unb beffen beftanbige Bewegung in allen

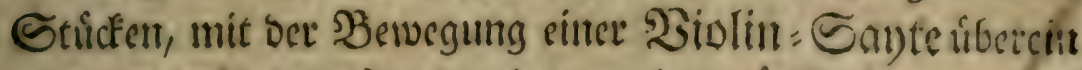
ouformuner fitheint, *) Dic unit bem sinem aufferfert Enve an

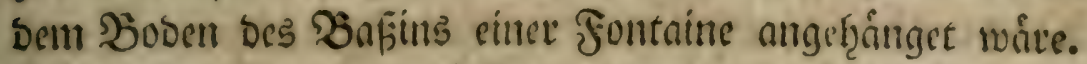
Stopet man aber unter siefem angeneţmen Ethaufpiele an

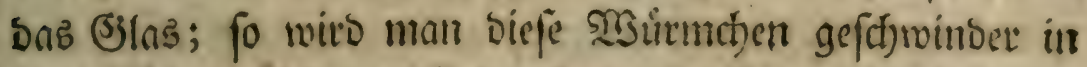

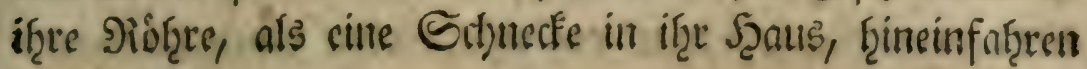
(p) fृen f).

Die

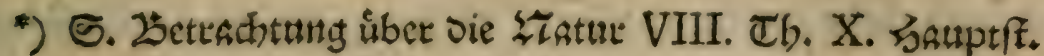
p. I 99.

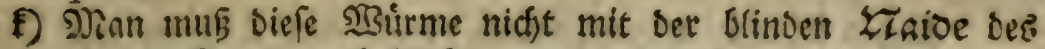
Seetn Sinnglevtuth traillers: Don DDurmetn p.90. ver: svechfeltr. Eie verftecEell ebenfalls wie biefe, ifjeen నopf im

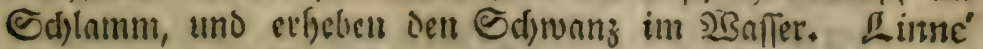
font fie nitl)t. Die Setren 2Sonnet uno Erembley, fagt Şert váuller p. 102. (29) lefsterer in uen Memoir. furles polypes Pl. 7. fig. 2. Gatien iffer im Dorbcy geben geoncht. Erfterer bat fie fier it ber 32 beob. befifriebell, uno ziobb:

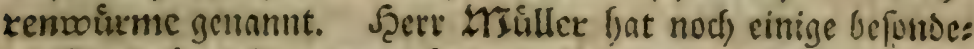

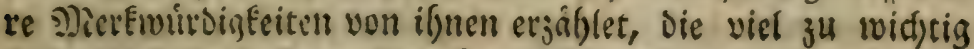
finto, als baf id) fie vurbenyelsen follte.

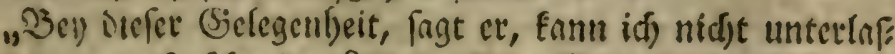
fen, Den maturforidyentien £efer auf ein Gd)aufpiel zubringen, veldjes iffnen bet unbetannte इoden Des lüfien 23 afler: it

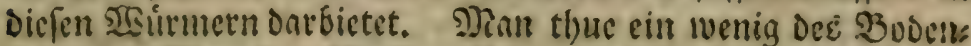

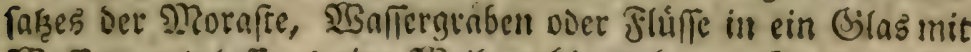

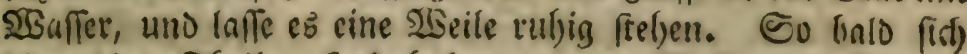
bie eroizte Tfeile gefentt baben, uno das 2 baffer Elat wordent,

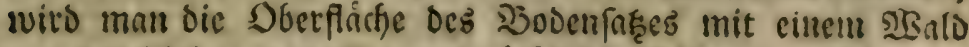
yoll butd)fid)rigen weiffen und róth(ichen \$idfyen verfdjicoener Lánge beferist feben; fie weroen fid) bin uno bee foblange(n, uno ben ber fleinften nulfern Serveyung verfchwinden; bely

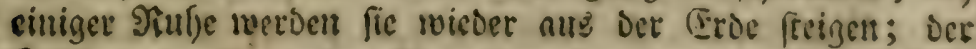

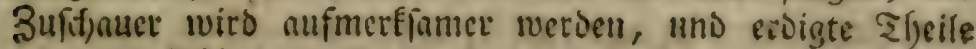

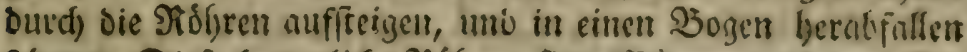

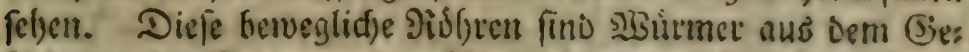
idjledte bee Eromurmb. Eif fieben oen 25oventas ser 


\section{Sedbadtutmgen über einige शttent}

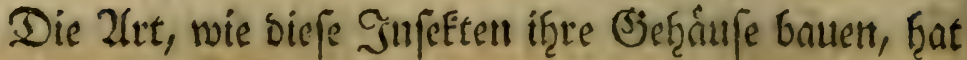

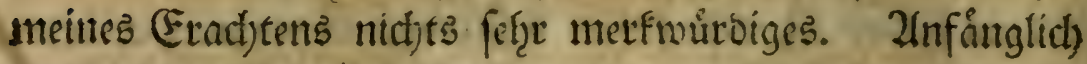

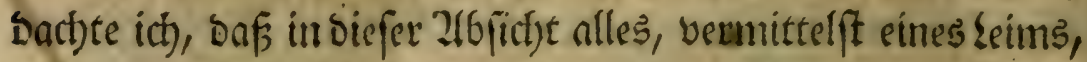

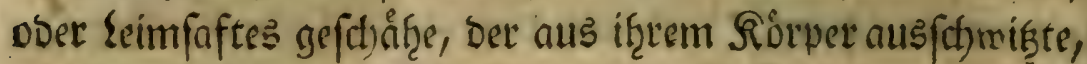

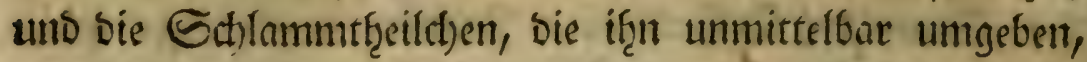

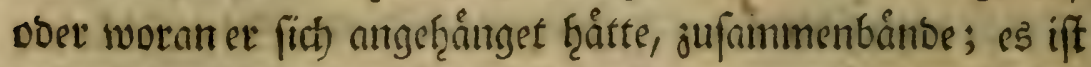
mir aber nacthger vorgefomment, als wenn fie firmnen fons nen; wenigftens hrabe idf) geglaubt, einige Faben ju bemer,

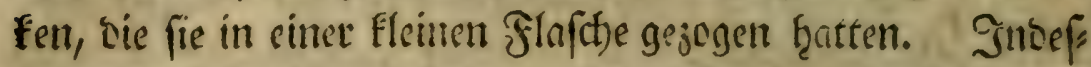

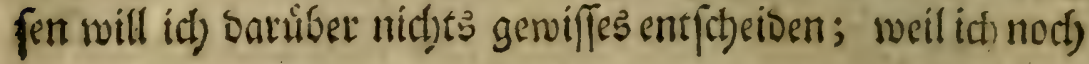

anbere

riffen Loffer unaufborlich outch ibre Leiber, uns bal: ten ibn loder. Bivifdent illnen wiro sie grame Sberflidye gleidf einem Yateer, in bem die erfen Eprufien ber Eant her: yorforieffen mit fleinen, theils weifen, theils gruinen lónglicís:

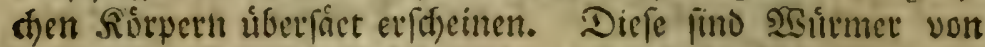
Der einfacblten 2lit, ofyne alle aud) Dem tervafneten Zluye fichtbare Drganifation. ",

Sid) Eann es nidjt untethifen, Sieffrabeen ber Platur,

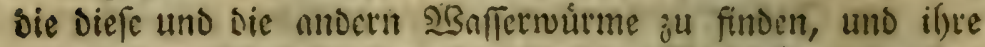

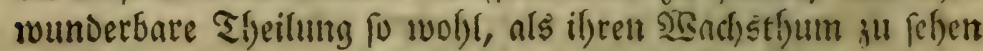

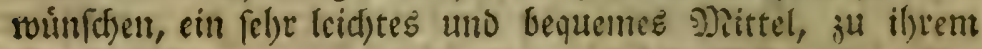

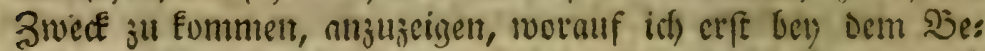

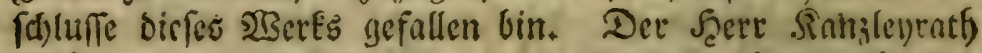

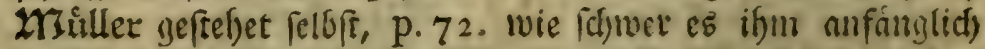

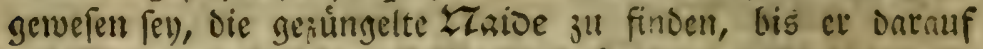

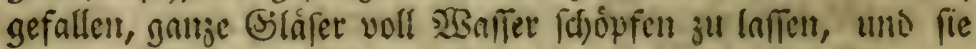
Darin ju fudfen. Slieine Wiethode (d)eint nodh (eid)ter zu

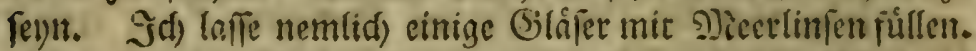

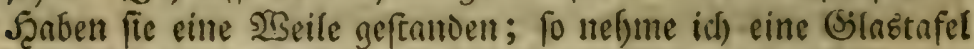

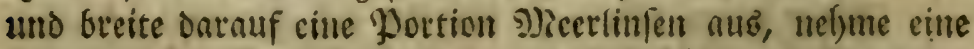

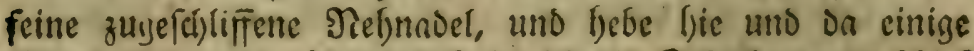

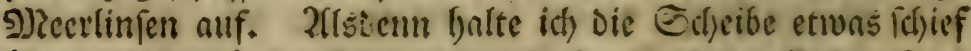
in

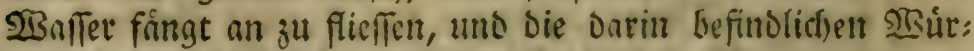
me zeigen fidf oen 2lugenblick. Sidh neltme fie hietauf mit

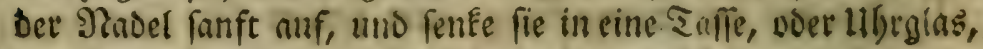

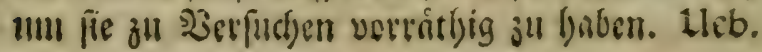




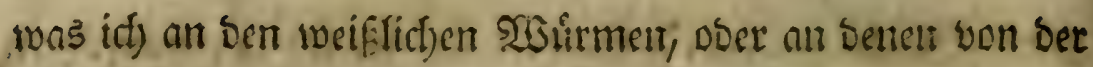

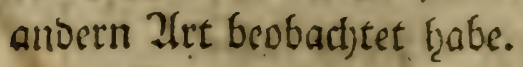

$C$ war init $A$ in gleiffem Zuffante. D, war an einem

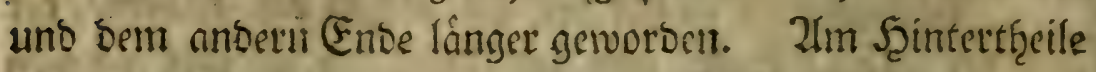

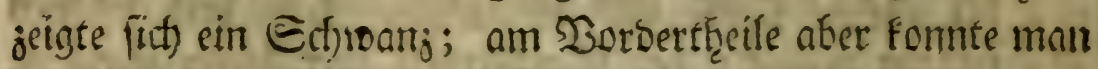

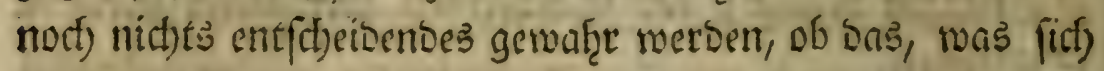
anfinty ju billoent, ein fiopf waire. E, roar wie B.

F fratte einen @etywang roteber befornment, woran ber

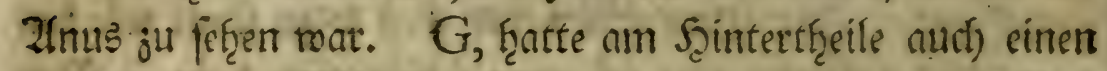
Echivanj getrieben; an Dorbertfeile aber fॄatte es Eins fotritte. $\mathrm{H}$, war wie C. I, fotien Den Infang ju machen, eitren Sorpf anjuferen.

Den neunjeşnten mar $A$, foft twie bent fiebjef̧ntent. $B$, fujien mir eitren Ropf befommen ju fraben. Sindeffer

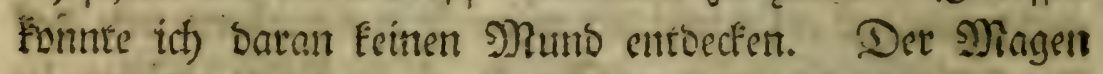

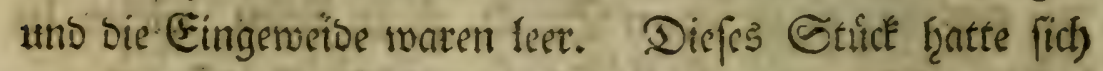

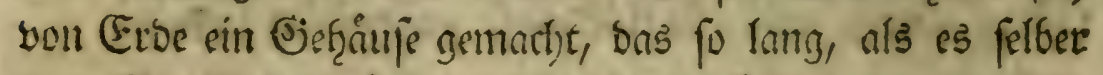

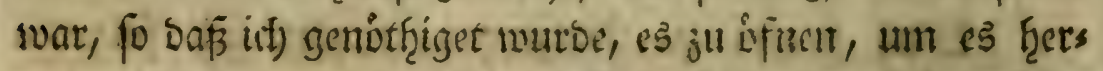

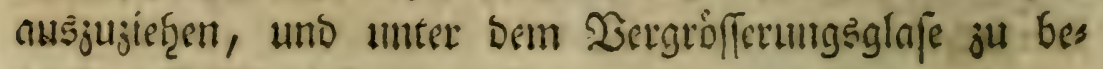
trad)ten.

C, war berjifjwumbet. D, ffient jwen Echwainje

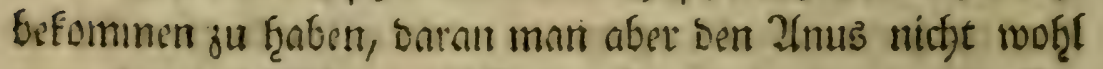

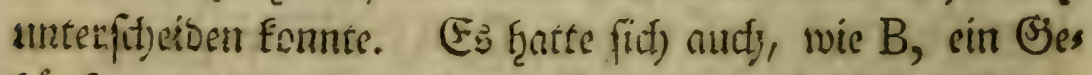

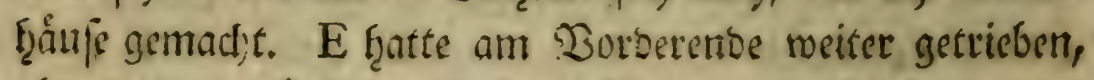

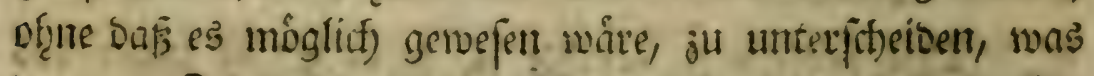

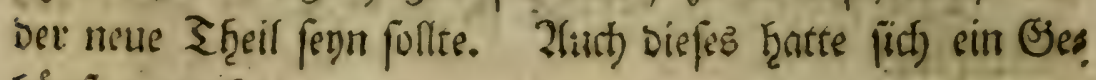
Fૃåule gemadtit.

F, war am Syinterende noch línger gerworben. Dies fe Љerlángerung, ober ber netue Schwanj mogte eiut Drittel

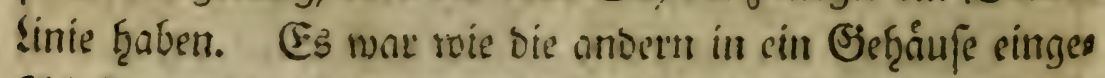

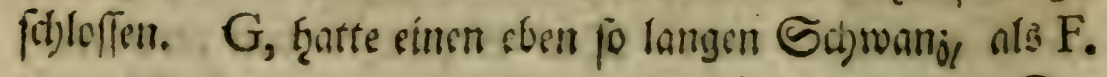


Der Sopf jeigte fict) nod) nidtet Dentliti). Seine Evinges

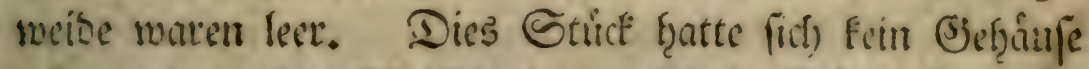

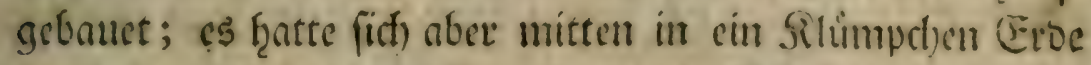
begeben. H war wie G. I. war in 2tbjiaft Des Siopfes faft wie $H$.

Den fect)s unb jwanjigften mat $A$, wie vorţer.

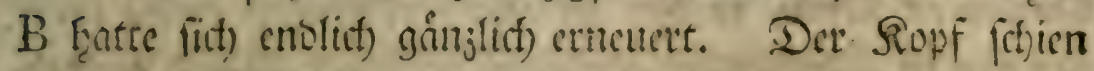
unter bem S)ifferfépe gut gebilset zu fenn. Gein Magen

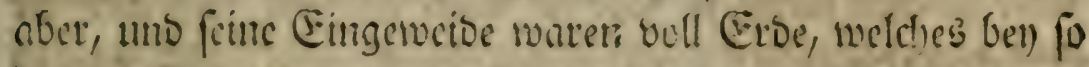
fleinen Etudfthat am meiften entfocioct. Es ift aljo fein

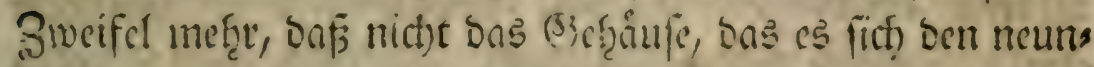
jestruten gemach)t, auf bie 2let follte gebautet fernt mie ich im

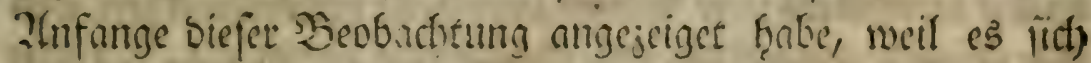

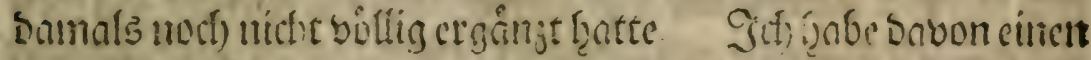

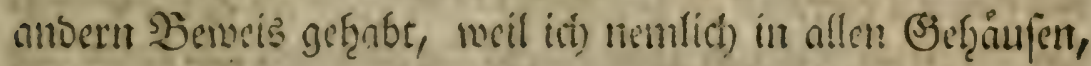
Die id) jerbrath, niemals dent geringften Fonden waf̧rgenoms men. Die Eroe Dowon feftien mir befféndis mit einer Zftet von scime, doce wentig haltbaren Sileijer verbunden jul peyn.

Den neun uns zwanjigften jeigte ficts, bnf D, E

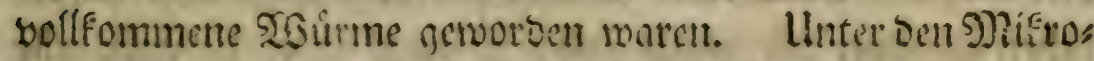
fEupe fotien ber Sopf fo, mie ar fenn mufte. Der bon E, (₹nf, II. fig. XI. t.) fatien fict) thatge am Enbe in jwelse ju treilen; $(0,0$,$) indeffen fratte weber bẹ eine, nod) Det$ unbere Naţrumg genommen. F, ģatte cinen Ed)wang von ciner f̧alben, bis jwen Drittel sinient. G war vollfsum

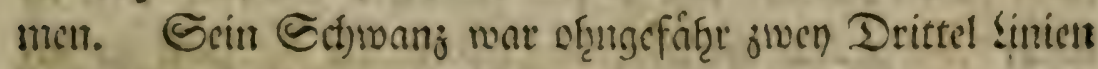
lantg. Der Sopf war firtrer; bies jeigte fich auth an als

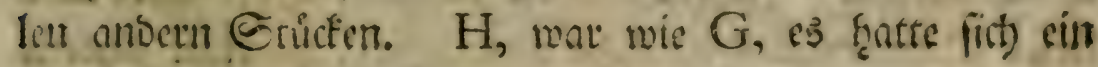

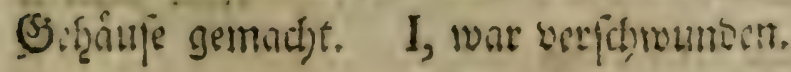




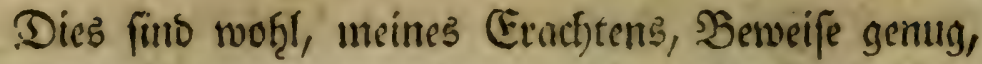

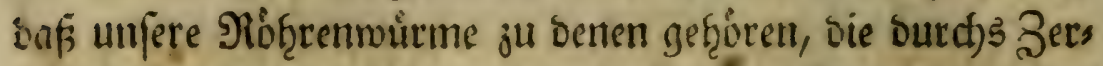

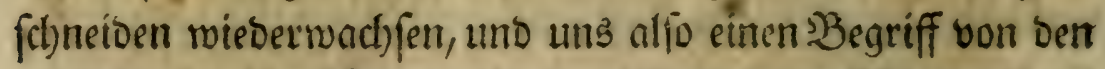

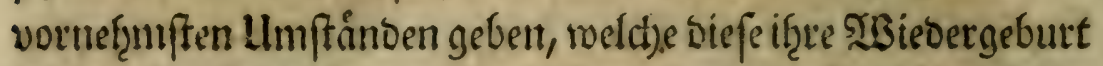

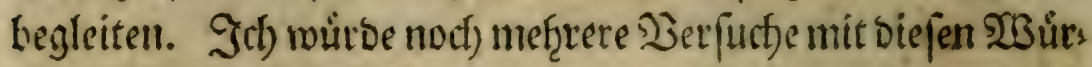

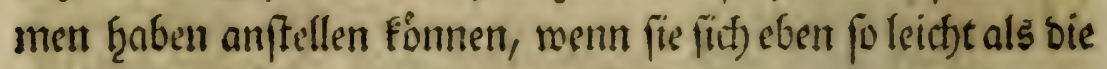
beobad)ten lieffen, wobon in bem vorţergethenben die Rebe

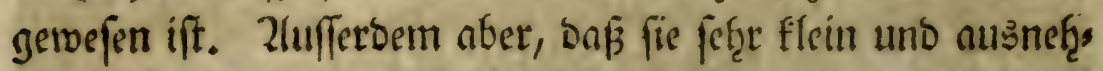

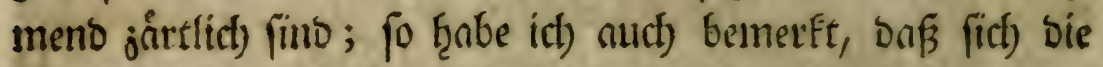
Stucke, in bie man fie jerfichneibet, eben fo motzht, als bie ganjen

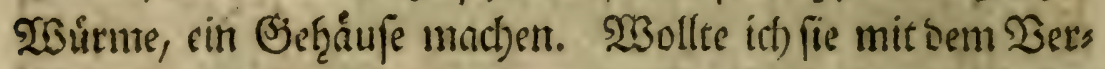

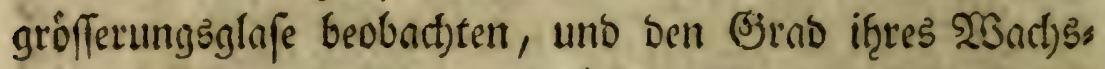

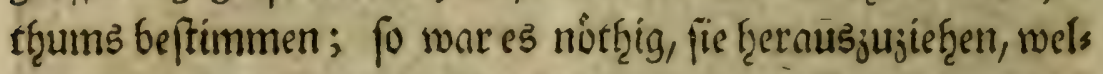

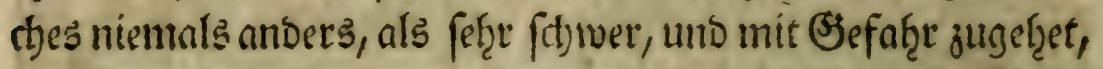

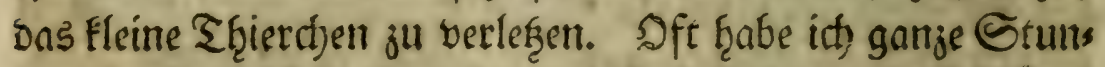

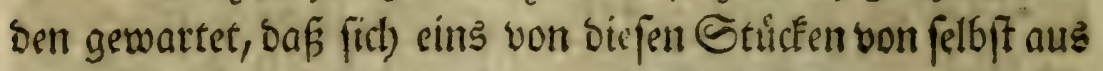

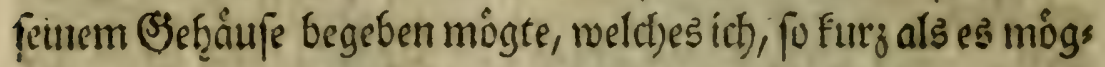

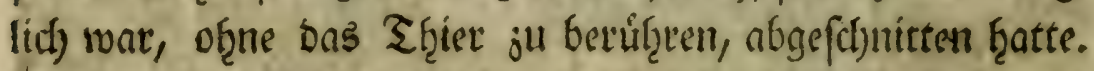

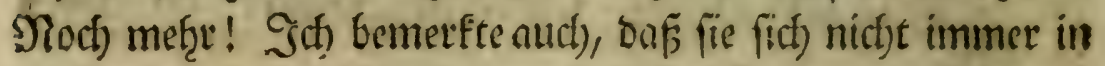

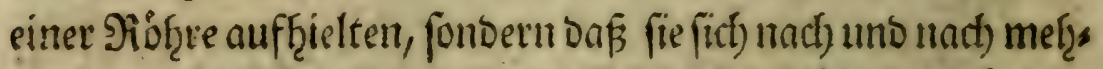
rete Dergleidjen baueten. Da fict) mun diefe gióf̨ren in åffers lithen sinanter alle gleid) finto; fo mus man fie nudf alle mit gleidjer Sorgfalt unterfut)en, um bie berwof̨nte Darums ter ju entoecten. Sisenn man aud) piefe Stúcfe, in Der 2(bfict)t in reinem 2 arffer ḩielte, foldtee Edjwierigfeiten ju

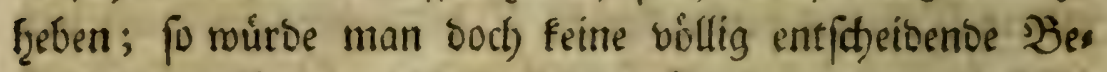

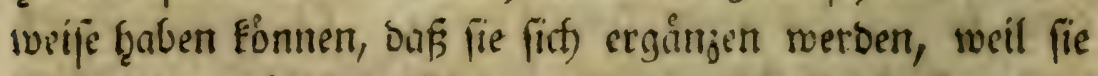

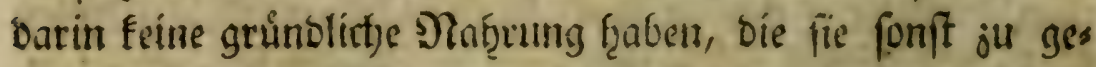

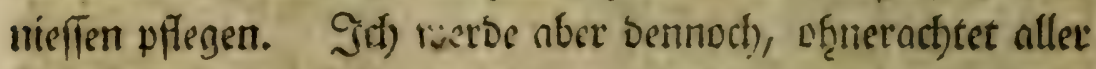
biefer Edywierigferiten, nid)t unterlaffen, ju einer anbern Zeit, siefe 3orfuidje rvieder vorjunef̨men. 


\section{Drel) uno Drenfigfte 3eobatiftung.}

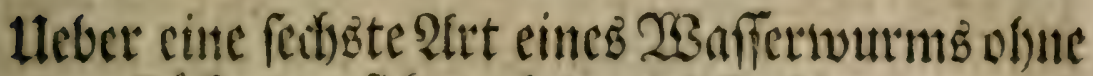

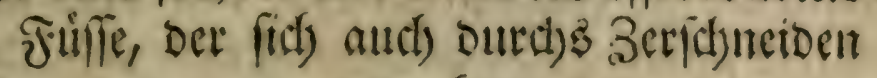
vermefret.

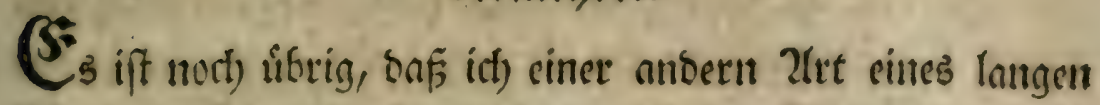
פisafferwurms gesenfe, mit ben ich) ben ?tufang gemadjt

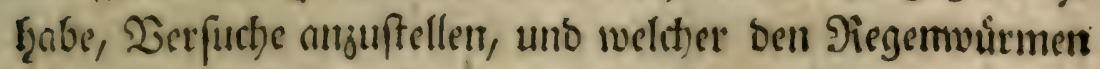

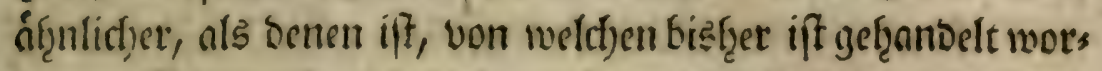

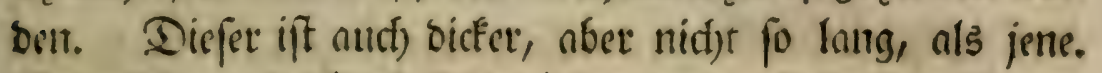

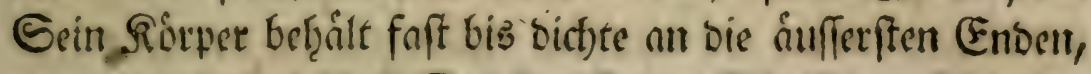

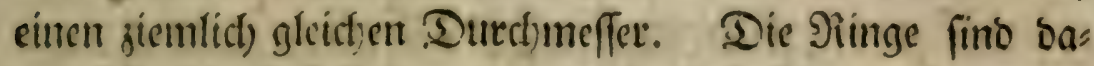

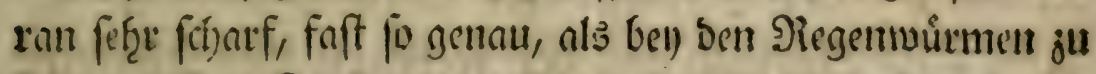
peren. Der Kopf endiget fich nuth mit ciner eben fo feis

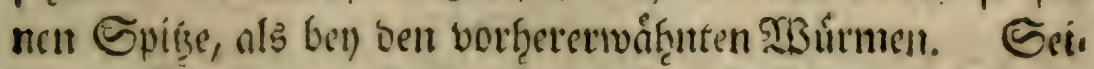

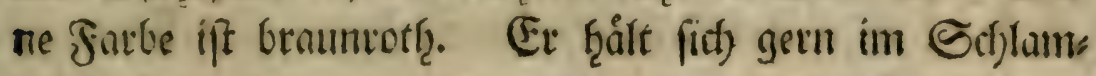
me nuf.

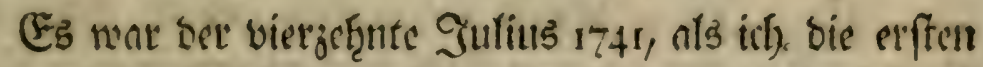

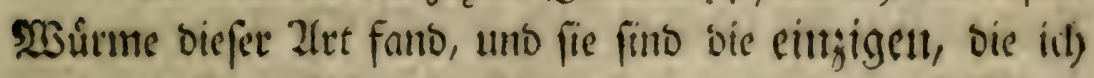

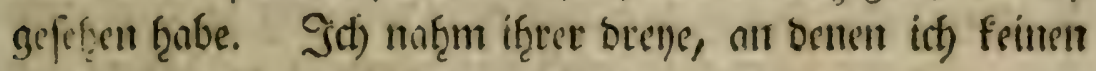
fonberlititen llnterjajied bemerfte.

2lu eben bem ₹nge foljnitt ith eitren querburd in jwen. Stúcfe; megen féner vielen B̧ewegungen ater wurbe bie erfte Senalfte einige !inten lătrger, als bie anoere. Diefe foum mir und) einigen Tagen weg. Den ad)ten 2tuguft

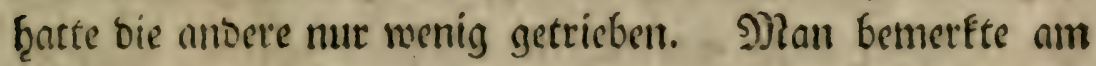
Zoorberenbe nute eime weifflidje Eprize, von ber Stärle eincr Diabelpipige; Der Sctimanj mar etwas langer geworben, unto das verfängerte Theild)en, bas in eine feime Spife jus ging, war eben fo weislid). 
Diefent Monat Ģinsurech, und im 2lnfantge bes folgctrs

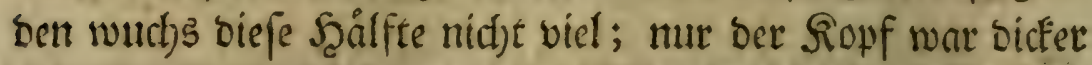

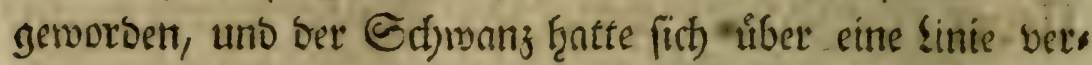

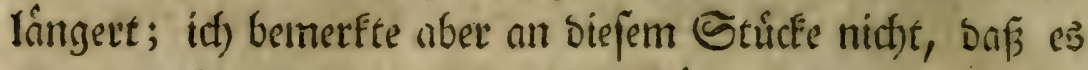
eine tḩiteriffhe Şandlung verrid)tet ḩâtte, woraus man féme vóllige Ergånzung foblieffen fỏnten. Es thad)te nicht cint

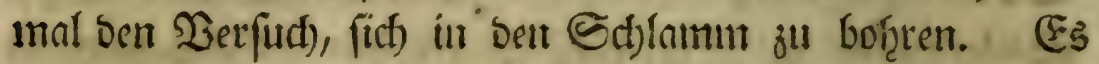

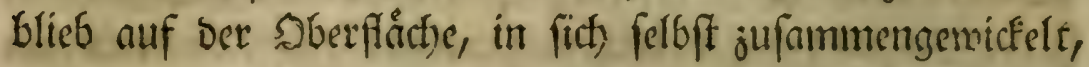

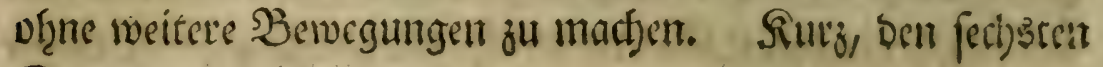
Eeptember ftarb c?.

\section{Siet und Drevpigite 3 cobadtutng.}

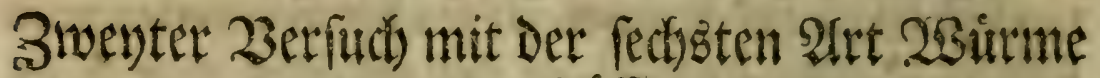
obne Эûfie.

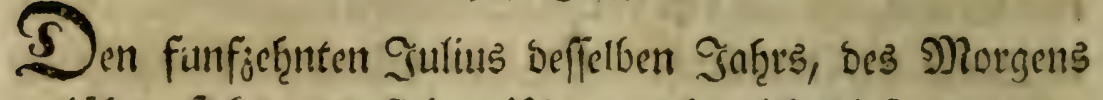

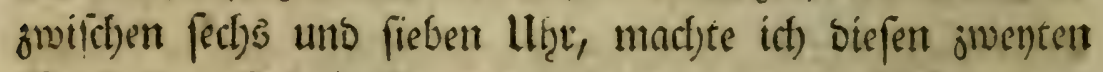

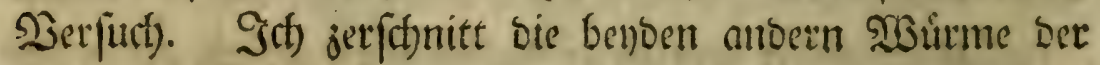
borigen 2 trt, Den einen in bren, ben anbern in bier Eturcfe.

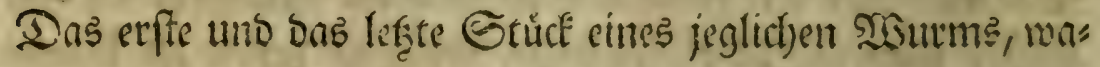
ren nati) Der Speration nod) bie munterften; bie anbern

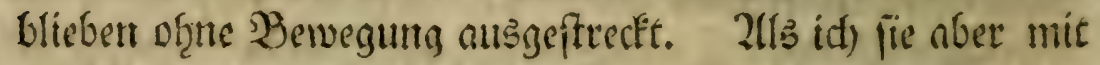
Der Spif̧e eintes Zaf̨nftod)ers beruthtete; fo bejeigten fie bas

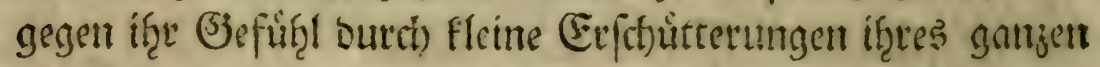

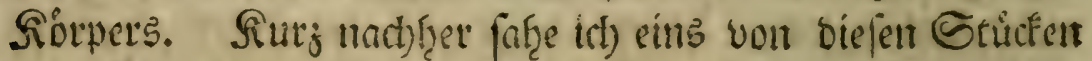

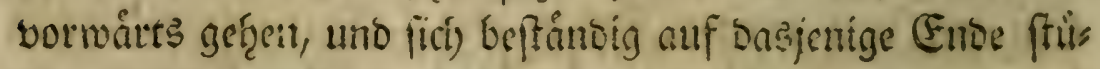

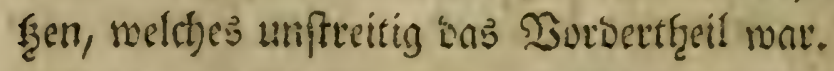

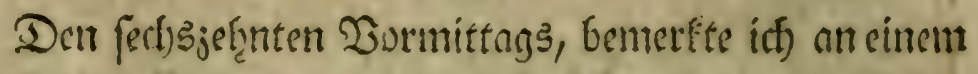
ber kulferfen Enben Dẻ zuventen Sticfes, von bem in bren

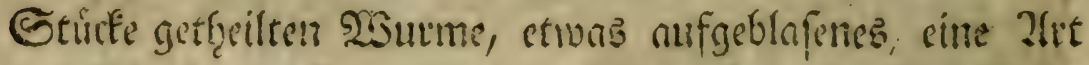

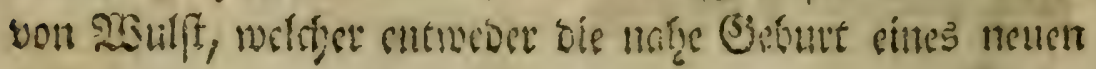


Sopfes ober Edjwanjes ju werfinbigen folien: Denti itín

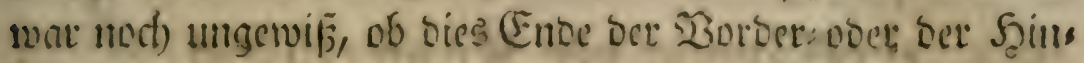

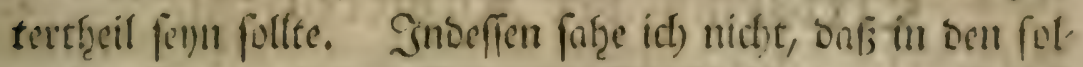

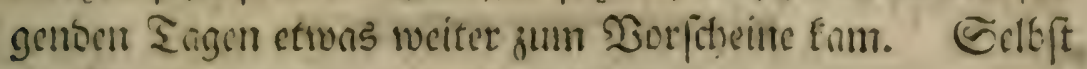
Der Sibulfit war furj barauf berfatwutuden.

Sim Zlufange bes 2lugufts war mur nod) bas erfie unts

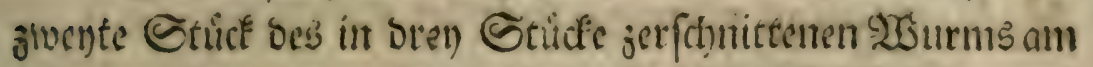
seben. Da idf ben act)ten diefes lefzere nufmerffamur, als.

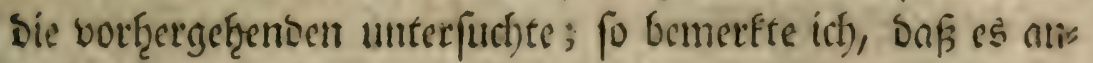
gefongen einen Ropf uno Sct)wanj ju befommen. Diefe

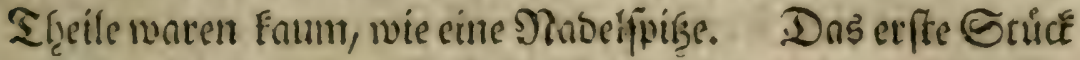

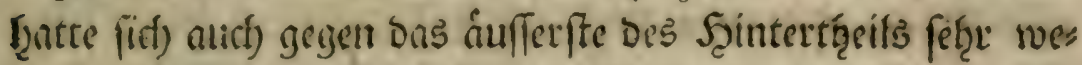
nig verlängert; es war aber ber 25 act) strfyum beffelben gerins ger, nls bes anberw.

Zm Ente des SMontats hiorte bas erfte nuf ju lebert.

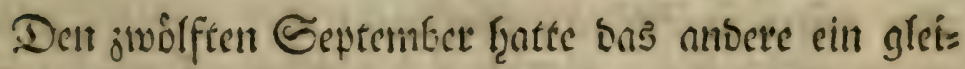

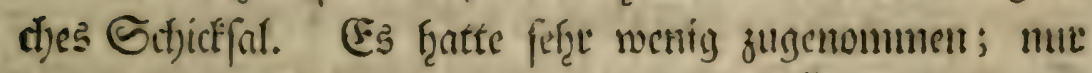

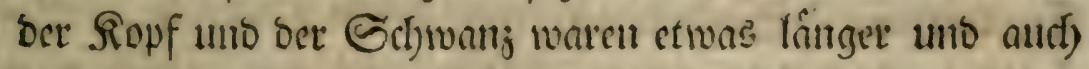

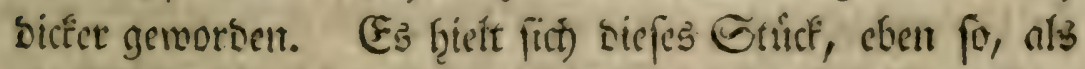

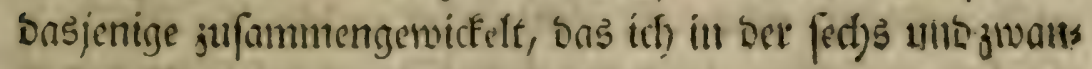

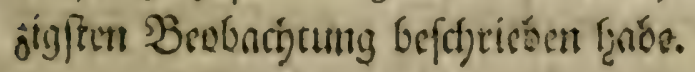

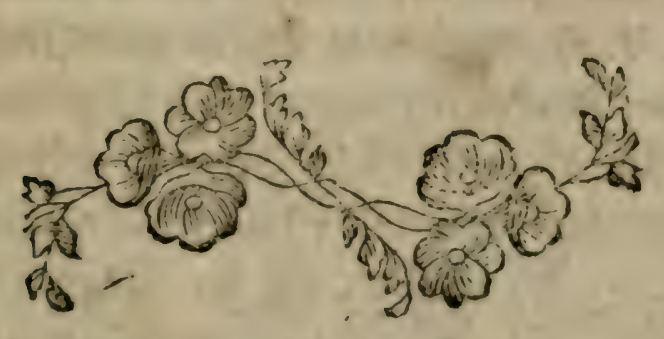




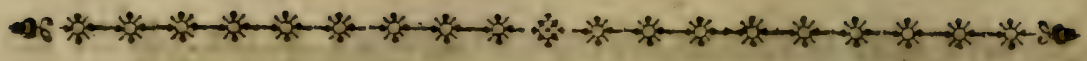

\section{Erflarututg Der Rupfertafelit.}

\section{Erifte Enfel.}

$\mathfrak{S}_{\text {ie }}$

ie Figuren I. II. III. IV. ftellen berjofiebene lange

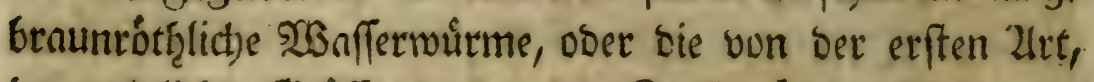
in naturlicjer (Stroffe vor. a, ber STopf; d, ber Sctwwanz.

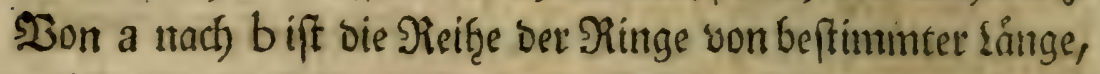
weld)e mit bein Ropfe in einem Ss:folge fortgeţet, uto als

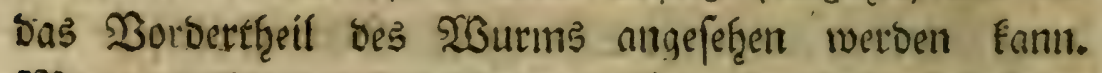

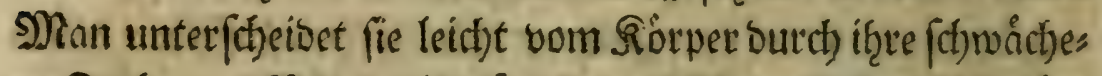

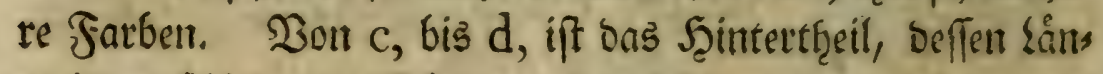

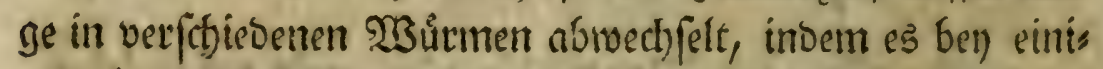
gen langer, bey antern aber furzer ift, nachoem fie frufteet ober fparer jeriajnitten, ober meḩr ober wentger gewact) fen fino. Die Farbe Gleibt baran beftandig fcluwächer, als am

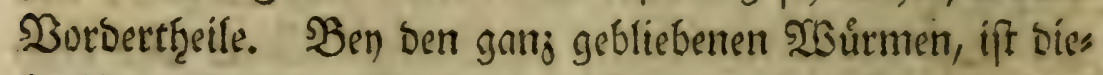
fer Unterfhted des ßorber uno Scintertheils f(t)werer, oder

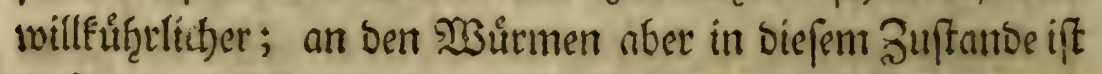
er felten ju finden. e, e, e, fint Rorner Der Excremente,

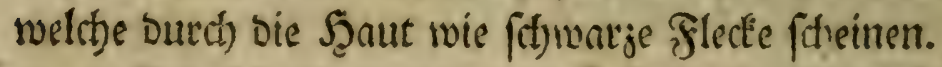

Fig. V. ift einer von biefen mit bem Dergrofferungs"

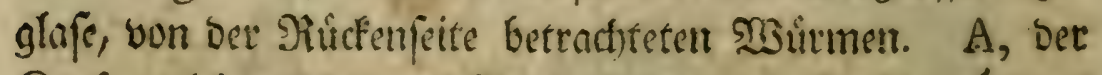
Sopf, weldyer fich in ber Breite bis a, a, etffrecte, wo jimen fleine Errf̧ôhungen fino, weld)e bie Gtelle ber lugen ju ber: treten foreinen; b, ber Sert, wo ber s) Juno iff. Er ets fd)eint hier nur, als ein fleimes braumes Flected)en, weil if̨n

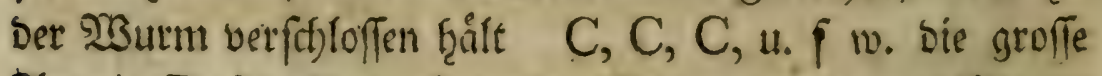
Arterie, D, D, D, u. F. w. Der Dorm, worin ser Magen 


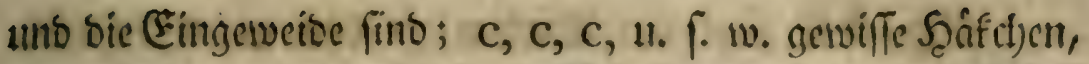

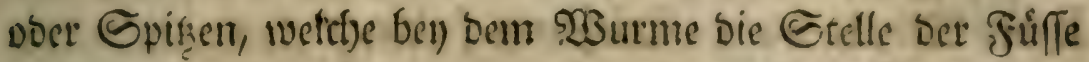
vertreten, unto-sie man mur von einer genviffen Esite fef̧en fann. SBisweilen foreinen fie boppelt, auch) bren unto victs Doppelt. d, d, d, u. f. w. Fleine Biefâfe, weldt)e 2logånge

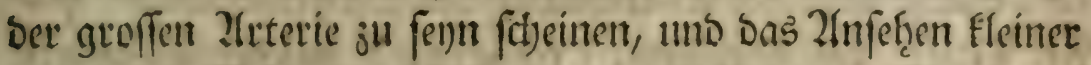

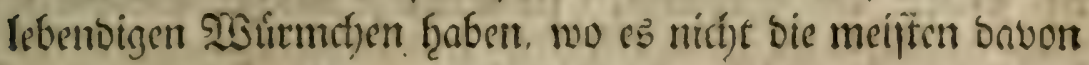

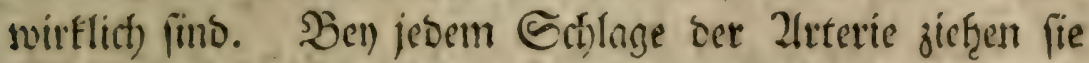

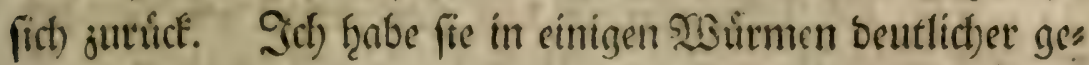

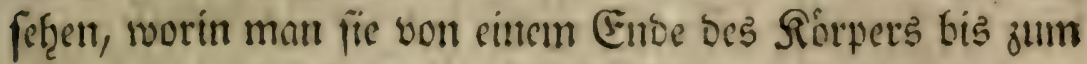
ambert bemerfen fonnte. E, Der Itums. $f, f, f, u$. f. w. Eroflümpchen die in ben Eingeweion gewefen, unt bavon fich Das GnfeEt aubleeren will. Die groffen braunen flecte, welitfe man in ber Nitte Des Förpes waterninmt, uno wels

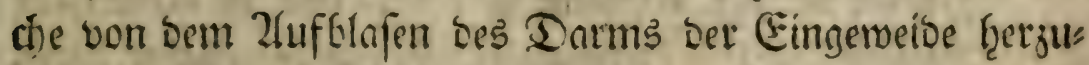

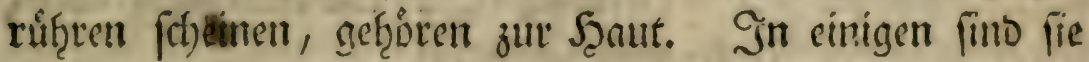
Feeller, in andern bunfler: Dies foume vom Zuftanbe Des Sulfetts. Tsirb es matt; fo verfolwintoen fie uno merben weis. Stingegent werben fie ben benen, bie lange ḩaben fos ftén múffen, nod) immer brauner.

Fig. VI, VII, VIII, und IX fint alle unter bem

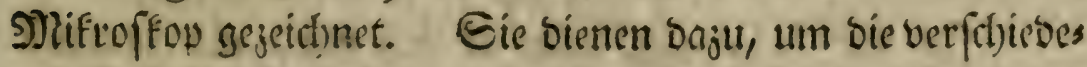

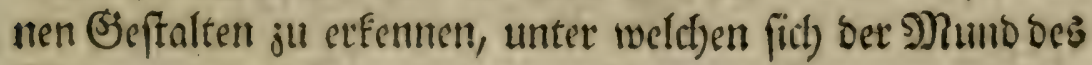
20utumes jeiget, wern er fict) auffthut.

Fig. VI. freflet ben Worbertf̧eil von oben betrachtet, vor. g, bie aurferfte Supfipize. h, sine 2lut von B̉lafe,

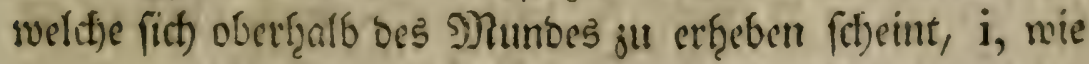

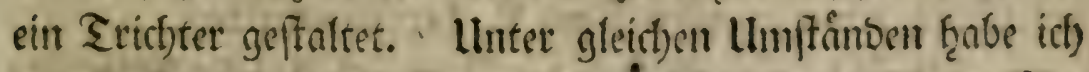

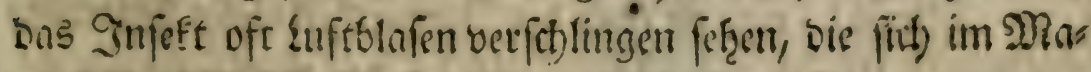

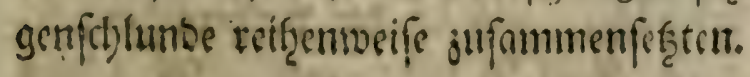




\section{Giflirutg Der Rupfertafelt.}

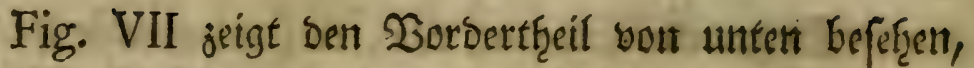
k, bet Mund, wie ein Tricţter geftaltet.

Fig. VIII. Das Sorbertf̧eil von "ber Seite; 1, eilte

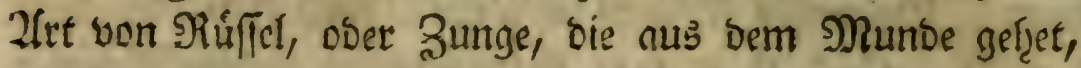

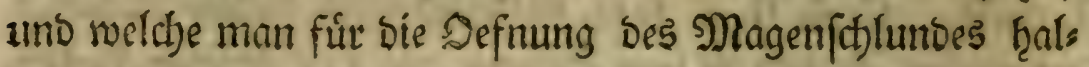
ten follte: Der Sthlunb, (pharinx) weldher auswárts geţet.

Fig. IX ftellet abermal ben §orbertf̧eil vor, von ser Esite betrachtet. m, ber Muno wie ein 2(usfdunitt.

Fig. X, XI, XII, XIII, uno XIV, ffellen ben burcd)

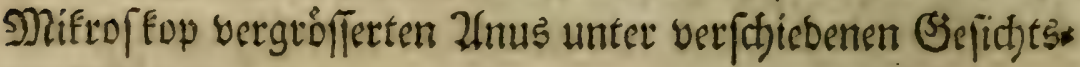
punften yor.

In Der X. fig. erfifteint er offen, wie er bie Erctes

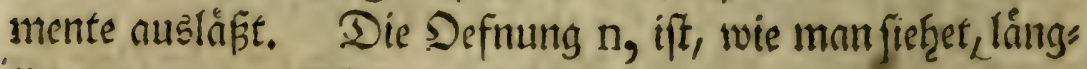

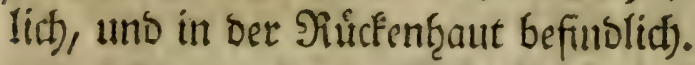

In Der XI, uno XII fig. iff bie Defnung, o, o, faft ơitfélrunb.

In ber XIII fig. erfitheint ber 2lmus nue noch unter

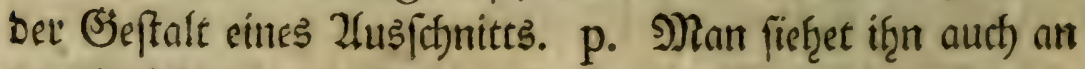
sen Stuicfen, beren Sctwanz erfít ju treiben angefangen.

In ber XIV fig. jeigt er fidt) nur, als brauner Strich, $\mathrm{q}$.

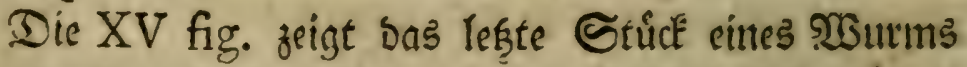
von ber vorţergethenben 2let, mit Dem Şanbglafe betract)tèt uno in bren) SŢeile jerf(t)nitten, meldfes, nactjoem es wie gerwoónglich, einen Ropf A, roicberbefoummen, anfängt an ber Eeite, einen jmenten Ropf B, hৃerauşutreiber.

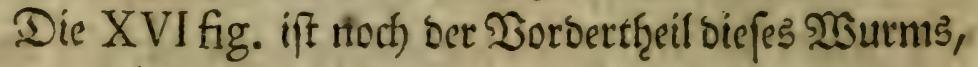

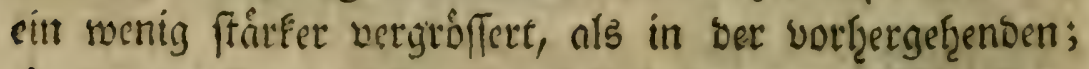
A, ber juerfi gewafjfere Sopf, B, Der gwente. S)lan fann 
benterfen, safi biefer jmente Sopf bon bem erften in ctwas interfitieben ift *).

Die XVII fig. zeiget ben Wurbettyenil eines anbern njsurms ber erften Zlrt, mit bem כergrofferungsglafe

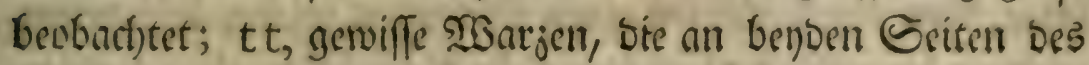
Ropfes f̧ervorigefommen fint.

Die XVI!I fig. biente baju, eine Borftellung von

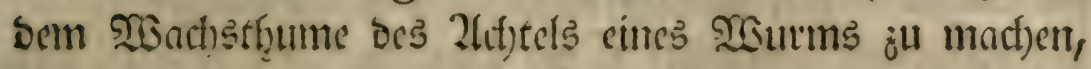
nemlich) vom II September, als bem Dperntionstage, bis jum erfiten Sftober. I) Diefes Id thel= Stucf uimittelbar nact) bem Eduitt beferent. 2) wie es ben 14.3 ) Den 16.

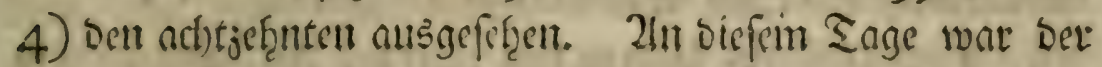
neue Ropf $t$, beynabe vollfommen; die autfer|te Spife aber war nod) nict)t fo lang, als fie fenta mufte. 5) wie ez ben 20. 6) wie es ben 26. Into 7) ben erften Dftober alts? gefef̧en.

Die XIX fig. fellet eine yon ben Soffen vor, worin id) meine șiurme aufbeţalte.

\section{Siweyte Sutpfertafel.}

Die I fig. frellet einen bon meinen meiffict) 2 Jirs men, ober von ber jroenten 2trt, in naturlidter Girdfe vor.

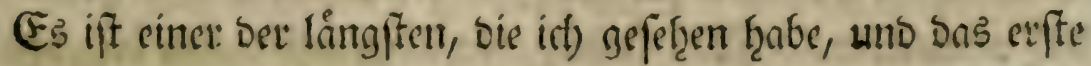
Sticf eines ansern, Den 23 September 1742 in bren Eticte jertfeilten, welthes fitt) Den 28 Ipril 1743 , von felbit in fo siel Etúcfe jertheilet ḩatte. $t$, Ber fopf, weldfer yout bem Sopfe ber rotfelichen nisume, obet berer von ter juenten 2(rt, gat nicht unterfchieden ift. g, bie Etelle, welche cit:

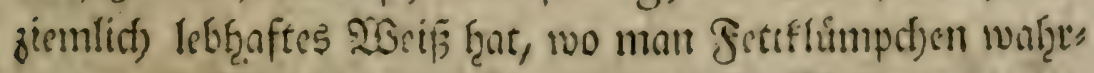

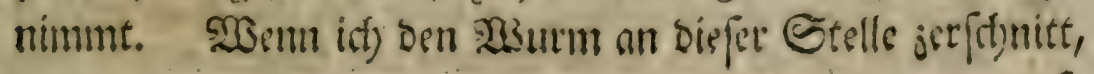

* Corps organif. Art. 249. 


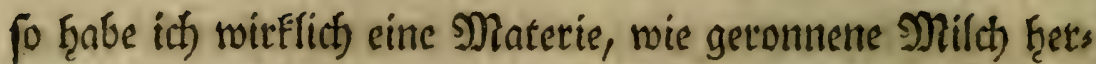

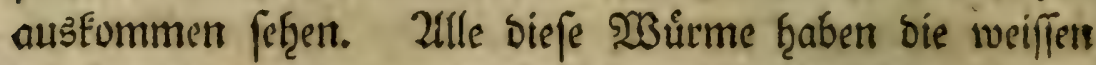

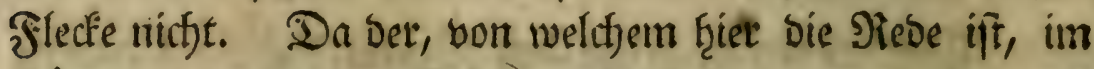
Sänner 1744 in brel) Stưdée jerf(d)nitten war; fo hat bas Ief̧te, fratt eines Ropfes einen Sdywanj wieber befommen,

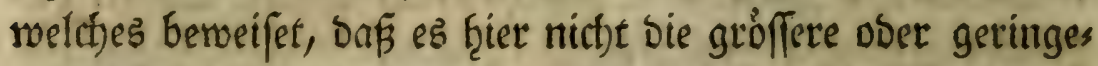

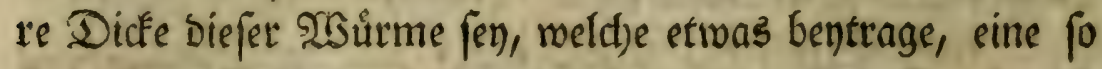
fontoerbare Errftjeimung ḩervor zubringen. Indeffen war id') anfänglich einigermaffen ju ber Mutf̧maffung geneiżt, baf

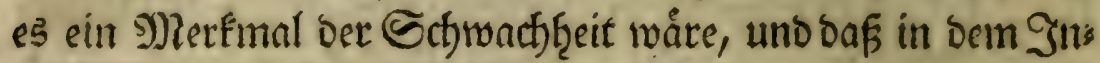

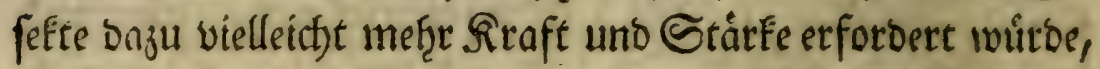
einen Sopf, als einen Safwanj ferborjubringen *).

Fig. II ift ein 2 Surm yon eben ber 2let, aber nictet fo fett, als ber vorige.

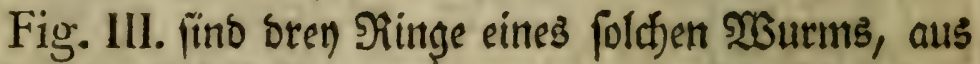
Der Mitte bes Sórper's genommen, uno burch) Mifrof fos

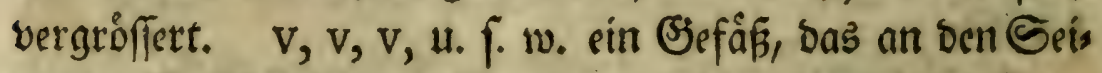
ten bes Infefts hererunterliegt, uno weldtes bon einem Enve Des Rörpers bis zum andern geţet. Mtan Eann es mur in Den 23 ürmen fef̧en, bie lange gef̧ungert ḩaben.

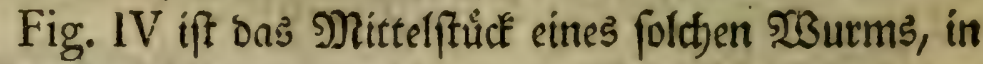

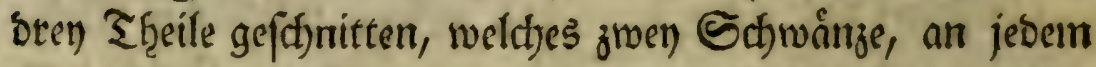

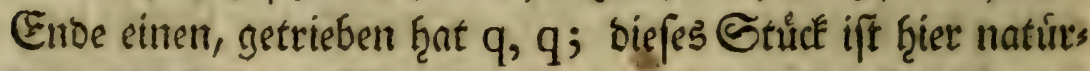
lict borgeffellt. Mtan fief̧et, aber nod) beffer fig. X, wo es burchs Seantoglas vergróffert ift, bá bas, was es am Dorberende getriefien f̧atte, eben fo dưnne war, als bas f̧ers

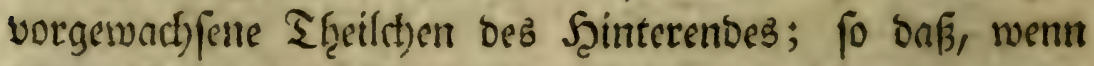

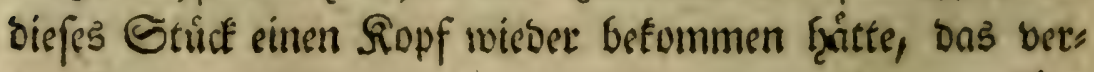
lains

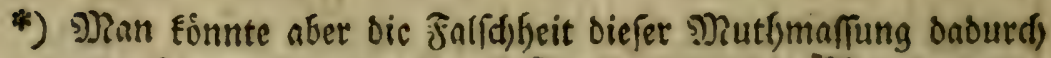
erweifen, wenn man einem 23 urme won Diefer Airt, Den man

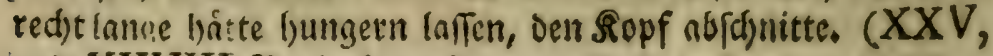
uno XXVIII 23evkadjtung). 


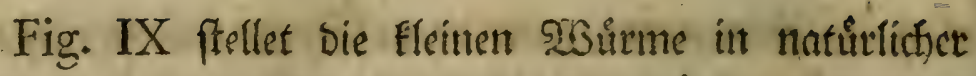

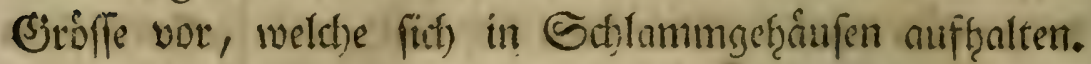

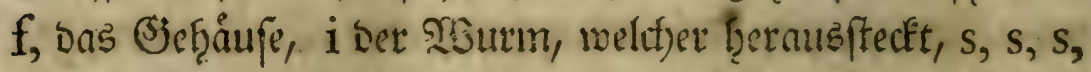

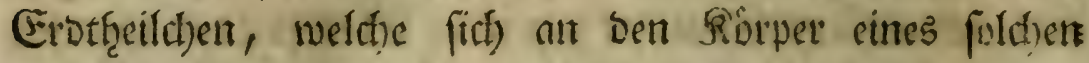
গ⿰氵 Geflammflict)e fpielct.

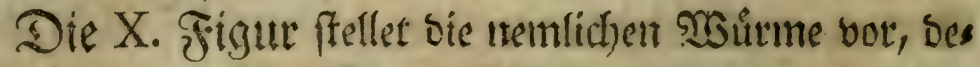

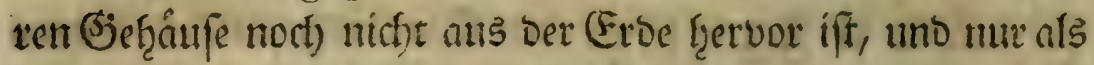

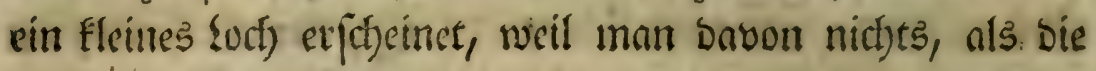
Defuning fie f̧et.

Die XI. Trigur zeiget ein, Surct, 5 Mifroffop vers

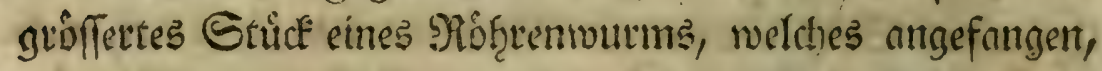
eitten Ropf zu treibent, t, bieper Siopf ber fict) am Endo in z(ven) Sìpfe, o, o, ju theilen fúfeint.

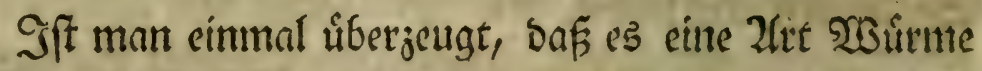

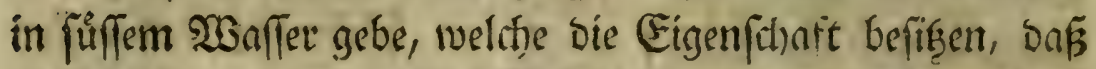

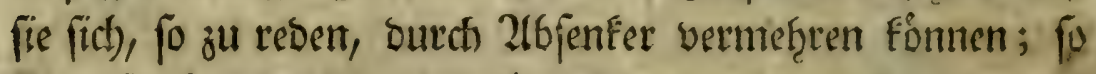

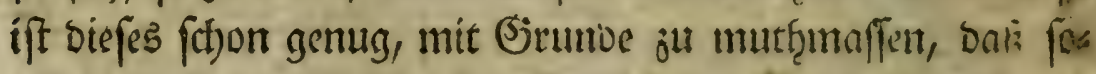

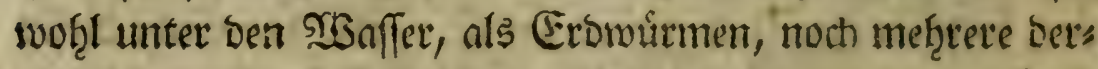

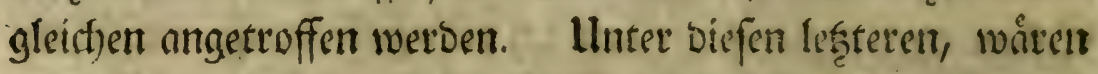

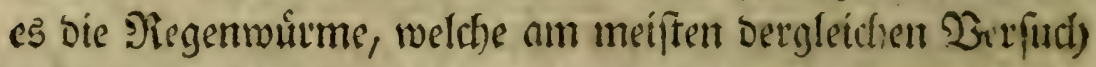

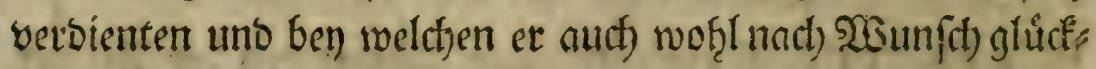

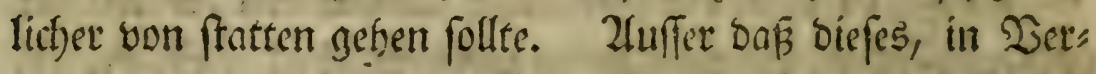

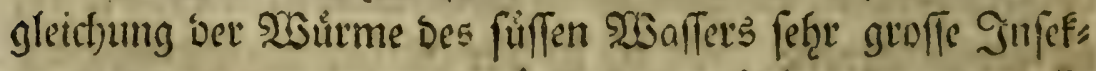

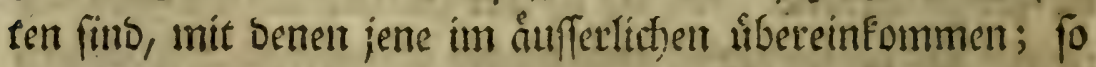
fint es úferbem nucl) Switter; es frat nemlich) jeber einzels

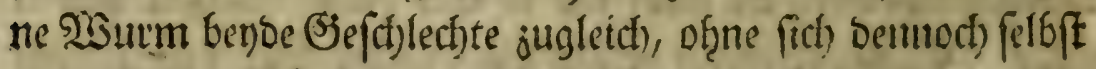

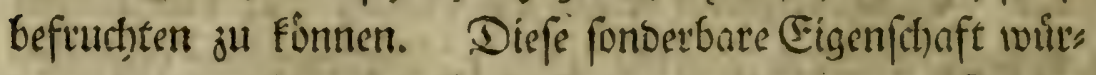

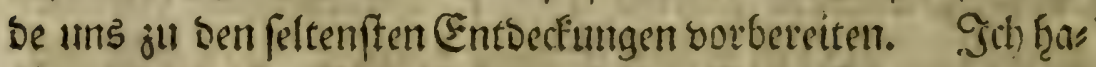
be alfo nicd)t unterlaffert, audd) viele Siegenwuirme, jut cbett

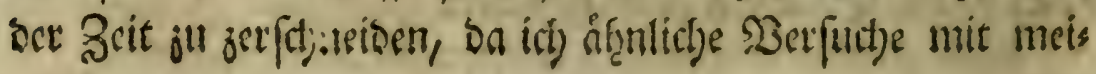




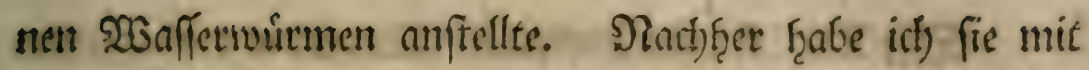
nener Sorgfalt wieder vorgenommen. Da iff) fie nber

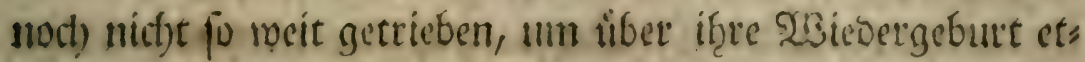
swas gewiffes ju beftimmen; fo will id) mict) beier mur bes

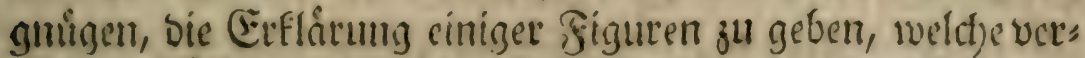

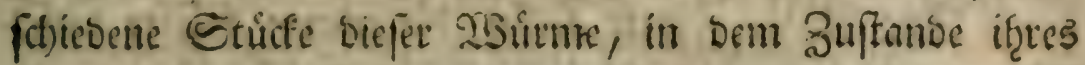

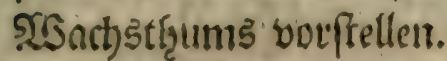

Fig. XII, XIII, XIV, XV, XVI, fo woht, als bie

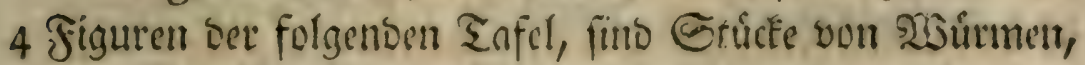
Die ben 27 Jullus 1743 jerf(t)nitten, und in ifzer naturs lititen Brofle vorgeffellet finto.

Die XII. Tigutur jeiget die erffe Şâlfte eines biefer

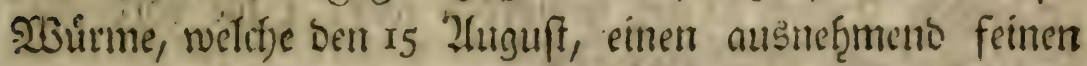
Stbruanj q, getrieben hृatte, welch)er ein Fleiner 223 urm zu

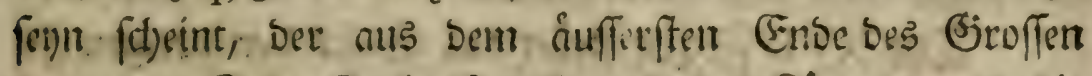
foummt. Esine Sarbe ift freller, als bes Rorpets, uno bie Singe fint Daran, einer bidtete neben bem anbern fharf ats

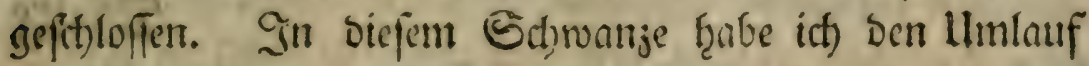

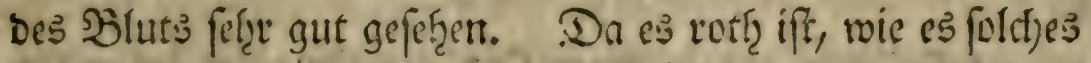

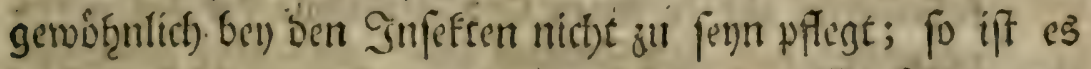
Teidfter, foldsem in fénem Laufe ju folgen. Es foficen mit auct), Dañ fich) Das Błefáfe, morin es lief, viel-weiter, als

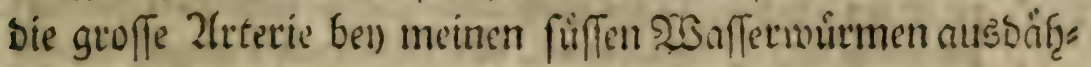
nete. Heberbem glaubte iid), in Diefem neugebilbeten Echwanje sie Sefnumgen, ober Suftló fher zu bemerfent,

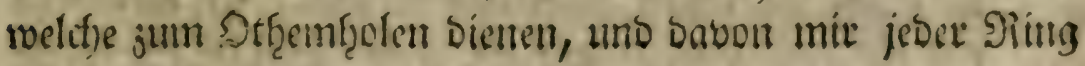
jmene ju haben fifien I).

\section{Die}

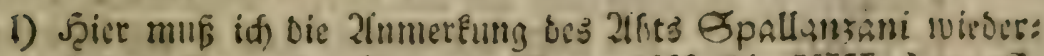

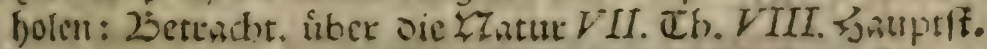
p. 151. "Iet Dotfaffic gielet lier auf lime Entoeclumgen

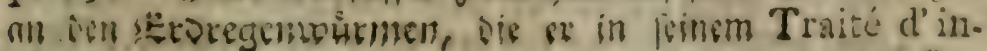




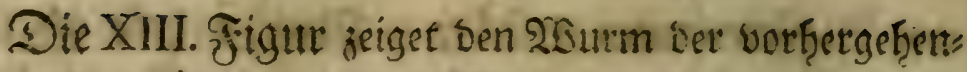

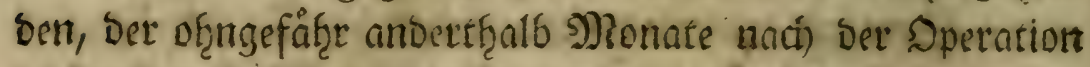

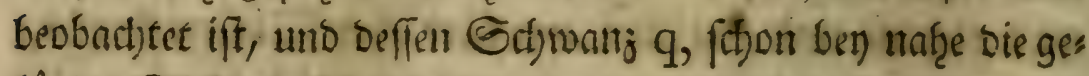
Ģơrige Didée erreidfet f̧at.

Die XIV. Figut ftellet bie jwente Şäffte Diefes SWurmes vor, welche nicht fondertich) gervathen ift. $\mathrm{c}$ ein

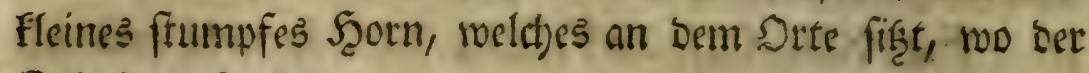
Stgutitt gefdidę̧en war.

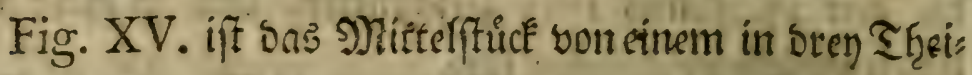
Te jerfornittenem SSurme, welcher den adten Geptember, an benben Enben lánger geworden mar: $t$ bie borberfte; $\mathrm{q}$, Die f̧interffe Derlångerung.

Die XVI. Figur frellet bas Stưck ber vorigen f̧̌s gut vor, wie es ben 23 Nobember gerwejen iff.

\section{Dritte}

fectologie, und in feinen Confiderations fur les corps

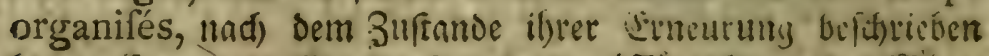

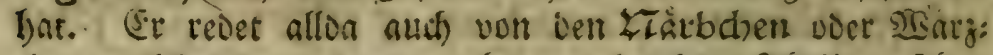
d)en, neldjes er an Dem neu ferworgeurad)ten Theile sefelfent

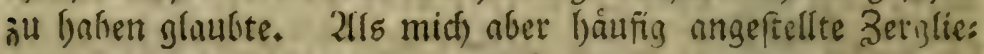

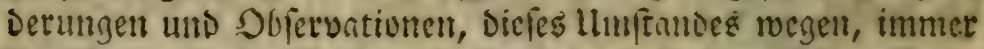

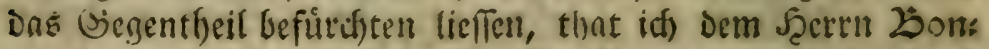
net bayon in einem Ed)reiben (Ertwál)nung; lię abre bod)

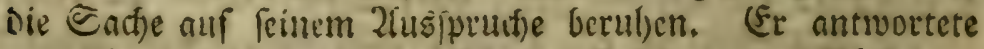

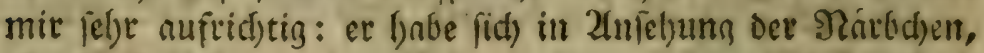
Doer Luftrófyen an Dem Erbiegenturtme geirtet, aber buof Die Sadje aud) nidjt gevié befauptet, ionoern nur vermuthet. (Er babe fid) an einem andern Site bayon entiffeidendoct aus: georúct: Confiderations fur les corps organifés T.II. p. 5. Art. 2.44. uno wifie mun gevie, onß $\mathrm{er}$ fíf geiret.

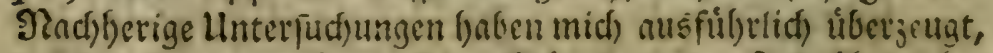

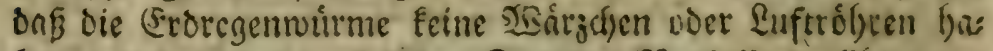

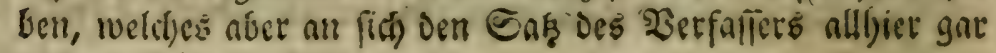
nid)t umftisft. " Heb. 


\section{Dritte Siupfertafel. *)}

Die I Figut seigt citren Điegennurm in naturtlicter

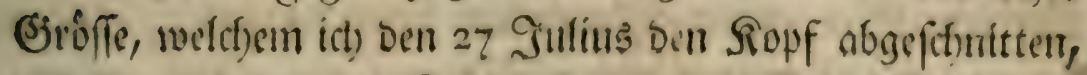
unto ber fitt) ben 20 September ju erneuern angefangen.

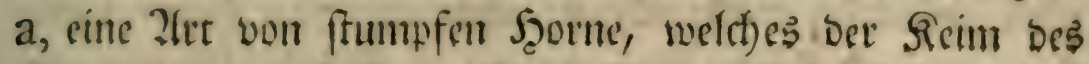
Sopfes, in bem Buftante feiner Entwicfelung if.

Die II. Titgur ift ber כorbertf̧eil eben beffelben

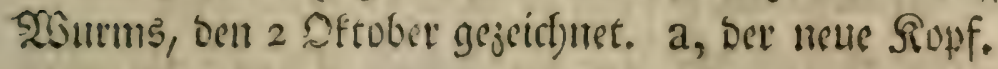

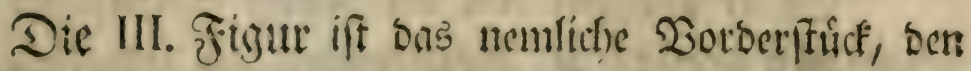
23 פluvember beobadtetet, a, Der Sopf, ber fict) weiter entwicfelt.

Die IV. Tigut jeigt ven 2 Bactigtfum bes 2 surmes Den 44 December. a, Der Sopf, Der ned) nidjt volltig wien Dergewantfert ift.

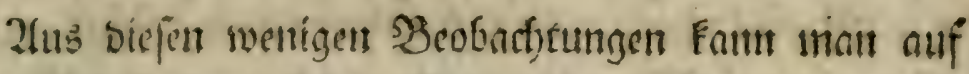

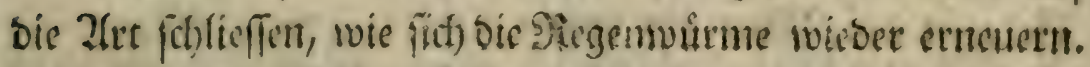

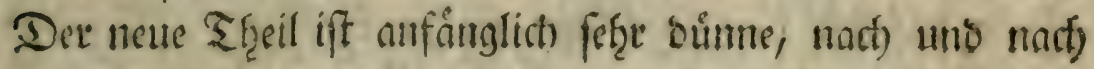

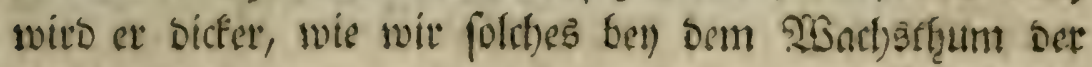
गुศ ju feiner פisprobuftiont viel langer Beit, ats bie Etuicfe meis

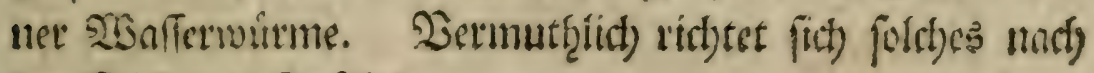
Der Dicke Des Ginfetts.

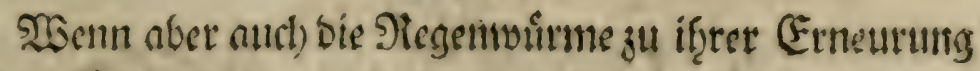

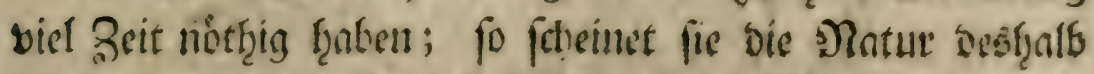

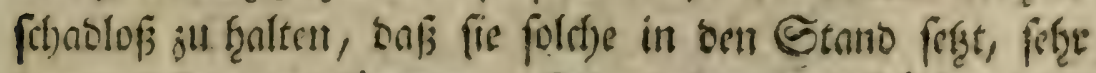
lange foiften gut fơntert. Sich) kૃabe eine Şấlfte vom

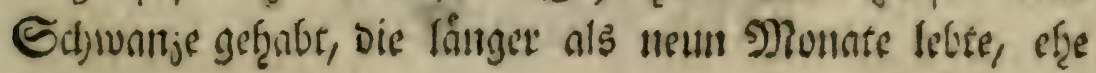

*) ఏcv fig. I.IV. vergyeidje man bic Confider. fur les corps organ. Art. : 44.

3onnet 2. Th. 
320 ErElăruntg Der Sitpfertafelt.

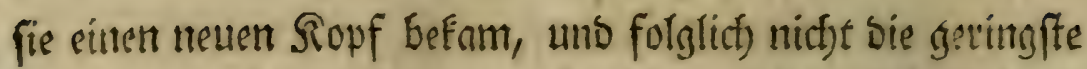

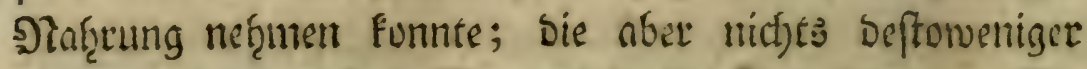

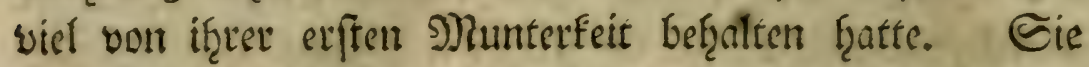
war gwar faft immer unberveglich), in fich feloft jufans

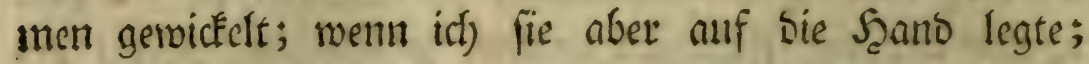

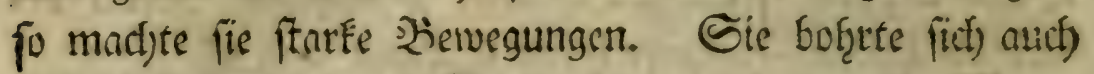
faft eben fo unter bie Erbe, wie es eitr ganjer 20 um suirtbe gethan f̧atent.

Es ift úbrigens eins ber beften Mittel, bie abges

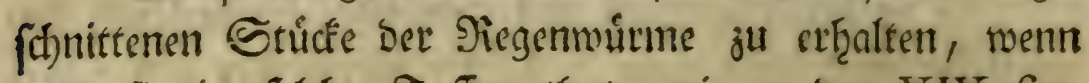
man fie in folche Saffen trgut, wie an Der XIX fig. Der erften Tafel ju fergen, ober it Suckécrglâjer, bie

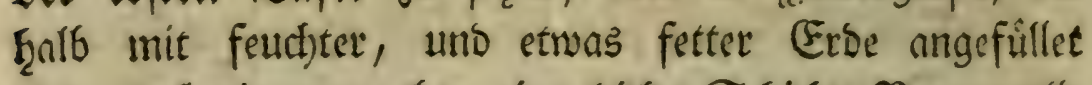
finto, auf bie man oben eine biffe Edjicht SBaumuvolle legent, folthe aber immer feuct)te f̧altent muf́; unto bainit

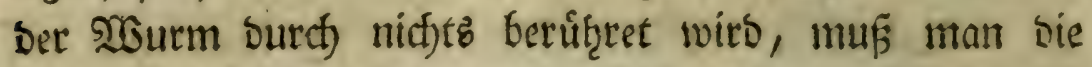

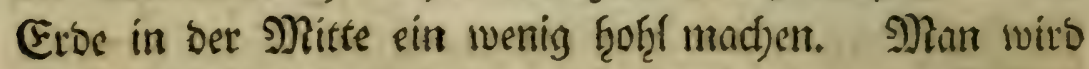

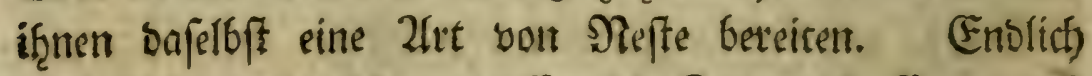

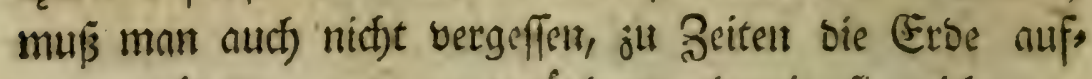

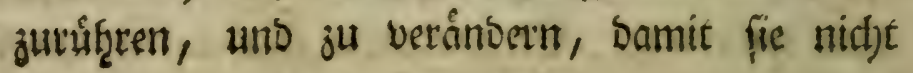
trocken werbe.

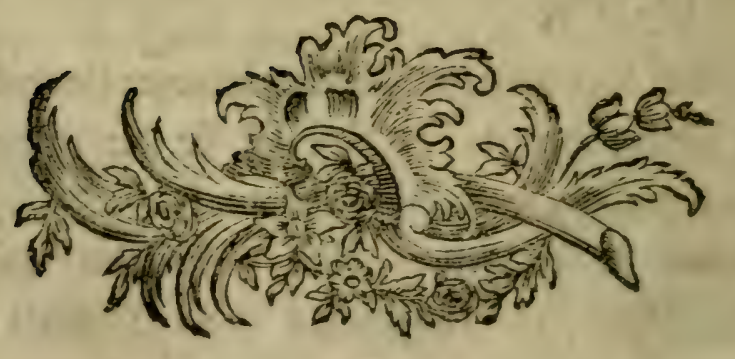




\section{शnbang}

einiger Beobaditugen

$$
\text { Des Heberfeferz }
$$

น́ber

berficiede withe

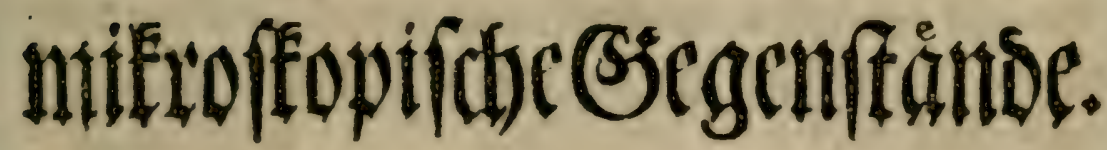



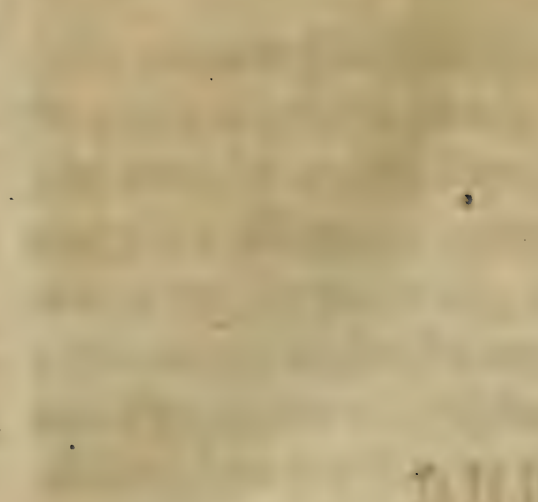

\section{มีเ}

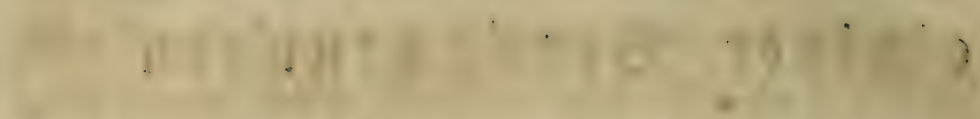

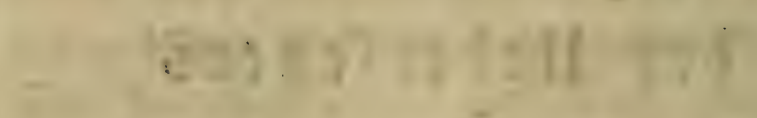

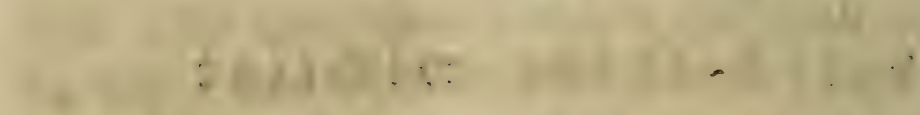

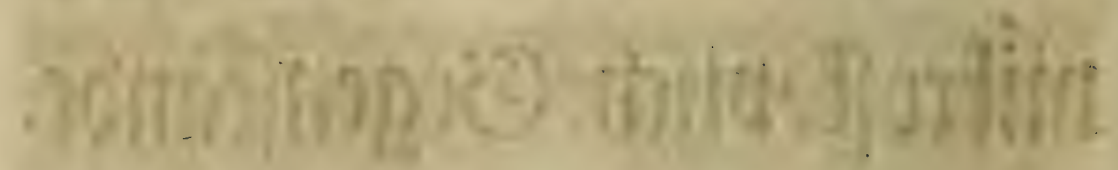

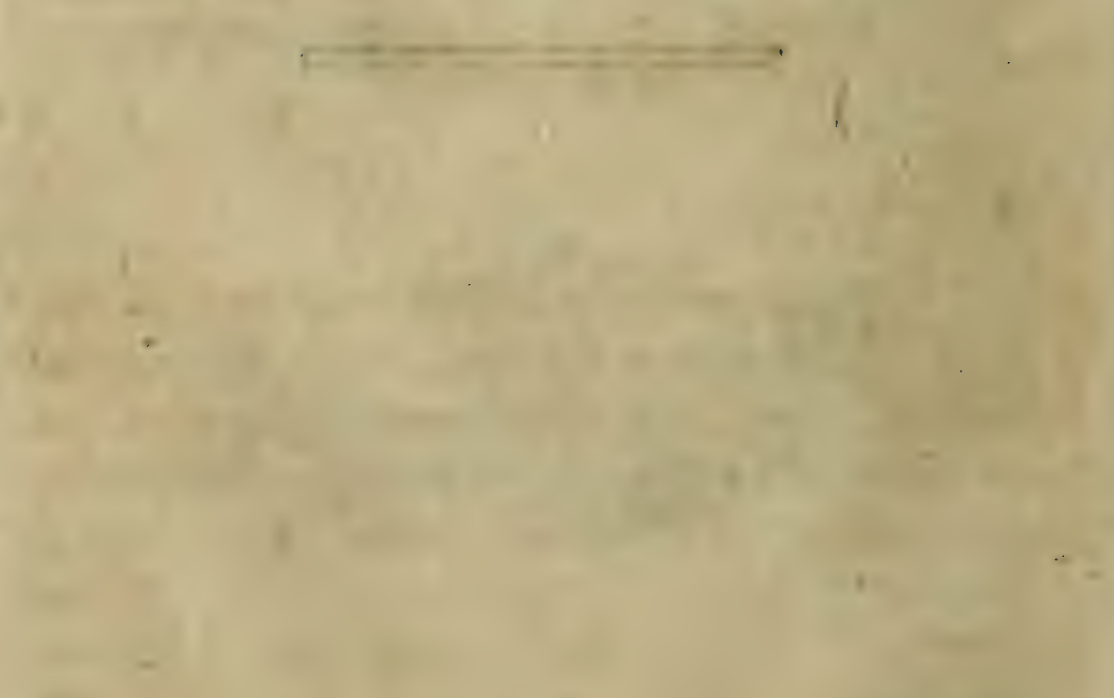

$$
\because \because
$$




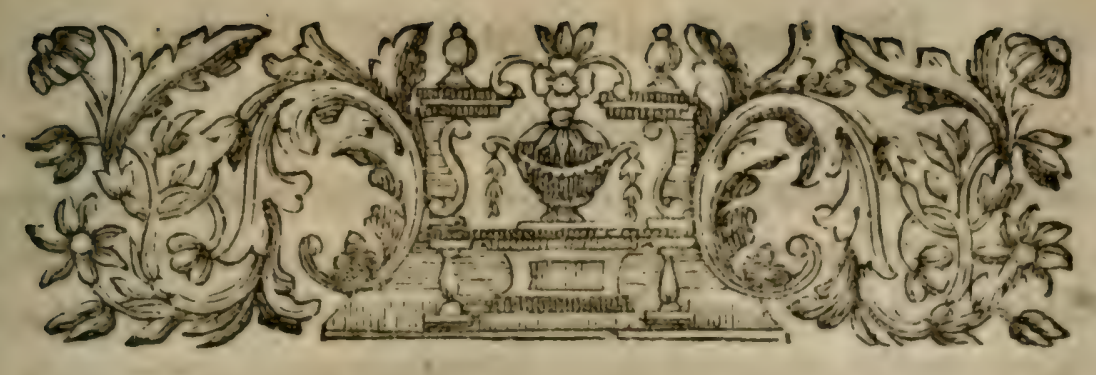

\section{I. $\mathfrak{A}(6)$ its nitt.}

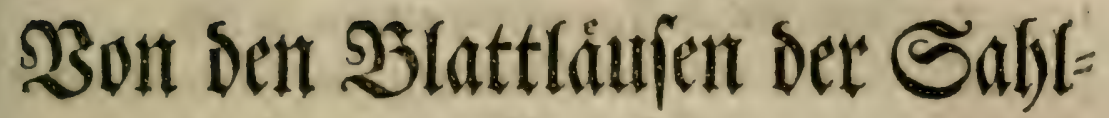 ibetide" $)$.}

\section{25cobadtunty.}

Sisie fid siefe Jmfeften in Truifjabre ergetget haben? Sigo und bee iveldyer Gielegenfeit foldjes juerft ent= Decter iff?

গู3

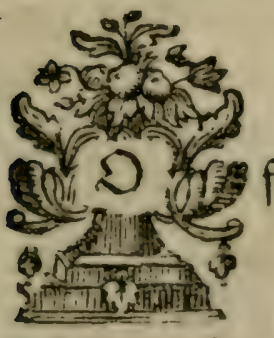

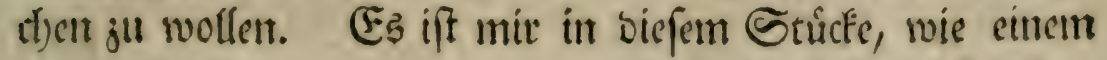
Enonet ergangen, ber ben eittem Spaf̧iergange bie etften

$$
\text { ¥ } 3
$$

Slatt:

a) Linn. S. N. ed. XII. Tom. II. p. 649. 1099. 2 8. caprea, foliis ovatis villofis, im gemeinem Eeten boollweioe.

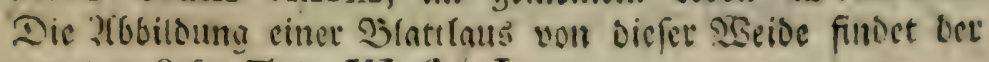
geneigte Lejer Tab. IV. fig. I. 


\section{Zon ben BIattlätent ber Saflmeibe.}

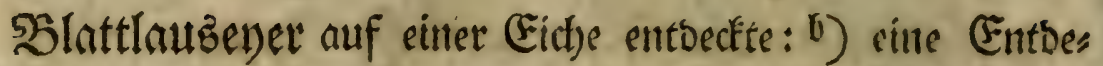

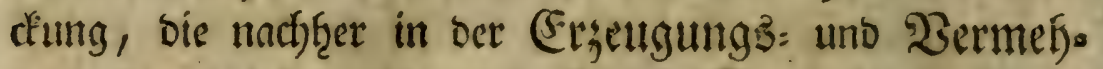

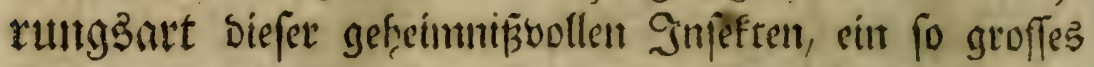
Sidit gegeben f̧at. EEr madgse fie im S(pril, unb faḩe ḩer" nact) wirflid) junge lebenoige B̧lattlanfe ausfomment.

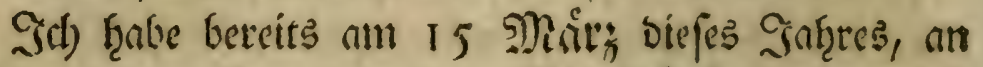
gewiffen anbern Gbattungen von Slattláujen, ebent biefe

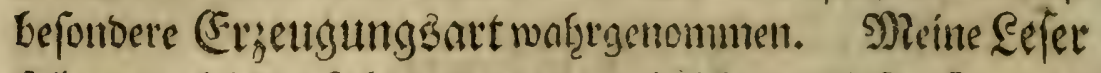
follen es gleid) erfanfreels, wo unb wie id) zu biefer fo anges nergmen, als gliucflichen Entoectumg gefommen bin.

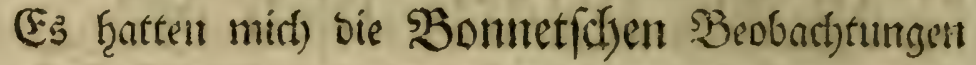

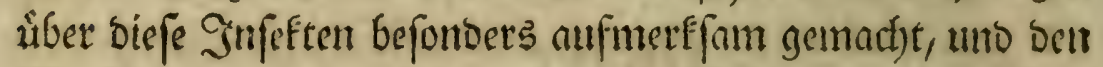

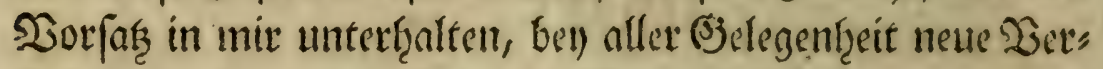

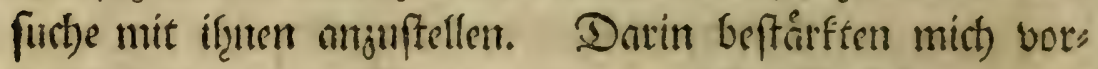
nemlity) sie eigenen sisorte meines groffen Dorgångers: c) Sie fint aller nuf fie gewendeten 2 ufmerffomeeit of neradjtet, noch nicht genutg ftudirt, unb rwir finoen

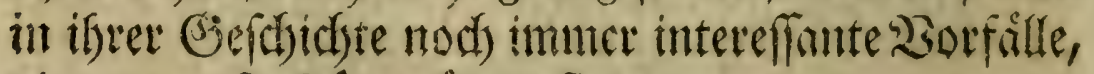
Die unb attatufláren librig find.,

Sielleict)t, Dachte ict), ift mir eine Entofectung an bies

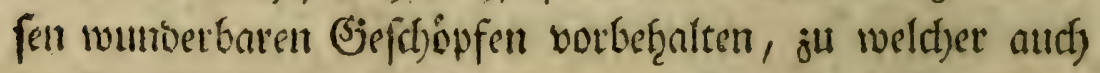

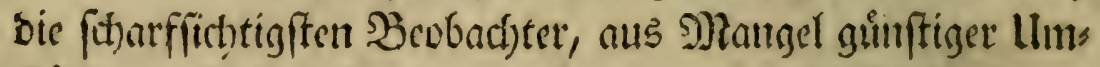

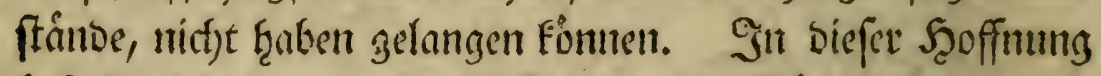

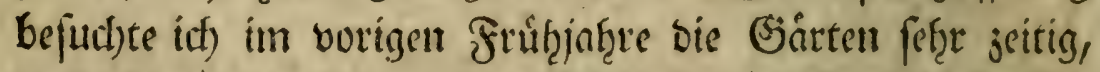
weil id) mir von ber warmen 23 itterung Deffo frufifere (3es burten der Snfeften verfiprach. Der beret's genannte

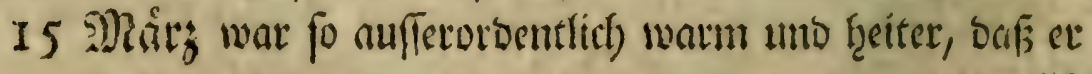

mict)

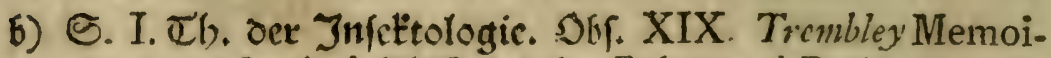
res pour fervir à l'hiftoire des Polypes. à Paris ${ }^{2} 744.8$. Pref. XVI. f.

c) Confiderations fur les Corps organifés. T. II. Art. 306. p. II 2 . 


\section{3on ben 23lattlăufen ber Salliweibe. 325}

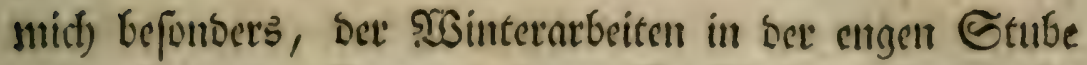
mutbe, in meinen Barten loctes. Sic Natur, biefe forgfofls

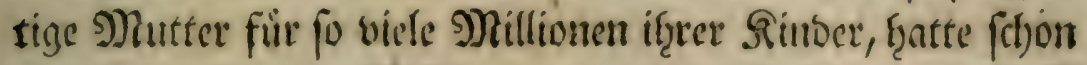

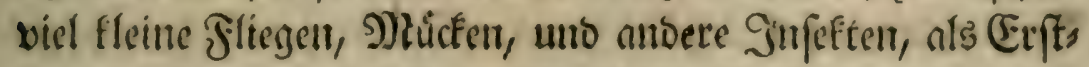
linge bes neuen !ebens, aus iţeen Sd)lupfivinfeln ber

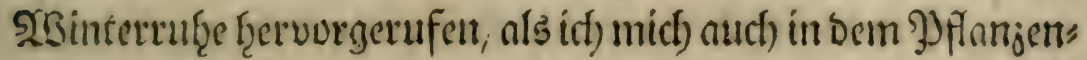

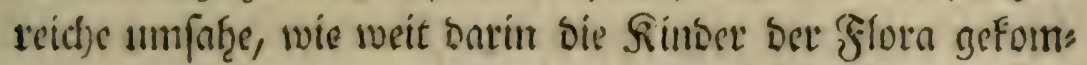

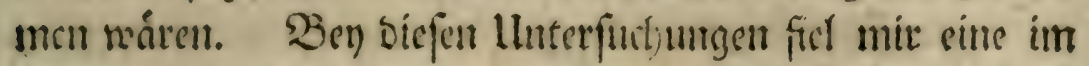

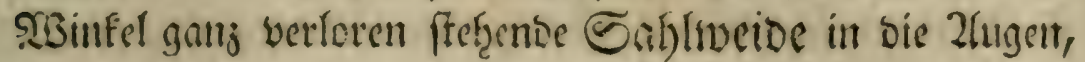

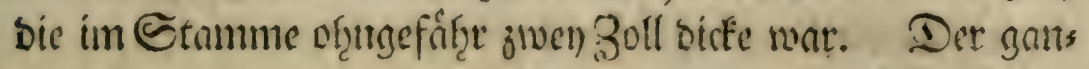
öc Stamm forwoghl, als a!le Z3weige Daran, waten überall, bejontoers at ben Sotent, wo bie Sinospen, und jungen ₹ries

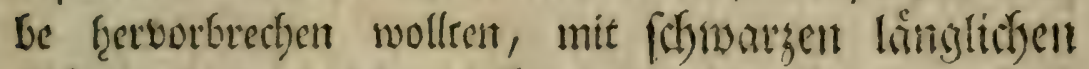

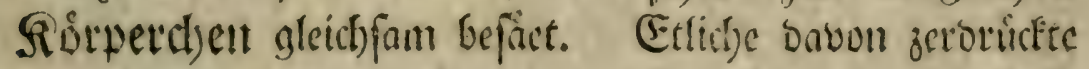

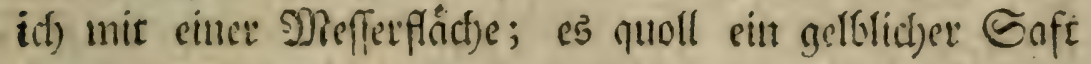

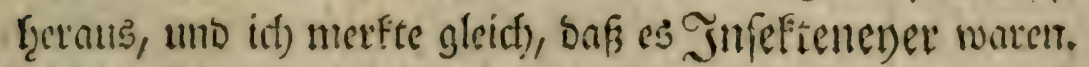

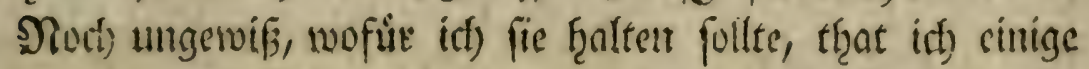

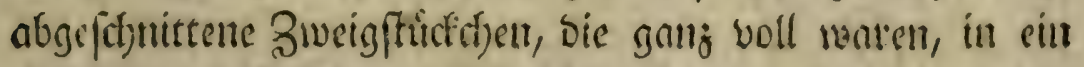

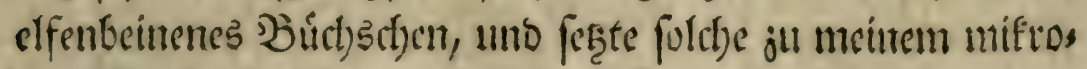
ffopiffoen 2tpparat in bie warme Etube.

Nach cinigen Tagen fiel es mir wieber cin, barnacl)

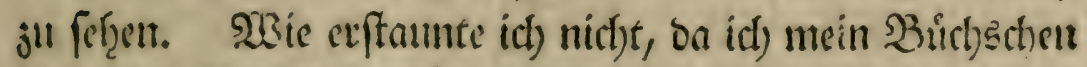

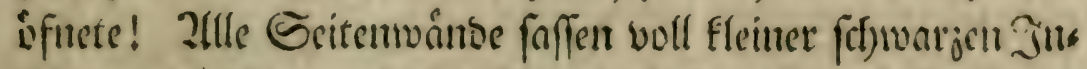
feftelt, viel Eleiner, als bie Nabelfnópfe; bem blofien Zluge

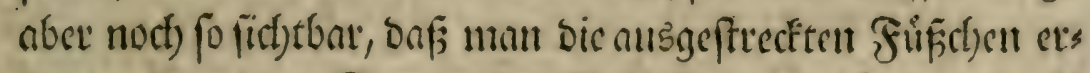
fennen fomute. Dem erften Zlnblicfe nach) Ģâtte man fic

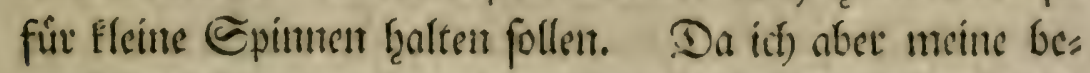

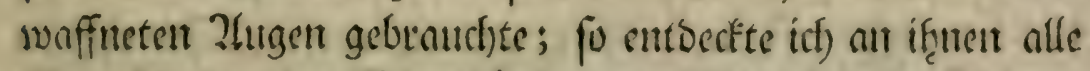
Eigenf(t)aften ber $\mathfrak{B l a t t l a ̈ u f e , ~ b e r e n ~} 2$ tet idl) in bem folgents

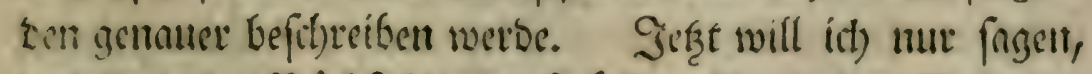

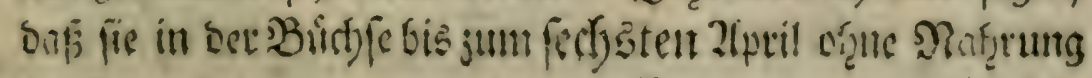

$$
\mathrm{X}_{4}
$$

rebs 


\section{Bon Den Slattláufen Der Safliveibe.}

Tebten. Eange gemug int einem swel) und zwantsigtiggigen

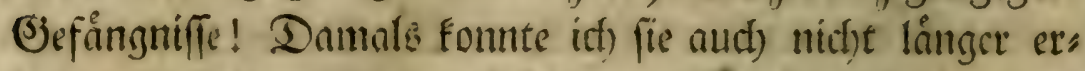

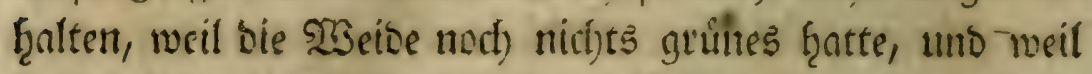
fie bor ber Zeet Durch bie Entubenvairme jur Beburt beföts bert waren.

SBell biefer Enttoectung tiberbaupt finben fith bod)

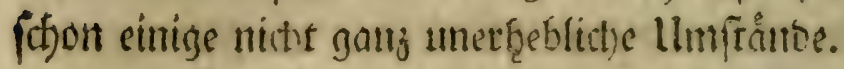

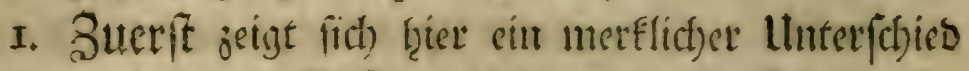

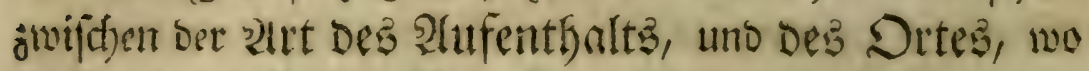
bieje, und bie Evonetichen Ener gefunton fino.

Gidf) erblicfte bie meinizent auf gants glattent 3mpigent, unt ouf eintm eben fo glatten @tamme; Denn bie 2ỉetioe

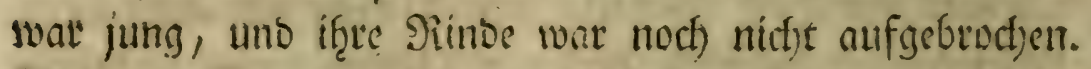
Sie waten zwor mit einem flebrigent Enfre angeleimt;

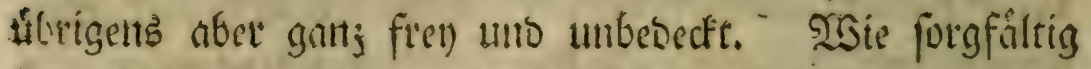

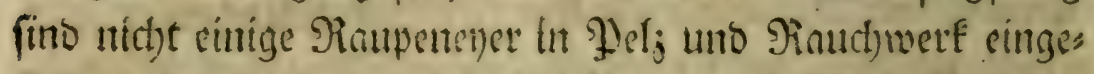
futtert, ober mit cinem teimfitt überjogen? Dieje Everdjent

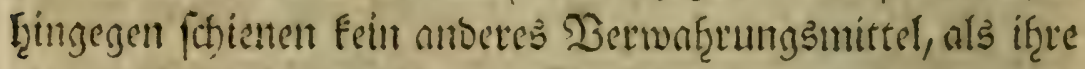
eigene Sct)aate ju ḩaben. Dennod) finto fie bent ganjent

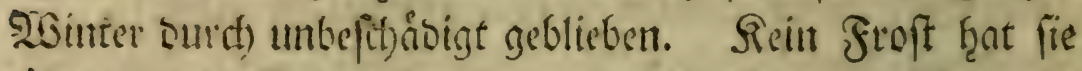
tobten; Fein Gethee frat fie verberben forment. Sift) vers muttre, bar bie Echanle, wotit bie Maffe bes fúnftigen

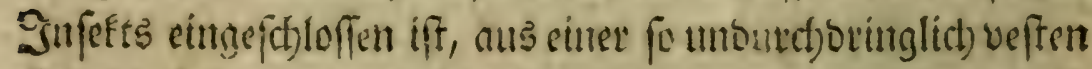

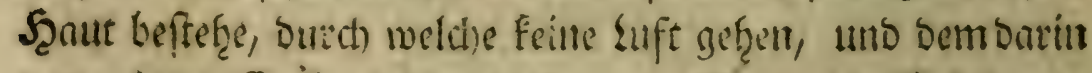

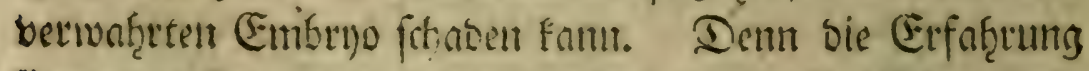
liegt vor Zfugen, bas fie gut uno frutifrbar geoblieben finto.

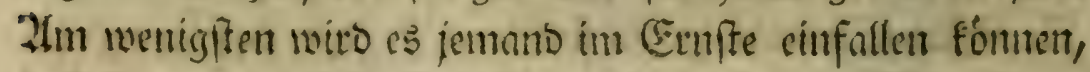

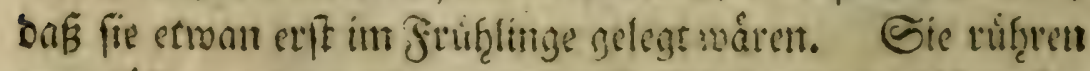

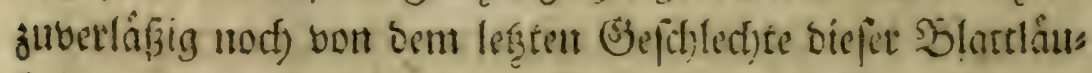

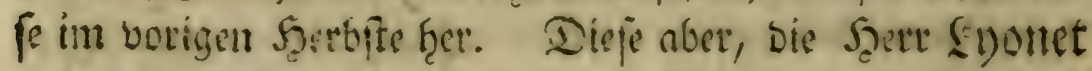

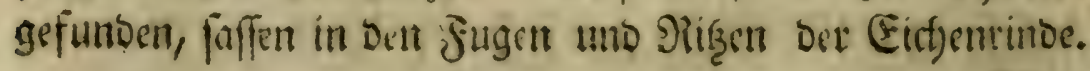




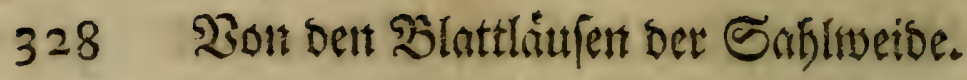

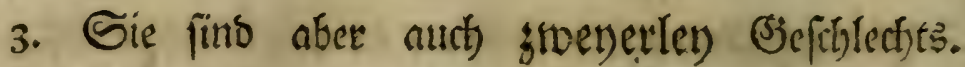

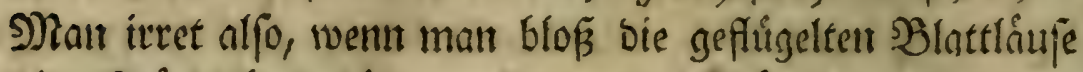

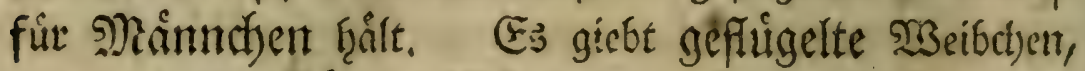
uno auch ungefligelte smanndien. Die erfferen befoms

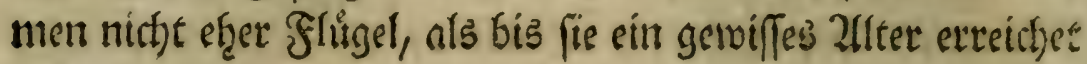
Fraben.

Man Fann fich) in Der Natur Eein zarteres Ojetwebe sorffellen, ats ben Flügel einer gruinen Blattlous, Detglets

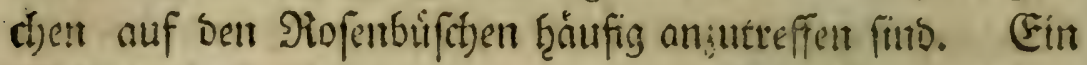
sMhictemfiugel ift bogegen unter bem Mifroffop, wie cin

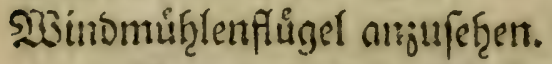

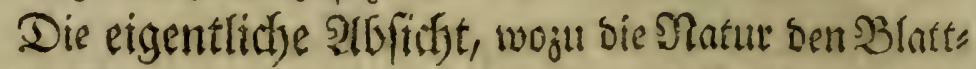

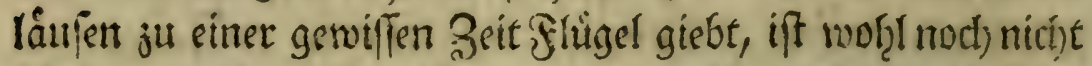

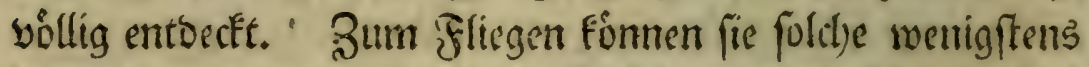
nicht fo, wie anbere gefligette Sinfeften gebraucber. Dns

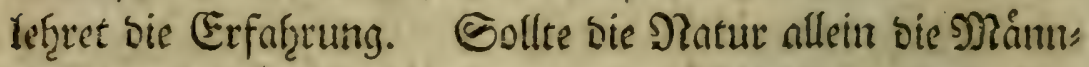
c)en Dannit verfergen fraben, wie man folct)es an anbern Sins Feften finbet; fo múften fie alle baunit verfehent fenn. Es gietot aber aud) ungeffugelte MRanncten. Sollten fie foldte

เuนเ

an belt Etamm set Şaume felfft an, da fie dent nicjt fo

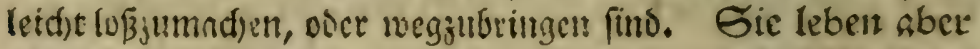
alsoenn nicht mebr, uno wenn man cine betfelben weg:

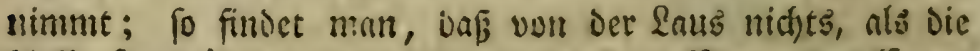
blofie fant rifrig, unter felbiget aber cine s)ientge von (syer'n

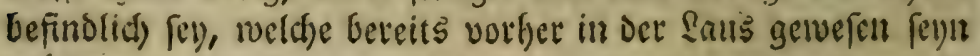
múten. ."

Tian vergleidje fiermit Guljers Kennzeidhen তe! Infet: ten 4. 3uitu. 1761. p. 109. Im 2lnfinge bes 2(unufte dec

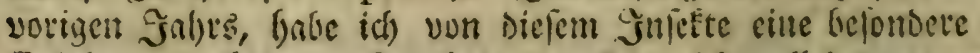

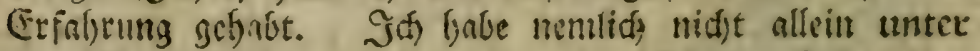

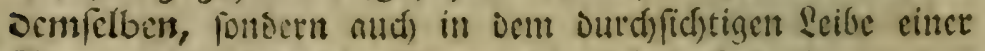

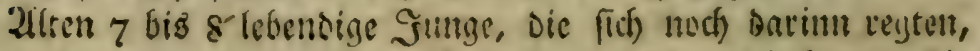
wabrgenonmen. (Fine (Eric)einung, die mid) bewor, sic

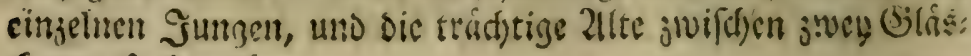
djen alsijubemabren. 


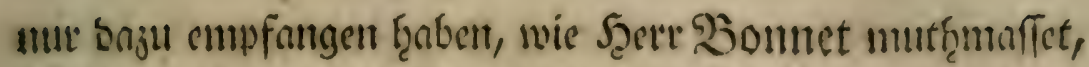
fict snourch ben ber Bewegung Der Zweige, von simem Blatte jum antocrn zu begeben; fo miiten fie ebenfals alle,

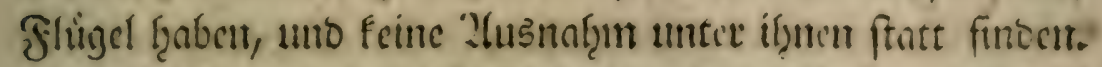

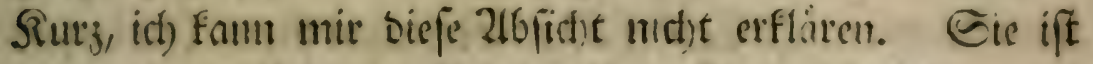

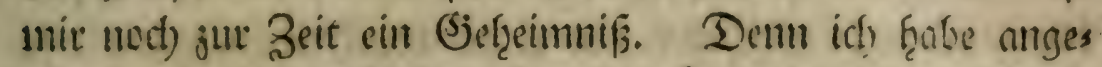
metft, onfis bie geflugetten eben fo trioge, als bie ungeflugels ten fints.

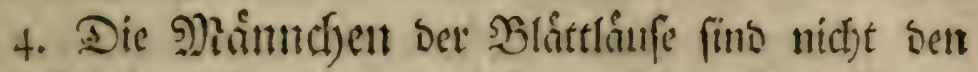
ganjen Gommer surch vorf̧alloen. Sie erjekenten erft genen ben Serbff. EEs ift ju vermuthen, baf fie ben ser Iefsten Sieburt ber lebendigen Jungen mit geboren wits

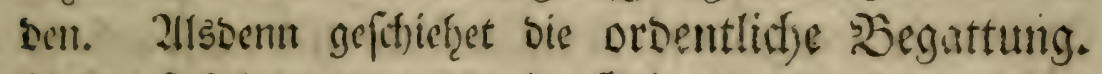
Zluf biefe folgt jwat noth eime Sjebutt; nber feituce lebens

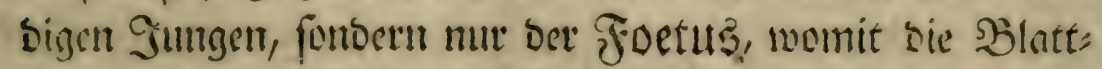

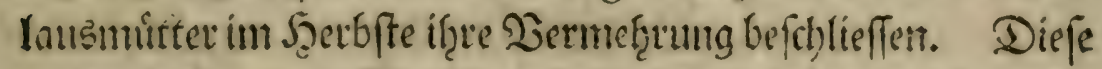
in ben seibert ber Meibden befundid)en Foetus ju befrut)s

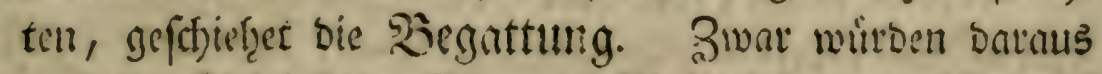
noch chumal lebenbige Sunge in Mntterleibe nuşgefommen,

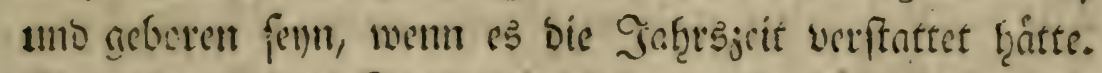

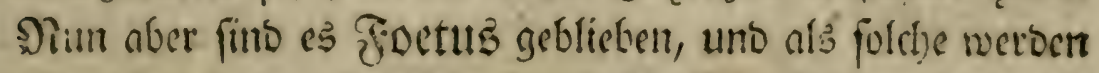

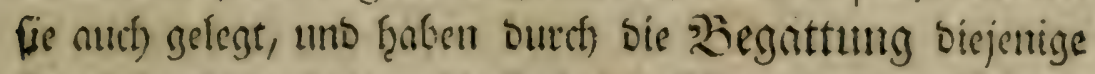

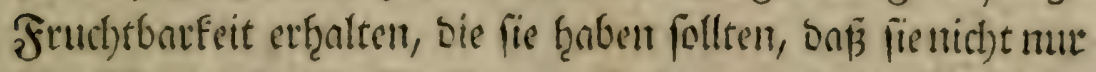

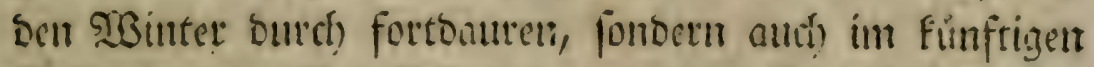

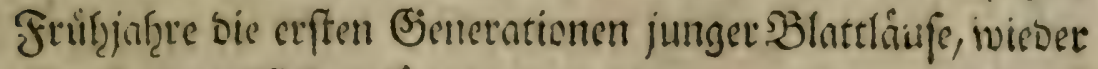
ats if̧nent entiftęen formten.

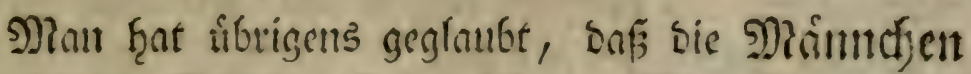

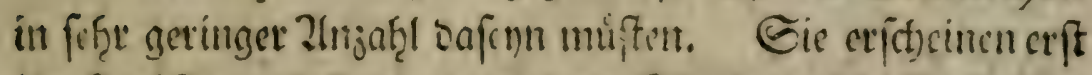
im Şertefte, uno fino weçen if̧ece Sitcinfect nicht fo beutlidh,

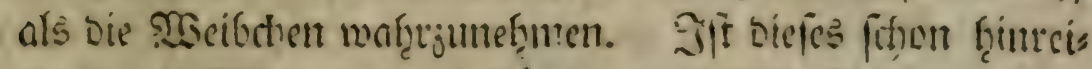

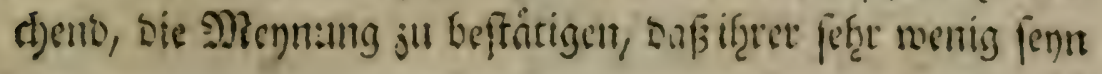
แกน์ 


\section{Von Den Blattlâfent Der Saflibeibe.}

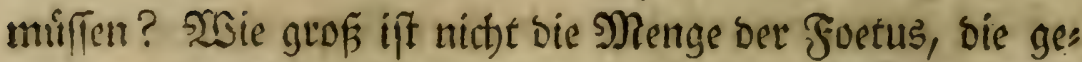
gen ben Feerbift noch erft follen befuchtet werben? Nisie

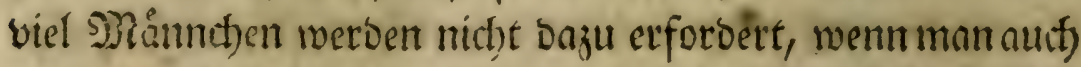
annimmt, Daf ein eitioiges metre, als einem 20 eibchen gुenug theun fant. Shre Eeben aber, wirb man fagen, ift von fefcr Furzer Dauer? Sft Dod Das Leben Der (Ephemeronfliege noch) furger. Die Matur fiefzet nicht auf bie Rirrze, over

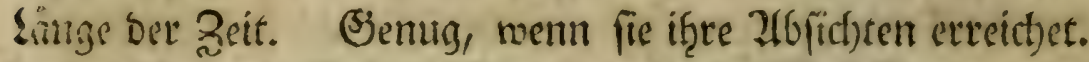

So weit if man bişger in ber llnterfuct)ung ber Ee" oeligungşart Diefer Sinfeften gefommen, Die Den פlaturfins

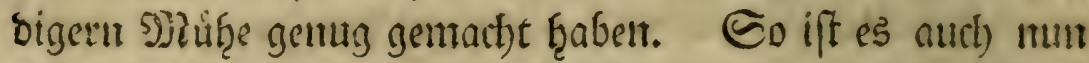

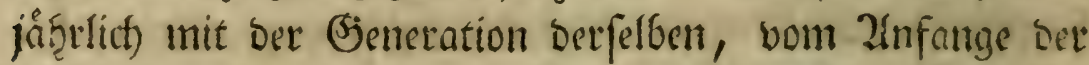

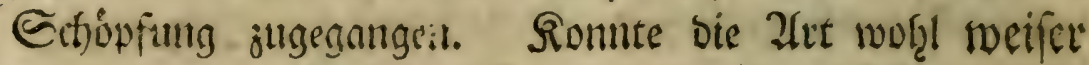
eingerichtet werben?

\section{25eobad)tunts. \\ Heber eben Diefe art von Blattlåurent.}

But weldyer Gattung fie gefboren?

Die vortefmeten und mertwurvigften Theile iferes

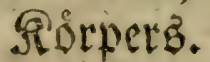

Ginige nette und befondere Endeckungen an benfelbent.

(5) e gegentuártige aft ber ß̧lattlåufe geçơret zu Der ev" ffen Slaffe biefer Janfetten. Şerr Bonnet f̧at fie nach)

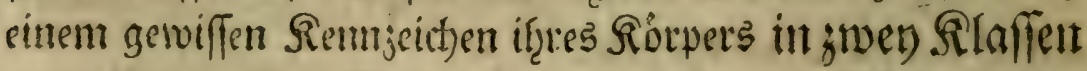

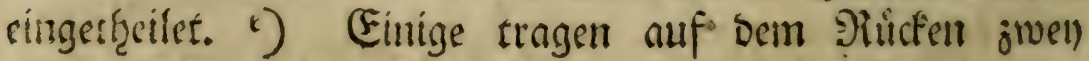
jiems

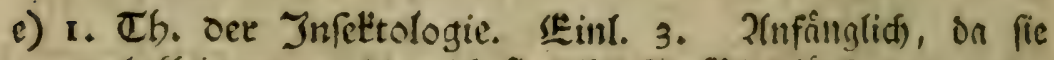

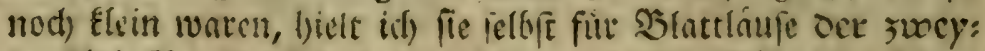

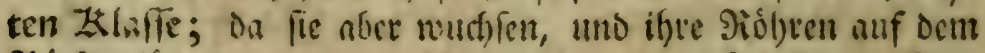

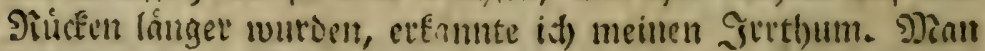

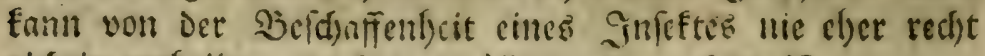

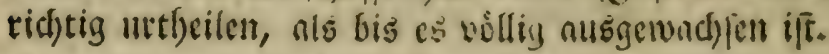




\section{Won den Şlattlâtuen Der Gafliweide.}

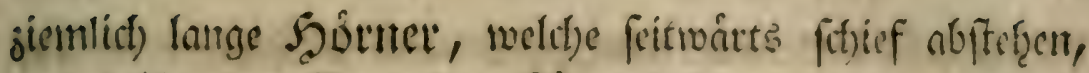
etwas tiber Den Fand Des Fiorpers Fertworragen, uno wie

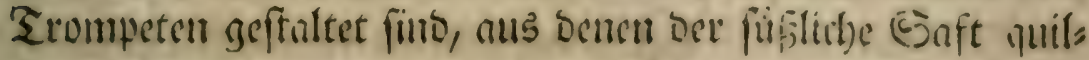
Iet, Der bie ?tmei(en an fitly loctt. Disfe mad)en die erife

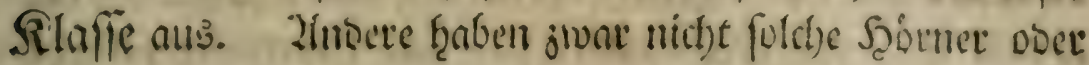

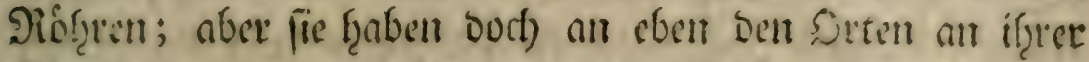

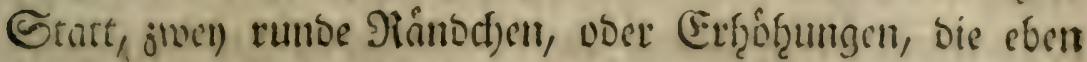
follten Suft won firt) geben. Diefe geçouren jutt juentent Slafie.

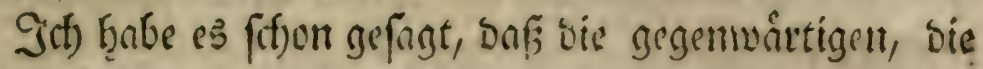

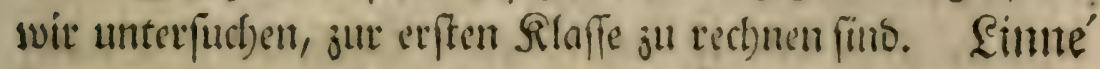

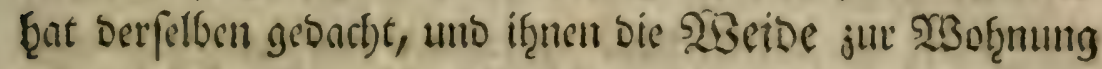

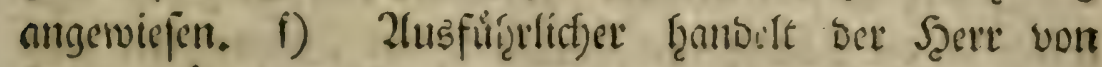
Reaumuir von biefer (S)nttung. 9) Es fommt mir abev Dodt) nict)t fo yor, nls wáre biefe figur ber meinigen vollfoums

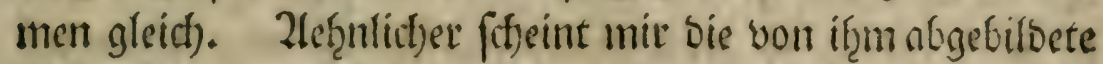

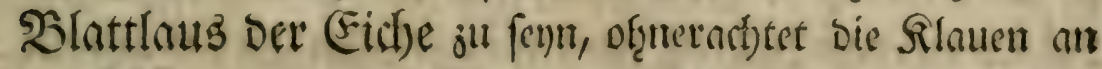
Den Fuffen baran vergeffen fint. Sielleidgt ift es eine Siats tunig mit ben unfrigen.

S(t) will mun meine SBeidenblattlaus nåk̨er bes

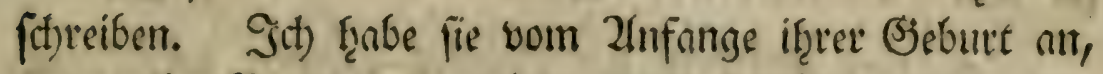

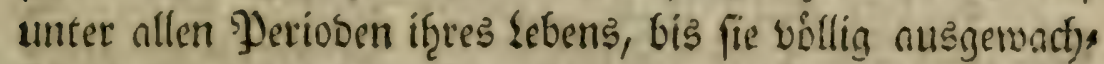

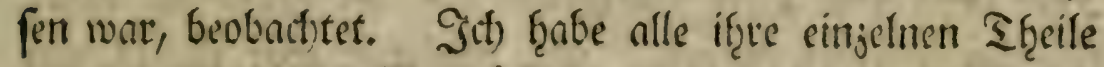
unter verfotiedenen Sergrofferungen betrad)tet. Seget will

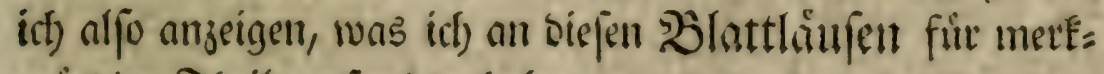
wuirbige Th heile gefunocn ţabe.

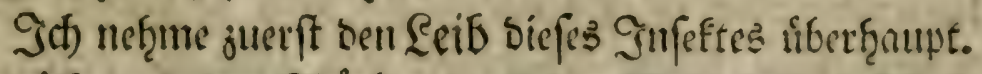

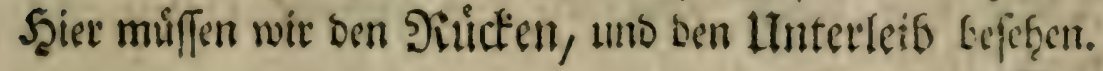
Micis

f) S. N. ed. XII. T. I. p. 736 . n. 26. habitat in Salicibus: caprea, viminali, pentandra.

9) Memoires pour fervir a l'liftoire des Infectes. Tom. III. P. 11. Mem. IX. p. 22. ed. gr. 12. Tab. XXII. fig. 2. 
Meine Sefer treten alfo mit ju meinem Mifroffop. Zuf

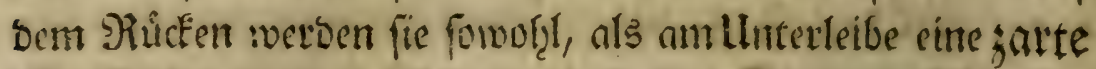

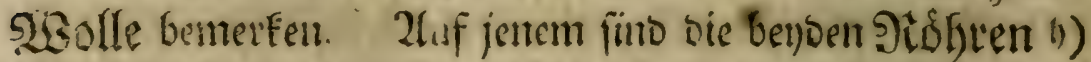
bie grópte Merfmuirbigfeit. Soben uno unten findet fict) eine

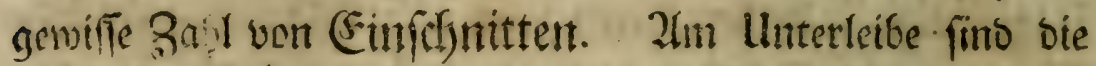
Tiilfe beveftiget. Feernach werber meíne sefer Den Siopf

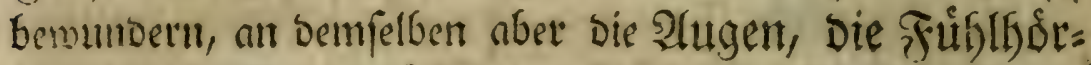
ner no sen Saugeruiffer unterfcheisen. Şuter iff alfo ber

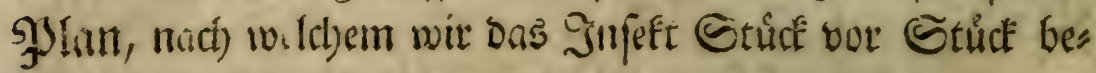
tract)sen wollen.

I. Das erfte ift ber Rótper uibertroupt. Sobalo bas Gnfeft ans ber Echaale gefomment war, mogte es chent= gefágr in ber Eånge cine hallse, in Der birette aber eine

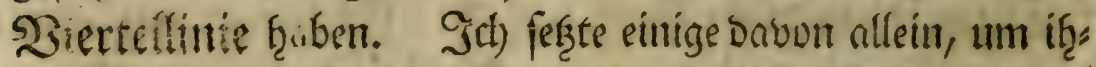

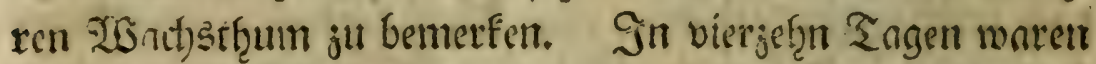

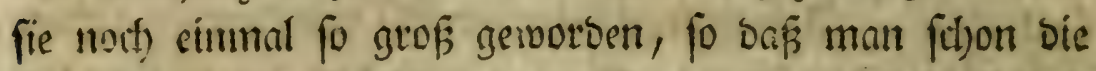

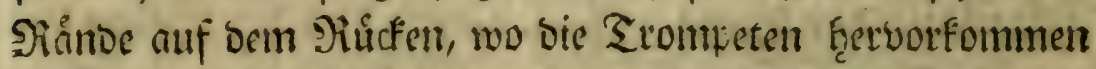
mollten, mit bloffen Zlugen feçen fonnte. Die Farbe bes Rorpers war fahl uno fiel itts sumfelgrane. taffen fie un's

a. Den SRickent bes Sulfefts genauet betraci)ten.

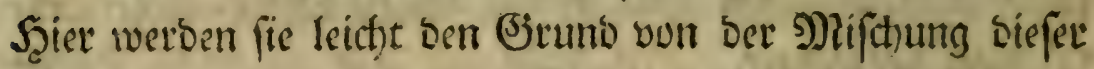

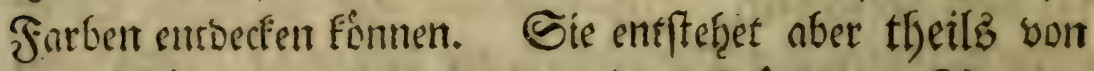

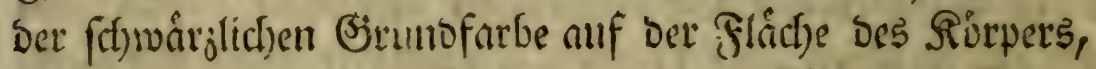

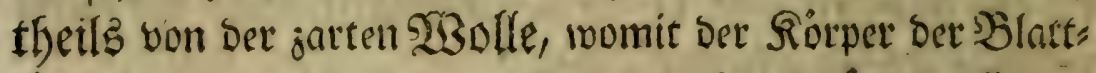

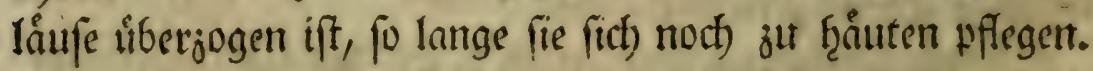

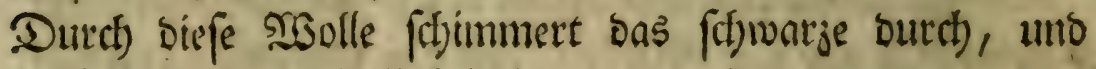
witid fafl.

Mian fant fich) unter bem MRiftoffope Feitrent pråd):

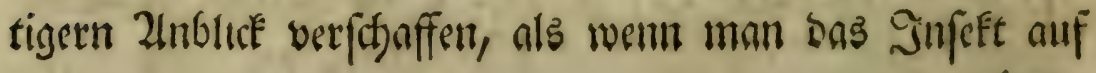
einem.

(j) -fig. I. d, d, 


\section{3on ben D̉lattláufen Der Saftweide.}

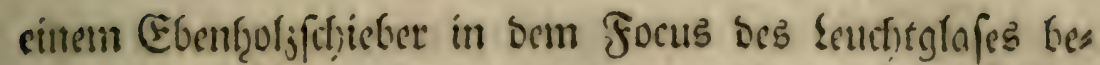

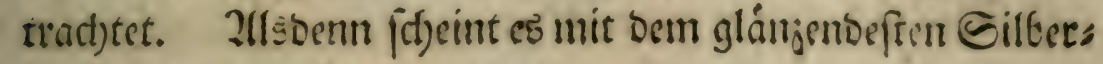
fioffe bedectit su fernn.

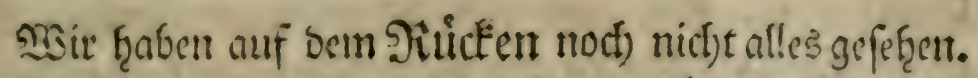
Soum Siupfe bis jum Zlffer getret in Der !ánge ein weiffer

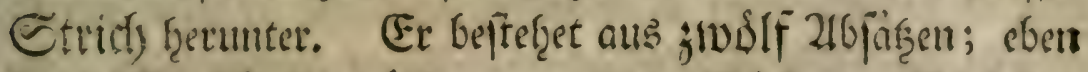

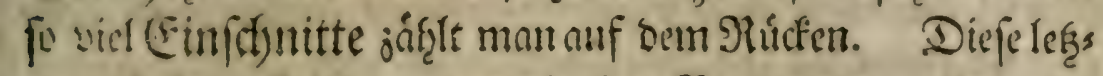
teren bzaben alle eithe proportionirte Breite gegen einanber. Die beriteften fint am Siopfe, unb nad) Dem Şintertf̧eile jut, merben fie unmer fofuader. $23_{0}$ jeber Einftunitt angefret,

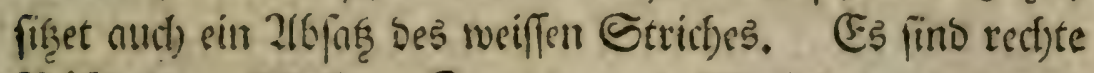

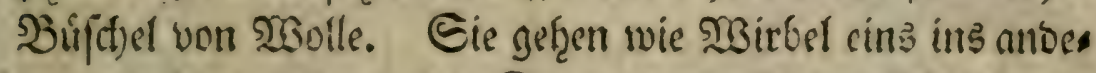

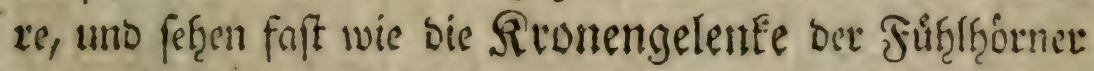
einiger Infeetten nus, bie immer eins in bem anbern frectert. Zluf Genben Geiten biefes Strids) liegen vier unid vier weiffe Flecke. Die benoen mittelffen auf jeber Eeite fitro

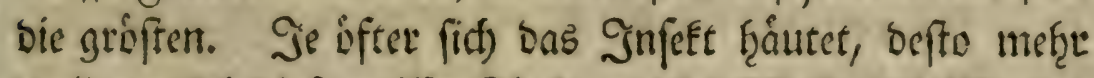
berlieren fid biefe weiffen flecte, uno bie 250 olle Des Rörpers úberţ̧aupt.

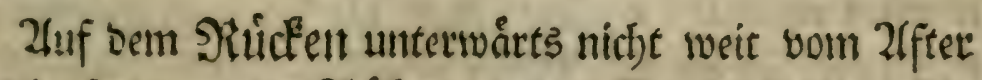

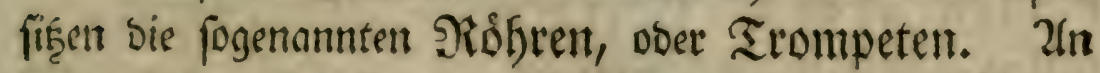
Den ineinigen find fie gegen bie fidwarje Farbe Des Siorpers purpurtoth. Sie ftȩ̂en wenigftens eine hralbe sinte von

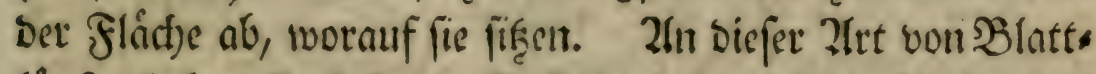
liuffen fraben fie faft bie Şejtalt einer fleinen Solbe ober Reule, beren bicfes Erbe oben ift. Da wo fie jugerumbet

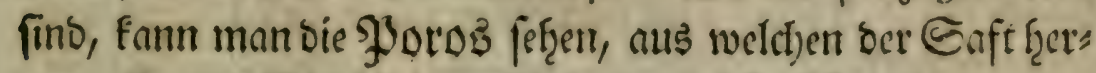
vorquillet. Sie fd)einen kibrigens, biefe Rörperchen, nus vielen fleinen Drifien ju befteţen, worin ber Saft abges fonbert wits, Dent fie von fich) geben. 


\section{Von Den Slattlåuen Der Eafliweibe.}

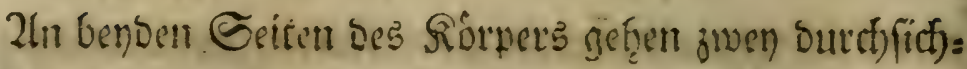

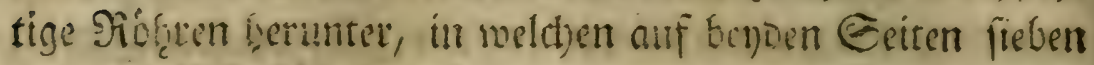

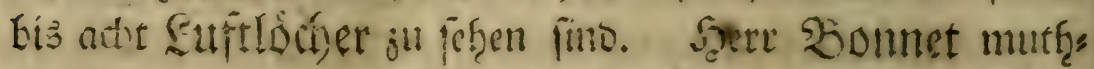

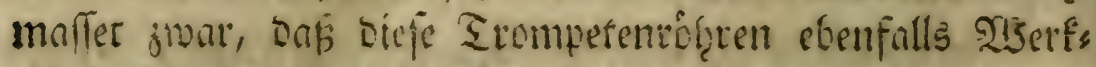
genge jum Sthemb̨olen watren. Sisenn man aber recht ges

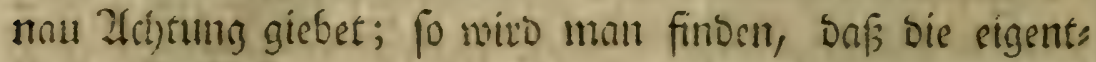

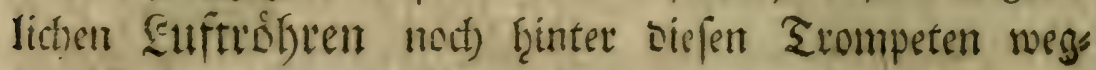
gef̧ent, uno nict)t mit if̧nen verbutuben finto.

Gith) befenne Gieer gern meine Unmiffentreit. Die

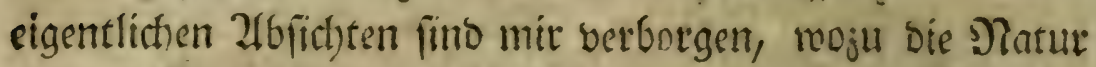
einigen Ş lattlänfen diefe 23 erf jenge gegebent ḩat. Das

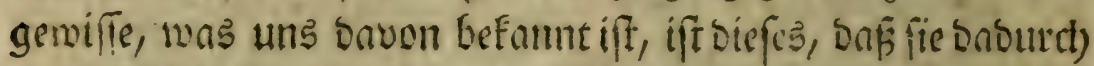

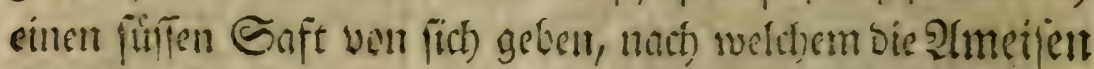

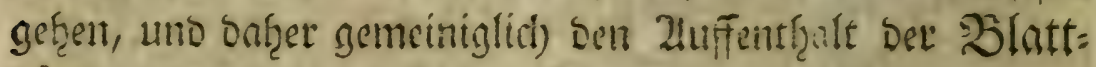

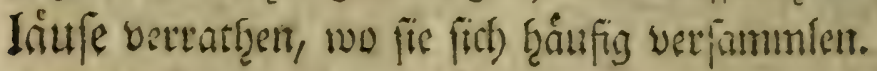

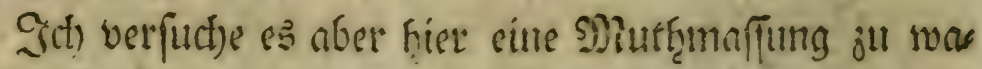
gent, sie fict blof auf meine (Erfafrumg grundes, bie idf)

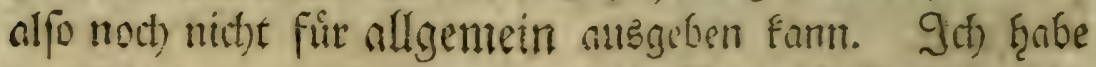

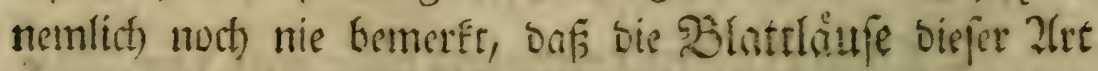
Surch) Den cigentlifien 2 ffter (Excrentente von fich gegeben

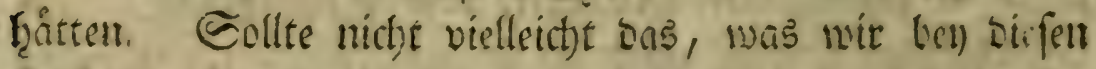

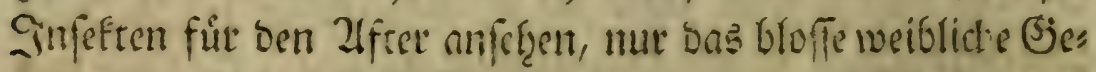
Gurtzgglied pentr; Diefe benben gioberen aber die Stefle Deß

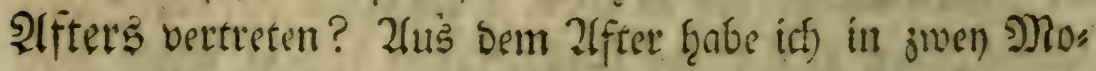

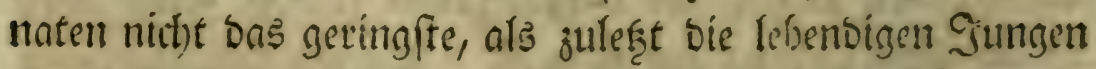

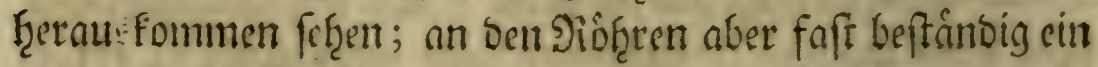

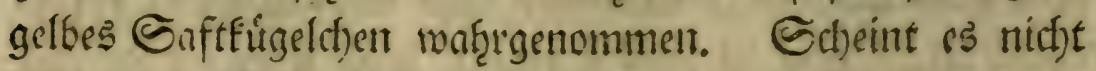

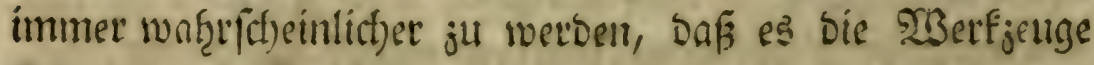

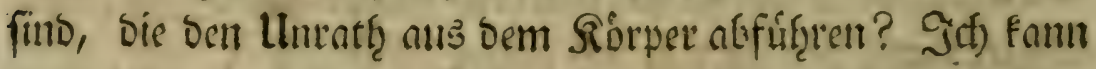
mict) itren. Sreuent toúrbe ifí) mid) abet, wenn eil anberee 


\section{S3on ben 23lattlínfar Der Sonflineide. 335}

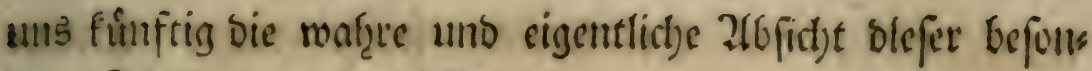
bern Shreile entbecken follte.

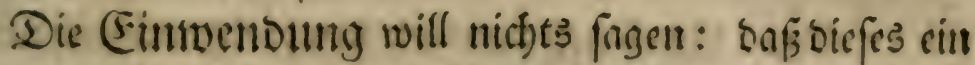

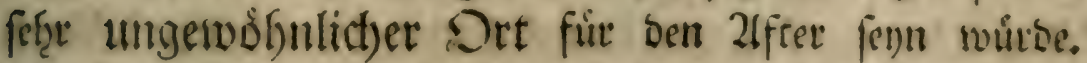

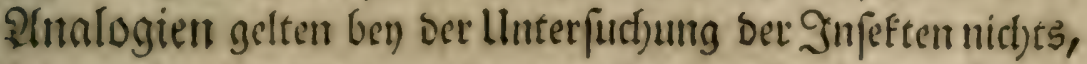

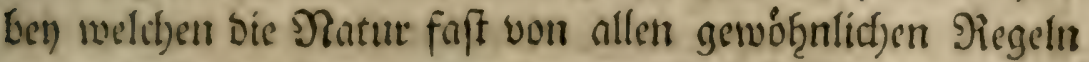

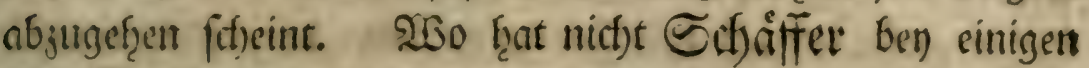

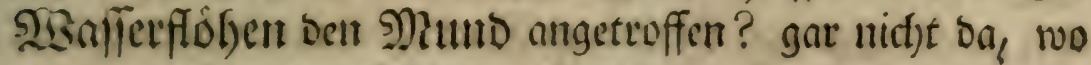

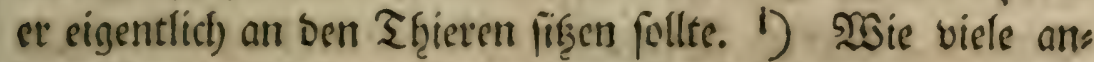
bere $\mathfrak{b e n f p i e l e ~ f i n t o ~ n i c h t ~ i n ~ b e r ~ N a t u r ~ b e f o u n t , ~ a n ~ b e n e n ~}$ swir gernoe dos Begentţeil von seen erblictent, was in bem

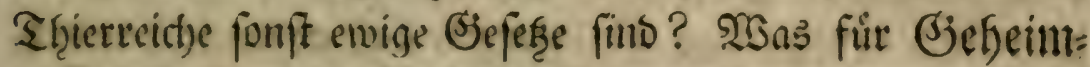

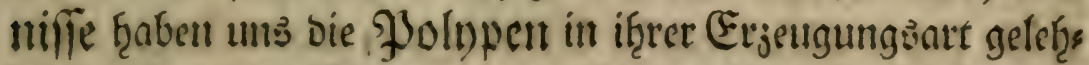

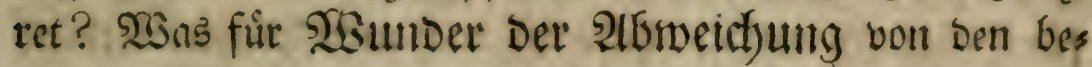

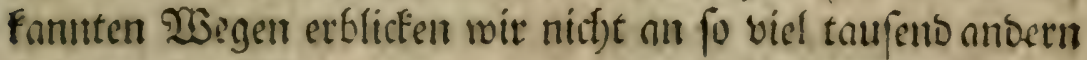
Jinjeften? Sisunder, bie man sf̧er für 2 (bentheure utọ

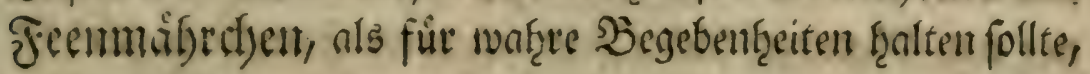

wenu

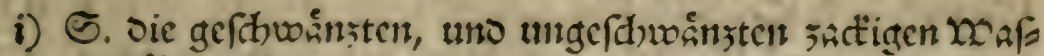

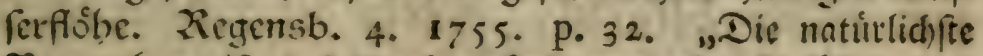

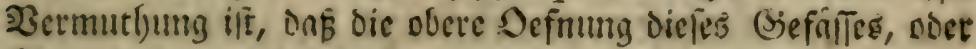

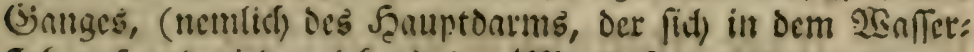

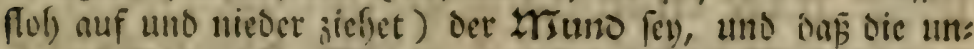
tere Definung Een 2 (fter ausmad)e. Jene glinto offunng hefindet fidf) alfo, imvendis jwifden uno innerfalb oen bev: Den Edgalen, gleid) oberlgalo oen Siefenfifien uno oen áály:

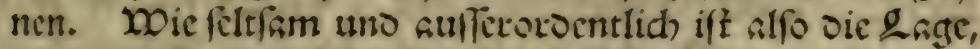

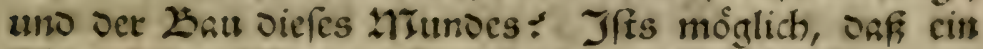
Thier feinen Atuno tief im Reibe, wentigitens feht woeit unter oen Ghasloeteln tơnne verborgen baben? Golls te man ibn nicht vielmebt, uno natiulicher Woeife, votu am Zlopfe fuchen: Id) babe :nid) Dariber faton oben

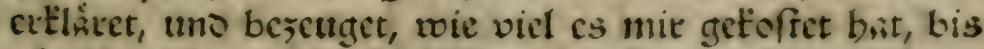
ich Dies Dorturtbeil itberftiegen babe: Das oer Mimo eines Ebiers, willescit born sin Kapfe firgen mille." 
336 Bon ben Slattlåuen ber Saffrweibe.

wenn nicfte die Erfafrung felbft unfre Sinne uibersengte.

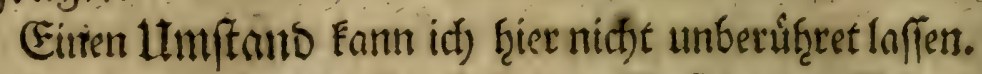

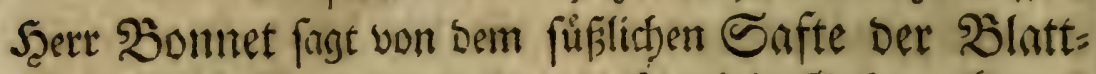
lâule, Daß mat Davon in Der Mledicin (Bebrauch ma=

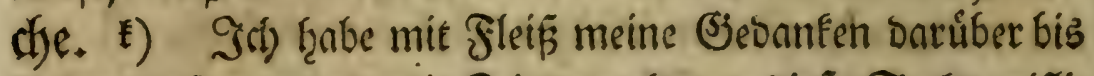

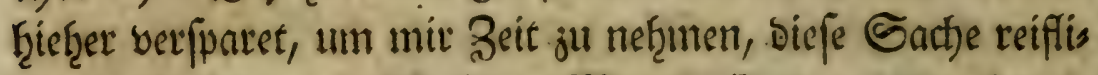

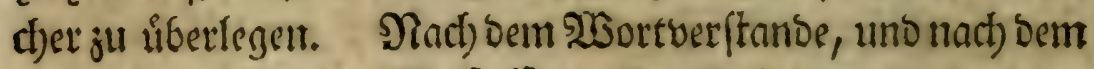

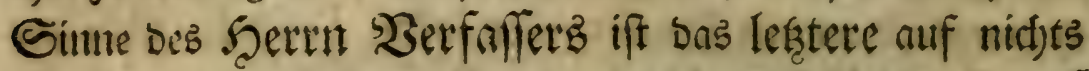
anders, als ouf bas vorţergef̧ento Feauptfubjeftum; auf

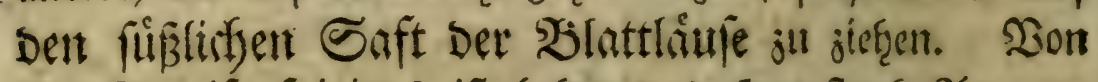

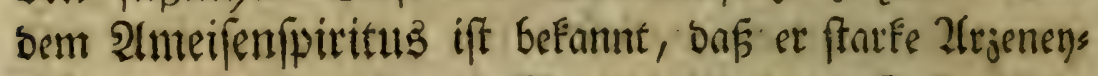
fráfte f̧abe; alleint was bie Mebicitit von jentem Safte allein

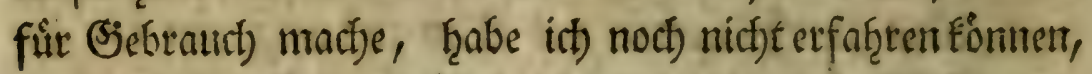

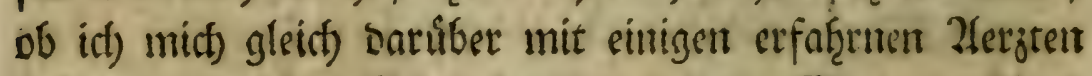

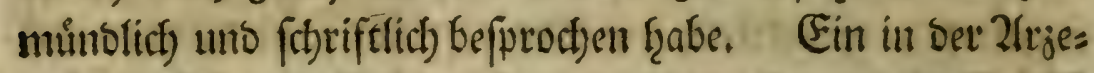

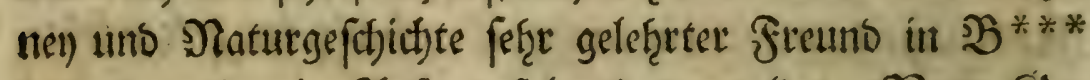

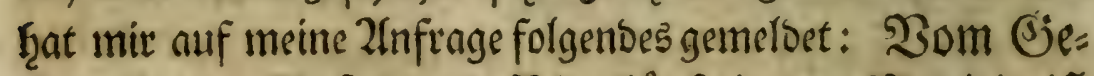

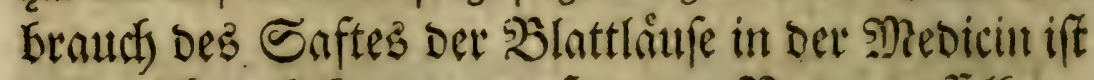
mir nichts befannt, wofern Der शrusen Defletbent, Durd) bie Imeifen, weldhe ifn vergefren, nidft mit=

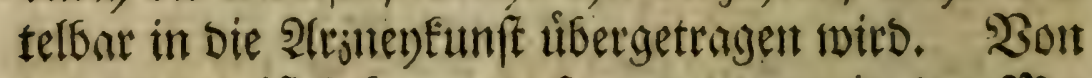
Den leftern iff Gefamit, Daß̉ man Davon in Der Mles

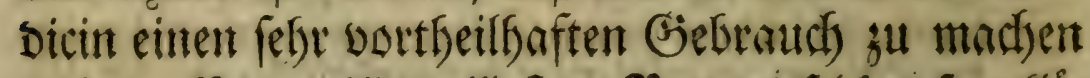

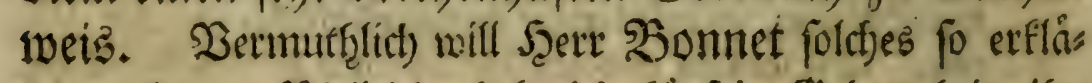

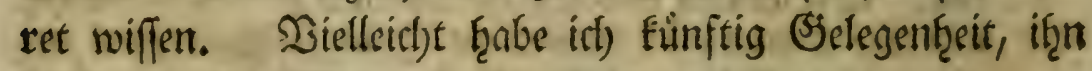
felfoft sum féme Mlennung fdjriftlich ju befragen.

b. Wir

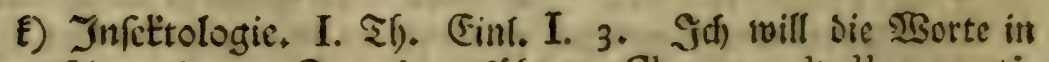
feimer eigenent Epruaffe anfuifien: Chacune d' elles petites cornes) eft un tuyau, par lequel fort une liquenr miellée, que les Fourmis recherchent, et dont la lisedecine fait uffuge. 


\section{Bon ben Şlattliatuen ber Saglneibe.}

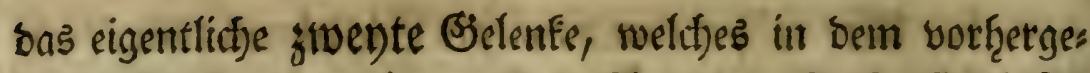

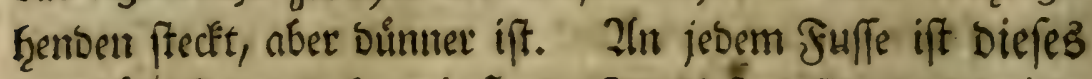
bas långfte uno haarigfte. In biefem fişt bas britte uno lekete, bas votn an ber Spife given jiemlich weit von

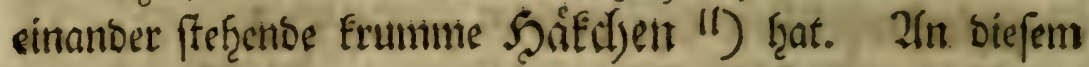
lef̧tern Sielenfe mußs eine ftarte Muffel fenn, weil das

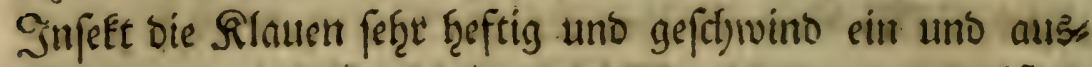
jief̧en fant. Es fdyeint gleichfan bamit ju greifent. 2tuch) biefes ift mit vielen Schârchen befeģt. Fs hृat aljo jeber Sus auffer ben betoen 2 iritbeln oren Gielenfe.

3. Son ben fiuffen foll unfer 2luge jum Ropfe ges ben. Daran fints Drev uiberans metFwurbige Theile zu beobadtert. Die Atugen, Die Fúblhormer, und Det Eamgetrifiel.

a. Die erfteren m) fins geperlt, von glänents

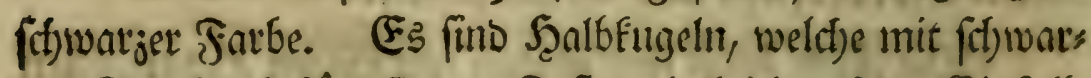
jen Rorallen befiet fint. Faft gerteth id) auf ben (Einfall, Diefe Rúgeld)en ju jợilen. Sich) f̧âtte es ficher burch mein Mifroffop geleiftet, went es mir nur moglid) getwe fen ware,

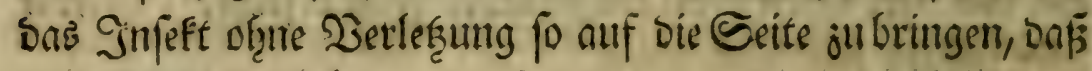
es frille gelegent bৃâtte.

b. Die Fuifliborner ") jeigen uns Feine geringere Gettentzeitent. Gie befteţen auch aus fünf Soclentent.

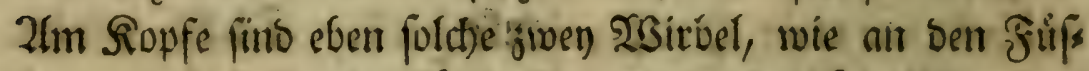
fen; bann folgt bas laingefte; Dann ein flirgeres, unt enolict) bas lerste und furzefte. fins wie bie Firfe an

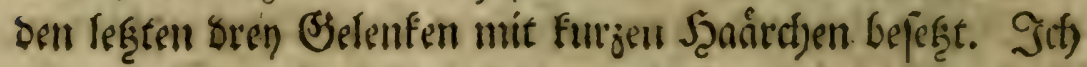
Ģabe

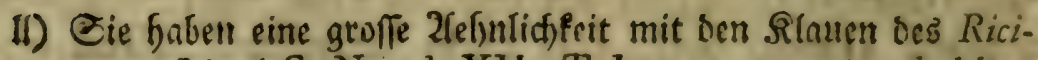
nus. Linné S. N. ed. XII. T. I. p. 1023. n. 7. habitat in bobus et canibus.

m) fig. $1, b, b . \quad$ n) $a, a$, 
2. Dae zwente geferet auf einen gang befonbern llms

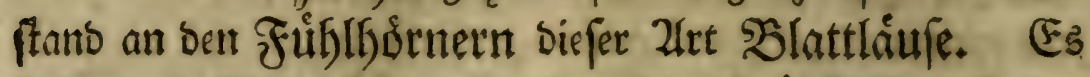
bzaben nemlid) biefétben an ben bèjoen äufferften Enven Sren iberaus zarte Spifen, bie wie ein Drengact p) in tridjterförmiger lage abjtef̧en. Man muß aber fdton eine ferter ftarfe Bergrofferung gebrauthen, wenn man fie

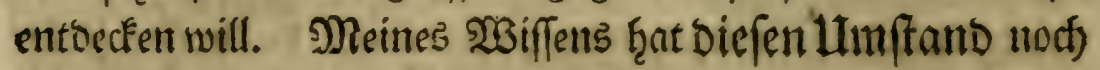
niemano bemerft. $\mathfrak{B e t r a d j e t}$ man fie recht genau; fo foteinen fie etwas gefrúmmet, wie fleine Slauent ju fenn.

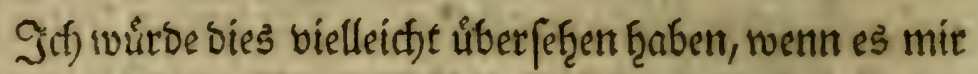
nid)t theil's barum fo nufgefallen wåre, weil man biş̧⿻上丨

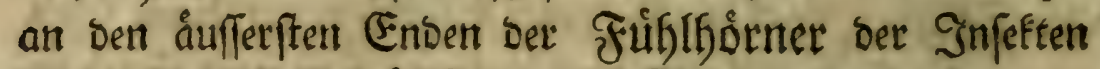

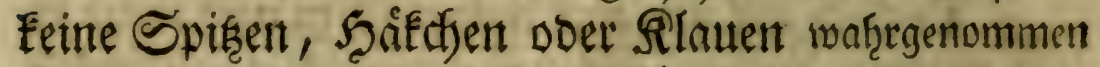

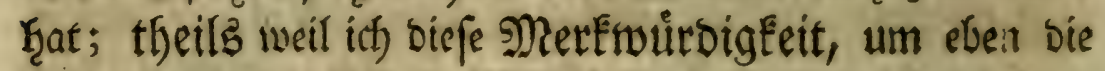
Beit an einem anbern, bel Eleineren Infefte, nod) weit

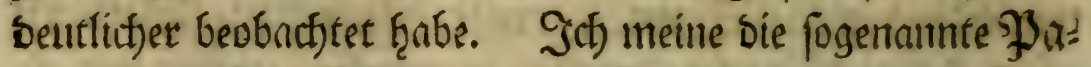
pier, ober Strublaus, a) weldye ber Ifberglaube bie ToDs temufre zu nenten pfiegt. (Einige worgenen auch it alten

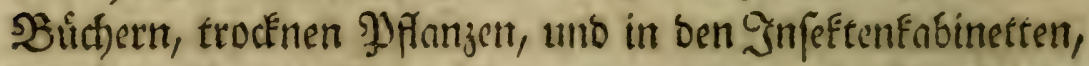

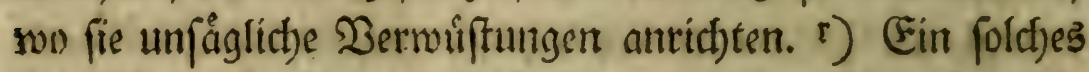

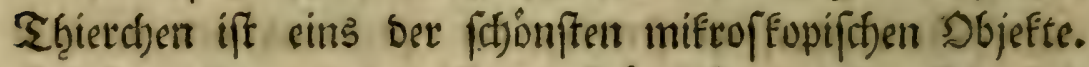

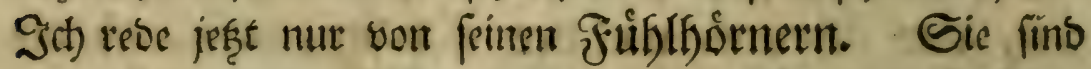

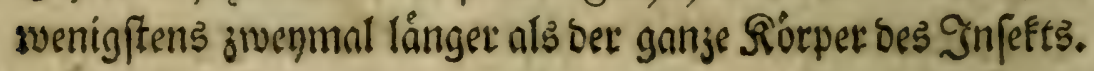
Jebes

4) fig. 2. a.

9) Linn. S. N. ed. XII. T. I. p. 1015. Termes, pulfato.

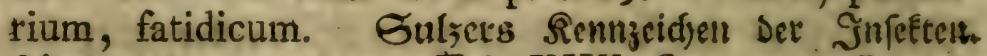
3ưrd) 176 r. 4. p. 179. Tab. XXII. fig. 144. Es giebt

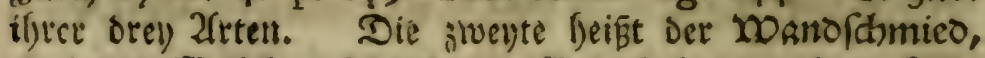

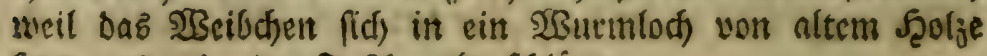

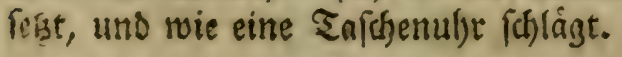

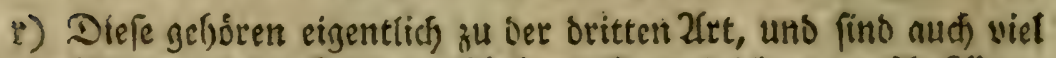

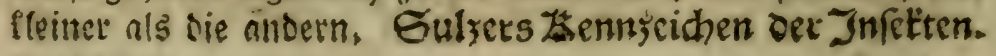
p. 880. 


\section{3on Den Şlattlâutlen ber Sabliveibe. 34I}

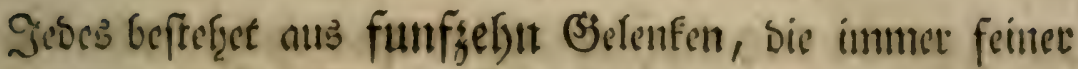
werben, je náfer fie Dem Ento fommerr.

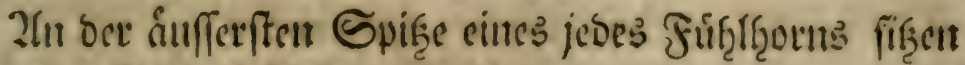

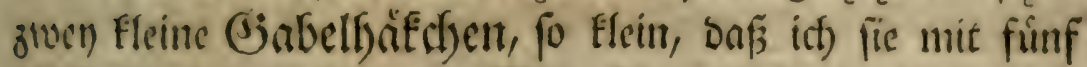
sinfent meines fegre guten Mifroffops niffot beimerfen fonts

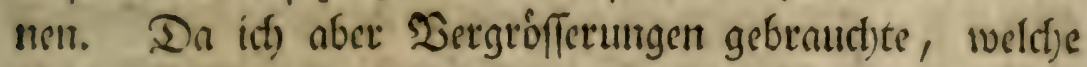

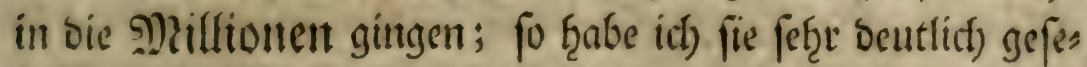

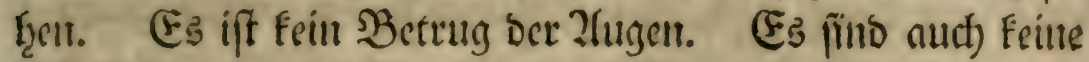

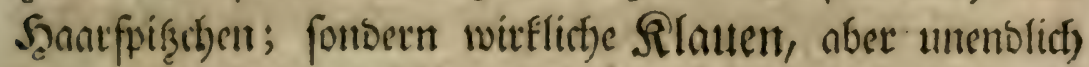
fleiner, als an ben Fúffen. Ilm meiner Sache vecht geviés ju fenn, hৃabe idl) wenigftents jwanjig fordjer Infeften beobad)tet, und fie an allen gefunben; ja auct) anbern jeigen

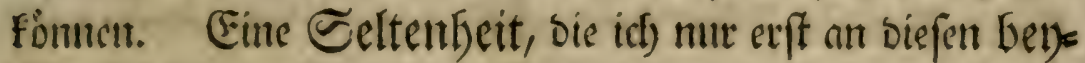
Den Imfeftenarten, Der Staublatis, uno Den SBlatts

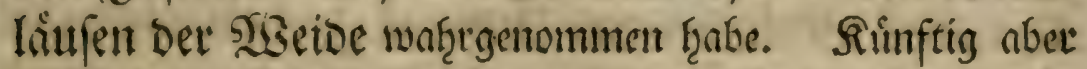
werbe idf) aufmerffanter auf siefen Ulmftant fenn. 2lllers

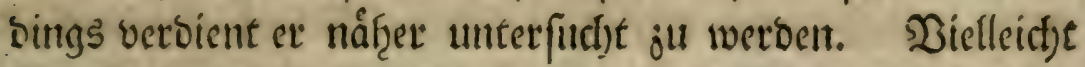

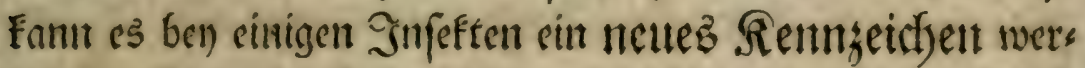

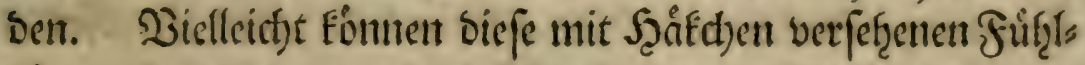
b̧ortuer ben sinigen noct) bie Stelle jwener Fúffe vertretent,

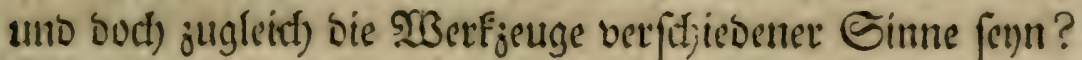

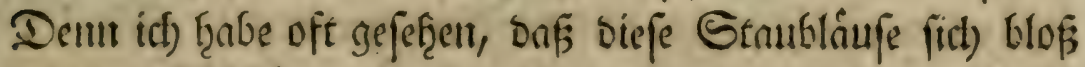

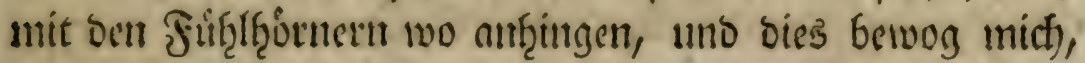

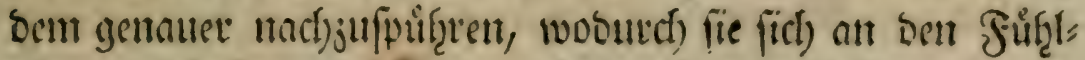

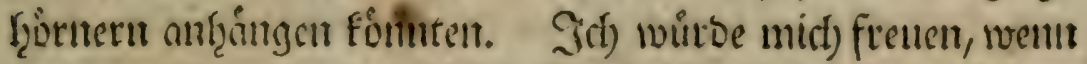

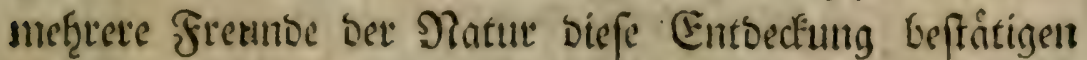

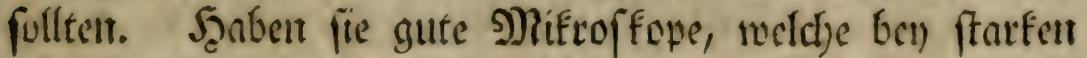

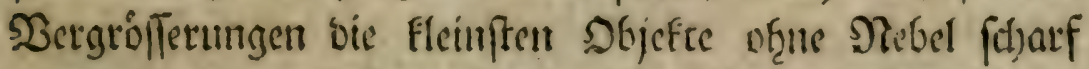

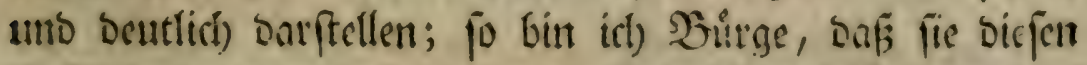

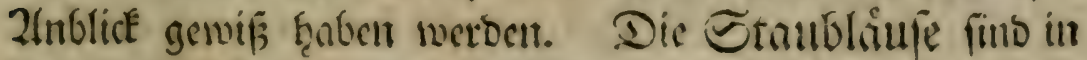

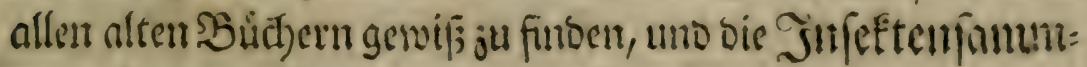




\section{Bon Den $\mathfrak{a l a t t l a ̊ u f e n t ~ D e r ~ S a f l w e i b e . ~}$}

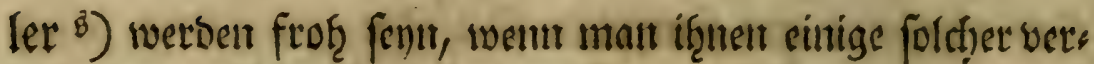

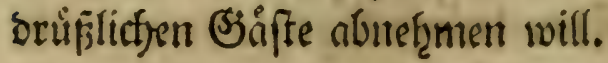

3. Meine Eejer werben nun wieber an bie Slattláule

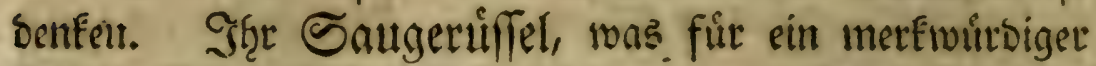

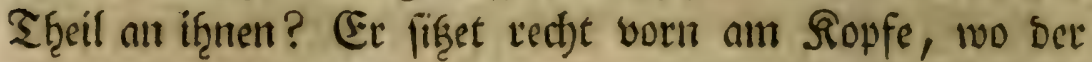
Mturo fenn follte, unto iff unten mit einem rumben, $23 i$ itfol

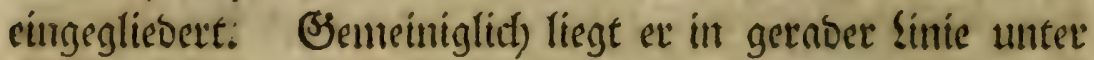

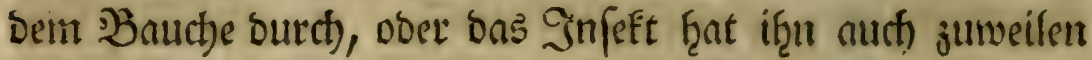
voin Rörper gerabe reeggeftresft. Man wirbe fich fertr. betruigen, wenn man das fû́r bas eigentlitite Saugewerte jentg f̧alten wollte, was man juerft erblicft. Es ift nichts als bie Scheide Deffelben, worin ber Sautgeftadyel als in einem Futterale, wie bey ben Sdynactenmuicten, liegt.

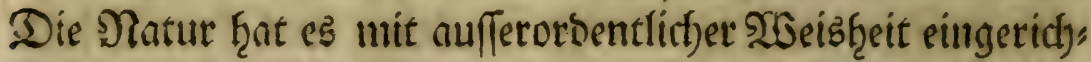

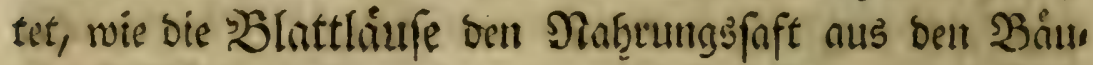

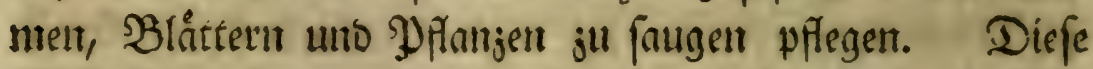

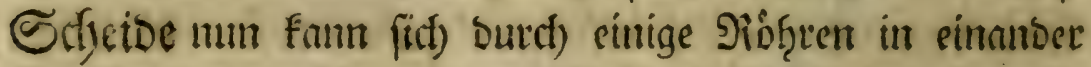

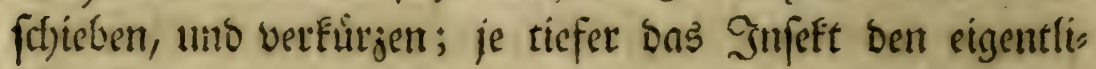
chen Saugeftachel in bie Rintoe eintes Srveiges eingefenfet

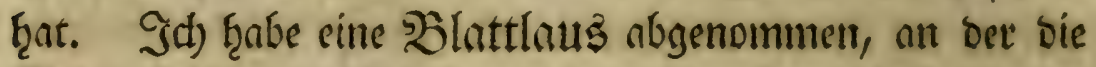
St)eibe bis jum Ropfe niebergejogen war; befto weiter aber ragte Der Stadjel aus berfelfen hervor.

Dies

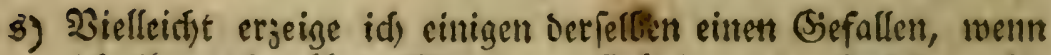

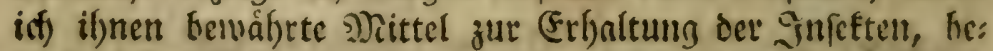

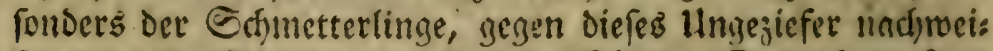

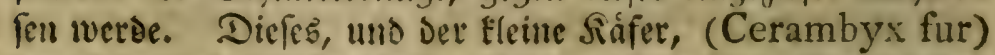

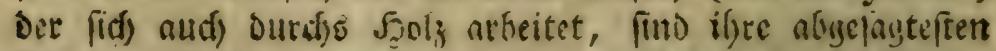

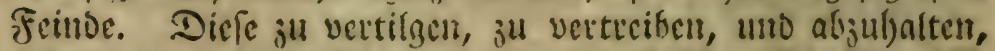

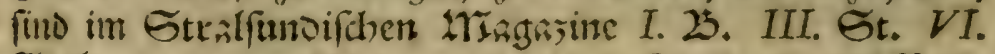

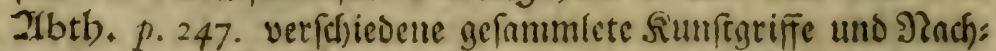

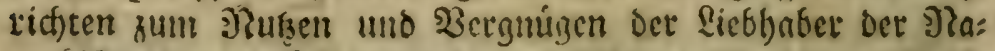

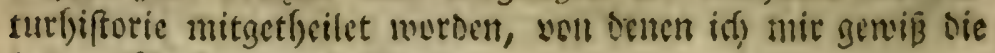
beften Sisinfullygen verfpredfe. 


\section{నon Den Şlattlälfen ber Enflueide.}

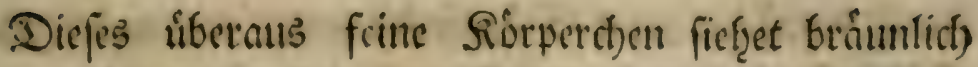

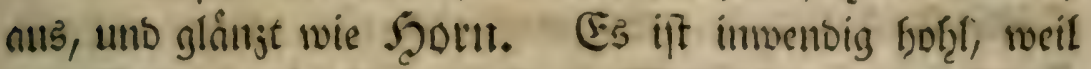

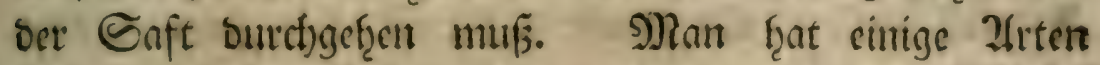
Scllmetterlingüfedern, baran fid) vorn finf Exizen von

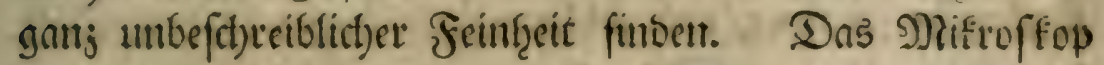

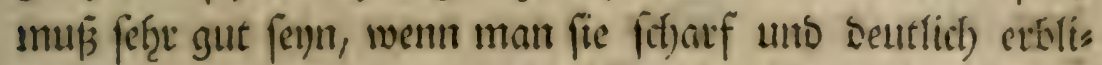
dfent will. Mit einter foldyen Epirge faum ich) mur bie

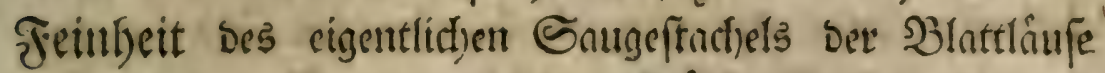

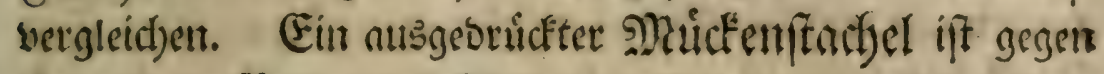
i็̨u wie ein bुnum anjuffęen.

Sit) werbe jef̧t Davon noch) einige befonbere Ents

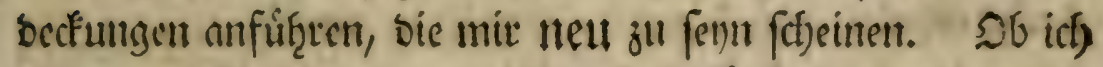
gleit) Den Etad)el Der meiffen Sblattláufe biefer 2(rt, als eine gerabe sinie gefeften frabe; fo finto mir boct) aud) cintige vorgefommen, Deren Stadjel j(wel) S(ngeln t) hatte, mels

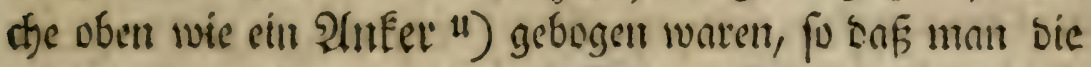

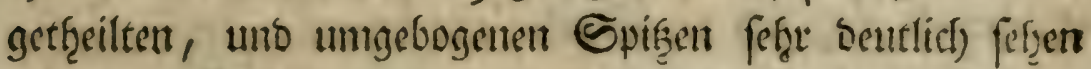

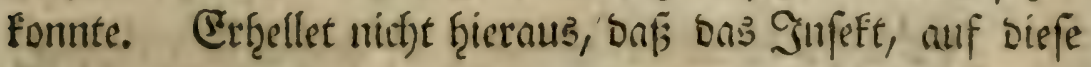
23eife, an mefre, als cinten Stre jugleid) fangen finme?

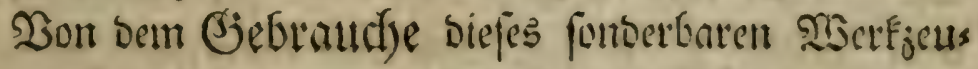

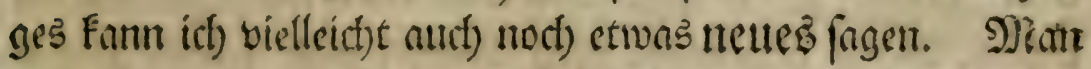

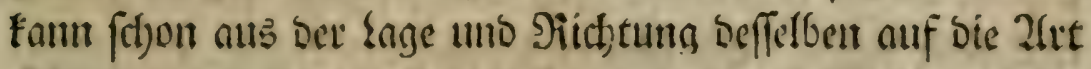

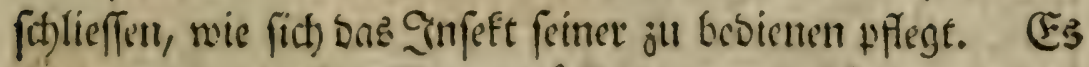

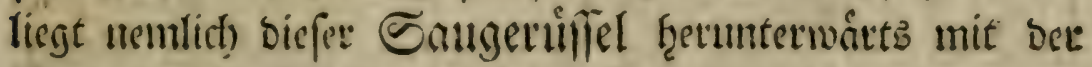

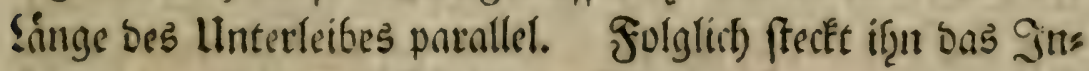
feft nicf)t gerabe yon fict) in oen Şmeig f̧imein. Es wuirbe

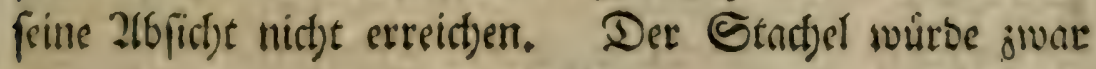
(2) 5

reichte

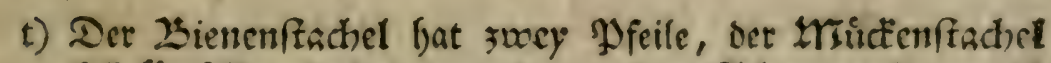
foll fins 2mineln baben, uno won Den Gdmetterlingen ift es befant genug, Daßj fie cinen soppelten Gangerinfel befiten.

ii) fig. 4, a, a. 


\section{20 on Dent Blattlliuffent der Safliweibe.}

(eid)t butch bie jarte Schaale bringen; auf bem Scolje abet sisiberftano finden. Es muf ifrn alfo anbers ricten.

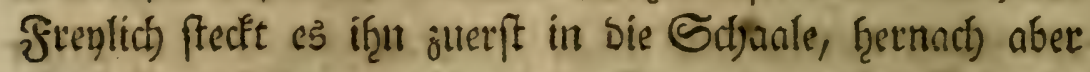
gleich in berfelben, zwifhen bem Stamme unb ber Sd)anle, fentrecht ferunter, und foldhergeftalt fauget es ben Saft bajmifchen weg. SRan fann es ganj Deutlich an ben Flecten fefren, wo bie sBlattlärfe gefeffen ţaben. Die

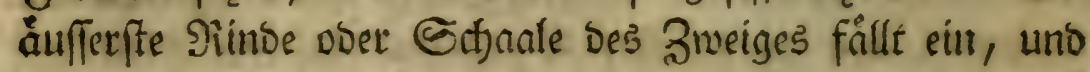
sviro weif, weil ber Saft Darutter weggefogen ift. Das Flectofyen felbft ift mur fo lang, fo weit Der Stachel gereis d)et ḩat. Daßs Der Stactjel mit Dem Siveige parallel frecte, crf̧ellet nuch) bataus, weil man bie Ḃlattlauts, bie man von eittem 3rweige afutergmen will, von unten in bie

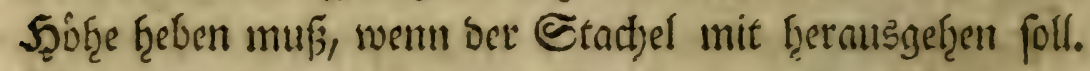

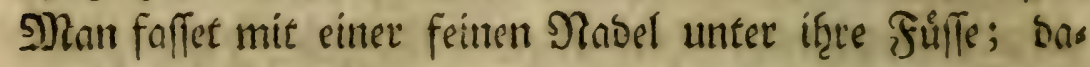
nit flammert fie fidf an; alsbenn făfret man fact)te in bie Scobere; fo jiffet fict) ber Gtachel mit heraus.

Ës wiro mantjen meiner Sefer fremo vorfommen, wie ith im Stante geme fen, alle biefe SBeobad)tungen an eis nem Sinfefte zu madjen, unt feine fleinften Şgeildben ju

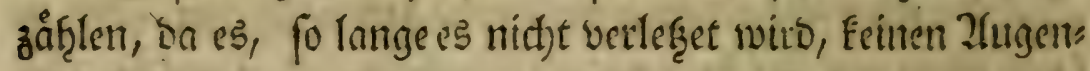
blide ftille liegt. Es ift mir fold)es in Infange frenlid), fower genugg geworbent, ja es war mir unmiglid), bie Shes

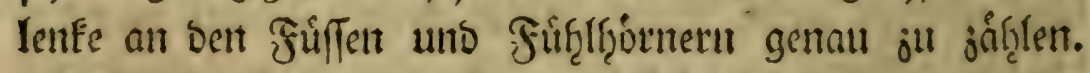
Jof mufte alfo auf sin anberes Shittel benfen, unt fold)es gaben mir bie Slattláufe feloft in bie Scainde. Jib fano

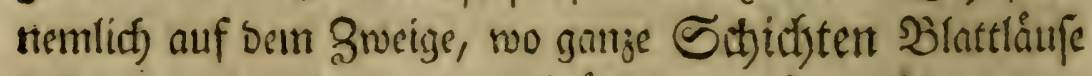

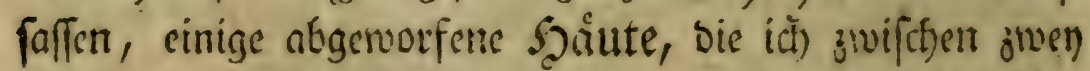

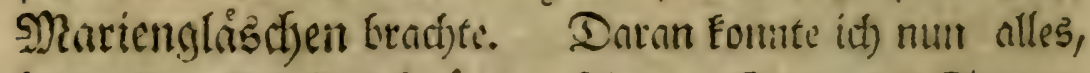
bis auf bie fleinften Szanitten ferzen. Sogar der Sauge= ruiffel mit ber Edjeide, unto Dem herborftef̧enden Gradjel, 
war Daran waḩrzunef̧men. Einte mir unbegreifficfe Sadje, daf das Gunfett einen feitrer wefentlid)en Theile, als ben ganzen Saugeruffel mit Seldeide uno Stad)el, fammet ber alten f̧aut abivirft, unt eineet netuen mieber bes

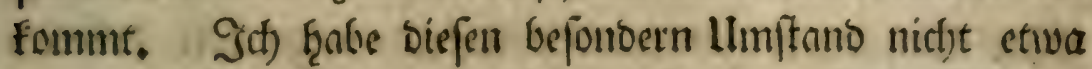

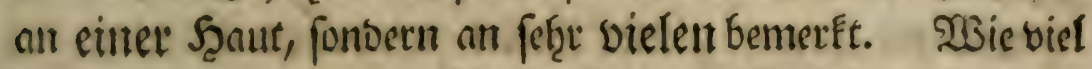

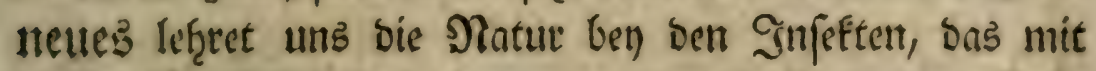

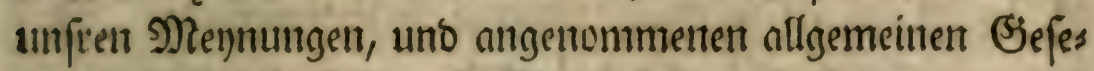

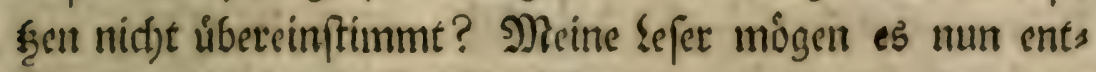

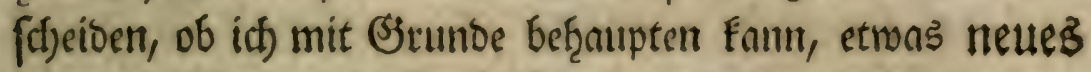
und befonberes an biefen Snfeften entbect't ju hraben.

Die Natur fel6fit erflaret uns aud) mandjes, was ans fonft verborgen, uno unbegreiflich bleibt. Ith ţabe

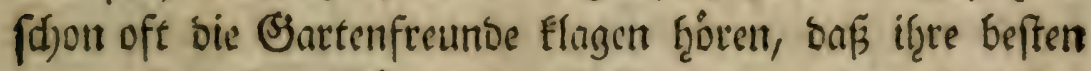

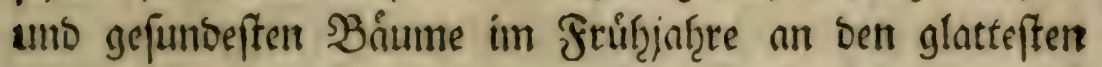
Etámmen, SBlafen uno viele meife Slecté befámen, wo bie Şaut ober Stjanle eingefallen wáre. Dies rúf่̧̧et bon

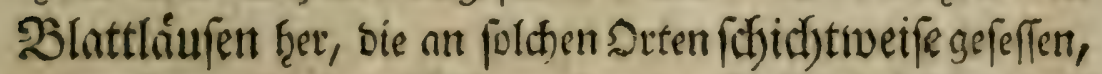

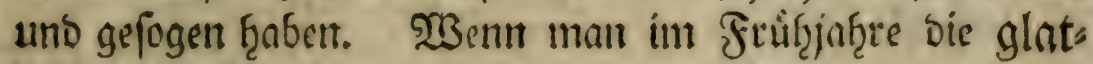
ten Dbft uno jungen Sranjbaume, oft mit wollenen ₹úchern aúceiben láfit; fo fann man biefem Hebel einigermanfen jus borfommen.

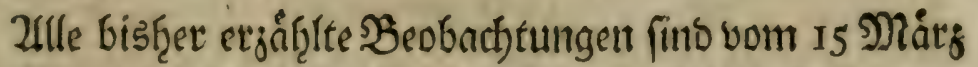

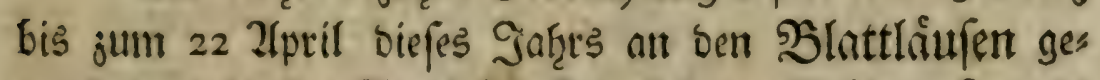
machet worben. 2frn biefem ₹age waren fie fityon fo weit

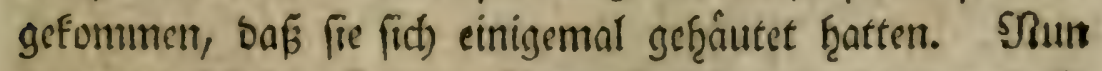
erwartete ich ben Beitpunft, ba fie fict) vermetreent, uno itg=

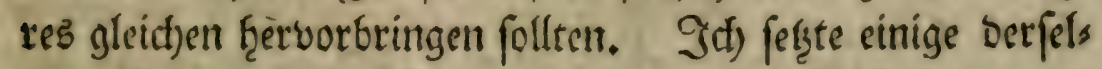

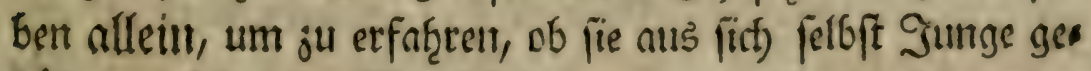

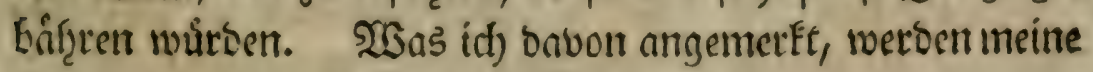
sefer in ber folgenden $\mathfrak{B}$ cobactstumg fintert. 
346 Won ben SBlattlaitfen ber Eaflunetoe.

\section{2beobactutung. \\ Heber eben Diefe Sulettent.}

Ob fie fid of the begattung vermegret Gaben?

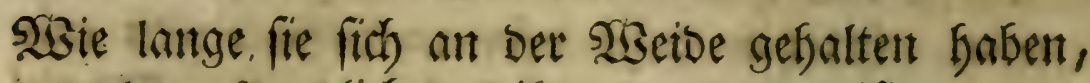
unb was endich) aus ifnen geworden ifit.

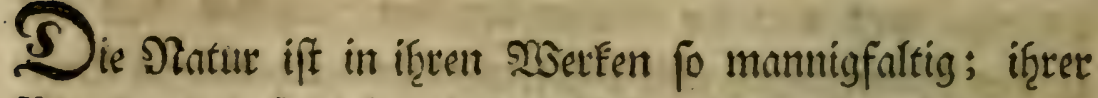
23iumber fint fo viel, anb bas fello, woriut fie arbeitet, fo

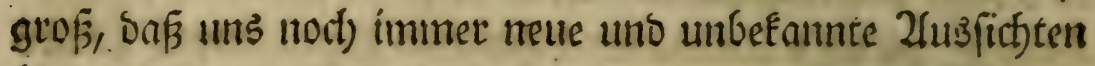

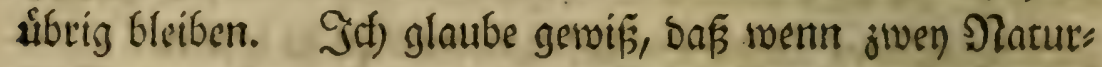

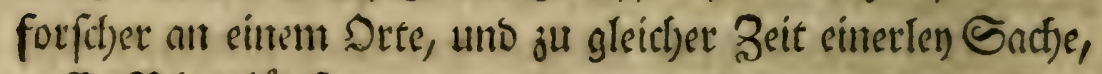

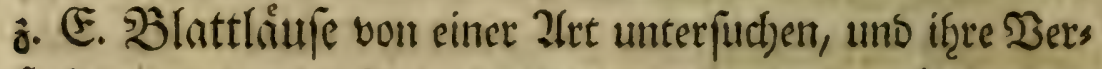

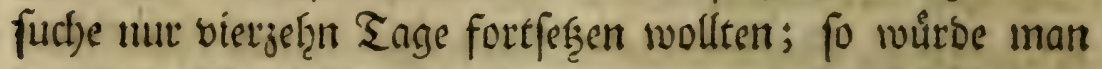

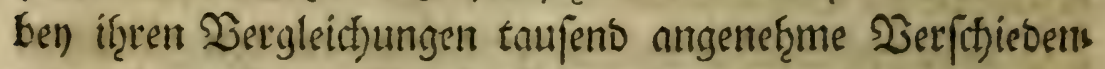

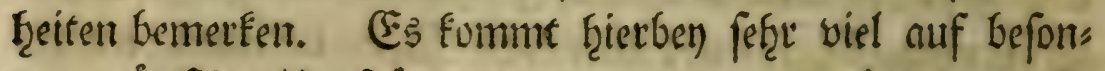
Dere guinftige Ummiftánto an, babon man unnóglide gevviffe פiegeln geben, ober fie jum boraus beftimmen fann. F)

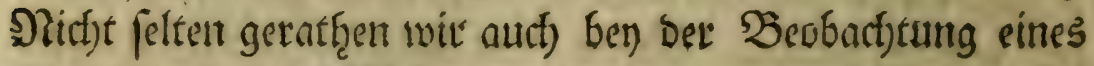
Dbjeftş auf einige शRebendinge, bie etwas gans anbers ber treffert, uno bie unb entweber ju neuen Entbectungen leiten,

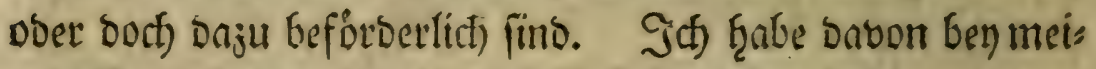

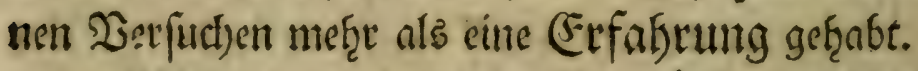

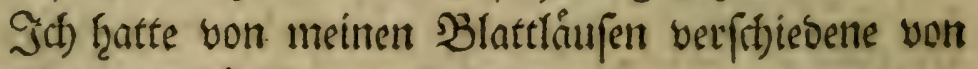

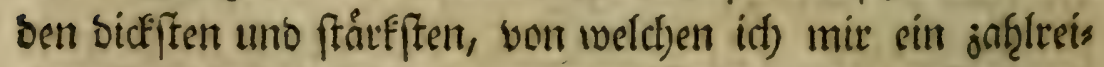

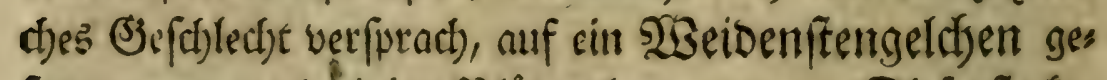

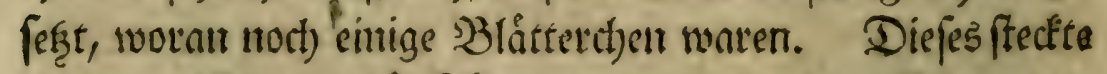
idt) in ein Blumentópfifien, ons mit feutster Erbe anges

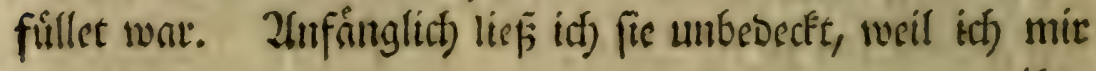
if̧re

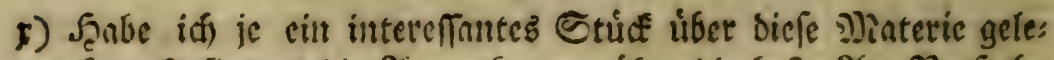
fen; fo funo es bie 3nmerfungen úber bie befte 2trt \$Berfudye

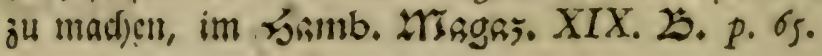




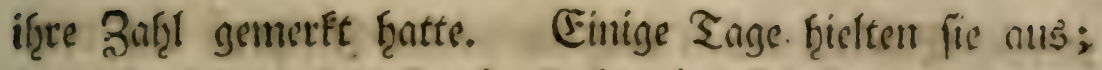
feernact) aber frodfen fie ab; fie begaben fict) fogar aus bem Bhlumentopfe tweg, unb lagen im Senffer tobt feerumr. Sith verfuct)te es noch einmal mit anbern, weil mein 2 Bseibens baum im Barten sinige f̧unbert abgeben fomnte; allein fie liefen mir abermal weg. Es fothient iq̨uren alfo ber ?tufents

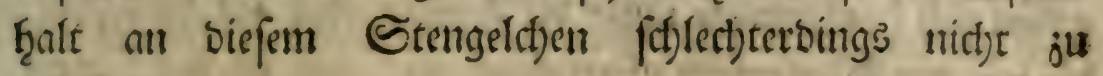
gefallen.

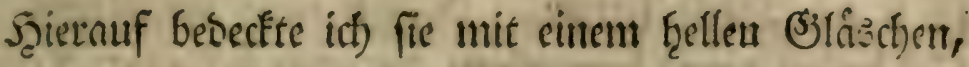

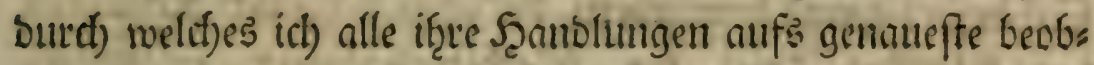
ad)ten fontute. Dies gefluatere am 23 Ifprit.

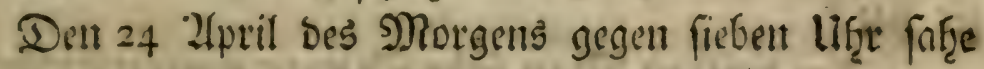
idf) wieber nact) meinen Einfieblern. Sie faffen noch gant

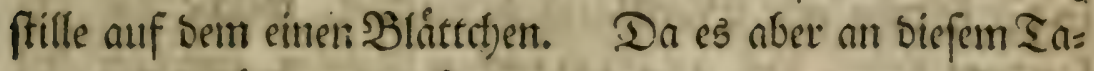
ge jiemlid) fúf̧̧le war; fo trug id) fie in bie worme Stube,

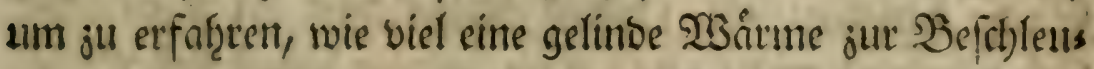

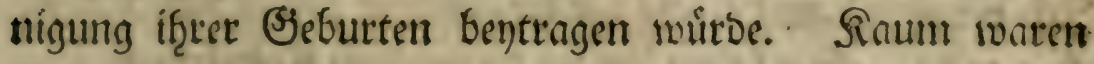
fie barin einige Etunbett gewefen; fo fing bie eine an, fiit)

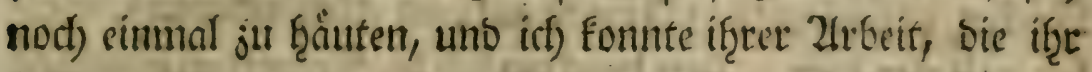
befd)werlid) genug ju fenn ichien, mit Wergnigen jufeţen.

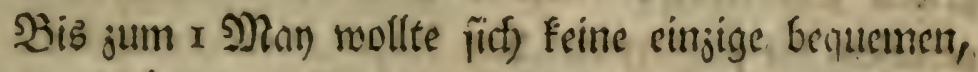

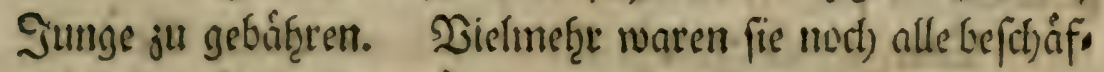
tiget, if̧re Şaut jut verainbern. Durt) Diefe miedertįolten.

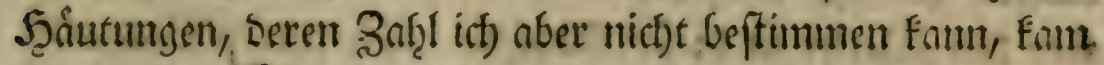

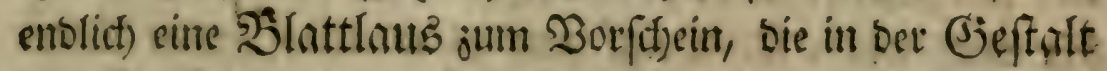
und Farbe son ben erften unterfitieben war. Sie mar

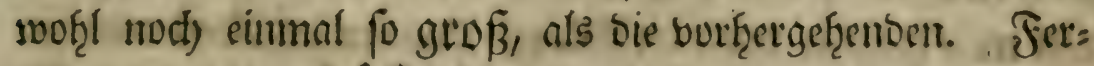
net waren igre Filiffe fo belle uno criffallartig gemorbent, Daf man fie auf Dem Tresiffen faum noch) fefren fonnte.

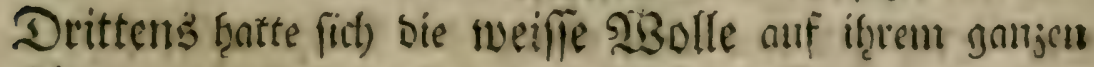
Rorper vertoren, und fie ḩatte cine Stalffarbe angenans 


\section{Bon Den ßłattlåufen Der Safliveide.}

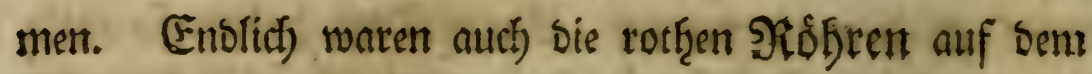
PRickent bennaţe eine sinie lang getworbert.

Es fiel um biefe Seit einigemal Piegenmetter ein, unb id) war neugierig ju fergen, wie fict) bie SBlattläufe an ber

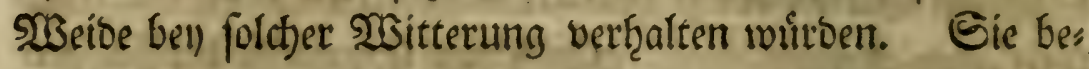
gaben fiit) ḩaufentweife unter bie Ziveige, ober auf bie Seite,

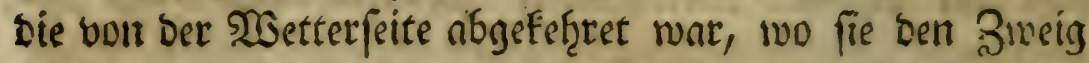

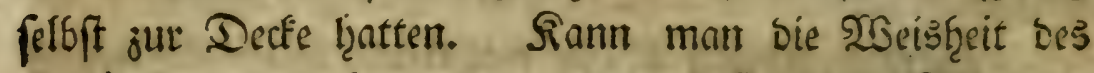
Edjopfers genug bemumbern, ber auch fo fleinen Fireaturen Den ftánffifen Trieb ber Selbifterbaltung eingepflant: jet frat?

Itm Dritten Man) f̧abe idf) unter meinen (Einfieblern in ber Stube eine Slattlaub beobactjet, weldte bas be:

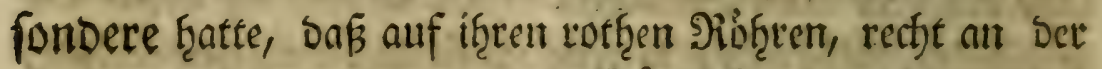
Epize Derfelben eit rothes Sriggeldyen ju feren war.

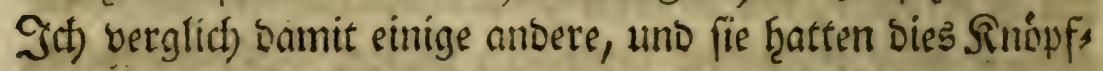

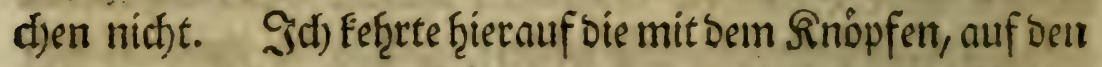

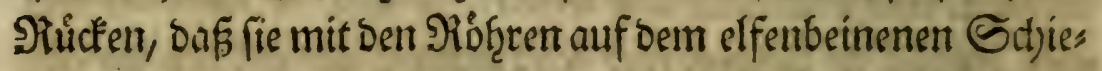

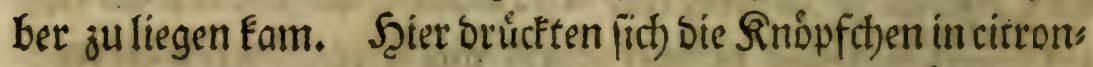

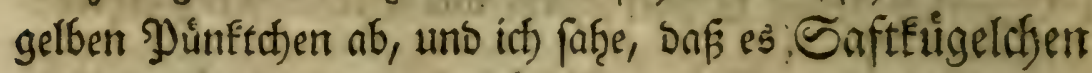

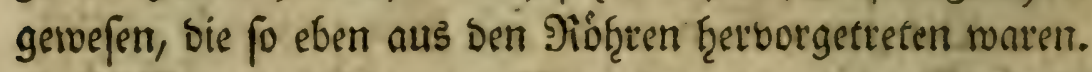
Som 3 biß jum 9 Nian ḩatte ich meine Beobadlys

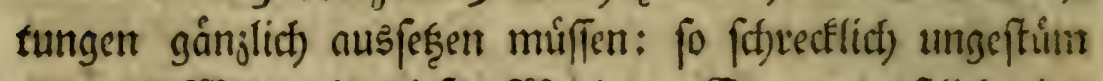

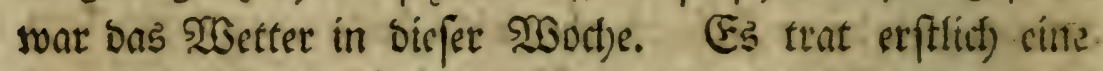

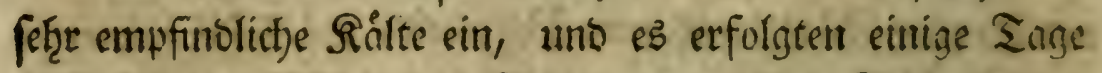
nath einanber foldt)e mit Sct)nee vermif(d)te S(d)lagregett, Daf man glaubte nicht im $\mathfrak{M}$ lane, fondern im December ju fenn. Unter biefen IImfränben gab idf) aile Scoffnung suf, aucf) nur sine einjige Blattlaus im Sorten wieber ju fint

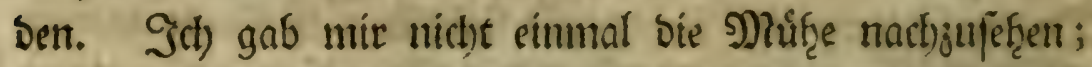
fonbern id) glaubte gewifis: ę mưrbe bie ganje familie 


\section{Bon ben 3̉Lattläuen der Sabineito.}

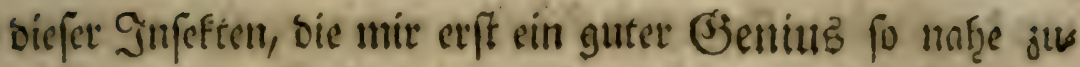

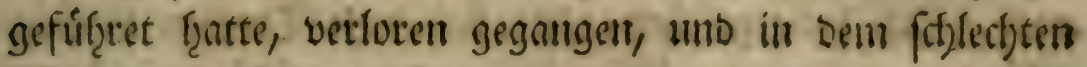
פ25etter umigefommen fernt.

Defro angenef̧mer war es fúr miff), n/s iich) Dent 9 Mar) Dns erffemal wieber meinen Sarten betrat, unb

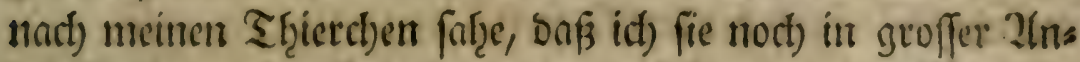
janfl antraf. Sie fratten firt) in Der Zacit alle, von Den Fleis nern Zweigen auf bie ftárfeen begeben, uno faffen fo Dichte

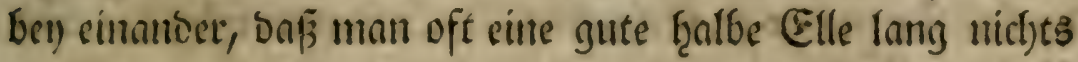
vom 3lveige forfen Eonte. Sie waren aud) in bet Beit gróffer und sicfer gerworbert. Zllles nber, was fie thaten, war biefes, baß̧ fiid) einige oft an if̧rem eingefententen Gaus

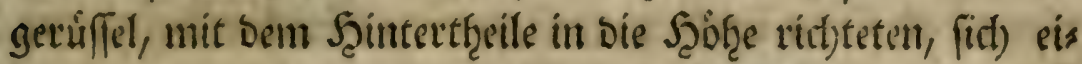

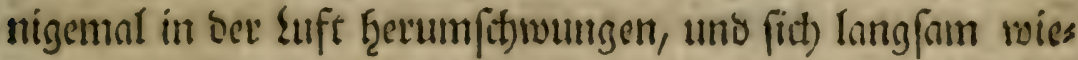

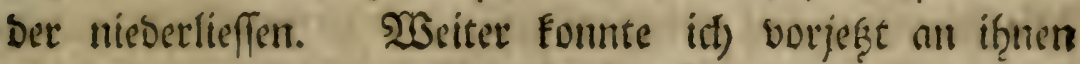

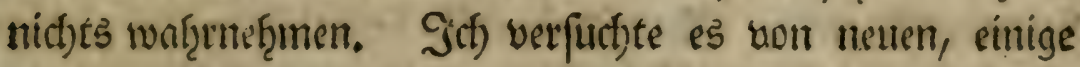
Davon auf ein Stengeld)en allein zu feģen, wveil bie vorigen Den Esengel verlaffen, und unten auf Dem Booben verf̧uns gert waren. - Zendf) biefe aber wollten nidyt bleiben; iff mogte fie bebecteen, ober fren) ftef̧en laffen. Sie frodfeur babon weg, unto fomen um.

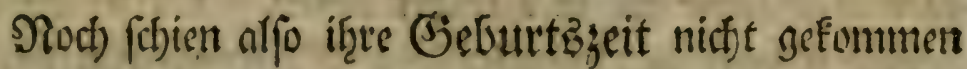

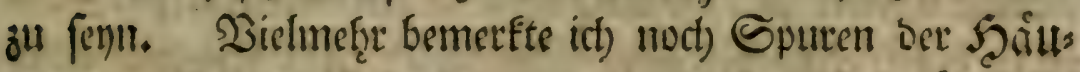
tung. Ilnbegreiffict) aber war mirs boch, Daf́ fo gairtlictle

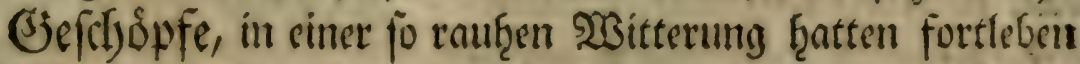

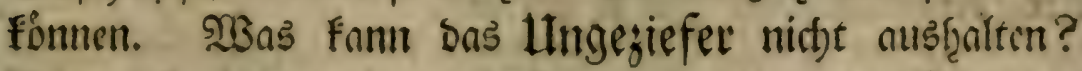
Jich merfe ficer nod) an, baf ich) glaube: man fónture bie Daturgefthid)te cines Infefts allegeit ridjtiger uno gewiffer beobad)ten, wenn es in feimer Freiffeit lebt, als wenn ç bes

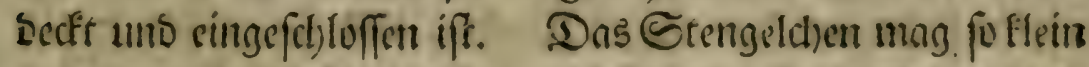

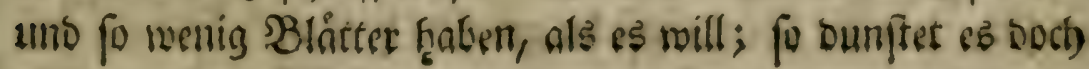




\section{Bon Den B̧lattláuent ber Safliweide.}

Imit ber feuthten Erobe ober. SWBaffer, worit es ftef̧et, etwats

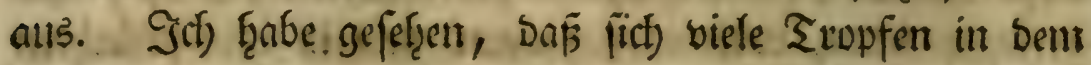

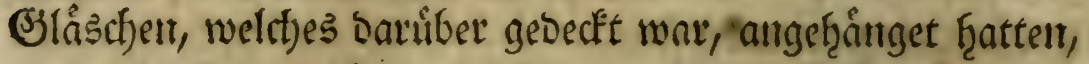
anb alle Seitentwainde bejalangen waren. Sollten nichte Diefe Dimfte, uns bie eingefdyloffene Suft bem Jnfefte in manthen Stücten Ģinberlich) (enn?

Mit Dem Is Mane trat eine aufferorbentlicbe Mak"

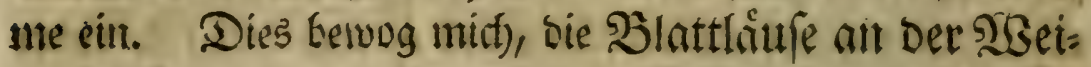
De felbft genauter ju beobachten. (Es fanben fid) baben vers fichiebene limftänbe, bie noch verbienten angemerfft ju merben. Die şlattláufe an fich waren bider und groffer geworbent.

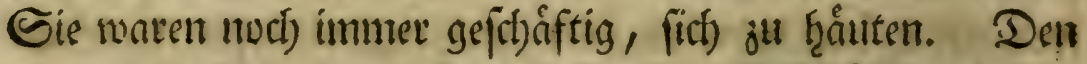
I6 traf ich fie in einer ganj befonbern (Siefdufaftigfeit ant. Der ganje Sibeidenbaum fotien faft ein seben ju fetut. Zlle Sweige wnien gleich) fant befäet: fo hatten fie fich) allents balben jerftreuet. פlur ferter wenige faffen mit eingefent tem Gaugeftact)el ftitle. Die ubrigen liefen unauffeorlich), bullo an bem Stanme, balo an ben Sweigen auf uno nicser: Ramen fie ants Enbe; fo Féfrten fie wieber um, uno ons

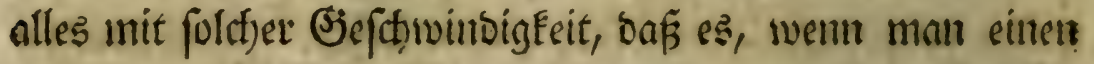

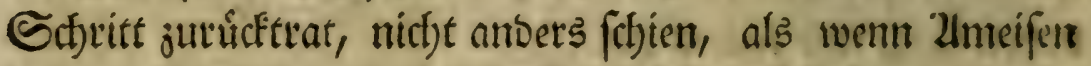
an bem BBaume auf unb nieber liefen. \$o fie etwa bob

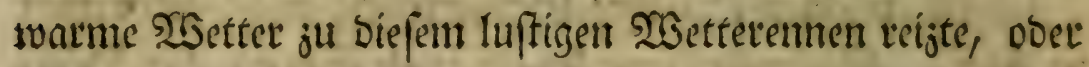

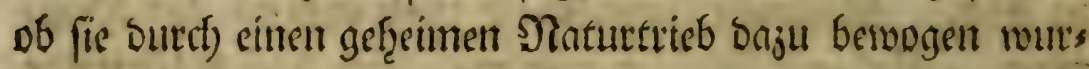

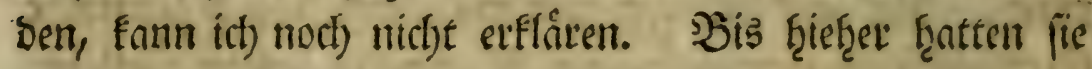
nod) feitue lebentigige Junge geboren.

Den biefer Gelegentreit F̧atte id sine befondere (Ev:

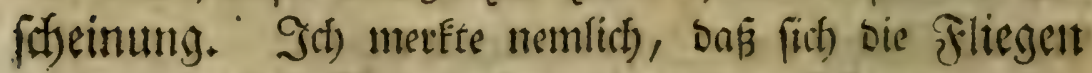

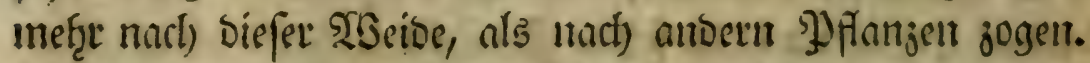
Einige faffen auf ben miffen flecten, unb fogen ben Enft

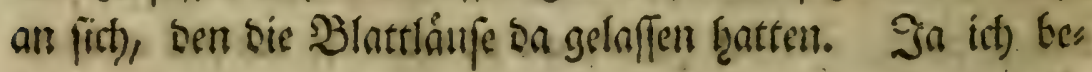




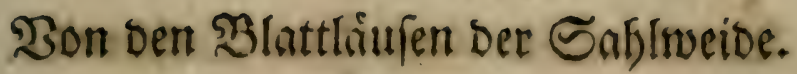

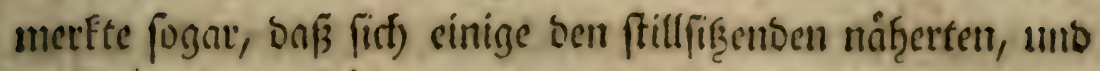

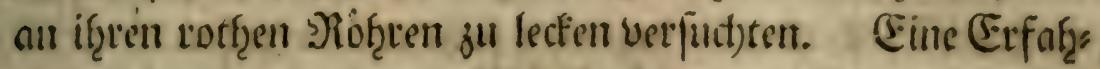
rung, baß ber Snft, ben biefe Jinfeftent bon fich) geben, wes gen feriner Sükigfeit, eine Eocffpeife für mefrere Tlbiers d)ent, als für bie ? I Ineifen fen.

Den fiebzeffnten gegen 2(bento befuct)te idf) meine

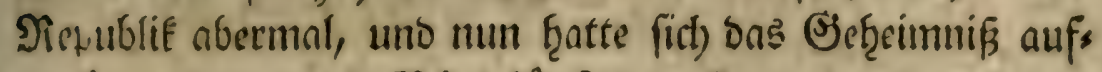
geflâtet, warum bie Slattlínfe ben ₹ng juvor, auf ben Ḋnume fo gevoaltig auf uno nicbergelaufen waren. ' Wers

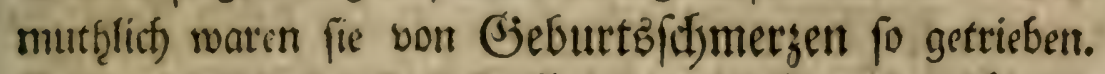
Detun num faḩe id) fie fofft alle lebentige Junge gebåh̨uen.

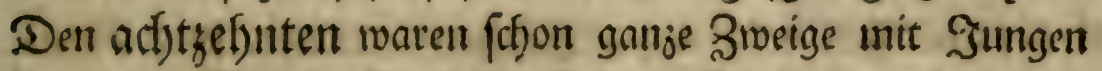
bebectst. Einige naf̧m id') auf einem Brosiglein mit in bie

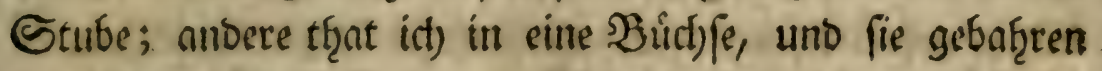
an benoen Orten Gunge. Sie Eamen, mie gemón̨ntia

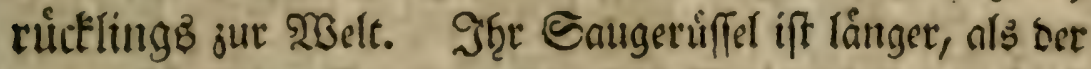
ganje Sírper. Er wirb aber nact) Droportion von ferbft fúrzer, jemeerze jener ausibádj)et.

Da id) mun Giererin meine Neubegierbe geftillet, uns

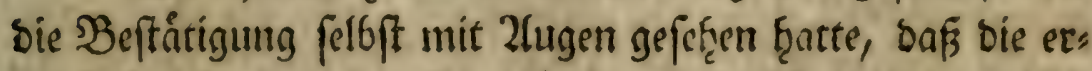

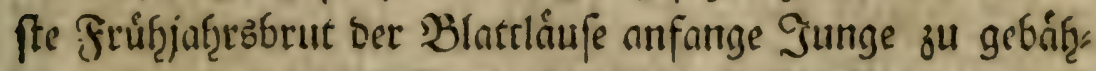

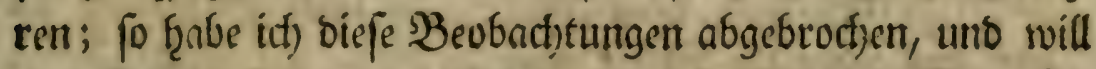

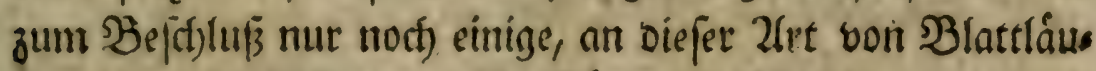

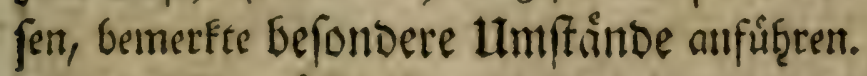

I. Ie groffer fie werben; je mefge verlaffin fie bie Blitter, bie Zweige; verfanmlen firf) am Stamme unb fónnen alsoetn füglid)er Stammláufe f̧eiffen.

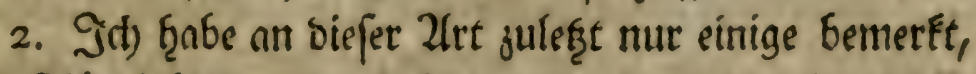

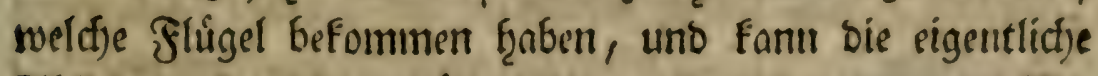

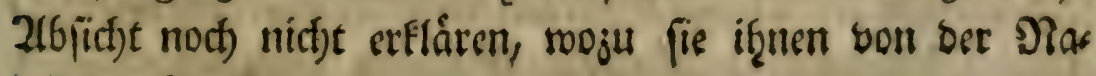
tur gegeben fint. 
352 3on Den 3 lattlaujen Der Sablweibe.

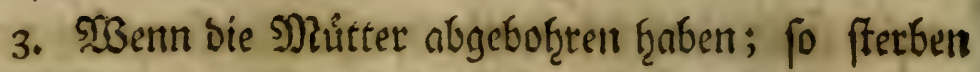

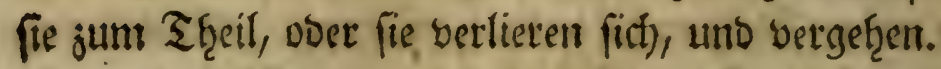

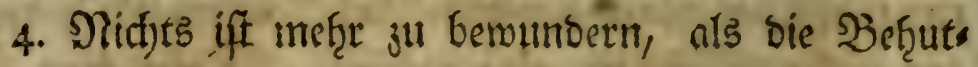

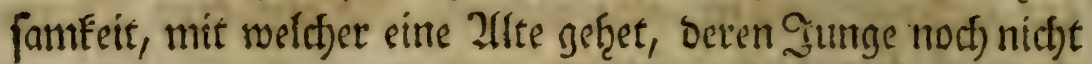

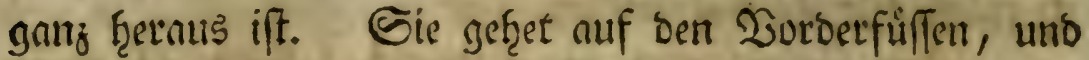

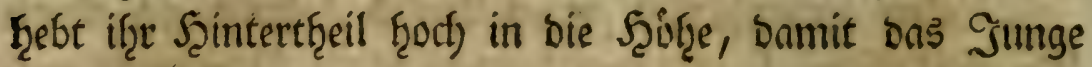
nicht befchábiget werbe.

5. Den 23 Man ḩaten fich alle silattláfe biefer

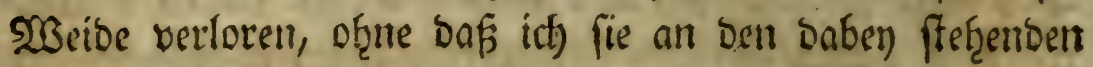

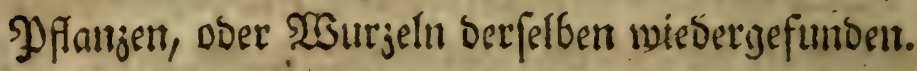

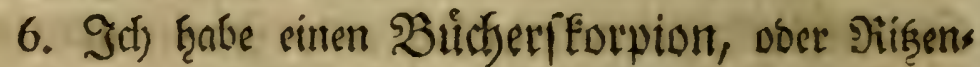

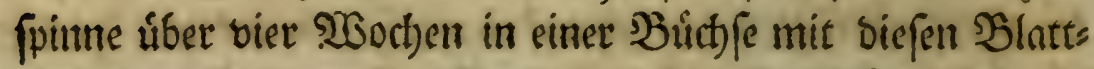
laufen gefuttert, befien Epeife fonft bic Staublinufe fint.

7. Der Şerr von Gieer zu Etockffrolm f̧at biefe

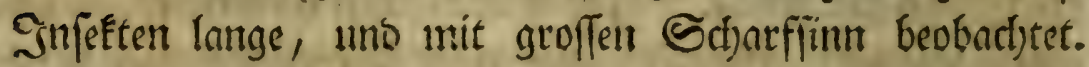

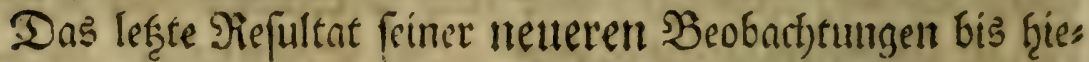
F̧er, ift biefes geblieben: , EEs iff nidfet jebe Blattlaus inmer „wecbjelameife bald ein Diviparum, bald ein Doiparum.

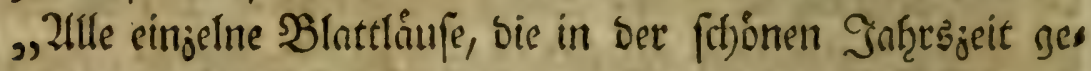

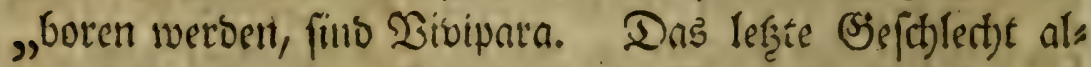

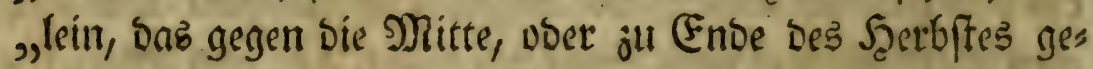
„,boren mirb, legt Ener. Es militbe aber biefes Beffthlectit

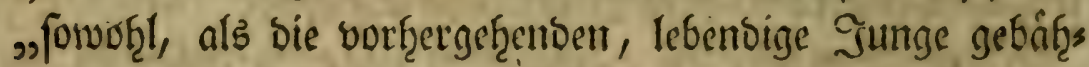

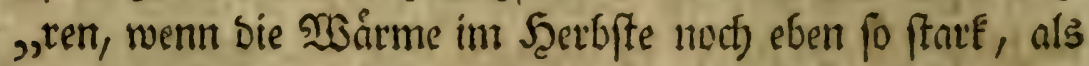

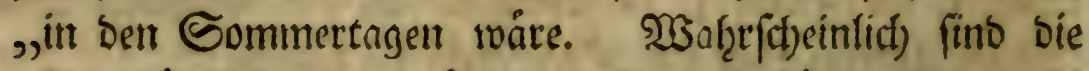
„Blattlaufe in einem wärmeren Elima beftånoig Divipara.

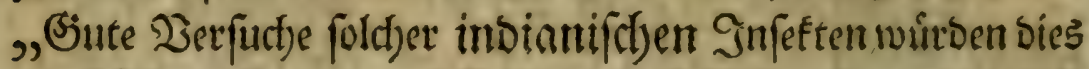

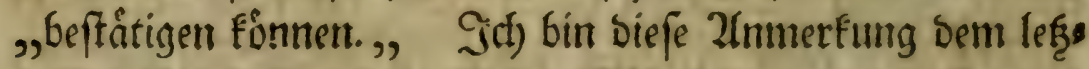
teren Edjreiben Des Şerrn Bonnet voln 30 Sumius fofulbig. 


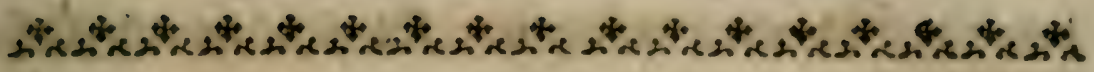

\section{Bufrảze}

einiger neuen Entbeckungen

an ben

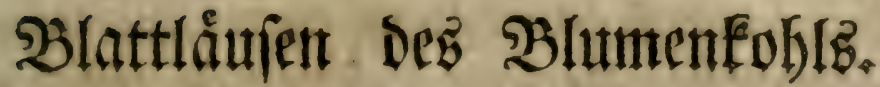

S)er 14 Julius war ber angenefrme ₹ng, ber mich) mit einigen gltudflict)en Entoectungen an einer 2(rt

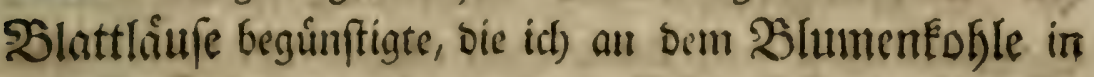
meincin Bsarten gewaflet wurbe. Sid) will fie einjoln f̧erjes Ȩent, wie ift) fie gemact)t f̧abe.

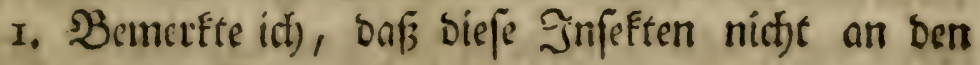

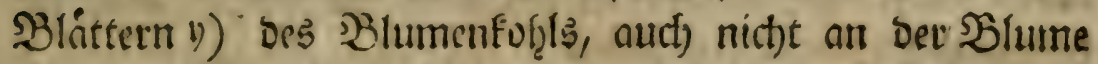
felloft, fortbern jwiffsen ben zarten Eproffen berfelben an if̧ren Stengeln faffen, und if̨ren Eaugeftact)el in bie,

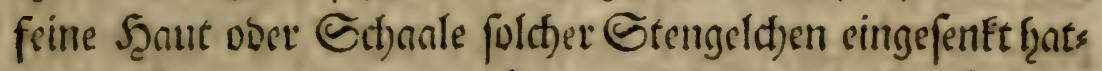

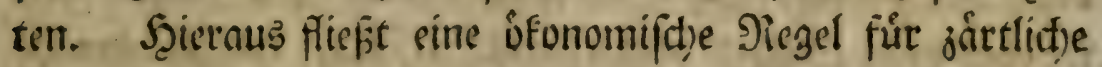

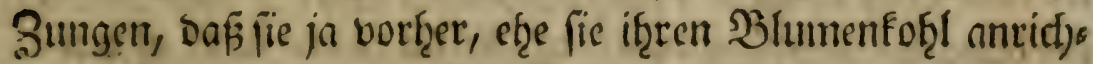

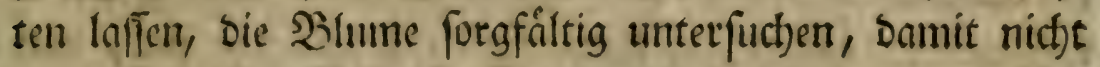
ganje Familien foldter Sinfesten mitgefuct)t werben. - SBes $_{e}$ tranffet man bie Şlume von oben, fo fiefret man nicfits. S3lâttert man fie aber aus einanber; fo mirb man biefe vers

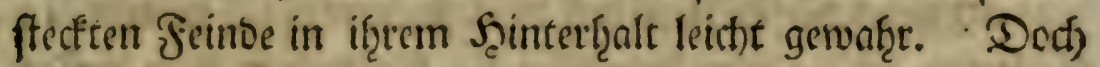
gef̧ioren nirff)t ganj ungeưbte Zlugen Daju, fie vont ber Fars be bes Blumenfofils genau ju unterf(t)eiben. Die liefact)

$$
82
$$

bavoit

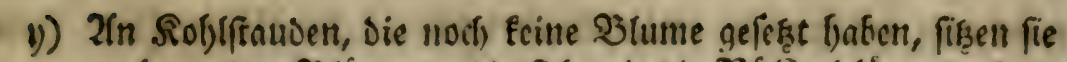

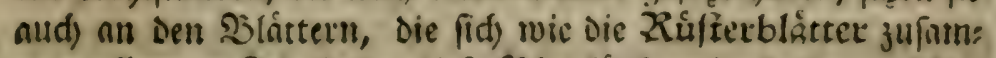

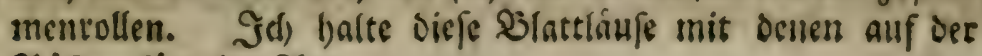
Dilifter fúr eine 2trt. 
354 3ulätze einiger neuen Entbeckungen

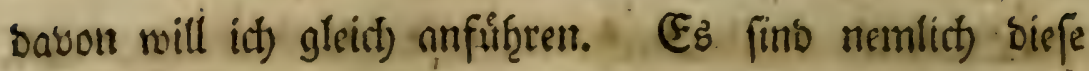
Şlattláule

2. mit einer meiffen und úberaus feinen $\mathfrak{S B O l l e ~ g a n j ~}_{\mathfrak{3}}$ überjogen. Man fann fie mit einem feinen Sinftrument Sagentweife abjiefenen. Sie ftrof̧t nicht fo von if̧nen ab,

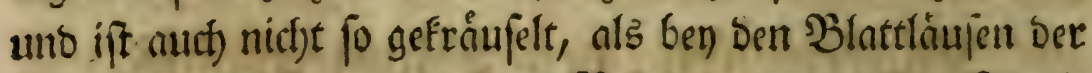
Shutbe uno EFpe, bie Seetr Sonnet im erften Theile unfrer Infeftologir S. 5. befdurieben ţat; fortbern fie bes becft den Rörper wie eine Scaut, uno iman follte es ef̧er füt Schimmel, als für sioolle anféten.

3. Ulebrigens find Diefe SBInttlåufe in wefentlict)en Etúcken von anbern 2(rten nid)t unterf(t)ieben; nur finto

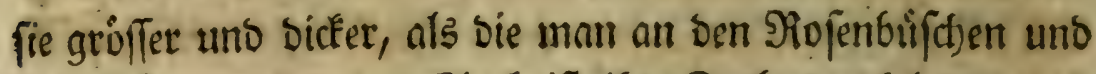
Zlpfelbåumen finbet. Zluch ift ifere Farbe bunfelgrau, uno

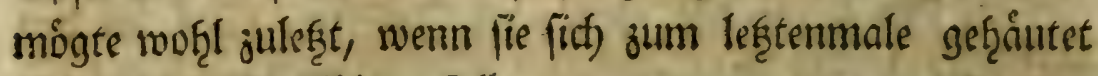
ḩaben, ins Staf̧iblaue fallen.

4. Die merfruirbigfte Entbectumg, bie id) an biefer (Bottung gemad)t, betrift einen 4 lmftand, weld)er bie 刃lens mung ber Naturforft)er beffítiget, Daß Eein Infett fen weldyes nicht mieder gon einem InfeEte, uno fo bennatze inz Unenolicfse, geplaget werbe. Sollte man woof̧l glauben, baf biefe fo fleinen Infeften, als bie Blattlinufe finto, von geniffen Eăufen gepeiniget werben? IIno bennuch Eann id) Dabon ein unleugbares Erempel anfiutzren.

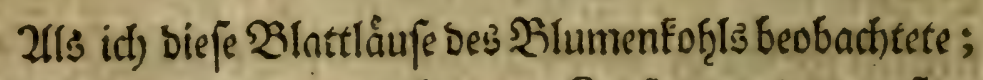
fo erblictete iff) an Der einen oben am Ropfe bor Dem erffen

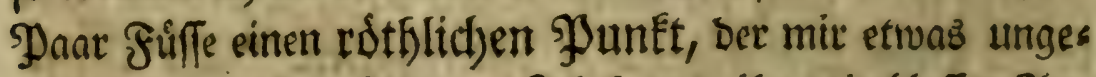

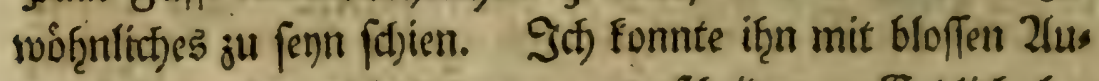
gen fergen, aber nict)ts baran unterf(t)eiben. Enolich bes

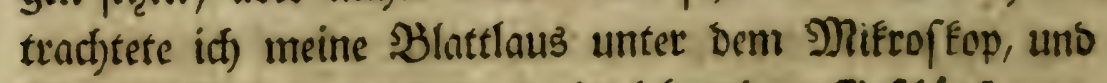

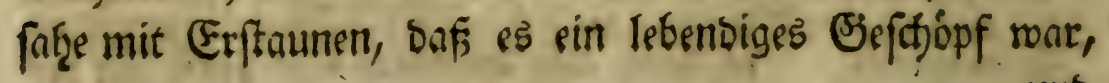




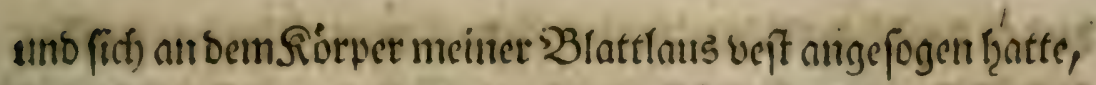

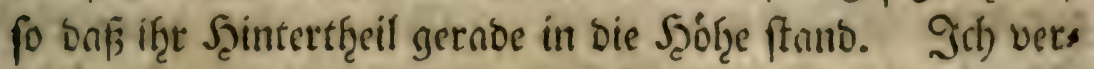
fudjte mit einer feinem ?abet, biefen fleitren Feino abjufons bern. Es glưfte mir, umb id) faţe mun bas rotţe গুuninfes

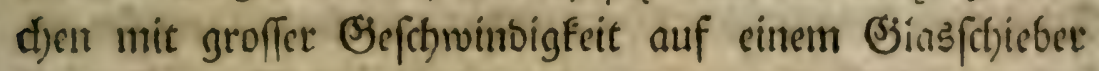

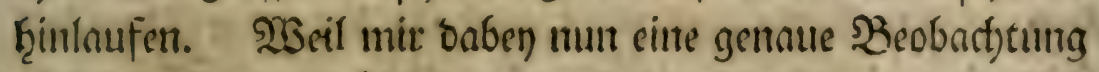

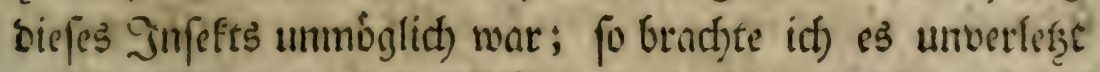

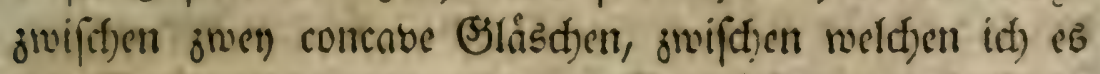

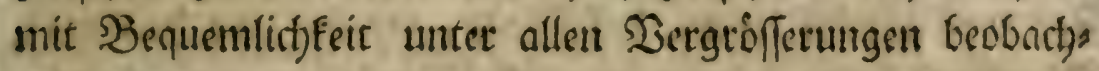
tent forinte.

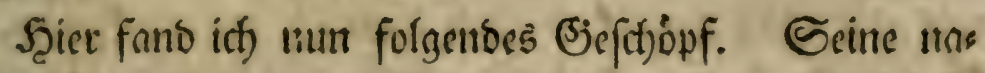
tuirlide) !ánge ift faum ein ?(d)tel sinie. Seine Farbe ift

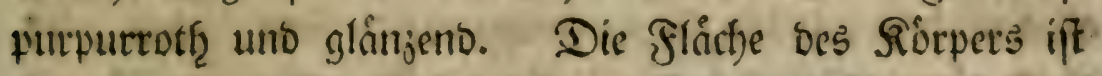
c) ngrinartig, deffen (B)eftalt aber enformig. 2lu ben Geio ten feerum frtoget bas Sinfett von Stadjeln, bie unter ciner ftarfent Dergriofferung lánger als guven Sinten fenn mogten.

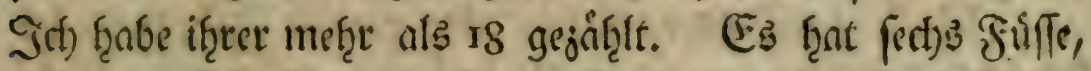

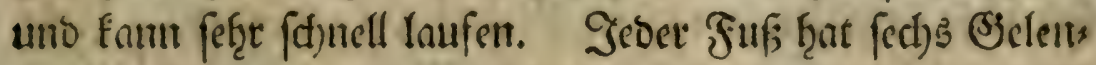

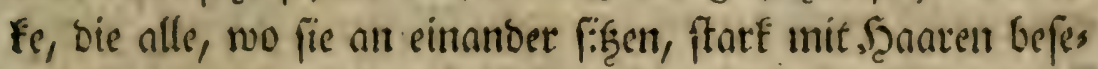

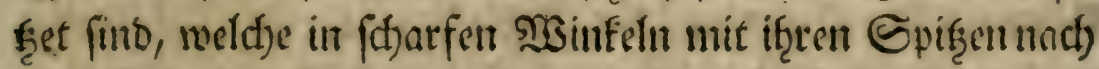

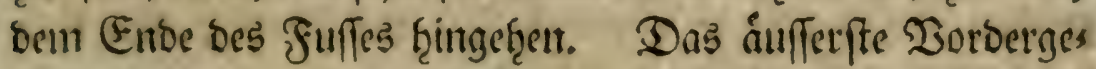

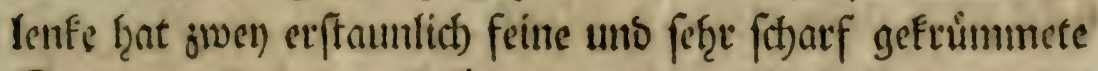
Rlauen; fie fint gabelformig, unto juifhen benden geteret

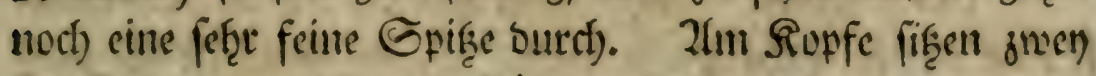

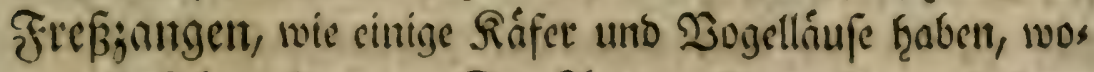
mit es fidh anfineipt. Die Plugent figen oben nuf Dem

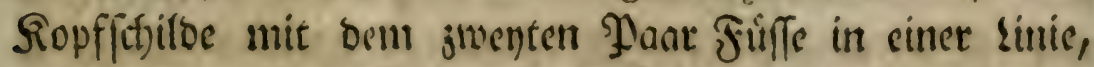
uno fint gepertt. Eine merfwuirbige Eage! Itnftreitig

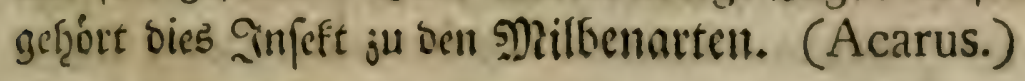

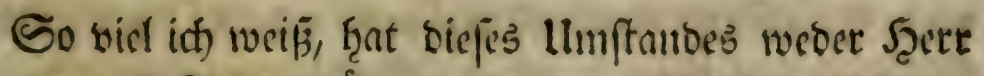

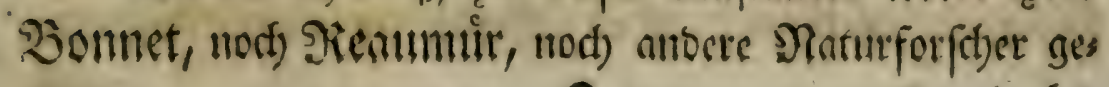


356 3ufátge einiger neuen Entbeckungent

bact)t, Daß́ bie Salattlåufe wieder von Eåulen gepla: get unto gefrefien werden. Erfferer f̧at groar die

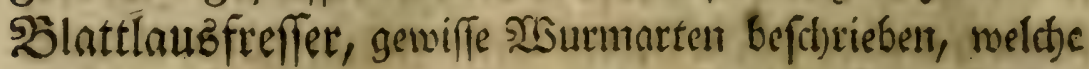

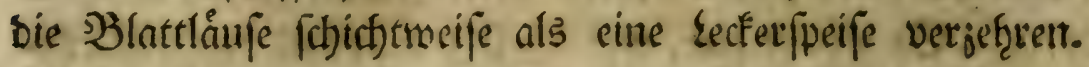
Diefe ifre Feinbe aber fitseinen if̧m unbefanmt genvefent ju

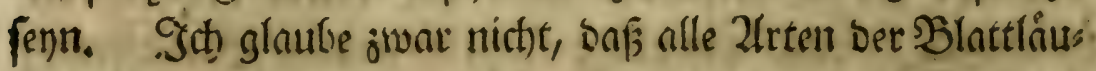
fe banit geplaget find; interfen bervififet bocth mein Exempel, bafz bie Eacje fetbft gegriutbet fern. Sdjon yor einiger Zeit traff id) auf eitrem 2 (pfelblatte, wo hic und ba einige

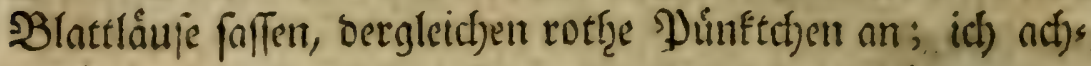

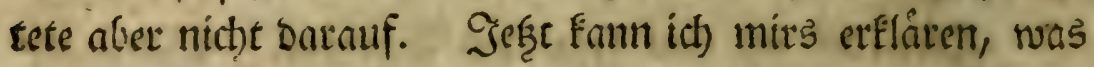
fie gervefen finto. Deswegen follte uns billig in ber Natur. alles midftig uno ber Beobadftung werth fenn, menn mits

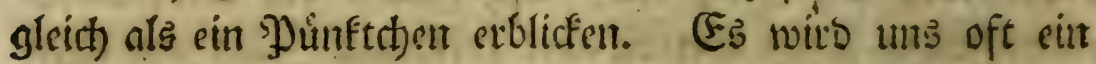

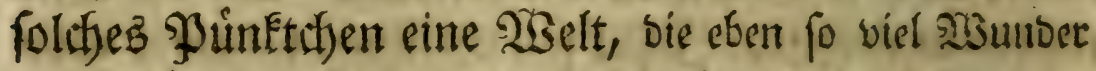

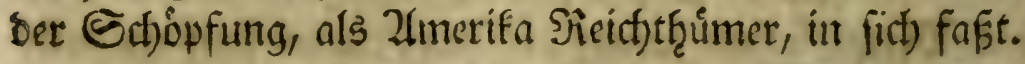

Sielleicht ift es nuct) nur eine gemiffe Janfersjeit, ba

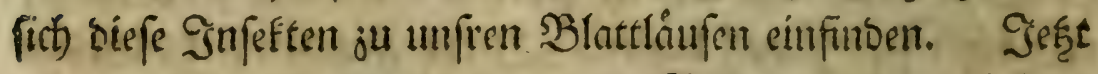
erinnete ich mid, bergleichen rotf̧e Mhilben, oud) an einigen Fleinen Slliegen, uno auf ber Sdj)eeintrant von Sinfufionten gefę̧en ju ḩabent. Eie warent aber viel länget, unt if̧re fectse Sứffe faffen bidfte am Siopfe.

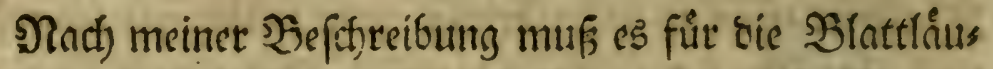

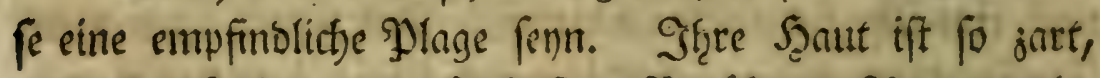
baj fie oft ben bem fanfteften Serufirzen fotson jerplas

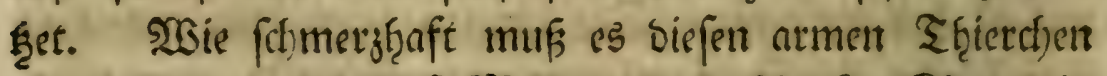

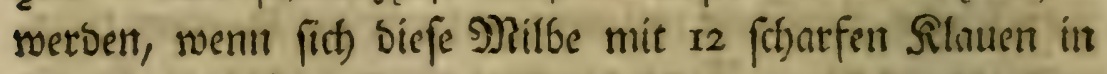

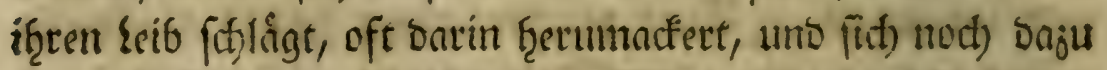
mit ben Ropfongen einfneipt? $23 e r$ weíf, ob nicht bavon biele Şlattlálfe frerben, bie man tobt ant ben Etcingeln

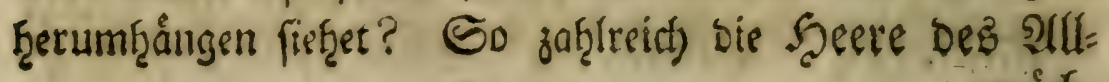




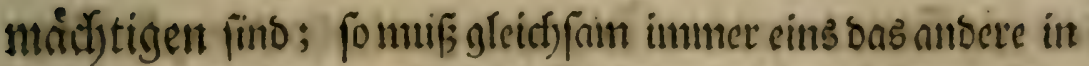

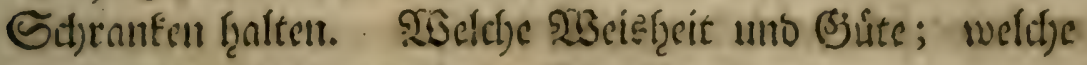

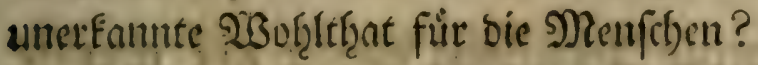

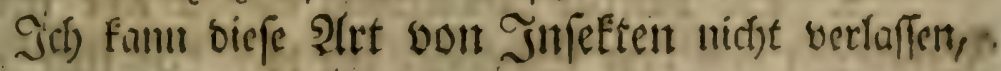

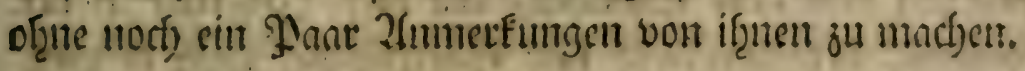

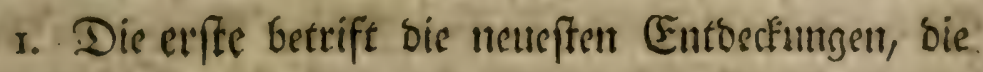

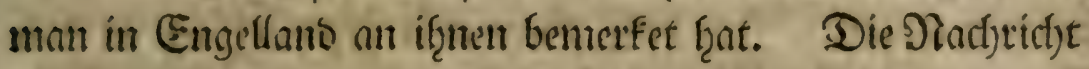

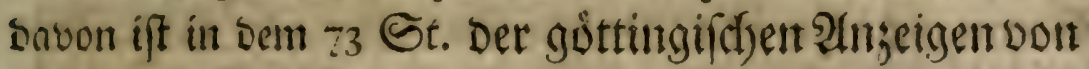
gelefytten Sachent von 19 Junius 1773. S. 6r9. befinds Iitf. Soltoont. ben Lokyer Davis ift r772 abigeoructe: Philofophical Transactions giviny fome account of the prefent fludies and labours of the ingenious. Vol. LXI. P.I. II. worin bie afbrantolungen bes?

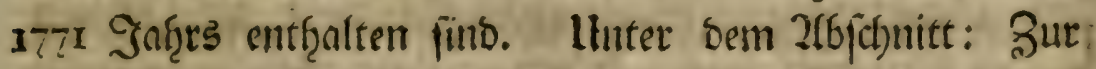

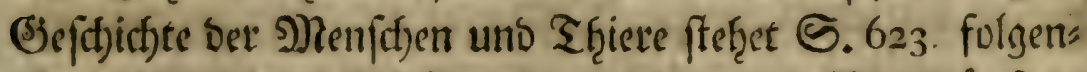
bes: Willęelm Sitiffarbfon yon Den Şlattlâufen.

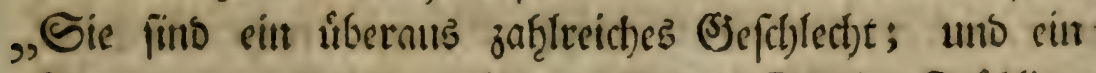
„Banum erjengt metret, als eine 2lut. Die in Frứfling

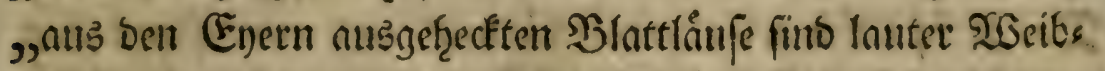

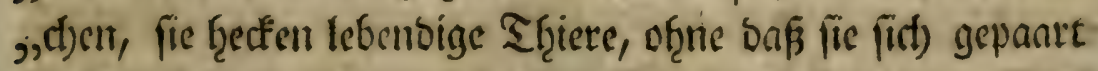

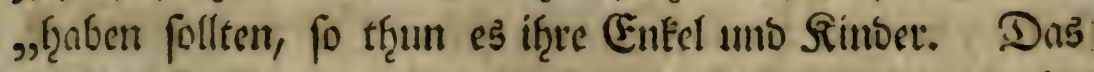

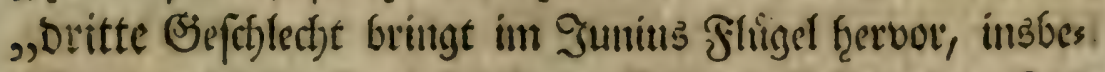

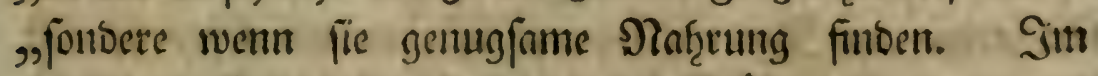

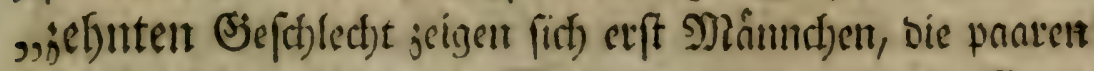

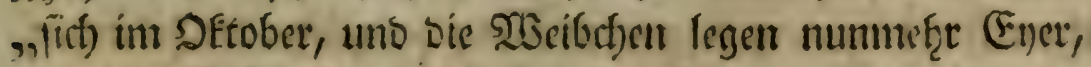

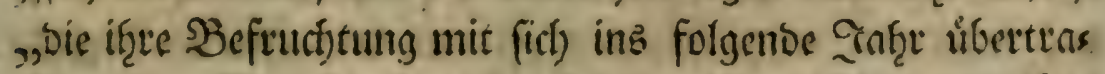

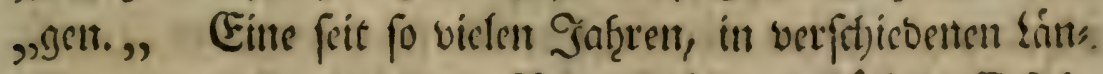

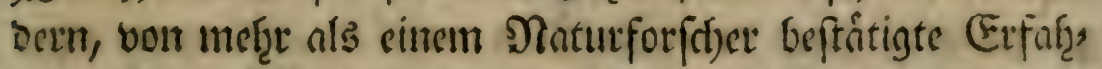

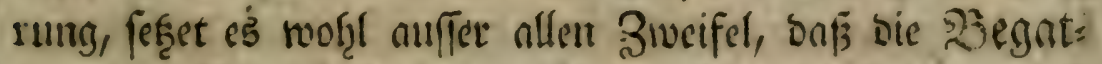

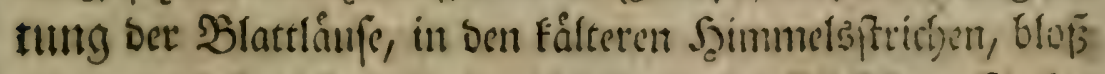

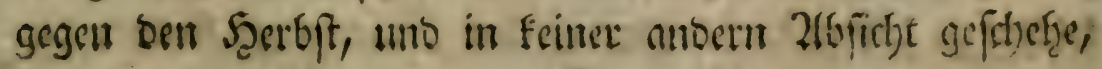

$$
34 \text { als }
$$




\section{3ufáfe einiger netten Entbeckungen}

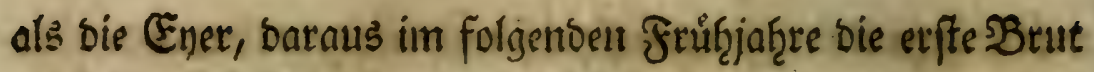
entfferęen foll, fruct)tbar ju mat)en.

2. Die zwente Znmerfung enthâlt eine traurige Erfaf̧rung von bem Edjaben, ben biefe Gurfeften in Der Defonomie, berl Dem Feld und Bartenbaue, tḩur fỏnten. Sin) felbft bin Dabon im vorigen Mlonat 2luguft ein 2lugens

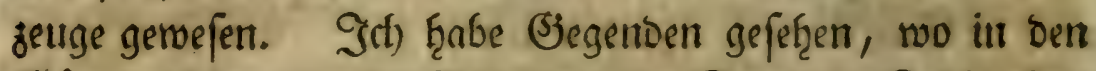
Ṡárten nich)t nur aller Bftumen uno Savoner s Sob̨l; fons

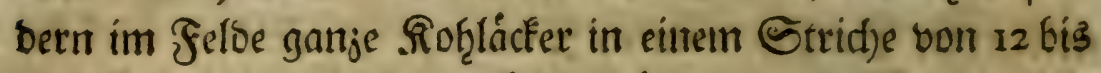
I5 MReilen, von ben Blattlaufen gånt litict) berwúftet waren.

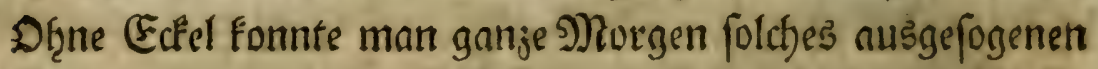

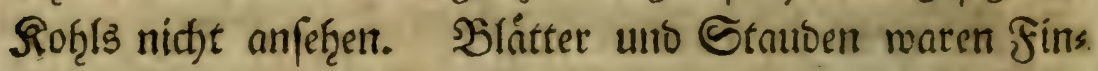

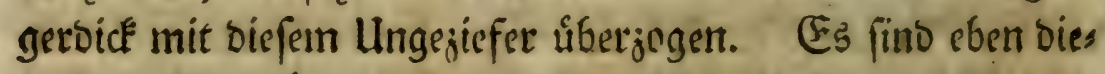
jenigen Blattlaufe, weldte bie Plüfterblafen verurfact)ent. Sie find ganj weis, uno mit einer furgen meiffen $2_{30}$ wie mit Sdjimmel beoectit. Der Sajabe erftrectet fich fo

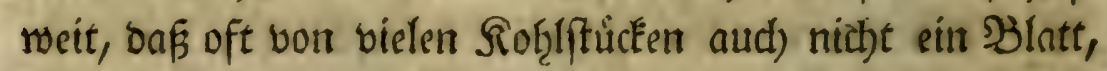

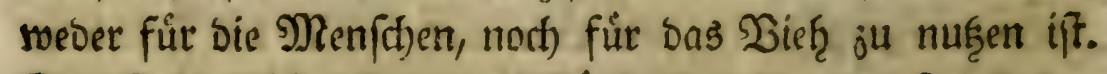

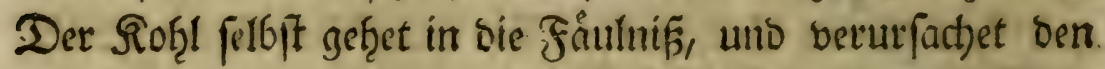

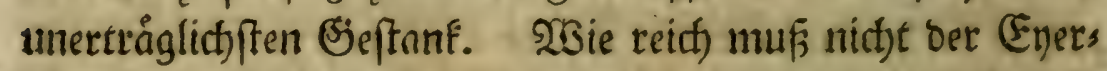

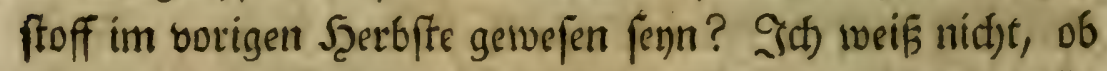
id) irre, menn id) bef̧aupte, bof ber Sommer allejeit befto

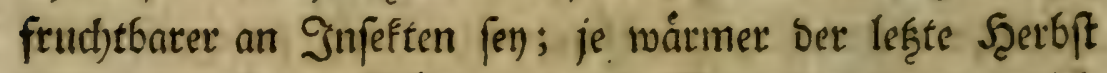

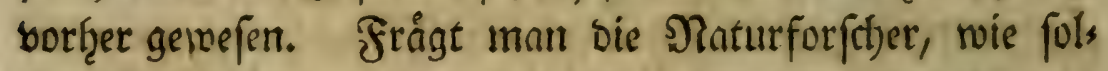
dem llebel f́onne geffeuret werben; fo múffen fie befennen,

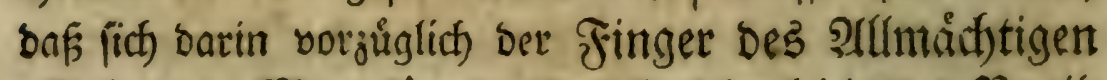
offenbate. Man fónnte frenlidy feint leidteres Dertils gungsmittel gegen biefe Julfeften angeben, nls wertn mair ber) Beiten ben Stoff, bie Ener, und erffe ßrut Derfelben ju

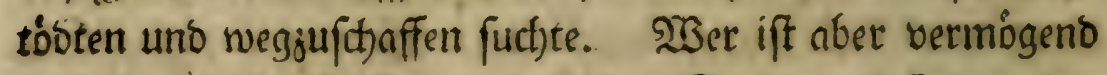
foldjes su leiffen? Doer wo ift Der Saame ju finden, ber groffens 


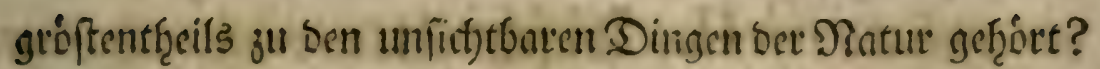

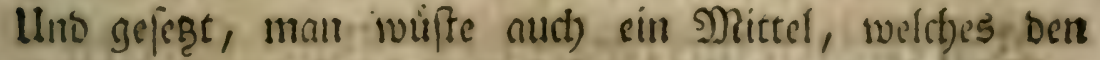
Blattlaufen felloft entgegen ivare. Siburbe biefer in als

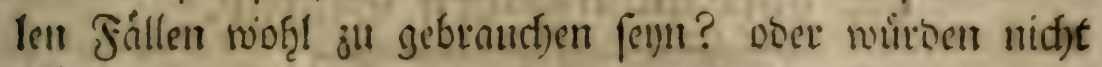

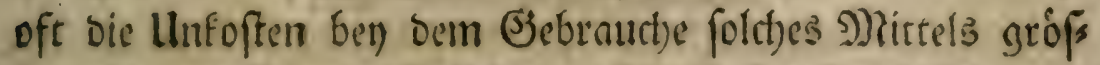
fer als ber S(t)noe fenn, Den biefe Ginfeften felloft verurs

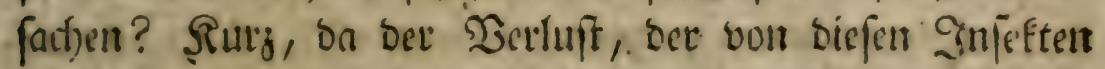

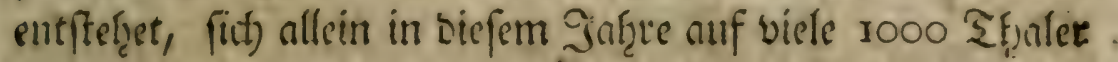

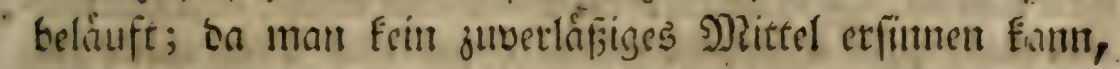

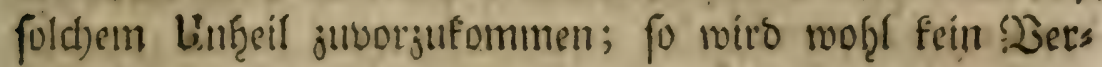
nunftiger juveifelln, Dafj bie gantje Sadje nicht ju ben Sied)ten und Slagnalien (Jottes geŗore, ber allein fas gen faun: Jid) will eud bie Jabre erftatten,

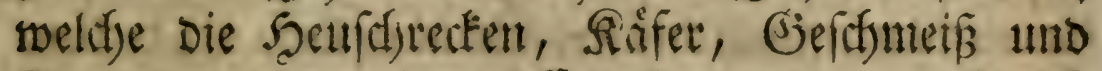
Slaupen, bie mein grofles Seer waren, fo ids unter euch fotsicte, gefreffen baben. Joel. 2,25 .

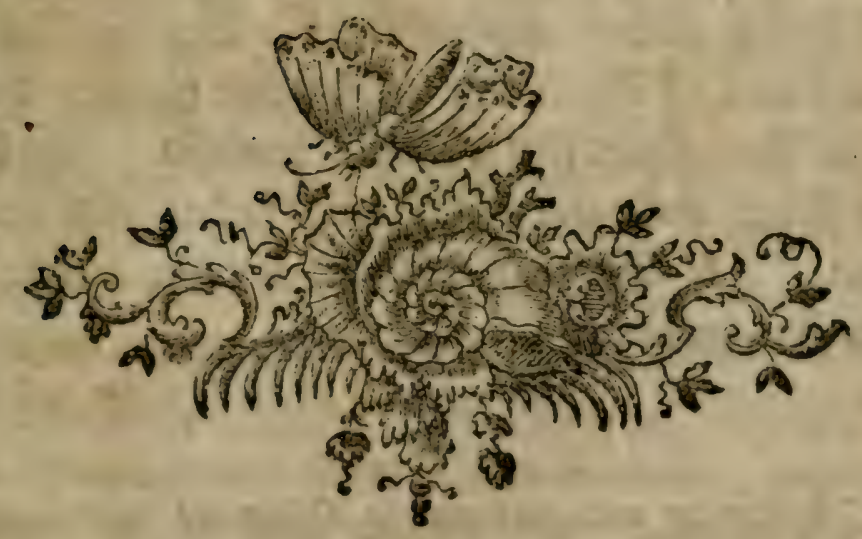




\section{Von einigen merfivindigen 2 Bafferinfeften}

\section{II. atbiftititt.}

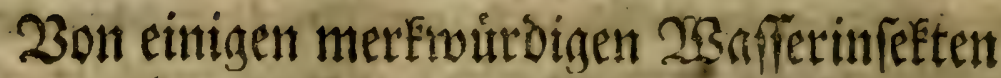
Der quedrimbutrgiften Gegend.

Cic. de nat. Deor. Lib. II. c. 47 .

Animantium vero quanta varietas eft? quanta ad eam rem vis, ut in fuo quaeque genere permaneant? - Enumerare voflum - quae fit in figuris animantium, et quam follers fubtilisque defcriptio partium, quamque admirabilis fabrica membrorum?

\section{(G)}

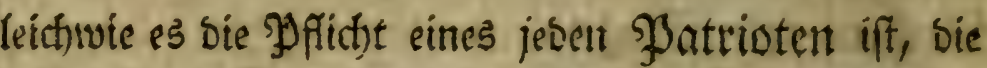
(Sefthith)te feines Daterlandes ju ftudieten; fo wurbe es

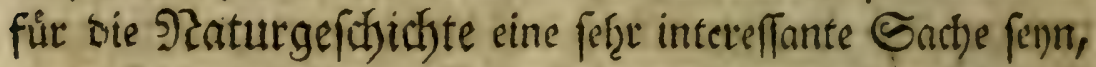
wenn folde an jedem Drte genauer unterfucht wirbe. ${ }^{8}$ )

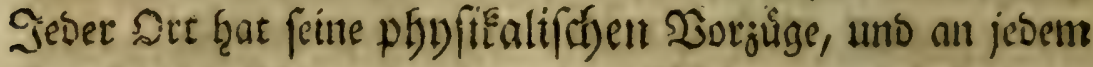
Drte f̧at bie Natur in jeben if̧rer Pleiche etwas befonders. Sage, Slima, Scold, Şerge, Siewäfier, uno bergleityen machen bieje Serfchiedenfeciten notfewendig.

Infere questinburgifde Ojegent liegt ain Fuffe bes

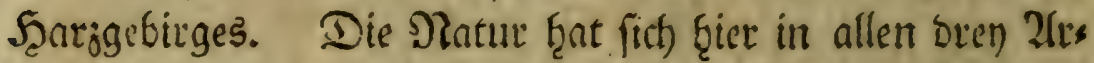

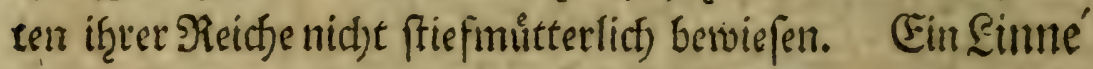
- unfer Beiten mufte nur ifcre Ectją̧e fuchen, unto ants sidjt bringen. Die Botanif follte idf) glauben, würbe baben am meiften gewinten.

Sin

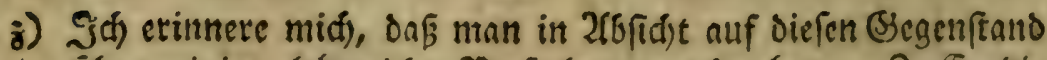

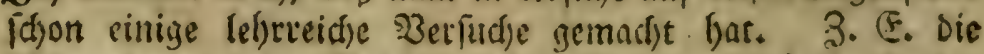

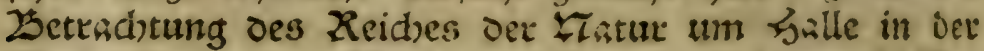

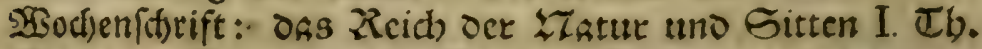
G. I13. Ferner voll oer Dressiner Giegent: in Den netuen

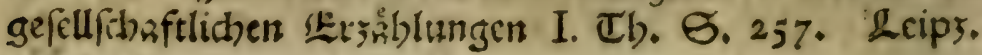
$758+8$. 


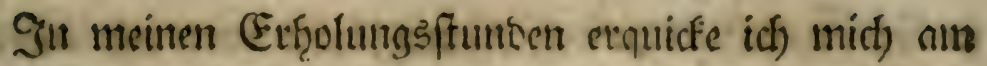
licbifent Durch) mifrof fopif the Betrad)tungen Der unermeflits

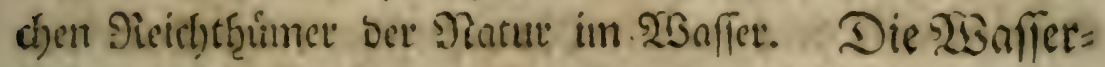
infeften, bie bem bloffen ?luge entaeghen, funto siner ber vors

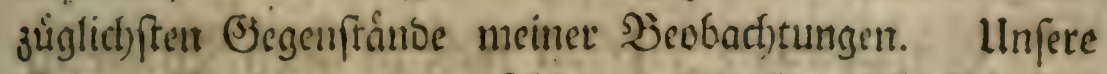
Begend if nid)t arm an foldzen wunberbaren (Sefdjopfen.

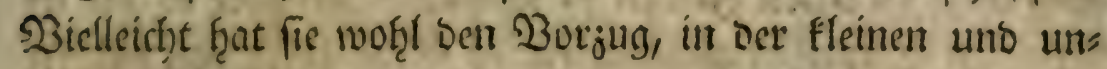

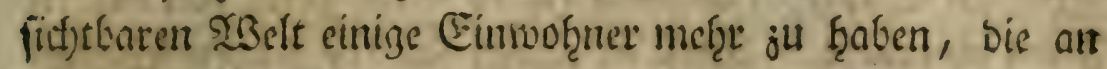

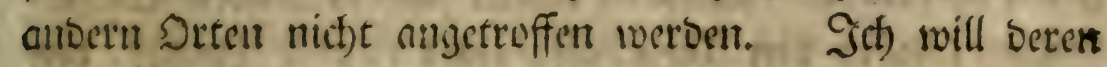
eintige i) bef(t)reibern, und meinent Sefern melben, wie ict) fie

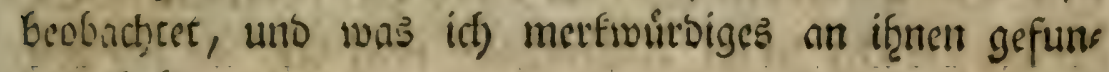
ben ḩabe.

\section{Srobachtung.}

Lleber einen 2 Bafferfloh, Der feinen (Fuerface an einem Dobgen unter Dem Leibe tright. Tab. IV. fig. 5 .

Siel werbe ich bon biefem InfeFte nidjet fogen formen, weil idt) es felbit mur einigemal geferen, uno froh gewefent Ein, Da

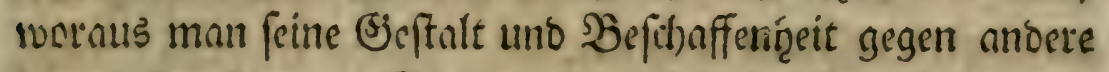
beuttheilen faum. So viel glaube ich aber fict)er bergauptent

a) Es. war anfónglid) mein ఇorfnk, nod) cinige neue 2aten von

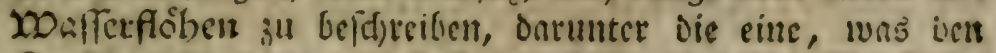
Siopf betrift, bie gennuefte 2tel)tilidyfeit mit einem Edowein:

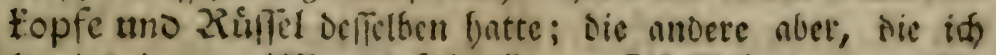

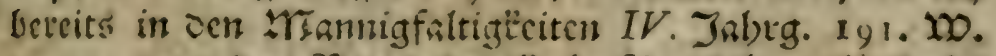

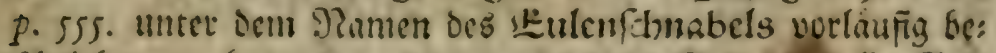

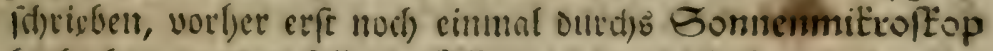
beofind)tet weroen follte. Zllein ich) mus mas mit oet lin:

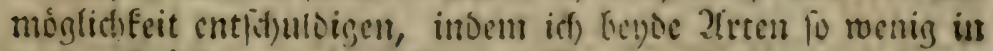

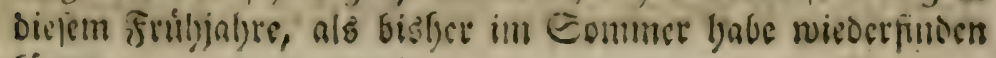
fómich. 


\section{Won einigen mertwuirbigen 23 afferinfeften}

zu Eonnen, bafs es zu ben neuen, uno nod) nie entbecften Ilrten berfelben geţore. WBenigftens ḩabe id) in ben Striften ber berufhmteften Naturforfafer frime Spur da= von gefunden.

Begentuattiges Snfeft ift nicht in allen STBaffern, aut) nicht gu allen Beiten ju filloen. Id) trabe es nie in ftefzenten Sưmpfen angetroffen, of foldhe gleich) von andern Zten roinmeln. "Blof in einem fonftrieffenden 2 saffers graben, uno in ben Jleerfinfen eines fleinen Selties, ben Diefer Sraben verurfadt, habe ith es juerft entbect. Es ift alfo ber ont feitres 2tuffentralts eben ser, wo idf Den (Eulenfadnabel gefunden. Sin Iusgange bes risinters,

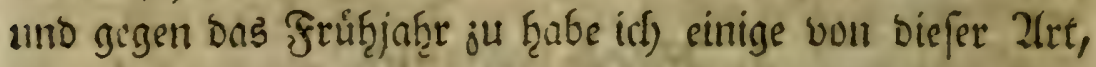
aber allejeit in Bergleit)ung gegen andere jaf̧lteichere Sats tungen, fefere menige angetroffen. Sie fino atid itberaus giartlich, uno bृalten fich auf bem Sdjieber faum einige SRinuten.

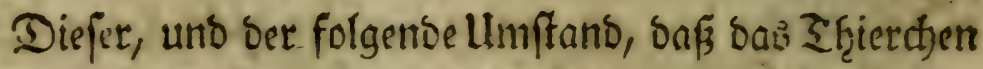

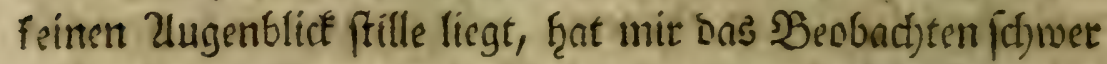
gemadit. Inteffen f̧abe ich) Dod) einige metfwurbige (E) is genfitjaften beffelben entoecft.

r. Sift feine Sieftalt uno Farbe von allen befounten

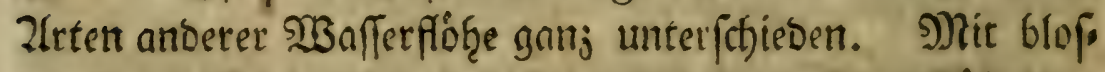
fen Zugen fann man jmar ein Fleines bervegliches fáferd)en fetcen, weiter aber nuch nidfts daran unterftheiden. Folgs lid) ift es unentidich Eleiner, nls bie aftigen 230 afferfiotze, bie Traubentråger, und andere befannte Ziten. B̉en allen ift bie Farbe nicht immer gleit). Einige fit)einen bunfects braut, anbere rótḩlich), grin uno gelblich) zu fer)!r. Ein Umitano, ber bermutb̨lid, wie bey bet verảnberten farbe atroes 


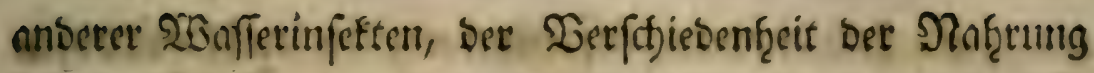
benzumeffen ift.

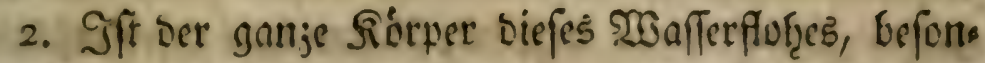

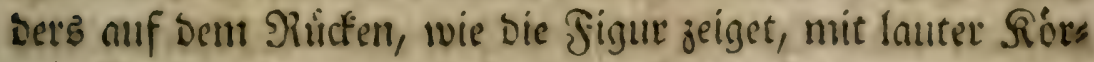

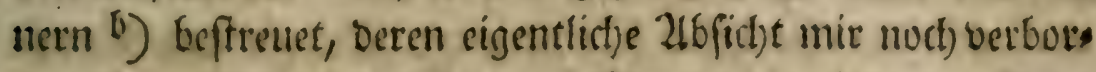

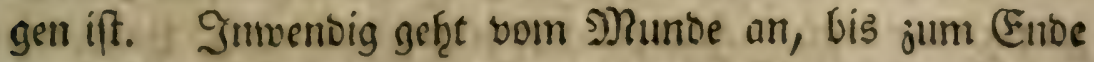
Des Iffers ein reiflitfer Darm '). Der ganje Sörper De? - Infefts ift úbrigenz unbebectit. Ėa geţơret unter bie Ed)aalentopen ŢGiert)en.

3. Fुat bas Zluge on biefem Infeft sine ganj anbere

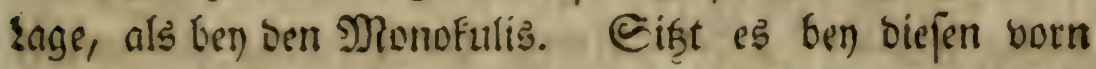

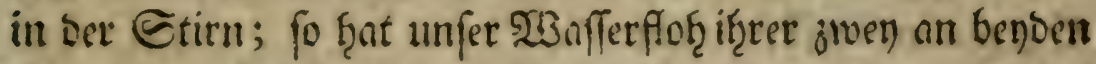
Geiten bes fopfes liegen, Die eben fo geperlt find, als ben Den ůbrigen.

4. Ift Diefes Sinfekt mit bren Praar jactigen J̧örnern oben am Fopfe, und unter Demfelben; am Ulnterleibe f̧inges

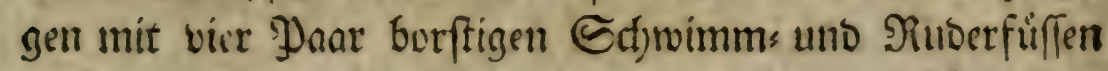

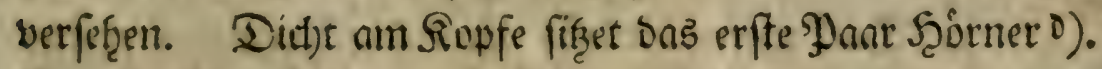
Die Rupffpige fheinet gleidffam mit Denfelben aubjugeţen.

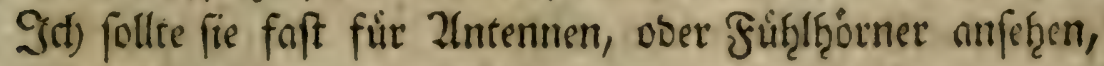
Deren jebes nul fieben ङelenfien beftęert. Sie fino alle mit

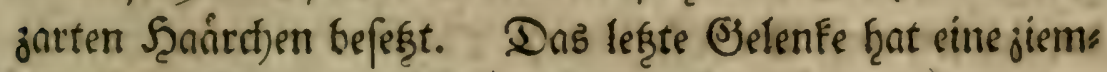

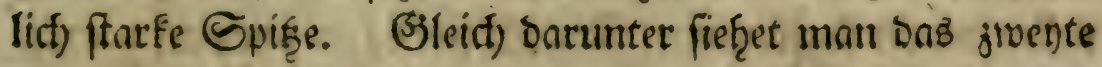
Syaar Şörner e), bie ganlj anbers eingerichtet firto. Sie beftefegen aus jwen Seauptgelenfen, Daven das crffe sicf)t am seibe firset, bas zmente aber fiti) mit bren Szanrfpigenen wie ein Dremjack endiget. Even fo find bie etras meiter

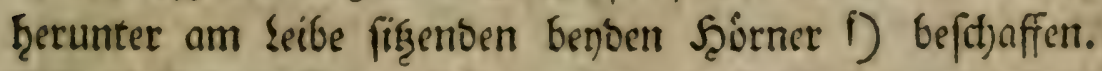

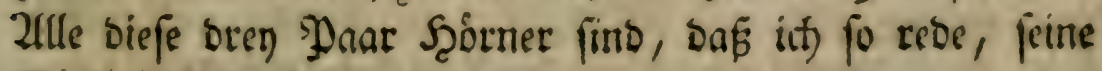
Borbertuber.
b) fig. $5 \cdot d$.
b) $b, b$.
c) d, d.
b) 2,2
f) $e, e$.

5. Jid 


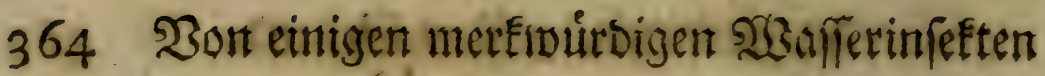

5. Id) fomme nuf cinen anosn merfwuitoigen Theil, ben bas Infeft unter bem Siopfe frat. Er beftati: get die Erfaferung; Daß bie গiatur bet) Den Snfeften oft von ber allgemeinen Siegel eine Ilustnafym mact)e, nach wel.

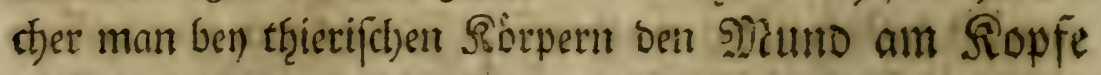
zu fuct)en pflegt. Seier firzet or wenigftens cinige sinien un: ter Dem Ropfe, tief in Der B̧urnf, uno ift ausmendig mit gowen ftarfen, beweilict)en unt frummen כâfnen g) verfes hren. SRan Fann es Deutlich feḩen, wie an biefem Drte bet weiffe Darin ben Ifnfang nimmt, unb mie alfo finter

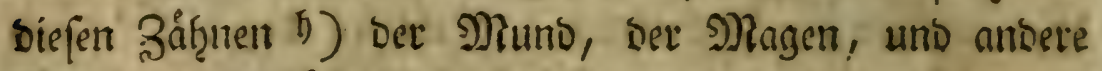
Berbaungsggefâfe fif̧en.

6. Es folgen die vier Siefenfüfle unter bent Bans (he, welche viele פiebenzmeige I) Grabent. Das Infeft phegt fie als flopiebern nusjubteiten, um fid) bamit int

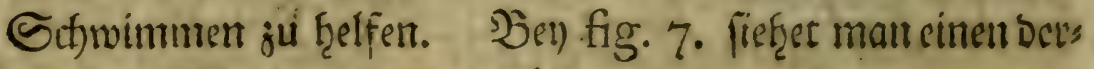
gleityen St)roimmfü verigroffert.

7. Der merfmurdigfte linterfáteidungstf̧eil biefez

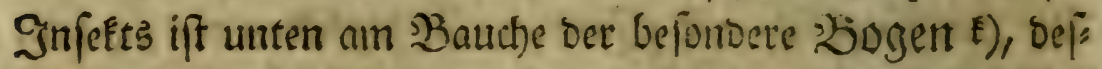
fen lestes Ende bis an den 2ifter reicter. 2fn biefem $\mathfrak{B} v$ : gen hianget mit eittem jacten Şánodyen Det (Everfact I),

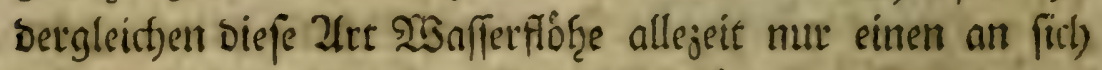
trágt, ba bie fogenannten Traubentríger juen an benden Seiten bes Sifwanjes f̧aben. Die Zlbficht, matum bie

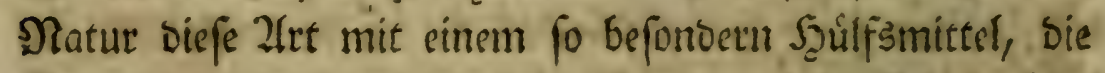
Ener ju tragen, verfetcen fૃat, ift mir noch) jur. Seit verbor: gen. Sie muf aus der ganjen Etruftur des Sefthopfs

erflí:

9) fig. 5. c, c.

b) Diefe Zrihne fat ber fectr D. Edhiffer gleidjfalls an feinen

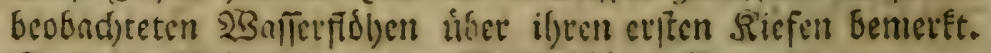
5. Deffen 266fandung von sisnterfiofen. Diegctis6. 1755.4. p. 33 .

i) fig. 5. f, f, f, f, f, f. ह) g, g. I) h. 
etflitet merbelt, uno wer f̧at biefe frifon vollfommen ergruitts

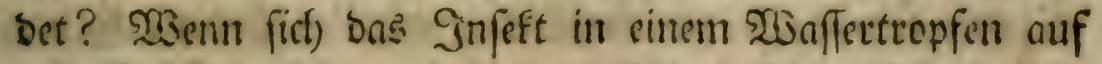
Dem Echicher hetumuválget; fo pflegt es feinen Enperfact oft

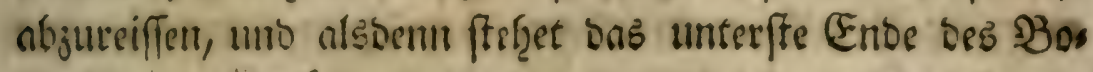
genb etwans abruáts.

8. Der St)manj biefes SBafferfor if getţeilet, uno

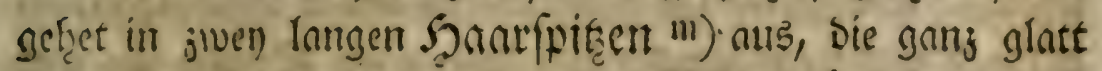
finto, unto nidf) Das geringite Nebenthaárdjen f̧aben.

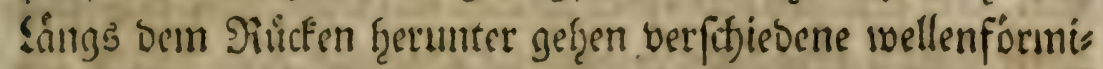

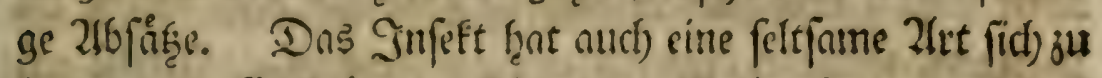
betwegen. Esz frúnmet fiit) wie ein Sieif zufammen, fo DaF

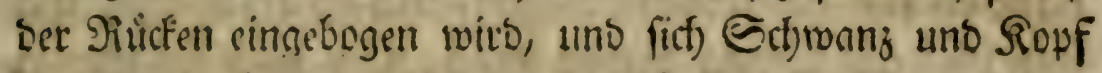

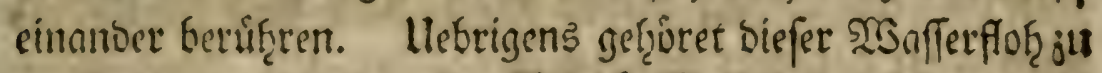

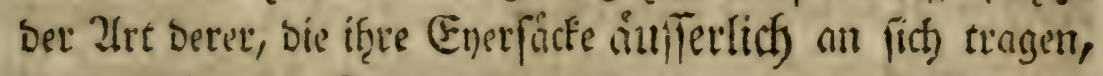
alls welctgen bie Gungen hervorfommen, ba fie ben Den fichanligten allezeit inmentig, innerf̧alb ter Sct)aale erjens get werben. Wosie mannigfaltig une verfdyieben ift niffet bie

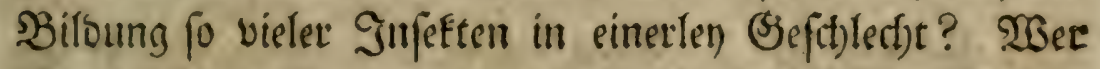
Sermunft und 2fugen ḩnt, wirb Giter bie beutlitffften Spuren

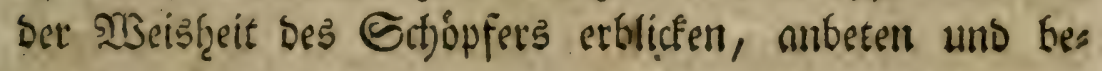
munoern.

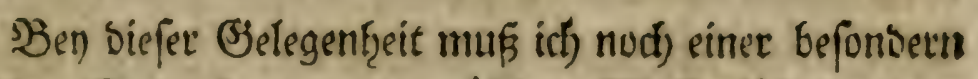

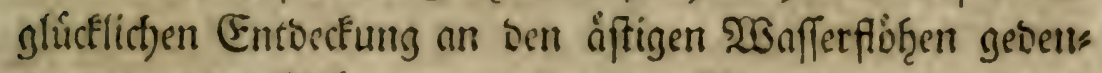

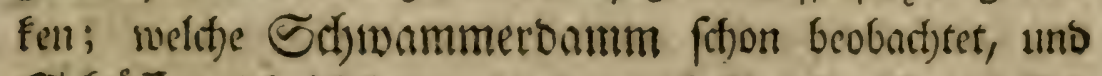

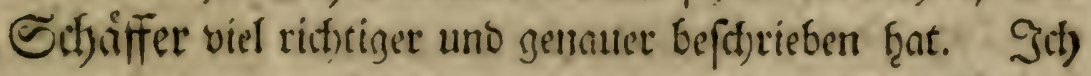
nenne fie barum glúcflich), weil leşterer unermübeter গaturs

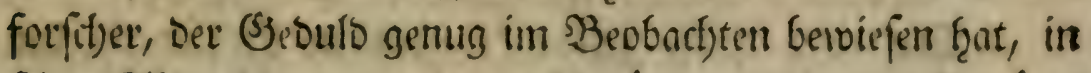

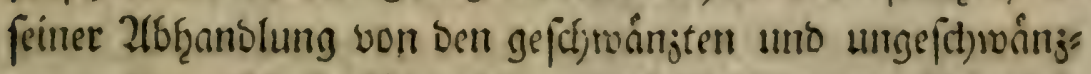

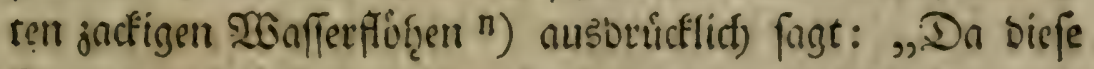

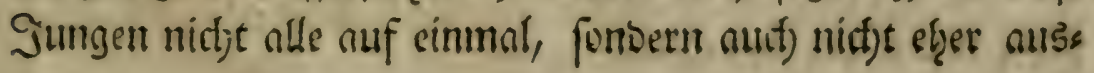

m) fig. 5. i, i.

n) p. 57. ges: 


\section{Vont einigen metEtwưbigen 233afierinjettent}

geffhuttet weroen, Doer fich) felbfit ju befrenen fuchen, als bis

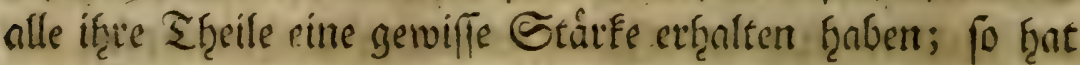

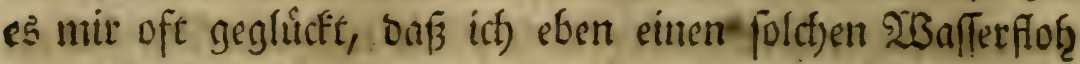
unter bie Berguófferung befam, in meldjem nur troch) jiven

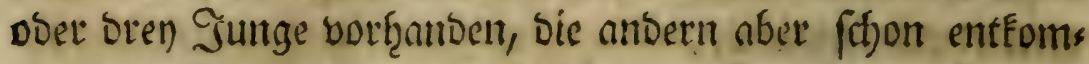
meit waren. Diefen ḩabe id) Denn Infangs lange zuges

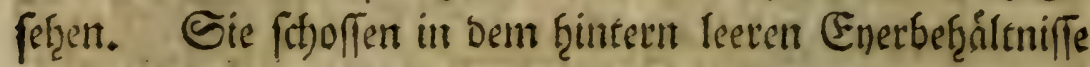
auf uns nieber, wentoeten firf) nach alien Seiten um unto

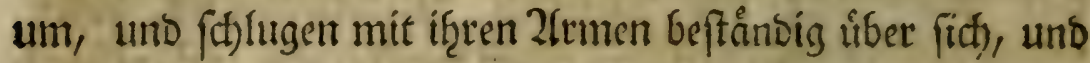

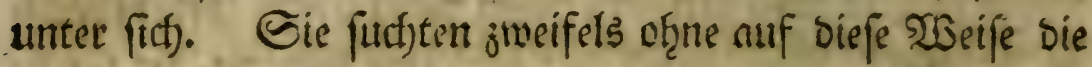

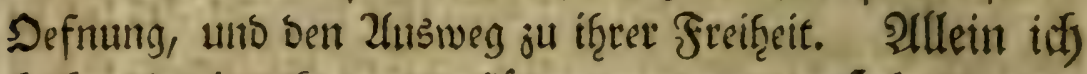
babe es nie absorten tómen, um zu erfabren, wo fid) Diefer 2 ușneg finden mag, und wie fie etrwan folchen ju nelmen pflegen.,

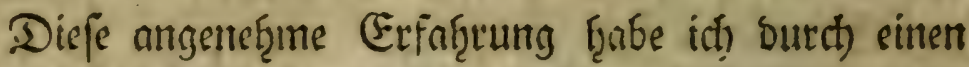

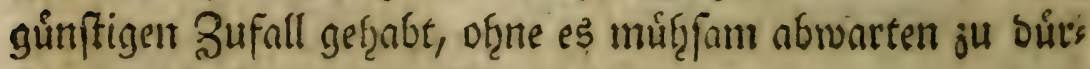
fen, bis bie Gungen ben ?lusgang fanben.

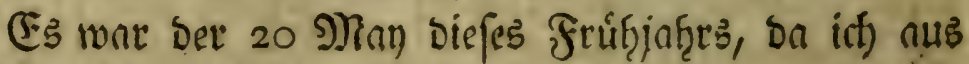
Dem fdymaten $\mathfrak{B}_{3}$ ffergraben, Der mich bisher init fo vies Ien Infeftent ver forget ḩatte, mit einemmale eine ganz untge,

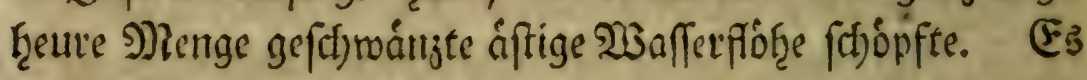
war mir leichte ntefere als bren unb viere ouf eimmal in eintent

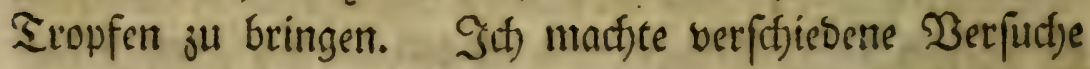
mit tį̧nen, uno war fo glứclict) viere in einem Tropfen ju

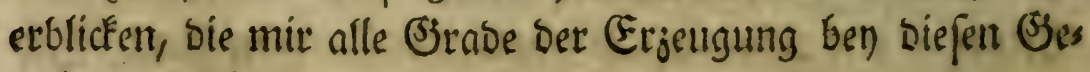
fdjopfen jeigten.

Die erfte f̧atte in bem befondert B̉ef̧alltniffe ber

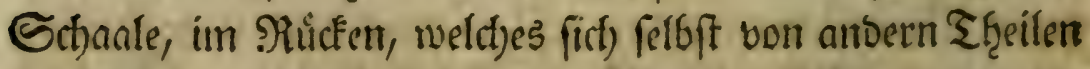

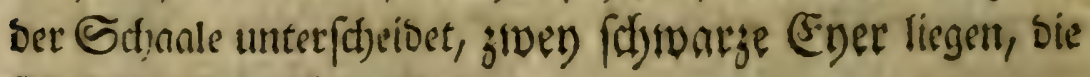
fiil) f̧in und ḩer berwegten. 
Die anbere Kृatte an sben bem Drte Dren Evyer lies gelt, bie aber fidjon mef̧e ausggebilbet waren, uno Daran man

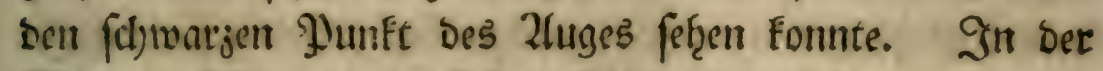

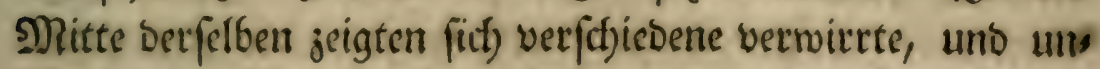
tei einander liegenbe gruine, Glaue, rotţe und gelbe Rórpers chen, bie cin artiges 2lnję̧en f̧atten.

Die britte ḩatte Dren lebendige Jünnge in fith, bie

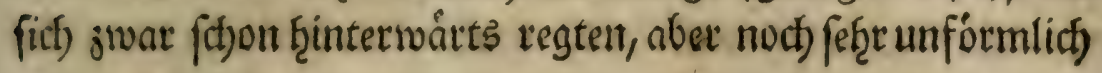
warer.

Die vierte zुab mir ben erwuinf(f)teften Inblick. Sie hantte fuinf lebendige Junge in fith), bie in ber Sthaale

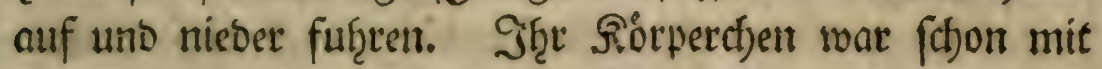
einer feinen Sdyaale bebectit. Der Sefwang war ein Eurs jer Bapfen. Die Şórner waren audf) fityon da, aber nue Die Şauptgelenfe berfectben; bie langen $\mathfrak{B} 0$ rber und Seiten fpişen feţltent nod).

Da ith) biefe 2 trut mit vielem $B e r g n i g e n$ betractetete, fohlupften einige etwas weiter in ber Schaale Gerunter.

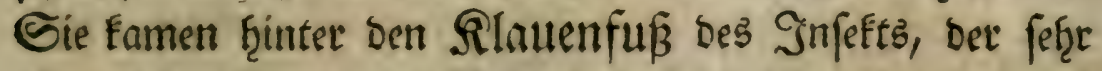
oft aus ber Epalte ber Sthaale beraustritt, unb vermittelft Diefer Bewegung wurben fie aus ber Schaale ḩerausges brúctét, ba fie benn fogleid) im 20 affer munter ţerumf̧ưpf.

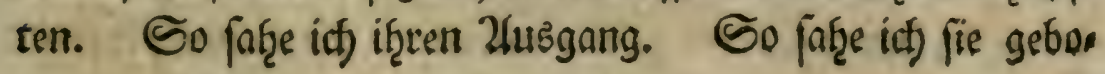
ren weroen.

\section{25eobad)tung.

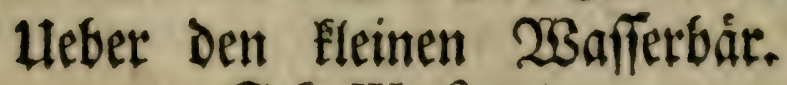 Tab. IV. fig. 7 .}

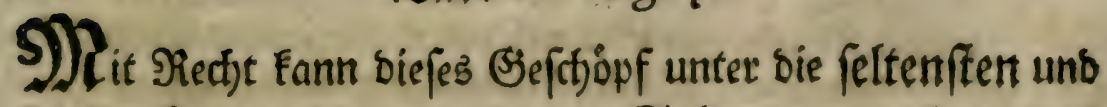
feltfamiften gerect)net werben. Selten nenne icf) ${ }^{2}$, weil icj) es im Winter nur einigemal, im Sommer gar nidfet ges Sonnet 2. Th. 


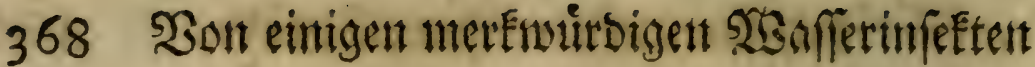

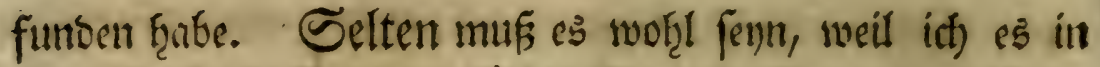
allen Derjecidjniffen ber gróften Daturforf(t)er, beren Zluge

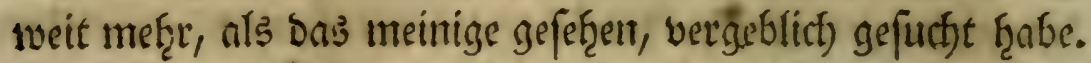

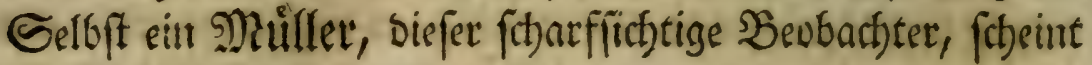
es nich)t entoectit jut ţabent o).

Seltfam ift biefes Thiercthen, weil ber ganje જ̧au féures Forpers aufferorsenttlicf) und feltfam ift, uno meil es

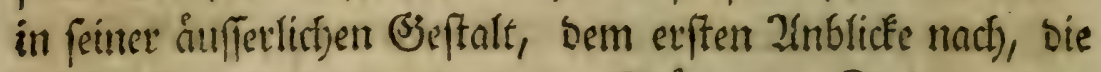

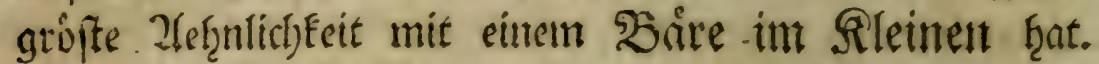

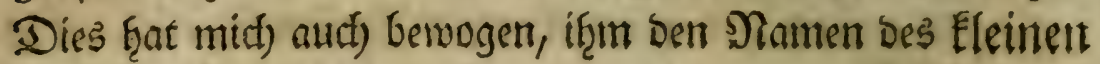
SBafferbárs ju geben P).

Man furchte fich inbeffent nicht, auch biefe Sirutb:

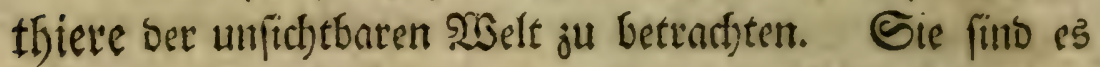

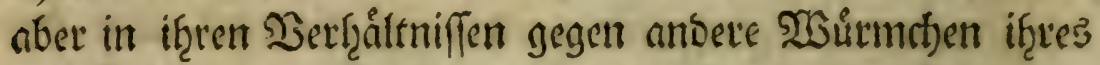

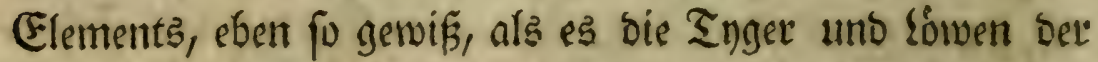

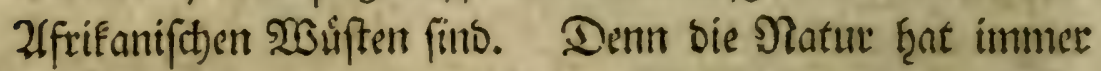
eins fir bas anbere beftinmt. So ift es in ber groffen

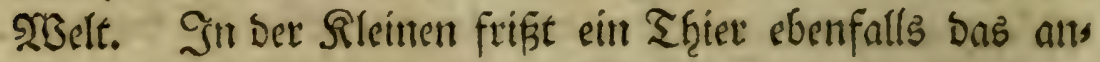
Deve, weil biefe mit jener burd) cinte Rette berbunben iff.

Man erblicf́t ja unter ben Jinfufionstficerchen alle migliche Thiergeftalten. Es ift wohl nidjt ju vermut: then, Dafa fie bie bloffen (bieftalten, nicht aber aud) bie (E):

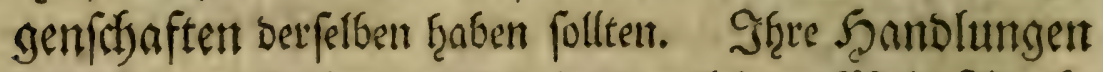
berweifen es offenbar, Daf es in ber fleinen siselt 9Raub=

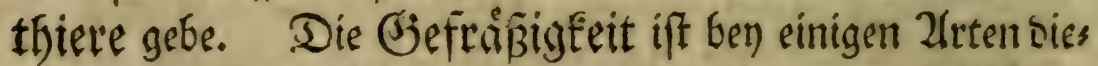

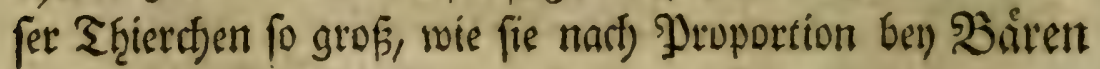

Ino

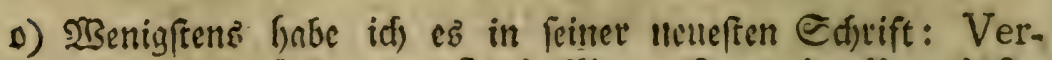
mium terreftrium et fluviatilium, feu animalium infuforiorum etc. fuccincta hiftoria Hafn. et Lipf., 773.4 . nic(s) bemertt.

p) Sçut man ond) Cercaria catellus, lupus; Trichoda camelus, lepus; Vorticella felis, catulus u. $\uparrow$ w. $\boldsymbol{\sigma}_{\text {. }}$ Mïller Vermium etc. hilt. p. 65. 67. 108. 


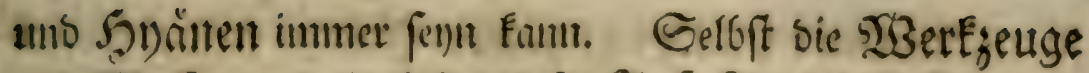

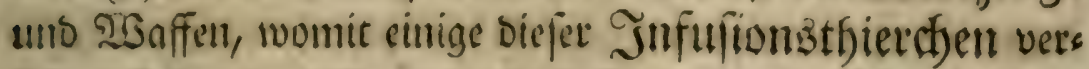

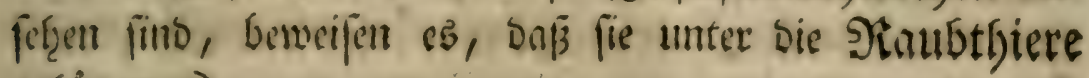
sef̧ổen 9).

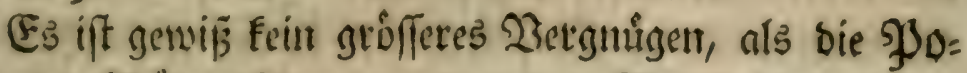

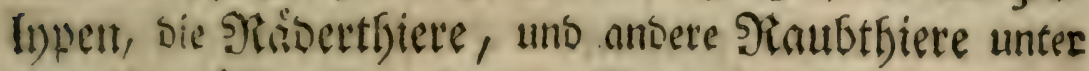

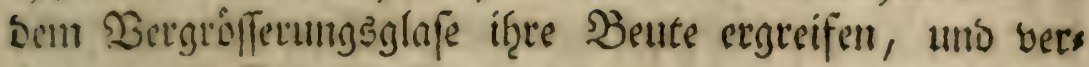
fothingan ju jefren. Doju fonn man of̧ne weite Sieifent,

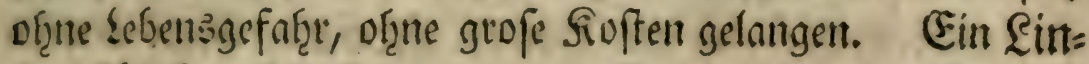

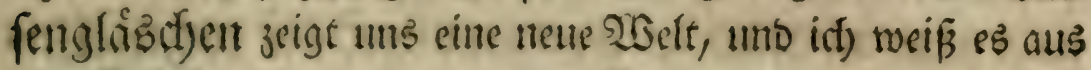

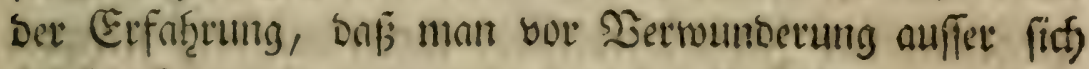
felloft geferęet witro, wern man biejent Inblicf jum erften: male f̧at ${ }^{r}$.

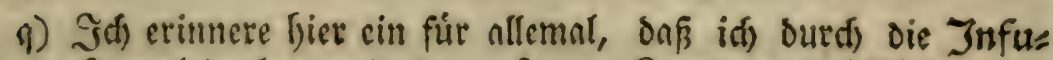

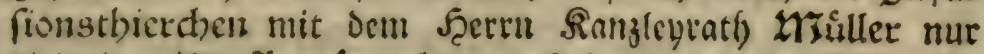

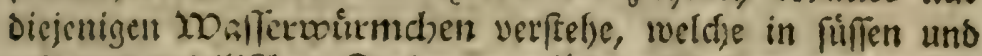

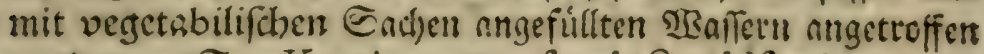
werden. S. Vermium etc. fuccineta hiftoria. p. 4. Unter oen kiaubtbieren der fleinen 2 salletwelt aber babe id nod) feine wiloere unt gefréphigere bemerft, als oie man gemeiniglid) in Den gruingewordenth Sisaffern oer Eifrernen, Der Eturmfaifer, Der Tróge, u. I. to. findet, uns Die ids im 17 St. Des bunnoverifden 2rangazins 1773 . Vefdriebent babe. Eie veribslingen mit einem 3uge ganje Scaufen am:

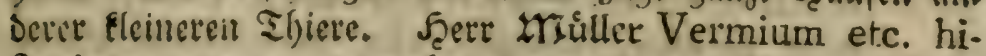
ftoria p. 131. n. 142. Wat fie unter Dem Namen: Brachionus vrceolaris begriffen. $\mathfrak{B}_{\mathrm{e} y}$ bem Ioblot obfervations d'hiftoire naturelle, faites avec le Microfcape etc. à Paris 17 54. 4. Tom. I. Part. II. Chap. XXX. p 68. Pl.9. find es bie Grenades aquatiques, couronnées et barbues.

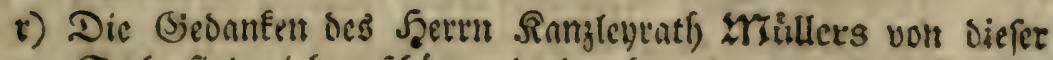
Sadje fint viel ju fdjón und cinneljmeno, nIร Daß̧ id] fie mei: nen Eefern votenthalten fónute. Er fant in Det Einleitung

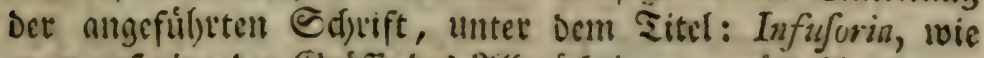
man auf eine ber Giroffe bes 2tumár)tigen gemáfie 2let davon urtbei: 


\section{Bon einigen merfmúrbigen 23 afferinfeetten}

Siefleidft bin idf yon meinem Biele gu weit abgefonts

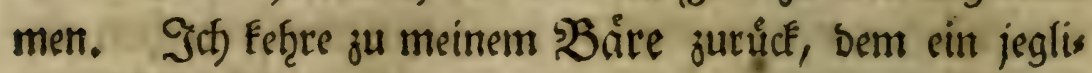
d)er biefen Namen juerfennen miro, ber if̧n nut einmal

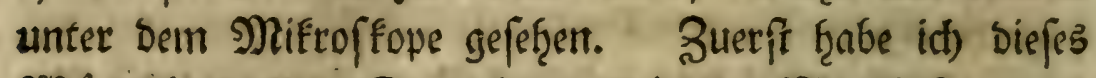
Wuirmiten am to December $177^{2}$ in ben Meetlinfen eines

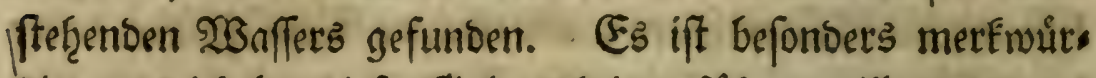

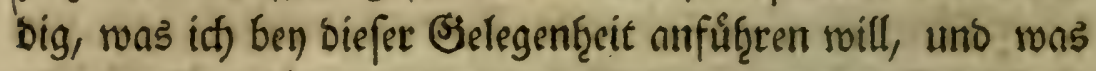

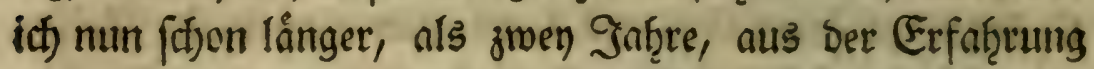

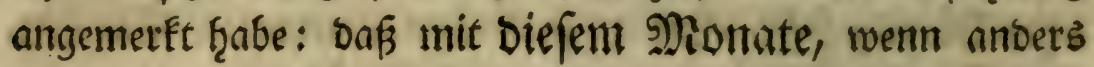

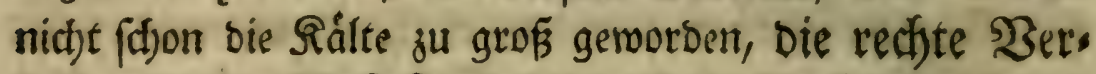
megrung Der Infufionstbiere ifren Infang nefme.

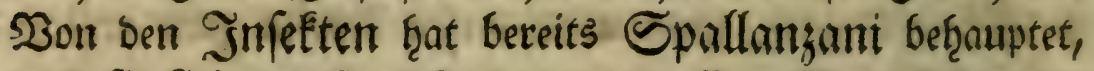
Daß̧ fie fich im Scerbfte begatten. ') Man finbet bas

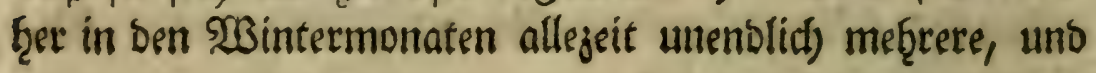

vers

urtheilen muife. Bielleid)t ift bas 25 ucf): Vermium etc. hiftoria nod) nidjt in vielen Şantoen. Scier fino feine SBorte: p. I. $f$.

Si quae de animalculis infuforiis dici poffunt, enarrentur, verbaque et oculorum acies fufficerent, dicendi nullus finis effet. Pauciffima magnificentiae et fplendoris Numinis optimi maximi documenta prodere mens humana valet, in plurimis ftupet et obmutefcit. Mundus invifibilium maioribus occlufus, centum abhinc annis, et quod excurrit, adiri coepit; monftra, forma et vitae ratione, inaudita, alit, miraculisque aeque abundat, ac remota Indiarum tellus, minori vero periculo perluftratur, vbique enim ante pedes praefto eft, nec auri fame vifitur. Vtrumque multa incolarum ftrage conquiritur; haec vero faepe vitae aggrefforum difpendio conftitit, ille mera patientia comparatur. Aciculae alterum, quae orbis terrarum hemifphaeria iunxit, alterum lenti, quae moleculas folares, moleculasque infuforias, remotifima rerum, fub eandem imaginem fiftit, debetur. In hoc intervallo quid iam magnum, quid parvum? Ens, quod hoc cogitat, et humana patitur.

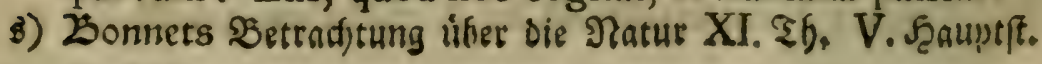
p. 375 . 
verffhicbenere Sbzierchen in Dem Meerlinfenwaffer, als in Den keiffeffen Sommertagen. Diefe Fruct)tharfeit Dauret

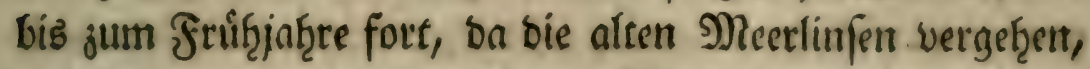

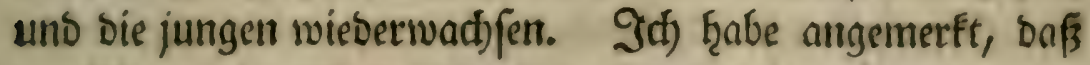

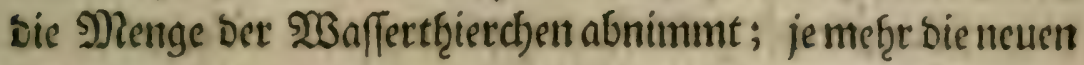

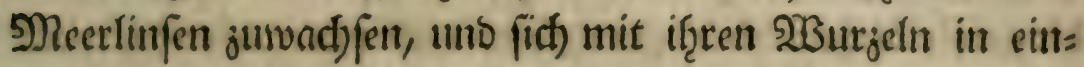

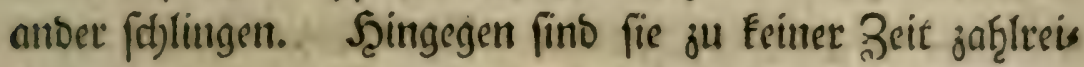
d)er, als twenn bie Meertlinfen im fpáten Şerbffte if̧re 23 urs

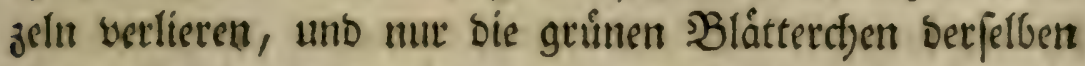
ober auf bem 2 Saffer fojwimmen. Tunft man berm nur ein foldjes sinst(t)en nuf Den Bllasfdjieber; fo wiro man gants oe Rolonien 25 affertf̧ierd)en von allerlen Irten waf̧rnef̧s

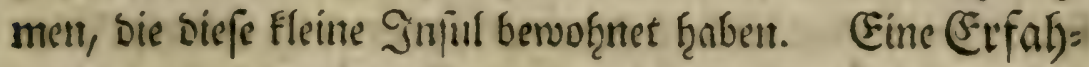
rung, Die bey allen Serfuchen bie פJrobe Ģalten wirb. Denn iff) habe fie ju oft wieberf̧olt. In ber Naturges forichte fino oft bie Eleinften IImiftánbe michtig. Dies

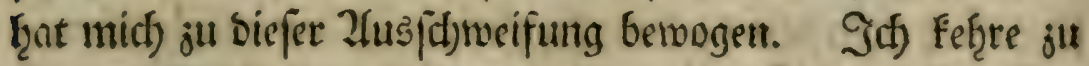

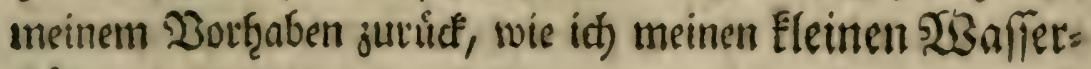
bår beobachtet ḩabe.

Dureth bie fofwaichern mifroffopifdjen Sinfen fant er

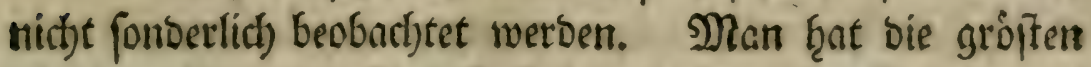
nótŗig, wenn man feine Beftalt uno STheile erfentren will.

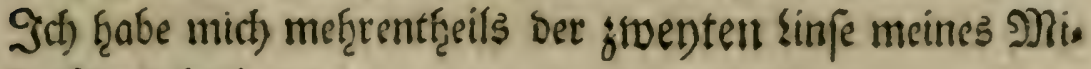
Froffops bebienet.

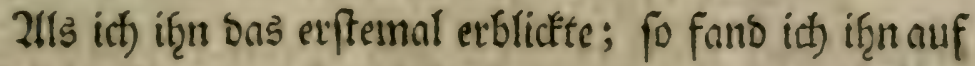

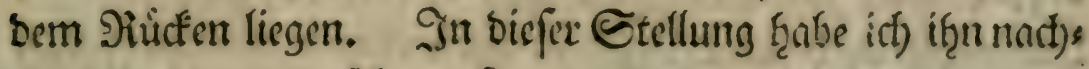
geffentos immer geferten; fo off idf if̧n noth) sinigenal ju bcobact)ten bas Blúct' gref̧abt.

Sein ganjer Rorper ift nidyt fo burd)fidftig wie Gel) anbern 2frten ber 20 offertf̧iere. Die Feaut, weldhe bie

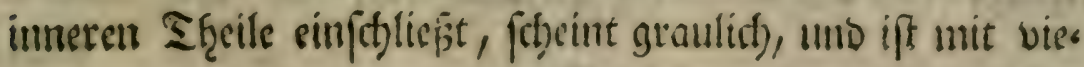
If 3 


\section{Won einigen metEmurbigent SisaffermfeEtent}

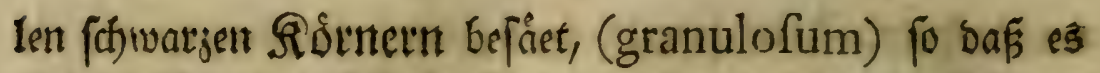

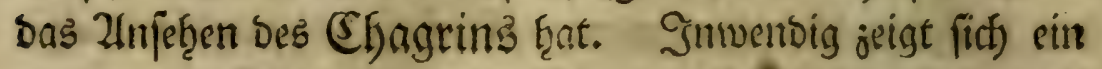

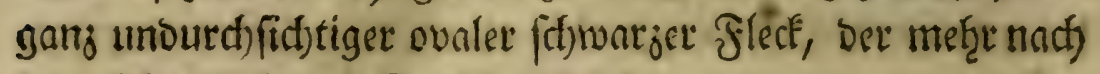
Dem Dbertheile bes Kopfes zullegt.

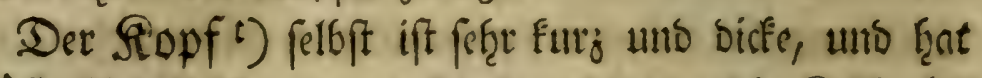

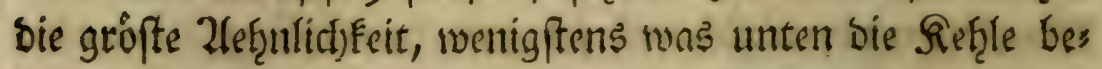
trift, mit einem Frofolyfopfe. In benben Geiten fiţen

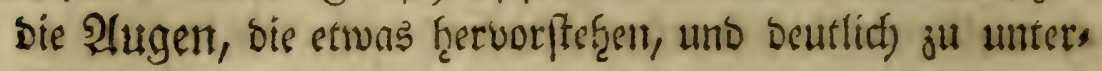
fifeiben finto.

Das Seintertheil gehet ftumpf ju, uno es ift baraur

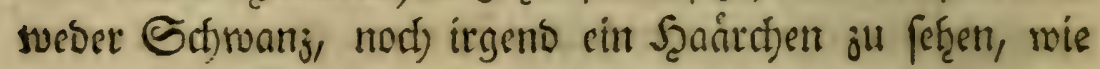
audf bergleidjen am gangen Rôrper nichte eins ju bemerfen

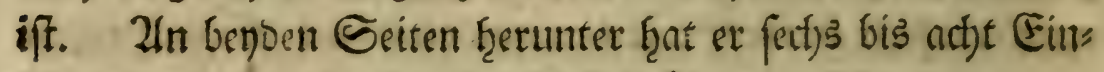

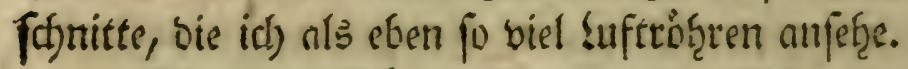

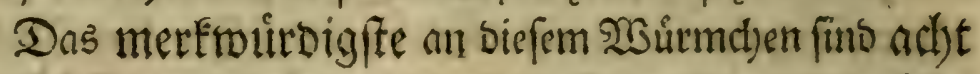

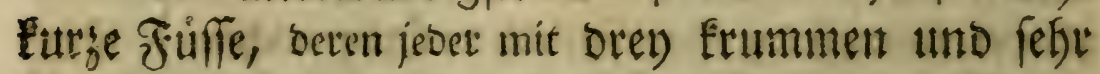
fd)arfen Silouen ") Gewaffinet ift. Seine ganje berwes

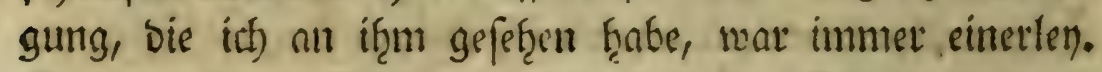

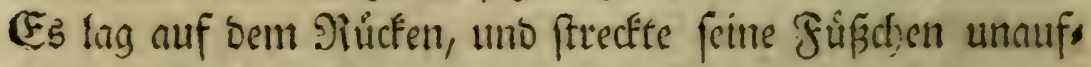

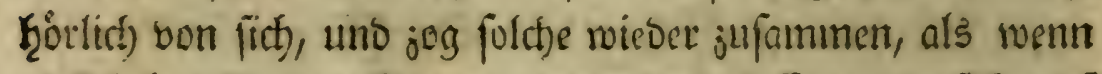

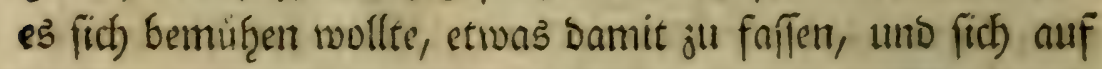

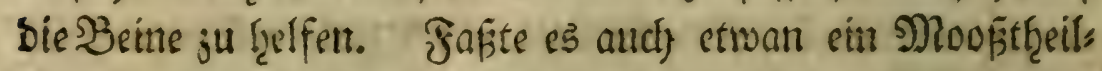
den, ober Dergleidfen, fo fonnte es sod) nicht auffomment.

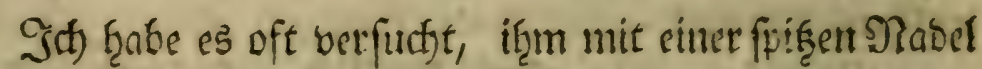

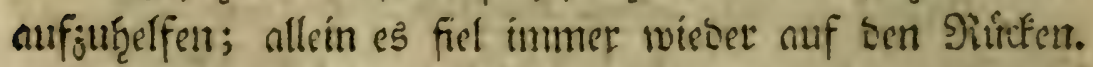

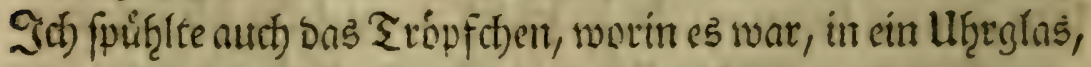

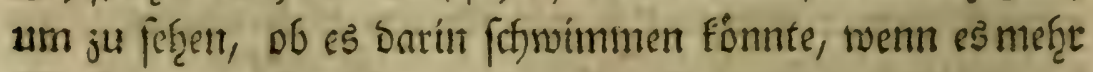
23affer unter fith faitte; aber eben fo menig.

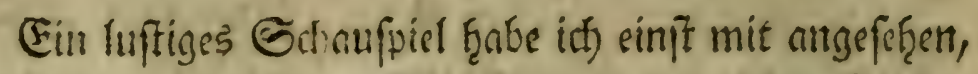

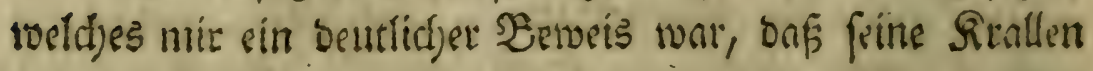
eben
t) fig. $7 \cdot a, b, b$.
u) c, c, c, c. 
efeet nidj)t allibufanft angreiffen muften, weenre s bamit ctwaz

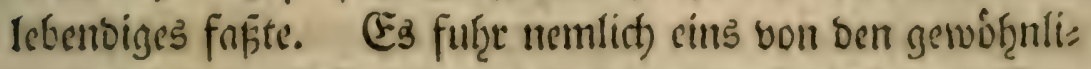

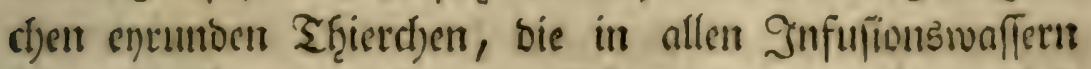

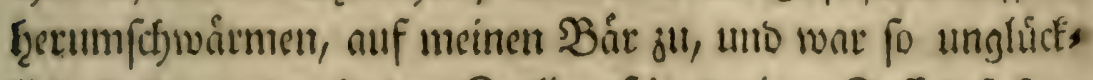

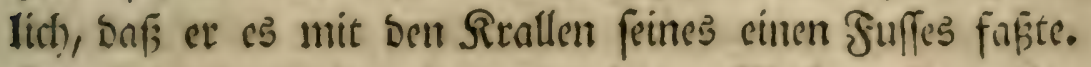

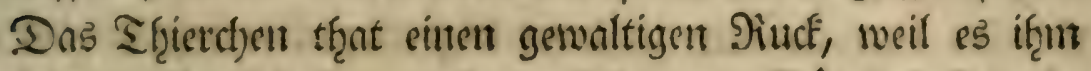

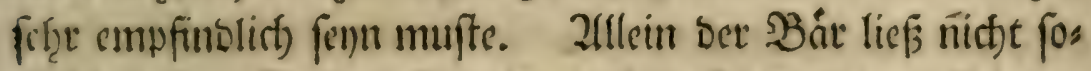

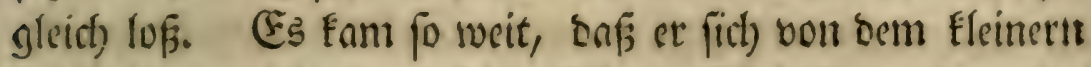

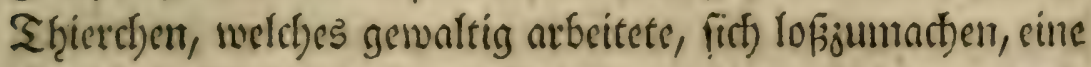

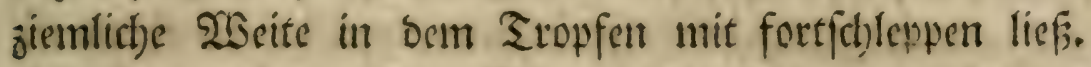

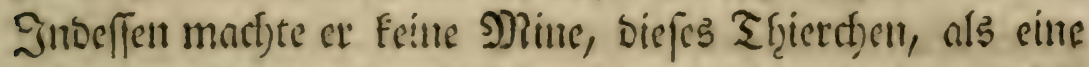
gefangente Sente, Durch) Zlnmenoung peinter anbern Fufffe

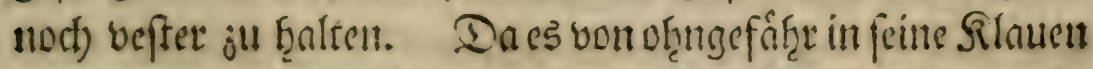
gefiummen war, fo forien es if̨m gleidyguiltig ju fenn, als

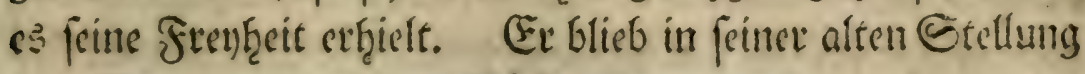

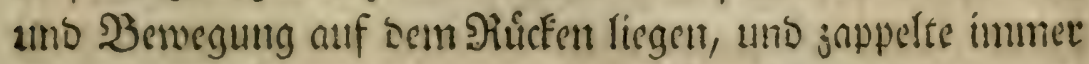
mit feinten Jüffen furt. Sit) verfolgte aber bas befreenete

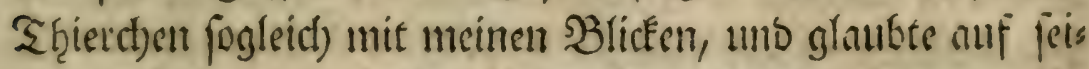
nem Piúcfen énen Siis ju bemerfen, wie es firf) bemt ancl) niç) mef̧e fo munter, als vortice bewegte. Es ging nadt)

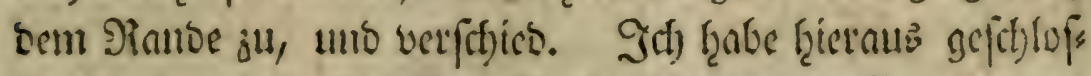

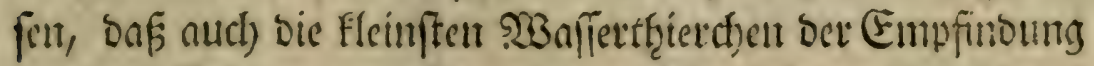

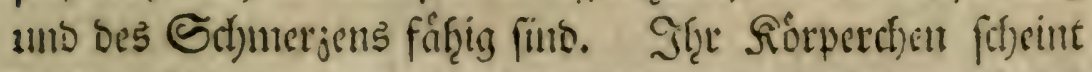

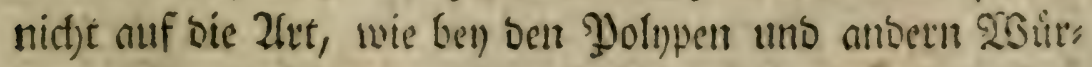

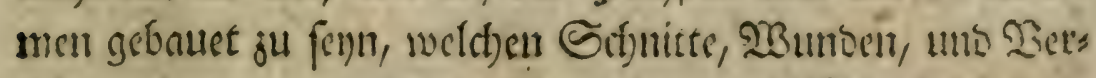

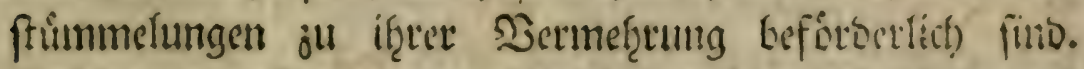
Edfopfer ber Elleptrantent und ?tromet, ber SBallfighty unt

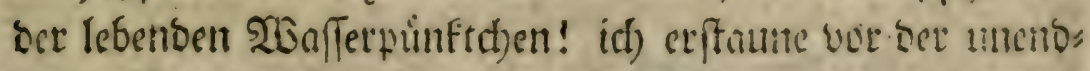

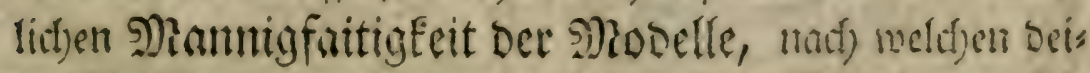

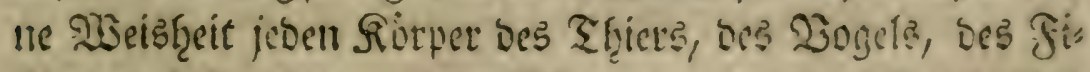

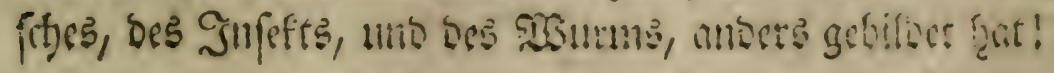




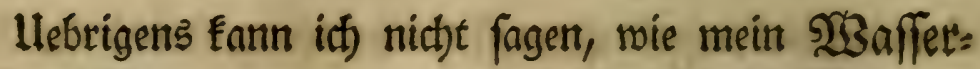
bâr feine Beute erjage, uno was er eigentlich für Nafrrung zu fich) nef̧me. Seine ganje lebensatt fateinet nithts anbers zu fenn, als fich) an ben Meerlinfen anz̧uf̧ingen, weil

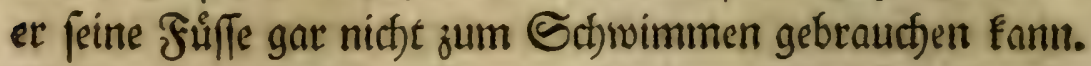
\$b if̧m aber bie 24 Slauen blof zum 2nnţången, ober

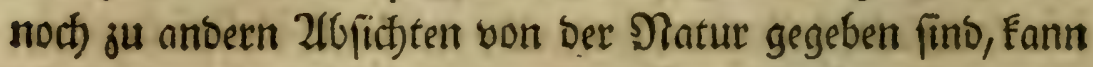
id) jeşe nod) niddet beftimumen. So biel aber ift gemín,

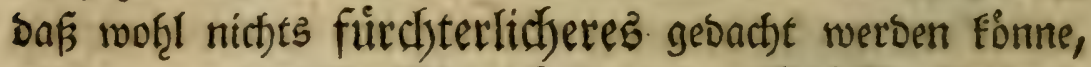
als wenn uns biefes Thierdyen in ber Giroffie eines eir gentlicfjen $\mathfrak{B a ̊ r g}$ er (cheinen follte.

Eins von biefen Thtierct)en ţabe id mit feinen গa:

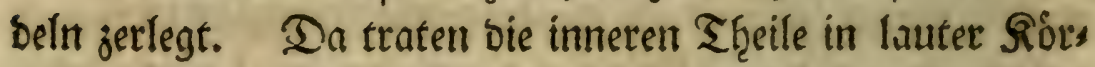
nern ḩeraus. Zluch ber oben genannte fhtwarge Sade fam hererbor, ben ich fur ben (Everfact halte. Die Rörner fof fen im $\mathfrak{2}_{5}$ affer herum, uno fobienen lauter burctfirtftige SBlästhen ju fenn. S2Better fonnte ith) von ben inneren Thęeilen nichts unterfat)eitoen.

Ein anbermal fano ith in einem Tropfen Meerlins fenwaffer, melches menigftens 6 พwsochen geftanden hratte,

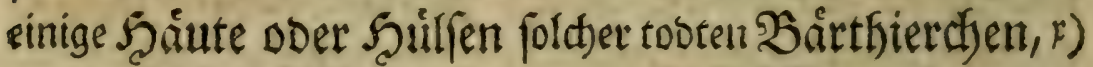

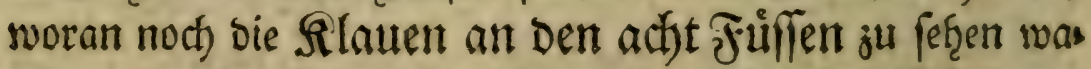
ren. Inwenbig in einer folthen Şaut, lagen eilf brautne ovale Roirperchen, mit ftwargen Flecten, worin bie Sungen eingefoloffen waren, Deren einige fid Darin wirf's fich nod) bervegten, wie ith und einige freunde jus

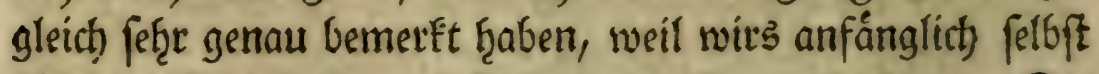

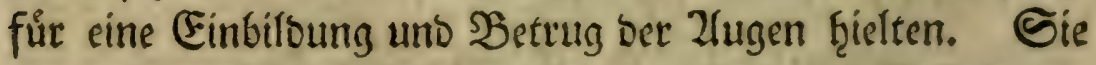

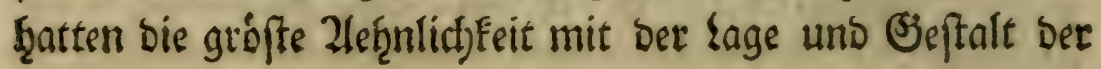
joges

3) Sid) will Damit iffer $\mathfrak{B}$ eltwanolung, wie bey den Sunfeeten, nidbt befbaupten. 
Fogenannten jungen Rugelthiere, Die auf eben'bie $\mathfrak{Z}$ rtt in ben 2(lten eingefftlofien fino y).

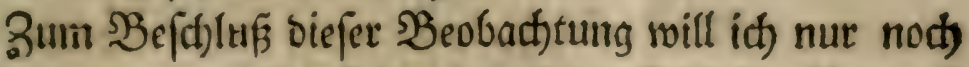

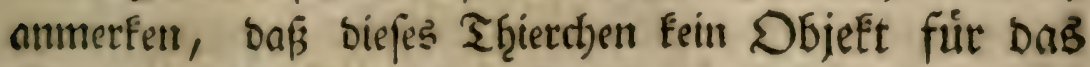
Sonnenmifroftep ift. Es ift ju undurchfifftig, uno es ift doran nict)ts beutlitfes ju bemerfert.

Da ber 2lllmád)tige fpradt): ę̧ merbe; ba bie (Erbe, 'biefer Tropfen am Enymer, aus feiner Sçand rann; Da ḩat

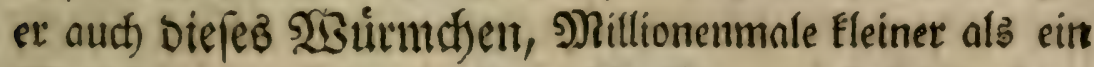

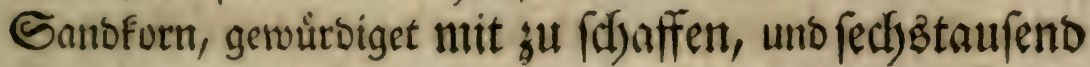

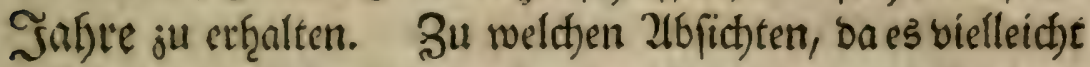
mein Zluge in biefem Sathre zum erftenmale erblicfet trat?

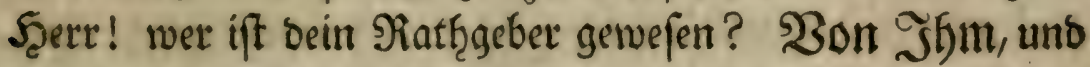

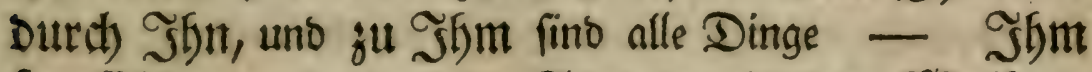

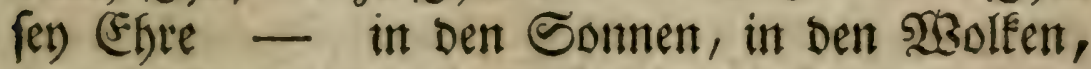
in Den Meeren, in Den Tiefen, in Der fidstbaren und unfidytbaren $\mathfrak{D B}_{\mathrm{B}} \mathrm{lt}$, in Den Sehemoten, uno in Dem

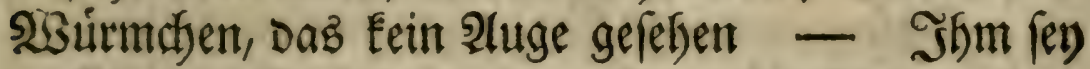

Egre in Ervigteit - Jam fen (EFre aud in meinem ग̧ergen. If 5

III. 25eobs

y) Diefes fettfame Tfier fat den Namen von feinet tugeleune Den (Sieftalt. (5̧ ntimmt aber unz̧ál)lige Geftalten an, Daß man g!aubt, gants antere Thiere ju leften. (Es hat oft oreyfig bis viersig junge fingetthiere in fith, Deren jebes rwieder 6 bis $\delta$ in fich hat, woraus man auf bie Frud)tbar: feit eilles cinz̧igen Iften id)lieffen Eaun, ba $\mathfrak{e s}$ fohon feiner

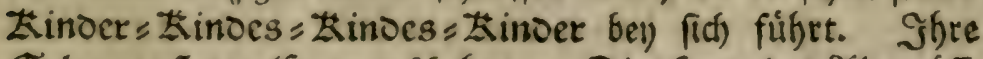
Geburt pfiegt alfo ju geldel)en. Die Şaut des aften off: net fid) an ocr Ecite. Die Jungen fhlupfen beralb. Die Siutter felbft aber, bie auf Dieje STeije geforen ljat, verges bet, unto if toie ein bisd)en weiffe Şaut anjufeben. Sidh

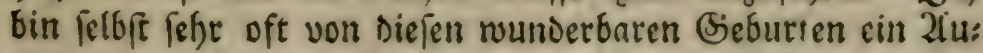
gengenge gervefen. Nian fanm fie bey Dem 2batee in feinen

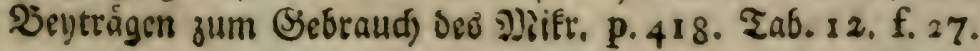




\section{Bon einigen metÊtwubigen 23 affertnfeetett}

\section{23eobact)tunty. \\ 3on Den Sugelquaduten. Tab. IV. fig. 8.}

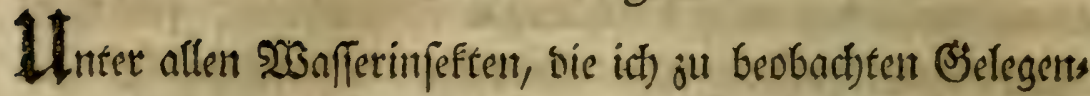

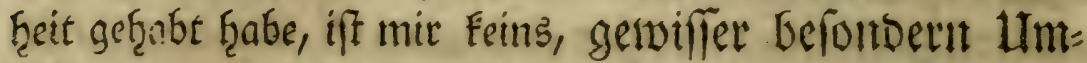
frainde wegent fo feltfam und wunberbar, nis biefes sorges

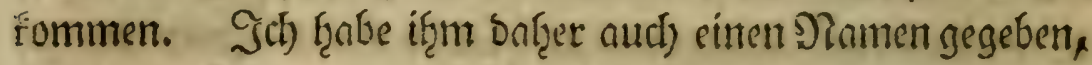
Der bielen fremo uno miserfprect)ent febeinen miro. Zlíleit

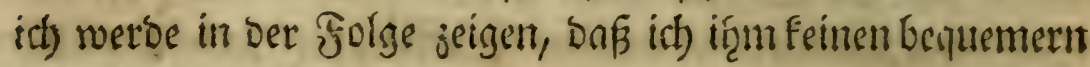
ḩabe benlegen formen.

Das Sugelquadrat if eine (Beffalt, weldye aus

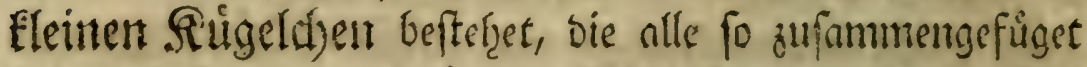

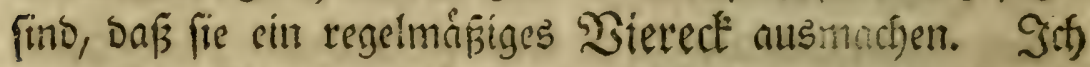
nenne bas (jantge vorlaufig eine (jeffalt, weil idf nod) nidft beftimmen fann, ob es nur ein eingiges Thier, ober ob jebe Sugel Deffelben ein befonderes Thier vorftetle.

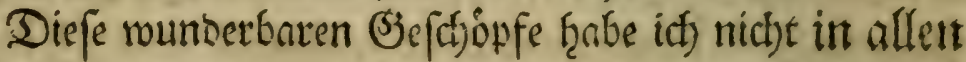

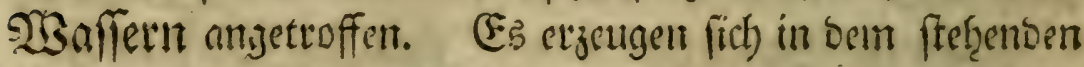
Diegentwaffer allerlen Sunfeften. Die mit vegetabiliffen

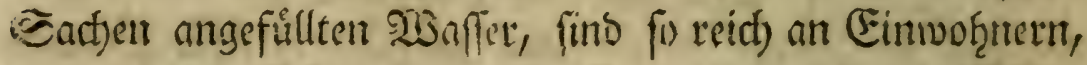

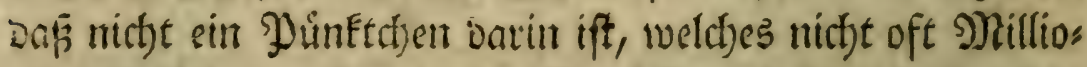

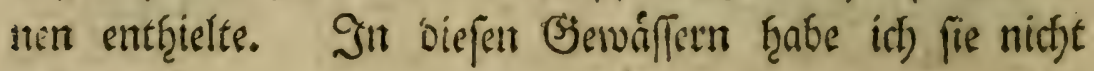
gefuntoert.

Ein Freutio von mir f̧at fie guterft in bem $25 a$ affer

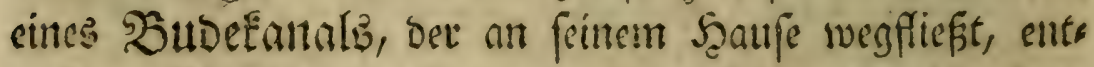

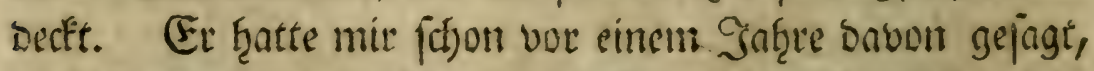
bicfer brave und mişbegierige Jretmo, bet an fich Fein

Gelefery

und itm Roefel Ginf. Soel. T. III. p. G7. Tot6. 10I, f. I-3.

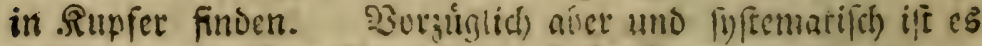
Befátreben in Otto Fr. Miiller hift. fucc. vermium etc. Hafn. 1773. 4. p. 32. Volivex globator. Linné S. N. ed. XII. p. 1325. 


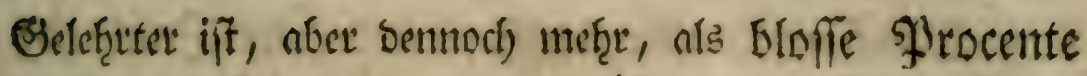

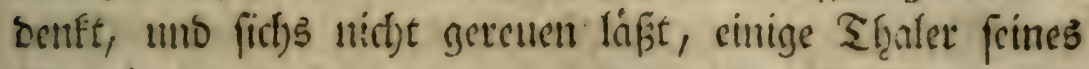

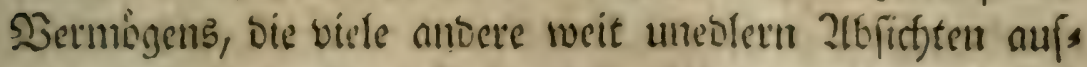

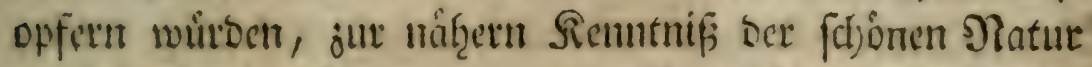

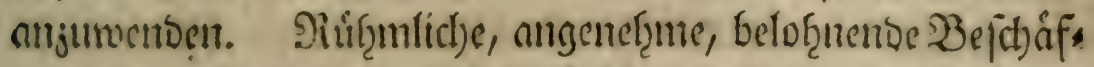

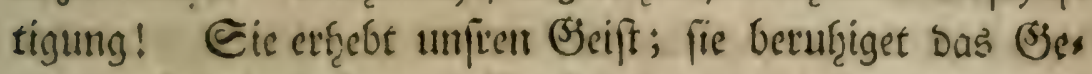

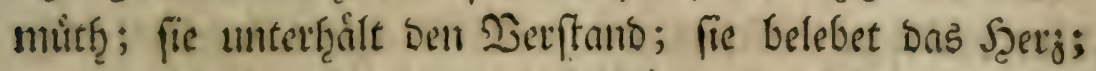

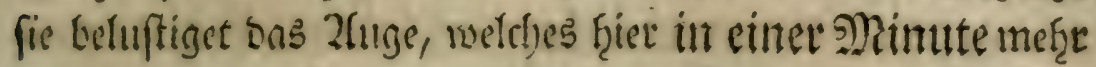

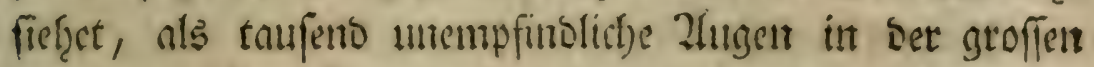

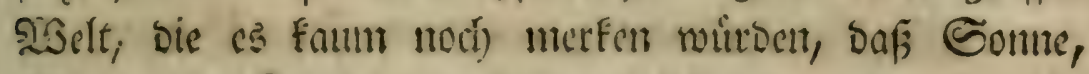
J)ono und Eterne ant Seimmel ftủnoen, wenn fie nidjet

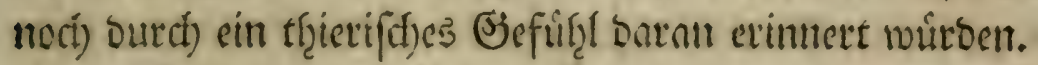

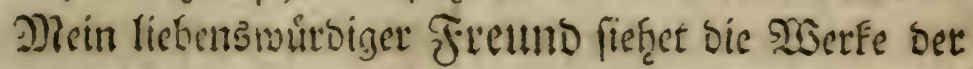
Dintur mit gan anbern $^{2}$ ftugen ant. Er jeigte mir in eis

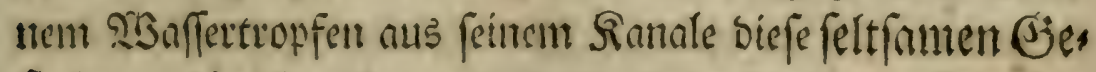

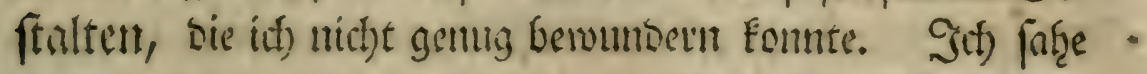

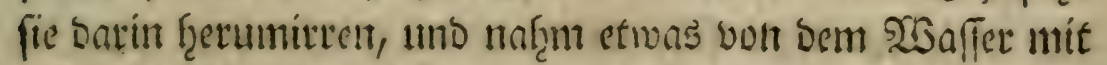

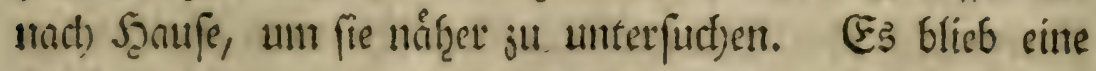
Beiflang in ber frenen suft ftergen. Eindlict) befatęe id) eins mal wieber sinen Sropfent, und erftaunte úber ben ?rublick

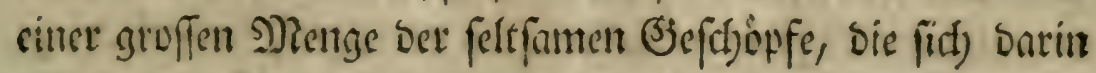
yor meinen 2lugen feetumbewegten.

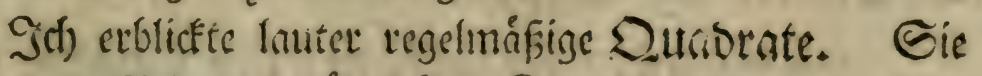

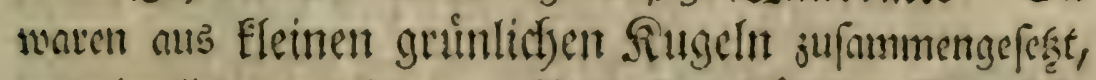

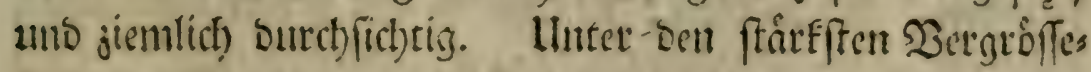

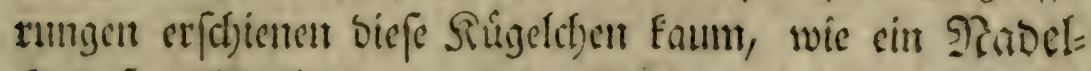
Enopf. Sostriter idf) an meifferit erftaunte, war biefes,

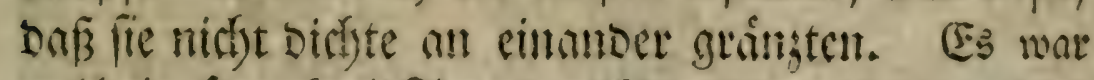

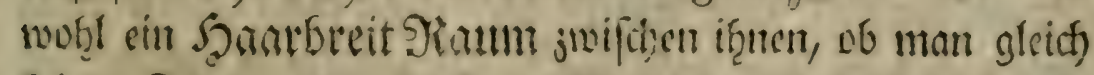

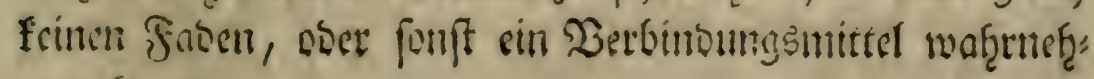
men fonnte. 


\section{Bon einigen merfmuirbigen গSGafferinféten}

Das fonderbarfte an if̨nen betraf if̧re Bahl, uns

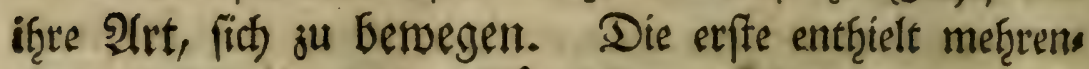

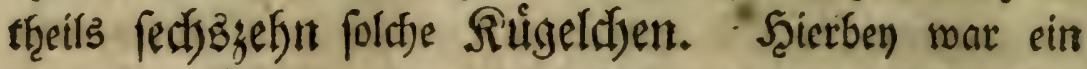
Sauptumftand zu bemerfen: Daß if̧er niemals mefr,

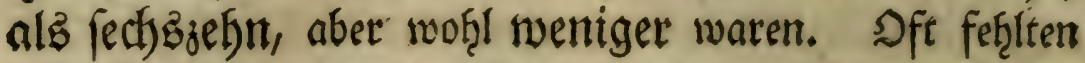
in ber Mitte, auch an ben Seiten einige. Dann war aber

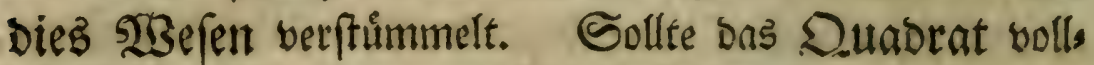

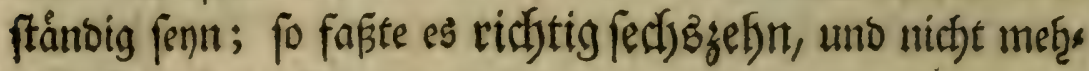
reve Rugeln in fich.

(Eben fo merktwurbig war aud) feine Betwegung unter Dem Mhifrof Fope. Denu mit bloffen 2(ungen war bas bon auth Fein Dưnftchen zu feţen. Es gefthahe nber feime Znt fich) zu bemegen, mit einer fold)en Regelmåzigfeit, baß biefe allein fuon im Stanbe war, Das Zuge bes Beobs nchters an fich ju jief̧en. In Bergleicf)ung mit anbern

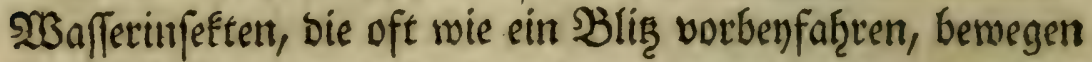
fict) biefe Duabrate fef̧r langfam, aber mit einer gerwiffen Dronung, uno Taftmánigfett, melche mich allein úbers

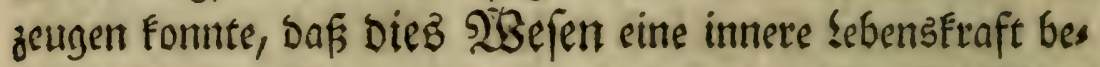

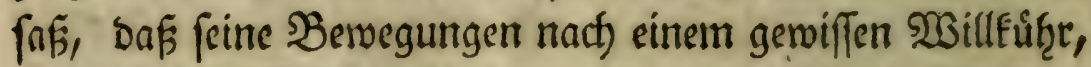

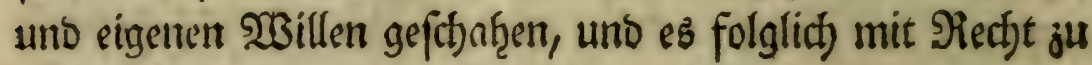
Den Thteren ju rectyen (en.

Bwenerlen if mir baben nod) fefge fonserbar vorges fommen. Daš erfte: Daf ich an Den Ritigelditen felb/t nicht bie geringfte Bebwegung wafrgenommen ḩabe. Das ziwente betrift bie Bemegumg bes gangen Duadrates felbft. Drbentlich brefeet fich fold)es jwar allejeit in Sircife f̧erum; feine Fládje aber bleibt nicht immer oben, unt nach) bem Iluge jugefeftrt. Dft menter es fich auf bie hoţe Rante um, unb tunnmelt fict) eben fo vegelmásig in feinem Rreife. Dan fann alsbenn nut sine Seite mit 
vier Rugelut fergent. Die unterften fint fo lange berborgen, bis fict) bas Duabrat wieber auf bie Seite legt. T2Serben etwa burd) einen Zufall einige Ritgeldfen bavon gettentet; fo brefret fich) Das Sjange fort; bie abgeriffenen Ruigeldyen aber fotwinmen an bie Seite, unb bleiben unberweglict.

Bey ber genauen Beobact)tung, bie idt) biefen felt fas

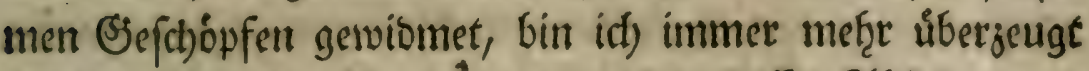
worben, baf́ if̧re B̉ewegungen nact) gewiffen 2lffict)ten ges

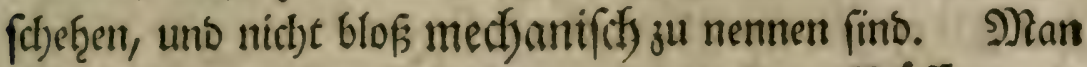

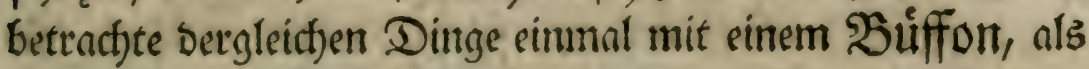
belebte organifitte Theilchen, und verfunde $\mathrm{es}$, ob man

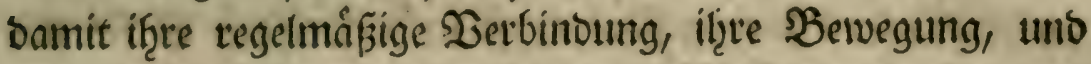
altbere llmftanoe vereinigen fann. Wiefleich) aber fommen biefe Risgeldyen butch einen bloffen Bufall zufammen! Gefést alfo: warum vereiniget aber ber Zufall nur immer

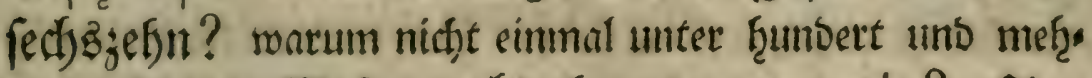

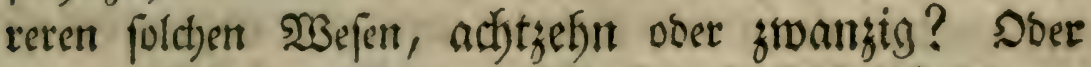

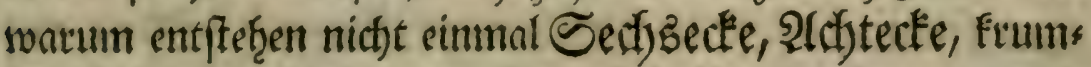
me, fojiefe unt sergleidjen Siguren? WBarum immer regels månige Suabrate mit fedjş̉efn - Rugeln? Ja! warum fogar in jeber Seite befferben gleithe Zanfelen von Rugeln? Rann man von Dem Sufalle eine folde regels másige Drbnung erwarten $\left.{ }^{3}\right)$ ?

Sch) Fomme ju ber Unterfurfung einer anbern Frage. Sino bie Rugeln biefer Dunorate eingelne Thtere, Doer nur Sblieber, Theile unb Jelenfe eines ganjen Dunbrats. Rann jebes Raigeldyen als ein befortberes Sficer vor fift)

leben?

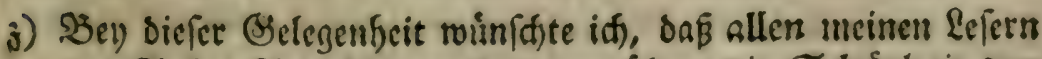
Die Eulzerfhen Llnterreoungen über oie Gdhónbeit oer IZatur, Berlin 1770. 8. infonderbeit Die furtreflidjen (je: Danten von Der đborbeit Des Jufälls, S. 70. befannt wers Den mógten. 


\section{Bon einigen merfwurbigen $\mathfrak{3}$ afferinfeEten}

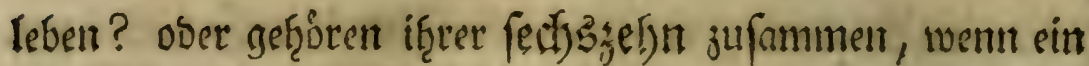
Banzes entiftef̧en foll? Sönnen fie firt) ju ciner gemiffen Beit trentren, 1 tho fict) mieser auf eine anbere 2let vereinigen?

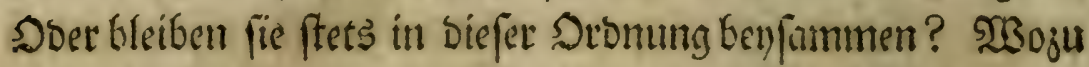

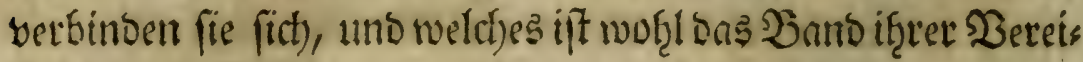

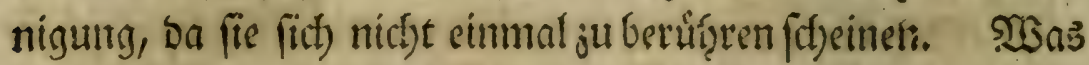
ift bie 2loficht therer freisformizen B̧erwegunty? uno warum

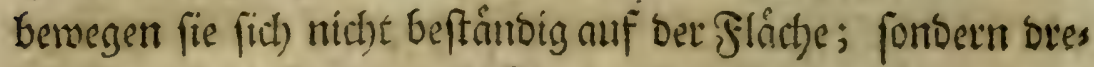

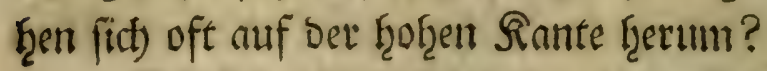

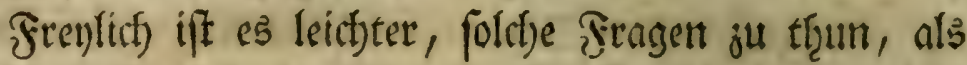
aufjulber uno ju beantworten. So fimpel bie Etruffur

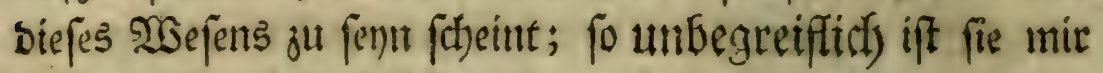

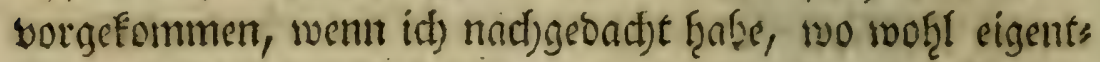
licf) Der Sif̧ Deb Eebens, und die Quelle Der Serves guntg Darin ju futyen fen. " ) Z(lles, was idl) Davon ver:

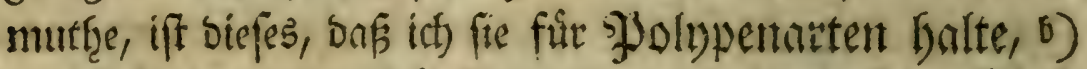
welche mit unendich) Eleinen uno Dem beften Gilâe unfiditbaren Fröben zufammenthaingent. Nod) eing

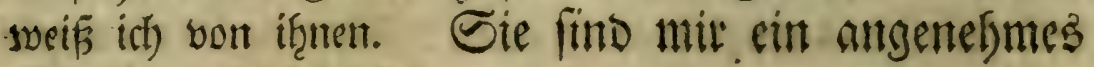
Bild Der Siefélligéeit gewefen.

IV. 25eob=

a) Ez gieft mefrete folche befondere Şaferturtmdjen, die bett

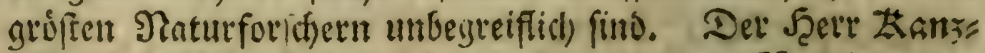

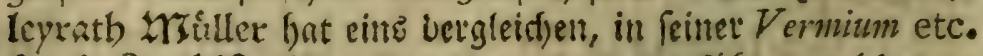
fuccineta hiftoria p. 98. n. 104. ansefuffert, weldes $\mathfrak{c k}$ Vorticella polymorpba nemet, 1 tiab savon fagt: Oculo punEtum agiliffimun viride, fub microfcopio momentis paucifimis tam multas et varias formas induit, vt nec calamo, nec verbis exprimi poflint; ex omnibus Naturae mirandis, quac videre milli contigit, boc fane maxime mirabile, ac fummum Naturae artificium quod animus ftupet, quo oculus bebefcit, inopsque Spectator quovis moneuto roget:

Quo teneam vultus mutantem Protea nodo?

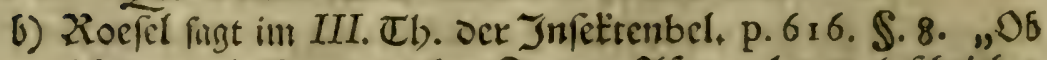
id) mun sleid) neunerley Corten 2ffterpolypen befoftiebett babe; 


\section{2eobad)tuntg. 23 on Dem Eidtelthiere. ฐat. IV. fig. 9.}

SI bermal cin neuer शame, ber cin befonberes Juffett uns

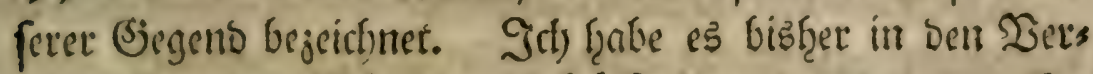

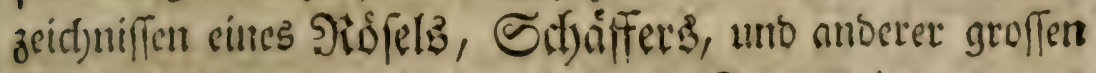

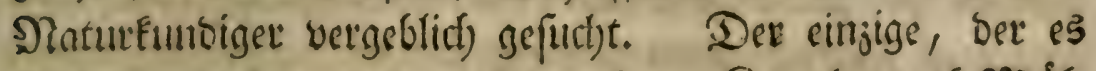

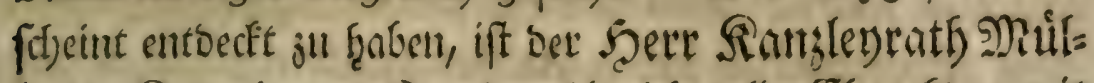

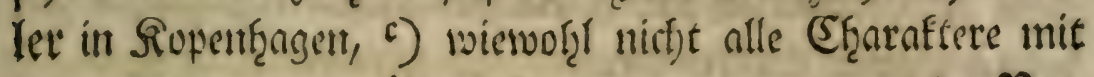
Dent meinigen genna tibereinfoummen, wie man aus Der 2 ers gleíc)ung fercen wirt.

Dies

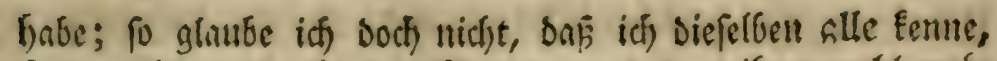

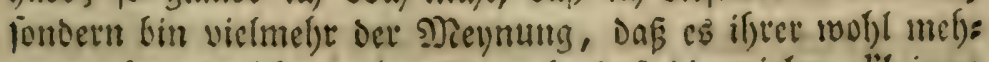
rete gebe; ja id) mutlymafle aucl), Doris Dic vielen Hleincit

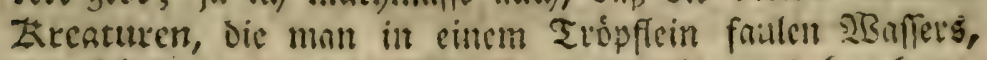

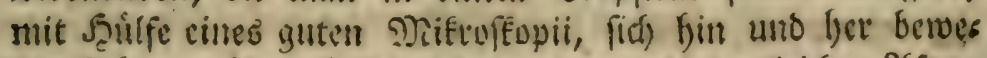

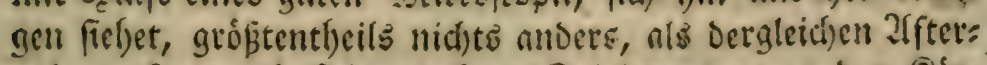

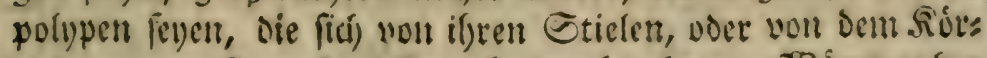
per, woran fie vefrgefeffen, binwegbegeben. Isaăren aber

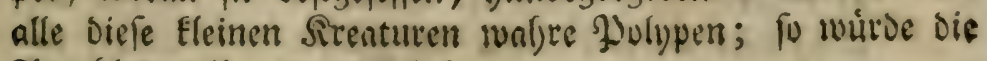

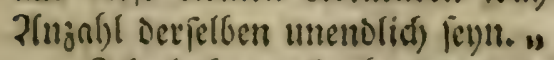

Ga) babe nadjgebenos eint afonlidje 2ltt jufammenge: reifeter Singetn in Dem siecrlinfentualfer gefunden. Eie fefienen mii mit bent gegentuártigen einige 2(cl)nlidjeeit ju

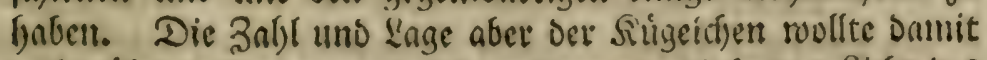

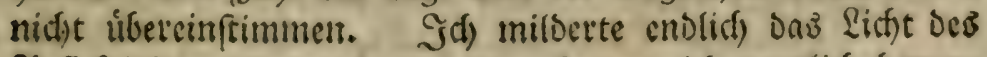

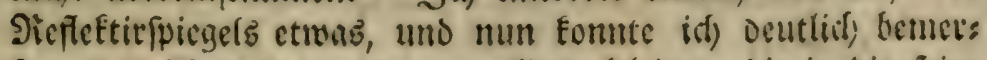

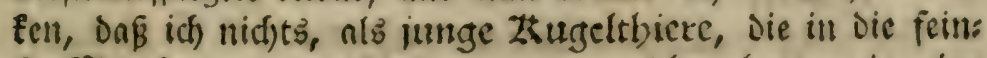

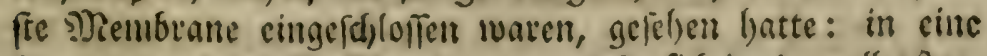

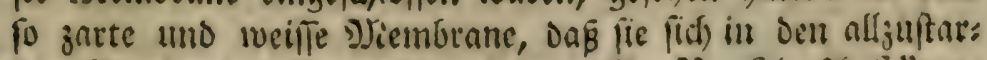

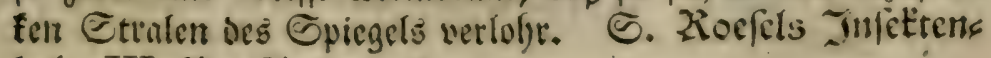
bel. III. 25. G. 619. ఏ. I2.

c) Vermium terreftrium etc. fuccineta hiftoria. p. 46. nr. 29. (Er netmet es Vibrio fals. IIt Der Ereflarung heipt is: Corpus pellucidum, ellipticum, antice in col. lum teretiusculum hyalinum trunci fere longitudine 


\section{Bon einigen merféturbsigen $\mathfrak{3}$ anferinfeEtten}

Diefes Thierchen hrabe ich fonft nirgends als in bem WBeifer eines hiefigen Sartens, an einigen einzelnen auf

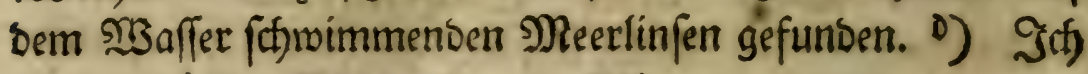
eile zur nåf̨ern B̉efanreibung Deffelben.

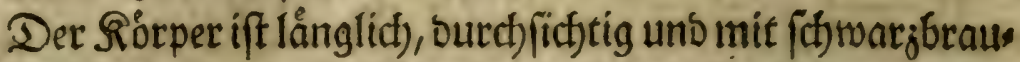
nen Punften, ${ }^{\text {) }}$ ) Der (ånge nach) beflecft. Şinten gef̧et berfelbe fpif̧ ju. Uleberf̧aupt ḩat bas Rörperchen nicht bie geringife Diffe; es ift roie ein fatmales bunntes Streif: d)en Эapier anjufęen. IIn beiben Seiten ţat es vier bis fünf zarte Einfannitte.

Im $\mathfrak{m o r b e r t h e i l e ~ D e s ~ \Re o r t p e r s , ~ D e r ~ n a c h ) ~ গ ু r o p o r t i o n ~}$

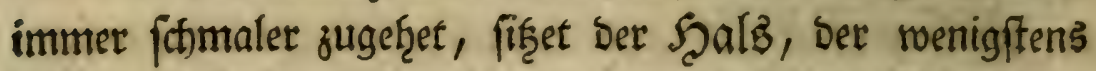
brenntal fo lang ift, als ber ganze keib bes Thtertertens. Es fann if̧n erftaunlich oft veránbern, jufammenjief̨en,

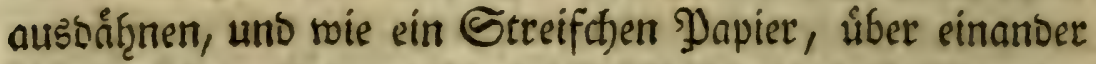
Flappen. 1) Die gewoinnlichfte (Seffalt Des Scalfes aber ift einer Sictuel s) ån̨nlicf), mesthalb ich es auch) bas

Sidfel:

attenuatum, poftice obtufum. Ipfe truncus fupra planus, fubtus convexus, feu gibbo inftructus, moleculis minimis impletus, globulis duobus hyalinis, altero intra extremitatem pofticam, altero in ipfo corporis medio.

Latere plano furfum vergente provehitur, gibbofum raro obvertit: formam falcis collo fere immobili imitatur.

Quoties deorfum tendit, collum aliquantum inflecti videtur.

In paludofis Lemna refertis.

b) Nacigel)ends auci in (tef)enden Seegraben einer benachbat: ten Gegend, oie mit Sdilf uno গieerlinfen ganj beoecfet waren.

e) fig $9: \mathrm{b}$.

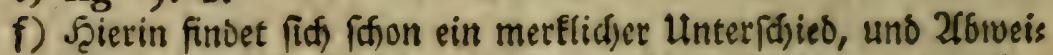

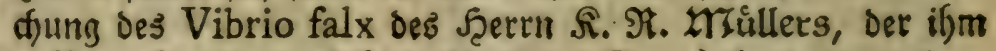
collum fere immobile zuldfreibt. Der 万als Des meinigen ift feinen Zfugenbliaf rubig.

g) fig. 9. $\mathrm{c}$. 
Siefleidft werben einige meiner !efer benEent, als f̧ấts

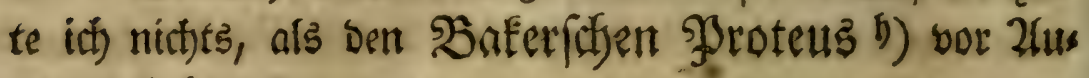
get getrabt.

Da idf) von meinem Sicheltfiere nur fệt wentis

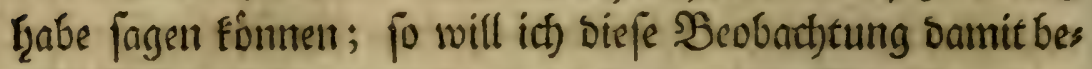

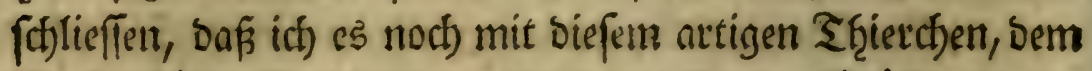

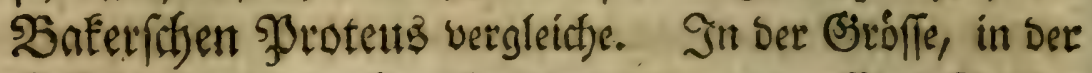

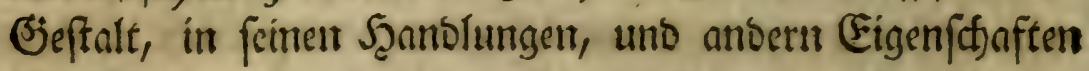
ift biefer bon jenem fefre weit unterfdjieben. Ex fdjwims

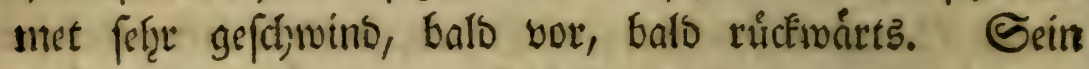

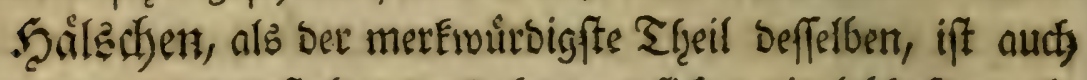
ganz anbers geftaltet, und beivegt fict) weit leb hafter, als

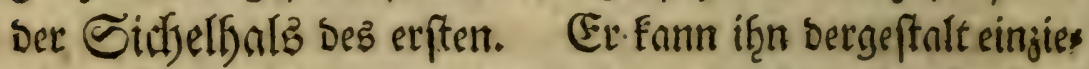

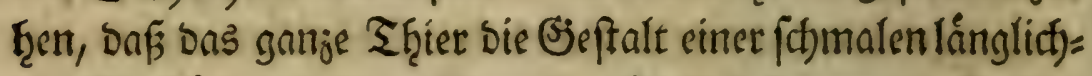
ten Flafdre mit einem ftumpfen Stalfe befommt. In Dies

6) In finen 25eytrágen sum Gebraudb, uno Derbefferung

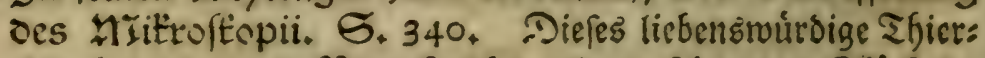

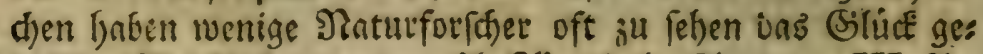

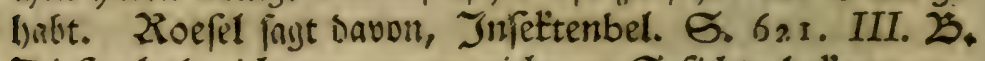
Diefes habe idh nun zwat nicht zu Gefichte betoonmen. J Vibrio Proteus; und fagt bayon: motus corporis lentus, colli vivax. Rarus, annis $1759-72$. bis tantum

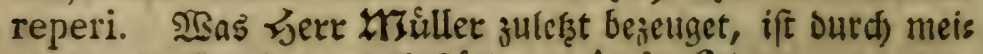
ne eigenen (Erfahrungen befrátiget: At in figuram 3, et 4, (Bakeri,) mihi nunquam fe mutavit, nec vllum organum rotatorium, aut cilia, nec colli totius occultationem, licet diu obfervaverim, vnquam vidi. Cl. Pallas, cui foli hucusque vifus eft, Rrachionum facit. "I. Jifl ba: be es feit jocey Jafjecen einige bundertmal, aber immer in

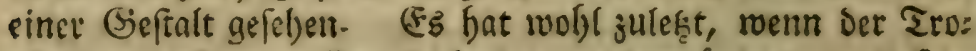

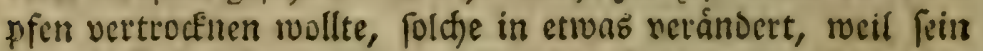
ganjes Siótpercten jerging. Goldthes faunn man aber feine

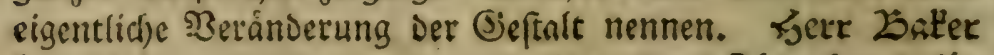

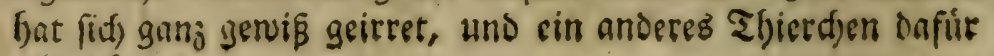
angeeferen. 


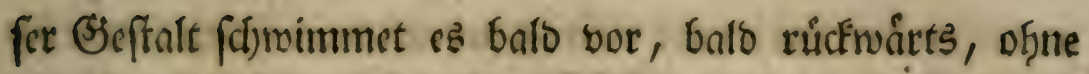
Daf; man etwas von Srganen, Şưfen, ano bergleid)en wafter

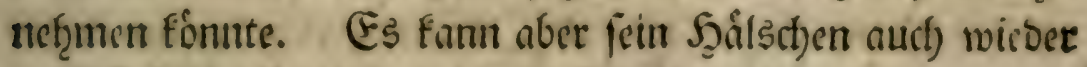
Dergeffalt verlángern, uno amsftreećen, Dafós man jweifelt,

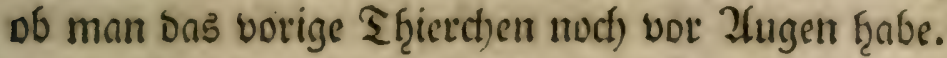

Da idf cinmal ben झroteus genemnet ţabe; fo will idf) boct) noch einige bejondere daran bemerfteErfaferengen mits theilen. Safer f̧at if̧m diefen Diamen bengelegt. T2Eeit

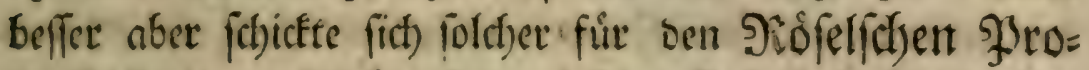

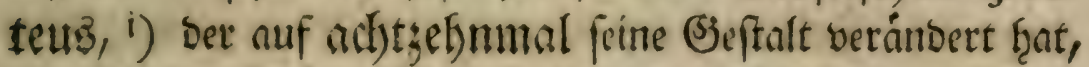

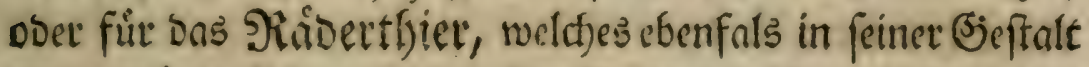

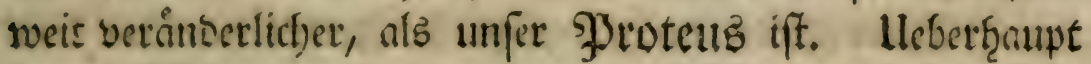

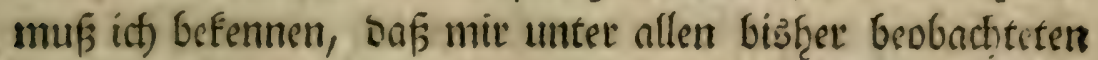

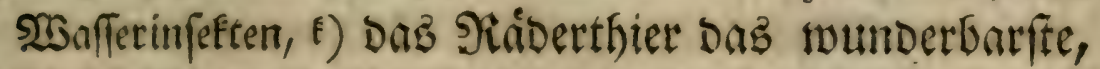
Diefer झroteus aber Das angenefmite gemefen. Die ganze Sróffe Des lef̧teren unter Dem Mifrof fop betrågt

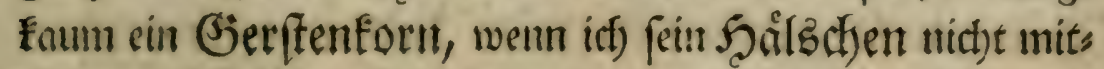
rectine. Diefez aber zitfert 2luge, 2lufmerffanfeit, uno unfere ganje Berwutioerung an fict). Er faum es fo lang

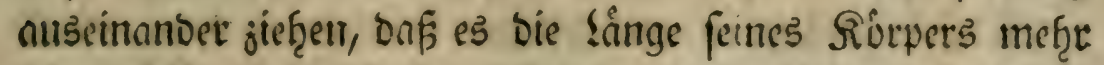

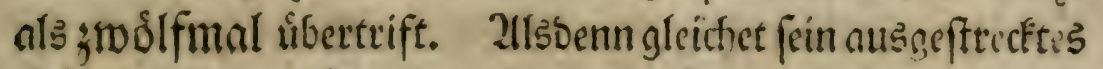

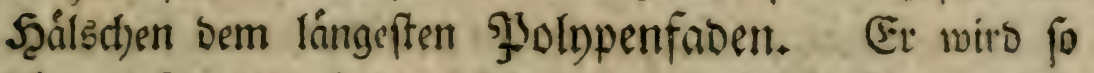

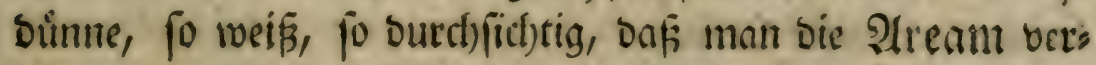

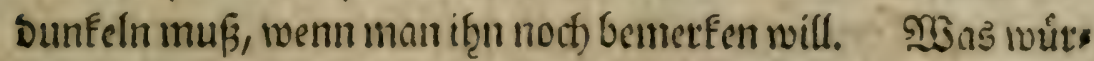

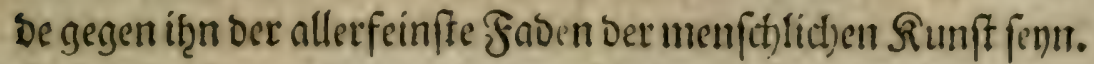
STas ift mit ber feinbeit eines Spinnenfadens ;u vergleis

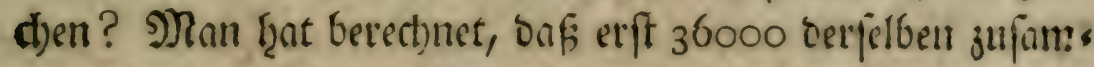
mengebreferet werben miffen, ef̧e ber feinfte feibene Faben dats $\mathfrak{B b} 2$

ดนร

i) Infêttenbel. III. \$. ธ. 621. ₹a6. CI.

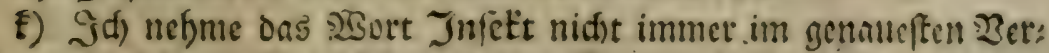

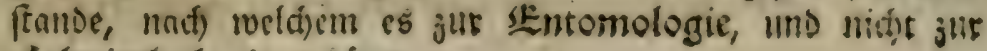
Zclmintbologie gebóret. 


\section{6 ßon einigen merfmuirbigen NỉnfierinfeEten}

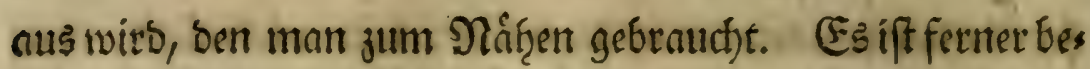
fannt, bafj jebe Der fectys 2 Barzen, aus welchen die Spin= ne ifre Faben jief̨t, trufend Defmungen trabe, Deren.jede ingren faben treift; folglich mus ber ftårffife Faben jeber Epinne aus 6000 Eleineren beftef̧en. T25as ift Das als

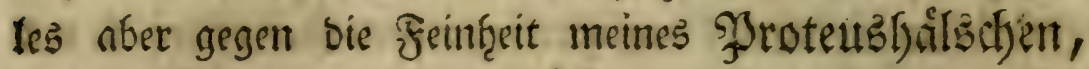
sveldjes s) Rillionemmate vergroffert, nod) immer unenolich feiner als bet zartefte Spinmefaden bleibt? unb, melches bas bervunternstwurbigite ju nennen, ein Sheil, cin telebtes Drgan eines lebenten Shberchen ift? SBie groß̧ ift Giot: teร Macht im Rleinen?

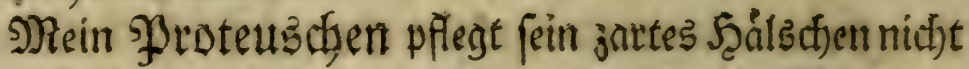

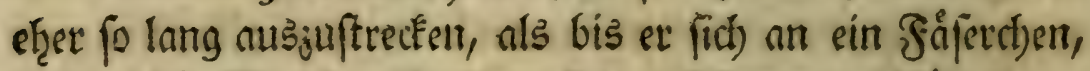

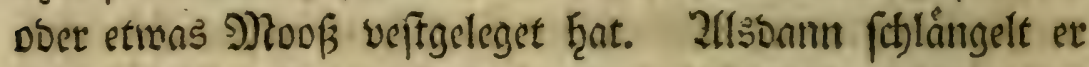

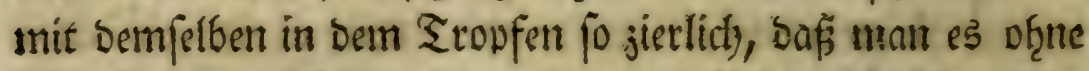

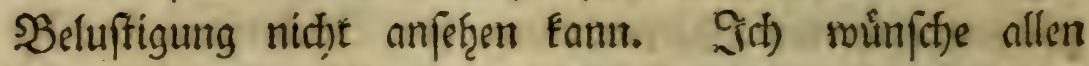

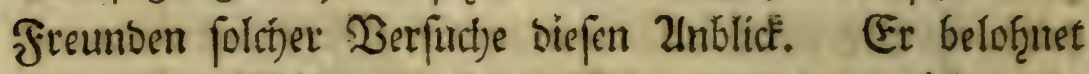

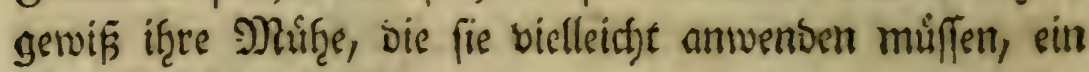

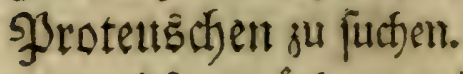

Dft gersth er mit feinem Scălschen unter etwas Moof, ober Untath in Dem Tropfen. M) Man verlieret if̧n

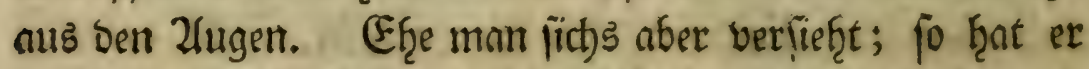

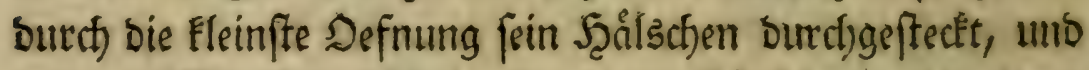
seit im Sropfen erblictet man sas Siopfit)en init einem

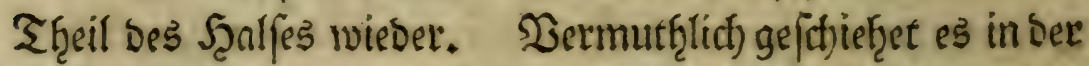
2(bfict)t, Naf̧rung ju fuct)en. Sith habe biefes Sthaupiel halbe Naichte bettact)tet, of̧ne ju ermúben. Z(uct) viele von meinen Freunben, bie es mit angefefren ḩaben, bृaben mir if̧re Zufriebenţeit Dariber nicf)t gemigfan bejeugen fonnen.

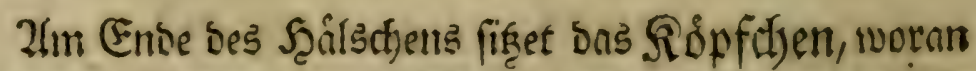
ich aber meder 2(ugen, nod) Mutr, nod) fonft etwas ḩabe 


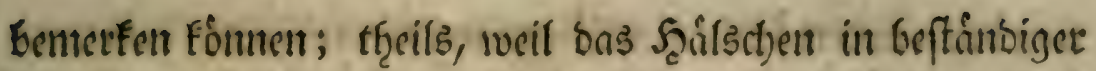
Betvegung war, tḩcils meil es fich) unter ben frâtfften 2 et. grófferungen als cin foft ummerflicies गJunftet)en jeigte. Giroffer Sdjoffer Des unendidyften Eleinen? wab fant

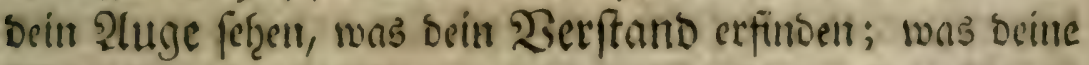
2iseibl)eit bereitu? uns wie vid blibt unfen 2lugen nod) verborgen? SRan mathe mut ben Sd)lus: erjasinet

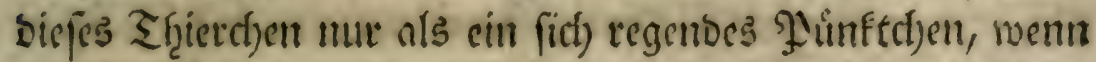

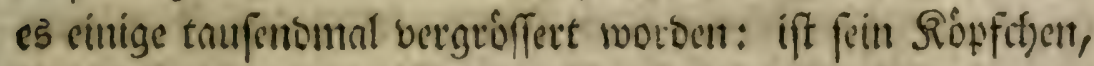

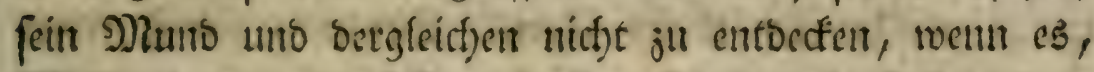
9) Rillionenmal vergeoffert, unfrem 2fuge bargefteflet wirb: 25ie Eleut, wie fubtil muf nun nid)t die פabrung fern,

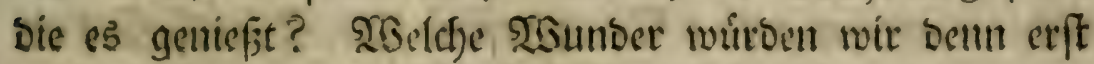

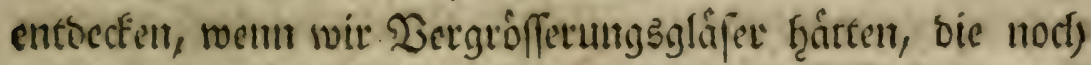
9) 2iflionemmal mefr wergrofferten, afs bie beften bie wir

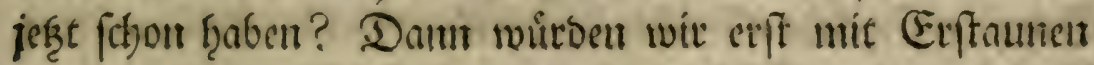
getwahte werben, twie weit, wie unendith weit wir nod) von

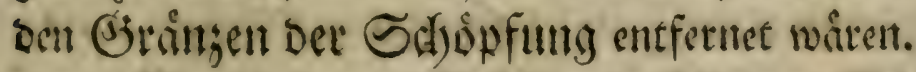

Eine befondere Erfaf̧ung foll Den Sdyfur biefer

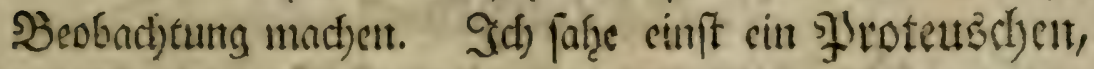
Des 2(bendos ben) Sidfte, fefre munter in feitum Elemente frers umf(d)wimmen. Es ḩatte fich unter Dem Etiele sinter 9) Reerlinfe verborgen, uno jublingelte fein Şälschen mit fels

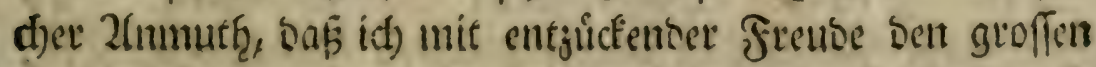

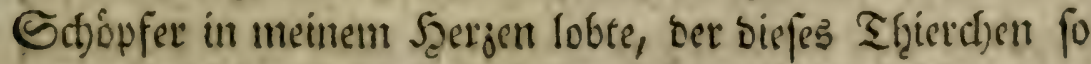
reigeno gebiloet hatte. Shier fahe idf die jufriederte

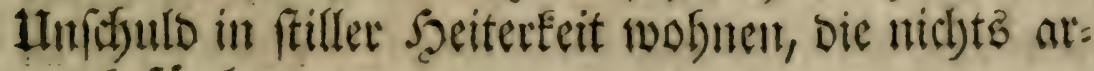
ges befird)tet.

Dan ftelle fid) mcine (Empfindung vor, als id) fefren

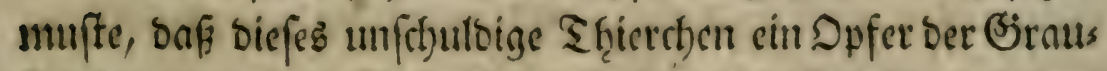

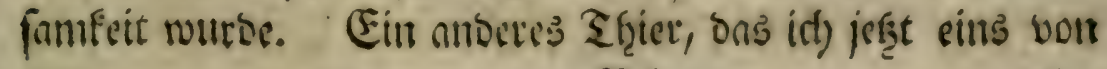


388 Bon einigen merknurbigen 23 affertinfeftett

Den ovalrunben Sdyantentf̧ieren nenten will, bie bald vor,

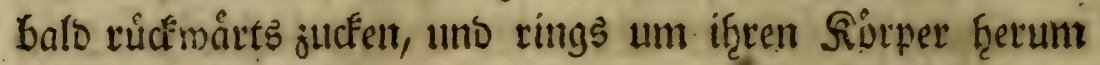

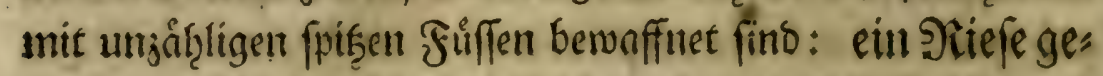
gen Den Jrotents! cin folches fam nuf mein fictjeres

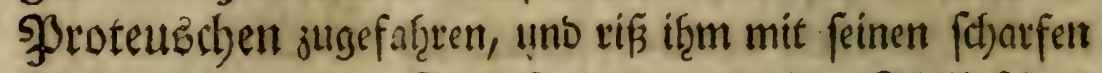
Fưffen nicht nur ben Ropf, fonbern auch einen Theil feines f̧ålschens ab. SBendes blieb einen 24ugenblicF in bem Sinubţ̨ieve, wotruf es feine zufanmengezogenen Fùtfe ifnes te, uno ben abgeriffenen Ropf fren hinfallen ließ, Dafs man. if̧u fonnte beutlict) liegen jef̧en. Der entrarffete Droteus aber fuhre plogelicl) juritcf, entflohe mit feinem vermunocten Sorperchen, uno itb fonnte if̨n nachgehenos in bem Sropfent nicht wieberfinden. So herrfhet Die Feindfeeligkeit

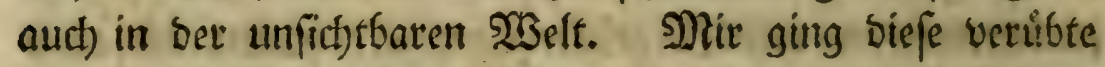

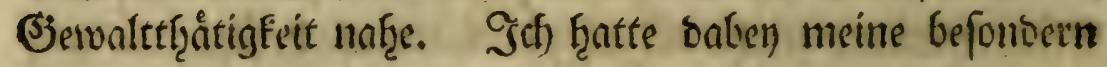
Gedanfen, weldye id) allen tefern úberlaffe, bie ben Gauf ber TSelt fenten. Mir vergieng bie tuft, lánger zu obferbis

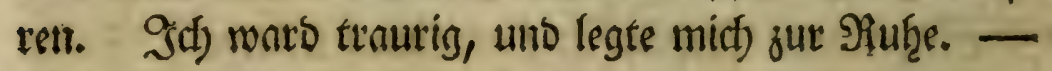

\section{25eobad)tung. Zon Dent jerplakęenden Thieren.}

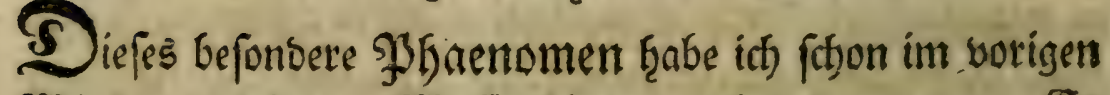

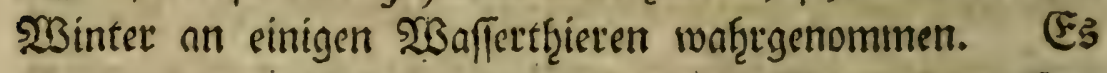

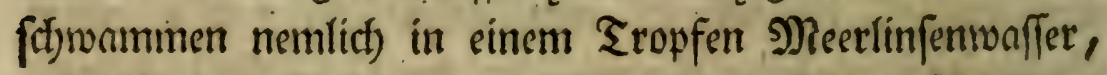
jwen bis bren braume, uno jiemlich breite Thiere fę̧r muns ter Gerum. Sie Ģatten bie Sieftalt einer SBairraupe, ivenn man fith foldte ofene Scaare geoentt. Man fonnte an if̧nen weder Ropf, nod) Filfe, trod) andere Theile unter fcheioen. Gin ber Mitte waren fie ctwag bidfer, als an

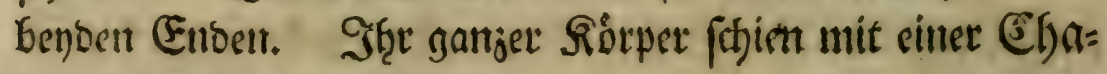
grinbalt uberjogen ju fenn. 


\section{Bon einigen merfwuirbigen 23 afferinfeftent}

Natur eines organi(iirten Rörpers nid)t vereinigen. Ith

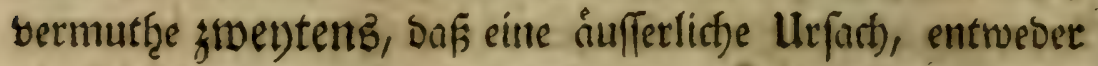
bie Suft, bie es nid)t ertragen fómuelt, ober ber 刃angel feis

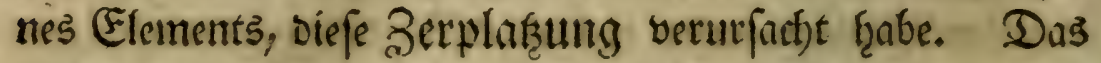
ganje Thier fom unir brittents niff)t anders bor, ols citt (Sd)laud), Der invenbig mit lauter Rörnern angefútlet

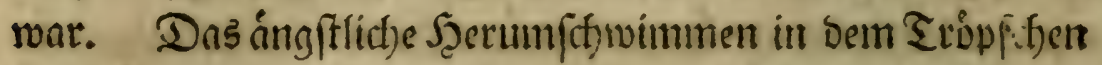

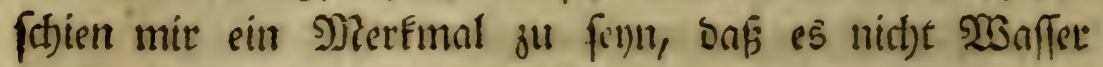

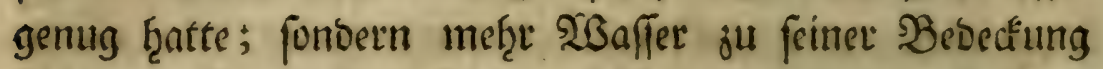

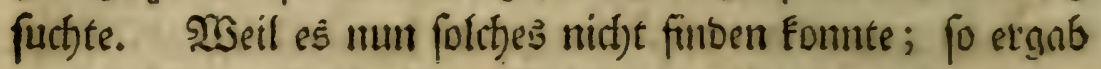

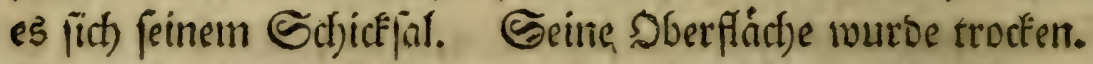
Daburd) jerplaşte bie Scaut, unb es fothuttete pein Einges weibe aus.

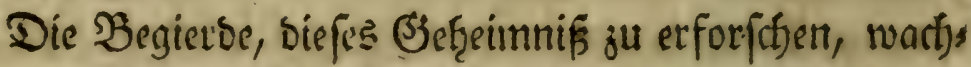

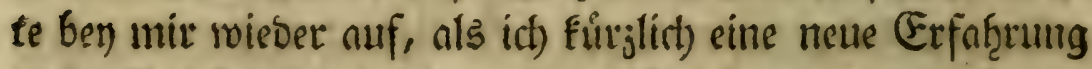

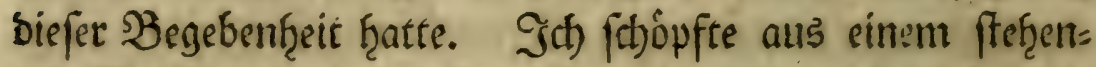

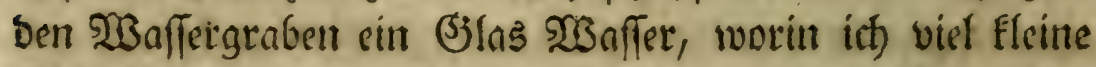

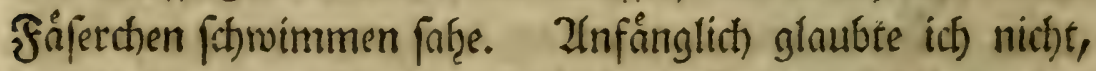

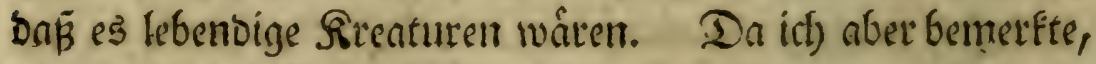

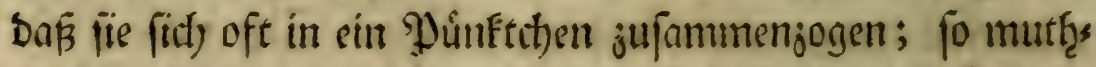
mafite ich, baf fie leben müfter. Soch fanto mich) auct) in meiner Mennung nid)t betrogen, nls ith einige bavon unter

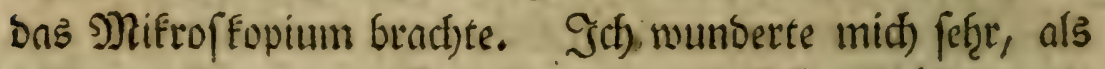
idh wenigftens eine fingerlange graulicje Siófre mit Eraunen Punten und Rónern erblickte.

Nan founte baran weber Ropf noct) $\Theta_{\text {chwang }}$ unters ffeiben. Ifn begben Enden war fie gernoe abgefdynitten, unt gar niffit voal, oder fonft auf eine andere jugerunbet.

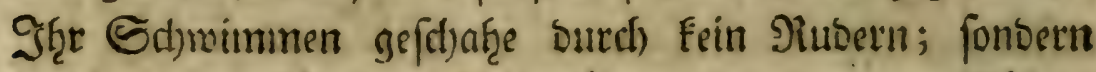

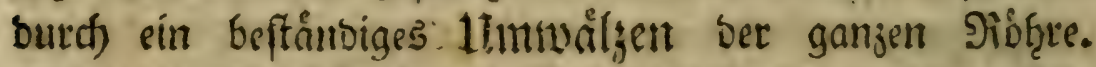
20 enn bas 20 affer abtrocknete; fo fonnte fie fidf) gerwaltig 
nufblafen, uto swutbe wohl' juetumal bicker, als fis vorfece

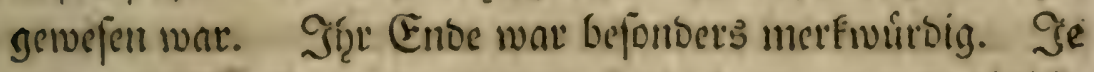
metre das sisaffer veroumftete, defto bicfer wurde fie feloft. Sn ber 9) Ritte bemerfte man einen (Einf(t)nitt, uno bns gans ze Shier lag unn frille. Szierauf entftano unter ifm cin befuncerer SBirbel. Injaghlige fotwarje Siorterchen frrónten unter feinem Bauct)e hervor: eten Dergleicfen,

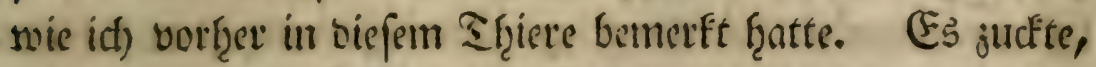
wie man einen Siblanch nuf uno jugietzt, ober mie bas

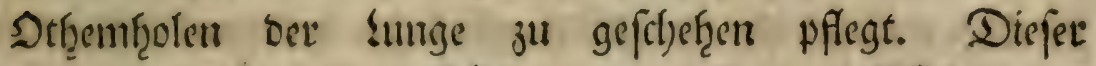

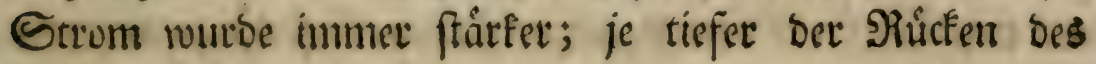
इriers einfiel.

Es erflarte finh mir mun biefer Sorfall im. mer beutlicher, uno es beftatigte fich meine borf̨ergetzente

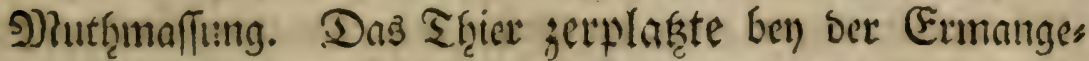
lung feines Elements, uno alle feine interen Theile, alle bie fotwargett, in eint burchfichtigen Scaut liegenden Siotners c)en, frounten unten fo lange. herents, bis bas ganje Thier

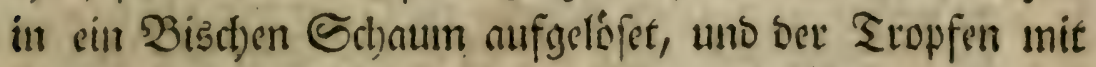
foldten fonwarjen Siórnetn angefúllet wai ').

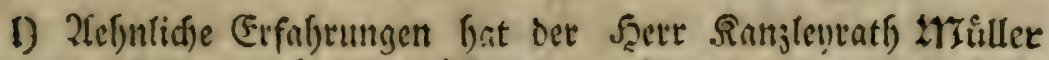
an finten gejungetten Fasioen walyenenummen, uno es als

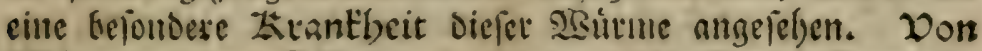
20 itmern oes finfen uno faljigen Lo affers. Zzopenth. 177r. 4. 5. 68. (di)reibt er: "Sd) mus nod) ciner befon:

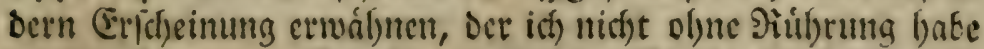
zufeben fömen. (5.

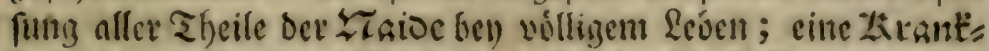

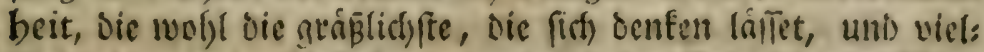

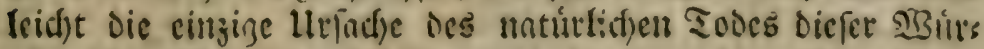

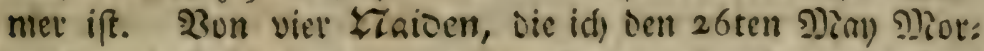

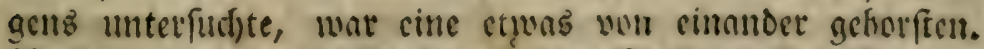

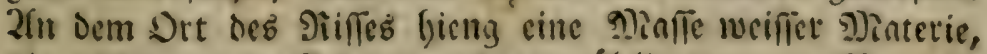
bie gleld) einem E(j) 


\section{Von einigen meréwuirbigen $\mathfrak{B}_{3}$ afferinfétet}

Muß man nid)t billig ůGer bie fonberbare Struftur folffer Rörper erffaunen, bie aus lauter Rórnern beftę̧en, uno fict in einem Zfugenbficte auflof fon fónten? Da man nun fiton an gevioffen 23 afferwúrmen, bie entweber natúrlidy, Doer burct) Runft getfeilet werben, und beren Stiffe bod) wieserwachfen, eben Dergleich)en నerånberung uno Zerbers ften bemerfet ḩat; fo fheint es mir wenigftents ben biefen lef̧tern, wenn fie von ber verżef̧renden Rranff̧eit antgegrifs

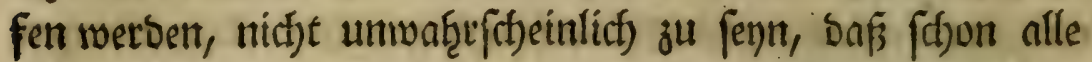

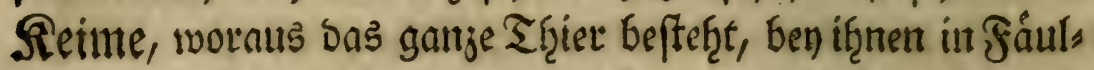

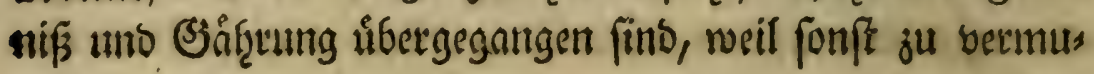

tḩen

outchfuthtigen zkigeldhen beftano, saneben lag ein grofferer Silumpen gleidhes sisefens. Jot war jweifelfaft, of ez eir

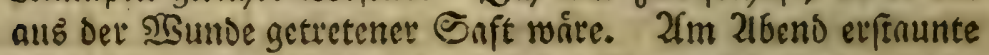
id) nidjt weniy, als id) fabe, baßs ber $2(3 u r m$ fid) in eine fold)e mufrebtafene פinterte verwandelt batte; es war feine Eput Der votigen Sseftalt votisantent, u. r. w. "n

Ş̧âtte ę Dodt Dicfem aufmerffamen

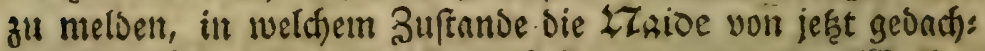
ter Sranflecit angegriffen fey: of fie ganj unter bem $25 a$ affer, ans alio vóllig bevecft gewefen, ober of fie zum SBeobadjter

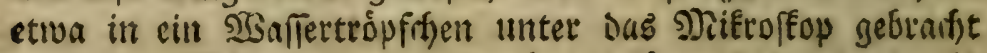

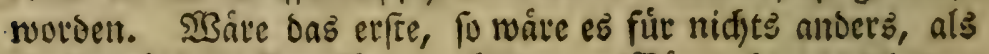

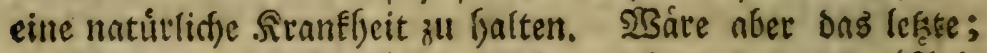

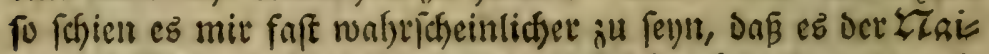

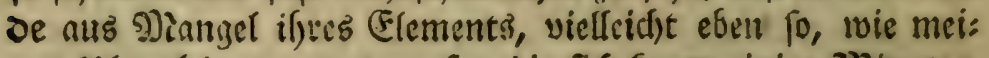
nen Plastbieten ergangen [el, bie fich Enum cinize J)inuten

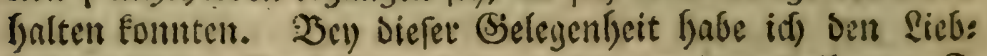

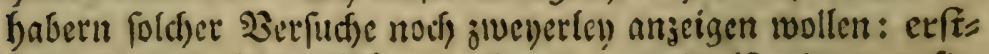

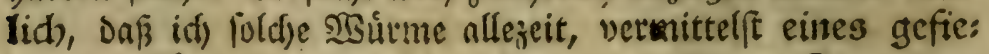

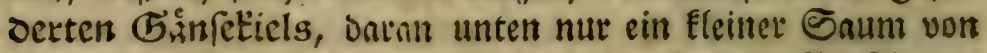
Febern gelaffen, weit bequemer, als burch cinen 'Dinfel, aus

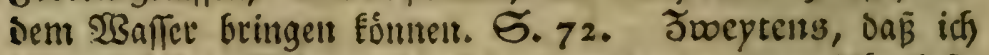

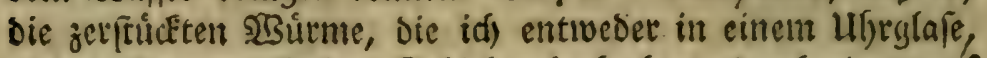
ober auf eintem fiad)en Sdjeber bevbad)tet, Dutd) einen auf fie fentredht berabflieffenoen Eropfen rocit glüflidjer, als

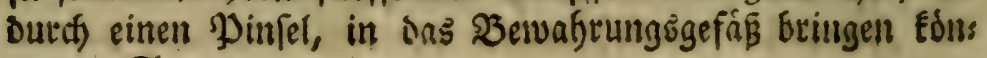
nen. 8. 73. 


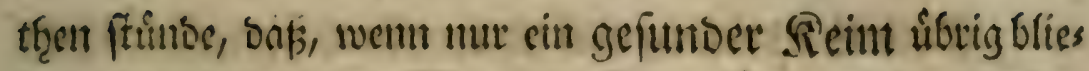

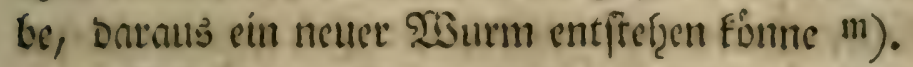

Sith fratte mit vorgenomment, buleşt nod) cinige gantz

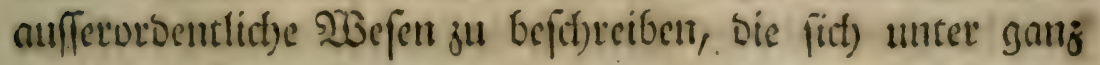
unfơrmlidjen uno bijarten (Seftalten zeigen. Sid) f̧abe aber gefunden, Daf firt) Dergleict)en Figuren weit beffer fe=

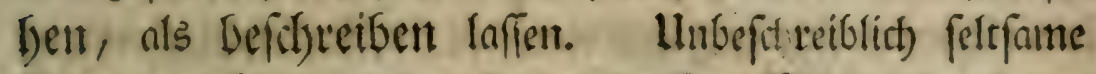
Sitenturen fotwimmen oft in groffer Mentge in eintem Tropfen. Şrete Beffalt gef̧et über nlle Sorfftellungen

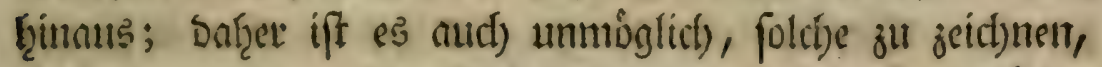

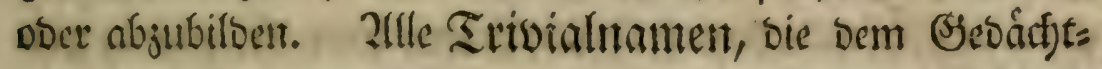

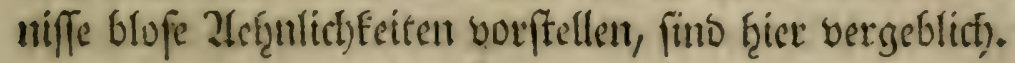

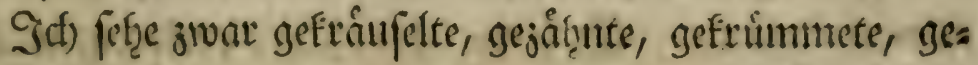

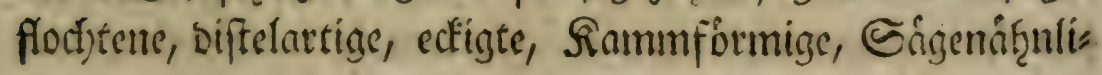
d)e, unto betigleitfent Siguren mefre; ich) ferge Simulabent,

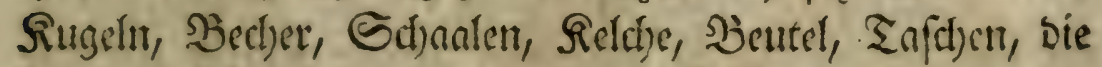

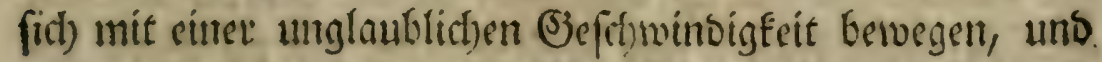

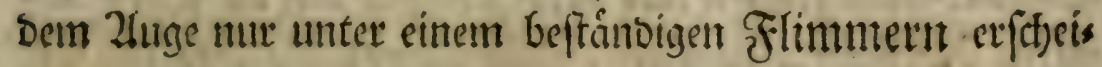

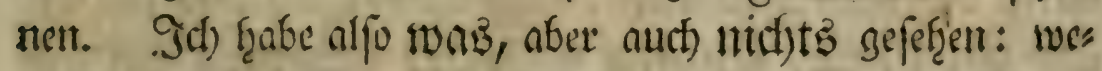

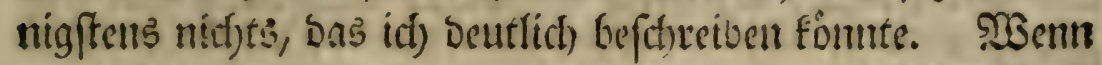

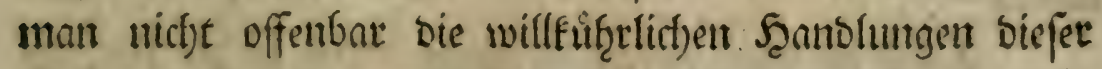

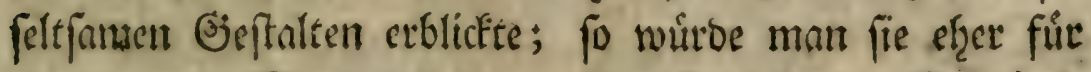

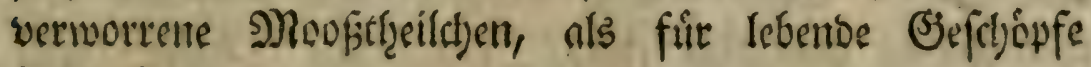
anfergetr.

Eituer

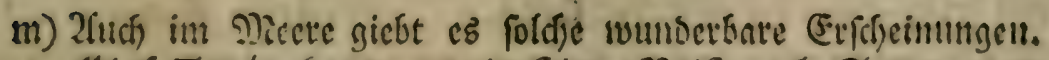
Olaf Totée, bat danon, in feiner Ricife nad, Guxate uno China, nach oer Limmitanen 2lusgabe. Leipsig 1772.8.

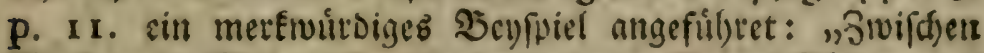
2ffrifa und פiadaga) Ear fanden vir em Eleines Ifhier, wel:

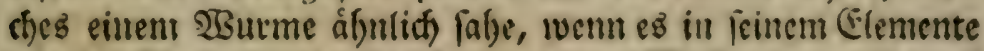

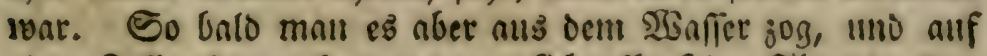
einen Teller (ente; fo trenneten fidd) alle feine Glicoer, tho jeoes Glies bewegte fidh befonders." 


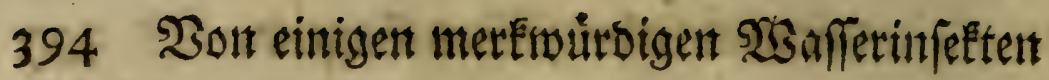

Einer Erfacinumg will id) bod) noct) gebenfen, bie id)

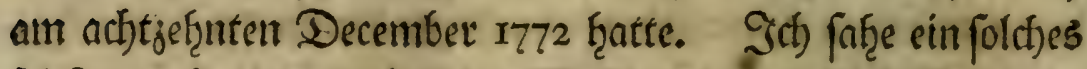

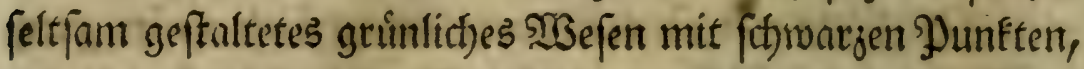
gaiii Jangfam in bem Tropfen heerumfdywimmen. Sori

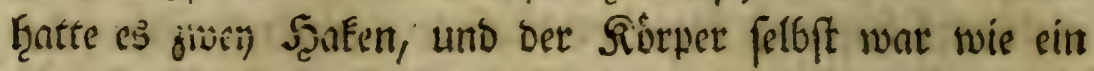
Ramrm eingeferbet. Balb wat es runto, balb oval. Entos lich) båf̧nte es fid) lang aus cinanber. Ifuf eimmal jergieng

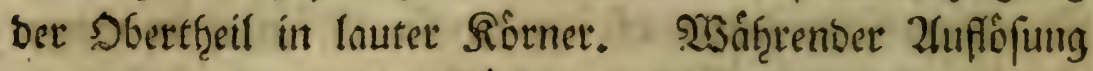
surben immer mefreere Backfthens firftbar, wounit es flims

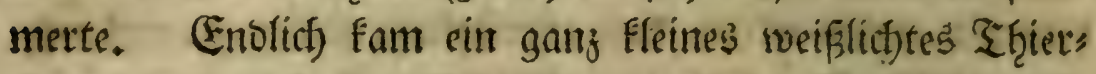

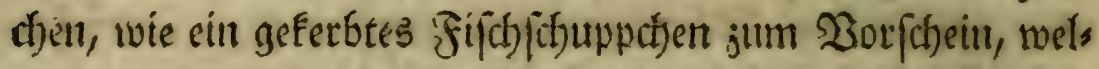
c)es givar noch inmer fortfinmerte, aber nun nicht weiter fommen fonnte. Es f̧atte feine Şuille verloten, worunter fein Rorpercben berborgen gewefen war.

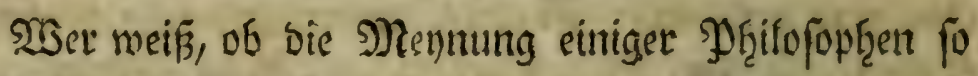
gar unwaf̧refdeinlich ift, baf unfer grober Rorper nur bie Shanle eines feinern und geiftigetn fen, Den bie Seele ben

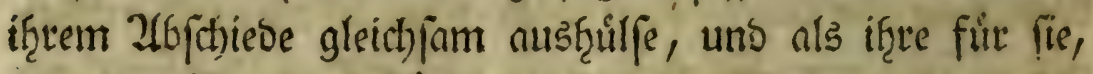

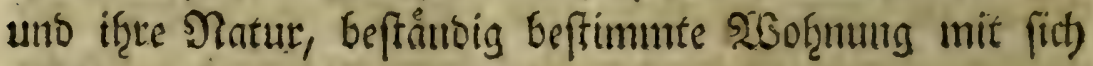
nef̧ine $\mathfrak{n})$ ?

Doch id thrte nodjmals sinen Blick in bie unfictsts

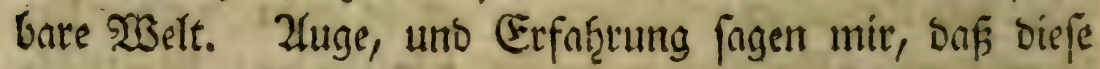
forberbaren Beftalten wahre Iebendige sfiere futo. Diefe Dorftellung madtet mit alles grofi, was ich mut biss

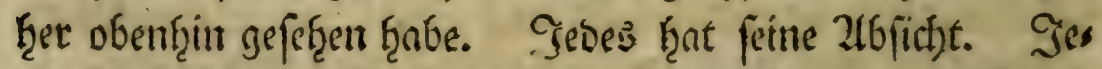
bes feine befonbere Eintidytung. Sebes feine cigene Stelle.

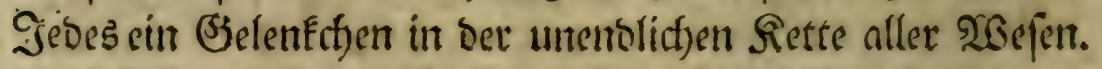
Die Giranjen ber Schopfung entfernen fid) immer weiter;

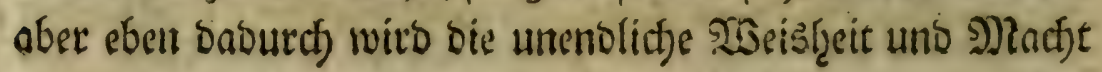

DeE

^) ङ. Iac. Bruckeri Hift, crit. philof. Tom. IV. Pars alt. p. 418. LXXII. 


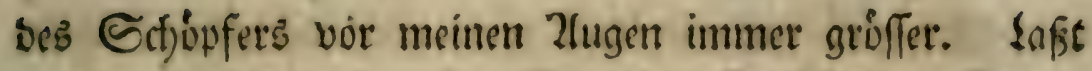

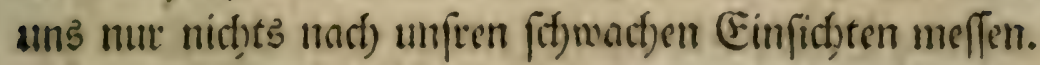

Ė̉ giebt biele, Die fidf) nimmermeţr vorffellen fons

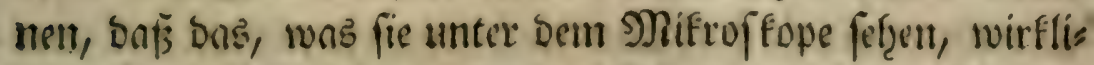

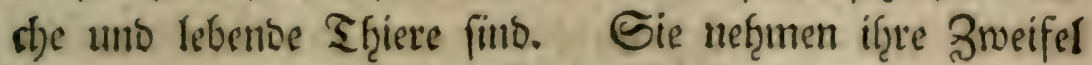

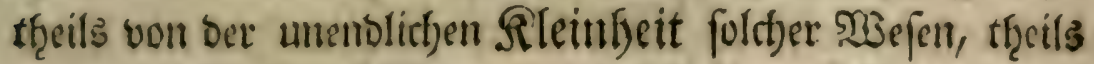

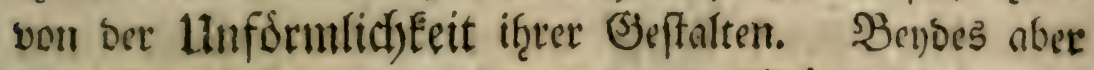
firto Einnuirfe, weldse fo menig die MRoglichfeit Der

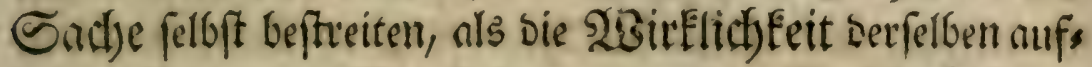
hৃeben founen. Sie fims nur von der Einforrainfung unfrer Sime und Einfictiten beergenommen.

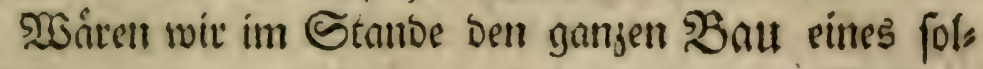

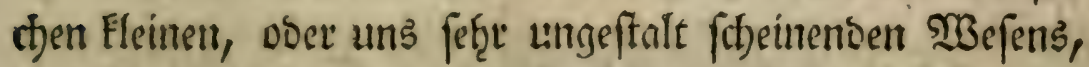

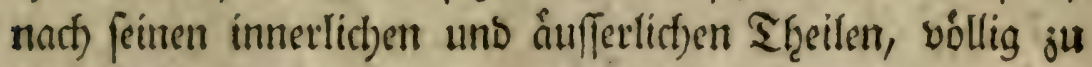
úberferen; whiften wir bie Beftimmung eines jeoen;

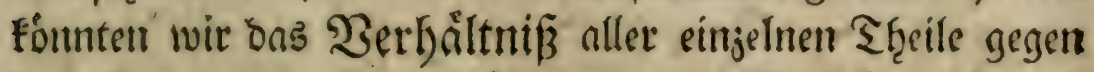
bas Ganje begreifen; warelt uns alle $2(6 f i d) t e n$ feines Daferns Gefant; fo wurton wir Da 2 Bumber Der

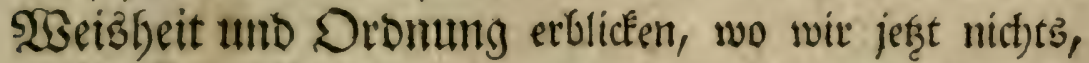

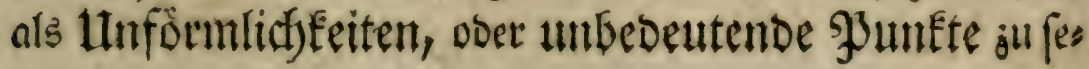
ţen vermennen.

Eben fo ift es auch mit uniren Sinnen befdaffen. Man etlaube mit Gicer mit den 23 orten eineß Miannes ju reben, Det unb bie naturlfict)en Dinge aus Dem rect)ten

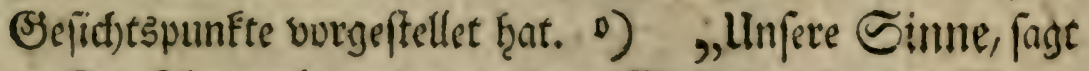
er, fint ferge grob, unto von Dem Einfad)en in ser NRatur unaus(pred)lid') entfernet. 233ie meit fie aber Bbott bavon

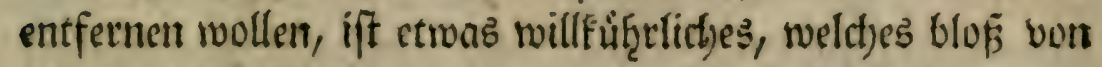

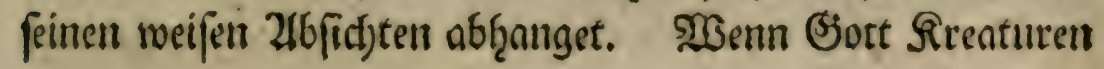

unges

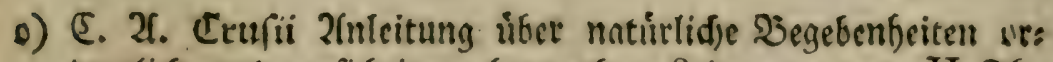
nentlits, uno votifidstig nadjsudenten. Eeipj, 1749.8. II. Tf). \$. 535. S. 1162 . 


\section{Won einigen merEtwuㅁoigen SBafferinfetten 4 .}

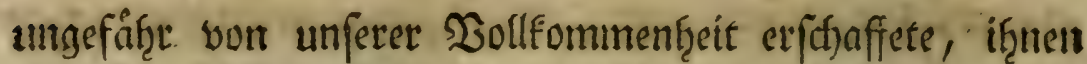

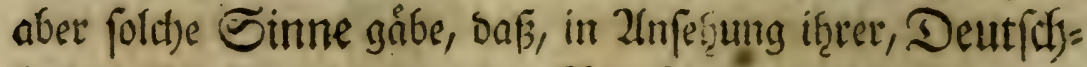

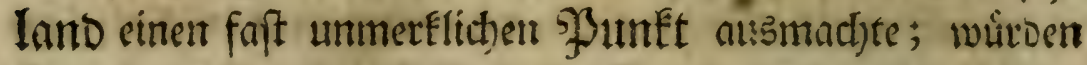
fie nieff), wenn fie blos nad) ben Sinnen urtheilen wollten

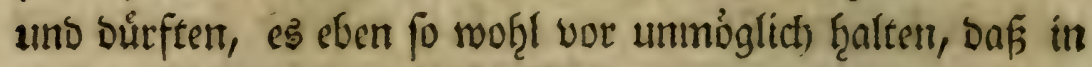

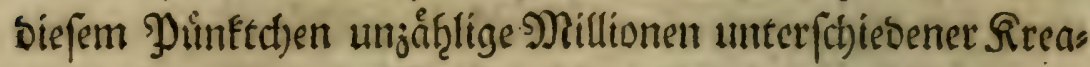

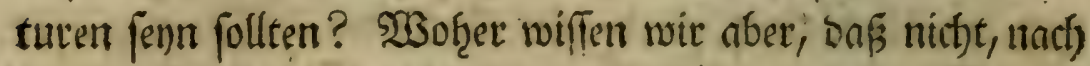
unfren Sinnen ju - rechnen, Der Eleinfte merffiche gु lunft,

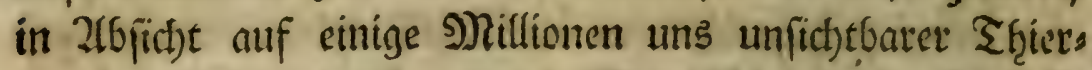
chen, eben Dab ift, was Dentifhland in 2rbficht auf einen eingigen 2)enichen, DDer moeres Thter ift p).

p) Dá oie Infurionstbierdhen wafre Thiere mit (Fmpfin:

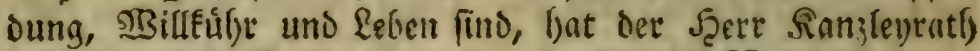
Erruller felye grindich erwiefet, in feinet: Vermium terreftrium et fluviatilium, feu animalium infuforiorum, helminthicorum et teftaceorum, non marinorum, fuccincta hiftoria. Hafn. 1773 . 4. p. 6. 7 fq.

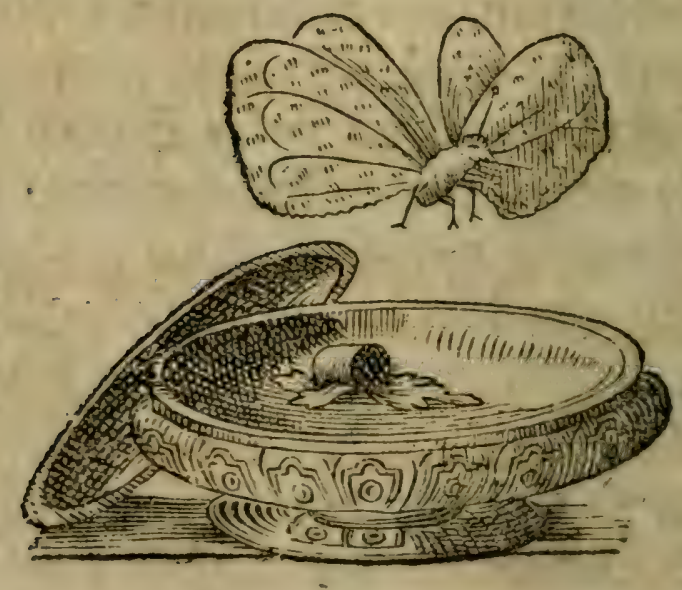


बiन

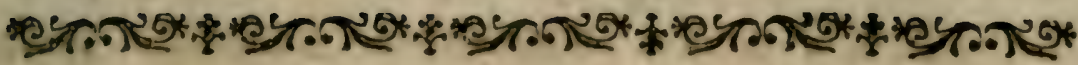

\section{Ertflårung Der IV Rupfertafer

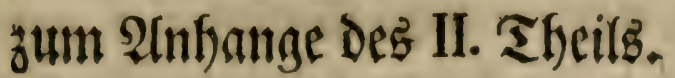

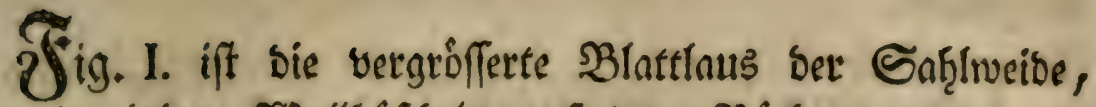

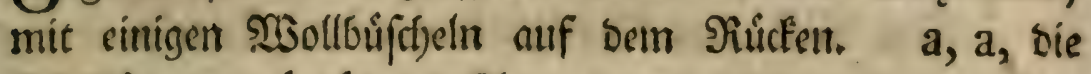

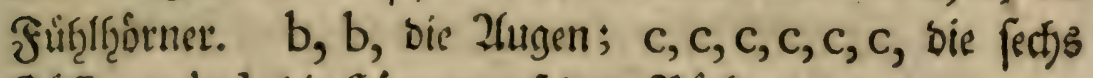

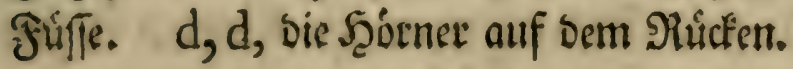

Fig. II. bie beyben leģten vergrófferten Selenfe cines

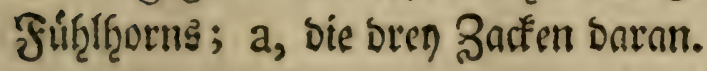

Fig. III. ftellet vor a, a, ben Ropf biefer Bilattlaus.

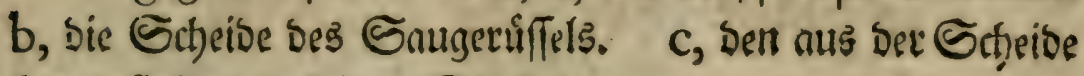
hervorffef̧enden feinen Stachel.

Fig. IV. if Der unten a, a, wie ein Zlnfer umgebos gene Eaugeftacjel.

Fig. V. ift bie neut 2lut ciner 2 Bafferflofg, a, a, bie erften Şörner, b, b, bas juente गुaar, c, c, bie benoen Båarne, d, d, ber weiffe inmeneige Darm, e, e, bus britte

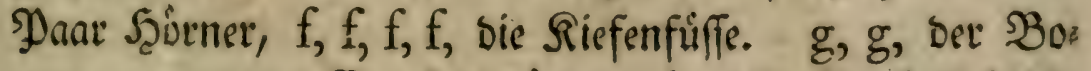
gen, woran ber Enerfacf f̧ănget, h, Der Ener fack felbfit, i, $i$, bie Ectjwantipipizen. 
398 ErElår. Der 4 Rupfert. gum 2(nhantrge Des II. Th.

Fig. VI. eint vergrófferter Riefenfup biçer 23afferfort.

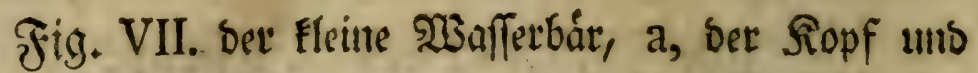
Munt. b, b, bie 2lugen, c, c, c, c, bie vier Füffe ber einen Seite. d, d, d, d, bie brenjactigen Silauen nar jebent.

Fig. VIII. bas Rugelquabrat mit 16 Sugeltit.

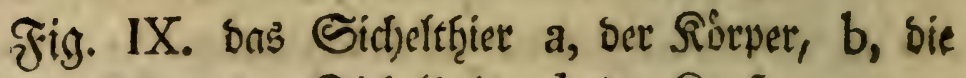
Şunftete Darauf, c, Der Eidjelfeals, d, Der Ropf.

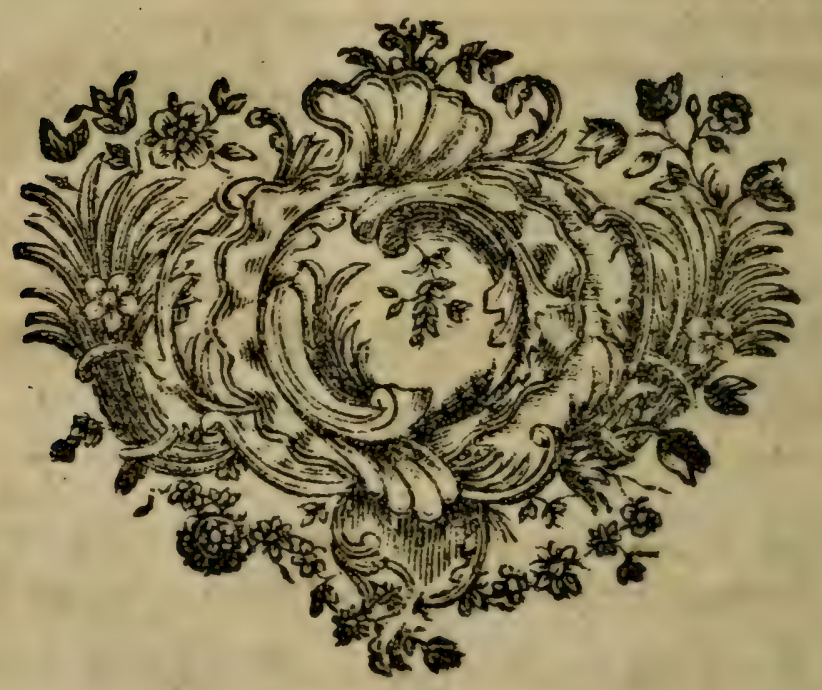




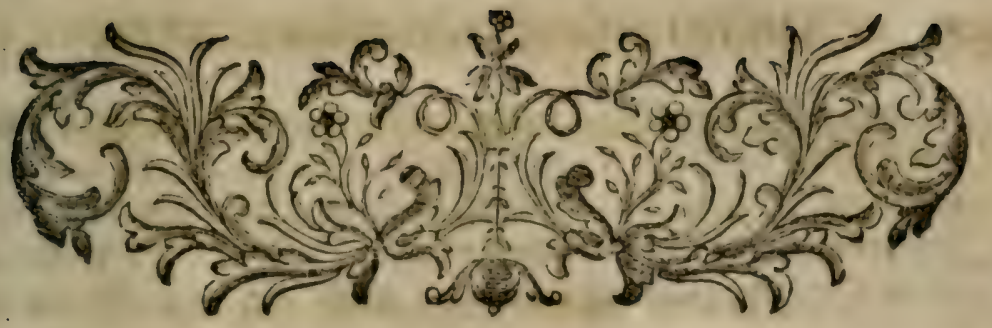

\section{Regifter \\ Der mertwirdigiten Sacten.}

\section{2}

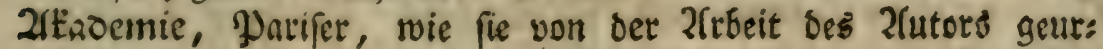
theilet

2 meifen, faugen aub ben Diófren bet SBlattlóufe cinen füfe: Snft

: : gel)en nad) cinigen S̉lnttläu (en mef)e als nad) den andern, 85

: : wefferen fíd), wenn fie beuntufiget werben, oaf. gegen fie

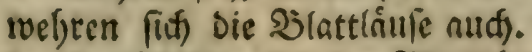

: : Gemád)tigen fida Der Dlattláule

: : ifre Epiritus bat 2(rjeney)Eráfte

2 (meifenlowe

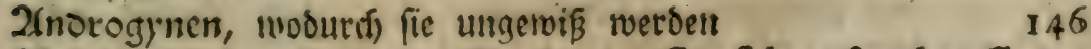

2lnbang einiger úberfergten 2lrtifel Der Confider. fur les Corps organif.

$:$ : eigener 2 bbljandfungen des Heberfeşers

2nňer, gleid)et ber Gangeftadjel einiger SBlnttláufe

Apbis.

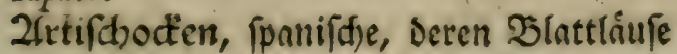

2fuftern vermefiren lich obue Begnttung

: : iveldse Infeften ifuen nabe fommen,

2utor, Defien Sbarafter uno Befenttni geirtet зи baben 247 .

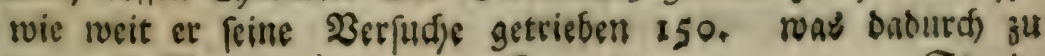
25onnet 2. Cb. 


\section{Viegifter ber-mertwúrbigften Sacifent.}

Etande gefommen 153. ob ex miber Die Efgrbatfeit in feinen 2(usbrúden verftuffen 157. fdjreibt von ber SRatul. Den ange: nebmiten Sioman 22. Deffen Giedanten von Det natirlidien Zertbeilung oet $\mathfrak{B}$ afferwútme 193. (d)en 2erfud) gefdriebel 242, swirb yon Det Netaplyylit befieget

\section{5.}

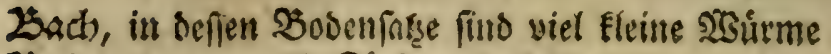

222

Saizongcs, newilie Fárbematerialien

I I

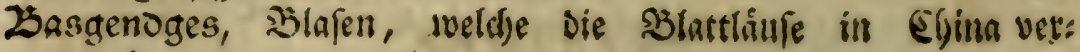
uriachen

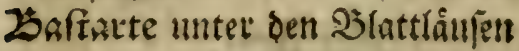

: ' unter ben ?taupen

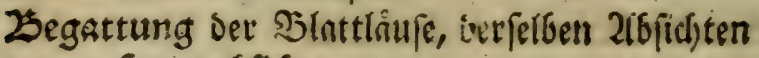

110

: : Jeauptabficjt

162

: : ofjne biefelbe ifi eine Betmeljtung nodj berounderns: múroijer

Leobachter, waร er zน thun bat

164 126

: : weld)e Rlippen er ju vermeiden 249

Leobachtungen, reeldje geid)ą̧ werbent

Zienen roeroen mit oen 23 Inttlâfen verglitien

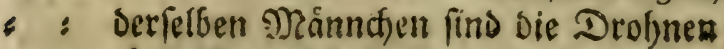

: iffe Stnctar baben jroen Pfeile

Zlätter, modurd) fie fid) zulammenrollen

: : vie eine Şaube werben

¿. wie 23 lafent rerbent

Dlattlaugfreffer, Deten verfoicoene 2rten

$\therefore$ : Qómen

: gleidjen bem Nemeái|cjen Róroen

25lattlécufe, wab fie find

: : wo fie anzutreffen

- Derfelben Bejareibung úberfaupt

$\therefore$ : ifje Éspertidjeu Tjeile

- Der Eiche fino Dicke uno grofi 682. Sidfren auf Dent Stúc|cet

: ScauptElafien bet fellon

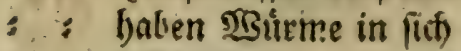

: geflugelte und ungeflugelte

5. 6

1. fino foft alle Trseibchen

- : gebáfrett lebendige Junge

$s$ : voie ifje Gungen jur $2 B$ clt fommet.

3 : babell viel foetlls im leibe

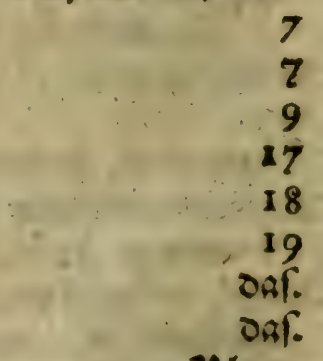




\section{Diegiffer Der merfinuirdigiten Sachen. 401}

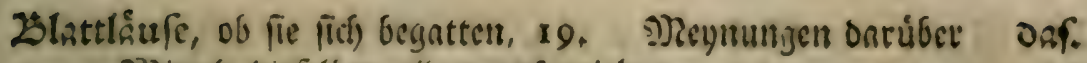

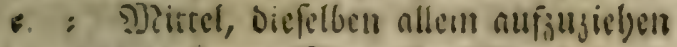

$\therefore$ : ungelseute sjienge berielben

8. : trie fie fici) bóuten

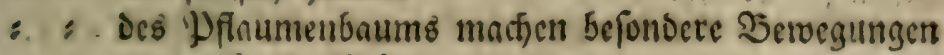

ORT.

: : wenn elfe fie 9Játter weroent

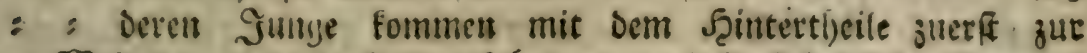

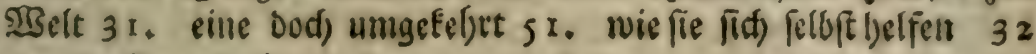

$\therefore$ : werden jornis

- : ob fie Die Gieburtş;cit in ifjer Genalt baben

: : vof fie in Dicjer Beit obne 9labrunu Gleiben

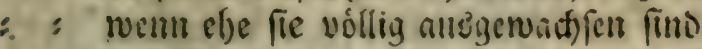

: : Des Spindelbaums, auf bie bált Der 2futor fefje viel 50

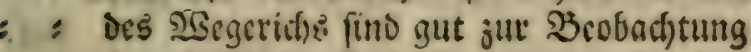

- : fino befondere Zrvitter.

: Deren 2irt mit furzem Eautgerúfel

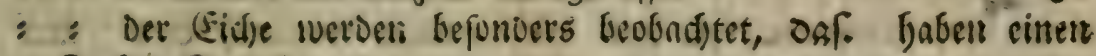
ftarken (Gerud)

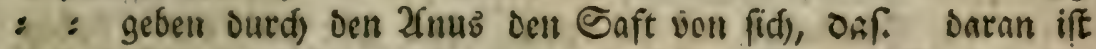

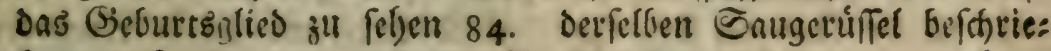
ben, Oaf. Eann man oft vor 2(meifen faum fellen 85. weljeren fid) Dazegen, Oar. Eleine gefligelte Derfelben begattet fid 86 . bringen Soctus bervor 93. wie bie befdfaffen 29. wodjfen nod), reenn fie idjon Slügel baben 102 , von iffun geljet bie Scaut nad) Dem Tooe ab ros. vermefreen fid ofyne Segats

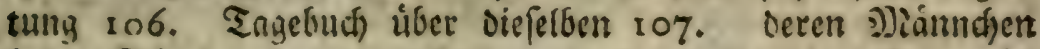
baben flugel und aud) nidjt 113. eine verliert Den Saugetú:

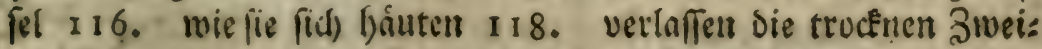
ge nidje I 19. legen Eyer barauf, Daf. bleiben lange obre

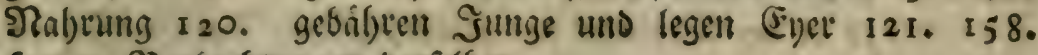
fernere SBeolinatungen derfelten

- s wie fie fid) iat Sointer erbalten 122. 124.

: : Émuten lifóne Farben geben 225.348349 .

: : bequemfre פJittel, fie allein nufjujiefjen

126

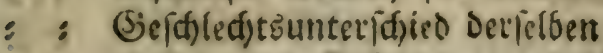

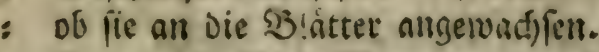

154

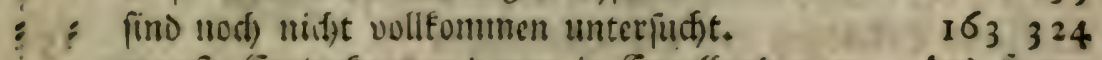

155

- nenefre Entoecfungen Daran in Engellano 357* Deb 5ุertu von Beer Gedanten onvon

352

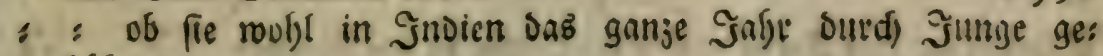
bábrent

: tuas cinige im jalfre 1773 am Rolgle vol Gidaden getijan 


\section{Regifter Der merfwúrbigften Sndjen.}

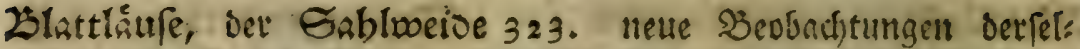
ben 324 . Eyer betfelben 325 . Gleiben tange ofne Maljtum, oar. be:

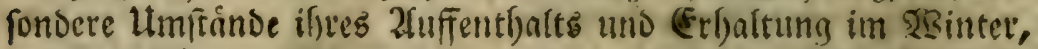
unto ungeftumen 2 setter 326.348 . 349. 3u weldjel Silnte fie

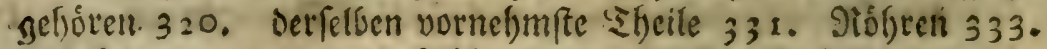
Quftiod)er 334. of die Sidflen Die Etelle Des 2fiters nertre:

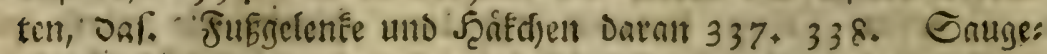

- rúffer 342. 343. wollent nidjt allein fich fegen laffen 346. Berjudse Damit 347. yerantorn ibre Jarbe, Oaf. babentrothe

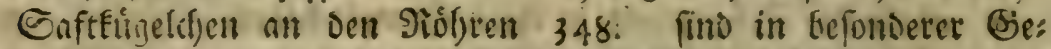
(d) aftigfeit 350. of die Gefurtsifhmerjen bedcute 35r. ge: báfren lefienoige Jumge, oar. fins bubely fefor beljutjam. 352.

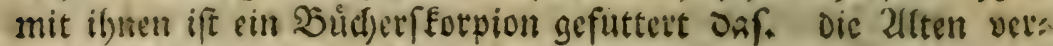
(ieren fith zulert,

: : Des Llumicufobls, befondere Nachritfen Dnvon 353. fino von Defien Farbe nidjt gut j!l unterfdeioen, Daf. Djelut:

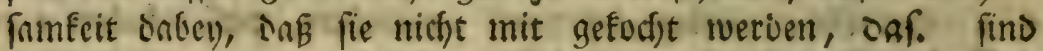

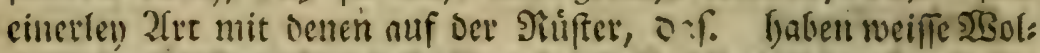
le, wic Echimmel suf fid 354 . fins felje bick; 0 af. babes

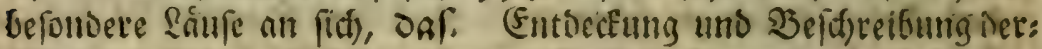
felben, onr. mus ifuen fefre empfindlid) ieun 356 , befondere 2orferfung onbey 357. fyun vielen Sd)noen 358

$:$ : furge Sheorie von ifluen im Sompenvio 327

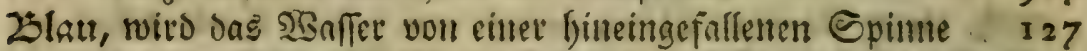
Zlut, glaubt \$lúmier an ben fingern ju baben, Oa è Juteften zeroruift

: : vie cE tt Den SButrmen umgetrieben twirs 127 : Gált feimen Sauf orventlid) in jer/djittenen Stúcfen: .242 Zlutigel haben gervifie Erife an fich 275

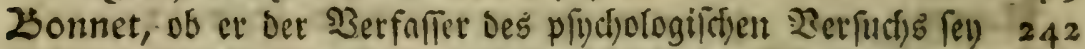

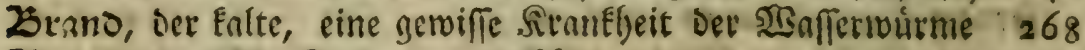
Ztreynius, deflen 2lufgabe angefúbrt $\therefore:$ ierfelben 2tuflófung.

25icberfforpion frift $\mathfrak{B}$ inttlanfe 168 : : Deflen cigentlidje Spcife

Lubel, Der neifie, warum cinize BSlattláne fo beifen 2 Súffons Erelárung von den SZInttlâuen 148 352 OR. S I 54

c.

Carmefin, cine sarbe von SIattláufen in Der Revante

Cerambyx für, cin ien Injeftenfabineten gefábrlicjer Sinfer 342

Cbagrin, 10 if die Şnut ciniget Thierdien

Cbina, oa madjt man von den Sלlattláufen Farben 
Coccus. 327. r. Edjilolaus.

Confiderations fur les corps organifés, onranb uiberiferte 2frtifel

Cxufus, beffen Gedanfen yon \olupenfeclen

$145^{\circ}$

: : wie man bie naturliden Dinge betrad)ten folle

Diafrole in dett Situment

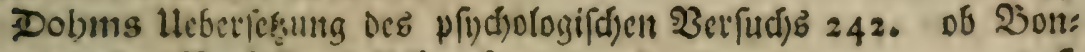
net der 3erfarfer Deffelben len ORF. Dornerupen bauten fid) fefonbers

趾.

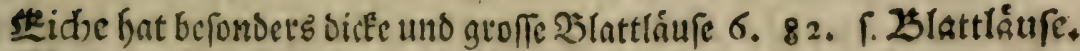
sEioere, Oeren Dewegungen, wentr if)r ber Sopf abuefdnitten 185

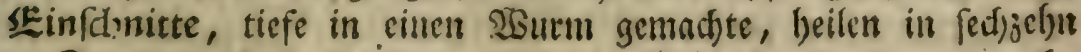
Stundert wieser

SElepbint unter oen BZlattláuen

265

Entengries beiffen Dic $2 B$ allerlinfen an cinigen Drten

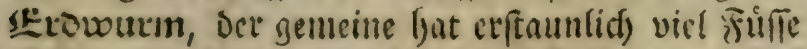

185

176

EFfiganle, Denen gleidht Det Scals bes Eidjeltbiets in Det Farbe

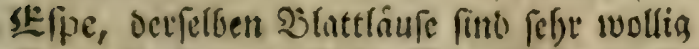

serciemente, wie fie die Slattlaufe von fid getent eyer, legen bie Şungferthen Dabin, wo viele Şlattlále fino fifen an befontorn Eticlen

: : Der 3 lattlaufe nuf trodênen 3weigen

: : figen bidjt an einander

จ.ศ.

$:$ : entoedft Eyonet zueeft

120

: : vertrocfnen in Det TSárme.

onf.

s. nuв Denfelben fommen Sunge

I 2 I

: : ob fie unn Den Maandien befrudtet werden

123

$\because$ : Berfudje Jamit

124

325

: - merben zu allen Beiten in den Şlattläulen gefunbet

D.र.

: : woju die leręten zelegten beftimmt fino

$16 \mathrm{I}$

: : vb fie Dutes die Begattung hefruchtet wersen

$16_{2}$

จ.ศ.

f.

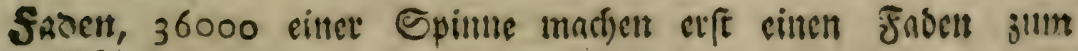
Ráljen 


\section{Ttesiffer ber merfwuirbigftent Sachett.}

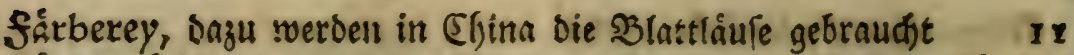

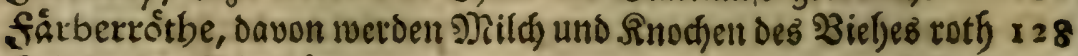
feinde ber $\mathfrak{B l a t t l a ́ u l e ~}$

: : vertuandeln fid) in Sliegen uno Rafert, fifche baben Qause

fiecteben, weiffe an Den 3meigen, was fie bebeuten

fliegen, getvilfe pringen wie Flofbe

Sक्मा.

$:$ : fohmetterlingsaitige

: ob es lebenuiggetáalsende gebe

27.3

: : Jaugen an ben SJlattláfen

344

crim Jaugen an den 23latthiufen

Slíg:l Der Dlattliure

: baben einige Gnjetten, andere nicht

$\begin{array}{llllll}82 & 83 & 113 & 158 & 328\end{array}$

foctus ier Blattlále

: : Szejuafienljeit berfelbet

- : fino roir flidfe (syer

Sranjbsume, wie Davnn die Slattlaufe abjulfalten

Steffpizen oer Infeften uno Siaupen

Sreybeit, Darin ift cin InfeEt nm beften is heobaditen

füblberner der SIlattlaule

$:$ : bahen vorn bes cinigen ein Dreyzace

- : Der Inteften

$s$ : Det Stnublaufe mit jibel Scáfdent

Sirfe, felfr vicle bat Der Siegentrurm

124

350

* : roie fie ż entoecfent,

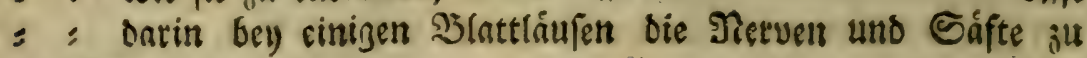
fefjen

: : Deren Giclenfe an einigen Blattláufen

- Der Rrebfe rodjlen wicder

(5.

Gallen, an ben \$flanzen, woljer fie entfteben

217

: : Infeften, roie fie fich vetmeigren

Geburt ber jungen Sinttliure

10

Geburtsglieder ier Blattliule

112113

Gefübl ber 2 Sanfermut'me ift felye zatt

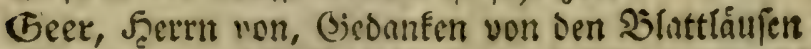

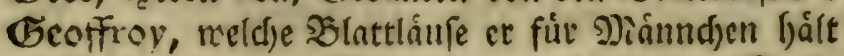

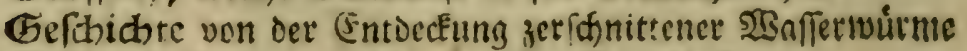

Gefthlechre, ganze aufgejogene ber stattlaule

171

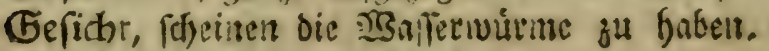

Gesourme, alleviey leud)tente

243

(5) 


\section{Tegiffer Der untertivirbigften Sentert. 405}

Glas, batan faingt fid) Der Sdyimmtel veft an

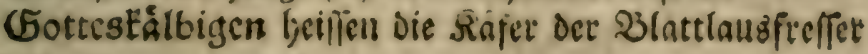

\section{Ђ.}

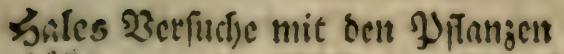

$20 \mathrm{r}$

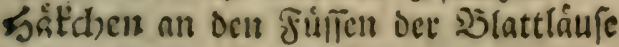

338

: : einiget Gtaubláufe

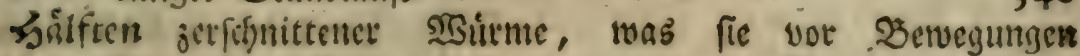
madjen

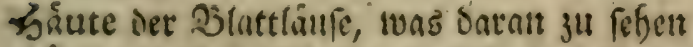

185

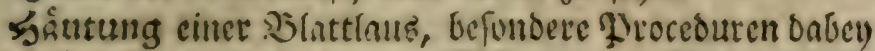

. 344

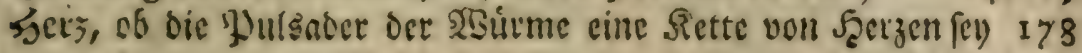

3.

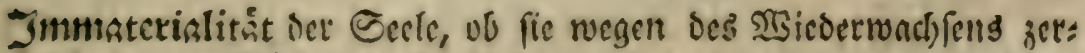

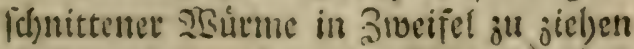

240. $24 \mathrm{I}$

Infulionstbiere, barunter find alle moglicje Tlyiergeftalten 368

: : Tefor gefrápigige Sinutitbiere

: : ifre ßermeljungşąt

$37^{\circ}$

$\therefore$ : firto wafre Tficte

Infeften, fligel Derfellien

$39.4 \pi$.

: cinige Detfelben retoen unfere Fnvuriten

S. 6

: : cintige baben Sligel, antere nicht

52. $\{3$

II 3

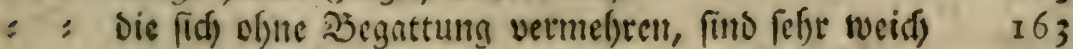

- : Dic ausggeluacijicuen fino am beften zu beurtf)eilen

330

: : toie Der Rlutor Diefes SBort verftelget

183

: : ob fie fitif im Sectbfre begattent

370

2. : Borfalán zu ifjer 23ertilgung in ven Sabitteten

- : baben Den frátefen Trieb zur Selbfterbalting

348

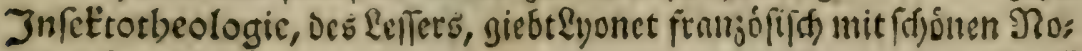
ten betaus

Jobanniswitmdben, warum ę fo f)eißt

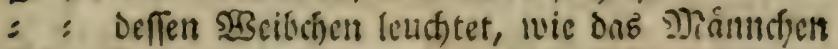

Jüngferchen, die Jliege mit goldenen 2lingen

$:$ : mertwúroiges Infeft,

122

- : wobjer es entfefjet,

Zzéfer, tuns eit ift

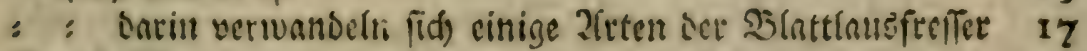

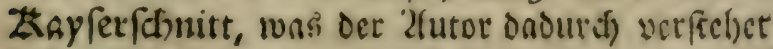

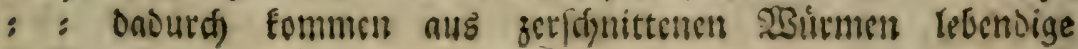
Junge 


\section{Tegiffer Der mertfwurbigiffent Sadfent.}

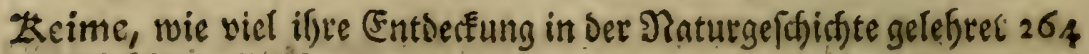
tzielfrof the rondifen fort

102

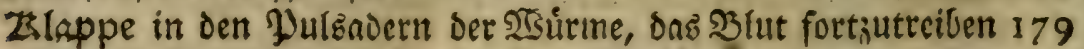

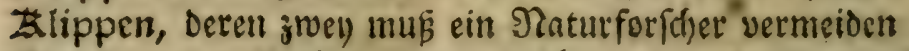

Znochen ves $23 i e b e s$ werden rotg, wenn es eit gerwiffes Rraut frifit

128

: : vachfen bis zu cinem gewifien Punfte

195

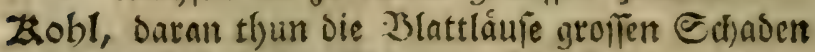

353.358

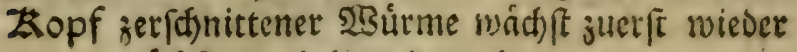

189. 223

$\because \because$ mád)ft an einigen boppelt

253

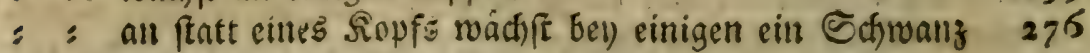

- - voir Durds bie 2fet des Edjnitts fervorgebradje

282

: : ob es ein Zeidjen Der Edjwadjheit, wenn ftatt cincs Sopfs ein Sd)rong wádjift

Krantbeiten Der sisafierwuitme

314

: : Der Đुolijpen uno Paniber

267

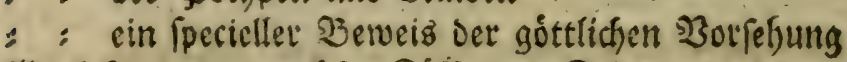

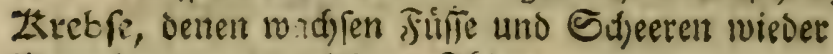

zugelquadrate, feltfinme Thiele

269

270

217

376

: wo fie entoectit fino

377

$\because$ : ifjec $\mathfrak{B}$ ejajreibung

: : vunberbarfte $\mathfrak{H m}$ itano ifrer Etruftut

ORI:

Daf.

- ifree Zalst, sie jeoes in fid fast

: vuarum nidjt mefre als led,jelin

= : Regelmápigfeit iffer Vocruegungen

: : of es gamze Tfjicre fino

: : of fie ju den Dofupenarten gefóten

378

Daf.

of.

379

380

- : fino cin Bilo der Befelligfeit

ORF.

Zugelthier, eins Der felt famfen

375

- : bat אindes: Sindesfinder in fid,

OG.

Oaf.

Zupfertafeln, EvElanung Derferben zum erften Theile

140

: Des znenten Theils

310

: : jum Zfnbange bes jueyten T)eils

397

\section{L.}

Råure, Befondere an Den Silattláuletr

: : Sie meifren fat der Zlaskéfer

354

: ant Ben rifichent

248

- an cinem Defrlinge, eir $23 e t r u g$

273

248

- : wowon die syolypen fterben

269

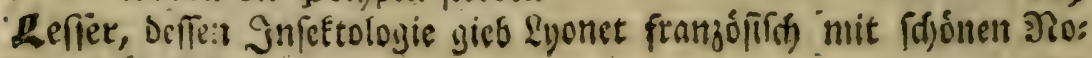
ten beraus 


\section{פiegiffer ber merfwuirbigften Sachen. 407}

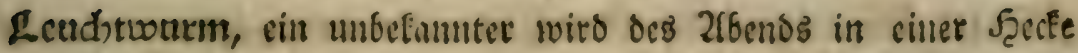
gefunden

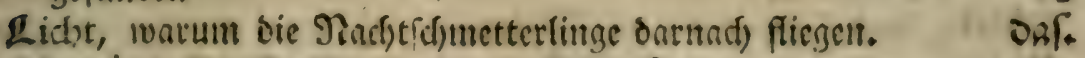

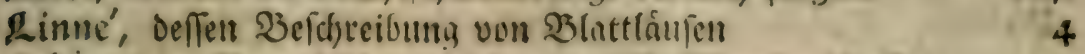

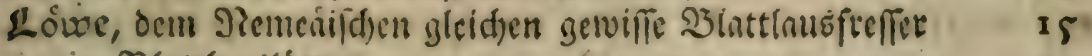
: : DSlattlaustórven

: : Der bie 2́meifen fribt

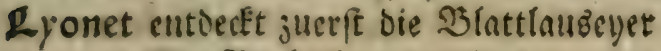

: : Befen S3eobadjeungstalent

12 I

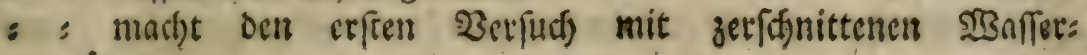
wútmen

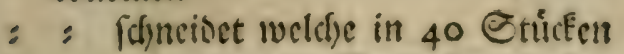

172

- : wic er zu oer (Entorétuni gefommen,

: : Yerbleidjung mit feinen Entbecfungen.

188

onf.

2x.

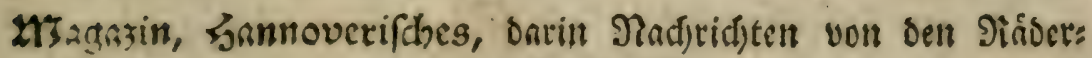
thieren

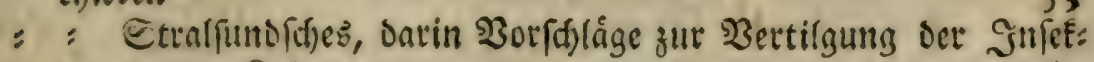
ten in Den Sibinten.

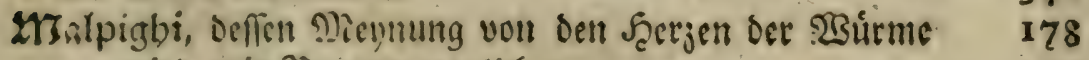

: $\quad$ vito mit Sonnet verglidjen

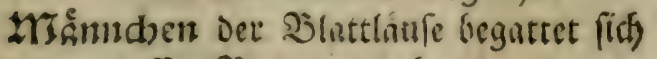

: : Befien Szetragen ondery

179

$\therefore$ : Defien aengeglied

86

Daf.

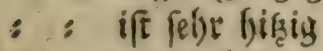

: : madit beftige S3eneegungen

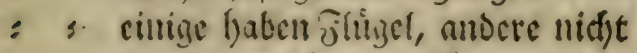

86

: : cineś ungeflúigelten ぶegnttung

: : Delient bisiges Setragen Dabel, 9o

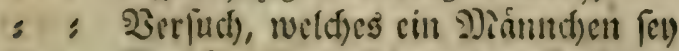

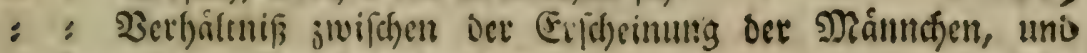
Eegejeit Der SBeibd)en

: : verne elje fie geforen rociber

115

Daf.

II 3

: : Fojeineri nidjet lange zu lebent

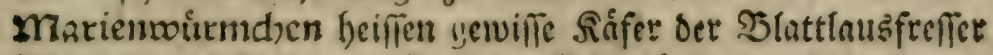
IMeoicin, ve batin ver Enft ver Blattláfe ju gebtaudjen meerlinfen, wemn barin die meiften Sulfeten miscrapbyfit belieget oen 2lutur $16 x$ 329

330

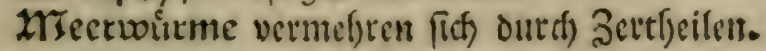
: : jetroelen von einander.

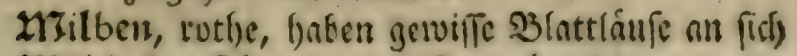
Mild, bet Silibe, wowon fie rotl) wiro 


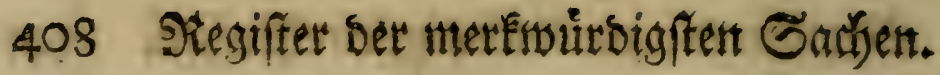

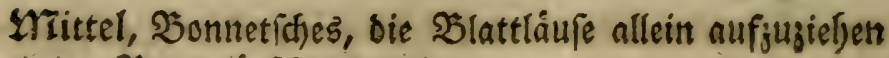

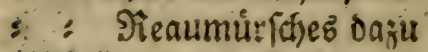

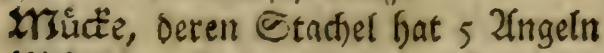

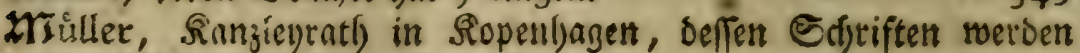
angefútert

: : Dellen Mennung von Den Şerzelt Ser 5 Bürme

170.172

- vow Der naturtidjen Zertl)cilung Der SIBtrme

179

: : Sefforeibung oet nuindertiaren 3eugungen der Nnitien

193

Xrano liket bey vielen Sinfeften nidjt am red)ten Orte

194

: mo ibn Gdáfier an den 2 Bafferfióben gefunden

335

OAR.

$2 \pi$.

2Tadtroogel, getvilie Schmetterlinge, sontum fie nach sem siffte flienen

18

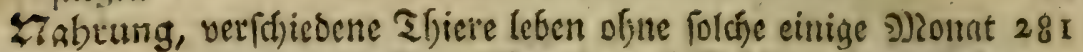

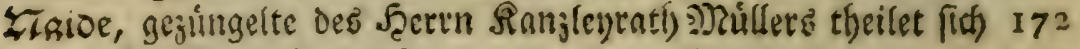

: : ifre ZeugungsipunEte

194

- : Wunier ifjer Fortplanjung

229

: Sirneflyeiten berfelben

269

ZIatur bat jeden Snfett die rechten Trielie gegebent

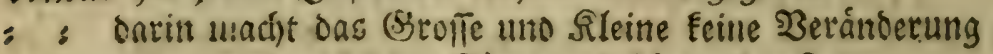

124

: : : " auth nicht Die Suluze und Iange Der Beit

$33^{\circ}$

Zaturforfdber, Unteridjec der alten uns neuen

52

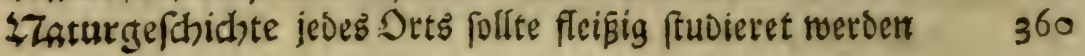

6.

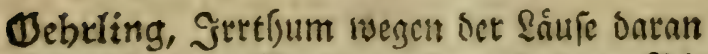

248

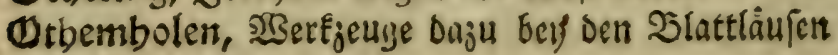

p.

PFlanzen, Scales 2erfudie Damit

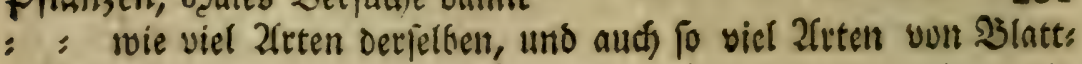
láulể

21

Pfitumenbaum, Defien Binttlálfe

21

Pbyfit, Darin Eaın man nic)t f Etupulós genug feyn

62

: Darin geiten nalgemeine Schlúfie nidj)t3

81

Plimiers Entocdinty rother Sarben an den Gufeteter

127

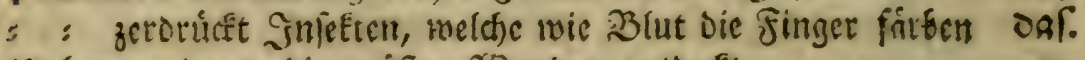
polypen, Baran bie greffen Sisunder entoefft

250

: : vie fie ifie Junnen jut 2 Belt lringen

252

: : fómen feclis Soppie befommen

254

frerben an einct Doppelten Siranefjeit

269

- : ocren Eelen, mo Erufii Giconnfer dawon 


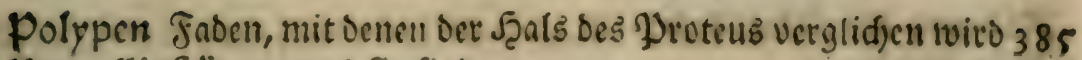
progellinfetten, was fie fino

plicerons, fo follten oie Silattliurfe cigentlid) nidjt beiffen Pulspoer Det sisurme, suito befdjticben

: : Neevnungen Dartiber

protetis, toas vor ein $23 a$ ferinfott

: แmus mit bem Eidjelthier nicht verivedfelt werben, 384

: : artige Ḃcoliad)tunyen Darúber

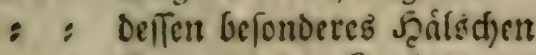

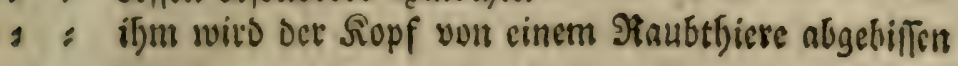

(1).

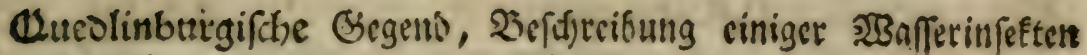
Derfelfen

360

x.

Rhoctbiere roctoen Fnyoriten

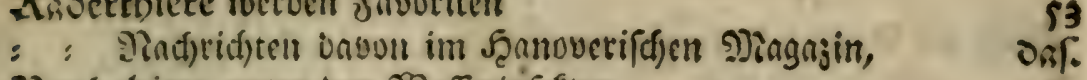
Rnubshiete unter ven 20 afferitifetten $\quad 368$

: : einizer Siefrábigfeit

: : wo joldje gefunden werden.

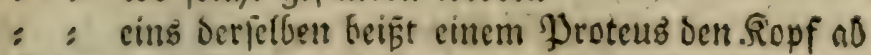

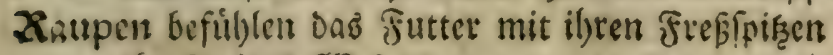

$: \quad$ ifte fettiges 2 Befen

od.

369

388

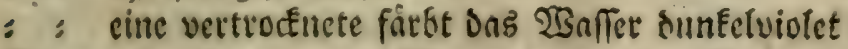

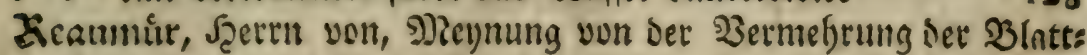
ไáule

: : : of es lehendiggebiffernde Inféten gefien fónme

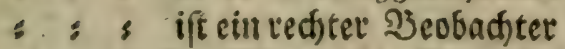

124

126

: Deffen Mittê, Die Blattlaufe allein aufjujiefen

Regenwourm bat einige taufeno sriffe

129

: : verbient unterfuntht zu wetoen

176

: : befielloen Ruft!ód)er

316

: : bey Demielben fat fid) ber 2futor geirter.

312 KReimarus, Deffen (Einwenoungen gegen Sunnets Met)nungen 217

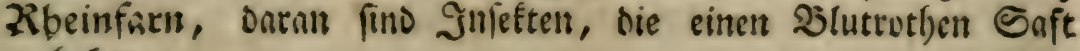
baben

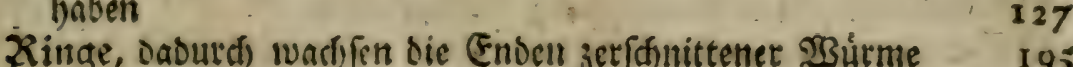
$\therefore$ - vie es bamit jugetse

Kasenfpinne if Der Buidjerfforpion

: : frifist SIattliufe,

: - was ifore cizentlide Epcife fey.

zoóbren, fo féfen gevilfe গSaffertbiete aus

352

Off.

On.

390

Xóbren, 


\section{Regiffer ber mertwurbigften Sacjent.}

Róbren, Dè Silattláufe

Kiobrenwuirme

: : reie mant fie in grofer \$anye befommen Eant,

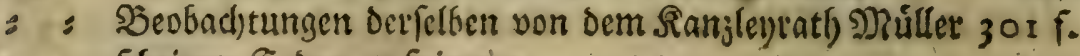

: Theinen Faven ju fpinten.

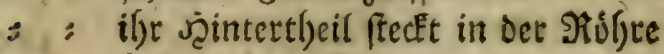

302

: Daben fúrze Geitenljaare

303

: : of fie burds Berfdineiden wicderwad) fent

: Edhuvieriafeit, fie nus Den פióbren zu fringen

OQ.5.

Roefels (Entieckungsgefer)id)te ver Jolupen

303. 304

306

258

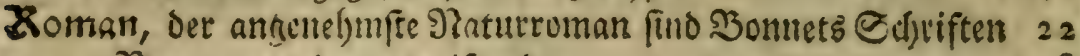
- : 2oräly vor den vergiftender

Rubia tinctorum, f. fårbertórbe.

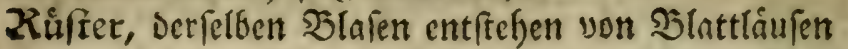

Oद्रा.

: : Derfelben Șlattlâufe fikcen aud) auf Dellı Solgle

10

G.

Gaft bet Blattlaufe faugen bie 2fmeifent

353

: nuid) Die Fliegen

s:

Eabloceioe, Binttlaufe Daran

336

Eaugeruffel der Şlattláufe, deffen Iage

323

F : Daran brefen fie fich berum

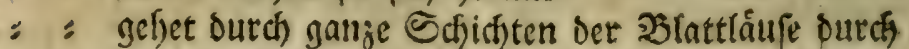

45

$s$ : an Den Silnttlaufen ber Sallrweite font befonoere Gelten: beitent

342

: : ift fefor fein und fpię 343. wie fie Damit faugen oafo

: : Der Edjmetterlinge if Doppelt

343

: tvie ein 2tnter geftenttet,

o.

Gchiloloxufe foneinen angewadjen zu felln

- : Gaben Junge bey fid

327

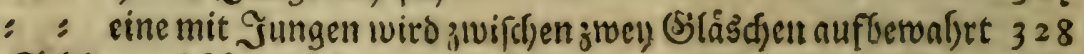

Gdrimmel hangt fid) veft am Silife an

263

Gchnatenmuiden, wie fie ausfricd)en 119 . Stadjel berfertben 343

Gchnitr, wov er an ben 2 surtmen muß gemacht wetoen

228

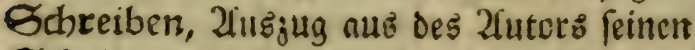

167

Gdhriften von Zeridyneisung ver STSaffervitrme

Sd)wans, ziefen einige 23lattlánfe laniz binter fid) ber

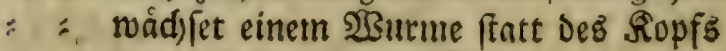

170. $17 \%$

: ziveent beformmt ein $2 \mathbb{3}$

8

276

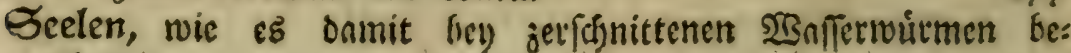
fijaffen

: : of Dergleidjen in jedem Reime préeriffite 


\section{Viegifter Der merfinutroigften Sacten. 4 II}

Geelen, oer Đolipen

: $\quad$ ob unfere nod) pinen feinetn Sórper unter bem grolien babelt

Gelbferbaltung, farfer Trieb der Infetten daju

394

Sidhelthiex, Defien Szeotiact)tung

: : merfivurtoige ふ̇ervegung

348

:.: Sidjellials̆,

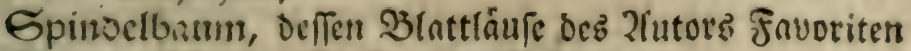

383

จ.ก.

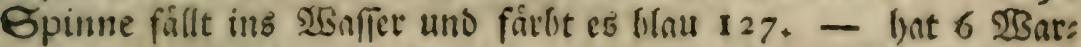
zen umo jede 1000 Defnungen 386. Feinfeit eines Spinnen: fridens

Springuxutme in Evifen

Etachel ber $23 a n i e n$

$:-$ Der Silattláufe

385

$\because$ : Der Siencr

245

: O Der s)irifen

Gtaublatrs beiß̄t die Todtenufte

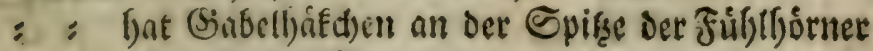

: : wie viclerlel) 2(rten es giebt.

: : roie Die Jinlettenfabintete bavor zu verivaljen

: Die Speife bes Brúdjerfforpions

Etigmata bely den Slattlâuen

Guljers Unterreoungen von Der Sdjonfjeit Der Natue weroen empfoblent

Gyfole und Diaftole in Den 23 surmen

E.

Cabellen iiber bie Bebutten ver Şlattlaufe

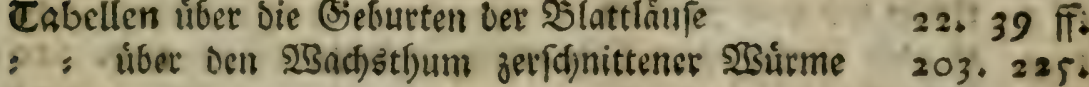

Tanacetum r. Xhbeinfarn.

23 . 289.295

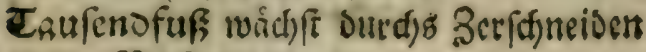

: : Berfudje Damit,

Celeologie, Datin vie beften Serweife

243

343

340

गू. O.f.

342

352

26

379

Ebermometertabeilen

Cheoric von den SBlattláufen im Sompentio

297

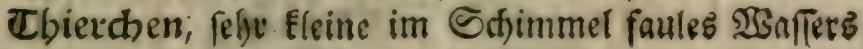

OAf. II.

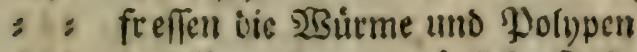

130

327

273

Daf.

- : Detfertben alle nur móglid)e (Seffalten in den İnfuftenen 368

: 73 jerplafentioe

388

: von fonberbaren Beftalten

393

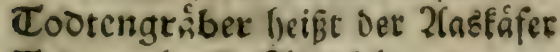

248

Cootenube T. Etrublans. 


\section{Segifter Der mertwirbigften Sactent.}

Torée, Slaf গitife unch Sulata mito anyefứlytt : : Daraus ein tefonderes Erempel,

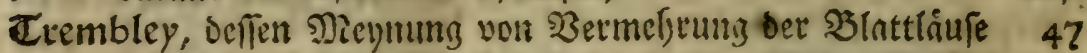
s : madjt Dem 2utor Zweifel, opr. und werden aufgelófet is $\mathrm{r}$

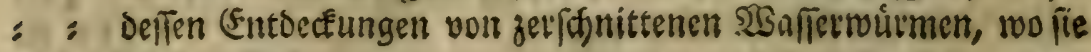
bejchrieben fino

$:$ : entbecft Die Wolypen

175

251

\section{U.}

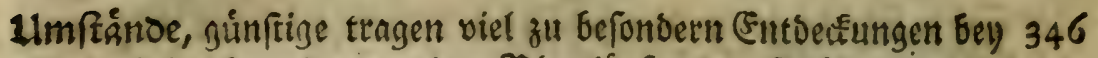
: - einige Eefonvere an ben Slattlaulen der Saljlncide 35 I

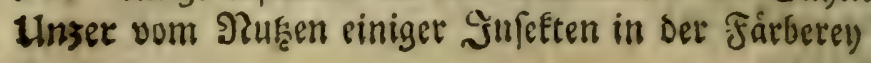

128

D.

Derfuche, mifroftopifore, tvie leidjt man fids babey itten fann

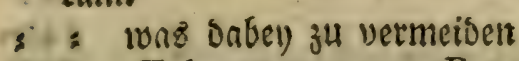

248,249

Vibrio Falx 382. - Proteus

249

384.

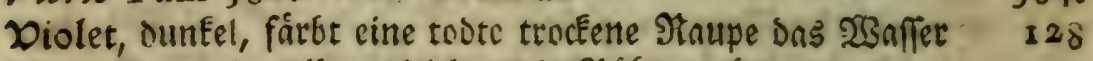

Diolinfagte, berfelden gleidjen die Siófrenturtme

301

100.

200achstbum, Det STlirme mit ben 'Pflanjen verglichen : wie weit er gelsen Eann.

191

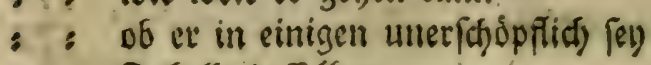

onf.

: : Tabelle defleloen

217

: Эeriuche Darúber

219

: tidjtet fich nadh Zufállen.

218

220

- ob Daju 23 alfer, doer (5rde ctwas beytrage

210. 220

: Unregelmábigfeit iabey

225

: " ob Dazu die Báme tung bentrage

200nzen baben Dell Stadjel unter Dem saudje

197

: Eóntun Farben geben

128

200:

200

: : Der Evpinne uno ifre Defmungen

200afferanle fommen lebendig aus einem 25 surmftucte

$25 I .296 \mathrm{f}$.

:- melyreré bergleition

386

244

- Berfuctje oanit

249

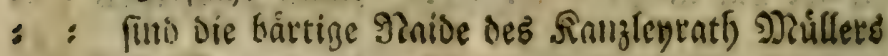

: : ilse Trcumungspuntet

258

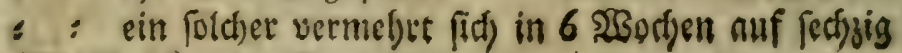

Dafferbăr, Oer Eleine 


\section{I4 Regifter Der merEfwirbigftent Sarchert.}

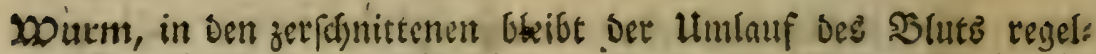
mápig

- : ifor jartes Gefúbl

- : fojeinen Zlugen zh baben,

243

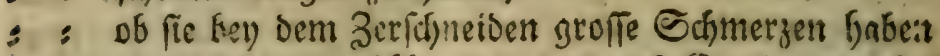

oaf.

$\therefore$ : ob fie lebendigyebáljiente ober audi Everlegende find, oar.

$:$ : ob fic fiff Polupcrattin vetmefsen

$247+248$

250

: : wetmefren fitf nuf eine bienfache 2irt

$2\{3$

: : einige befonmunt zrocy Siupfe

253

- : firo gewinten Sernefgeiten unterivorfen

267

: :

: : einige frerben, wenn fie jerftummelt werben

267277

: : ifre Ilnter/d)eiounisgeid)in

287

: : einige fretben wen ifnen der Sopf abge/d)nitten wird 294

:: : bráunfiche werden zrifchnitten uno beobad)tet

:1: [eichte Nietbode, fie in Dell פJetrlinfen jul finden

295 fi.

302

: Dergleidjen ofute friffe

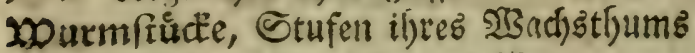

$307.308,309$

: : weldje nidjt wiéce wadjien

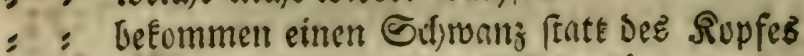

200 ourzeln, Daran fęcen fid) Die Ṡlattlaufe

189

194

283. 284

๖.

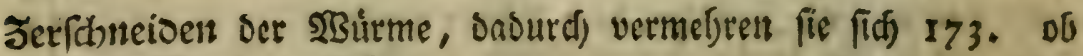
Davon Regcín ju geben

settbeilung ift Den SEnferwuirmen naturfics

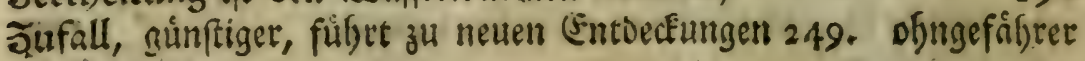

iff thóridjt

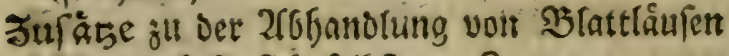

awitter, of fie fid) felbft jur Beugung genug fins

190

192

379

353

146

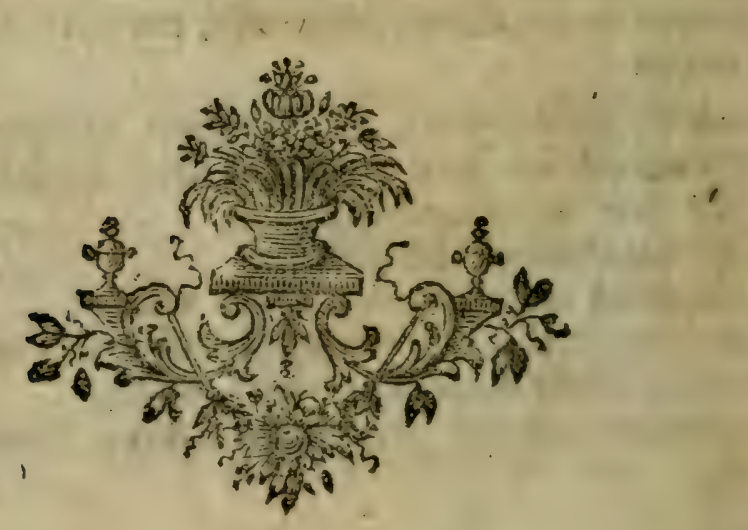




\section{litunuen iuber die}

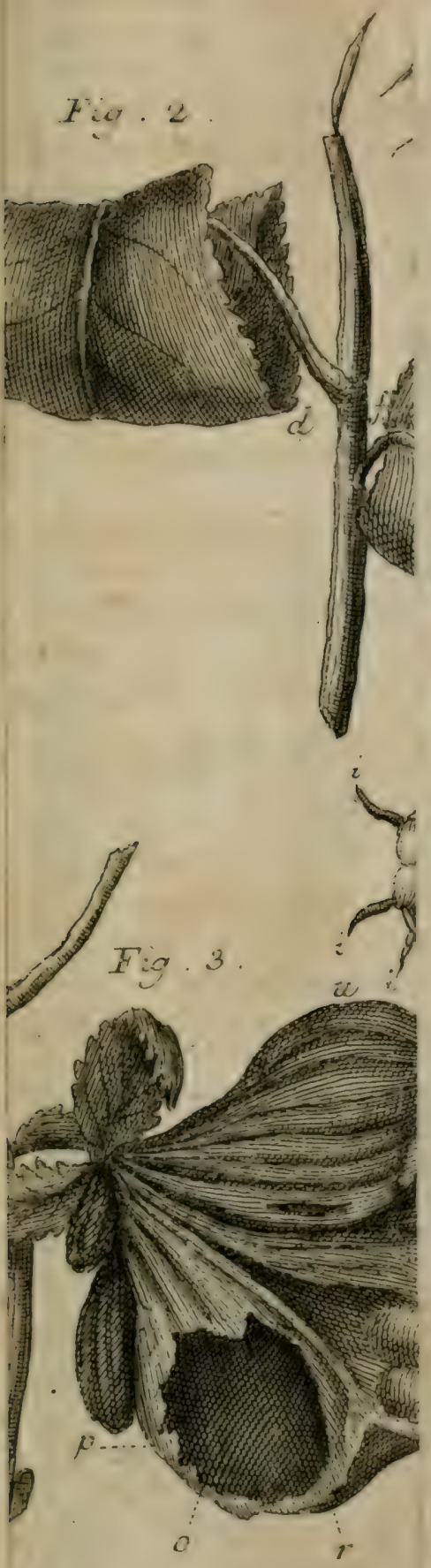




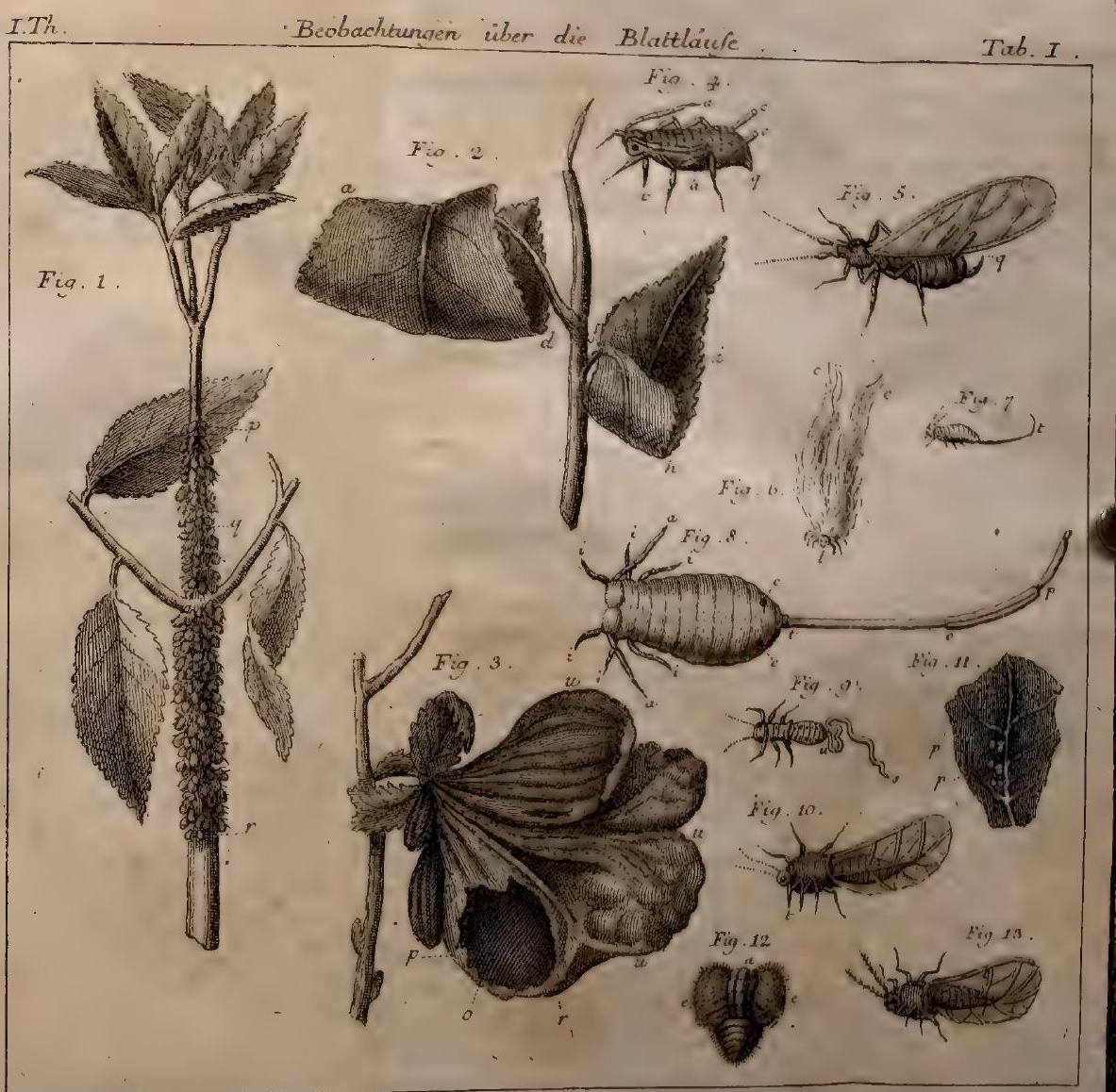


Inthe nepl ines.

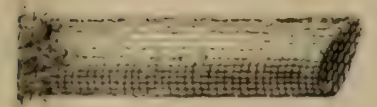

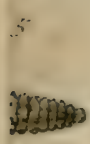

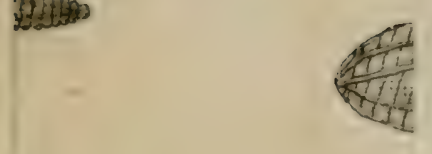

$F: 9$ is.

istents

$5<=2$

triverus

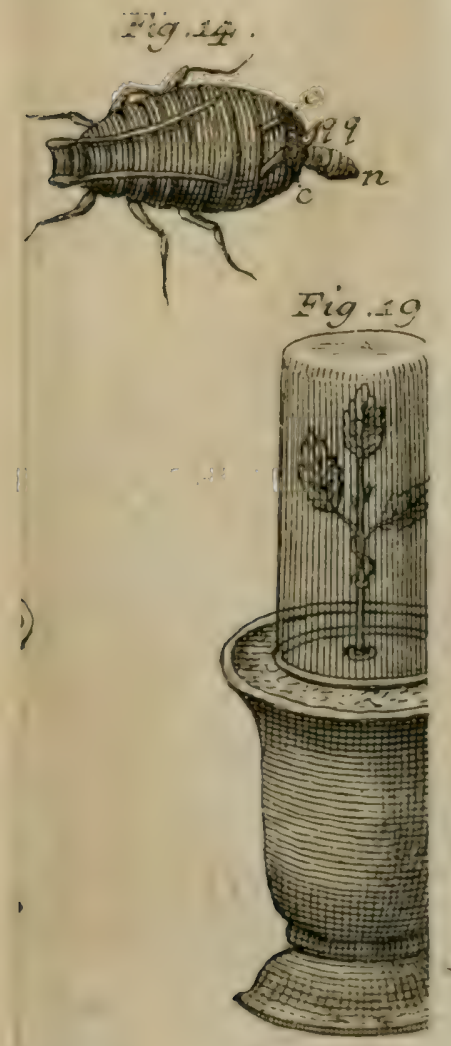


twe der fusfen tios
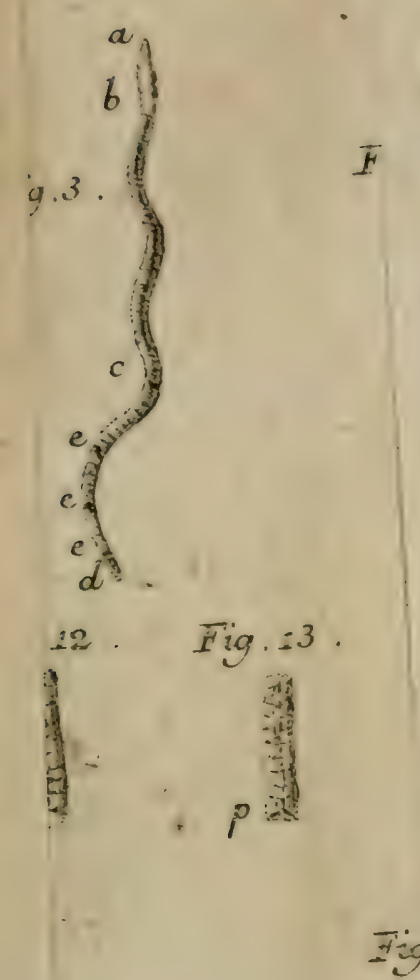

Fig

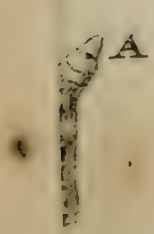

$t$

Fig 18 .

$3^{3} \int^{x} \cdot 9^{5}$ 


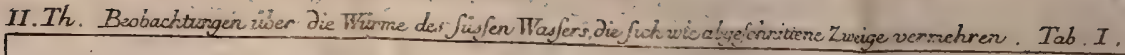
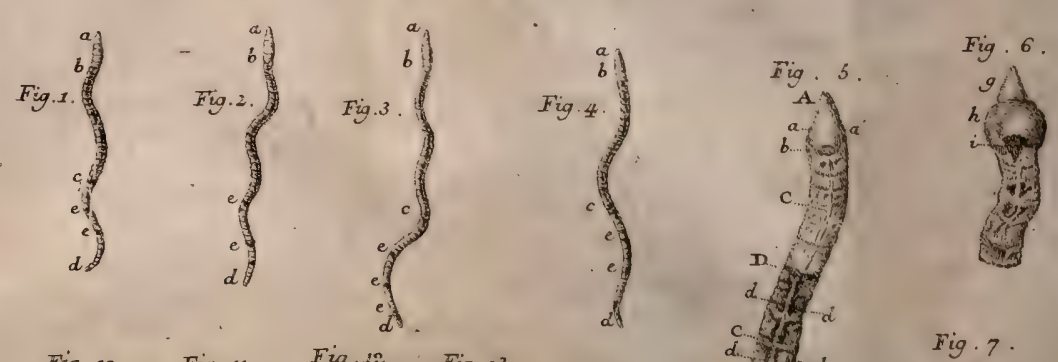

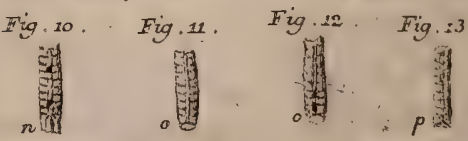
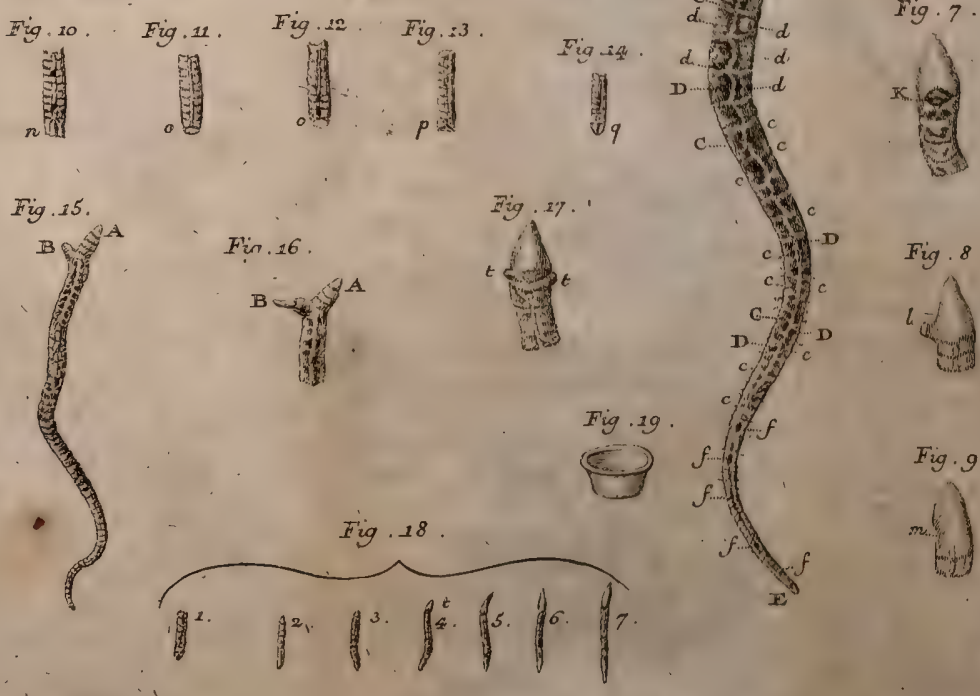
des liefsen 7 tiafse

sig. 4 .

$q^{4}$
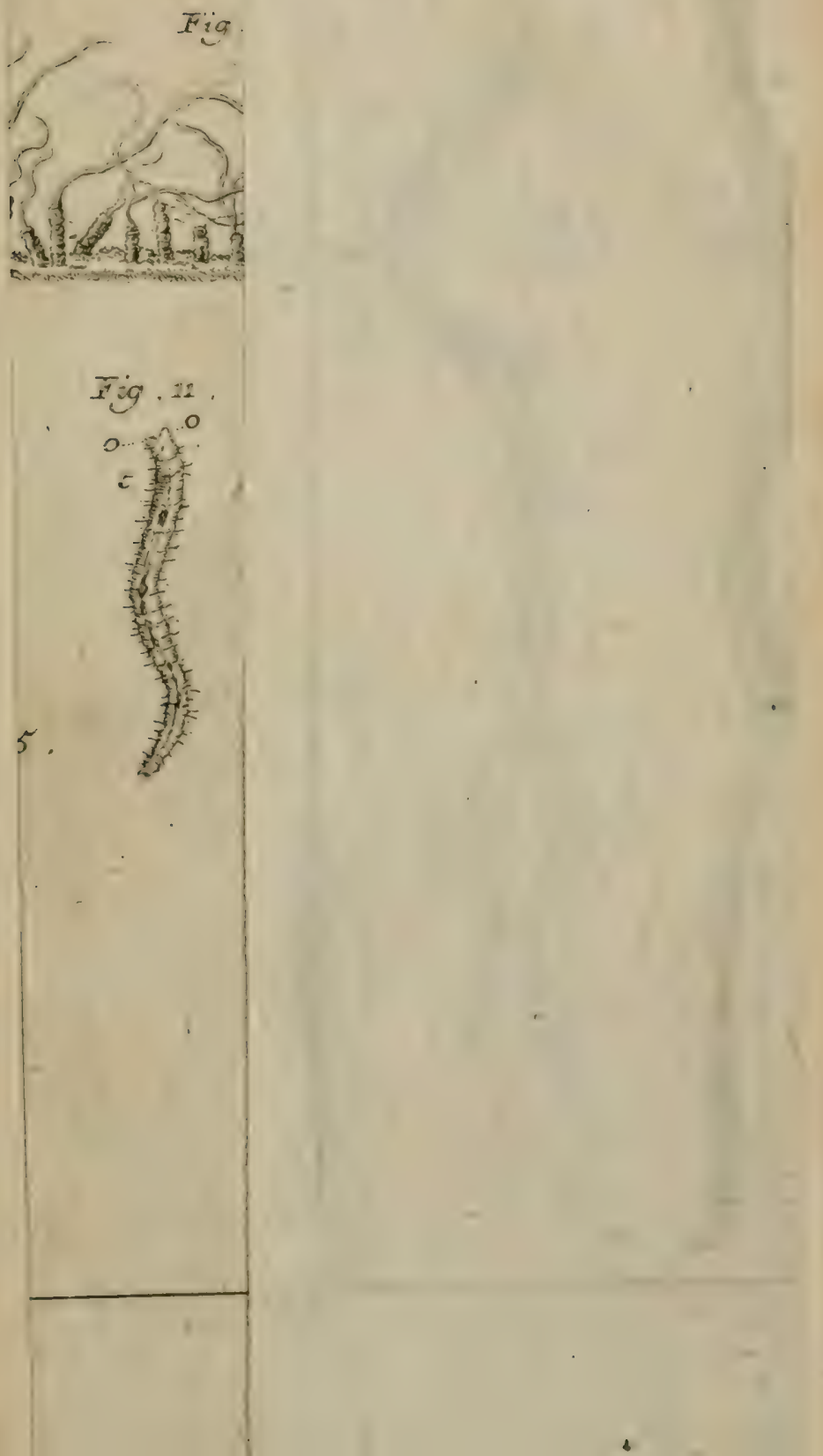


$$
\left.\frac{-3 i}{3 i}\right\}\{\}
$$


Würme des Jüsen Wajsers, diu me Zweige vermetiren.

Fig. 3 .

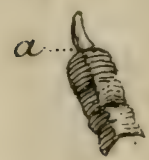

Fig. 4

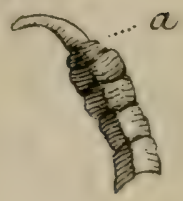

ig. 2
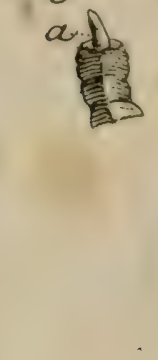



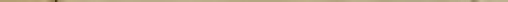




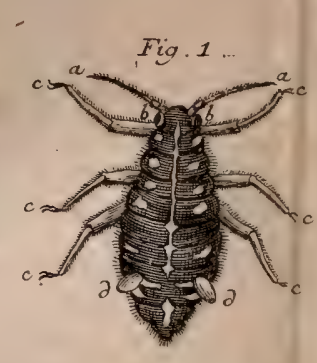

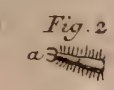
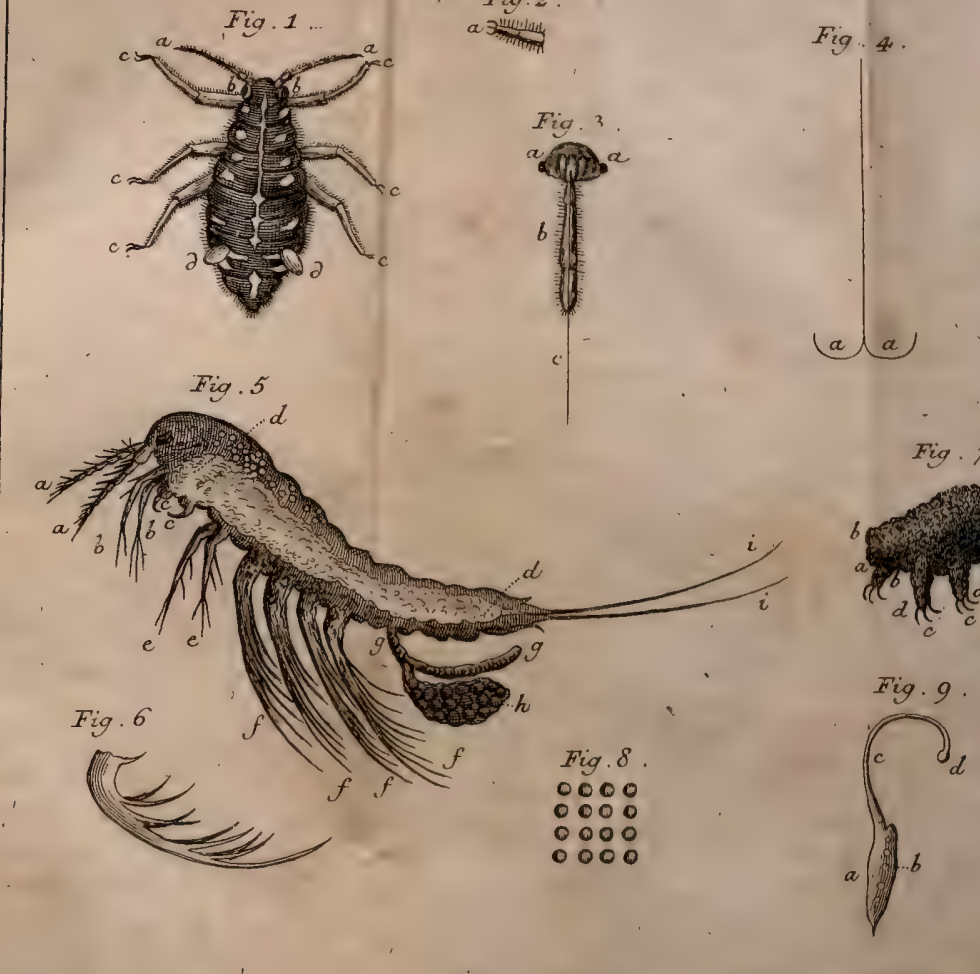

$y=$

(3)

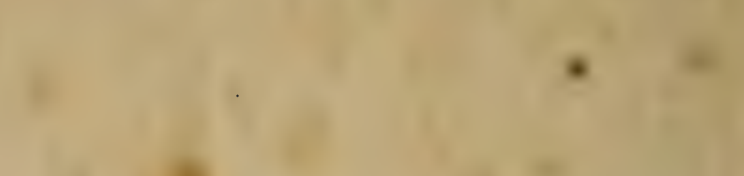

\section{-}

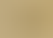

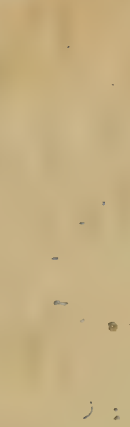

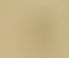
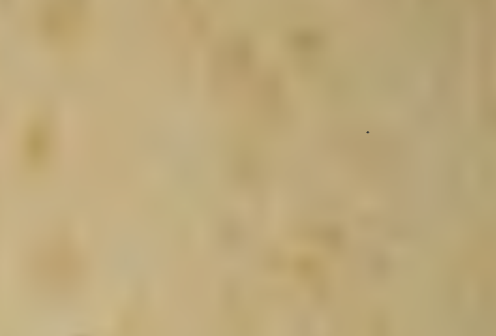

$+$
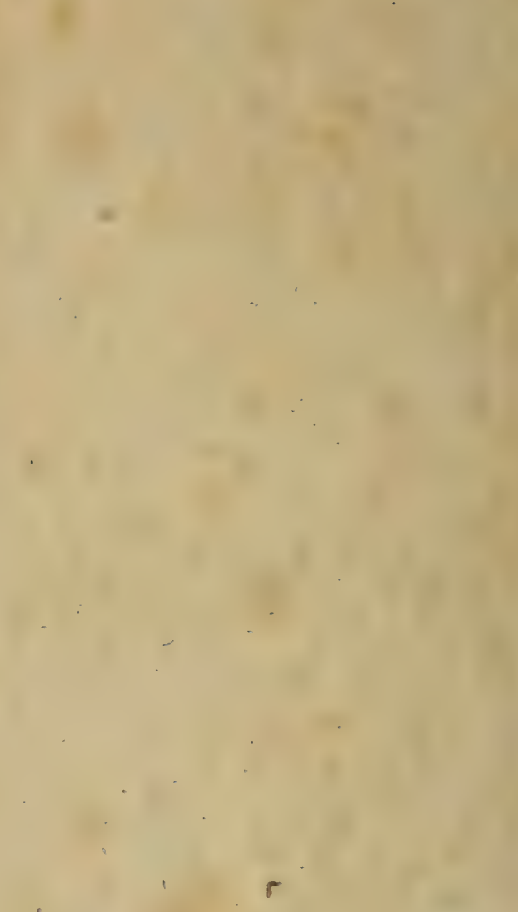

$\therefore$
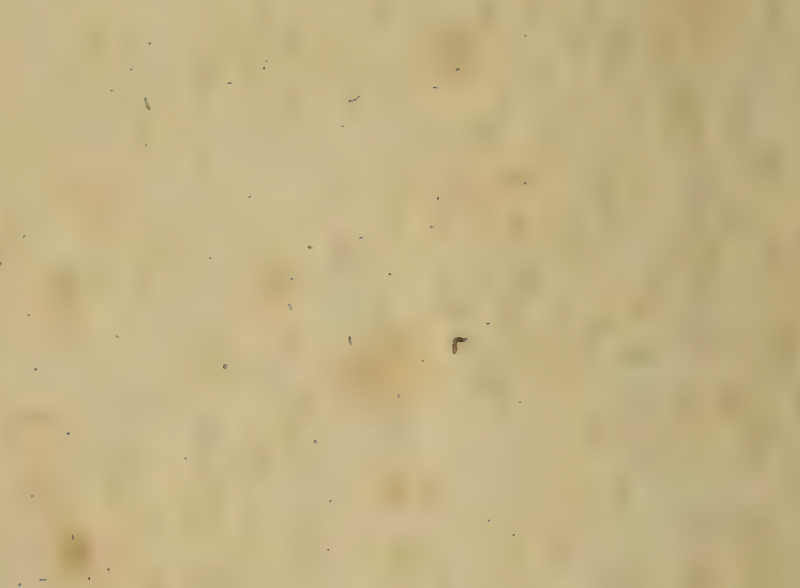

-

8

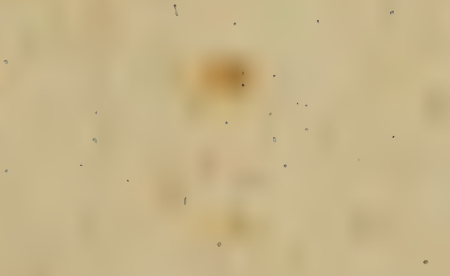






